REREIVED

AUG 081994

NUREG/CR-6144

OSTI

BNL-NUREG-52399

Vol. 2, Part 1B

\title{
Evaluation of Potential
}

\section{Severe Accidents During}

Low Power and Shutdown

Operations at Surry, Unit 1

Analysis of Core Damage Frequency from
Internal Events During Mid-Loop Operations

Main Report (Chapters 7-12)

Prepared by

T. L. Chu, Z. Musicki, P. Kohut, D. Bley, J. Yang, B. Holmes,

G. Bozoki, C. J. Hsu, D. J. Diamond, D. Johnson, J. Lin,

R. F. Su, V. Dang, D. Ilberg, S. M. Wong, N. Siu

Brookhaven National Laboratory

Prepared for

U.S. Nuclear Regulatory Commission 


\section{AVAILABILITY NOTICE}

Availability of Reference Materials Cited in NRC Publications

Most documents cited in NRC publications will be available from one of the following sources:

1. The NRC Public Document Room, 2120 L Street, NW., Lower Level, Washington, DC 20555-0001

2. The Superintendent of Documents, U.S. Government Printing Office, Mail Stop SSOP, Washington. DC 20402-9328

3. The National Technical Information Service, Springfield, VA 22161

Although the listing that follows represents the majority of documents cited in NRC publications, it is not intended to be exhaustive.

Referenced documents available for inspection and copying for a fee from the NRC Public Document Room include NRC correspondence and internal NRC memoranda: NRC bulletins, circulars, information notices, inspection and investigation notices: licensee event reports: vendor reports and correspondence; Commission papers: and applicant and licensee documents and correspondence.

The following documents in the NUREG series are available for purchase from the GPO Sales Program: formal NRC staff and contractor reports, NRC-sponsored conference proceedings, international agreement reports, grant publications, and NRC booklets and brochures. Also avallable are regulatory guides, NRC regulations in the Code of Federal Regulations, and Nuclear Regulatory Commission Issuances.

Documents available from the National Technical Information Service include NUREG-series reports and technical reports prepared by other Federal agencies and reports prepared by the Atomic Energy Commission. forerunner agency to the Nuclear Regulatory Commission.

Documents available from public and special technical libraries include all open literature items. such as books, journal articles, and transactions. Federal Register notices, Federal and State legislation, and congressional reports can usually be obtained from these libraries.

Documents such as theses, dissertations, foreign reports and translations, and non-NRC conference proceedings are available for purchase from the organization sponsoring the publication cited.

Single copies of NRC draft reports are available free, to the extent of supply, upon written request to the Office of Administration. Distribution and Mail Services Section. U.S. Nuclear Regulatory Commission. Washington, DC 20555-0001.

Copies of industry codes and standards used in a substantive manner in the NRC regulatory process are malntained at the NRC Library, 7920 Norfolk Avenue, Bethesda. Maryland, for use by the public. Codes and standards are usually copyrighted and may be purchased from the originating organization or, if they are American National Standards, from the American National Standards Institute, 1430 Broadway, New York, NY 10018.

\section{DISCLAIMER NOTICE}

This report was prepared as an account of work sponsored by an agency of the United States Government. Neither the United States Government nor any agency thereof, or any of their employees, makes any warranty, expressed or implied, or assumes any legal liability of responsibility for any third party's use, or the results of such use, of any information, apparatus, product or process disclosed in this report, or represents that its use by such third party would not infringe privately owned rights. 


\section{DISCLAIMER}

Portions of this document may be illegible in electronic image products. Images are produced from the best available original document. 
NUREG/CR-6144

BNL-NUREG-52399

Vol. 2, Part 1B

\section{Evaluation of Potential}

Severe Accidents During

Low Power and Shutdown

Operations at Surry, Unit 1

\section{Analysis of Core Damage Frequency from Internal Events During Mid-Loop Operations}

Main Report (Chapters 7-12)

Manuscript Completed: January 1994

Date Published: June 1994

Prepared by

T. L. Chu, Z. Musicki, P. Kohut, D. Bley ${ }^{1}$, J. Yang, B. Holmes²,

G. Bozoki, C. J. Hsu, D. J. Diamond, D. Johnson ${ }^{1}$, J. Lin',

R. F. Su ${ }^{3}$, V. Dang 3 , D. Ilberg ${ }^{4}$, S. M. Wong, N. Siu ${ }^{3}$

Brookhaven National Laboratory

Upton, NY 11973

\section{Prepared for}

Division of Safety Issue Resolution

Office of Nuclear Regulatory Research

U.S. Nuclear Regulatory Commission

Washington, DC 20555-0001

NRC FIN L1922

'PLG Inc., 4590 MacArthur Boulevard, Newport Beach, CA 92660-2027

${ }^{2}$ AEA Technology, Winfrith, Dorchester, Dorset, England, DT2 8DH

${ }^{3}$ MIT, Cambridge, MA 02139 (N. Siu currently at EG\&G, Idaho Falls, ID 83415)

${ }^{4}$ Soreq Nuclear Research Center, Yavne 70600, Israel 


\begin{abstract}
Traditionally, probabilistic risk assessments (PRA) of severe accidents in nuclear power plants have considered initiating events potentially occurring only during full power operation. Some previous screening analyses that were performed for other modes of operation suggested that risks during those modes were small relative to full power operation. However, more recent studies and operational experience have implied that accidents during low power and shutdown could be significant contributors to risk.

During 1989, the Nuclear Regulatory Commission (NRC) initiated an extensive program to carefully examine the potential risks during low power and shutdown operations. The program includes two parallel projects being performed by Brookhaven National Laboratory (BNL) and Sandia National Laboratories (SNL). Two plants, Surry (pressurized water reactor) and Grand Gulf (boiling water reactor), were selected as the plants to be studied.

The objectives of the program are to assess the risks of severe accidents initiated during plant operational states other than full power operation and to compare the estimated core damage frequencies, important accident sequences and other qualitative and quantitative results with those accidents initiated during full power operation as assessed in NUREG-1150. The scope of the program includes that of a level-3 PRA.
\end{abstract}

The objective of this volume of the report is to document the approach utilized in the level- 1 internal events PRA for the Surry plant, and discuss the results obtained. A phased approach was used in the level-1 program. In phase 1, which was completed in Fall 1991, a coarse screening analysis examining accidents initiated by internal events (including internal fire and flood) was performed for all plant operational states (POSs). The objective of the phase 1 study was to identify potential vulnerable plant configurations, to characterize (on a high, medium, or low basis) the potential core damage accident scenarios, and to provide a foundation for a detailed phase 2 analysis.

In phase 2, mid-loop operation was selected as the plant configuration to be analyzed based on the results of the phase 1 study. The objective of the phase 2 study is to perform a detailed analysis of the potential accident scenarios that may occur during mid-loop operation, and compare the results with those of NUREG-1150. The scope of the level-1 study includes plant damage state analysis, and uncertainty analysis. Volume 1 summarizes the results of the study. Internal events analysis is documented in Volume 2. It also contains an appendix that documents the part of the phase 1 study that has to do with POSs other than midloop operation. Internal fire and internal flood analyses are documented in Volumes 3 and 4. A separate study on seismic analysis, documented in Volume 5, was performed for the NRC by Future Resources Associates, Inc. Volume 6 documents the accident progression, source terms, and consequences analysis.

In the phase 2 study, system models applicable for shutdown conditions were developed and supporting thermal hydraulic analysis were performed to determine both the timing of the accidents and success criteria for systems. Initiating events that may occur during mid-loop operations were identified and accident sequence event trees were developed and quantified. In the preliminary quantification of the midloop accident sequences, it was found that the decay heat at which the accident initiating event occurs is an important parameter that determines both the success criteria for the mitigating functions and the time available for operator actions. In order to better account for the decay heat, a "time window" approach was 
developed. In this approach, time windows after shutdown were defined based on the success criteria established for the various methods that can be used to mitigate the accident. Within each time window, the decay heat and accident sequence timing are more accurately defined and new event trees developed and quantified accordingly. Statistical analysis of the past outage data was performed to determine the time at which a mid-loop condition is reached, and the duration of the mid-loop operation. Past outage data were used to determine the probability that an accident initiating event occurs in each of the time windows. This probability is used in the quantification of the accident sequences.

The mean core damage frequency of the Surry plant due to internal events that may take place during mid-loop operations is 5E-06 per year, and the 5th and 95th percentiles are 5E-07 and 2E-05 per year, respectively. This can be compared with the mean core damage frequency from internal events of $4 \mathrm{E}-05$ per year estimated in the NUREG-1150 study for full power operations. 


\section{TABLE OF CONTENTS}

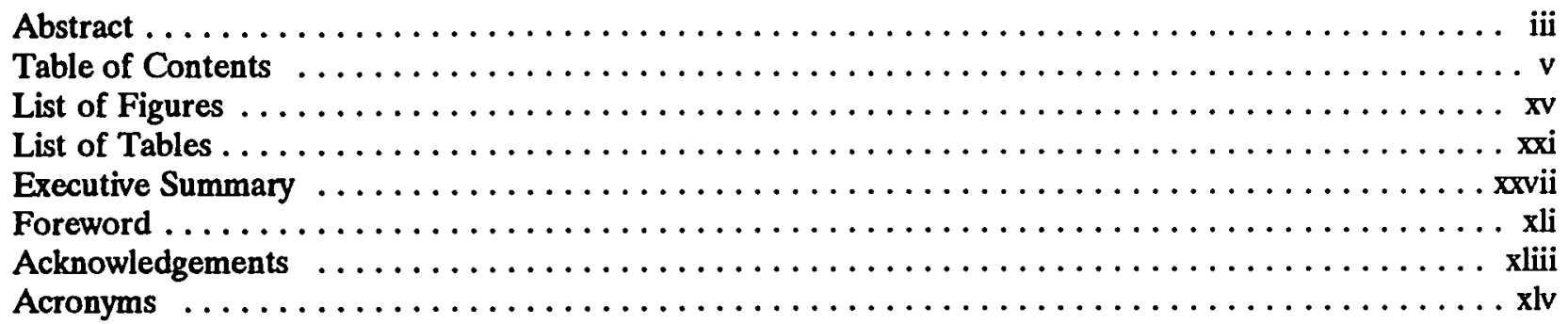

1. $\quad$ Introduction and Approach

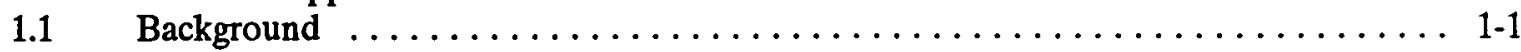

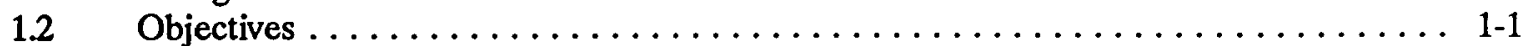

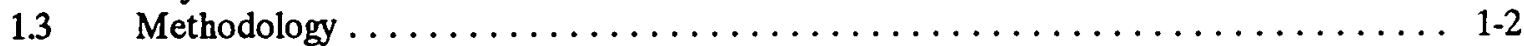

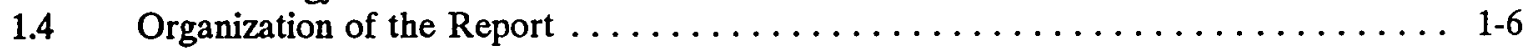

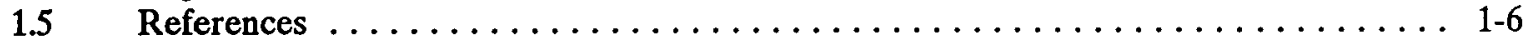

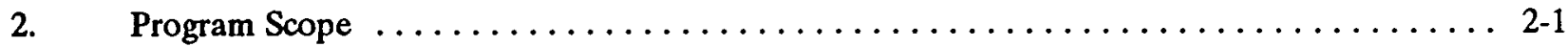

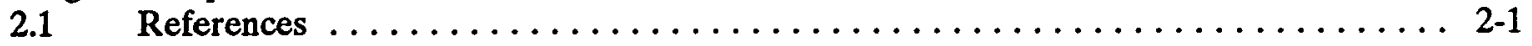

3. Definition and Characterization of Outage Types and Plant Operational States (POSs) 3-1

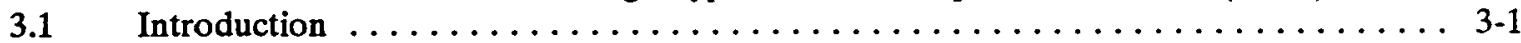

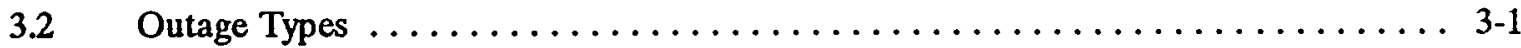

3.3 Definition of Plant Operational States for a Refueling Outage . . . . . . . . . 3-1

3.4 Plant Operational States for Other Types of Outages $\ldots \ldots \ldots \ldots \ldots \ldots \ldots \ldots \ldots \ldots \ldots$

3.5 Low Power and Shutdown Outage Activities $\ldots \ldots \ldots \ldots \ldots \ldots \ldots \ldots \ldots \ldots \ldots$

3.5.1 POS 1-Low Power Operation and Reactor Shutdown $\ldots \ldots \ldots \ldots \ldots \ldots$ 3-3

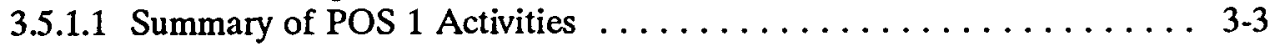

3.5.1.2 Significant POS 1 Activities ................... 3.3

3.5.1.3 Associated POS 1 Operating Procedures ............ 3-4

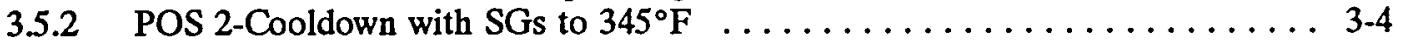

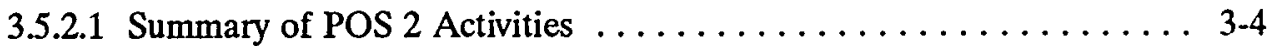

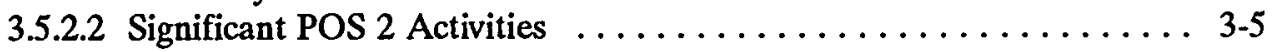

3.5.2.3 Associated POS 2 Operating Procedures .......... $\ldots \ldots \ldots$

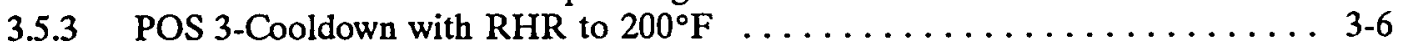

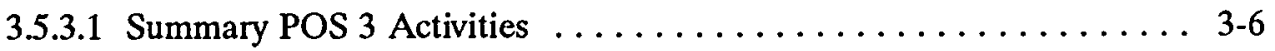

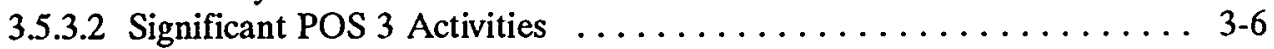

3.5.3.3 Associated POS 3 Operating Procedure ........... 3.6

3.5.4 POS 4-Cooldown to Ambient Temperatures (using RHR) $\ldots \ldots \ldots \ldots \ldots$. $\ldots .7$

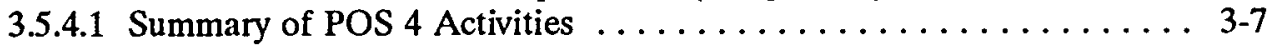

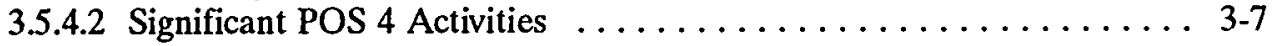

3.5.4.3 Associated POS 4 Operating Procedures .............. 3-7

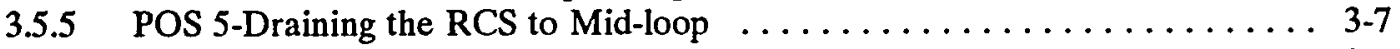

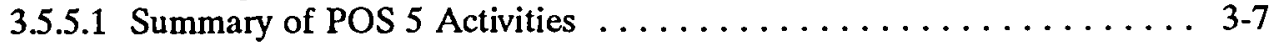

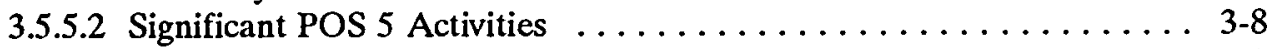

3.5.5.2.1 Draining the RCS to 5\% Pressurizer Level $829.0 \mathrm{ft}$ ) $\ldots$ 3-8

3.5.5.2.2 Draining the RCS from 5\% Pressurizer Level

$(29.0 \mathrm{ft})$ to Mid-Nozzle $(12.5 \mathrm{ft}) \ldots \ldots \ldots \ldots \ldots \ldots$ 3-9

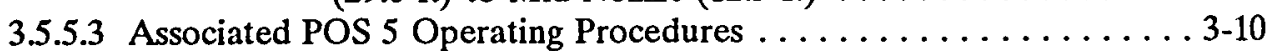

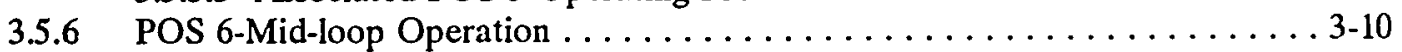


Table of Contents (continued)

3.5.6.1 Summary of POS 6 Activities (including Significant ones) . . . . . 3-10

3.5.6.2 Associated POS 6 (Maintenance) Operating Procedure ........ . 3-10

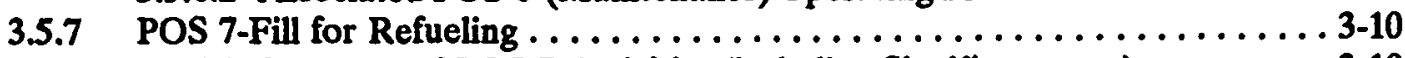

3.5.7.1 Summary of POS 7 Activities (including Significant ones) $\ldots \ldots \ldots$ 3-10

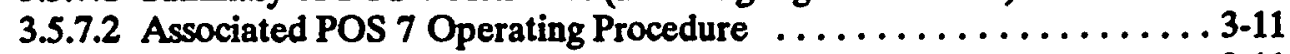

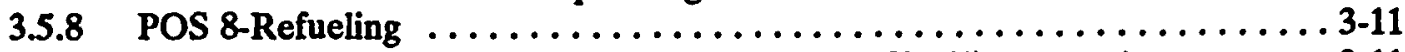

3.5.8.1 Summary of POS 8 Activities (including Significant ones) $\ldots \ldots \ldots$ 3-11

3.5.8.2 Associated POS 8. Operating Procedures .................... 3-11

3.5.9 POS 9-Draining RCS to Mid-loop After Refueling ............. 3-11

3.5.9.1 Summary of POS 9_Activities (including Significant ones)_....... . . . 3-11

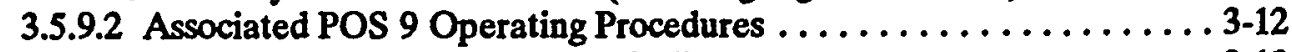

3.5.10 POS 10-Mid-loop Operations After Refueling ................ 3-12

3.5.10.1 Summary of POS 10 Activities (including Significant ones) $\ldots \ldots \ldots 3-12$

3.5.10.2 Associated POS 10 (Maintenance) Operating Procedures . . . . . . 3-12

3.5.11 POS 11-Refill RCS Completely (After Mid-loop Operation) $\ldots \ldots \ldots \ldots \ldots$ 3-12

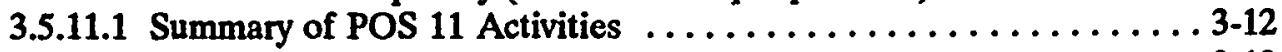

3.5.11.2 Significant POS 11 Activities ..................

3.5.11.3 Associated POS 11 Operating Procedures $\ldots \ldots \ldots \ldots \ldots \ldots \ldots .13$

3.5.12 POS 12-RCS Heatup Solid and Draw Bubble $\ldots \ldots \ldots \ldots \ldots \ldots \ldots \ldots . . \ldots \ldots \ldots$

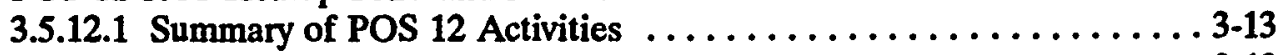

3.5.12.2 Significant POS 12 Activities . . . . . . . . . . . . . . . 3-13

3.5.12.3 Associated POS 12 Operating Procedures $\ldots \ldots \ldots \ldots \ldots \ldots .14$

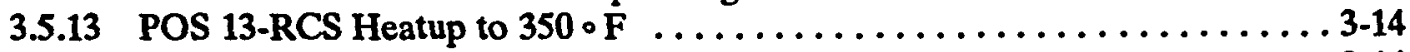

3.5.13.1 Summary of POS 13 Activities ................

3.5.13.2 Significant POS 13 Activities . . . . . . . . . . . . . . . . 3-14

3.5.13.3 Associated POS 13 Operating Procedures .............. 3-14

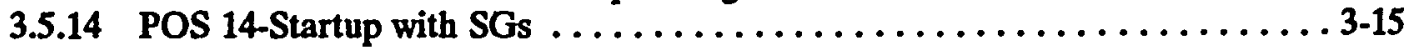

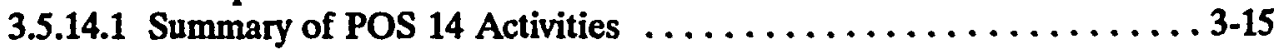

3.5.14.2 Significant POS 14 Activities ..................... 3.

3.5.14.3 Associate POS 14 Operating Procedures .............. 3-15

3.5.15 POS 15-Reactor Startup and Low Power Operation ............. 3-15

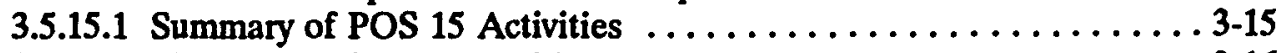

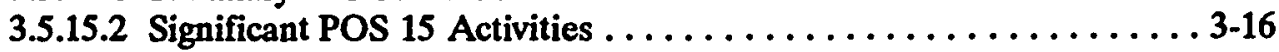

3.5.15.3 Associated POS 15 Operating Procedures ............ 3-17

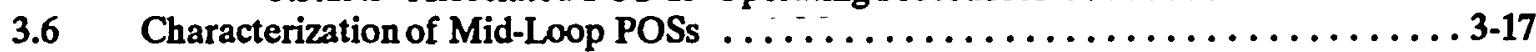

3.7 References: .......................................

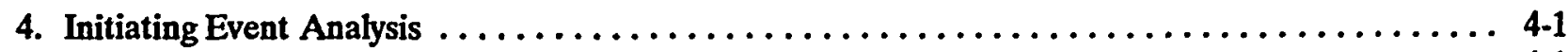

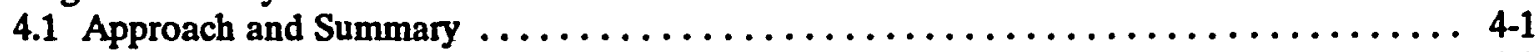

4.1.1 Review of Existing Shutdown Studies . . . . . . . . . . . .

4.1.2 Review of Procedures Used during Shutdown $\ldots \ldots \ldots \ldots \ldots \ldots \ldots \ldots \ldots$ 4-2

4.1.3 Review of Initiators for Power Operations ................ 4-3

4.1.4 Review of NRC Generic Letters, Information Notices, Bulletin, and Circulars 4-3

4.1.5 Review of Other Documents $\ldots \ldots \ldots \ldots \ldots \ldots \ldots \ldots \ldots \ldots \ldots \ldots \ldots$

4.1.6 References ................................. 4-4

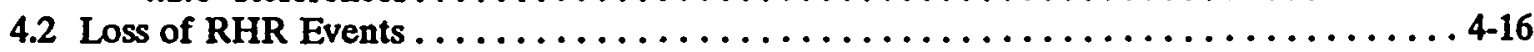

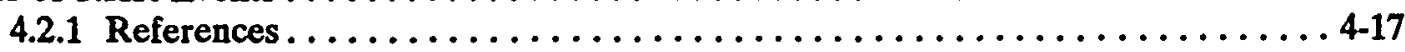

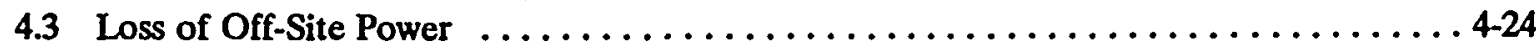

4.3.1 Statistical Analysis of Loss of Offsite Power Frequency and Recovery . . . . . 4-24

4.3.2 Definition, Logical Model and Quantification of Categories of 
Table of Contents (continued)

Loss of Offsite Power and Station Blackout Initiators $\ldots \ldots \ldots \ldots \ldots \ldots$. . . . .

4.3.2.1 System Configuration $\ldots \ldots \ldots \ldots \ldots \ldots \ldots \ldots \ldots \ldots \ldots \ldots .41$

4.3.2.2 LOSP Categories . . . . . . . . . . . . . . . . . . 4-41

4.3.2.3 Fault Trees for Breakdown of LOSP Initiator Into Categories . . . . . 4-42

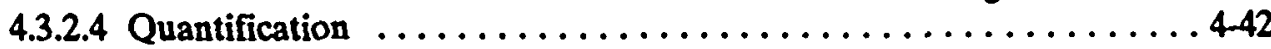

4.3.3 References...............................4-43

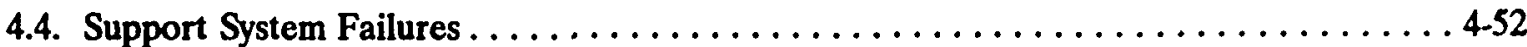

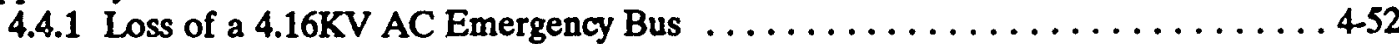

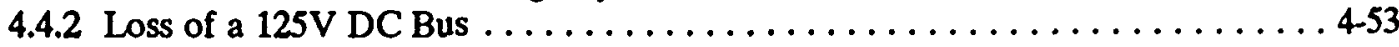

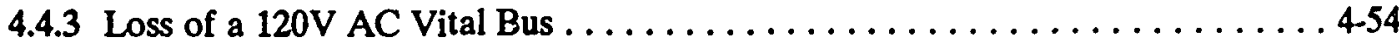

4.4.4 Loss of Instrument Air ........................ 454

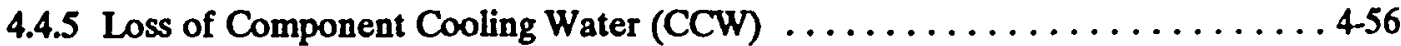

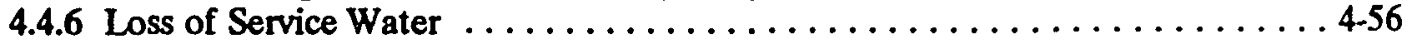

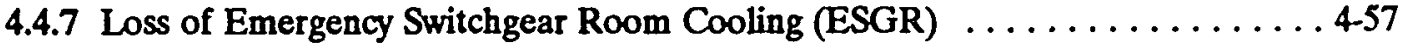

4.4.8 Loss of Charging Pump Cooling . . . . . . . . . . . . . . . . 4-58

4.4.9 Non-Recovery Curves for Support System Failures . . . . . . . . . . . 4-58

4.4 .10 References ............................. 4.58

Appendix 4.4.7.A Fault Tree to Determine the Frequency of the Initiator

"Loss of Emergency Switchgear Room (ESGR) Cooling" for POS (6) and (10). . . . . 4-66

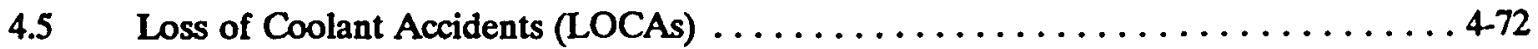

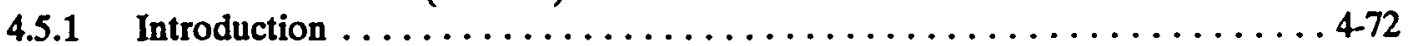

4.5.2 LOCAs Unique to Shutdown States . . . . . . . . . . . . . 4 -72

4.5.3 Applicability of LOCA Categories in Various Plant States . . . . . . . . . 4-75

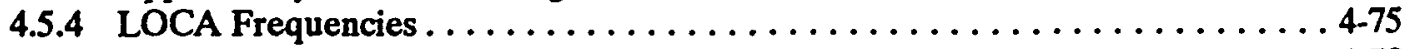

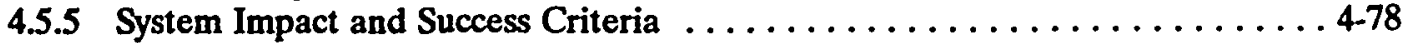

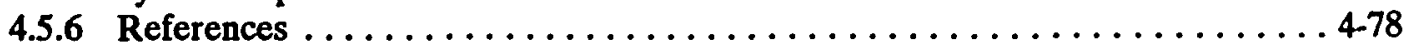

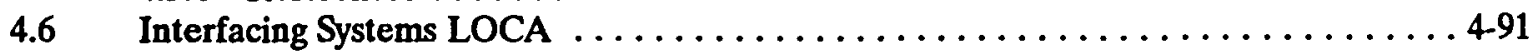

4.6.1 Extended Interfacing System LOCA Analysis . . . . . . . . . . . . . 4-91

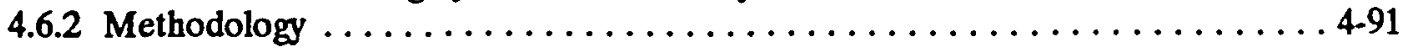

4.6.3 ISLOCA Scenarios . . . . . . . . . . . . . . . . . . . 4-91

4.6.3.1 Low Pressure Safety Injection System V-Event Scenario . . . . . . . 4-92

4.6.3.2 Residual Heat Removal System ISLOCA Scenarios . . . . . . . . . 4 4-93

4.6.3.2.1 Interfacing Configurations of the RHRS . . . . . . 4-93

4.6.3.2.2 RHR Suction Line and RHR Discharge Line ISLOCAs

V-Event Through the RHR-CVCS Letdown Line . . . . . 4-95

4.6.3.2.3 V-Event through the RHRS-CVCS Letdown Line

Associated With the Low Temperature

Overpressurization (LTOP) of the RHRS . . . . . 4-98

4.6.3.2.4 V-Event Through the RHRS-RWST Connecting Line . . . 4-98

4.6.3.3 Accumulator Discharge Line ISLOCA Scenario . . . . . . . . . 4-99

4.6.4 References............................ 4-101

APPENDIX 4.6.A - List of Component Failure Rates Used in the ISLOCA Analysis . . . . . 4-112

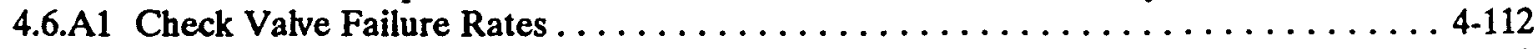

4.6.A1.1 Check Valve, Large Reverse Leakage . . . . . . . . . . . . 4-112

4.6.A1.2 Check Valve Failure to Operate (to Close) on Demand . . . . . . . . 4-112

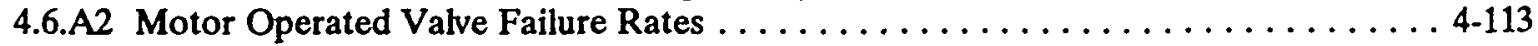

4.6.A2.1 MOV Internal Leakage $\ldots \ldots \ldots \ldots \ldots \ldots \ldots \ldots \ldots \ldots \ldots \ldots \ldots \ldots \ldots \ldots \ldots \ldots \ldots .113$ 
Table of Contents (continued)

4.6.A2.2 MOV Disk Fails Open While Indicating Closed ............. 4-113

4.6.A2.3 MOV Transfers Open ....................... 4-113

4.6.A2.4 MOV Failure to Operate (to Close and Stay Closed) $\ldots \ldots \ldots \ldots \ldots \ldots$ 4-113

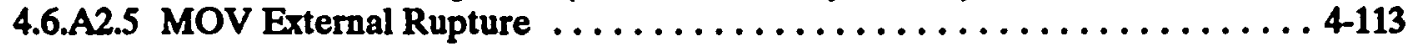

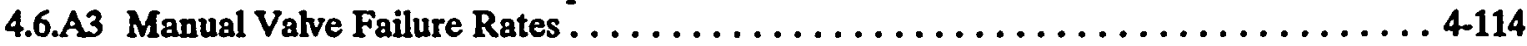

4.6.A3.1 Manual Valve Massive Internal Leakage . . . . . . . . . . . . . 4-114

4.6.A3.2 Manual Valve Fails to Close ......................... 4-114

4.6.A3.3 Manual Valve Inadvertently Left Open by the Operator.

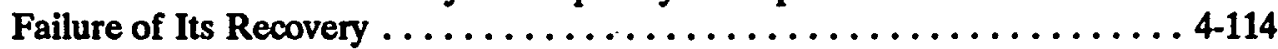

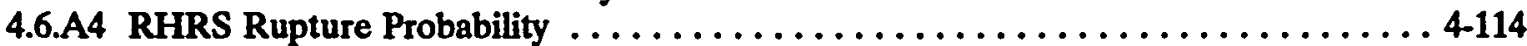

4.6.AS Rupture Probability of the RHRS-CVCS Letdown Line .. . . . . . . . . . . . 4-116

4.7 Steam Generator Tube Rupture (SGTR) $\ldots \ldots \ldots \ldots \ldots \ldots \ldots \ldots \ldots \ldots \ldots \ldots$

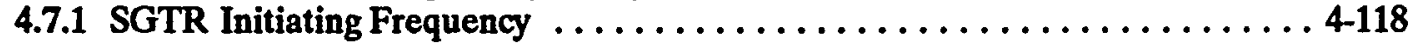

4.7.2 Success Criteria ............................ 4-119

4.8 Spurious Emergency Safety Features Actuation Signals (SI, CLS, RMT) . . . . . . 4-121

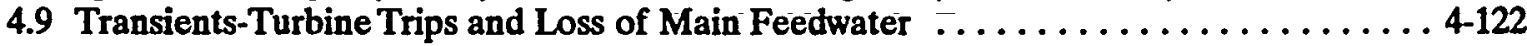

4.9.1 Identification and Grouping of Transient Initiating Event $\ldots \ldots \ldots \ldots \ldots$ 4-122

4.9.2 Estimation of Transient Initiating Event Frequencies . . . . . . . . . 4-123

4.10 Estimate of Core Damage Frequency Due to Pressurized Thermal Shock . . . . . 4-129

4.10.1 The Pressurized Thermal Shock Phenomenon ............... . . 4-129

4.10.2 The Assessment of Core Damage Frequency due to PTS

in the Surry NUREG-1150 Study . . . . . . . . . . . . . . . . 4-129

4.10.3 Assessment of PTS Core Damage Frequency During

Low Power Operation and Shutdown at Surry $\ldots \ldots \ldots \ldots \ldots \ldots \ldots$ 4-130

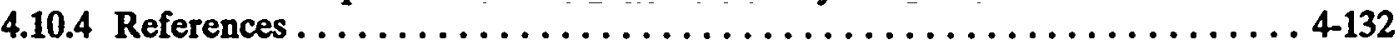

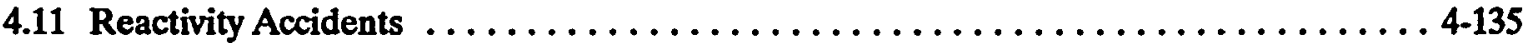

4.11.1 General Comments .......................... 4-135

4.11.2 Addition of Diluted Accumulator Water $\ldots \ldots \ldots \ldots \ldots \ldots \ldots \ldots$ 4-135

4.11.2.1 Description of Event . . . . . . . . . . . . . . . . . .

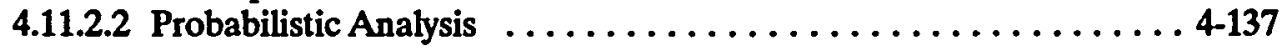

4.11.3 Addition of Diluted RWST Water $\ldots \ldots \ldots \ldots \ldots \ldots \ldots \ldots \ldots \ldots \ldots$ 4-137

4.11.3.1 Description ......................... 4-137

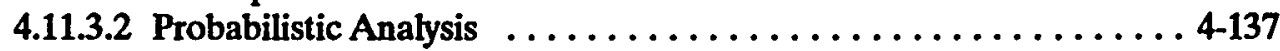

4.11.4 Boron Dilution Due to Maintenance Problems $\ldots \ldots \ldots \ldots \ldots \ldots \ldots \ldots$ 4-138

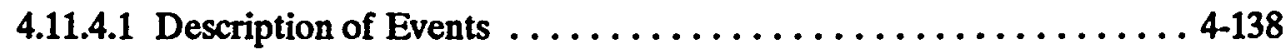

4.11.4.2 Dilution When Cleaning Cavity . . . . . . . . . . . . .

4.11.4.3 Dilution due to Steam Generator Maintenance . . . . . . . . . . 4-138

4.11.4.4_Probabilistic.Analysis_........................... . 4-139

4.11.5 Uncontrolled Boron Dilution from CVCS . . . . . . . . . . . . . 4-139

4.11.5.1 Description of Event $\ldots \ldots \ldots \ldots \ldots \ldots \ldots \ldots \ldots \ldots \ldots \ldots$ 4-139

4.11.5.2 Probabilistic Analysis ..................... 4-139

4.11.6 Boron Dilution via the-RHR $\ldots \ldots \ldots \ldots \ldots \ldots \ldots \ldots \ldots \ldots \ldots \ldots$ 4-140

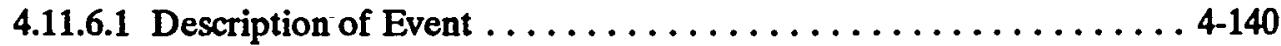

4.11.6.2 Probabilistic Anałysis .................... 4-140

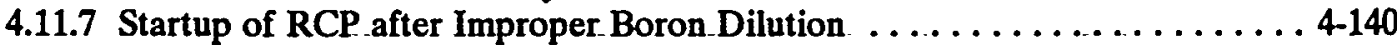

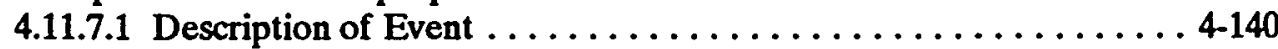

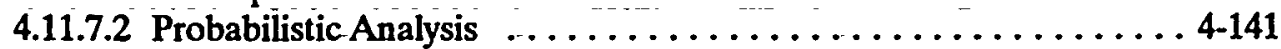

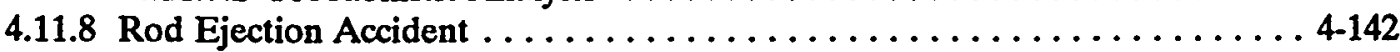

4.11.8.1 Description of Event $\ldots \ldots \ldots \ldots \ldots \ldots \ldots \ldots \ldots \ldots \ldots \ldots \ldots .142$

4.11.8.2 Probabilistic Analysis . . . . . . . . . . . . . . 4-142 
4.11.9 Misloading of Fuel Assemblies .................... 4-143

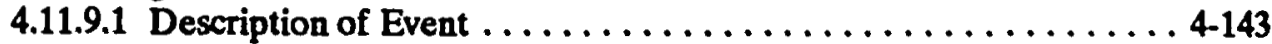

4.11.9.2 Probabilistic Anałysis ..................... 4-143

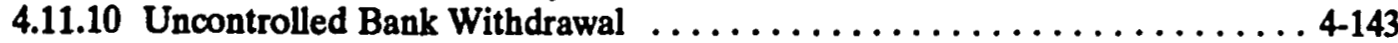

4.11.10.1 Description of Event $\ldots \ldots \ldots \ldots \ldots \ldots \ldots \ldots \ldots \ldots \ldots$ 4 143

4.11.10.2 Probabilistic Analysis . . . . . . . . . . . . . . . . 4-143

4.11.11 References . . . . . . . . . . . . . . . . . . . . . . . . 4-144

4.12 Initiating Events That Are Applicable to the Mid-Loop POSs . . . . . . . . 4-145

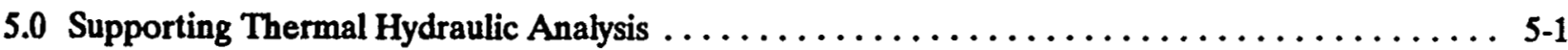

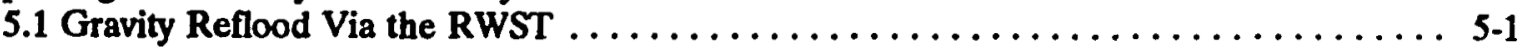

5.1.1 The Melcor Model . . . . . . . . . . . . . . . . . . . . . . . . . . 5-1

5.1 .2 Results .................................. 5-3

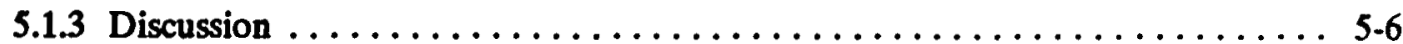

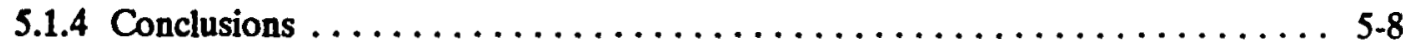

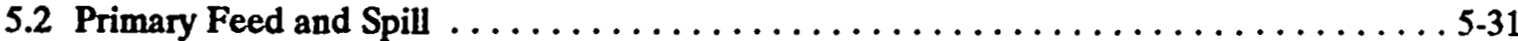

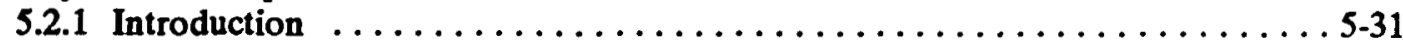

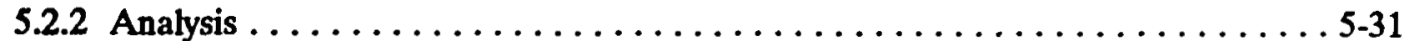

5.2 .3 Discussion of Results ......................... 5-34

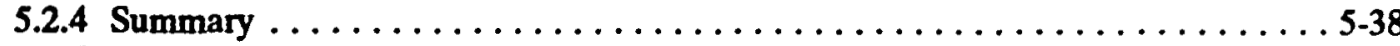

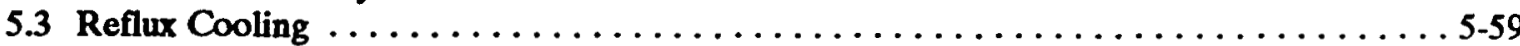

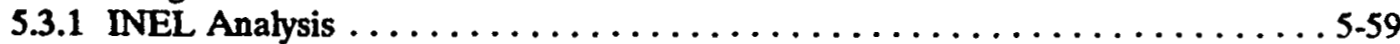

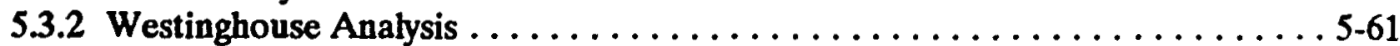

5.3.3 Summary and General Remark . . . . . . . . . . . . . . . . . 5-63

5.4 Summary of Results and Their Application to PRA Assumptions . . . . . . . . . 5-65

5.5 References: ................................... 5-70

6.0 System Descriptions and Fault Tree Analysis

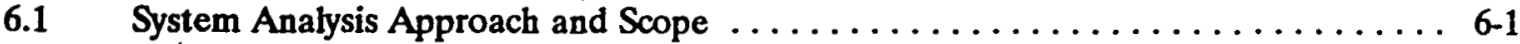

6.2 .1 Accumulator System . . . . . . . . . . . . . . . . . .

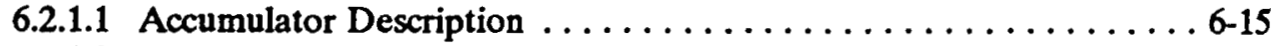

6.2.1.2 Accumulator Interfaces and Dependencies ........... 6.15

6.2.1.3 Accumulator Operational Constraints . . . . . . . . . . . 6 6-16

6.2.1.4 Accumulators Shutdown Configuration ..............6.16

6.2.1.5 Accumulator System Logic . . . . . . . . . . . . . . 6-16

6.2.2 Auxiliary Feedwater System ....................... 6-18

6.2.2.1 Auxiliary Feedwater System Description . . . . . . . . . . 6 6-18

6.2.2.2 Auxiliary Feedwater System Interfaces and Dependencies . . . . . . 6 6-18

6.2.2.3 Auxiliary Feedwater System Operating Constraints . . . . . . . . . 6 6-19

6.2.2.4 Auxiliary Feedwater System Shutdown Configuration . . . . . . . . 6-19

6.2.2.5 Auxiliary Feedwater Logic Model . . . . . . . . . . . . . . . 6-19

6.2.3 Charging Pump Cooling System ................... 6-24

6.2.3.1 CPC System Description . . . . . . . . . . . . . . . . 6-24

6.2.3.2 Charging Pump Cooling System Interfaces and Dependencies . . . . 6-25

6.2.3.3 CPC System Operational Constraints .............. 6-25

6.2.3.4 CPC System Shutdown Configuration . . . . . . . . . . 6-25

6.2.3.5 CPC System Logic Model . . . . . . . . . . . . . . . . . . . . . 6-26

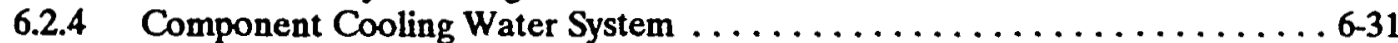

6.2.4.1 System Configuration and Description............. 6-31

6.2.4.2 Dependehcy on Other Support Systems . . . . . . . . . 6 6-32 
Table of Contents (continued)

6.2.4.3 CCW System Operating Constraints . . . . . . . . . . 6-32

6.2.4.4 Fault Tree Modeling of the CCW System . . . . . . . . . 6-33

6.2.4.5 Assumptions in the Fault Tree Models . . . . . . . . . . . 6-33

6.2 .5 Instrument Air System . . . . . . . . . . . . . . . . . . . . 6-41

6.2.5.1 Instrument Air System Description . . . . . . . . . . . . 6-41

6.2.5.2 Instrument Air System Interfaces and Dependencies . . . . . . . . 6-42

6.2.5.3 Instrument Air System Operating Constraints . . . . . . . . 6-42

6.2.5.4 Instrument Air System Shutdown Configuration . . . . . . . . 6-42

6.2.5.5 Instrument Air System Logic Model ............... . 6-42

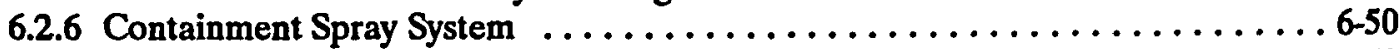

6.2.6.1 Containment Spray System Description . . . . . . . . . . 6-50

6.2.6.2 Containment Spray System Interfaces and Dependencies . . . . . . 6-51

6.2.6.3 Tech Specs and Minimum Equipment List ........... 6-51

6.2.6.4 Testing, Maintenance and Shutdown Configuration . . . . . . . 6-51

6.2.6.5 Modifications to the 1150 Fault Trees . . . . . . . . . . . . 6-51

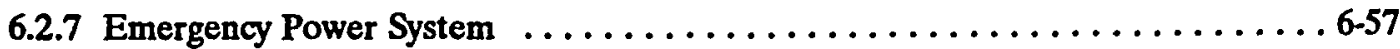

6.2.7.1 EPS Description . . . . . . . . . . . . . . . . . . 6-57

6.2.7.2 EPS Interfaces and Dependencies ............... 6.61

6.2.7.3 Technical Specifications and Periodic Tests ...........6-63

6.2.7.4 Fault Tree Modeling . . . . . . . . . . . . . . . . . . . 63

6.2.7.4.1 General Description ................6.6. 6.63

6.2.7.4.2 Assumptions in the Fault Tree Model of the EPS . . . . 6-64

6.2.7.5 Modification in the Line up of the EPS during Schedule maintenance of

main components $\quad 6-64$

6.2.8 Emergency Switchgear Room Ventilation Systems .............. 6-75

6.2.8.1 Normal Air Conditioning Chilled Water System . . . . . . . . 6-75

6.2.8.2 Backup Air Conditioning (Central) Chilled Water System . . . . . 6 6-76

6.2.8.3 Emergency Switchgear and Relay Rooms Air Conditioning

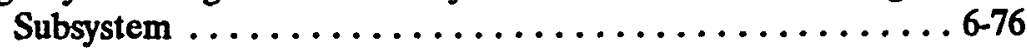

6.2.8.4 Interfaces and Dependencies................. $\ldots \ldots \ldots 7$

6.2.8.5 Fault Tree Modeling . . . . . . . . . . . . . . . . . 6-77

6.2.9 High Pressure Injection/Recirculation System . . . . . . . . . . . . . 6.86

6.2.9.1 High Pressure Injection/Recirculation System Description ... . . . . 6 6-86

6.2.9.2 HPI/HPR System Interfaces and Dependencies . . . . . . . . 6-88

6.2.9.3 HPI/HPR System Operational Constraints $\ldots \ldots \ldots \ldots \ldots \ldots \ldots 6.68$

6.2.9.4 HPI/HPR System Shutdown Configuration ............. 6-89

6.2.9.5 HPI/HPR System Logic Model . . . . . . . . . . . . . . 6-93

6.2.10 Low Pressure Injection/Recirculation System . . . . . . . . . . . . 6 6-103

6.2.10.1 Low Pressure Injection/Recirculation System Description . . . . . . 6-103

6.2.10.2 LPI/LPR System Interfaces and Dependencies . . . . . . . . 6-104

6.2.10.3 LPI/LPR' System Operational Constraints . . . . . . . . . . . . . . 6-104

6.2.10.4 LPI/LPR System Shutdown Configuration . . . . . . . . . 6-104

6.2.10.5 LPI/LPR System Logic Model . . . . . . . . . . . . 6-105

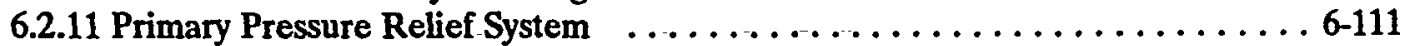

6.2.11.1 Primary Pressure Relief System Description $\ldots \ldots \ldots \ldots \ldots \ldots$ 6-111

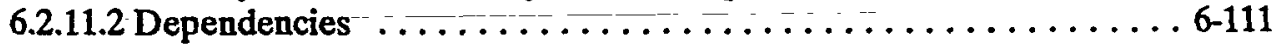

6.2.11.3 Tech Specs and Minimum Equipment List $\ldots \ldots \ldots \ldots \ldots \ldots 6-111$

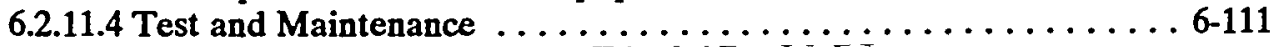

6.2 .11 .5 Faul Tree Modifications $\ldots \ldots \ldots \ldots \ldots \ldots \ldots \ldots \ldots \ldots \ldots \ldots \ldots \ldots \ldots \ldots \ldots .111$

6.2.12 The Recirculation Spray Systems -- Inside (ISR) and Outside (OSR) . . . . 6 6-116 
6.2.12.2 Support System Dependencies . . . . . . . . . . . . 6-117

6.2.12.3 Tech Specs and Minimum Equipment List . . . . . . . . 6-118

6.2.12.4 Testing and Maintenance of the RS system $\ldots \ldots \ldots \ldots \ldots \ldots 6-118$

6.2.12.5 Modifications to the 1150 Fault Trees ..............6 6-118

6.2.13 Residual Heat Removal System . . . . . . . . . . . . . . . 6 6-126

6.2.13.1 Residual Heat Removal System Description ........... 6 6-126

6.2.13.2 Residual Heat Removal System Interfaces and Dependencies . . . 6-127

6.2.13.3 Residual Heat Removal System Operating Constraints . . . . . . 6-127

6.2.13.4 Residual Heat Removal System Shutdown Configuration . . . . . . 6-128

6.2.13.5 Residual Heat Removal System Logic Model . . . . . . . . . 6-128

6.2.14 Service Water System/Circulating Water System . . . . . . . . . . . . . 6-134

6.2.14.1.1 Service Water System Description . . . . . . . . . . . . 6-134

6.2.14.1.2 Service Water System Interfaces and Dependency . . . . . . . 6-134

6.2.14.1.3 Service Water System Operational Constraints . . . . . . . . 6-134

6.2.14.1.4 Service Water System Shutdown Configurations . . . . . . . . 6-135

6.2.14.1.5 Logic Models of Service Water System . . . . . . . . . . 6-135

6.2.14.2.1 Circulating Water System Description ........ 6-135

6.2.14.2.2 Circulating Water System Interfaces and Dependency . . 6 6-136

6.2.15 Steam Generator Recirculation and Transfer System ............. 6-143

6.2.15.1 Steam Generator Recirculation and Transfer System Description . . 6-143

6.2.15.2 Steam Generator Recirculation and Transfer System Interfaces and

Dependencies ......................6. 6-144

6.2.15.3 Steam Generator Recirculation and Transfer System Operating

Constraints . . . . . . . . . . . . . . . . . 6 -144

6.2.15.4 Steam Generator Recirculation and Transfer System Shutdown

Configuration ..................... 6-144

6.2.15.5 Steam Generator Recirculation and Transfer System Logic

Model .........................6.145

6.2.16 Steam Generator Secondary Relief System ... . . . . . . . . . . 6-148

6.2.16.1 Steam Generator Secondary Relief System Description . . . . . . 6-148

6.2.16.2 Steam Generator Secondary Relief System Dependencies . . . . . . 6-149

6.2.16.3 Steam Generator Secondary Relief System Operational

6.2.16.4 Steam Generator Secondary Relief System Shutdown

Configuration .......................6. 6-149

6.2.16.5 Steam Generator Secondary Relief Logic Model . . . . . . . . . 6-150

6.2.17 Consequence Limiting Control System ................. 6-151

6.2.18 Reactor Protection System . . . . . . . . . . . . . . . . . . 6-151

6.2.19 Recirculation Mode Transfer System . . . . . . . . . . . . . 6-156

6.2.20 Safety Injection Actuation System . . . . . . . . . . . . . 6-156

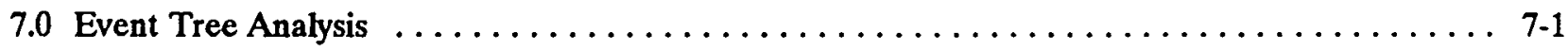

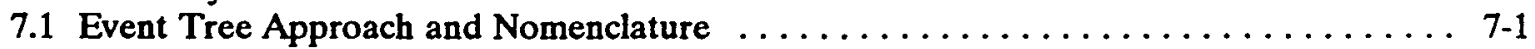

7.1.1 References: ........................... $7-4$

7.2 Success Criteria for the Time Window Approach $\ldots \ldots \ldots \ldots \ldots \ldots \ldots \ldots \ldots 7.8$

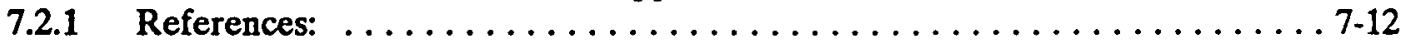

7.3 Loss of Residual Heat Removal Event Trees . . . . . . . . . . . . . . . . . 7-21

7.3.1 Event Tree for Over-draining to Mid-Loop (RHR2A) $\ldots \ldots \ldots \ldots \ldots \ldots$ 7-21

7.3.1.1 "Over-Draining to Mid-Loop" POS 6 - Refueling Event Tree . . . . 7-21

7.3.1.2 "Over-Draining to Mid-Loop" Event Tree - Refueling POS 10 . . 7-25 
Table of Contents (continued)

7.3.1.3 "Over-Draining to Mid-Loop" Event Tree -

Drained Maintenance POS 6 ................... 7-25

7.3.2 Event Trees for Loss of Inventory (RHR2B) $\ldots \ldots \ldots \ldots \ldots \ldots \ldots \ldots$ 7-38

7.3.3 Event Trees for Total Loss Residual Heat Removal (RHR3) . . . . . . . . 7-49

7.3.4 Event Trees for Loss of Operating Train of RHR (RHR4) ... . . . . 7-60

7.3.5 Event Trees for Recoverable_Loss_of RHR_(RHR5) $\ldots \ldots \ldots \ldots \ldots \ldots \ldots$ 7-71

7.3.6 References: .............................. 7-82

7.4 Loss of Offsite Power and Station Blackout Event Trees $\ldots \ldots \ldots \ldots \ldots \ldots \ldots \ldots$

7.4.1 Event Trees for Loss of Offsite Power with

Both Emergency Buses Available (LI) . . . . . . . . . . . . . 7 7-86

7.4.1.1 L1 Event Tree for Window 1 of R6 (L1W1R6) . . . . . . . 7-86

7.4.1.2 L1 Event Tree for Window 1 of D6 (L1W1D6) . . . . . . . . 7.89

7.4.1.3 L1 Event Tree for Window 2 of R6 (L1W2R6) . . . . . . . 7-90

7.4.1.4 L1 Event Tree for Window 2 of D6 (L1W2D6) . . . . . . . 7-90

7.4.1.5 L1 Event Tree for Window 3 of R6 (L1W3R6) . . . . . . . . 7-90

7.4.1.6 L1 Event Tree for Window 3 of R10 (L1W3R10) . . . . . . 7-91

7.4.1.7 L1 Event Tree for Window 3 of D6 (L1W3D6) . . . . . . . . 7-91

7.4.1.8 L1 Event Tree for Window 4 of R6 (L1W4R6) . . . . . . . . 7-91

7.4.1.9 L1 Event Tree for Window 4 of R10 (L1W4R10) . . . . . . . . 7-91

7.4.1.10 L1 Event Tree for Window 4 of D6 (L1W4D6) . . . . . . . . . . . 7-91

7.4.2 Event Tree for Loss of Offsite Power with only One Emergency

Bus Available (L2) ....................... 7-91

7.4.3 Event Tree for Loss of Offsite Power with Only One Emergency Bus at Unit One and Station Black-out at Unit 2 (L3) $\ldots \ldots \ldots \ldots \ldots$ 7-92

7.4.4 Event Trees for Station Blackout at Unit 1 (B1) . . . . . . . . . . . 7-92

7.4.4.1 B1 Event Tree for Window 1 of R6 (B1W1R6) . . . . . . . . 7 7-94

7.4.4.2 B1 Event Tree for Window 1 of D6 (B1W1D6) $\ldots \ldots \ldots \ldots \ldots$ 7-95

7.4.4.3 B1 Event Trees in Other Windows ............... 7-96

7.4.5 Event Trees for Station Blackout at Both Units (B2) $\ldots \ldots \ldots \ldots \ldots \ldots$ 7-96

7.4.6 References .............................. 7-96

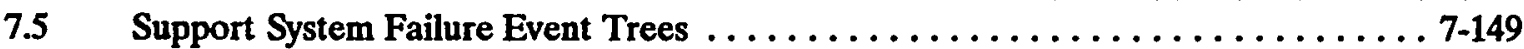

7.5.1 Event Trees for Loss of a $4.16 \mathrm{kV}$ AC Emergency Bus ............. 7-149

7.5.1.1 "Loss of a 4.16 kV AC Emergency Bus" Event Tree -

Refueling POS 6 ..................... 7-150

7.5.1.2 "Loss of a 4.16 kV AC Emergency Bus" Event Tree -

Refueling POS $10 \ldots \ldots \ldots \ldots \ldots \ldots \ldots \ldots \ldots \ldots \ldots \ldots \ldots$ 7-151

7.5.1.3 "Loss of a 4.16 kV AC Emergency Bus" Event Tree -

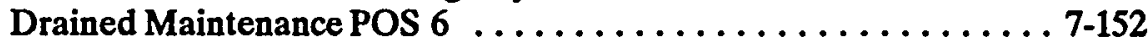

7.5.2 Event Trees for Loss of a $120 \mathrm{~V}$ AC Vital Bus (VB) ............ 7-164

7.5.2.1 "Loss of a 120 V AC Vital Bus" Event Tree -

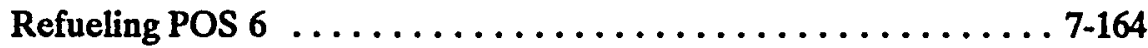

7.5.2.2 "Loss of a $120 \mathrm{~V}$ AC Vital Bus" Event Tree

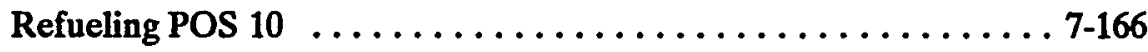

7.5.2.3 "Loss of a $120 \mathrm{~V}$ AC Vital Bus" Event Tree-

Drained Maintenance POS 6 ................... 7-166

7.5.3 Event Trees for the "Spurious ESFAS Signal" $\ldots \ldots \ldots \ldots \ldots \ldots \ldots$ 7-178

7.5.3.1 "Spurious ESFAS Signal" Event Tree - Refueling POS 6 . . . . . 7-178

7.5.3.2 "Spurious ESFAS Signal" Event Tree - Refueling POS 10 . . . . . 7-179

7.5.3.3 "Spurious ESFAS Signal" Event Tree - Drained Maintenance POS 6 7-180 


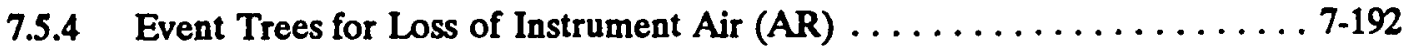

7.5.5 Event Trees for Loss of Component Cooling Water (CC) . . . . . . . . 7-204

7.5.5.1 "Loss of CCW" Event Tree - Refueling POS $6 \ldots \ldots \ldots$. . . . . .204

7.5.5.2 "Loss of CCW" Event Tree - Refueling POS $10 \ldots \ldots \ldots$. . . . 7-206

7.5.5.3 "Loss of CCW" Event Tree - Drained Maintenance POS 6 . . . . . 7-206

7.5.6 Event Trees for Loss of Emergency Switchgear Room Cooling (SR) . . . . . 7-218

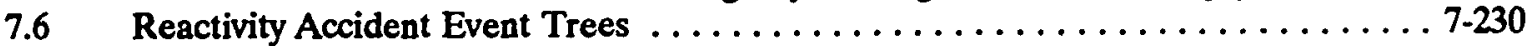

7.6.1 Uncontrolled Boron Dilution from CVCS . . . . . . . . . . . . 7.230

7.6.2 Probabilistic Analysis of Boron Dilution Events During RCS Mid-Loop

Operation . . . . . . . . . . . . . . . . .

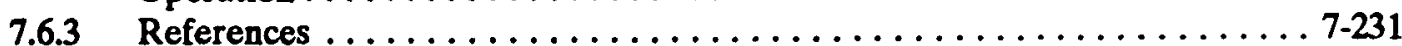

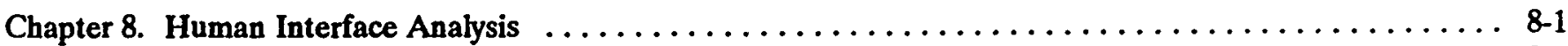

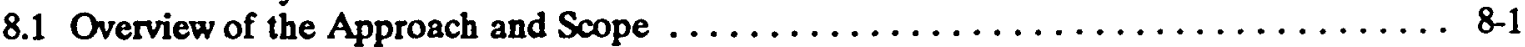

8.2 Plant Design and Practice - Special Features at Surry $\ldots \ldots \ldots \ldots \ldots \ldots \ldots \ldots$. $8-2$

8.2.1 Surry Plant Procedures and Training $\ldots \ldots \ldots \ldots \ldots \ldots \ldots \ldots \ldots \ldots$ 8-2

8.2.2 Surry Plant Operational Staffing $\ldots \ldots \ldots \ldots \ldots \ldots \ldots \ldots \ldots \ldots \ldots \ldots$ 8-3

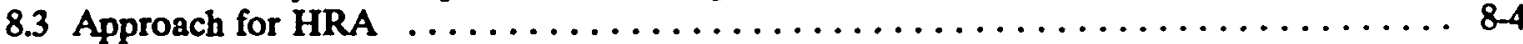

8.3.1 Incorporation Of Human Actions Into The Plant Model .......... 8.5

8.3.2 Routine Actions Before An Initiating Event ............... 8-6

8.3.3 Methodology For Evaluation Of Dynamic Operator

Actions and Recovery Actions $\ldots \ldots \ldots \ldots \ldots \ldots \ldots \ldots$ 8-6

8.3.3.1 Qualitative Evaluation $\ldots \ldots \ldots \ldots \ldots \ldots \ldots \ldots \ldots$ 8 6 .7

8.3.3.2 Quantitative Evaluation $\ldots \ldots \ldots \ldots \ldots \ldots \ldots \ldots \ldots$ 8-8

8.3.3.3 Quantification Process $\ldots \ldots \ldots \ldots \ldots \ldots \ldots \ldots \ldots$ 8-10

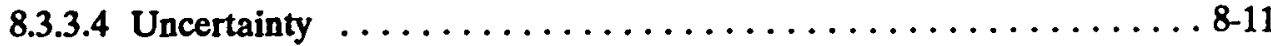

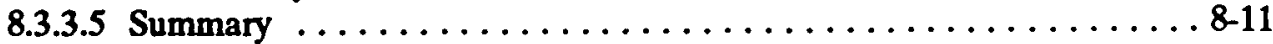

8.4 Actions while at Mid-loop $\ldots \ldots \ldots \ldots \ldots \ldots \ldots \ldots \ldots \ldots \ldots \ldots \ldots \ldots \ldots \ldots \ldots \ldots \ldots \ldots \ldots .12$

8.4.1 Human Responses . . . . . . . . . . . . . . . . . . . .

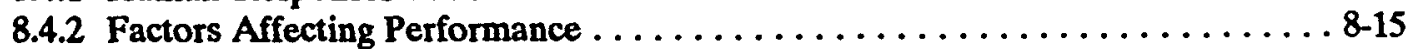

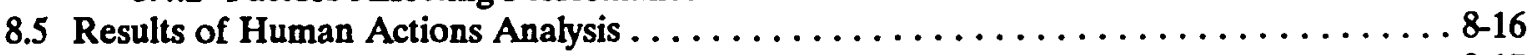

8.5.1 Qualitative Description Of The Dynamic Human Actions . . . . . . . . \& 817

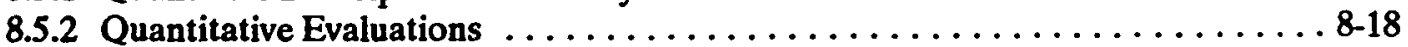

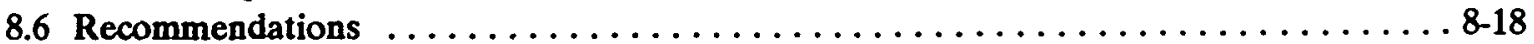

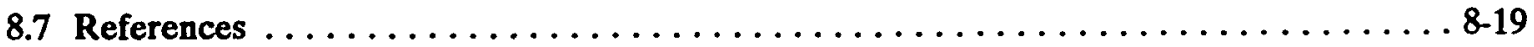

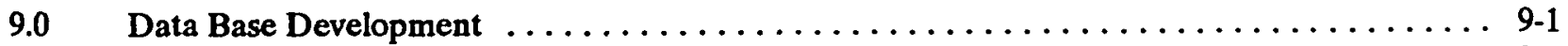

9.1 Maintenance Unavailability . . . . . . . . . .

9.2 Duration and Frequency of Plant Operational States . . . . . . . . . . . .

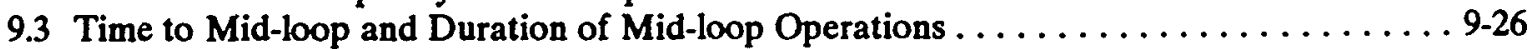

9.4 Use of $\log$ Book Data . . . . . . . . . . . . . . . . . . . . . . . . . . .

9.4.1 Isolation of RCS LOOPs . . . . . . . . . . . . $\ldots \ldots \ldots \ldots \ldots$

9.4.2 Steam Generator in Wet Layup vs Drained $\ldots \ldots \ldots \ldots \ldots \ldots \ldots \ldots \ldots . \ldots \ldots$

9.4.3 RCS Vented with Pressurizer Safety Valves Removed ............ 9-31

9.4.4 Time Period in Which the RCS Is Closed and The

Temporary Seals at the Seal Table Were Installed ............. 9-31

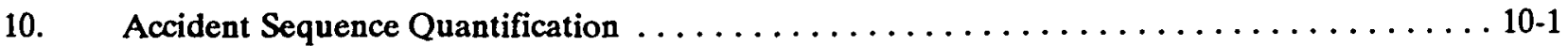

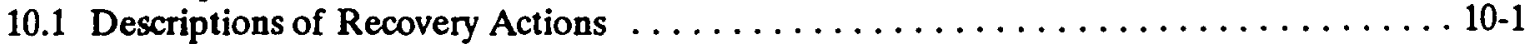

10.2 Results . . . . . . . . . . . . . . . . . . . . . . . . . . 
Table of Contents (continued)

10.3 Descriptions of Dominant Core Damage Cutsets $\ldots \ldots \ldots \ldots \ldots \ldots \ldots \ldots \ldots \ldots \ldots$

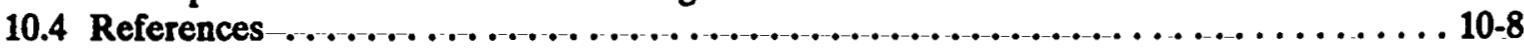

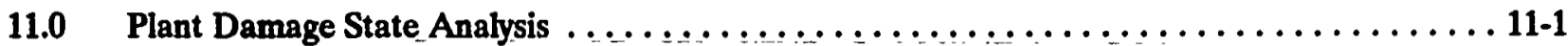

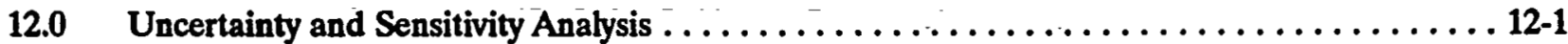

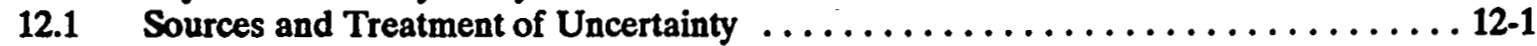

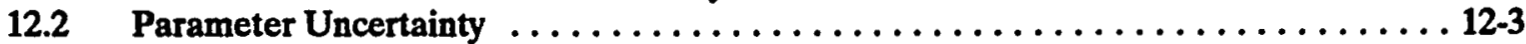

12.3 - Uncertainty-Analysis Results . . . . . . . .............................. 12-5

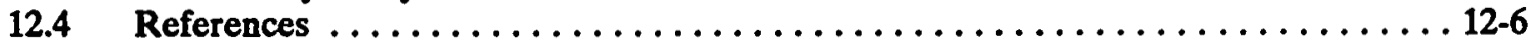

NUREG/CR-6144 xiv 


\section{LIST OF FIGURES}

Figure No.

Title

Page No.

3.1 Connection of the Standpipe System to the Vessel Head Vent $\ldots \ldots \ldots \ldots \ldots \ldots \ldots$

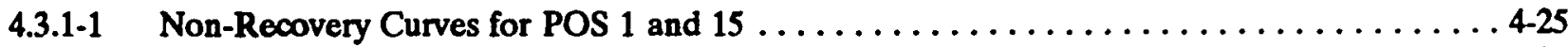

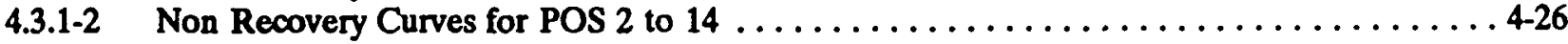

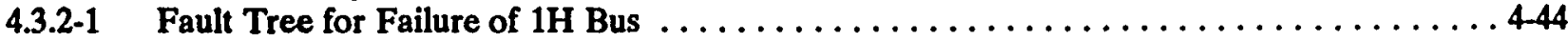

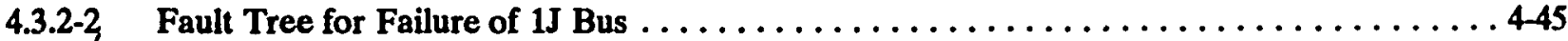

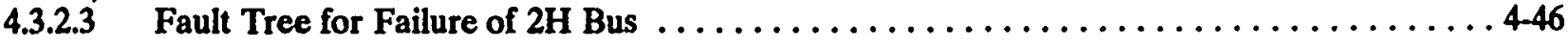

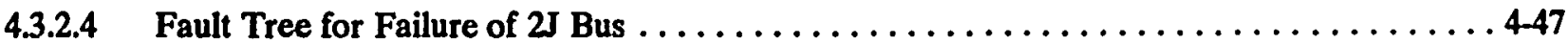

4.4.7-A-1 Fault Tree for Initiating Event "Loss of Emergency Switchgear Room Cooling" . 4-66

4.6.1 Schematic of the Low Pressure Safety Injection System V-Event Pathway . . . . . . . . 4-102

4.6.2 Schematic of the External Nonintrusive de Magnet

Check Valve Monitoring Method . . . . . . . . . . . . . . . . . . . . 4-103

4.6.3 Disc Position and Motion Diagram of a 10-inch Carbon Steel

Check Valve Monitored by the External dc Magnet Method. . . . . . . . . . . . . 4-104

4.6-4 Schematic of the Residual Heat Removal System

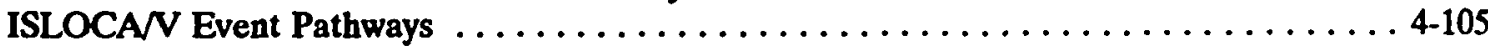

4.6-5 Schematic of the Accumulator ISLOCA Pathways $\ldots \ldots \ldots \ldots \ldots \ldots \ldots \ldots \ldots \ldots$ 4-106

5.1-1 State 6 (24 hours), Mid-loop Operation, Loops are Isolated $\ldots \ldots \ldots \ldots \ldots \ldots \ldots \ldots \ldots$

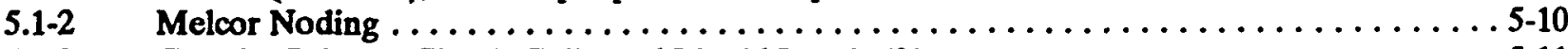

5.1-3 Case 3 - Primary Circuit Collapsed Liquid Levels $(\mathrm{ft}) \ldots \ldots \ldots \ldots \ldots \ldots \ldots \ldots \ldots \ldots$

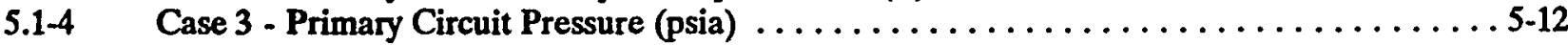

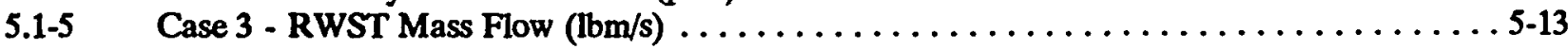

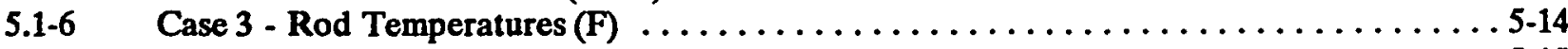

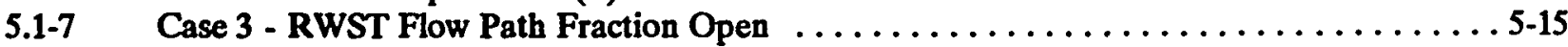

5.1-8 Case 3 - Pressurizer and RWST Liquid Levels $(\mathrm{ft}) \ldots \ldots \ldots \ldots \ldots \ldots \ldots \ldots \ldots \ldots$

5.1-9 Case 3 - SRV Manifold Mass Flow (lbm/s) $\ldots \ldots \ldots \ldots \ldots \ldots \ldots \ldots \ldots \ldots \ldots \ldots$

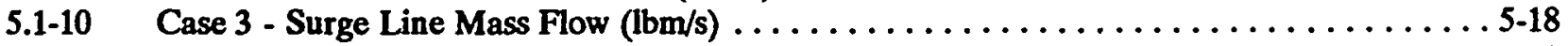

5.1-11 Case 3 - Containment Vapor Temperatures (F) $\ldots \ldots \ldots \ldots \ldots \ldots \ldots \ldots \ldots \ldots \ldots$

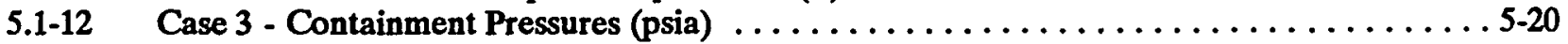

5.1-13 Impact of Delayed Injection - Pressurizer Pressure (psia) $\ldots \ldots \ldots \ldots \ldots \ldots \ldots \ldots \ldots$ 5-21

5.1-14 Impact of Delayed Injection - SRV Manifold Flow Velocity $(\mathrm{ft} / \mathrm{s}) \ldots \ldots \ldots \ldots \ldots \ldots$ 5-22

5.1-15 Impact of Delayed Injection - RWST Mass Flow $(\mathrm{lbm} / \mathrm{s}) \ldots \ldots \ldots \ldots \ldots \ldots \ldots \ldots \ldots \ldots$

5.1-16 Case 3 - Hot Leg $C$ and Pressurizer Vapor Temperatures $(F) \ldots \ldots \ldots \ldots \ldots \ldots \ldots$

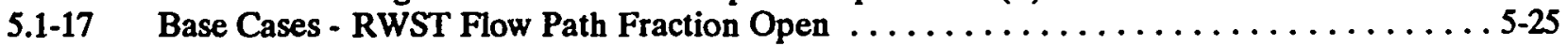

5.2-1 Diagram of RCS and Pressurizer . . . . . . . . . . . . . . . .

5.2-2 PRV Pressure at Decay Time of 1 Day and with the Opening of 2 PORVs ....... 5-42

5.2-3 PRV Pressure at Decay Time of 2 Days and with the Opening of 2 PORVs ........ 5-43

5.2-4 PRV Pressure at Decay Time of 29 Days and with the Opening of 2 PORVs . . . . . . 5-44

5.2-5 PRV Pressure at Decay Time of 1 Day and with the Opening of 1 PORV $\ldots \ldots \ldots \ldots 5-45$

5.2-6 PRV Pressure at Decay Time of 2 Days and with the Opening of 1 PORV ........ 5-46

5.2-7 PRV Pressure at Decay Time of 29 days and with the Opening of 1 PORV ......... 5-47 
List of Figures (continued)

6.2.1-1 Accumulator System Simplified Sketch $\ldots \ldots \ldots \ldots \ldots \ldots \ldots \ldots \ldots \ldots \ldots \ldots \ldots \ldots$

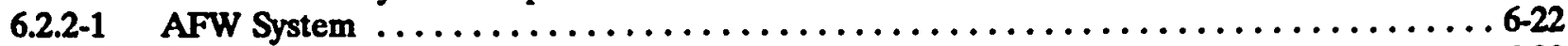

6.2.3-1 CPC System Simplified Sketch ............................... 6-29

6.2.4-1 Simplified Flow Diagram. Component Cooling Water System,

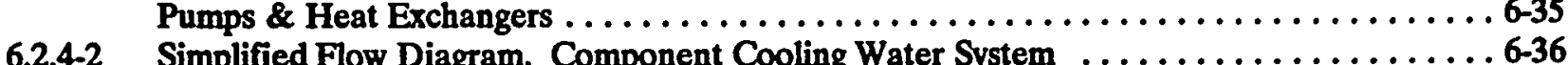

6.2.4-3 Simplified Flow Diagram. Component Cooling Water System, RC

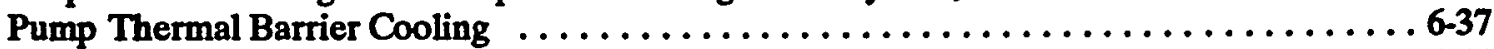

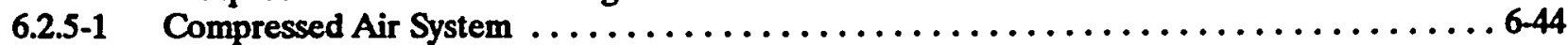

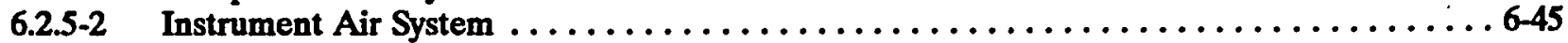

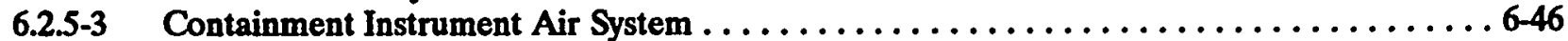

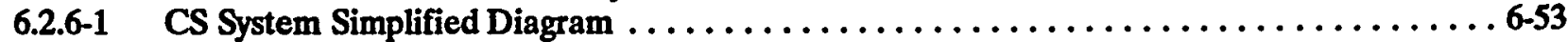

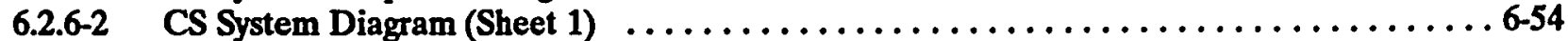

6.2.7-1 Simplified Diagram showing the EPS (Unit 1)

as part of the Basic Electrical Distribution System . . . . . . . . . . . . . . . 6-68

6.2.7-2 Plant 4160 VAC Electrical Distribution System (Unit 1 and Unit 2) $\ldots \ldots \ldots \ldots \ldots$.6.

6.2.7-3 Detailed Diagram of the EPS (Unit 1) .......................... 6-70

6.2.8-1 Emergency Switchgear Room Ventilation System Service Water Side . . . . . . . . . . 6-79

6.2.8-2 Emergency Switchgear Room Ventilation System Chilled Water Side . . . . . . . . . . 6-80

6.2.8-3 Central Chilled Water System Support for

Emergency Switchgear Room Ventilation System Chilled Water Side . . . . . . . . . 6-81

6.2.9-1 HPI/HPR System Simplified Sketch $\ldots \ldots \ldots \ldots \ldots \ldots \ldots \ldots \ldots \ldots \ldots \ldots \ldots \ldots$ 6-100

6.2.10-1 LPI/LPR System Simplified Sketch . . . . . . . . . . . . . . . . . . . . . 6-109

6.2.11-1 PPRS System Simplified Sketch $\ldots \ldots \ldots \ldots \ldots \ldots \ldots \ldots \ldots \ldots \ldots \ldots \ldots \ldots \ldots \ldots, 112$

6.2.11-2 Primary Pressure Relief System Dependency Diagram $\ldots \ldots \ldots \ldots \ldots \ldots \ldots \ldots \ldots \ldots 6-113$

6.2.12-1 RS System Simplified Diagram . . . . . . . . . . . . . . . . . . . . . 6-121

6.2.12-2 Recirculation Spray System ............................. 6-122

6.2.13-1 Simplified Drawing of the RHR System (Use 1150 drawing 4. Modify if necessary) . . . . 6-130

6.2.13-2 Component Cooling Water Supply to Loads Inside the Containment . . . . . . . . 6-131

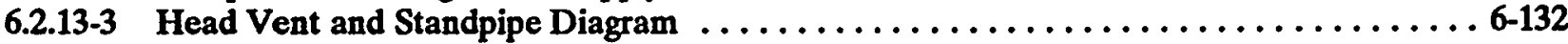

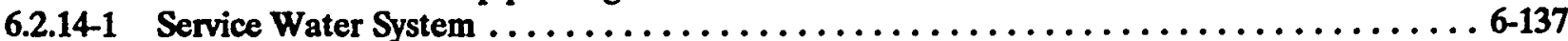

6.2.15-1 Steam Generator Recirculation and Transfer Systems . . . . . . . . . . . . . . 6-146

6.2.16-1 Simplified Diagram Main Steam System Steam Generator

to Main Steam Header . . . . . . . . . . . . . . . . . . . . . . . . . . . . . 6-151

6.2.16-2 Simplified Flow Diagram Main Steam Condenser Steam Dump Valves . . . . . . . . 6-152

7.1-1 Event Tree (R5W1R6) for a Recoverable Loss of RHR(RHR5) Initiating Event

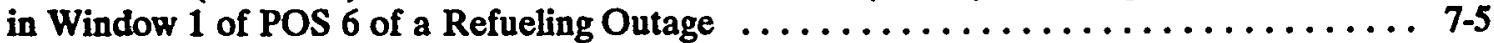

7.1-2 Fault Tree for the " $T$ "Top Event of Event Tree R5W1R6 ................. 7.6

7.1-3 High Level Fault Tree for Recovery of RHR Given a RHR5

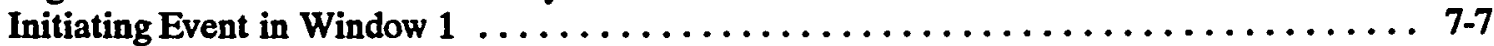

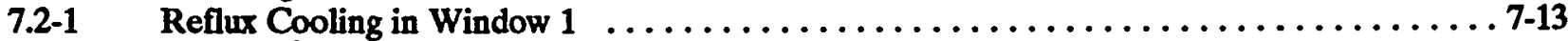

7.2-2 Feed and Bleed $R C S$ with $V$ failed in RHR4, Window $1 \ldots \ldots \ldots \ldots \ldots \ldots \ldots \ldots$ 7-14

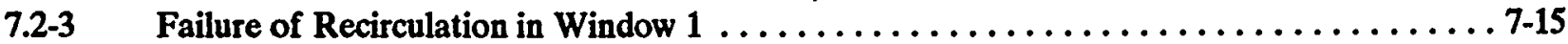

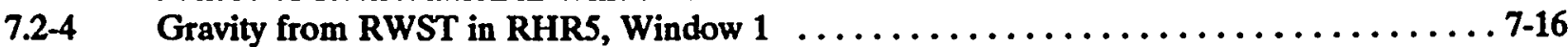

7.3.1-1 Event Tree for Over-draining to Mid-loop in Window 1 R6 (RAW1R6) .......... 7-28

7.3.1-2 Event Tree for Over-draining to Mid-loop in Window 2 R6 (RAW2R6) . ......... 7-29

7.3.1-3 Event Tree for Over-draining to Mid-loop in Window 3 R6 (RAW3R6) . . . . . . . 7-30

7.3.1-4 Event Tree for Over-draining to Mid-loop in Window 4 R6 (RAW4R6) . . . . . . . . 7-31

7.3.1-5 Event Tree for Over-draining to Mid-loop in Window 1 D6 (RAW1D6) . . . . . . . . 7-32 
7.3.1-6 Event Tree for Over-draining to Mid-loop in Window 2 D6 (RAW2D6) ........ 7-33

7.3.1-7 Event Tree for Over-draining to Mid-loop in Window 3 D6 (RAW3D6) . . . . . . . . 7-34

7.3.1-8 Event Tree for Over-draining to Mid-loop in Window 4 D6 (RAW4D6) ......... 7-35

7.3.1-9 Event Tree for Over-draining to Mid-loop in Window 3 R10 (RAW3R10) . . . . . . . 7-36

7.3.1-10 Event Tree for Over-draining to Mid-loop in Window 4 R10 (RAW4R10) . . . . . . . 7-37

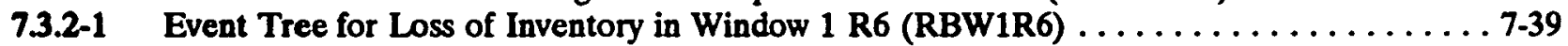

7.3.2-2 Event Tree for Loss of Inventory in Window 2 R6 (RBW2R6) . . . . . . . . . . . . 7-40

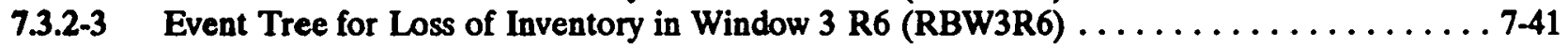

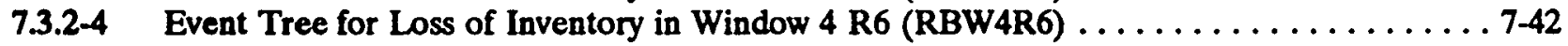

7.3.2.5 Event Tree for Loss of Inventory in Window 1 D6 (RBW1D6) . . . . . . . . . . . . . . . 7-43

7.3.2-6 Event Tree for Loss of Inventory in Window 2 D6 (RBW2D6) . . . . . . . . . . . 7-44

7.3.2-7 Event Tree for Loss of Inventory in Window 3 D6 (RBW3D6) . . . . . . . . . . . . 7-45

7.3.2-8 Event Tree for Loss of Inventory in Window 4 D6 (RBW4D6) . . . . . . . . . . . . 7-46

7.3.2.9 Event Tree for Loss of Inventory in Window 3 R10 (RBW3R10) . . . . . . . . . . . 7-47

7.3.2-10 Event Tree for Loss of Inventory in Window 4 R10 (RBW4R10). . . . . . . . . . 7-48

7.3.3-1 Event Tree for Total Loss of RHR in Window 1 R6 (R3W1R6) . . . . . . . . . . 7-50

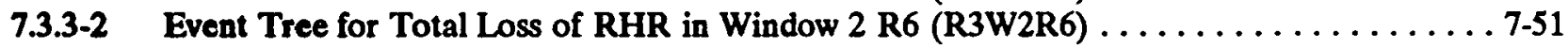

7.3.3-3 Event Tree for Total Loss of RHR in Window 3 R6 (R3W3R6) . . . . . . . . . . 7-52

7.3.3-4 Event Tree for Total Loss of RHR in Window 4 R6 (R3W4R6) . . . . . . . . . 7-53

7.3.3-5 Event Tree for Total Loss of RHR in Window 1 D6 (R3W1D6) $\ldots \ldots \ldots \ldots \ldots \ldots$ 7-54

7.3.3-6 Event Tree for Total Loss of RHR in Window 2 D6 (R3W2D6) $\ldots \ldots \ldots \ldots \ldots \ldots$ 7-55

7.3.3-7 Event Tree for Total Loss of RHR in Window 3 D6 (R3W3D6) $\ldots \ldots \ldots \ldots \ldots \ldots$

7.3.3-8 Event Tree for Total Loss of RHR in Window 4 D6 (R3W4D6) $\ldots \ldots \ldots \ldots \ldots \ldots$ 7-57

7.3.3-9 Event Tree for Total Loss of RHR in Window 3 R10 (R3W3R10) . . . . . . . . . 7-58

7.3.3-10 Event Tree for Total Loss of RHR in Window 4 R10 (R3W4R10) . . . . . . . . . . 7-59

7.3.4-1 Event Tree for Loss of Operating Train of RHR in Window 1 R6 (R4W1R6) . . . . . . 7-61

7.3.4-2 Event Tree for Loss of Operating Train of RHR in Window 2 R6 (R4W2R6) . . . . . . 7-62

7.3.4-3 Event Tree for Loss of Operating Train of RHR in Window 3 R6 (R4W3R6) . . . . . . 7-63

7.3.4-4 Event Tree for Loss of Operating Train of RHR in Window 4 R6 (R4W4R6) . . . . . . 7-64

7.3.4-5 Event Tree for Loss of Operating Train of RHR in Window 1 D6 (R4W1D6) . . . . . . 7-65

7.3.4-6 Event Tree for Loss of Operating Train of RHR in Window 2 D6 (R4W2D6) . . . . . . 7-66

7.3.4-7 Event Tree for Loss of Operating Train of RHR in Window 3 D6 (R4W3D6) . . . . . . 7-67

7.3.4-8 Event Tree for Loss of Operating Train of RHR in Window 4 D6 (R4W4D6) . . . . . . 7-68

7.3.4-9 Event Tree for Loss of Operating Train of RHR in Window 3 R10 (R4W3R10) . . . . . 7-69

7.3.4-10 Event Tree for Loss of Operating Train of RHR in Window 4 R10 (R4W4R10) . . . . . 7-70

7.3.5-1 Event Tree for Recoverable Loss of RHR in Window 1 R6 (R5W1R6) . . . . . . . . 7-72

7.3.5-2 Event Tree for Recoverable Loss of RHR in Window 2 R6 (R5W2R6) . . . . . . . 7 73

7.3.5-3 Event Tree for Recoverable Loss of RHR in Window 3 R6 (R5W3R6) . . . . . . . . 7 7-74

7.3.5-4 Event Tree for Recoverable Loss of RHR in Window 4 R6 (R5W4R6) . . . . . . . . 7-75

7.3.5-5 Event Tree for Recoverable Loss of RHR in Window 1 D6 (R5W1D6) . . . . . . . . 7 7-76

7.3.5-6 Event Tree for Recoverable Loss of RHR in Window 2 D6 (R5W2D6) . . . . . . . . 7-77

7.3.5-7 Event Tree for Recoverable Loss of RHR in Window 3 D6 (R5W3D6) . . . . . . . . 7-78

7.3.5-8 Event Tree for Recoverable Loss of RHR in Window 4 D6 (R5W4D6) ......... . 7-79

7.3.5-9 Event Tree for Recoverable Loss of RHR in Window 3 R10 (R5W3R10) . . . . . . 7 7-80

7.3.5-10 Event Tree for Recoverable Loss of RHR in Window 4 R10 (R5W4R10) . . . . . . . 7-81

7.4-1 L1 Event Tree for Window 1 of R6 (L1W1R6) $\ldots \ldots \ldots \ldots \ldots \ldots \ldots \ldots \ldots \ldots 7$

7.4-2 L1 Event Tree for Window 1 of D6 (L1W1D6) $\ldots \ldots \ldots \ldots \ldots \ldots \ldots \ldots \ldots \ldots$ 7-98

7.4-3 L1 Event Tree for Window 2 of R6 (L1W2R6) $\ldots \ldots \ldots \ldots \ldots \ldots \ldots \ldots \ldots \ldots$

7.4-4 L1 Event Tree for Window 2 of D6 (L1W2D6) $\ldots \ldots \ldots \ldots \ldots \ldots \ldots \ldots \ldots \ldots \ldots$

7.4-5 L1 Event Tree for Window 3 of R6 (L1W3R6) $\ldots \ldots \ldots \ldots \ldots \ldots \ldots \ldots \ldots \ldots$ 
List of Figures (continued)

7.4-6 L1 Event Tree for Window 3 of R10 (L1W3R10) . . . . . . . . . . . . . 7-102

7.4-7 L1 Event Tree for Window 3 of D6 (L1W3D6) $\ldots \ldots \ldots \ldots \ldots \ldots \ldots \ldots \ldots \ldots \ldots$

7.4-8 L1 Event Tree for Window 4 of R6 (L1W4R6) $\ldots \ldots \ldots \ldots \ldots \ldots \ldots \ldots \ldots \ldots$ 7-104

7.4-9 L1 Event Tree for Window 4 of R10 (L1W4R10) $\ldots \ldots \ldots \ldots \ldots \ldots \ldots \ldots \ldots \ldots \ldots \ldots$

7.4-10 L1 Event Tree for Window 4 of D6 (L1W4D6) $\ldots \ldots \ldots \ldots \ldots \ldots \ldots \ldots \ldots \ldots \ldots$

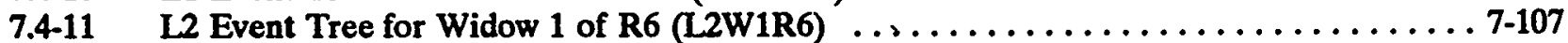

7.4-12 L2 Event Tree for Window 1 of D6 (L2W1D6) $\ldots \ldots \ldots \ldots \ldots \ldots \ldots \ldots \ldots \ldots$ 7-108

7.4-13 L2 Event Tree for Window 2 of R6 (L2W2R6) $\ldots \ldots \ldots \ldots \ldots \ldots \ldots \ldots \ldots \ldots \ldots$

7.4-14 L2 Event Tree for Window 2 of D6 (L2W2D6) $\ldots \ldots \ldots \ldots \ldots \ldots \ldots \ldots \ldots \ldots \ldots$

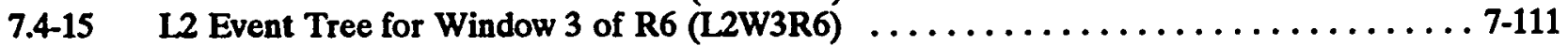

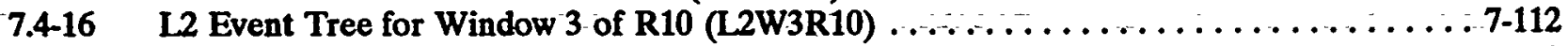

7.4-17 L2 Event Tree for Window 3 of D6 (L2W3D6) $\ldots \ldots \ldots \ldots \ldots \ldots \ldots \ldots \ldots \ldots \ldots \ldots$

7.4-18 L2 Event Tree for Window 4 of R6 (L2W4R6) .................... 7-114

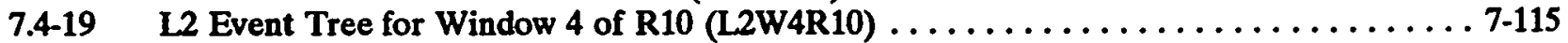

7.4-20 L2 Event Tree for Window 4 of D6 (L2W4D6) .................... 7-116

7.4-21 L3 Event Tree for Window 1 of $R 6(L 3 W 1 R 6) \ldots \ldots \ldots \ldots \ldots \ldots \ldots \ldots \ldots \ldots \ldots \ldots$

7.4-22 L3 Event Tree for Window 1 of D6 (L3W1D6) $\ldots \ldots \ldots \ldots \ldots \ldots \ldots \ldots \ldots \ldots \ldots$

7.4-23 L3 Event Tree for Window 2 of R6 (L3W2R6) . . . . . . . . . . . . . . 7-119

7.4-24 L3 Event Tree for Window 2 of D6 (L3W2D6) $\ldots \ldots \ldots \ldots \ldots \ldots \ldots \ldots \ldots \ldots \ldots \ldots$

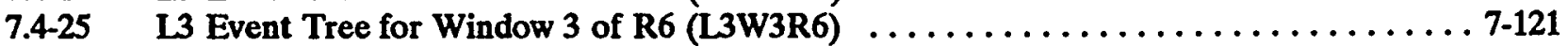

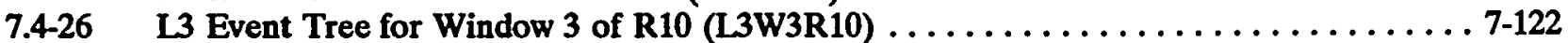

7.4-27 L3 Event Tree for Window 3 of D6 (L3W3D6) $\ldots \ldots \ldots \ldots \ldots \ldots \ldots \ldots \ldots \ldots \ldots \ldots$

7.4-28 L3 Event, Tree for Window 4 of R6 (L3W4R6) $\ldots \ldots \ldots \ldots \ldots \ldots \ldots \ldots \ldots \ldots$ 7-124

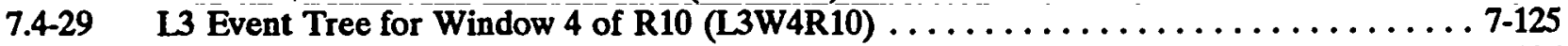

7.4-30 L3 Event Tree for Window 4 of D6 (L3W4D6) ................... 7.126

7.4-31 Event Tree for Unit-1 Station Blackout in Window 1 of R6 (B1W1R6) . . . . . . . . 7-127

7.4-32 Event Tree for Unit-1 Station Blackout in Window 1 of D6 (B1W1D6) . . . . . . . 7-128

7.4-33 Event Tree for Unit-1 Station Blackout in Window 2 of R6 (B1W2R6) . . . . . . . 7-129

7.4-34 Event Tree for Unit-1 Station Blackout in Window 2 of D6 (B1W2D6) ......... 7-130

7.4-35 Event Tree for Unit-1 Station Blackout in Window 3 of R6 (B1W3R6) ......... 7-131

7.4-36 Event Tree for Unit-1 Station Blackout in Window 3 of R10 (B1W3R10) . . . . . . . 7-132

7.4-37 Event Tree for Unit-1 Station Blackout in Window 3 of D6 (B1W3D6) . . . . . . . 7-133

7.4-38 Event Tree for Unit-1 Station Blackout in Window 4 of-R6 (B1W4R6) . . . . . . . . 7-134

7.4-39 Event Tree for Unit-1 Station Blackout in Window 4 of R10 (B1W4R10) . . . . . . 7 7-135

7.4-40 Event Tree for Unit-1 Station Blackout in Window 4 of D6 (B1W4D6) . . . . . . . 7-136

7.4-41 Event Tree for Station-Blackout-at Both-Units-in-Window-1-of-R6-(B2W1R6) _......7-137

7.4-42 Event Tree for Station Blackout at Both Units in Window 1 of D6 (B2W1D6) . . . . . 7-138

7.4-43 Event Tree for Station Blackout at Both Units-in-Window 2 of- R6 (B2W2R6) . . . . . . 7-139

7.4-44 Event Tree for Station Blackout at Both Units in Window 2 of D6 (B2W2D6) . . . . . . 7-140

7.4-45 Event Tree for Station Blackout at Both Units in Window 3 of R6 (B2W3R6) . . . . . . 7-141

7.4-46 Event Tree for Station Blackout at Both Units in Window 3 of R10 (B2W3R10) . . . . . 7-142

7.4-47 Event Tree for Station_Blackout at Both Units in Window 3 of D6 (B2W3D6) . . . . . . . 7-143

7.4-48 $\ldots$, Event-Tree-for-Station-Blackout-at-Both-Units-in-Window-4-of-R6-(B2W4R6)_...... . ......7-144

7.4-49 /Event Tree for Station Blackout at Both Units in Window 4 of R10 (B2W4R10) . . . . . 7-145

7.4-50 Event Tree for Station Blackout at Both Units in Window 4 of D6 (B2W4D6) $\ldots . . . .7$ 7-146

7.5.1-1 Event Tree for Loss of $4 \mathrm{KV}$ Bus in Window 1-of-R6-(4KW1R6) $\ldots \ldots . \ldots \ldots \ldots \ldots .7-154$

7.5.1-2 Event Tree for Loss of 4KV Bus in Window 1 of R6 (4KW2R6) $\ldots \ldots \ldots \ldots \ldots \ldots 7-155$

7.5.1-3 Event Tree for Loss of 4KV Bus in Window 3 of R6 (4KW3R6) . . . . . . . . . 7-156

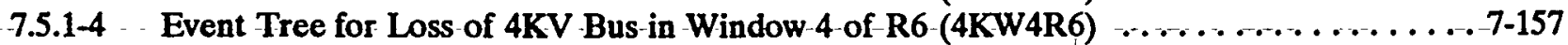

7.5.1-5 Event Tree for Loss of 4KV Bus in Window 3 of R10 (4KW3R10) . . . . . . . 7-158

NUREG/CR-6144 xviii 
List of Figures (continued)

7.5.1-6 Event Tree for Loss of 4KV Bus in Window 3 of R10 (4KW3R10) . . . . . . . 7-159

7.5.1-7

7.5.1-8

7.5.1.9

7.5.1-10

7.5.2-1

7.5.2-2

7.5.2-3

7.5.2-4

7.5.2-5

7.5.2.6

Event Tree for Loss of 4KV Bus in Window 1 of D6 (4KW1D6)

$7-160$

Event Tree for Loss of 4KV Bus in Window 2 of D6 (4KW2D6) $\ldots \ldots \ldots \ldots \ldots \ldots$ 7-161

Event Tree for Loss of 4KV Bus in Window 3 of D6 (4KW3D6) $\ldots \ldots \ldots \ldots \ldots \ldots 7-162$

Event Tree for Loss of $4 \mathrm{KV}$ Bus in Window 4 of D6 (4KW4D6) $\ldots \ldots \ldots \ldots \ldots \ldots 7-163$

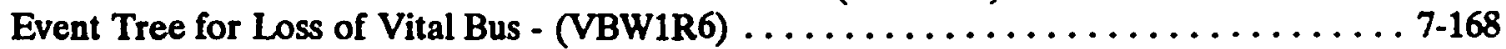

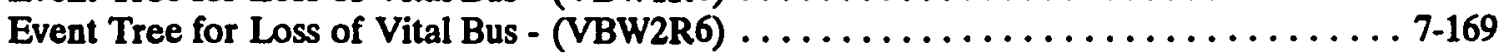

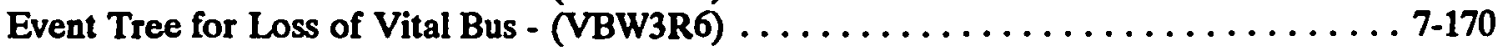

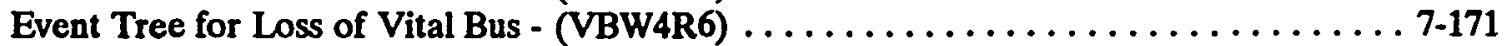

7.5.2-7

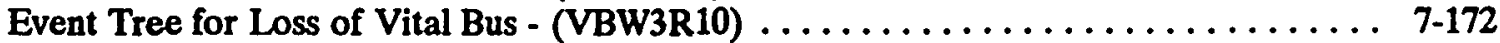

$7.5 .2-8$

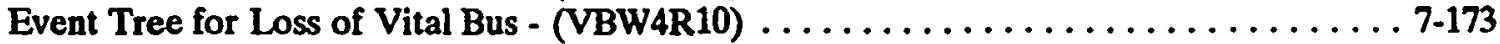

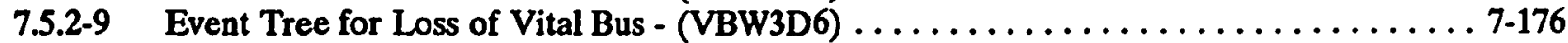

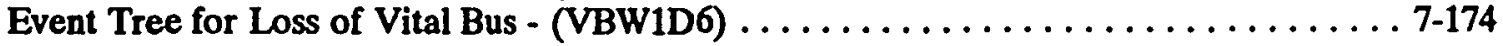

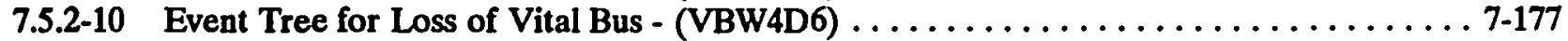

7.5.3-1 Event Tree for Spurious SI - in Window 1 of R6 (SIW1R6) . . . . . . . . . . . 7-182

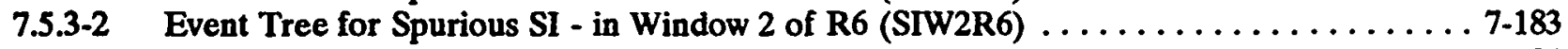

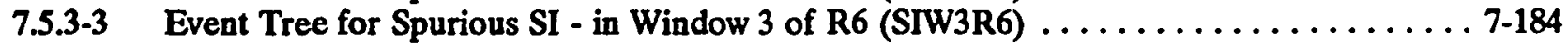

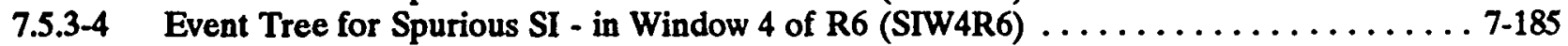

7.5.3-5 Event Tree for Spurious SI - in Window 3 of R10 (SIW3R10) . . . . . . . . . 7-186

7.5.3-6 Event Tree for Spurious SI - in Window 4 of R10 (SIW4R10) $\ldots \ldots \ldots \ldots \ldots \ldots \ldots$ 7-187

7.5.3-7 Event Tree for Spurious SI - in Window 1 od D6 (SIW1D6) $\ldots \ldots \ldots \ldots \ldots \ldots \ldots$ 7-188

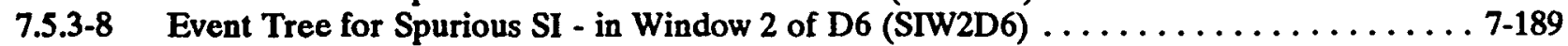

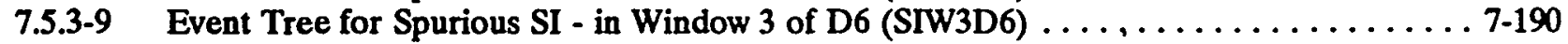

7.5.3-10 Event Tree for Spurious SI - in Window 4 of D6 (SIW4D6) . . . . . . . . . . . . 7-191

7.5.4-1 Event Tree for Loss of Instrument Air in Window 1 R6 (ARW1R6) . . . . . . . . . 7-194

7.5.4-2 Event Tree for Loss of Instrument Air in Window 2 R6 (ARW2R6) 7-195

7.5.4-3 Event Tree for Loss of Instrument Air in Window 3 R6 (ARW3R6) . . . . . . . . . 7-196

7.5.4-4 Event Tree for Loss of Instrument Air in Window 4 R6 (ARW4R6) . . . . . . . . . . 7-197

7.5.4-5 Event Tree for Loss of Instrument Air in Window 1 D6 (ARW1D6) . . . . . . . . 7-198

7.5.4-6 Event Tree for Loss of Instrument Air in Window 2 D6 (ARW2D6) . . . . . . . . . . 7-199

7.5.4-7 Event Tree for Loss of Instrument Air in Window 3 D6 (ARW3D6) . . . . . . . . 7-200

7.5.4-8 Event Tree for Loss of Instrument Air in Window 4 D6 (ARW4D6) . . . . . . . . . 7-201

7.5.4-9 Event Tree for Loss of Instrument Air in Window 3 R10 (ARW3R10) . . . . . . . . 7-202

7.5.4-10 Event Tree for Loss of Instrument Air in Window 4 R10 (ARW4R10) . . . . . . . . 7-203

7.5.5-1 Event Tree for Loss of CCW in Window 1 of R6 (CCW1R6) . . . . . . . . . . . 7-208

7.5.5-2 Event Tree for Loss of CCW in Window 2 of R6 (CCW2R6) . . . . . . . . . . . 7-209

7.5.5-3 Event Tree for Loss of CCW in Window 2 of R6 (CCW3R6) . . . . . . . . . . . 7-210

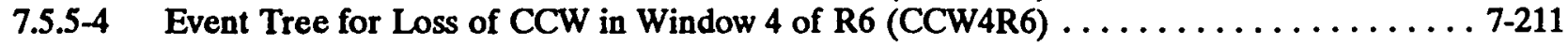

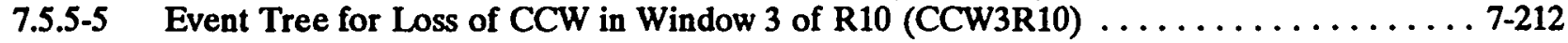

7.5.5-6 Event Tree for Loss of CCW in Window 4 of R10 (CCW4R10) . . . . . . . . . . 7-213

7.5.5-7 Event Tree for Loss of CCW in Window 1 of D6 (CCW1D6) . . . . . . . . . . . 7-214

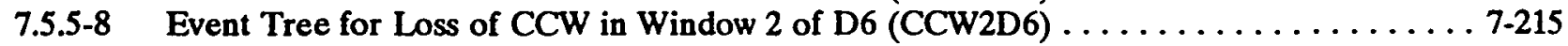

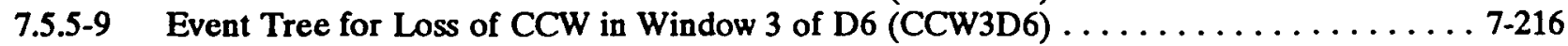

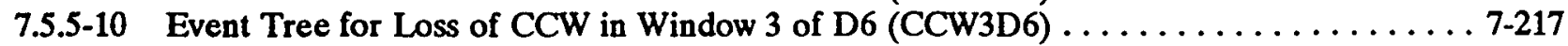

7.5.6-1 Event Tree for Loss of ESGR Cooling in Window 1 of R6 (SRW1R6) . . . . . . . 7-220

7.5.6-2 Event Tree for Loss of ESGR Cooling in Window 2 of R6 (SRW2R6) . . . . . . . . . 7-221

7.5.6-3 Event Tree for Loss of ESGR Cooling in Window 3 of R6 (SRW3R6) . . . . . . . . 7-222

7.5.6-4 Event Tree for Loss of ESGR Cooling in Window 4 of R6 (SRW4R6) . . . . . . . . . 7-223

7.5.6-5 Event Tree for Loss of ESGR Cooling in Window 3 of R10 (SRW3R10) . . . . . . . . 7-224 
List of Figures (continued)

7.5.6-6 Event Tree for Loss of ESGR Cooling in Window 4 of R10 (SRW4R10) . . . . . . . . 7-225

7.5.6-7 Event Tree for Loss of ESGR Cooling in Window 1 of D6 (SRW1D6) . . . . . . . . . 7.226

7.5.6-8 Event Tree for Loss of ESGR Cooling in Window 2 of D6 (SRW2D6) . . . . . . . . 7-227

7.5.6-9 Event Tree for Loss of ESGR Cooling in Window 3 of D6 (SRW3D6) . . . . . . . . . 7-228

7.5.6-10 Event Tree for Loss of ESGR Cooling in Window 4 of D6 (SRW4D6) . . . . . . . . . 7-229

7.6-1 Surry Reactivity Accident Due to Unplanned Boron Dilution During RCS

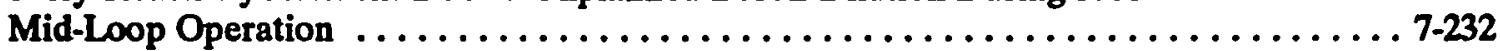

9.1-1 An Example of Information Collected on Component Down Time During a Refueling Outage .............................. 9-3

9.1-2 Time-Line Diagram for Safety-Related Component Down Time that Covered Mid-loop Operations (POS 6) during Surry 1, 1986 Refueling Outage .......... 9-5

9.1-3 Time-Line Diagram for Safety-Related Component Down Time-that Covered Mid-loop Operations (POS 6/POS 10) during Surry 2,1986 Refueling Outage . . . . . . 9 9-6

9.1-4 Time-Line Diagram for Safety-Related Component Down Time that Covered Mid-loop Operations (POS 6/POS 10) during Surry 1, 1990 Refueling Outage ....... 9-7

10.1 An Example Event Tree for Calculating Failure_Probability_

of Recovery Actions . . . ..................... 10-9

$10.2 \quad$ Main Steam Non-Return Valve $\ldots \ldots \ldots \ldots \ldots \ldots \ldots \ldots \ldots \ldots \ldots \ldots \ldots \ldots \ldots \ldots \ldots \ldots$

10.3 Surry Station 4Kv Electrical Distribution System $\ldots \ldots \ldots \ldots \ldots \ldots \ldots \ldots \ldots \ldots \ldots$ 


\section{LIST OF TABLES}

S.1 Summary of Results-Core-Damage Frequency by Initiating Event and

Plant Operational States . . . . . . . . . . . . . . . . . . . . . . . . . . . . . .

Comparison of Total Core-Damage Frequency with NUREG-1150 and IPE . . . . . . xxvix

Result of the Uncertainty Analysis for Total Core-Damage Frequency (per year) . . . . . . x xl

Summary of Results-Core Damage Frequency by

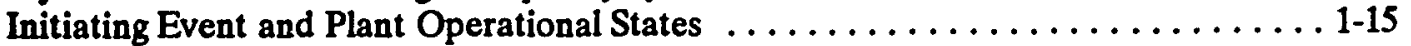

1.2 Comparison of Total Core Damage Frequency with NUREG-1150 and IPE $\ldots \ldots \ldots \ldots \ldots \ldots \ldots \ldots \ldots \ldots \ldots \ldots \ldots \ldots$

1.3 Result of the Uncertainty Analysis for Total Core Damage Frequency(per year) $\ldots \ldots \ldots \ldots \ldots \ldots \ldots \ldots \ldots \ldots \ldots$

3.1 Operational Modes Defined in Technical Specifications

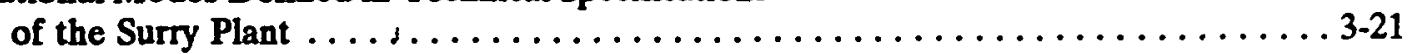

3.2 Operational Modes Westinghouse Standard Technical Specifications

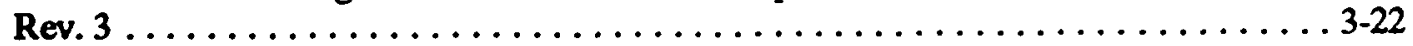

Outage Types and Their Estimated Frequencies

(based on data in 1985-1989) $\ldots \ldots \ldots \ldots \ldots \ldots \ldots \ldots \ldots \ldots \ldots \ldots \ldots \ldots \ldots \ldots \ldots \ldots \ldots \ldots .23$

Parameters Used in the Definition and

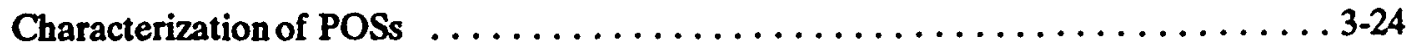

Estimated Durations of Plant Operational Modes (based on data in 1985-1989) $\ldots \ldots \ldots \ldots \ldots \ldots \ldots \ldots \ldots \ldots \ldots \ldots \ldots \ldots \ldots \ldots \ldots \ldots \ldots .25$

Plant Operational States for Surry Unit 1 - Low Power and Shutdown Outage Activities . . 3-32

Duration of Plant Operational States - Non-Drained Maintenance w.RHR (N1) ...... 3-33

Duration of Plant Operational States - Non-Drained Maintenance w/o RHR (N2) . . . . 3-34

Duration of Plant Operational States - Drained Maintenance D . . . . . . . . . . 3-35

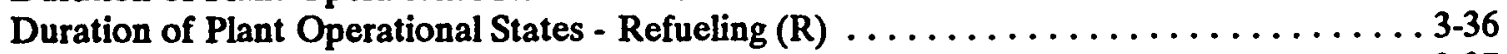

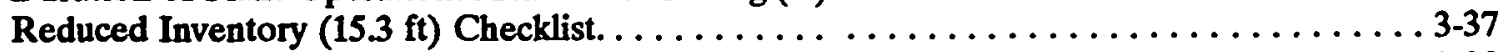

Time to Mid-loop, and Duration of Mid-loop $\ldots \ldots \ldots \ldots \ldots \ldots \ldots \ldots \ldots \ldots \ldots \ldots \ldots \ldots \ldots \ldots$

Probability that the Initiating Event Occurs in the Time Windows $\ldots \ldots \ldots \ldots \ldots \ldots$ 3-39

Probability that the RCS Loops Are Isolated So that Cooling Is Unavailable or Ineffective . 3-40

Probability that the Safety Valves on the Pressurizer Are Removed ............ 3-41

4.1-1 Approach Used in Identification of Initiating Events $\ldots \ldots \ldots \ldots \ldots \ldots \ldots \ldots \ldots$

4.1-2 Initiating Events Categories $\ldots \ldots \ldots \ldots \ldots \ldots \ldots \ldots \ldots \ldots \ldots \ldots \ldots \ldots \ldots \ldots \ldots$

4.1-3 Applicability of Initiating Events to Plant Operational States $\ldots \ldots \ldots \ldots \ldots \ldots \ldots \ldots$ 4-9

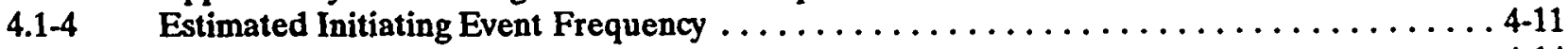

4.1.5 Operating Procedures that Were Reviewed Step by Step $\ldots \ldots \ldots \ldots \ldots \ldots \ldots \ldots$ 4-14

4.1.6 Summary of Findings in Reviewing NRC Information Notices, Bulletin,

Generic Letters, and Circulars Potential Degradation of Systems

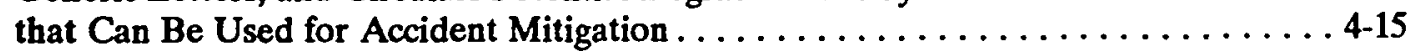

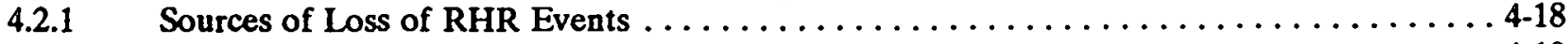

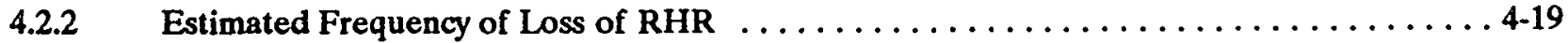

4.2-3 Data Used in Two Stage Bayesian Analysis $\ldots \ldots \ldots \ldots \ldots \ldots \ldots \ldots \ldots \ldots \ldots \ldots \ldots$ 4-20

4.2-4 Data Used in Two Stage Bayesian Analysis

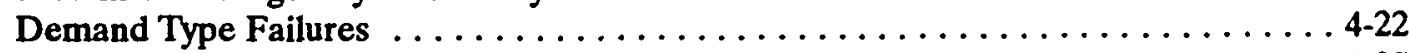

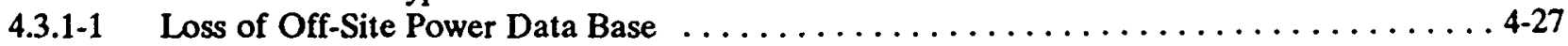

4.3.1-2 Loss of OffSite Power Data Base Events Considered as Category IV

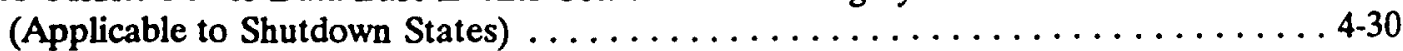

4.3.1-3 Data Used in Estimating Loss of Offsite Power Frequency (up to 1988) . . . . . . . . 4-31 
List of Tables (continued)

4.3.1-4 Estimated Frequency of Loss of Offsite Power Using Data up to End of $1988 \ldots \ldots \ldots$. . . . .

4.3.1-5 Mean Non-Recovery Curves for POSs 1 and $15 \ldots \ldots \ldots \ldots \ldots \ldots \ldots \ldots \ldots \ldots$

4.3.1-6 Mean Non-Recovery Curves for POS 2 to $14 \ldots \ldots \ldots \ldots \ldots \ldots \ldots \ldots \ldots \ldots \ldots \ldots$

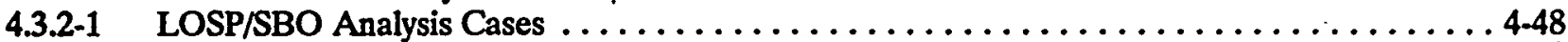

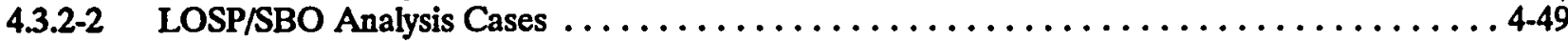

4.3.2-3 Conditional Probabilities of Various Bus Failures $\ldots \ldots \ldots \ldots \ldots \ldots \ldots \ldots \ldots \ldots \ldots$ 4-50

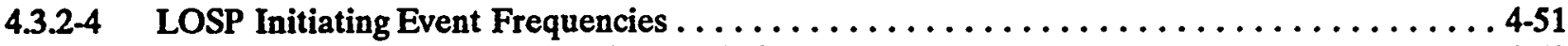

4.4-1 Data Used in Two Stage Bayesian Analysis . . . . . . . . . . . . . . . . . . 4-59

4.4-2 Data used in Two Stage Bayesian Analysis for Loss of Instrument Air . . . . . . . . . 4-61

4.4-3 Mean Non-Recovery Curves for Support System Initiators $\ldots \ldots \ldots \ldots \ldots \ldots \ldots \ldots \ldots$ 4-64

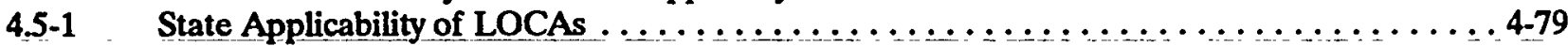

4.5-2 Fraction of Time that the Plant stays in the POSs $\ldots \ldots \ldots \ldots \ldots \ldots \ldots \ldots \ldots \ldots \ldots 4-80$

4.5-3 A LOCA Frequency vs. POS vs. Outage Type (Without ISL Contribution) . . . . . . . 4-81

4.5-4 A LOCAs Initiator Frequency (/yr) Corresponding to-POS-Specific Event Trees

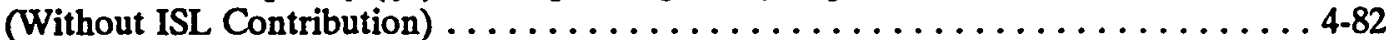

4.5-5 A LOCAs Initiator Frequency With ISL Contribution $\ldots \ldots \ldots \ldots \ldots \ldots \ldots \ldots \ldots$ 4-83

4.5-6 S1 LOCA Initiator Frequency vs. POS vs. Outage Type (Without ISL Contribution) . . . . 4-84

4.5-7 S1 LOCA Initiator Frequency Corresponding to POS-Specific Event Trees . . . . . . . . . 4-85

4.5-8 S2 LOCA Initiator Frequency vs. POS vs. Outage Type (Without ISL Contribution) . . . . 4-86

4.5-9 S2 LOCA Initiator Frequency Corresponding to POS-Specific Event Trees . . . . . . . . 4 4-87

4.5-10 S3 LOCA Initiator Frequency vs. POS vs. Outage Type $\ldots \ldots \ldots \ldots \ldots \ldots \ldots \ldots \ldots$ 4-88

4.5-11 S3_LOCA_Initiator_Frequency-for_POS-Specific Event Trees.................................4-89

4.5-12 Other LOCA Initiator Frequencies Considered in Report . . . . . . . . . . . . . 4-90

4.6-1 Core Damage Frequency in Various POSs due to the LPIS V-Event Scenario . . . . . . 4-107

4.6-2 Initiating Frequencies for Small, Medium and-Large-LOCAs-Inside-Containment due to ISLOCAs through RHR Suction and Discharge Lines

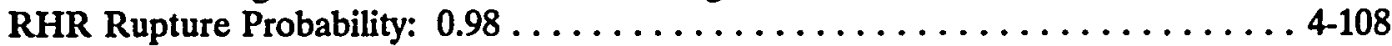

4.6-3 Core Damage Frequencies due to "V-Events"

through the RHR-CVCS Letdown Line . . . . . . . . . . . . . . . 4-109

4.6-4 Core Damage Frequencies due to V-Events through the Connecting Line to the RWST . 4-110

4.6-5 Initiating.Frequencies for_Small and_Medium_LOCAs_Inside Containment due to ISLOCAs through the Accumulator Discharge Lines

Probability for the Loss of Accumulator Integrity: 1.0_.... ... ................ . . . . 4-111

4.6-A1 RHR System Rupture Probabilities as a Function of RCS Pressure

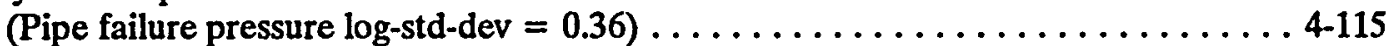

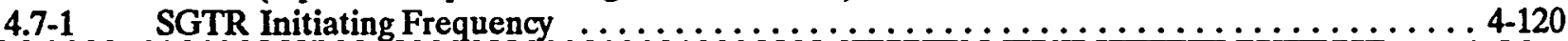

4.9-1 Initiating Event Categorization for Surry Plant At Low Power/Shutdown States . . . . . . 4-124

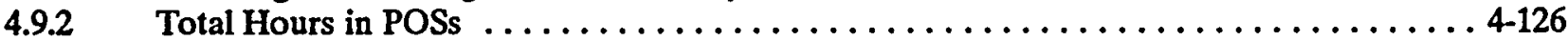

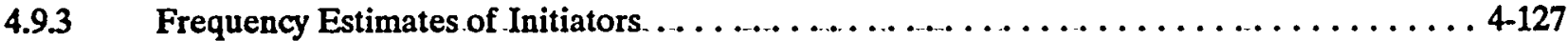

4.9-4 Frequency Estimates of Transient Event Categories . . . . . . . . . . . . . . 4-128

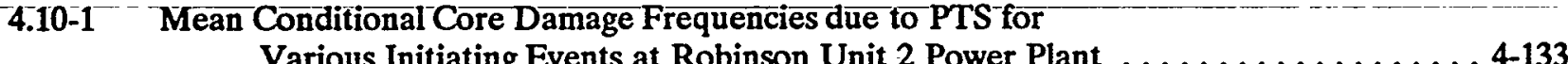

4.10-2 PTS Core Damage Frequencies due to Various Initiating Events

During Low Power Operation and Shutdown at Surry Unit 1 Power Plant . ..... 4-134

4.12-1 Initiating Events that Are Applicable to the Mid-Loop POSs $\ldots \ldots \ldots \ldots \ldots \ldots \ldots \ldots$ 4-146

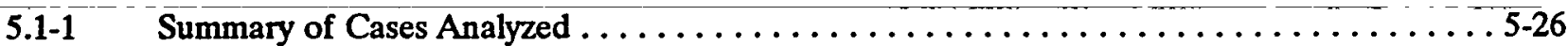

5.1-2 Base Case Results. Cold Leg Injection after 30 minutes,

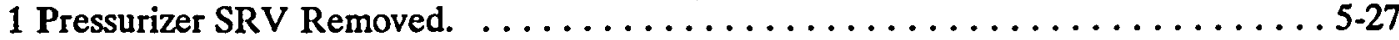

5.1-3 No Injection, 1 Pressurizer SRV Removed $\ldots \ldots \ldots \ldots \ldots \ldots \ldots \ldots \ldots \ldots \ldots \ldots .28$ 
5.1-4 Cold Leg Injection after 30 minutes,

3 Pressurizer SRVs Removed. . . . . . . . . . . . . . . . . . . . . . . . . 5-29

5.1-5 Effect of Delayed Cold Leg Injection,

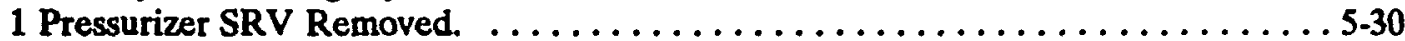

5.1-6 Effect of Delayed Cold Leg Injection,

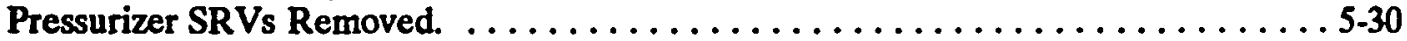

5.2-1 Summary of Case 1 (Bleed Only-2 PORVs OPEN-SRV CLOSED) $\ldots \ldots \ldots \ldots \ldots \ldots 5-48$

$5.2-2$

$5.2-3$

$5.2-4$

$5.2-5$

$5.2-6$

5.3 .1

$5.4-1$

$5.4-2$

Summary of Case 2 (Bleed only-1 PORV Open-SRV Closed $\ldots \ldots \ldots \ldots \ldots \ldots \ldots \ldots-50$

Summary of Case 3 (Bleed Only-SRVs \& 2 PORVs OPEN) $\ldots \ldots \ldots \ldots \ldots \ldots \ldots \ldots$ 5-52

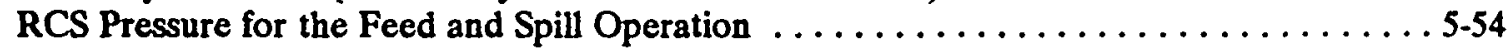

RCS Fill Time and RWST Depletion Time (Time in Hour) $\ldots \ldots \ldots \ldots \ldots \ldots \ldots 56$

Summary of Feed-and-Steam Operation Time in Minute) $\ldots \ldots \ldots \ldots \ldots \ldots \ldots \ldots$ 5-58

Steam Generator Secondary Water Boil-Off Time $\ldots \ldots \ldots \ldots \ldots \ldots \ldots \ldots \ldots \ldots . \ldots \ldots$

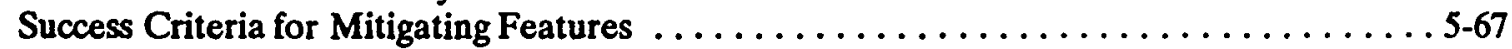

Definition and Characterization of Time Windows $\ldots \ldots \ldots \ldots \ldots \ldots \ldots \ldots \ldots \ldots$

6.1-1 System Fault Trees and Their Applicable POSs $\ldots \ldots \ldots \ldots \ldots \ldots \ldots \ldots \ldots \ldots$

6.1-2 System, Component, and Event Identifiers

Part 1: System Identifiers ....................... 6-7

6ystem, Component, and Event Identifiers
Part 2: Component Identifiers $\ldots \ldots \ldots \ldots \ldots \ldots \ldots \ldots \ldots \ldots \ldots \ldots \ldots \ldots \ldots$

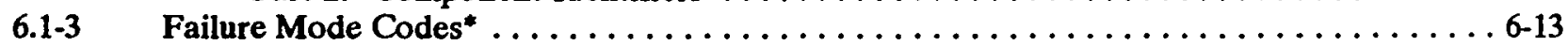

6.2.2-1 AFW System Component Status and Dependency Summary AFW System . . . 6 6-23

6.2.3-1 CPC Component Status and Dependency Summary . . . . . . . . . . . 6-30

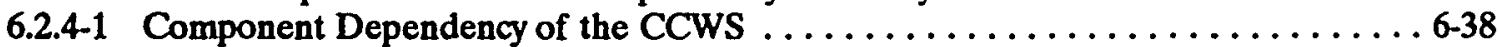

6.2.4-2 Top Event Definition and Identifiers for CCWS $\ldots \ldots \ldots \ldots \ldots \ldots \ldots \ldots 6$. $\ldots \ldots$

6.2.5-1 Instrument Air System Component Status and Dependency . . . . . . . . . 6-47

6.2.5-2 Impacts of loss of Turbine Building Instrument Air System and Containment . . 6 6-49

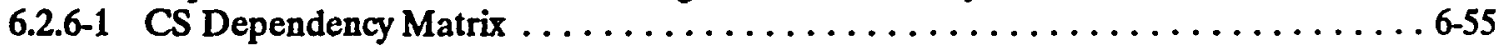

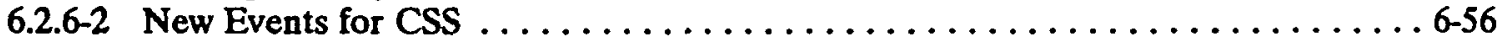

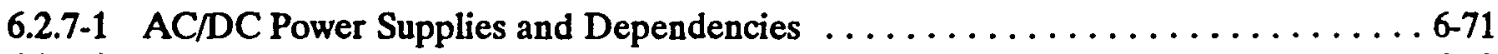

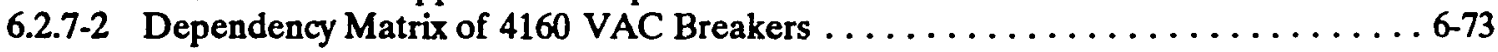

6.2.7-3 Top Event Definitions and Identifiers for the EPS $\ldots \ldots \ldots \ldots \ldots \ldots \ldots 6-74$

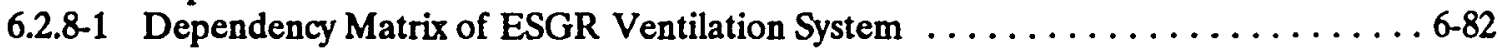

6.2.9-1 HPI/HPR Component Status and Dependency Summary . . . . . . . . . 6-101

6.2.10-1 LPI/LPR Component Status and Dependency Summary ............ 6-110

6.2.11-1 PPRS Component Status and Dependency Summary ............. 6-114

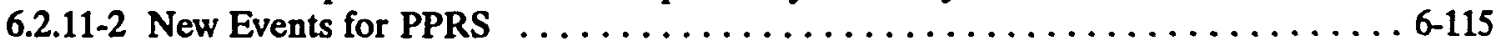

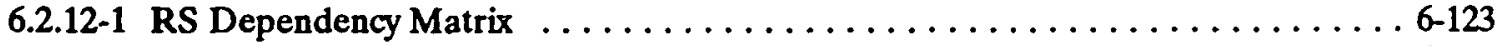

6.2.13-1 RHR System Component Status and Dependency Summary . . . . . . . . 6-133

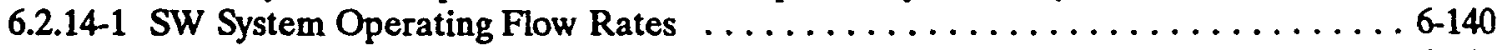

6.2.14-2 Power Supply of the Emergency Service Water Pumps ............ . 6-141

6.2.14-3 Power Supplies for Circulation Water Inlet and Outlet Isolation Valves . . . . . 6-142

6.2.15-1 Steam Generator Recirculation and Transfer Systems

Component Status and Dependency Summary ............... 6-147

6.2.16-1 Steam Generator Secondary Relief System Component Dependency . . . . . . . 6 6-153

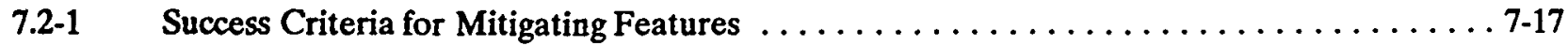

7.2-2 Definition and Characterization of Time windows $\ldots \ldots \ldots \ldots \ldots \ldots \ldots \ldots \ldots \ldots \ldots \ldots$ 
List of Tables (continued)

7.2-3 Probability that the RCS Loops Are Isolated Such that Reflux Cooling Is Unavailable or

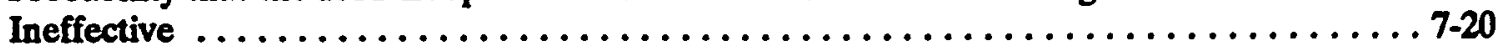

7.2-4 Probability that the Safety Valves on the Pressurizer Is Removed $\ldots \ldots \ldots \ldots \ldots \ldots \ldots$ 7-20

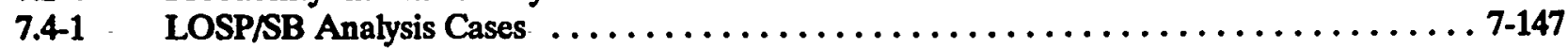

7.4-2 Power Supplies for Circulating Water Main Condensers' Inlet and Outlet Valves . . . . . 7-148

7.6-1 Summary of Inadvertent RCS Boron Dilution Which Occurred

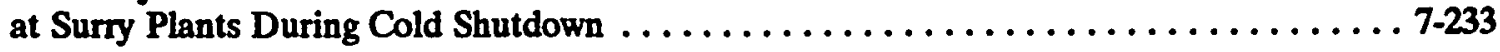

-8.1 Guidance Regarding Information to-Include in Operator-Response-Forms $\ldots \ldots \ldots \ldots \ldots$ 8-22 8.2 Guidance for Scoring the Degree of Difficulty Presented by Each PSF Associated with Each

Dynamic Human Action . . . . . . . . . . . . . . . .

8.3 Guidance for Assigning Relative Weights to the PSF Scores

Associated with Each Dynamic Human Action . . . . . . . . . . . . . . . 8-30

8.4 Summary of the Relationship between -the-Scoring-and-Weighing-Processes ..... . . 8-37

8.5 Qualitative Descriptions of Dynamic Human Actions

Evaluated for the Surry Shutdown PRA $\ldots \ldots \ldots \ldots \ldots \ldots \ldots \ldots \ldots \ldots \ldots . \ldots \ldots$

8.6 Qualitative Descriptions of Dynamic Human Actions

Evaluated for the Surry Shutdown PRA . . . . . . . . . . . . . . . . . . 8-39

8.7 Qualitative Descriptions of Dynamic Human Actions

Evaluated for the Surry Shutdown PRA ...................... 8-40

8.8 Qualitative Descriptions of Dynamic Human Actions

Evaluated for the Surry Shutdown PRA ...................... 8-42

8.9 Qualitative Descriptions of Dynamic Human Actions

Evaluated for the Surry Shutdown PRA . . . . . . . . . . .

8.10 Relationship between Loss of Support System/

Loss of Offsite Power/Safety Injection Initiating Events

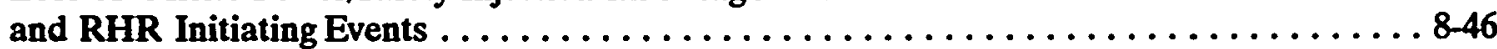

$8.11 \quad$ Recovery Factors Initiators $R A, R B, R 3, R 4$ and $R 5 \ldots \ldots \ldots \ldots \ldots \ldots \ldots \ldots \ldots$

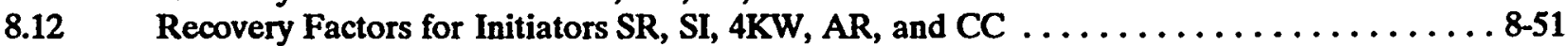

8.13 Qualitative Results of BNL/Surry Human Action Evaluations $\ldots \ldots \ldots \ldots \ldots \ldots \ldots$ 8-55

9.1-1 Maintenance Unavailability Estimates Based on Data Collected

from $\log$ Books and Minimum Equipment Lists $\ldots \ldots \ldots \ldots \ldots \ldots \ldots \ldots \ldots$

9.1-2 Component Downtime (that covered POS-6/POS-10) for Surry 1, May 1986 . . . . . . . . 9-11

9.1-3 Component Downtime (that covered POS-6/POS-10) for Surry 2, October 1986 . . . . . . 9-12

9.1-4 Component Downtime (that covered POS-6/POS-10) for Surry 1, October $1990 \ldots . . . . .9$ 9-15

9.1-5 Modified Maintenance Unavailability for POS 6 and POS $10 \ldots \ldots \ldots \ldots \ldots \ldots . . .16$

9.2-1 Duration of Plant Operational States - Non-Drained Maintenance w.RHR (N1) . . . . . . 9-18

9.2-2 Duration of Plant Operational States - Non-Drained Maintenance w/o RHR (N2) . . . . . 9-19

9.2-3 Duration of Plant Operational States - Drained Maintenance (D) . . . . . . . . . . 9-20

9.2-4 Duration of Plant Operational States - Refueling (R) $\ldots \ldots \ldots \ldots \ldots \ldots \ldots \ldots \ldots \ldots$ 9-21

9.2-5 Conservative Estimates of the Earliest Time (after shutdown) That a POS Can Be Reached 9-22

9.2-6 Operational Experience Data of Elapsed Time to Mid-loop at Surry . . . . . . . . 9-23

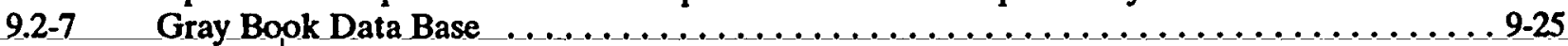

9.3-1 Characteristics of Time to Mid-loop and Characteristic Duration of Mid-loop . . . . . . 9-27

9.3-2 Distribution of the Time When the Accident Initiating Event Occurs . . . . . . . . 9-28

9.3-3 Probability that IE Occurs in the Window . . . . . . . . . . . . . . . . . . . . 9-29

9.4-1 Probability that the RCS Loops Are Isolated Such that Reflux

Cooling Is Unavailable or Ineffective . . . . . . . . . . . . . . . . . . . .

9.4-2 Probability that the Safety Valves on the Pressurizer Are Removed . . . . . . . . . . 9-34

NUREG/CR-6144 . 
List of Tables (continued)

10.1 Core Damage Frequencies of Loss RHR Event Trees RAW\#R6

Over-Draining to POS 6 of Refueling . . . . . . . . . . . . .

10.2 Core Damage Frequencies of Loss RHR Event Tree RBW\#R6

Inventory Problem in POS 6 of Refueling . . . . . . . . . . . . . . . . . 14

10.3 Core Damage Frequencies of Loss RHR Event Tree R3W\#R6

Non-Recoverable Loss of RHR in POS 6 of Refueling . . . . . . . . . . . . . . 10-16

10.4 Core Damage Frequencies of Loss RHR Event Tree R4W\#R6

Non-Recoverable Loss of Operating Train of RHR in POS 6 of Refueling . . . . . . . 10-17

10.5 Core Damage Frequencies of Loss RHR Event Tree R5W\#R6

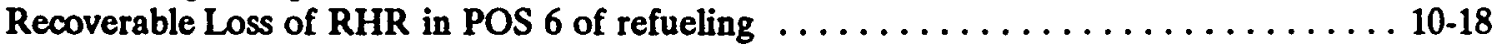

10.6 Core Damage Frequencies of Loss RHR Event Tree RAW\#D6

Over-Draining to POS 6 of Drained Maintenance . . . . . . . . . . . . . . . 10-19

10.7 Core Damage Frequencies of Loss RHR Event Tree RBW\#D6

Inventory Problem in POS 6 of Drained Maintenance . . . . . . . . . . . . . 10-20

10.8 Core Damage Frequencies of Loss RHR Event Tree R3W\#D6

Non-Recoverable Loss of RHR in POS 6 of Drained Maintenance . . . . . . . . . . 10-21

10.9 Core Damage Frequencies of Loss RHR Event Tree R4W\#D6

Non-Recoverable Loss of Operating Train of RHR

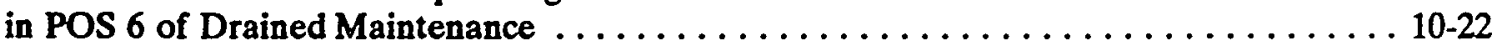

10.10 Core Damage Frequencies of Loss RHR Event Tree R5W\#D6

Recoverable Loss of RHR in POS 6 of Drained Maintenance . . . . . . . . . . . 10-23

10.11 Core Damage Frequencies of Loss RHR Event Tree- RAW\#R10

Over-Draining to POS 10 of Refueling . . . . . . . . . . . . . . . . . . 10-24

10.12 Core Damage Frequencies of Loss RHR Event Tree RBW\#R10

Inventory Problem in POS 10 of Refueling . . . . . . . . . . . . . . . .

10.13 Core Damage Frequencies of Loss RHR Event Tree R3W\#R10

Non-Recoverable Loss of RHR in POS 10 of Refueling . . . . . . . . . . . . 10-26

10.14 Core Damage Frequencies of Loss RHR Event Tree R4W\#R10

Non-Recoverable Loss of Operating Train of RHR in POS 10 of Refueling . . . . . . . 10-27

10.15 Core Damage Frequencies of Loss RHR Event Tree R5W\#R10 . . . . . . . . . 10-28

10.16 Core Damage Frequencies of Loss of Offsite Power for Event Tree L1W\#D6 . . . . . . 10-29

10.17 Core Damage Frequencies of Loss of Offsite Power for Event Tree L1W\#R6 . . . . . 10 10-30

10.18 Core Damage Frequencies of Loss of Offsite Power for Event Tree L1W\#R10 . . . . 10-32

10.19 Core Damage Frequencies of Loss of Offsite Power for Event Tree L2W\#D6 . . . . . . 10-33

10.20 Core Damage Frequencies of Loss of Offsite Power for Event Tree L2W\#R6 . . . . . . 10-34

10.21 Core Damage Frequencies of Loss of Offsite Power for Event Tree L2W\#R10 . . . . 10-36

10.22 Core Damage Frequencies of Loss of Offsite Power for Event Tree L3W\#D6 . . . . . . 10-37

10.23 Core Damage Frequencies of Loss of Offsite Power for Event Tree L3W\#R6 . . . . . 10-38

10.24 Core Damage Frequencies of Loss of Offsite Power for Event Tree L3W\#R10 . . . . . 10-40

10.25 Core Damage Frequencies of Unit-1 Blackout for Event Tree B1W\#D6 . . . . . . . . . 10-41

10.26 Core Damage Frequencies of Unit-1 Blackout for Event Tree B1W\#R6 . . . . . . . . 10-42

10.27 Core Damage Frequencies of Unit-1 Blackout for Event Tree B1W\# R10 . . . . . . . 10-44

10.28 Core Damage Frequencies of 2-Units Blackout for Event Tree B2W\#D6 . . . . . . . 10-45

10.29 Core Damage Frequencies of 2-Units Blackout for Event Tree B2W\#R6 . . . . . . . 10-46

10.30 Core Damage Frequencies of 2-Units Blackout for Event Tree B2W\#R10 . . . . . . . 10-48

10.31 Core Damage Frequencies of Loss of 4KV Event Tree 4KW\#D6 . . . . . . . . . . 10-49

10.32 Core Damage Frequencies of Loss of $4 \mathrm{KV}$ Event Tree $4 \mathrm{KW} \# \mathrm{R} 6 \ldots \ldots \ldots \ldots \ldots \ldots$ 10-50

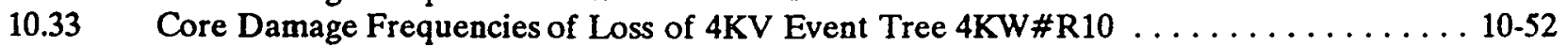

10.34 Core Damage Frequencies of Inadvertent SI Signal - SIW\#D6 . . . . . . . . . . . 10-53

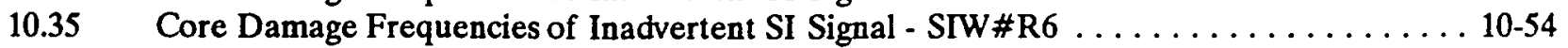


List of Tables (continued)

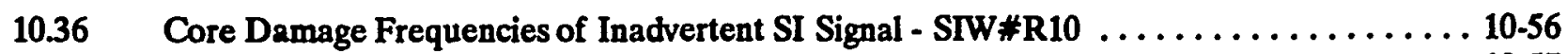

10.37

10.38

10.39

10.40

10.41 Core Damage Frequencies of Loss RHR Event Tree ARW\#D664

Core Damage Frequencies of Loss of Vital Bus - VBW\#D6 . . . . . . . . . . . 10-57

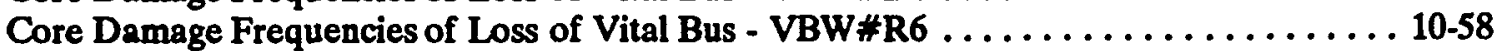

Core Damage Frequencies of Loss of Vital Bus - VBW\#R10 . . . . . . . . . 10-60

Core Damage Frequencies of Loss RHR Event Tree ARW\#R6

Loss of Instrument Air in POS 6 Refueling ....................... 10-61

10.42 Core Damage Frequencies of Loss RHR Event Tree ARW\#R10

Loss of Instrument Air in POS 6 Refueling . . . . . . . . . . . . . . . . . . 10-62

10.43

Loss of Instrument Air in POS 6 Refueling .................... 10-63

10.44

10.45

10.46

10.47

10.48 Core Damage Frequencies for SR Loss of Emergency Switchgear

Core Damage Frequencies of Loss of CCW - CCW\#D6 . . . . . . . . . . . . 10-64

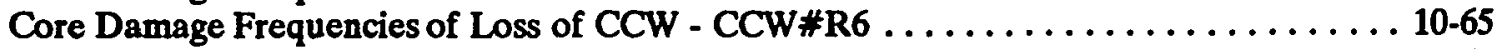

Core Damage Frequencies of Loss of CCW - CCW\#R10 . . . . . . . . . . . . . 10-66

Core Damage Frequencies for SR Loss of Emergency Switchgear Room Cooling

for Event Tree SRW\#D6 . . . . . . . . . . . . . . . . . . . . . . . . 10-67

10.49

10.50

Core Damage Frequencies for_SR_Loss of Emergency_Switchgear

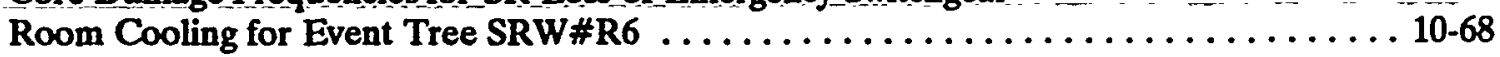

Room Cooling for Event Tree SRW\#R10 . . . . . . . . . . . . . . . . . 10-69

Dominant Core Damage Cutsets After Recovery Actions . . . . . . . . . . . . . . 10-88

10.51 Recovery Actions and Their Applicability to the Event Tree

Sequences (Loss of RHR and Loss of Instrument Air) . . . . . . . . . . . . . 10-92

10.52 Recovery Actions and Their Applicability to the

Loss of Support System Event Trees . . . . . . . . . . . . . . . . . . . . 10-98

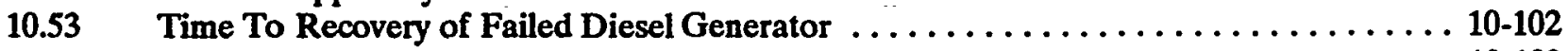

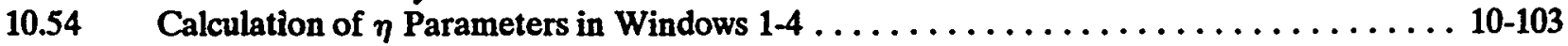

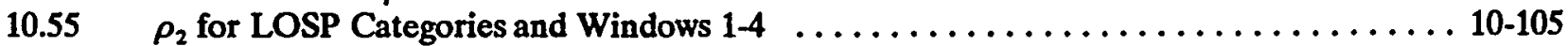

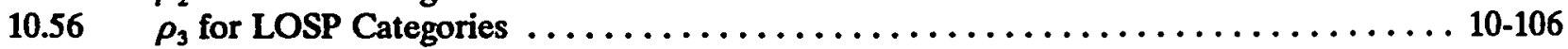

10.57 LOSP Recovery Actions, Parameters $\left(\eta, \eta_{1} \eta_{2}, \rho_{2}\right.$ and $\left.\rho_{3}\right)$ and

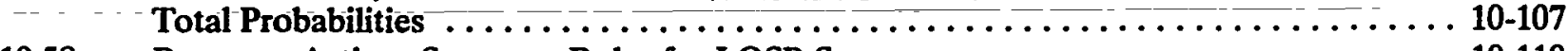

10.58 Recovery Actions Sequence Rules for_LOSP Sequences . . . . . . . . . . . . . 10-110

10.59 Summary of Results-Core Damage Frequency by Initiating Event

and Plant Operational States . . . . . . . . . . . . . . . . . . . . . . . 10-129

10.60 Core Damage Frequency as a Function of the Time Windows and POSs (per year) . . 10-130

10.61 - Fraction of a Year that the-Plant-is-in-a-Time Window-of - -POS $\ldots \ldots \ldots \ldots$ 10-131

10.62 Instantaneous Core Damage Frequency As a Function of the

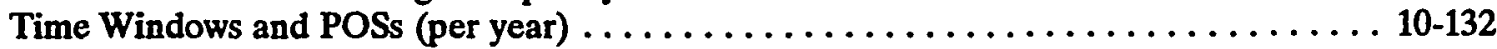

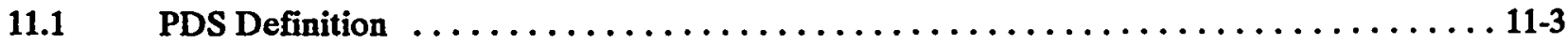

$11.2 \quad$ Plant Damage State Assignment of the Dominant Cutsets $\ldots \ldots \ldots \ldots \ldots \ldots \ldots \ldots \ldots$

11.3 Results of Uncertainty Analysis of Plant Damage States $\ldots \ldots \ldots \ldots \ldots \ldots \ldots \ldots \ldots$

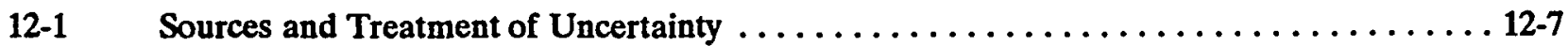

12.2 Failure Data Associated with the Correlation Classes . . . . . . . . . . . . . . 12-9

12.3 Result of the Uncertainty Analysis for Total Core Damage Frequency(per year) . . . . 12-13 


\section{S.1 Background}

\section{S. EXECUTIVE SUMMARY}

This volume presents the results of a level one probabilistic risk assessment (PRA) of the Surry Nuclear Power Plant for accidents initiated during mid-loop operations. It also contains accident initiating event analysis, and system analysis for other low power and shutdown conditions. The work was performed by Brookhaven National Laboratory (BNL) for the Nuclear Regulatory Commission (NRC) Office of Nuclear Regulatory Research (RES) in support of the NRC response to the Chernobyl accident; and the program was later modified by the NRC staff's follow-up actions to the March 20, 1990 Vogtle incident.

A phased approach was taken in this project. In phase 1, a broadly-scoped screening analysis, which included internal fires and flooding, was completed in November, 1991. This analysis produced a preliminary level one PRA for accidents initiated during low power and shutdown (LP\&S) and also gave insights on potential accident scenarios and potentially vulnerable configurations during low power and shutdown conditions. Phase 2 focused on a detailed analysis of mid-loop operation which was selected because many incidents have occurred during mid-loop operations throughout the world. Further, recent studies, including phase 1 of this program, found that the core-damage frequency during mid-loop operation is comparable to that of power operation. This report documents the results of the analysis of phase 2 internal events. It contains also an appendix, Appendix I, that documents an updated version of the key chapters/sections of the Phase 1 draft report. The work on internal fire, internal flood, seismic analysis, and level $2 / 3$ analysis are reported in separate volumes.

Surry Unit 1 was chosen for this study in part because the Surry plant was previously analyzed in the Reactor Safety Study and NUREG-1150, and in part because Virginia Power offered to cooperate. The core-damage frequency during low power and shutdown calculated in this study will be compared with that calculated in NUREG-1150 for accidents during full power. The Surry plant has two Pressurized Water Reactors (PWRs), each rated at 788 megawatts (electrical) capacity, and is located near Surry in Virginia. Grand Gulf, a boiling water reactor, was selected as the plant for a parallel analysis performed by Sandia National Laboratories (SNL).

Throughout the study, the LP\&S team had many trips to the Surry plant to gather plant information, walk down the plant, and participate in meetings with the Virginia Power staff. The draft reports were also provided to Virginia Power for their comments. The comments received were resolved and incorporated into the final report.

A total of 5 meetings of the Senior Consulting Group (SCG) were held, during which the BNL and SNL staff presented the details of the analyses as well as the approaches used in various tasks. The SCG members provided their suggestions and comments. The comments from the SCG were addressed by the PRA teams at the two labs and the proposed resolutions were presented at the following SCG meeting.

In addition to the comments from the SCG and Virginia Power, an internal BNL Quality Assurance team reviewed the draft reports and provided comments. The comments received were resolved and incorporated into the final report.

\section{S.2 Objectives}

The objectives of phase 2 of this program are:

1) Estimate the frequencies of severe accidents that might be initiated during mid-loop operation, 
S. Executive Summary (continued)

2) Compare the estimated core-damage frequencies, important accident sequences, and other qualitative and quantitative results of this study with those of accidents initiated during full power operation (as assessed in NUREG-1150), and

3) Demonstrate methodologies for accident sequence analysis for plants in modes of operation other than full power.

\section{S3 Methodology}

Due to the changing plant configuration during low power and shutdown operation, it was necessary to define different outage types, and different plant operational states (POSs) within each outage type. Within each POS, the plant configuration continues to change with time, and the decay heat continues to decrease. These factors significantly affect scenario frequencies. Therefore, a "time window" approach was developed in which different time windows were defined representing different levels of decay heat and success criteria. Within each time window, the approach used in performing the PRA for a particular POS in a particular outage type is similar to that used in the NUREG-1150 study. The approach includes typical PRA tasks, such as identification of initiating events, development of fault trees and event trees, and their quantification. The following is a summary of the approach used in the key tasks of this study. We believe that the approached developed in this study can be readily adopted for studies of POSs other than mid-loop and for other PWRs.

\section{Outage Types, Plant Operational States and Time Windows}

Outages were-grouped-into-four-different-types:-refueling, drained-maintenance,-non-drained-maintenance with use of the residual heat removal (RHR) system, and non-drained maintenance without the RHR system. Due to the continuously changing plant configuration in any outage, plant operational states (POSs) were defined and characterized within each outage type. Each POS represents a unique set of operating conditions (e.g. temperature, pressure, and configuration). For example, in a refueling outage, up to 15 POSs were used, representing the evolution of the plant throughout a refueling from low power down to cold shutdown and refueling, and back-up to low power. An extensive effort was made to collect Surry-specific data to characterize each POS, that included reviewing operating and abnormal procedures for shutdown operations, the shift supervisor's log books, and the monthly operating reports, and performing supporting thermal hydraulic calculations. Three mid-loop POSs, in which the reactor coolant system (RCS) level is lowered to the mid-plane of the hot leg, were selected for detailed analysis. Two of them occur in a refueling outage, POSs R6 and R10, and one in a drained maintenance outage, POS D6. They are characterized by different levels of decay heat, and different plant configurations, such as the number of RCS loops that are isolated, and whether or not the RCS has a large vent. R6 represents a mid-loop operation that takes place early in a refueling outage allowing the RCS loops to drain quickly to permit eddy current testing of the steam generator tubes. R10 takes place after the refueling operation is completed to allow additional maintenance of equipment in the RCS loops. D6 represents mid-loop operation in which maintenance activities require the plant to go to mid-loop, and is characterized by the highest level of decay heat among the three mid-loop POSs.

To more accurately define the decay heat level when an accident is initiated, a time-window approach was developed. Four time windows after shutdown were defined, each with its unique set of success criteria reflecting the decay-heat level. For POSs R6 and D6, all four windows were needed. For POS R10, only time windows 3 and 4 were applicable. One hundred and sixty event trees were developed for 16 initiating events.

During the latest Surry Unit 1 refueling outage that started on February 28, 1992, the utility changed previous practice and avoided going to mid-loop operation. It is our understanding that the plant staff intends to continue this new practice. However, it is believed that certain maintenance requirements may prevent totally

NUREG/CR-6144

xxviii 
avoiding going to mid-loop in the future. With NRC concurrence, BNL developed the PRA model based on outages (that included mid-loop operation) before the February 1992 refueling. Since the results are presented on a per-unit-time basis, the present results can be used to draw conclusions on the management of mid-loop outages.

\section{Initiating Event Analysis}

To identify initiating events, review of existing studies, licensee event reports, (LERs), published NRC documents, and current Surry operating procedures was performed. This approach should ensure that any incident that has occurred or any scenario that has been studied will be considered in the present study. However, no systematic approach was undertaken, such as a failure mode and effect analysis (FMEA) or a hazard and operability study (HAZOP), to further assure that all possible initiating events in all possible operating states were identified.

\section{Event Tree Analysis}

In phase 1 of this study, accident scenarios were developed for all low power and shutdown POSs. For those POSs that are similar to power operations, (e.g., low power operations), the relevant NUREG-1150 event trees developed for Surry were reviewed and modified (if necessary) to reflect the current plant design and operation. For other POSs, event trees were developed in group discussions, involving typically four or more BNL staff members with expertise in PWR operations, PRA, human reliability analysis (HRA), and thermal hydraulics. Fequent communications were held with the staff at Virginia Power to ensure that the PRA reflects the current plant design and operations.

In phase 2, the event trees developed for the mid-loop POSs were reviewed and modified to incorporate additional information obtained in the system analysis, and to reflect our current understanding of the expected operator responses to the accidents. A two-day meeting with Virginia Power operations personnel was held to discuss potential accident scenarios, and the expected responses of the plant and operator.

\section{System Analysis}

The fault tree models, developed as part of NUREG-1150 study, were reviewed and modified, when necessary, to develop two fault tree models for the plant applicable to shutdown and to low power operation for each system. The system configuration during shutdown was identified by reviewing the operating procedures used during shutdown, shift supervisor's log books, and the system training manual. Typically, the following changes were made to NUREG-1150 fault trees to derive the fault trees applicable to shutdown conditions.

1) Valve failure modes were changed. The position of valves during shutdown may be different from that during power operation. Therefore, the applicable failure modes of the valves will be different from those of power operations.

2) Human error events associated with backup of automatic actuated systems or components which failed were modified to manual actuation with no automatic backup.

3) Maintenance unavailabilities relevant to the specific POS were estimated. For mid-loop POSs, the reduced inventory check list was used to determine whether certain maintenance events are permitted; those events prohibited, e.g., diesel generator maintenance, were deleted from the model.

4) System success criteria were changed, if necessary. 


\section{S. Executive Summary (continued)}

Definition of Core-Damage - In the NUREG-1150 study, core-damage is defined for PWRs to be the RCS level reaching the top of active fuel. Due to the high decay heat level, the difference between this time and the time of cladding failure is small. In the low power and shutdown condition, the decay heat level may be significantly lower, and this difference becomes more significant. In this study, core-damage is defined to be the collapsed RCS level reaching 2.5 feet above the bottom of the core. This is based on the result of a MELCOR calculation of RCS level in the core region when cladding temperature reaches 1340 degree F, above which phenomena such as clad oxidation and ballooning will have an impact on core behavior. Time to core- damage is used in the level-1 study as the time available for operator actions such as initiating safety injection. The more realistic estimate of the time available has the tendancy of lowering the associated human error probabilities.

\section{Supporting Thermal Hydraulic Analysis}

The main purpose of the thermal hydraulic analysis was to support the development of event trees and quantification of accident sequences. Thermal hydraulic considerations are the basis of the time-window approach. Basically, the time windows were defined on the times when the success criteria of important mitigating functions change. In the phase 1 study, assumptions were made based on simple "back of the envelope" calculations. It was found that more detailed calculations were needed to confirm the simple calculations, and support the assumptions made.

In the phase 2 study, a more detailed calculation was done to determine the timing of a feed and bleed operation during mid-loop operation. The calculation also gave information on the amount of water from the refueling water storage tank (RWST) needed to sustain the feed and bleed operation, as well as the timing of core uncovery for different initial conditions.

The MELCOR code also was used to assess whether or not -gravity feed from the RWST-could be-used to provide long term cooling (i.e. 24 hours, decay heat removal). It was found that although gravity feed is sufficient only when the decay heat is low, it can provide a few hours for restoring other means of removing decay heat even when the decay heat is high.

For reflux cooling, the studies at the Idaho National Engineering Laboratory (INEL), Westinghouse, and Virginia Power were used to determine the success criteria. The analysis of feed and spill, gravity feed and reflux cooling were used to determine the boundary of the time windows. For example, the time boundary between windows 2 and 3 was chosen to be the time when recirculation is not necessary for the first 24 hours after the accident started. The boundary was estimated to be 10 days, based on the inventory available in the refueling water storage tank (RWST) and the flow needed in the feed-and-spill operation.

\section{Quantification}

A Bayesian approach was used to estimate the initiating event frequencies. The basic event data for hardware failures were derived from the NUREG-1150 data base for Surry. The IRRAS computer code was used to quantify the fault tree and event tree. An uncertainty analysis of the total core- damage frequency was performed by propagating the uncertainty of the parameters used in the model. 
Human Reliability Analysis

Two types of human error events were identified and modeled in this study: pre- and post-accident errors. The pre-accident errors identified in the NUREG/CR-4550 study for Surry were adopted, together with others identified in the system analysis task and added to the system fault trees.

To evaluate human actions and recovery actions that follow an initiator we first qualitatively defined the event scenario, required actions, important factors affecting operator performance, and the consequences of the action being unsuccessful. Two types of post accident human errors were modeled, failure to diagnose and failure to carry out the needed action given successful diagnosis. They were used in the fault trees for the top events of the event trees. It was assumed that, given failure to diagnose, the operator would fail to perform the needed actions; therefore, core-damage would result. The same basic event representing failure to diagnose was used in all fault trees of a given event tree. On the other hand, failure to carry out the action given successful diagnosis would only fail the specific top event of the event tree.

The qualitative evaluation of the actions and the important parameters that affect operator's performance were used to derive the human error probabilities (HEPs) by adapting the success likelihood index methodology. This methodology assumes that the likelihood of operator error in a particular situation depends on the combined effects of a small set of performance-shaping factors (PSFs) that influence the operator's ability to accomplish the action.

To quantify the HEPs, the PSFs were rated with weights that reflect the relative influence of each PSF on the likelihood of the success of the action, and a score that reflects whether the PSF helps or hinders the operator in carrying out the actions. With the rating for PSF, the numerical model was calibrated using well-defined actions obtained from analysis for other PRAs. Calibration ensures that the error probabilities are realistic and consistent with the data, observed human behavior, and the results from comparable expert evaluations of similar activities.

\section{Data Base Analysis}

An extensive effort was devoted to collecting data to characterize the plant during shutdown.

1) A data base of initiating events was compiled for the initiating event analysis.

2) The shift supervisor's log books, outage schedules, minimum equipment list, and monthly operating report were reviewed to collect the data needed to estimate the frequency of shutdown, duration of plant operational states, and maintenance unavailabilities.

3) The shift supervisor's log books were reviewed to determine the time that the plant is in different configurations. For example, the reactor coolant loops were found to be isolated for a long period in a refueling.

\section{S.4 Results and Insights}

Table S-1 summarizes the results of the event tree quantification, showing the core-damage frequency as a function of the initiating events and POSs. The core damage frequency is the frequency that core-damage occurs while the reactor is at mid-loop, and includes the fraction of a year that the reactor is at mid-loop. POS 6 of a drained maintenance outage (D6), and POS 6 of a refueling outage are the most dominant POSs. 


\section{S. Executive Summary (continued)}

Their characteristics are high decay-heat level and a relatively short time available for operator action.In contrast, POS 10 of a refueling outage has a very low decay heat, and its core-damage frequency is approximately one order of magnitude lower.

Table S-2 compares the results of this study with those of NUREG-1150 and the individual plant examination (IPE) performed by Virginia Power. The results are displayed in two ways. - The core-damage frequency, shown in the first row, is the frequency that core-damage occurs when the plant is at mid-loop, and the conditional core-damage frequency, shown in the third row, is the core-damage frequency divided by the fraction of time the plant is at mid-loop. The former accounts for the fact that the plant is at mid-loop only a small fraction of the time, while the latter is the conditional frequency at which core-damage occurs given the plant is at mid-loop. The contribution to total core-damage frequency due to mid-loop operations is approximately one eighth of that of power operation as estimated in NUREG-1150, since the plant is in midloop operation approximately $7 \%$ of a year. The numbers in the parentheses of the third row of the table are the conditional probability of core-damage due to over-draining events, given that the plant enters mid-loop operation in the POS.

The core-damage frequencies shown in the first row of Table S- 2 are additive. That is, the sum of the coredamage frequencies of the 3 POSs is the total core-damage frequency of mid-loop operation. This total, 5 E-06 per year, can be added to the core-damage frequency of power operation, e.g., 4 E-05 per year for NUREG-1150. Therefore, the sum of $4.5 \mathrm{E}-05$ per year is the frequency per year that core-damage occurs while the plant is at full power or mid-loop operation.

The conditional core-damage frequency shown in the third row of Table S-2 is a measure of how susceptible a plant configuration is with respect to core-damage. For example, the fact that the conditional core-damage frequency of mid-loop operation, 8 E-05 per year, is higher than that of full power operation, 4 E-05 per year, shows that mid-loop operation is more susceptible to core-damage than full power operation, although the plant is at mid-loop only a small fraction of the time.

Table S-3 lists the key uncertainty characteristics of the core-damage frequencies for mid-loop operation and power operation, and shows that the core-damage frequency for mid-loop operation has a broader distribution than that of power operation. Note also that the mean total CDF in Table S-3 is slightly different for the total CDF in Tables S-1 and S-2. This is because the numbers in Tables S-1 and S-2 are point estimates whereas the information in Table S-3 reflects an uncertainty analysis.

The following insights were gained from this study. They are based on the Surry specific design and operation. Their applicability and significance with respect to other PWRs have to be assessed separately.

Operator Response- The dominant cause of core-damage was the operator's failure to mitigate the accident. (Note that there is very large uncertainty in the human error probabilities used in this study.) In general, it would be beneficial to have good training, procedures, and instrumentation to ensure that the utility's staff can respond to shutdown accidents.

Procedures for Shutdown Accidents- Very few procedures are available for accidents during shutdown; the procedure for loss of decay heat removal, AP 27.00, is the only one that was written specifically for the shutdown scenarios analyzed in this study. The procedure is conservativewith regard to the equipment needed to establish reflux cooling and feed-and-bleed. In this study, the use of fewer than the number of steam generators specified in the procedure for reflux cooling was treated as a recovery action, and a more realistic success criteria was used for feed-and-bleed when the decay heat is high. In most cases, the information in the procedures for power operation is helpful, for shutdown accidents. For example, the procedure for station blackout, ECA-0.0, gives instructions for dumping steam to the condenser. Credit for this procedure was taken 
into account in this study. However, some procedures written for power operation would mislead the operator if followed during shutdown. For example, the procedure for loss of offsite power, AP 10.00 , states that "When the EDG is the only source of power to an emergency bus, the Component Cooling Pump should NOT be in service". During shutdown, CCW flow to the RHR heat exchanger is necessary for decay heat removal. Therefore, following this procedure under these circumstances would not be the most appropriate operator response.

Instrumentation- It was recognized that the level instrumentation used during mid-loop operation, i.e., standpipe level instrumentation and ultra-sonic level instrumentation, has limited applicability during a shutdown accident. The standpipe system indicates the correct level only when there is no build-up of pressure in the system. The ultra-sonic level instrumentation only provides level indication when the level is within the reactor coolant loops, and therefore, may not be useful during a feed and bleed operation.

Supporting Thermal Hydraulic Analysis- The thermal hydraulic behavior of the reactor coolant system is rather complex, mainly because the pressurizer is usually the relief path for coolant or steam, and the vessel head does not have a large vent. When performing thermal hydraulic analysis in support of the PRA effort, consideration must be given to longer term system behavior, at least 24 hours into the accident. In this study, such calculations were done for feed-and-bleed operation using a charging pump, and with gravity feed from the RWST. It is believed that additional calculations would be helpful to better understanding the effectiveness of reflux cooling, and feed and bleed using a low pressure injection pump. In this study, the conservative results of the Virginia Power Technical Report \# 865 (Revision 1, dated July 3, 1992) were used to determine the number of steam generators needed as a function of time after shutdown, because such criteria are explicitly written in the procedure for loss of RHR. In the event trees and fault trees, it was assumed that if there were too few, then no credit was given to reflux cooling. In this case, reflux cooling still would help. In fact, a review of the studies performed by Westinghouse and Idaho National Engineering Laboratory found that one steam generator is sufficient for any level of decay heat. To take some credit for reflux cooling in this case, a recovery action with failure probability 0.1 was applied to those core-damage cutsets that involve failure of reflux cooling due to insufficient steam generators. It was assumed that hot-leg injection using a low head injection pump is adequate to prevent core-damage. Due to the low shut-off head of the pumps, approximately $150 \mathrm{psig}$, the concern is that if boiling takes place in the system, the low head pump may be unable to inject.

Maintenance Unavailability- A review of shift supervisor's log books and minimum equipment lists for three refueling outages showed that the maintenance unavailabilities of equipment that can be used to mitigate an accident were very high. For example, two out of three charging pumps were found to be tagged out practically throughout the whole mid-loop period. The two low-head injection pumps also were unavailable a large fraction of the time. Generic letter 88-17, requires the plant to have one high-head pump and one lowhead pump available. In our quantifications, we assumed that charging pump $A$, charging pump cooling water pump A, and low head injection pump B are available. Based on the check list used for reduced inventory conditions, it was also assumed that the maintenance of diesel generators, $4 \mathrm{kv}$ emergency buses, and stub buses is not allowed.

We found that maintenance unavailability is the dominant cause of equipment unavailability. In combination with human errors, maintenance of the charging pump cooling water pump, the charging pump, and the low head injection pump appear in the dominant cutsets for some of the core-damage sequences.

Isolation of Reactor Coolant Loops- It was found that isolation of the RCS loops is an important contributor to core-damage frequency. Review of the plant shutdown experience indicated that the reactor coolant loops are isolated for extended periods in a refueling outage, making the steam generators unavailable for decay-heat removal upon loss of RHR. In a cold shutdown condition, the steam generators are usually maintained in the 


\section{S. Executive Summary (continued)}

wet lay-up condition with the secondary side filled with water. During mid-loop operation, the availability of the SGs makes reflux cooling a possible method of mitigating a loss of RHR; this might be the only mitigation function available in a station blackout.

Single Failures of the RHR System- The RHR system at Surry has no active safety function (i.e., it does not perform the safety injection function in scenarios initiated at full power). Consequently, many single component failures can cause loss of RHR. In the RHR system, a single suction line from the loop A hot leg and a single flow control valve HCV-1758 are used. During its operation, a single CCW header provides cooling to both RHR pump seal coolers and the operating RHR heat exchanger, and two CCW return lines from the RHR system are used. Hence, a failure of the trip valve 109A or B in one of the two CCW return lines can cause loss of the system. These trip valves also fail closed on loss of instrument air, or vital bus. It was found that closure of the TV-109 valves is a significant contributor to loss of RHR. It was assumed that the opening of the RHR flow control valve HCV-1758 as a result of loss of vital bus III will cause RHR pump run out; this also was a significant contributor to loss of RHR.

Valve Arrangement of Auxiliary Feedwater System and Main Steam System During Shutdown- The auxiliary feedwater system has six MOVs (151A,B, C, D, E, and F) in the flow path to the steam generators, that are normally closed during shutdown. They are difficult to locate during a station blackout. Similarly, the main steam non-return valves are normally closed during shutdown, and have to be opened to use steam dump to the condenser. They depend on offsite power and would be very difficult to open without it.

Potential for Plugging the Containment Sump When Recirculation Is Needed- Because of activitiesinside the containment, transient material and equipment are brought into it during shutdown. For example, large plastic Herculite sheets are often used to separate work areas from the rest of the containment. If an accident requiring recirculation from the containment sump occurs, as is the case in time windows 1 and 2 , the material would increase the potential for plugging the containment sump.

\section{S.5 Conclusion}

This study shows that the core-damage frequency during mid-loop operation at the Surry plant is comparable to that of power operation. The probability distribution of the core damage frequency during mid-loop operation is wider than that of power operation. This is due to the large uncertainty in the human error probabilities used in this study. It was identified that only a few procedures are available for mitigating accidents that may occur during shutdown. Procedures written specifically for shutdown accidents would be useful. Realistic thermal hydraulic analysis should be used as the basis of the procedures.

It was assumed that reduced inventory check list was followed, and found that the maintenance unavailability of equipment not on the list were dominant contributors to system unavailability. However, the check list is believe to be sufficient for ensuring the availability of essential equipment.

\section{S.6 Key Assumptions and Sources of Uncertainty}

The following is a discussion of the various modeling issues and how they were treated in this study.

Changing plant practices and information- BNL observed that the plant is aware of the potential safety concerns of reduced inventory operations and is constantly improving its practice regarding such operation. This is reflected in the improvement in the operating procedures and abnormal procedures used during shutdown, as well as changes in the plant practice. The most significant change in plant practice started in 
the refueling outage of unit one in 1992, during which mid-loop operation was totally avoided; this appears to be the new policy. Another way of reducing the risk is to carry out reduced inventory operation while the fuel in the core is removed during refueling operation.

To limit the changes in the model developed for this study to account for the changes in plant practice and information, it was decided to use the procedures and other plant information available as of April 30, 1993. Regarding the plant's policy of avoiding mid-loop operation, it was decided that this study would use the data collected from past outages before the unit 1 refueling outage of 1992 . Consequently, the estimated coredamage frequency, could be an overestimation of that of the current plant. However, it is emphasized that the core-damage frequency calculated in the current study was reduced significantly by changes made after the start of the study and before April 1, 1993.

Changing Plant Confipuration- Due to the activities taking place during shutdown, the plant configuration changes with time, which, in turn, affects the likelihood of accident initiating events and the plant's ability to mitigate the accidents. In this study, the constantly changing plant configuration is approximated by a few discrete configurations, by introducing different outage types, POSs, and time windows. It also is reflected by the different basic events and different event trees for different outage types, POSs, and time windows. The following is a description of the basic events and how they are varied.

Initiating event frequency- The initiating events are assumed to occur with constant rates independent of the outage type or POS. The conditional probability that an IE occurs in a POS is calculated as the product of the rate and the duration of the POS. The initiating event frequency is the frequency of the POS multiplied by the conditional probability. The frequency that it occurs in a given time window of a given POS of a given outage type is the initiating event frequency times the conditional probability of the time window of the given POS.

Loop isolation probability- Isolating the loops makes it impossible to establish reflux cooling. Its probability was estimated by judgment using the information from the log books for outages, and an outage plan for a refueling outage. It was estimated as a function of the outage types, and time windows.

Removal of pressurizer safety valves- The fraction of time that the safety valves are removed in a given time window of a given POS in a given outage type was estimated by judgment, using information from the log books for outages, and an outage plan for a refueling outage. With the safety valves removed, it is possible to use gravity feed from the RWST, but not reflux cooling because of inventory loss through the opening.

Maintenance unavailabilities- Maintenance unavailability was estimated as a function of the POSs of a refueling outage by reviewing the log books for 3 refueling outages. The data was collected for the period when the plant was at mid-loop. Due to lack of sufficient information, it is assumed to be independent of the time windows. It was also assumed that the data for a refueling outage is applicable to a drained maintenance outage.

Success Criteria- The success criteria for shutdown conditions were determined by reviewing various studies, and performing supporting thermal hydraulic analysis based on the Surry-specific design. The changing level of decay heat was accounted for by defining four time windows after shutdown, each with its own set of success criteria. In general, whenever the success criteria for one system or mitigating function changes, a new time window needs to be defined, and potentially, more than four time windows would be needed. The use of four, therefore, is a trade-off between the accuracy of the model and the level of effort needed to arrive at a solution; it is believed that four time windows gives an adequate representation. 


\section{S. Executive Summary (continued)}

During development of the time window approach, it was recognized that the procedure for loss of RHR, AP27.00 , is conservative with respect to the success criteria for reflux cooling and feed-and-spill, and does not include all possible methods of establishing recirculation. These are the areas in which the plant model used in this study deviated from the abnormal procedure. The following describes how these issues were treated.

Reflux cooling- In AP 27.00, the number of steam generators (SGs) needed for reflux cooling is given as a function of the decay heat, e.g, 3 SGs are needed for the first 75 hours after shutdown. This value is based on the thermal hydraulic consideration of Virginia Power NE technical report 865. From a review of existing studies performed by INEL and Westinghouse on reflux cooling, and BNL calculations, we determined that one steam generator should be sufficient. Therefore our current understanding is that one SG would be sufficient, while the abnormal procedure states that three would be needed. The issue is, how much credit should be given to reflux cooling when less than three SGs are available. In this study, the success criterion based on the procedure was used in the logic model, and whenever reflux cooling was failed due to insufficient SGs, a recovery action was entered with a failure probability of 0.1 .

Feed-and-spill- In AP27.00 and its supporting study (Virginia Power NE technical report 865), the number of pumps and PORVs needed for this operation was determined based on the flow from the RWST needed to maintain sub-cooling, the capacity and shut-off head of the pumps, and the relieving capability of the PORVs. For example, during the first 129 hours after shutdown, 2 charging pumps and 2 PORVs would be needed. This success criterion was derived from the requirement to maintain sub-cooling, and is more stringent than the criterion needed for feed-and-bleed during an accident that occurs during full power operation. An alternative to feed-and-spill, (i.e. feed-and-steam), which is also discussed in technical report 865 , is much less demanding in terms of the needed flow. However, feed and steam is not the recommended method because of the difficulty in maintaining the RCS level, and the potential for over pressurization. In this study, a success criterion of 1 charging pump and 1 PORV was used, based on the understanding that this is sufficient to prevent core-damage.

Recirculation- AP 27.00 instructs the operators to establish high pressure recirculation by using the lowpressure injection pump to take suction from the containment sump, and discharge to the suction of the high pressure injection system; this requires that a low head injection pump and a charging pump are available. In the fault tree model for recirculation, two alternative methods also are modeled, low-pressure feed-andsteam (by taking suction from the containment sump), and low-pressure feed and spill (by taking suction from the sump and using spray recirculation). In these modes, low-headinjection-is needed- The feed-and-steam mode requires that the safety valves be removed to provide an adequate vent path, and does not require cooling of the sump water. The feed-and-spill operation requires operation of the spray recirculation systems to cool the water in the sump, so that sub-cooling in the reactor vessel can be established.

Operator Response- The operator's actions modeled in this study were identified in developing the event trees. The identification process involved reviewing abnormal and emergency procedures, and discussing the accident scenarios with plant personnel. In most cases, the operator's responses to various accidents are identified in the procedures. For example, abnormal procedures for loss of RHR, loss of instrument air, and loss of offsite power give guidance on what to do in case of respective losses during shutdown. The latter two procedures are not written specifically for shutdown conditions. In case of a station blackout, the procedure written for power operation in mind, (1-ECA-0.0), does not address shutdown conditions. Therefore, only the relevant steps in the procedure are applicable. Similarly, for other initiating events, such as loss of component cooling, spurious safety injection, and loss of a vital bus, there is no specific procedure for shutdown condition, and the ability of the operators to use the relevant steps in the procedures for power operations becomes very important. As discussed under success criteria, some of the operator's actions modeled in this study are not explicitly spelled-out in the existing plant procedures, and some recovery actions modeled are extension of the existing procedures.

NUREG/CR-6144 
The operator actions needed to mitigate an accident are included in the high level fault trees. A high level fault tree models one method of mitigating the accident, e.g., feed-and-spill operation which typically contains two human error events, and one transfer to the fault tree for hardware failures. One human error event represents the failure of the operator to diagnose, so that the correct actions cannot be decided upon; the other represents failure to carry out the action after correct diagnosis. Assuming that the failure to diagnose would lead to core damage, many of the dominant core-damage cutsets are caused by such events. Human error probabilitieswere quantified using the method of failure likelihood index that involves assessing weights and scores on various performance-shaping factors, and calibration using the HEPs from existing studies. 
S. Executive Summary (continued)

Table S.1 Summary of Results-Core-Damage Frequency by Initiating Event and Plant Operational States

\begin{tabular}{|c|c|c|c|c|c|c|}
\hline \multirow[b]{2}{*}{1.} & \multirow{2}{*}{$\begin{array}{ll} & \text { Initiating Event } \\
\text { Loss of RHR }\end{array}$} & \multirow[t]{2}{*}{ IE Frequency } & \multicolumn{4}{|c|}{ Core-Damage Frequency (per year) } \\
\hline & & & R6 & R10 & D6 & Total \\
\hline & RHR2A-Over Draining & 1.6E-02/Demand & $1.8 \mathrm{E}-7$ & $5.3 \mathrm{E}-8$ & $2.6 \mathrm{E}-7$ & 4.9E-7 \\
\hline & RHR2B-Failure to Maintain Level & $1.2 \mathrm{E}-05 \mathrm{hr}$ & 2.1E-08 & $2.0 \mathrm{E}-8$ & $2.9 \mathrm{E}-8$ & $7.0 \mathrm{E}-8$ \\
\hline & RHR3-Non-Recoverable Loss of RHR & 4.1E-06/hr & $1.5 \mathrm{E}-7$ & 8.4E-9 & 3.0E-7 & 4.6E-7 \\
\hline & RHR4-Non-Recoverable Loss of Operating Train of RHR & $5.3 \mathrm{E}-06 / \mathrm{hr}$ & $7.6 \mathrm{E}-9$ & $1.2 \mathrm{E}-9$ & 2.3E-8 & $3.2 \mathrm{E}-8$ \\
\hline & RHR5-Recoverable Loss of RHR & $2.1 \mathrm{E}-05 / \mathrm{hr}$ & $4.0 \mathrm{E}-8$ & 4.1E-09 & $9.3 \mathrm{E}-8$ & $1.4 \mathrm{E}-7$ \\
\hline 2. & LOOP-Loss of Offsite Power & $7.0 \mathrm{E}-06 / \mathrm{hr}$ & & & & \\
\hline & L1-Both $1 \mathrm{H}$ and $1 \mathrm{~J}$ Energized & $6.2 \mathrm{E}-06 / \mathrm{hr}$ & 3.3E-7 & $7.0 \mathrm{E}-8$ & $7.6 \mathrm{E}-7$ & $1.2 \mathrm{E}-6$ \\
\hline & $\mathrm{L} 2-1 \mathrm{H}$ and $2 \mathrm{H}$ energized, not $1 \mathrm{~J}$ & $7.4 \mathrm{E}-07 / \mathrm{hr}$ & $1.0 \mathrm{E}-7$ & $1.3 \mathrm{E}-8$ & 1.7E-7 & 2.9E-7 \\
\hline & L3-1H energized, not $1 \mathrm{~J}$, unit 2 blackout & $3.8 \mathrm{E}-08 / \mathrm{hr}$ & 4.2E-8 & $1.3 \mathrm{E}-8$ & $9.9 \mathrm{E}-8$ & $1.5 \mathrm{E}-7$ \\
\hline & B1-Unit 1 Black Out & $2.0 \mathrm{E}-08 / \mathrm{hr}$ & $4.8 \mathrm{E}-8$ & $1.1 \mathrm{E}-8$ & $1.7 \mathrm{E}-7$ & 2.3E-7 \\
\hline & B2-2 Unit Blackout & $3.2 \mathrm{E}-09 / \mathrm{hr}$ & $3.8 \mathrm{E}-8$ & $4.2 \mathrm{E}-8$ & $1.1 \mathrm{E}-7$ & $1.9 \mathrm{E}-7$ \\
\hline 3. & $4 \mathrm{KV}$-Loss of $4 \mathrm{kv}$ Bus & $2.1 \mathrm{E}-05 / \mathrm{hr}$ & $1.4 \mathrm{E}-7$ & $1.9 \mathrm{E}-8$ & $2.4 \mathrm{E}-7$ & $4.0 \mathrm{E}-7$ \\
\hline 4. & VITAL-Loss of Vital Bus & $5.6 \mathrm{E}-06 / \mathrm{hr}$ & $2.8 \mathrm{E}-8$ & $5.1 \mathrm{E}-9$ & $7.3 \mathrm{E}-8$ & $1.1 \mathrm{E}-7$ \\
\hline 5. & AIR-Loss of Outside Instrument Air & $2.1 \mathrm{E}-6 / \mathrm{hr}$ & $7.9 \mathrm{E}-10$ & - & $3.2-9$ & 4.0E-9 \\
\hline 6. & CCW-Loss of CCW & $3.8 \mathrm{E}-06 / \mathrm{hr}$ & $6.3 \mathrm{E}-8$ & $1.1 \mathrm{E}-10$ & 2.1E-7 & $2.7 \mathrm{E}-7$ \\
\hline 7. & SWGR-Loss of Emergency Switchgear Room Cooling & $1.8 \mathrm{E}-08 / \mathrm{hr}$ & $3.6 \mathrm{E}-8$ & $1.2 \mathrm{E}-8$ & 7.4E-8 & $1.2 \mathrm{E}-7$ \\
\hline 8. & ESFAS-Inadvertent Safety Feature Actuation & $1.1 \mathrm{E}-04 / \mathrm{hr}$ & $2.7 \mathrm{E}-7$ & $2.7 \mathrm{E}-8$ & $6.8 \mathrm{E}-7$ & $9.8 \mathrm{E}-7$ \\
\hline 9. & Dilute-Boron Dilution (CDF) & $2.0 \mathrm{E}-07 / \mathrm{hr}$ & & & & $6.8 \mathrm{E}-08$ \\
\hline TOTAL & & & $1.5 \mathrm{E}-6$ & $3.0 \mathrm{E}-7$ & $3.3 \mathrm{E}-6$ & $5.1 \mathrm{E}-6^{*}$ \\
\hline
\end{tabular}

* Not including boron dilution 
Table S.2 Comparison of Total Core-Damage Frequency with NUREG-1150 and IPE

\begin{tabular}{|c|c|c|c|c|c|}
\hline Study & \multicolumn{5}{|c|}{ Results } \\
\hline \multirow{4}{*}{$\begin{array}{l}\text { PWR Low Power and Shutdown Study } \\
\text { (Mid-Loop POSs, Internal Events Only) }\end{array}$} & & R6 & $\mathbf{R} 10$ & D6 & TOTAL \\
\hline & $\mathrm{CDF}^{\circ}$ per year & $\begin{array}{c}1.5 \mathrm{E}-06 \\
(1.8 \mathrm{E}-07)^{* *}\end{array}$ & $\begin{array}{l}3.1 \mathrm{E}-07 \\
(5.5 \mathrm{E}-08)^{* *}\end{array}$ & $\begin{array}{c}3.3 \mathrm{E}-06 \\
(2.7 \mathrm{E}-07)^{* *}\end{array}$ & $\begin{array}{l}\text { 5.1E-06 } \\
(5.0 \mathrm{E}-07)^{* *}\end{array}$ \\
\hline & $\begin{array}{l}\text { Fraction of } \\
\text { a year the plant } \\
\text { is in mid-loop }\end{array}$ & $1.6 \mathrm{E}-02$ & $1.5 E-02$ & $3.5 \mathrm{E}-02$ & $6.6 \mathrm{E}-02$ \\
\hline & $\begin{array}{l}\text { Conditional } \\
\text { CDF }^{* 0 *} \text { per year } \\
\text { (CDP) }\end{array}$ & $\begin{array}{c}8.1 \mathrm{E}-05 \\
(3.0 \mathrm{E}-07)\end{array}$ & $\begin{array}{c}1.7 \mathrm{E}-05 \\
(1.8 \mathrm{E}-07)\end{array}$ & $\begin{array}{l}8.6 \mathrm{E}-05 \\
(2.2 \mathrm{E}-07)\end{array}$ & $\begin{array}{c}7.6 \mathrm{E}-05 \\
(2.4 \mathrm{E}-07)\end{array}$ \\
\hline NUREG-1150 (Internal Events Only) & \multicolumn{5}{|c|}{ 4.0E-05 } \\
\hline IPE(Internal Events Onty) & \multicolumn{5}{|c|}{ 7.4E-05 } \\
\hline
\end{tabular}

- CDF reflects the fraction of time the plant is at mid-loop

* Contribution of over-draining events

*** Frequency of core-damage given that the plant is at mid-loop (core damage frequency due to non-over-draining events divided by the fraction of time the plant is at mid-loop)

CDP probability of core-damage due to over-draining to the POS 
Table S.3 Result of the Uncertainty Analysis for Total Core-Damage Frequency (per year)

\begin{tabular}{|c||c||c||}
\hline & $\begin{array}{c}\text { Mid-Loop } \\
\text { Operation } \\
\text { (per year) }\end{array}$ & $\begin{array}{c}\text { Full Power } \\
\text { Operation* } \\
\text { (per year) }\end{array}$ \\
\hline Mean & $4.9 \mathrm{E}-06$ & $4.0 \mathrm{E}-05$ \\
\hline 5th Percentile & $4.8 \mathrm{E}-07$ & $6.8 \mathrm{E}-06$ \\
\hline 50th Percentile & $-2.1 \mathrm{E}-06$ & $2.3 \mathrm{E}-05$ \\
\hline 95th Percentile & $1.5 \mathrm{E}-05$ & $1.3 \mathrm{E}-04$ \\
\hline Error Factor & 5.7 & 4.4 \\
\hline
\end{tabular}

* NUREG-1150 


\section{FOREWORD}

\section{(NUREG/CR-6143 and 6144) \\ Low Power and Shutdown Probabilistic Risk Assessment Program}

Traditionally, probabilistic risk assessments (PRA) of severe accidents in nuclear power plants have considered initiating events potentially occurring only during full power operation. Some previous screening analysis that were performed for other modes of operation suggested that risks during those modes were small relative to full power operation. However, more recent studies and operational experience have implied that accidents during low power and shutdown could be significant contributors to risk.

During 1989, the Nuclear Regulatory Commission (NRC) initiated an extensive program to carefully examine the potential risks during low power and shutdown operations. The program includes two parallel projects performed by Brookhaven National Laboratory(BNL) and Sandia National Laboratories(SNL), with the seismic analysis performed by Future Resources Associates. Two plants, Surry (pressurized water reactor) and Grand Gulf (boiling water reactor), were selected as the plants to be studied.

The objectives of the program are to assess the risks of severe accidents due to internal events, internal fires, internal floods, and seismic events initiated during plant operational states other than full power operation and to compare the estimated core damage frequencies, important accident sequences and other qualitative and quantitativeresults with those accidents initiated during full power operation as assessed in NUREG-1150. The scope of the program includes that of a level-3 PRA.

The results of the program are documented in two reports, NUREG/CR-6143 and 6144. The reports are organized as follows:

For Grand Gulf:

NUREG/CR-6143 - Evaluation of Potential Severe Accidents during Low Power and Shutdown Operations at Grand Gulf, Unit 1

Volume 1: $\quad$ Summary of Results

Volume 2: $\quad$ Analysis of Core Damage Frequency from Internal Events for Operational State 5 During a Refueling Outage

Part 1: Main Report

Part 1A: Sections 1 - 9

Part 1B: Section 10

Part 1C: Sections $11-14$

Part 2: Internal Events Appendices $A$ to $H$

Part 3: Internal Events Appendices I and J

Part 4: Internal Events Appendices $\mathrm{K}$ to $\mathrm{M}$

Volume 3: $\quad$ Analysis of Core Damage Frequency from Internal Fire Events for Plant Operational State 5 During a Refueling Outage

Volume 4: $\quad$ Analysis of Core Damage Frequency from Internal Flooding Events for Plant Operational State 5 During a Refueling Outage

Volume 5: Analysis of Core Damage Frequency from Seismic Events for Plant Operational State 5 During a Refueling Outage 
Foreword (continued)

Volume 6: $\quad$ Evaluation of Severe Accident Risks for Plant Operational State 5 During a Refueling Outage

Part 1: Main Report

Part 2: Supporting MELCOR Calculations

For Surry:

NUREG/CR-6144 Evaluation of Potential Severe Accidents during Low Power and Shutdown Operations at Surry Unit-1

Volume 1: $\quad$ Summary of Results

Volume 2: $\quad$ Analysis of Core Damage Frequency from Internal Events during Mid-loop Operations

Part 1: Main Report

Part 1A: Chapters 1 - 6

Part 1B:_Chapters 7 - 12

Part 2: Internal Events Appendices A to D

Part 3: Internal Events Appendix E

Part 3A: Sections E.1 - E.8

Part 3B: Sections E.9 - E.16

Part 4: Internal Events Appendices $F$ to $H$

Part 5: Internal Events Appendix I

Volume 3: $\quad$ Analysis of Core Damage Frequency from Internal Fires during Mid-loop Operations

Part 1: Main Report

Part 2: Appendices

Volume 4: $\quad$ Analysis of Core Damage Frequency from Internal Floods during Mid-loop Operations

Volume 5: $\quad$ Analysis of Core Damage Frequency from Seismic Events during Mid-loop Operations

Volume 6: Evaluation of Severe Accident Risks during Mid-loop Operations

Part 1: Main Report

Part 2: Appendices 


\section{ACKNOWLEDGEMENTS}

The authors wish to acknowledge the following individuals for their contribution to the study.

Ms. Candee Lovett, of Virginia Power, for promptly providing the plant information needed for developing the model.

Mr. Kenneth Russell of Idaho Nuclear Engineering Laboratory for his help in using the latest versions of the IRRAS computer code.

Ms. Florence O'Brien, Kathy Ryan, and Barbara Kponou for their working long hours throughout the project in providing secretarial support.

Mr. William J. Luckas for his help with interpretation of plant information and participation in the accident scenario development.

Ms. Cheryl Conrad, Mr. Chun-Chang Chao of National Tsing Hua University, Taiwan, and Mr. Tsu-Jen Lin of Institute of Nuclear Energy Research, Taiwan, for their technical support. 



\section{ACRONYMS}

Acronym

ACC

AEOD

AFW

AHU

ANS

AOT

AOV

AP

ASEP

ASME

ATWS

BAT

BHEP

BAST

BIT

BNL

BRT

CAS

$\mathrm{CCW}$

CD

CDF

CEDM

CESSAR

CFR

CIS

CLCS

CPC

NUREG/CR-6144
Meaning

Accumulator

Office for Analysis and Evaluation Operational Data, US NRC

Auxiliary Feedwater

Air Handling Unit

American Nuclear society

Allowed Outage Time

Air Operated Valve

Abnormal Procedure

Accident Sequence Evaluation Program

American Society of Mechanical Engineers

Anticipated Transient Without Scram

Boric Acid Tank

Basic Human Error Probability

Boric Acid Storage Tank .

Boron Injection Tank

Brookhaven National Laboratory

Boron Recovery Tank

Compressed Air System

Component Cooling Water

Core Damage

Core Damage Frequency

Control Element Drive Mechanism

Combustion Engineering Standard Safety Analysis

Report

Code of Federal Regulation

Containment Isolation Signal

Consequence Limiting Control System

Charging Pump Cooling

$\mathrm{xlv}$ 
CPS

CRA

CS

CSD

CSR

CSS

CST

CVCS

CW

DHR

ECA

ECCS

EDG

EF

ELO

EP

EPS

ESF

ESFAS

ESGR

ESR

FAI

FCV

FMEA

FO

FW

GOP

HAZOP

HEP

HHSI

HPI

HPR
Containment Pressure Suppression

Control Rod Assembly

Containment Spray

Cold Shutdown

Cable Spreading Room

Containment Spray System

Condensate Storage Tank

Chemical and Volume Control System

Circulating Water

Decay Heat Removal

Emergency Contigency Action

Emergency Core Cooling System

Emergency Diesel Generator

Error Factor

End of Licensed Life

Emergency Procedure

Emergency Power System

Emergency-Safety Feature

Emergency Safety Feature Actuation System

Emergency Switchgear Room

Emergency Switchgear Room

Fail as Is

Flow Control Valve

Failure Mode and Effect Analysis

Fail Open

Feed Water

General Operating Procedure

Hazard and Operability Study

Human Error Probability

High Head Safety Injection

High Pressure Injection

High Pressure Recirculation 


\section{HRA}

HSD

HVAC

HX

HZP

IAEA

IAW

IE

INEL

IPE

IRRAS

ISD

ISLOCA

ISR

KV

LCO

LER

LHS

LHSI

LOCA

LOSP

LPR

LP\&S

LTOP

$\mathrm{MCC}$

MCR

MELCOR

MFW

MOP

MOV

NUREG/CR-6144
Human Reliability Analysis

Hot Shutdown

Heating Ventilation and Air Conditioning

Heat Exchanger

Hot Zero Power

International Atomic Energy Agency

In Accordance With

Initiating Event

Idaho National Engineering Laboratory

Individual Plant Evaluation

Integrated Reliability and Risk Analysis System

Intermediate Shutdown

Interfacing Systems LOCA

Inside Spray Recirculation

Kilo-volt

Limiting condition of Operation

Licensee Event Report

Latin Hypercube Sampling

Low Head Safety Injection

Loss of Coolant Accident

Loss of Offsite Power

Low Pressure Recirculation

Low Power and Shutdown

Low Temperature Overpressurization

Motor Control Center

Main Control Room

A Computer Code for Nuclear Reactor Severe Accident Source Term and Risk Assessment Analysis

Main Feedwater

Maintenance Operating Procedure

Motor Operated Valve

xlvii 
MSTV

MW

MWt

NC

NO

NPSH

NRC

NRR

NRV

NSAC

NSS

NSS

OD

oOs

OP

OSR

PCS

PCV

PG

PORV

POS

PPM

PPRS

PRA

PRT

PRZR

PSA

PSF

PSIA

PSID

PSIG
Main Steam Trip Valve

Mega-watt

Mega-watt Thermal

Normally Closed

Normally Open

Net Positive Suction Head

Nuclear Regulatory Commission

Nuclear Reactor Regulation, US NRC

Non-Return Valve

Nuclear Safety Analysis Center

Normal Station Service

Nuclear Steam System

Operator Depressurization

Out of Service

Operating Procedure

Outside Spray Recirculation

Power Conversion System

Pressure Control Valve

Primary Grade

Pilot Operated Relief Valve

Plant Operational State

Parts Per Million

Primary Pressure Relief System

Probabilistic Risk Assessment

Pressurizer Relief Tank

Pressurizer

Probabilistic Safety Analysis

Performance Shaping Factor

Pound Per Square Inch Absolute

Pound Per Square Inch Defferential

Pound Per Square Inch Gauge 


\section{Acronyms}

PTL

PTS

R\&D

RC

RCCA

RCP

RCS

REA

RES

RF

RF

RHR

RMP

RMT

RMTS

RPS

RPV

RSS

RTND

RTS

RVLIS

RWST

RX

RY

SBO

SCSS

SFP

SG

SGRCT

SGRTS
Pull-to-lock

Pressurized Thermal Shock

Refueling and Drained Maintenance

Reactor Coolant

Zeactor Control Cluster Assembly

Reactor Coolant Pump

Reactor Coolant System

Rod Ejection Accident

Office of Nuclear Regulatory Research, US NRC

Recovery Factor

Range Factor

Residual Heat Removal

Remote Monitoring Panels

Recirculation Mode Transfer

Recirculation Mode Transfer System

Reactor Protection System

Reactor Pressure Vessel

Reserve Station Service

Reference Temperature for Transition to Nil-Ductility

Return to Service

Reactor Vessel Level Indication System

Refueling Water Storage Tank

Reactor

Reactor year

Station Blackout

Sequence Coding Search System

Spent Fuel Pool

Steam Generator

Steam Generator Reactivity

Steam Generator Recirculation and Transfer 
SGTR

SI

SIAS

SIS

SLB

SNL

SRV

SV

SWS

TAF

TOP

TWC

UFSAR

VCT

VEPCO

WR
Steam Generator Tube Rupture

Safety Injection

Safety Injection Actuation System

Safety Injection System

Steam Line Break

Sandia National Laboratories

Safety Relief Valve

Safety Valve

Service Water System

Top of Active Fuel

Temporary Operating Procedure

Through the Wall Crack

Updated Final Safety Analysis Report

Volume Control Tank

Virginia Electric Power Company

Wide Range 


\section{EVENT TREE ANALYSIS}

\subsection{Event Tree Approach and Nomenclature}

Event trees model the responses of the plant and operators to the initiating events. For power operations, there are various procedures to assist the operators. In most cases, many of the possible scenarios were recognized and analyzed, and methods for mitigating the initiating events are specified in the procedures. The procedures give good guidance on developing event trees. For shutdown conditions, very few procedures are written specifically for possible accidents. For the Surry plant, the only procedure that is specifically written for shutdown accidents analyzed in this study, is the procedure for loss of decay heat removal, AP-27.00 ${ }^{[1]}$, Revision 4, February 15, 1993. It provides guidance on restoring RHR, primary inventory makeup and alternate methods of decay heat removal. In addition, the Virginia Power technical report \# $865^{[2]}$, revision 1 and its supplement $t^{[3]}$ give a supporting analysis and updated guidance for ensuring adequate backup of decay heat removal after a loss of RHR. For other initiators, the expected responses of the plant and operator are not as clearly defined. Therefore, information gathered from the procedures developed for power operations has to be used. In the procedures for loss of offsite power ${ }^{[4]}, \mathrm{AP} 10.00 \mathrm{Rev} .7$, and loss of instrument air ${ }^{[5]}$, AP $40.00 \mathrm{Rev} .3$, the operators are instructed to check if the unit was on RHR, and a few steps needed to restore RHR are given. No other procedure has guidance specifically for the shutdown accidents analyzed in this study.

We developed event trees in this study by a talk-through format. Typically, a team of 4 members, including engineers with background and training in the area of plant operations, PRA, and thermal hydraulics met to discuss the plant's initial conditions and the responses to the initiators. Related procedures and documents were reviewed, and then, accident scenarios were developed. The process was very time consuming and sometimes agreement was hard to reach. In general, it was found that deterministic analysis is very helpful to better understand the behavior of the plant. The expected responses of the plant and possible operator actions were also discussed with plant operations personnel during a two-day meeting at the plant.

In the time window approach, each accident initiating can occur in 4 different time windows and 3 POSs. In principle, 12 event trees would be needed to delineate the possible accident scenarios. Because POS 10 of a refueling outage occurs after refueling is completed, it cannot occur in time windows 1 and 2. Therefore, ten event trees were developed for each initiating event.

The structure of the event trees that we developed differs from that of a typical event tree in that the first top event of the event tree is used as part of the calculation of initiating event frequency. That is, the first top event (the "I" top event) is used to calculate the frequency that the initiating event occurs in the POS and time window. For example, Figure 7.1-1 is the loss of RHR event tree for an initiating event (RHR5) that occurs in time window 1. The first top event "IR5W1", shown in Figure 7.1-2, represents the fault tree that is used to calculate the frequency that the RHR5 initiating event occurs in window 1 of the POS. Its top gate is an "AND" gate with a basic event, representing the rate that the R5 initiating event occurs, and an "OR" gate as its input. The "OR" gate has three "AND" gates as inputs. Each "AND" gate, combined with the hourly rate that the initiating event occurs, is used to calculate the frequency that the RHR5 initiating event occurs in each of the three POSs. "HOUSE" events are used to select the right part ("AND" gate) of the fault tree that is appropriate for the POS being analyzed. For example, the left most "AND" gate is used to calculate the frequency that the initiating event occurs in POS 6 of a refueling outage. As discussed in chapter 4, this frequency is the product of the frequency of refueling outage, the frequency of the initiating event, the duration of POS 6 of a refueling outage, and the probability that the initiating event occurs in time window 1 , given that it occurred in this POS. 


\section{Event Tree Analysis}

Most other top events of the event trees have the same structure as that shown in Figure 7.1-3 for restoring RHR subsequent to the loss of RHR event. Two high-level human error events represent failure to diagnose the initiating event and failure to carry out the action, and a transfer to the system fault trees models hardware failures. Human errors at a lower level, e.g., operator failure to open a valve, are included in the system fault trees. This approach allows the system fault trees to be shared by many top events in the event trees.

The following is the convention used to name POSs, event trees, event tree top-events, and human-error events in the high-level fault trees. It was used in the computer model, using the IRRAS code.

(1) The name of an event tree has three parts, the initiating event, window number, and POS. For example, "R5W1R6" represents the event tree for non-recoverable loss of RHR (R5) in window 1 (W1) in POS 6 of a refueling outage (R6).

\section{Initiating Event}

RA-over draining to mid-loop

RB-failure to maintain level

R3-non recoverable loss of RHR

R4-non-recoverable loss of operating train of RHR

R5-recoverable loss of RHR

SI-inadvertent safety injection

CC-loss of ccw

$4 \mathrm{~K}$-loss of $4 \mathrm{kv}$ bus

L1-loss of offsite power case 1

L2-loss of offsite power case 2

L3-loss of offsite power case 3

B1-Unit 1 blackout

B2-2 unit blackout

VB-loss of vital bus

AR-loss of instrument air

SR-loss of emergency switch-gear room cooling

Window Number

W1-Window 1

W2-Window 2

W3-Window 3

W4-Window 4

POS and Outage Týpe

R6-POS 6 of a refueling outage

R10-POS 10 of a refueling outage

D6-POS 6 of a drained maintenance outage

(2) The names of event tree top events are chosen by adding a prefix to the event tree name (without the POS designator) to represent the generic type of the top event. For example, the fourth top event "SR5W1" in Figure 7.1-1 has a prefix of "S" to represent reflux cooling using the steam generators. The high-level fault trees were built such that they depend on the initiating event and time window, but are 
independent of the POSs. Therefore, the POS designators are not needed in naming the top events. The following is a list of the prefixes for the generic top events.

I-Initiating Event Frequency Calculation

H-Recovery of Support System Failures

M-RCS Makeup

R-Restore RHR

V-RCS Vented

F-RCS Feed-and-Spill

S-Steam Generator Feed-and-Bleed

G-Gravity Feed from RWST

N-Recovery of Off-Site Power

- C-High Pressure Recirculation

P-Spray Recirculation-both ISR and OSR (not a top event, an input to " $\mathrm{Cl}$ event)

(3) The names of human error events modeled in the system fault trees follow the convention of NUREG/CR-4550, and are indicated by "XHE" in the names. The name of high-level human error events consists of the following fields separated by hyphens:

(a) The first letter in the name is either an " $\mathrm{A}$ " or "D" representing failure to take Action and failure to Diagnose, respectively. (X-,2 letters)

(b) Name of event tree without POS designator, (XXXX-,5 letters)

(c) "XHE" representing a human error event, (XHE-, 4 letters)

(d) a one-letter top event prefix representing the generic top event type, (X-, 2 letters)

(e) a sequence number indicating the sequence that the event is applicable to. (XX,2 letters)

For example, A-R5W1-XHE-SF-9 means that in sequence 9 of the event tree "R5W1", the operator fails to establish feed to the steam generators. In this example, "SF" was used instead of "S" because 3 separate operator actions are modeled. "SF" represents feeding the SGs. "S1" represents bleeding the SGs before rupture of the PRT rupture disk. "S2" represents bleeding the SGs and closing the PORVs after the PRT has ruptured. D-R5W1-XHE represents failure to diagnose the loss of RHR in window 1, resulting in core damage. 
7 Event Tree Analysis

\subsubsection{References}

1. "Loss of Decay Heat Removal Capability," Virginia Power Surry Power Station, Abnormal Procedure 1-AP27.00, Revision 4, February 15, 1993.

2. "Background and Guidance for Ensuring Adequate Backup Decay Heat Removal Following Loss of RHR Surry and North Anna Power Stations,", Nuclear Analysis and Fuel Nuclear Engineering Services, Virginia Power, NE Technical Report No. 865, Revision 1, June 1992.

3. "North Anna Power Station, Surry Power Station, NE Technical Report 856 Rev. 1, Supplemental Information", Virginia Power, October 9, 1992.

4. "Station Blackout," Virginia Power Surry Power Station, Abnormal Procedure 1-AP 10.00, Revision 7, July $2,1992$.

5. "Non-Recoverable-Loss of Instrument Air," Virginia Power Surry Power-Station, Abnormal Procedure AP 1-40.00, Revision 3, December 19, 1991. 


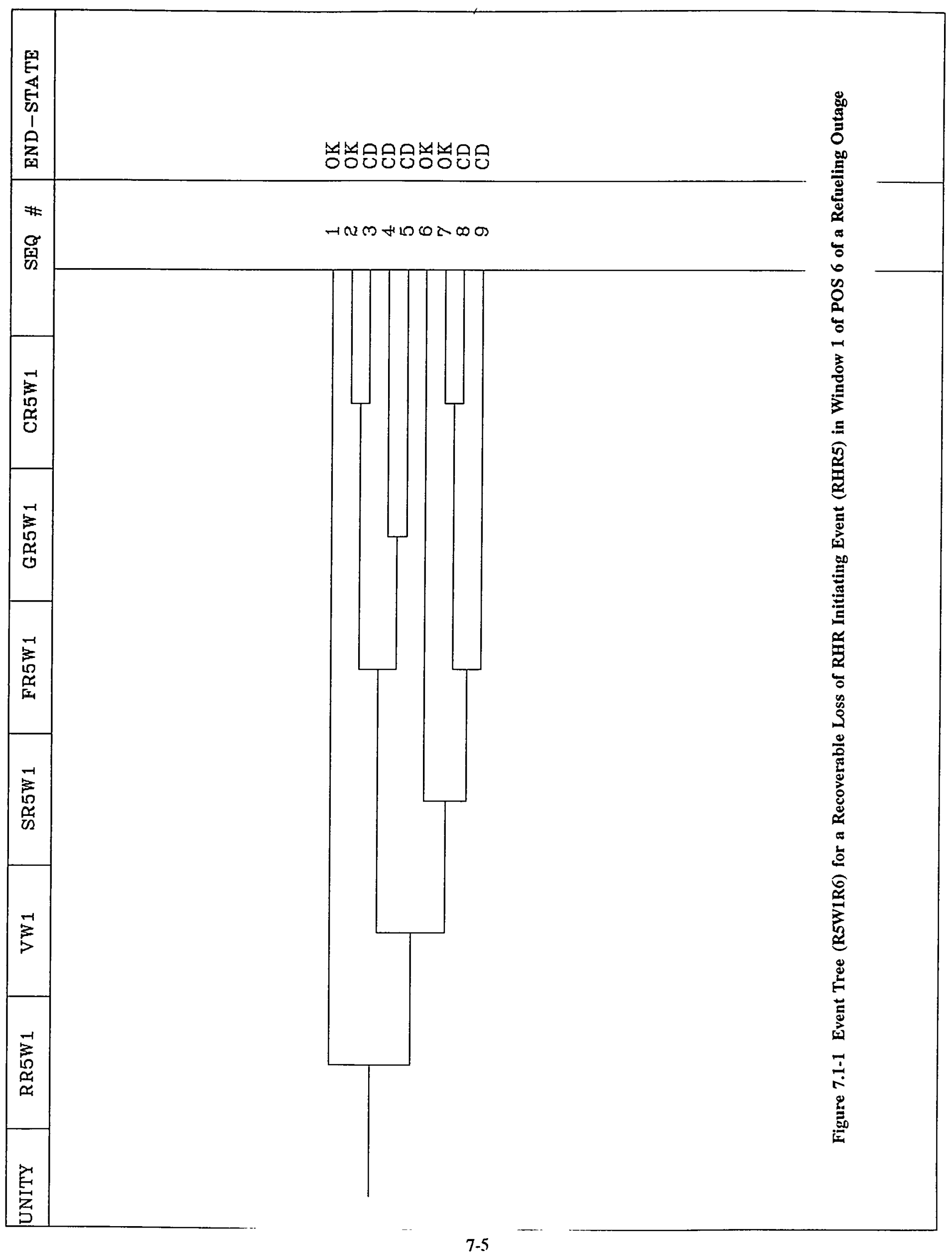




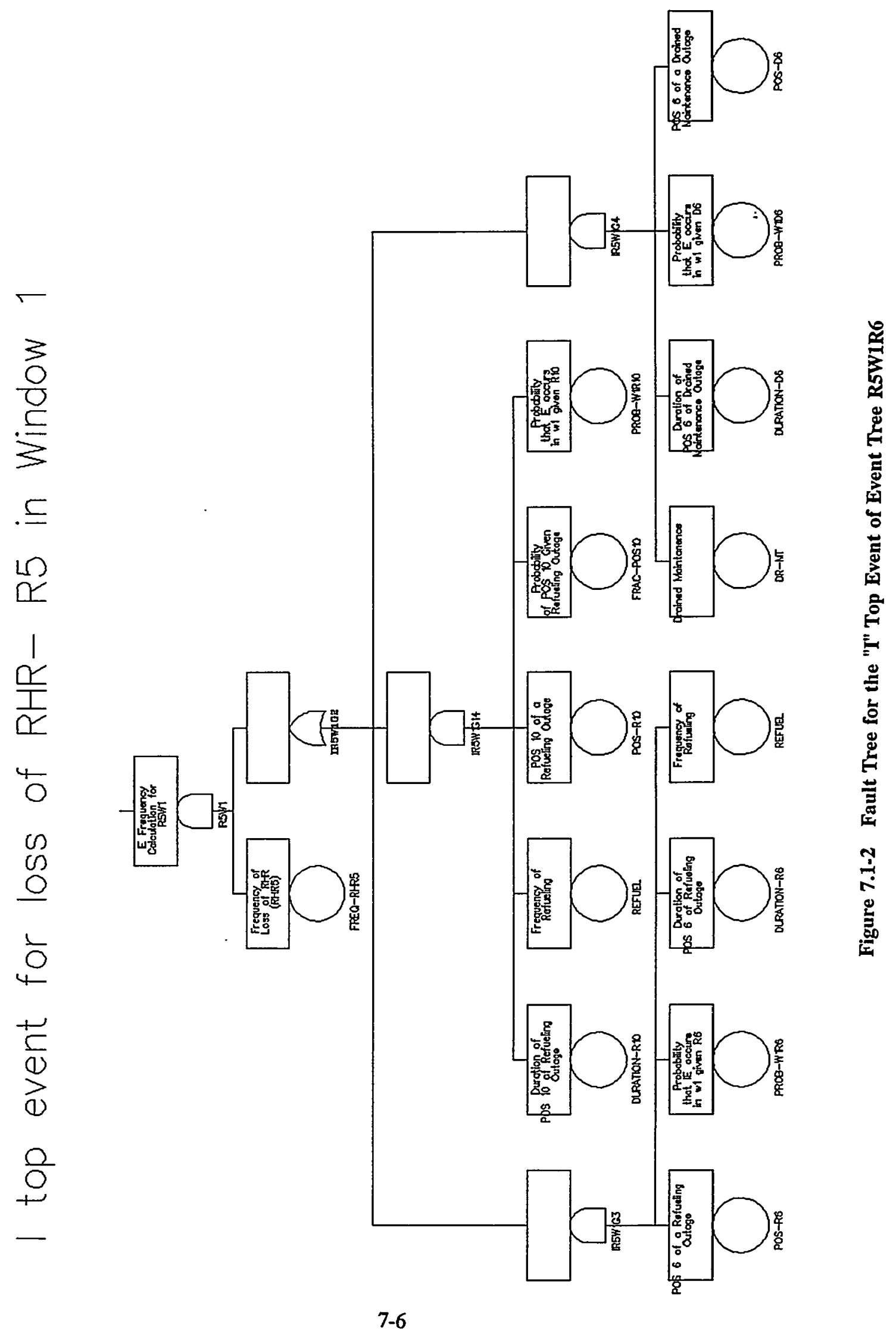




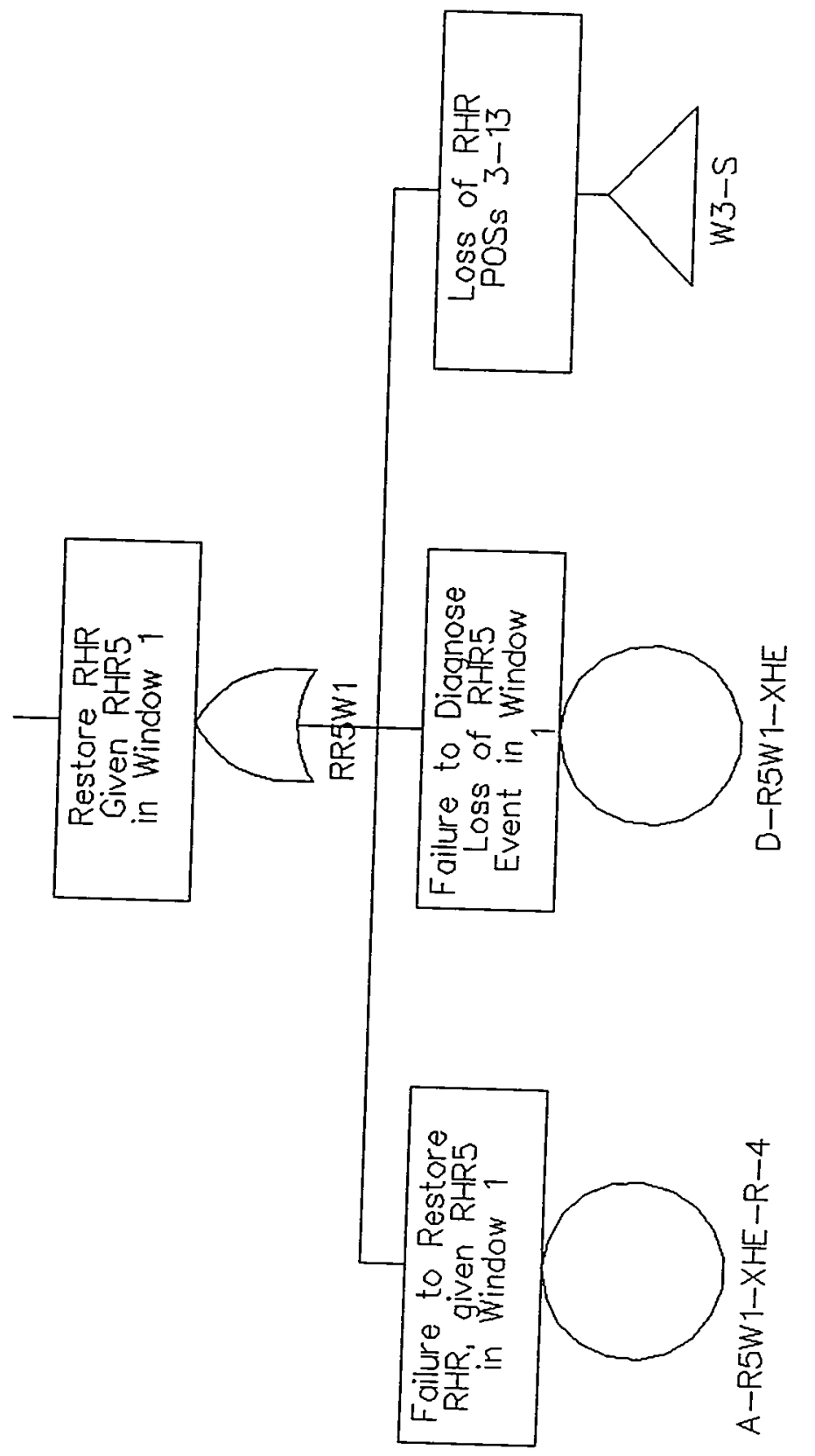

告) 


\section{Event Tree Analysis}

\subsection{Success Criteria for the Time Window Approach}

In chapter 5, we analyzed the thermal-hydraulic behavior of the reactor coolant system (RCS) in response to a loss of RHR during mid-loop operation. Three alternate cooling methods were investigated, i.e., gravity feed from RWST, reflux cooling, and feed-and-bleed operation. Gravity feed was analyzed using the MELCOR code $^{[1]}$ covering different levels of decay power corresponding to 1 day to 29 days after the shutdown. Reflux cooling was based largely on studies by Idaho National Engineering Laboratory ${ }^{[2-4]}$, and the Westinghouse Corporation ${ }^{[J}$. Feed-and-spill operation was analyzed using simplified models developed for the LP\&S program, covering a large range of initial and operating conditions. For all three cooling methods, we attempted to identify the conditions under which the operation could be successful.

In this section, the results of chapter 5 are summarized and their use in the event tree analysis is described. In this study, a mission time of 24 hours is used; that is, we assumed that if the operators can prevent core damage during the first 24 hours after an initiating event, then it can be avoided because of the additional help that would become available. Thermal hydraulic calculations are used to determine the success criteria of the various systems or mitigation functions based on the 24-hours mission time. In addition, the calculations determine the timing of the accident scenarios and the time available for the operators to act.

Table 7.2-1 summarizes the success criteria as functions of the decay heat. Table 7.2-2 summarizes the success criteria for the time windows, and the timing of the important events that determine the time available for operator actions. Table 7.2-2 differs from table 7.2-1 in the success criteria for feed-and-bleed. The latter shows the success criteria based on Virginia Power technical report $865^{[6]}$, which is intended to maintain sub-cooling in the RCS to allow restoration 6 of RHR, and is conservative in preventing core damage. Table 7.2-2 is more realistic in some areas, and is used in the PRA analysis.

The following important assumptions were made about the possible plant configurations that affect the plant's ability to mitigate the accident cenarios:

(1) In a refueling outage, the plant keeps the loops isolated for an extended period. If the reactor coolant loops are isolated, no heat removal using steam generators can be taken credit for. Table 7.2-3 summarizes the estimated fraction of time that the loops are isolated in the time windows, such that reflux cooling would be ineffective (the success criteria specified in table 7.2-2 is not satisfied); this value was estimated in chapter 9 , based on a review of the log books of past refueling outages. In a drained maintenance, one loop is assumed to be isolated for maintenance.

(2) If the safety valves on the pressurizer are removed, then gravity feed from RWST is possible. Review of the log books for past refueling outages indicates that the 3 safety valves are usually removed at the same time. Table 7.2-4 lists the estimated probability that the safety valves are removed in each time window of each POS. Section 5.1 analyzed gravity feed from RWST and found that before 32 days after shutdown, gravity feed from RWST is not adequate to provide 24 hours of decay heat removal. Therefore, in windows 1 to 3 , if gravity feed is the only way to remove decay heat in a given sequence, then there would be additional time for recovery actions before core damage occurs. In window 4, successful gravity feed is assumed to terminate the accident. In reviewing the log books of drained maintenance outages, no removal of safety valve was found. Therefore, we assumed that gravity feed is not possible in a drained maintenance.

(3) For reflux cooling to take place to remove decay heat, the following conditions must exist: 
(a) The RCS must not be vented with the pressurizer safety valves removed, otherwise, steam loss through the vents is assumed to defeat reflux cooling.

(b) The pressurizer PORVs are normally open during mid-loop operation. Inventory loss through them during reflux cooling can uncover the core in a few hours. Therefore, as part of the procedure of establishing reflux cooling, the operators are supposed to close the PORVs.

(c) The number of steam generators needed for reflux cooling was based on the Virginia Power technical report \# 865. For example, in window 2, 2 out of 3 steam generators are needed.

(d) The ability to relieve secondary pressure in the needed steam generators must be maintained by opening the steam generator PORVs, or dumping steam to the condenser.

(e) The amount of water in the steam generator is sufficient for approximately 10 hours of reflux cooling. Therefore, to remove decay heat for 24 hours, feed to the steam generators is required.

The following discussions summarize the success criteria of the generic top events of the event trees.

Reflux Cooling The success criteria for reflux cooling was based on Virginia Power Technical Report 865. It is also specified in AP 27.00. There, the number of steam generators needed is specified as a function of decay heat. It is known that the success criteria is conservative. Also, it is assumed that the operators would follow the procedure. For Window 1 of a drained maintenance, this means that the success criteria cannot be satisfied, because 3 steam generators are needed and only 2 are available. In such case, the possibility of using 2 steam generators is modeled as a recovery action.

As part of the procedure for establishing reflux cooling, the operators are supposed to close the vessel head vent and PORVs to ensure no inventory is lost through these openings. In section 5.3, it was estimated that the leakage through the tygon tube connected to the vessel head is insignificant. If the PRT rupture disks are ruptured, the leakage through an open PORV is large enough to lead to core damage in a few hours. If reflux cooling is established before the PRT is ruptured, the PRT becomes a part of the RCS boundary, and no significant loss of inventory is expected. Therefore, if the operators can establish reflux cooling by venting the secondary side of the SGs before PRT rupture disks rupture, then there is no need to close the PORVs. If reflux cooling is established after PRT ruptures, then the PORVs must be closed to prevent inventory loss. It is assumed that reflux cooling is sufficient to remove decay heat if it is established before the core is uncovered. When reflux cooling is established, the SG inventory is sufficient for about 10 hours. Feeding the steam generator after the SG inventory becomes low is modeled as a long-term operator action.

Figure 7.2-1 is the high-level fault tree for the reflux cooling top event of the example event tree.

Feed-and-Spill Section 5.2 documents the determination of the success criteria for feed-and-spill operation. There, both the Virginia Power Technical Report 865 and BNL analysis are discussed. Table 7.2-1 summarizes the success criteria, based on the Virginia Power Technical Report 865 which is the basis of AP 27.00. In AP 27.00, LHSI to hot legs is the preferred method for feed-and-spill. If hot leg injection is not available, then cold leg injection is used. If LHSI is not available, the HHSI is used. Similar to LHSI, HHSI prefers hot leg injection to cold leg injection. The needed number of PORVs is specified as a function of the time after shutdown. The operators are expected to throttle the injection flow to maintain $200 \mathrm{~F}^{0}$ at the core exit thermal couple.

The success criteria in the Virginia Power technical report are intended to maintain sub-cooling in the RCS. In reality, much more relaxed success criteria are sufficient to prevent core damage. For example, the Virginia Power technical report requires that 2 charging pumps and 2 PORVs are needed for feed-and-spill during the first 129 hours. As an alternative to feed-and-spill, the report discussed the option of using feed-and-steam operation that demands much less flow from the RWST. If only 1 charging pump and 1 PORV are available, 


\section{Event Tree Analysis}

feed-and-steam should be sufficient to keep the core covered as long as water is available in the RWST. The success criteria of Table 7.2-2 is used in this study.

To account for the low shut off head of the LHSI pumps, the time at which RCS pressure reaches 165 psia was determined and used as the time available for operator to use LHSI. For HHSI, it is assumed that the time to core damage is the time available. In the high-level fault trees, two separate human error events are used.

Figure 7.2-2 is the high-level fault tree for the feed-and-spill top event of the example event tree.

Recirculation As the level in the RWST becomes low, the operators are instructed to establish either RWST cross connect or high- head recirculation. Section 5.2 estimated that approximately 10 days after shutdown, recirculation is not needed. The calculation shows that with successful feed-and-spill, the core will not be damaged within 24 hours-after the-loss of RHR-initiating event. Therefore, high-pressure recirculation is needed only during the first 10 days after shutdown; this 10 days is used as the boundary between windows 2 and 3. In time window 2, either high-pressure recirculation or cross-connection of RWSTs would be sufficient to remove decay heat for 24 hours. In the fault-tree model for high-pressure recirculation in window 2 , failure of recirculation requires failure to cross connect the RWSTs. In time window 1, cross connection of RWSTs is not sufficient for 24 hours, and is not taken credit for.

AP 27.00 provides instructions on how high-pressure recirculation can be established, and states the possible need for the spray recirculation heat exchangers. High-pressure recirculation is established by using the low pressure injection pump to take suction from the containment sump, and discharge to the suction of the highpressure injection-system. In-the-fault tree-model for-recirculation-Figure-7:2-3,-two alternative-methods-also are modeled; the low-pressure feed-and-steam by taking suction from the containment sump, and the lowpressure feed-and-spill by taking suction from the sump and using spray recirculation. In both modes, only low head injection is needed. The feed-and-steam mode requires that the safety valves are removed to provide an adequatevent path; and-does-not-require cooling of-the-sump-water- The-feed-and-spill operation requires operation of the spray recirculation systems to cool the water in the sump, so that subcooling can be established.

Spray Recirculation In section 5.2, it was estimated that during the first 10 days after shutdown the RWST inventory is not sufficient for feed-and-spill and recirculation is needed. High-pressure recirculation would introduce steam into the containment, introducing the potential of containment failure. In this study, we assumed that if spray recirculation is not available, then the containment would fail. The impact of containment failure on recirculation is that there is a small probability, 0.02 , that the low head pumps would lose their needed net positive suction head. This cause of failure is similar to the failure mode considered in NUREG-1150, that is, failure of recirculation is modeled as a potential failure mode of the low-head injection pumps.

Another function of the spray recirculation systems is to support the operation of low-pressure feed-and -spill by taking suction from the containment sump. It cools the containment sump water so maintaining subcooling in the reactor vessel.

Gravity feed from RWST Gravity feed from RWST is established by opening the low-head injection flow path from RWST to the RCS cold legs or hot legs. The RCS must be vented by removing the SVs on the pressurizer so that gravity flow can be established. Depending on the level of decay heat and the number of SVs removed, gravity feed may or may not provide 24 hours of cooling after the initiating event. The analysis 
documented in section 5.1 found that with $1 \mathrm{SV}$ removed approximately 32 days after shutdown (5MW decay heat), the core is damaged after 24 hours. Therefore, 32 days was chosen as a boundary of the time windows. In the PRA model, for an accident initiating event that takes place after 32 days after shutdown, gravity feed from RWST is sufficient to terminate the accident. For accidents that start before 32 days, gravity feed from RWST would give some additional time for operators to restore failed mitigation systems. Table 7.2-2 lists the additional amount of time for each of the time windows. These times are the estimated delays in core damage based on the modeling of gravity feed using MELCOR, and the amount of time that subcooling is maintained, as estimated in attachment 9 of AP 27.00. Operator recovery using these times is modeled as recovery actions in the event-tree analysis. In section 5.1, sensitivity calculations were made to determine the effect of the timing of gravity feed. They showed that at 2 days after shutdown (13.2 MW) with only $1 \mathrm{SV}$ on the pressurizer removed, gravity feed from RWST became ineffective if initiated after 50 minutes after the loss of RHR, due to the build up of RCS pressure. For lower decay heat, gravity feed is effective if established less than 1 hour before the core is uncovered. The review of refueling outage log books found that the plant usually remove the 3 SVs together. Therefore, the vent capacity of the safety valves is always sufficient for gravity feed. The time available for the operators to establish gravity feed is assumed to be the same time as that before core uncovery occurs.

Figure 7.2-4 is the high-level fault tree used for the gravity feed top event in the example event tree R5W1R6. In this study, the use of gravity feed from RWST is taken credit for only in station blackout. In other cases, there are many other methods of mitigating an accident, and use of gravity feed is judged to be either not needed or not helpful. In these cases, the human-error probability of establishing gravity feed was assigned a value of 1.0. 


\section{Event Tree Analysis}

\subsubsection{References}

1. Summers, R.M., et. al., "MELCOR 1.8.0: A computer code for Nuclear Reactor Severe Accident Source Term and Risk Assessment Analysis, "NUREG/CR-5531, Sandia National Laboratories, Albuquerque,NM, January 1991.

2. Naff, S.A., et. al., "Thermal Hydraulic Processes During Reduced Inventory Operation with Loss of Residual Heat Removal," NUREG/CR-5855, Idaho National Engineering Laboratory, April 1992.

3. Fletcher, C.D., et. al., "Thermal-Hydraulic Processes Involved in Loss of Residual Heat Removal During Mid-Loop Operation, EGG-East-9337, Idaho National Engineering Laboratory, October 1990.

4. Wald, L.W., et. al., "Consequence of the Loss of Residual Heat Removal Systems in Pressurized Water Reactors," NUREG/CR-5820, Idaho National Engineering Laboratory, May 1992.

5. Audreycheck, T.S., et. al., "Loss of RHRs Cooling While the RCS is Partially Filled," WCAP - 11916, Westinghouse Electric Corporation, July 1988.

6. "Background and Guidance For Ensuring Adequate Decay Heat Removal when RCS Loop Stop Valves are closed, Surry and North Anna Power Stations, "NE Technical Report No. 865, Rev.1, Virginia Power, June 1992. 


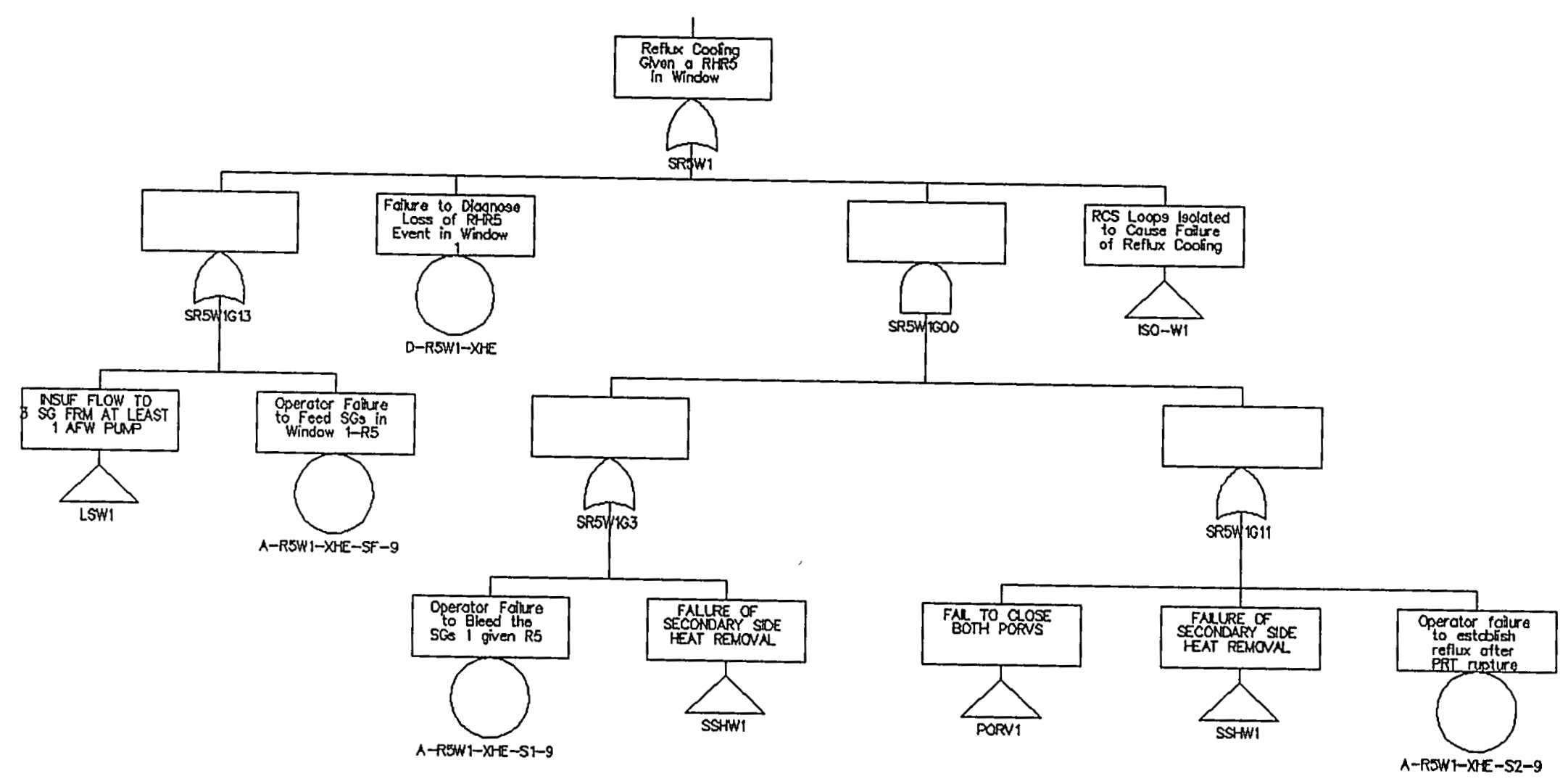

Figure 7.2-1 Reflux-Cooling Top Event for RHR5 in Window 1 of POS R6 


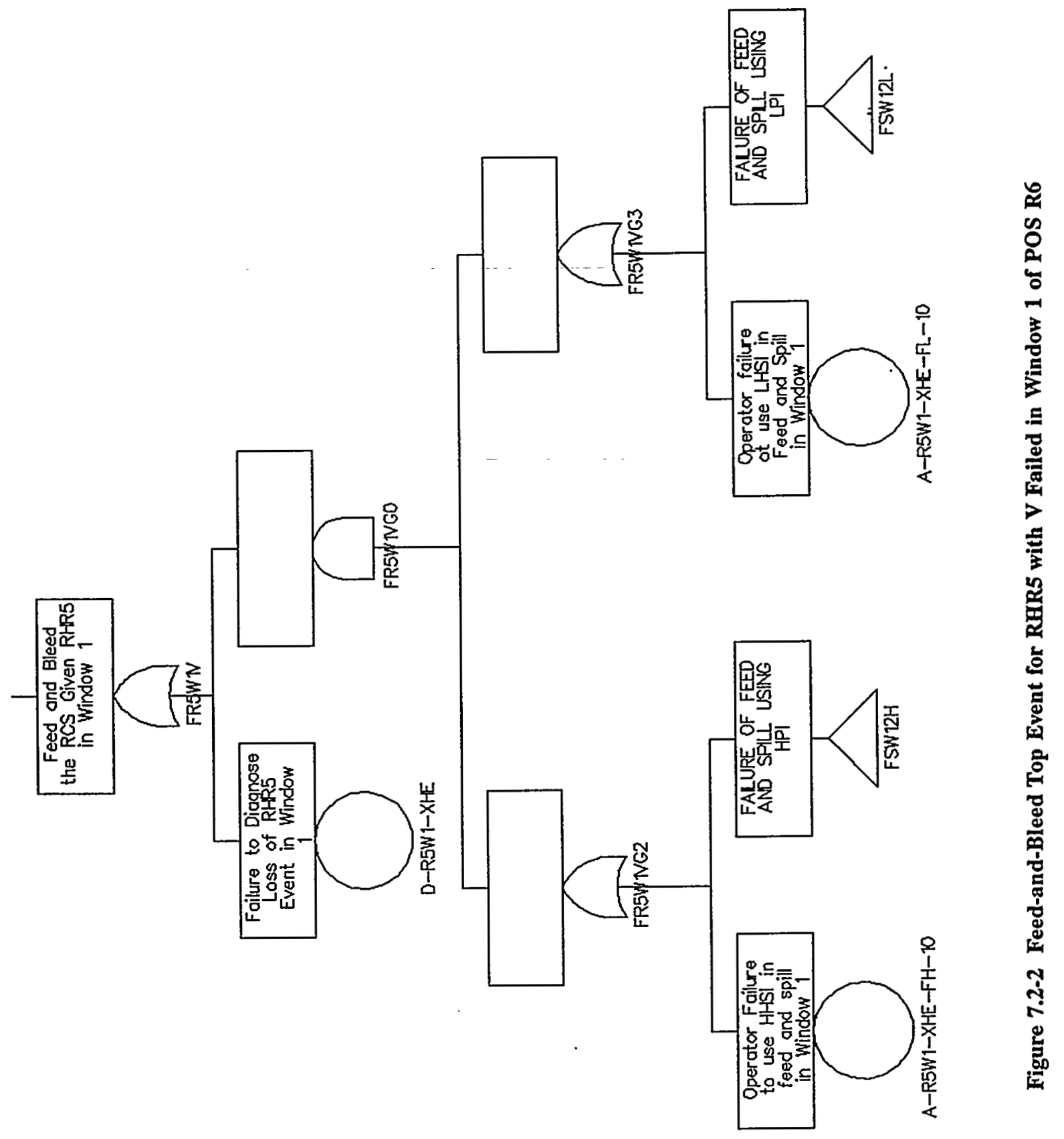




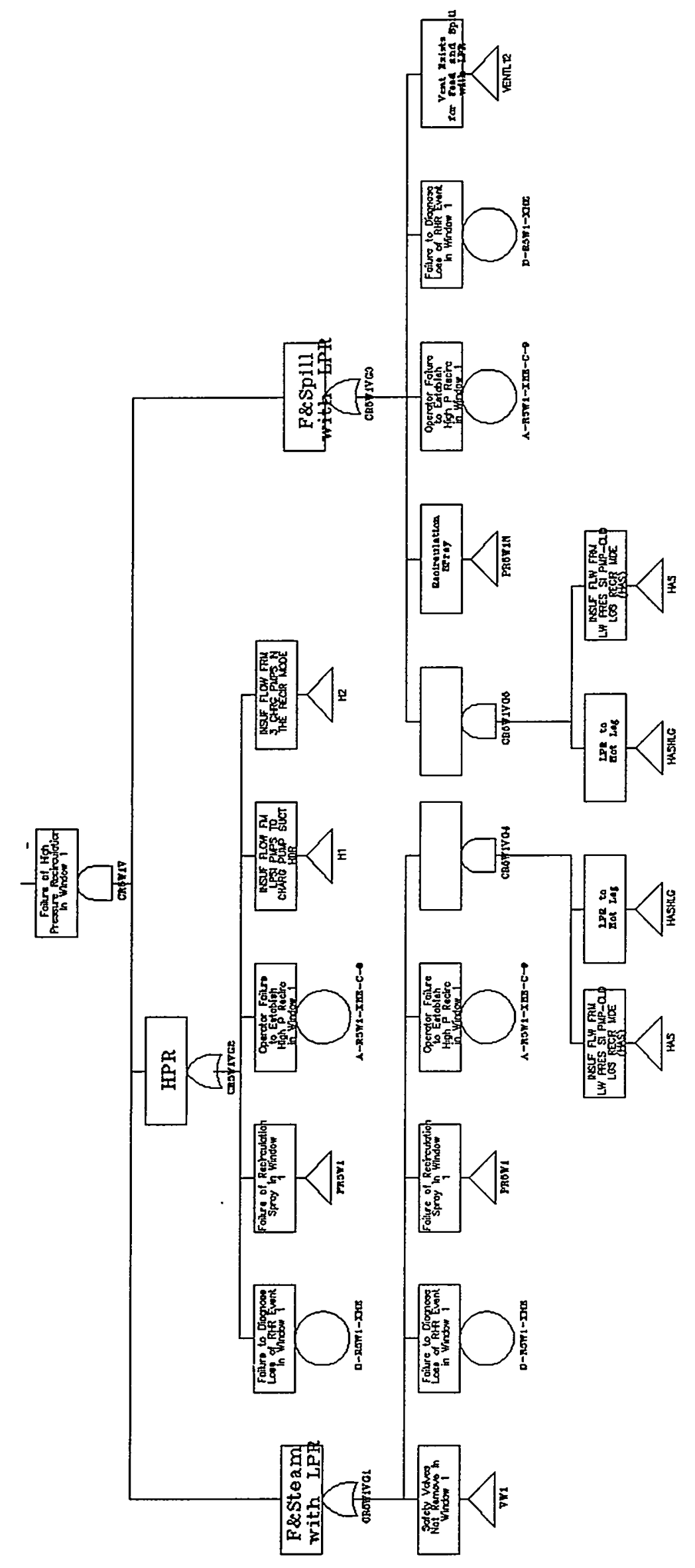

余 


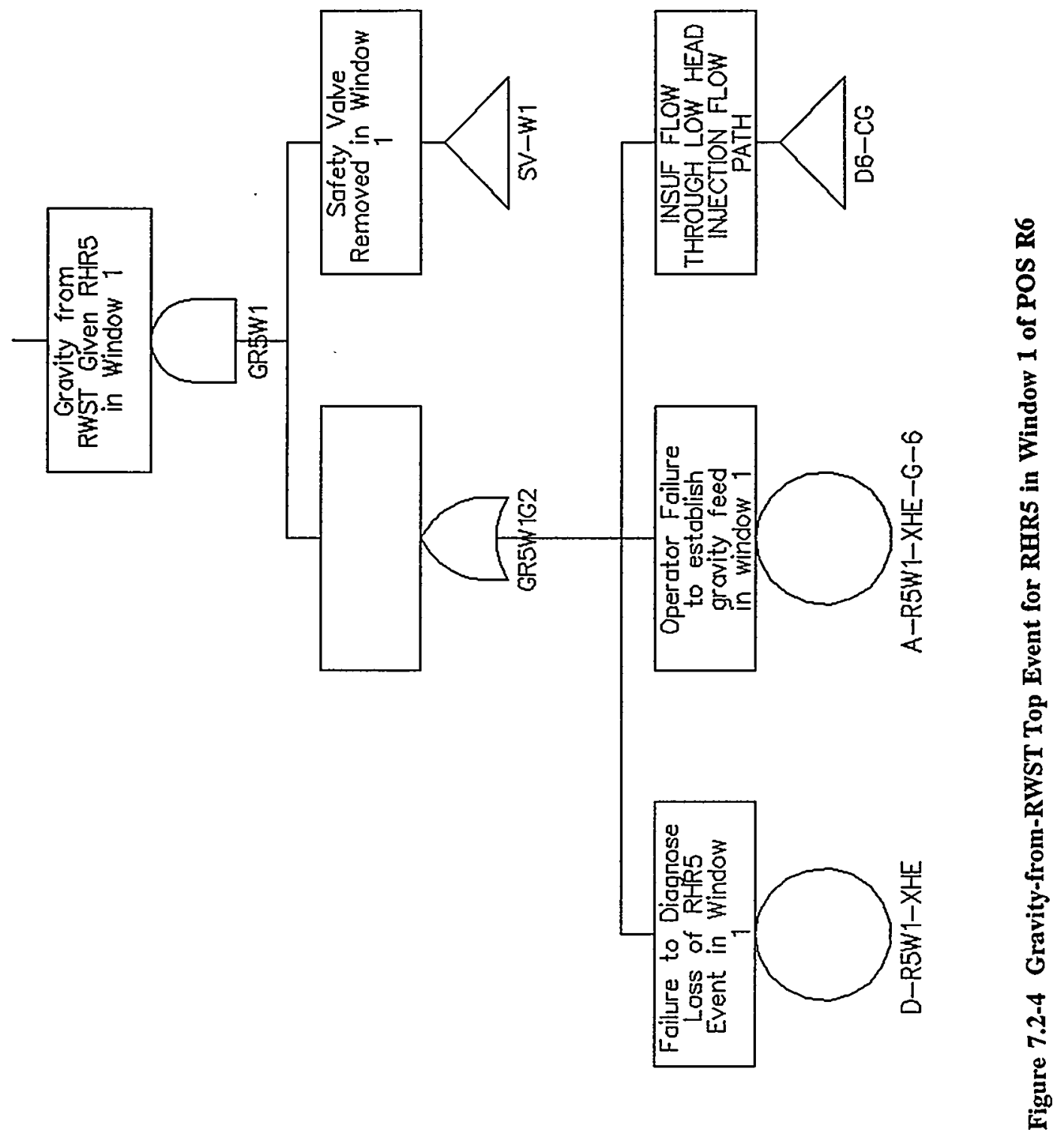


Table 7.2-1 Success Criteria for Mitigating Features

\begin{tabular}{|c|c|c|c|}
\hline Feature & Time Window & \multicolumn{2}{|c|}{ Success Criteria } \\
\hline \multirow[t]{4}{*}{ Reflux Cooling ' } & & Short Term & Long Term \\
\hline & $<75$ hours & 3 SGs & AFW to 3 SGs \\
\hline & $\begin{array}{l}>=75 \text { hours and } \\
<475 \text { hours }\end{array}$ & 2 SGs & AFW to 2 SGs \\
\hline & $>=475$ hours & $1 S G$ & AFW to $1 \mathrm{SG}$ \\
\hline \multirow[t]{5}{*}{ Feed-and- Spill } & $<107$ hour & \multicolumn{2}{|c|}{$1 \mathrm{LHSI} *(\mathrm{SV}$ removed $+2 \mathrm{PORV})$} \\
\hline & $>107$ hours & \multicolumn{2}{|c|}{1 LHSI $*$ (SV removed +1 PORV) } \\
\hline & $<129$ hours & \multicolumn{2}{|c|}{$2 \mathrm{HHSI} *(\mathrm{SV}$ removed +2 PORV $)$} \\
\hline & $\begin{array}{l}>129 \text { and }<138 \\
\text { hours }\end{array}$ & \multicolumn{2}{|c|}{$1 \mathrm{HHSI} *(\mathrm{SV}$ removed +2 PORV $)$} \\
\hline & $>=138$ hours & \multicolumn{2}{|c|}{$1 \mathrm{HHSI} *(\mathrm{SV}$ removed +1 PORV $)$} \\
\hline \multirow[t]{4}{*}{ Gravity Feed } & $<70$ hours & \multicolumn{2}{|c|}{ at least $1 \mathrm{SV}$ removed, less than 1 hour of subcooling } \\
\hline & $\begin{array}{l}>70 \text { hours and } \\
<150 \text { hours }\end{array}$ & \multicolumn{2}{|c|}{ at least $1 \mathrm{SV}$ removed, 2 hours of subcooling } \\
\hline & $\begin{array}{l}>150 \text { hours and } \\
\text { less than } 768 \text { hours }\end{array}$ & \multicolumn{2}{|c|}{ at least $1 \mathrm{SV}$ removed, 3 hours of subcooling } \\
\hline & $>=768$ hours & \multicolumn{2}{|c|}{ at least $1 \mathrm{SV}$ removed, sufficient for 24 hours } \\
\hline \multirow[t]{3}{*}{ Recirculation } & $<=3$ days & \multicolumn{2}{|l|}{ needed } \\
\hline & $\begin{array}{l}>3 \text { days and } \\
<=10 \text { days }\end{array}$ & \multicolumn{2}{|c|}{ not needed if RWSTs are cross tied, otherwise needed } \\
\hline & $>10$ days & \multicolumn{2}{|l|}{ not needed } \\
\hline \multirow{3}{*}{$\begin{array}{l}\text { Spray } \\
\text { Recirculation }\end{array}$} & $<=3$ days & \multicolumn{2}{|c|}{ needed to prevent recirculation failure } \\
\hline & $\begin{array}{l}>3 \text { days and } \\
<=10 \text { days }\end{array}$ & \multicolumn{2}{|c|}{$\begin{array}{l}\text { not needed if RWSTs are cross tied, otherwise needed to prevent } \\
\text { recirculation failure }\end{array}$} \\
\hline & $>10$ days & \multicolumn{2}{|l|}{ not needed } \\
\hline
\end{tabular}


7 Event Tree Analysis

Table 7.2-2 Definition and Characterization of Time Windows

\begin{tabular}{|c|c|c|c|c|}
\hline & WINDOW 1 & WINDOW 2 & WINDOW 3 & - WINDOW 4 \\
\hline Definition & $-<=75$ hours & $\begin{array}{l}>75 \text {-hours-and } \\
<=240 \text { hours }\end{array}$ & $\begin{array}{l}>240 \text { hours and }- \\
<=32 \text { days }\end{array}$ & $>-32$ days -- \\
\hline $\begin{array}{l}\text { Representative } \\
\text { Decay Heat }\end{array}$ & $13.23 \mathrm{MW}(2$ days) & $10 \mathrm{MW}$ (5 days) & $7 \mathrm{MW}(12$ days $)$ & $5 \mathrm{MW}$ (32 days) \\
\hline \multicolumn{5}{|l|}{ Success Criteria } \\
\hline Reflux Cooling & 3 SGs & $2 S G$ & 2 SG & $1 \mathrm{SG}$ \\
\hline \multicolumn{5}{|c|}{ Feed and Bleed } \\
\hline LHSI & $\begin{array}{l}1 \mathrm{LHSI}(\mathrm{SV} \\
\text { removed + } 2 \\
\text { PORV })\end{array}$ & $\begin{array}{l}1 \mathrm{LHSI}^{*}(\mathrm{SV} \\
\text { removed }+2 \\
\text { PORV })\end{array}$ & $\begin{array}{l}1 \mathrm{LHSI} *(\mathrm{SV} \\
\text { removed + } \\
1 \mathrm{PORV})\end{array}$ & $\begin{array}{l}\text { 1LHSI *(SV removed } \\
+1 \text { PORV) }\end{array}$ \\
\hline HHSI & $\begin{array}{l}1 \mathrm{HHSI}^{*}(\mathrm{SV} \\
\text { removed + } 1 \\
\text { PORV) }\end{array}$ & $\begin{array}{l}1 \mathrm{HHSI}^{*}(\mathrm{SV} \\
\text { removed }+1 \\
\text { PORV) }\end{array}$ & $\begin{array}{l}\text { 1HHSI*(SV } \\
\text { removed + } 1 \\
\text { PORV) }\end{array}$ & $\begin{array}{l}\text { 1HHSI*(SV removed } \\
+1 \text { PORV })\end{array}$ \\
\hline Gravity Feed & $\begin{array}{l}1 \text { SV removed * } \\
\text { LHSI flow path } \\
\text { provides } \\
4.3 \text { hours for } \\
\text { operator actions } \\
\text { (with less than } 2 \\
\text { hours of } \\
\text { subcooling) }\end{array}$ & $\begin{array}{l}1 \mathrm{SV} \text { removed * } \\
\text { LHSI flow path } \\
\text { provides } 6.5 \text { hours } \\
\text { for operator actions } \\
\text { (with } 2 \text { hours of } \\
\text { subcooling) }\end{array}$ & $\begin{array}{l}1 \text { SV removed * } \\
\text { LHSI flow path } \\
\text { provides } \\
12 \text { hours for } \\
\text { operator actions } \\
\text { (with } 2 \text { hours of } \\
\text { subcooling) }\end{array}$ & $\begin{array}{l}1 \text { SV removed * } \\
\text { LHSI flow path } \\
\text { provides sufficient } \\
\text { cooling for } 24 \text { hours } \\
\text { (with more than } 3 \\
\text { hours of subcooling) }\end{array}$ \\
\hline \multirow[t]{2}{*}{ Recirculation } & \multirow{2}{*}{$\begin{array}{l}\text { needed(HPR + } \\
\text { LPF\&Steam } \\
\text { + LPF\&Spill) }\end{array}$} & 1 RWST,needed & \multirow[t]{2}{*}{ not needed } & \multirow[t]{2}{*}{ not needed } \\
\hline & & $\begin{array}{l}2 \mathrm{RWST} \text {, not } \\
\text { needed }\end{array}$ & & \\
\hline \multirow{2}{*}{$\begin{array}{l}\text { Recirculation } \\
\text { Spray }\end{array}$} & \multirow[t]{2}{*}{ needed } & 1 RWST,needed & \multirow[t]{2}{*}{ not needed } & \multirow[t]{2}{*}{ not needed } \\
\hline & & $\begin{array}{l}2 \text { RWST,not } \\
\text { needed }\end{array}$ & & \\
\hline \multicolumn{5}{|c|}{ Probability that IE Occurs in the Window } \\
\hline D6 & $\begin{array}{l}0.117 \\
(0.31)^{*}\end{array}$ & $\begin{array}{l}0.436 \\
(0.454)\end{array}$ & $\begin{array}{l}0.375 \\
(0.21)\end{array}$ & $\begin{array}{l}7.20 \mathrm{E}-02 \\
(2.6 \mathrm{E}-02)\end{array}$ \\
\hline
\end{tabular}


Table 7.2-2 (continued)

\begin{tabular}{|c|c|c|c|c|}
\hline & WINDOW 1 & WINDOW 2 & WINDOW 3 & WINDOW 4 \\
\hline R6 & $\begin{array}{l}1.7 \mathrm{E}-02 \\
(5.82 \mathrm{E}-02)\end{array}$ & $\begin{array}{l}0.543 \\
(0.7)\end{array}$ & $\begin{array}{l}0.41 \\
(0.24)\end{array}$ & $\begin{array}{l}3.4 \mathrm{E}-02 \\
(1.48 \mathrm{E}-03)\end{array}$ \\
\hline R10 & 0.0 & 0.0 & $\begin{array}{l}0.016 \\
(2.2 \mathrm{E}-02)\end{array}$ & $\begin{array}{l}9.84 \mathrm{E}-01 \\
(0.98)\end{array}$ \\
\hline \multicolumn{5}{|c|}{ * RHR2A based on time to mid-loop } \\
\hline Decay Heat & $13.23 \mathrm{MW}(2$ days $)$ & $10 \mathrm{MW}(5$ days $)$ & $7 \mathrm{MW}(12$ days $)$ & $5 \mathrm{MW}$ (32 days) \\
\hline Time to Boiling & $15 \mathrm{~min}$. & $20 \mathrm{~min}$. & 27 min. & $37 \mathrm{~min}$ \\
\hline $\begin{array}{l}\text { Time to Tygon } \\
\text { Tube Rupture( } 40 \\
\text { psia) }\end{array}$ & $23 \mathrm{~min}$. & $31 \mathrm{~min}$. & $43 \mathrm{~min}$. & 59 min. \\
\hline $\begin{array}{l}\text { Time to PRT } \\
\text { Rupture(100 } \\
\text { psig) }\end{array}$ & $51 \mathrm{~min}$. & $63 \mathrm{~min}$. & $78 \mathrm{~min}$. & $96 \mathrm{~min}$. \\
\hline Time to 165 psia & $\begin{array}{l}41 \text { min. with } 2 \\
\text { PORV } \\
43 \text { min. with } 1 \\
\text { PORV }\end{array}$ & $\begin{array}{l}63 \text { min. with } 2 \\
\text { PORV } \\
60 \text { min. with } 1 \\
\text { PORV }\end{array}$ & $\begin{array}{l}227 \text { min. with } 2 \\
\text { PORV } \\
89 \text { min. with } 1 \\
\text { PORV }\end{array}$ & $\begin{array}{l}352 \text { min. with } 2 \\
\text { PORV } \\
147 \text { min. with } 1 \\
\text { PORV }\end{array}$ \\
\hline Time to 615 psig & $\begin{array}{l}145 \text { min. with } 1 \\
\text { PORV } \\
\text { - with two }\end{array}$ & - & - & - \\
\hline $\begin{array}{l}\text { Time to RWST } \\
\text { Depletion }\end{array}$ & $10 \mathrm{hrs}$ & $13.5 \mathrm{hrs}$ & $18.7 \mathrm{hrs}$ & $38.6 \mathrm{hrs}$ \\
\hline $\begin{array}{l}\text { Time to AFW } \\
\text { Initiation(with } \\
25 \% \text { SG } \\
\text { inventory } \\
\text { remaining) }\end{array}$ & $743 \mathrm{~min}$. & $669 \mathrm{~min}$. & $925 \mathrm{~min}$. & $628 \mathrm{~min}$. \\
\hline $\begin{array}{l}\text { Time to Core } \\
\text { Uncovery }\end{array}$ & 120 min. & $157 \mathrm{~min}$. & 209 min. & 273 min. \\
\hline $\begin{array}{l}\text { Time to Core } \\
\text { Damage }\end{array}$ & $219 \mathrm{~min}$. & 297 min. & 411 min. & $557 \mathrm{~min}$. \\
\hline
\end{tabular}


7 Event Tree Analysis

Table 7.2-3

Probability that the RCS Loops Are Isolated

Such that Reflux Cooling Is Unavailable or Ineffective

\begin{tabular}{|c|c|c|c|}
\hline & R6 & R10 & D6 \\
\hline W1 & 0.3 & - & True \\
\hline W2 & 0.7 & - & False \\
\hline W3 & True & True & False \\
\hline W4 & True & True & False \\
\hline
\end{tabular}

Table 7.2-4

Probability that the Safety Valves on the Pressurizer Are Removed

\begin{tabular}{|c|c|c|c|}
\hline & R6 & R10 & D6 \\
\hline W1 & 0.01 & - & False \\
\hline W2 & 0.05 & - & False \\
\hline W3 & 0.9 & 0.9 & False \\
\hline W4 & 0.3 & 0.3 & False \\
\hline
\end{tabular}


7 Event Tree Analysis

\subsection{Loss of Residual Heat Removal Event Trees}

Figures 7.3-1 to 7.3-50 are the event trees for the loss of RHR initiating events applicable to mid-loop operations. The initiating events are described in section 4.2. In the time window approach, each accident initiating can occur in 4 different time windows and 3 POSs. In principle, 12 event trees would be needed to delineate the possible accident scenarios. Because POS 10 of a refueling outage occurs after refueling is completed, it cannot occur in time windows 1 and 2; this is demonstrated in the conditional probability that an accident initiating event occurs in the time windows of table 7.2-2. Therefore, ten event trees were developed for each initiating event. They were based on abnormal procedure AP 27.00, revision 4, supplemented with information obtained during meetings with plant personnel, and information documented in Virginia Power technical report ${ }^{[1]}$ on "Background and Guidance for Ensuring Adequate Backup Decay Heat Removal Following Loss of RHR".

In sections 7.1 and 7.2, the nomenclature used in the event trees and high level fault trees was discussed, using event tree R5W1R6 and its associated high-level fault trees as an example. In this section, the accident sequences defined in the event trees are discussed.

\subsubsection{Event Tree for Over-draining to Mid-Loop (RHR2A)}

This event occurs at the beginning of the POS due to overdraining. It may be annunciated by the shutdown cooling low-level annunciator and RHR heat exchanger low-flow annunciator, and indicated by motor amperage and flow oscillation, and excessive noise on the RHR pump. The expected responses of the operator include stopping the votexing pump, locally venting the RHR pump if necessary, restoring RCS level, and restoring RHR.

\subsection{1 "Over-Draining to Mid-Loop" Event Tree - Refueling POS 6}

Window 1 (RAW1R6)

The event tree top events of this event tree, Figure 7.3.1-1, are described below.

\section{IRAW1 - Over Draining}

This top event is used to calculate the frequency of the initiating event that overdraining occurs in window 1 of the refueling outage. The overdraining event is modeled as a basic event. As discussed in section 7.1, the fault tree for this top event was built so that it can be used to quantify the frequency for all 3 POSs, R6, D6, and R10. HOUSE events are used to select the portion of the tree that is applicable to the POS.

\section{MRAW1 - RCS Makeup}

This event tree represents RCS inventory makeup using the charging pumps, low-head injection pumps, or gravity feed from RWST. Only a small amount of makeup is needed to raise the level to allow restoration of the RHR. It is assumed that if the RHR is not restored before the rupture disks of the pressurizer relief tank break (51 minutes for time window 1), it will be impossible to restore RHR due to the radiation inside the containment. 


\section{Event Tree Analysis}

\section{RRAW1 - Restore RHR}

This event represents restoration of the RHR, after the RCS inventory is restored. The restoration requires local venting the RHR pumps, verifying RHR heat sink, and restarting a RHR pump.

\section{VRAW1 - RCS Initially Vented}

This event represents the initial condition that the RCS is vented with the three pressurizer safety relief valves removed; it does not represent an operator action. It is needed in the event trees, because it affects subsequent events. Each safety valve leaves a 4-inch diameter opening on top of the pressurizer. If the RCS is vented this way, then gravity feed from RWST is possible. However, it was assumed that reflux cooling will not be possible, due to the potential loss of inventory through the vents on the pressurizer. Venting through the safety valves allows gravity feed from the RWST.

\section{SRAW1 - Steam Generator Feed-and-Bleed}

This event represents use of reflux cooling to remove heat. Reflux cooling is possible when the reactor coolant loops are not isolated, and the secondary side of the steam generators are in wet lay-up. Loop isolation and draining of the SGs are modeled as failure causes for this top event. The number of steam generators needed and the time to secondary dry out depend on the decay heat, and are estimated in chapter 5 . Based on AP 27.00, for time window 1, 3 steam generators are needed. Based on Table 7.2-2, the secondary inventory in the steam generators is sufficient for 743 minutes. Venting of the secondary side can be done by dumping steam to the condenser, or venting to the atmosphere using the steam generator PORVs. Dumping steam to the condenser requires opening the bypass valves around the MSTV, the main steam non-return valves, and the steam dump valves. In this time window, the initial SG inventory can last approximately 743 minutes. Therefore, the SGs must be fed with auxiliary feedwater pumps.

\section{FRAW1 - Primary Feed-and-Bleed}

This event represents primary feed-and-bleed using a charging pump or low-head injection pump, and relieving through the pressurizer PORVs. According to abnormal procedure, AP 27.00, cold leg injection is preferred, but hot leg injection is an option. According to reference 1 , feed-and-spill operation is preferred to the feedand-steam operation. In the former, the operators feed the RCS until the system is completely filled and there is spilling out through the PORVs. In this mode, the injected flow must be high enough to keep the reactor coolant sub-cool, making it easy to restore RHR. For time window 1 (represented by decay heat 2 days after shutdown), $644 \mathrm{gpm}$ of flow from is necessary to remove decay heat; the flow from one charging pump, 600 gpm or less, is not enough. The other concern with this mode of decay-heat removal is whether or not the amount of water is sufficient. The unit 1 RWST should be sufficient for approximately 10 hours of injection. When the RWST level becomes low, recirculation has to be initiated.

In the feed-and-steam operation, much less flow is needed, and the RWST inventory can, potentially, last much longer. However, the control of the injected flow and level poses an operational challenge. There is the potential for pressurized thermal shock and over-pressurization if the vent path is insufficient.

In time window 1, we decided that 1 charging pump with 1 open PORV flow path is sufficient for the feedand-bleed operation. This is more relaxed than what is required for feed-and-bleed during power operations where two PORVs are needed. In the case of low-pressure injection pumps, 2 PORVs are needed to ensure that the system pressure is below 165 psia. The PORVs are normally blocked open with the block valves de- 
energized open. It is assumed that there is a small chance that one PORV flow path is closed, due to the problem of PORV leakage during power operations. For bleeding purposes, the flow path can be re-opened.

In those sequences in which the VW1 top event is successful, i.e., the pressurizer safety valves are removed, the fault tree for the feed-and-bleed operation contains an event representing removal of the safety valves. This event is needed to quantify these sequences correctly, because treatment of the successful event is not automatically included. For those sequences in which the VW1 top event failed, i.e., the safety valves are not removed, the basic event representing this condition is automatically included as the cutset of the VW1 top event.

\section{CRAW1 - Recirculation}

Recirculation can be established in 3 ways. The first method, high-pressure recirculation, is defined in AP 27.00, and requires one charging pump running and taking suction from the discharge of a low pressure injection pump that is running and taking suction from the containment sump. This method requires two pumps and the associated flow path to be available. The second method, feed-and-steam with the lowpressure injection pump, uses the pump to take suction from the containment and inject into the RCS. In chapter 5 , it was estimated that the water in the containment sump would be approximately 140 degrees $F$. Therefore, NPSH should not be a problem. To bleed the steam successfully, it is assumed that the pressurizer safety valves have to be removed. The third method, low-pressure feed-and-spill, uses the low-pressure injection pump to take suction from the containment sump, and inject into the RCS. For this method to succeed, at least one of the spray recirculation systems have to operate to cool the water in the containment sump.

In time window 1, cross connection of RWSTs is not sufficient to support feed-and-spill operation for 24 hours. Therefore, it is not taken credit for.

In those sequences in which the VW1 top event is successful, i.e., the pressurizer safety valves are removed, the fault tree for the recirculation operation contains the event representing removal of the safety valves. This is needed to correctly quantify these sequences because the treatment of the successful event is not automatically included. For sequences in which the VW1 top event failed, i.e., safety valves are not removed, the basic event representing this condition is automatically included as the cutset of the VW1 top event.

\section{GRAW1 - Gravity Feed from RWST}

Gravity feed from RWST is possible if the pressurizer safety valves are removed; therefore, this is modeled in the fault tree as a necessary condition. For window 1, this method of removing decay heat is not sufficient for 24 hours. However, it delays core damage by more than 4 hours, and potentially, allows the operator to establish other ways of removing decay heat. Gravity feed is modeled in the event tree, and if successful, is assumed to lead to core damage. The fault tree for gravity feed is basically the fault tree for low-head injection with the pump-failure mode removed. It is assumed that if the associated pump is down for maintenance, then the flow path through the pump is unavailable.

We conservatively assumed that the human-error probability associated with establishing gravity feed is one except for station blackout scenarios in which gravity feed may be the only method of decay heat removal. The frequency of those sequence with no credit given to gravity feed was found to be insignificant. 


\section{Event Tree Analysis}

\section{Sequence Descriptions of Event Tree RAW1R6}

Sequence 4: In this sequence, an overdraining event (IRAW1) occurs in window 1 of a refueling outage. The RCS makeup (MRAW1) is successful, but restoration (RRAW1) of RHR is not. The pressurizer safety valves are removed (VW1) that makes reflux cooling (SRAW1) impossible. Feed-and-spill operation (FRAW1) is successful, and recirculation (CRAW1) fails.

Sequence 5 - This sequence is similar to sequence 4, except that feed-and-spill fails, but gravity feed from RWST is successful, so that there is more time for the operator to recover from the preceding failures. Recovery actions could be applied to this sequence. Because the human-error probability for gravity feed is set to "TRUE", this sequence becomes logically impossible.

Sequence 6 - This sequence differs from sequence 5 in that the gravity feed from RWST fails. The HEP for gravity feed is set to "TRUE".

Sequence 9 - This sequence is the same as sequence 4, except that the pressurizer safety valves (VW1) are not removed that allow reflux cooling. Reflux cooling fails in this sequence, and causes core damage to occur.

Sequence 10 - In this sequence, the RHR is not restored (RRAW1), safety valves are not removed (VW1), reflux cooling is failed (SRAW1), and feed-and-spill failed (FRAW1).

Sequence 12 - In this sequence, RCS makeup (MRAW1) fails, making restoring RHR (RRAW1) impossible. The pressurizer safety valves (VW1) are removed, so that reflux cooling (SRAW1) is impossible. Feed-andspill (FRAW1) is successful, and recirculation (CRAW1) is not.

Sequences 13 to 18 - These sequences are similar to sequences 5 to 10 , except that RHR can not be restored due to failure of RCS makeup, while in sequence 5 to 10, restoration of RHR itself failed.

\section{Window 2 (RAW2R6)}

The event tree, Figure 7.3.1-2, for time window 2 has the same structure as that of window 1. The only differences are in the timing of the scenarios, and in the success criteria for recirculation and reflux cooling. Due to the difference in timing of the accidents, the various HEPs may differ. Those event tree top events that have different success criteria than those of window 1 are described below.

SRAW2 - Steam Generator Feed-and-Bleed

The success criteria for time window 2 is that 2 steam generators are needed for reflux cooling.

CRAW2 - Recirculation

In time window 2, cross connection of RWSTs would provide 24 hours of feed-and-spill. In the fault tree for failure of recirculation, failure to cross-connect the RWSTs is a required condition. It is assumed that for cross connection to be successful, a unit 1 charging pump must be available and the operator action must be successful. No credit was taken for this in the logic model. The use of unit 2 charging pump is modeled as a recovery action. 
Window 3 (RAW3R6)

This event tree, figure 7.3.1-3, differs from that of window 1 in that no top event representing reflux cooling or recirculation is used. Reflux cooling is not possible because the RCS loops are known to be isolated in this time window during refueling. Recirculation is not necessary, because the flow needed for feed-and-spill operation is low enough so that the RWST inventory is sufficient for 24 hours.

Window 4 (RAW4R6)

This event tree, figure 7.3.1-4, should be identical to that of window 3, except that here successful gravity feed does not damage the core. The thermal hydraulic analysis of section 5.1 found that after 24 days the decay heat is low enough so that gravity feed from RWST is sufficient to remove decay heat for 24 hours. The top event on reflux cooling was inadvertently kept in this event tree, so that the event tree appears different from that of window 3; this does not affect the results, because reflux cooling is always failed in this time window.

\subsection{2 "Over-Draining to Mid-Loop" Event Tree - Refueling POS 10}

POS 10 of a refueling outage occurs after refueling is completed. As a result, it can only take place in windows 3 and 4. The event trees for POS 10, Figures 7.3.1-5 to 7.3.1-6, have the same structure as those of POS 6 of a refueling outage. The only differences are the maintenance unavailabilities,conditional probability of the time windows, and the frequency of the POSs. Section 3.6 gives detailed discussions on the differences among the POSs.

\subsubsection{3 "Over-Draining to Mid-Loop" Event Tree - Drained Maintenance POS 6}

Besides the frequency and conditional probabilities of time windows, POS 6 of a drained maintenance outage differs from the POS6 of refueling outage in

1. the probability of RCS loop isolation,

2. the removal of the pressurizer safety valves, and

3. the probability that the steam generators are drained.

Tables 7.1-3 and 7.1-4 summarize the differences of items 1 and 2. In a drained maintenance, it is assumed that one RCS loop is unavailable/isolated for maintenance. Depending on the time window, the success criteria for reflux cooling may or may not be satisfied. It is also assumed that the safety valves on the pressurizer are not removed. Therefore, gravity feed is not an option for a drained maintenance. The probability that the SGs are drained is modeled as a failure mode for reflux cooling. These differences, and their effects on the event trees and fault trees, are discussed for each time window.

\section{Window 1 (RAW1D6)}

The event tree for this POS, figure 7.3.1-7, differs from that of RAW1R6, figure 7.3.1-1, in that the safety valves are not removed, and success criteria for reflux cooling cannot be satisfied. In this POS, the safety valves are not removed making gravity feed impossible. Reflux cooling is failed because the success criteria of requiring 3 SGs cannot be satisfied. Therefore, top events VW1, SRAW1, and GRAW1 of event tree RAW1R6 do not appear in this event tree. The top events in this event tree have the same meaning as those of R6. Due to the differences in the frequency of the POSs, conditional probability of the time window, 


\section{Event Tree Analysis}

probability of SGs draining, and probability of RCS loops isolation, the quantitative results of the sequences in this event tree differ from those of RAW1R6.

\section{IRAW1 - Over Draining}

This top event is used to calculate the frequency of the initiating event that overdraining occurs in window 1 of the drained maintenance outage. The overdraining event is modeled as a basic event in the fault tree. The frequency of the initiating event in this event tree differs from that of RAW1R6 because of the differences in the frequency of outage type, and conditional probability of time window.

\section{MRAW1 - RCS Makeup}

This event tree represents RCS inventory makeup using the charging pumps, low-head injection pumps, or gravity feed from RWST. It is identical to the same top event in the event for R6.

\section{RRAW1 - Restore RHR}

This event represents restoration of the RHR, given that the RCS inventory is restored. The restoration requires local venting the RHR pumps, verifying RHR heat sink, and restarting a RHR pump. Again, this top event is the same as that of R6.

\section{FRAW1 - Primary Feed-and-Bleed}

This top event is the same as that of R6.

\section{CRAW1 - Recirculation}

This top event is the same as that of R6.

Window 2 (RAW2D6)

This event tree, figure 7.3.1-8, differs from that of R6, figure 7.3.1-2, in that the safety valves are not removed and gravity feed is not possible. As a result, top events VW2 and GRAW2 are not used in the event tree. The rest of the top events are the same as those of R6, with the following difference in quantification:

\section{IRAW2 - Over Draining}

This top event is used to calculate the frequency of the initiating event that overdraining occurs in window 2 of the drained maintenance outage. The overdraining event is modeled as a basic event in the fault tree. The frequency of the initiating event in this event tree differs from that of RAW2R6 because of the differences in the frequency of outage type, and conditional probability of time window.

\section{SRAW2 - Reflux Cooling}

In time window 2, 2 SGs are needed for reflux cooling. For a drained maintenance, one RCS loop is assumed to be isolated. Therefore, the 2 remaining loops should be sufficient for reflux cooling. For a refueling outage, the RCS loops are either isolated together or not isolated. Loop isolation in a refueling outage is modeled as a basic event that fails reflux cooling.

Window 3 (RAW3D6)

The event tree, figure 7.3.1-9, differs from that of R6, figure 7.3.1-3, in that safety valves are not removed, reflux cooling is possible, and gravity feed is not in this time window of a drained maintenance outage. In 
time window 3 of a refueling outage, the RCS loop are all isolated, so reflux cooling is impossible. The top events of this event tree represent the same top events for R6, except the following:

\section{IRAW3 - Over Draining}

This top event is used to calculate the frequency of the initiating event that overdraining occurs in window 3 of the drained maintenance outage. The overdraining event is modeled as a basic event in the fault tree. The frequency of the initiating event in this event tree differs from that of RAW3R6 because of the differences in the frequency of outage type, and conditional probability of time window.

\section{SRAW3 - Reflux Cooling}

In time window 3,2 SGs are needed for reflux cooling. For a drained maintenance, one RCS loop is assumed to be isolated. Therefore, the 2 remaining loops should be sufficient for reflux cooling. For a refueling outage, the 3 RCS loops are isolated. Therefore, this top event is not used in the event tree for R6.

\section{Window 4 (RAW4D6)}

The event tree, figure 7.3.1-10, differs from that of R6, figure 7.3.1-4, in that safety valves are not removed, reflux cooling is possible, and gravity feed is not in this time window of a drained maintenance outage. In time window 4 of a refueling outage, the RCS loop are all isolated, making reflux cooling impossible. The top events of this event tree represent the same top events for R6, except the following:

\section{IRAW4 - Over Draining}

This top event is used to calculate the frequency of the initiating event that overdraining occurs in window 4 of the drained maintenance outage. The overdraining event is modeled as a basic event in the fault tree. The frequency of the initiating event in this event tree differs from that of RAW3R6 because of the differences in the frequency of outage type, and conditional probability of time window.

\section{SRAW4 - Reflux Cooling}

In time window 4, only 1 steam generator is needed for reflux cooling. For a drained maintenance, one RCS loop is assumed to be isolated. Therefore, the 2 remaining loops are more than sufficient for reflux cooling. For a refueling outage, 3 RCS loops are isolated. Therefore, this top event is not used in the event tree for R6. (We note that the top event of reflux cooling appears in figure 7.3.1-4 for the refueling outage; it was left there inadvertently. In quantifying the event tree, this top event is automatically failed.) 


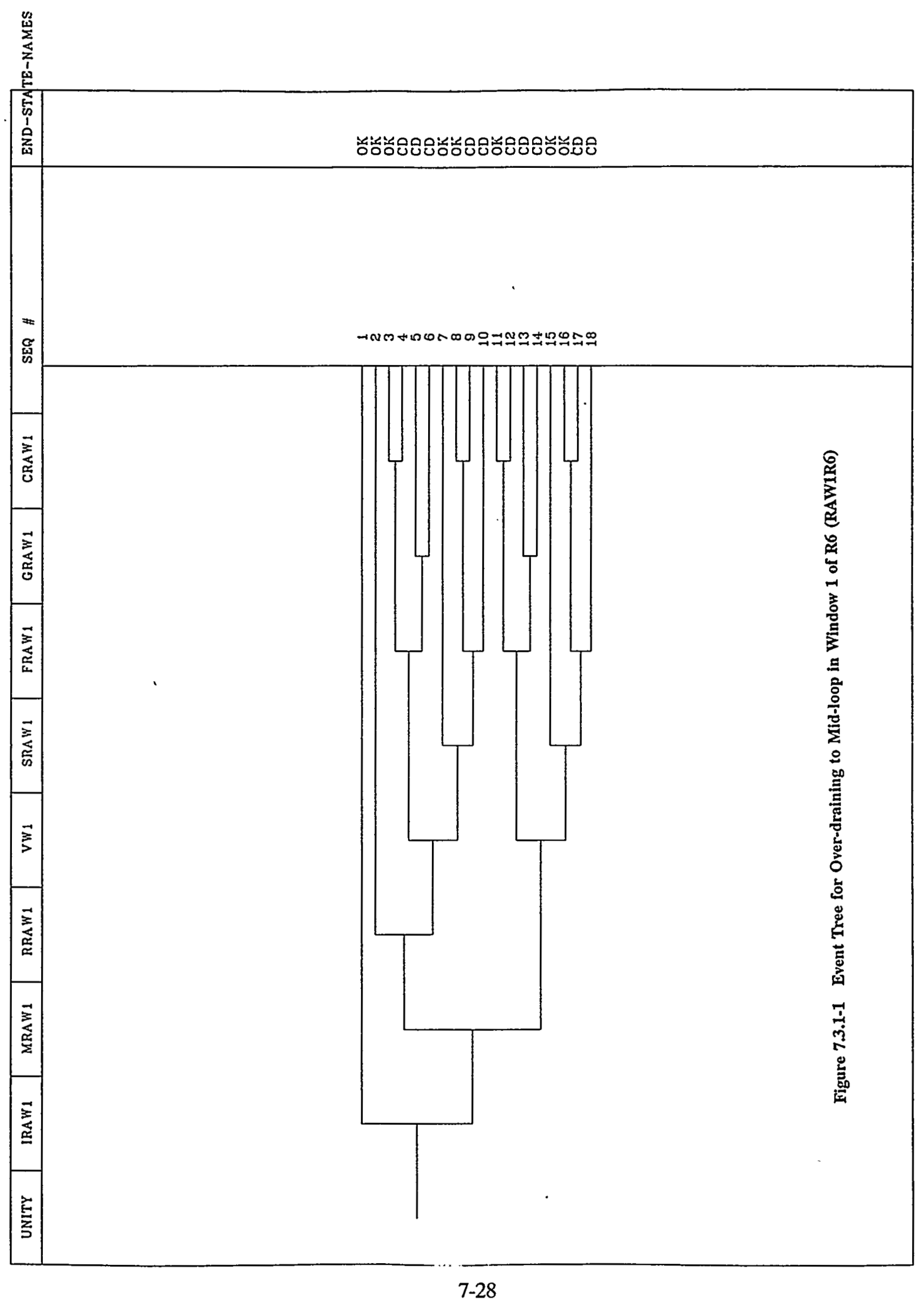




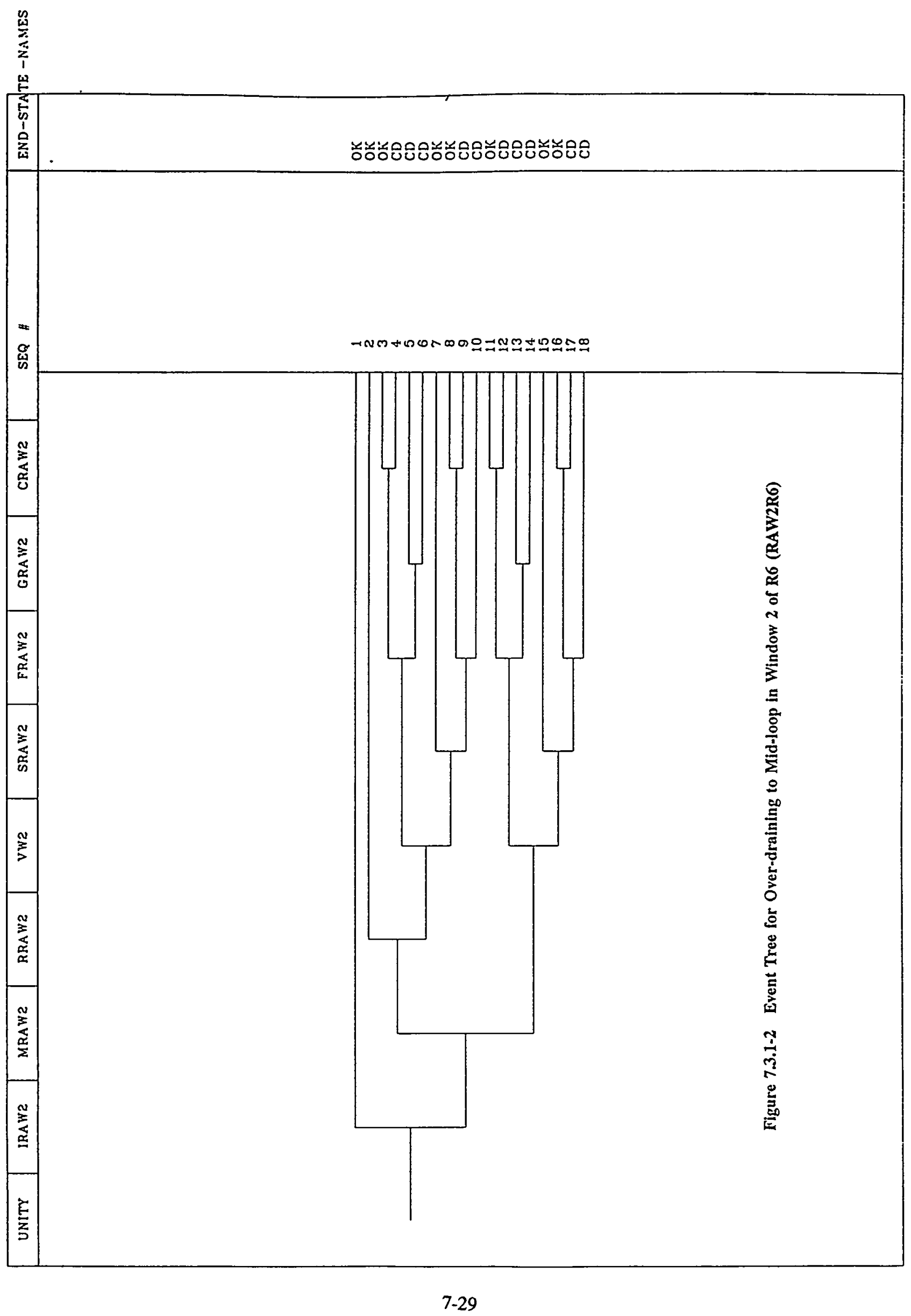




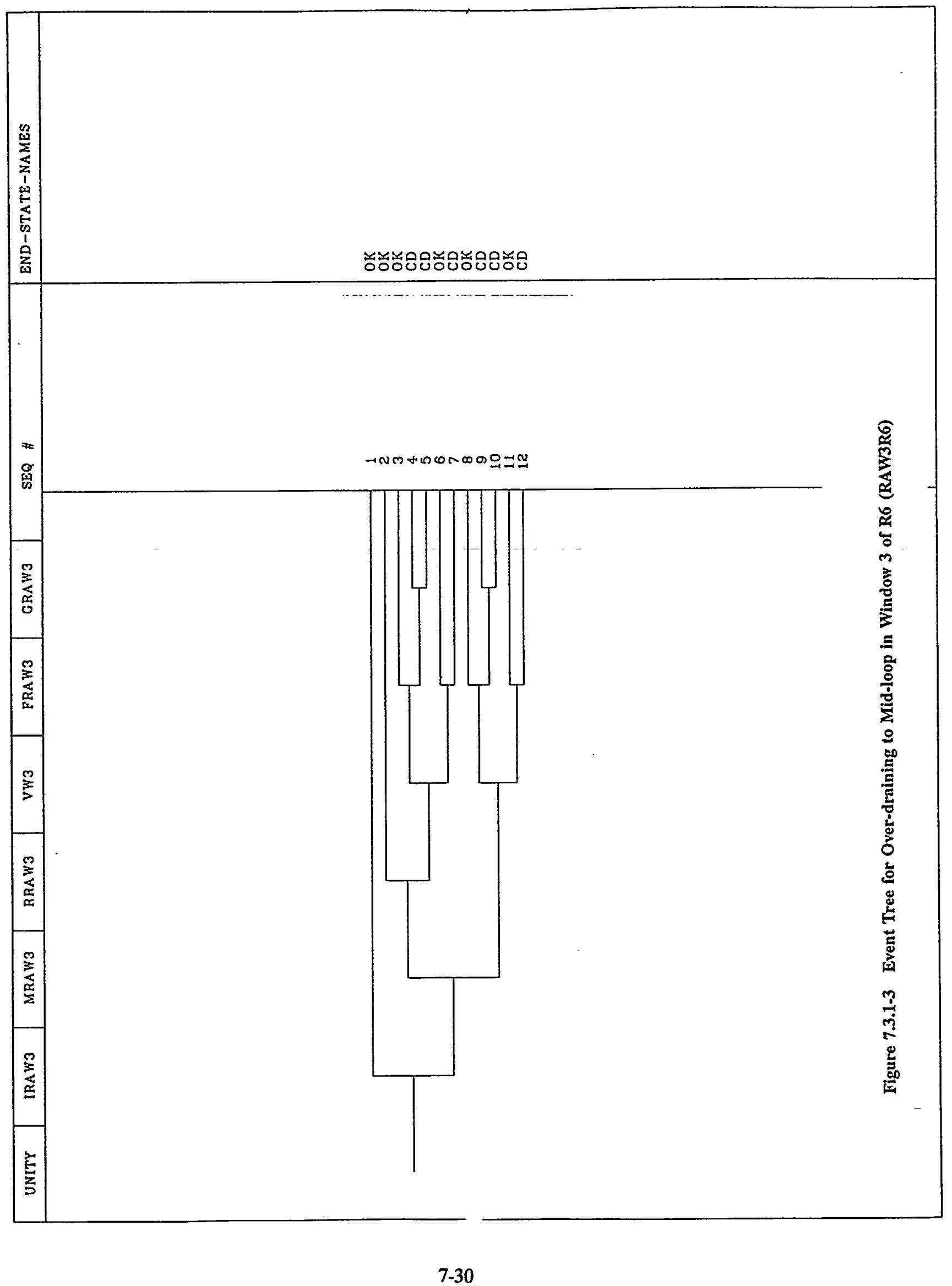




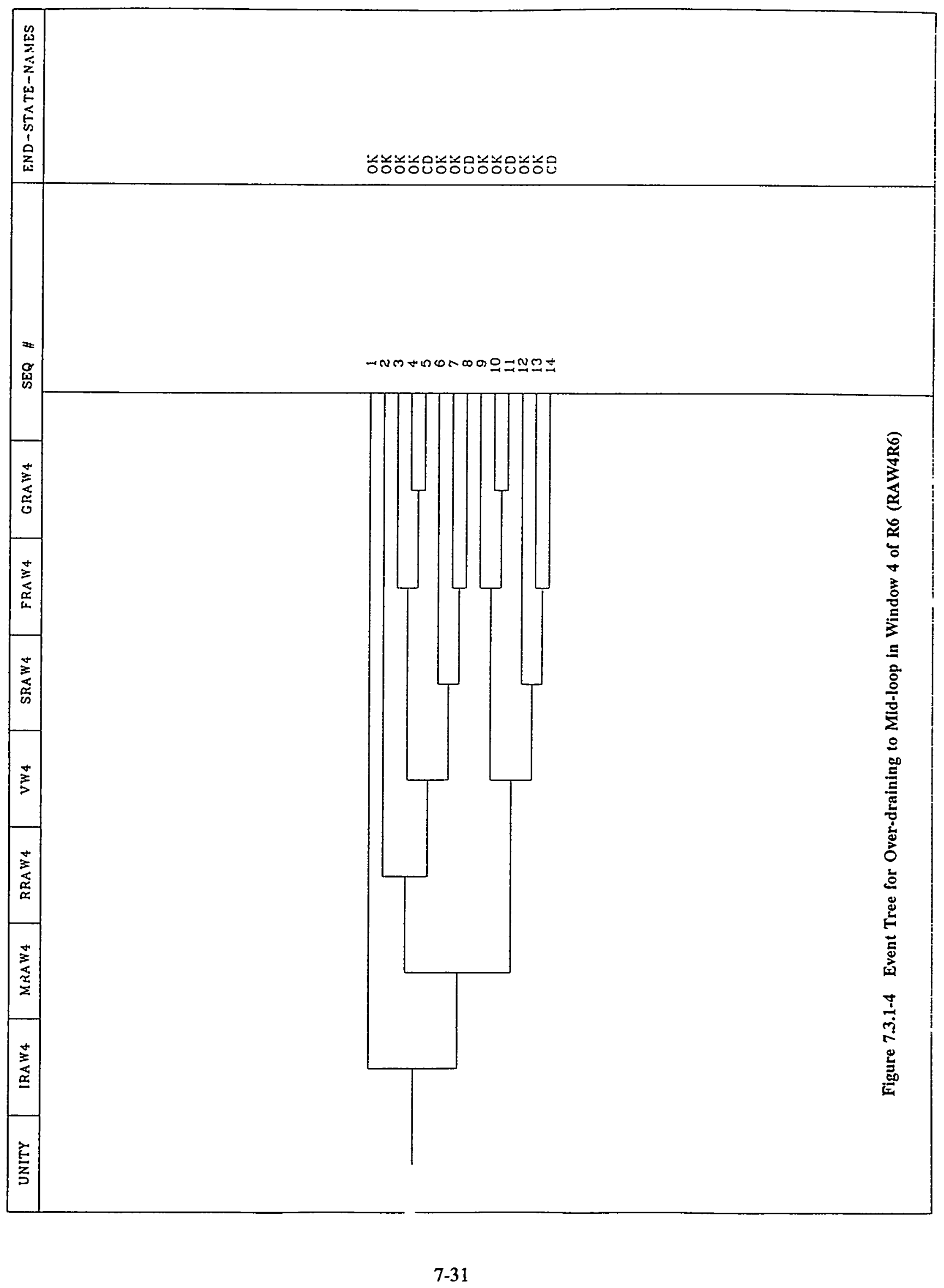




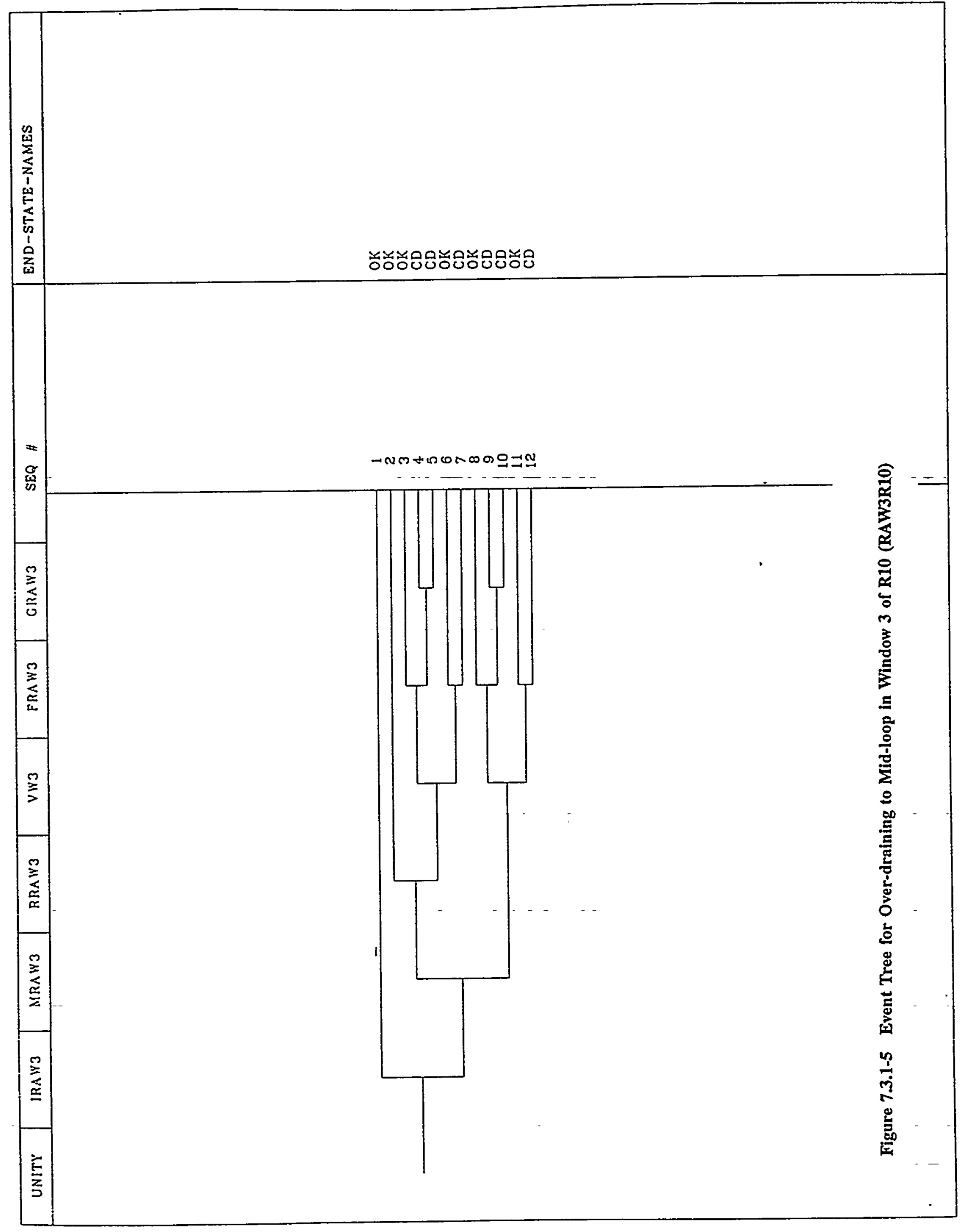




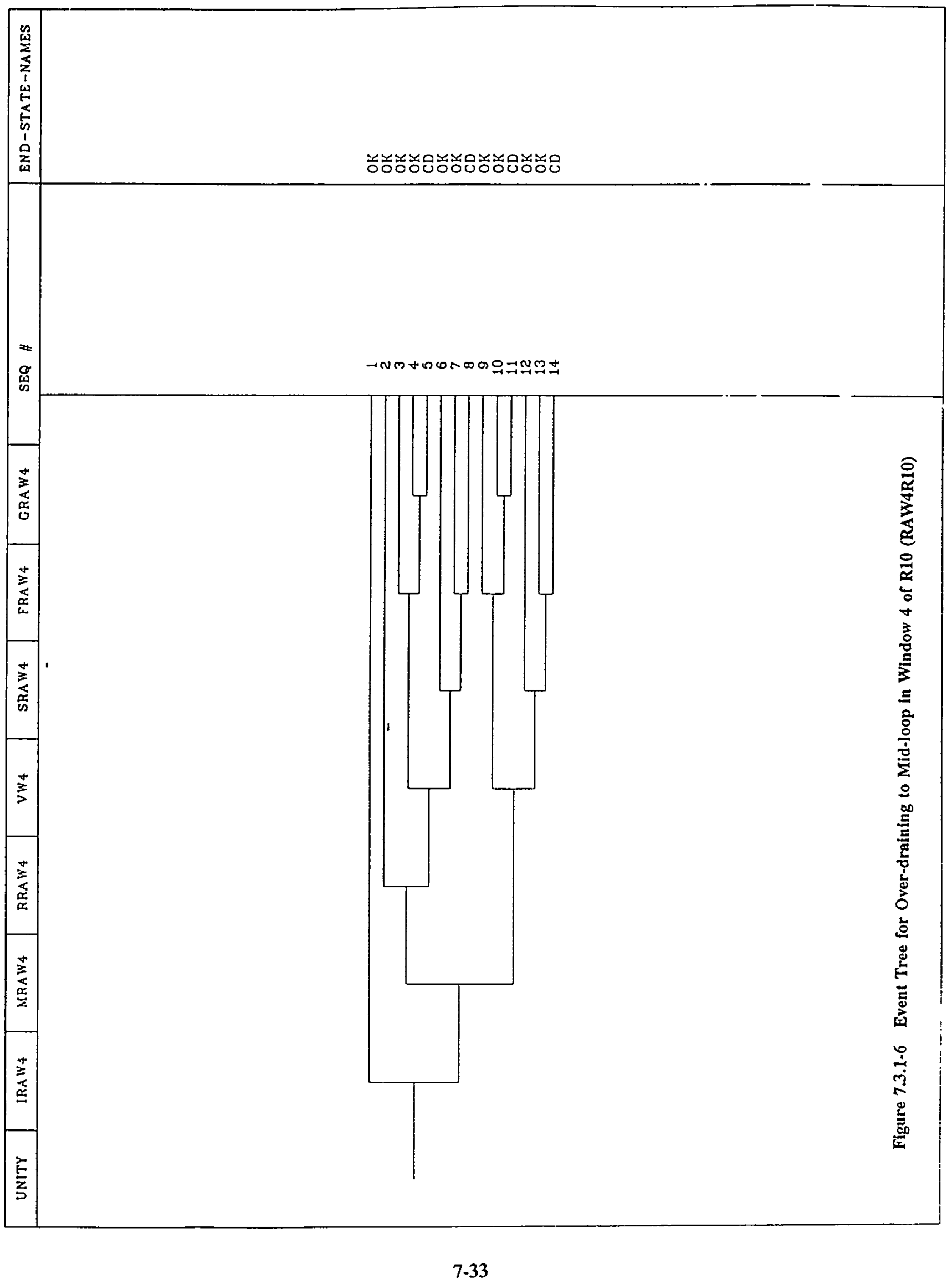




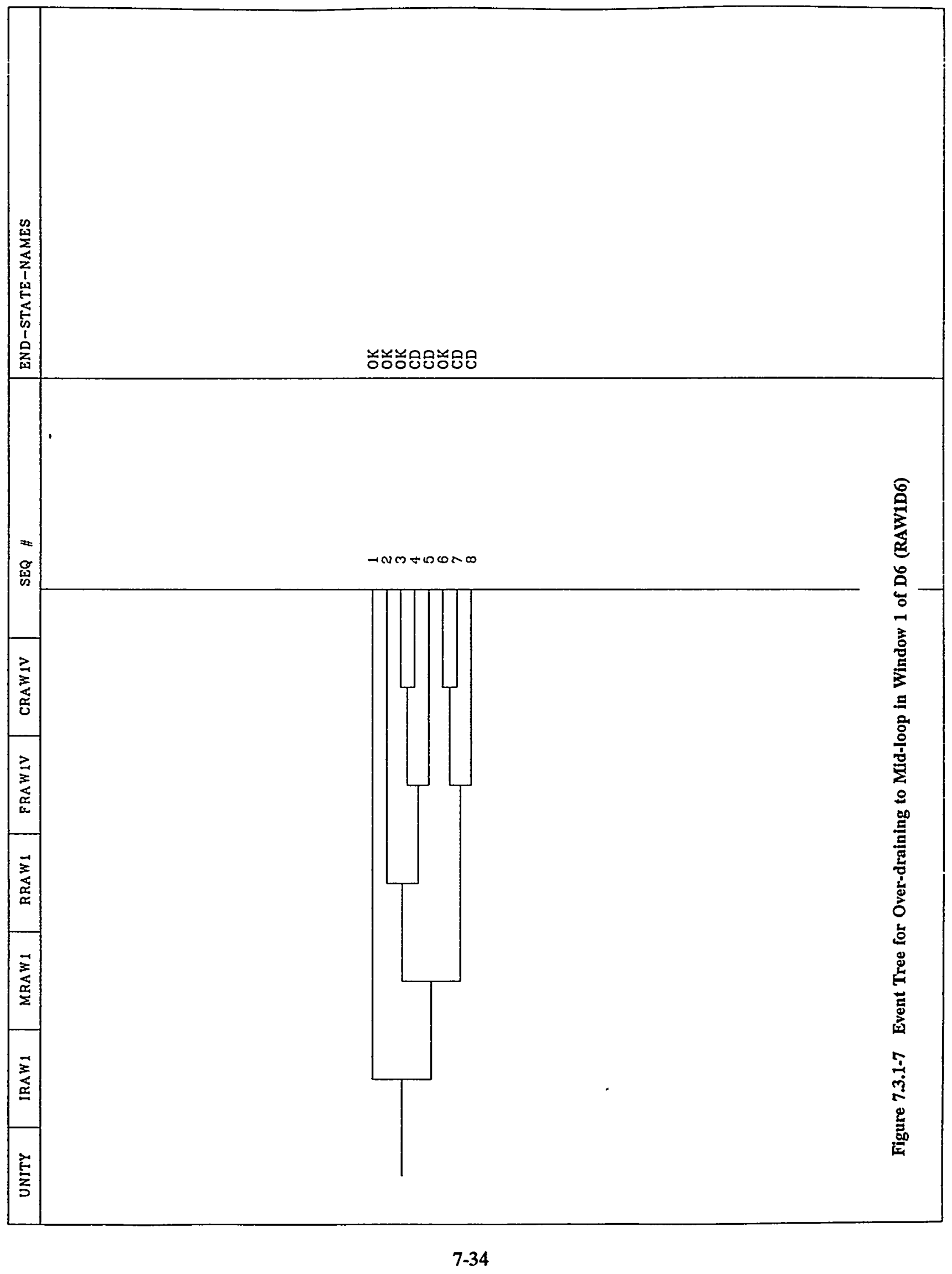




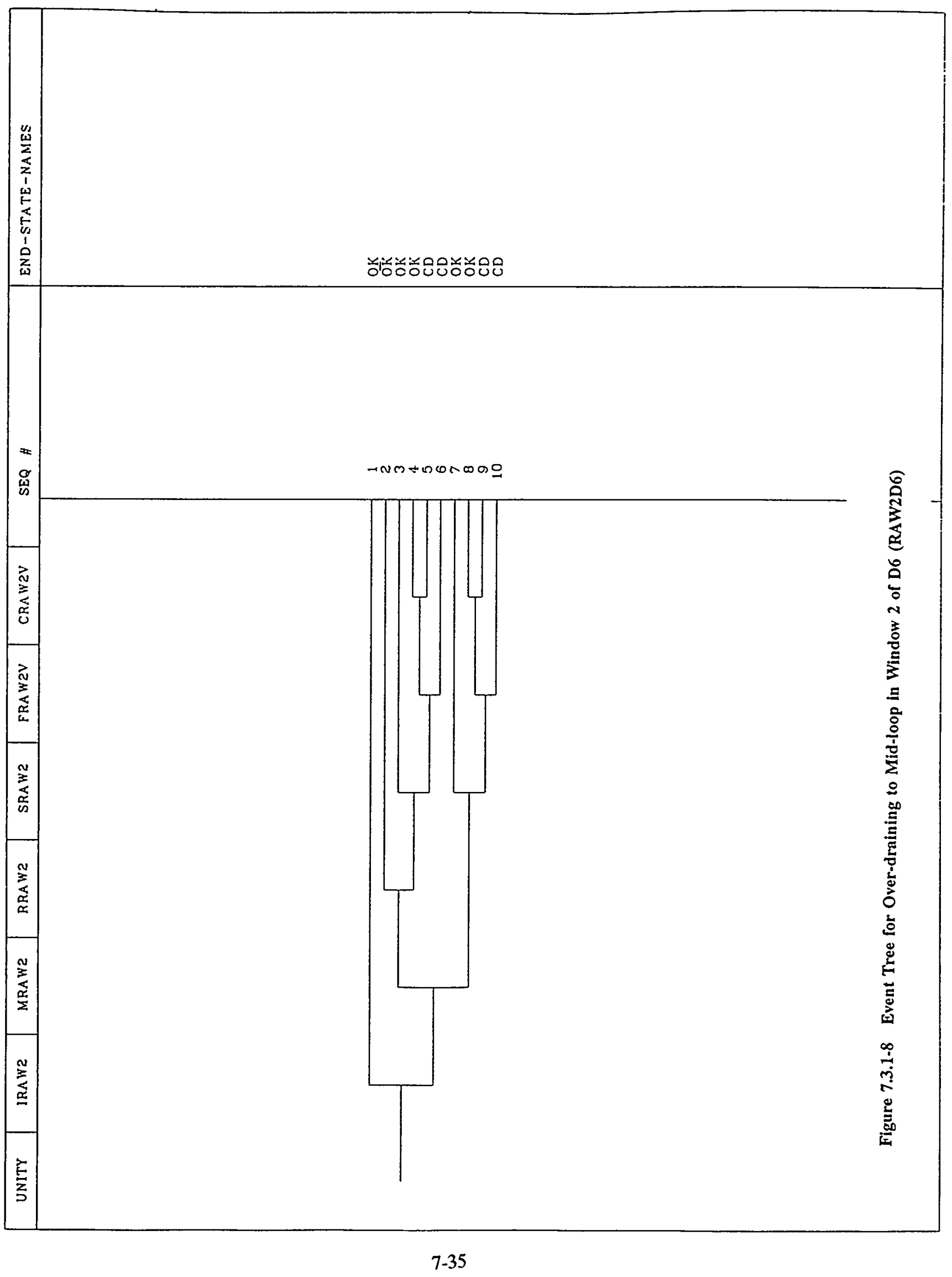




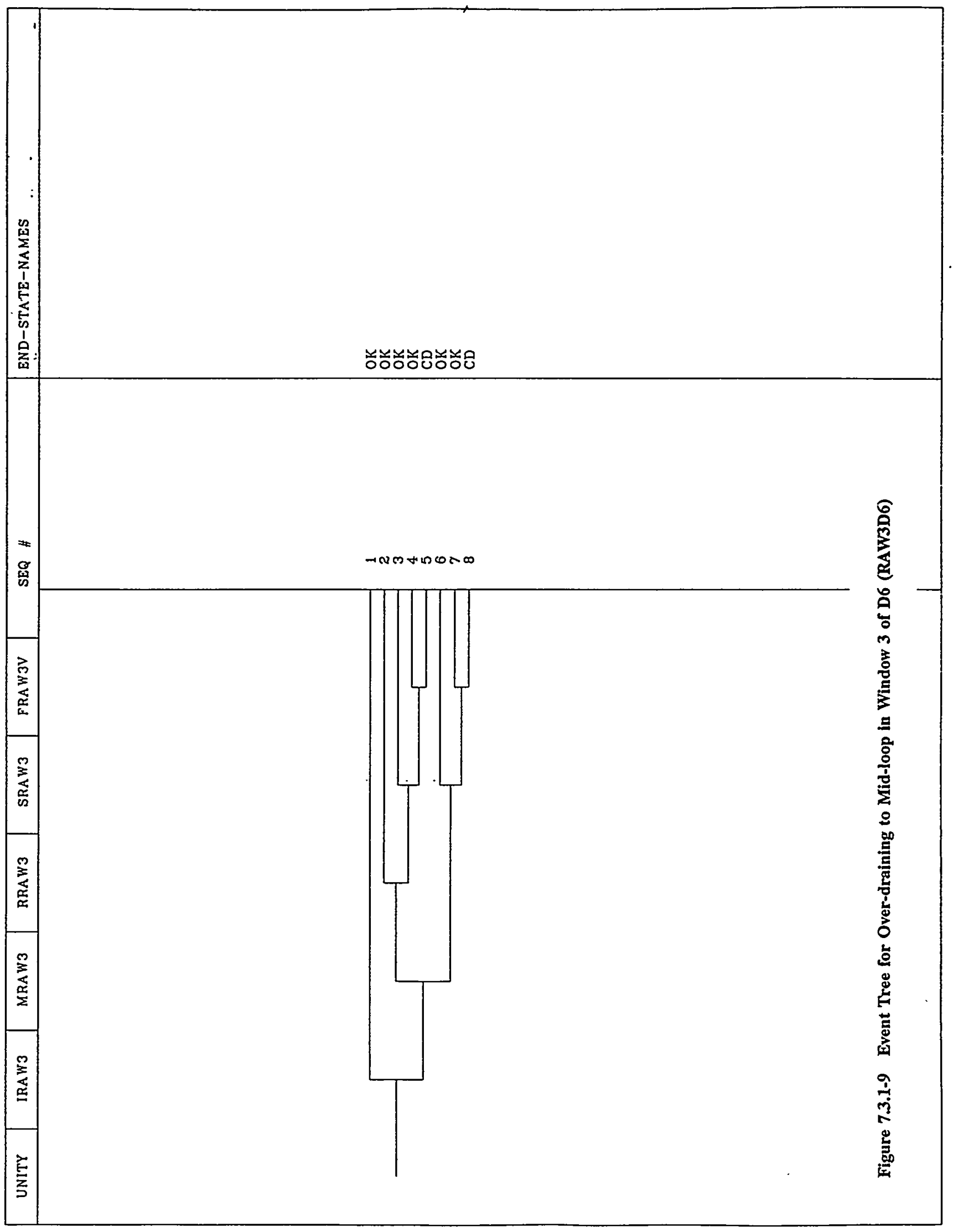




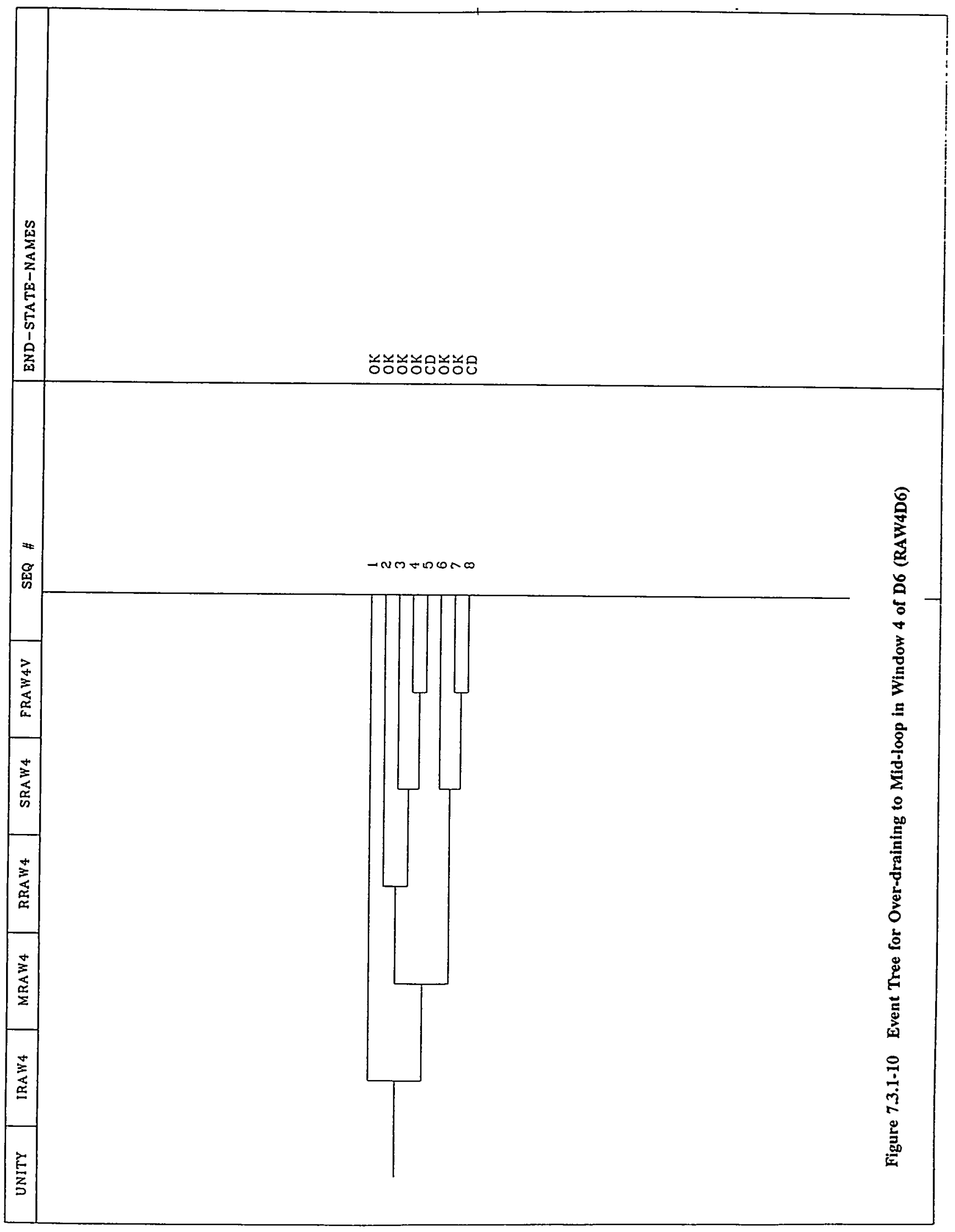


7 Event Tree Analysis

\subsubsection{Event Trees for Loss of Inventory (RHR2B)}

This initiating event is very similar to the over-draining event discussed in section 7.3.1; it differs in that this event could occur any time during mid-loop, while RHR2A event occurs at the beginning. This difference is accounted for in the conditional probability of the time windows. These probabilities for RHR2A were calculated from the distribution of time to mid-loop. The same for RHR2B and other initiating events were calculated using the distribution of time to mid-loop plus the duration of mid-loop times, a uniform random variable. Table 7.2.-2, tabulates these probabilities, and shows that RHR2A has higher probability of occurring in the earlier windows.

The event trees for this initiating event are shown in figures 7.3.2-1 to 7.3.2-10. They have the same structure as the event trees for RHR2A; the only difference between the two sets is the way the initiating event frequency is calculated, using the "I" top event. In the "I" top event for RHR2A, the probability of overdraining is used, while for RHR2B as well as other initiating events, the probability that the initiating event occurs is calculated as the product of an hourly frequency of the initiating event and the duration of the POS. 


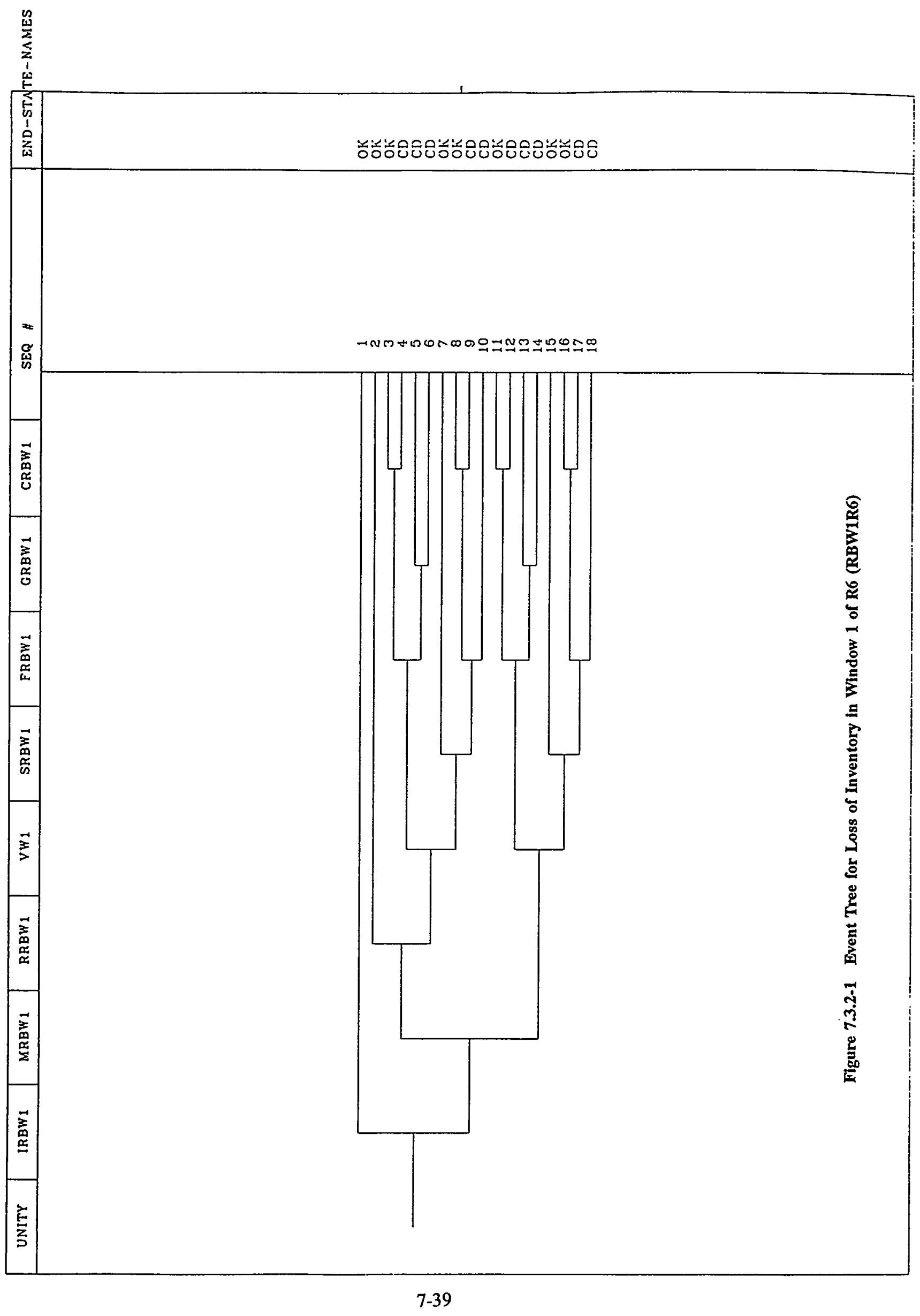

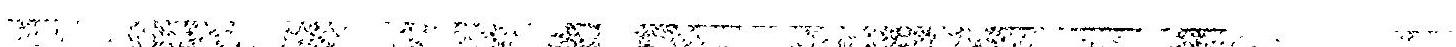




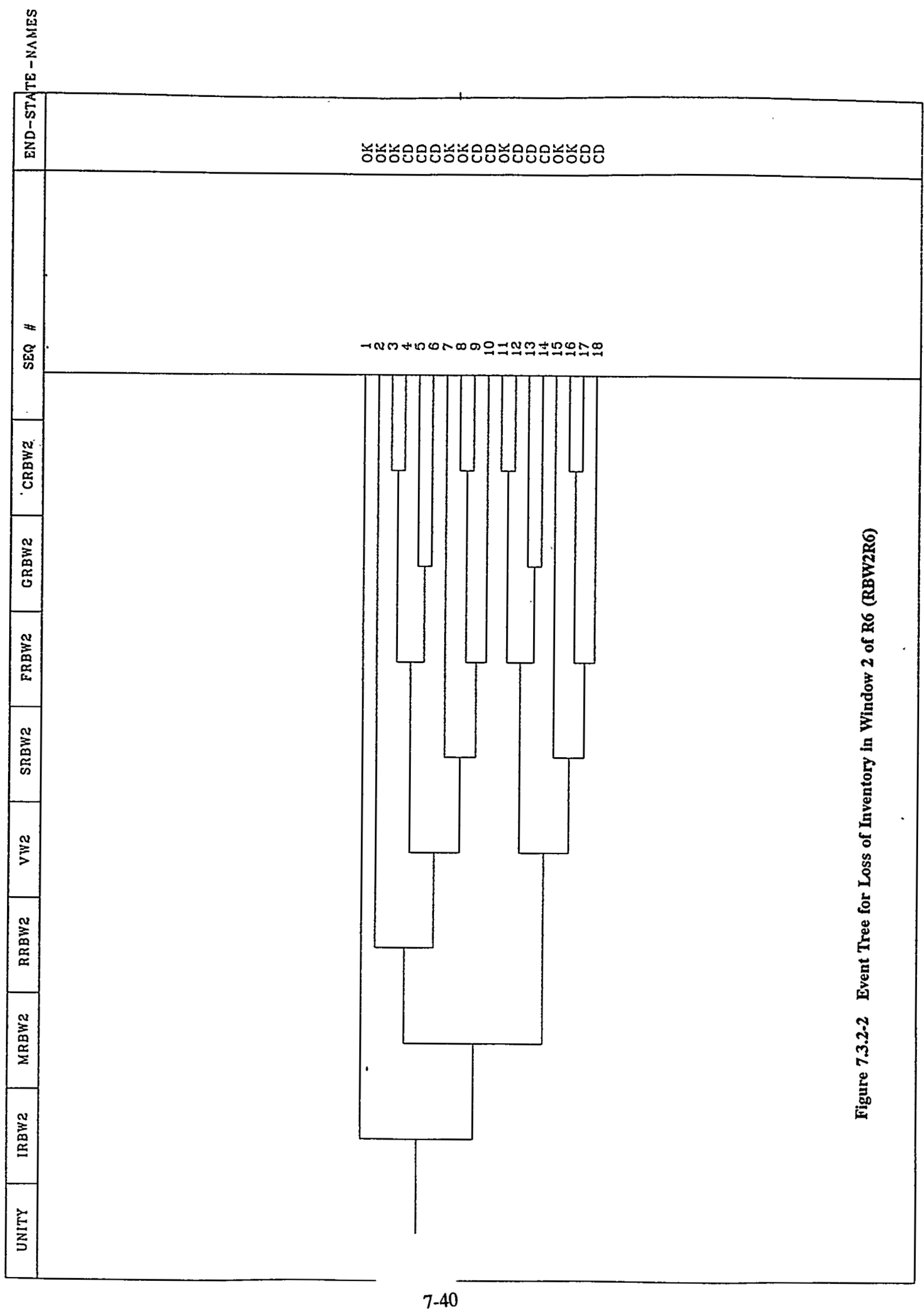




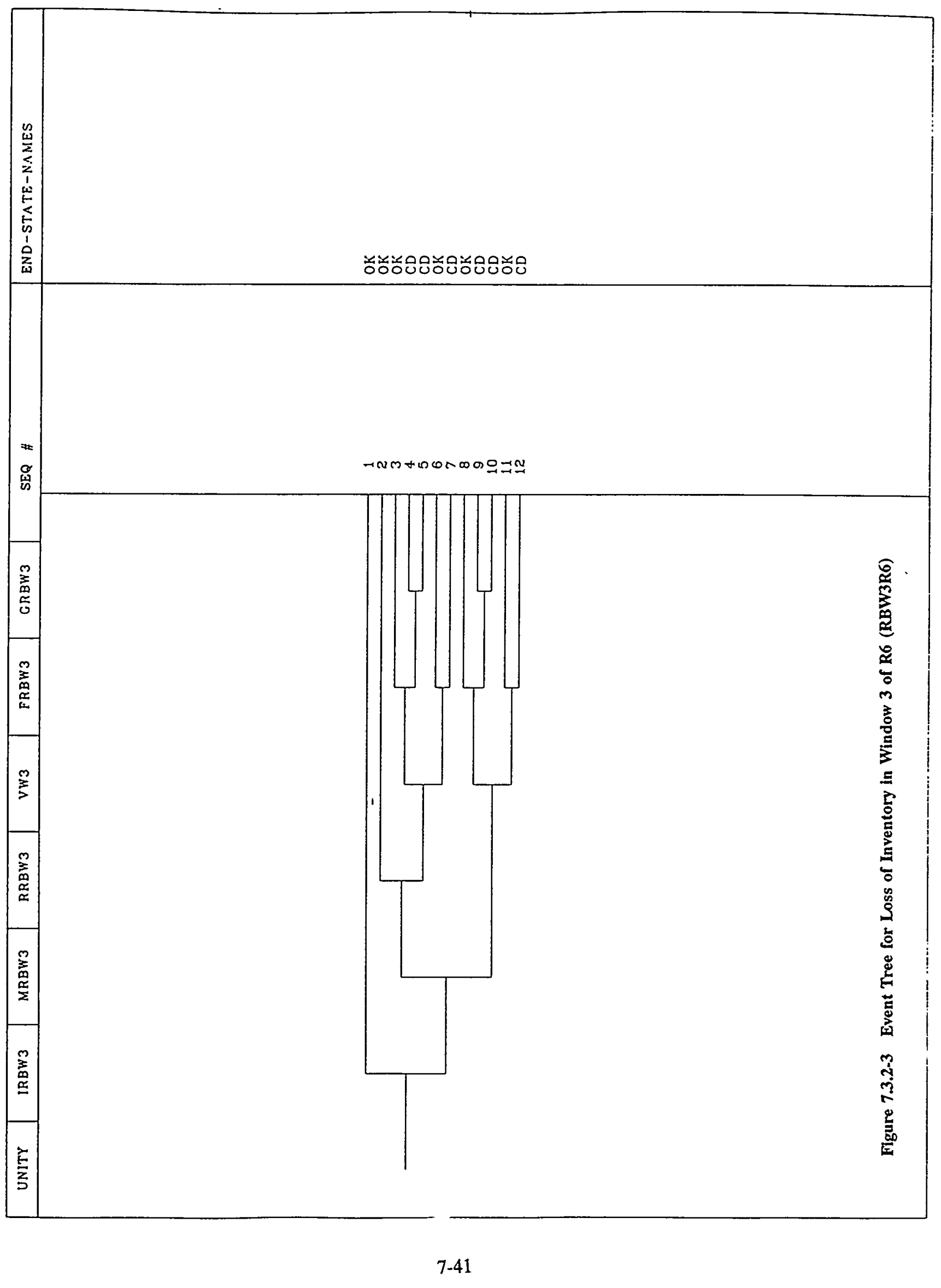




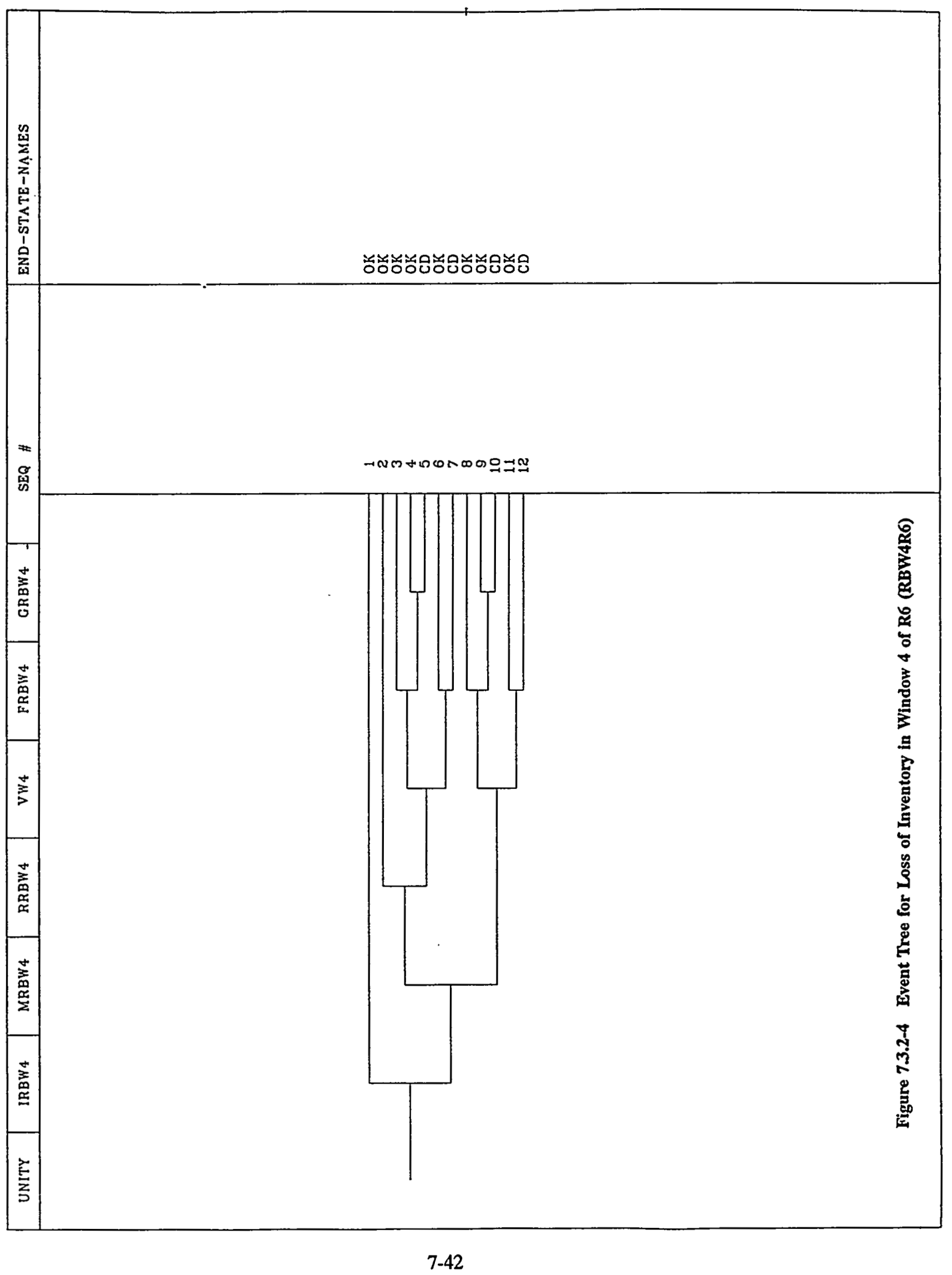




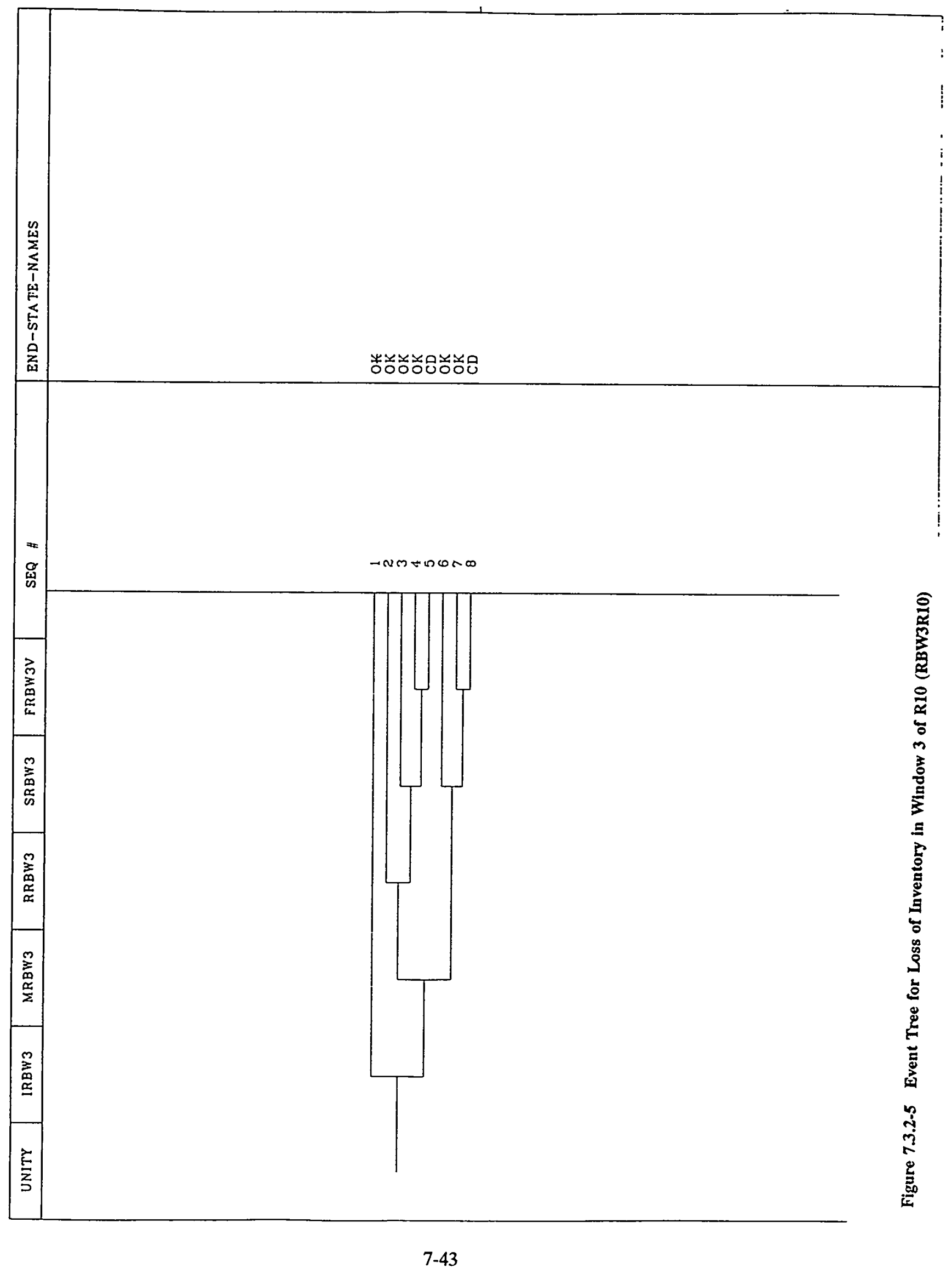




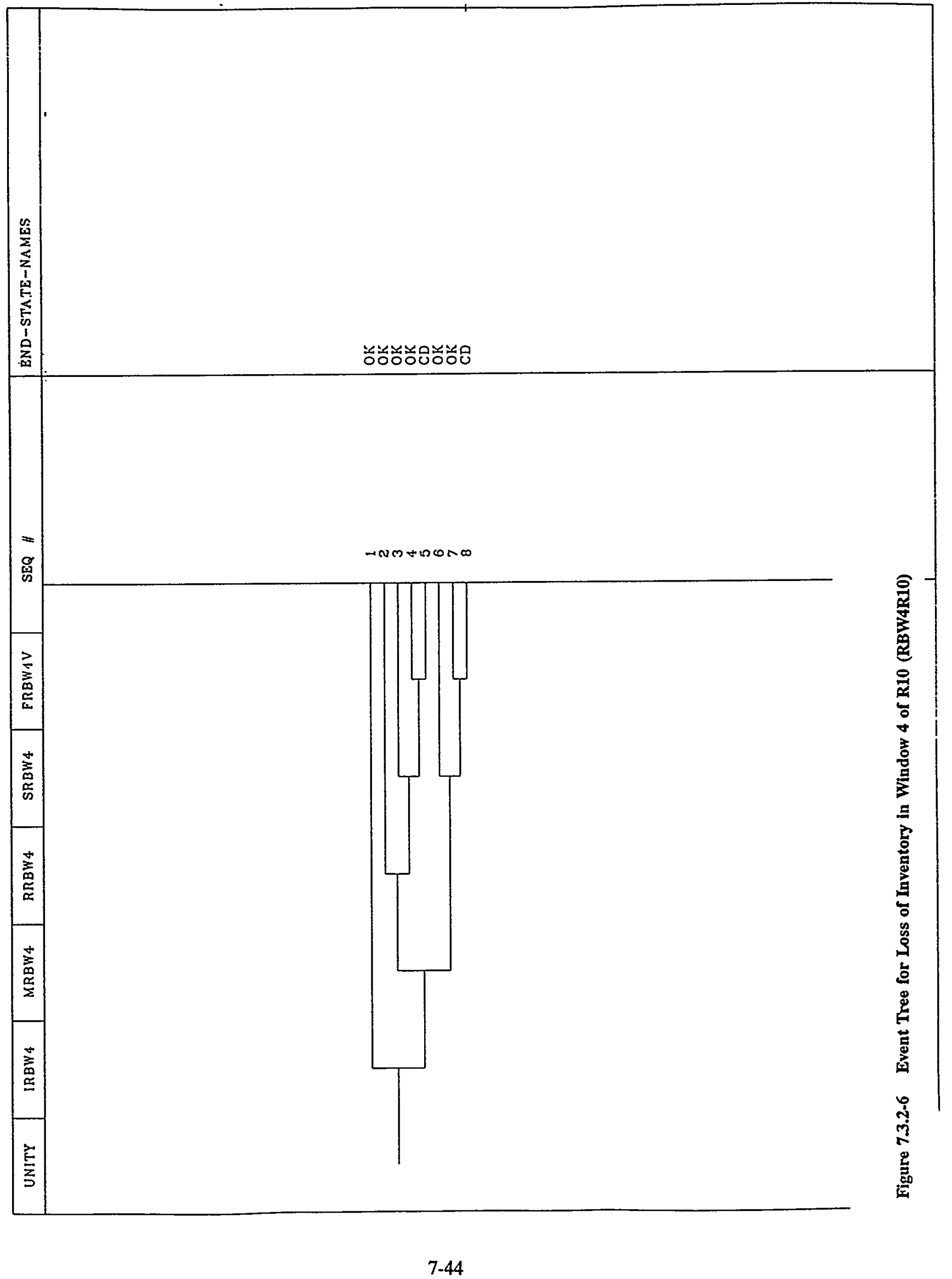




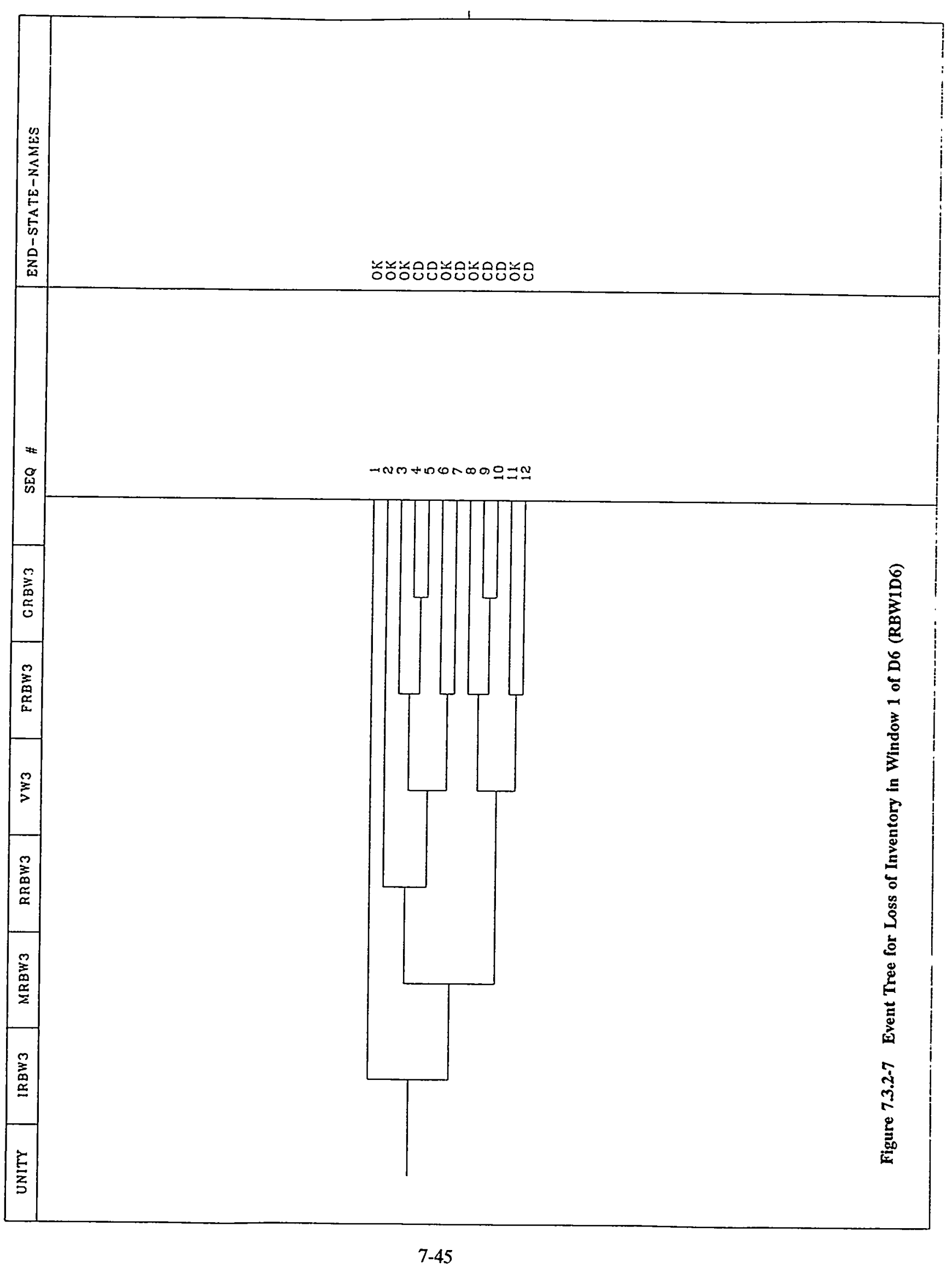




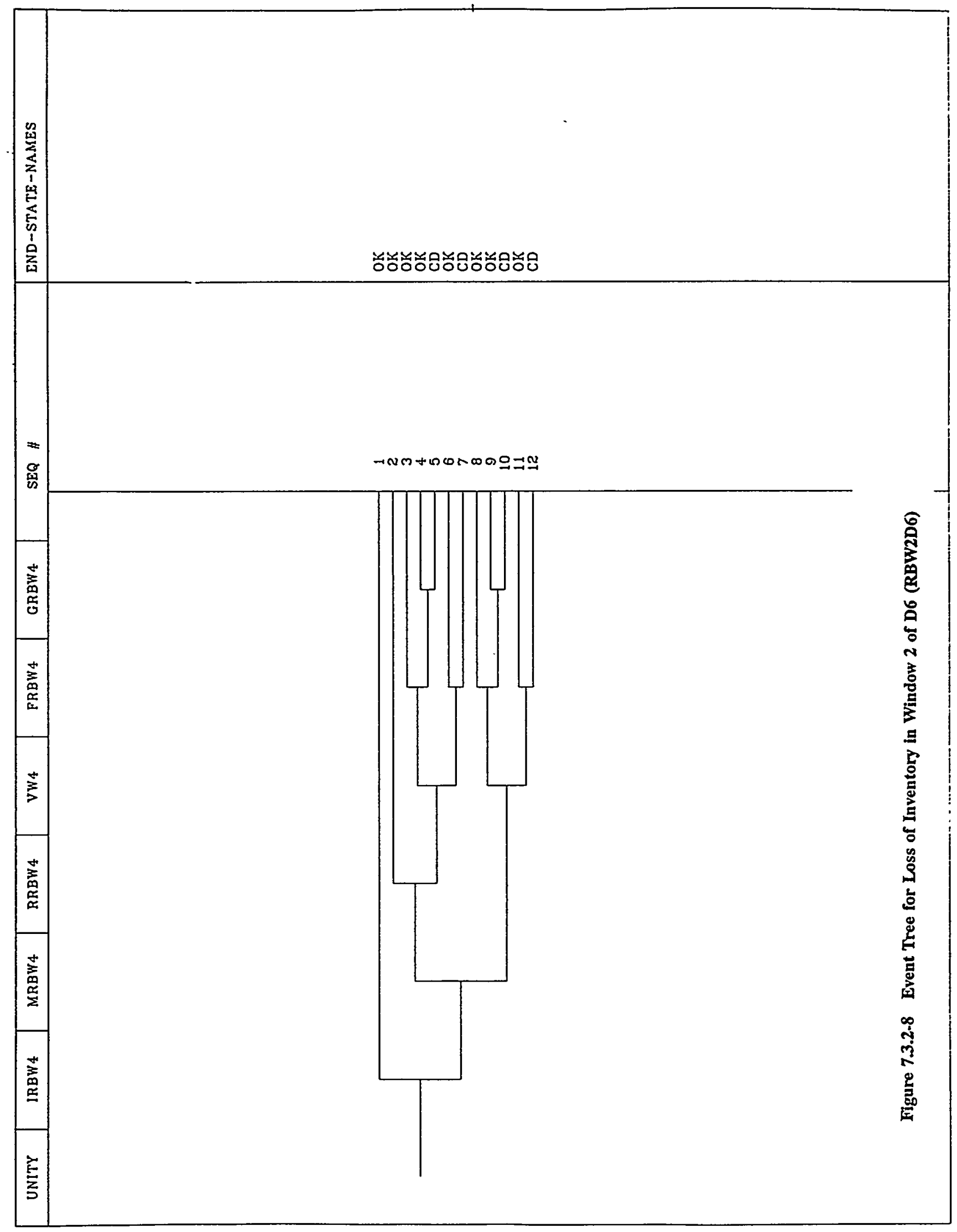




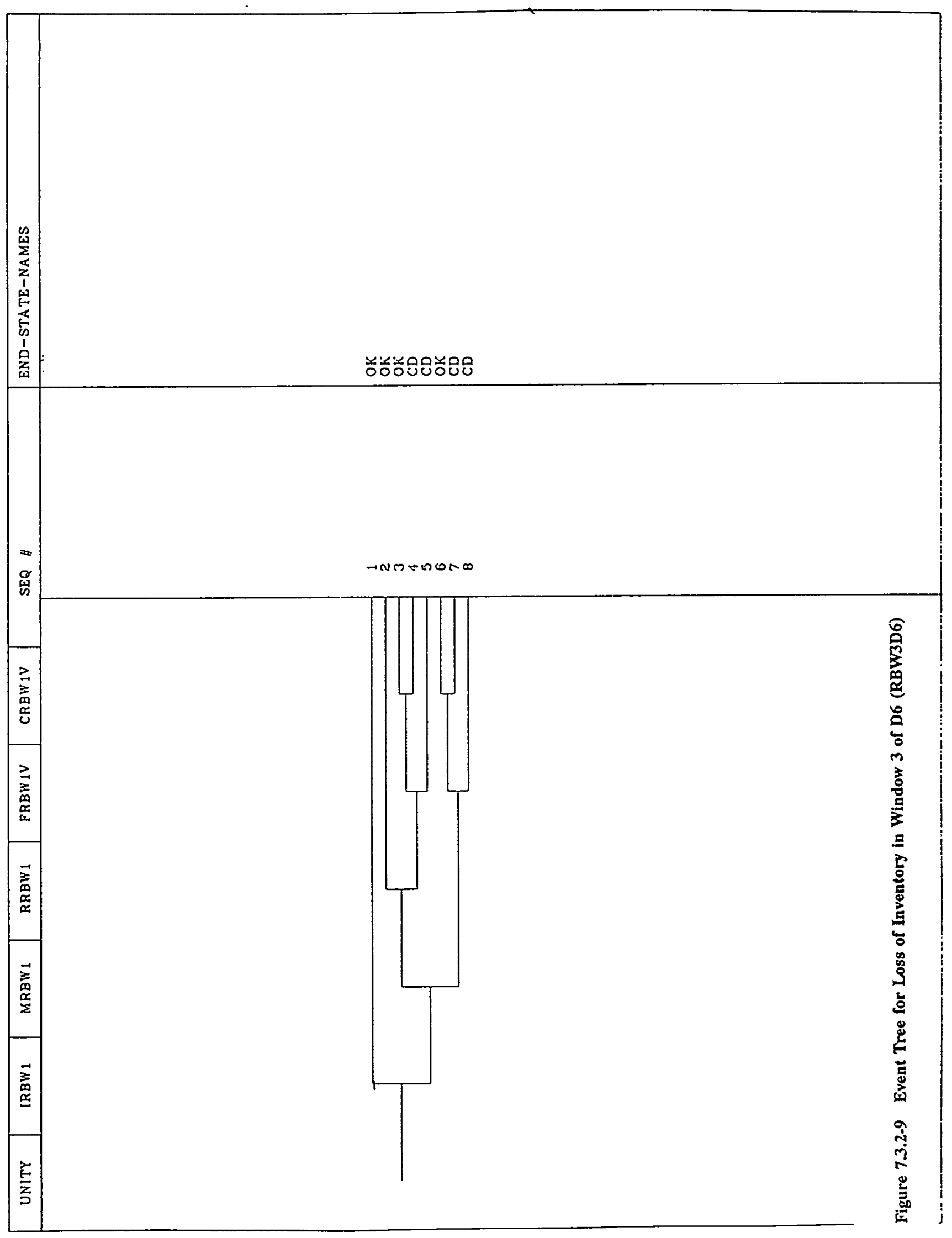




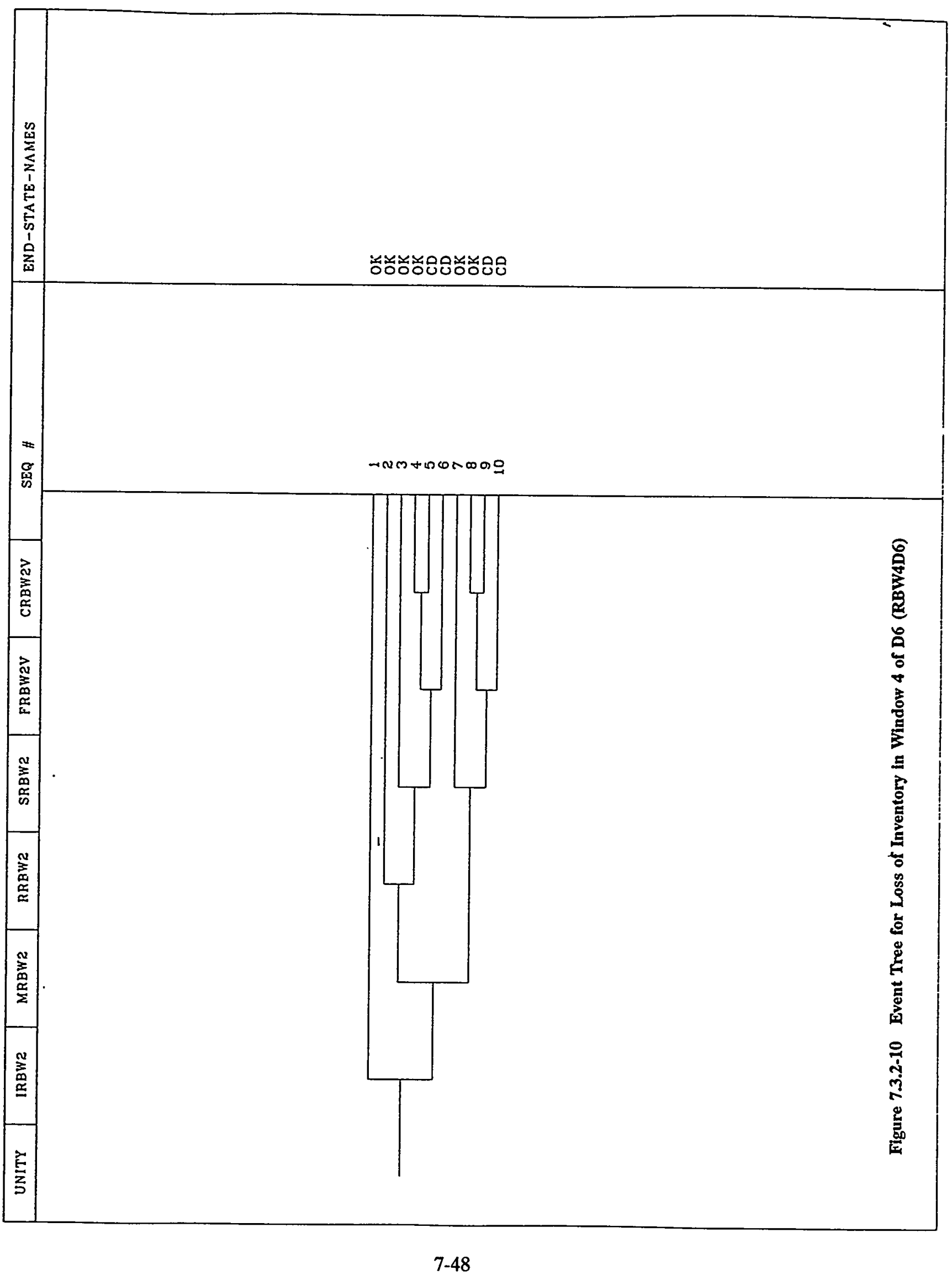




\subsubsection{Event Trees for Total Loss Residual Heat Removal (RHR3)}

This initiating event represents a loss of RHR event that can not be easily recovered from. For example, a small leak in the RHR system requiring isolation of the system would be assigned to this category. The event trees for this initiating event, Figure 7.3.3-1 to 7.3.3-10, were derived from the event trees for RHR2B by removing the top events on RCS makeup and recovery of RHR and replacing the RHR2B frequency with that of RHR3 in the " $\mathrm{I}$ " top events. The HEPs used in the event trees may also be different. 


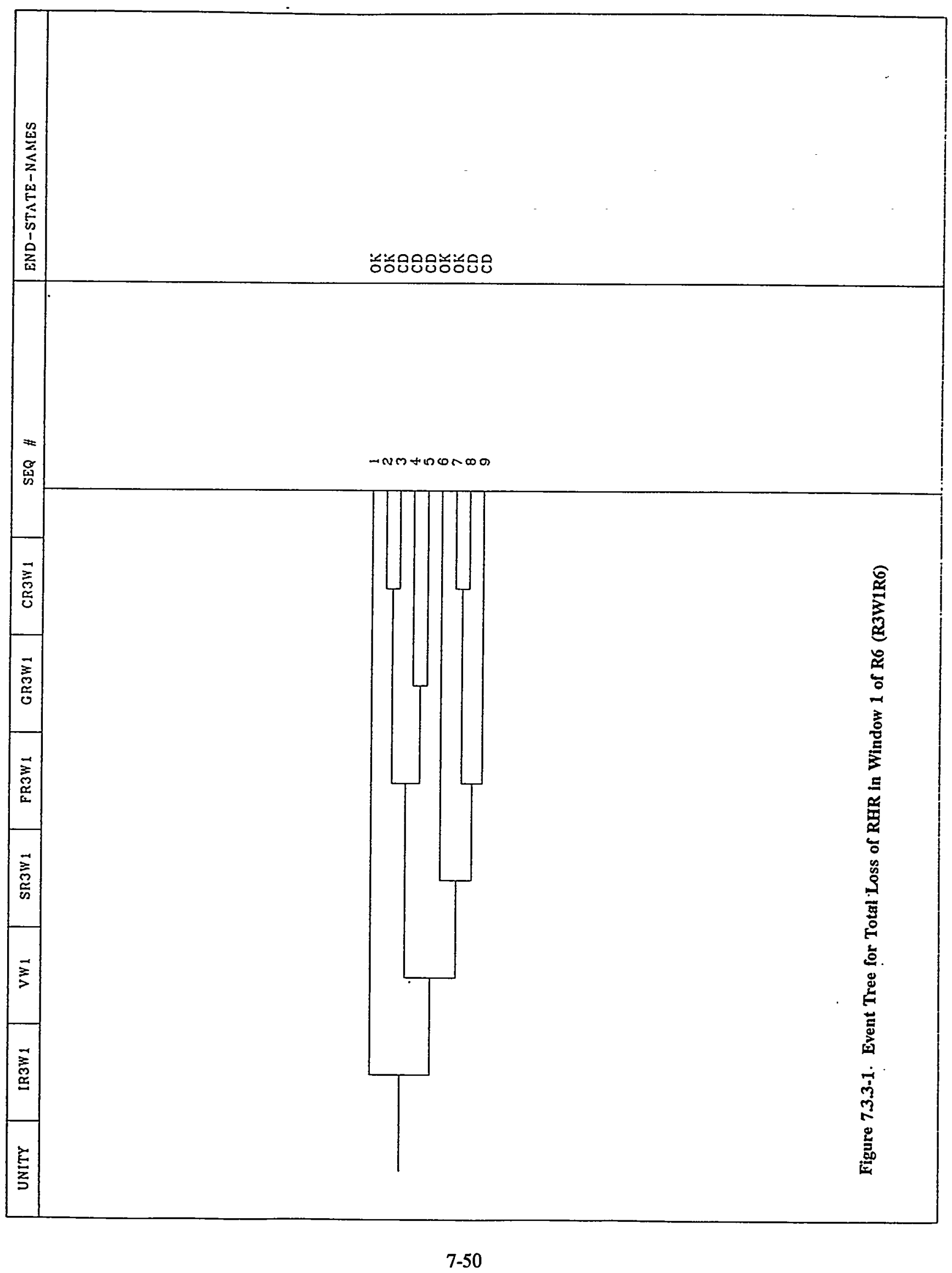




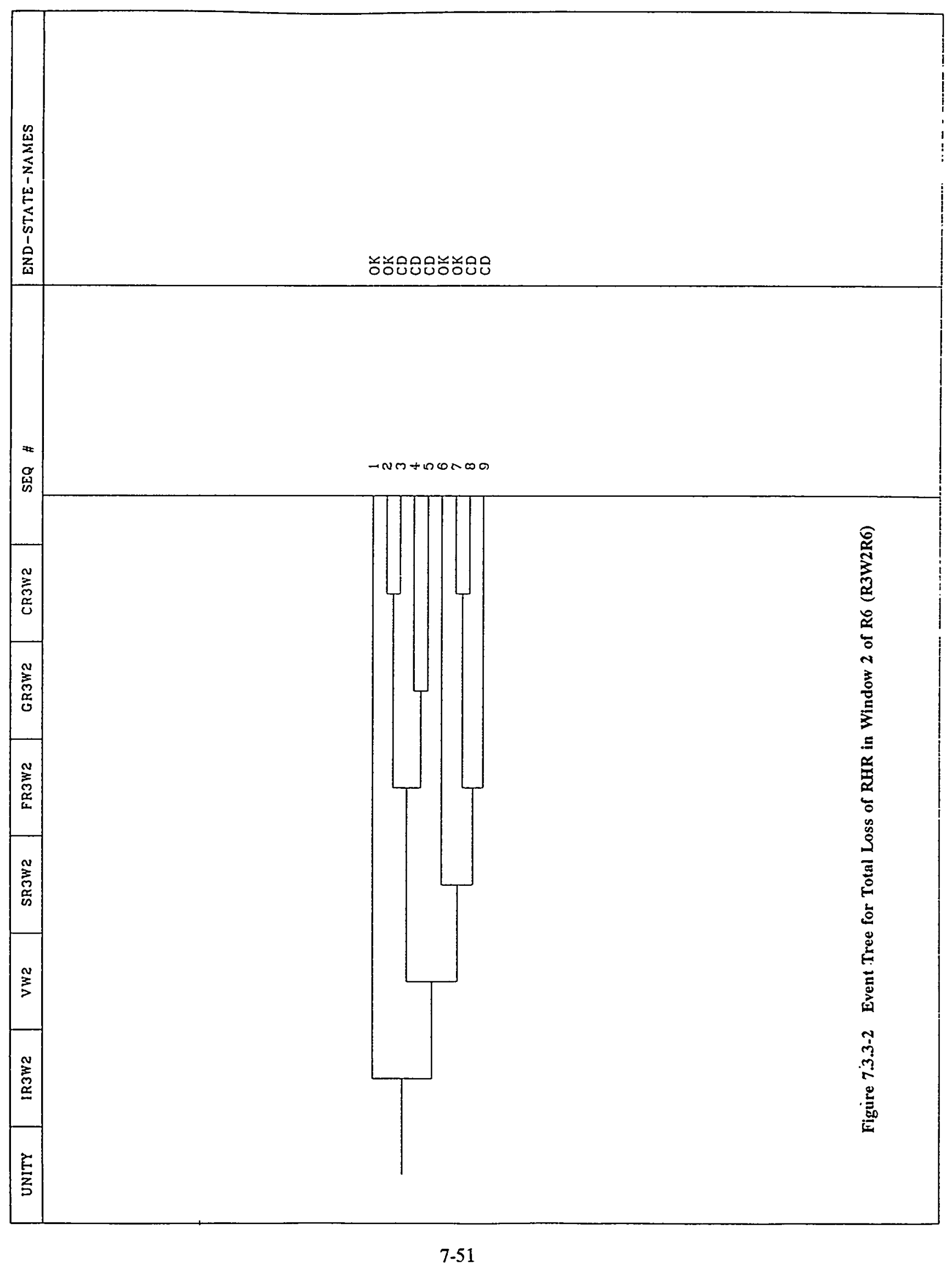




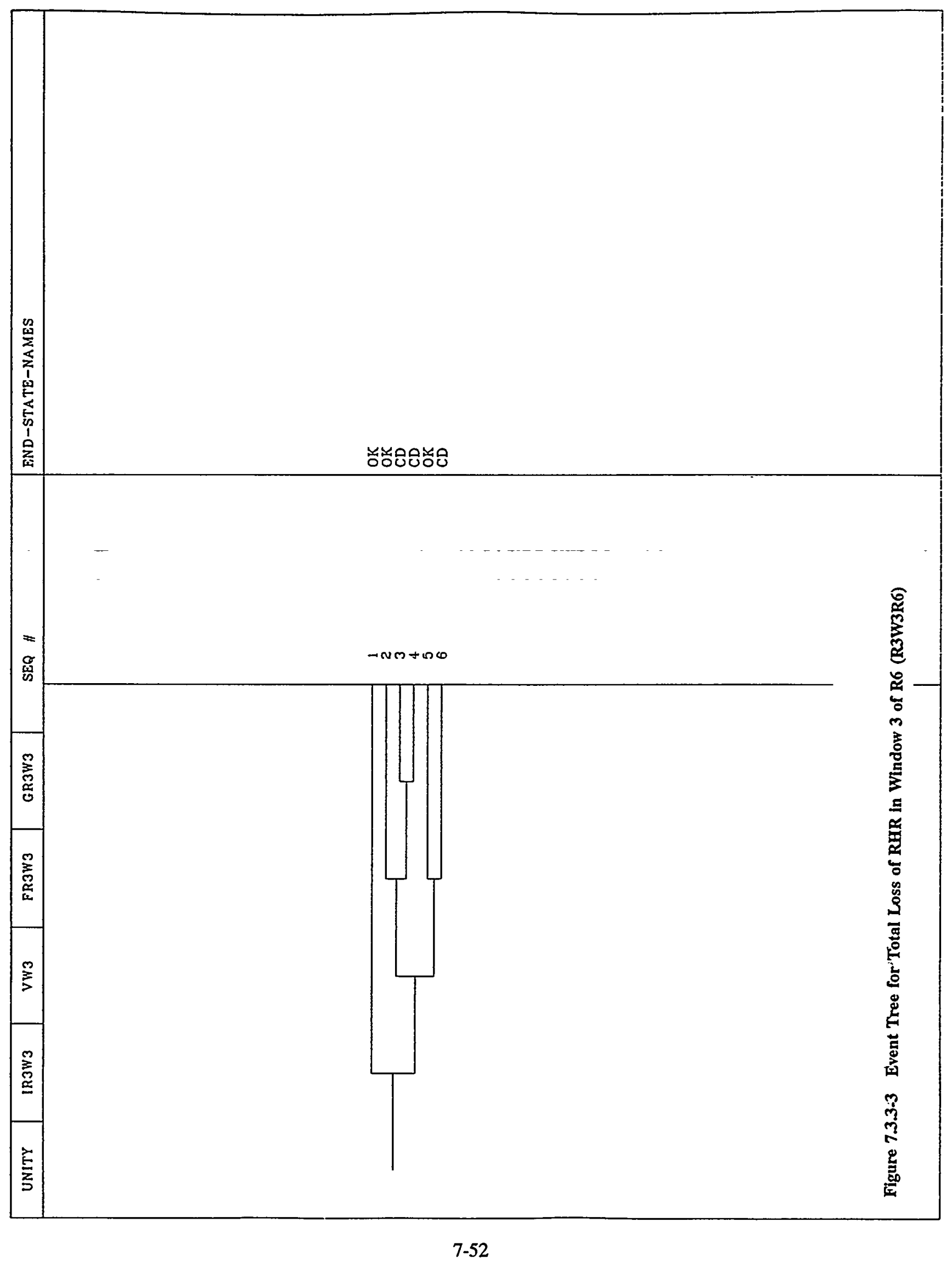




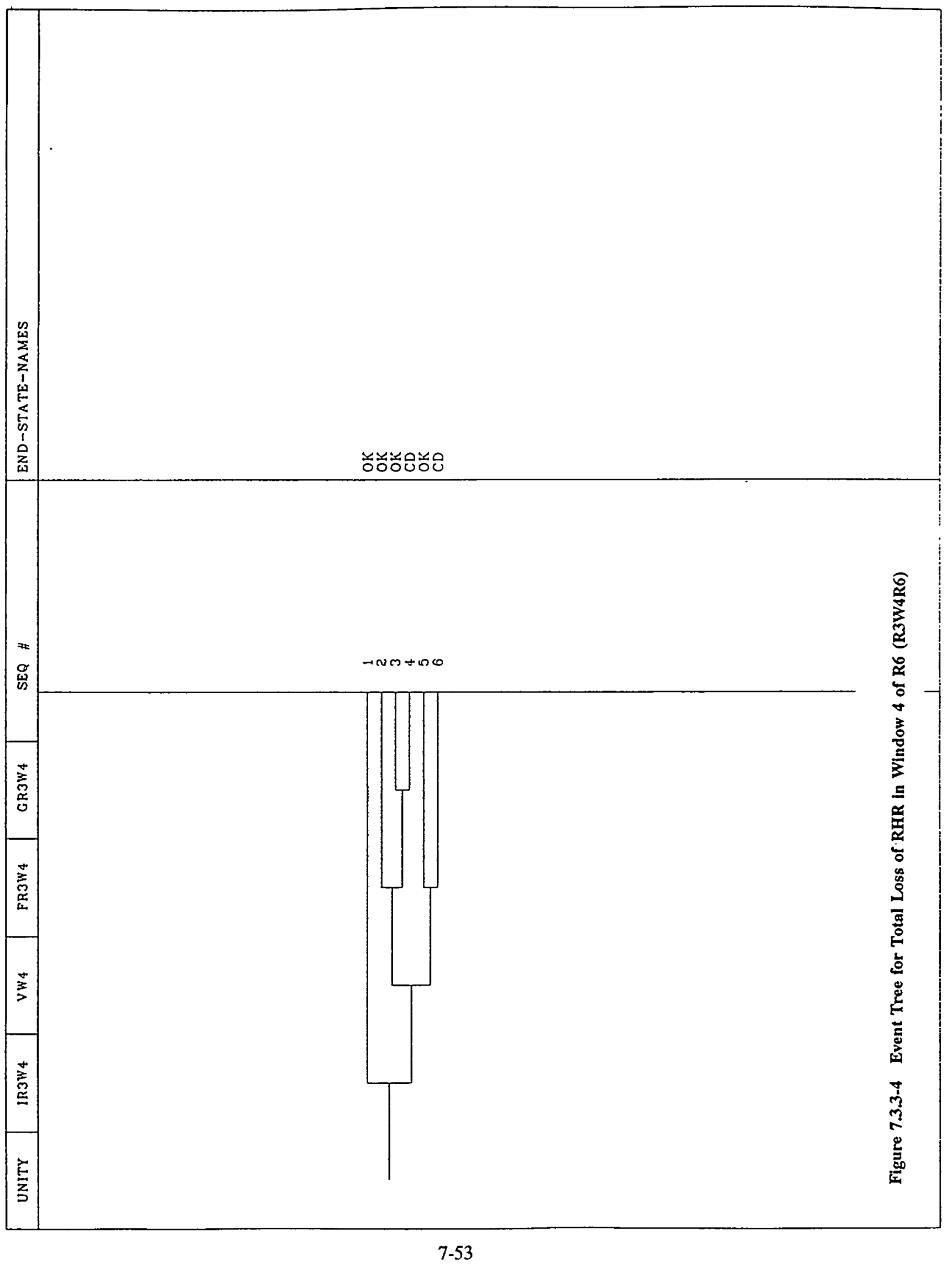




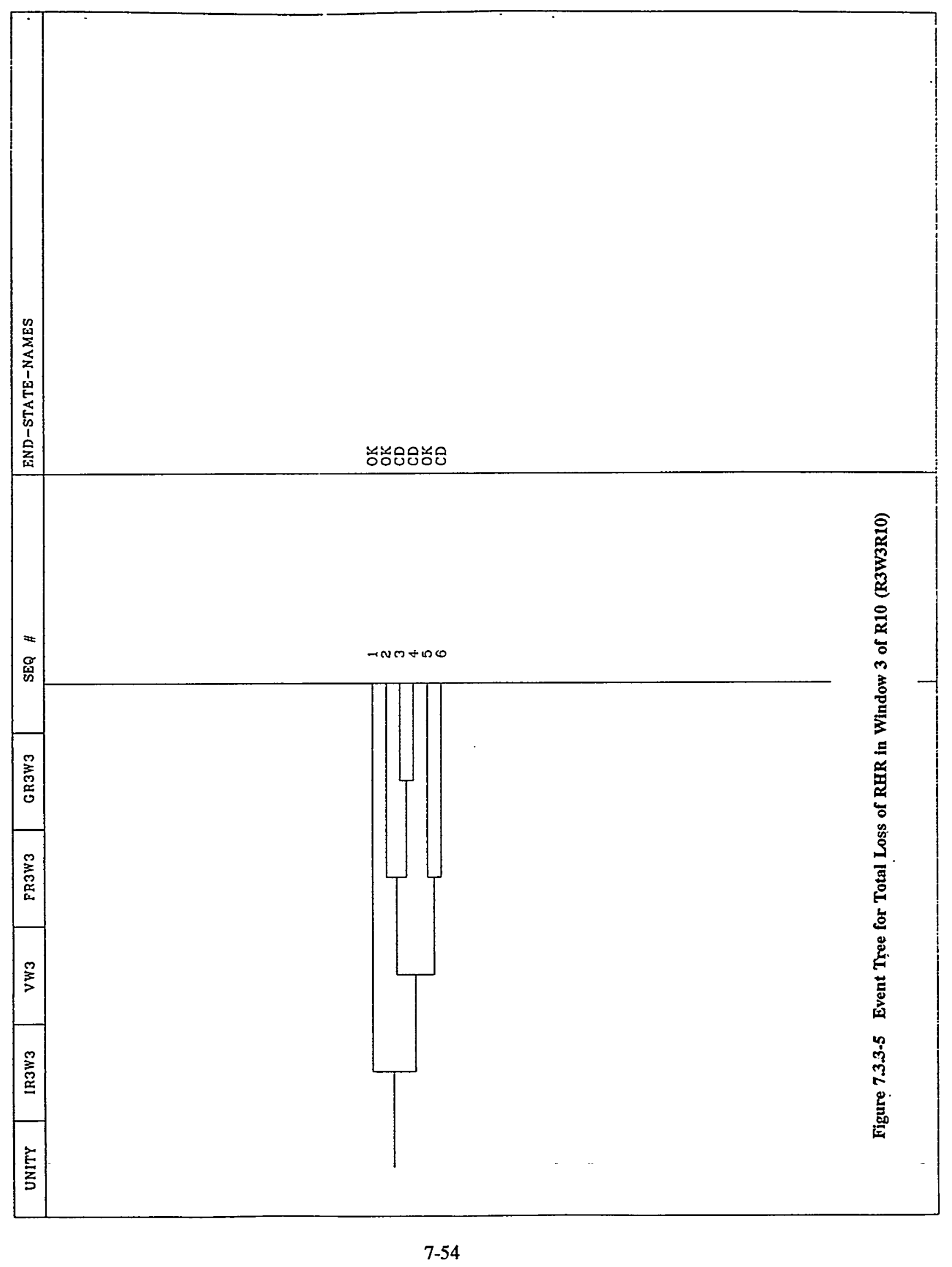




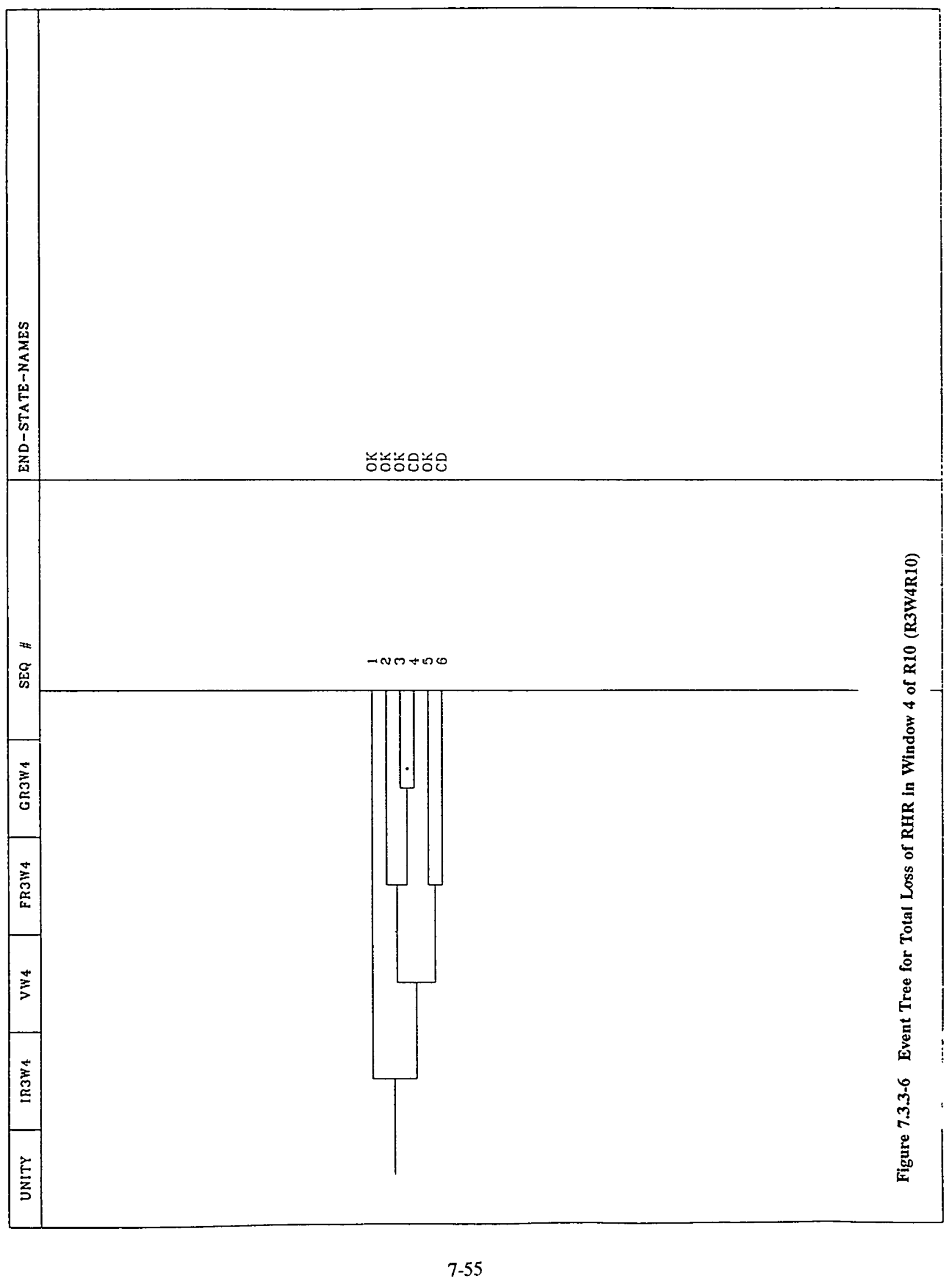




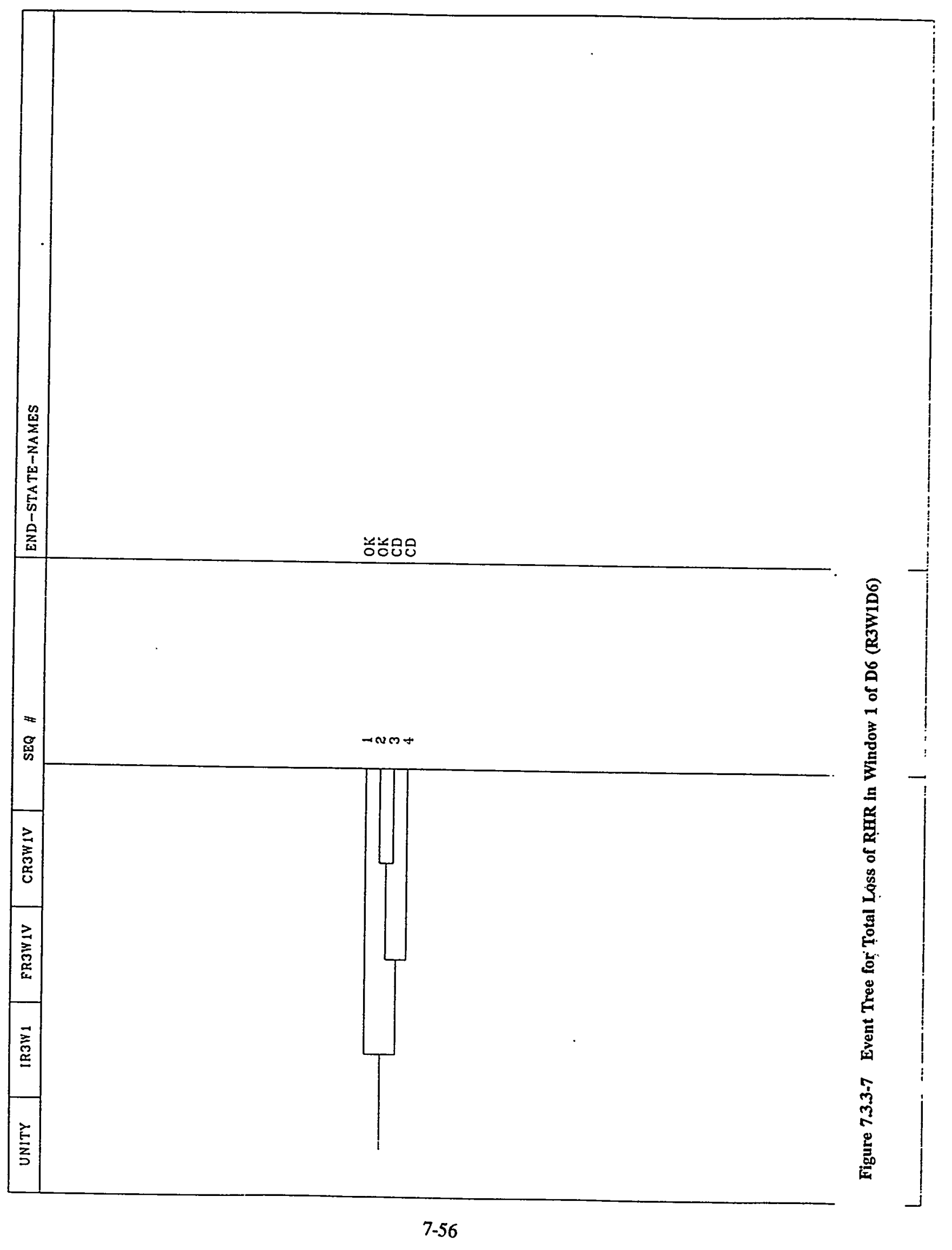




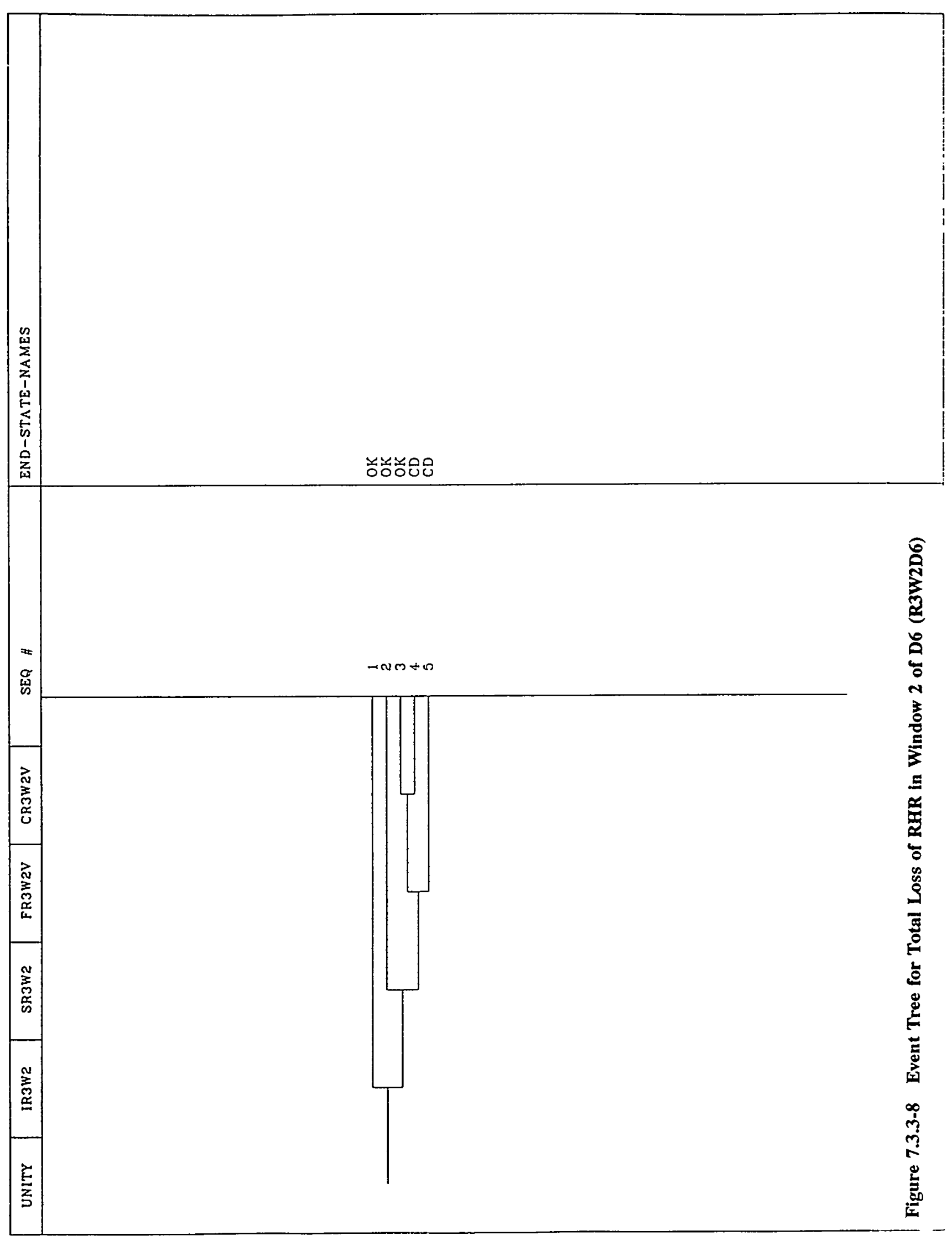




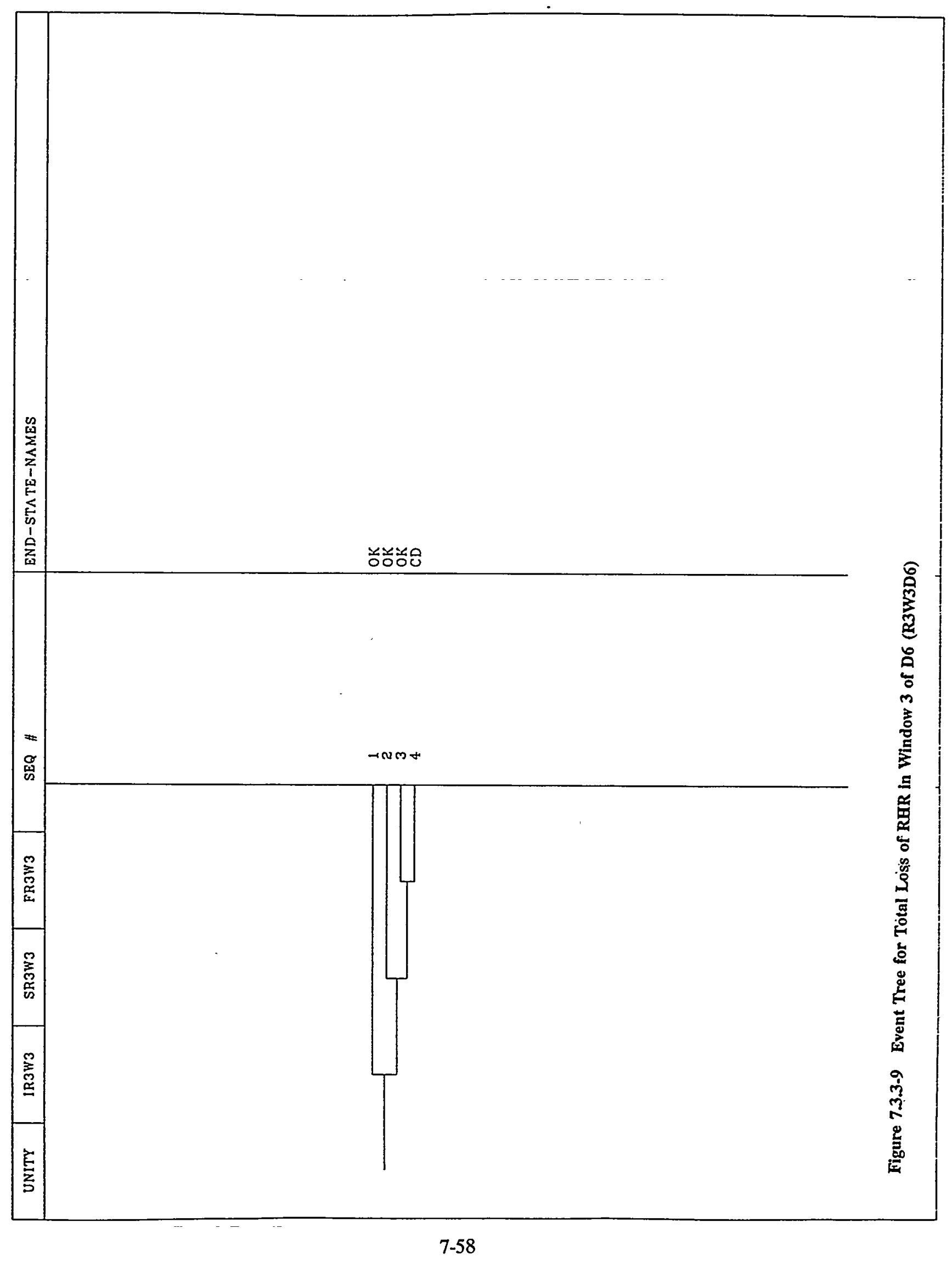




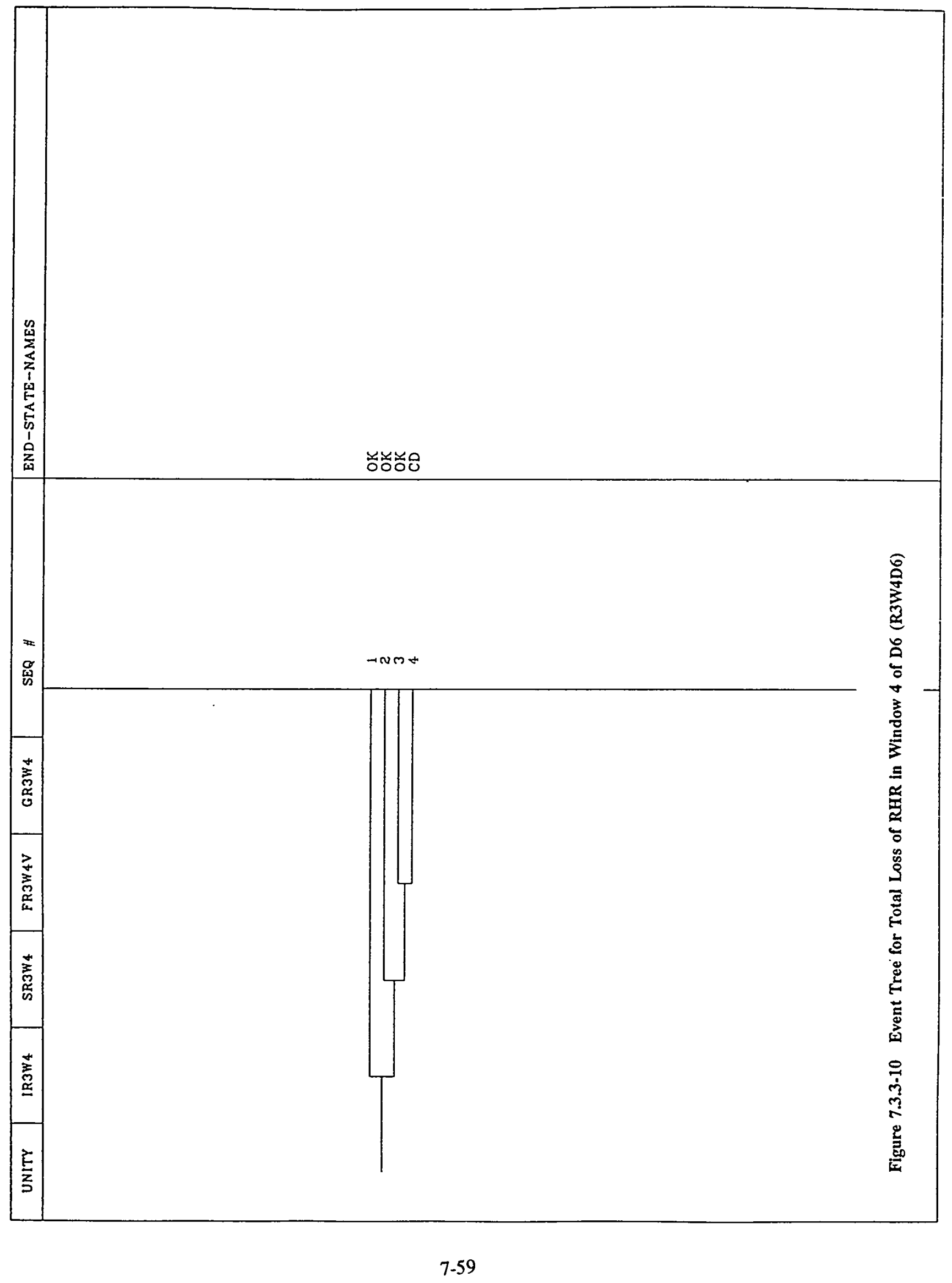


7 Event Tree Analysis

\subsubsection{Event Trees for Loss of Operating Train of RHR (RHR4)}

This initiating event represents an event that causes failure of the operating train of the RHR system, and the failure can not be recovered within the time frame of the accident scenarios that may result. For example, a hardware failure of the operating RHR pump would be assigned to this category. The event trees for this initiating event, Figure 7.3.4-1 to 7.3.4-10, were derived from those for RHR2B by removing the top event on RCS makeup and failing the normally running RHR train by setting a house event "HOUSE-RHR5" to true. Other differences between the two sets of event trees are the frequency of the initiating event and the HEPs used. 


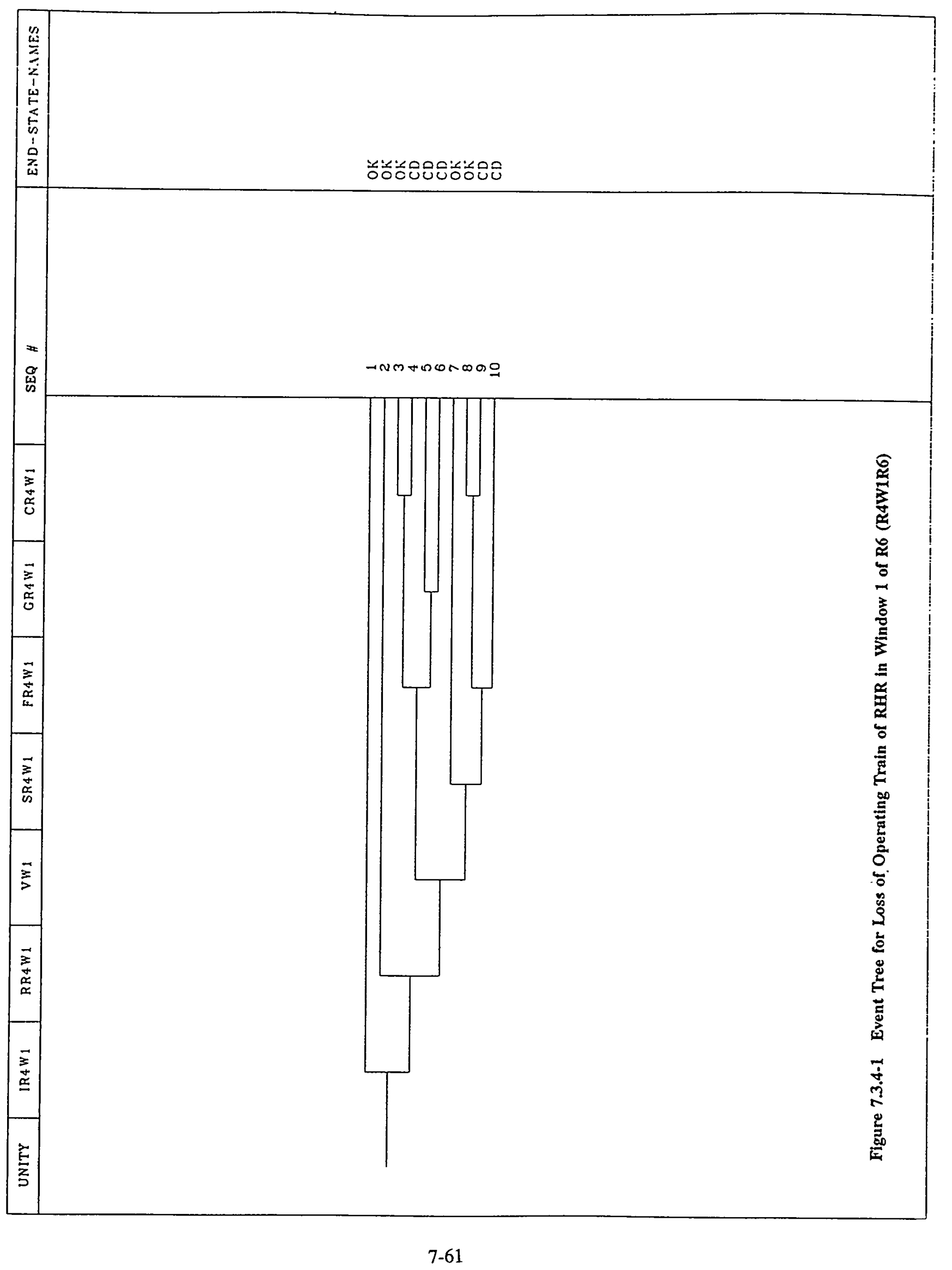




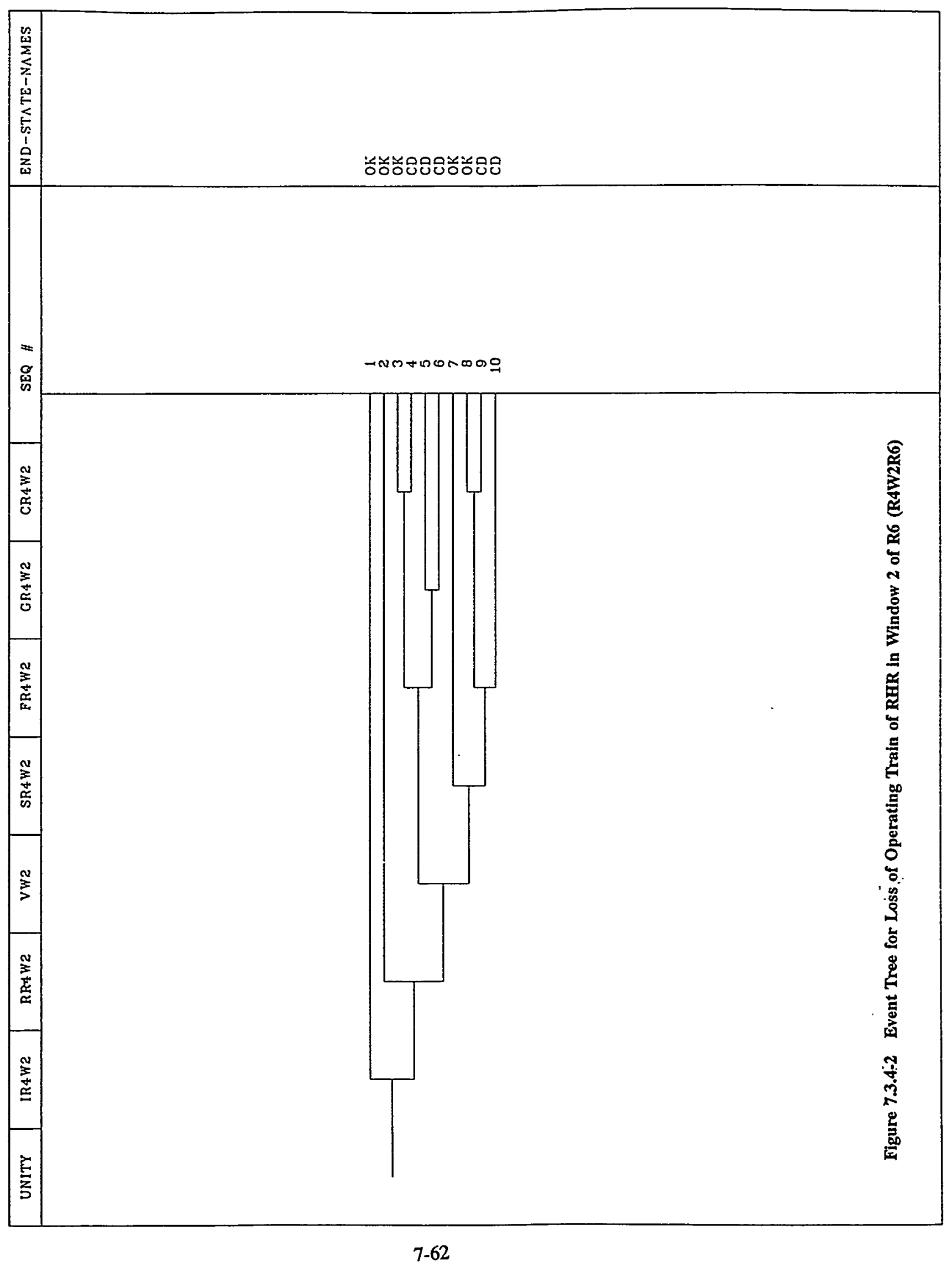




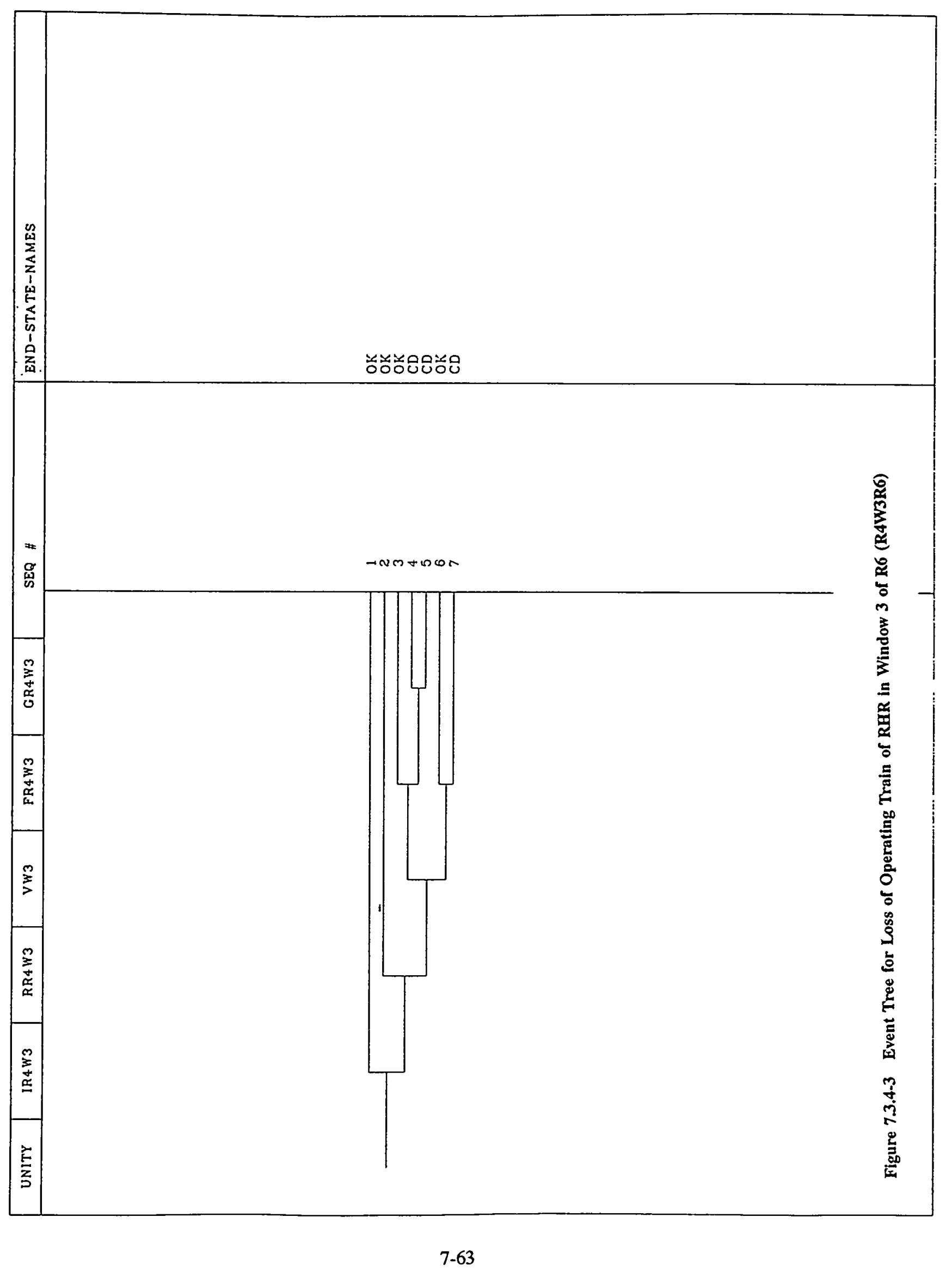




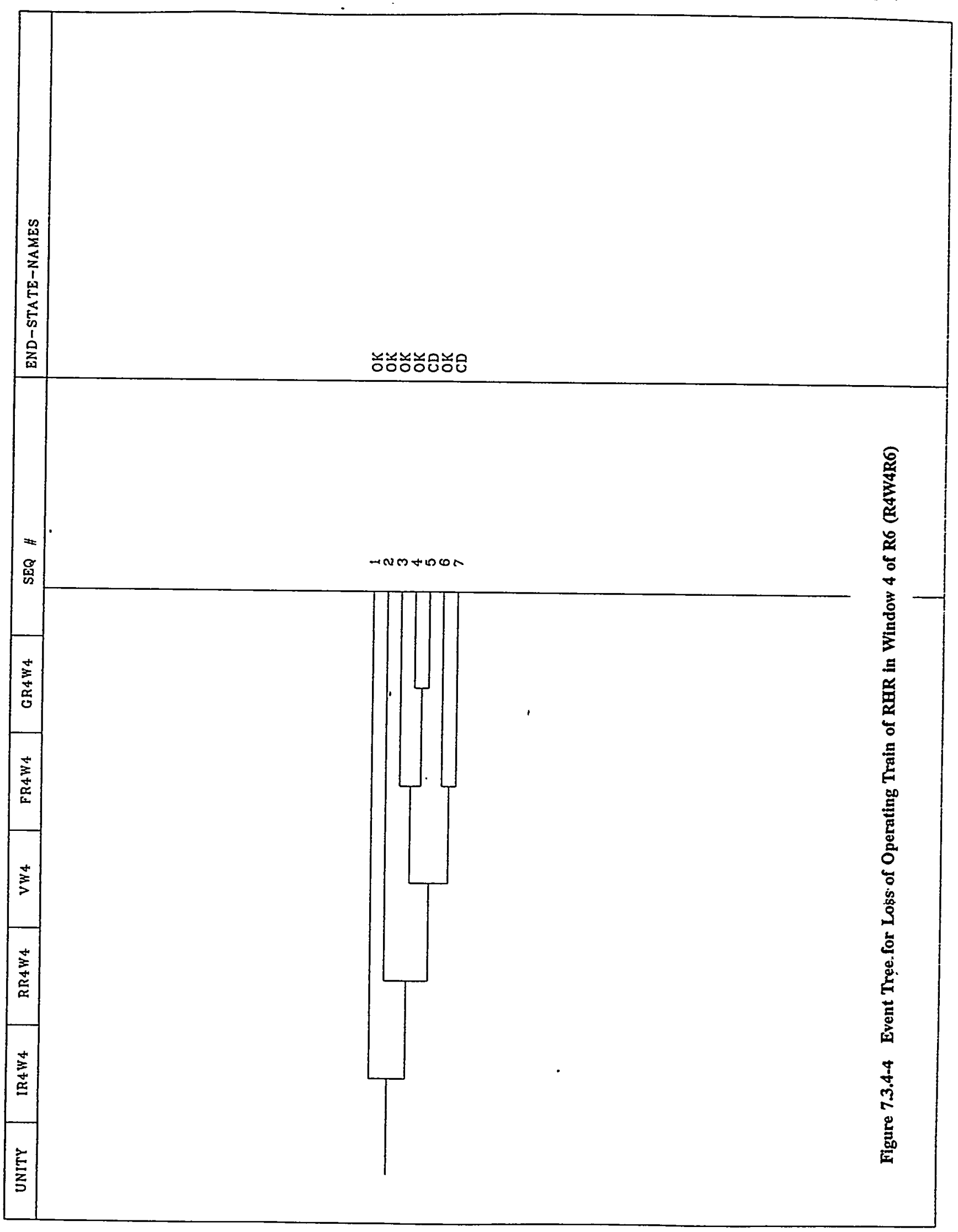




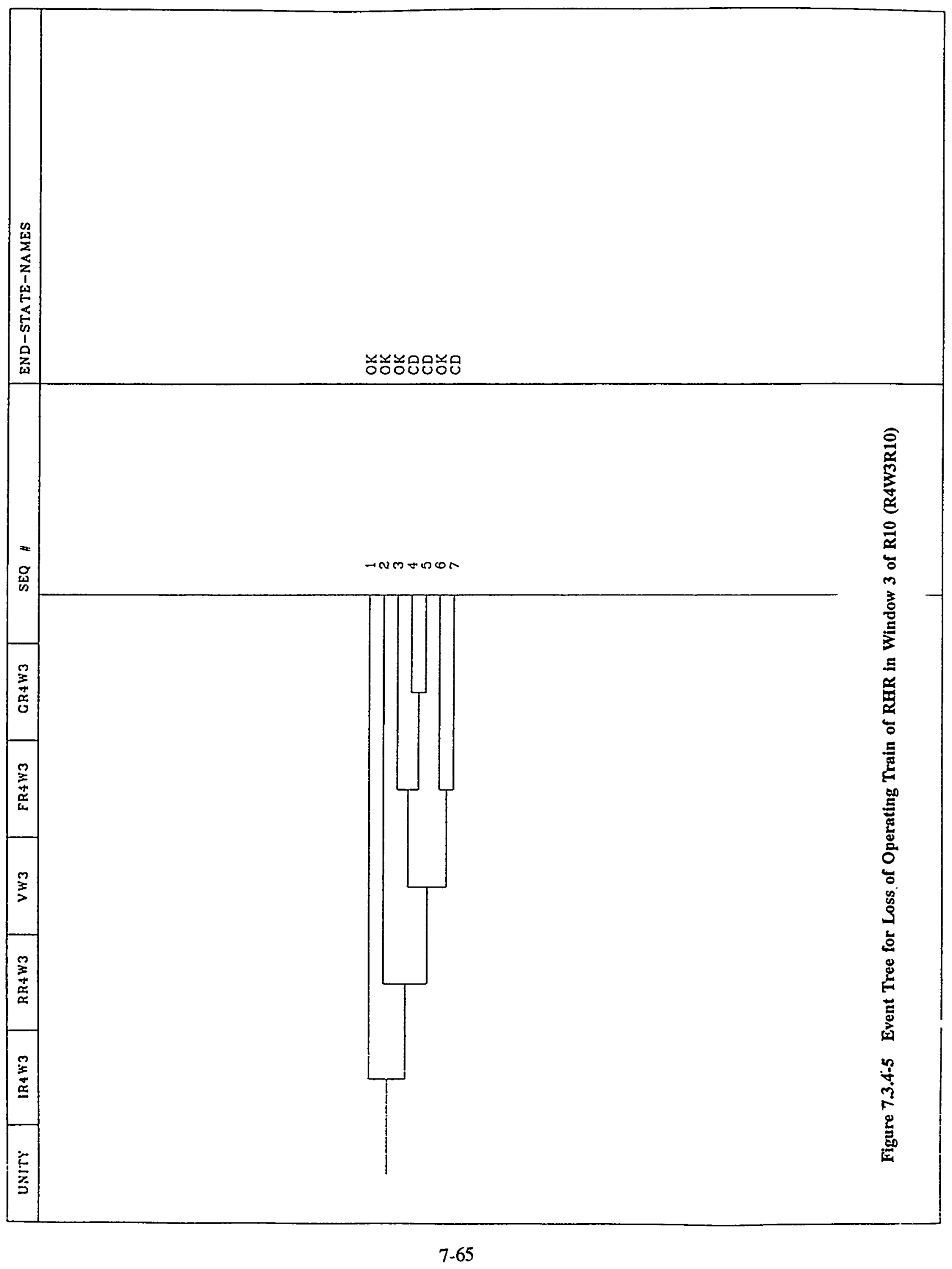




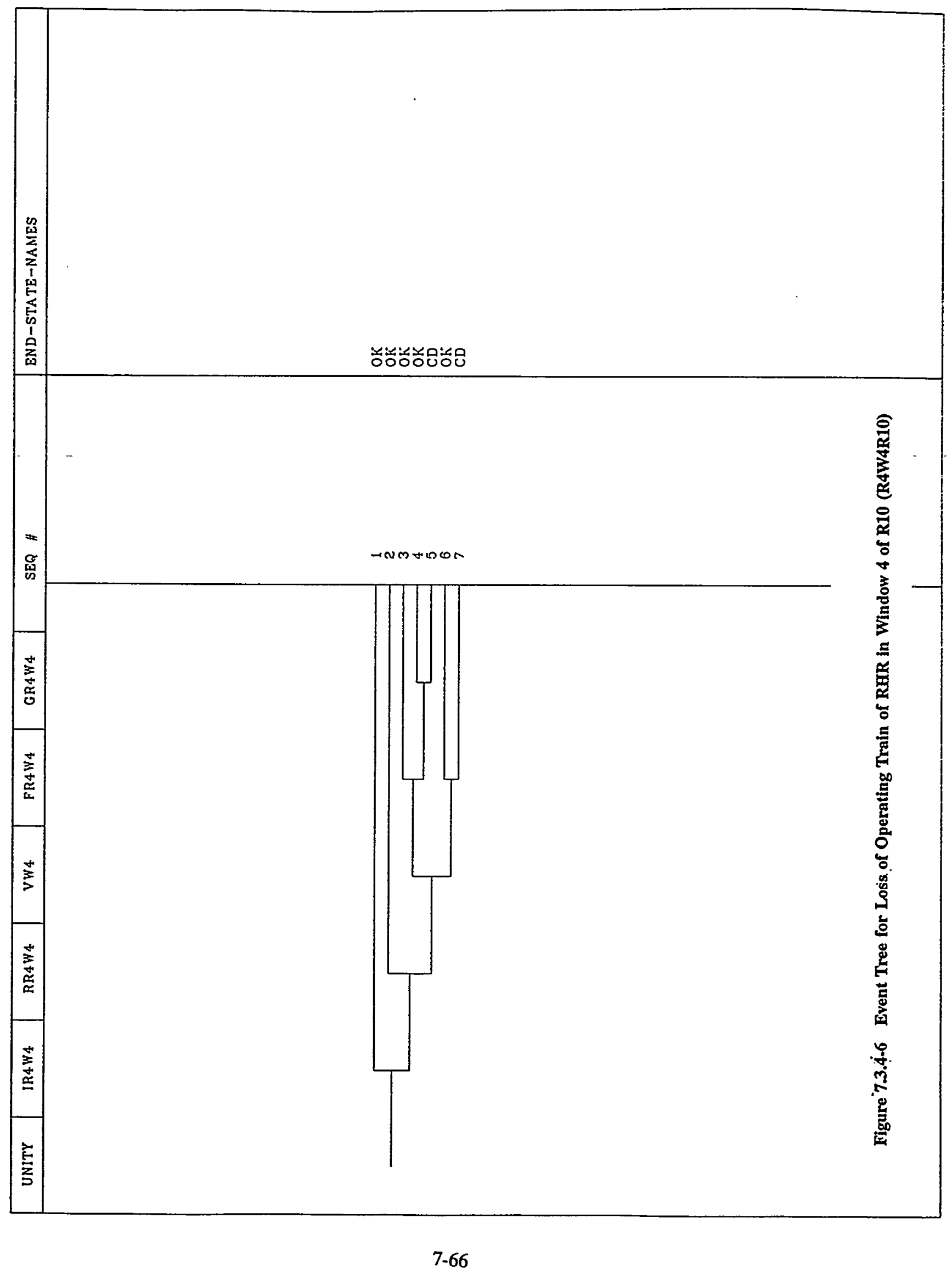




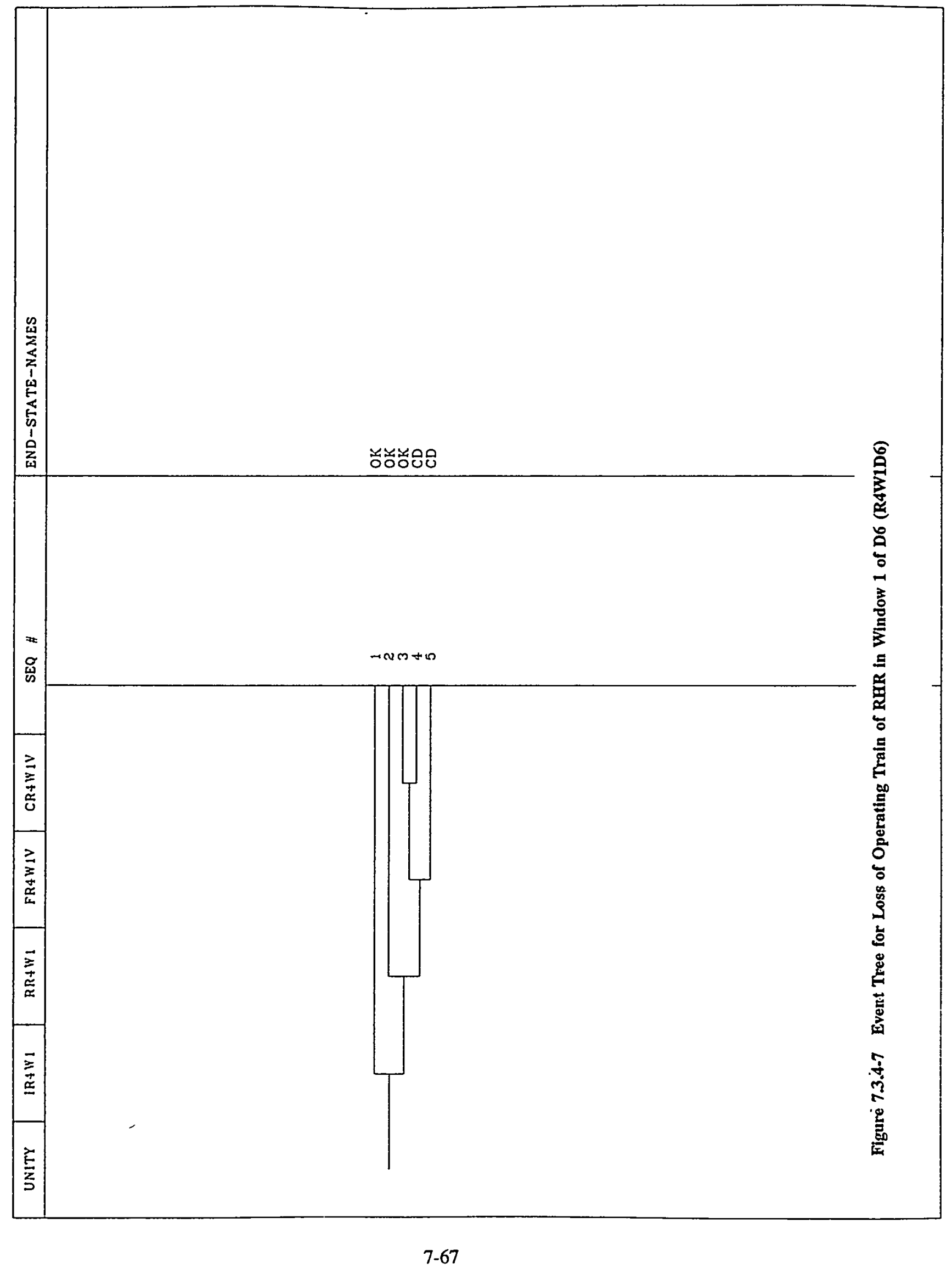




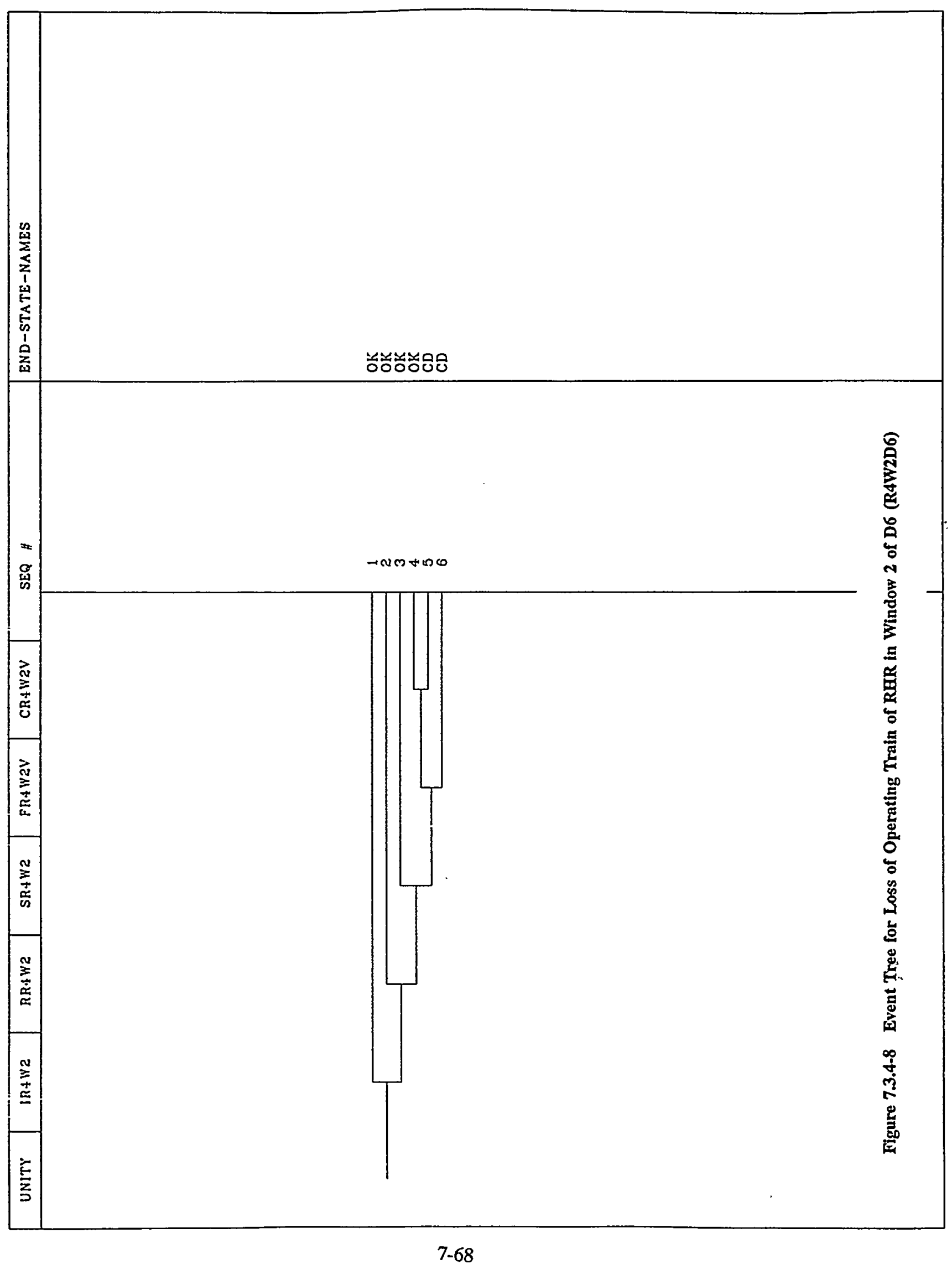




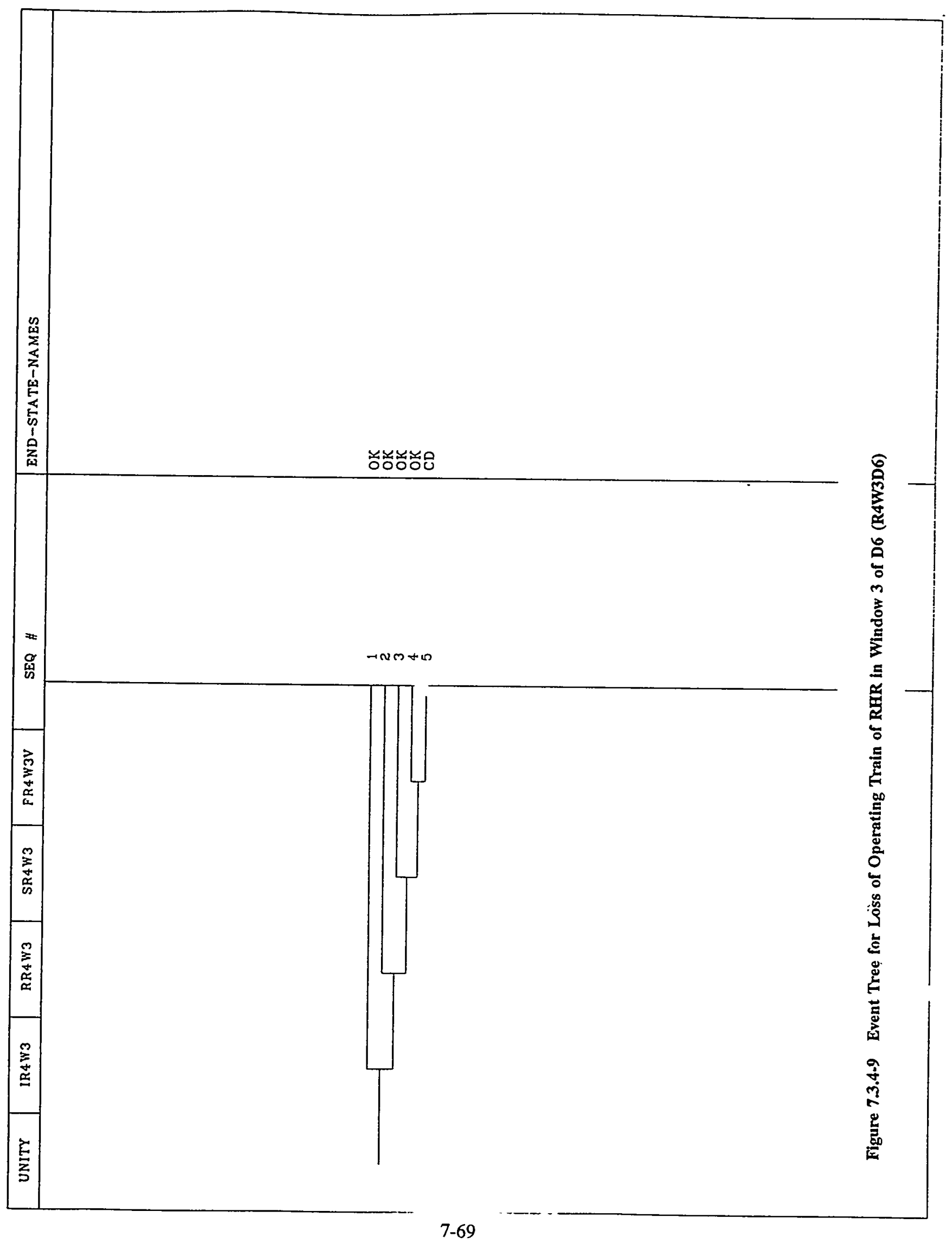




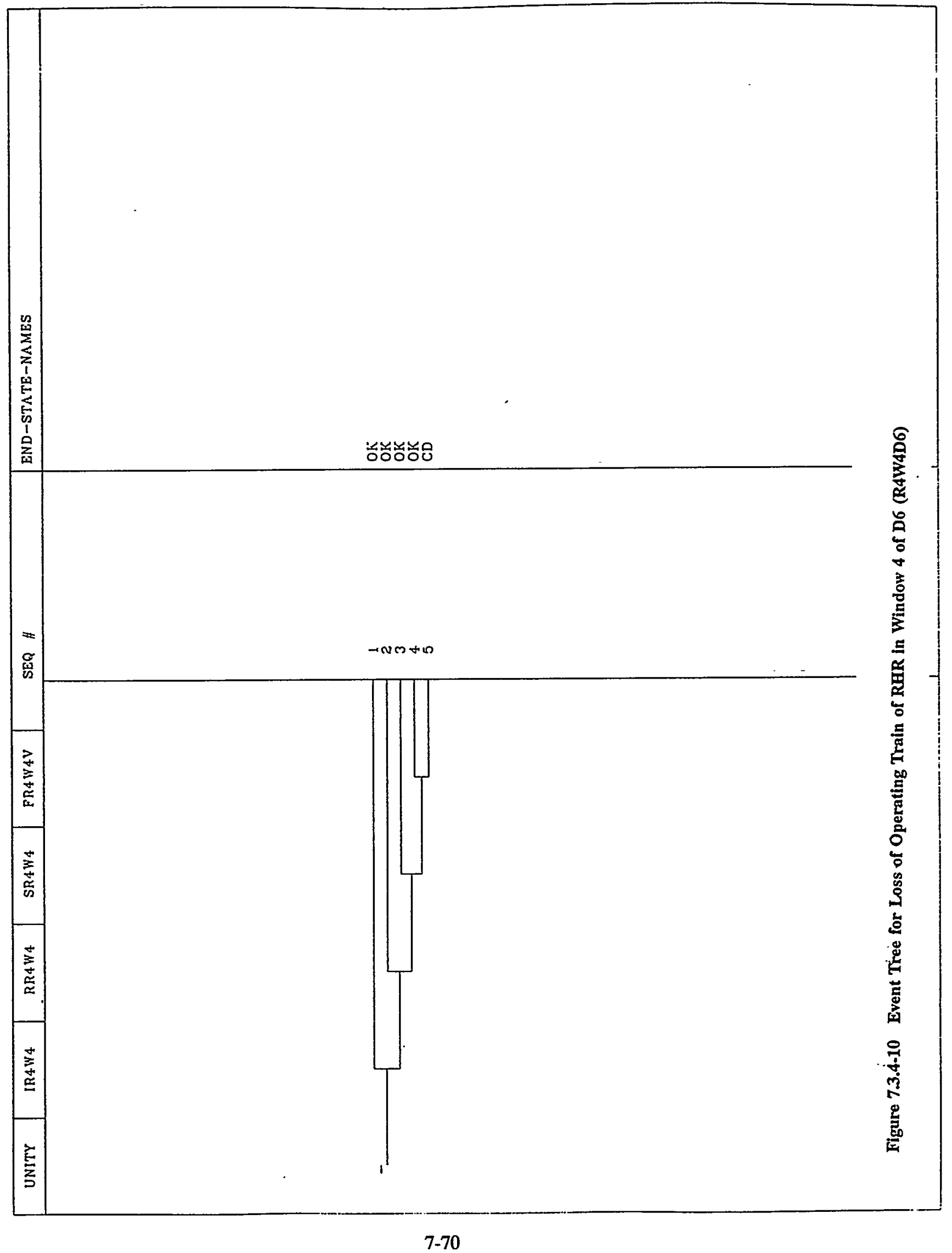




\subsubsection{Event Trees for Recoverable Loss of RHR (RHR5)}

This initiating event represents interruption of the RHR that can be recovered in the time frame of the accident scenarios that may result: for example, a spurious trip of the RHR pump would be assigned to this category. The event trees for this initiating event, Figure 7.3.5-1 to 7.3.5-10, were derived from those for RHR2B by removing the top event on RCS makeup. Other differences between the two sets of event trees are the frequency of the initiating event and the HEPs used. 


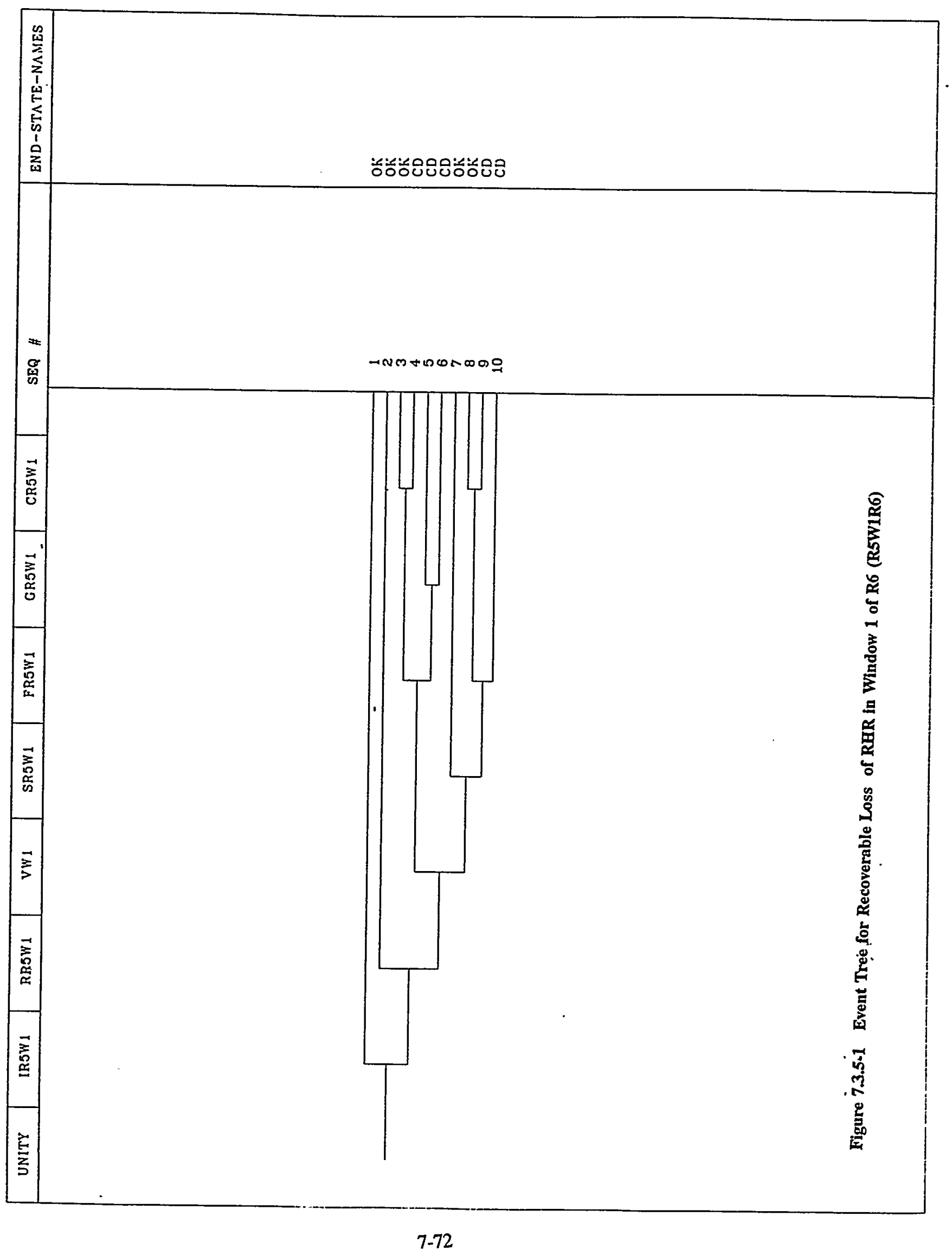




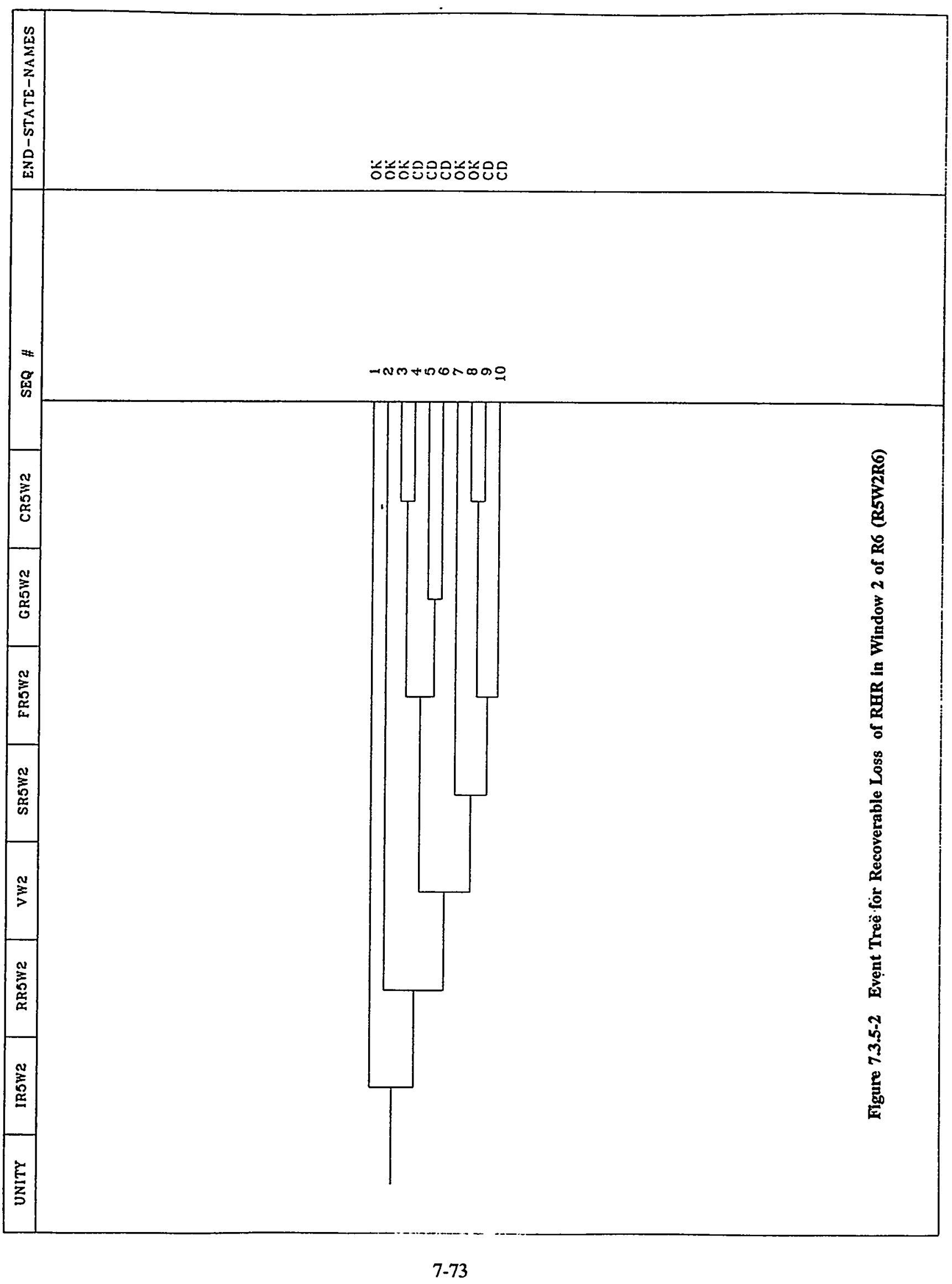




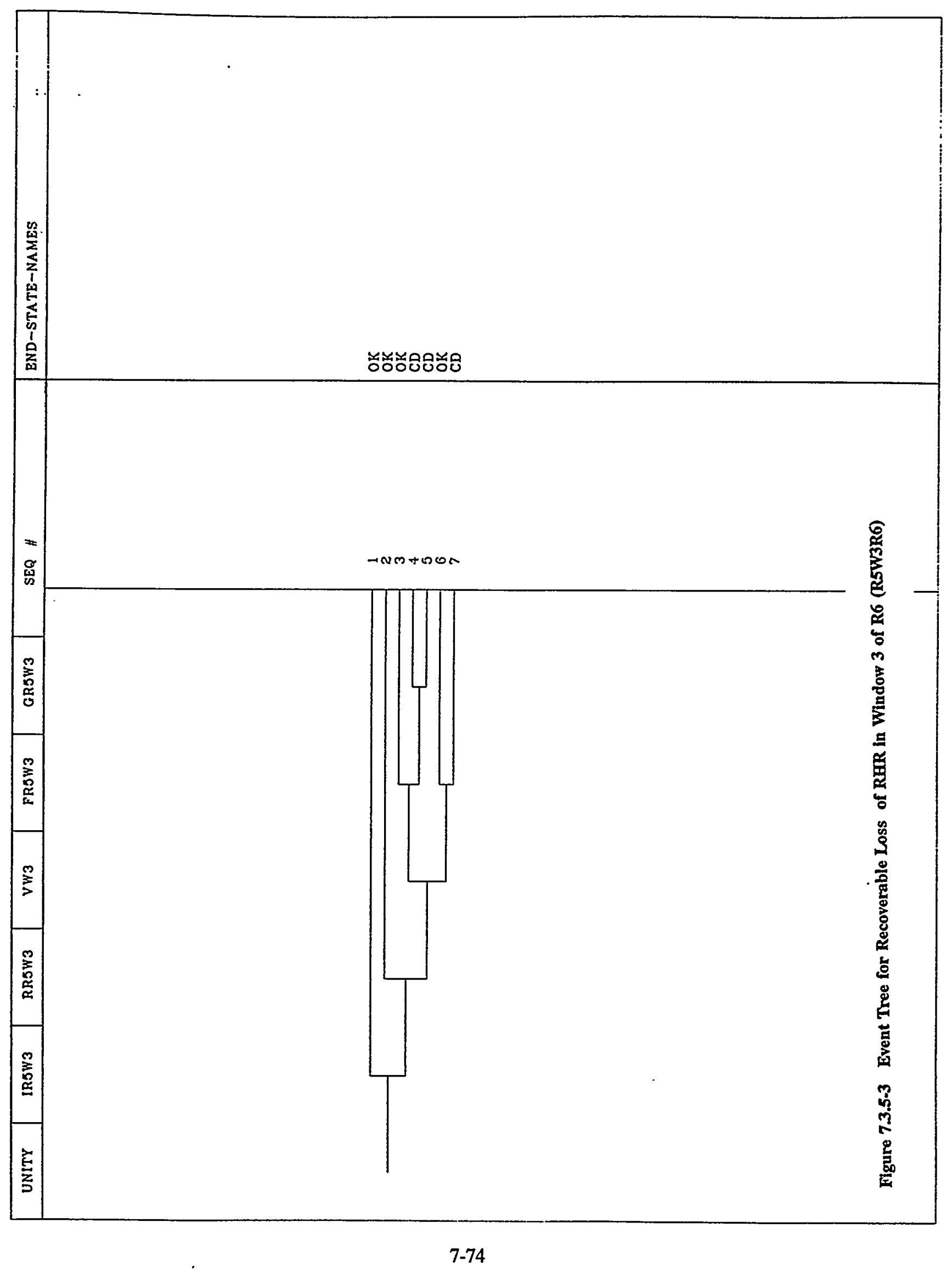




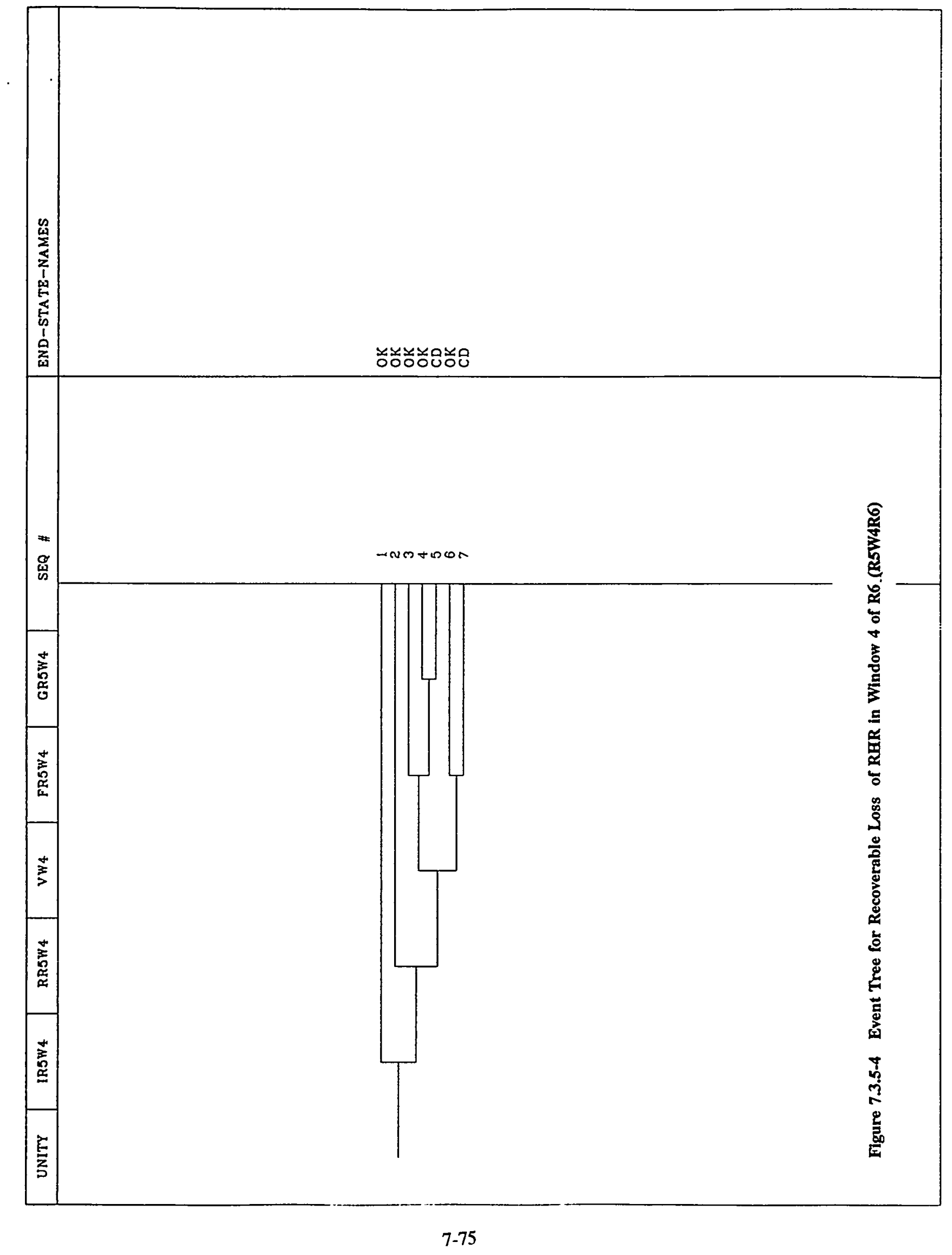




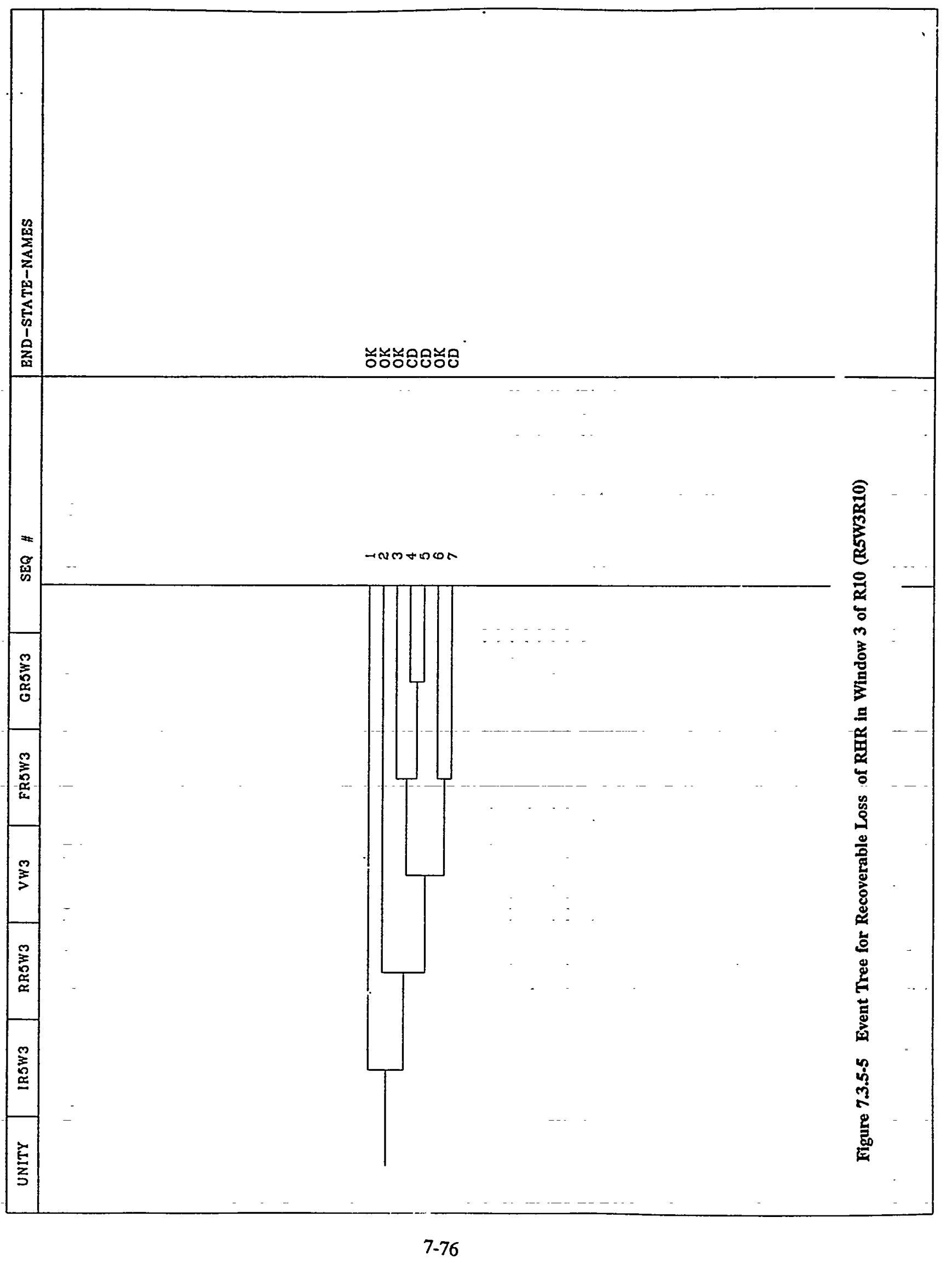




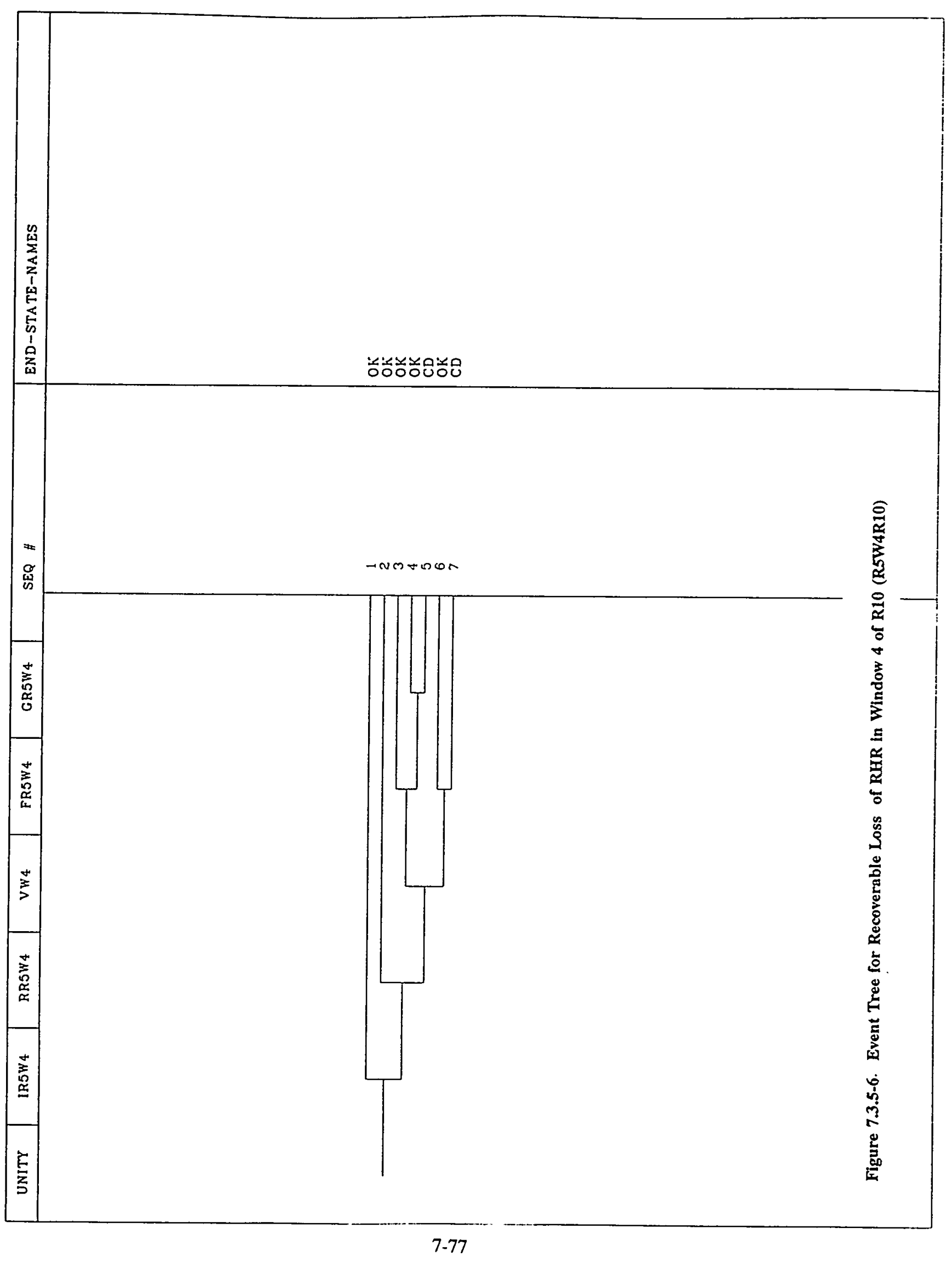




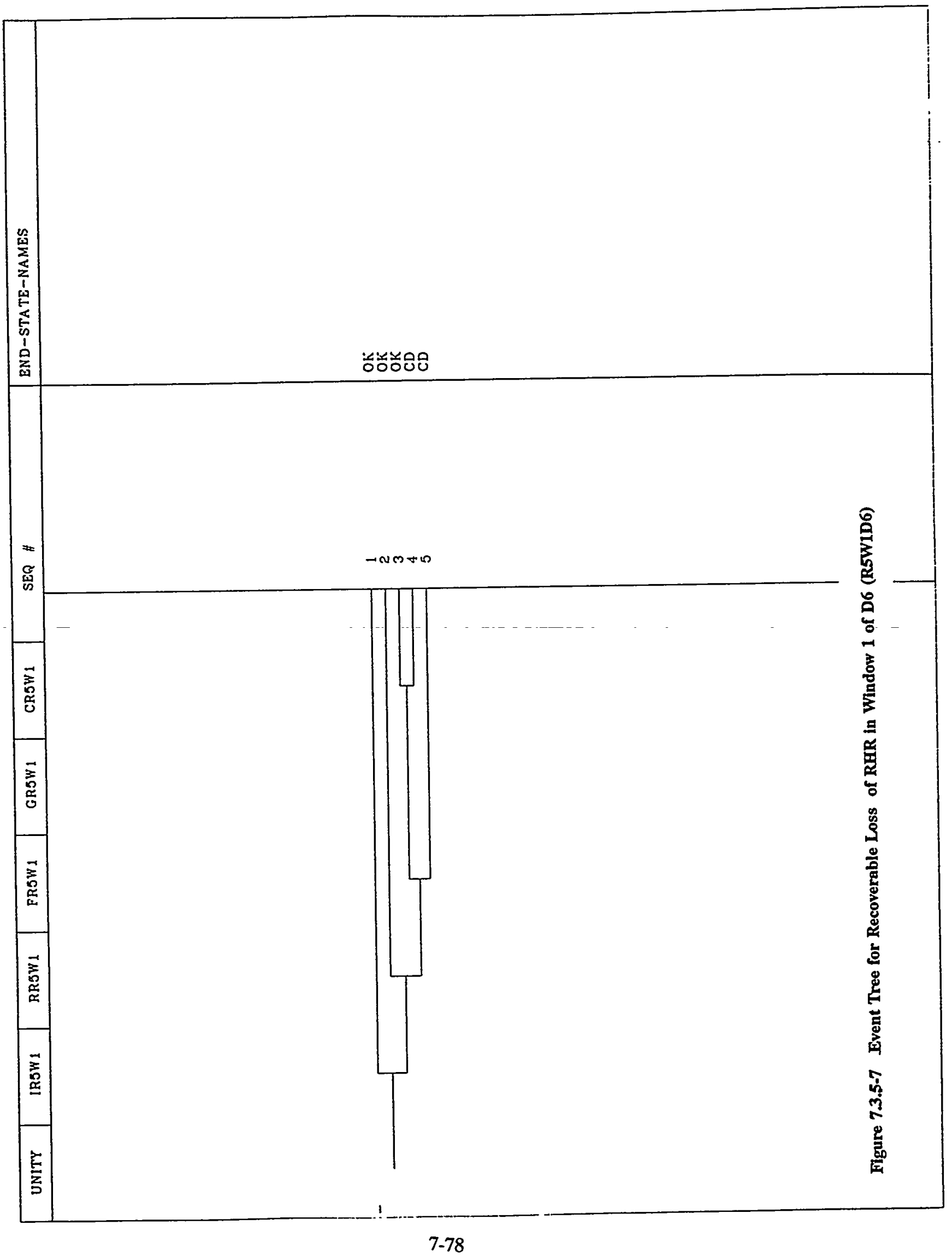




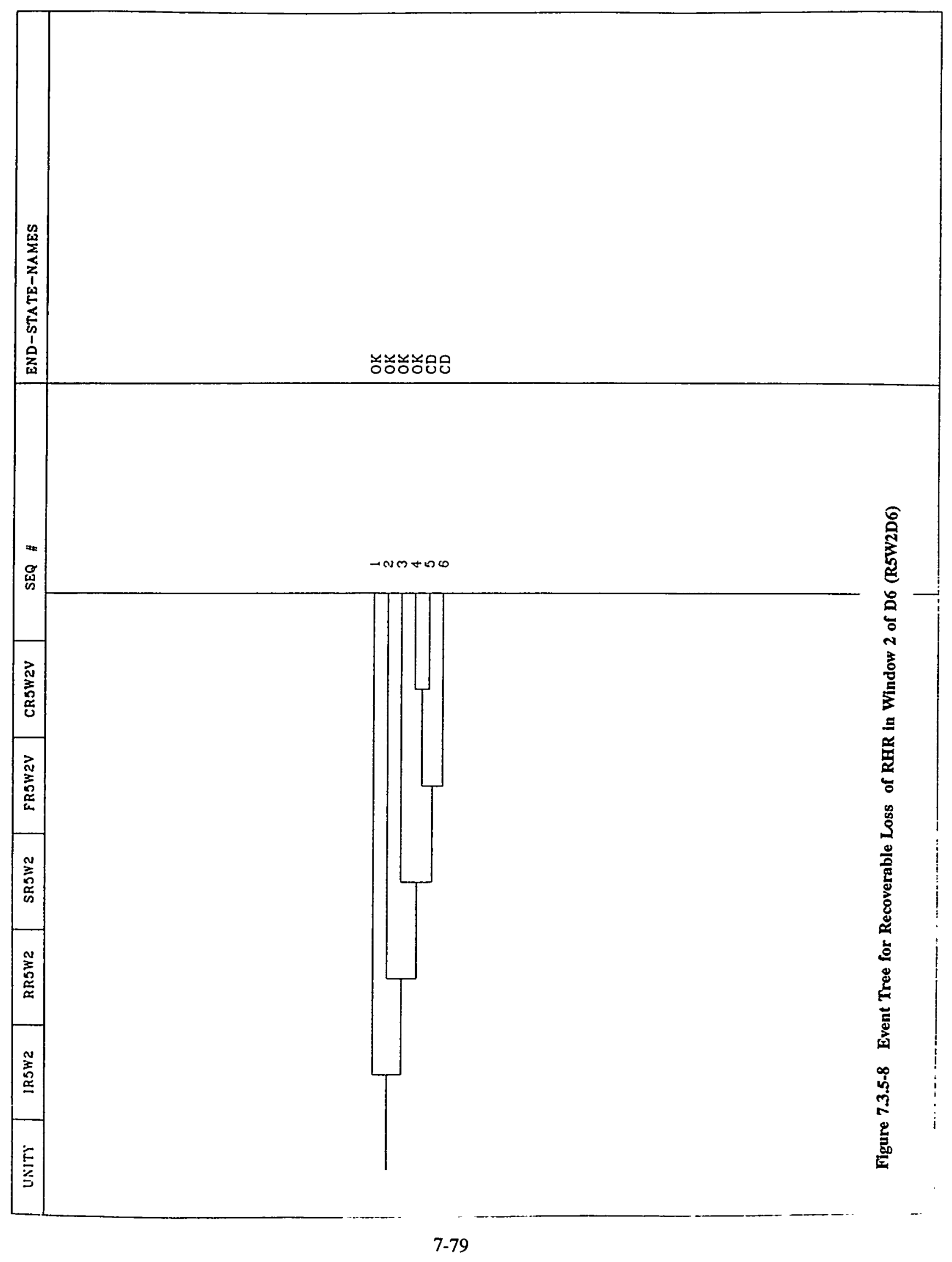




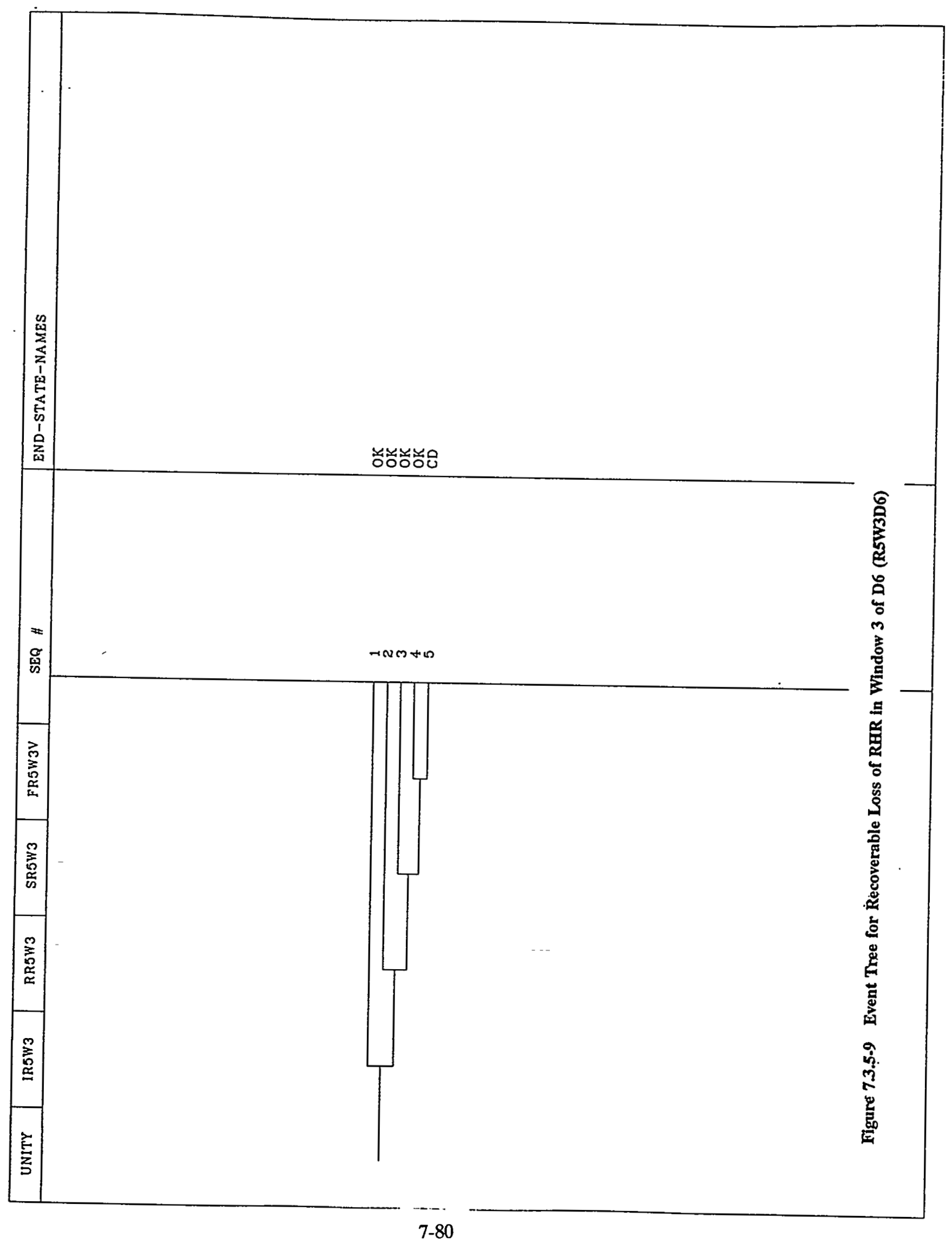




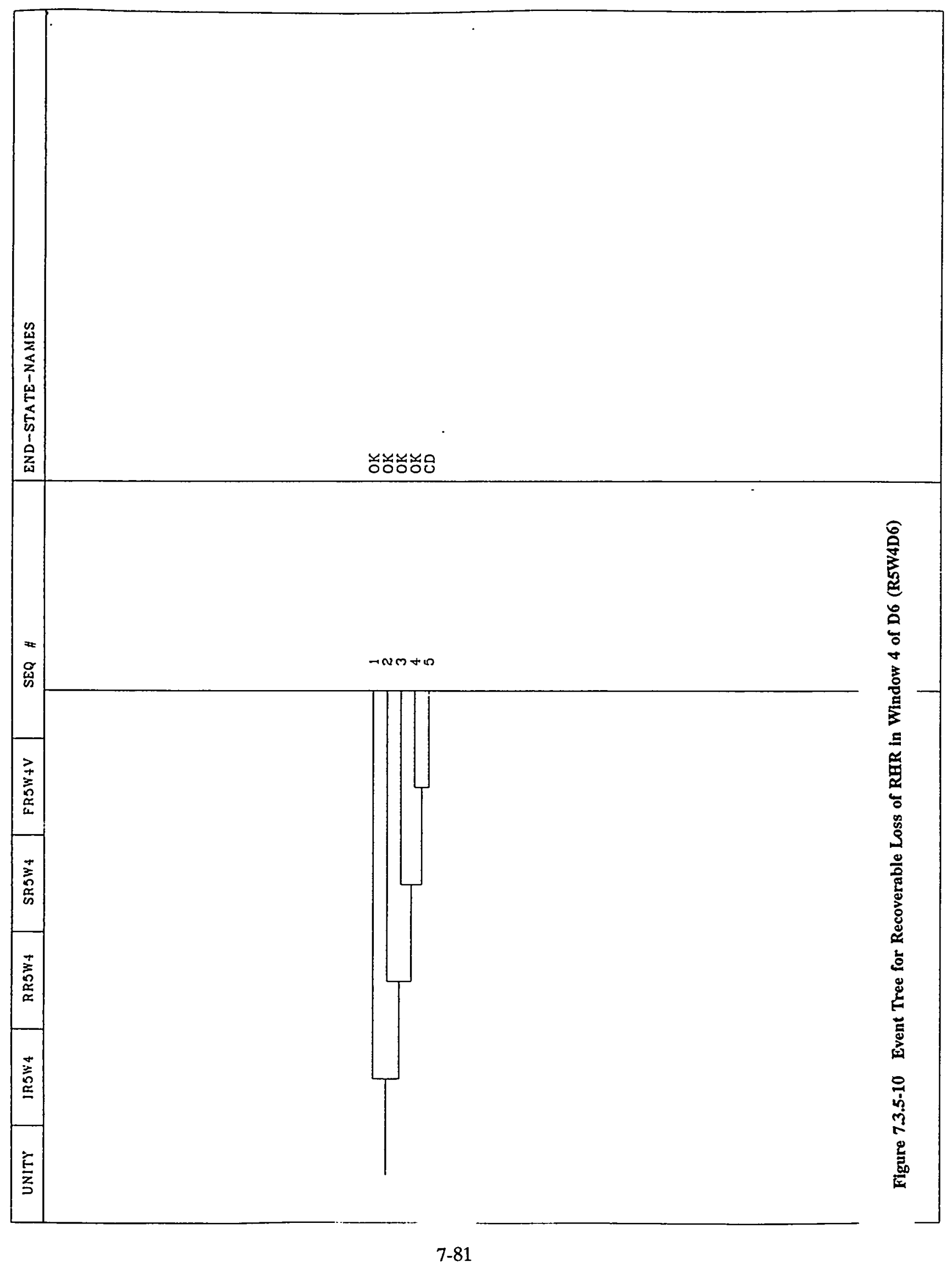


7 Event Tree Analysis

\subsubsection{References}

1. "Background and Guidance for Ensuring Adequate Backup Decay Heat Removal Following Loss of RHR Surry and North Anna Power Stations," Nuclear Analysis and Fuel Nuclear Engineering Services, Virginia Power, NE Technical Report No. 865, Revision 1, June 1992. 


\subsection{Loss of Offsite Power and Station Blackout Event Trees}

This section describes the event tree models that were developed to investigate accident sequences initiated by a loss of offsite power event during mid-loop operations at the Surry Nuclear Plant. Upon loss of offsite power (LOSP), the supply breakers to the $4.16 \mathrm{kV}$ AC buses open, the emergency diesel generators (EDGs) start automatically and each EDG output breaker closes to load the EDG on to its respective $4.16 \mathrm{kV}$ emergency $A C$ buses. EDG 1 is aligned to the $1 \mathrm{H} 4 \mathrm{kV} \mathrm{AC}$ bus, while EDG 3 (the swing DG) can be connected to the $1 \mathrm{~J}$ (Unit 1) or 2J (Unit 2) $4 \mathrm{kV}$ AC bus. These $4 \mathrm{kV}$ AC buses provide power to the HPI pumps, the stub buses which each supply power to one CCW and RHR pump, and the $480 \mathrm{~V}$ AC buses through transformers. The $480 \mathrm{~V}$ AC emergency buses are $1 \mathrm{H}, 1 \mathrm{H}-1,1 \mathrm{~J}$, and $1 \mathrm{~J}-1$ in Unit 1 's electrical distribution system. The $1 \mathrm{H} 480 \mathrm{~V}$ AC bus provides power to pumps such as the $\mathrm{A}$ train low pressure injection pump, or the A trains of the spray recirculation systems; the $1 \mathrm{H}-1480 \mathrm{~V}$ AC bus feeds the motor control centers (MCCs) which provide power to various motor operated valves (MOVs) and small pumps such, as the charging pump cooling pumps. In the LOSP scenario, the $1 \mathrm{~A} 125 \mathrm{Vdc}$ bus provides control power to the switchgear for the pumps powered from the $1 \mathrm{H}$ buses, and if all $\mathrm{AC}$ power is lost, this bus is powered from the DC battery $1 \mathrm{~A}$.

In accordance with the approach discussed in Section 7.1 of this study, event trees were developed to evaluate the LOSP initiating event at plant operational states (POS) during the mid-loop configuration for five boundary conditions.

(1) LOSP where both $4 \mathrm{kV}$ emergency buses $1 \mathrm{H}$ and $1 \mathrm{~J}$ are available,

(2) LOSP where $4 \mathrm{kV}$ emergency buses $1 \mathrm{H}$ (or $1 \mathrm{~J}$ ) and $2 \mathrm{H}$ (or $2 \mathrm{~J}$ ) are available,

(3) LOSP where only $4 \mathrm{kV}$ emergency buses $1 \mathrm{H}$ (or $1 \mathrm{~J}$ ) are available and station blackout at Unit 2,

(4) Station blackout (SBO) at Unit 1, and

(5) Station blackout at both units.

In the first case (L1), EDGs 1 and 3 (swing diesel generator) are aligned to $4 \mathrm{kV}$ emergency buses $1 \mathrm{H}$ and $1 \mathrm{~J}$ respectively, and both EDGs are assumed to start successfully and continue operating to supply emergency $\mathrm{AC}$ power to vital safety equipment throughout the LOSP event. In the second scenario (L2), either combination of EDGs 1 and 2, EDGs 1 and 3, or EDGs 2 and 3, are successful. Therefore, the $4 \mathrm{kV}$ emergency buses $1 \mathrm{H}$ (or $1 \mathrm{~J}$ ) and $2 \mathrm{H}$ (or $2 \mathrm{~J}$ ), or combinations thereof, are assumed to be available to provide $A C$ power to safety-related equipment. In the third case (L3), either EDG 1 or 3 is assumed to start successfully and continue operating to supply emergency $A C$ power to vital safety equipment at Unit 1 . One of the two EDGs may be in maintenance, and Unit 2 is under station blackout conditions as a result of EDG 2 being unavailable due to its failure to start or continue to run. Therefore, only one $4 \mathrm{kV}$ emergency bus $1 \mathrm{H}$ (or $1 \mathrm{~J}$ ) is assumed to be available at Unit 1. For the fourth case (B1), SBO at Unit 1 occurs when there is no emergency $\mathrm{AC}$ power supply to its vital safety equipment. EDG 1 fails to start or continue to run; however, there is one operable DG at Unit 2 to provide AC power to operate cross-connectable systems, such as the charging and AFW systems. This DG could be EDG 2, supplying power to the $2 \mathrm{H}$ bus, or EDG 3 supplying power to the $2 \mathrm{~J}$ bus. A critical event during an $\mathrm{SBO}$ is depletion of the batteries which will result in loss of instrumentation and control power. In the fifth case (B2), an SBO at both units is caused by the unavailability of all three DGs upon loss of offsite power. This condition arises when EDG 1 and EDG 3 are 


\section{Event Tree Analysis}

in failed states, and EDG 2 is under maintenance. Therefore, the unavailability of $A C$ power at Unit 2 results in the unavailability to provide charging flow and AFW supply from Unit 2 systems.

Table 7.4-1 lists the diesel-generator unavailability states corresponding to each of the five LOSP/SBO cases. In section 4.3.2, fault trees were developed to determine the conditional probabilities for these five cases. By combining the success, failure, or maintenance states of each EDG, the conditional probabilities of the five LOSP/SBO cases were derived. The assumptions made in modelling EDG failures are similar to those made in Section 6.2.7.4.2 for developing the Emergency Power System (EPS) fault trees. In addition, maintenance unavailability of EDG 1 and EDG 3 during mid-loop operations is not allowed because of the requirements stipulated in the newly implemented "Reduced Inventory (15.3 ft) Checklist", which is included as an attachment in the station operating procedure OP-RC-005 (Rev. 1, 4/07/92). Specifically, this checklist requires that EDG 1 and EDG 3 be verified operable before the RCS level is dropped to its reduced inventory configuration. Procedure OP-RC-005 also requires that the checklist is completed once every shift while the RCS is in this configuration.

Since failures of the diesels to start and run are incorporated in the definition of the LOSP initiator, these failures are disallowed from the subsequent model (unless power is recovered and a subsequent LOSP event occurs). This is true also for some other failures (e.g. failures of the batteries used to power the switches connecting the EDGs to the appropriate electrical buses). The failure of various components to start (e.g. RHR pumps, CCW pumps,) also is included in the model, as these will be temporarily disconnected after a LOSP.

The LOSP and SBO event trees were developed by considering the specific actions required of the hardware and operators to recover the plant from the LOSP event in the related Surry plant procedures:

(a) AP-10.00: Loss of Offsite Power (Rev. 7, 7/2/92)

(b) AP-17.00: Auto Start Failure of 1 or 2 EDG (Rev. 1, 3/28/91)

(c) AP-27.00: Loss of Decay Heat Removal Capability (Rev. 4, 2/15/92)

(d) ECA-0.0: Loss of All AC Power (Rev. 6, 4/27/92)

(e) 1-FR-H.1: Response to Loss of Secondary Heat Sink (Rev. 4, 3/28/91)

The procedures for loss of offsite power emphasize full power operation; therefore, some interpretation may be needed to apply them to mid-loop LOSP events. For instance, the procedure cautions the operator not to reconnect the CCW pump (which is on the stub bus) if the only source of power is a diesel generator. The EDG maximum load is $2750 \mathrm{~kW}$, and this may be approached, if, at full power, a LOCA coincides with a loss of offsite power. The following equipment may be running at the same time, shortly after the event: charging pumps (600 HP each, with possibility of 2 pumps on the same bus), AFW pump (400 HP), CSS (250 HP), ISR (300 HP), OSR (300 HP), and LPI (300 HP). At Surry, the spray recirculation systems (ISR and OSR) run concurrently with the injection spray system (CSS). In addition, some smaller systems will be connected (charging pump cooling, recirculation fans). A CCW pump has a rating of $600 \mathrm{HP}$, i.e. it is relatively big in terms of power consumption. Therefore, loading it onto a diesel under these conditions may bring the diesel generator down (and it is not strictly necessary, if everything else is working). However, in the events analyzed here for mid-loop operation, the diesel's power requirements will be much smaller, depending on the availability of equipment. An RHR pump has a capacity of $300 \mathrm{HP}$, and CCW is needed to operate the RHR 
system. Therefore, if an attempt is made to restart the RHR, it is assumed that the operators will connect the CCW pump(s).

As discussed in section 7.2, success criteria in the procedures were relaxed when we judged that the operators (or the TSC) will realistically try to save the core rather than strictly follow the rigid guidelines. For example, low pressure recirculation is taken credit for when the pressurizer safety valves are removed.

An LOSP event will have the following consequences: Compressed air will be lost, at least temporarily (due to loss of bearing cooling water to the instrument air compressor), which will incapacitate the RHR (as the CCW valves $109 \mathrm{~A}$ and $\mathrm{B}$ will close) and the reflux bleed path via steam generator PORVs. It is assumed (and included in the model) that the operators will quickly recover from this loss (as written in the procedure) by connecting the standby diesel compressor and/or using fire-water to cool the bearings of the instrument air compressor. Even then, further action may be needed to operate the steam generator PORVs, as the semivital bus is used for control power. This bus can be powered from either emergency bus (via MCCs 1H1-1 or 1J1-1), so it may be necessary to align this semi-vital bus to the live source of emergency power, depending on the initiator (in a blackout, control of the steam generator PORV will be lost). If the SG PORVs cannot be recovered, reflux cooling (which is the preferred method of cooling, except for a restart of the RHR system) can be effected by dumping the steam into the condenser. If the condenser is not available, the steam eventually will be dumped inside the turbine building (the procedure cautions that this building should first be evacuated). For the steam dump to work, the operators have to open the main steam non-return valve (along with the manual bypass valve around the main steam trip valve). This valve is powered from normal buses, so it must be opened manually, which is not a simple operation.

On loss of compressed air, the air-operated valves cross-connecting the two Units' RWSTs will fail open, so this connection will be established automatically, at least initially.

The charging, LPI, recirculation spray, and AFW systems will lose power temporarily and then be reconnected to the live buses. In case of charging, it may be possible to cross-connect from Unit 2.

AFW also can be cross-connected (from any pump on Unit 2, including the steam-driven pump, as Unit 2 is assumed to be initially at power). The steam-driven pump on Unit 1 will not work due to the low quality of the steam. A fallback option for AFW is to use fire-water to replenish the steam generator secondary (which is not necessary until several hours into the accident).

Since the LPI is needed for recirculation and since LPI train A, charging trains B and C, and spray recirculation train $B$ are assumed down for maintenance, the recirculation function will have a high unavailability unless both emergency buses are powered. If bus $1 \mathrm{H}$ is down, then high-pressure recirculation and spray recirculation both will be down. Low pressure recirculation will be up, but this configuration will work only if the pressurizer safety valves are removed. These valves are never removed in drained maintenance, and have a certain probability of not being removed in a refueling outage. If bus $1 \mathrm{~J}$ is down, then the low-pressure recirculation system, an essential component of recirculation function, will be down and recirculation will not work. The recirculation function is needed in windows 1 and 2 (unless the RWSTs are successfully cross-connected in window 2). 


\section{Event Tree Analysis}

In case of a blackout at either Unit (initiators $\mathrm{L} 3, \mathrm{~B} 1$ and B2), there is a high probability that service water will be lost to both Units due to draining of the Intake Canal through the open condenser $96^{\prime \prime}$ intake lines. These lines are likely to be open even on Unit 1 (the shutdown Unit). These valves have to be closed manually in the absence of emergency power, which probably will take longer than the time to drain the Canal. If the service water is lost, then the RHR, the charging system, and the recirculation sprays will be lost.

If all else fails, gravity feed can be used to extend the time to core damage. This option will give a full 24 hours of cooling in window 4. Gravity feed uses essentially the same flowpath from the RWSTs as the forced feed-and-bleed, so certain valves may need power; without power, these valves can be opened manually.

The success criteria used in the event trees and the timing of the accident scenarios were determined by the thermal hydraulic analysis discussed in Chapter 5. These analyses also estimated the time available for AC power recovery to allow mitigating actions. Recovery of offsite power is modeled as a top event in the event trees. The time for offsite power recovery was taken to equal the time to uncovery of the core if no action is taken, since, after that, reflux cooling will not be effective due to loss of inventory. In some scenarios, some mitigating function may be operating but is not sufficient to provide 24 hours of decay heat removal (gravity feed, reflux cooling or feed-and-bleed). After the cutsets were generated, the offsite power non-recovery probability was adjusted to account for additional time available should certain mitigating features be effective.

Once offsite power is recovered, the conditional probability of core damage will be significantly reduced. Instrument air will be recovered, so reflux cooling will have a higher availability (steam generator PORVs will be operable, as power will be available to the semi-vital bus and compressed air will be available from regular sources); also, the RHR system will have a higher availability once instrument air is recovered. The feed-andbleed function will have a higher availability because there will be no degradation in power supplies coincident with a high probability of maintenance of trains (e.g. trains $\mathrm{B}$ and $\mathrm{C}$ of charging are in maintenance, as are train B of LPI and train B of the recirculation sprays). The same is true for the AFW system (train B has a high probability of downtime due to maintenance). Circulating water pumps will be started to recover the service water system if it was lost in a blackout (see discussion in L3, B1 and B2). Also, there will be a higher probability of help from Unit 2. For instance, for charging cross-connect, charging pump $2 \mathrm{C}$ must be operable, i.e. electrical bus $2 \mathrm{H}$ must be up, which may or may not have been before the recovery of offsite power.

In the following Sections, the event trees for each LOSP category will be discussed. Ten event trees for each LOSP category were constructed to define the accident sequences; one for each combination of time windows and POSs. They are shown in Figures 7.4-1 to 7.4-50. The event trees for L1, L2 and L3 are identical for a given window and POS, although the structure of certain fault trees will be different and some basic events will be quantified differently.

\subsubsection{Event Trees for Loss of Offsite Power with Both Emergency Buses Available (L1)}

\subsubsection{L1 Event Tree for Window 1 of R6 (LIW1RG)}

In Window 1, the plant conditions are characterized by a decay heat load of $13.2 \mathrm{MW}$ attained in 2 days after shutdown from full-power operation. Figure 7.4-1 shows the event tree for the LOSP initiating event, L1, where both $4 \mathrm{kV}$ AC emergency buses $1 \mathrm{H}$ and $1 \mathrm{~J}$ are available. Following a LOSP, the RHR pump is tripped 
by load shedding of stub buses from the $4 \mathrm{kV}$ emergency buses. The stub buses must be manually reconnected to the $4 \mathrm{kV}$ emergency buses to restore power supply to the RHR pumps, before the core starts to boil, otherwise the RHR pumps will be vapor-bound and unstartable. Because of the estimated decay-heat load in the reactor coolant system (RCS), the time to core uncovery is 2.0 hours if no mitigating systems are available to keep it covered and cooled. If the ability of the RCS to remove decay heat is lost due to the inability to restore RHR pumps, the operator must control RCS temperature by dumping secondary steam to the main condenser via main turbine steam dump valves. Long-term makeup to the steam generators (SGs) is required, while RCS makeup can be provided by gravity feed from RWST inventory when depressurized, or by feed-and-bleed operation using a charging pump or low head injection pump. Long-term cooling has to be supplied by the recirculation systems when feed-and-bleed or gravity feed are used. Recovery of offsite $\mathrm{AC}$ power within 2.0 hours would restore the plant to stable conditions; therefore, non-recovery of offsite $\mathrm{AC}$ power is modeled in the event tree as a decision point for successful mitigation of the initiator. Due to the similarity of top event definitions for the L2W1R6 and L3W1R6 event trees, only the top events of the L1W1R6 event tree are described below:

\section{IL1W1 - LOSP Initiator}

This event represents the frequency of occurrence of LOSP category L1 in window 1. A house event inside the fault tree is used to switch between POS R6 and POS D6, with the proper initiator frequency assigned.

\section{RL1W1 - Restore RHR}

This top event represents the restoration of the RHR pumps and the return to pre-initiator conditions. Upon LOSP, the stub buses that supply power to the RHR pumps are shed from the emergency buses, and must be manually reconnected to restore power to the RHR pumps. When the stub buses are reconnected to the energized $4 \mathrm{kV}$ emergency buses, the CCW system also is restored to service. Except for CCW pump P-1A, one CCW pump (P-1B, P-1C or P-1D) per unit is initially started in the loading sequence to provide cooling water to the RHR heat exchangers (HXs), and other components. The restoration of RHR pumps to service may require local venting to prevent injection of air into the RHR lines, and also verifying that heat removal is availablevia CCW flow through the RHR heat exchangers before restarting the pumps. This event is asked first, because RHR would have to be restored immediately after the initiator; once the core starts to boil, the RHR pumps will become vapor-bound and restarting will be very difficult.

VW1 - RCS Initially Vented

This top event represents the plant evolution in which the RCS is initially vented when the three pressurizer safety relief valves are removed. The removal of each safety valve gives a 4-inch-diameter opening on top of the pressurizer. If the RCS is vented in this way, gravity feed of the RWST inventory can be used for makeup to the RCS. However, reflux cooling ("fall back" cooling) is not possible in this configuration due to the potential loss of RCS inventory through the vents on the pressurizer.

NL1W1 - Non-recovery of Offsite Power

This event represents failure to recover offsite $\mathrm{AC}$ power within the allowable time before core uncovery (2.0 hours). 


\section{Event Tree Analysis}

\section{SL1W1 - Steam Generator Feed-and-Bleed}

This top event represents the use of reflux cooling to adequately remove heat and prevent core damage. Reflux cooling is possible when the RCS loops are not isolated, and the secondary side of the SGs is in wet layup. Also, AFW is needed for long-term makeup to the SGs. Isolation of the RCS loop and drained SGs are modeled as failure causes for this top event. In window 1, successful removal of decay heat is accomplished by all 3 SGs in the reflux cooling mode, and the secondary side inventory is adequate to prevent drying out of the SGs for the first 10 hours. Afterwards, AFW has to supply makeup water to the secondary side. When secondary steam is generated, it can be dumped via the main condenser to the Turbine Bldg. deck, or through the SG PORVs to the atmosphere.

\section{FL1W1 - Primary System Feed-and-Bleed}

This event represents forced flow, using a charging pump or low head injection pump to provide RCS makeup, and bleeding through the pressurizer PORVs or RHR relief valve. According to recent thermal-hydraulic studies made by VEPCO personnel, a feed-and-spill mode of operation is preferred where the operators are directed to feed the RCS through any cold-leg injection path until the primary system is completely full and spilling out of the PORVs. In this mode, the injection flowrate must be adequate to maintain a subcooled RCS, and thus, allow RHR flow to be more easily established. In Window 1, $644 \mathrm{gpm}$ of injection flow would be needed. Such flow rate can only be supplied by a low pressure injection pump and is beyond the capacity of a charging pump. However, as discussed in section 7.2, feed-and-steam operation can be performed by a charging pump. In this study it was judged that one charging pump and one PORV or one low head injection pump and 2 PORVs would be sufficient. A concern with this mode of removing decay heat is the adequacy of fluid inventory. The unit $1 \mathrm{RWST}$ inventory is sufficient for approximately 10 hours of unthrottled injection flow. Discussions with Surry plant operators indicate that in-core thermal couples would be used to determine that adequate subcooling is achieved before throttling the injection-flow.- In addition, the unit-2 RWST can be cross-tied to further supply any needed injection flow, provided the charging pumps are used for injection. Thereafter, injection and heat removal has to be accomplished with recirculation systems. In window 2, the inventory in 2 RWSTs is sufficient for 24 hours of feed-and-bleed operation; recirculation is not needed. The PORVs are normally blocked open with a small chance, probability of 0.05 , that one PORV is closed.

\section{GLIW1 - Gravity Feed from RWST}

This event represents gravity feed of RWST inventory through the low-head injection flowpath to the RCS if $\mathrm{RCS}$ is vented when pressurizer safety relief valves are removed from service. In Window 1, this mode of removing decay heat provides an additional 4.3 hours to allow the operators to establish alternate means of decay heat removal. Successful actions to establish gravity feed do not preclude potential core-damage, and therefore, further recovery actions are necessary to mitigate the onset of core-uncovery. - Therefore, in our event tree, success of gravity feed results in core damage, pending operator recovery. No credit is given for recirculation systems as the pumps are assumed failed (otherwise forced feed-and-bleed would have been successful). The logic model for the gravity feed option is represented by a modified fault tree for the unavailability of the low-head injection, deleting basic events representing pump failure modes.

\section{CL1W1 - Recirculation Systems}

This event represents the recirculation systems. According to AP27.00, recirculation injection is accomplished by a combination of high-head and low-head pumps. Recirculation heat removal is accomplished by the heat exchangers in the recirculation sprays' circuits. Failure of the sprays results in only a $2 \%$ chance of 
recirculation failing if the full combination of HHSI and LHSI pumps is used (taken from the NUREG-1150 analysis $\left.{ }^{[1]}\right)$. If the HHSI is not available, two methods of recirculation were taken credit for (as discussed in section 7.2), low pressure feed-and-spill and low pressure feed-and-steam. The low pressure feed-and-spill requires that the sprays must operate for the LHSI pump to be effective in pushing the coolant out of the pressurizer PORVs (there is not enough head for the pressure drop from saturated coolant flowing out the PORVs). In low pressure feed-and-steam operation with the safety valves removed, the LHSI pump has adequate head to overcome the pressure drop, even in the absence of sprays. The LHSI pump then is subject to the same $2 \%$ probability of failure if the recirculation sprays are unavailable.

\section{Core Damage Sequence Description for L1W1R6 event tree}

Sequence 4 has a loss of offsite power initiator with failure to recover RHR. The safety valves are removed, which means reflux cooling cannot be used. Offsite power is recovered within 2 hours and forced feed-andbleed works in the injection mode. However, failure of recirculation eventually leads to core damage.

Sequence 5 is similar, except forced feed-and-bleed fails. Gravity feed is successful, but insufficient to keep the core cooled for 24 hours. Any actions taken after gravity feed are addressed in the recovery analysis.

Sequence 6 is similar to sequence 5, except that gravity feed fails.

Sequences 8,9 , and 10 are similar to sequences 4,5 , and 6 , respectively, except that offsite power is not recovered within $2 \mathrm{hrs}$.

In Sequence 13, RHR is not recovered after the initiator, pressurizer safety valves are not removed, but reflux cooling fails nevertheless. Offsite power is recovered within 2 hours, forced feed-and-bleed works, but recirculation fails, causing core damage (gravity feed cannot be used because the safety valves were not removed).

Sequence 14 is similar, except forced feed-and-bleed fails, resulting in core damage.

Sequences 17 and 18 are similar to sequences 13 and 14 , respectively, except that offsite power is not recovered within 2 hrs.

\subsubsection{L1 Event Tree for Window 1 of D6 (L1W1DO)}

This event tree, Figure 7.4-2, has a similar structure to the POS R6 trees except events VW1, reflux cooling and gravity feed are absent. In POS D6, one loop is isolated, so 2 steam generators are not enough to provide reflux cooling. VW1 is not questioned because the safety valves are not removed in drained maintenance. Therefore, gravity feed cannot be used. 


\section{Event Tree Analysis}

\section{Core Damage Sequence description for L1W1D6 event tree}

Sequence 4 has the LOSP initiator followed by failure to recover RHR, recovery of offsite power within $2 \mathrm{hrs,}$ success of forced feed-and-bleed in the injection mode, but failure in recirculation mode, resulting damage to the core.

Sequence 5 is similar, except feed-and-bleed fails in the injection mode, resulting in early core damage.

Sequences 7 and 8 are similar to sequences 4 and 5, respectively, except that offsite power is not recovered within 2 hrs.

\subsubsection{L1 Event Tree for Window 2 of R6 (L1W2RG)}

The event tree structure and sequence logic of this event tree, Figure 7.4-3, are the same as those for the L1W1R6 event tree. Success criteria of top events are somewhat relaxed due the to lower decay power (10 MW). The time available to recover offsite power increases to $2.62 \mathrm{hrs}$. Only 2 steam generators are needed for successful reflux cooling (+ AFW for long-term cooling after 10 hours). Gravity feed will provide an additional 6.5 hours, and cross-tying the RWSTs (with charging available)will give at least-24-hours of cooling, i.e., recirculation would not be needed.

\subsubsection{L1 Event Tree for Window 2 of D6 (L1W2DO)}

This tree,Figure 7.4-4, is similar to the window 1 tree in D6 (i.e., Figure 7.4-2), except that credit is taken for reflux cooling, because, with one loop isolated in this POS, reflux cooling will still be successful with two steam generators. The core-damage sequences are 5, 6, 9, and 10 (corresponding to 4, 5, 7, and 8 in the L1W1D6 trees, except that reflux cooling is an additional failure in all of these sequences).

\subsubsection{L1 Event Tree for Window 3 of R6 (L1W3R6)}

This tree, Figure 7.4-5,-is-similar to-W1R6-and-W2R6-trees; except that all three-loops are isolated, so there is no reflux cooling, but decay power is sufficiently low (7 MW) that recirculation cooling is not needed in the first 24 hours. Gravity feed is still not sufficient for 24 hours (so its failure results in core damage, pending analysis of recovery actions), but provides an additional 12 hours of cooling. Success criteria are further relaxed; the time for recovery of offsite power increases to $3.46 \mathrm{hrs}$. Two SGs are still needed for reflux cooling, but AFW is not needed for 15 hours.

Sequences 4, 5, 7, and 8 have the safety valves removed. Sequences 4 and 7 have failure of forced feed-andbleed but success of gravity feed (which is insufficient to prevent core damage); sequence 4 has offsite power recovered within 3.5 hours. Sequences 5 and 8 are similar to 4 and 7 , except that gravity feed fails.

Sequences 10 and 12 are caused by failure of forced feed-and-bleed (with or without restoration of offsite power); gravity feed cannot be used because the pressurizer safety valves are not removed. 
7 Event Tree Analysis

\subsubsection{L1 Event Tree for Window 3 of R10 (L1W3R10)}

This event tree, Figure 7.4-6, has exactly the same structure as that of L1W3R6. The only differences are the frequency that the initiating event occurs and maintenance unavailabilities.

\subsubsection{L1 Event Tree for Window 3 of D6 (L1W3D6)}

In D6, only one loop is isolated, so credit can be given to reflux cooling in window 3. The tree structure in Figure 7.4-7 is similar to that of L1W2D6 trees, except recirculation cooling is not needed, so that successful forced feed- and-bleed avoids core damage. The core-damage sequences are 5 and 8, resulting from failure of reflux cooling, forced feed-and-bleed, and non-restoration of RHR. In addition, in sequence 5, offsite power is restored within 3.5 hours.

\subsubsection{L1 Event Tree for Window 4 of R6 (L1W4R6)}

This event tree, Figure 7.4-8, has a similar structure to the corresponding L1W3R6 event tree, except that now gravity feed is sufficient to cool the core for at least 24 hours, due to a lower decay power ( $5 \mathrm{MW})$; hence, its success avoids core damage within the $24 \mathrm{hr}$ mission time. The success criteria are further relaxed; offsite power recovery is credited within 4.6 hours after the initial event. Only one SG is needed for reflux cooling (and AFW is not needed for 10 hours, as only one SG is assumed available).

The description of the core damage sequences' is the same as that of L1W3D6, except that sequences involving success of gravity feed are no longer core damage (sequences 4 and 7 ).

\subsubsection{L1 Event Tree for Window 4 of R10 (L1W4R10)}

This event tree, Figure 7.4.1-9, has exactly the same structure as that of L1W4R6. The only differences are the frequency that the initiating event occurs and maintenance unavailabilities.

\subsubsection{L1 Event Tree for Window 4 of D6 (L1W4D)}

This event tree, Figure 7.4.1-10, is the same in structure, and the core damage sequences are the same as in window 3.

\subsubsection{Event Tree for Loss of Offsite Power with Only One Emergency Bus Available (L.2)}

The L2 event trees are shown in Figures 7.4-11 to 7.4-20. The event tree model for this initiator is similar to that of the L1 initiator. Basic events (such as HEPs) may be given different values due to availability of only one bus. Some fault trees are changed to account for availability of only one emergency bus, with a probability calculated for unavailability of $1 \mathrm{H}$ vs. $1 \mathrm{~J}$ bus in this event (see section 4.3.2), which will impact the availability of equipment powered from these buses. Also, the availability of $2 \mathrm{H}$ bus is calculated in case it is necessary to cross-connect the charging pump cooling systems.

Otherwise, the descriptions of event trees and sequences for L2 event trees is the same as those of the L1 event trees. 


\subsubsection{Event Tree for Loss of Offsite Power with-Only One-Emergency Bus-at Unit One and Station Black-out at Unit 2 (L3)}

The $\mathrm{L} 3$ event trees are not shown in Figures 7.4-21 to 7.4-30. The event tree model for this initiator is similar to that of the L1 initiator. Basic events (such as HEPs) may be given different values due to availability of only one bus. Some fault trees are changed to account for availability of only one emergency bus, with a probability calculated for unavailability of $1 \mathrm{H}$ vs. $1 \mathrm{~J}$ bus in this event (see section 4.3 .2 ), which will impact the availability of equipment powered from these buses.

Another consideration in the $\mathrm{L} 3$ event tree (blackout on Unit 2)-is the availability of service water and its impact on frontline systems. The Intake Canal drains quickly (30-60 min) unless the condenser valves are closed. This is because the main circulating water (CW) pumps run on normal power, and the emergency service water pumps are badly mismatched to the outflow through the condenser inlet lines. Also, the outlet isolation valves automatically close to the $25 \%$ open ( $75 \%$ closed) position on receipt of a blackout signal. However, this is not perceived to have much effect on the flow through the valves (it may make them easier to close) due to their construction. Also, there is a certain chance that the shutdown Unit will not have water running through its condensers due to maintenance. The vacuum priming system may be off, which will slowdown the outflow from the Canal. These considerations will not have much effect on the conclusion that powered closure of these valves is the only option, because the manual closure will take too much time.

Table 7.4-2 shows the power sources of these valves. Those marked "106" and " 206 " are the condenser inlet valves for Unit 1 and Unit 2, respectively, whereas the valves marked " 100 " and "200" are the condenser outlet valves for the two_Units. If power is available to-the-1J-bus,-all-8-condenser-lines can be successfully-isolated through a combination-of-inlet-and outlet valves.-If-power-is-available-to-the $2 \mathrm{I}$ - bus, there-are provisions (hardware and procedure) for tying the $2 \mathrm{~J}$ bus to the MCC $1 \mathrm{~J} 1-1 \mathrm{~A}$, so that the Canal can again be isolated from the condensers. If either $1 \mathrm{H}$ or $2 \mathrm{H}$ (but not both) buses have power, then only 4 out of 8 lines can be isolated, and the-buses-must-be-cross-tied to close the remaining lines-(the procedures are in place for this action).

In the model for initiating events $\mathrm{L} 3$ and $\mathrm{B} 1$, a high-level HEP event is used to model failure of the operator to isolate the Canal.

If offsite power is recovered ('N' event successful), the model assumes service water is recovered, as the CW valves are assumed closed by the operators once the power is available. Otherwise, the descriptions of event trees and sequences for $\mathrm{L} 3$ event trees are the same as those of the $\mathrm{L} 1$ event trees.

\subsection{4-Event-Trees for Station-Blackout at-Unit 1-(B1)}

Event trees were constructed to analyze the accident sequences during mid-loop operation where Unit 1 has no $A C$ power, but Unit 2 has one operable $D G$, that could be EDG2, supplying power to the $2 \mathrm{H}$ bus, or EDG3, supplying power to the $2 \mathrm{~J}$ bus. As shown on Figures 7.4-31 to 7.4-40, these event trees are B1W1R6, B1W1D6, B1W2R6, B1W2D6, B1W3R6, B1W3R10, B1W3D6, B1W4R6, B1W4R10, and B1W4D6 which represent the response to the initiating event at the mid-loop POSs of the two outage types. During SBOs, loss of instrument air causes the main steam-trip valves (MSTVs) to fail closed, the SG PORVs to fail closed, while AFW flow distribution to the SGs is lost. A critical event in timing for SBO evaluations is the depletion 
of the vital batteries causes the loss of instrumentation or control power throughout the plant. The batteries at the Surry plant are designed for a two-hour load discharge; however, depletion time could be extended by shedding non-essential loads. An assumption of four hours to the expected battery depletion was considered in the SBO sequences in the event tree models that are discussed next.

Important considerations during an SBO event are the preservation of the RCS inventory, the removal of decay heat by the supply of feedwater to the steam generators, and the extension of battery life. In the Unit 1 SBO scenarios, cross-connecting the Unit 2 charging pump to provide HPI flow for RCS makeup is a reliable, alternative source of fluid inventory to the primary system. We note that the charging pumps depend on the Charging Pump Cooling (CPC) system to provide cooling to the charging pump's seal coolers (via the charging pump cooling water system) and the lube-oil coolers (via the charging pump service water system). Seal cooling is not required as long as the pumped fluid is below $115^{\circ} \mathrm{F}$ (the RWST water is kept at $45^{\circ} \mathrm{F}$, except right after refueling, i.e. possibly in POS 10 ${ }^{[2]}$. Therefore, the CPC system would be needed only in recirculation mode, and only if the recirculation sprays are not working (only windows 1 and 2 would be affected). If needed, the ultimate heat sink for this system would be the service water. The lubricating oil to charging pump bearings also is cooled by service water via lube-oil coolers of the CPC system. Therefore, sufficient service water is necessary for the continued operation of charging pumps in either unit of the Surry station.

The service water lines tap off the 96-inch circulating water inlet pipes upstream of the inlet isolation valves of the main condenser. Circulating water or service water inventory is gravity-fed from the Intake Canal, which depends on the difference in pressure head between the Intake Canal and the Discharge Tunnel. The Intake Canal inventory, which is commonly shared by both units of the Surry nuclear station, is provided by the motor-driven Circulating Water Pumps (CWPs), which draw suction from the James River. When offsite AC power supply is lost, the CWPs become unavailable. Then, if the main condenser is not isolated, the outflow of circulating water through the condenser will be much greater than the makeup provided by the diesel-driven emergency service water pumps. The canal may be drained before the offsite AC power needed to operate CWPs is restored, depending on the number of condensers that are not isolated. The inlet and outlet isolation MOVs of the condensers are powered by the $4 \mathrm{kv}$ emergency $\mathrm{AC}$ buses. As described in Section 6.2.14.2.2, the distribution of power supply for these MOVs ensures that at least one isolation MOV in each of the eight CW lines can be closed to conserve Intake Canal level if the offsite AC power supply is lost.

If there is a station blackout at both units, there will be no electrical power to operate the CW isolation MOVs. Assuming that all eight $\mathrm{CW}$ lines are filled with running water when both units are at full power, it is conservatively estimated that the canal would drain in about $\mathbf{3 0}$ minutes to an hour. This estimate is conservative because credit can be taken for operational constraints on the plants configuration during shutdown conditions. For example, if Unit 1 is in a refueling outage, part or all of the four tube bundles of the main condenser may be under eddy-current testing. Then, the associated inlet and outlet $\mathrm{CW}$ lines are required to be isolated. Also, when a unit is in cold shutdown, the Discharge Tunnel is open to the atmosphere via the vacuum breaker vents. This configuration would reduce the gravity flow through unisolated $\mathrm{CW}$ lines, and thus, somewhat increase the time to canal drainage.

In previous PRA studies (e.g., NUREG-1150 ${ }^{[1]}$ ), manual isolation of the condenser isolation valves by the operator was identified as a viable means to maintain sufficient inventory in the Intake Canal in the event of loss of offsite AC power or station blackout at one unit. However, from discussions with Virginia Power 


\section{Event Tree Analysis}

personnel, we estimated that it would take two operators about 30 minutes to close the handwheel of any one of the 96-inch butterfly-type isolation valves. We concluded that manual isolation of the condensers to conserve Intake Canal inventory during SBO is not achievable. Thus, remote isolation of condenser inlet and outlet valves by electrical means is considered in the SBO event trees. In the case of SBO at Unit 1, there is at least one operable EDG at Unit 2. If the $2 \mathrm{~J}$ bus is energized, either the inlet or outlet MOV in each of the eight $\mathrm{CW}$ lines is powered by the $2 \mathrm{~J}$ bus and can be closed electrically (this is possible because the $2 \mathrm{~J}$ bus can be cross-tied to the MCC $1 \mathrm{~J} 1-1 \mathrm{~A}$, normally connected to the $1 \mathrm{~J}$ bus on Unit 1; this MCC powers a sufficient combination of inlet and outlet CW MOVs to successfully isolate the Canal from the condensers). If only the $2 \mathrm{H}$ bus is energized and $2 \mathrm{~J}$ bus is not, then local cross-tying of the $2 \mathrm{H}$ and $2 \mathrm{~J}$ buses is required to establish power supply to the Unit $1 \mathrm{CW}$ MOVs. The conservative assumption is that $2 \mathrm{~J}$ bus is not energized during a Unit 1 station blackout.

When SBO occurs at Unit 1 during mid-loop conditions, the RHR pumps are tripped and the capability to remove decay heat is lost. If the RCS is vented, RCS makeup from Unit 2 charging system, or gravity feed from RWST inventory can be used to maintain RCS water level upon loss of RHR capability. If the SGs are in wet layup conditions, the SG inventory is a heat sink that helps to mitigate any heatup of the primary system unless the RCS loops are isolated for maintenance.

\subsubsection{B1 Event Tree for Window 1 of R6 (B1W1RG)}

The B1 event tree for window 1 of $\mathrm{R} 6$ is shown in Figure 7.4-31. The top events of the event tree are described below:

\section{IB1W1 - SBO Initiator}

This event represents the SBO occurrence, B1 at Unit 1, where no emergency AC power supply is available to its vital safety equipment. EDG 1 fails to start or continue to operate after start; however, one operable DG at Unit 2 could provide AC power to cross-connectable systems, such as the charging and AFW systems.

\section{VB1W1 - RCS Initially Vented}

This top event represents the RCS-vented conditions, such as when the pressurizer safety relief valves are removed.

NB1W1 - Non-recovery of AC Power

This event represents the failure to restore $\mathrm{AC}$ power within the allowable time for mitigating actions. If the power is restored, the event tree transfers to the R5 event tree. Then, event " $\mathrm{R}^{\prime \prime}$ in that event tree (restoration of RHR) is set to "T", as the RHR pumps are assumed to be vapor-bound and not recoverable.

\section{SB1W1 - Steam Generator Feed-and-Bleed}

This top event represents the use of reflux cooling to adequately remove heat when the RCS loops are not isolated, and the secondary side of the SGs are in the wet layup condition. It is assumed failed in the logic model, and venting the SGs and cross-connecting the AFW are treated as recovery actions.

\section{CHGW1 - Cross-connection of Unit 2 Charging System}

This event represents the cross-tie of the operable Unit 2 charging pump to provide RCS makeup to the primary system for feed-and-bleed operation to maintain RCS cooldown and depressurization. The unavailability of $\mathrm{AC}$ power results in the need to balance charging flow at both units by manually throttling the valves. As discussed in section 7.2, the inventory of RWST is not sufficient to provide 24 hours of feed- 
and-spill operation. Therefore, the success of this top event still leads to core damage. However, it provides more time for recovery actions such as recovery of offsite power and reflux cooling.

\section{GB1W1 - Gravity Feed from RWST}

This event represents gravity feed of RWST through the low-head injection flowpath to the RCS when the RCS is vented. In POS 6 of the refueling outage, this mode of decay heat removal cannot effectively remove decay heat within 24 hours. However, it provides an additional time beyond 4 hours to allow the operators to establish alternate ways to remove decay heat.

\section{Sequence Description of B1W1R6 Event Tree}

Sequence 1 characterizes the initial conditions in POS 6 of a refueling outage before the SBO initiator, B1, occurs, where no AC power supply is available to either $4 \mathrm{kV}$ emergency buses $1 \mathrm{H}$ or $1 \mathrm{~J}$. However, there is one operable DG at Unit 2 to provide $A C$ power to its vital equipment. The availability of $A C$ power supply at Unit 2 allows the operators to attempt to cross-tie vital equipment for various recovery actions. Sequences 2 through 5 delineate the sequences when the RCS is vented. Sequence 2 represents successful recovery of offsite AC power before core uncovery and transfers to the R5W1R6 (recoverable loss of RHR) event tree for further evaluation. In sequence 3, RCS makeup from Unit 2 charging system is sufficient in the near term to maintain RCS cooldown when RHR capability is lost in a SBO. However, the core is damaged due to the unavailability of long-term cooling via recirculation systems. Sequence 4 represents the unavailability of RCS makeup from the Unit 2 charging system; however, gravity feed from the RWST will delay core damage so recovery actions can be considered. Sequence 5 represents unavailability of RCS makeup from either sources, forced flow from Unit 2 charging system or gravity feed from the RWST inventory. Core damage results from RCS boiloff.

Sequences 6 through 8 delineate outcomes when RCS is not vented. Sequence 6 represents the successful restoration of offsite AC power supply and is transferred to the R5W1R6 (recoverable loss of RHR) event tree for further evaluation. Sequence 7 is a logically impossible sequence, because reflux cooling is not taken credit for in the logic model and is modeled as a recovery action. In sequence 8, forced flow from the Unit 2 charging system provides RCS makeup to prevent heatup of the primary system and subsequent core damage in the near term. In sequence 9, the unavailability of RCS makeup from the Unit 2 charging system results in RCS boiloff and subsequently, the core is damaged.

\subsubsection{B1 Event Tree for Window 1 of D6 (B1W1D6)}

The B1 event tree for window 1 of D6 is shown in Figure 7.4-32. The top events of this event tree have the same definition as those of the event tree for R6. The 2 event trees differ in their structure due to the facts that the safety valves on the pressurizer are not removed in D6, and in window 1 , the success criterion for reflux cooling cannot be satisfied in D6.

\section{Sequence Description of B1W1D6 Event Tree}

Sequence 1 characterizes the initial conditions in POS 6 of the drained maintenance outage. Sequence 2 represents the recovery of AC power supply and transfers to the R5W1D6 (recoverable loss of RHR) event tree for further evaluation. In sequence $3, \mathrm{RCS}$ makeup from the Unit 2 charging system is sufficient to maintain RCS cooldown and depressurization. In the near term, however, core damage results due to unavailability of recirculation systems on Unit 1 . Sequence 4 represents the unavailability of RCS makeup 


\section{Event Tree Analysis}

from the Unit 2 charging system to the primary system, and this results in RCS boiloff and the ensuing core damage.

\subsubsection{B1 Event Trees in Other Windows}

The differencesbetween sequences and event tree structure in other windows are similar to the considerations described in Section 7.4.1, for L1 event trees.

\subsubsection{Event Trees for Station Blackout at Both Units (B2)}

Station blackout at both units occurs when all three diesel generators are unavailable upon loss of offsite power. Due to the unavailability of AC power supply at Unit 2, the charging pump flow to provide RCS makeup to the Unit 1 primary system is not available. Therefore, the event tree models for dual unit SBO event, B2, differ from the single unit SBO event trees only in that the availability of charging flow from Unit 2 is not considered.

As shown in Figures 7.4-41 to 7.4-50, the event tree models developed for the dual unit SBO event are the B2W1R6, B2W1D6, B2W2R6, B2W2D6, B2W3R6, B2W3R10, B2W3D6, B2W4R6, B2W4R10, and B2W4D6 event trees which represent the response to the initiating event, B2, at the mid-loop POSs. The definitions of top events for these event trees are similar to the single unit SBO event, B1; therefore, the descriptions are analogous. The accident sequences identified for the $\mathrm{B} 2$ event are also analogous to those identified for the B1 event, without considering the availability of RCS makeup from the Unit 2 charging system.

\subsubsection{References:}

1. Bertucio, R.C. and Julius, J.A. "Analysis of Core Damage Frequency: Surry, Unit 1, Internal Events", April, 1990, NUREG/CR-4550.

2. Virginia Power Company, "10CFR50 Appendix R Report, Surry Power Station - Units 1 and $2^{\text {n }}$, Chapter 10, Volume IV. 


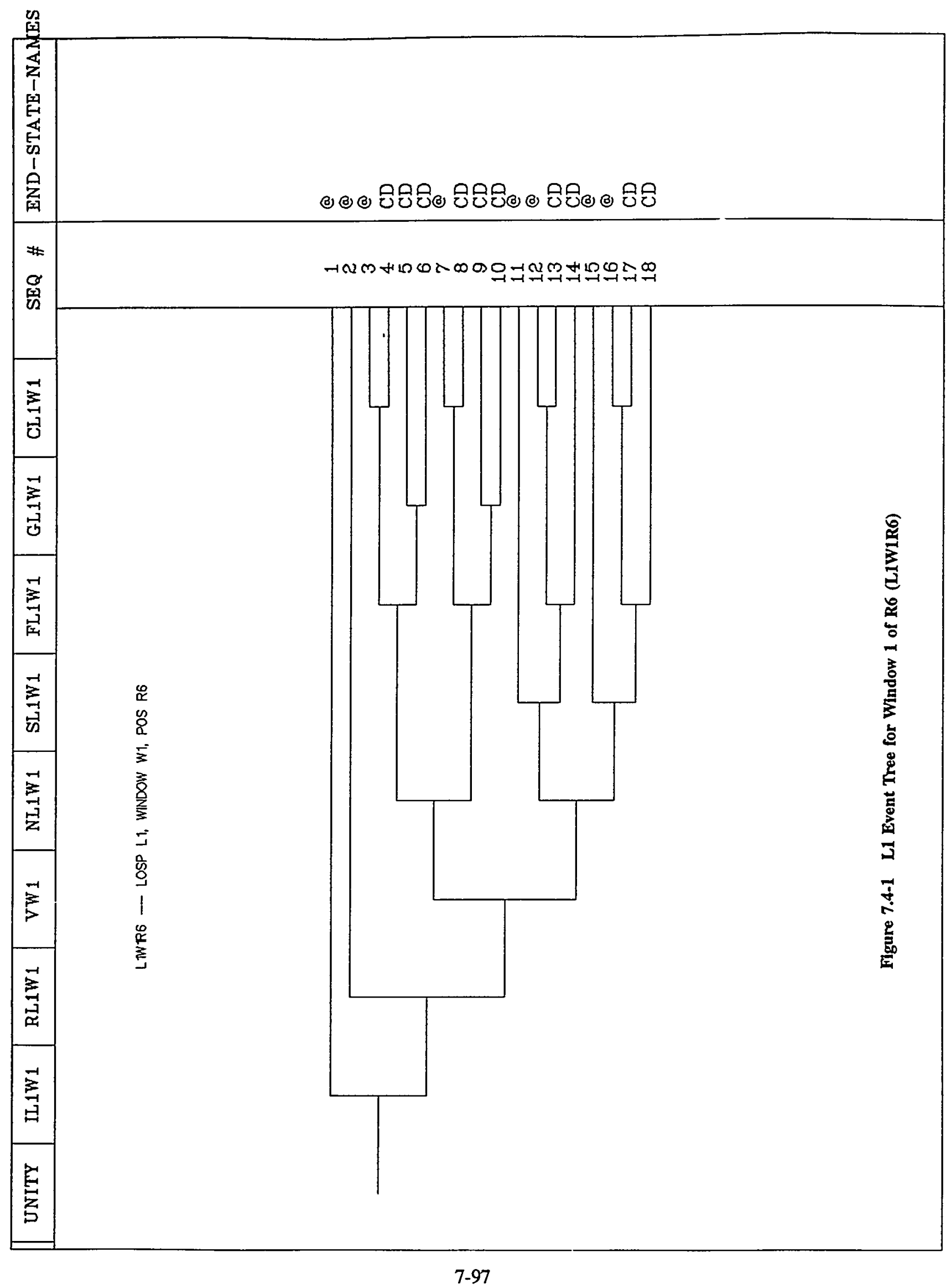




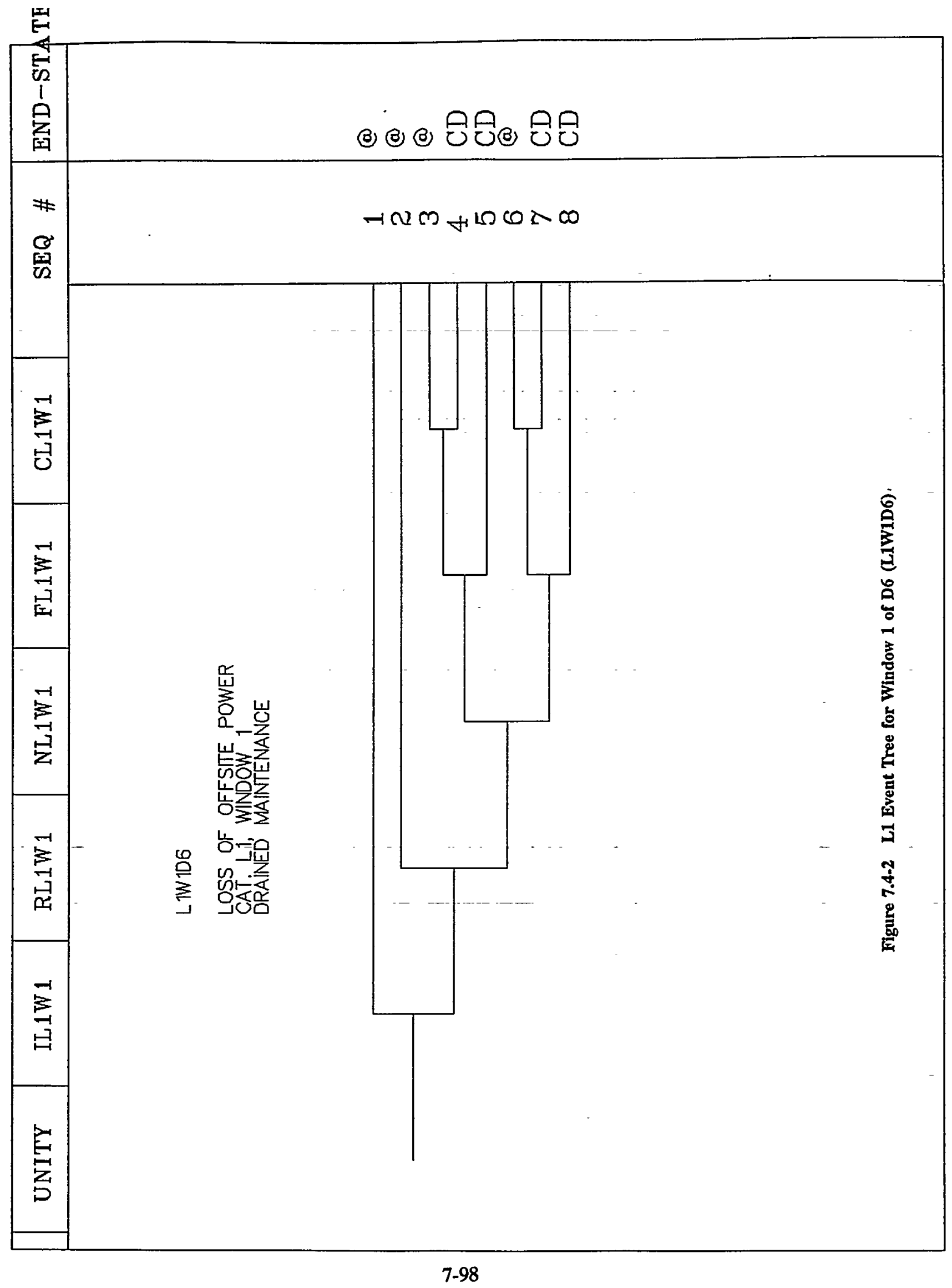




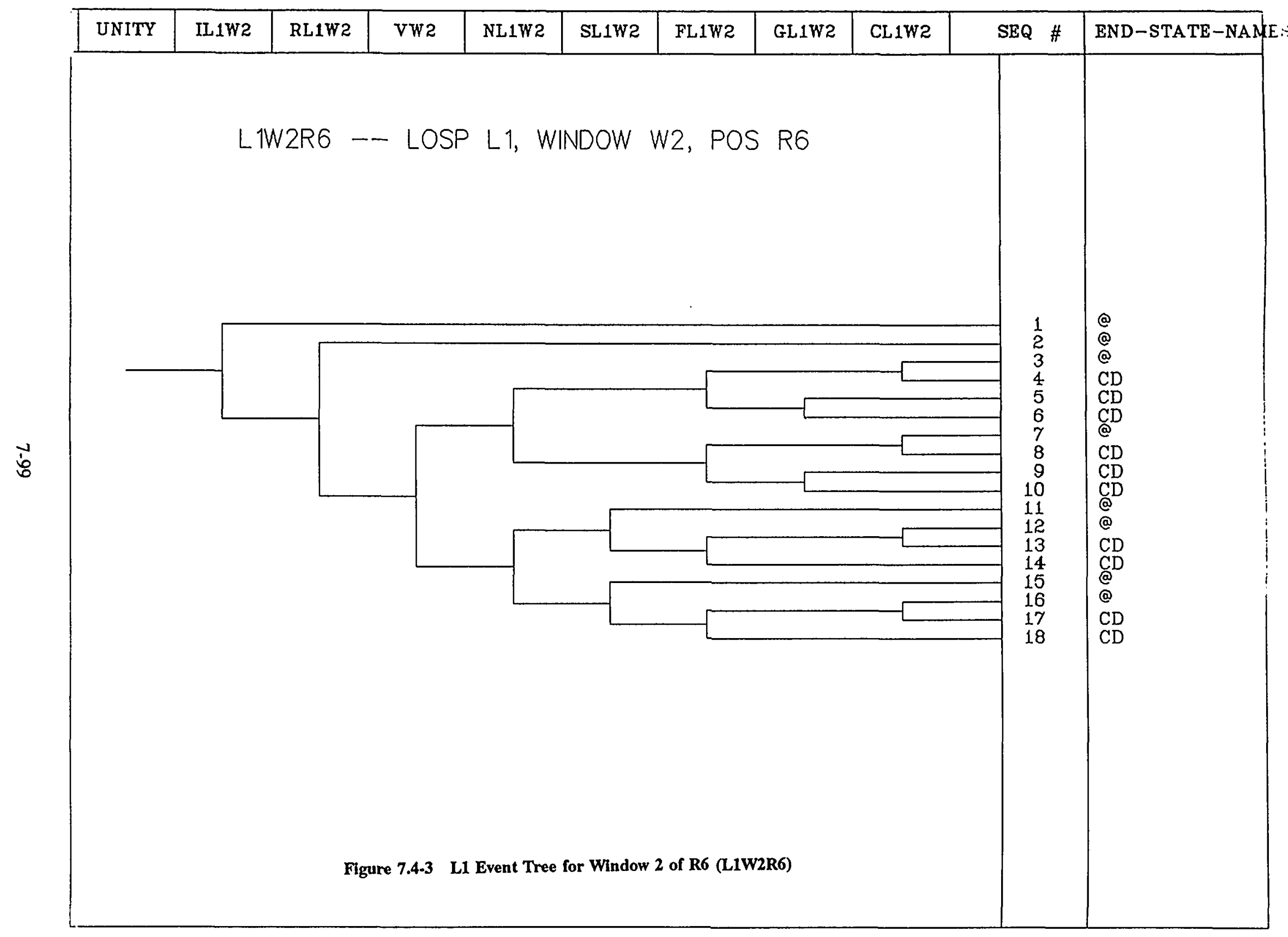




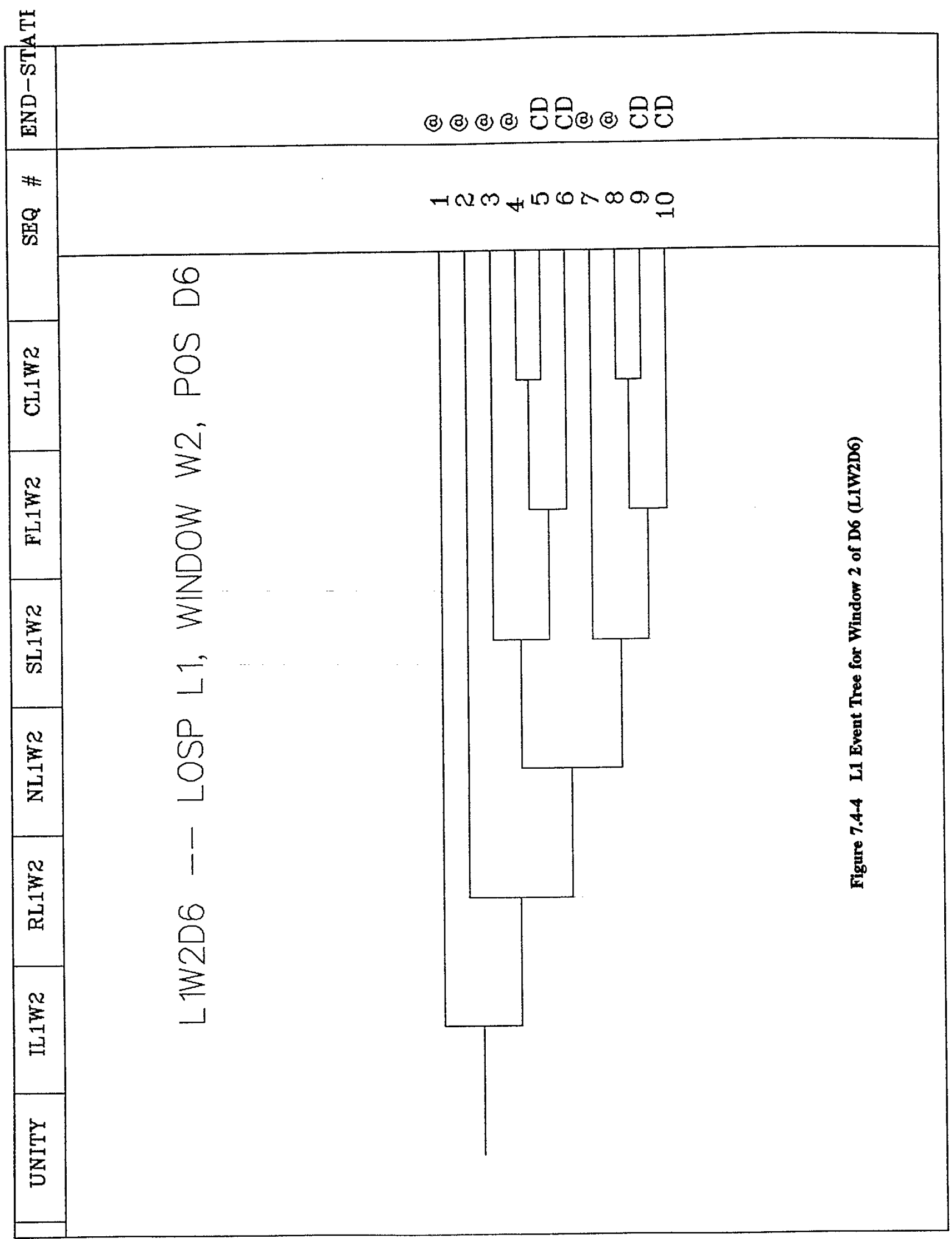




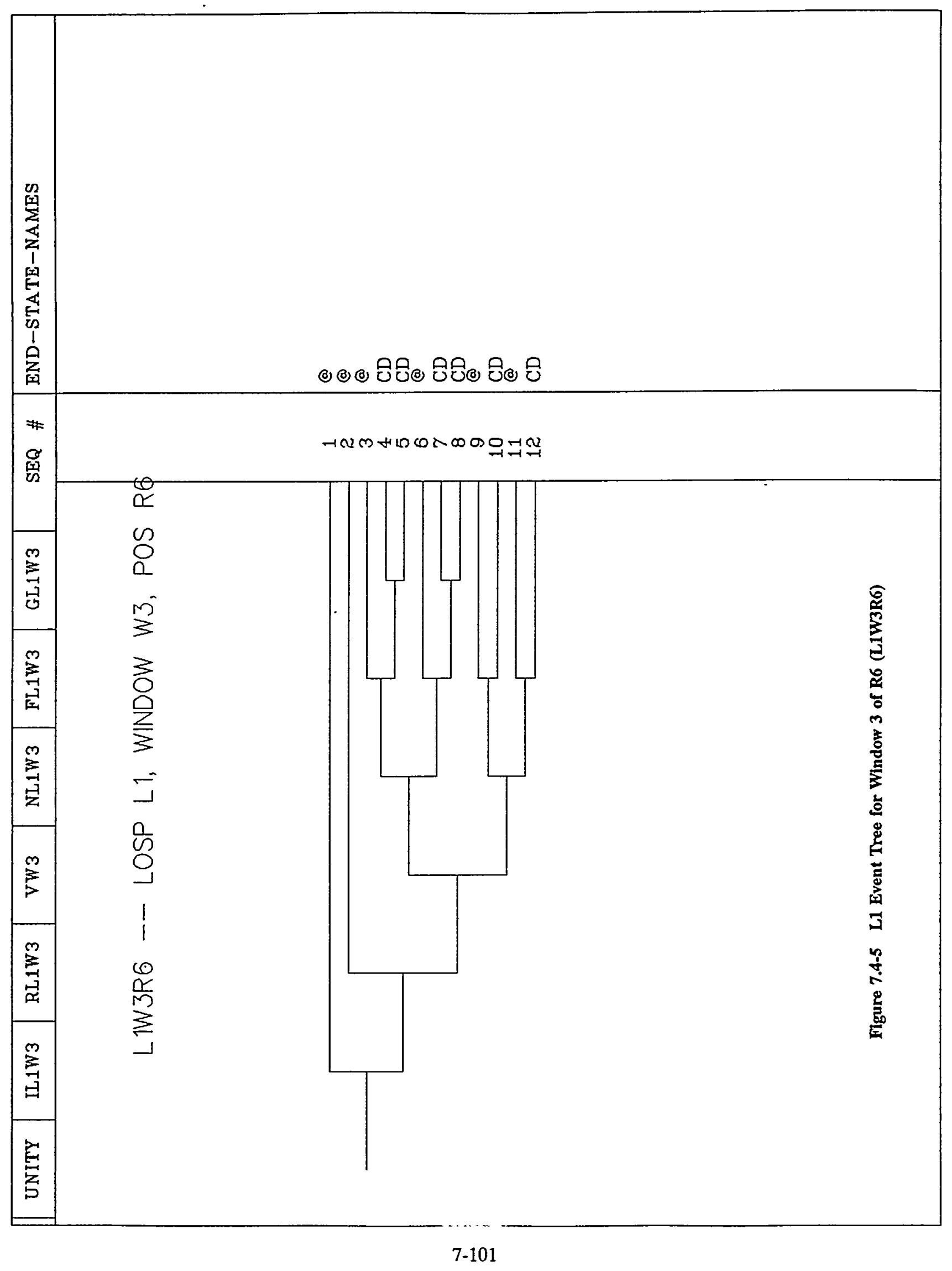




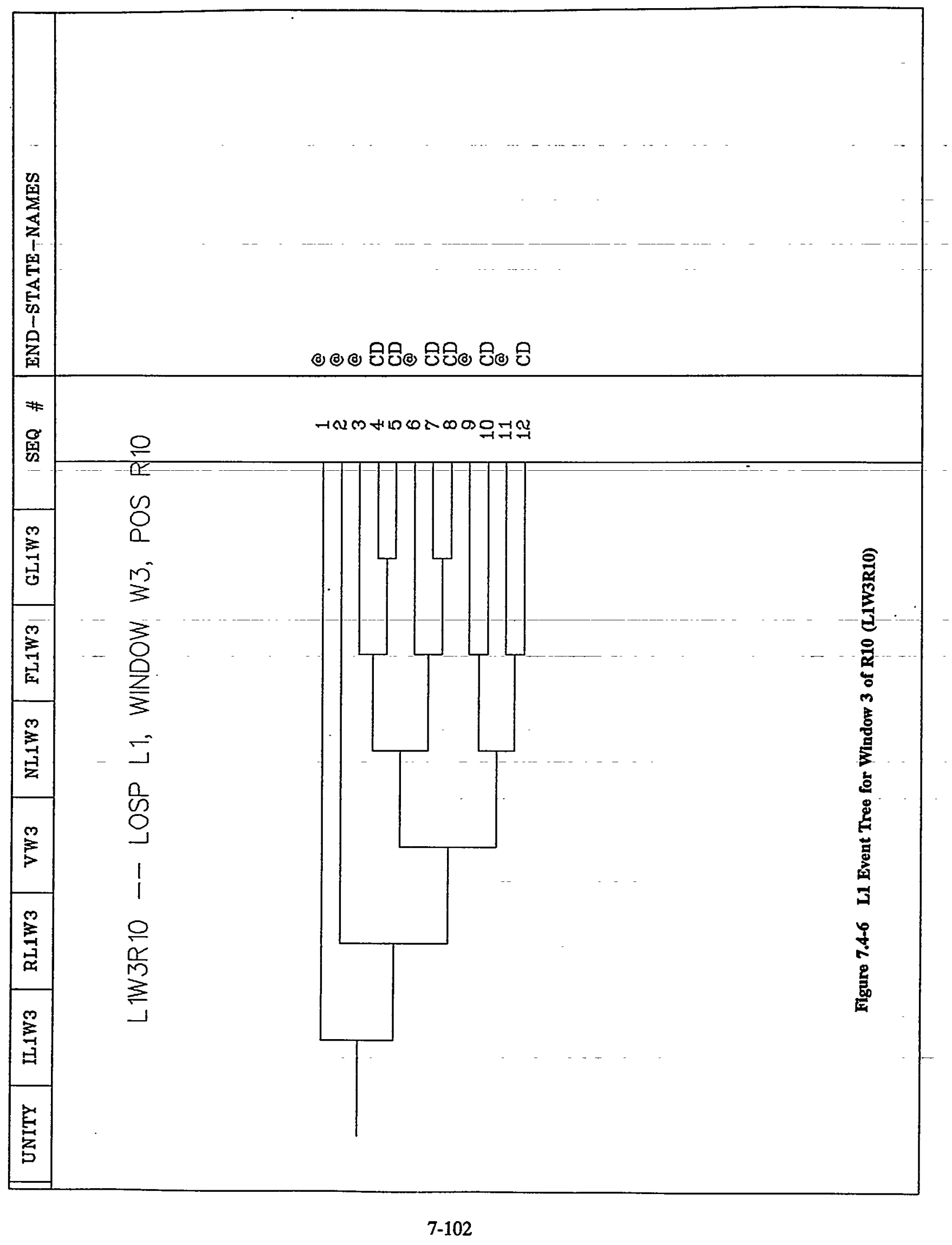




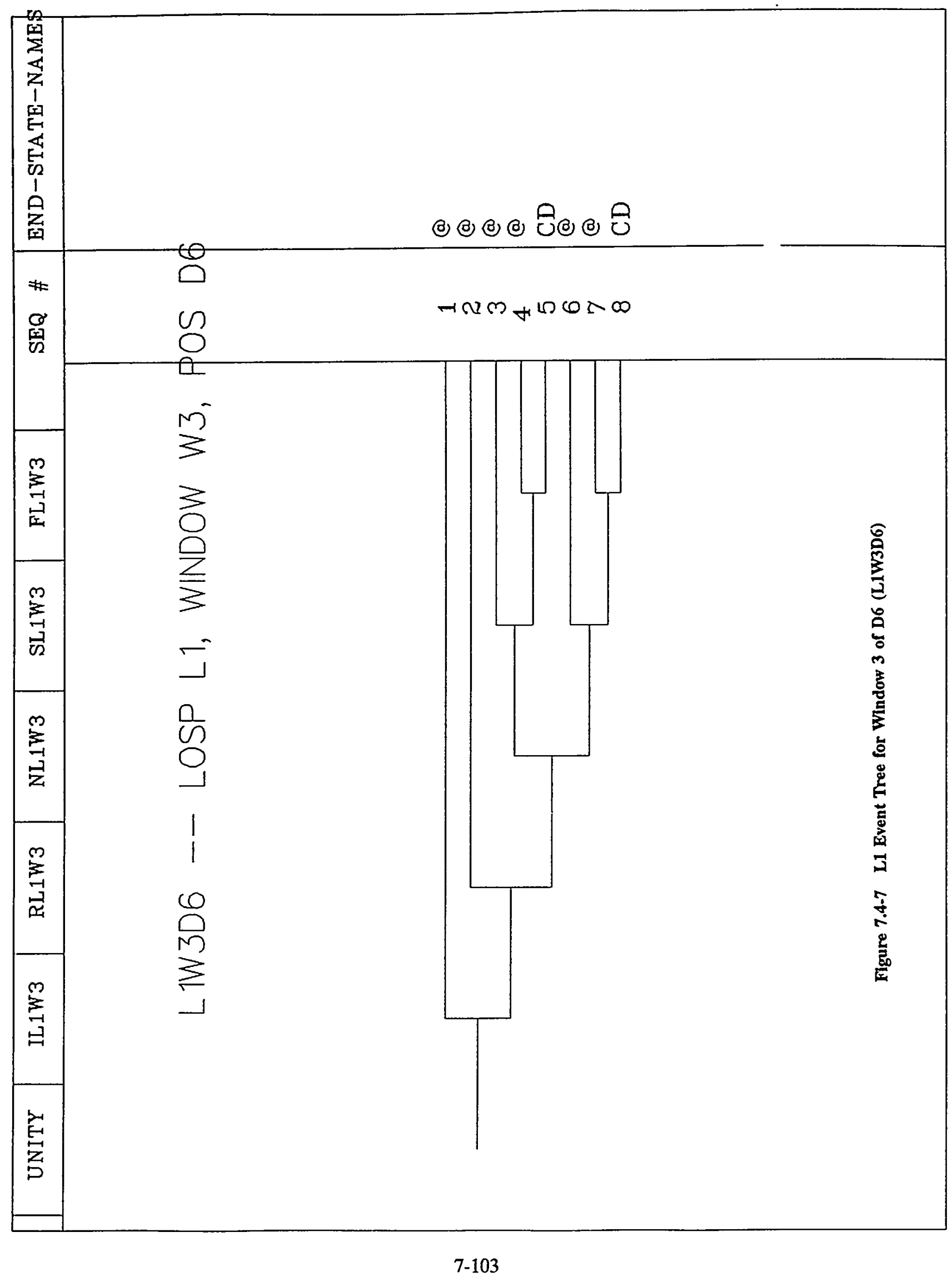




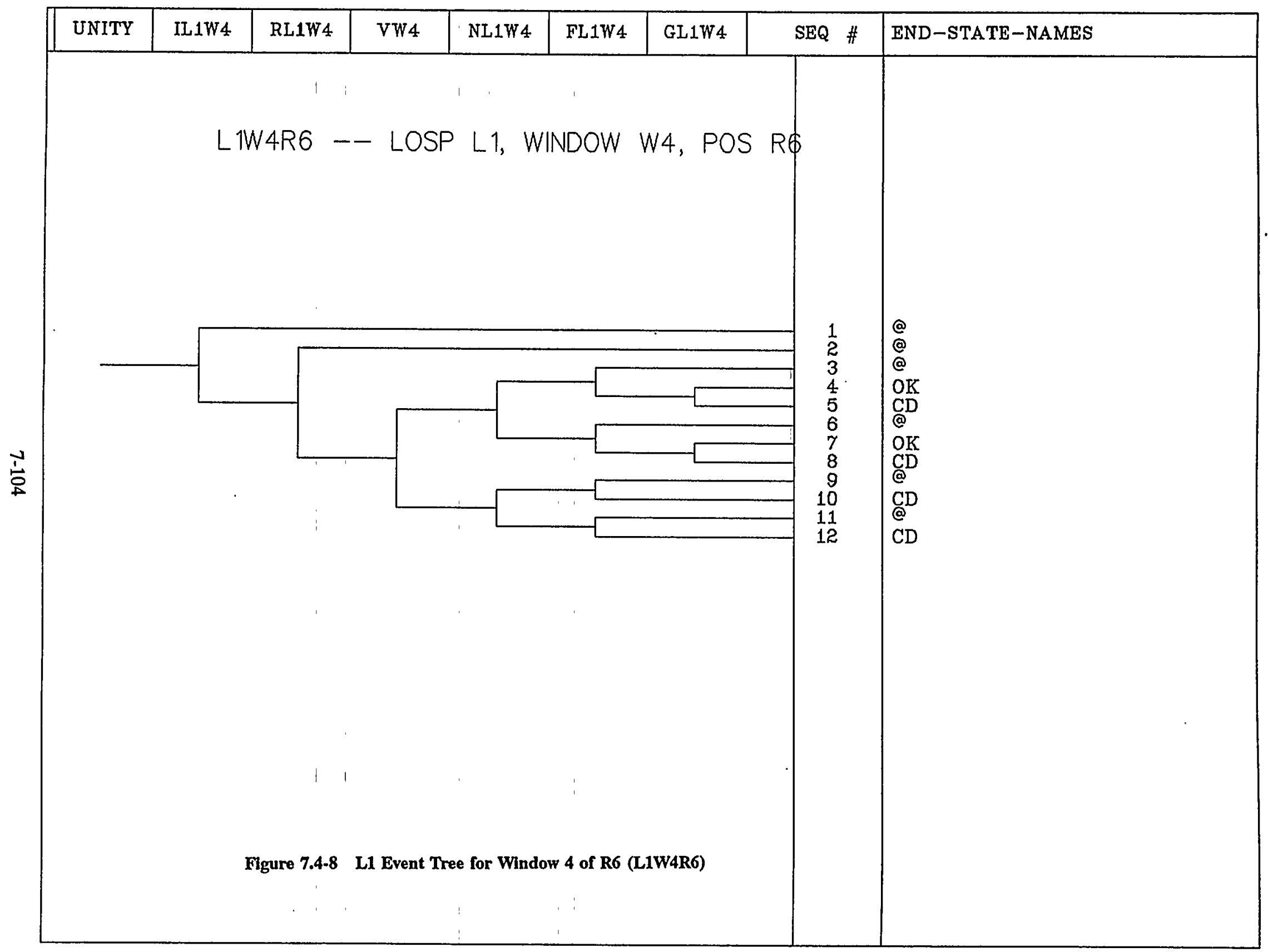




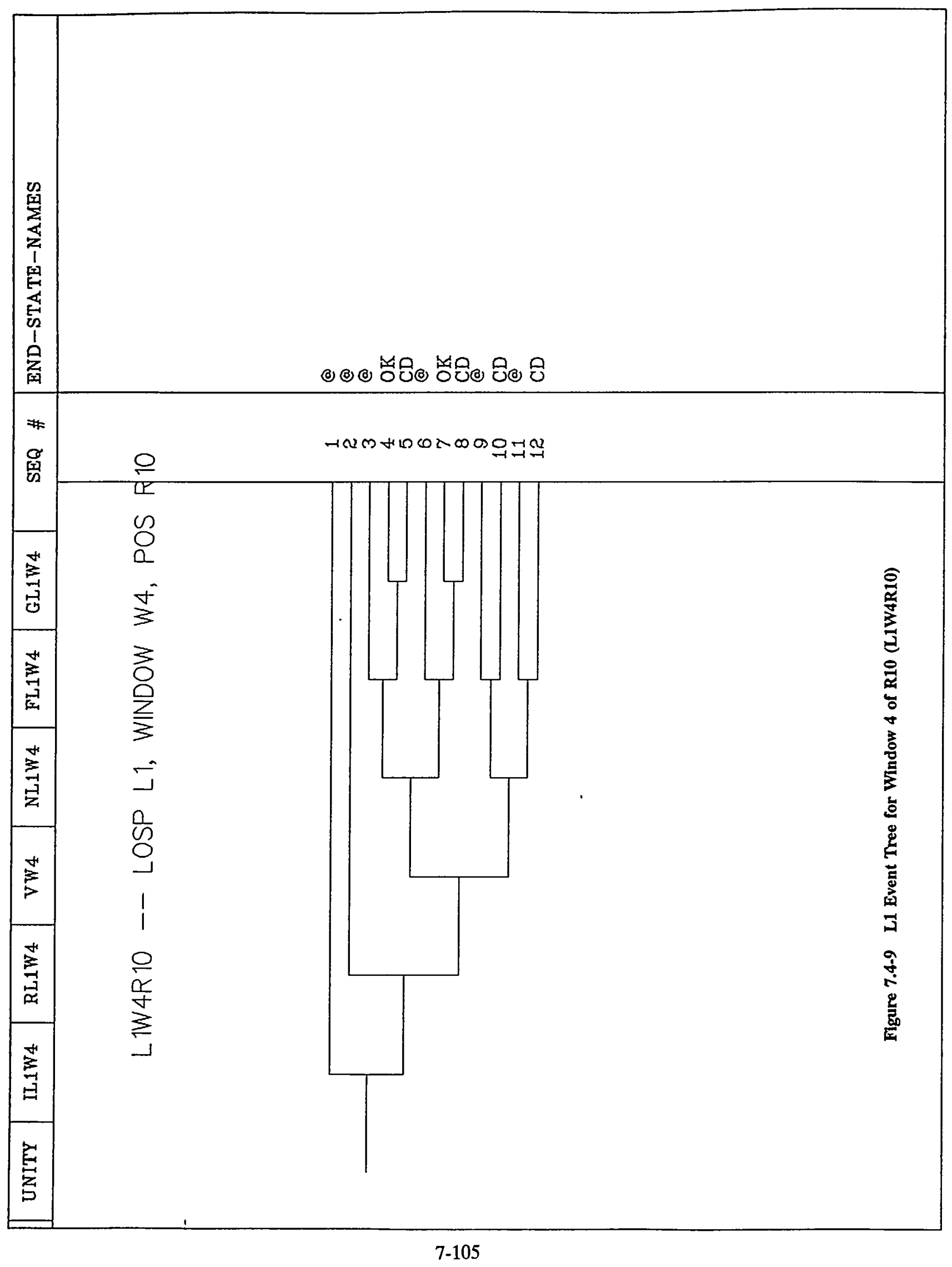




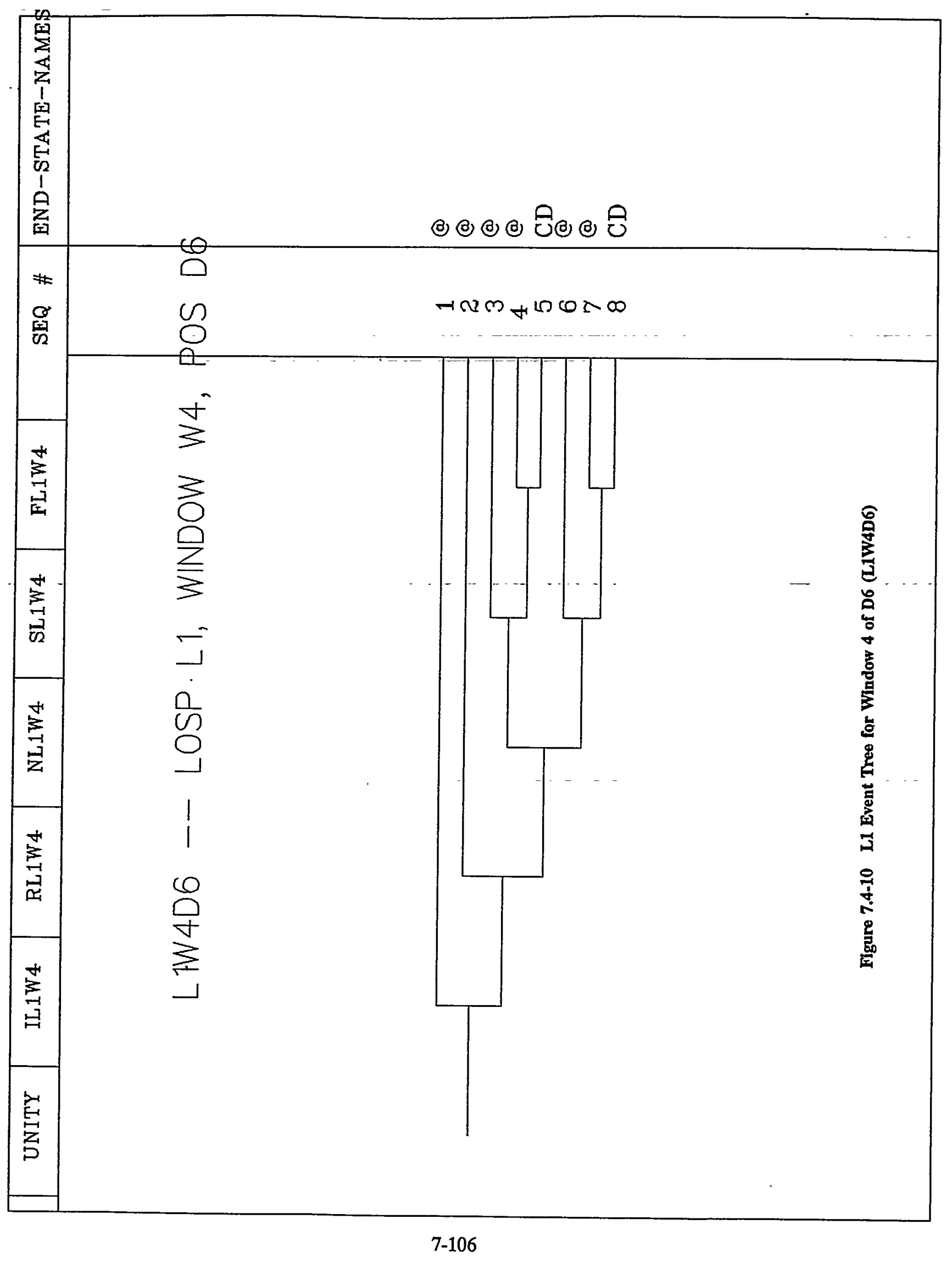




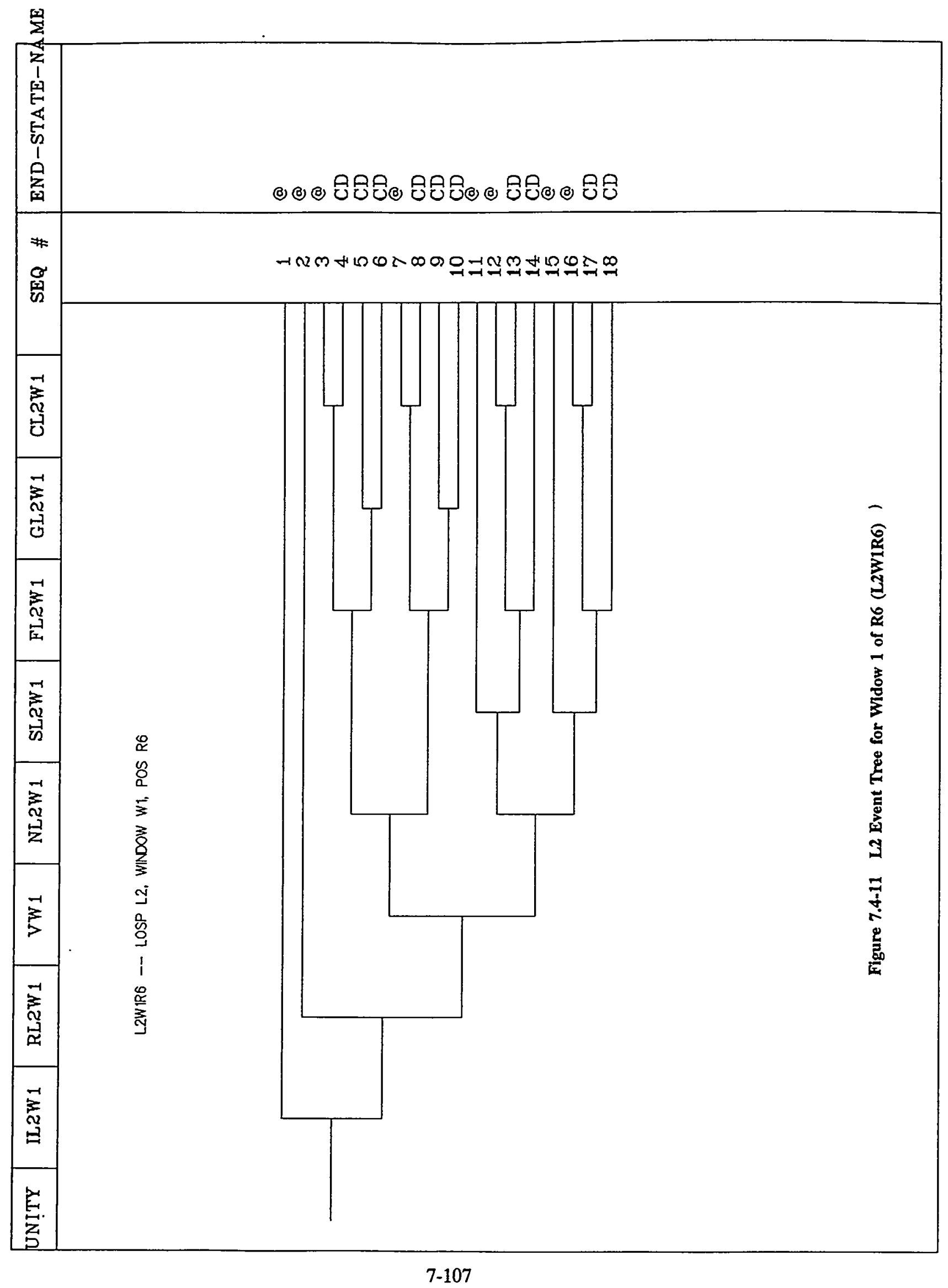




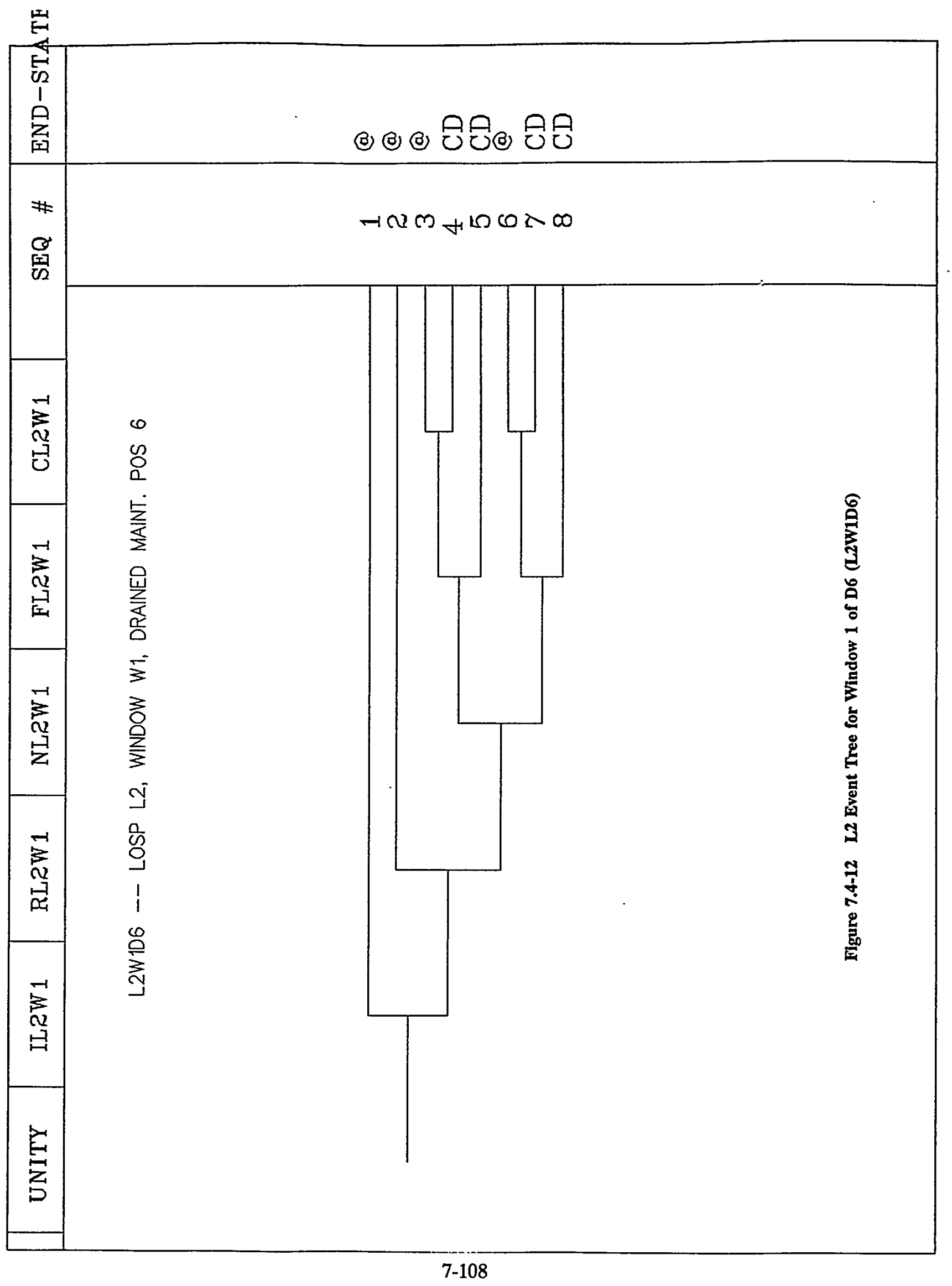




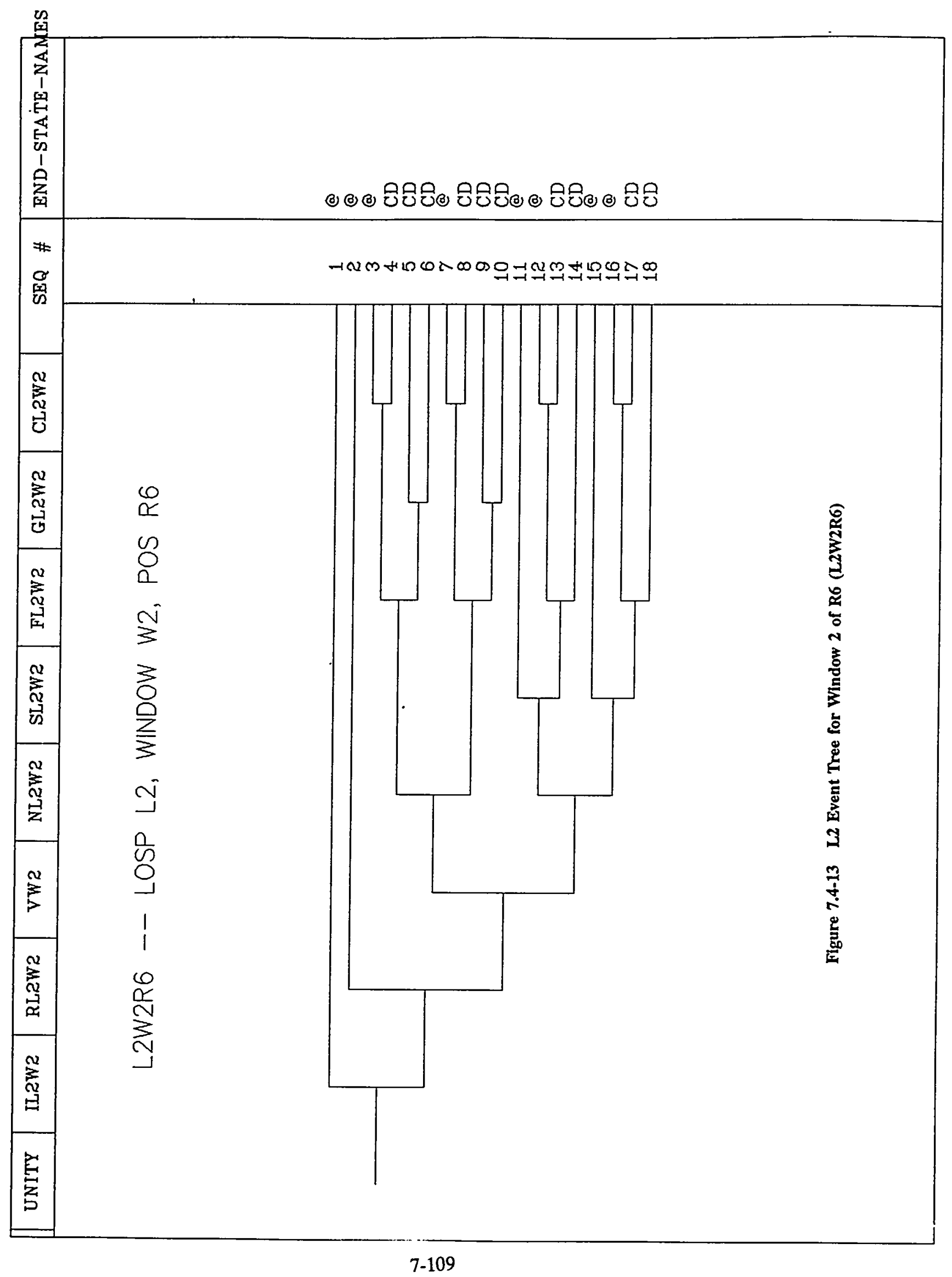




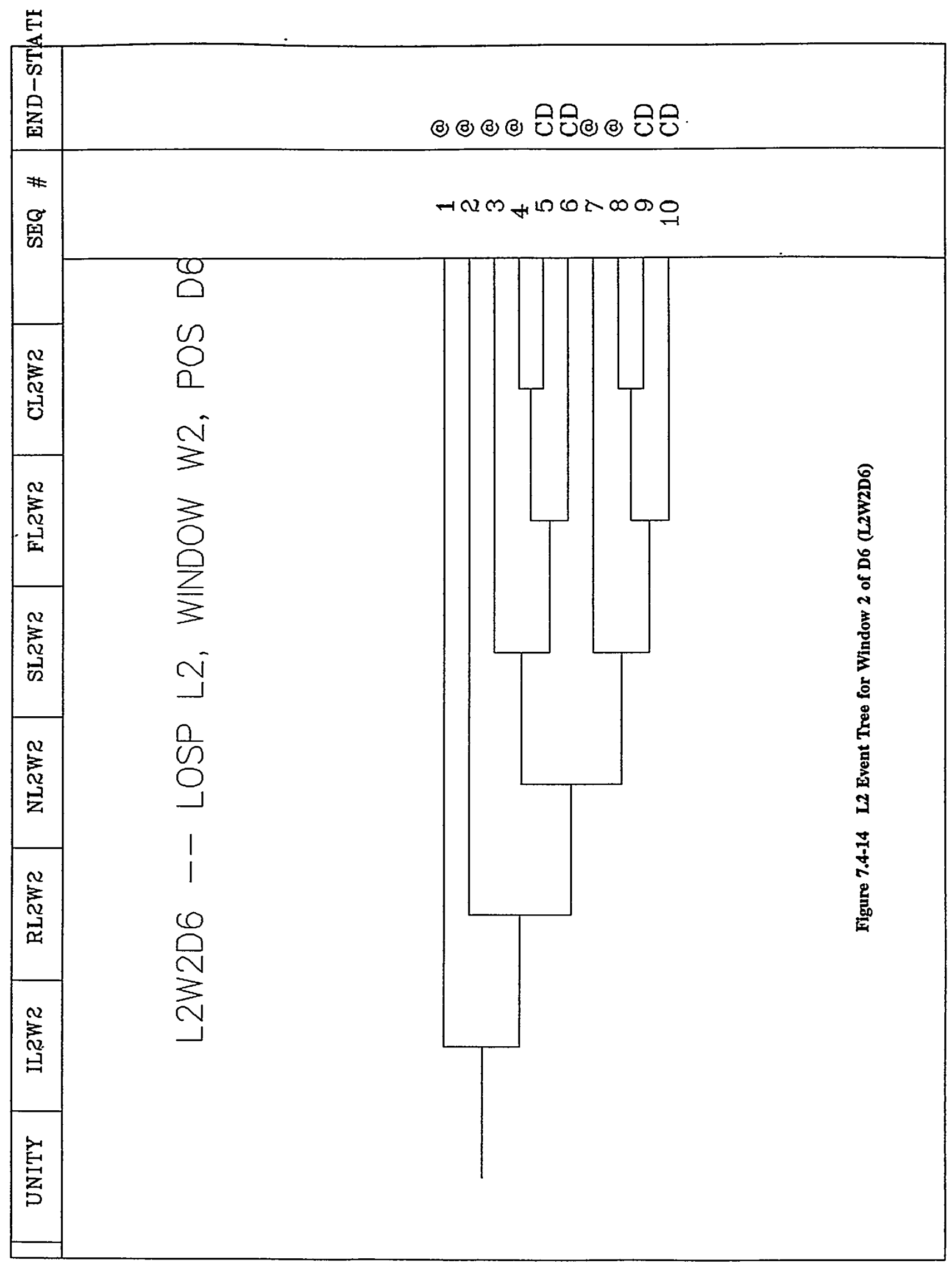




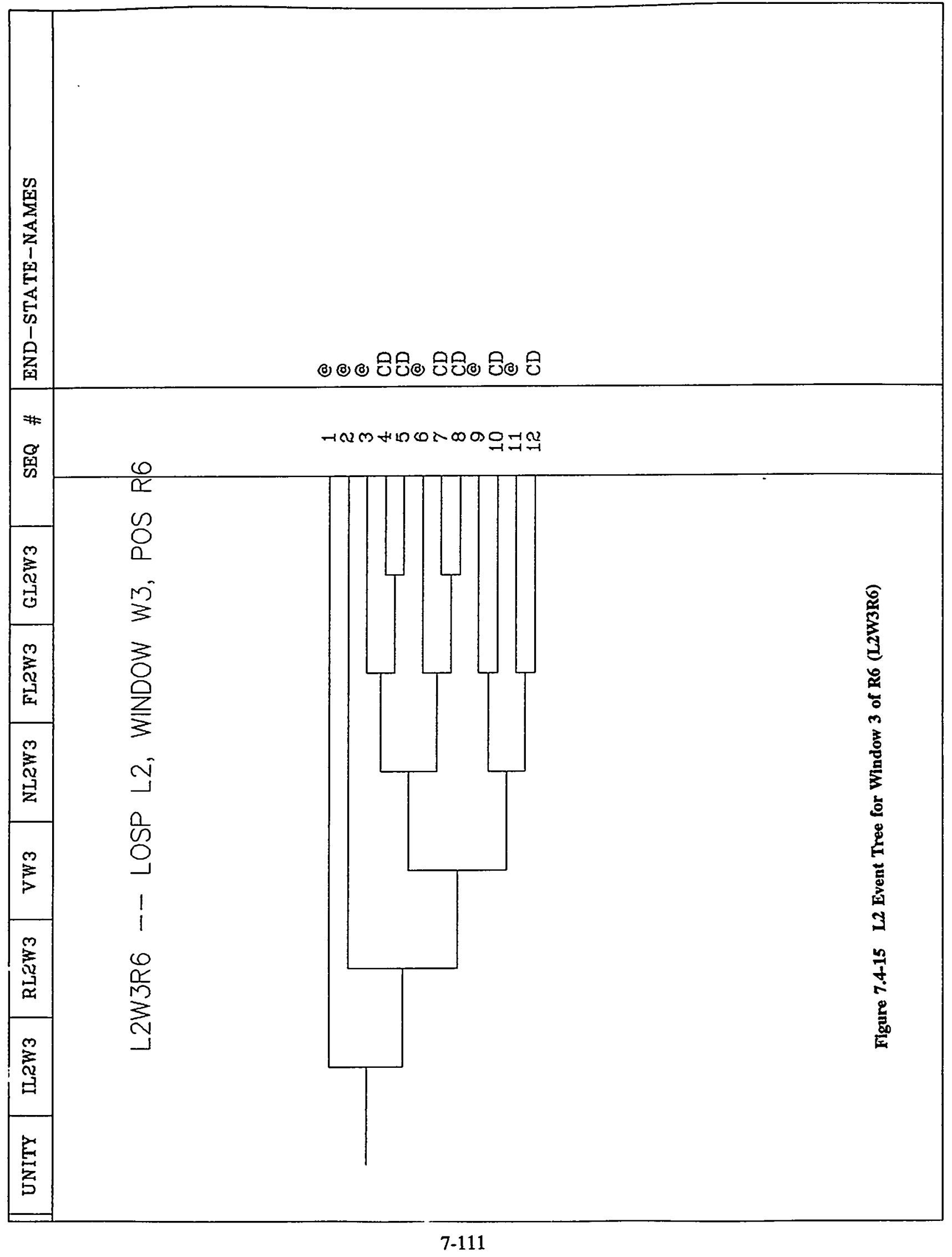




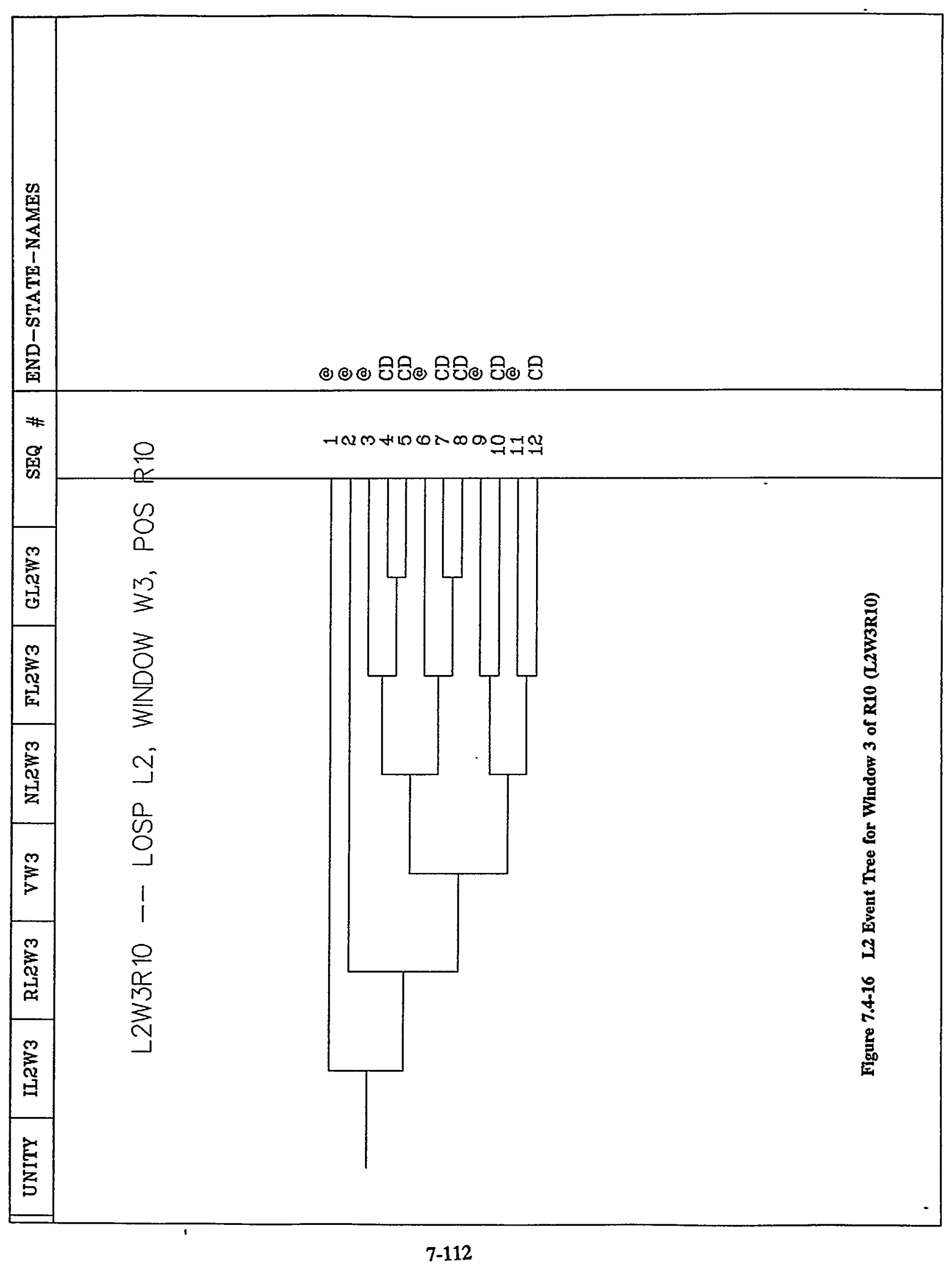




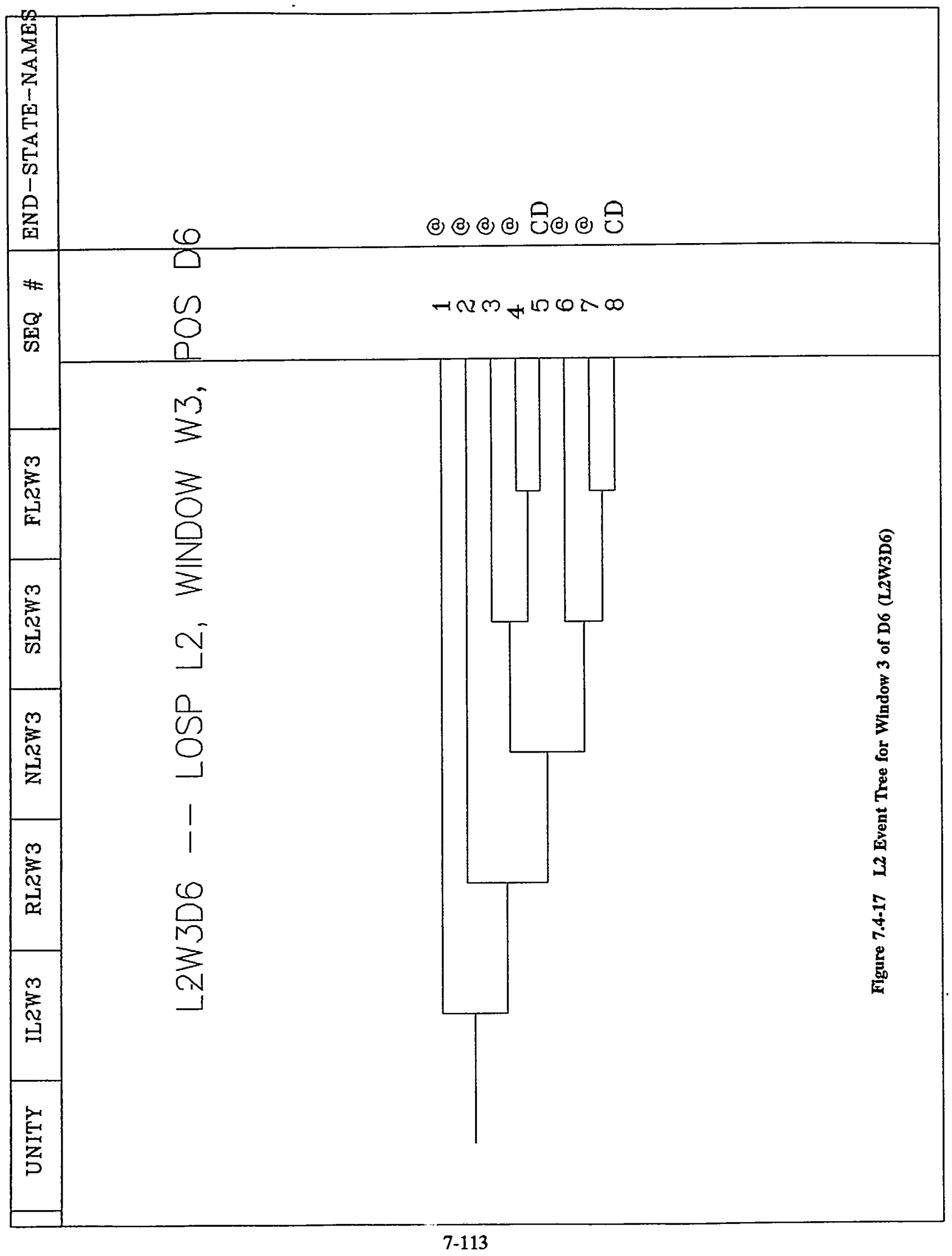




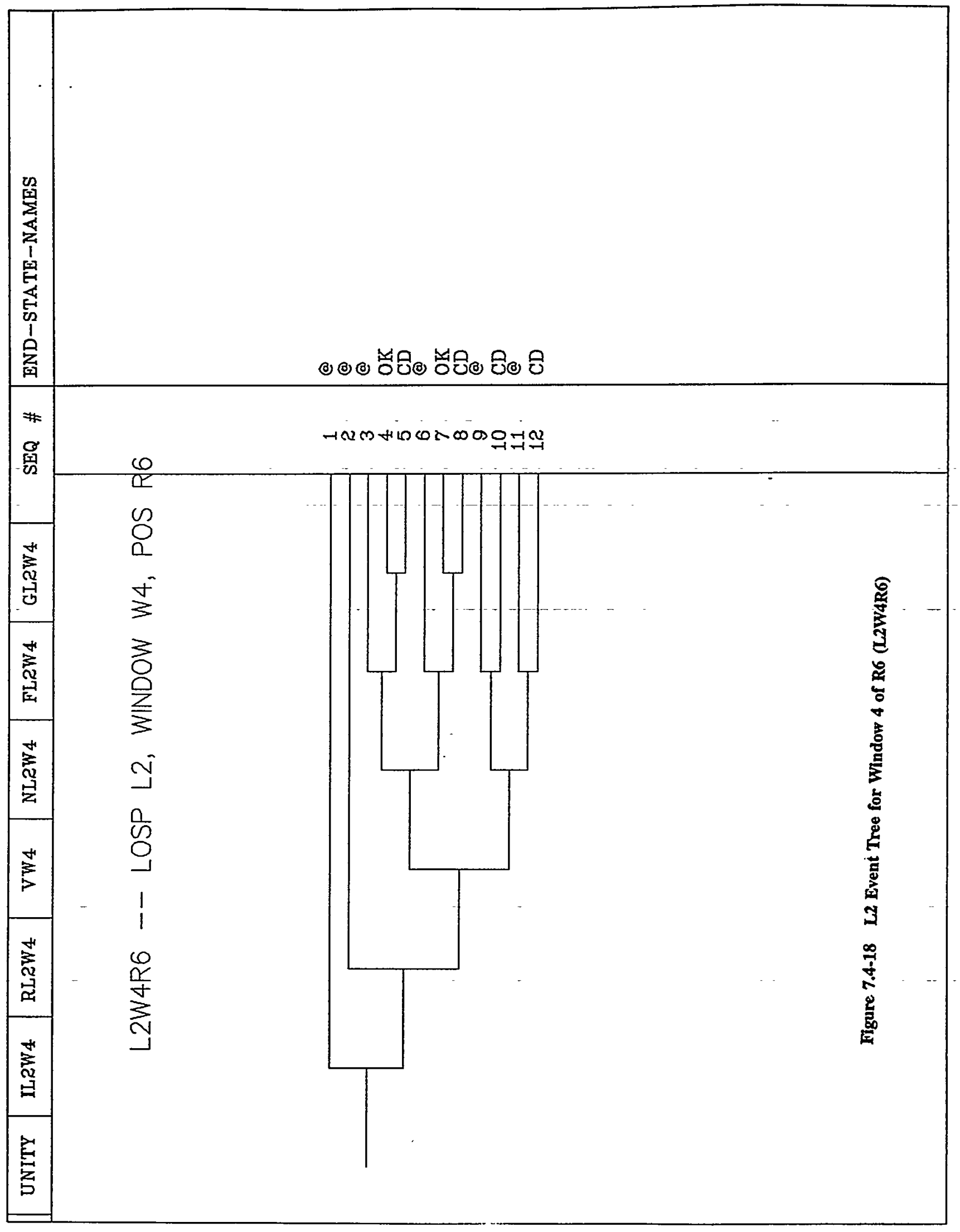




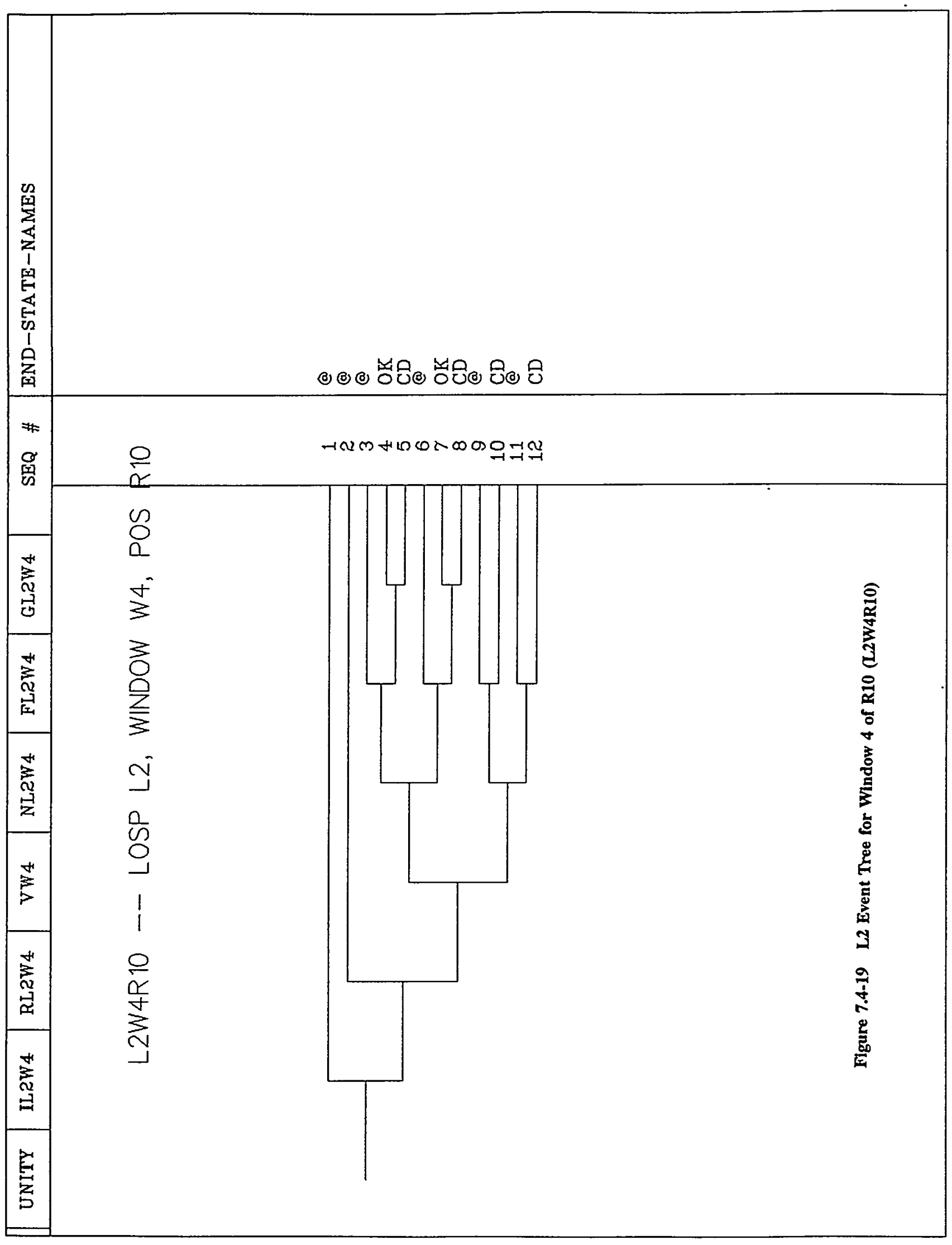




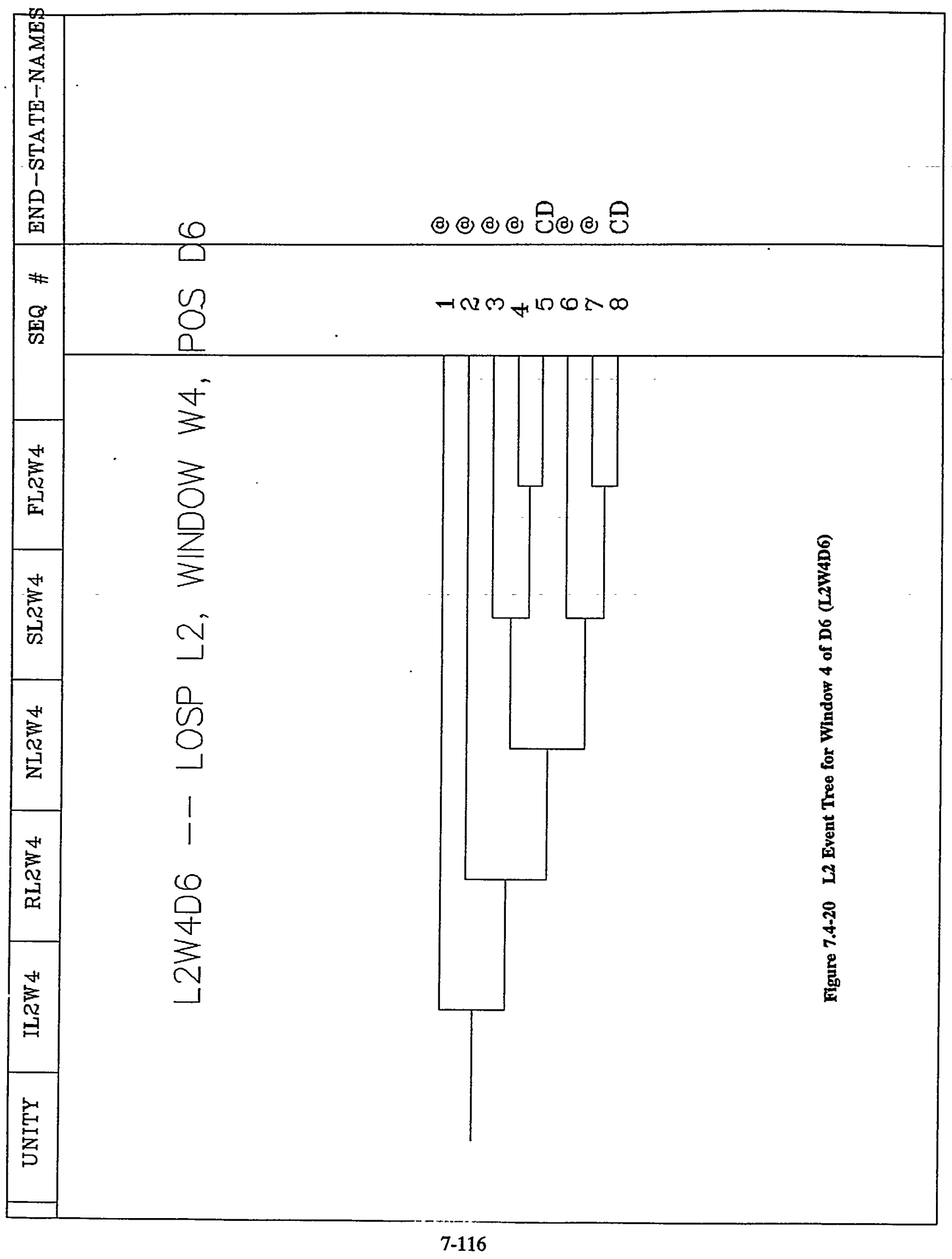




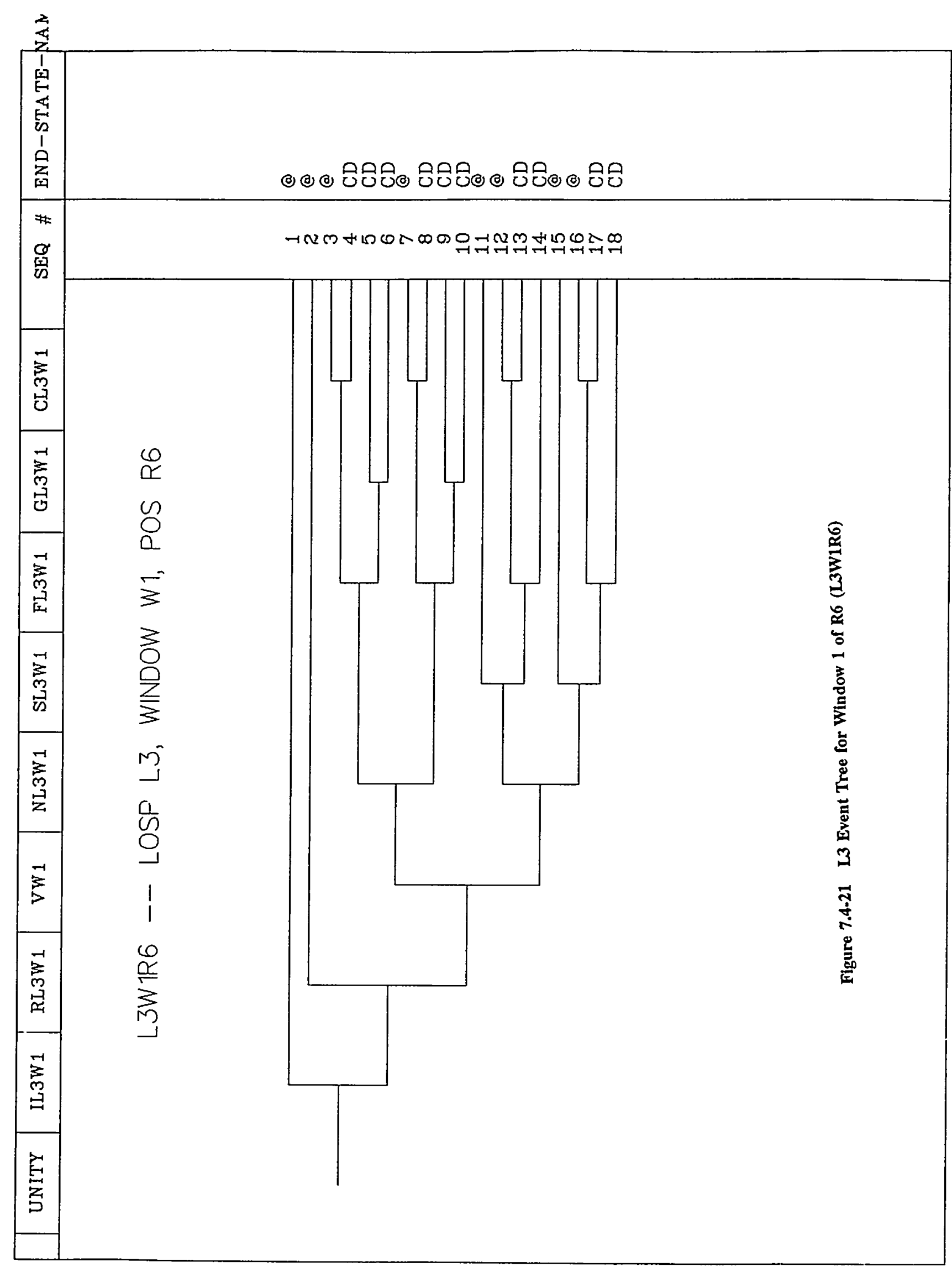




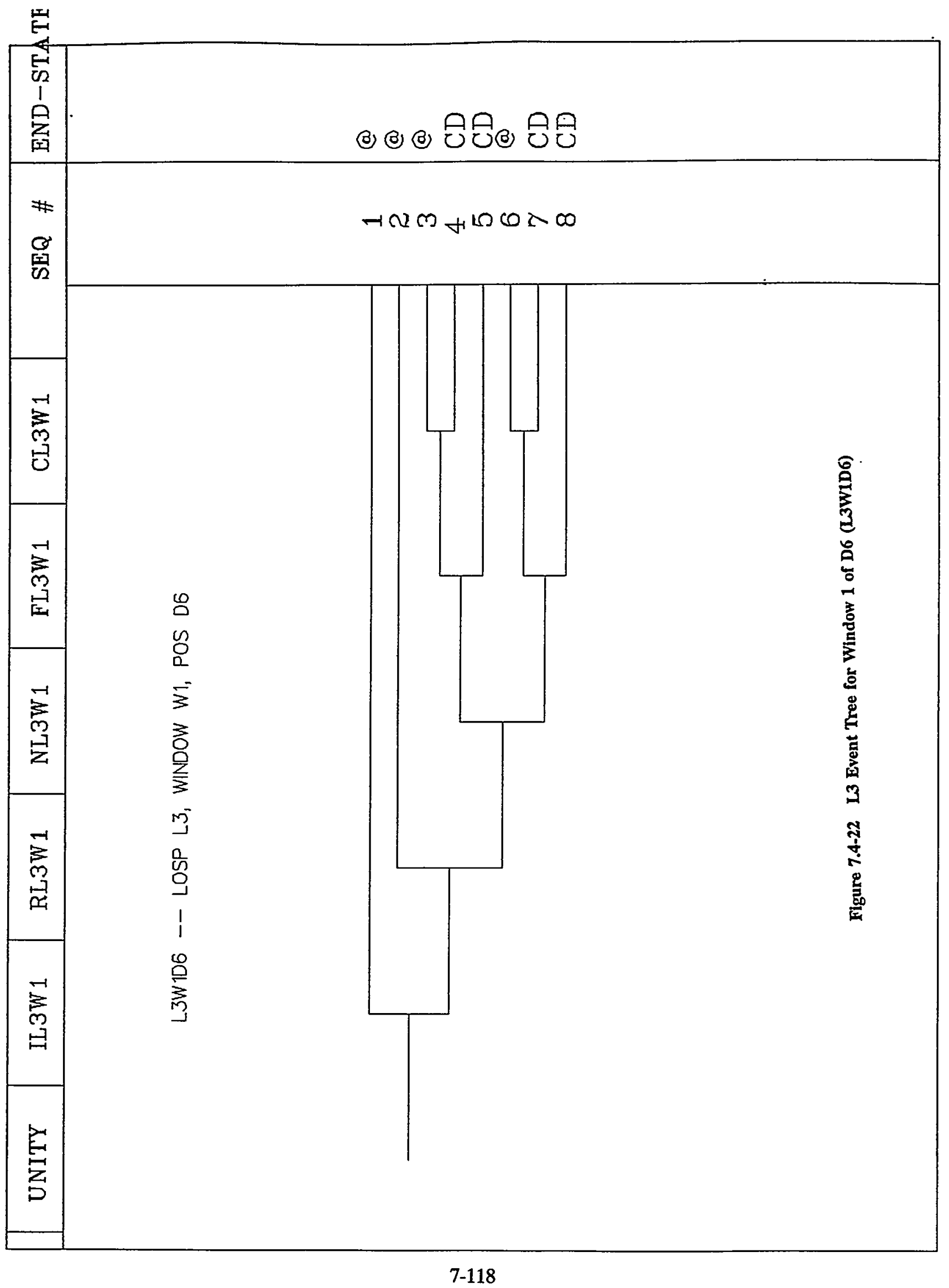




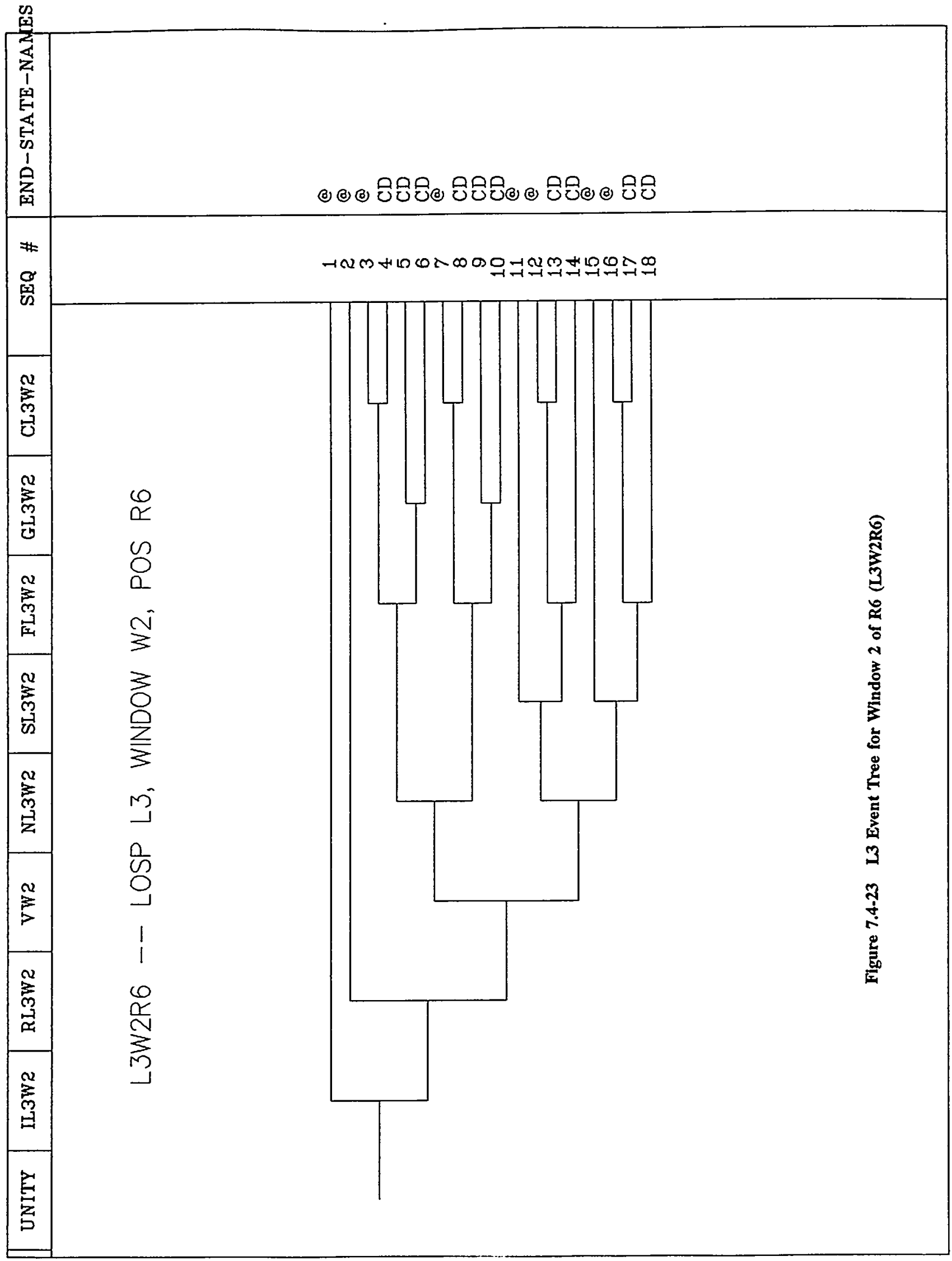




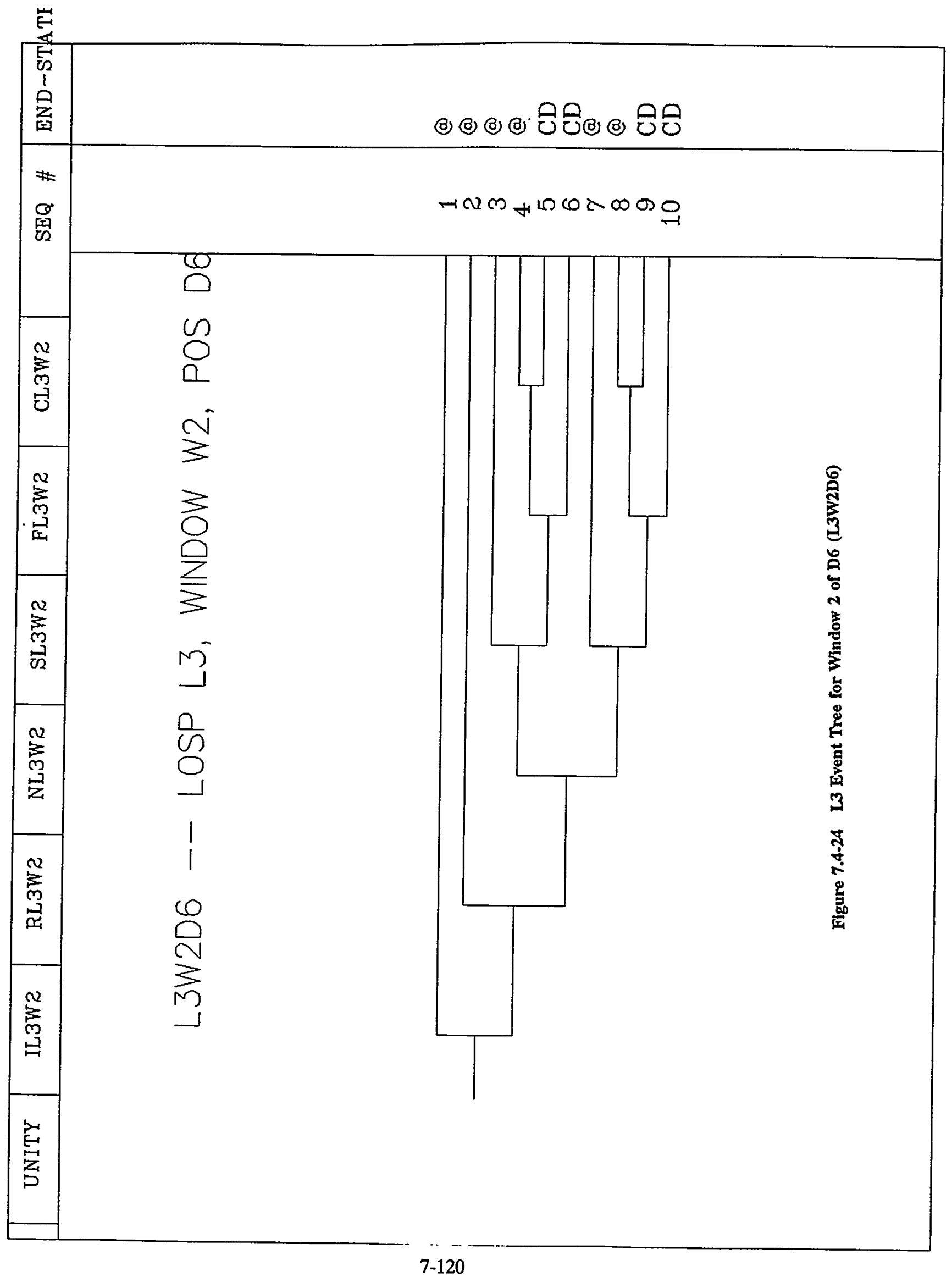




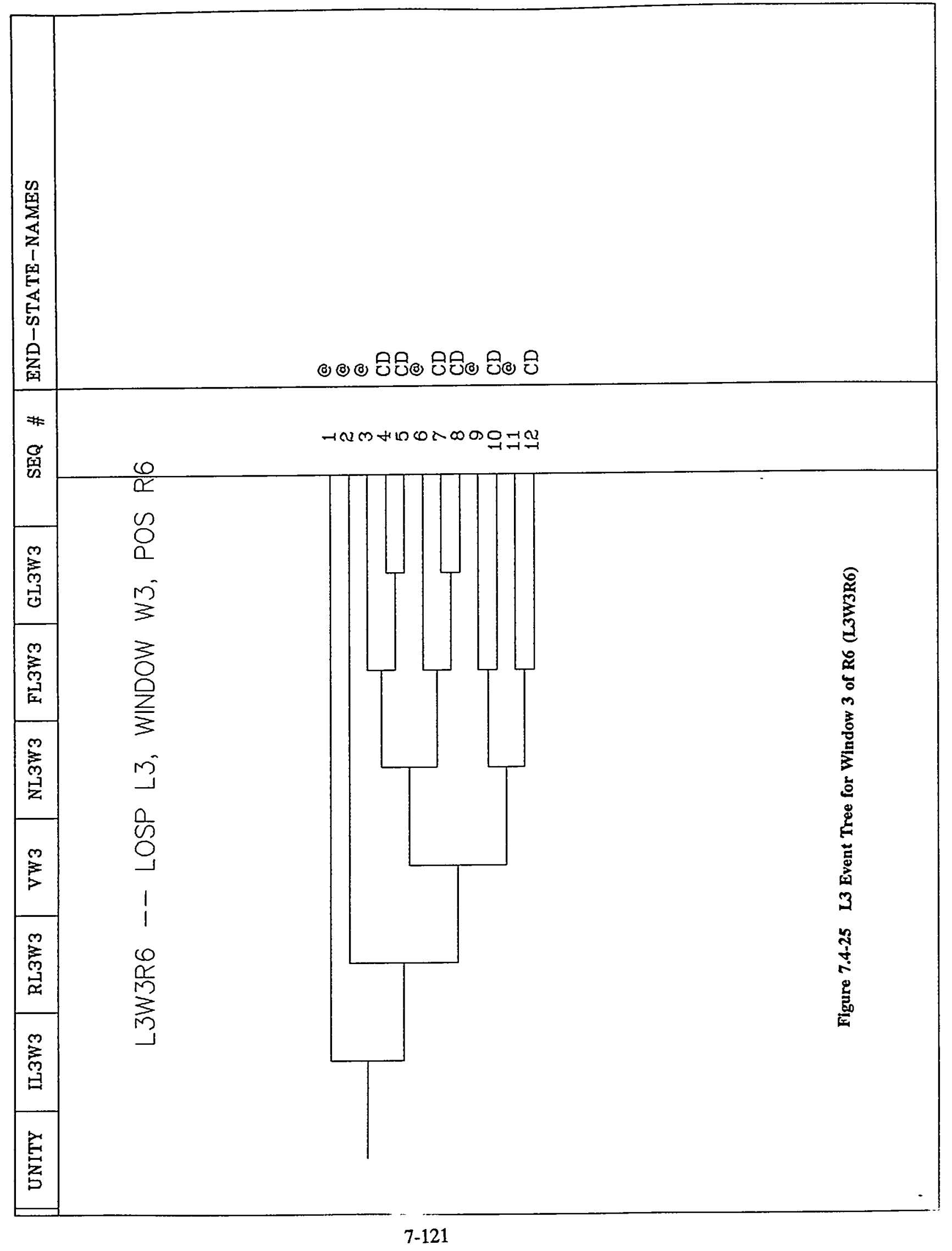




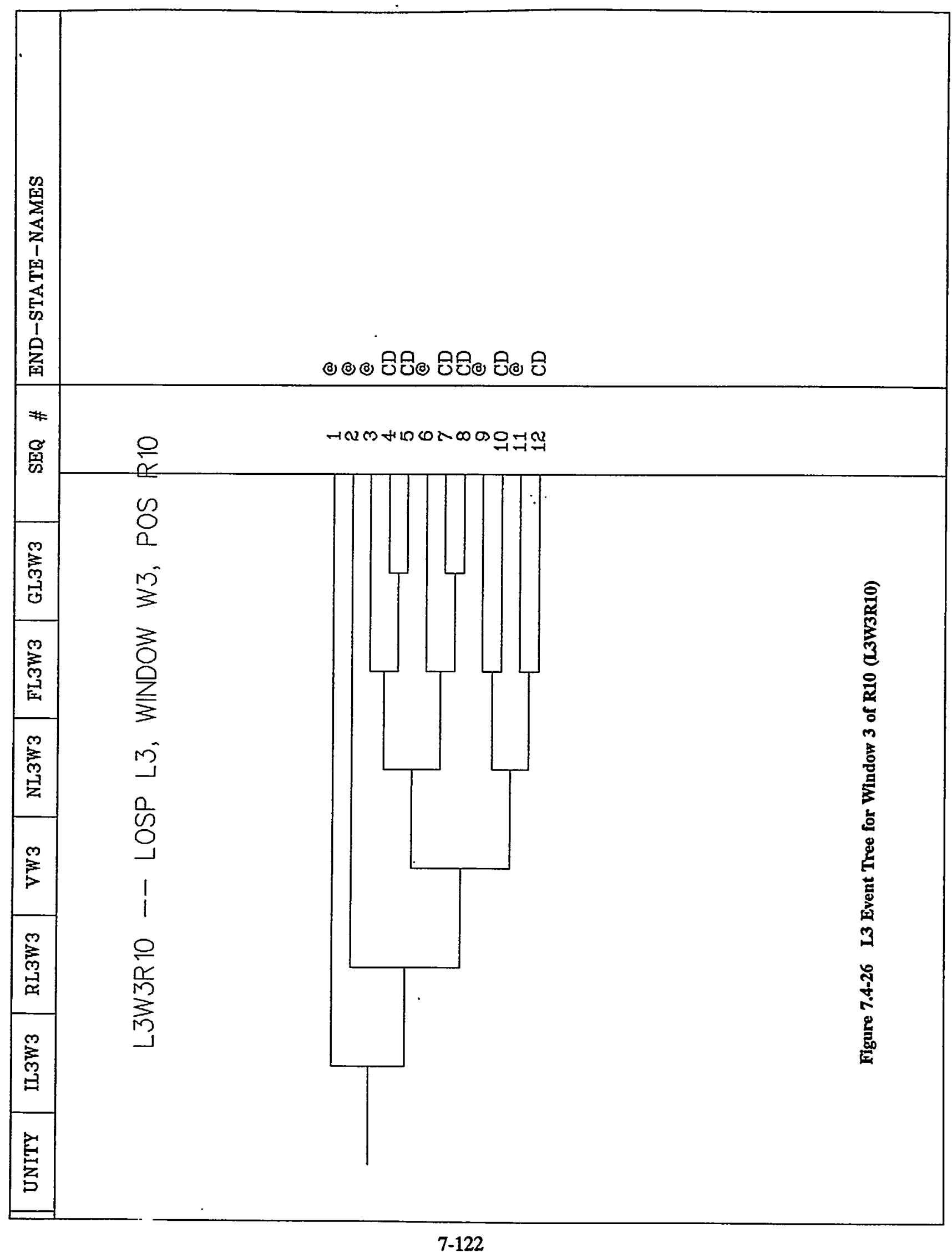




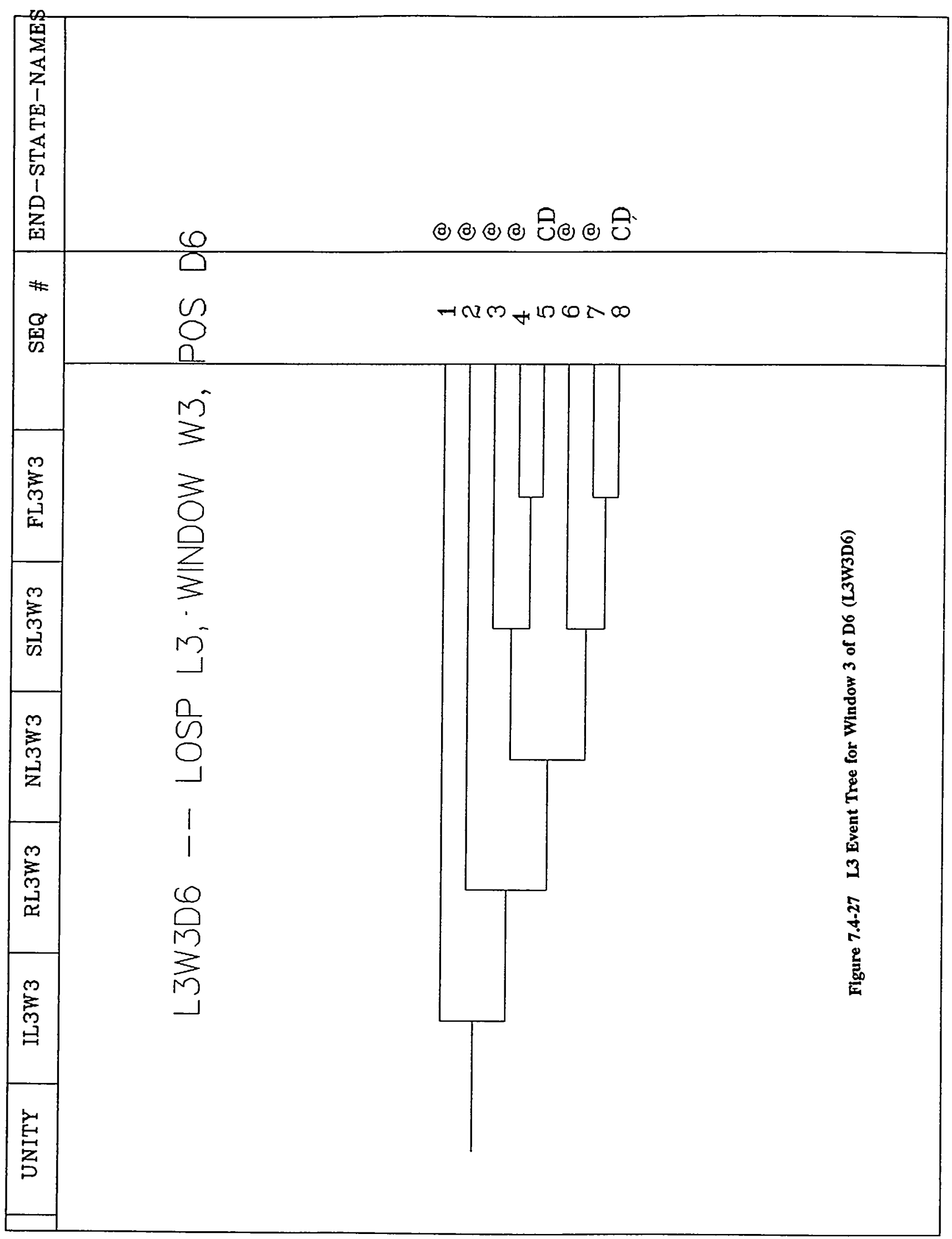




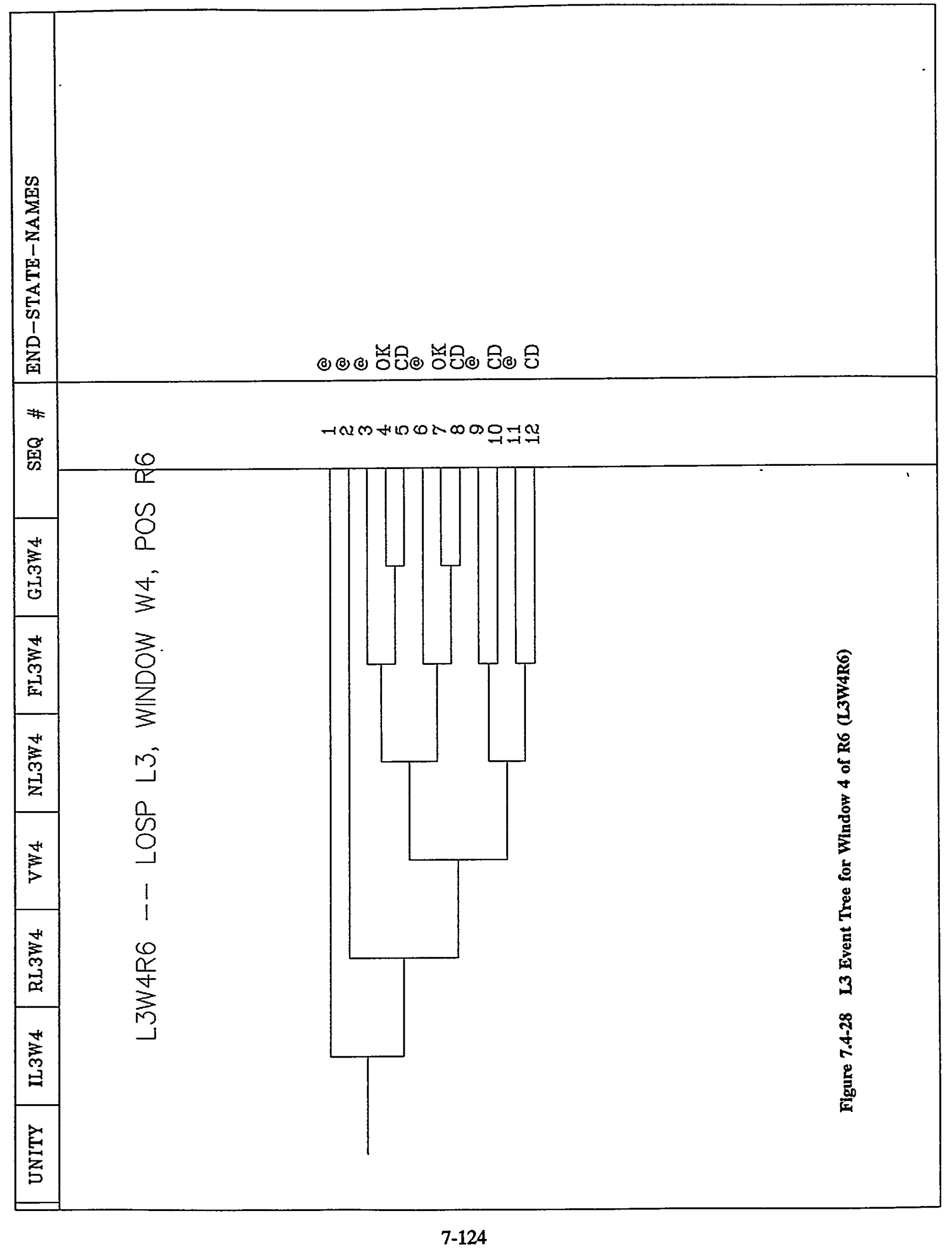




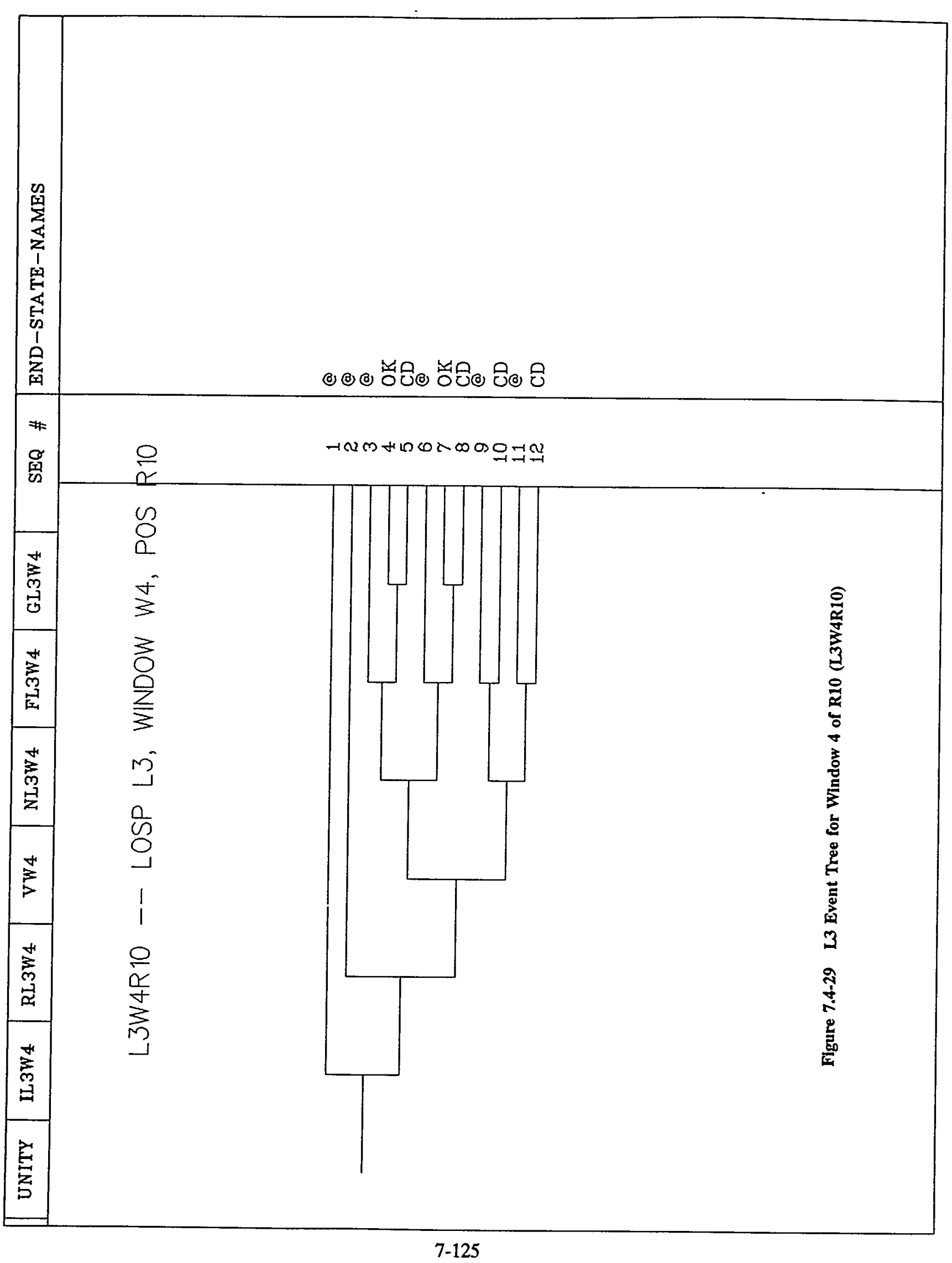




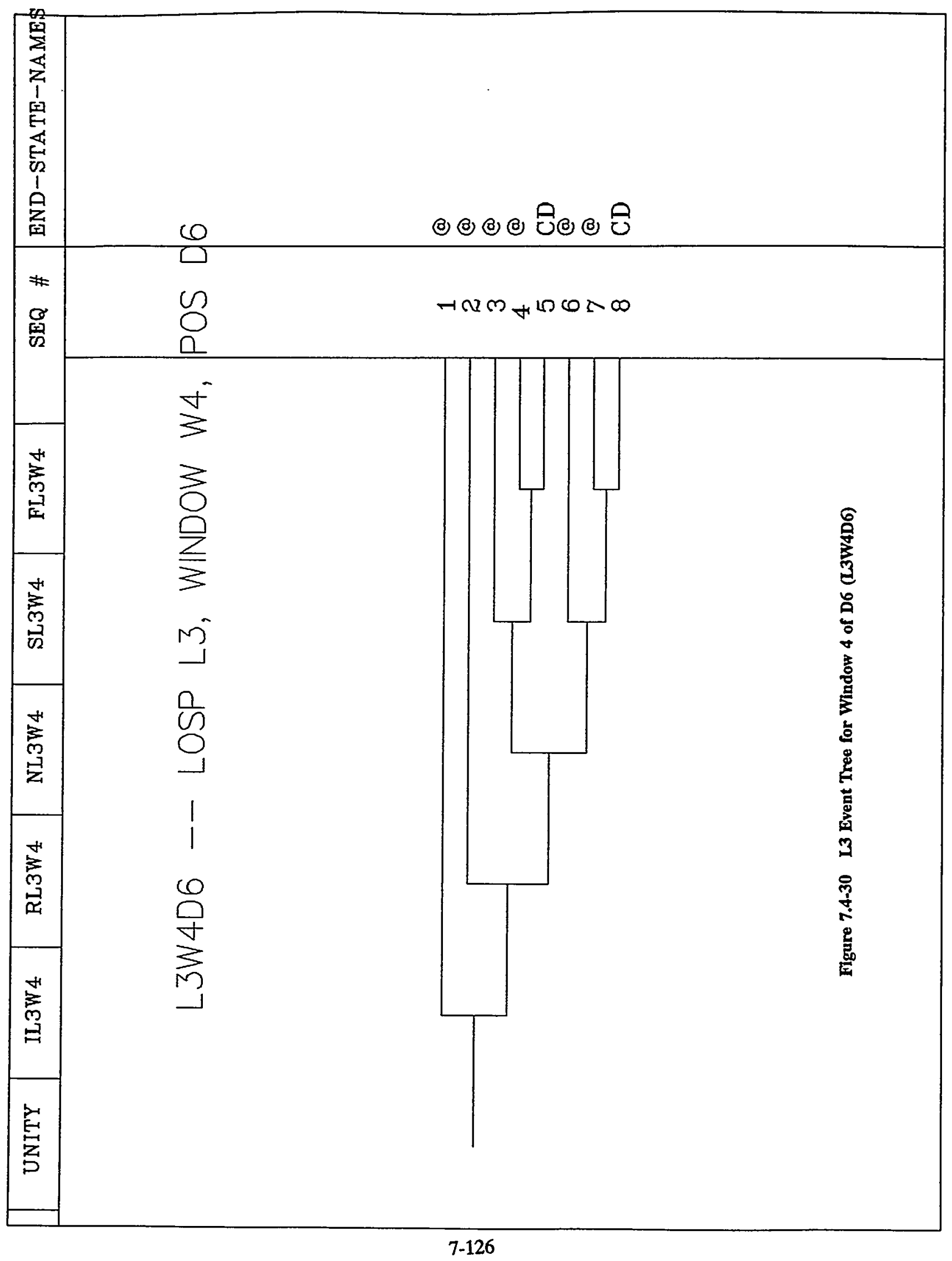




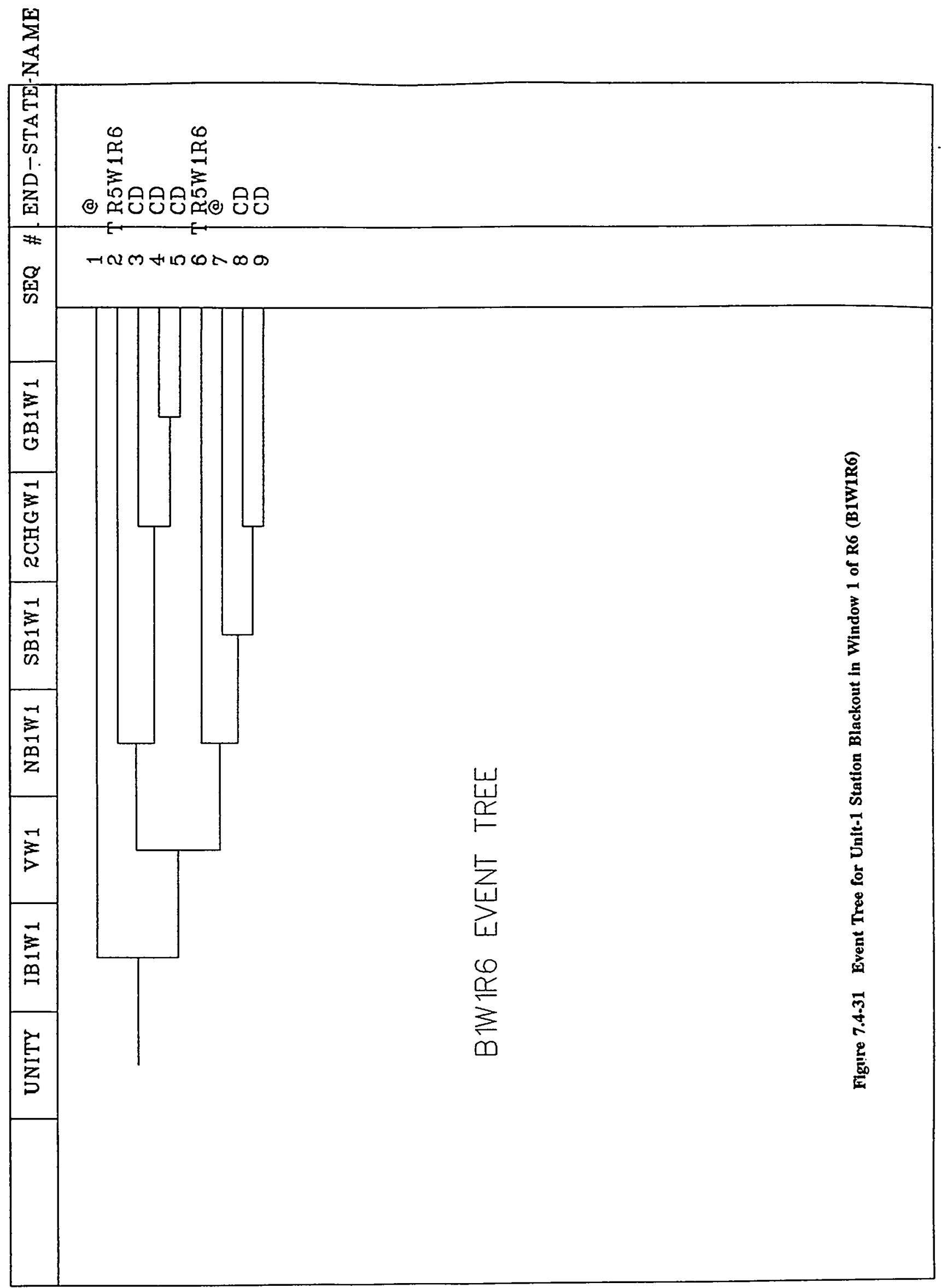




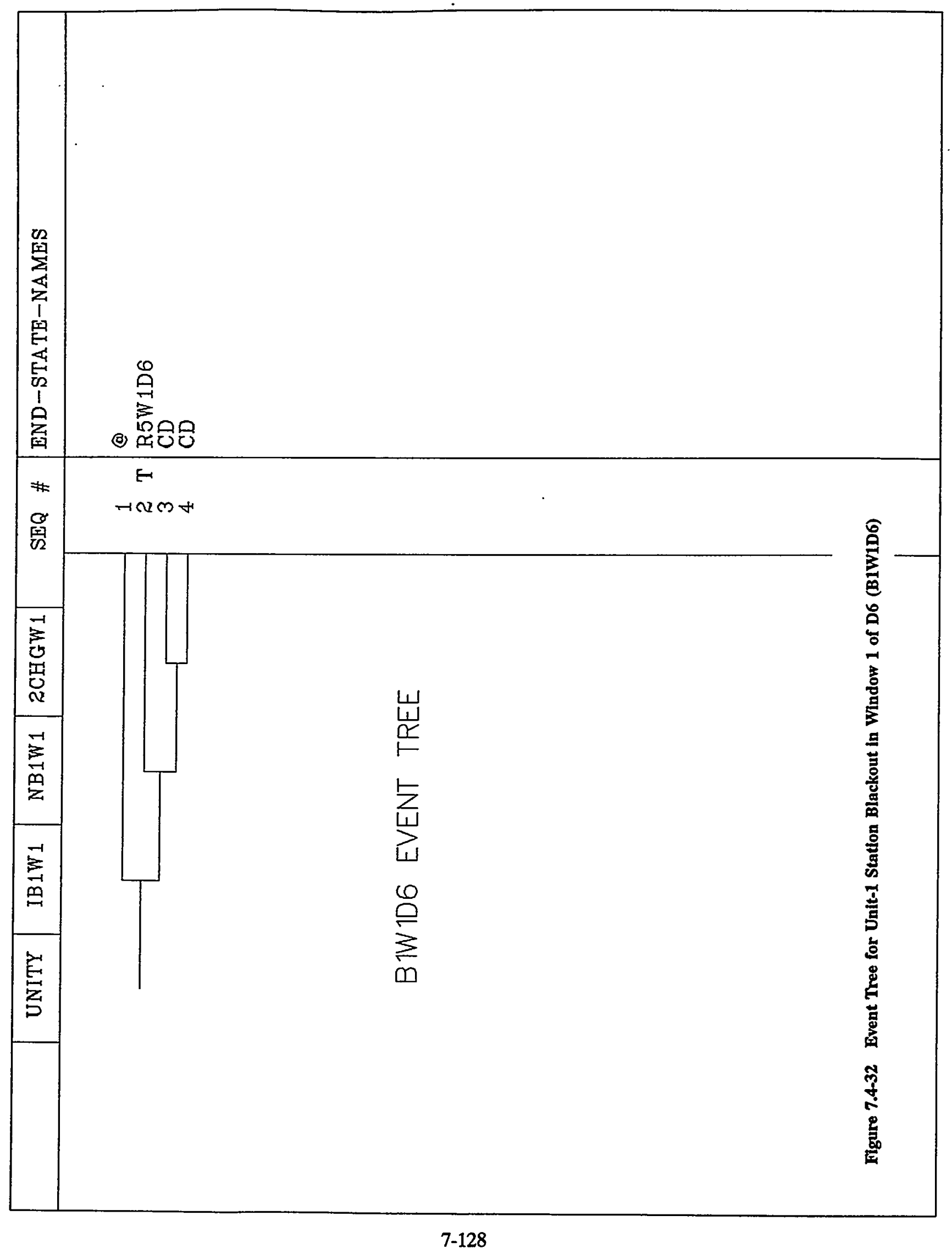




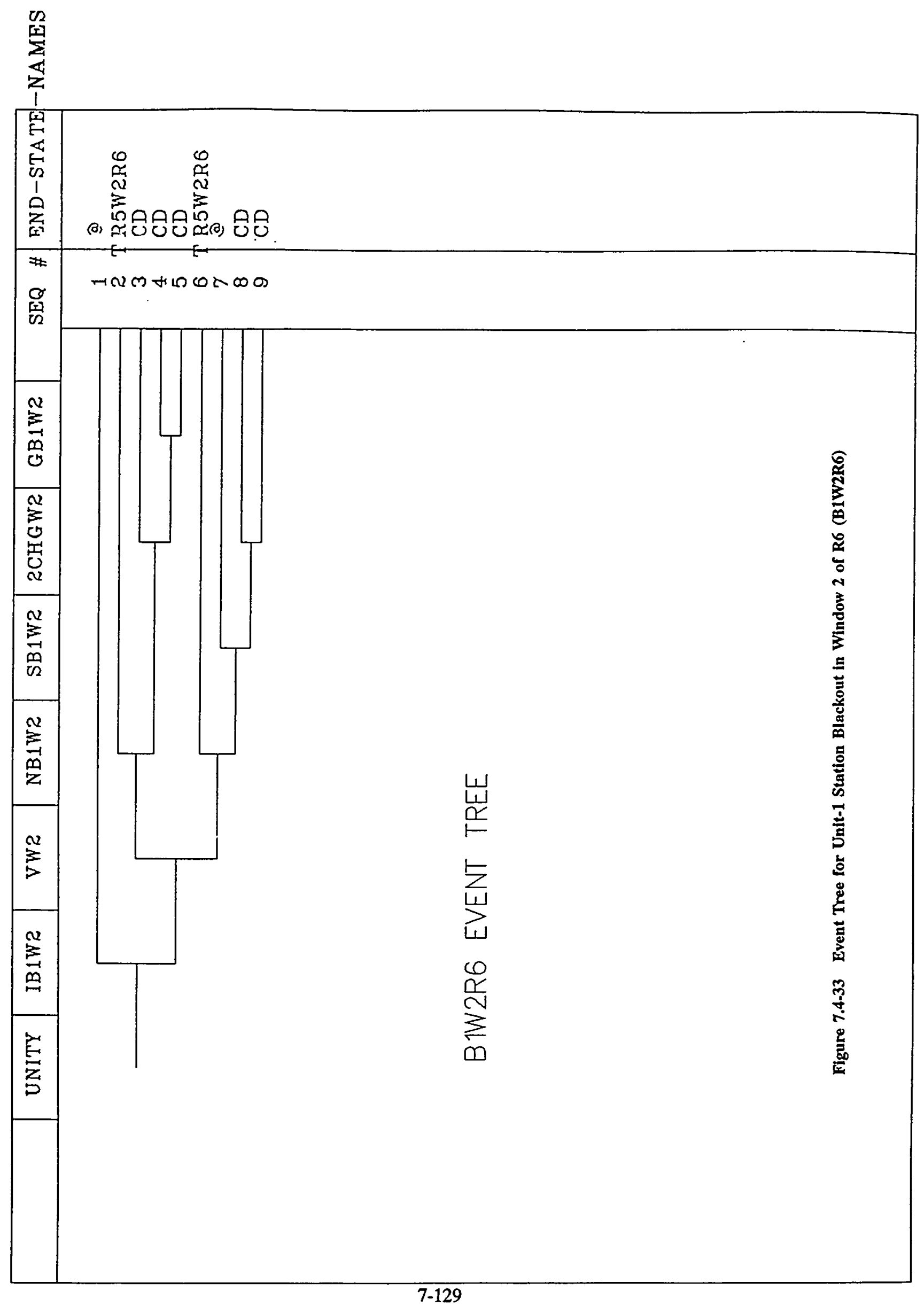




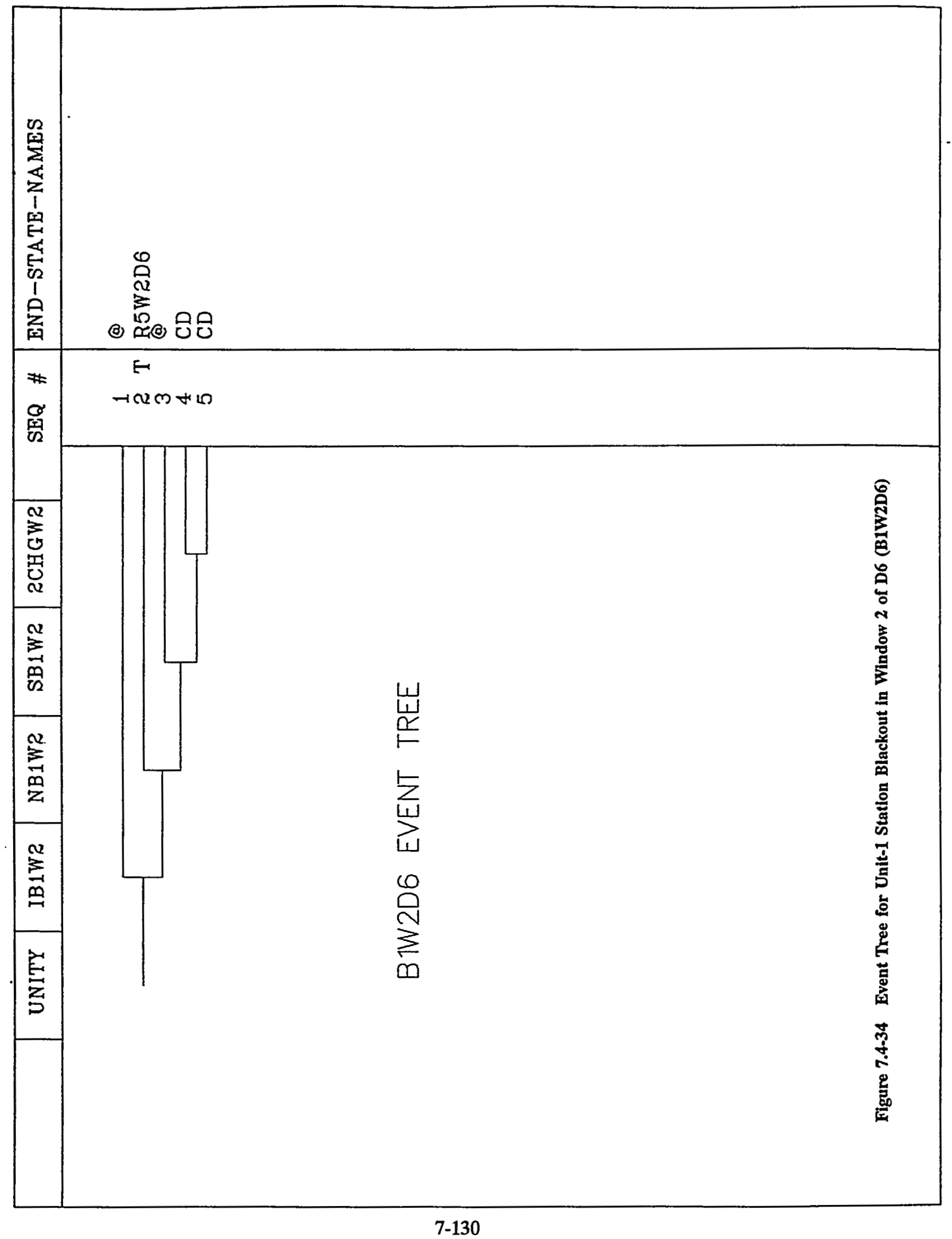




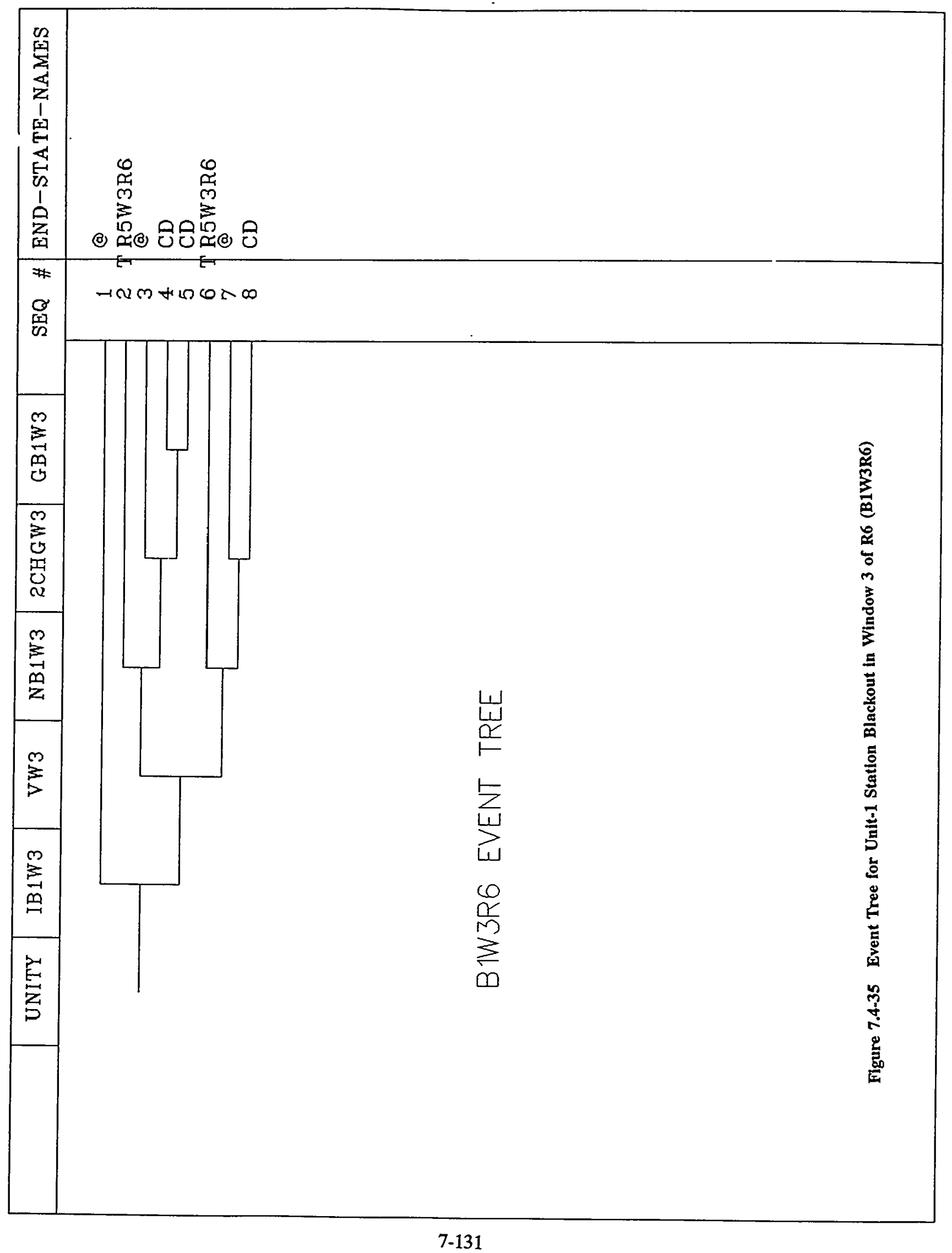




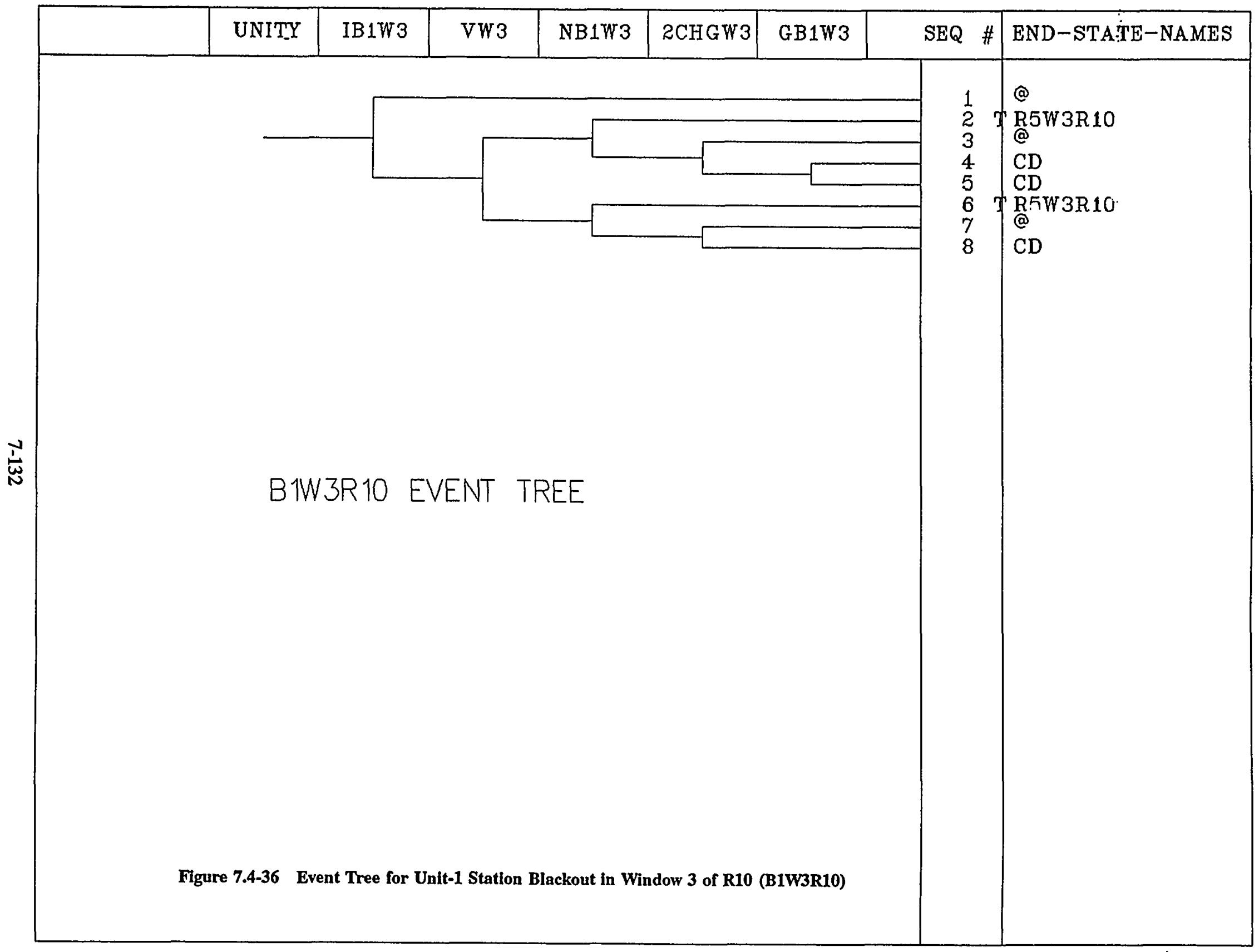




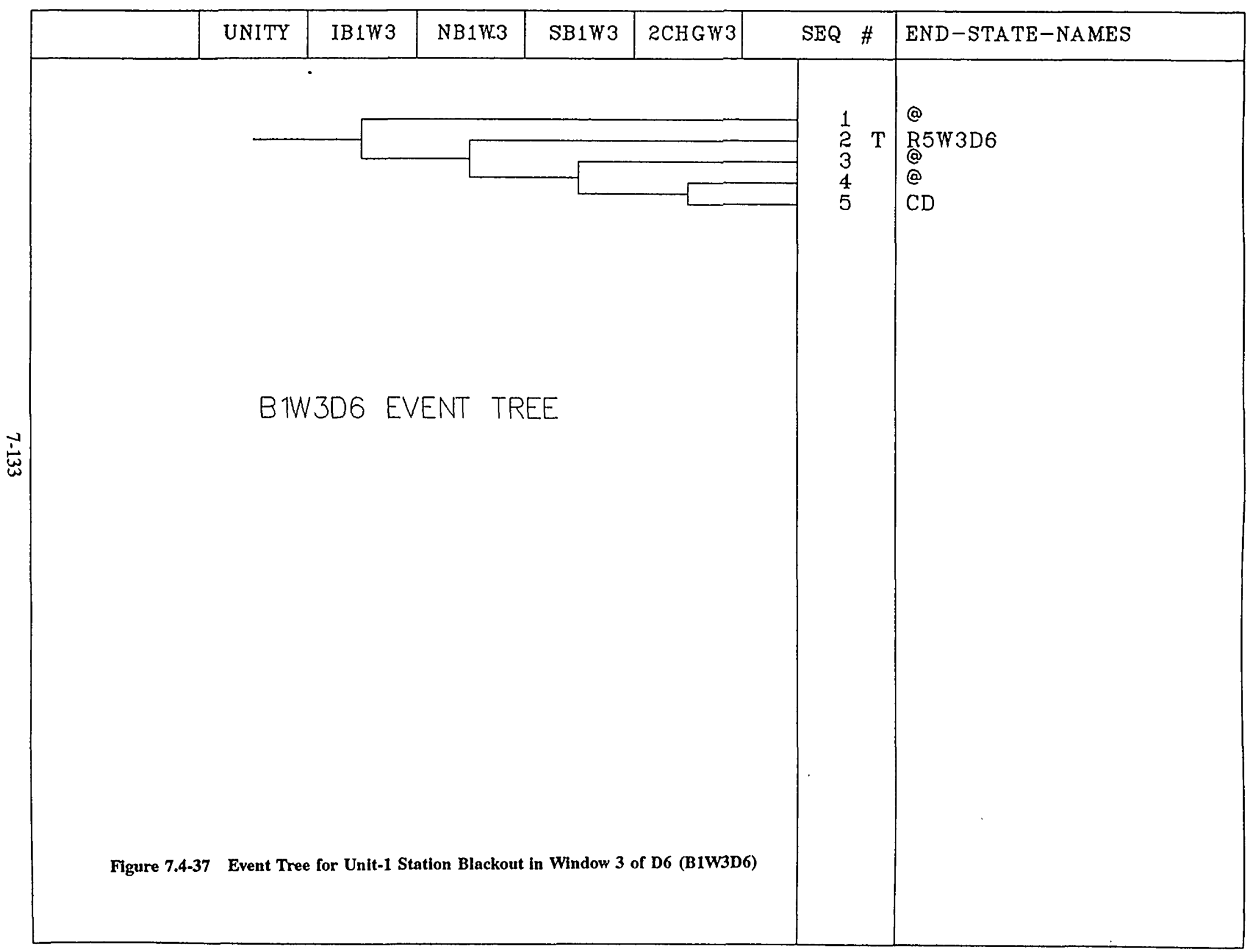




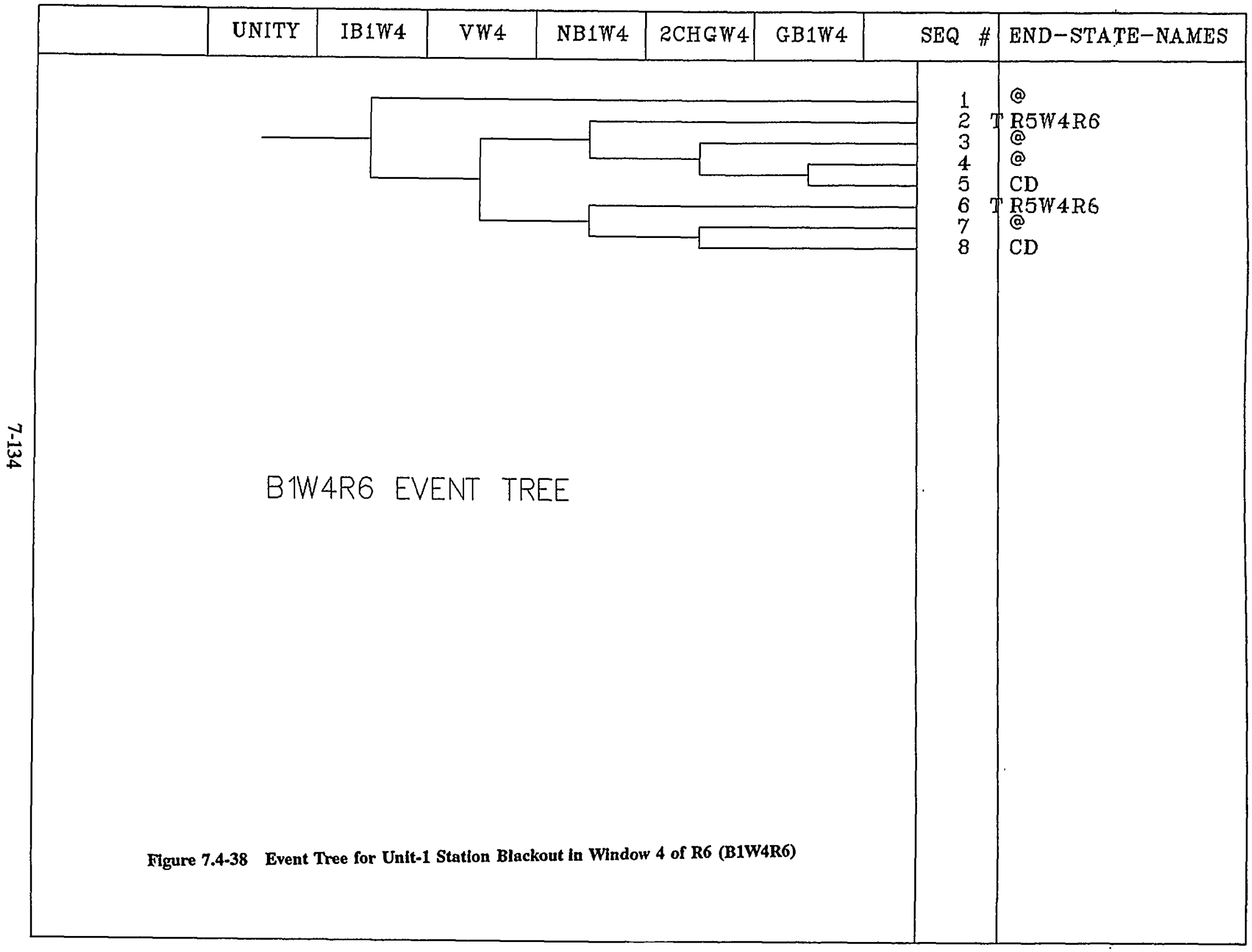




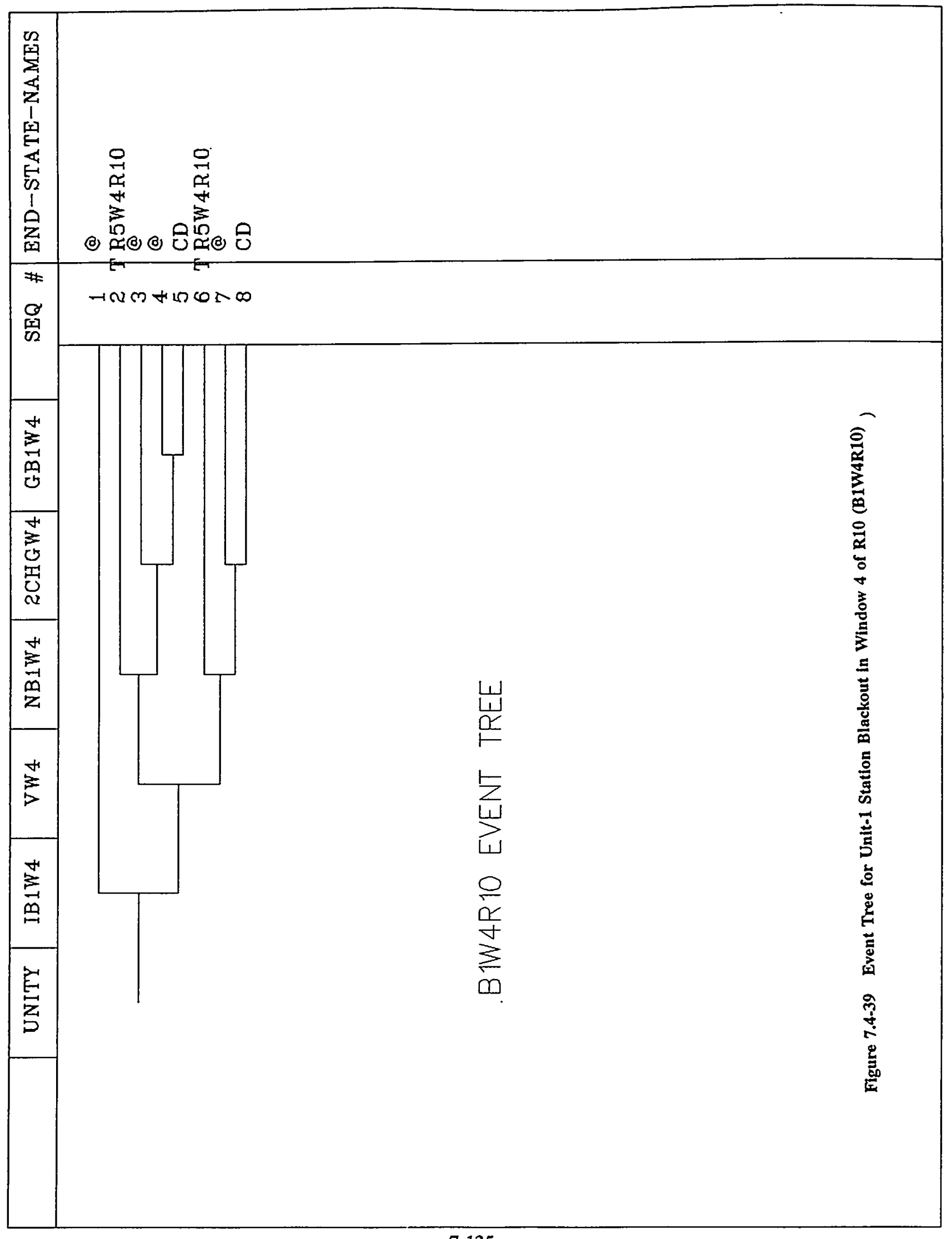




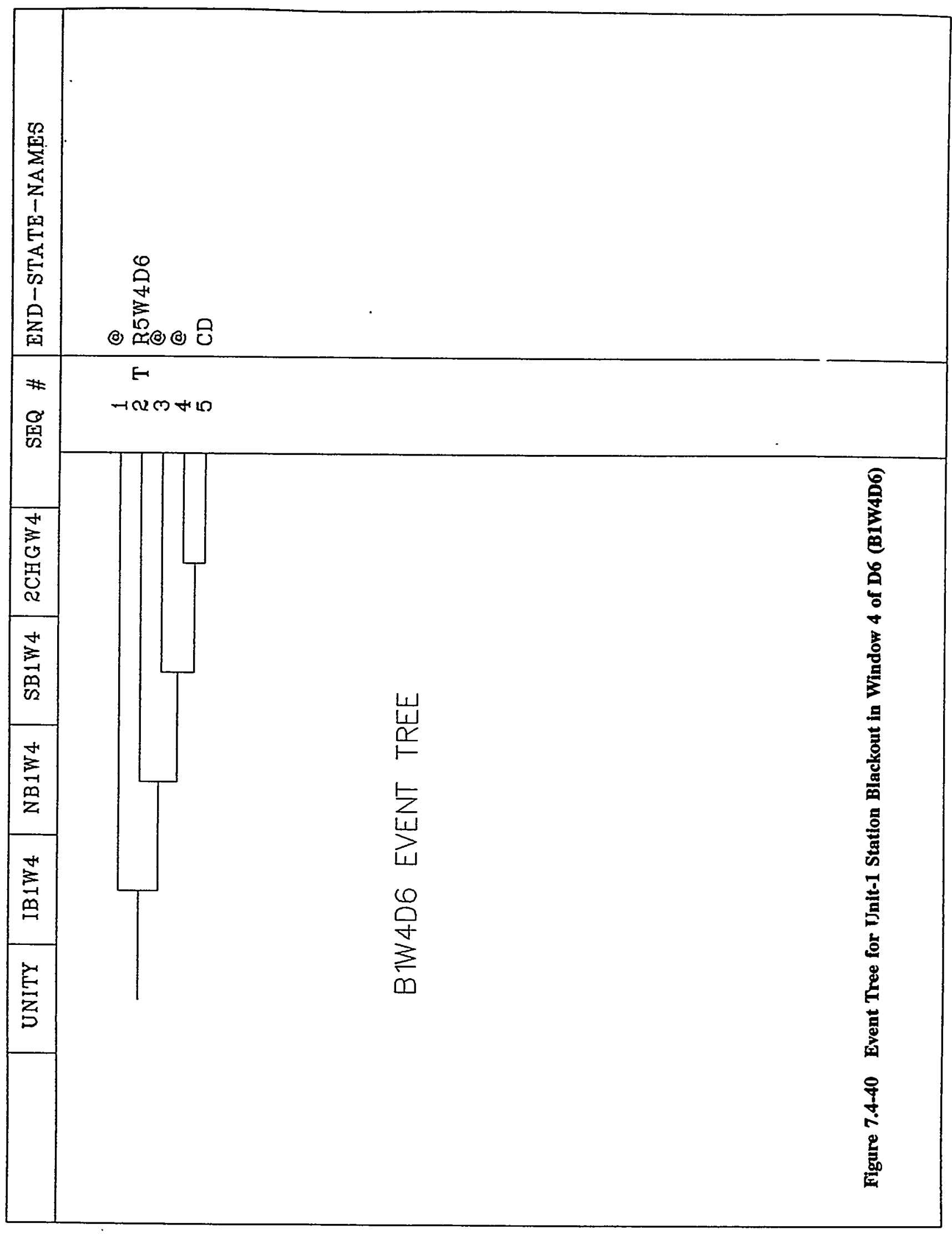




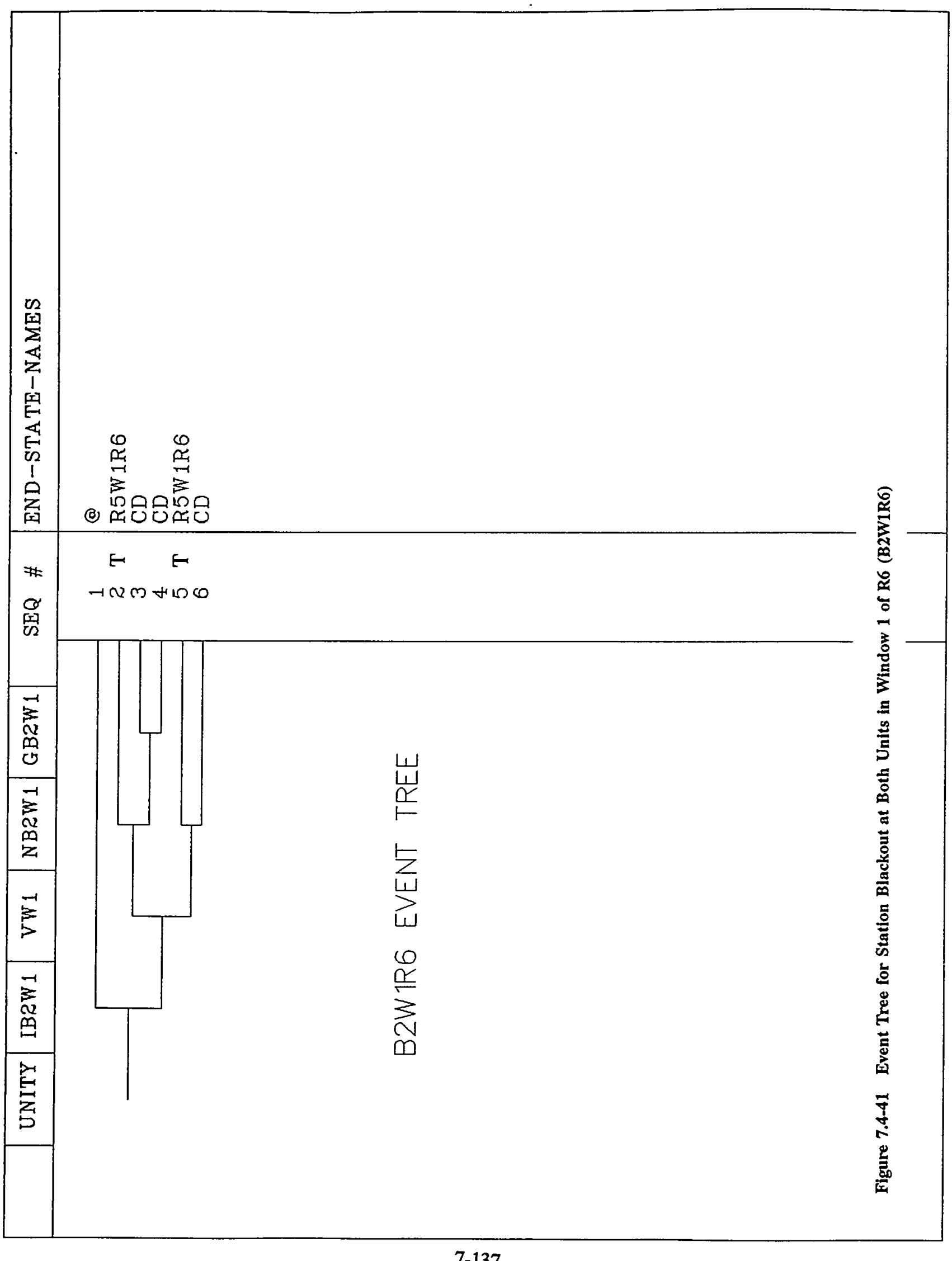




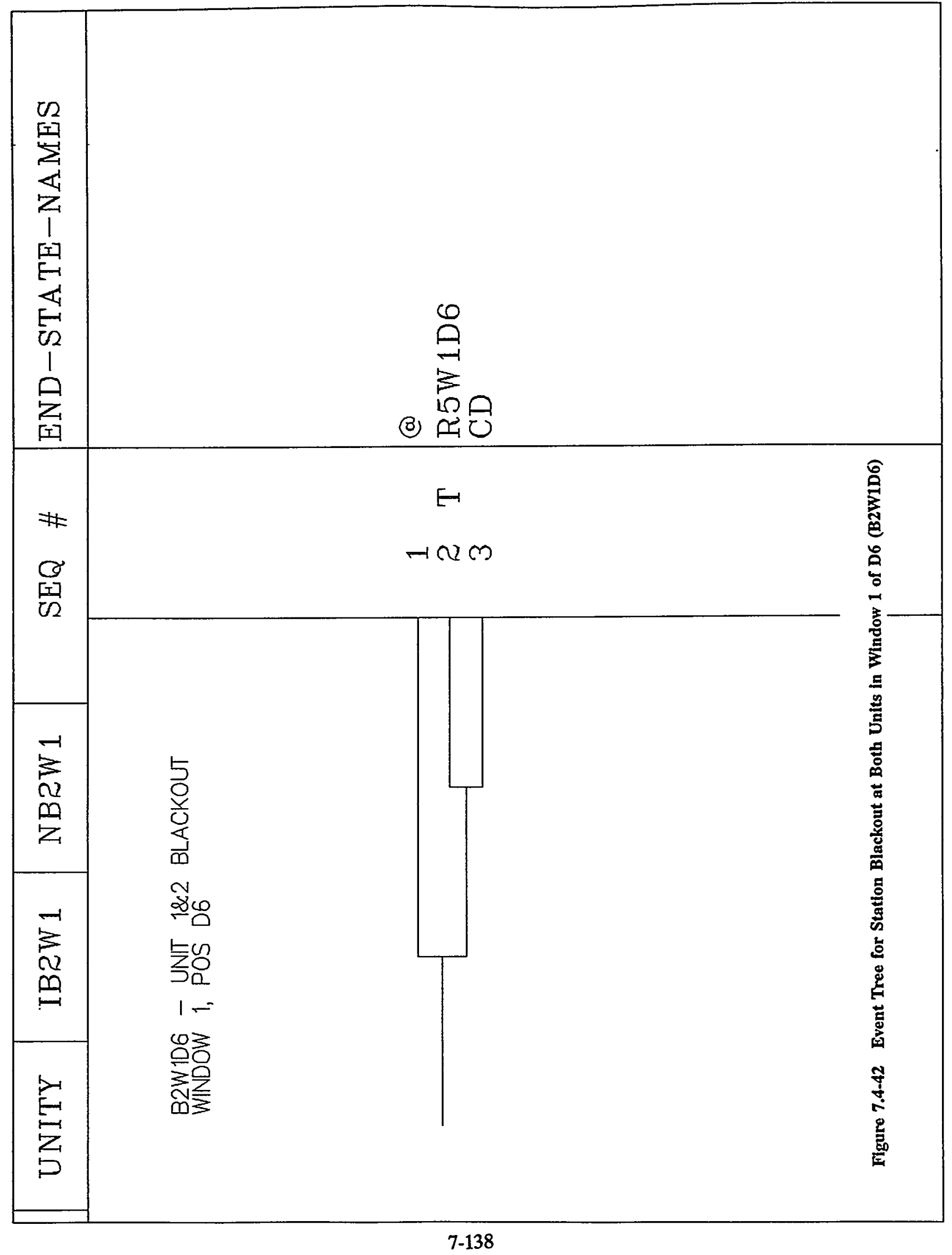




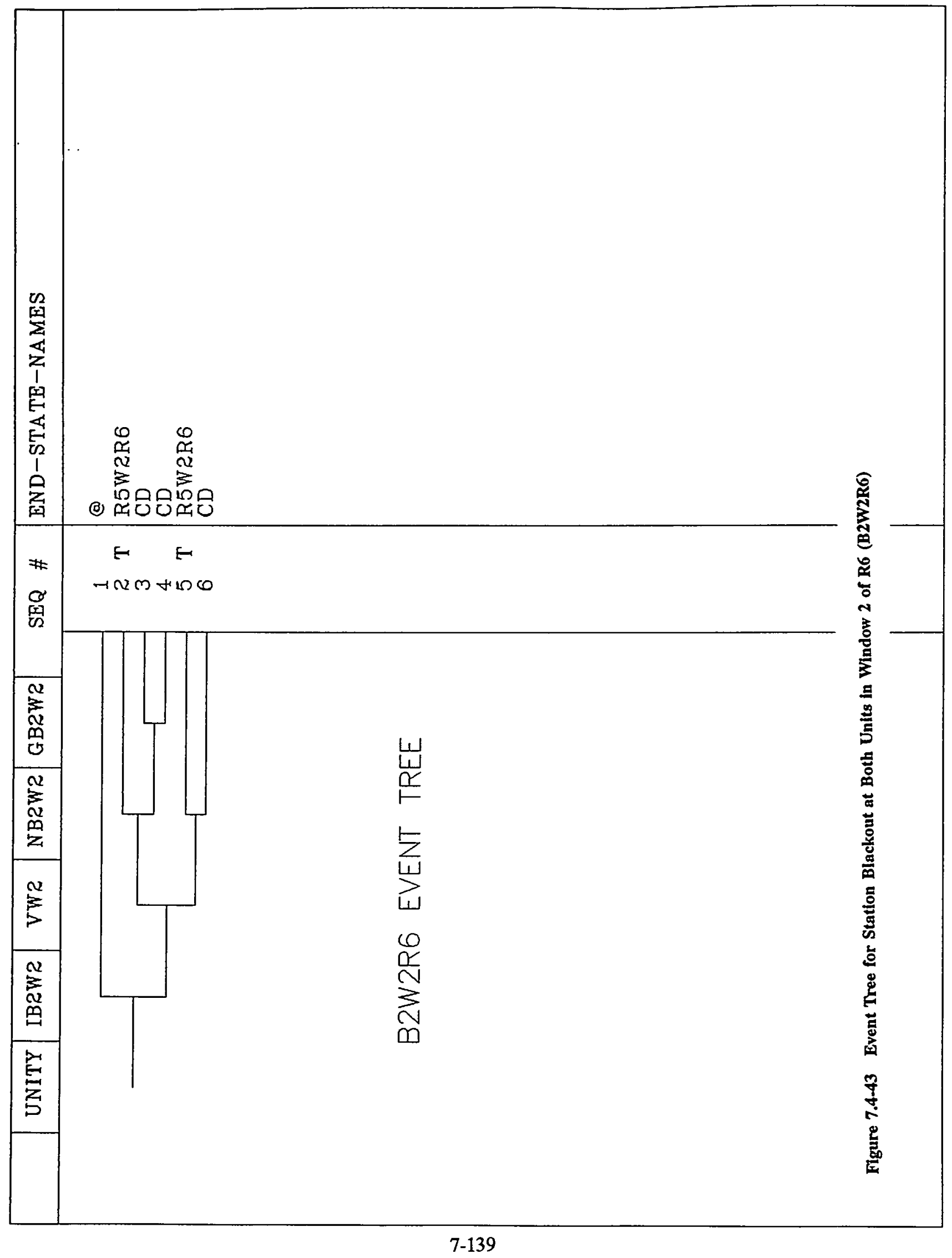




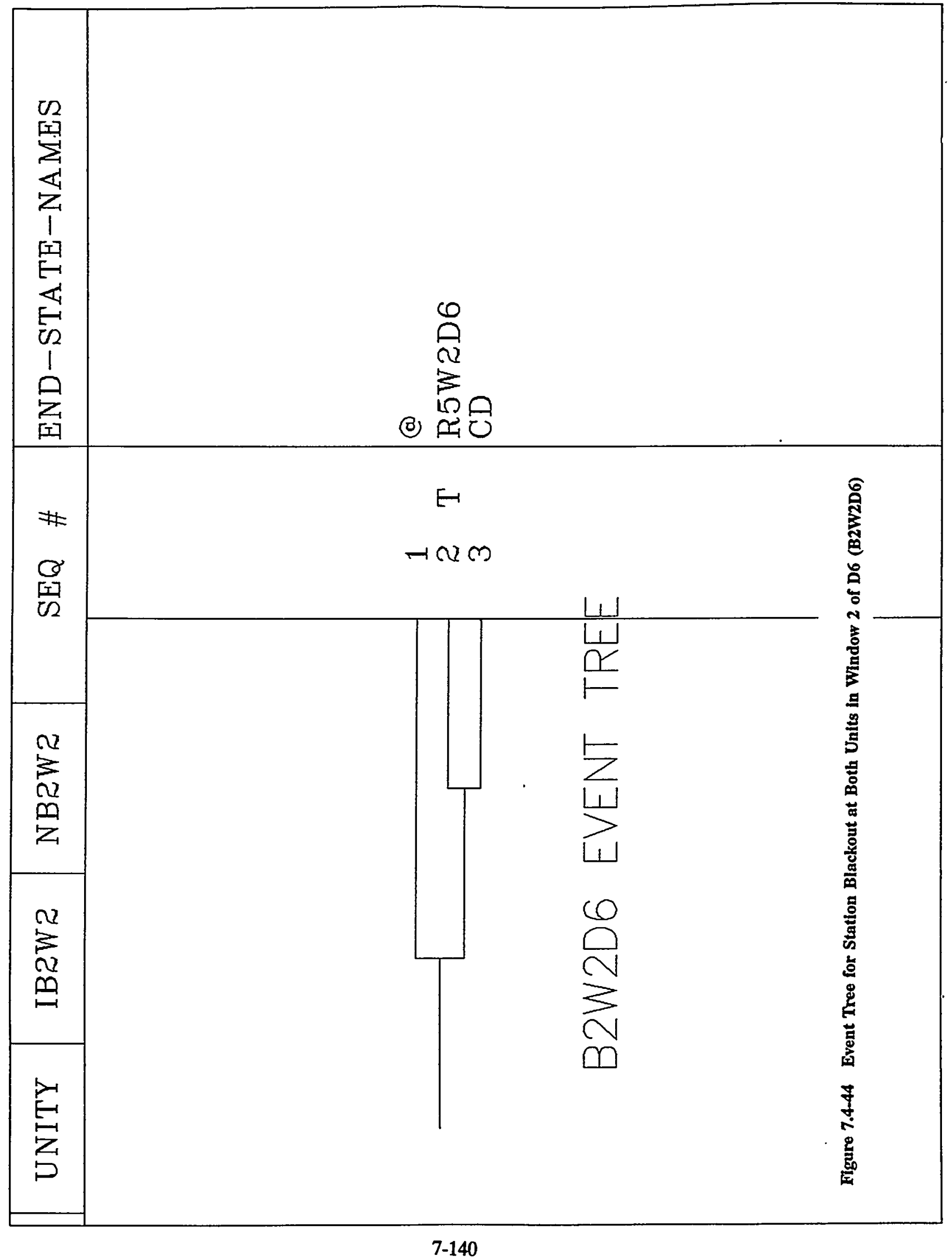




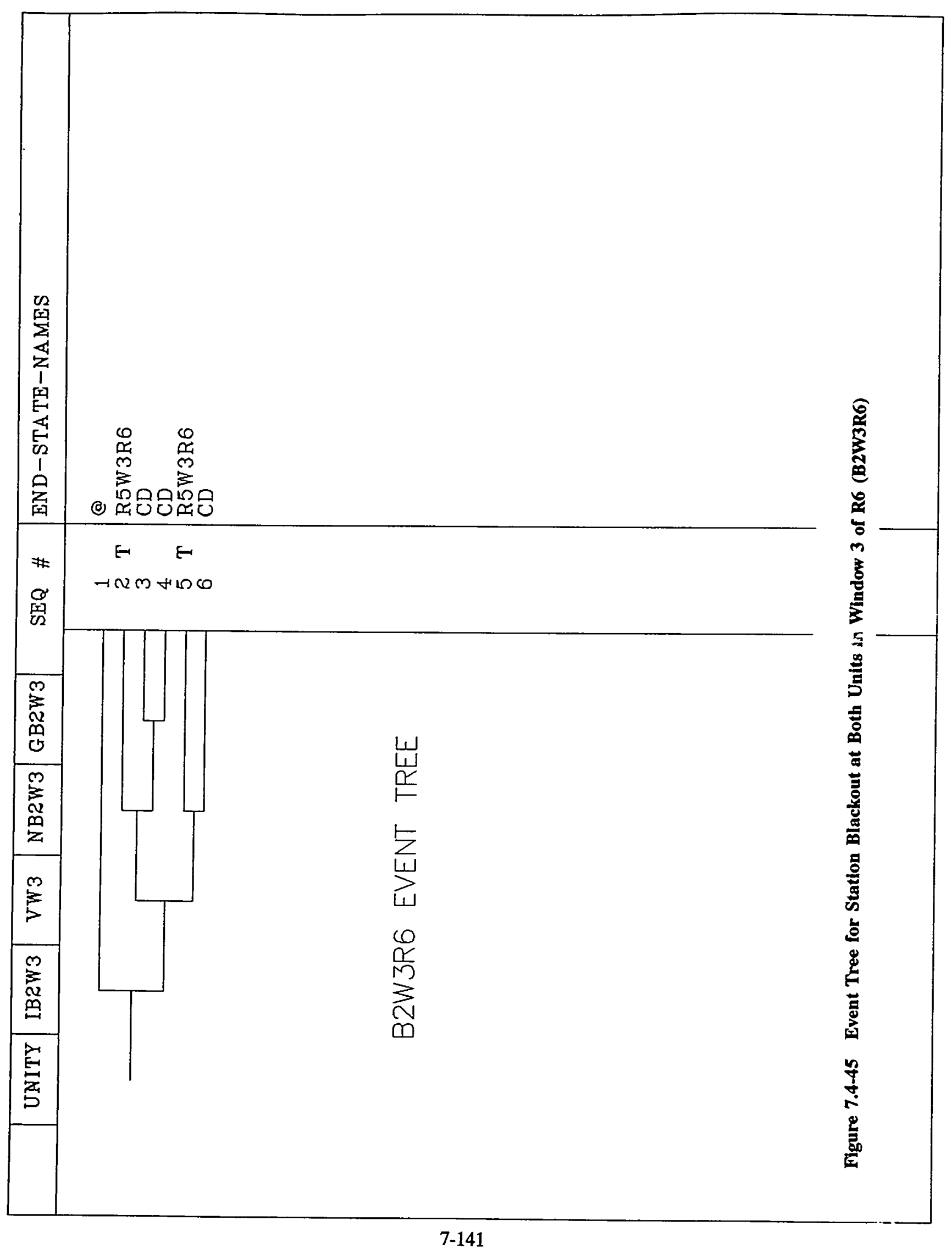




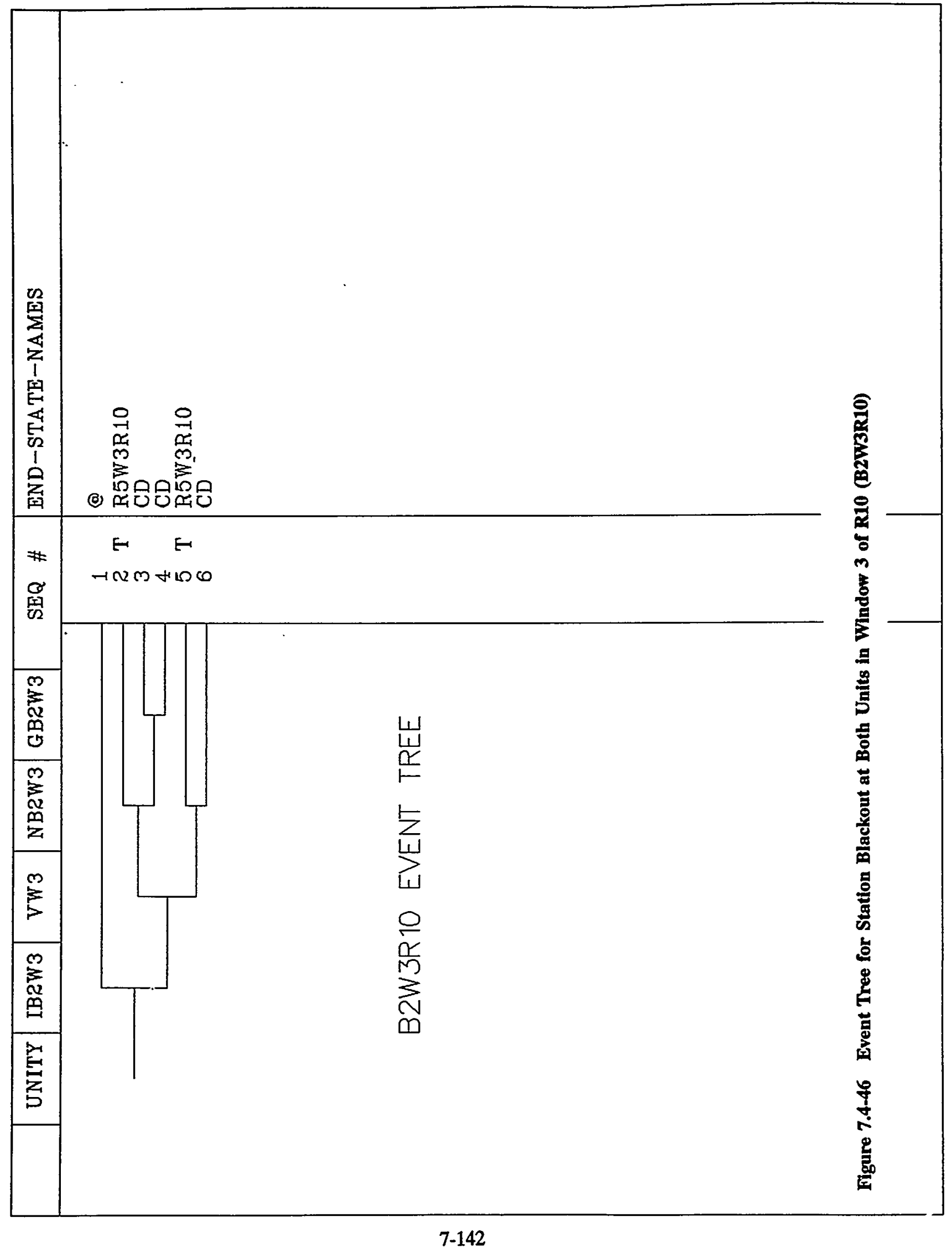




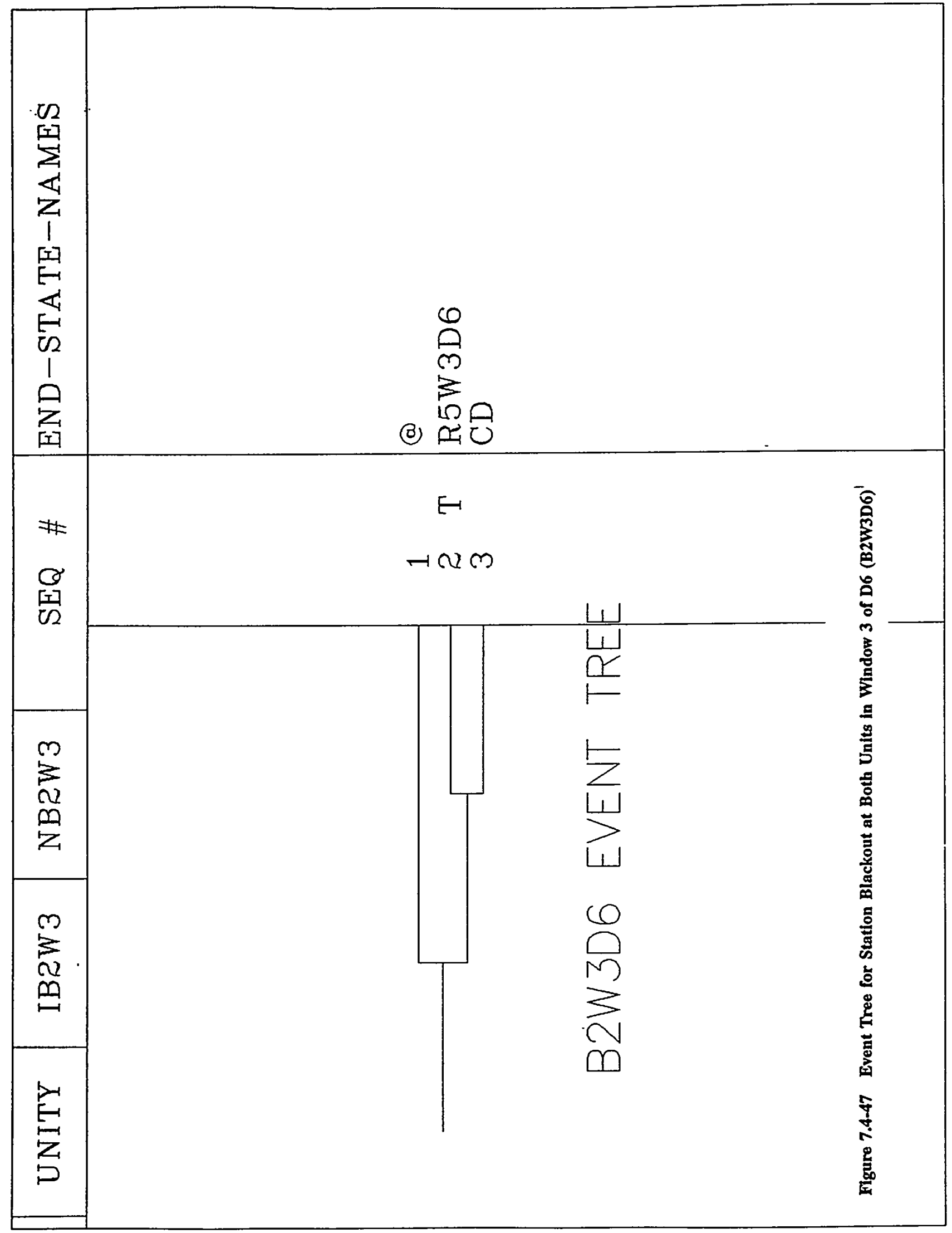




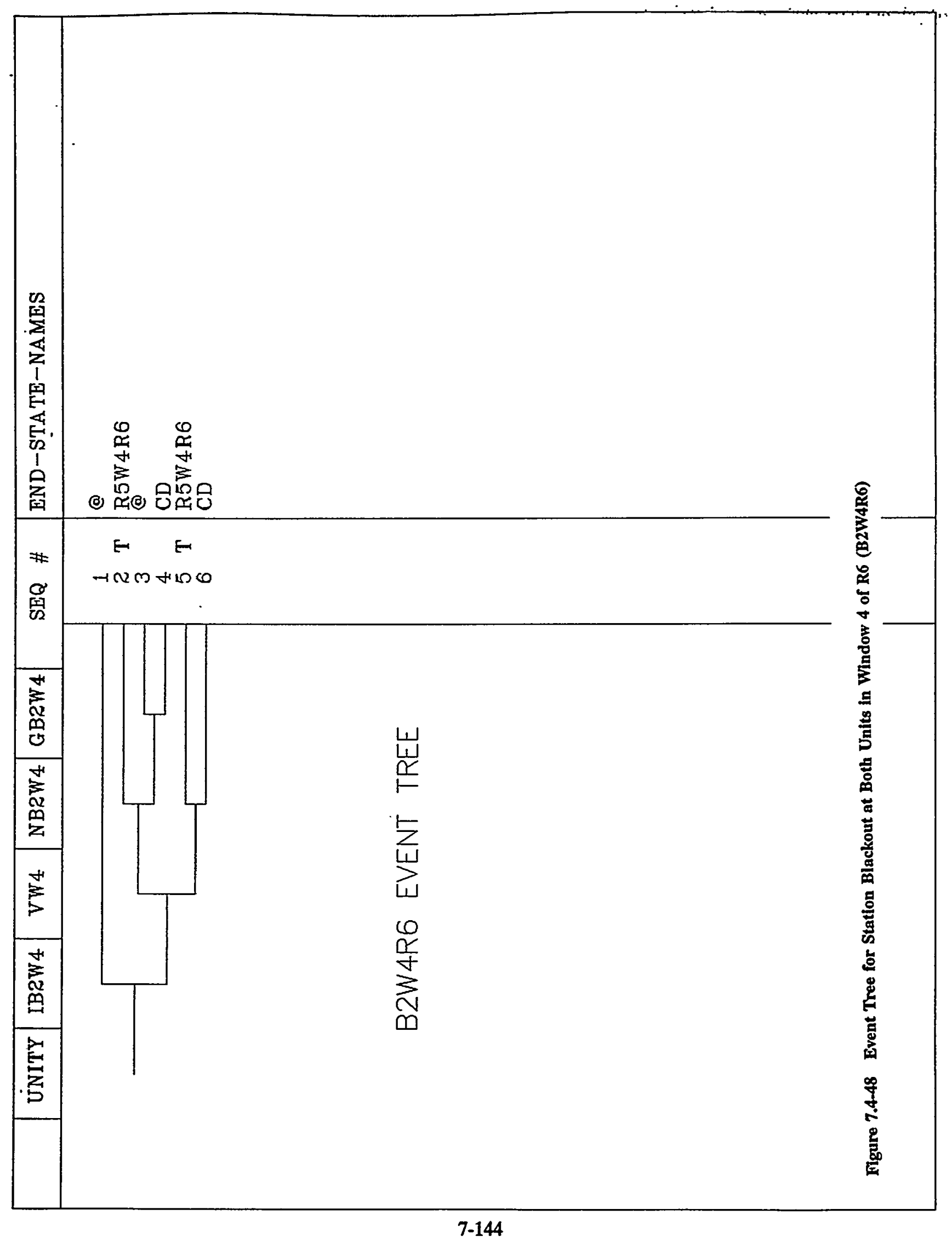




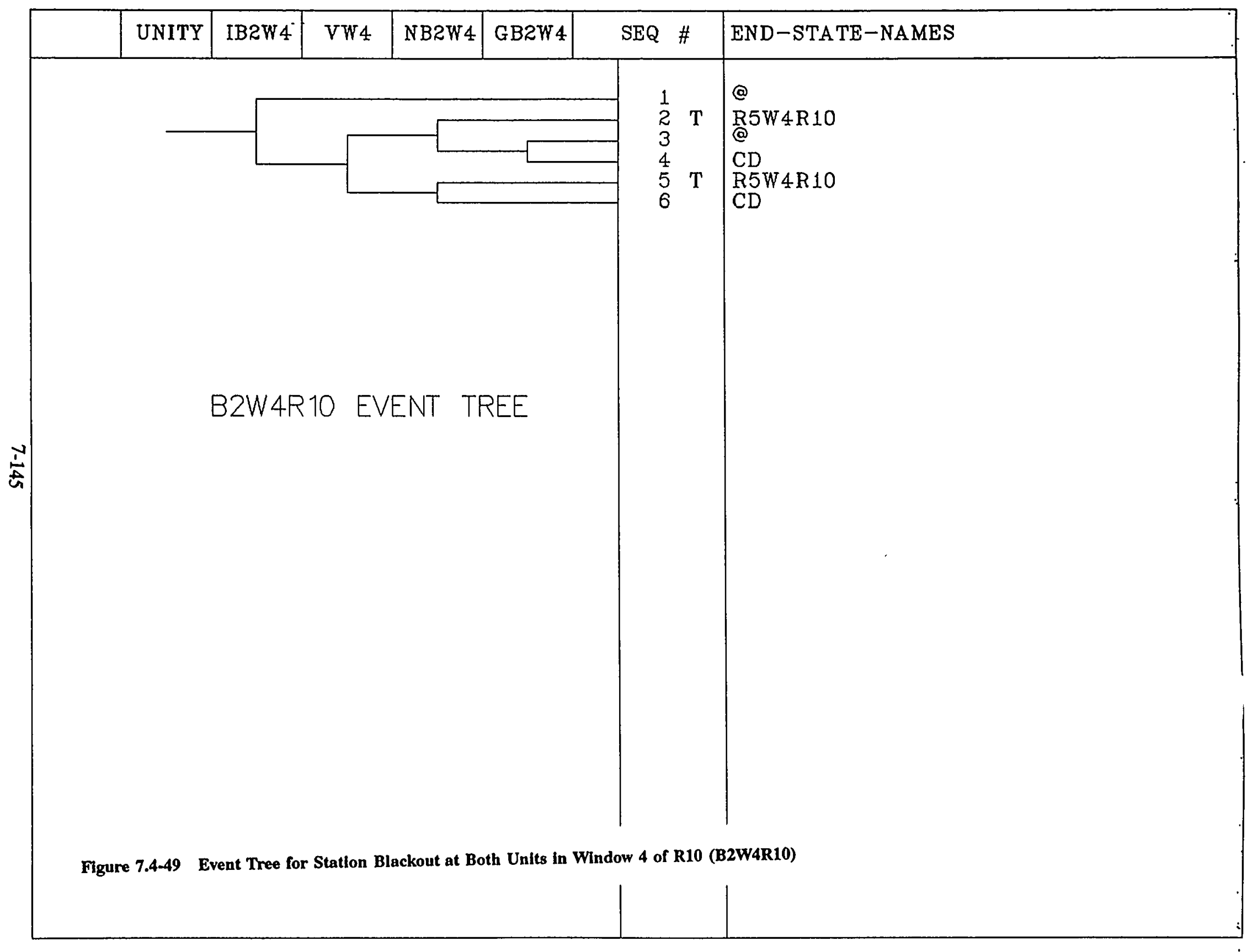




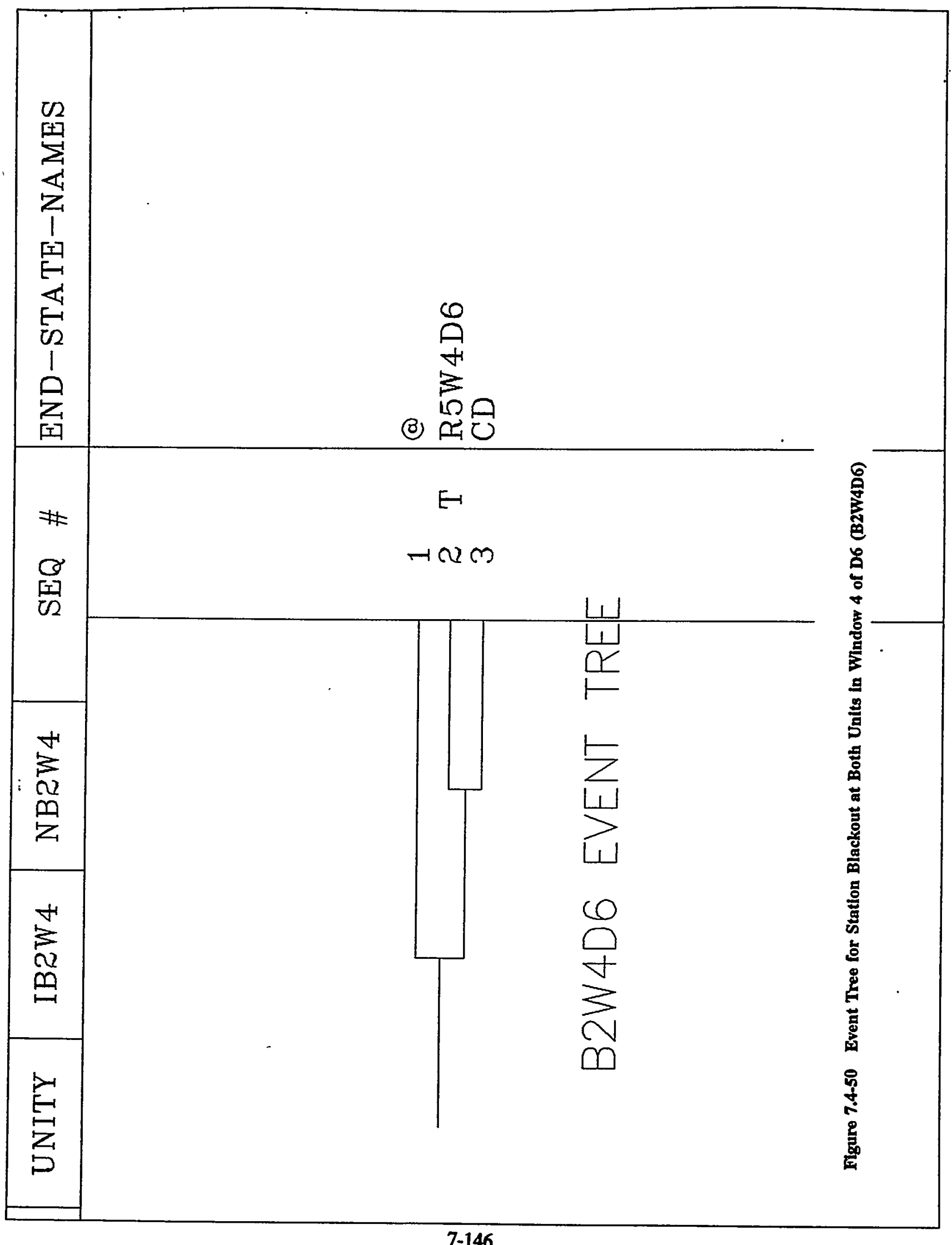


Table 7.4-1

LOSP/SB Analysis Cases

\begin{tabular}{|c|c|c|c|c|}
\hline \multirow{2}{*}{$\begin{array}{c}\text { LOSP/SB } \\
\text { Case }\end{array}$} & \multirow{2}{*}{$\begin{array}{c}\text { DG \#1 } \\
\text { (1H Bus) }\end{array}$} & \multirow{2}{*}{$\begin{array}{c}\text { DG \#2 } \\
\text { (2H Bus) }\end{array}$} & \multicolumn{2}{|c|}{ DG \#3 } \\
\hline & & & (1J Bus) & (2J Bus) \\
\hline $\begin{array}{l}\text { L1 } \\
\text { L1 }\end{array}$ & $\begin{array}{l}\text { S } \\
\mathbf{S}\end{array}$ & $\begin{array}{l}\mathbf{F} \\
\mathbf{S}\end{array}$ & $\begin{array}{l}\mathbf{S} \\
\mathbf{S}\end{array}$ & \\
\hline $\begin{array}{l}\text { L2 } \\
\text { L2 } \\
\text { L2 } \\
\text { L2 } \\
\text { L2 }\end{array}$ & $\begin{array}{l}\text { S } \\
\text { S } \\
\text { S } \\
\text { S } \\
\text { F }\end{array}$ & $\begin{array}{l}\mathrm{S} \\
\mathrm{S} \\
\mathrm{F} \\
\mathrm{M} \\
\mathrm{S}\end{array}$ & $\mathbf{F}$ & $\begin{array}{l}\text { S } \\
F \\
S \\
S\end{array}$ \\
\hline $\begin{array}{l}\text { L3 } \\
\text { L3 } \\
\text { L3 }\end{array}$ & $\begin{array}{l}\mathbf{S} \\
\mathbf{S} \\
\mathbf{F}\end{array}$ & $\begin{array}{c}\mathbf{F} \\
\mathbf{M} \\
\mathbf{F}\end{array}$ & $\begin{array}{l}\mathbf{F} \\
\mathbf{S}\end{array}$ & $\begin{array}{l}F \\
F\end{array}$ \\
\hline $\begin{array}{l}\text { B1 } \\
\text { B1 } \\
\text { B1 } \\
\text { B1 }\end{array}$ & $\begin{array}{l}F \\
F \\
F \\
F\end{array}$ & $\begin{array}{l}\mathbf{S} \\
\mathbf{S} \\
\mathbf{F} \\
\mathbf{M}\end{array}$ & $\mathbf{F}$ & $\begin{array}{l}\text { S } \\
F \\
S \\
S\end{array}$ \\
\hline $\begin{array}{l}\text { B2 } \\
\text { B2 }\end{array}$ & $\begin{array}{l}\mathbf{F} \\
\mathbf{F}\end{array}$ & $\begin{array}{c}\mathbf{F} \\
\mathbf{M}\end{array}$ & $\begin{array}{l}\mathbf{F} \\
\mathbf{F}\end{array}$ & $\begin{array}{l}\mathbf{F} \\
\mathbf{F}\end{array}$ \\
\hline
\end{tabular}

NOTES:

F - DG fails to start, fails to run, or fails to load onto The emergency bus

M - DG down for maintenance, only maintenance on DG 2 taken into account here, and in which case DG 3 is assumed as being aligned to $2 \mathrm{Jbus}$

S - Success 
7 Event Tree Analysis

Table 7.4-2

Power Supplies for Circulating Water Main Condensers' Inlet and Outlet Valves

\begin{tabular}{|c|c|c|}
\hline $\begin{array}{l}\text { Motor-operated } \\
\text { valves }\end{array}$ & Power Supply & Breaker \\
\hline MOV-CW-100A & MCC 1J1-1A & $3 \mathrm{~A}$ \\
\hline MOV-CW-100B & MCC 1H1-1 & $8 \mathrm{~A}$ \\
\hline MOV-CW-100C & MCC 1J1-1A & 3B \\
\hline MOV-CW-100D & MCC 1H1-1 & 7A \\
\hline MOV-CW-106A & MCC 1H1-1 & $7 \mathrm{C}$ \\
\hline MOV-CW-106B & MCC 1J1-1A & $3 C$ \\
\hline MOV-CW-106C & MCC 1H1-1 & $6 \mathrm{~B}$ \\
\hline MOV-CW-106D & MCC 1J1-1A & $3 D$ \\
\hline MOV-CW-200A & MCC 1J1-1A & $4 \mathrm{D}$ \\
\hline MOV-CW-200B & MCC 2H1-1 & $8 \mathrm{~A}$ \\
\hline MOV-CW-200C & MCC 1J1-1A & $4 \mathrm{E}$ \\
\hline MOV-CW-200D & MCC 2H1-1 & $7 \mathrm{~A}$ \\
\hline MOV-CW-206A & MCC 2H1-1 & $7 \mathrm{C}$ \\
\hline MOV-CW-206B & MCC 1J1-1A & $5 \mathrm{~A}$ \\
\hline MOV-CW-206C & MCC 2H1-1 & $6 B$ \\
\hline MOV-CW-206D & MCC 1J1-1A & $5 \mathrm{D}$ \\
\hline
\end{tabular}




\subsection{Support-System Failure Event Trees}

This section describes the event trees developed for the following initiating events:

(1) Loss of $4.16 \mathrm{kV}$ AC Emergency Bus.

(2) Loss of a $120 \mathrm{~V}$ AC Vital Bus.

(3) Spurious ESFAS Signal.

(4) Loss of Instrument Air.

(5) Loss of Component Cooling Water.

Ten event trees were developed for each initiating event. The different event trees reflect the different system configurations and other conditions in the respective mid-loop operation modes: POS 6 -Refueling, POS 10 Refueling, and POS 6 - Drained Maintenance, as well as the different success criteria used in different time windows.

The event trees were based on:

(a) abnormal procedure AP 27.00 Rev. 4 describing the operator's actions given a generic loss of the RHR system,

(b) abnormal procedures describing the operator's actions given loss of a particular support system (under power operation),

1-ECA-0.0 Loss of All AC Power (Rev. 6), 4/22/92

1-ECA-0.1 Loss of All AC Power Without SI Required (Rev. 6), 4/22/92

1-ECA-0.2 Loss of all AC Power With SI Required (Rev. 4), 4/22/92

O-AP-17.00Auto Start Failure of \#1 or \#2 EDG (Rev. 1), 3/29/91

O-AP-17.01\#1 or \#2 EDG Fails to Accept Electrical Load (Rev. 1),3/28/91

O-AP-17.02Auto Start Failure of 3 EDG (Rev. 0), 8/14/90

O-AP-17.03\#3 EDG Fails to Accept Electrical Load (Rev. 1), 3/28/91

1-AP-10.01 Loss of Vital Bus I (Rev. 3), 4/23/92

1-AP-10.02 Loss of Vital Bus II (Rev. 2), 4/23/92

1-AP-10.03 Loss of Vital Bus III (Rev. 2), 4/23/92

1-AP-10.04 Loss of Vital Bus IV (Rev. 1), 4/23/92

1-AP-10.05 Loss of Semi-Vital Bus (Rev. 1), 12/12/91

1-AP-15.00 Loss of Component Cooling (Rev. 1), 12/5/91

O-AP-40.0 Non-Reversible Loss of Instrument Air (Rev. 3), 12/5/91

(c) information obtained from plant personnel.

The support system event trees are similar to the event trees for loss of RHR. Each loss of support system initiating event has its own impacts on the plant. The impacts and how they were modeled are discussed in this section. The recovery from such loss is modeled as a top event, the " $\mathrm{H}^{\mathrm{n}}$ top event, in the event trees. The recovery is modeled using the recovery curves estimated using industry data. (see Chapter 4 and Appendix D)

\subsubsection{Event Trees for Loss of a 4.16 kV AC Emergency Bus}

"Loss of a $4.16 \mathrm{kV}$ AC Emergency Bus" initiator is defined as a power failure either due to a loss of preferred feed from the Reserve Station Service Supply or due to a local bus/breaker failure (short), causing a momentary loss of all the loads on the bus affected. The power can be recovered after the failure is cleared by the associated diesel generator, by the RSS Supply or by backfeed. 


\section{Event Tree Analysis}

We selected, the loss of $4.16 \mathrm{kV}$ AC Emergency Bus " $\mathrm{H}$ " event for analysis because it interrupts the operating RHR train. The associated event tree treats the "Loss of a $4.16 \mathrm{kV}$ AC Emergency Bus" event as a loss of RHR event, coupled with the unavailability of one of the two essential power supplies to the RHR System.

\subsubsection{1 "Loss of a 4.16 kV AC Bmergency Bus" Event Tree - Refueling POS 6}

\section{Window 1}

The event tree, 4KW1R6, applicable to this POS in this window is presented in Figure 7.5.1-1.

The top events of the tree represent the following events:

I4KW1 - Probability of "Loss of a $4.16 \mathrm{kV}$ AC Emergency Bus" initiating event during W1

The initiating event frequency, as well as the duration of W1, were based on industrial experience (see Chapter 4 and Appendix D).

\section{H4KW1 - Recovery of the 4.16 kV AC Emergency Bus $\mathrm{H}$}

The recovery assumes, as was mentioned above, that the direct failure of the bus was cleared before power is resupplied to the bus. The time for successful recovery is taken to be equal to the time to boiling of the coolant in this POS. The non-recovery factor (PRNR $=0.018$ ) represents the inability of the associated diesel generator to start $(P=.05)$ and provide the power demand of the loads ( $4 \mathrm{KV}$ bus non-recovery, $\mathrm{PNR}=.35$; PRNR $=\mathrm{P}^{*} \mathrm{PNR}$ ). The non-recovery factor of the $4 \mathrm{KV}$ bus was determined from operating experience that is documented in Appendix $\mathrm{D}$.

\section{R4KW1 - Restoring RHR}

The event represents the restoration of the RHR system, conditional on the preceding event: if Emergency Bus $H$ is recovered, both RHR trains $A$ and $B$, can be rendered operable; however, if it is not recovered, the operator will restore only the standby RHR train. The restoration of the RHR requires local venting of the RHR pumps, verifying RHR heat sink, and restarting an RHR pump.

\section{VW1 - RCS Vented}

The event represents the initial condition of the RCS, whether or not the three pressurizer safety relief valves are removed. The event is required because it affects the applicability of alternative heat-removal techniques: gravity-feed from the RWST needs vented RCS. The availability of reflux cooling is affected also because such cooling cannot be accomplished if there was a loss of RCS inventory through the vents of the pressurizer (each safety valve removed leaves a 4-inch diameter opening on top of the pressurizer). For such an event, a probability of 0.01 was estimated in window 1 (see Sections 3.6 and 9.4).

S4KW1 - Reflux Cooling through the Steam Generators

The event represents the reflux cooling to remove heat. It is described in detail in the previous section for this POS. Its availability is evaluated with and without the availability of the Emergency Bus $\mathrm{H}$.

\section{F4KW1 - Primary Feed-and-Bleed}

The event represents the feed-and-bleed (spill) operation of the primary systems that is described in section 7.2. Its availability is determined in the event tree with and without the availability of the Emergency Bus $H$.

\section{G4KW1 - Gravity Feed from the RWST}

The event represents the gravity feeding of RWST water into the RCS through the LPI System; it can only be used if the RCS is vented. The gravity feed and its preconditions are discussed thoroughly in the previous section. Its availability is evaluated in the event tree with and without the availability of the Emergency Bus H. 


\section{C4KW1 - Recirculation}

The feed-and-bleed method must be supplemented by the recirculation function to insure long-term heat removal.

The event tree shows that Sequences $4,5,6,9,10,13,1415,18$, and 19 lead to core damage, because of the failed methods of decay- heat removal. We note that Sequences $4,5,6,9$, and 10 have to be quantified with recovered Emergency Bus $H$, and Sequences 13 through 19 with the condition that Emergency Bus $H$ is not available.

\section{Window 2}

Figure 7.5.1-2 shows the event tree, $4 \mathrm{KW} 2 \mathrm{R} 6$, applicable to this $\mathrm{POS}$ in window 2. The meanings of the top events are similar to top events in window 1 , and only those are described which are different (the notation changes by replacing W1 to W2, i.e., I4KW1 - I4KW2, etc.)

\section{H4KW2 - Recovery of 4KV Bus}

The $4 \mathrm{KV}$ bus non-recovery probability is .25 and the total non-recovery probability, including the failure of the diesel generator to start, is PRNR $=.013$.

VW2 - RCS Vented

The probability of removal of the pressurizer safety valves is estimated at .05 .

\section{C4KW2 - Recirculation}

If the unit 2 RWST can be cross-connected to unit 1 RWST, then there is no need for a recirculation function.

Window 3

Figure 7.5.1-3 shows the event tree, 4KW3R6.

\section{H4KW3 - Recovery of 4KV Bus}

The value of PRNR $=.009$.

VW3 - RCS Vented

The probability that the safety valves are removed, $P=.9$.

Window 4

Figure 7.5.1-4 shows the event tree, 4KW4R6.

H4KW4 - Recovery of 4KV Bus

The value of PRNR $=.008$.

VW4 - RCS Vented

The probability that the safety valves are removed, $P=.3$.

\subsubsection{2 "Loss of a 4.16 kV AC Emergency Bus" Event Tree - Refueling POS 10}

\section{Window 3}

The event tree, 4KW3R10, applicable to this POS is given in Figure 7.5.1-5. Due to the different conditions and features characterizing this POS, top events questioning the availability of reflux cooling (S) and the necessity of recirculation function are not needed. 


\section{Event Tree Analysis}

The meanings of the top events are identical to those involved in the window 3 POS 6 - Refueling Event Tree.

I4KW3 - Initiating event probability during R10

H4KW3 - Recovery of Emergency Bus H, provided by the associated diesel generator

R4KW3 - Restoration of the RHR

VW3 - RCS Vented

F4KW3 - Primary Feed-and-Bleed

G4KW3 - Gravity-Feedfrom the RWST

In the event tree, the following sequences lead to core damage: Sequences: $4,5,7,10,11$, and 13 . Sequences 4,5 , and 7 are quantified with recovered Emergency Bus $H$, and Sequences 10, 11, and 13 with the condition that Emergency Bus $\mathbf{H}$ is not available.

\section{Window 4}

Figure 7.5.1-6 shows the event tree, 4KW4R10. The top events are functionally the same as in window 3 , and identical to the POS 6 refueling event tree.

\subsubsection{3 "Loss of a 4.16 kV AC Emergency Bus" Event Tree - Drained Maintenance POS 6}

Window 1

The event tree, 4KW1D6, applicable to POS 6 - Drained Maintenance is shown in Figure 7.5.1-7. Due to stringent success criteria for successful heat removal, there is only one alternate technique besides the RHR System: Primary Feed-and-Bleed, coupled with the recirculation function.

The top events are described below:

I4KW1 - Initiating event probability during D6

H4KW1 - Recovery of Emergency Bus $\mathrm{H}$, as provided by the associated diesel generator

R4KW1 - Restoration of the RHR

F4KW1 - Primary Feed-and-Bleed

C4KW1 - Recirculation Function.

In the event tree, the following sequences lead to core damage: Sequences $4,5,8$, and 9. Sequences 4 and 5 are quantified with recovered Emergency Bus $H$, Sequences 8 and 9 are quantified with the condition that Emergency Bus $\mathrm{H}$ is not available.

Window 2

The event tree 4KW2D6 is presented in Figure 7.5.1-8.

S4KW2 - Reflux Cooling

Reflux cooling is available in this window for drained maintenance. 
7 Event Tree Analysis

Window 3

Figure 7.5.1-9 shows the event tree, 4KW3D6. The recirculation function (c) is removed.

Window 4

The event tree, 4KW4D6, is given in Figure 7.5.1-10, which is the same as window 3 with the appropriate top events. 


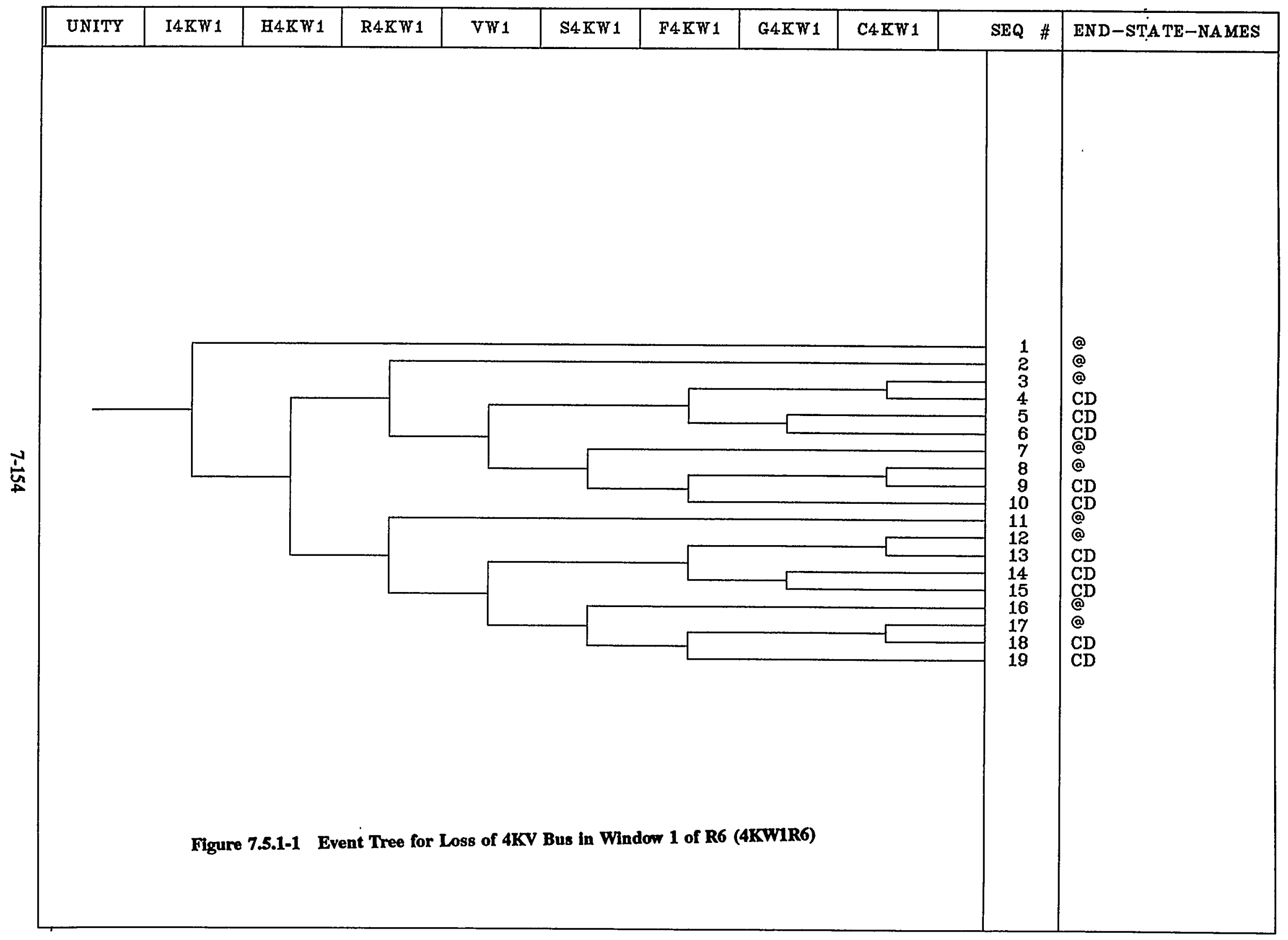




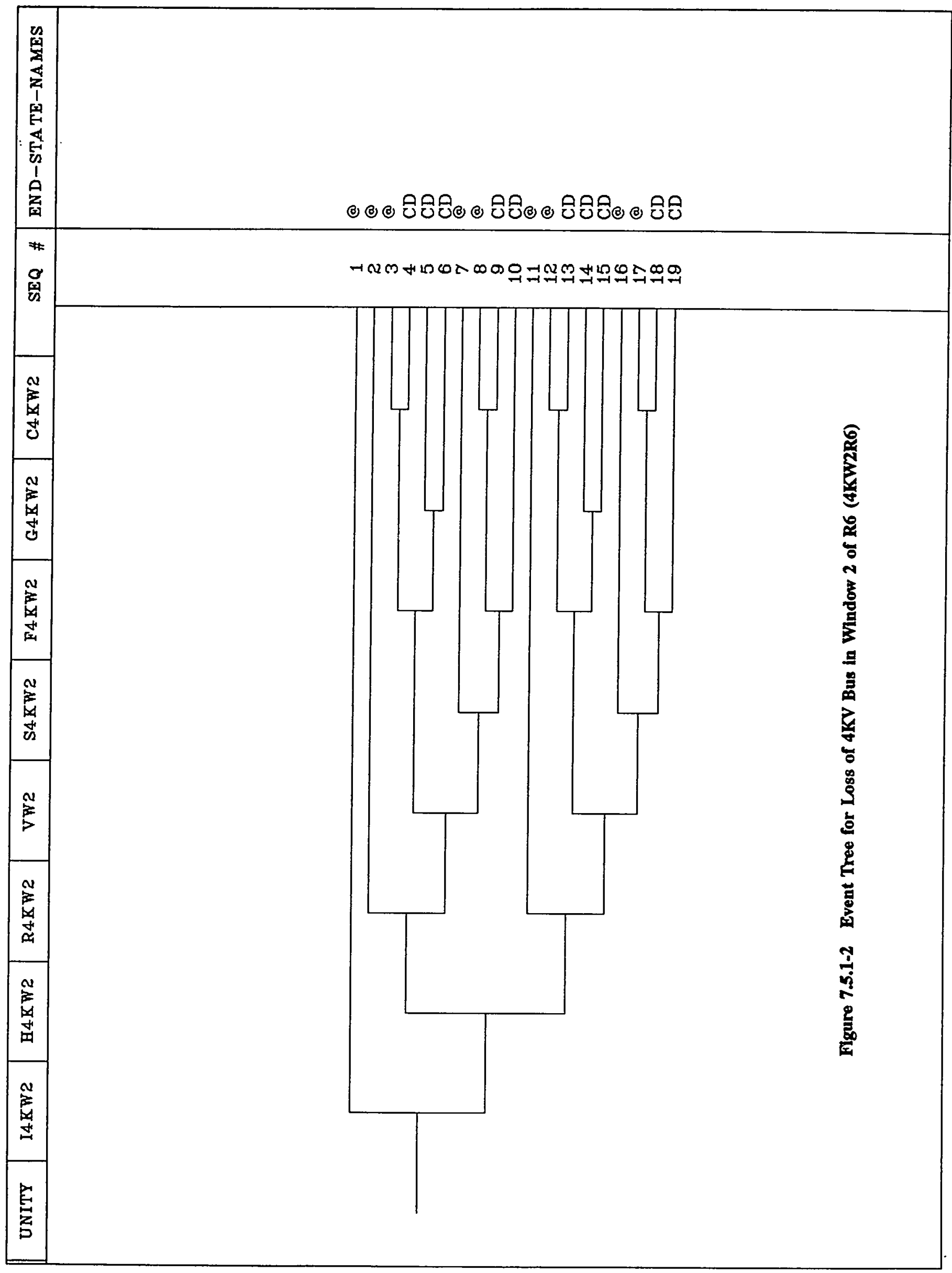




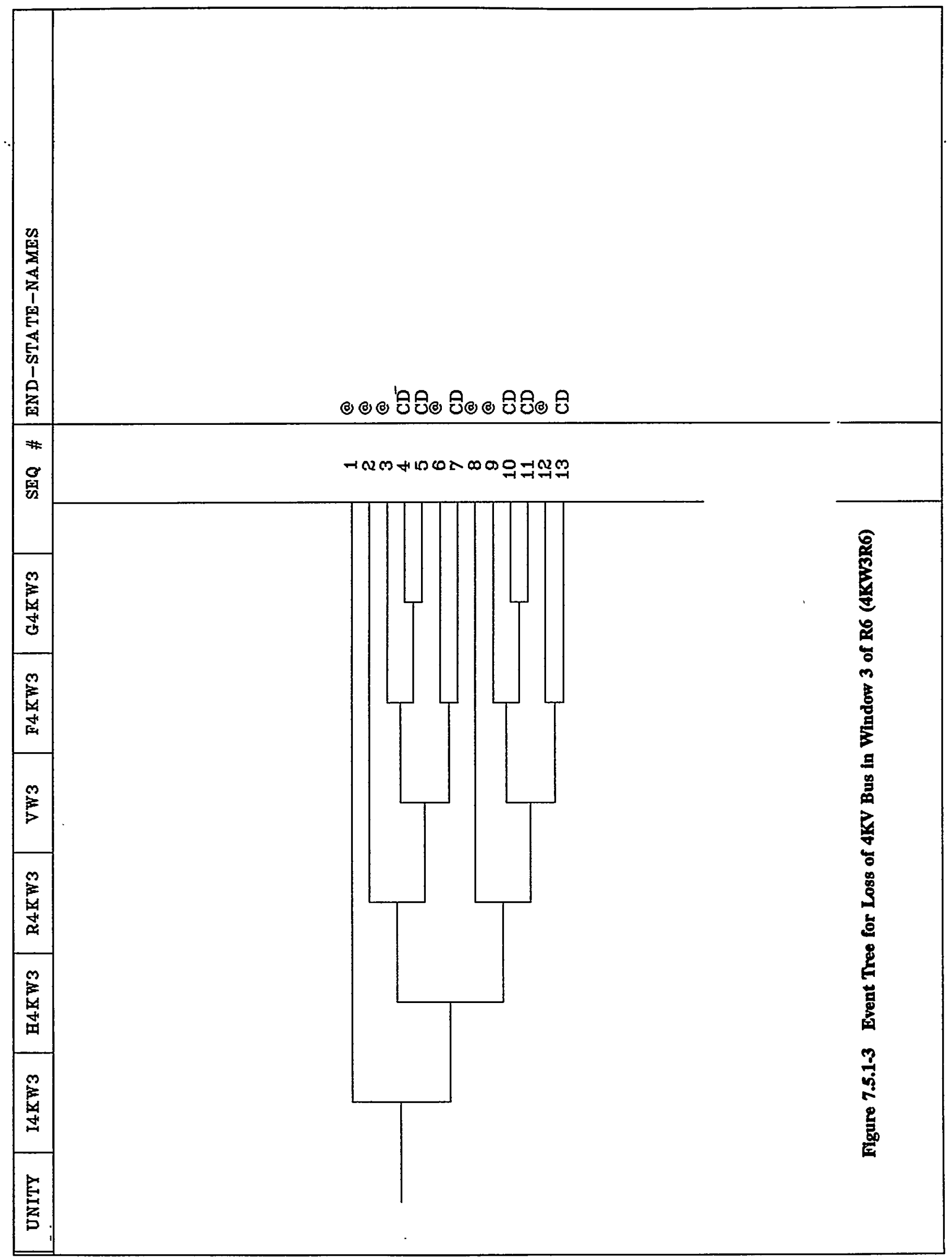




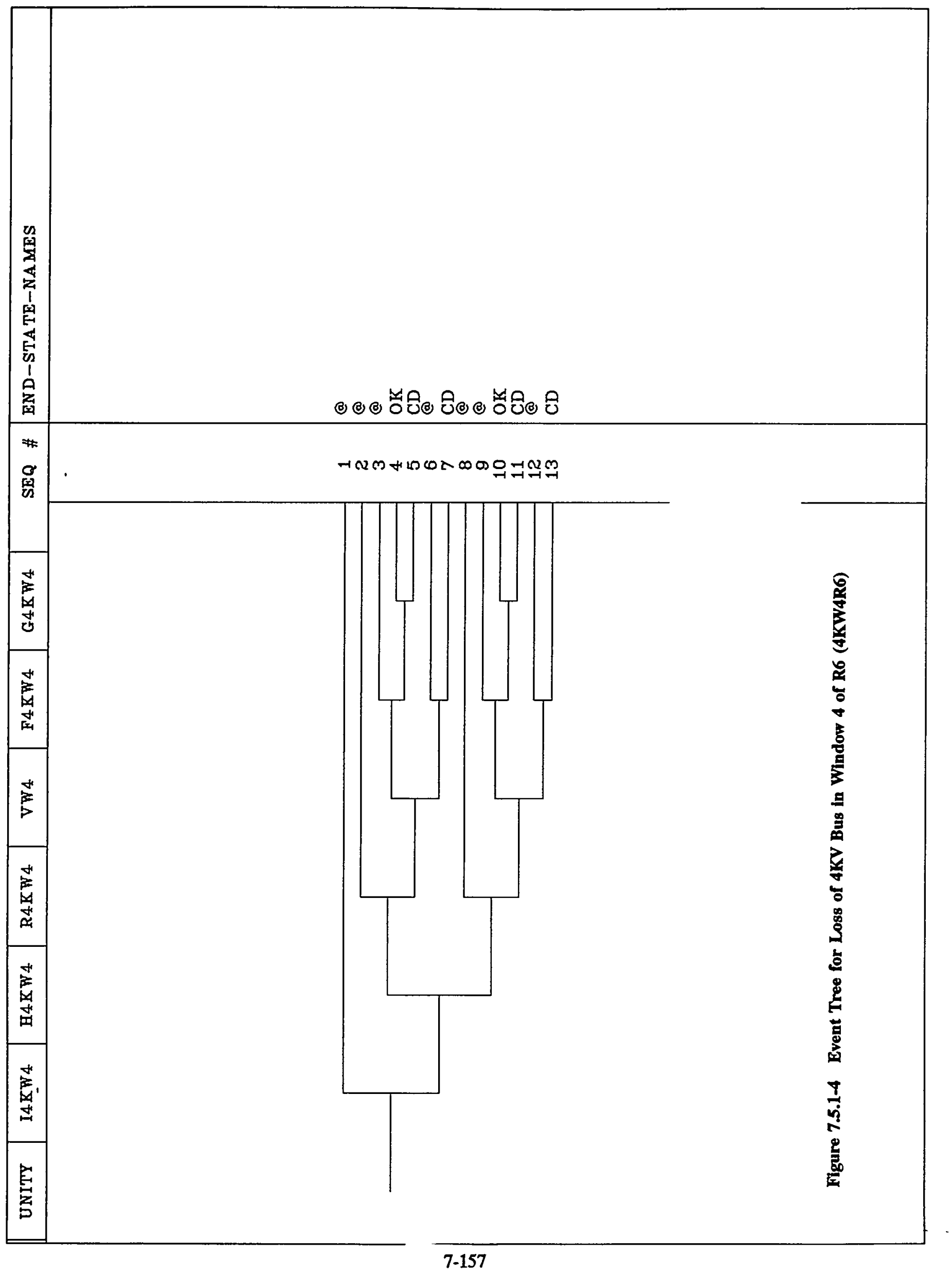




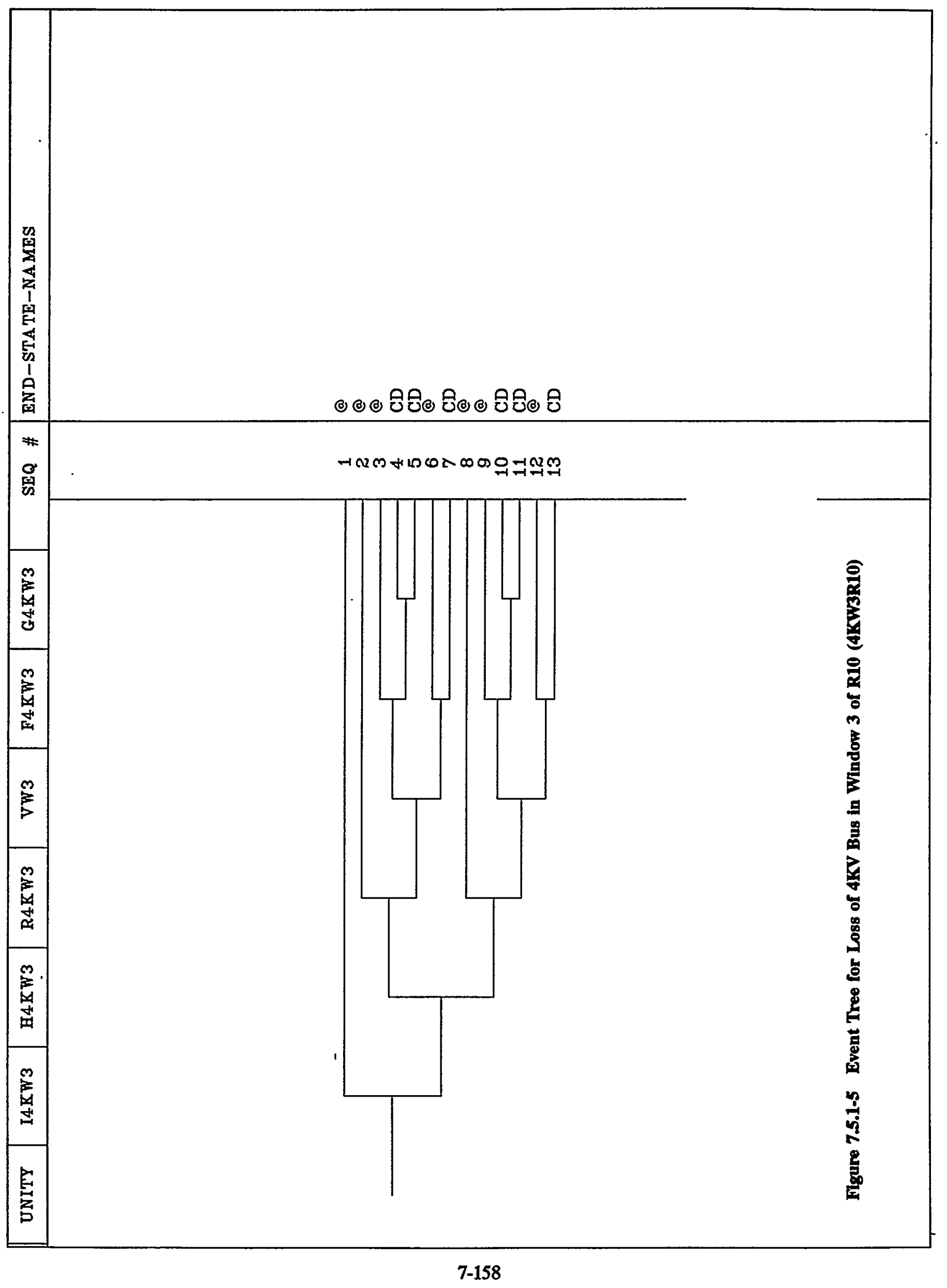




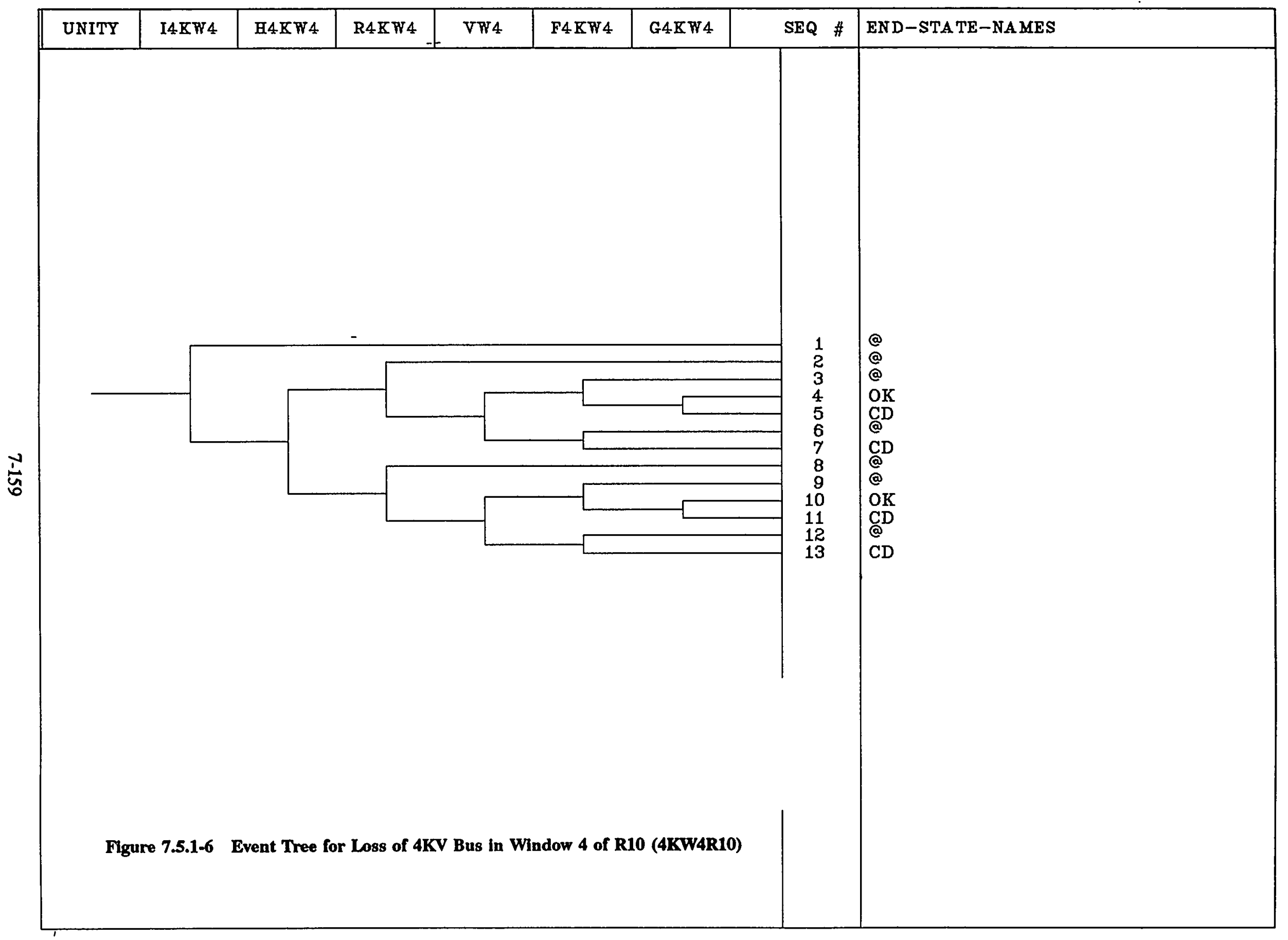




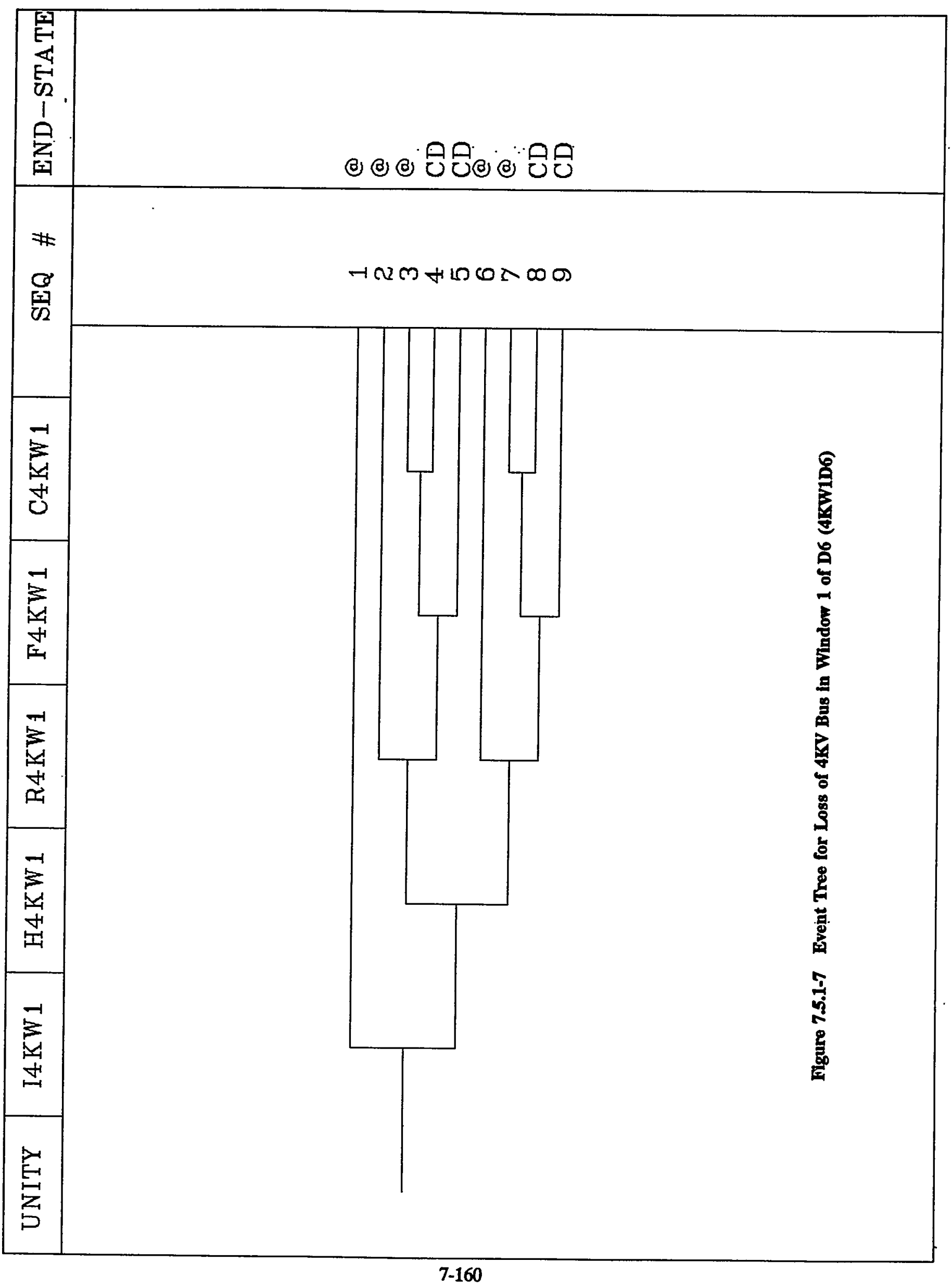




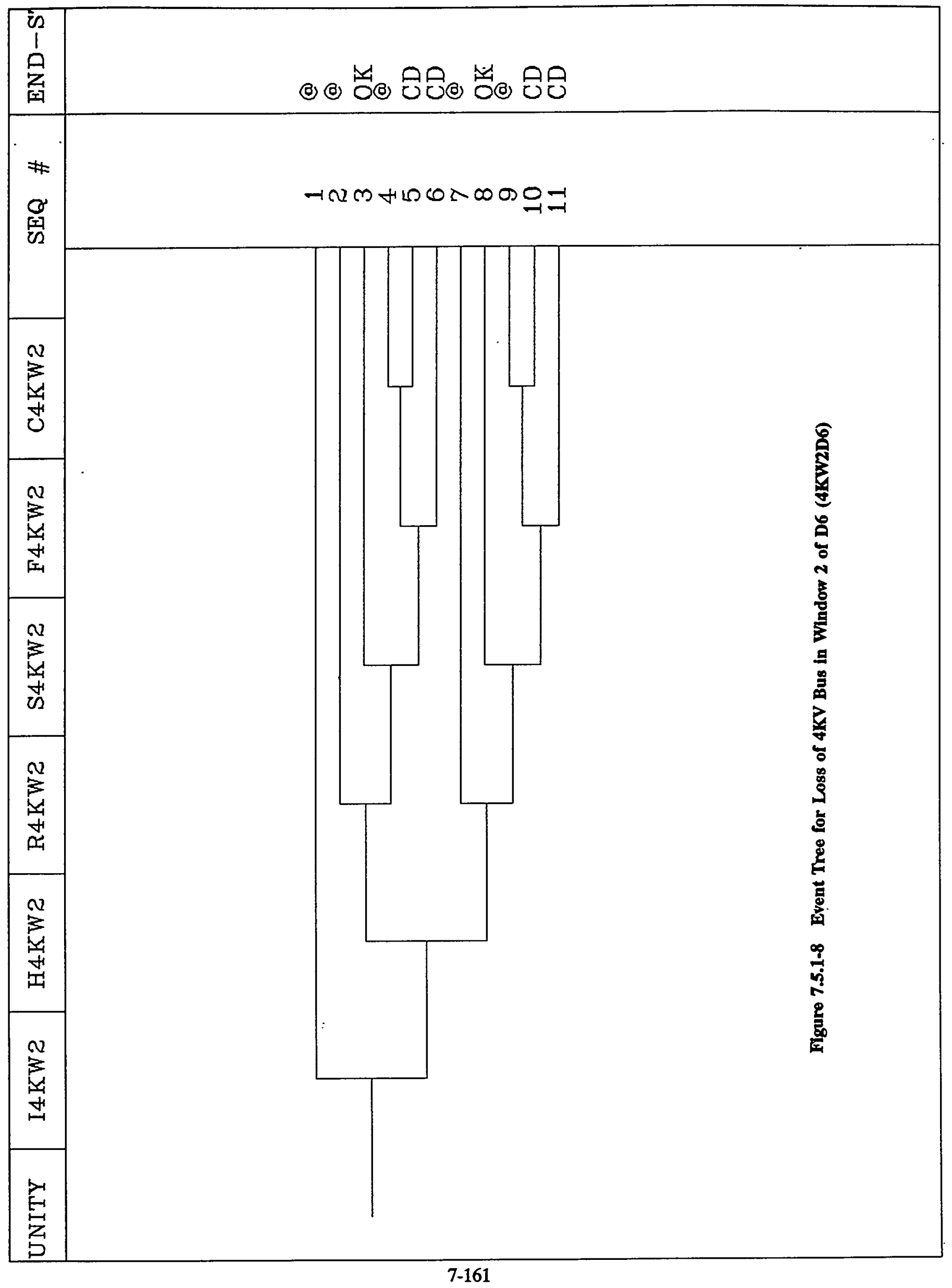




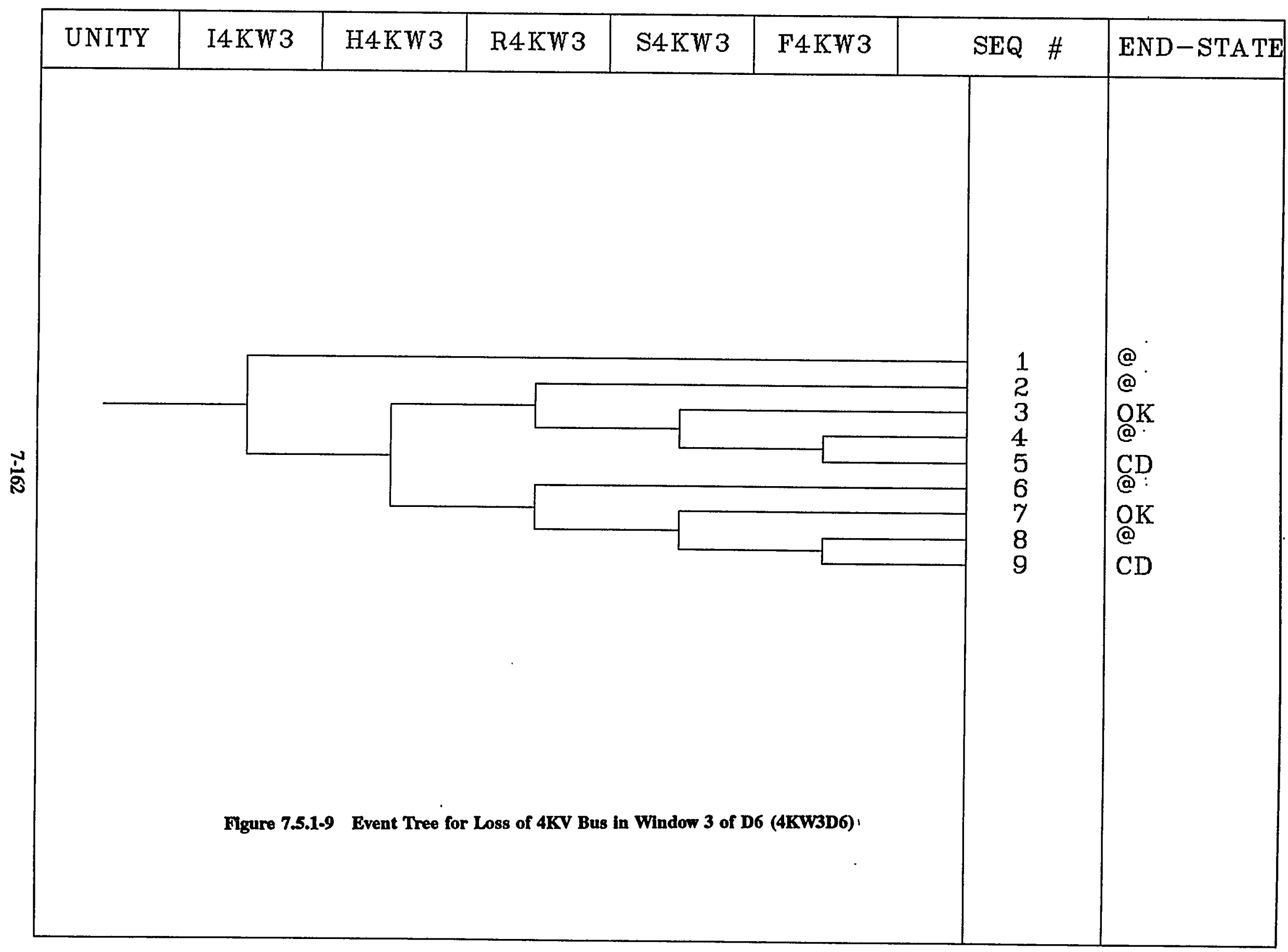




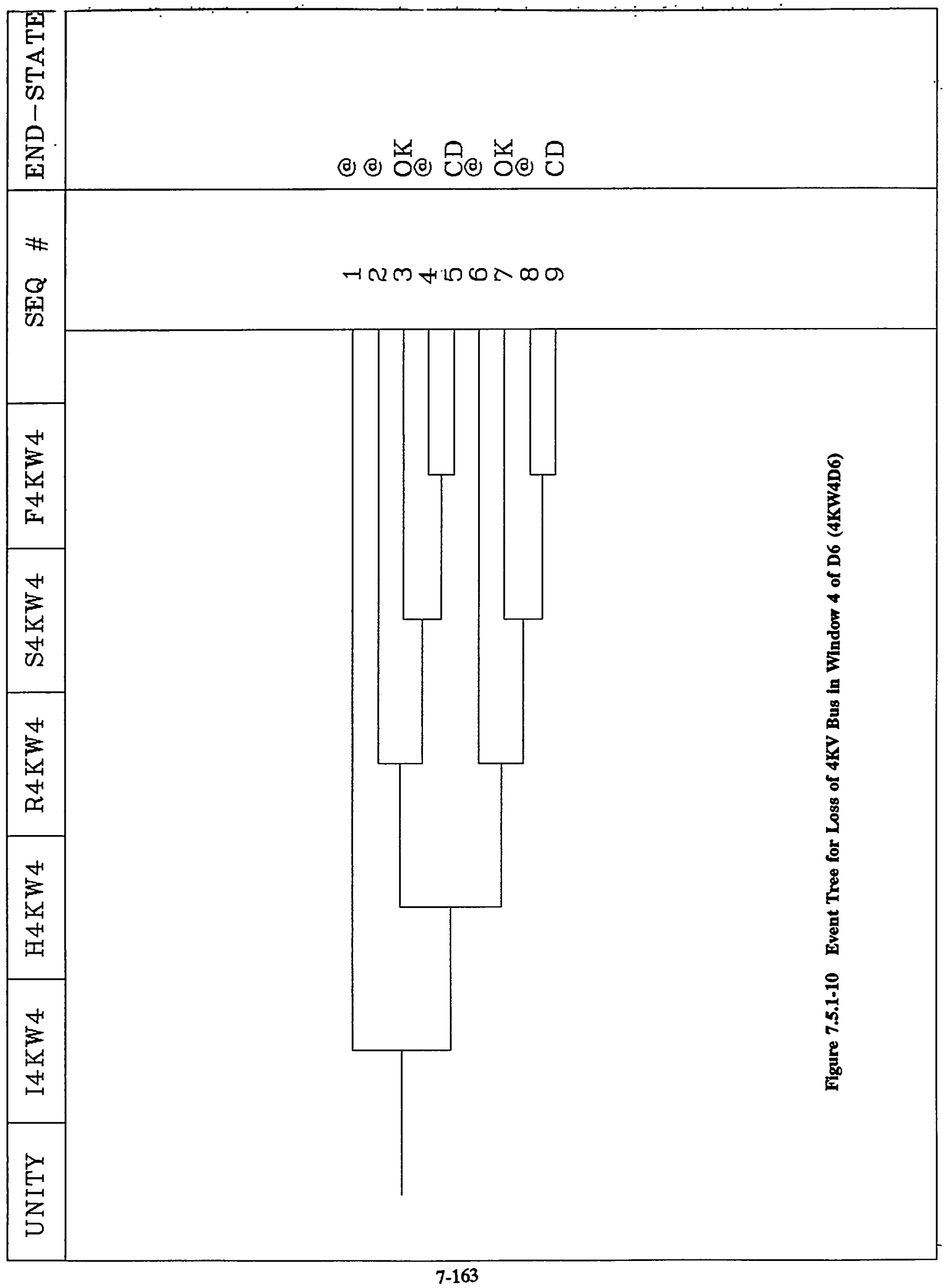




\section{Event Tree Analysis}

\subsubsection{Event Trees for Loss of a $120 \mathrm{~V}$ AC Vital Bus (VB)}

In Section 4.4.3 we pointed out that during mid-loop operations "Loss of a $120 \mathrm{~V}$ AC Vital Bus" is a valid initiator with the potential to damage the core. The loss of $120 \mathrm{~V} \mathrm{AC}$ Vital Bus 1-III was selected as representative ${ }^{1}$ of the initiator. The loss of this bus interrupts the operation of the RHR system because it causes the flow control valve 1-RH-HCV-1758 (RHR HX flow) to fail open with the potential of starting RHR pump runout.

The bus can be recovered after its local failure has been cleared. If not, the operator has to adjust the flow control valve locally to restore the operation of the RHR. If the operator could not regain flow control, but started the standby RHR train, there would be a risk of losing the whole RHR.

\subsection{1 "Loss of a 120 V AC Vital Bus" Brent Tree - Refueling POS 6}

\section{Window 1}

Figure 7.5.2-1 presents the event tree, VBW1R6, applicable to this POS in Window 1.

The top events of the tree represent the following events:

IVBW1 - "Loss of a $120 \mathrm{~V}$ AC Vital Bus" initiating event probability

The initiating event frequency, as well as the duration of W1 were determined from industrial experience (see Appendix D).

\section{HVBW1 - Recovery of the $120 \mathrm{~V}$ AC Vital Bus, 1-III}

The recovery presupposes that the bus failure has been cleared before power is resupplied to it. The interval for successful recovery is taken to be equal to the time to boiling of the coolant in this time window. The recovery factor (.3) corresponding to this interval was determined using experienced data. The recovery data describing Vital Bus/RHR recovery as a function of time are given in Section 4.4.9.

\section{RVBW1 - Restore RHR}

The event represents the restoration of the RHR system. The restoration is conditional on the preceding event: if Vital Bus 1-III is recovered before boiling takes place it is assumed that the operating RHR pump is not affected. If the bus is not recovered, the operating RHR pump is failed and the operator has to enter the containment and manually adjust the RHR flow control valve 1-RC-HCV 1758. The restoration of the RHR requires local venting of the pumps, verifying the heat sink, and starting the standby RHR pump.

VW1 - RCS Vented

${ }^{1}$ The loss of Vital Bus 1-I or 1-II has the possibility of failing the operation of the RHR because it causes the isolation valve 1-TV-CC-109A or 109B (CCW return from RHR) to close. If the 109A valve is closed, CCW is lost to the operating RHR heat exchanger. Closure of the 109B valve will isolate the CCW to both RHR pump seal coolers. According to plant personnel, loss of RHR pump seal cooling does not represent real initiating event because the RHR pumps can operate, even for 24 hours, without seal cooling provided that relatively cool water is circulating in the RHR. Therefore, it would be conservative to assume that loss of bus 1-II leads to loss of RHR. If the Vital Bus cannot be recovered, the operator will have to local manually open the 109 valve with a portable air bottle and restore the CCW to RHR. 
The event represents the initial condition of the RCS, whether the three pressurizer safety relief valves are removed or not. The event is required because it affects the applicability of alternative heat removal techniques: gravity feed from the RWST needs vented RCS. The availability of reflux cooling also is affected because such cooling is not possible if there was a loss of RCS inventory through the vents of the pressurizer (each safety valve removed leaves a 4-inch diameter opening on top of the pressurizer). For such an event, a probability of 0.01 was estimated in window 1 (see Sections 3.6 and 9.4).

\section{SVBW1 - Reflux cooling through the Steam generators}

The event represents the reflux cooling to remove heat, that is fully described in Section 7.2. The availability of the reflux cooling is evaluated with and without the availability of Vital Bus 1-III.

\section{FVBW1 - Primary Feed-and-Bleed}

The event represents the feed-and-bleed (spill) operation of the primary system that also is described in Section 7.2. The availability of the feed-and-bleed operation is determined in the event tree with and without the availability of Vital Bus I-III.

\section{GVBW1 - Gravity Feed from the RWST}

The event represents the gravity feeding of RWST water into the RCS through the LPI System; this can only be used if the RCS is vented. The gravity feed and its preconditions are discussed in Section 7.2. The availability of the gravity feed is evaluated in the event tree with and without the availability of Vital Bus 1-III.

\section{C4KW1 - Recirculation}

Recirculation function provides long term heat removal once the RWST inventory is injected.

The event tree shows that Sequences $4,5,6,9,10,13,14,15,18$, and 19 lead to core damage because of the failure of decay heat removal. Sequences $4,5,6,9$, and 10 have to be quantified with recovered Vital Bus 1-III, and sequences $13,14,15,17,18$, and 19 with the condition that Vital Bus 1-III is not available.

\section{Window 2}

Figure 7.5.2-2 shows the event tree, VBW2R6.

\section{HVBW2 - Recovery of Vital Bus}

The value of non-recovery of the vital Bus is PRNR $=.2$.

VW2 - RCS vented

The probability of safety valves being removed is estimated at .05 .

Window 3

The event tree, VBW3R6, is presented in Figure 7.5.2-3. Reflux cooling is not available due to isolation of the loops. Recirculation is not needed due to low decay heat.

\section{HVBW3 - Recovery of Vital Bus}

The value of non-recovery of the vital bus is PRNR $=.15$.

VW3 - RCS vented

Safety valves removed, $P=.9$.

\section{Window 4}

Figure 7.5.2-4 gives the event tree, VBW4R6. In this time window, reflux cooling is not available due to isolation of the RCS loops, and recirculation is not needed due to low decay heat level. 


\section{Event Tree Analysis}

HVBW4 - Recovery of Vital Bus

The value of non-recovery of the vital bus is $P R N R=.12$.

VW4 - RCS vented

Safety valves removed, $P=.3$.

\subsection{2 "Loss of a $120 \mathrm{~V}$ AC Vital Bus" Brent Tree - Refueling POS 10}

\section{Window 3}

The event tree, VBW3R10, applicable to this POS is presented in Figure 7.5.2-5. Due to the different conditions and features characterizing this POS, the top events questioning the availability of reflux cooling $(S)$ and recirculation function $(C)$ are not needed.

The meanings of the top events are very similar to those involved in the POS 6 - Refueling Event Tree. However, for completeness, they are described again emphasizing the differences.

IVBW3 - Initiating event probability during the duration of R10

HVBW3 - Recovery of the Vital Bus

The non-recovery probability is .15 .

\section{RVBW3 - Restore RHR}

The event represents the restoration of the RHR. The difference between this and the same event of W1 tree is that more time is available for the operator to accomplish the task.

\section{VW3 - RCS Vented}

FVBW3 - Primary Feed-and-Bleed

\section{GVBW3 - Gravity Feed from the RWST}

In the event tree the following six sequences lead to core damage: Sequences $4,5,7,10,11$, and 13. Sequences 4, 5 , and 7 are quantified with recovered Vital Bus 1-III. Sequences 10, 11, and 13 are quantified with the condition that the Vital Bus is not available.

\section{Window 4}

The event tree for this time window is shown in Figure 7.5.2-6. It has the same structure as that of window 3 except that those sequences with successful gravity feed lead to successful termination.

\subsubsection{3 "Loss of a 120 V AC Vital Bus" Event Tree - Drained Maintenance POS 6}

\section{Window 1}

Figure 7.5.2-7 shows the event tree, VBW1D6, applicable to POS 6 - Drained Maintenance condition. Due to the stringent success criteria for successful heat removal, there is only one alternate technique besides the RHR System: Primary Feed-and-Bleed coupled with the recirculation function.

The top events are described below: 
IVBW1 - Initinting event probability

HVBW1 - Recovery of the Vital Bus

The time for successful recovery is shorter than in W1; correspondingly, the probability recovery is smaller (.71).

RVBW1 - Restoration of the RHR

FVBW1 - Primary Feed-and-Bleed

CVBW1 - Recirculation Function

In the event tree, the following sequences lead to core damage: Sequences $4,5,8$, and 9 . Sequences 4 and 5 are quantified with recovered Vital Bus 1-III. Sequences 8 and 9 are quantified with the condition that the Vital Bus is not available.

Window 2

The event tree, VBW2D6, is presented in Figure 7.5.2-8

SVBW2 - Reflux cooling

Reflux cooling is available.

Window 3

Figure 7.5.2-9 shows the event tree, VBW3D6. The recirculation function (C) is removed.

Window 4

The event tree, VBW4D6, is presented in Figure 7.5.2-10 similar to window 3, and the top events are described in tree VBW4R6. 


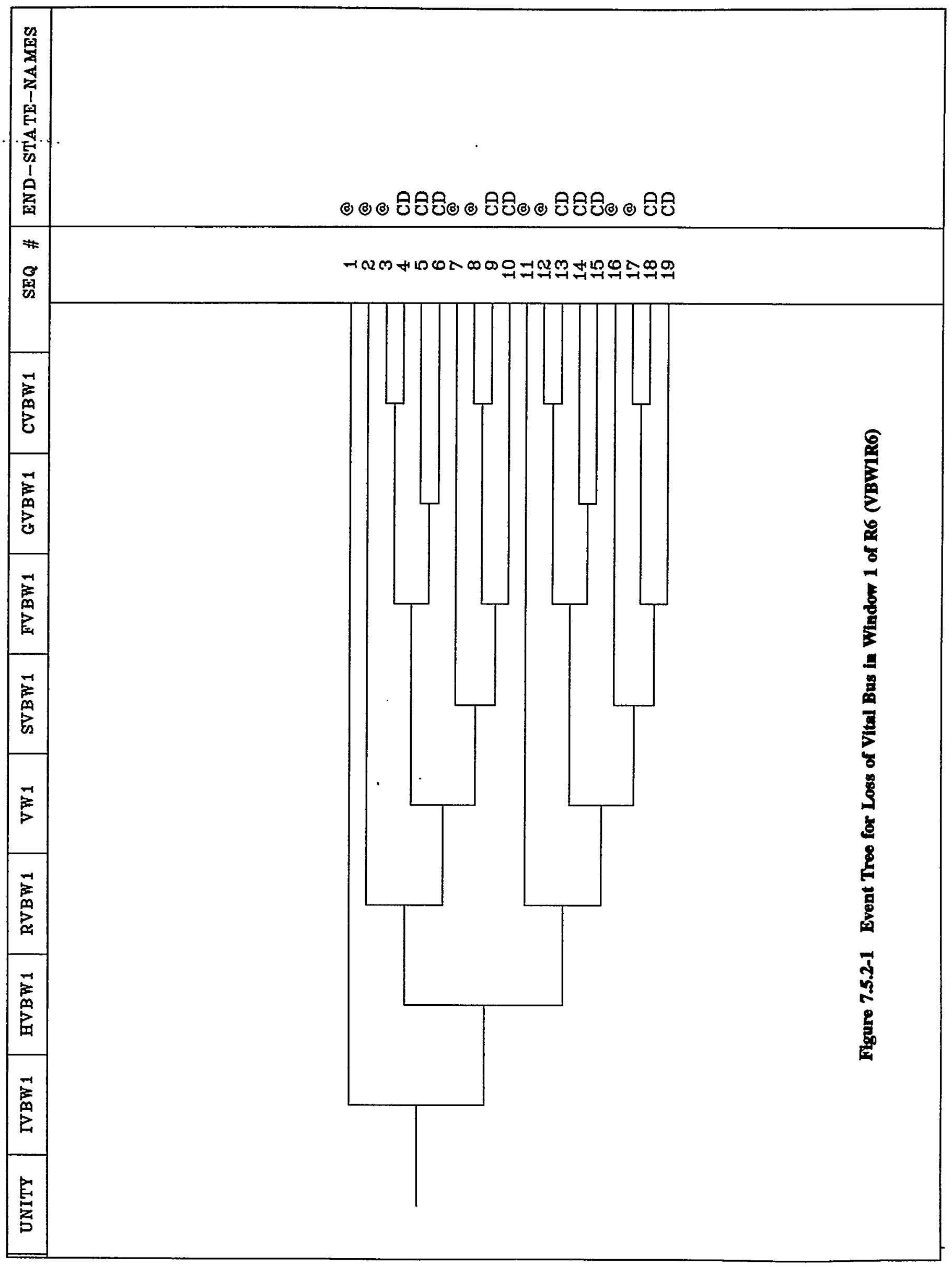




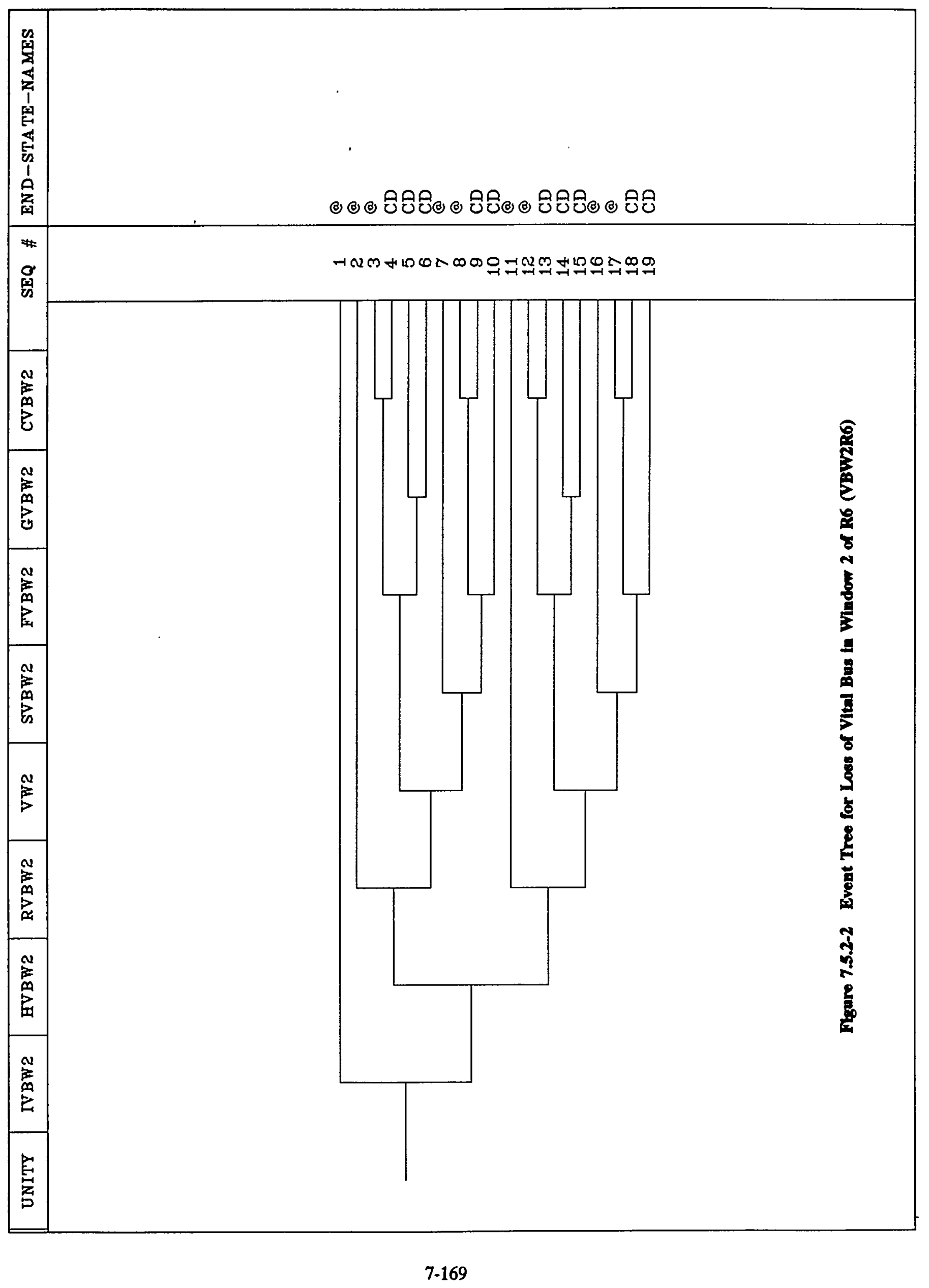




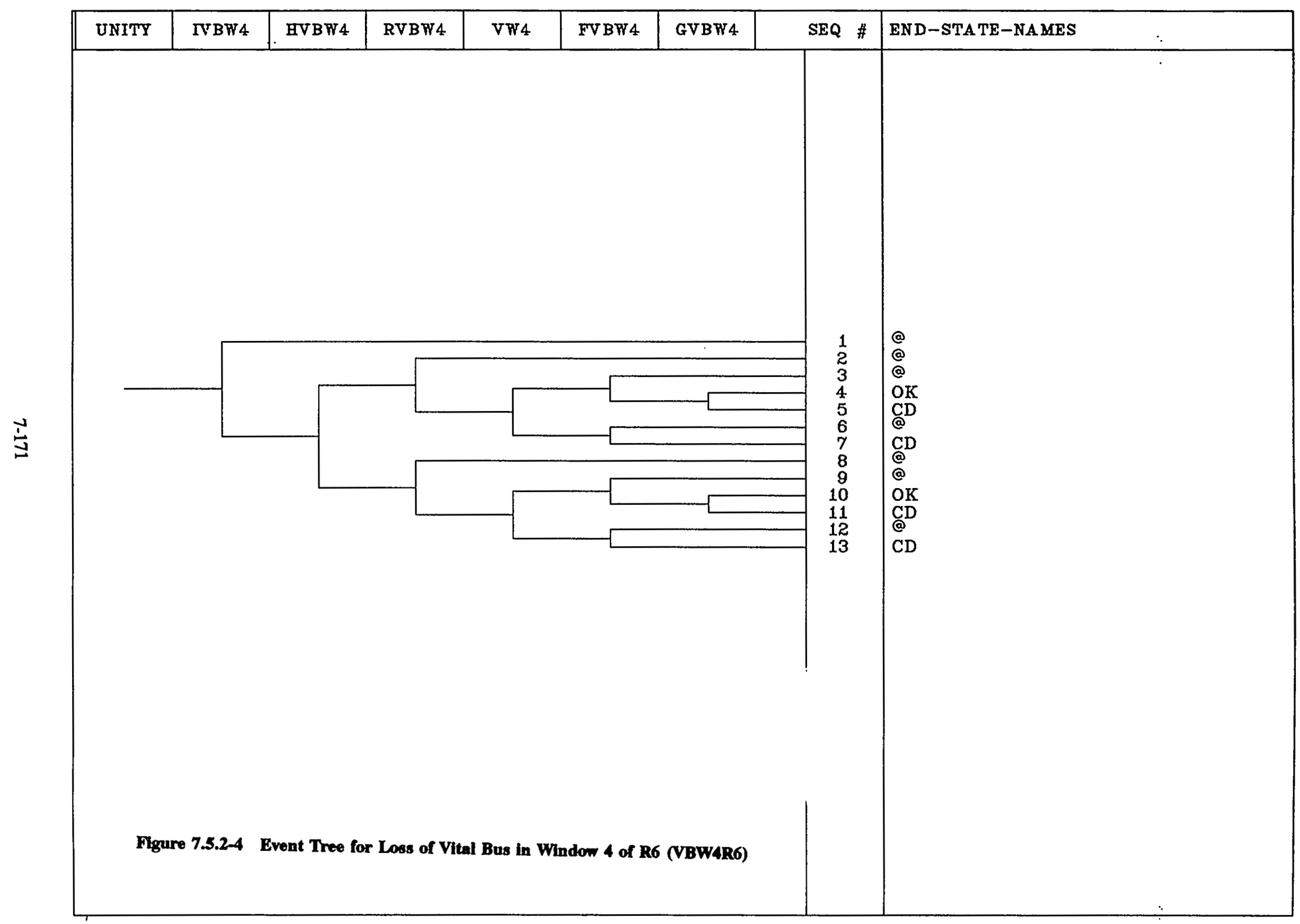




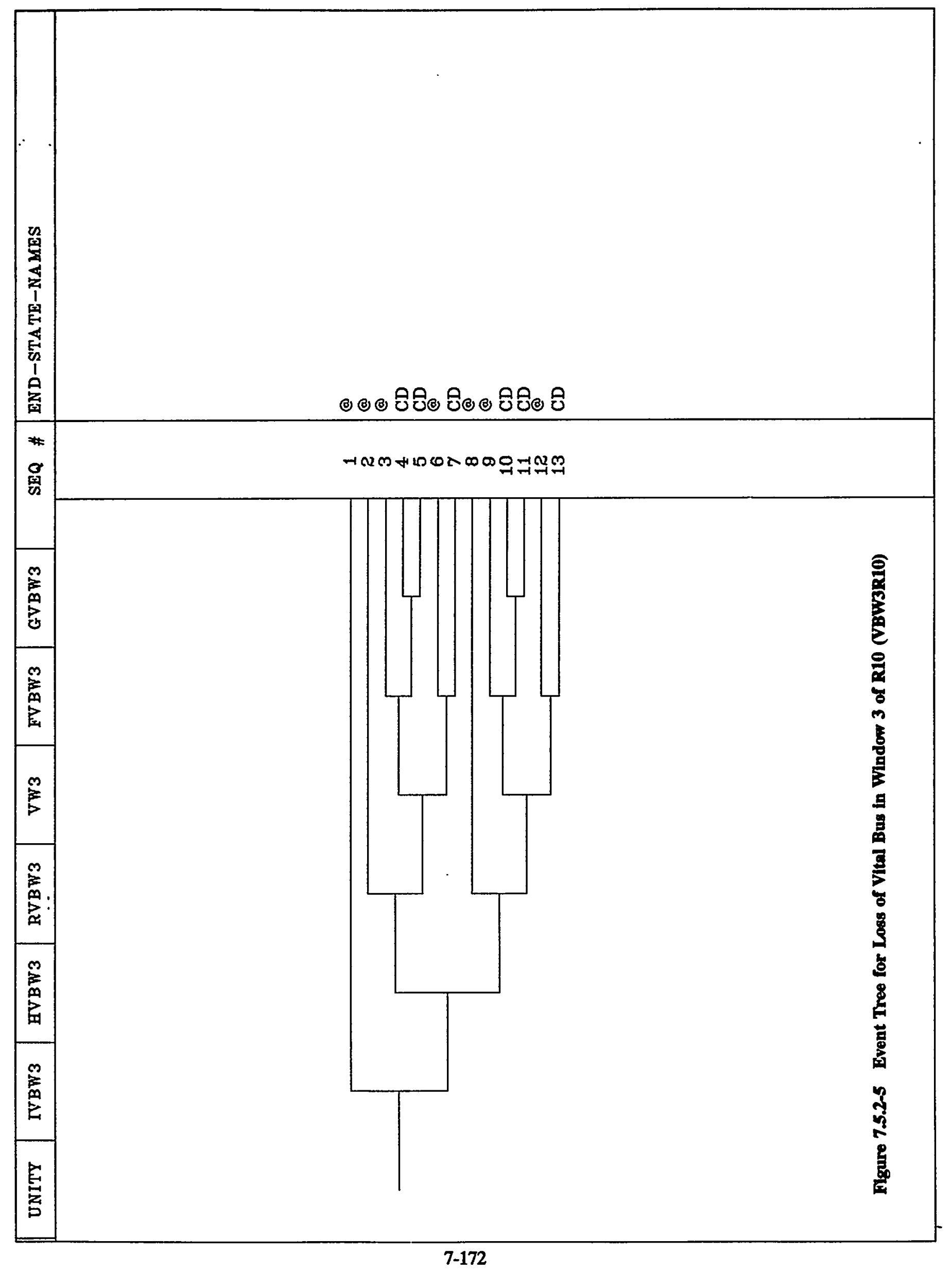




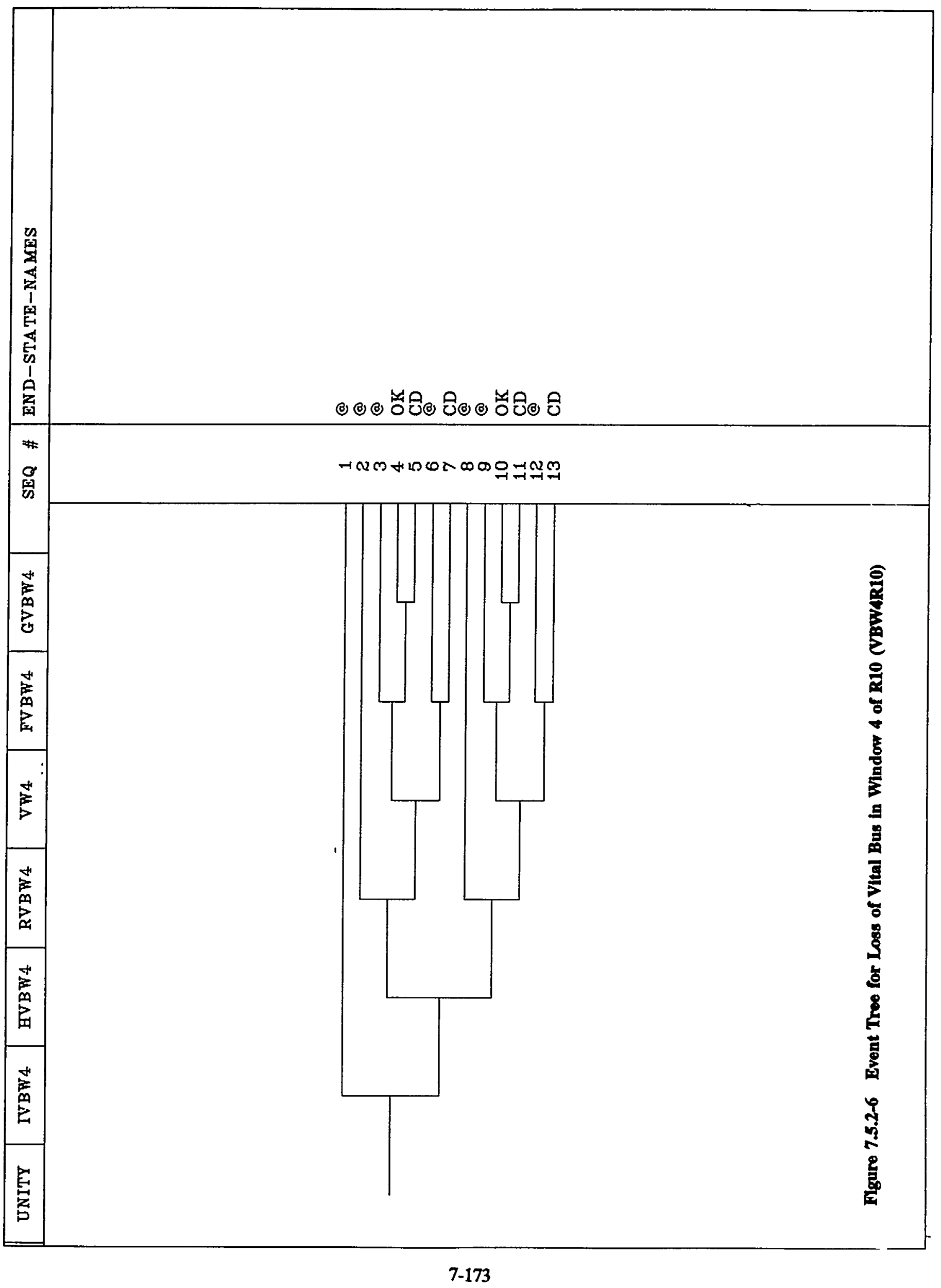




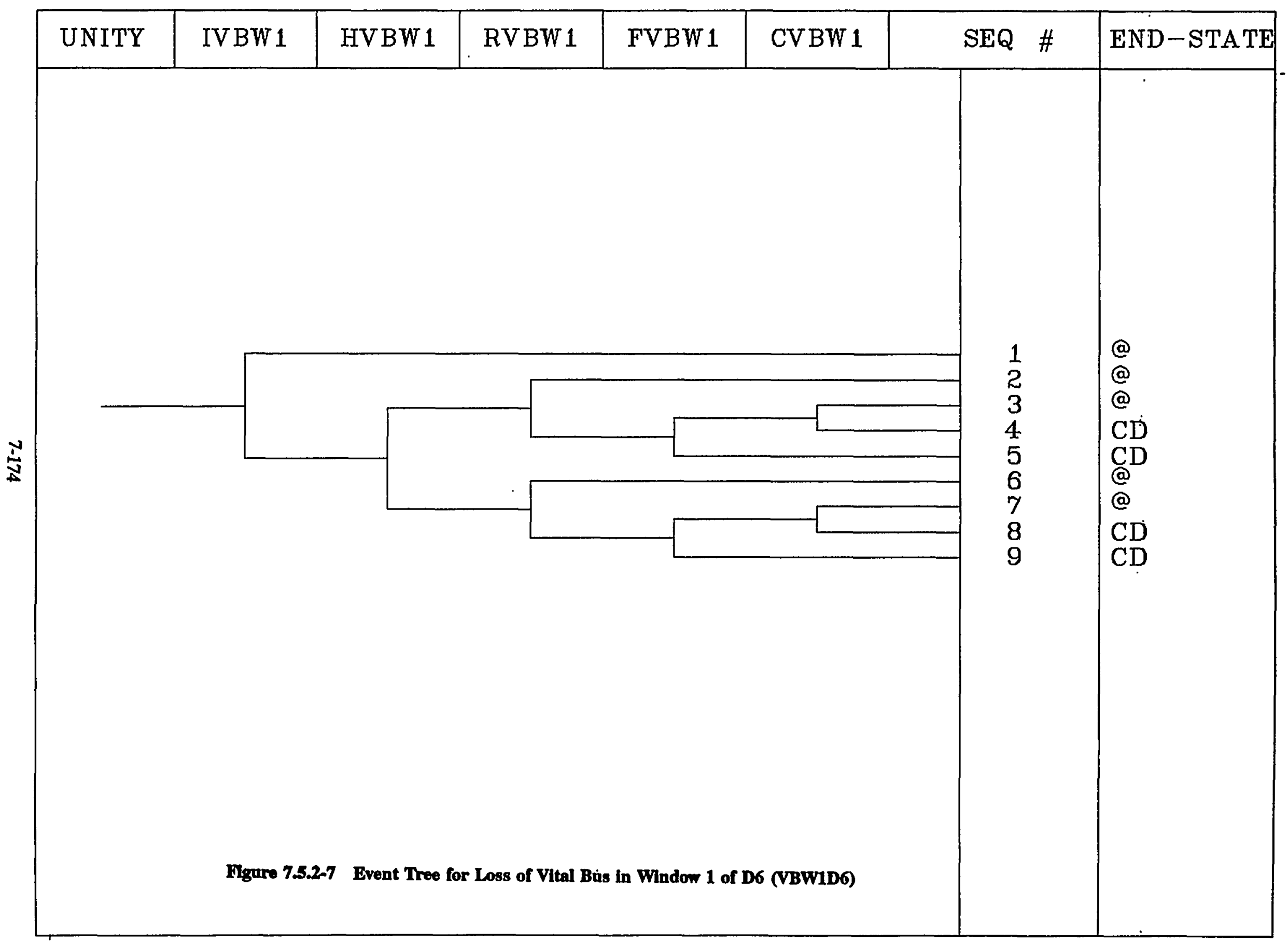




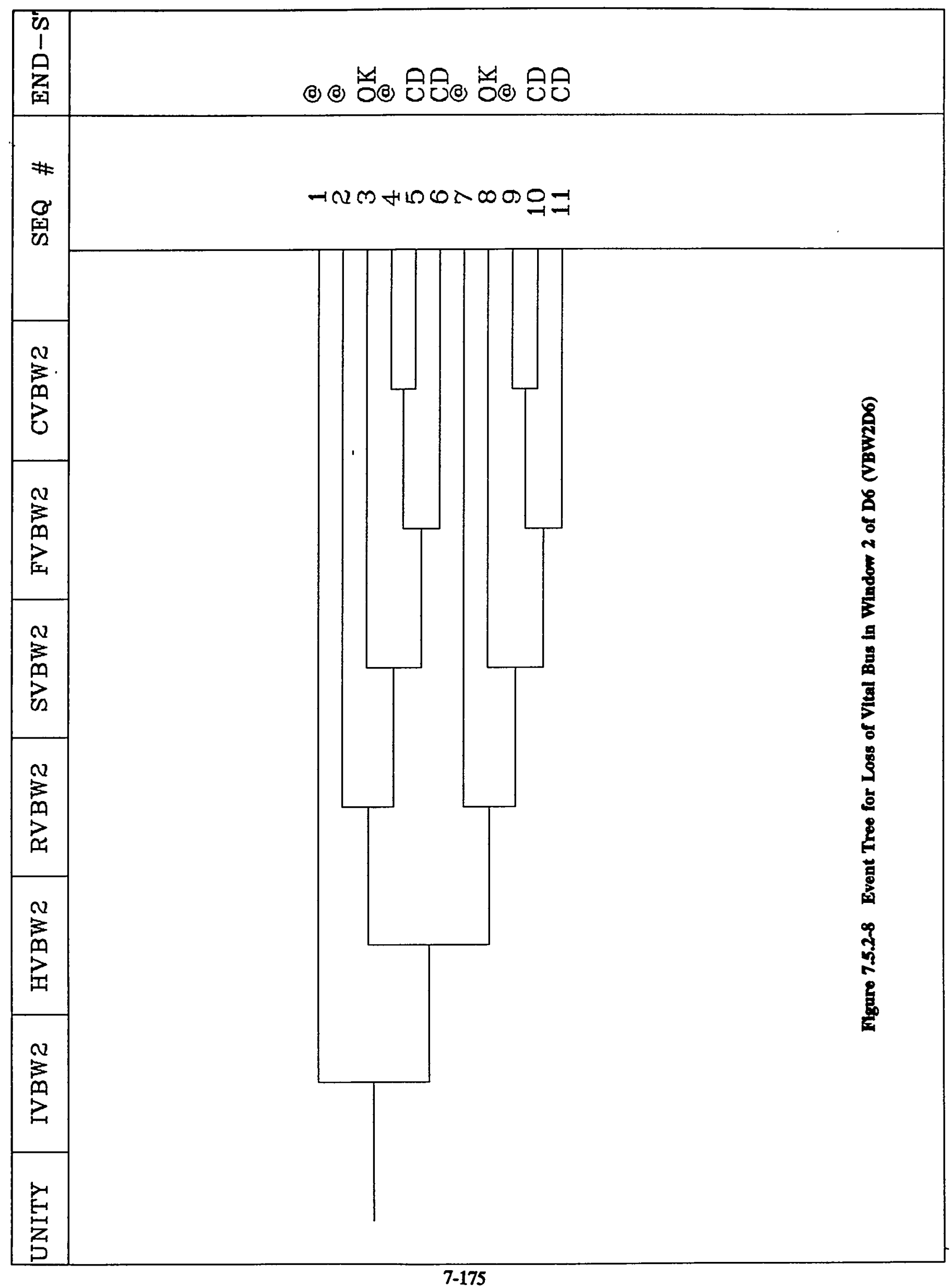




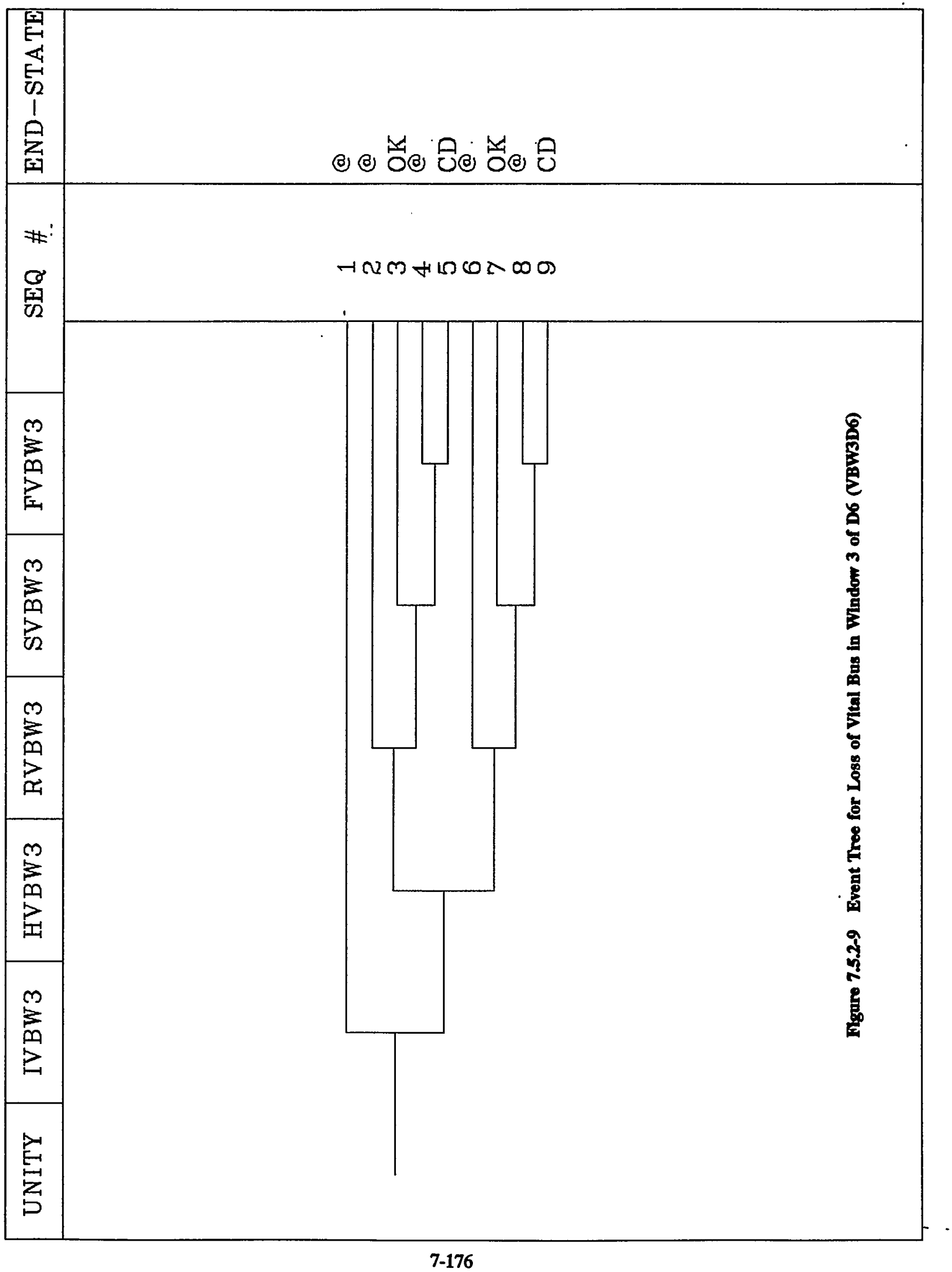




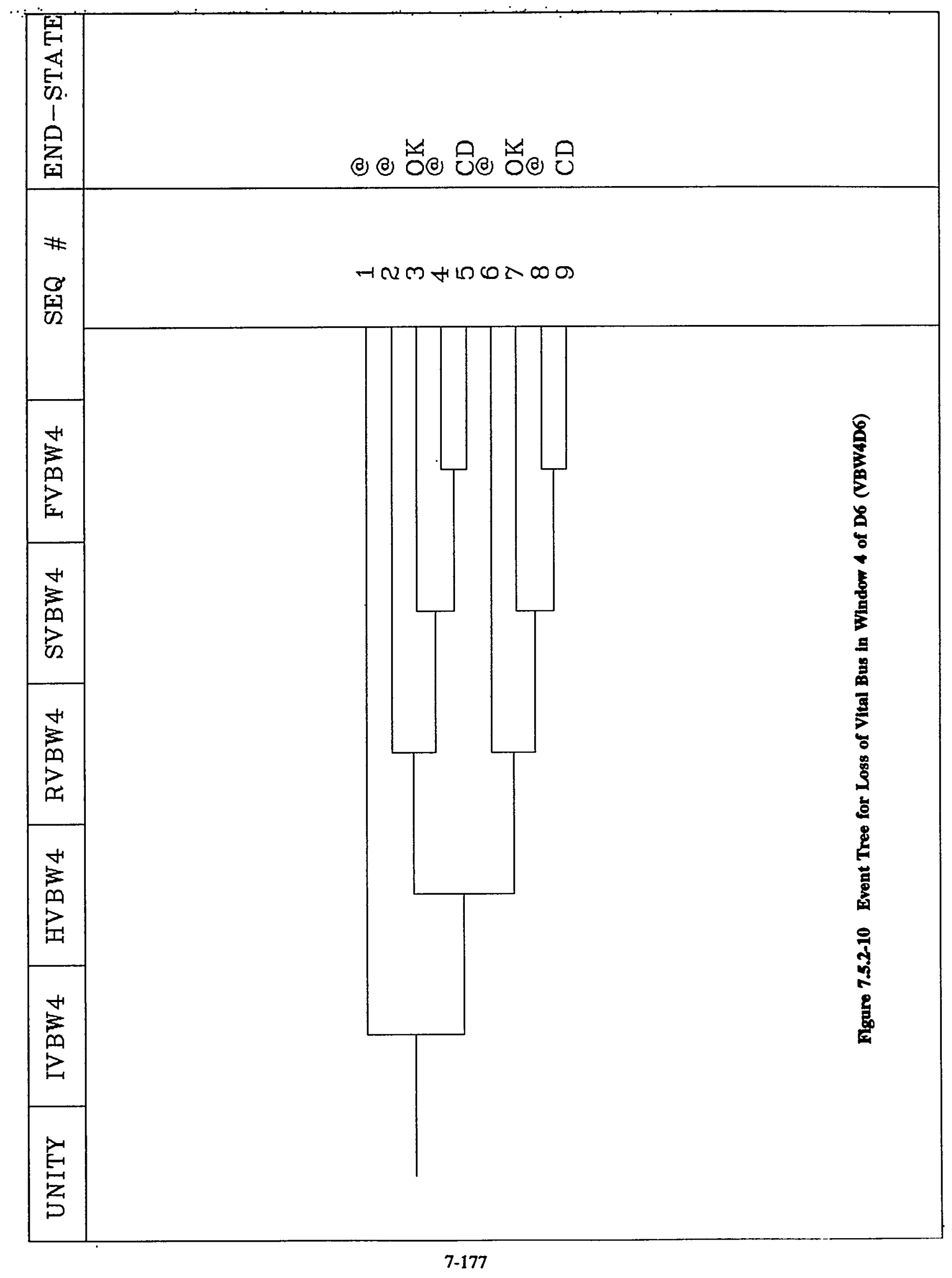




\section{Event Tree Analysis}

\subsubsection{Event Trees for "Spurious ESFAS Signal" (SI)}

Spuriously generated signals, ESFAS, Safety Injection (SI), and Consequence Limiting Safeguard-Hi (CLS-Hi) signals, have the potential to initiate accident scenarios which may lead to core damage. These signals represent a separate initiating event category, the "Spurious ESFAS Signal" initiator. Such signal interrupts the operation of the RHR by closing the containment isolation valves 1-CC-TV-109A and 1-CC-TV-109B.

The event can be recovered by resetting the spurious signal or manually opening one of the isolation valves and restoring the operation of the RHR.

\subsection{1 "Spurions RSFAS Signal" Event Tree - Refueling POS 6}

\section{Window 1}

Figure 7.5.3-1 shows the event tree, S1W1R6, applicable to this POS.

The top events of the tree represent the following events:

ISIW1 - The probability of Spurious ESFAS Signal" initiating event

The initiating event frequency, as well as the duration of $\mathrm{W} 1$, were determined from industrial experience (see Appendix A).

\section{HSIW1 - Recovery of the Spurious ESFAS Signal}

The recovery assumes that the direct cause of generating spurious ESFAS signal was cleared before the signal is reset. The time for successful recovery is taken to be equal to the time to boiling of the coolant in this POS. The non-recovery factor (.35) corresponding to this time was determined using experience data. The recovery data describing Spurious ESFAS Signal/RHR recovery as a function of time are given in Appendix D.

\section{RSIW1 - Restoring RHR}

The event represents the restoration of the RHR system, is conditional on the preceding event: if the spurious ESFAS signal is reset, both RHR trains can be rendered operable. However, if it is not recovered, the operating RHR pump is assumed failed due to loss of seal cooling and both isolation valves 1-CC-109A and $B$ have to be opened. Valve 1-CC-109A Provides flow through the RHR heat exchanger and valve 1-CC109B to the pump seal coolers.

\section{VSIW1 - RCS Vented}

The event represents the initial condition of the RCS, whether the three pressurizer safety relief valves are removed or not. The event is required because it affects the applicability of the alternative-heat removal technique: gravity feed from the RWST needs vented RCS and reflux cooling is not possible if there was an RCS inventory loss through the vents of the pressurizer (each safety valve removed leaves a 4-inch diameter opening on top of the pressurizer). For such an event, a probability of 0.01 was estimated in Window 1 (see Sections 3.6 and 9.4).

SSIW1 - Reflux cooling through the Steam Generators

The event represents the reflux cooling to remove decay heat; it is described in Section 7.2.

FSIW1 - Primary Feed-and-Bleed

The event represents the feed-and-bleed (spill) operation of the primary system. 


\section{GSIW1 - Gravity Foed from the RWST}

The event represents the gravity feeding of RWST water into the RCS through the LPI System. That can only be used if the RCS is vented. The gravity feed and its preconditions are discussed in section 7.2.

\section{CSIW1 - Recirculation}

The Feed-and-Bleed method of heat removal must be supplemented by the recirculation function to insure long term heat removal.

The event tree one can see that Sequences $4,5,6,9,10,13,14,15,18$, and 19 lead to core damage, because of failure of decay heat removal.

Window 2

The event tree, SIW2R6, applicable to this POS in window 2 is presented in Figure 7.5.3-2. The meanings of the top events are similar to top events in window 1 , and only those are described which are different.

HSIW2 - Recovery from spurious SI

The spurious ESFAS signal non-recovery probability is .22 .

\section{VW2 - RCS Vented}

The probability of pressurizer safety valves removal is estimated at .05 .

CSIW2 - Recirculation

If the unit 2 RWST can be cross-connected to the unit 1 RWST, then there is no need for recirculation.

Window 3

Figure 7.5.3-3 shows the event tree, SrW3R6.

HSIW3 - Recovery from Spurious SI

The value of PRNR = .16.

VW3 - RCS Vented

The probability that the safety valves are removed $P=.9$ : Reflux cooling is unavailable (Function $S$ ), and there is no need for Recirculation (Function C).

Window 4

The event tree SIW4R6 is presented in Figure 7.5.3-4.

HSIW4 - Recovery from Spurious SI

The value of PRNR $=.13$.

VW4 - RCS Vented

The probability that the safety valves are removed $P=.3$.

\subsection{2 "Spurions ESTAS Signal" Event Tree - Refueling POS 10}

\section{Window 3}

The event tree, SIW3R10, applicable to this POS is given in Figure 7.5.3-5. Due to the different conditions and features characterizing this POS, the top events questioning the availability of reflux cooling (S), and the necessity of recirculation function are not needed. 


\section{Event Tree Analysis}

The meanings of the top events are identical to those in POS 6 - Refueling Event Tree.

ISIW3 - Initiating event probability during R10

HSIW3 - Recovery from Spurious SI

RSIW3 - Restoring RHR

VW3 - RCS Vented

FSIW3 - Primary Feed-and-Bleed

GSIW3 - Gravity Feed from the RWST

For the event tree the following sequences lead to core damage, sequences $4,5,7,10,11$, and 13 .

Window 4

The event tree, SIW4R10, is presented in Figure 7.5.3-6. The top events are functionally the same as in Window 3.

\subsection{3 "Spurious ESFAS Signal" Event Tree - Drained Maintenance POS 6}

\section{Window 1}

The Figure 7.5.3-7 is the event tree, SIW1D6, applicable to POS 6 of Drained Maintenance. Due to stringent success criteria for successful heat removal, there is only one alternate technique besides the RHR system: Primary Feed-and-Bleed coupled with the recirculation function.

The top events are described below:

ISIW1 - Initiating event (ISI) probability throughout D6

HSIW1 - Recovery from Spurious SI

RSIW1 - Restoration of the RHR

FSIW1 - Primary Feed-and-Bleed

CSIW1 - Recirculation Function

In the event-tree, sequences $4,5,8$, and 9 lead to core damage.

Window 2

The event tree, SIW2D6 is presented in Figure 7.5.3-8.

SSIW2 - Reflux Cooling

Reflux cooling is available.

Window 3

Figure 7.5.3-9 shows the event tree, SIW3D6. The recirculation function (C) is removed. 
Window 4

The event tree, SIW4D6, is presented in Figure 7.5.3-10, the same as in Window 3 with the appropriate top events. 


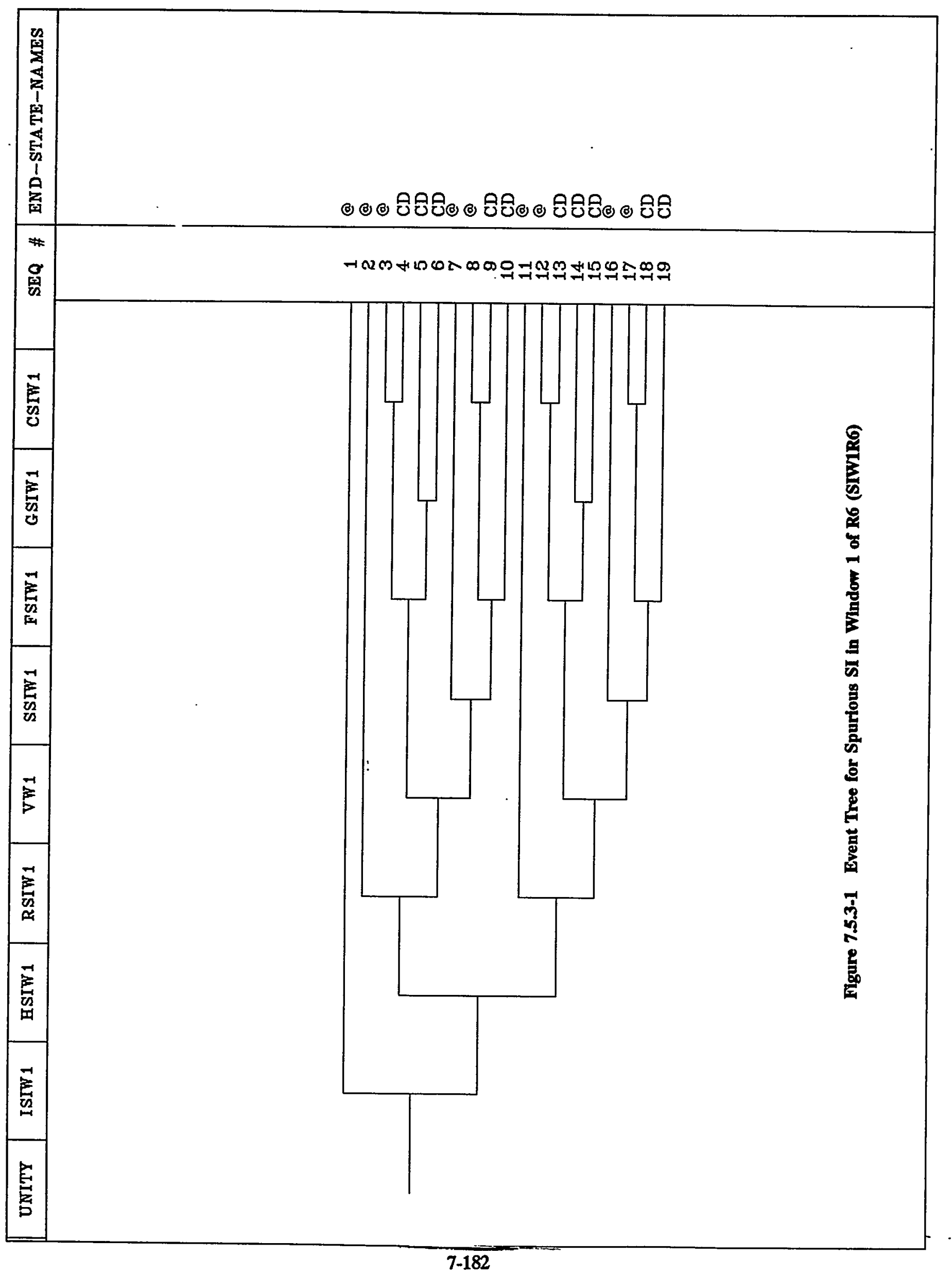




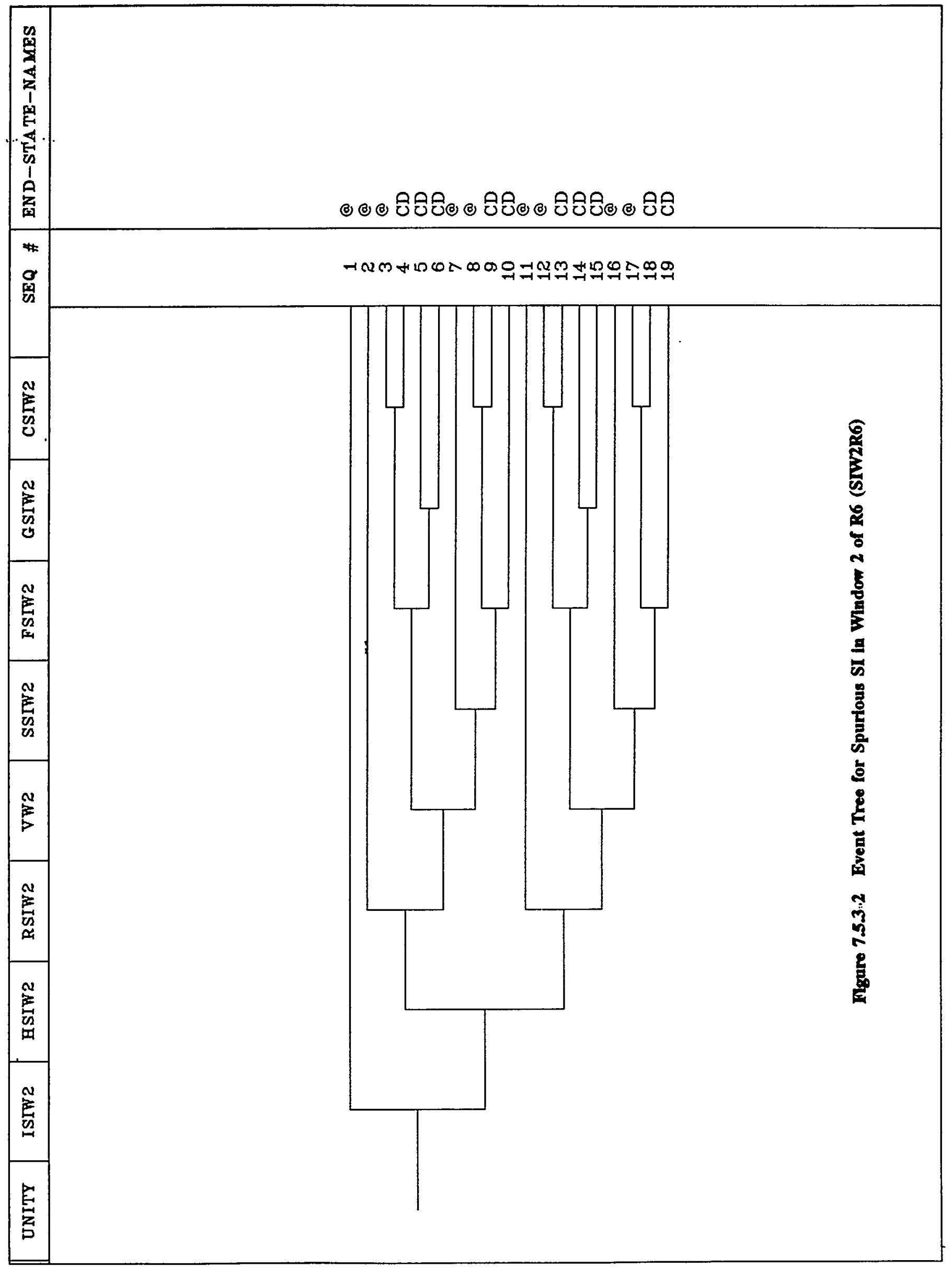




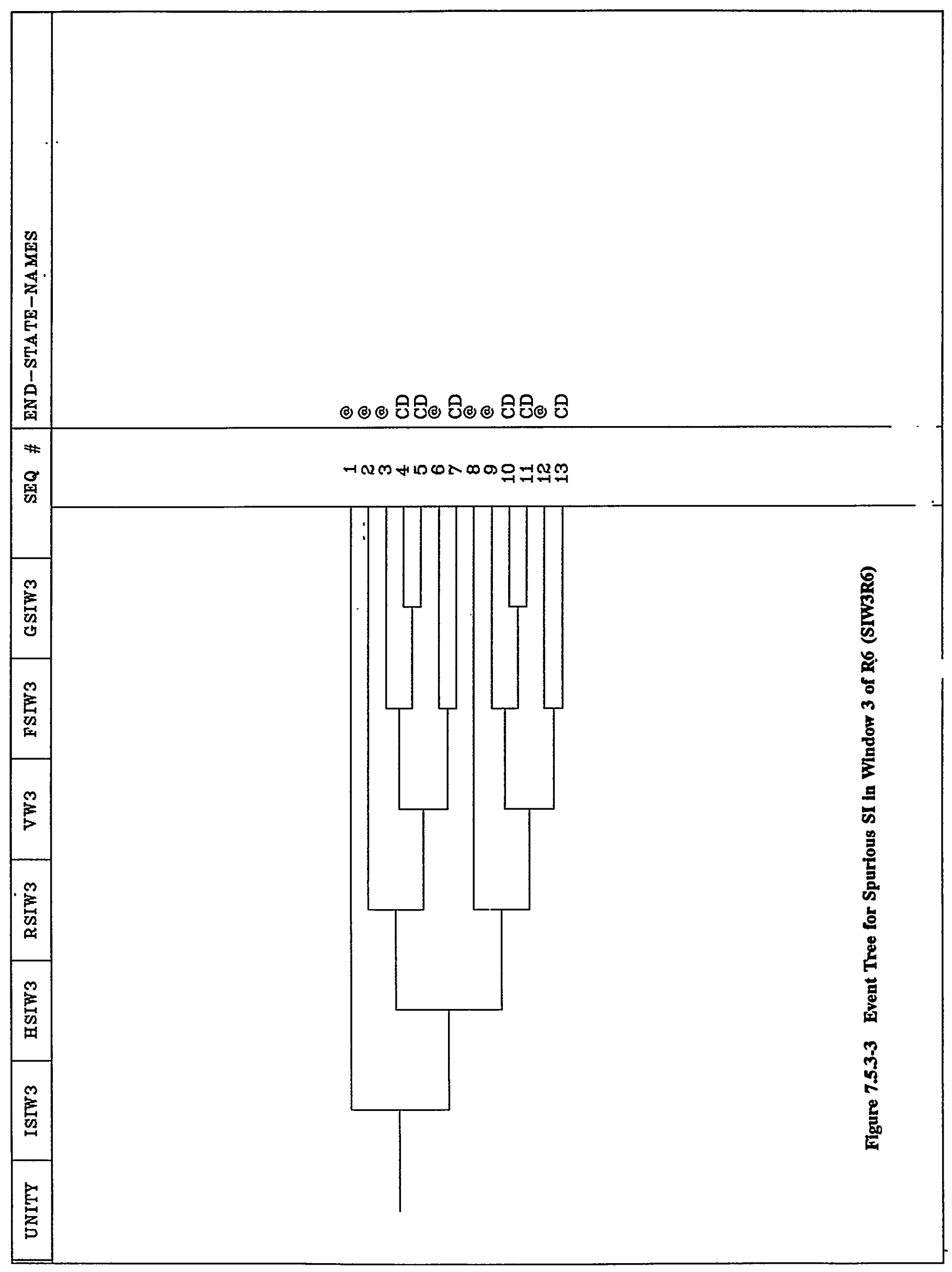




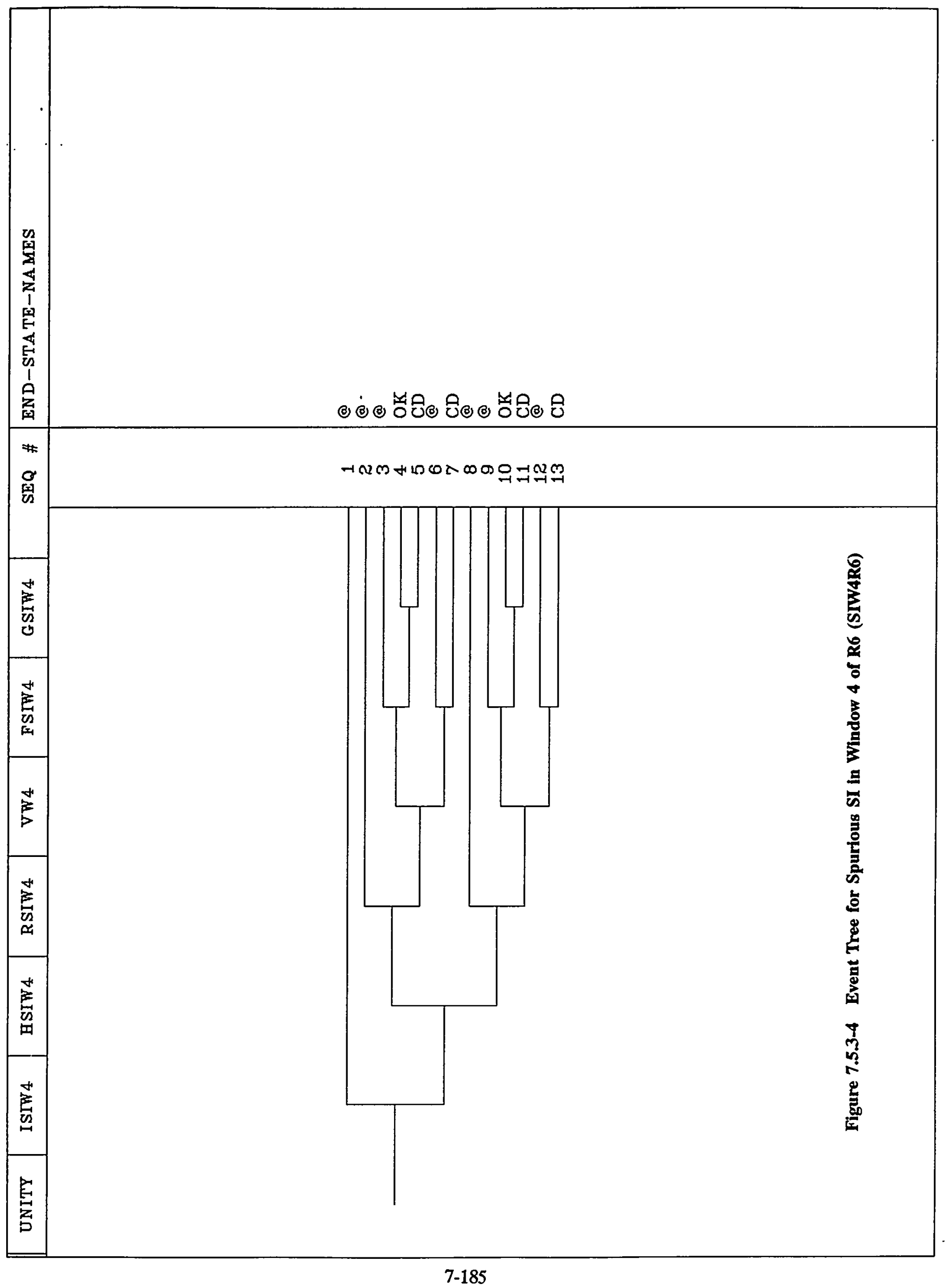




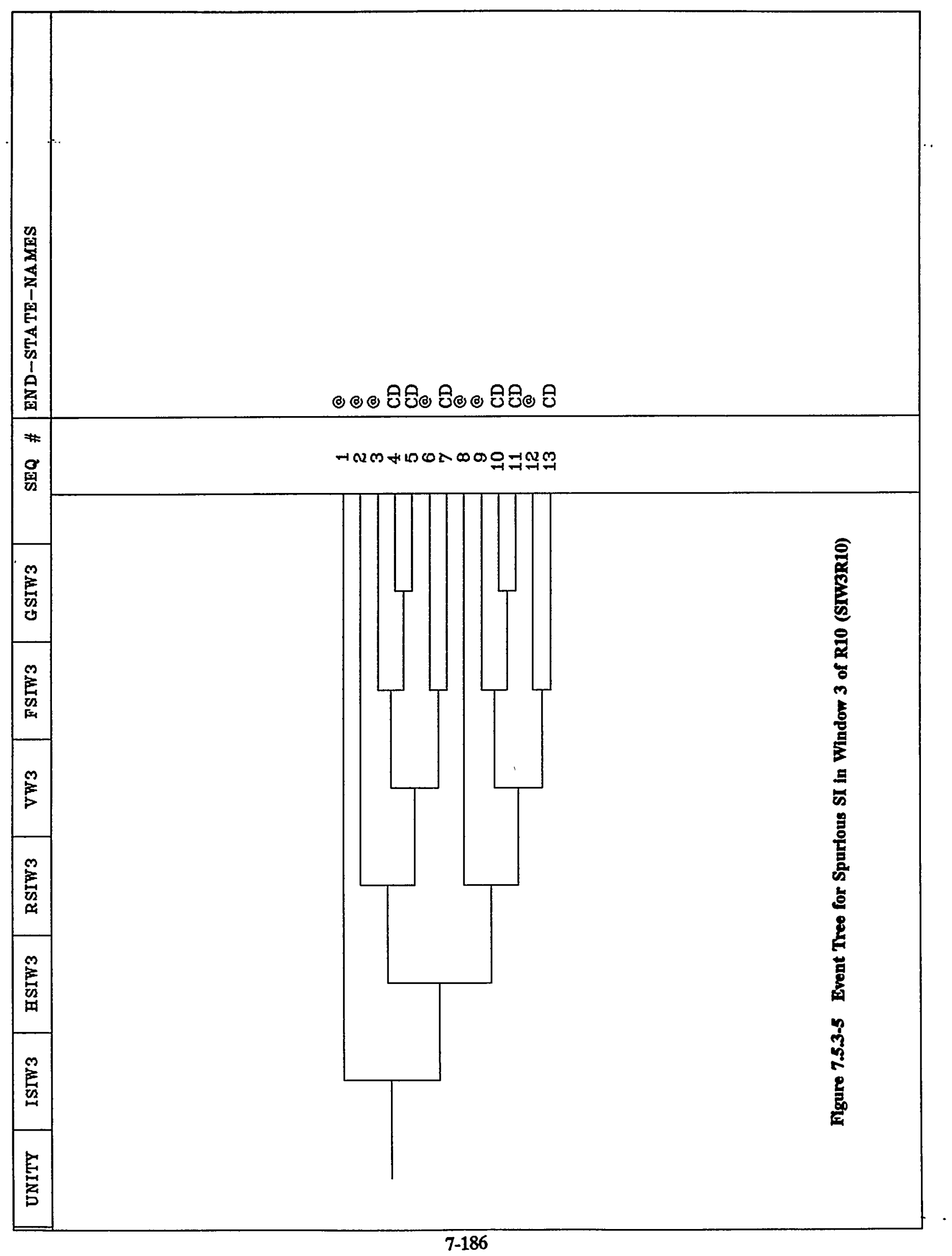




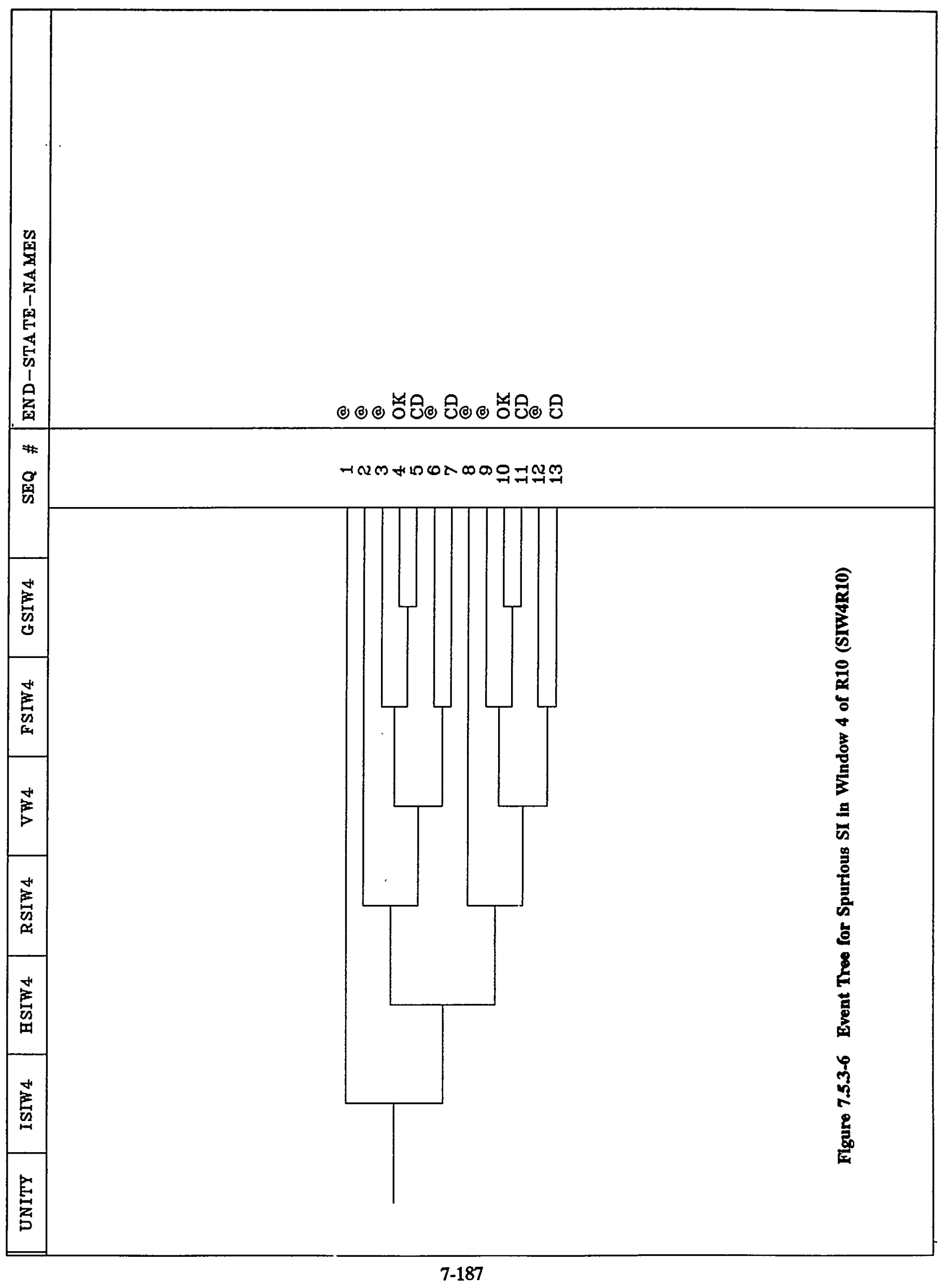




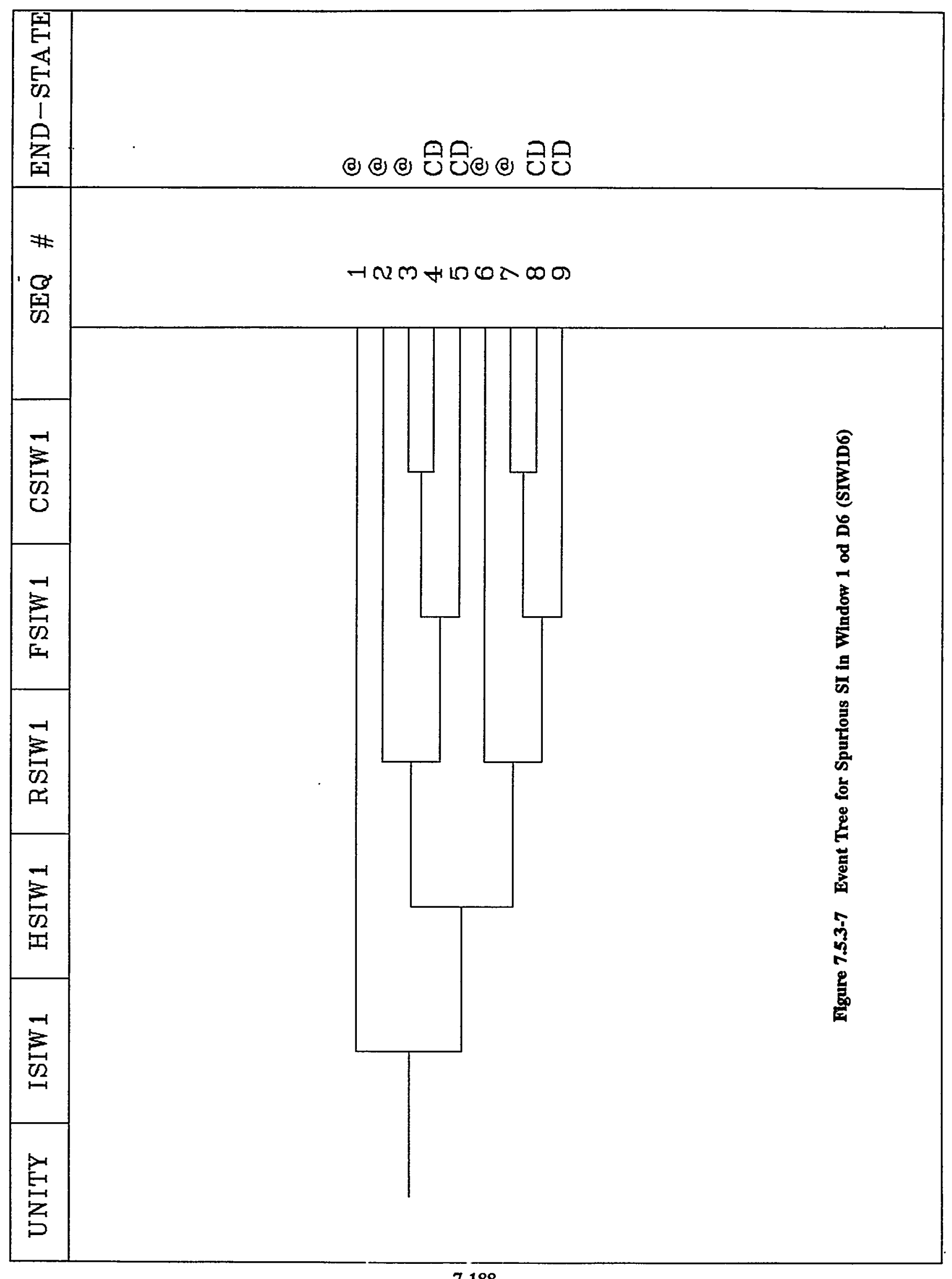




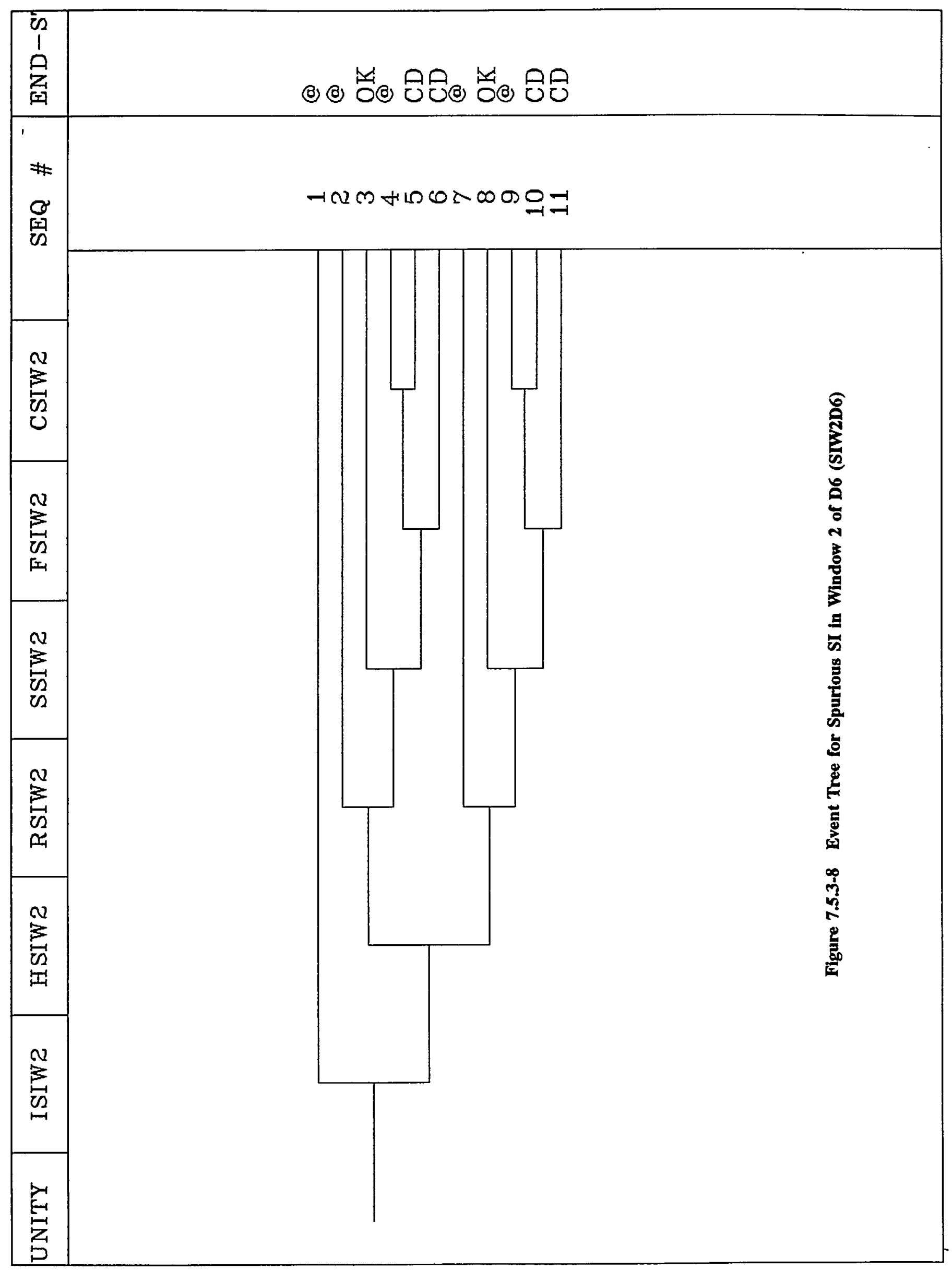




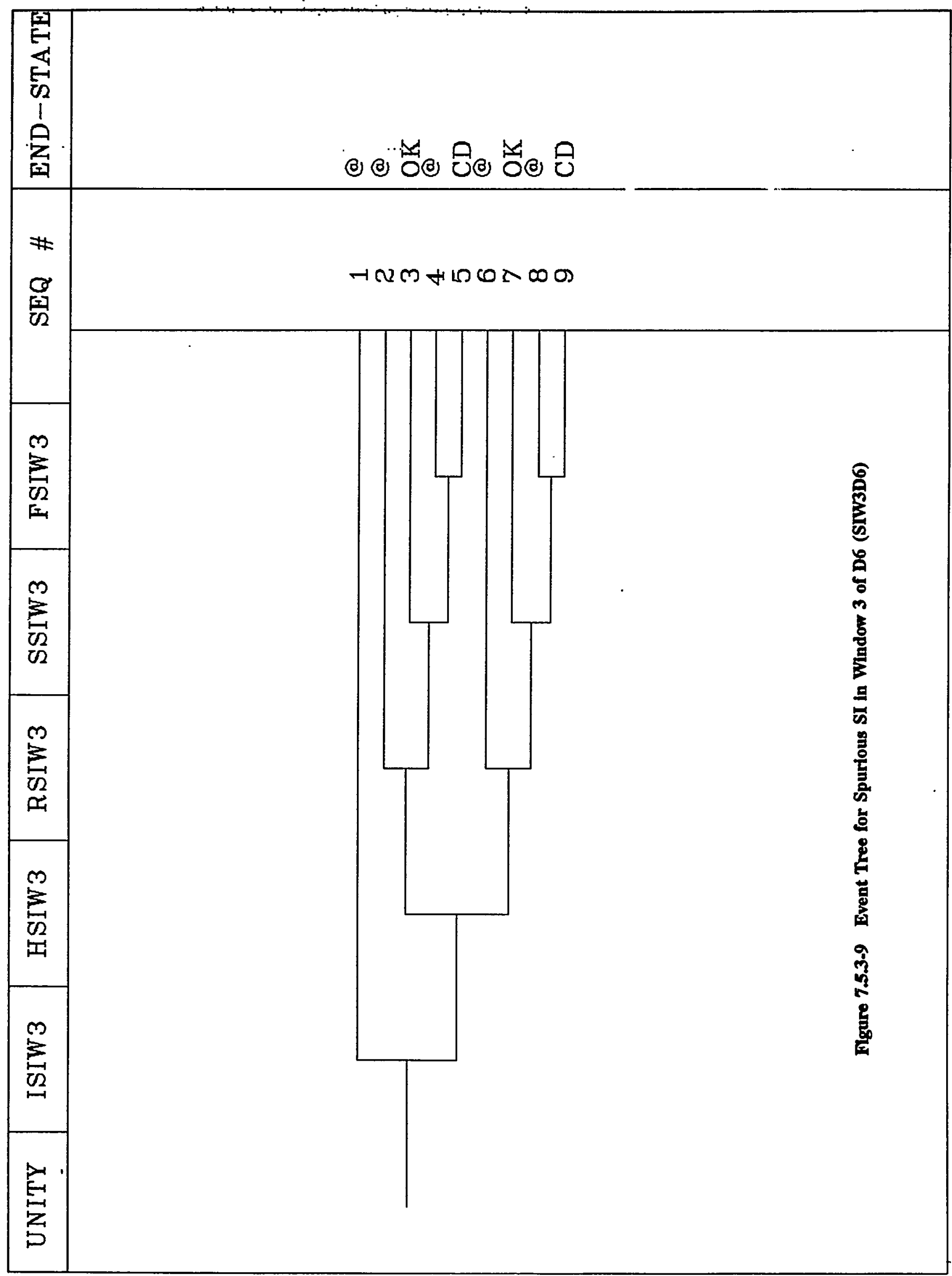




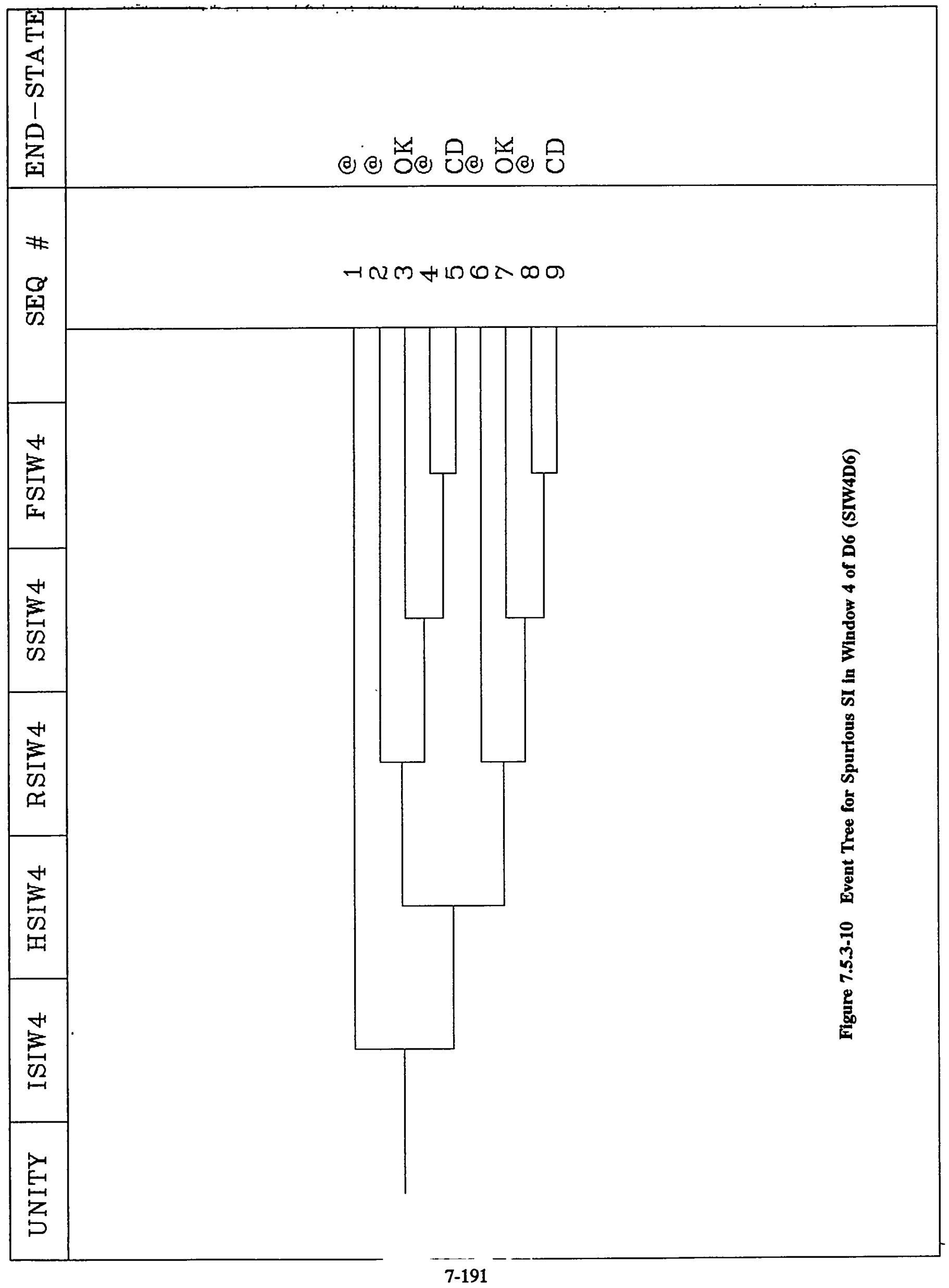




\section{Event Tree Analysis}

\subsubsection{Event Trees for Loss of Instrument Air (AR)}

Loss of instrument air while at mid-loop will cause the $109 \mathrm{~A}$ and $\mathrm{B}$ valves in the CCW return lines from the RHR system to fail closed. Therefore, there is a loss of RHR. Other impacts of loss of instrument air are discussed below:

(1) Loss of instrument air to the main steam relief valves MS-RV-101 A/B/C will cause them to fail closed and become inoperable. To relieve the steam generators and dump steam to the condenser, the operators will have to locally open the by-pass valves, 1-MS-84, 1-MS-116 and 1-MS-155, and the steam dump valves TCV-MS-105 A and $B$. The main steam non-return valves NRV $101 \mathrm{~A}, \mathrm{~B}$ and $\mathrm{C}$ in the flow path can be remotely operated as long as offsite power is available. The steam dump valve will also lose the air needed to operate. However, they can be locally operated in the turbine building.

(2) The RHR flow control valve HCV-1758 will fail open and FCV-1605 will fail closed, causing full RHR flow through the RHR heat exchangers.

(3) 1-SW-263 in the service-water supply to the emergency switchgear room cooling system will fail closed causing loss of redundancy in the service-water supply.

(4) Letdown will be isolated by the air-operated valves HCV-1142 and TV-1204 in the letdown line. A full charging flow to loop B cold leg will occur, due to the failed open charging flow control valve, FCV1122.

The procedure for loss of instrument air, AP 40.00, instructs the operators to block open valve TV-CC-109 A or B using a portable air bottle, and locally throttle the CCW outlet valve, 1-CC-104 or 100, for the inservice RHR heat exchanger; this should restore the RHR function. Then, the operators are instructed to isolate charging by closing the charging line isolation valves MOV-1289A and manual valve 1-CH-304. The operators also will attempt to determine the cause for loss of air, and restore instrument air. If the loss is due to failure of the dryer, then the operator will bypass it. If the loss is due to a leak, the procedure gives the locations of various isolation valves that can be closed to isolate the instrument air system from other air systems, or different parts of the instrument air system. When the instrument air is restored, the operators will return the air supply to 109 valves to the normal condition and unblock the valves, return the RHR flow control valves to normal position, and open the outlet valve for the in-service RHR heat exchanger.

Upon loss of offsite power, the normally running service air compressor would lose its power, and the instrument air compressor should start automatically to supply the instrument air loads. Because the instrument air compressor depends on bearing cooling water for cooling, and the bearing cooling water cooling system depends on offsite power, the compressor would eventually fail. In the procedure for loss of offsite power, the operators are instructed to use the fire pump to provide cooling to the instrument air compressor; these are modeled in the loss of offsite power and station blackout event trees.

Figures 7.5.4-1 to 7.5.4-10 are the loss of instrument air event trees for the 3 mid-loop POSs in 4 different time windows. They are somewhat similar in structure to the loss of RHR event trees, except that an additional top event, " $\mathrm{H}$ " top event, representing recovery of instrument air, was included as the first mitigating event. The recovery of the instrument air is modeled using the recovery curve derived in appendix $D$. If instrument air is recovered before the RCS boils, then it is assumed that RHR can be easily recovered and the transient is terminated successfully. If the instrument air is not restored before RCS boiling, then RHR has to be recovered by the local actions of the operator. It is conservatively assumed that the running RHR pump is failed due to either run out or cavitation, and the standby pump is the only pump that can be used. In the 
fault tree for the RHR system, loss of instrument air would lead to a failure of the RHR system. To take credit for the local action of the operator in restoring RHR, this dependency is removed by setting a house event, HOUSE-AIR, to false. In the fault tree for reflux cooling, loss of instrument air would cause failure of the SG PORVs, steam dump valves, and reflux cooling. The same house event is used to remove the dependency of steam dump valves on instrument air to take credit for the operator opening the steam dump values locally.

The top events in the event trees for loss of instrument air that differ from those of the loss of RHR event trees are described below. Window 1 of R6 is used as an example, and other time windows and POSs are similar, except for the frequency of the POSs, probability of time windows, non-recovery probability of instrument air, and the HEPs.

\section{IARW1 - Probability of Loss of Instrument Air}

This event is used to calculate the probability of loss of instrument air in the POS. For window 1 of R6, it is equal to the product of

1. frequency of refueling outage,

2. frequency of loss of instrument air,

3. the duration of the POS R6, and

4. the conditional probability that it occurs in window 1, given it occurs in R6.

\section{HARR6 - Recovery of Instrument Air}

This event represents recovery of instrument air before the RHR pump is damaged. We assumed that before the CCW to the RHR is restored, the RHR pump continues running. Because of the fully open flow-control valve 1758, the RHR pump run out may cause the running pump to fail. Another reason for failure of the running pump occurs when the RCS becomes saturated; then, it fails due to loss of seal cooling. In window 1 , this allows 15 minutes for restoring instrument air. In appendix $\mathrm{D}$, a recovery curve was estimated using the experienced data on loss of instrument air. A successful restoration of instrument air is assumed to successfully terminate the accident. Failure to restore instrument air is assumed to cause failure of the running RHR pump; other impacts were modeled by failing the system and letting the fault-tree logic of the systems account for the impacts.

\section{RARR6 - Restoring RHR}

This event represents restoration of RHR by locally opening the 109 valves and starting the standby RHR pump, if instrument air is not recovered. The $109 \mathrm{~A}$ or B valve can be opened using a portable air bottle, and then, blocked open. The standby RHR pump can be started from the control room. Due to the failed open flow-control valve, the RHR flow has to be throttled by manually throttling the RHR heat-exchanger outlet valve.

\section{SARW1 - Reflux Cooling}

This event represents the establishment of reflux cooling by opening the non-return valves from the control room, locally opening the manual valves around the MSTVs and steam dump valves, and, later, establishing feed to the steam generators. 


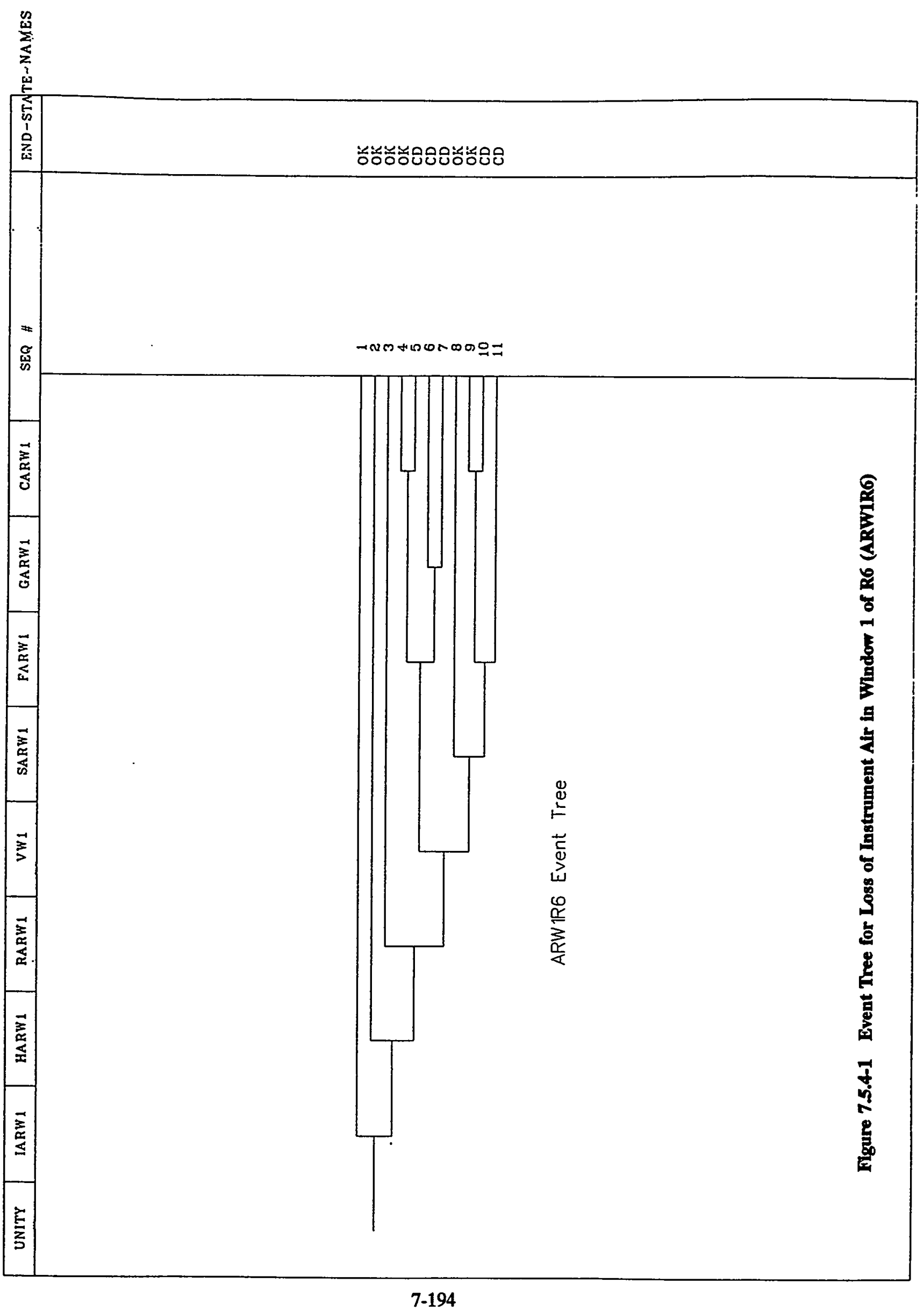




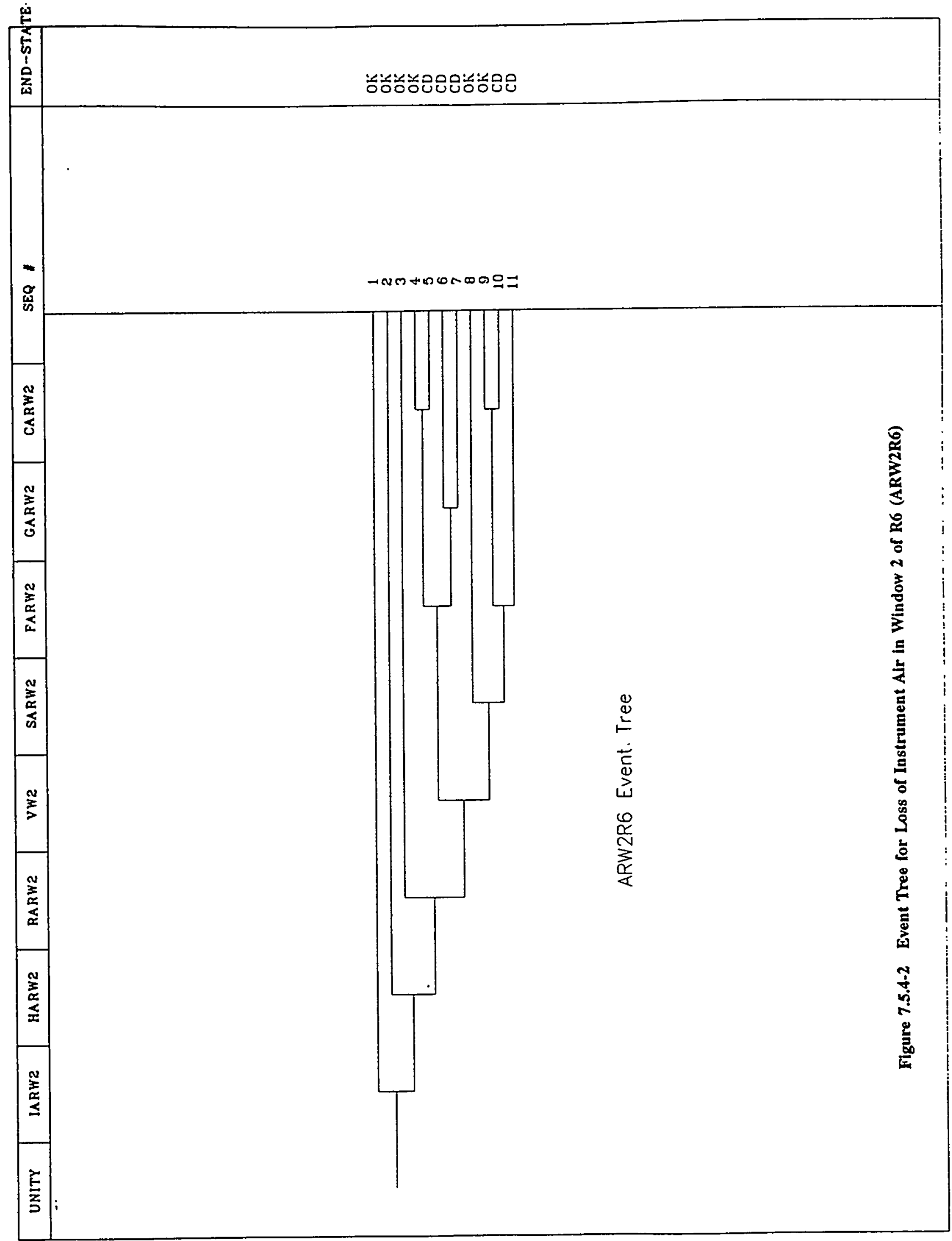




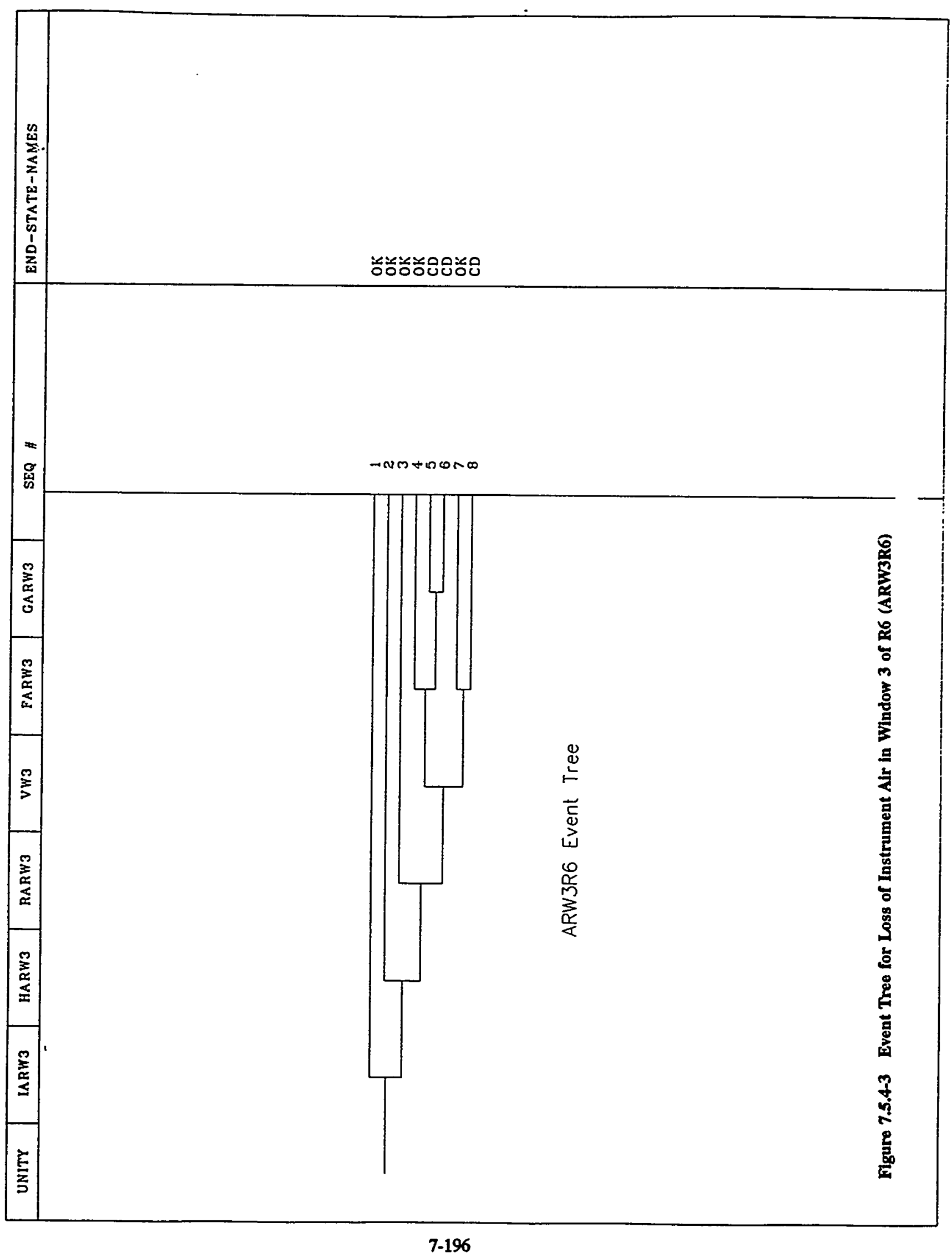




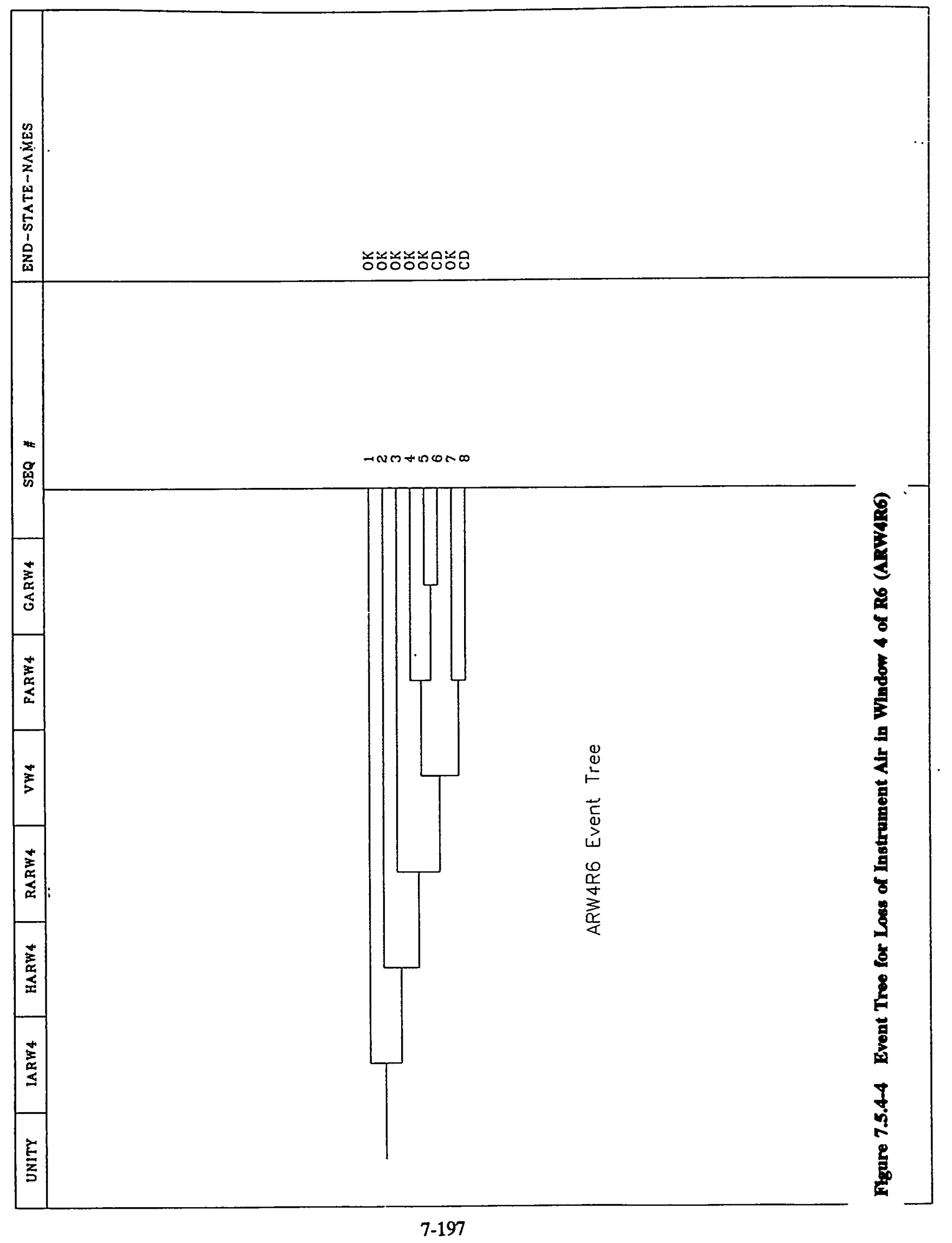




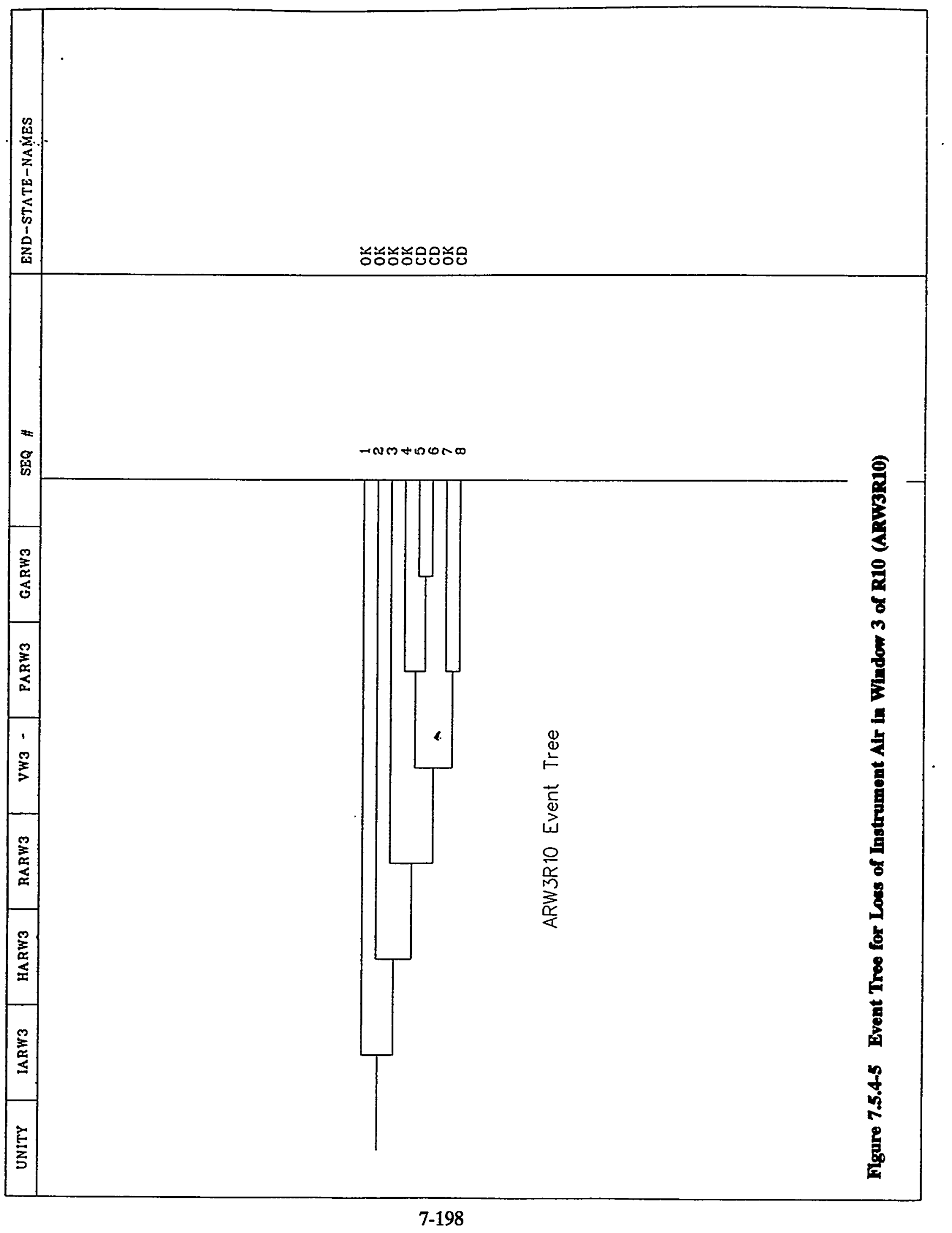




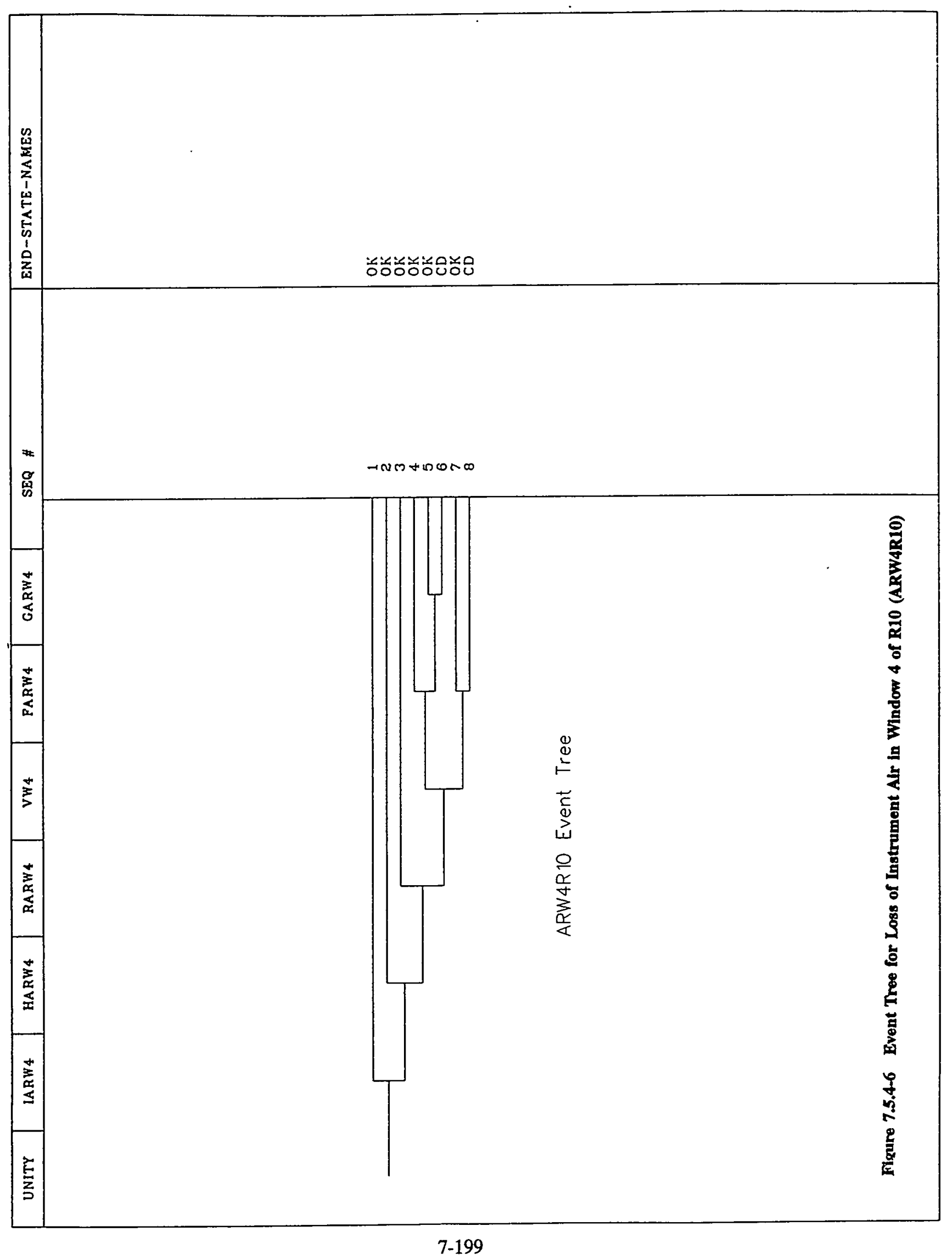




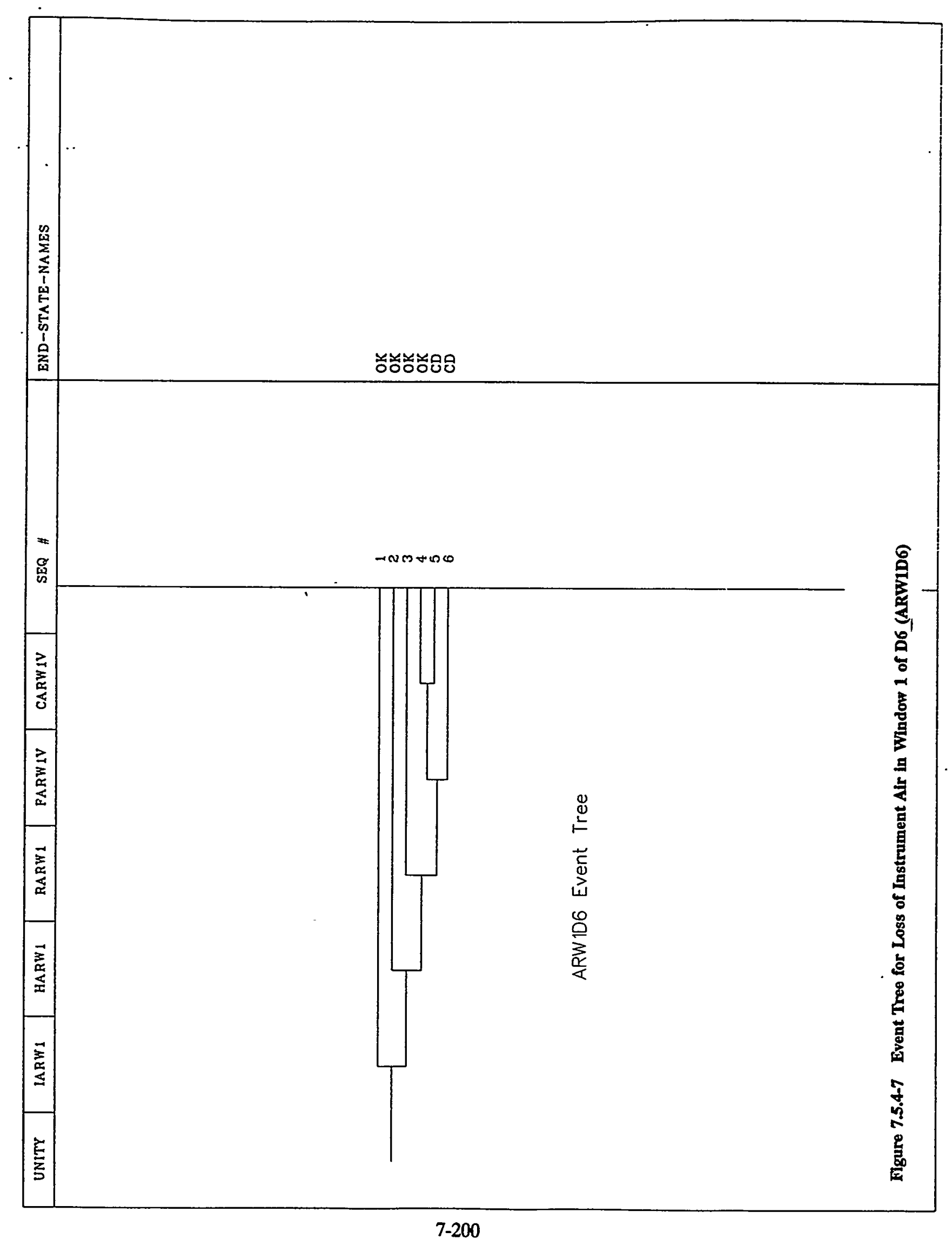




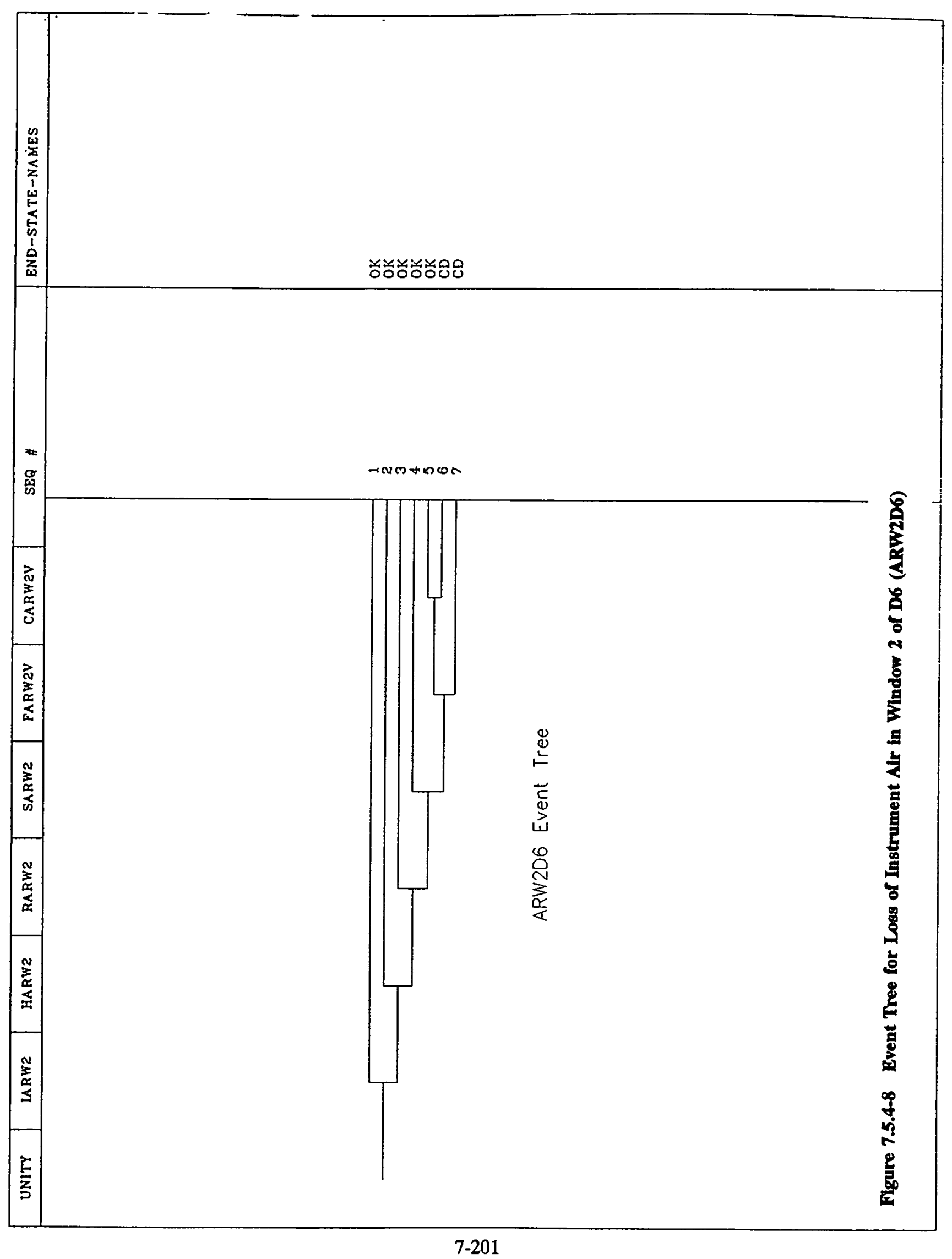




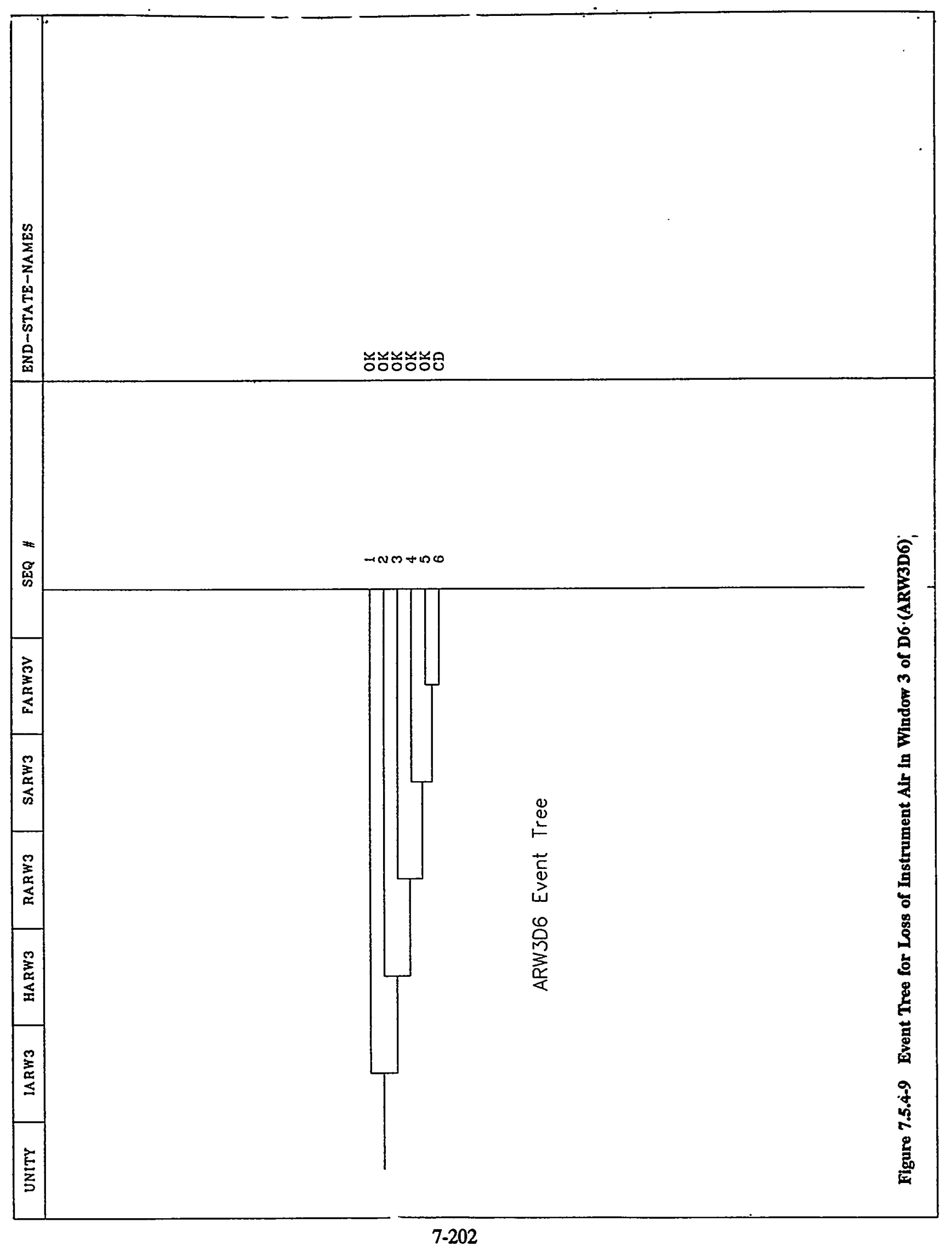




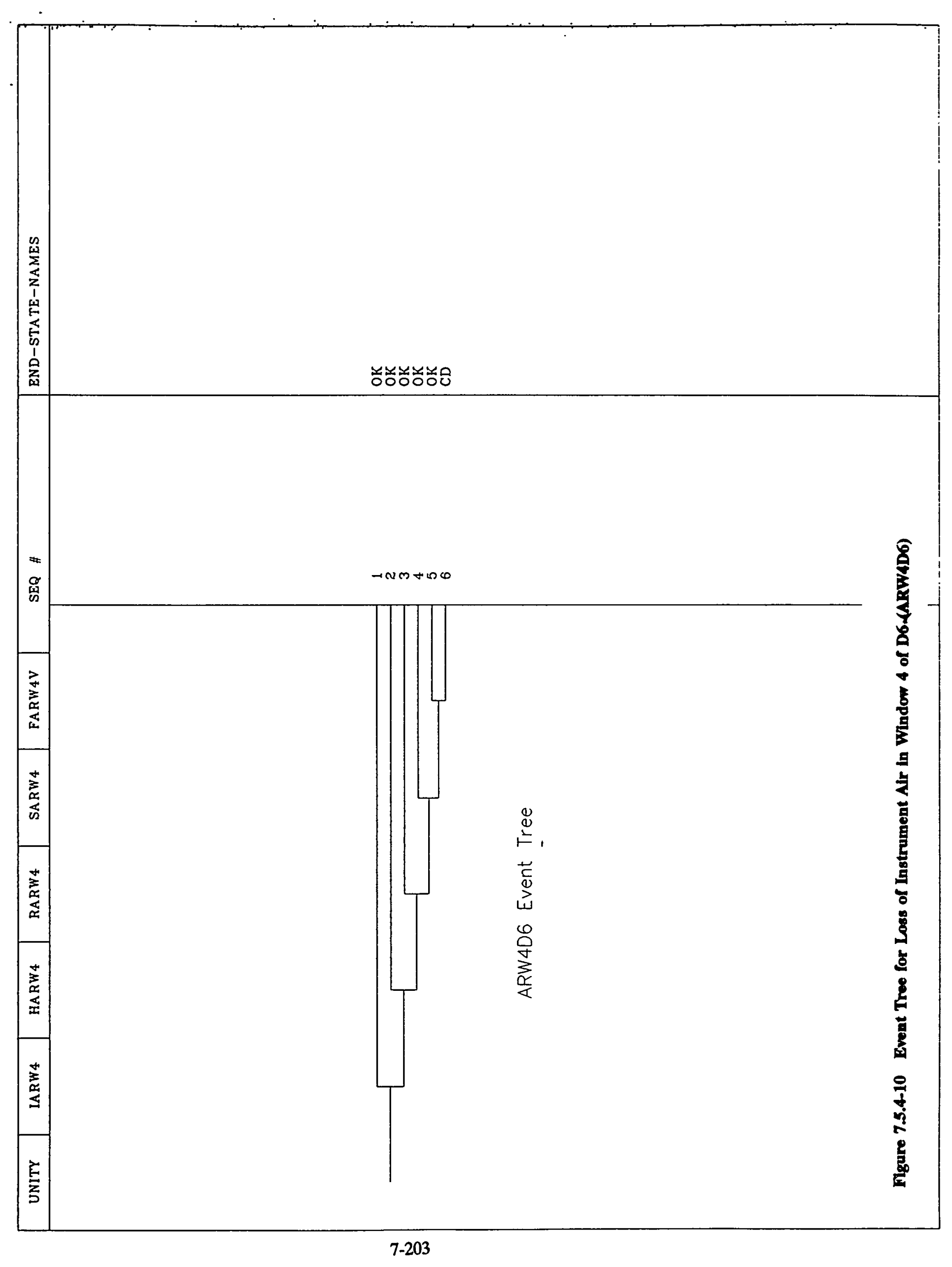




\section{Event Tree Analysis}

\subsubsection{Event Trees for Loss of Component Cooling Water (CC)}

A loss of Component Cooling Water (CCW) event is defined as the total loss of CCW function at both units without any backup service available (see Section 4.4 .5 for more details). The RHR heat exchangers, as well as the RHR pumps, reject heat to the CCW system whose loss effectively leads to the loss of decay-heat removal (failure of the RHR heat exchangers) and the direct loss of the operating RHR pump. Therefore, a loss of CCW event must be treated as a loss of RHR event coupled with the unavailability of the CCW function.

Three event trees were developed for the mid-loop POSs in each windows to reflect the different system configurations and other conditions in the respective operating modes, POS 6 Refueling, POS 6 Drained Maintenance, and POS 10 windows 1, 2,3, and 4. The event trees are derived from the generic loss of RHR event tree, specialized for the loss of CCW conditions.

\subsection{1 "Loss of CCW" Event Tree-Refueling POS 6}

\section{Window 1}

Figure 7.5.5-1 shows the event tree, CCW1, applicable in this POS. The top events represent the various alternate possibilities for heat removal available to the operator:

ICCW1 - Loss of CCW Initiating Probability

The initiating probability represents the loss of CCW function at both units. It was established, based on operating experiences, and discussed in detail in Section 4.4.5. It is the combination of the loss of CCW initiating event frequency with the duration of the POS 6 refueling period in window 1.

\section{HCCW1 - Recovery of the CCW System}

The loss of the CCW system leads to the loss of RHR heat-removal from the RHR heat exchangers, and the RHR pumps also lose their cooling, which may directly damage the operating pump. For loss of heat exchanger cooling, the effect is a slow heat-up of the reactor core. Based on the calculations in Chapter 5 , given the loss of heat removal by the RHR system, void formation in the primary coolant is expected to occur after about 12 minutes.

The loss of cooling to the RHR pump seals could lead to some direct damage, but even this may take some time, estimated as 30-60 minutes per pump. Therefore, if it is recovered in about 20 minutes, the loss of CCW event may not challenge the mitigating systems and not lead to a loss of the RHR system.

The top event, HCCW1, questions the non-recovery probability of the loss of CCW event, which, again, was obtained from the operating experiences $(P R N R=.8)$.

VW1 - RCS Vented

This top event represents the question of venting the RCS. The removal of heat by gravity feeding of the RCS requires that the RCS is vented; this may be done in POS 6 by removing the pressurizer safety valves.

\section{SCCW1 - Steam Generator Reflux Cooling}

This top event represents an alternate method of decay-heat removal using the steam generators. In this case, the primary side would boil and the steam could condensate in the steam generators if heat transfer to the secondary side can be established. This may be assured by letting the SG inventory boil and releasing the generated steam either through the secondary-side relief valves or by using the turbine bypass and the main condenser. Section 7.2 discusses in more detail this mode of cooling and decay-heat removal. 


\section{FCCW1 - Feed-and-Bleed of the RCS}

This top event represents the feed-and-bleed operation to the primary system. The RCS may be fed by the charging/HPI or LPI system. The pressure of the RCS is not expected to increase greatly, during the initial heat-up period, because it is vented and the LPI system could provide additional coolant. However, later in the accident, the LPI injection may be prevented by the gradual build up of pressure in the RCS, since the vent capacity is relatively small, and this may be increased if the rupture disk on the pressurizer relief tank ruptures.

\section{GCCW1 - Gravity Feed to the RCS}

This top event represents the gravity feeding of RWST water into the RCS through the LPI system; it can only be used if the RCS vented.

The first 3 sequences are successes without core damage. Sequence 2 represents the case when the CCW recovers in the first 20 minutes and decay-heat removal can be reestablished by the RHR system. It is assumed that, if the operating RHR pump is damaged, the other RHR pump is available and may be restarted.

Sequences $4,5,6,9$, and 10 lead to core damage.

\section{Window 2}

The event tree, CCW2R6, applicable to this POS in window 2 is presented in figure 7.5.5-2. The meanings of the top events are similar to top events in window 1 , and only those are described which are different.

\section{H4KW2 - Recovery of CCW}

The CCW system non-recovery probability is .45 .

VW2 - RCS Vented

The probability of pressurizer safety valves removal is .05 .

CCCW2 - Recirculation

If the unit 2 RWST is cross-connected to the unit 1 tank, then there is no need for recirculation.

Window 3

Figure 7.5.5-3 shows the event tree, CCW3R6.

H4KW3 - Recovery of CCW

The value of PRNR $=.25$.

VW3 - RCS Vented

The probability that the safety valves are removed $P=.9:$ reflux cooling is unavailable (Function $S$ ), and there is no need for recirculation (Function $\mathrm{C}$ ).

Window 4

The event tree, CCW4R6, is presented in Figure 7.5.5-4.

H4KW4 - Recovery of CCW

The value of PRNR $=.15$

VW4 - RCS Vented

The probability that the safety valves are removed $P=.3$. 
7 Event Tree Analysis

\subsubsection{Tows of CCW Event Tree - Refueling FOS 10}

\section{Window 3}

In POS 10, all three RCS loops are isolated and the SGs cannot be used for alternate heat-removal. The event tree was modified accordingly (Figure 7.5.5-5). The top events are essentially the same as for CCW3R6.

\section{CCW3 - Loss of CCW Initiating Probability}

The initiating probability expresses the probability of the loss of CCW event during POS 10 in a refueling period.

\section{HCCW3 - Recovery of the CCW System}

The recovery time base is 1 hour, which is the period before the primary coolant starts to boil. It is assumed that the RHR pumps are not damaged, even after the loss of seal cooling.

\section{VW3 - RCS Vented}

FCCW3 - Feed-and-Bleed of the Primary System

GCCW3 - Gravity Feed of the Primary System

Sequences 4,5 , and 7 lead to core damage.

Window 4

The event tree CCW4R10 is presented in Figure 7.5.5-6. The top events are functionally the same as in window 3, and identical to the ones in the POS 6 event.

\subsubsection{3 "Loss of CCW" Event Tree - Drained Maintenance POS 6}

Decay-heat removal through the secondary side is not available, since successful reflux cooling would require 3 SGs, but only two are available. In addition, the pressurizer safety valves are not removed, potentially preventing the use of the gravity feed function. Figure 7.5.5-7 presents the event tree, CCW1D6.

\section{ICCW1 - Loss of CCW Initiating Probability}

The initiating event probability is functionally similar to the one used previously.

\section{HCCW1 - Recovery of the CCW System}

The operating RHR pump is assumed not to be damaged during this time period.

\section{FCCW1 - Feed-and-Bleed of the RCS}

Identical to the same top event in the POS 6 refueling event tree, CCW1R6.

CCCW1 - Recirculation Function

In POS 6 - Drained Maintenance, the only option to remove decay heat is to use feed-and-bleed, given the failure of the RHR system. Sequences 4 and 5 lead to core damage.

Window 2

The event tree CCW2D6 is presented in Figure 7.5.5-8.

SCCW2 - Reflux Cooling

Reflux Cooling is available in this window for drained maintenance. 


\section{Event Tree Analysis}

\section{Window 3}

Figure 7.5.5-9 shows the event tree CCW3D6. The recirculation function (c) is removed.

Window 4

The event tree CCW4D6 is shown in Figure 7.5.5-10, which is the same as in window 3 with the appropriate top events. 


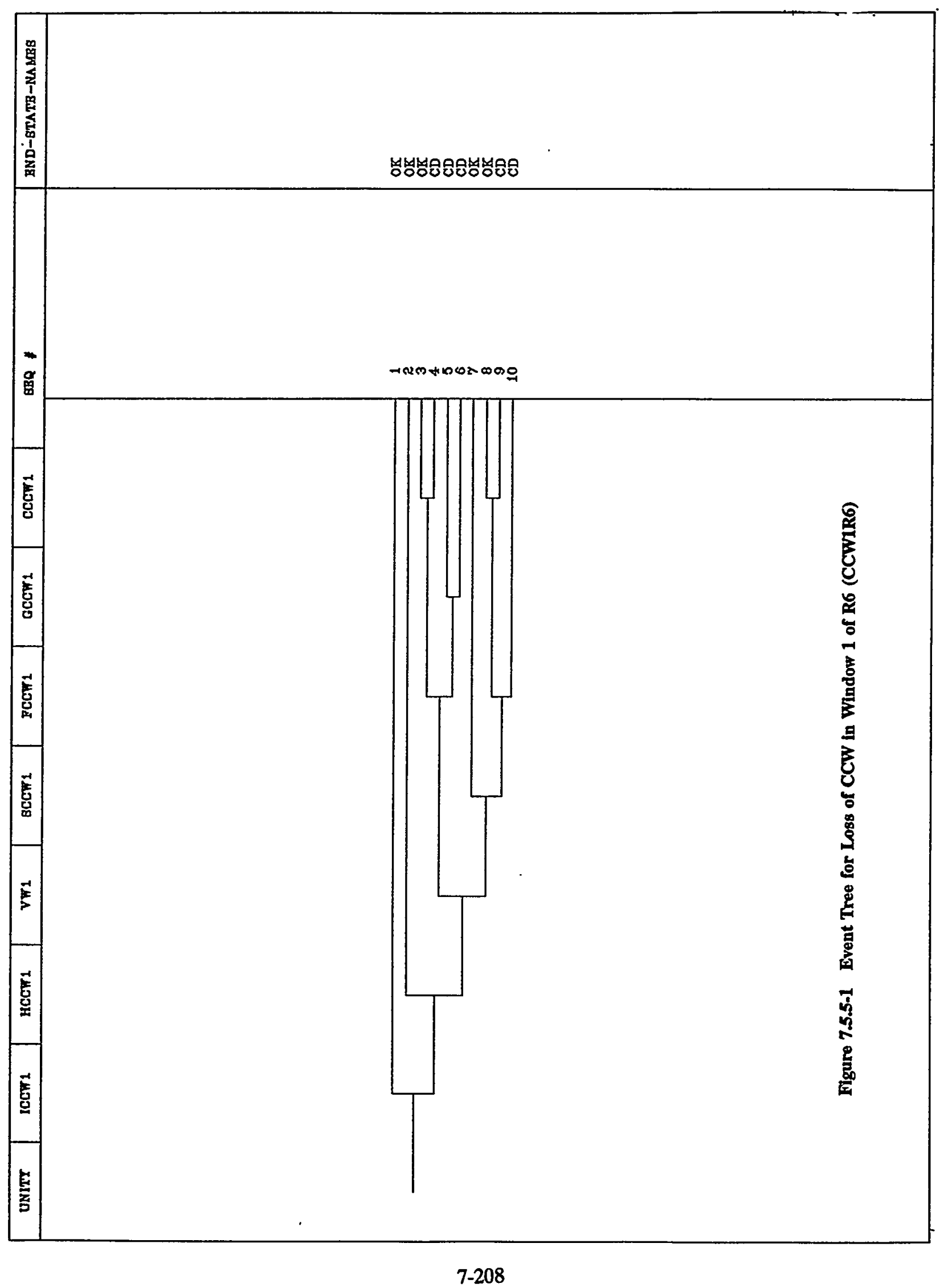




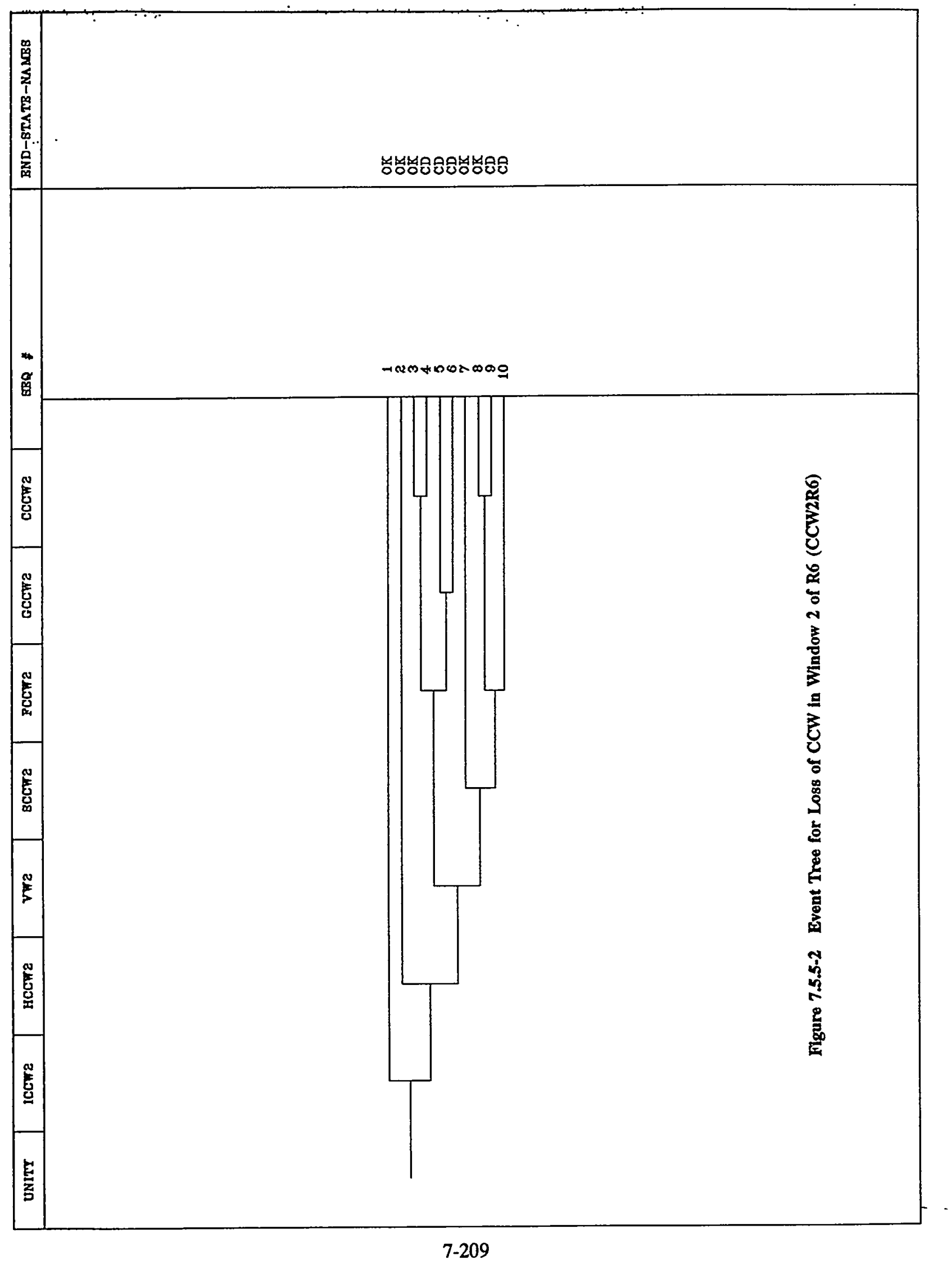




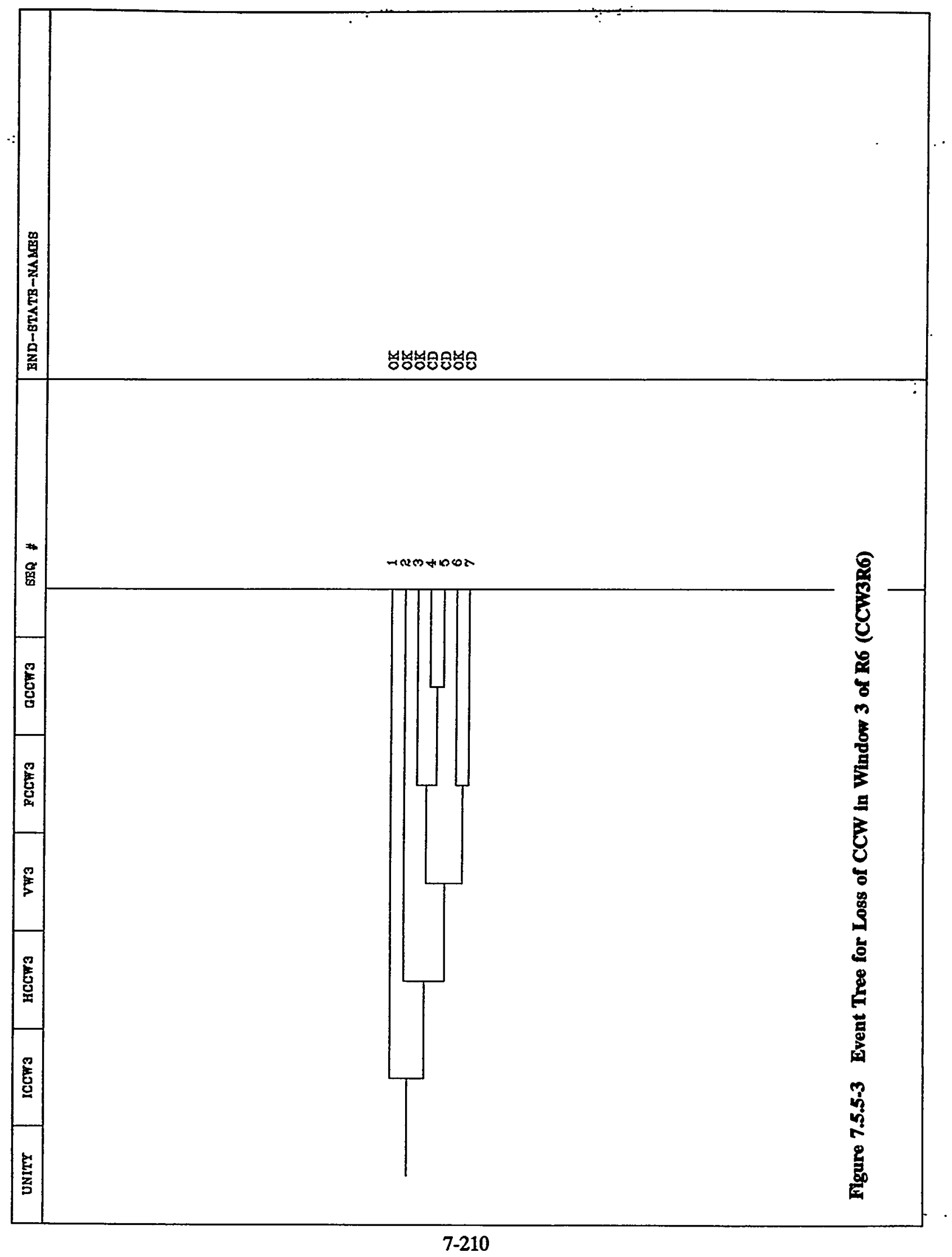




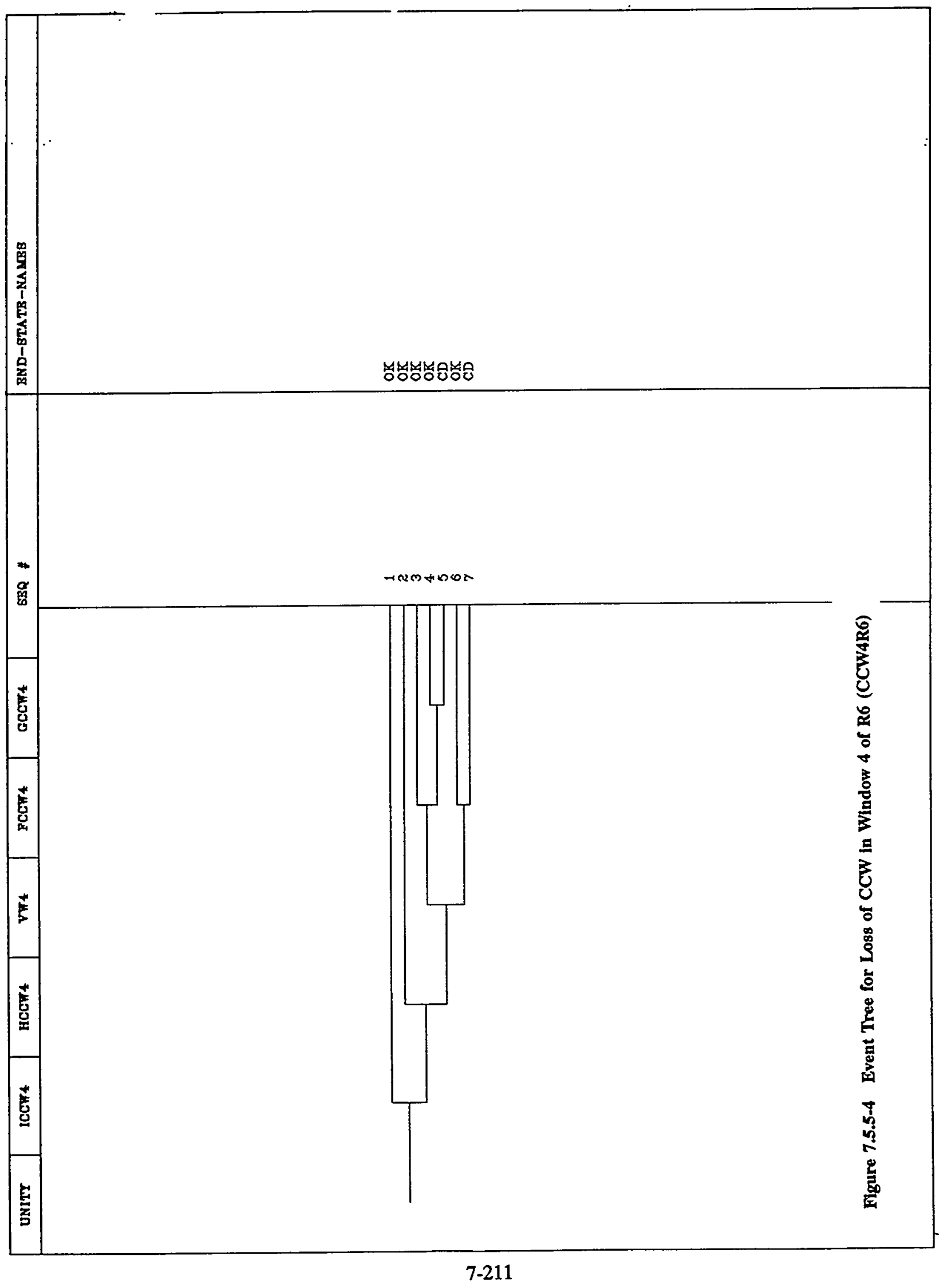




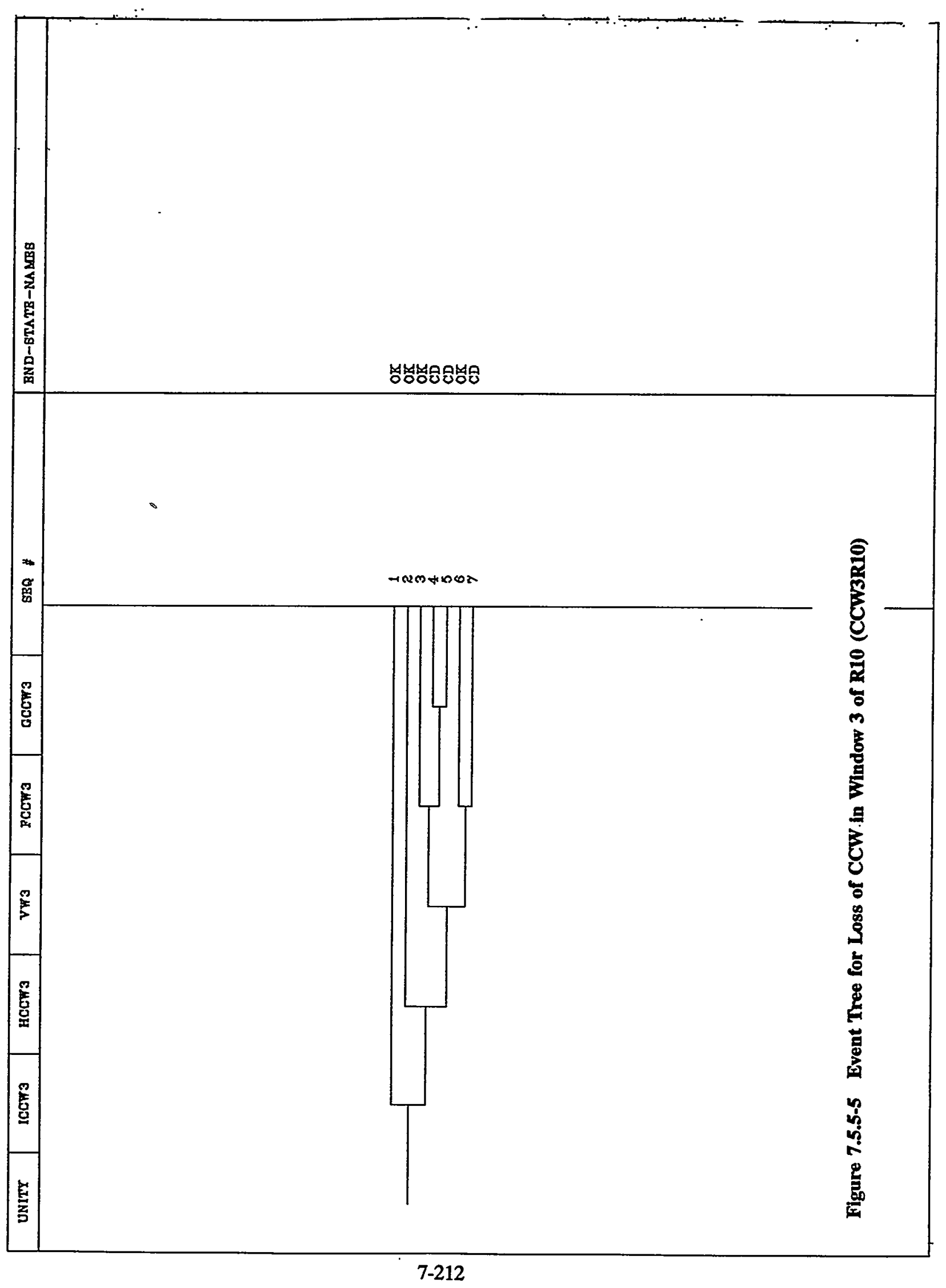




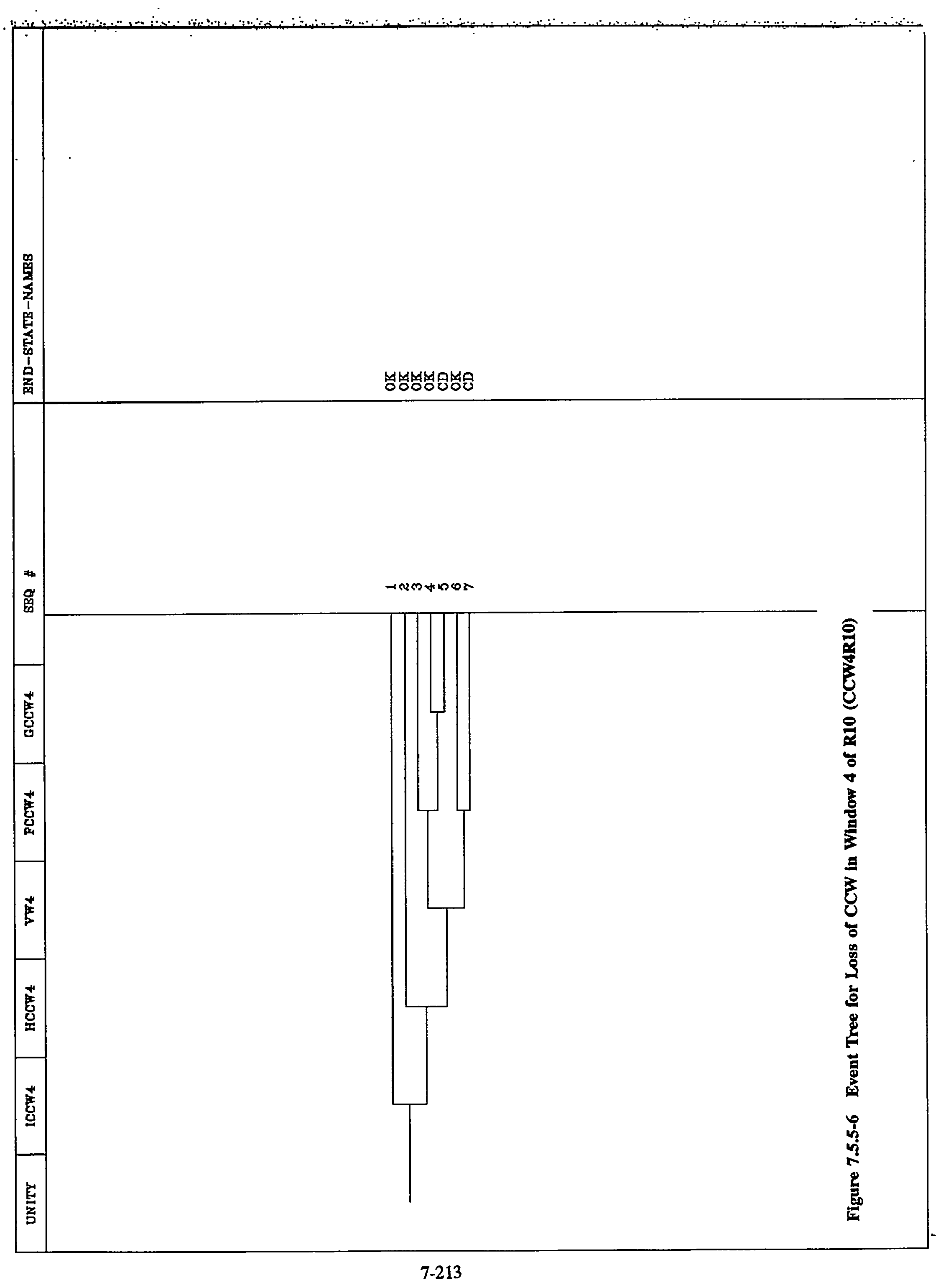




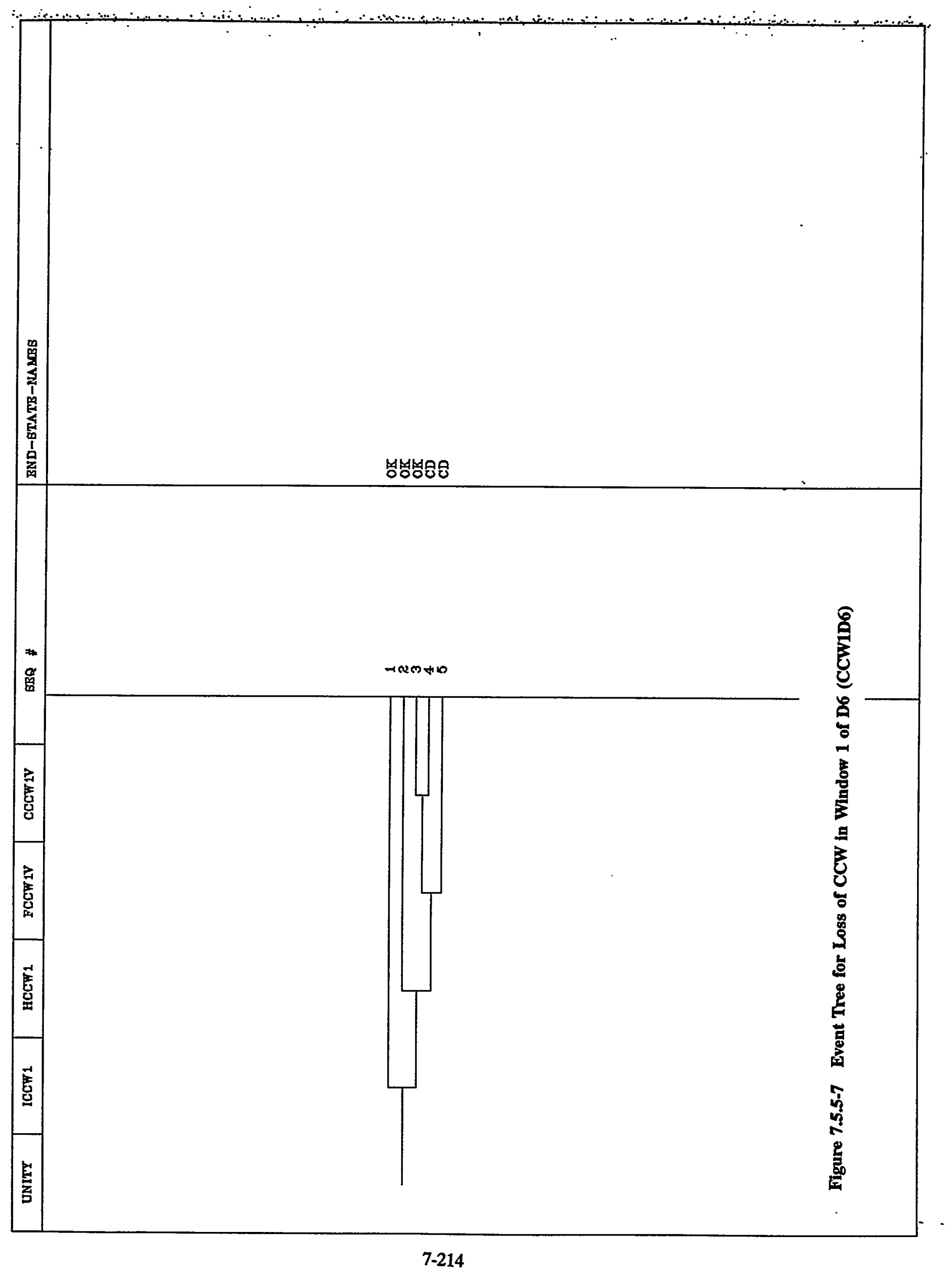




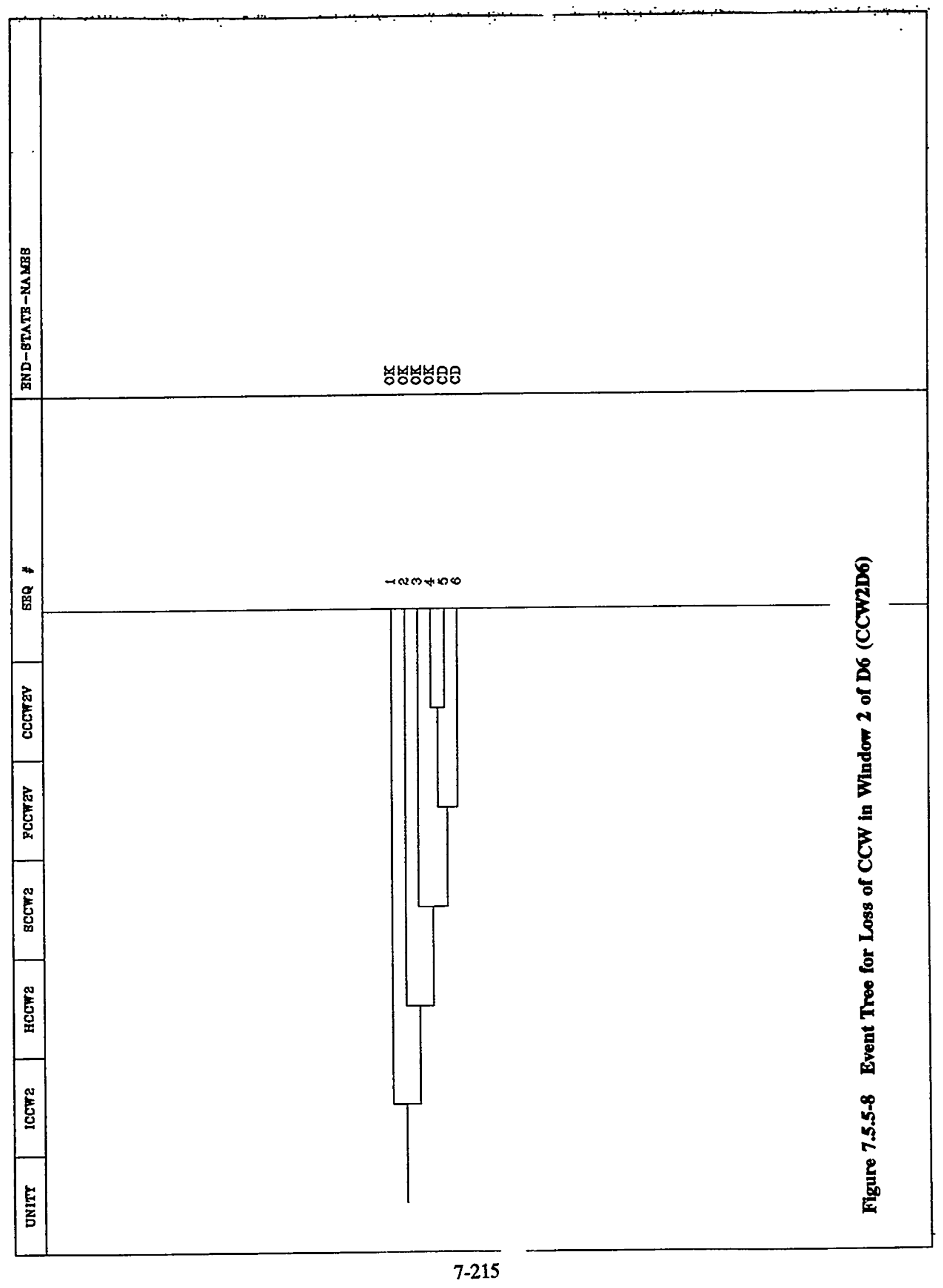




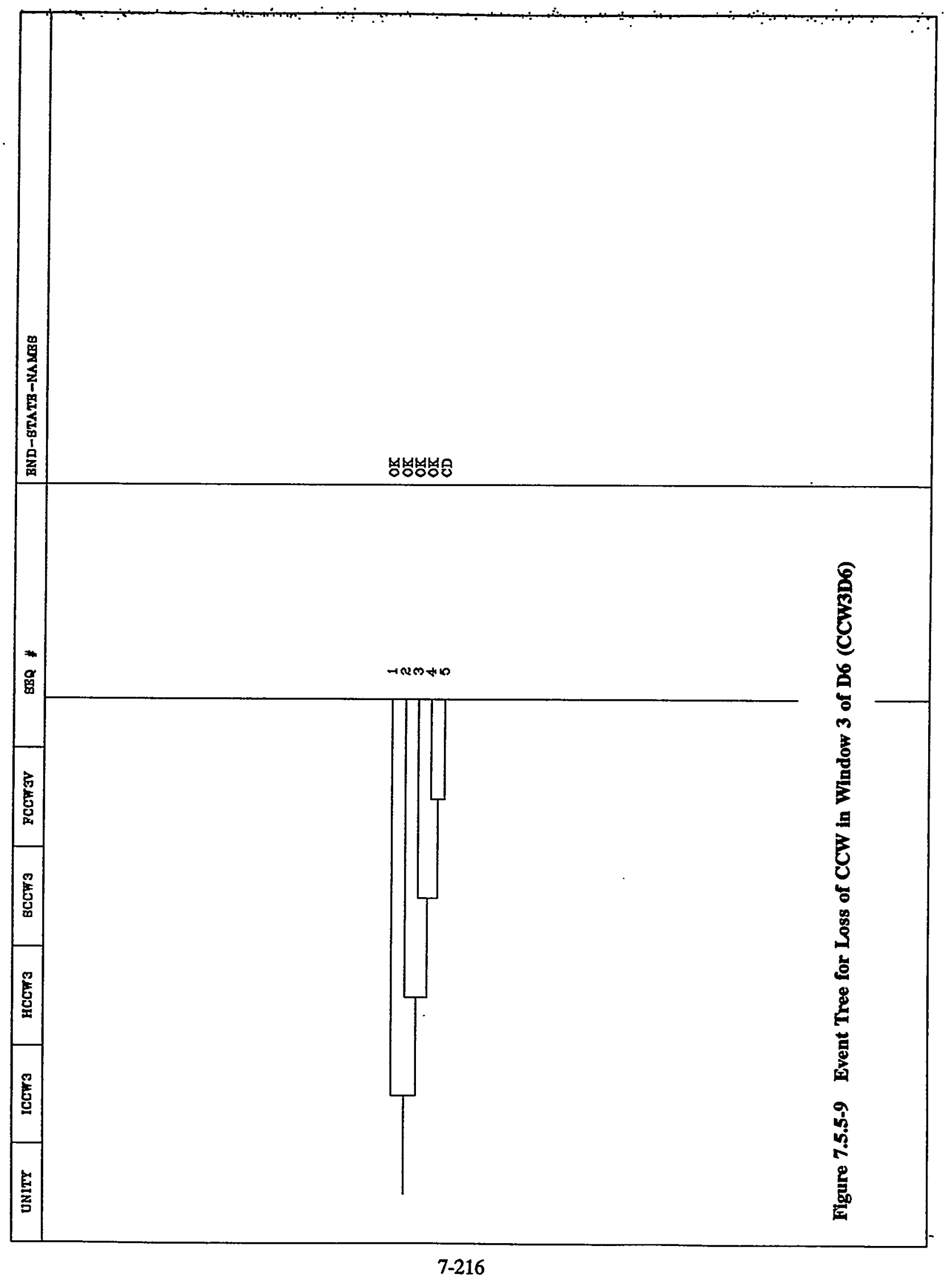




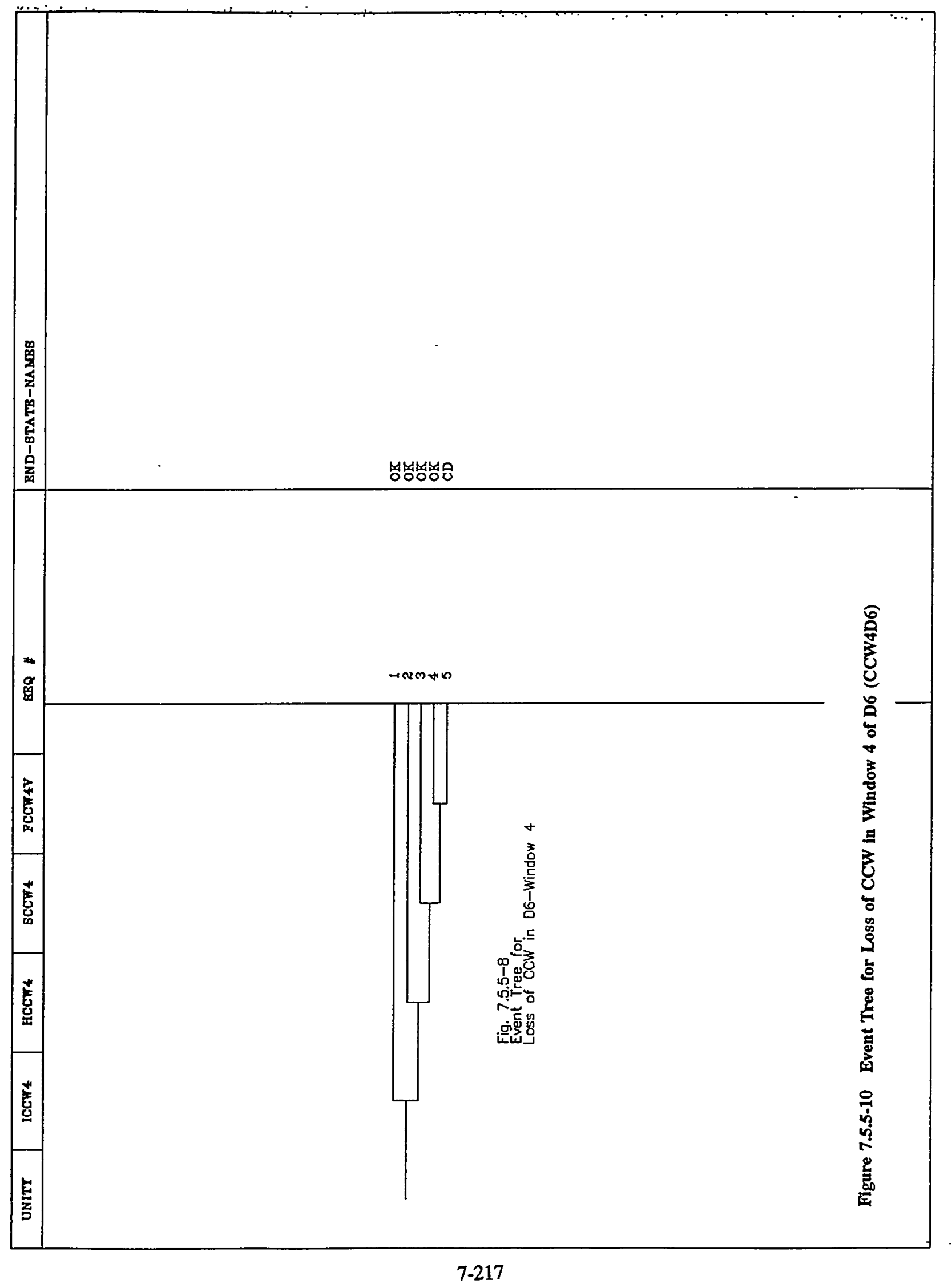




\section{Event Tree Analysis}

\subsubsection{Event Trees for Loss of Emergency Switchgear Room Cooling (SR)}

This section describes the event tree models that were developed to analyze the accident sequences initiated by a loss of emergency switchgear room (ESGR) cooling event during mid-loop operations in two types of outages at the Surry nuclear plant. ESGR ventilation is required to maintain the temperature in the emergency switchgear room below the acceptable limit at both Units 1 and 2 under abnormal and normal operating conditions. The acceptable limit was defined as $120^{\circ} \mathrm{F}$, and, at temperatures above this limit, several deleterious effects could degrade the functionality of the electrical equipment. The most important failure modes of electrical equipment operating under adverse ambient temperatures include spurious transfer of the relays, loss of thermal overload margin in the load breakers which trip the circuit breakers, and eventual failure of solid-state components in the UPS subsystems. The temperatures at which each of these types of electrical equipment failures would occur was not specifically determined.

Cooling and ventilation for the ESGR is provided for both units by a single air conditioning system consisting of air handling units (AHUs) and a Chilled Water System (CHWS). The CHWS is a closed-cycle system consisting of six pumps and three chillers; the heat sink for the normal ESGR chillers is the Service Water System. Backup chilled water is supplied by the Backup Air-Conditioning Chilled Water System. The backup chillers can be cross-connected to a single Main Control Room/ESGR AHU group by opening two manual valves; one on the supply and the other on the discharge of the chilled water side of the AHUs. Loss of ESGR ventilation as an initiating event was assessed by fault-tree modeling considering that operational constraints require at least one ESGR AHU and that any two of three chillers are operable when any unit is in shutdown.

If ESGR cooling is lost due to failures of the chillers or service water, there is no immediate impact on the unit. As the emergency switchgear room will heat up eventually, it is postulated that loss of vital power supplies or perturbations in DC power supply will trip the unit. The emergency systems are operable for a limited time as long as DC control power is available. Depending on the cause of the loss of room cooling, it is possible to restore ventilation by cross-connecting chilled water from the Central Conditioning System chillers or by establishing cross flow of air from the Unit 2 ESGR. This must be accomplished prior to loss of $\mathrm{AC}$ and DC power supplies. Failure to restore room cooling causes a station blackout that eventually damages the core. Thus, the event tree models for the loss of ESGR cooling during mid-loop operations are somewhat similar in structure to those developed for the Unit 1 SBO event, B1.

Figures 7.5.6-1 through 7.5.6-10 show the event trees for loss of switchgear room cooling (SR initiator).

If not recovered in time, this initiator will damage the emergency equipment in the switchgear room so that it cannot be recovered. This equipment is the power source for all the frontline systems. The only systems that can be used are the reflux bleed (via the steam dump), gravity feed, and cross-connect of Unit 2 charging. As a recovery action, feeding the steam generators with AFW from Unit 2 or with fire-water is a possibility.

Due to the similarity of top event definitions for the other windows and POSs, only the top events of the SRW1R6 event tree, Figure 7.5.6-1, are described below:

ISRW1 - SR Initiator - This event represents the loss of ESGR occurrence, SR, where failure of ESGR ventilation results in heat up of the room and causes the eventual failure of the $4 \mathrm{kv}$ AC distribution system and $\mathrm{DC}$ power supplies.

ARCW1 - Restore ESGR Cooling - This top event represents the restoration of the ESGR ventilation system by cross-connecting the Central Air Conditioning System chillers to the ESGR chilled water system. 
VW1 - RCS Initially Vented - This top event represents the plant configuration in which the RCS is initially vented with the pressurizer safety relief valves removed.

SSRW1 - Steam Generator Feed-and-Bleed- This top event represents the use of reflux cooling to adequately remove decay heat and prevent core damage. Reflux cooling is possible when the RCS loops are not isolated, and the secondary side of the SGs is in the wet layup condition. The PORV control will be lost due to loss of emergency power, so the bleed operation has to be accomplished by dumping the steam into the condenser. The feed function from Unit 1 will be unavailable, as the AFW systems depends on emergency power. The feed function is not necessary for the first 10 hours; it can then be accomplished by AFW cross-tie from Unit 2 , or by using fire-water to replenish the steam generators' secondary side.

2CHSW1 - Cross-connection of Unit 2 Charging System - This event represents the cross-tie of the operable Unit 2 charging pump to provide RCS makeup to the primary system for feed-and-bleedoperation to maintain RCS cooldown and depressurization.

GSRW1 - Gravity Feed from RWST - This event represents gravity feed of RWST inventory through the low head injection flowpath to the RCS if the RCS is vented. In window 1 , this option provides about 4 hours of cooling. In window 4, gravity feed is enough for at least 24 hours, which is defined as the mission time. In other windows, the allowable time can be extended by cross-connecting the two Units' RWSTs.

The descriptions of the sequence outcomes in the event trees are similar to those for the sequences initiated by the Unit 1 SBO event, B1, thus, the descriptions are not discussed here. 


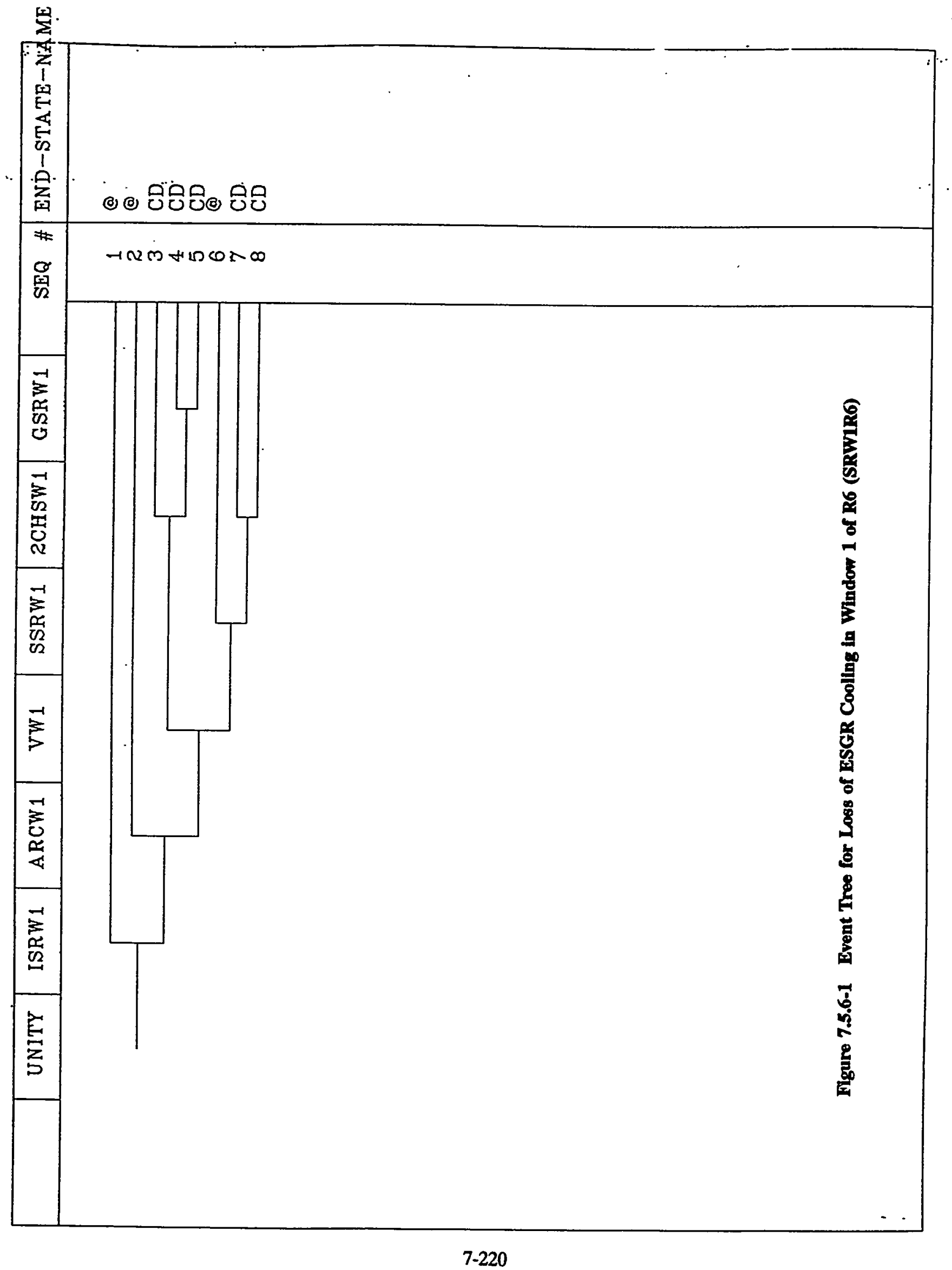




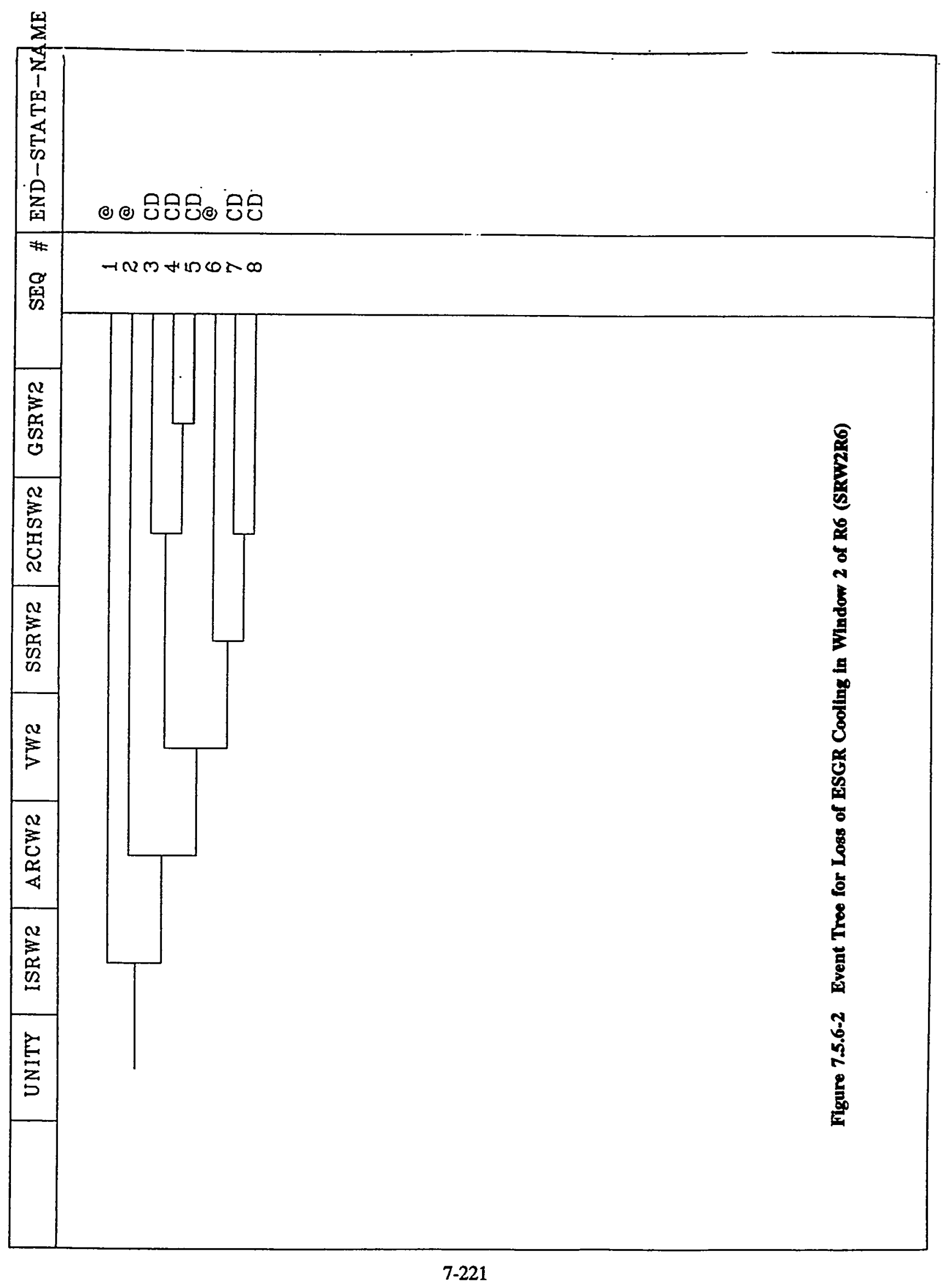




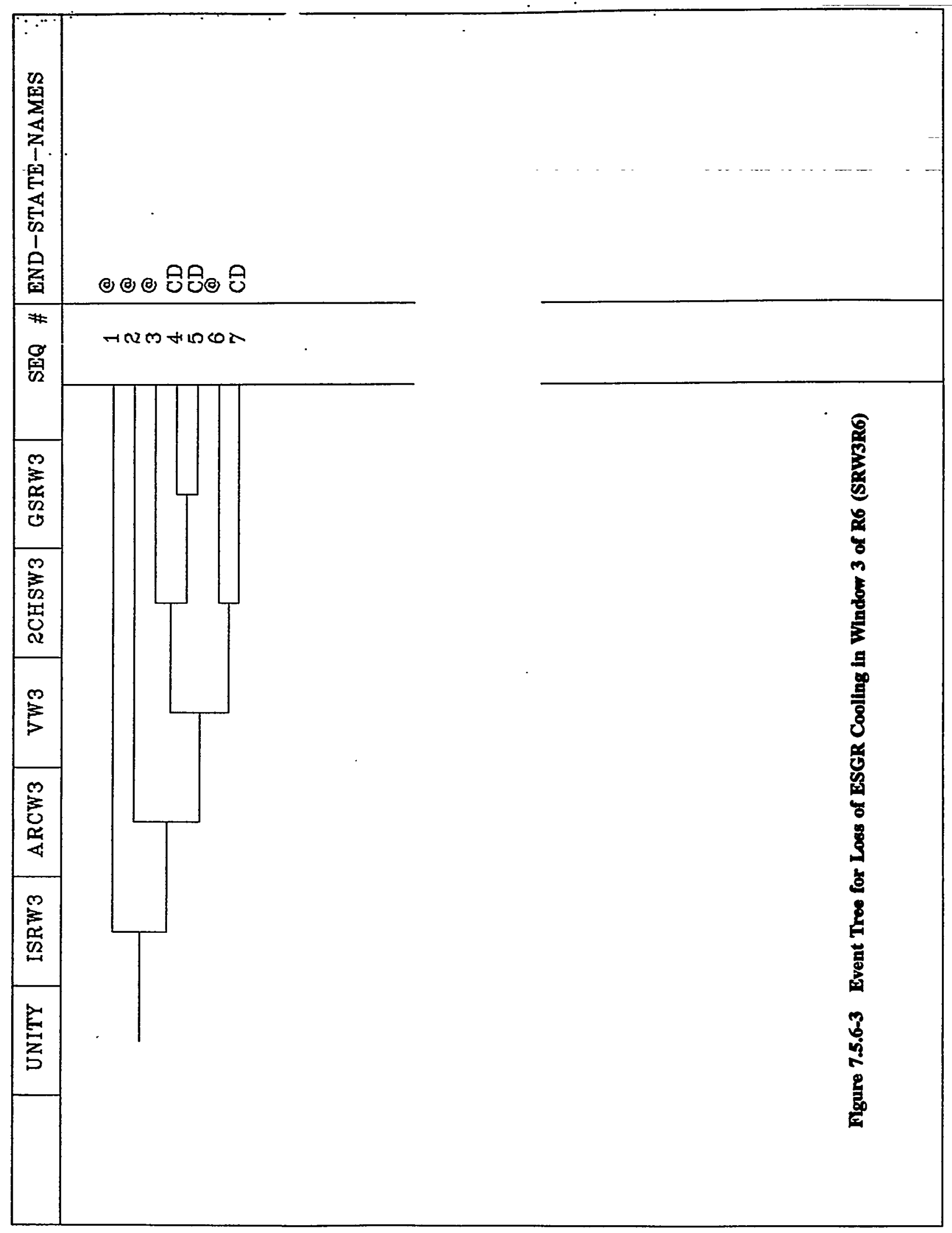




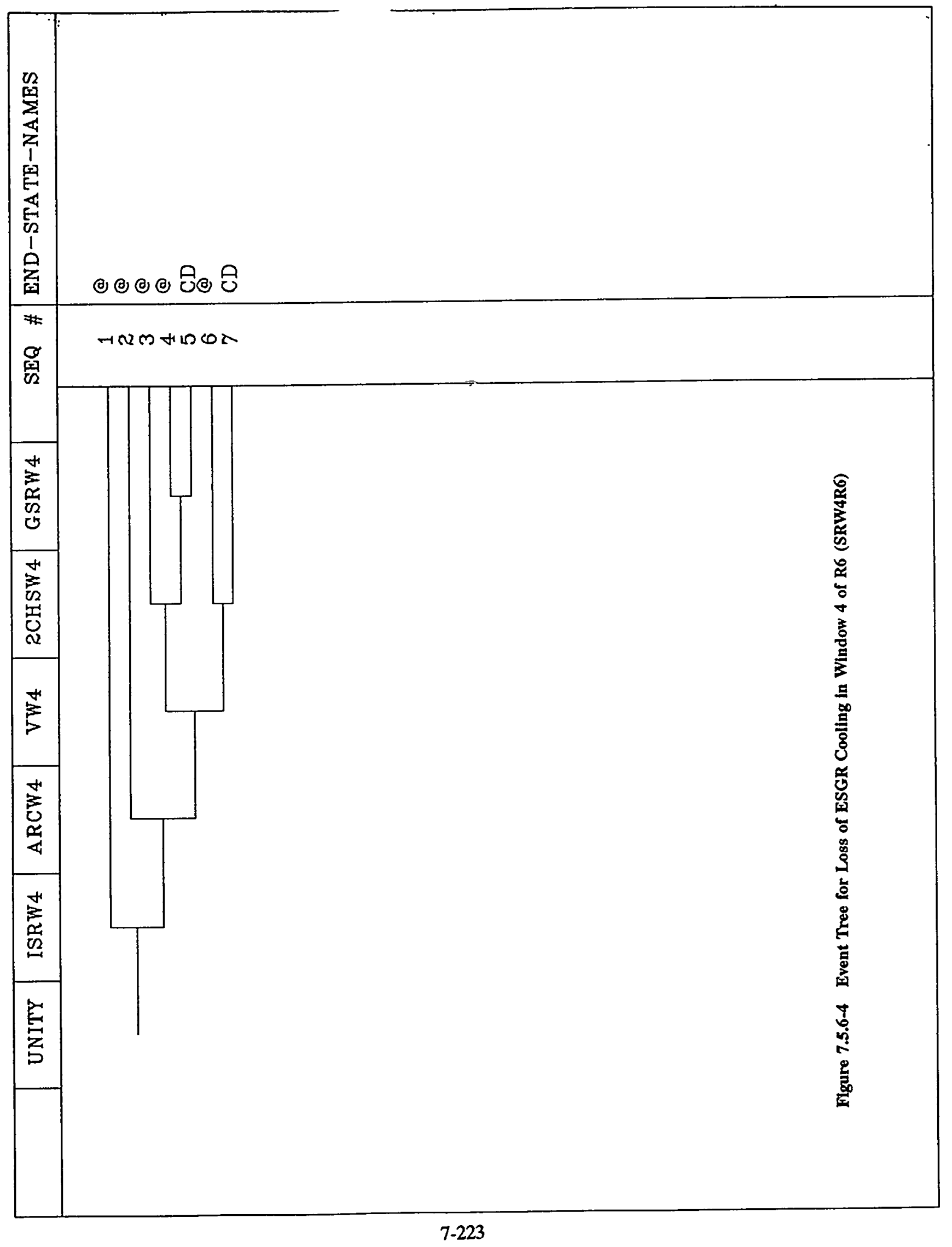




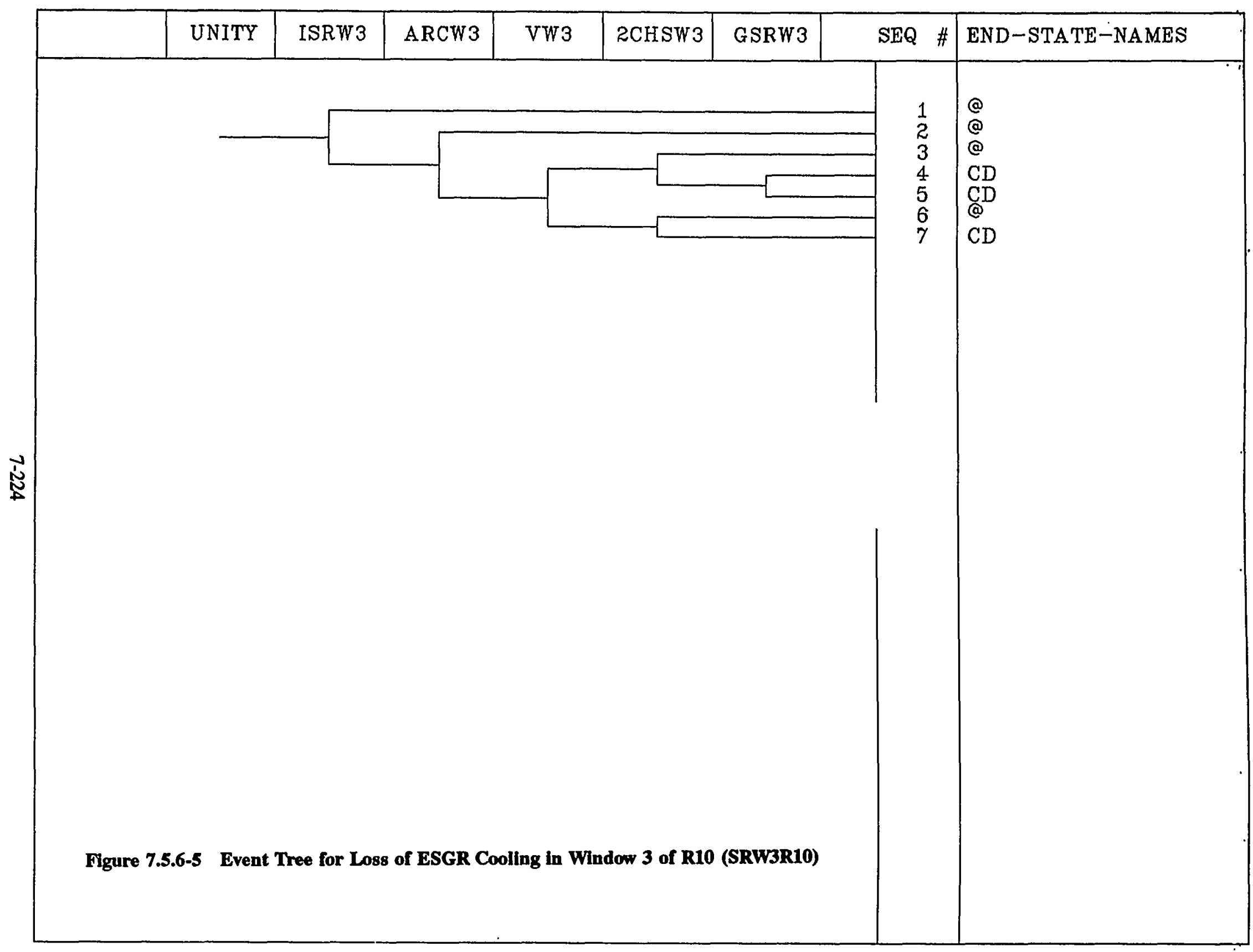




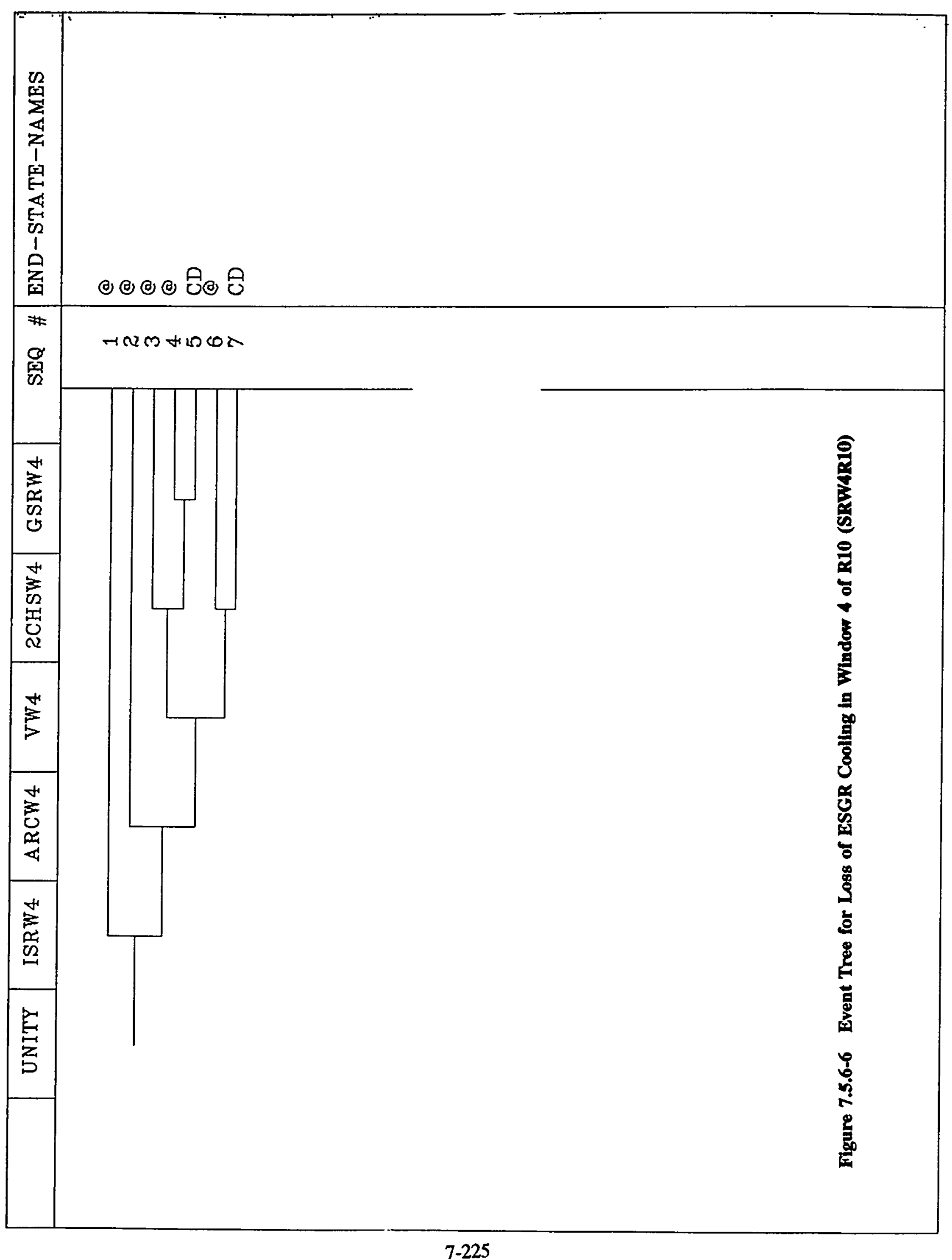




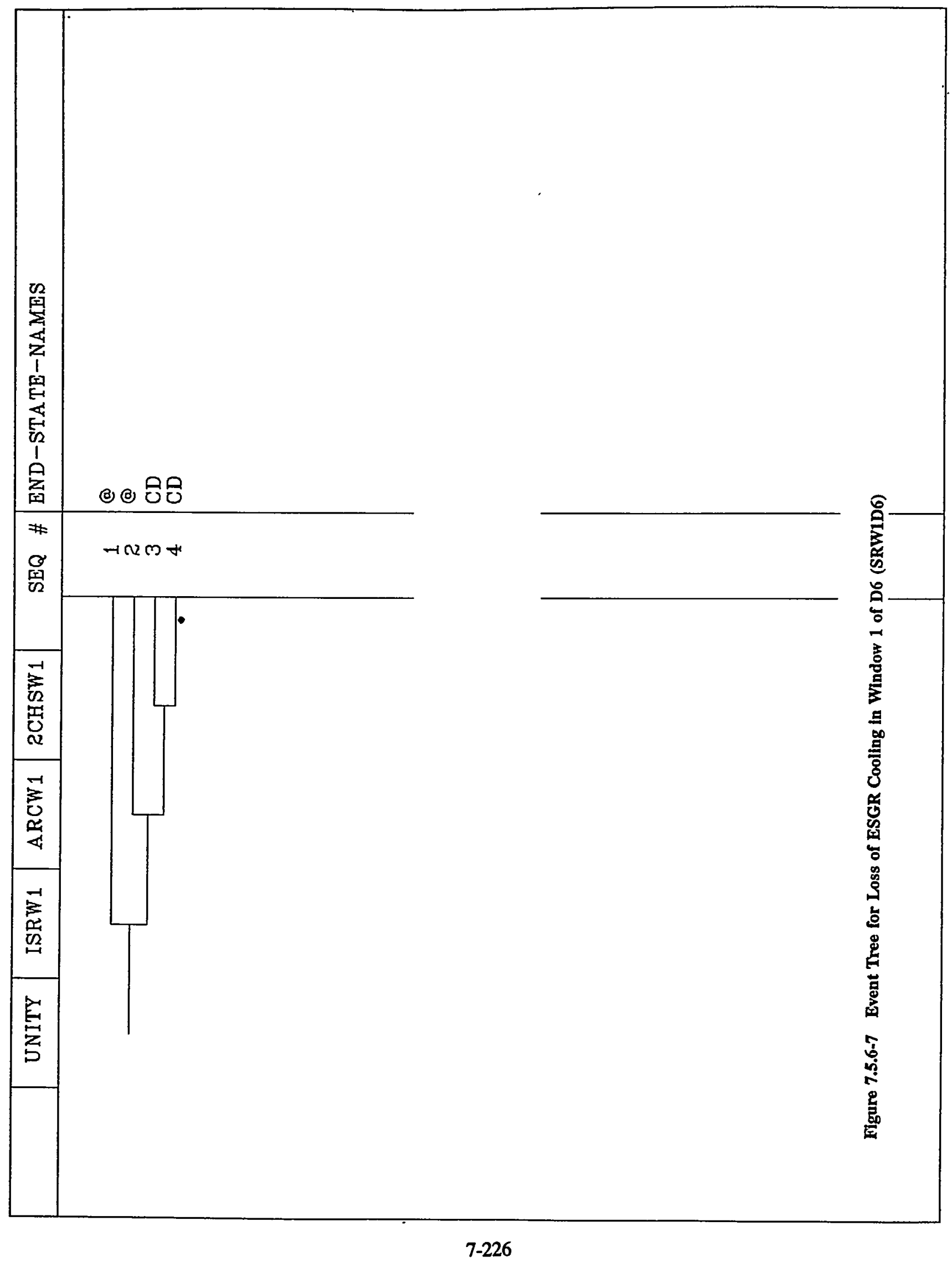




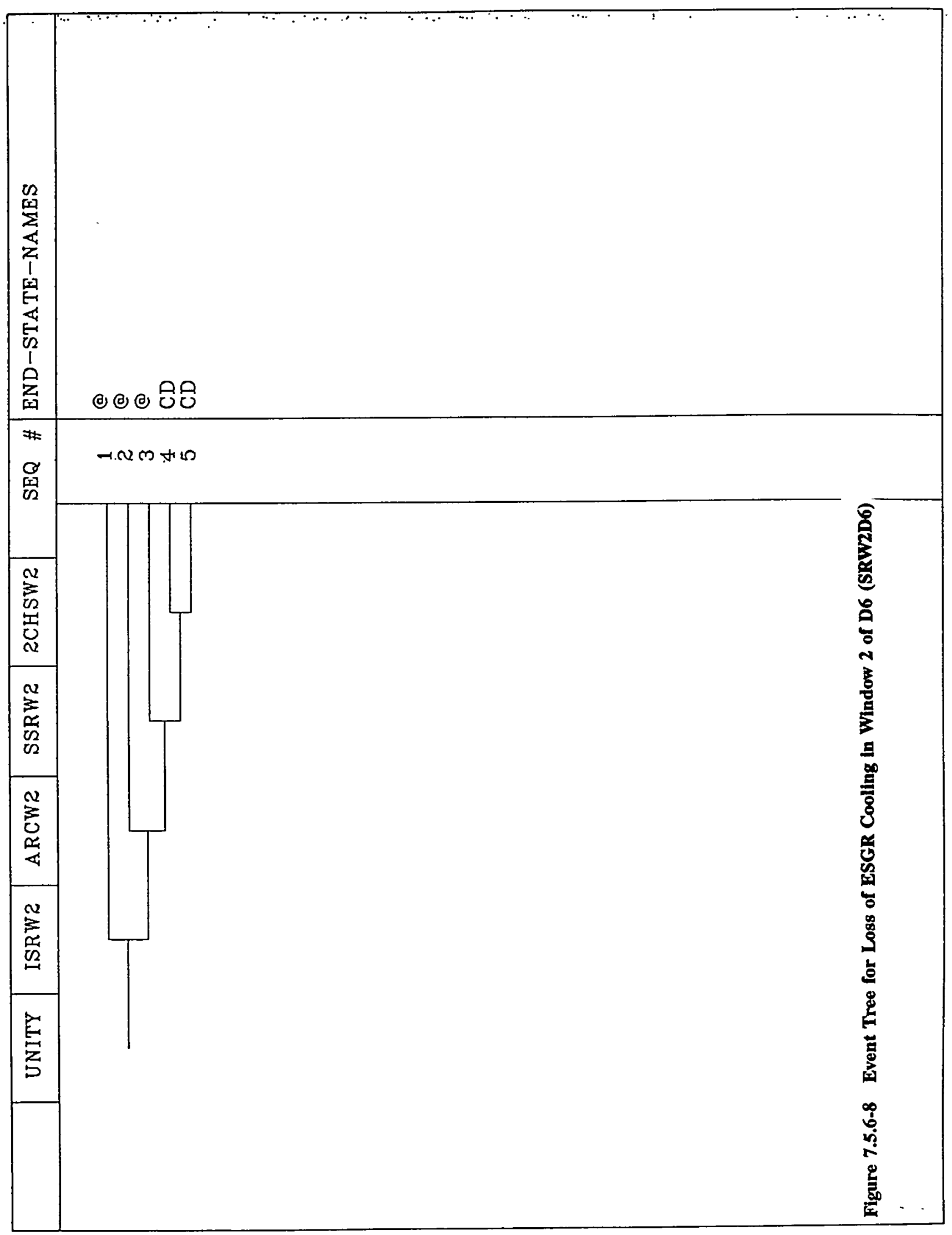




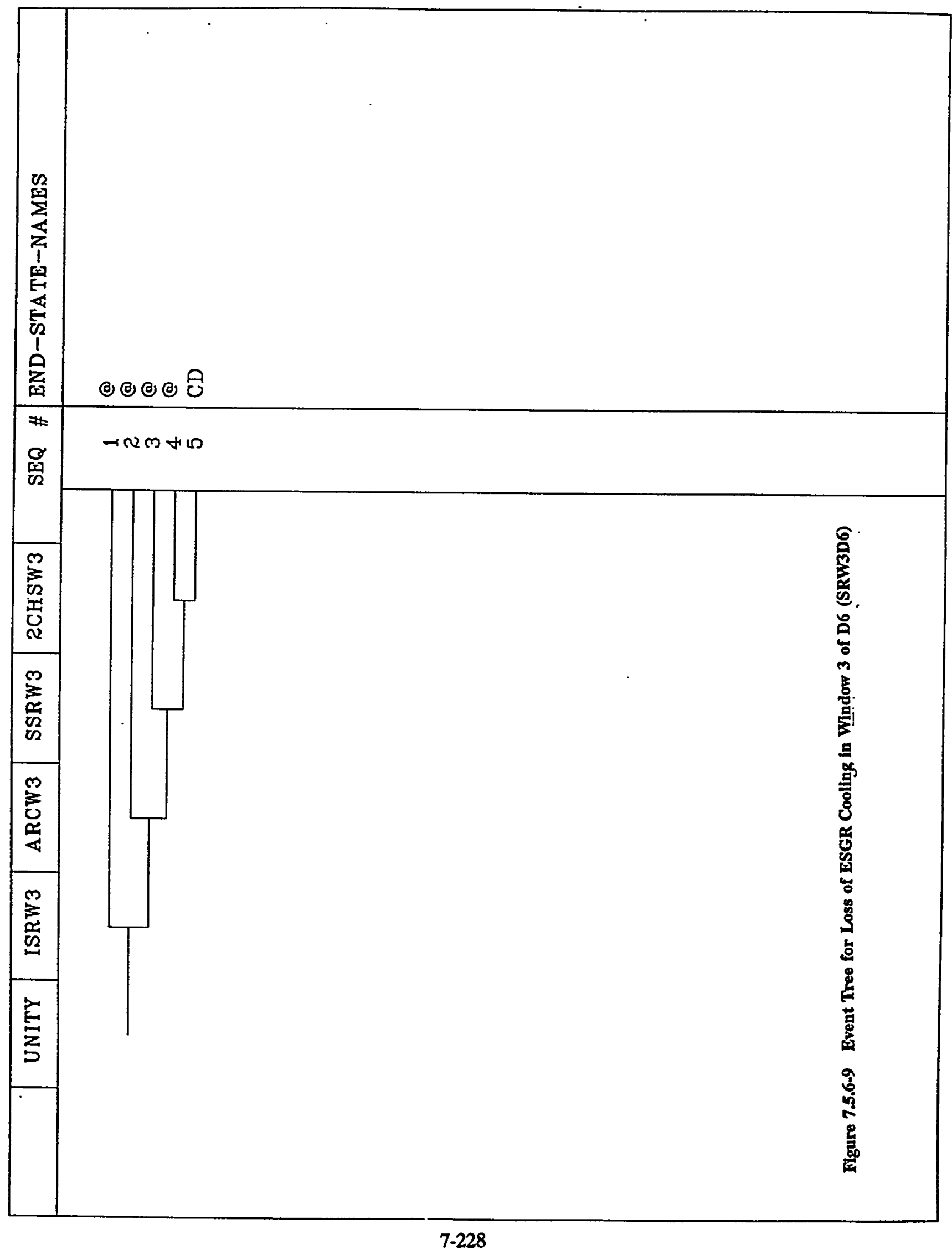




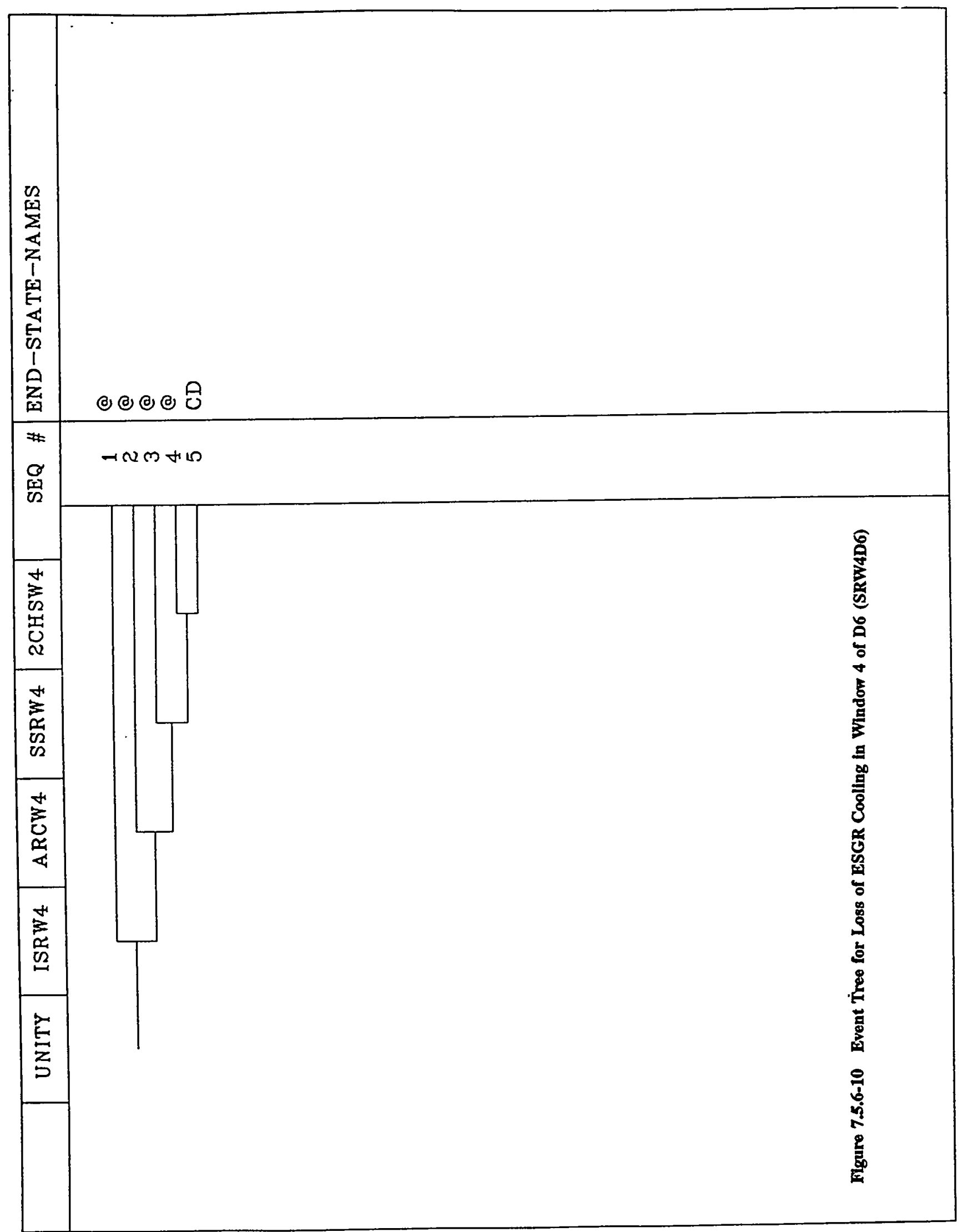




\subsection{Reactivity Accident Event Trees}

In Section 4.11, we discussed several categories of potential reactivity events during shutdown including the following:

(1) Addition of diluted accumulator water.

(2) Addition of diluted RWST water.

(3) Boron dilution due to maintenance problems.

(4) Uncontrolled boron dilution from CVCS.

(5) Boron dilution via the RHR.

(G) Startup of RCP after improper boron dilution.

(7) Rod ejection accident.

(8) Misloading of fuel assemblies.

(9) Uncontrolled bank withdrawal.

After screening each of these categories, we determined that only uncontrolled boron dilution from CVCS (category 4) during mid-loop operations is relatively risk significant, requiring an in-depth study. The probabilistic assessment of this reactivity accident for Surry is presented next.

\subsubsection{Uncontrolled Boron Dilution from CVCS}

The Surry Chemical and Volume Control System (CVCS) is composed of two major subsystems, charging and letdown, and makeup. The operation of the two subsystems is coordinated to perform the various functions of the CVCS, the primary purposes of which include the following: 1) Adjusts boron concentration in the RCS for reactivity control; 2) Maintains proper water inventory in the RCS; 3) Provides high pressure flow to the RCS upon initiation of safety injection (SI); 4) Maintainsproper concentration of corrosion-inhibiting chemicals in the RCS; and 5) Injects seal water into the reactor coolant pumps (RCPs).

Uncontrolled boron dilution is defined as the reduction in the RCS boron concentration caused by the inadvertent addition of unborated water. Such an event can occur as a result of operator errors or CVCS equipment failures, such as failure in the blending system or failure in the boric acid/demineralized water makeup flow path to the suction of the charging pump.

If allowed to continue, uncontrolled dilution could add enough positive reactivity to cause recriticality during reactor shutdown, leading eventually to core damage. Although inadvertent dilution can occur during any plant operating state (POS), the problem can become particularly acute if it occurs when the RCS is in midloop operation (POSs 6 and 10) when, because of the relatively small amount of water remaining in the RCS, the effects can be more easily felt and transients can proceed faster. Furthermore, since the RCS is operating at near atmospheric pressure, addition of neutronic power to the decay heat can easily cause the reactor coolant to heat up quickly and eventually boil, inducing RHRS failure. Therefore, for Surry, the probabilistic analysis of reactivity accidents due to boron dilution from CVCS, centered on those which are assumed to occur when the RCS is in mid-loop operation.

\subsubsection{Probabilistic Analysis of Boron Dilution Events During RCS Mid-Loop Operation}

From 1973 through 1985, there were six reported incidents of uncontrolled boron dilution at Surry Units 1 and 2, five of which occurred during cold shutdown and one during hot shutdown. One half of these events were attributed to equipment failures, the other half to human errors. Table 7.6-1 briefly describes the five dilution events that occurred during cold shutdown. 
To estimate the core-damage frequency associated with boron dilution during RCS mid-loop operations, an event tree was developed (Figure 7.6-1). Since the five Surry events did not necessarily occur during mid-loop operations, we estimated the probability that they occurred during mid-loop operations. To do this, we divided the average duration of mid-loop operation ( $277 \mathrm{hrs} / \mathrm{yr})$ by the average number of hours the RHR was in operation during shutdown ( $3332 \mathrm{hrs} / \mathrm{yr})$. Taking the reactor years during the period given above to be 25 years, the initiating event frequency was calculated as $1.66 \mathrm{E}-2$ event/year.

When an inadvertent dilution from CVCS occurs, the first positive indication of low boron concentration in the RCS could come from a high neutron-flux alarm. Assuming a balance between charging and letdown flows, the alarm could come on about 40 minutes after the inception of the accident. Upon receiving the alarm, the operator is instructed to look for the cause of dilution and terminate it by, for example, stopping the charging pump and isolating letdown. Depending upon the dilution flow rate, there is about 20 to 30 minutes to take these mitigative actions before criticality is reached. Once recriticality occurs, the reactor power will cause the reactor coolant to heat up rapidly, and eventually boil. This will induce cavitation of RHRS pumps and, hence, failure of RHRS. To terminate the boron dilution event at this point would require the operator to actuate emergency boration by injecting borated water into the RCS via the CVCS or the lowhead safety injection (LHSI) lines. Failure to initiate the emergency boration and supply makeup to the RCS will lead to core damage.

The branch point probability assigned to the fourth event-tree top event (no makeup water to RCS) takes into account both operator's failure to initiate the makeup flow and failure of the low-pressure injection system. The second top event models the possible failure of the high neutron flux alarm. The failure probability of the alarm was calculated based on an alarm failure rate of $6.06 \mathrm{E}-6$ per hour ${ }^{[1]}$ and an average mid-loop operation duration of 277 hours at Surry. Even if the high flux alarm fails, the operator could realize the abnormal situation through other symptoms of contingency, such as an increase in coolant temperature or failure of RHRS pumps. If the operator becomes aware of the adverse circumstance after RHRS is lost, emergency boration would have to be started within 15 to 20 minutes to prevent core damage. All the human error probabilities used in this event tree are taken from Swain and Guttmann ${ }^{[2]}$. Quantification of the event tree yields a core damage frequency of $6.8 \mathrm{E}-8 / \mathrm{yr}$ for boron dilution events during RCS mid-loop operations at Surry.

\subsubsection{References}

(1) Davis, R.E., et al, "PRAM Procedures Guide, Volume 1: Analysis of Accidents Leading to Radiological Releases at a High-Level Waste Repository" Draft, Department of Nuclear Energy, Brookhaven National Laboratory, February, 1988.

(2) Swain, A.D. and Guttmann, H.E. "Handbook of Human Reliability Analysis with Emphasis on Nuclear Power Plant Applications," NUREG/CR-1363, Idaho National Engineering Laboratory, 1982. 


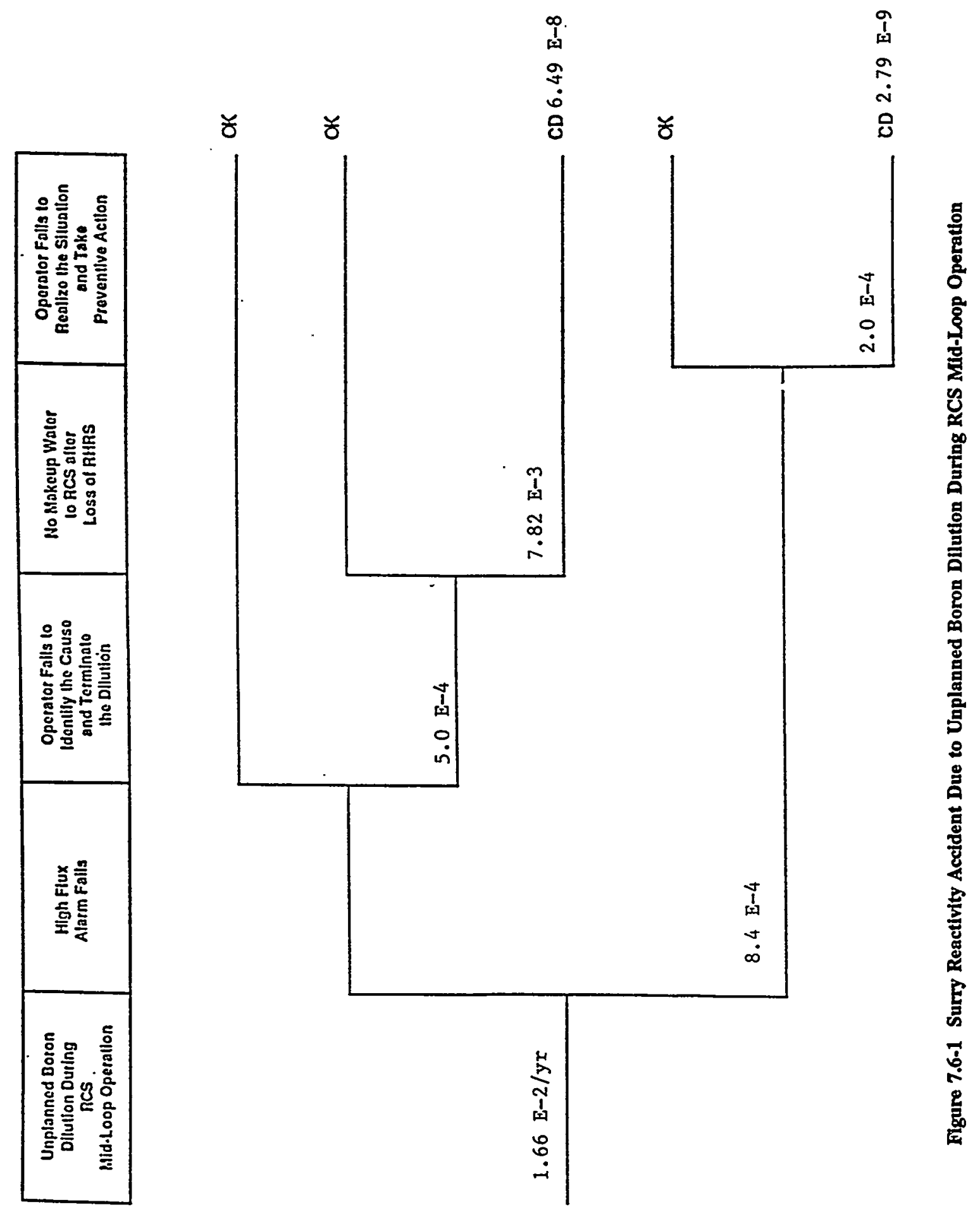


Table 7.6-1 Summary of Inadvertent RCS Boron Dilution Which Occurred at Surry Plants During Cold Shutdown

\begin{tabular}{|c|c|l|}
\hline Unit & \multicolumn{1}{|c|}{ Date } & \multicolumn{1}{|c|}{ Brief Description of Event } \\
\hline 1 & $2 / 24 / 75$ & $\begin{array}{l}\text { Over 4 days, too great a flow of primary -grade } \\
\text { water to the blender produced a boron } \\
\text { concentration of } 1312 \text { ppm, which diluted RCS } \\
\text { from the required 2000 ppm to 1842 ppm. }\end{array}$ \\
\hline 2 & $7 / 30 / 76$ & $\begin{array}{l}\text { Leakage from three tubes that had been cut } \\
\text { while removing a section of the seventh tube } \\
\text { support plate on the secondary side of the steam } \\
\text { generator diluted the RCS boron concentration } \\
\text { from 2356 to 1836 ppm. }\end{array}$ \\
\hline 2 & $4 / 6 / 78$ & $\begin{array}{l}\text { A failed flow controller caused the primary-grade } \\
\text { water valve to overfeed during blending. The } \\
\text { RCS boron concentration decreased from 1372 to } \\
\text { 1259 ppm in 13 hours. The failure also affected } \\
\text { the deviation of the primary-grade water flow. }\end{array}$ \\
\hline 1 & $5 / 12 / 80$ & $\begin{array}{l}\text { Inadvertent deboronation of the RCS occurred } \\
\text { when a mixed-bed demineralizer was placed in } \\
\text { service without verifying that boron concentration } \\
\text { of the effluent was equalized with that of the } \\
\text { RCS. }\end{array}$ \\
\hline 2 & $\begin{array}{l}\text { RCS boron dilution occurred at cold shutdown. } \\
\text { The dilution was caused by problems in the boric } \\
\text { acid/P.G. water blend system, which was used to } \\
\text { control boric acid concentration in the RCS. } \\
\text { Inaccurate operation of boric acid controller. }\end{array}$ \\
\hline & $10 / 85$ & \\
\hline
\end{tabular}




\section{HUMAN INTERFACE ANALYSIS}

Human reliability of the Surry plant operators is analyzed for a small subset of plant operating conditions. Only those event sequences originating during reactor shutdown with the reactor coolant loops drained to midloop in the hot legs are considered. In truth, the Surry Low Power and Shutdown Probabilistic Risk Assessment (PRA) analyzes a "Surry-like" plant that is assumed to operate under administrative controls that differ from those currently in place at Surry. In particular, the model assumes more time at midloop than Surry management currently anticipates, and assumes that the "Surry-like" plant does not procedurally prevent entering reduced inventory at less than 200 hours after shutdown as in the current version of Surry Procedure OP-RC-005 (Reference 8-1). The model, while based on former practice at Surry, can be valuable to the U.S. Nuclear Regulatory Commission (NRC) because it is representative of current operations at many pressurized water reactors (PWR).

This analysis supports the Brookhaven National Laboratory (BNL) Phase 2 PRA for midloop conditions. PLG analysts Dr. Dennis C. Bley, Dr. David H. Johnson, and Mr. James C. Lin performed the human reliability analysis (HRA). In support of this effort, they participated in the development of the POS 6 and POS 10 event trees at BNL, reviewed the available thermal-hydraulics calculations (performed by BNL, Virginia Power, and the Westinghouse Owners Group), reviewed the Phase 1 and draft Phase 2 BNL shutdown PRA reports (References 8-2 and 8-3), and studied plant procedures. Dr. Bley visited the plant to interview operators and to tour the facility.

\subsection{Overview of the Approach and Scope}

The Senior Consulting Group that reviewed the Phase 1 Surry Low Power and Shutdown PRA recommended an HRA approach similar to that used in NSAC-84 (Reference 8-4). We have developed an extension to the NSAC-84 HRA based on success likelihood index methodology (SLIM) (Reference 8-5) that provides a more structured ranking scheme to ensure internal consistency. The project scope precluded a complete integration of the HRA approach with the accident sequence analysis. At this time, the capability of the HRA to track dependencies among human actions, and dependencies relative to previous hardware failures, exceeds the ability of the event tree/fault tree computer model to incorporate and process this detailed information in an efficient way. A related NRC project is developing data and methods to support integration and consideration of correlated impacts on human performance (Reference 8-6).

The HRA identifies key dependency issues and flags them for consideration during the comprehensive human reliability analysis following the work described in Reference 8-6. For the current analysis, we have tried to match the most appropriately conditioned human actions to the event tree models. That is, using judgment based on our PRA and HRA experience, we have quantified the human action events that we believe would most contribute to the risk if the full set of dependent actions were analyzed on a cutset-by-cutset basis. The current event tree model imbeds the human actions within a series of functional top events that include hardware failures in safety systems and their support systems. The imbedded human actions are modeled in two parts: a global diagnosis event affecting all actions and the top event-related action events.

The crux of the judgment for selecting human action models was that, for subsequent events, the most important cases would be those in which the previous event tree's functional top event failures were caused by equipment failure or were the result of the physics of the process rather than the cognitive failure of the operator. Rough estimates indicate that, in many cases, equipment failure dominates those top events. In most other cases, because global diagnosis has been successful, the operators are on the right track, but the 


\section{Human Interface Analysis}

difficulties of the physical operation (e.g., residual heat removal (RHR) pump venting) are causing long time delays. There are substantial cues to encourage the operators to proceed to alternative cooling options. In addition, the procedures are reasonably clear in this regard; training, simulator exercise, and experience are supportive; and discussions with Surry operators have demonstrated that their focus is on moving through alternative options until clear evidence (instrument readings) demonstrates that cooling is restored and system conditions are returning to normal.

\subsection{Plant Design and Practice - Special Features at Surry}

Earlier PRAs and examinationsof operational events during shutdown at PWRs (References 8-7 through 8-9) have identified several characteristics of shutdown operations that contribute to risk. The most significant include time at midloop (especially soon after shutdown when decay heat levels are high), the lack of reliable indications of reactor coolant system (RCS) level and RHR flow, the lack of alarms to warn operators in case of a loss of cooling, the lack of automatic functions, and the lack of training and procedures.

Surry has implemented many of the recommendations of the available guidance for controlling shutdown PWR risk (References 8-10 through 8-13) that directly address the most important scenarios contributing to shutdown risk. In addition, there are design features that make the plant less vulnerable to certain scenarios.

Surry has implemented administrative and response procedures for shutdown conditions, and a training program for operators. The plant has loop isolation valves, which permit draining a loop for maintenance without maintainingdrained conditions in all three loops. Plant policy is to minimize time drained to midloop. If extensive reduced inventory work is required, the plan is to off-load the core.

The RHR system provides no other service (such as safety injection), and is completely inside containment. No automatic trip function is provided for the RHR isolation valves so a major cause of interruption of cooling at other plants is eliminated. Two independent, permanently installed level systems are provided. One is a standpipe with local indication by flags on the standpipe. The other is an ultrasonic sensor on one loop. Both are monitored and alarmed in the control room. The RHR pump piping and valves are configured so that if one pump vortexes and becomes air bound, the other pump remains flooded. After level is restored, the pump lineup can be shifted from the control room, and the standby pump can be started without first venting the air bound pump.

\subsubsection{Surry Plant Procedures and Training}

The keynote procedure for shutdown conditions is AP-27.00, "Loss of Decay Heat Capability" (Reference 8-14). According to plant personnel, this procedure has been in the plant for 5 years, and the operators have performed simulator drills for shutdown conditions, including midloop operations, for that entire time.

The procedure follows standard Westinghouse Owners Group format defining the entry conditions (initiating events), then sequentially diagnosing the event and restoring stable conditions. Loss of inventory problems are addressed first, followed by other causes for interruption of cooling. Restoration is orderly: first, trying to recover normal modes of RHR cooling; next, checking time until boiling, protecting personnel, isolating containment, and trying steam generator cooling (reflux cooling if drained); and then moving on to feed and spill, use of a charging pump from the opposite unit, and gravity feed. 
The operators are well trained on this procedure. We have reviewed the simulator drill scenarios and critiques. The operators train on all of the basic scenarios that were analyzed. In addition, they have a sense of the potential importance of these actions and indicate that they would not wait long in a configuration that failed to yield the expected temperature reduction. They understand that the ultimate measure of the effectiveness of any cooling mode is the core exit thermocouple temperatures, which are displayed on the control panel and monitored throughout the procedure. The procedure is based on vendor and utility thermal-hydraulics analyses for shutdown conditions (References 8-15 and 8-16).

Additional procedures apply during shutdown. There are general operating procedures that guide cooldown, depressurization, and draining operations (References 8-17 through 8-23). These provide detailed requirements for maintaining control of the shutdown machine. There are special procedures, such as OC-28, "Operational Check, Assessment of Maintenance Activities for Potential Loss of Reactor Coolant Inventory" (Reference 8-24), and a reduced inventory checklist (Reference 8-1), that provide special guidance for reducing the chance of loss of cooling events when RCS maintenance can lead to reduced inventory conditions. Other procedures have been expanded to provide a focus on shutdown conditions. For example, in AP-40.00, "Non-Recoverable Loss of Instrument Air" (Reference 8-25), if the unit is shut down on RHR, the first step requires use of a portable air bottle and fitting to reopen the containment isolation valves in the component cooling water system that supplies the RHR heat exchanger. We found the bottles and fitting in the Appendix $\mathbf{R}$ locker, as expected.

Similarly, the blackout, loss of AC power, loss of intake canal level, main control room inaccessibility, and fire procedures (References 8-26 through 8-30) provide important guidance.

\subsubsection{Surry Plant Operational Staffing}

Crew staffing for the two-unit plant includes the following:

- Three to Four Senior Reactor Operators (SRO). At least one SRO is required in the control room at all times; usually two will be there.

- One Shift Supervisor (SRO) for both units.

- Two to three Assistant Shift Supervisors (SRO).

- Four to Five Licensed Reactor Operators (RO). Three in the control room and one to two outside; after shutdown, a second RO is shifted to the shutdown plant.

- Eight Auxiliary Operators (AO).

- One Shift Technical Advisor (STA). The STA is assigned to licensing, not operations. STAs are not licensed. They take the same licensed operator requalification training (LORT) and testing. STAs perform calculations (shutdown margin, mass balance, etc.) and know technical bases for operations (ultrasonic level detector, critical safety function monitoring, etc.).

During alert or higher emergency action levels, the Technical Support Center (TSC) must be called to action. Approximately 15 to 20 people staff the TSC, including the plant superintendent, the emergency manager, and four or five department heads. During the daytime, the center is manned within about 15 minutes; at other times, when people must be called in, less than 1 hour is required. A review of Plant Procedure EPIP-1.01, 
"Emergency Action Level Table (Tab A) System Shutdown, or Assessment System Shutdown" (Reference 8-31), indicates that, for cold shutdown conditions at midloop, the TSC will be called to duty for the following defined conditions:

\author{
Secondary System Cooling Capability Unavailable \\ AND \\ Loss of \{(Service Water) OR (Component Cooling) OR (RHR)\} \\ AND \\ $\operatorname{RCS} \mathrm{T}>140^{\circ} \mathrm{F}$
}

\title{
8.3 Approach for HRA
}

Human errors and human solutions are vital parts of nuclear power plant operation and accident response. In fact, the causes for nearly all plant problems can ultimately be traced to some form of human fallibility, and nearly all plant problems can be solved by humans if they are provided with the appropriate information, guidance, and tools. Within the context of this study, however, the evaluation of human errors encompasses only those actions accomplished within the plant that directly:

- Impact the availability of support or safety systems at the time of the initiating event.

- Mitigate against core damage during the sequence of events following the initiating event.

With this in mind, the following types of human action's are evaluated:

- Routine Actions before an Initiating Event. Routine actions considered in the PRA involve restoring a component or flow path to normal after completing the testing, inspection, or maintenance, and ensuring that the sensing equipment is correctly aligned and calibrated for automatic response to emergency actuation conditions. Errors that are important to plant risk leave safety-related equipment disabled or in an undetected, misaligned state, causing it to be unavailable to accomplish its function on demand during an event sequence.

- Actions That Can Cause Initiating Events. Actions that can initiate plant transients are implicitly accounted for in the quantification of initiating event frequencies to the extent that these human actions are the cause of such events. Generic plant data are used to assign total initiating event frequencies of which human errors is only one cause. These types of human actions are accounted for in the initiating event analysis and are not discussed further here. However, as pointed out in References 8-4 and 8-6, human-induced initiating events during shutdown often influence the likelihood of subsequent human failures. This issue is being addressed in the program of Reference 8-6.

- Dynamic Operator Actions Accomplished during the Plant Response to an Initiator. Guided by the plant abnormal and emergency response procedures, the operators make active decisions and take appropriate actions in response to a complex series of stimuli during the sequence of events following an initiator. They are scenario specific and include well-defined tasks for manual initiation, control, and alignment of plant emergency equipment or selected backup systems. Usually, the operators must complete a particular activity within a specified period of time to avoid an unfavorable change in the state of the plant. These actions are an integral part of the plant response to the initiating event. 
- Recovery Actions. Recovery actions generally involve recovery from failures that completely or partially disable the standard system response during an event sequence. They generally involve alignment of alternate systems or repair and restoration of the failed system. They may be well defined in procedures or based on general guidance and the training and knowledge of the operators and plant staff. For the purposes of this study, recovery actions are those identified through the first quantification, after the dominant scenarios have been identified.

\subsection{Incorporation of Human Actions into the Plant Model}

The approach to human interaction modeling provides a systematic and consistent framework for identifying, evaluating, and documenting human responses at all levels of the study. The approach emphasizes a detailed interview with plant operators and a thorough review of their procedures.

Quantified human error probabilities (HEP) can be incorporated into the plant model in a number of ways, depending on the influence of the action on other events in the sequence and, in particular, how they impact the quantification of other events. The potential dependencies of HEPs on other elements of the plant model can strongly affect how the action and subsequent events are quantified. There are three general types, as follows:

- Plant-human dependency accounts for the impact of the plant instrumentation and other performance indications on the ability of the operators to accomplish the action. They are scenario dependent and influence the potential-for-failure that the operators face when responding to the scenario.

- Human-plant dependency accounts for those actions that can cause more than one system to fail. The event trees that are used to express the plant response to an initiating event can serve as a vehicle to represent these dependencies.

- Human-human dependency involves the increased potential for making a series of errors once the first error is made.

Depending on the type of dependency involved, any one of the following approaches can be used to incorporate human actions into the overall risk model:

- An action may be included within the system fault trees if the human error affects subsequent events in the sequence in the same way as hardware causes of system failure. Errors that occur before the initiating event, and some dynamic operator actions, fall into this category.

- If failure of an operator action that fails a system has a different effect on the subsequent response of the plant than a hardware failure, a separate top event may be used to represent the human action. Dynamic operator actions may, but not always, fall into this category.

- Recovery actions are often appended to accident sequence cutsets as separate basic events. In this way, they can be made very cutset-specific and not alter the remainder of the model. 


\section{Human Interfáce Analysis}

\subsubsection{Routine Actions before an Initiating Event}

Routine human actions considered in the PRA are system-specific activities performed by one or more operations staff members as part of their normal workday duties to align a safety function properly before leaving it in its ready condition. These include:

- Realignment of a component or flow path to normal after completing the testing, inspection, or maintenance.

- Removal of jumpers or other temporary system alterations to restore it back to service.

- Calibration and alignment of sensing equipment to ensure proper automatic response to emergency actuation conditions.

Errors that are important to plant risk cause the system to be unavailable to accomplish its function properly following an initiating event. Failure modes that could produce this condition involve, primarily, leaving safety-related equipment disabled or, in an undetected misaligned state, causing it to fail to operate upon demand.

The system analyst is responsible for evaluating routine actions that cause equipment unavailability. This approach is used because the system analyst is most familiar with the equipment, its location, control room alarms and indications, and details of all procedures and other guidance impacting the maintenance and surveillance testing of the system.

Normally, only surveillance procedures are evaluated to identify specific causes of equipment unavailability. Maintenance procedures are evaluated only if the operability of the system is not verified by a surveillance procedure at the conclusion of the maintenance or repair activity.

These routine actions were quantified in the Phase 1 report (Reference 8-2) and are unchanged.

\subsubsection{Methodology for Evaluation of Dynamic Operator Actions and Recovery Actions}

Dynamic operator actions and recovery actions that take place following an initiator are identified and qualitativelydescribed during the construction of the plant model event trees and quantification of the accident sequence, respectively. The licensed plant operators were consulted for evaluation and feedback on the process for restoring RHR cooling and establishing alternate decay heat removal. The qualitative descriptions for the operator actions are expanded to account for all factors significant to quantification. The methodology laid out in this section is an abbreviated approach to adapt to project scope. Rather than evaluation by teams of operators, quantification is based on the judgment of the analysts. Because of the similarity in assigned weights, only one calibration group was used.

The analysts bring extensive experience to the evaluation including actual nuclear plant operations and supervision, performance of many PRAs, thorough familiaritywith emergency operating procedures, interviews with many operators at many plants, and performance of many HRAs with extensive operator interaction, including quantitative evaluations by multiple crews of operators. 
Although multiple calibration groups were not used, the calibration actions bracketed the range of HEPs from $1 \times 10^{-5}$ to $1 \times 10^{-1}$. The actions were rank ordered by likelihood index and verified by extensive consistency checking. Given confidence in the rank ordering and the HEP endpoints, error among the intermediateHEPs is limited.

Section 8.3.3.1 describes the qualitative process by which the actions are identified and described. Section 8.3.3.2 describes the procedure used for evaluations within the context of the failure likelihood index (FLI) methodology (Reference 8-32), a modified version of SLIM. Finally, Sections 8.3.3.3 and 8.3.3.4 summarize the quantification process, including an assessment of uncertainty.

\subsubsection{Qualitative Evaluation}

The purposes of the qualitative evaluation are to:

- Identify dynamic operator actions to include in the event tree sequence evaluation.

- Identify recovery actions to realistically model the accident sequence.

- Ensure that the impact of the success or failure of those actions is properly modeled.

- Develop descriptions of those actions in a form that will facilitate evaluation.

During event tree construction and accident sequence evaluation, a variety of operator tasks are considered for inclusion in the model. These include:

- Manual actions required in abnormal and emergency procedures to prevent core damage following an initiating event.

- Control of preferred cooling systems.

- Backup of automatically controlled systems.

- Immediate response to failures of active systems.

Once individual actions are identified for evaluation, the action boundary conditions, success criteria, and event scenario timing are identified and recorded on the Operator Response Forms. The Operator Response Form follows the format shown in Table 8-1. The purpose of this form is to provide a consistent format to convey the context of the action to the evaluation team who will analyze its potential-for-failure, and to provide a short summary of what is required to accomplish it. The available thermodynamic calculations supporting the timing considerations and arguments supporting engineering judgments regarding timing are contained in Chapter 5.

The first two sections of the form set up the situation facing the operators. They describe where in the event tree model this action will take place and what indications the operators are expected to respond to in the control room. The next three sections describe what is involved in accomplishing the action, the relevant training and experiences, and those factors that compete for the operators' attention or divert them from the task. Two sections are then provided to describe what happens in the event sequence model if the action succeeds or fails. Finally, the time frame over which the action can be expected to be accomplished is addressed. 


\section{Human Interface Analysis}

Plant-human dependencies are described explicitly on the Operator Response Form, both in the section that relates the action to the plant model and in the discussion of required actions and competing factors. This permits the assessment team to understand the context of the action during the quantification of the action so that the dependencies can be reflected properly in the final error frequency.

The Operator Response Form presents human-human dependencies by asking the assessment team to identify with the situation at hand and to consider how an operating team may have made previous errors from which they must recover. They are then asked to identify ways to recognize and recover from previous errors when quantifying the dependent action.

\subsubsection{Qunatitative Evaluation}

This study uses an adaptation of SLIM to elicit judgment and to convert the operator evaluations into quantitative error frequencies. SLIM is based on the following assumptions:

- The likelihood of operator error in a particular situation depends on the combined effects of a relatively small set of performance-shaping factors (PSF) that influence the operator's ability to accomplish the action successfally.

- Evaluators can address each of these PSFs independently so that the overall evaluation can be expressed as the sum of the results of each PSF to form a numerical likelihood index.

- The actual quantitative error rate is related to the numerical likelihood index by a logarithmic relationship.

- The logarithmic relationship can be calibrated on a situational basis by use of appropriately selected calibration tasks having generally accepted error rates.

The basis for the logarithmic relationship between the likelihood index and error rate is documented in References 8-5, 8-33, and 8-34. Each of the other assumptions is addressed in the implementation procedure below.

A small set of generic PSFs has been selected that are judged to encompass the major influences on operator success or failure. These PSFs were chosen after a review of both the instructions and examples of the SLIM documentation and the discussion of PSFs in Reference 8-34. Seven PSFs have been chosen to relate the impact of the following:

- Conditions of the work setting under which the action must be accomplished. The PSFs are as follows:

- Significant preceding and concurrent actions; i.e., the dependencies between actions.

- Plant interface and indications.

- Adequacy of time to accomplish the action. 
- Requirements of the task itself. The PSFs are as follows:

- Procedural guidance.

- Complexity of the task relative to resources, coordination, and location.

- Psychological and cognitive condition of the operators. The PSFs are as follows:

- Training and experience relative to the action.

- Stress due to the situation and environmental conditions.

Performance-shaping factors are evaluated against two criteria:

- A rating relates the degree to which the conditions of PSF help or hinder the operator to perform the action.

- A weight relates the relative influence of each PSF on the likelihood of the success of the action.

The evaluation of dynamic human errors with SLIM is made consistent by the development of a set of forms and instructions to explain and expand on the rating procedures for the PSFs. These instructions constitute behaviorally anchored rating scales (BARS) of Reference 8-35 that enhance consistency throughout the evaluation process.

- Table 8-2 provides detailed guidance regarding the definition, interpretation, and application of each PSF and the thought process that could lead to a specific potential-for-failure rating.

- Table 8-3 provides a summary of the definition of each PSF and detailed guidance regarding the thought process that could lead to a relative influence weight.

- Table 8-4 summarizes the relationship between the rating and weighting processes. The rating addresses the actual conditions under which the action must be accomplished. The weight is equivalent to the operators stating how much the conditions relative to a specific PSF actually impact the potential for success or failure of the action. If it is not a factor that controls their ability to do the action, it is weighted low or insignificant.

The SLIM methodology has been modified so that the evaluators scale the potential-for-failure, rather than the potential for success, when they rate the action. This change in orientation produces an FLI rather than a success likelihood index. This approach has the advantage of quantitatively highlighting the causes of operator difficulty. A high rating combined with a high weight produces a large FLI. This permits efficient analysis of the potential problem areas and trends.

The shift to FLI is a simple algebraic transformation that does not affect the underlying assumptions of SLIM. While the benchmarking of MAUD (Reference 8-5), Embrey's computer code to enforce consistency among the weighting factors, may no longer apply, we do not rely on MAUD. Rather, we enforce consistency through the BARS of Table 8-3, and we review the rank-ordered actions for reasonableness.

The independence of the PSFs is addressed by the definition at the top of each evaluation form that emphasizes the different influences that each PSF is intended to address. While independence is impossible 


\section{Human Interface Analysis}

to achieve, the structured approach defined by the form provides a practical approach for controlling the influence of one PSF on another. Another major premise of the SLIM methodology is that the evaluation team can rate the weight and rate independently. The thought process necessary to distinguish between these two orientations of the process is stressed in Table 8-4.

During evaluation of the operator actions, the evaluation team is also requested to consider a number of possible errors. These include:

- Nonresponse Errors, Also Called Errors of Omission. This would include problems generated by both the plant interface and the competition of other actions.

- Time and Resource Limitations. For certain actions, the operators are requested to identify the number of people and the coordination required to get the job done. The potential-for-failure will then be impacted by the personnel and communications they have available.

- Nonviable Errors. Under some conditions, the operators may correctly diagnose the accident scenario but select the wrong response. These errors are believed to be governed by operator slips; e.g., selecting the wrong controls for the tasks. The control room feedback problems that could keep such errors from being detected are also considered.

\subsubsection{Quantification Process}

The quantification process is done in a series of stages.

First, a normalized weight for each PSF is obtained by dividing the weight assigned by the evaluation team by the total of all of the weights for that particular action.

The FLI is calculated by multiplying the normalized weight of the PSF by its rating and adding that result to similar results for the other PSFs, or

$$
\mathbf{F L I}=\boldsymbol{\Sigma}_{w_{i} R_{i}}
$$

where

$$
\begin{aligned}
& i=\text { PSF that has an influence on the error rate of the action. } \\
& w_{i}=\text { weight of } \mathrm{PSF}_{\mathrm{i}} \text {, normalized so that } \sum_{w_{i}}=1 \text {. } \\
& \mathbf{R}_{\mathrm{i}}=\text { potential-for-failure rating for } \mathrm{PSF}_{\mathrm{i}} \text {, from } 0 \text { to } 10 .
\end{aligned}
$$

The error rate of each action is estimated by comparing the overall FLI to a correlation that follows the relationship:

$$
\text { Logarithm (human error rate) }=A+B(F L I)
$$

The coefficients of the correlation are obtained from a least squares fit of the FLI of calibration actions that have reasonable or generally accepted error rates in the industry. 
To provide error rates that are consistent with other studies, the calibration of the human error rate model generally uses well-defined actions obtained from evaluations for other PRAs and other statistical or analytical evidence of failure frequencies for these actions. A human interaction database that encompasses these sources and provides this documented evidence is available for events occurring at power.

No such database is yet available for shutdown events. Reference 8-6 offers a first gathering of the necessary data, but events from Reference $8-4$ are used for calibration at this time. The calibration procedure should ensure that the numerical error rate estimates are realistic and consistent with available data, observed human behavior, and the results from comparable expert evaluations of similar activities.

The use of some combinations of calibration actions may produce human error rates of 1.0 per demand for FLI values of less than 10 . When this occurs, all actions with an FLI above that value are quantified as being guaranteed to fail.

A series of spreadsheets is used to accomplish the quantification process.

\subsubsection{Uncertainty}

The point estimate calculations are mean values because the calibration tasks provide mean values. Uncertainty is quantified by direct judgment based on consideration of the absolute value of the point estimate mean, type of action modeled, and judgments concerning the range of possible specific scenarios imbedded in the definitions of events analyzed. For dynamic actions (A) and recovery actions (R), previous successful actions have occurred. We believe that the uncertainty range should be larger as the mean value decreases. The more frequent errors are of types we have observed on many occasions, while the rare events rely more heavily on judgment and decomposition. For $\mathrm{A}$ and $\mathrm{R}$ events, we assign lognormal distributions with the following range factors:

\begin{tabular}{|l|c|}
\hline \multicolumn{1}{|c|}{ Mean of Distribution* } & Range Factor \\
\hline$(x)<1 \times 10^{-3}$ & 5 \\
$1 \times 10^{-3} \leq(x)<1 \times 10^{-1}$ & 3 \\
$1 \times 10^{-1} \leq(x)$ & 2 \\
\hline *Truncated lognormal if $(x)>1 \times 10^{-1}$. \\
\hline
\end{tabular}

For diagnosis events (D), the mean values are almost all very low, in the $1 \times 10^{-6}$ to $1 \times 10^{-4}$ range. Given the alarms and procedures at the plant, failing to diagnose and act in response to an initiating event is difficult to imagine. Still, such events do happen. In particular, they occur when some unusual characteristic of the initiating event of the sequence interferes with the operators' normally straightforward thinking process. Thus, we believe that the distributions should be skewed toward low values, with a high end tail that affects the mean. For diagnosis events, we assign a lognormal distribution with a range factor of 20 . Numerical experiments with such a distribution will convince the reader that it meets the requirements stated above.

\subsubsection{Summary}

The error rates resulting from the evaluation and the quantification are displayed in tabular format. This permits easy review, comparison, and identification of the most important factors influencing each assessment. 


\section{Human Interface Analysis}

It is important to recognize that the quantification of human error rates is only a small portion of the information obtained from the SLIM approach. The trends of weights and ratings provide much valuable information regarding the evaluator's judgment with respect to the focus of safety-related actions and the difficulties involved in accomplishing them.

\subsection{Actions while at Midloop}

Several hundred specific actions are considered in this analysis, and over 150 are quantified directly. Others are assigned HEPs equal to one of those actually quantified directly because of similarities in required response, cues, timing, and all other factors.

The large number of specific action scenarios are actually special cases of a small number of functional responses defined by plant procedures and colored by special conditions of the sequence of events that leads to the need for action. To aid in understanding the many special cases, we organize their presentation under the following topics:

- Human Responses

$$
\begin{array}{ll}
- & \text { Global Actions } \\
- & \text { Primary Cognitive Response } \\
-\quad & \text { Specific Activities } \\
-\quad & \text { Recovery Actions }
\end{array}
$$

- $\quad$ Factors Affecting Response

- Initiating Event

- Previous/Concurrent Hardware Failures and Human Actions

- Other Performance-Shaping Factors 


\subsubsection{Humnn Responses}

All of the actions discussed and quantified in this section fall into four broad categories, as shown in the following table. Under each category, there are several specific cases described.

\begin{tabular}{|c|c|c|c|}
\hline Category & Specific Cases & Code & Discussion \\
\hline \multirow[t]{3}{*}{ Global Actions } & & & $\begin{array}{l}\text { These global events strongly affect other } \\
\text { actions within the same event tree. If they } \\
\text { fail, the subsequent actions that depend on } \\
\text { them cannot succeed. }\end{array}$ \\
\hline & Diagnosis & D & $\begin{array}{l}\text { The initiator for each event tree creates a } \\
\text { loss of RHR cooling condition that must } \\
\text { be recognized. Furthermore, it must be } \\
\text { understood to the extent that appropriate } \\
\text { procedures are begun that can restore } \\
\text { core cooling within the time available. }\end{array}$ \\
\hline & $\begin{array}{l}\text { Isolation of } \\
\text { Canal }\end{array}$ & $\mathrm{A} 2$ & $\begin{array}{l}\text { The loss of power events trip the major } \\
\text { water supplies to the canal. If action is } \\
\text { not taken quickly, the canal will drain } \\
\text { through the main condensers, and service } \\
\text { water cooling will be lost. No actions that } \\
\text { involve equipment that requires cooling } \\
\text { (pumps and heat exchangers) can succeed. }\end{array}$ \\
\hline Categary & Specific Cases & Code & Discussion \\
\hline \multirow[t]{4}{*}{$\begin{array}{l}\text { Primary Cognitive } \\
\text { Responses }\end{array}$} & & A- & $\begin{array}{l}\text { These actions are associated with the } \\
\text { individual top events in the event trees. } \\
\text { They represent the likelihood that, given a } \\
\text { successful diagnosis (and, if necessary, } \\
\text { successful isolation of the canal), the } \\
\text { operators carry out the actions required by } \\
\text { procedure to provide core cooling. }\end{array}$ \\
\hline & Make-Up & $\mathbf{M}$ & $\begin{array}{l}\text { If the reactor vessel level falls, either } \\
\text { because of active overdraining or failure to } \\
\text { properly maintain level, the operators can } \\
\text { restore level to permit recovery of RHR } \\
\text { system flow. }\end{array}$ \\
\hline & $\begin{array}{l}\text { Restore RHR } \\
\text { Cooling }\end{array}$ & $\mathbf{R}$ & $\begin{array}{l}\text { If the loss of RHR cooling is recoverable, } \\
\text { the operators can shift to standby } \\
\text { equipment or recover failed equipment. }\end{array}$ \\
\hline & $\begin{array}{l}\text { Steam } \\
\text { Generator } \\
\text { Bleed and } \\
\text { Feed Cooling }\end{array}$ & $\mathbf{S}$ & $\begin{array}{l}\text { The reactor can be cooled by boiling water } \\
\text { on the secondary side of the steam } \\
\text { generator. For conditions analyzed here, } \\
\text { only reflux cooling is possible, as described } \\
\text { in Chapters } 5 \text { and } 7 \text {. While procedures } \\
\text { call for feeding the steam generators, the } \\
\text { cases of interest have sufficient inventory } \\
\text { to support steaming alone. }\end{array}$ \\
\hline
\end{tabular}




\begin{tabular}{|c|c|c|}
\hline \multirow[t]{2}{*}{$\begin{array}{l}\text { Primary Feed } \\
\text { and Bleed }\end{array}$} & $\mathbf{F}$ & $\begin{array}{l}\text { Under the guidance of recent } \\
\text { thermal-hydraulic calculations, the mode } \\
\text { of preference for this cooling method is } \\
\text { known as fill and spill. The procedures } \\
\text { and training are being modified to follow } \\
\text { this approach-forced feeding of the } \\
\text { primary until water spills out the power } \\
\text { operated relief valves. Operators indicate } \\
\text { that they would throttle flow gradually to } \\
\text { conserve water as long as the RCS is } \\
\text { cooling down. }\end{array}$ \\
\hline & $2 \mathrm{CH}$ & $\begin{array}{l}\text { For scenarios in which no injection source } \\
\text { is available, procedures guide operators to } \\
\text { the use of the adjacent unit's charging } \\
\text { pump. }\end{array}$ \\
\hline Gravity & $G$ & $\begin{array}{l}\text { For many cases, gravity draining water to } \\
\text { the RCS can provide acceptable cooling. } \\
\text { Often this cooling mode cannot provide } \\
\text { long-term stability, but can greatly extend } \\
\text { the time available for recovery of other } \\
\text { cooling paths. }\end{array}$ \\
\hline $\begin{array}{l}\text { Recovery of } \\
\text { Room Cooling }\end{array}$ & ARC & $\begin{array}{l}\text { For loss of emergency switchgear } \\
\text { ventilation scenarios, early recovery by } \\
\text { opening doors and rigging portable fans } \\
\text { can avoid the loss of RHR initiating event } \\
\text { entirely. When the operators respond } \\
\text { effectively to high room temperature } \\
\text { alarms, no impact on the plant occurs. }\end{array}$ \\
\hline
\end{tabular}




\begin{tabular}{|l|l|l|l|}
\hline \multicolumn{1}{|c|}{ Category } & Specific Cases & \multicolumn{1}{|c|}{ Code } & \multicolumn{1}{c|}{ Discussion } \\
\hline Specific Activities & & $\begin{array}{l}\text { Individual } \\
\text { Identificatio } \\
\text { n Code }\end{array}$ & $\begin{array}{l}\text { In several cases, detailed low level } \\
\text { operator actions associated with specific } \\
\text { equipment recovery in support of the } \\
\text { activities described above are modeled } \\
\text { separately in the fault trees. In such } \\
\text { cases, diagnosis (global) and the cognitive } \\
\text { aspects of the detailed action are } \\
\text { quantified by high level events in the fault } \\
\text { tree. If those activities are successful, } \\
\text { then the lower level actions are possible. }\end{array}$ \\
\hline Recovery & & R- & $\begin{array}{l}\text { Recovery actions beyond those indicated } \\
\text { above are considered on a limited } \\
\text { case-by-case (i.e., cutset-by- cutset) basis. }\end{array}$ \\
\hline
\end{tabular}

Note that the decomposition of human actions shown above is for the convenience of coupling the HRA with the event tree/fault tree model. It is not a cognitive model of human behavior. Nevertheless, it is a scheme for decomposing the actions into a form amenable to application of the analysis process of Section 8.3.

\subsubsection{Factors Affecting Performance}

Once the required actions are understood, we must go further to understand them within the context of their application. We can think of the continuum of factors affecting performance in terms of a discrete set of conditions as described below.

\begin{tabular}{|l|l|}
\hline \multicolumn{1}{|c|}{ Factor } & \multicolumn{1}{|c|}{ Phase 2 PRA Model } \\
\hline Initiating Event & $\begin{array}{l}\text { Each human action is conditioned on the initiating event that } \\
\text { begins the event sequence. They are all identified and explicitly } \\
\text { considered. In some cases, the effects of different initiators are } \\
\text { identical, and the same quantification is used for those cases. The } \\
\text { detailed cause of the initiating event is not considered in Phase 2. }\end{array}$ \\
\hline $\begin{array}{l}\text { Previous/Concurrent Hardware } \\
\text { No Other Complicating Factors }\end{array}$ & $\begin{array}{l}\text { All actions are first analyzed under this condition. For the reasons } \\
\text { described in Section 8.1, this value of the human action } \\
\text { quantification is used for some cases in which complicating factors } \\
\text { should degrade human performance. Therefore, some cutsets with } \\
\text { additional failures are optimistically quantified. That such cutsets } \\
\text { would have negligible impact on risk should be verified at the time } \\
\text { of the comprehensive HRA. } \\
\text { The impact of the action occurring on different branches of an } \\
\text { Event Tree Sequence }\end{array}$ \\
\hline
\end{tabular}




\begin{tabular}{|c|c|}
\hline Factor & Phase 2 PRA Model \\
\hline \multicolumn{2}{|l|}{$\begin{array}{l}\text { Previous/Concurrent Hardware } \\
\text { Failures and Human Actions } \\
\text { (continued) }\end{array}$} \\
\hline $\begin{array}{l}\text { Isolated Hardware Failures and } \\
\text { Maintenance Activities that } \\
\text { Create an Impediment to } \\
\text { Successful Action Due to the } \\
\text { Hardware Failure Alone, but } \\
\text { Create No Confusion and } \\
\text { Require No Special Response }\end{array}$ & $\begin{array}{l}\text { These effects are not modeled, except that possible failure of the } \\
\text { backup equipment is modeled. Because they have little impact on } \\
\text { human cognitive response, and because few situations have } \\
\text { extremely short time windows for action, these cases are expected } \\
\text { to have a minimal impact on the results. }\end{array}$ \\
\hline $\begin{array}{l}\text { Significant Support System } \\
\text { Failures }\end{array}$ & $\begin{array}{l}\text { These effects are not modeled except for some recovery action } \\
\text { cases. They can lead to very severe degradation in human } \\
\text { performance for scenarios with substantial functional failures, but } \\
\text { such cases are expected to be of very low frequency. }\end{array}$ \\
\hline $\begin{array}{l}\text { Previous Failure of Human } \\
\text { Action }\end{array}$ & $\begin{array}{l}\text { These effects are not thoroughly modeled except for some recovery } \\
\text { action cases. However, if diagnosis fails, all subsequent actions are } \\
\text { failed. Otherwise, because diagnosis was successful, the operators } \\
\text { are on the right track. Therefore, the failures are probably due to } \\
\text { minor slips or physical difficulties that can be bypassed by } \\
\text { continuing with the procedure. While we do not expect this } \\
\text { approach to lead to major errors in quantification, the validity of } \\
\text { this judgment requires verification through detailed modeling. }\end{array}$ \\
\hline $\begin{array}{l}\text { Other Performance- Shaping } \\
\text { Factors }\end{array}$ & $\begin{array}{l}\text { The other performance-shaping factors described in Section } 8.3 \text { are } \\
\text { thoroughly considered. }\end{array}$ \\
\hline Time after Shutdown & $\begin{array}{l}\text { No special maintenance unavailability conditions that apply during } \\
\text { each POS are considered other than positions of the LIVs, } \\
\text { inventory in the steam generators, and likelihood of the pressurizer } \\
\text { safety valves being removed. Draindown initiators must happen on } \\
\text { entering the respective POS. Realistic treatment of timing } \\
\text { throughout each POS is supported through the use of multiple time } \\
\text { windows. Time is discretized into four ranges that affect success } \\
\text { criteria differently as described in Chapter } 5 \text {. }\end{array}$ \\
\hline
\end{tabular}

Thus, the current analysis is thorough' in terms of modeling actions for which the operators are well trained. However, for some unlikely but possible situations, the analysis is optimistic. It is believed that the overall impact of not quantifying such situations will be small. That belief must be tested during the comprehensive work that is to follow (Reference 8-6).

\subsection{Results of Human Actions Analysis}

The event tree and systems evaluations identified the dynamic operator actions and recovery actions that are listed in Tables 8-5 through 8-9 as being potentially important influences for the mitigation of severe core damage sequences. The reasoning for their explicit inclusion in the plant model is discussed in the description of the fault trees/event trees and the definition of the event tree top events in Chapters 6 and 7 . This section presents the following: 
- Qualitative description of the tasks required to accomplish the actions successfully, and the conditions under which they must be accomplished.

- Quantitative evaluation of performance-shaping factors reflecting the evaluation team's judgments regarding the potential-for-failure for successfully accomplishing the actions.

- Mean value of the human error rates derived from the quantification evaluation using the adaption of the SLIM methodology discussed in Section 8.3.3.

\subsubsection{Qualitative Description of the Dynamic Human Actions}

For the loss of RHR initiating events, Tables 8-5 through 8-9 present the qualitative evaluation (i.e., Operator Response Forms) for each analyzed dynamic human action. The qualitative evaluations for the inadvertent safety injection signal, loss of support system, and loss of offsite power initiating events are similar, and are described in Table 8-10. Tables 8-11 and 8-12 show the qualitative evaluation for each recovery action modeled. The descriptions on the forms were developed by the human action analysts, with information provided by the event tree and fault tree analysts regarding the conditions under which each action is demanded. The forms are written in accordance with the guidelines contained in Section 8.3.3.1. Sufficient detail is provided to define the context of the action. The justifications of the time windows for the actions are presented in Chapter 5.

The naming convention for the human error basic events used the following format:

\section{A-BBCC-DDD-EEE-F}

where

$A$ is the type of human action event:

D for the global diagnosis part of the dynamic human actions.

A for the action part of the dynamic human actions.

$\mathrm{R}$ for recovery actions.

$\mathrm{BB}$ is the initiating event designator:

RA for overdraining.

RB for failure to maintain level.

R3 for nonrecoverable loss of RHR.

R4 for nonrecoverable loss of the operating RHR train.

R5 for recoverable loss of RHR.

SI for inadvertent safety injection.

$\mathrm{CC}$ for loss of CCW.

AR for loss of instrument air.

SR for loss of emergency switchgear room cooling.

$\mathrm{VB}$ for loss of a vital bus.

$4 \mathrm{~K}$ for loss of a $4-\mathrm{kV}$ emergency bus.

$\mathrm{Ll}$ for loss of offsite power Case 1.

L2 for loss of offsite power Case 2.

L3 for loss of offsite power Case 3.

BI for Unit I blackout.

B2 for Unit 2 blackout. 


\section{Human Interface Analysis}

CC is the time window W1, W2, W3, or W4 as defined in Chapter 5. For recovery events, the POS D6, $\mathbf{R 6}$, or $\mathbf{R} 10$ is also necessary.

DDD is the designation for dynamic actions and recovery actions: XHE.

EEE is the identifier for human actions:

$M$ for makeup of RCS inventory.

$\mathbf{R}$ for restoration of RHR.

$F$ for RCS feed and bleed.

$S$ for steam generator feed and bleed.

$G$ for gravity feed from RWST.

Or a unique identifier with one to three characters for the recovery considerations.

$F$ is the sequence number in the event tree.

For global failure to diagnose, core damage is assumed to result, and no sequence number is needed. For failure to take the correct action, a sequence number is necessary.

\subsubsection{Quantitative Evaluations}

The evaluation team quantitatively assessed the weights and potential-for-failure ratings of the seven PSFs in accordance with the guidelines in Section 8.3.3.2, as summarized in Tables 8-2 and 8-3. Calibration actions obtained from evaluations in NSAC-84 (Reference 8-4) are used to derive the failure rates. The calibration PSF weights and ratings were provided by the analysts based on the discussions in NSAC-84.

To keep the differences in judgments explicit, no adjustment is made to the normalized weights or individual PSF rating of either the evaluated actions or the calibration actions during this process. The FLI evaluations are converted to human error rate estimates in accordance with the procedures outlined in Section 8.3.3.3. The quantitative results for mean value HEPs covered a wide range:

- Diagnoses: $\quad 1 \times 10^{-6} \rightarrow 5 \times 10^{-2}$

- Actions: $\quad 1 \times 10^{-4} \rightarrow 1.0$

- Recoveries $1 \times 10^{-4} \rightarrow 0.3$

The individual human error rates are organized in Table 8-13. Evaluation details, and the weights and ratings for the PSFs, are shown in Table 8-14.

\subsection{Recommendations}

Assumptions made to support the quantifications need to be verified to increase confidence in the results of this human action analysis. In addition, we believe that it is important to test the assumption that low frequency scenarios involving dependent human actions not rigorously quantified will not contribute substantially to risk. The dependencies involve previous human failures and previous support system failures. The comprehensive HRA program is designed to provide this information (Reference 8-6).

However, as discussed elsewhere in this report, there are reasons to believe that the effects of dependencies among human actions during shutdown are not as severe a problem at Surry as at other PWRs. The most significant problems during shutdown identified in References 8-6 through 8-9 have been addressed by the modifications at Surry. Table 8-15 summarizes special factors affecting human response at PWRs, and compares the impacts of those factors during full-power operations, shutdown at most plants, and shutdown 
at Surry. The additional alarms, procedures, and training at Surry lead to the conclusion that modeling human response at Surry should be more similar to full-power operations at other PWRs than shutdown conditions at them. Dependency is still an issue but is more on the order of that found in a typical full-power PRA.

For those modeling shutdown at other PWRs, more thorough care for dependencies will be required than is found here. The results of the comprehensive HRA program (Reference 8-6) will be especially important.

\subsection{References}

8-1. Virginia Power, Operating Procedure, "Draining the RCS from 5\% Pressurizer Level (29.0 ft) to Mid-Nozzle (12.5 ft)," Surry Power Station, 1-OP-RC-005, Rev. 1, April 7, 1992.

8-2. Chu, T-L., et al., "PWR Low Power and Shutdown Accident Frequencies Program, Phase 1A Coarse Screening Analysis," Rough Draft Letter Report, Brookhaven National Laboratory, November 13, 1991.

8-3. Chu, T-L., et al., "PWR Low Power and Shutdown Accident Frequencies Program, Phase 2 Internal Events," Rough Draft Letter Report, Brookhaven National Laboratory, August 31, 1992.

8-4. Bley, D. C., et al., "Zion Nuclear Plant Residual Heat Removal PRA," Pickard, Lowe, and Garrick, Inc., prepared for Electric Power Research Institute, EPRI/NSAC Report NSAC-84, July 1985.

8-5. Embrey, D. E., et al., "SLIM-MAUD: An Approach To Assessing Human Error Probabilities Using Structured Expert Judgment," Brookhaven National Laboratory, prepared for U.S. Nuclear Regulatory Commission, NUREG/CR-3518, Vols. 1-2, March 1984.

8-6. Barriere, M., W. Luckas, D. Whitehead, A. Ramey-Smith, D. Bley, W. Brown, S. Cooper, J. Wreathall, M. Donovan, J. Forester, P. Haas, and G. Parry, "An Analysis of Operational Experience during Low Power and Shutdown and A Plan for Addressing Human Reliability Assessment Issues, "Brookhaven National Laboratory, prepared for U.S. Nuclear Regulatory Commission, NUREG/CR-6093, BNL-NUREG-52388 June 1994.

8-7. Vine, G., et al., "Residual H.at Removal Experience Review and Safety Analysis - Pressurized Water Reactors," Electric Power Research Institute, Nuclear Safety Analysis Center, NSAC-52, January 1983.

8-8. Mollerus Engineering Corporation, "Residual Heat Removal Experience Review and Safety Analysis — Pressurized Water Reactors, 1982-1989," prepared for Electric Power Research Institute, Nuclear Safety Analysis Center, NSAC-156, August 1991.

8-9. Jones, W. R., "AEOD Special Evaluation - Review of Operating Events Occurring during Hot and Cold Shutdown and Refueling," December 1991.

8-10. Westinghouse Electric Company, "Background Information for Westinghouse Owners Group Abnormal Response Guideline ARG-1, Loss of RHR While Operating at Mid-Loop Conditions," March 15, 1991.

8-11. EG\&G Idaho, Inc., "Thermal-Hydraulic Processes Involved in Loss of Residual Heat Removal During Reduced Inventory Operation," Technical Report EGG-EAST-9337, Rev. 1, February 1991.

8-12. U.S. Nuclear Regulatory Commission, "Shutdown and Low-Power Operation at Commercial Nuclear Power Plants in the United States," Draft Report for Comment, NUREG-1449, February 1992. 
8 Human Interface Analysis

8-13. Nuclear Management and Resources Council, Inc., "Guidelines for Industry Actions to Assess Shutdown Management," NUMARC 91-06, December 1991.

8-14. Virginia Power, Abnormal Procedure, "Loss of Decay Heat Removal Capability," Surry Power Station, 1-AP-27.00, Rev. 4, February 18, 1993.

8-15. Technical Report NE-865, "Background and Guidance for Ensuring Adequate Decay Heat Removal following Loss of RHR," Surry and North Anna Power Stations, June 1992.

8-16. Technical Report NE-801, "Evaluation and Development of Setpoints for Abnormal Response Guideline ARG-1, Loss of RHR While Operating at Mid-Loop Conditions," Surry Power Station Units 1 and 2, December 1990.

8-17. Virginia Power, General Operating Procedure, "Unit Shutdown, RCS Cooldown from HSD to $345^{\circ} \mathrm{F}$ - 350%," Surry Power Station, 1-GOP-2.4, Rev. 1, February 27, 1992.

8-18. Virginia Power, General Operating Procedure, "Unit Shutdown, RCS Cooldown from $345^{\circ} \mathrm{F}-350^{\circ} \mathrm{F}$ to $195^{\circ}$ F," Surry Power Station, 1-GOP-2.5, Rev. 1, February 27, 1992.

8-19. Virginia Power, General Operating Procedure, "Unit Shutdown, RCS Cooldown from $195^{\circ} \mathrm{F}$ to Ambient," Surry Power Station, 1-GOP-2.6, Rev. 1, February 27, 1992.

8-20. Virginia Power, Operating Procedure, "Draining the RCS to 5\% Pressurizer Level (29.0 ft)," Surry Power Station, 1-OP-RC-004.

8-21. Virginia Power, Operating Procedure, "Isolation and Drain of One Reactor Coolant Loop with the Drained Loop Stop Valves Closed and RHR in Service," Surry Power Station, 1-OP-RC-006, Rev. 0, March 2, 1992.

8-22. Virginia Power, Operating Procedure, "Isolation and Drain of All Reactor Coolant Loops with All Loop Stop Valves Closed and RHR in Service," Surry Power Station, 1-OP-RC-007, Rev. 0., March 2, 1992.

8-23. Virginia Power, Operating Surveillance Procedure, "Unit 1 Safety Systems Status List for Cold Shutdown/Refueling Conditions," Surry Power Station, 1-OSP-ZZ-004, Rev. 1, March 6, 1993.

8-24. Virginia Power, Operational Check, "Assessment of Maintenance Activities for Potential Loss of Reactor Coolant Inventory," Surry Power Station, OC-28, January 22, 1991.

8-25. Virginia Power, Abnormal Procedure, "Non-Recoverable Loss of Instrument Air," Surry Power Station, 0-AP-X0.00, Rev. 3, December 19, 1991.

8-26. Virginia Power, Abnormal Procedure, "Station Blackout," Surry Power Station, 0-AP-10.00, Rev. 5, September 19, 1991.

8-27. Virginia Power, Emergency Contingency Action, "Loss of All AC Power," Surry Power Station, 1-ECA-0.0, Rev. 6, April 27, 1992.

8-28. Virginia Power, Abnormal Procedure, "Loss of Intake Canal Level," Surry Power Station, 0-AP-12.01, Rev. 2, January 31, 1992.

8-29. Virginia Power, Abnormal Procedure, "Main Control Room Inaccessibility," Surry Power Station, 0-AP-20.00, Rev. 1, no date. 
8-30. Virginia Power, Abnormal Procedure, "Fire Protection - Operator Response," Surry Power Station, 0-AP-48.00, Rev. 3, no date. .

8-31. Virginia Power, Emergency Procedure, "Emergency Action Level Table (Tab A) System Shutdown or Assessment System Shutdown," Surry Power Station, EPIP-1.01.

8-32. Chien, S. H., A. A. Dykes, J. W. Stetkar, and D. C. Bley, "Quantification of Human Error Rates Using a SLIM-Based Approach," Proceedings of the 1988 IEEE Fourth Conference on Human Factors and Power Plants, Monterey, California, June 5-9, 1988.

8-33. Embrey, D. E., "The Use of Performance Shaping Factors and Quantified Expert Judgment in the Evaluation of Human Reliability: An Initial Appraisal," Brookhaven National Laboratory, prepared for U.S. Nuclear Regulatory Commission, NUREG/CR-2986, May 1983.

8-34. Rosa, E., et al., "Application of SLIM-MAUD: A Test of an Interactive Computer-Based Method for Organizing Expert Assessment of Human Performance and Reliability," Brookhaven National Laboratory, prepared for U.S. Nuclear Regulatory Commission, NUREG/CR-4016, September 1985.

8-35. Jacobs, R., J. Mathieu, F. Landy, et al., "Organizational Processes and Nuclear Power Plant Safety," Proceedings of the Probabilistic Safety Assessment International Topical Meeting, pp. 211-215, Clearwater Beach, Florida, January 26-29, 1993. 
Table 8-1. Guidance Regarding Information To Include in Operator Response Forms

TASK IDENTIFIER with the summary reproduced from operation action summary table.

\section{PRECEDING EVENTS}

- List initiating events after which action may be required.

- Briefly summarize sequence of events leading to action.

- Base the sequences on the fault tree and event tree descriptions.

- Bound the range of possibilities (identify if influenced by initiating event).

- Identify any abnormal plant responses that may complicate the situation.

\section{INDICATIONS OF PLANT CONDITION}

- List what the operating crew sees that permits diagnosis that the action is required.

- Estimate, how long the condition could exist before indications sufficient for diagnosis are available to the operators.

- Describe parallel indications that can mask the action requirement.

\section{PROCEDURAL GUIDANCE/REOUIRED ACTIONS}

- Reference the procedure and steps that will be followed.

- State whether the task is an immediate memorized action.

- Briefly summarize the aspects of the action that could influence the operators' ability to diagnose and accomplish it.

- Identify considerations in addition to procedures that could influence likelihood of success.

\section{TRAINING AND EXPERIENCE}

- List the relevant training and experience for this type of scenario.

\section{CONCURRENT ACTIONS/COMPETING FACTORS}

- Identify concurrent actions that could compete for attention.

- Briefly describe alarms, environmental conditions, and other distractions that could impact the operating shift's concentration and produce stress.

- Discuss important aspects of the operator team interactions.

\section{INDICATION OF SUCCESSFUL COMPLETION/SUCCESS IMPACT}

- Characterize plant state upon completion based on fault tree and event tree success criteria.

- Describe how the operators can determine they have been successful.

\section{FAILURE IMPACT}

- Characterize the plant condition following failure to accomplish based on fault tree and event tree success criteria.

- Identify later actions the operators have available to respond with once the plant has made a transition to the failed condition.

\section{TIME CONSTRAINTS}

- List thermal/hydraulic and physical/equipment response considerations that influence time available before transition to failed condition.

- Summarize what is known about time required to both diagnose and accomplish the tasks. 
Table 8-2 (Page 1 of 7). Guidance for Rating the Potential for Fallure Presented by Each PSF Associated with Each Dynamic Human Action

PSF: Task Complexity

Definition: This performance-shaping factor rates the effect of multiple requirements on task success. It can range through the entire gamut of coordination, multiple locations, remote operations, variety of tasks, and communications requirements. It also rates the availability of resources.

Scaling Guidance: Compare different types of complexity, or lack of complexity, by judging how much the operator is helped or hindered. Consider how the system is designed to avoid error if complex actions must be accomplished. Also consider the availability of resources to accomplish the various parts of the action.

\section{Rating Example of Thought Process That Might Produce This Rating}

- 0 Very clearly understood and straightforward task with no interpretation of current situation required.

$-1$

- 2 Skill-based response by one operator with SRO concurrence that can be performed and verified at one location.

$-3$

$-4$

- 5 Series of tasks accomplished under direct control of one operator with SRO concurrence with a rule-based response.

$-6$

- 7 Knowledge-based response.

- 8 Tasks involving coordination of more than one operator at more than one location.

- 9 Tasks with contingencies that require coordinating decisions during different stages of the transient event and among multiple operators at,multiple locations.

$-10$

Notes: 
8 Human Interface Analysis

Table 8-2 (Page 2 of 7). Guidance for Rating the Potential for Failure Presented by Each PSF Associated with Each Dynamic Human Action

\section{PSF: Plant Man-Machine Interface and Indications of Conditions}

Definition: This performance-shaping factor relates the impact of the man-machine interface on the likelihood of success. It measures the degree to which the instruments, alarms and controls available to the operators at the time.when the-action must be-accomplished assist them to preform the action.

\section{Scaling Guidance:}

Rating Example of Thought Process That Might Produce This Rating

- 0 A wide variety of instruments and/or alarms focus the operators' attention on the blatant need to act and provide an easy method to do so. Feedback on success is obvious.

$-1$

- 2 Alarms and indications are clear and easily interpreted. Feedback is readily available close to the point of action.

$-3$

$-4$

- 5 Indications for this action are found within a familiar pattern of alarms, which operators are trained to diagnose.

$-6$

$-7$

- 8 Action requires that two or more operators work together because of controls and indications that are far apart.

$-9$

- 10 Indications confuse the operators and cause actions that could be wrong or inappropriate.

Notes: 
Table 8.2 (Page 3 of 7). Guidance for Rating the Potential for Failure Presented by Each PSF Associated with Each Dynamic Buman Action

\section{PSF: Adequacy of Time To Accomplish Action}

Definition: Measure of time required to act compared with the time available and the effect on success. The rating reflects the operator's confidence that the task can be accomplished in time to avert a change to a failed state.

Scallng Guidance: Judgment should be based on the time required compared with the time available to recognize, diagnose, and accomplish the action. Judgment about the length of these times may be reflected by noting the task description times. Both the absolute difference in time and the ratios of the time may be useful for making these judgments.

\section{Rating Example of Thought Process That Might Produce This Rating}

- 0 Adequate time to accomplish action, bring in assistance if necessary, and correct errors.

- 1 Time is on the operator's side.

- 2 Enough time to complete procedures carefully and methodically with some outside assistance.

- 3 Enough time to complete procedures carefully and methodically if no outside assistance needed.

$-4$

- 5 Enough time to complete at a normal speed and to verify results, but with limited time to correct significant errors.

$-6$

- 7 Success requires rapid, practiced operator actions with little time to correct anything but a small slip. Requires skillful and well-trained actions for success with any problem endangering the chance for success.

$-8$

$-9$

- 10 Time required about the same as time available. Operators can complete the task, but it will be a very close call.

Notes: If the time required to complete the action exceeds time available, the action is guaranteed to fail. Under these circumstances the reason why the action cannot be done is documented and no PSF evaluation is required. 


\section{Human Interface Analysis}

Table 8-2 (Page 4 of 7). Guidance for Rating the Potential for Fallure Presented by Each PSF Associated with Each Dynamic Human Action

\section{PSF: Significant Preceding and Concurrent Actions}

Definition: Preceding and concurrent actions set the stage for the modeled action and make it necessary and obvious to the operators. They can also divert the operators' attention from this action or even cause failure. (If necessary, some strongly dependent failures may be accounted for by specific split fractions in the event trees.) Lack of preceding actions may create a surprise effect that should be accounted for in this performance-shaping factor.

\section{Scaling Guidance:}

\section{Rating Example of Thought Process That Might Produce This Rating}

- 0 Previous actions focus operators on the urgent need to act.

- 1 There are no distractions from this action; it could also get close supervision and follow-up, if

$-2$ necessary.

- 3 Operators are alerted to the need for possible action and are expecting it.

- 4 Another step in standard or procedure-based responses.

- 5 Action is not a surprise, but previous actions create some competition for operator attention.

$-6$

- 7 This is one of many concurrent actions and could possibly be overlooked. Operator is taking recovery actions from one or two previous problems.

- 8. Operators are busy with other work and this is an unexpected, unusual transient.

- 9 Previous operator problems create an unusual situation.

- 10 The need to accomplish this action is unexpected and inconsistent with previous actions.

Notes: 
Table 8-2 (Page 5 of 7). Guidance for Rating the Potential for Failure Presented by Each PSF Associated with Each Dynamic Human Action

\section{PSF: Procedural Guidance}

Definition: This performance-shaping factor accounts for the extent to which plant procedures enhance the operator's ability to perform the action. The operator may have available not only step-by-step instructions but also guidance on when the action has been correctly done.

\section{Scaling Guidance:}

Rating Example of Thought Process That Might Produce This Rating

- 0 Procedures are clear and definite. Operators can easily follow them.

$-1$

- 2 Procedures are clear and definite. Operators can easily follow them but clarity could be impacted by recent changes or other modifications.

$-3$

$-4$

- 5 Procedures are available. Some operator interpretation of procedures required to perform specific actions.

- 6 Sequence of steps in procedure may require operators to return a place that has been passed (eg. continuous action (WHEN) or retainment override steps)

- 7 Procedures are being used but because of the need to act, the operator can use them only as a backup check.

- 8 Action is a chance event for which procedures can give only vague guidance.

- 9 Procedures are poorly written and may be misleading.

- 10 There are no procedures for this action.

Notes: 
Table 8-2 (Page 6 of 7). Guidance for Rating the Potential for Fallure Presented by Each PSF Associated with Each Dynamic Human Action

PSF: Training and Experience

Definition: This performance-shaping factor measures-the effect of the familiarity and confidence the operators have about the actions.

Scaling Guidance:

Rating Example of Thought Process That Might Produce This Rating

- 0 Action is normally carried out during plant trip situations. Operators are thoroughly familiar with this action and competent at it.

- 1 Action is repeatedly carried out during simulator training. Operators are thoroughly familiar with this action and competent at it.

- 2 Actions that are normally carried out during typical plant trip situations can be easily applied to this situation. Operators are well trained.

- 3 Action is part of focus on safety functions. It is subject to thorough and repeated training.

- 4 Action receives emphasis during normal training.

- 5 Action is part of normal training, but receives no particular emphasis. Same action is used during surveillance testing.

- 6 Nonroutine action that is included in annual training. Surveillance test routinely carried out has different steps than the required action.

- 7 Nonroutine action that is included in annual training.

- 8 Nonroutine action that is an option in annual or biannual training.

- 9 Nonroutine action tha! gets no simulator training.

- 10 Action is unfamiliar or contrary to normal operational practice; e.g., defeating a safety system and no procedures.

Notes: 
Table 8-2 (Page 7 of 7). Guidance for Rating the Potential for Failure Presented by Each PSF Associated with Each Dynamic Human Action

PSF: Stress

Definition: This performance-shaping factor accounts for the impact of adverse environmental conditions and situations that may endanger the operator or damage or contaminate either the plant or the environment. Depending on its nature and level, stress can serve as an incentive to accomplish the action, or provide a diversion of attention that increases the likelihood of failure.

Scaling Guidance: Rating should focus on how the presence of stress will affect the concentration of the operator on successfully accomplishing the action. In this context, stress can have both beneficial and detrimental effects, and it is the judge's responsibility to assess the relative importance of the two.

Rating Example of Thought Process That Might Produce This Rating

- 0 Stress level has made the operators alert, but they are not yet threatened; provides best incentive to act.

$-1$

- 2 Stress level is moderate; operators are aware of potential consequences; situation is typical of training or experience.

$-3$

- 4 Stress level is too low to keep the operators alert.

- 5 Stress level is moderate; operators are aware of potential consequences; situation is unusual.

- 6 Concern about possible outcome is increasing.

- 7 Fatigue or the tediousness effect performance.

- 8 Potential loss is high if action is not successful; situation is unfamiliar. Consequences are high enough to create physical tension.

- 9 Action must be done under severe environmental conditions of heat and humidity, loud noise, or significant vibration.

- 10 Operators fight fear, tension and uncertainty while acting. Consequence could be high radiation exposure, significant release, core damage, or threat to life.

Notes: 
Table 8-3 (Page 1 of 7). Guidance for Assigning Relative Weights to the PSF Ratings Associated with Each Dynamic Human Action

Significant Preceding and Concurrent Actions: The rating evaluates the impact of the preceding scenario and other concurrent actions for either focusing the operators on or distracting them from accomplishing the action.

The weight relates whether the above factors have any influence on the potential for the successful completion of this action.

\section{Weight Example of Thought Process}

0 Insignificant Other PSFs, such as time and indications, are so important to the success of this action that what else has previously occurred or is going on has no influence on the success of this action.

1 Low Other PSFs, such as time and indications, are so important to the success of this action that what else has previously occurred or is going on has little influence on the success of this action.

2 Normal The action must be accomplished in the context of what else is going on. We have no reason for considering it more or less important than other PSFs.

4 High The context in which the requirement for this action arises is a prime influence in our potential for successfully completing it. 
Table 8.3 (Page 2 of 7). Guldance for Assigning Relative Weights to the PSF Ratings Associated with Each Dynamic Human Action

Plant Man-Machine Interface and Indications of Conditions: Scaled on the ability of the man-machine interface to provide the information necessary to make the action a success.

The weight measures whether the above factors have any influence on the potential for the successful completion of this action.

Weight Example of Thought Process

0 Insignificant Other factors dominate so much that I don't care how bad or good the indications are because they are not going to change the likelihood of the success of this particular action.

1 Low This is a skill-based action done in response to many alarms, with little or no diagnosis required. I can easily verify my action in a variety of ways.

2 Normal Patterns of indications are required to take action and verify proper plant response, but no, sophisticated diagnostics or control are required.

4 High The success of the action is not possible without the proper response to feedback from the plant instruments. We must use specific parameters to diagnose the problem and/or control the plant. 


\section{Human Interface Analysis}

Table 8-3 (Page 3 of 7). Guidance for Assigning Relative Weights to the PSF Ratings Associated with Each Dynamic Human Action

Adequacy of Time To Accomplish Action: Measure of how the relationship between the time required to recognize and to accomplish the action to the time available can influence the likelihood of success.

The weight relates whether the above factors have any influence on the potential for the successful completion of this action.

\section{Weight Example of Thought Process}

0 Insignificant Events evolve so gradually that the relationship between available and required time does not matter. If we fail to do the action, it will be due to reasons other than time.

1 Low A slowly evolving situation in which there should be sufficient time to act. Under these circumstances, other PSFs would tend to be more important for determining the potential for successful accomplishment.

2 Normal Task must be done within a fairly well-understood period of time that has some flexibility.

4 High Time frame in which we must accomplish the action is well defined. The transitions that present the initial requirement to accomplish the action are not gradual. If the action is not accomplished, something definite will happen at a well-understood point in the transient. 
Table 8-3 (Page 4 of 7). Guidance for Assigning Relative Weights to the PSF Ratings Associated with Each Dynamic Human Action

Procedural Guidance: The rating evaluates the extent to which the written procedures enhance the operator's ability to perform the task correctly.

The weight relates whether the above factors have any influence on the potential for the successful completion of this action.

Weight Example of Thought Process

0 Insignificant Immediate action task in which the operators do not have time, nor are expected, to refer to the procedure before acting.

1 Low Specific skill-based actions for which procedures provide only general guidance regarding options.

2 Normal Operators are tracking and responding to plant status using procedures, indications, and other cognitive resources.

4 High Tasks that would be very difficult to accomplish without procedures. 
8 Human Interface Analysis

Table 8-3 (Page 5 of 7). Guidance for Assigning Relative Weights to the PSF Ratings Associated with Each Dynamic Fuman Action

Task Complexity: The rating evaluates how the presence or the lack of the following influences the potential for the success of this action: available resources, multiple objectives, coordination, communication, location of action, and sequencing of tasks.

The weight relates whether the above factors have any influence on the potential for the successful completion of this action.

Weight Example of Thought Process

0 Insignificant Other PSFs dominate the considerations of the action so much that the complexity (or lack of complexity) of this action has little or no influence on the potential for its failure.

1 Low Other PSFs control the likelihood for the success of this action, but complexity does have some influence.

2 Normal The number and sequencing of tasks and coordination necessary to accomplish them, along with other factors definitely have an influence.

4 High It makes a big difference to us that this type of action is simple and straightforward, of normal complexity, or really hard to accomplish without communication, coordination, sequencing, etc. 
Table 8-3 (Page 6 of 7). Guldance for Assigning Relative Weights to the PSF Ratings Associated with Each Dynamic Human Action

Training and Experience: The rating evaluates the degree to which familiarity, skill level, and confidence that the operators have regarding an action can influence its success.

The weight relates whether the above factors have any influence on the potential for the successful completion of this action.

Weight Example of Thought Process

0 Insignificant

1 Low Simple actions that we are confident of being able to do when other factors are controlling whether we can do them.

2 Normal Training and experience will have an influence on our ability to do this action, but many other factors are of similar importance.

4 High Skill- or knowledge-based task for which the operators must rely on their training and experience to be successful. 
Table 8-3 (Page 7 of 7). Guidance for Assigning Relative Weights to the PSF Ratings Associated with Each Dynamic Human Action

Stress. The rating evaluates the impact of the state of mind of the operators as they attempt to accomplish the action or their ability to successfully concentrate on the requirements summarized in the other six PSFs.

The weight relates whether the above factors have any influence on the potential for the successful completion of this action.

Weight Example of Thought Process

0 Insignificant

1 Low Other PSFs are so important to the success of this action that our frame of mind has little influence.

2 Normal Operators are tracking plant status and required responses during a transient.

4 High Because of the nature of the situation (either environmental or threat), our frame of mind will have a strong impact on our ability to focus on the other PSFs that influence success. 
Table 8-4. Summary of the Relationship between the Rating and Weighting Processes

Rating: With respect to the things addressed by this PSF, are the conditions under which the action must be accomplished helping or hindering us to successfully complete it? In other words, we are rating the impact of the conditions on our likelihood to fail in accomplishing the action. Interpretation of the range of ratings:
0-3 Helps
4-6 Is Neutral
7-10 Hinders

Weight: Does a variation between helping and hindering have more influence on the probability that we will fail to complete it than other PSFs? In other words, is this PSF a focus of the action? Do we key in on the things addressed by this PSF?

$0 \quad$ Insignificant compared to other PSFs.

1 Low: unimportant compared to other PSFs.

2 Normal: about the same as other PSFs.

4 High: much more important than other PSFs.

\section{Weighting Thought Process}

1. Initially set the weights of every PSF equal to 2.

2. Adjust weights of the PSFs only if you believe that their importance for judging the likelihood of accomplishing the action is significantly (a factor of 2) greater or less than the other PSFs. The weights will be normalized so that the maximum overall failure likelihood index will be a 10 , so the effect of increasing all of the weights is the same as increasing none.

3. Generally, actions requiring similar types of skills have the same PSF weights. Some examples of groups of actions where differences in the focus may require different PSF weights are as follows:

- Immediate recognition and reaction.

- Actions where diagnosis of need would dominate success.

- Actions requiring a long sequence of manipulations.

- Local actions involving coordination of activities.

- $\quad$ Adjusting or controlling against indications.

Impact of Weight on How the Failure Likelihood Index Changes

Weight Rating Change Producing the Same Change in the FLI

$\begin{array}{rl}1 & 1 \rightarrow 9 \\ 2 & 3 \rightarrow 7 \\ 4 & 4 \rightarrow 6\end{array}$




\section{Human Interface Analysis}

Table 8-5. Qualitative Descriptions of Dynamic Human Actions Evaluated for the Surry Shutdown PRA MRA(B):

Operator makes up RCS inventory following a loss of RHR at mid-loop.

\section{PRECEDING EVENTS}

- Lose of RHR due to

- over-drining (RA) or

- friluro to meintuin RCS leval (RB).

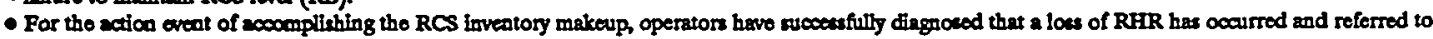
1.AP-27.00 (Lous of Docry Heat Remoral Capability).

\section{INDICATIONS OF PLANT CONDITIONS}

- Lon RCS lava.

- Contrd room RCS andipo lovel 1-RC-LI-100A (ming not bo wourato when RCS boiling tarts).

- Contrd rocon cold shutdown RCS level narrow range 1-RC-LR-105.

(ultraconic indiention of RCS level within the loop, i.en from middle to top of the loop; may be partially unurailable when vital bus is unavailable)

- RCS standpipo lavel local indication.

- Shutdown cooling low lovel mnunciator B-C-8.

- RAR pump motor amperage occillation.

- Emcosive RHR pump noire.

- No RHR flo

- Control rocm RHR flow indication 1-RH-FT-1605.

- RHR heat emonger low flow annumciator B-C-6.

\section{PROCEDURAL GUIDANCE}

- 1-OP-RC-005 Draining the RCS from 5\% Presurizer Level (29.0 ft) to Mid-Nozzle (12.5 ft); for RAW1(23,4)-XAIE-M-12

- Step 5.2: Draining the RCS from 5\% Pressurizer Level to between $18.3 \mathrm{ft}$ and $15.3 \mathrm{ft}$

(There is no level indication from $0 \%$ in the presurizer to $24.0 \mathrm{At}$ in the standpipo)

- Step 5.3: Requirements for entering Recuced Inveatory (leas than $15.3 \mathrm{ft}$ ).

- Step 5.A: Draining from 15.3 it to 12.5 ff (Mid-Nozale)

- 1-AP-27 00 Lose of Docry Heat Removal Capability

- Steps 2 \& 9: Stop inventory lows and restore RCS level by increasiog RCS makeup (dose letdown line preasure control valve 1-CH-PCV-1145

and open charging flow contral valve 1-CH-FCV-1122).

- Stepe 4, 11, 15, 27, and 28: Stop and isolate vortesing RHR pump; start other RHR pump.

\section{TRAINING AND EXPERIENCE}

- Operators train on this scenario during simulator drills.

- Eperience in maintaining RCS inventory and retoring RCS level during previous mid-loop operations.

\section{CONCURRENT ACTIONS/COMPETING FACTORS}

- None.

\section{INDICATION OF SUCCESSFUL COMPLETION/IMPACT OF SUCCESS}

- RCS level is retored.

- RCS standpipe level and cold shutdown RCS levd narrow range are stable.

- Volume control tank level is stable.

- VCT level control valve 1-CH-LCV-1115A is not diverting to the boron recovery tank.

- Standby RHR pump may be sarted and RHR flow may be restored.

\section{MPACT OF FAILURE/ADDITIONAL CUES}

- RHR pamps coctinue to vorters no RHR flow.

- As RCS heats up RCS temperature increases; loss of subcooling and alarms.

- Boilofi would lead to decreasing RCS levels.

\section{TIME CONSTRAINTS}

- Time until boiling and time until core damage are time window dependent and are given in Chapter 5.

- It may be diffeult to reatoro RHR when RCS starts boiling.

- Reatoration of level should have taken only a fer minutes.

\section{SPECIAL CASES ANALYZED}

- D-RAW1 (2,3,4)-XHE. Operator diagroses that a loss of RHR bas cocurred due to over-draining at mid-loop. (Also see tables for RRA, SRA, FRA, and GRA) - D-RAW1 $(2,3,4)$-XHE. As described above for-D-RAW1 $(2,3,4)-X H E$, except-tho initiating event is failure to maintain RCS level.

-A-RAW1 $(2,3,4)$-XHE-M-12. Operator makes up following over-draining at midloop.

- A-RBW1 (2,3,4)-XFE-M-12. As described above for A-RAW1(2,3,4)-XHE-M-12, except the initiating event is failure to maintain level at midloop. 
Table 8-6. Qualitative Descriptions of Dynamic Human Actions Evaluated for the Surry Shutdown PRA

RRA(B,45):

Restore RHR cooling following a loss of RHR at mid-loop.

\section{PRECEDING EVENTS}

- Loes of RHR duo to

- over-draining (RA)

- Gallure to maintain RCS leval (RB),

- operating RHR triln tillure (R4), or

- recoverable RHR fillure (RS).

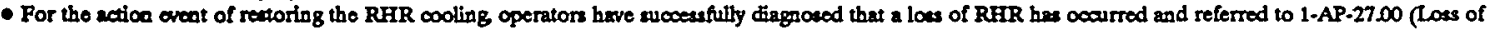

Decay Heat Remonal Copability).

- Operator havo wococifully reatored the RCS inventory (for RA(B)W1(23,4)-XIIE-R-S).

\section{INDICATIONS OF PLANT CONDITIONS}

- Low RCS loval (for RA(B)W1(2,3,4)-XHE-R-5), reatored RCS level (for RA(B)W1(2,3,4)-XYE-R-S), and slowly docrearing RCS level.

- Control room RCS standpipo levd 1-RC-LI-100A (may not be wocurato when RCS boiling trarrs).

- Control room cold ahutdown RCS level narrow range 1-RC-L.R-10S.

(Ulinecric indication of RCS level within the loop, ie. from middle to top of the loop; may be partially unavailatle when vital bus is unavailatle)

- RCS atandpipe level local indication.

- Shutdown cooling low level annunciator B-C-8.

- RHR pump motor amperage cecillation (for RA(B)W1(2,3,4)-XHE-R-5).

- Encoutive RHR pump noiso (for RA(B)W1(2,3,4)-XHE-R-5).

- No RHR flow

- Control room RHR flow indication 1-RH-FI-1605.

- RHR beat exchanger low flow annumciator B-C-6.

\section{PROCEDURAL GUIDANCE}

- 1-AP-27.00 Loes of Decay Heat remoral Capability.

- Stcpe 4, 11, 15, 27, and 28: Stop and isolate vortexing RHR pump; start other RHR pump.

\section{TRAINING AND EXPERIENCE}

- Operators troin on thil conario during simulator drills.

- Experienco in reatoring RHR cooling during previous mid-loop operations.

\section{CONCURRENT ACTIONS/COMPETING FACTORS}

- Reatore RCS level (for RA(B)W1 (2,3,4)-XIHE-R-5)

\section{INDICATION OF SUCCESSFUL COMPLETION/IMPACT OF SUCCESS}

- RHR flow is reatored; RCS temperature is stable or decreasing

\section{IMPACT OF FAILURE/ADDITIONAL CUES}

- RHR pumps continue to vortex (for RA(B)W1(2,3,4)-XHE-R-5); no RHR flow.

- As RCS beats up RCS temperature inereases; loss of subcooling and alarms.

- Boilofi would lead to decreasing RCS levels.

\section{TIME CONSTRAINTS}

-Time until boiling and time until core damage are time vindor dependent and are given in Chapter 5.

- Reatoration of level should have taken only a few minutes (for RA(B)W1(2,3,4)-XHE-R-5). Stopping the vortecing RHR pump, and starting the standby RHR pump

should not take

more than several minutea.

\section{SPECIAL CASES ANALYZED}

- D.RAW1(2,3,4)-XTE. Operator diagnoses that a loes of RHR has ocaurred due to over-draining at mid-loop.

(Also see tables for MRA, SRA, FRARG, and GRA)

- D-RBW1 (2,3,4)-XHE. As described above for D-RAW1 $(2,3,4)-X H E$, except the initiating event is failure to maintain RCS level.

- D-R4W1 (2,3,4)-XHE. As described above for D-RAW1 $(2,3,4)$-XHE, except the initiating event is loss of one (operating) RHR train.

- D-RSW1 (23,4)-XHE. As described above for D-RAW1 (23,4)-XHE, except the initiating eveat is rocoverable loss of RHR.

- A-RAW1 $(2,3,4)$-XHE-R-5. Operator restores RHR coling following over-draining at midloop.

- A-RBW1 (2,3,4)-XHE-R-5. As deceribed above for A-RAW1 $(2,3,4)$-XHE-R-5, except the initiating event is failure to maintain level; all else is identical. Une same value as A-RAW1 $(2,3,4)-X$ THE-R-5.

- A-R4W1(23,4)-XHE-R-5.1 As described above for A-RAW1 $(2,3,4)$-XHE-R-5, except the initiating event is loss of one RHR train (operaring); no preceding actions; no Indication of low or retored RCS levels; there may nor be RHR pump motor amperage oudillation and excestive RHR pump noise.

- A-RSWI (23,4)-XFE-R-5. Idestical to A-R4W1 $(2,3,4)$-XHE-R-5, except the initiating eveat is a recoverable loss of RHR.

Use same value as A-R4W1(2,3,4)-XHE-R-S. 


\section{Human Interface Analysis}

Table 8-7 (Page 1 of 2). Qualitative Descriptions of Dynamic Human Actions Evaluated for the Surry Shutdown PRA

\section{SRA(B,3,4,5):}

Operator actablith noem geoerator bloed and foed (reflux cooling) following a lons of RIR at mid-loop.

\section{PRECEDING EVENTS}

- Loses of RHar duo to

- over-drining (RA),

- fillure to maintain RCS level (RB),

- unrecoveriblo RHR fillure (R3)

- operating RER trin filluro (R4), or

- rocoverable RHR filluro (RS).

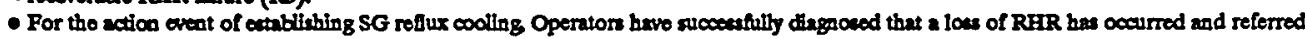

to 1-AP-27.00 (Low of Doens Heat Removal Cepability).

- Reatoration of RCS level bes frilod (for RA(B)W1(23,4)-XHE-S-16) or Reatoration of RHR cooling has failed after mocesefully reatoring level

(for RA(B,4,5)W1 $(2,3,4)-X T E-5-9)$.

\section{INDICATIONS OF PLANT CONDITIONS}

- Low RCS level (for RA(B)W1(2,3,4)-XHE-S-9(16)), reatorod RCS level (in the event of failuro to reatore RHR cooling for RA(B)W1(2,3,4)-XHE-S-9)), and ilowing decrearing RCS level.

- Contral room RCS tandpipo level 1-RC-II-100A (may not be scaurato if RCS bolling tarts).

- Coctrol room cold shutdown RCS level narrow range 1-RC-LR-105.

(ultrasonic indication of RCS level within the loop, ien from middle to top of the loop; may be partially unavailable if vital bus is unavailablo)

- RCS stendpipe level local indication.

- Shutdomn cooling lon leval annundator B-C-s.

- RHR pump motor amperage cecillation (for RA(B)W1(2,3,4)-XFE-S-9(16)).

- Erocivo RAR pump nolso (for RA(B)W1(2,3,4)-XHES-9(16))

- No Rhr fión

- Control room RHR flom indication 1-RFz-FI-1605.

- RAR heat exchanger lon flom annumciator B-C-6.

- Incore thermal couples for RCS temperature monitoring (may bo partially unavailable if vital bus is unavailabio).

\section{PROCEDURAL GUIDANCE}

- 1-AP-27.00 Loas of Decuy Heat Removal Capability

- Stepe 25, 27, and 28 and Attachment 5, Past 4: Maintain SGs mear 33\% NR level and dump steam using SG PORVs or main condenser to control RCS temperature.

\section{TRAINING AND EXPERIENCE}

- Operators trin ox this secnario churing simulator drills.

\section{CONCURRENT ACTIONS/COMPETING FACTORS}

- Restoration of RCS leval (for RA(B)W1(2,3,4)-XHE-S-9(16)).

- Restoration of RAR cooling (for RA(B,4,5)W1 $(2,3,4)$-XFAE-S-9).

\section{INDICATTON OF SUCCESSFUL COMPLETION/MMPACT OF SUCCESS}

- SG preasuro is stabio or slowly decreasing

- SG level is slowly decreatiog if water is not feeting into the SG.

- WR hot leg temperatures are stable or slowly decreasing.

- WR cold leg temporatures aro at aturition for SG presare.

- RCS level is atable.

- Succesuful decy heat remoral is established.

\section{IMPACT OF FAILURE/ADDITIONAL CUES}

- SG prectare is lncreating if steam dump is unewcessful.

- SG level is docreaving if no water is provided to the SGs.

- A RCS heats up RCS temperaturo increases; loss of nubcooling and alarms.

- Boiloff would lead to decreasing RCS levals.

\section{TMME CONSTRAINTS}

- Tirno until boiling and time until core damage are time window dependent and are given in Chapter 5.

- Ectabliehing SG reflux cooling should only take a few minutes if instrument air and semi-vital bus are available and if providing water to the SGs is not necessary. 
Table 8.7 (Page 2 of 2). Qualitative Descriptions of Dynamic Human Actions Evaluated for the Surry Shutdown PRA

\section{SPECLAL CASES ANALYZED}

- D-RAW1(23,4)-XHE

- D.RBWI (2,3,4)-XIE

- D-R3W1 (23,4) XXHE

- D-RAW1 (2, 3,4)-XHE

- D-RSWI $(2,3,4)$-XHE

- A.RAW1 $(2,3,4)$-XHES-9.

- A-RAWI (23,4)-XHE-S-16.

- A-RBWI (2,3,4)-XIRE-S-9.

- A.RBWI (23,4)-XHES-16.

- A-R3W1(2,3,4)-XHE-S-8.

- A-RAW1(23,4)-XHE-S-9.

- A.RSW1(2,3,4)-XFR.S.9.
Operator dizpoces thet a loss of RHR has ocourred two to ovor-drining at midtloop.

(Alwo 200 tables for MRA, RRA, FRA, and GRA)

As devcribed above for D-RAW1 $(2,3,4)$-XFE, omet the initiating avent is biture to maintain RCS level

As dewcribed above for D-RAW1 $(2,3,4)$-XHE, exopt the initinting aveat is unrecoverible locs of RHR.

As described above for D-RAW $(23,4)-X H E$, exoppt the initiating ereat is lows of cono (operating) RHR train.

As deacribed above for D.RAW1 $(2,3,4)$-XFE, except the initiating aveat is recoverablo loas of RHR.

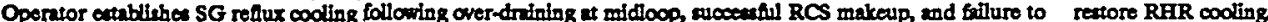

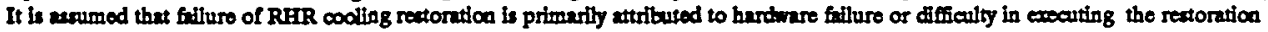
proceses (i.e, not due to incompetent operator performineo).

Oporator ectablithes SG refux cooling following over-dratning at midloop and fillure to provide RCS makeap. It is angumod that failuro of RHR cooling reatontion is primarily attributod to hardware fillure or diffeulty in excouting the reatoration process (i.en nor due to incompetent operator performenco).

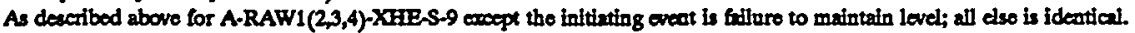

Une same value as A-RAW1 $(2,3,4)-X H E-5-9$.

As described above for A-RAW1 $(2,3,4)$-XFE-S-16 exopp the initiating oveat is friture to maintain level; all eles is ideaticat. Une same viluo as A-RAW1 $(2,3,4)$-XXTE-S-16.

As deccribed above for A-RAW1 $(2,3,4)-X H E-S-9$ exopx adoquate RCS level hes been muintainod and an unrecoverable lous of RHR has ocarred; all else is ideatical; no preceding weticas; no indication of low or rextored RCS levels; there may not bo RHR pump motor amporas cocllation and excentivo RHR pump noise.

As deacribed above for A-R3W1 (2,3,4)-XHES-8 exopt adequate RCS leval has been maintained the inlitiating event is loss of cone RHR troin (operating), and rectorntion of RFR cooling has frilod; proceding metions do nox indude frilure of RCS makeup; no incication of Low or reatored RCS levela; there my not be RHR pump motor amperise cecillation and wexive RHR pump ncise. Use tame valuo as A-RAW1 $(2,3,4)$-XHE-S-9.

Idential to A-RAWI $(2,3,4)$-XHES-9, exopt the initiating event is a recoverable loes of RHR.

Use same value as A-RAW1 (2,3,4)-XHE-S-9. 
Table 8-8 (Page 1 of 2). Qualitative Descriptions of Dynamic Human Actions Evaluated for the Surry Shutdown PRA

FRA(B,3,4,5):

Operator cutablithes RCS foed and bleed following lows of RHR at mid-loop.

\section{PRECEDING EVENTS}

- Lose of RHR due to

- over-draining (RA),

- filluro to maintain RCS lovel (RB),

- uncoverablo RHR fillure (R3),

- operating RHR troin fillure (R4), or

- recoverablo lose of RHR (R5).

- For the actice event of entublishing RCS feed and bleed, operators have successfulty diageored that a loss of RHR has oceurred and referred to

1-AP-27.00 (Lows of Decay Heat Remoral Capability).

- RCS feed and bieed is considered in 4 sequences:

- Preesurizer rafery valve(s) was reenoved, restoration of RCS inventory has been successful (for RA(B)W1(2,3,4)-XHE-F-5), and recovery of RHR cooling has failed (RA(B,4,5)W1(2,3,4)-XHE-F-5).

- Pressurizer safery valvo(s) was not removed, restoration of RCS inventory has been successful (for RA(B)W1(2,3,4)-XHE-F-9), recovery of RFR cooling bas failed (for RA(B,4,5)W1 (2,3,4)-XHE-F-9), and SG bleed and foed has not been establiathed.

- Pressurizer safery valve(s) was removed and restoration of RCS inventory has falled (for RA(B)W1(2,3,4)-XHE-F-12).

- Pressurizer safety valve(s) was not removed, restoration of RCS inventory has failed (for RAR(B)W1(23,4)-XHE-F-16), and SG bleed and feed has not been established.

\section{INDICATIONS OF PLANT CONDITIONS}

- Low RCS level (in the event of over-draining or failure to maintain level; for RA(B)W1(2,3,4)-XHE-F-5(9,12,16)), restored RCS level (in the event of successful RCS makeup; for

RA(B)W1 $(2,3,4)$-XIE-F-5(9)), and slowly docreasing RCS level.

- Control room RCS standpipe level 1-RC-LI-100A (may not bo aceurate when RCS boiling starts).

- Contral room cold shutdown RCS level narrow range 1-RC-LR-105.

(ultrasonic indication of R'S level within the loop, i.e., from middle to top of the loop; may be partially unavailable if vital bus is unavailable)

- RCS standpipo level local indication.

- Shutdosn cooling low level annunciator B-C-8.

- RHR pump motor amperage oscillation (in the event of over-draining or failure to maintain level; for RA(B)W1(2,3,4)-XHE-F-5(9,12,16)).

- Encssive RHR pump noise (in the eveat of over-draining or failure to maintain level; for RA(B)W1(2,3,4)-XHE-F-5(9,12,16)).

- No RHR flom

- Control room RHR flow indication 1-RH-FI-1605.

- RTR heat exhanger low flow annumciator B-C-6.

- Incore thermal couplea for RCS temperature (may be partially unavailable if vital bus is unavailable) and sub-coling monitoring.

\section{PROCEDURAL GUIDANCE}

- 1-AP-27.00 Los of Decery Heat Removal Capability.

- Steps 23, 25, 27, 27, and 28 and Attachmeat S, Parts 2 and 3: Feed and bieed of RCS and charging pump croes connect from unit 2; cold leg injection is the preferred cooling

path; however, this procedure instructs the operators to use the hot leg injection path first; this procedure only instructs the operators to

open I PORV (both PORVs are blocked open in the mid-loop operation); this procedure does not mention the feed and spill mode of operation which is the preferred mode of operation, suppresses core boiling and maintains RCS subcooling

\section{TRAINING AND EXPERIENCE}

- Operators train $\infty$ this secarario during simulator drills.

\section{CONCURRENT ACTIONS/COMPETING FACTORS}

- Restoration of RCS inveatory (for RA(B)W1(2,3,4)-XHE-P-5(9,12,16)).

- Reatoration of RHR cooling (for RA(B,4,5)W1(2,3,4)-Xt1E-P-5(9)).

- Establishing SG bleed and feed.

\section{INDICATION OF SUCCESSFUL COMPLETION/IMPACT OF SUCCESS}

- RCS temperatures are stable or slowly decreasing

- RCS sub-coling is maintained.

- Flor injection into RCS from HHSI or LHSI.

- Blecting flow out of the pressurizer.

- PORV discharge temperature.

- Pressurizer relief tank level.

- Sufficient RCS level.

- Successful decay heat removal is established.

\section{IMPACT OF FAILURE/ADDITIONAL CUES}

- As RCS heats up RCS temperanure increases; loss of subcooling and alarms.

- Boiloff would lead to docreasing RCS levels. 
Table 8-8 (Page 2 of 2). Qualitative Descriptions of Dynamic Human Actions Evaluated for the Surry Shutdown PRA

\section{TIME CONSTRAINTS}

- Time until bolling and time until core damage are time window dependent and are given in Chapter 5.

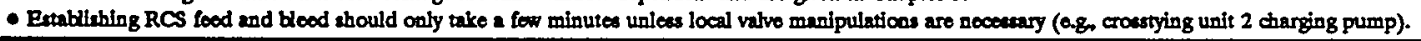

\section{SPECIAL CASES ANALYZED}

- D-RAWI (23,4)-XHE. Operator diagnowes that a lows of RHR has cocurred due to over-draining at mid-loop.

- D-RBW1(2,3,4)-XHE (Also ve tables for MRA, RRA, SRA, and GRA)

As described above for D-RAW1 $(2,3,4)$-XHE, exoept the initiating event is failure to maintain RCS level.

- D-R3WI $(2,3,4)$-XIE. As dewribed above for D-RAW1 $(2,3,4)-X H E$, croept tho initiating event is unrecoverable loss of RHR.

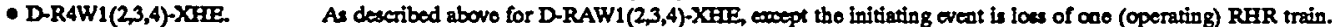

- D-RTW1 (2,3,4)-XFE. As described above for D-RAW1 $(2,3,4)$-XFE, eropt the initiating event is recoverable lows of RHR.

- A-RAW1 $(2,3,4)$-XFE-F-S. Operator establishes RCS feed and bleed following over-draining at midloop, wocesful RCS makeup, failure to restore RHR cooling and pressurizer safety valve removed. It is assumed that failure of RHR cooling reatoration is primarily attributed to handware failure or diffeculty in excuting the restoration process (Le, not die to incompetent operator performanco).

- A-RAW1 (2,3,4)-XFE-F-9. Operator establithes RCS feed and bleed following over-draining at midloop, successful RCS makeup, failure to restore RHR cooling and failure to establish SG refiux cooling It is assumed that failures of RHR cooling restoration and failure of SG reflux cooling are primarilyattributed to hardware failures or difficulty in executing the restoration or establishing process (i.e., not due to incompetent operator performance).

- A-RAW1 (2,3,4)-XHE-F-12. Operator establishes RCS foed and bleed following over-draining at midloop, failure to provide RCS makeup, and pressurizer safety valve removed. It is assumed that failure of RCS makeup is primarily attributed to hardware failure or diffeulty in executing the reatoration process (1.e., not due to incompetent operator performanco).

- A-RAW1 (23,4)-XHE-F-16. Operator establishes RCS feed and bleod following over-draining at midloop, tailure to provido RCS makeup, and failure to establish SG refiux cooling It is aseumed that failure of RCS makeup and SG reflux cooling are primarity attributed to hardware failure or difficulty in excouting the restoration process (i.e., not due to incompetent operator performance).

- A-RBW1 (2,3,4)-XFIE-F-5. As described above for A-RAW1 $(2,3,4)$-XHE-F-5 expept the initiating eveat is failure to maintain level; all else is identical. Use same value as A.RAW1 $(2,3,4)$-XFE-F-5.

- A-RBW1(2,3,4)-XTIE-F-9. As described above for A-RAW1 $(2,3,4)-X F E-F-9$ exept the initiating event is failure to maintain level; all else is identical. Use same value as A-RAW1 $(2,3,4) \cdot$ XYRE-F-9.

- A-RBW1 $(2,3,4)$-XHE-F-12. As described above for A-RAW1 $(2,3,4)$-XHE-F-12 except the initiating event is failure to maintain level; all else is identical. Use same value as A-RAW1 $(2,3,4)-X$ HE-F+12.

- A-RBW1 (2,3,4)-XHE-F-16. As described above for A-RAW1 $(2,3,4)$-XHE-F-16 cocept the initiating event is failure to maintain level; all else is ideatical. Use same value as A-RAW1 $(2,3,4)$-XHE-F-16.

- A-R3W1 (2,3,4)-XHE-F-4. As described above for A-RAW1 $(2,3,4)$-XHE-F-12 exoept adequate RCS level has been maintained and an unrecoverable loss of RHR has cocurred;all else is identical; no preceoding actions; no indication of low and restorod RCS levels; there may not be RHR pump motor amperage oscillation or excessive pump noise.

- A-R3W1 (2,3,4)-XHE-F-8. As described above for A-RAW1 (2,3,4)-XHE-F-16 except adequate RCS level has been maintained and an unrecoverable loss of RHR has occurrediall elee is identical; no prececting actions; no indication of low and restored RCS levels; there may not be RHR pump motor amperage oscillation or excessive pump noise.

- A-R4W1 (2,3,4)-XFE-F-5. As described above for A-RAW1 (2,3,4)-XHE-F-5 exopt adequate RCS level has been maintained and the initiating eveat is loss of one RHR train (operating); preceding actions do not indude success of RCS makeup; no indication of low and restored RCS levels; there may not be RHR pump motor amperage cocillation and excessive pump noise.

Ure same value as A-RAW1 $(2,3,4)-X H E-F-5$.

- A-R4W1 (2,3,4)-XHE-F-9. As described above for A-RAW1 $(2,3,4)$-XHE-F-9 eccept adequate RCS level has been maintained and the initiating event is loss of ono RHR train (operating); preceding actions do not indude success of RCS makeup; no indication of low and restored RCS levels; there may not be RHR pump motor amperage oscillation and ewestive pump noise.

Use same value as A-RAW1(2,3,4)-XHE-F-9.

- A.RSW1 (2,3,4)-XHE-F-S. Identical to A.R4W1 $(2,3,4)$-XFE-F-5, cocept the initiating event is a recoverable loss of RHR

Use same value as A-RAW1 $(2,3,4)$-XIIR-F-5.

- A-RSW1 (2,3,4)-XHE-F-9. Identical to A-R4W1 $(2,3,4)$-XHE-F-9, except the initiating event is a recoverable loss of RHR Use same value as A-RAW1 $(2,3,4)$-XHE-F-9. 


\section{Human Interface Analysis}

Table 8-9 (Page 1 of 2). Qualitative Descriptions of Dynamic Human Actions Evaluated for the Surry Shutdown PRA

\section{GRA(B,3,4,5)R6:}

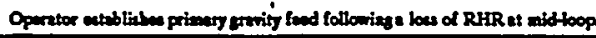

\section{PRECEDING EVENTS}

\section{- Loen of RHR don to}

- omdraining (RA)

- trilura to metiatuia RCS lomi (RB)

- zarcocomable RHR fiture (RS)

- operatiog RHRR traie biture (RS), o

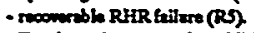

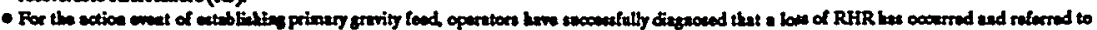

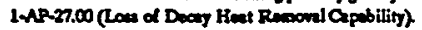

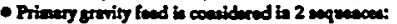

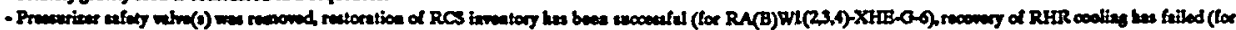

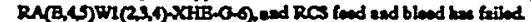

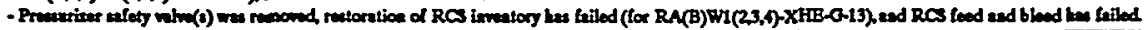

\section{INDICATIONS OR PLANT CONDITIONS}

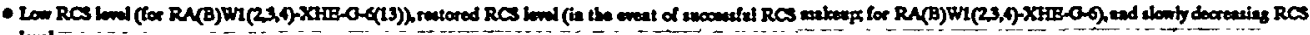

Lond

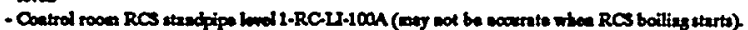

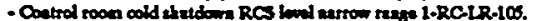

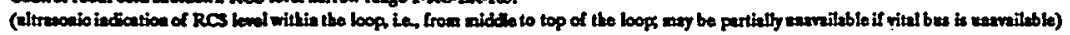

- RCS stendpipe lenel local inciontion.

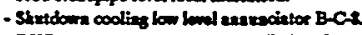

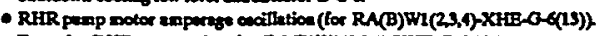

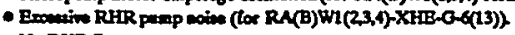

- No RHRáo

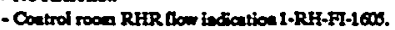

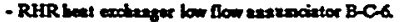

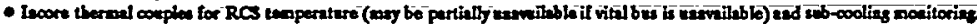

\section{PROCEDURAL GUIDANCE}

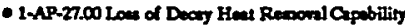

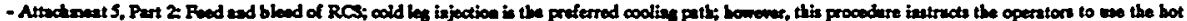

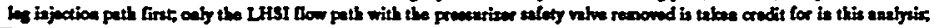

\section{TRAINING AND EXXPERIENCE}

- Operators trair on this rovatrio dering sinulator dith.

\section{CONCURRENT ACTIONS/COMPETING FACTORS}

- Reatoration of RCS invelory (for RA(B)W1(23,4)-XHE-O-6(13))

- Rectoration ol RHR coolies (for RA(B,45)WI(23,4)-XHE-G-G).

- RCS food ead blead.

\section{INDICATION OF SUCCESSFULCOMPLETIONMMPACT OF SUCCESS}

- RCS tenperaturee ure atable or sbonty decreetip.

- From injoction into RCS tron LrssL.

- RWST kend in decrusine

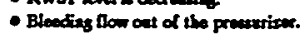

- Promerizer dischargo temperatera.

- Promarizer reliel tank lowed.

- Serticieat RCS lent

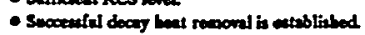

\section{MMPACT OF RAILURE/ADDTTIONAL CUES}

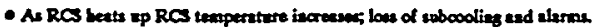

- Boilofl world lead to decrmies RCS lovels.

\section{TIME CONSTRAINTS}

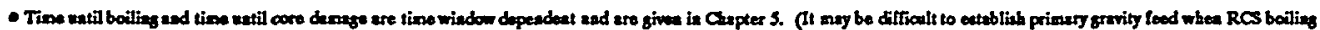
atarts?

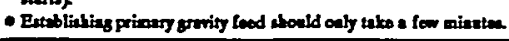


Table 8 -9 (Page 2 of 2). Qualitative Descriptions of Dyanic Hnman Actions Evaluated for the Surry Shutdown PRA

\section{SPECLAL CASES ANALYZED}

- D-RAW1(2, 4)-XFIE.

- D-RBW1(2,3,4)-XHE

- D-R3W1 (23,4)-XIFE

- D-RAW1 $(2,3,4)$-XKEE

- D-RSW1 $(2,3,4)$-XHE

- A-RAW1 $(2,3,4)$-XHE-G6.

- A-RAW1(2,3,4)-XAE-G-13.

- A-RBW1(2,3,4)-XHE-a-6.

- A-RBW1 (2,3,4)-XHR-G-13.

- A-R3W1 (2,3,4)-XHE-G-5.

- A-RAW1 (2,3,4)-XIE-G-6.

- A-RJWI(2,3,4)-XHE-G-6.
Operator diagroces that a loes of RHR hes ocourred due to over-drining at mid-loop.

(Alwo 200 tables for MRA, RRA, SRA, and FRA)

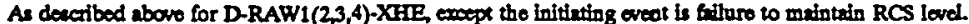

As described above for D-RAW1 $(23,4)$-XIE, expept tho initiating eveat is unrocoverable lows of RHR.

As described above for D-RAW/ $(2,3,4)$-XHE, expe tho initieting oveat is lows of coe (operaing) RHR trin.

As deccribed above for D-RAW1 $(2,3,4)$-XHE, woopt the initiating eveat is recoverable lows of RHR.

Operator ettablithex primery grwity food following over-draining at midloop, mocoutful RCS makeup, fallure to rearore RHR cooling.

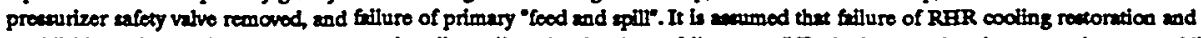

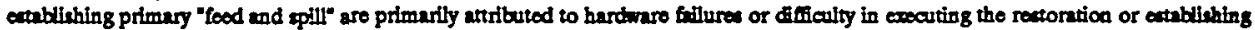
procese; i. nol dio to incompetent operntor performanco.

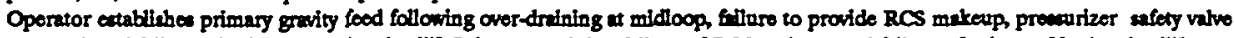

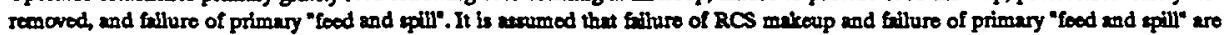

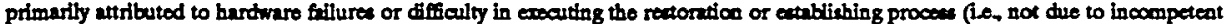
operator performano).

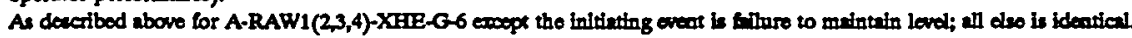

Uto rame value as A-RAW1 (2,3,4)-XHE-G-6.

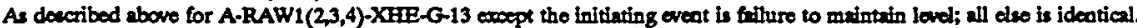
Uno umo value is A-RAW1 $(2,3,4)$-XHE-G-13.

As dectibod above for A-RAW/ (23,4)-XHE-G-13 expepe adequate RCS level bas been meintained and an unrecoverablo lows of RFR hes cocurred; no indication of low or reatored RCS levels; there may not be RHR pump motor emperase oceillation and ecoesivo RHR pump noise; precoding actions do not indude increase RCS makeup and recovery of RHR cooling all elso is ideatical.

As describod abovo for A-RAWI (2,3,4)-XHE-G-6 croept adequate RCS level has been maintainod and the initiating event is loss of one RHR trin (Operating); procoding actions do not indude suocess of RCS makeup.

Une ramo value as A-RAW1 (2,3,4)-XHE-G-6.

Identical to $A \cdot R 4 W 1(2,3,4)-X H E-G-6$, expt the initiating eveat is a recoverable loss of RHR. Ure nemo value as A-RAW1 (2,3,4)-XHE-G-6. 


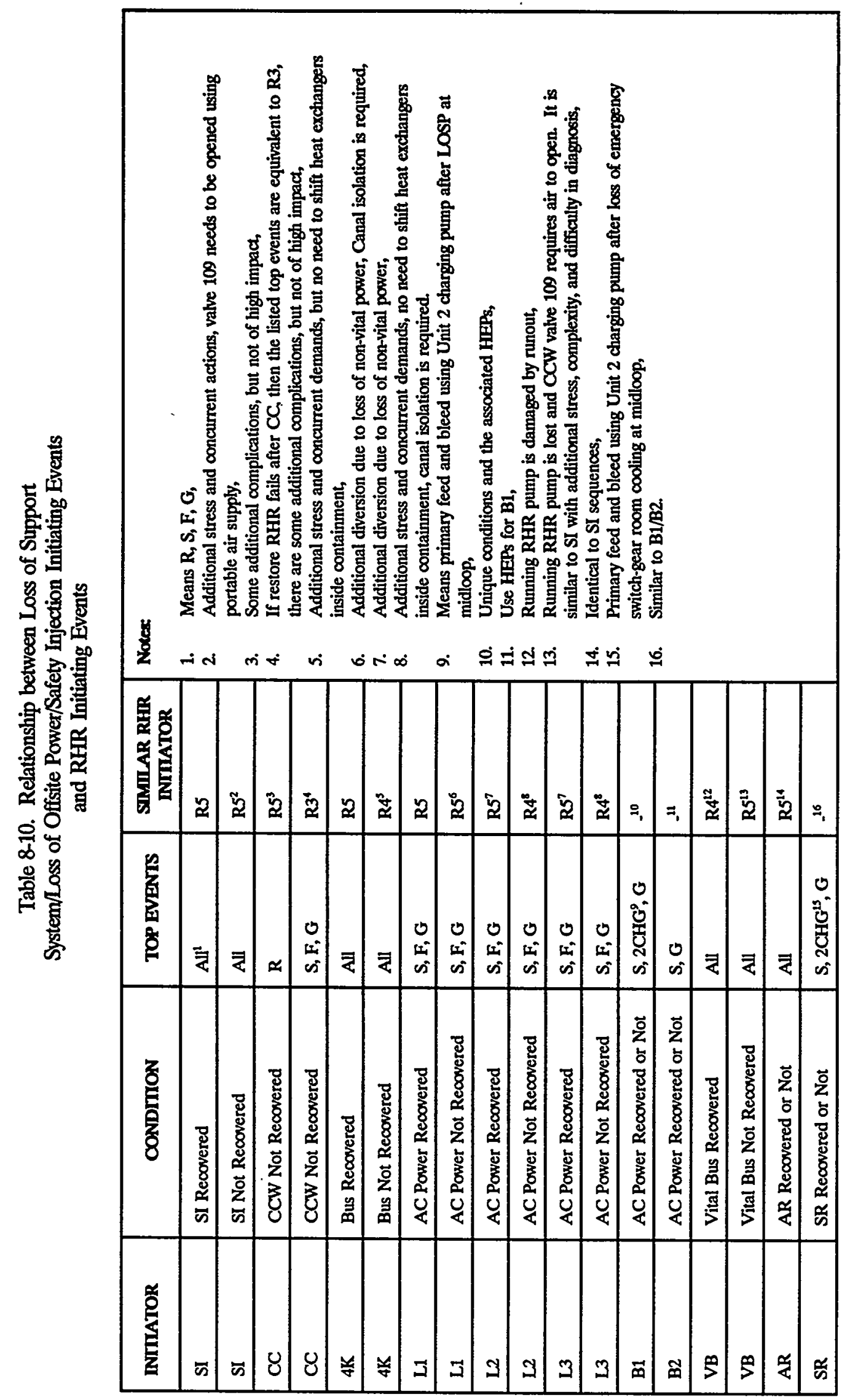




\begin{tabular}{|c|c|c|c|c|c|c|}
\hline 8 & $\begin{array}{l}F \\
8 \\
8 \\
0 \\
0\end{array}$ & $\stackrel{0}{n}$ & 7 & 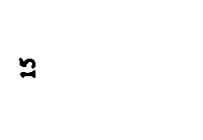 & 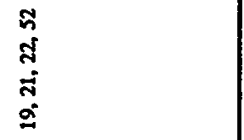 & 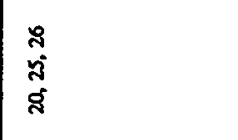 \\
\hline $\begin{array}{l}\frac{1}{2} \\
\frac{2}{2} \\
\frac{1}{2}\end{array}$ & 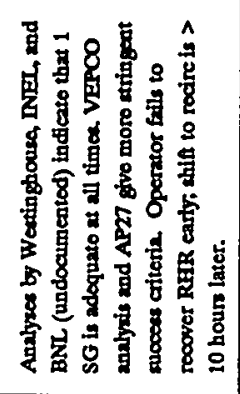 & 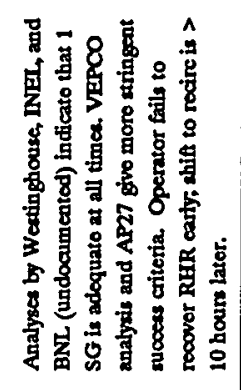 & 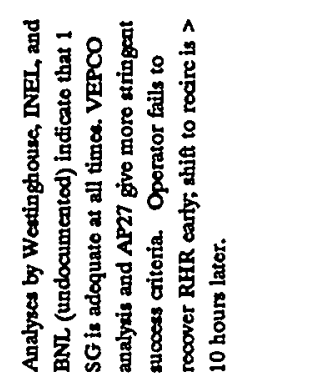 & 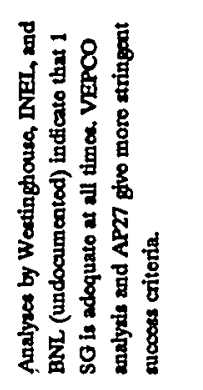 & 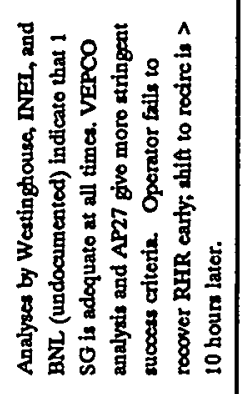 & 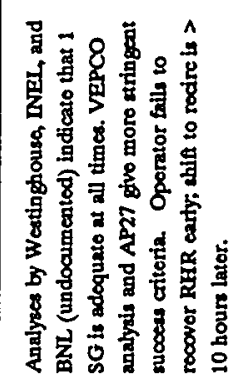 \\
\hline$\frac{3}{4}$ & $\begin{array}{l}\stackrel{8}{8} \\
\text { 离 } \\
\frac{7}{7}\end{array}$ & 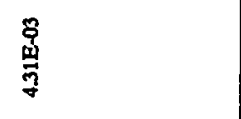 & $z$ & $z$ & $z$ & $z$ \\
\hline 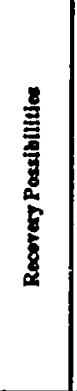 & 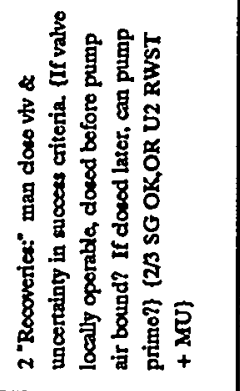 & 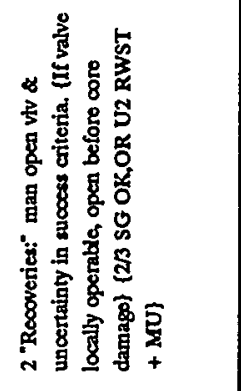 & 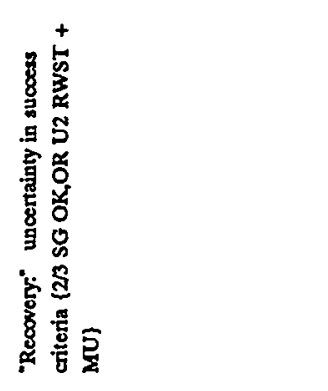 & 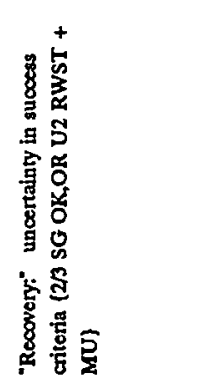 & 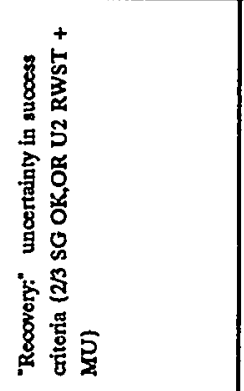 & 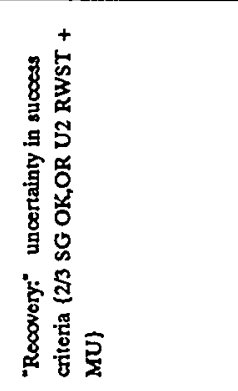 \\
\hline 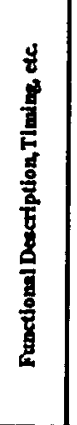 & 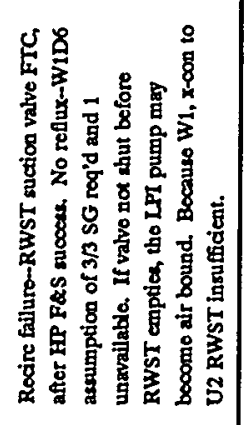 & 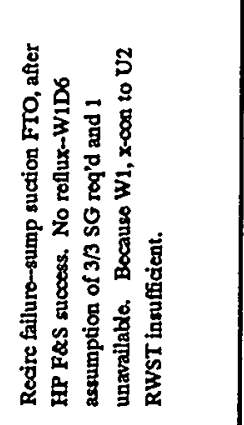 & 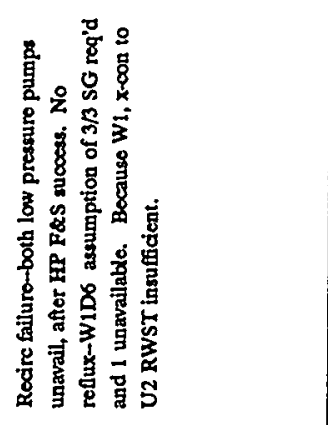 & 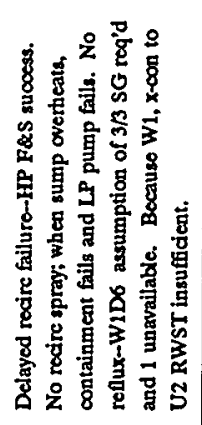 & 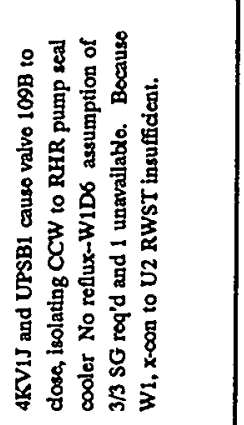 & 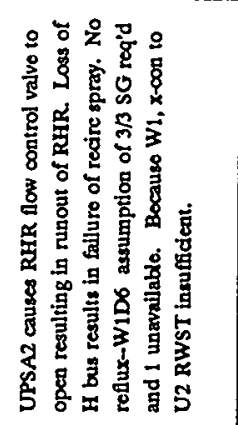 \\
\hline 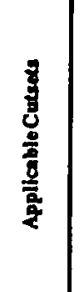 & 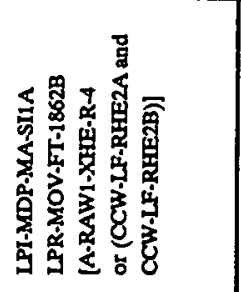 & 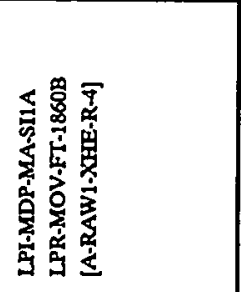 & 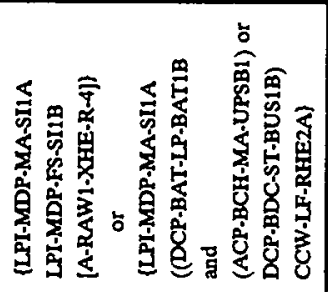 & 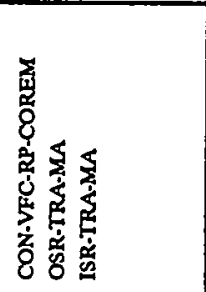 & 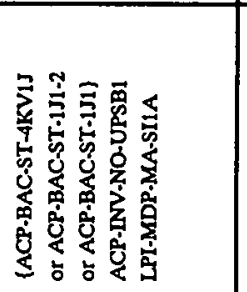 & 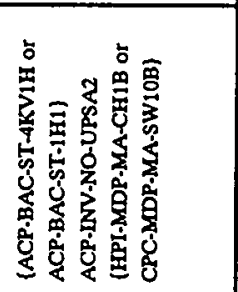 \\
\hline 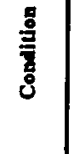 & $\frac{\overline{4}}{8}$ & $\frac{\bar{\alpha}}{\frac{\pi}{8}}$ & $\frac{\pi}{8}$ & $\frac{2}{8}$ & $\frac{\bar{s}}{\frac{\Sigma}{2}}$ & $\frac{\bar{\alpha}}{\frac{\pi}{8}}$ \\
\hline 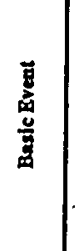 & 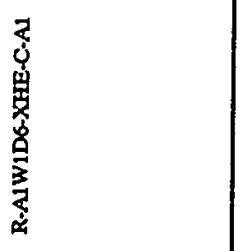 & 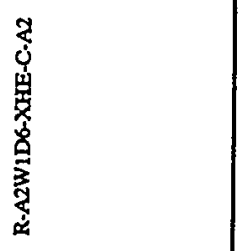 & 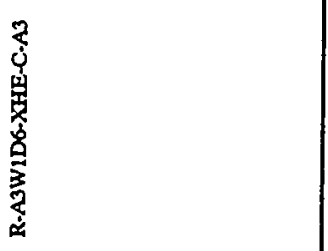 & 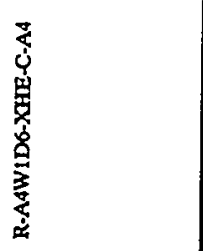 & 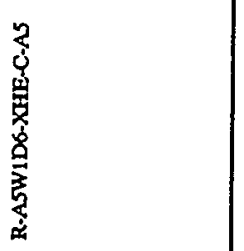 & 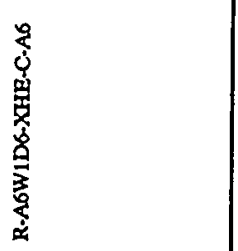 \\
\hline
\end{tabular}




\begin{tabular}{|c|c|c|c|c|c|c|c|}
\hline 9 & 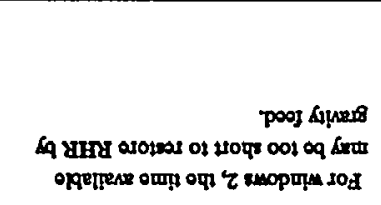 & $\mathbf{N}$ & 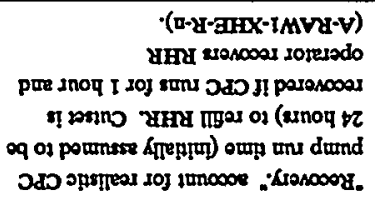 & 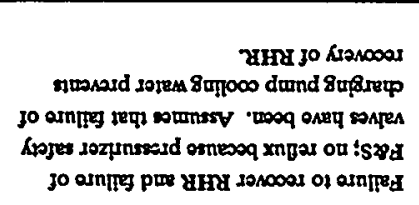 & 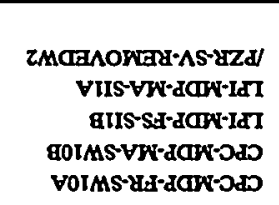 & VoxTAzO & 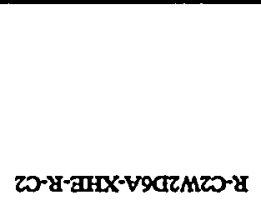 \\
\hline tos c & 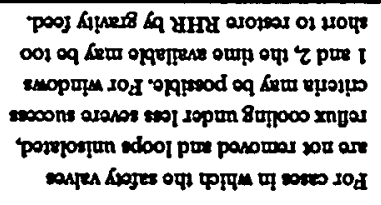 & $\mathbf{N}$ & 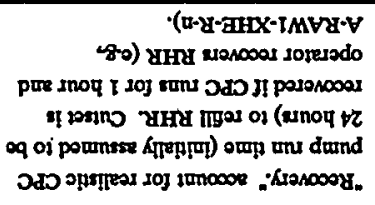 & 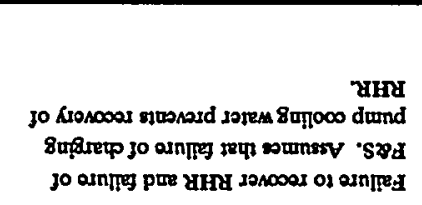 & 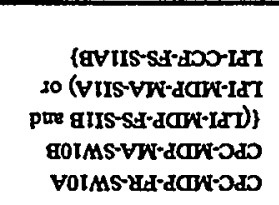 & voatmis & 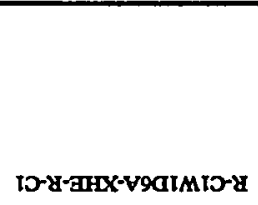 \\
\hline 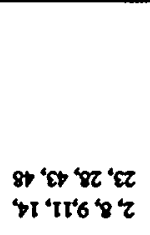 & 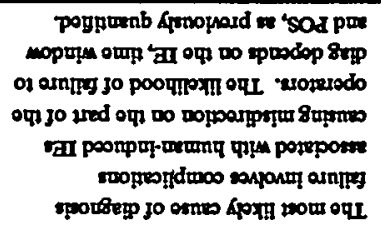 & $\mathbf{N}$ & SHesosas oN & 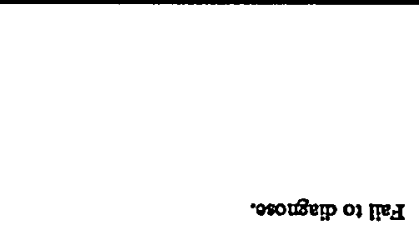 & 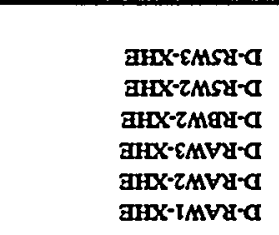 & 98atg & 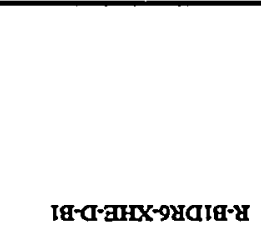 \\
\hline $\boldsymbol{8 \varepsilon}$ & 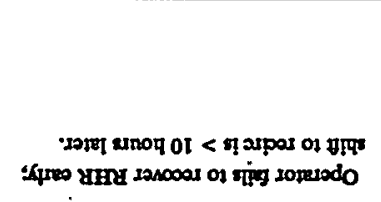 & EO-actr & 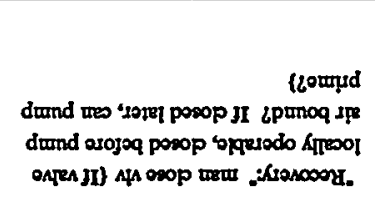 & 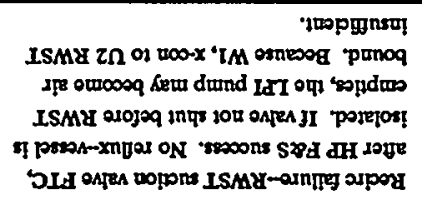 & 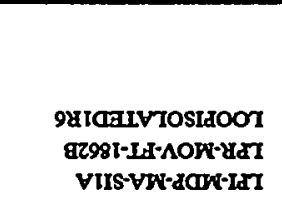 & Ivlogims & 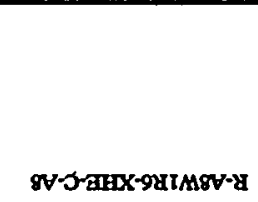 \\
\hline$\angle \varepsilon^{\prime} g \varepsilon^{\prime} \varepsilon \varepsilon$ & 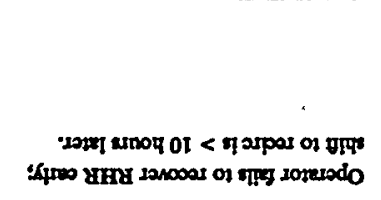 & co-ast'e & & 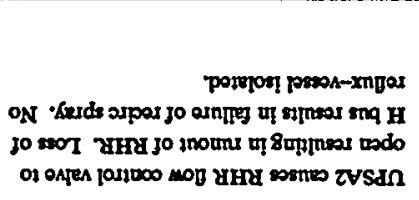 & 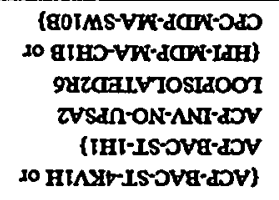 & [V]9\&zMLV & 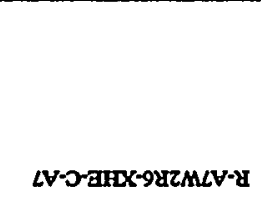 \\
\hline Is 'os & 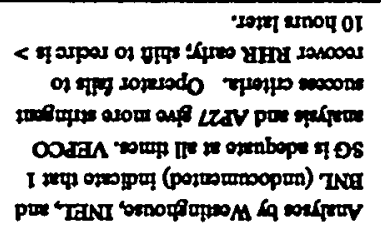 & $\mathbf{N}$ & 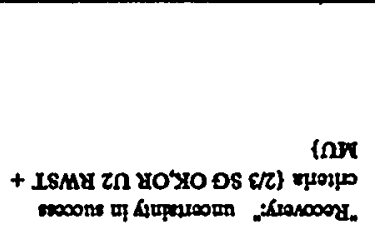 & 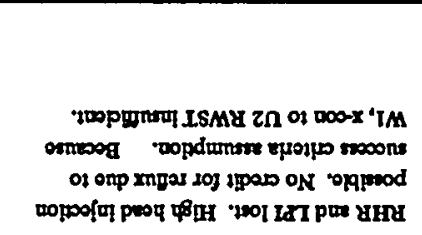 & 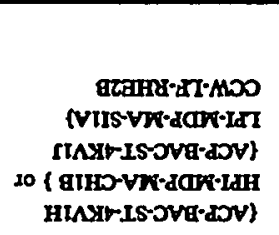 & [v]gatmov & ov-o-arxx-gaimov-y \\
\hline ecksorad & mined roppond & meprev & 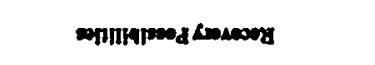 & 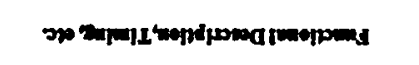 & 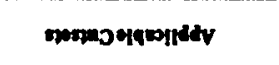 & 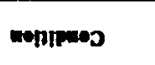 & ต \\
\hline
\end{tabular}


Table 8-11 (Page 3 of 4). Recovery Factors Initiators RA, RB, R3, R4 and RS

\begin{tabular}{|c|c|c|c|c|c|c|c|}
\hline Beake Erout & Comititon & Applicablic Cutsens & Fmetiomal Dectipdon, Timime ace. & Rocovery Pcestiblition & Hation & 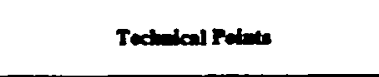 & 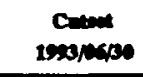 \\
\hline R-C2W3D6A-XHE-R-C2 & C2W3D6A & $\begin{array}{l}\text { CPC-MDP-FR-SW10A } \\
\text { CPC-MDP-MAASW10B } \\
\text { LPI-MDP-FS-SIIB } \\
\text { LPI-MDP-MA-SIIA } \\
\text { /PZR-SV-REMOVEDW3 }\end{array}$ & 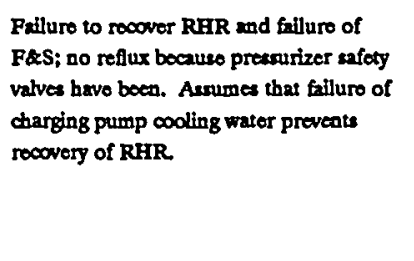 & 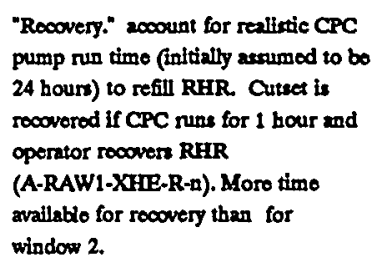 & $\mathbf{N}$ & & 16 \\
\hline R-C2W3D6A-XFE-R-C2 & C2W3D6A & $\begin{array}{l}\text { CPC-MDP-FR-SW10A } \\
\text { CPC-MDP-MA-SW10B } \\
\text { LPI-MDP-FS-SIIB } \\
\text { LPI-MDP-MA-SIIA } \\
\text { /PZR-SV-REMOVEDW3 }\end{array}$ & $\begin{array}{l}\text { Failure to rocover RHR and failure of } \\
\text { FQS; no refulx bocause preasurizer tafety } \\
\text { valves have boen. Assumes that fallure of } \\
\text { charging pump cooling water prevents } \\
\text { rocovery of RHR. }\end{array}$ & 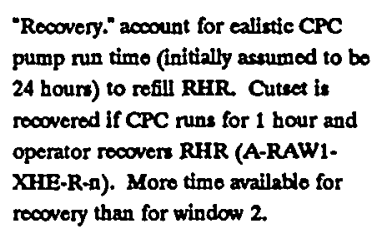 & $\mathbf{N}$ & & 16 \\
\hline $\begin{array}{l}\text { R-C3W4R10A-XIIE-R. } \\
\text { C3 }\end{array}$ & CWWAR1OA & $\begin{array}{l}\text { CPC-MDP-FR-SW10A } \\
\text { CPC-MDP-MA-SW10B } \\
\text { LPI-MDP-FS-SI1B } \\
\text { LPI-MDP-MA-SIIA }\end{array}$ & $\begin{array}{l}\text { Failuro to rocover RHR and fallure of } \\
\text { F\&S. Assumes that fillure of charging } \\
\text { pump cooling water prevents reovery of } \\
\text { RHR. }\end{array}$ & $\begin{array}{l}\text { "Rocovery." account for realistic CPC } \\
\text { pump run timo (initially assumod to bo } \\
24 \text { hours) to refill RHR Cutset is } \\
\text { rocowered if CPC runs for } 1 \text { hour and } \\
\text { operator rocower, RHR (e.g. } \\
\text { A-R1OW4-XHE-R-n). }\end{array}$ & $\mathbf{N}$ & $\begin{array}{l}\text { For cases in which the safety valves } \\
\text { are not removod and loope unieolatod, } \\
\text { reflux cooling undor les severe stocess } \\
\text { criteria may be pousible. }\end{array}$ & 29 \\
\hline R-D1W2R6-XHE-C-D1 & D1W2R6 & $\begin{array}{l}\text { (CPC-MDP-FR-SW10A or } \\
\text { ACP-BAC-ST-AKV1H) } \\
\text { (CPC-MDP-MA-SW10B or } \\
\text { HPI-MDP-MA-CH1B) } \\
\text { (OSR-TRA-MA } \\
\text { ISR-TRA-MA) }\end{array}$ & $\begin{array}{l}\text { Rocirc spray failure, sucoessful low head } \\
\text { F\&S, unrecoverablo loss of RHR }\end{array}$ & $\begin{array}{l}\text { cross connect unit } 2 \text { charging pump } \\
\text { and RWST. }\end{array}$ & $3.15 \mathrm{E}-03$ & $\begin{array}{l}\text { ReAlux cooling is not poesibla. Low of } \\
\text { bus H fails HPT pump A and } \\
\text { rociraulation. }\end{array}$ & $7,27,30$ \\
\hline R-E1W2D6-XHE-C-E1 & E1W2D6 & $\begin{array}{l}\text { ACP-BAC-ST-4KV1H } \\
\text { AFW-MDP-MA-PW3B } \\
\text { (HPI-MDP-MA-CH1B or } \\
\text { CPC-MDP-MA-SW10B\} }\end{array}$ & 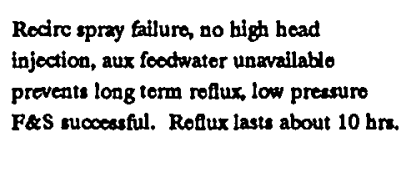 & $\begin{array}{l}\text { action requirod starting at } 10 \text { brs } \\
\text { extends time to } 21 \text { brs. Gro pump or } \\
\text { unit } 2 \text { AFW noodod for long term } \\
\text { sucoses. Recovery considess only the } \\
\text { use of unit } 2 \text { AFW. }\end{array}$ & $1.20 \mathrm{E}-04$ & $\begin{array}{l}\text { grwity food could bo usod to atend } \\
\text { time to allig unit } 2 \text { AFW }\end{array}$ & 12,13 \\
\hline R-P1WIDG-XHE-C-FI & FTWID & A-RJW1-XHE-C-8 & Operator falls to eatablish rocire. & 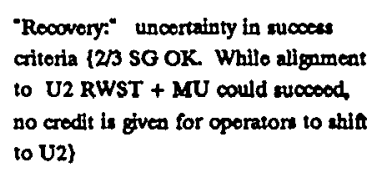 & $\mathbf{N}$ & $\begin{array}{l}\text { Revidit bends for quantification of } \\
\text { oveat. }\end{array}$ & 24 \\
\hline R-G1W2DRG-XHE-C-G1 & G1W2DR6A & $\begin{array}{l}\text { ACP-BAC-ST-AKV1H } \\
\text { ACP-INV-NO-UPSA2 } \\
\text { AFW-MDP-MA-FW3B } \\
\text { (HPI-MDP-MA-CH1B or } \\
\text { CPC-MDP-MA-SW10B) }\end{array}$ & 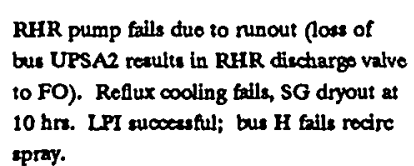 & $\begin{array}{l}\text { 1. food SG via U2 AFW or fro pump; } \\
\text { or, 2. food reactor via U2 RWST and } \\
\text { charging pump }\end{array}$ & $1.03 \mathrm{E}-04$ & & $\begin{array}{c}32,35,40,42 \\
4,46\end{array}$ \\
\hline
\end{tabular}


Table 8-11 (Page 4 of 4). Recovery Factors Initiators RA, RB, R3, R4 and R5

\begin{tabular}{|c|c|c|c|c|c|c|c|}
\hline Beasc Event & Comaltion & Appllatiblocuteds & 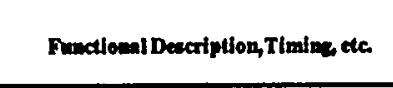 & Recorres Poudblillese & $\begin{array}{l}\text { Human: } \\
\text { Aation }\end{array}$ & Tadmeal Poduts & 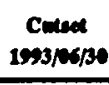 \\
\hline R-HIWIDRG-XHE- 27 & HIWIDRGA & RWT-TNK-LP-RWST & RWST inventory low. & revisit mystem model for RWST & $\mathbf{N}$ & & 34,45 \\
\hline
\end{tabular}




\begin{tabular}{|c|c|c|c|c|c|}
\hline 8 & $\begin{array}{l}8 \\
8 \\
8 \\
9\end{array}$ & $\boldsymbol{A}$ & $\begin{array}{l}\stackrel{\infty}{\infty} \\
\stackrel{\infty}{\infty} \\
\mathbb{A}^{-}\end{array}$ & \% & $\stackrel{n}{ \pm}$ \\
\hline$\frac{1}{8}$ & 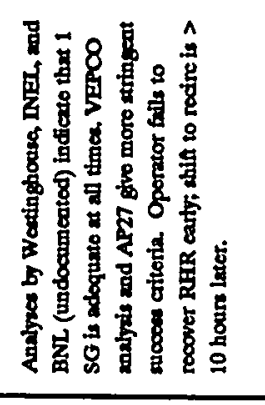 & 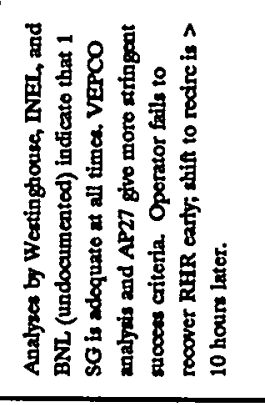 & 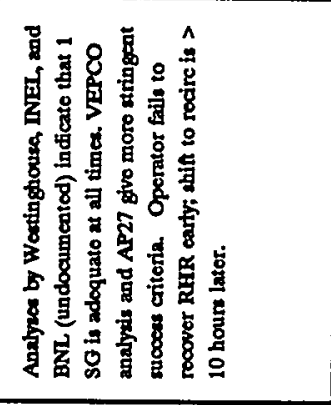 & 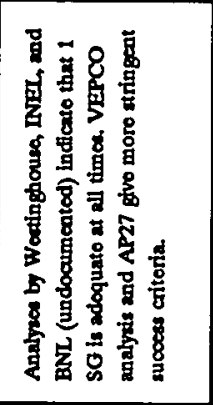 & 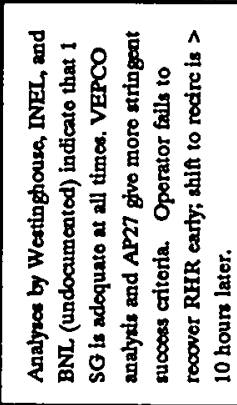 \\
\hline $1 \frac{1}{4}$ & $\begin{array}{l}8 \\
9 \\
9 \\
\end{array}$ & 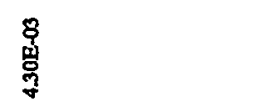 & $z$ & $z$ & $z$ \\
\hline$\frac{2}{3}$ & 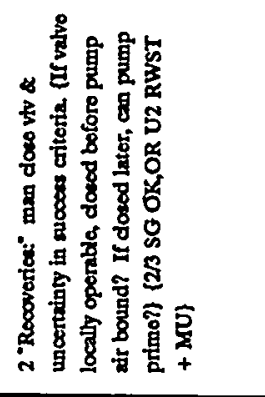 & 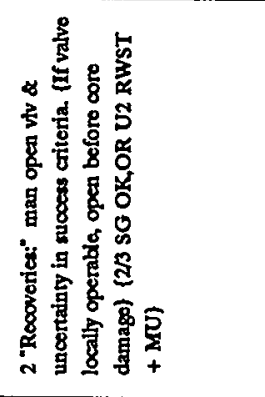 & 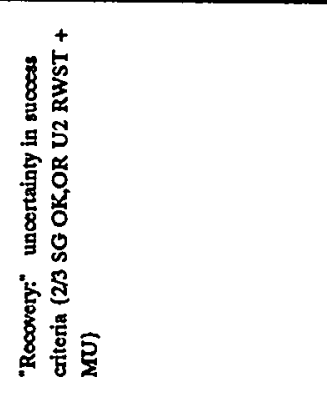 & 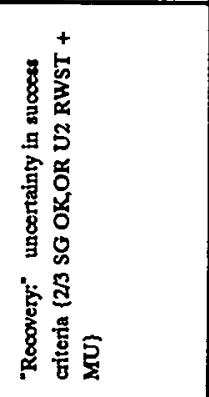 & 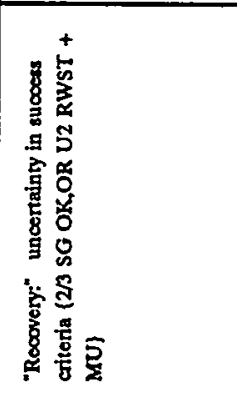 \\
\hline 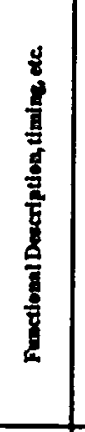 & 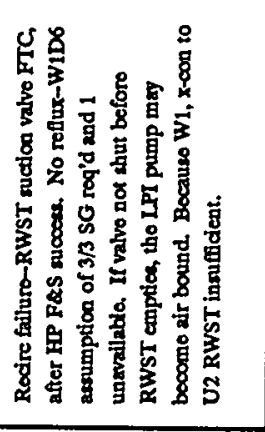 & 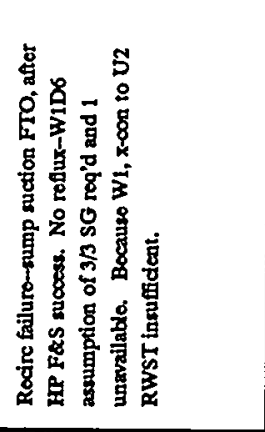 & 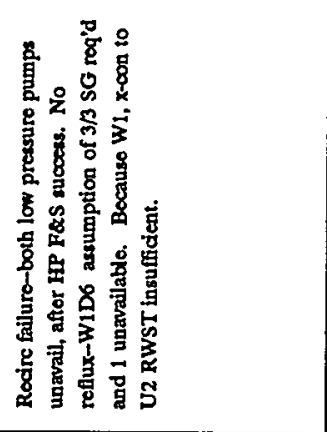 & 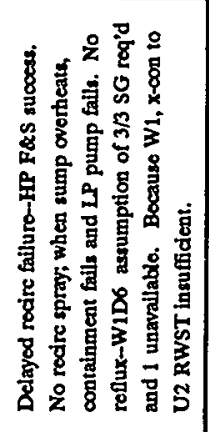 & 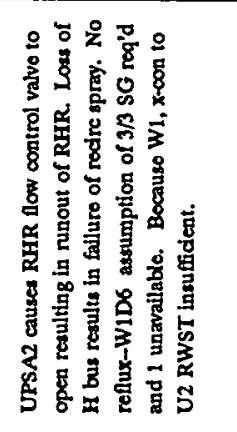 \\
\hline 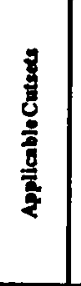 & 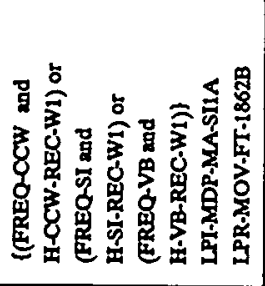 & 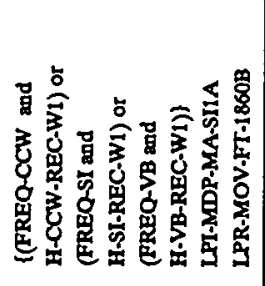 & 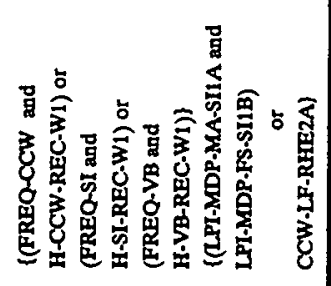 & 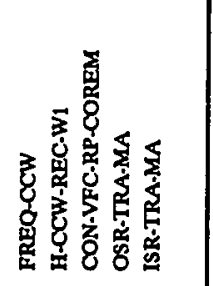 & 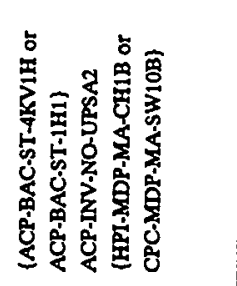 \\
\hline 竧 & $\frac{\bar{\alpha}}{\frac{\pi}{2}}$ & 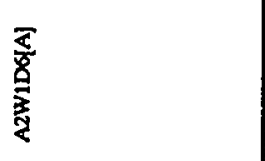 & $\frac{\bar{\alpha}}{\frac{\pi}{z}}$ & 茎 & $\frac{\overline{3}}{8}$ \\
\hline $\begin{array}{l}\text { 总 } \\
\text { 总 } \\
\text { 尊 }\end{array}$ & 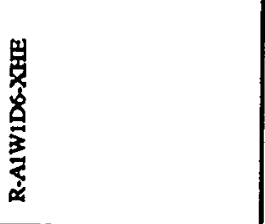 & 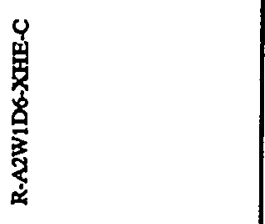 & 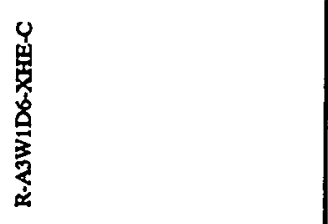 & 是 & 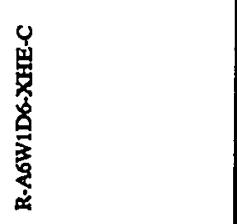 \\
\hline
\end{tabular}




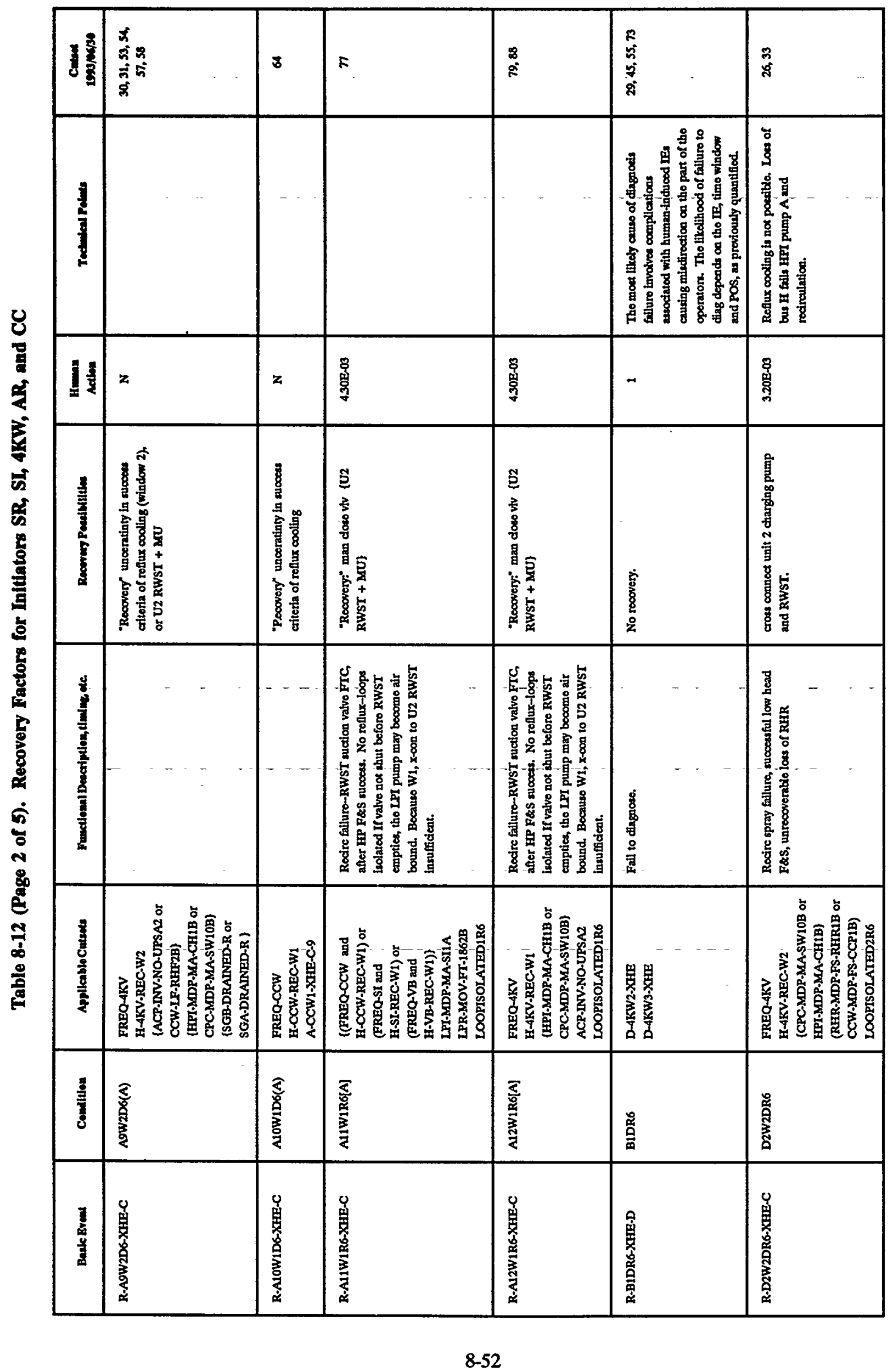




\begin{tabular}{|c|c|c|c|c|c|}
\hline 8 & 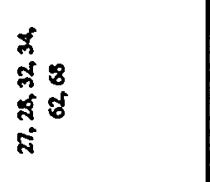 & $\begin{array}{l}6 \\
8 \\
8 \\
8 \\
8\end{array}$ & 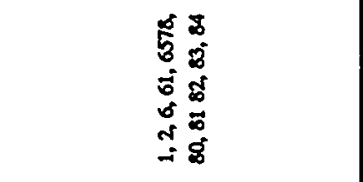 & 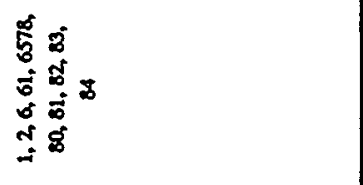 & 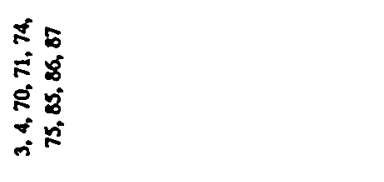 \\
\hline $\begin{array}{l}\frac{1}{2} \\
\frac{1}{8} \\
8 \\
8\end{array}$ & 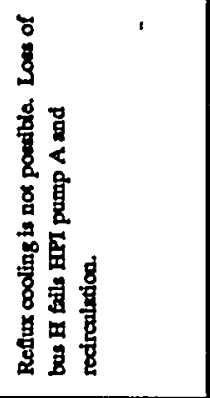 & 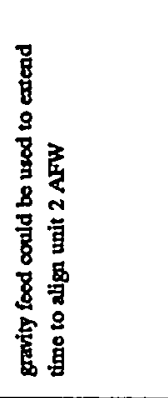 & & & \\
\hline $\int_{x}^{\frac{1}{4}}$ & 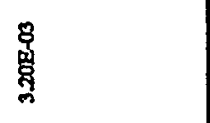 & $\begin{array}{l}\text { ఫ్ర } \\
\text { : }\end{array}$ & 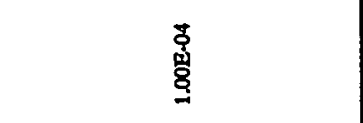 & 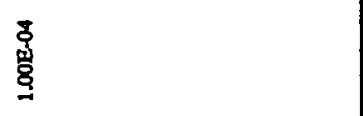 & 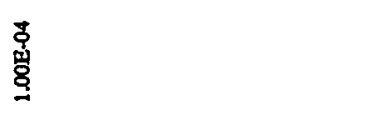 \\
\hline $\begin{array}{l}8 \\
8 \\
8 \\
8 \\
8\end{array}$ & 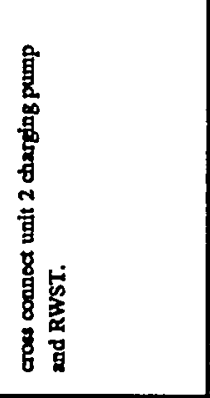 & 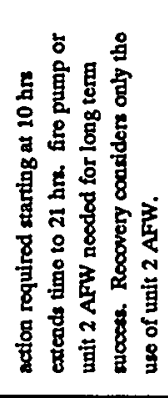 & 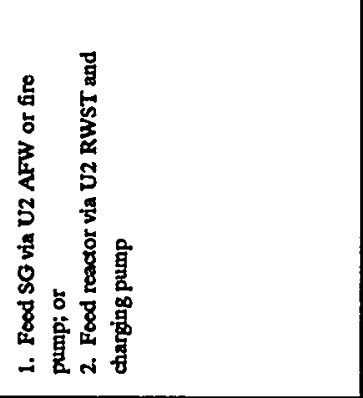 & 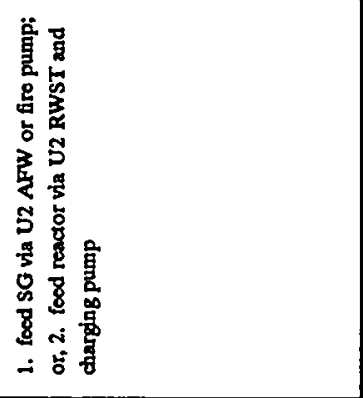 & 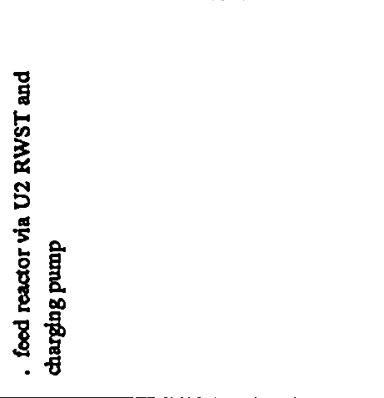 \\
\hline 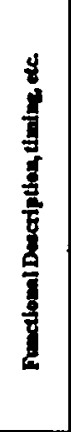 & 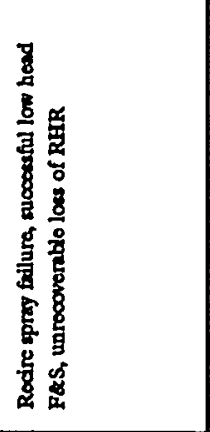 & 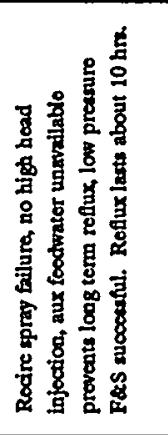 & 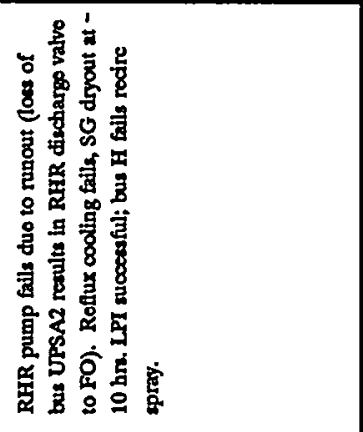 & 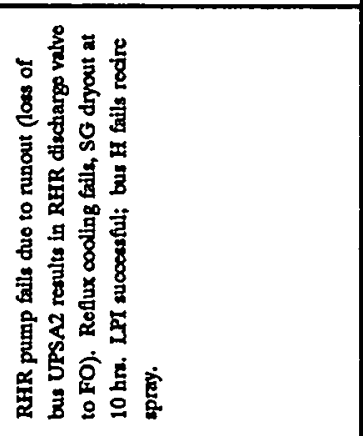 & 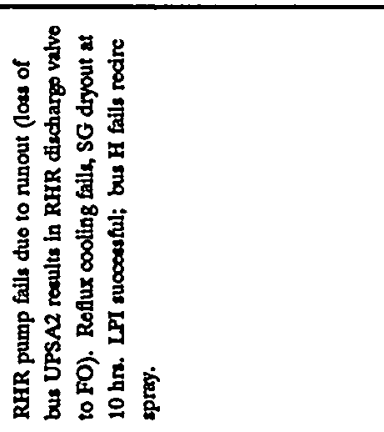 \\
\hline $\begin{array}{l}8 \\
0 \\
0 \\
\frac{8}{8} \\
\frac{8}{2}\end{array}$ & 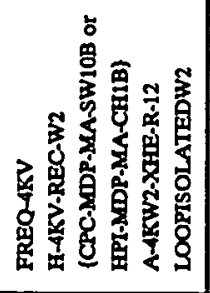 & 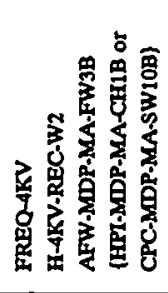 & 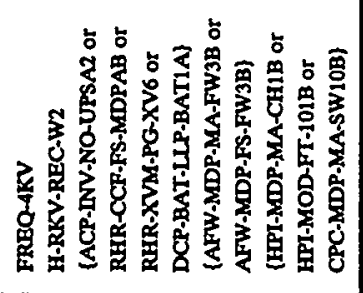 & 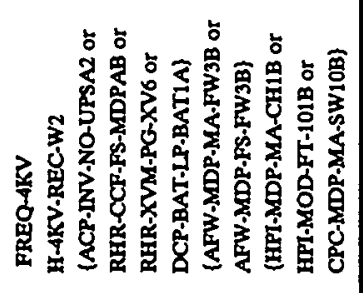 & 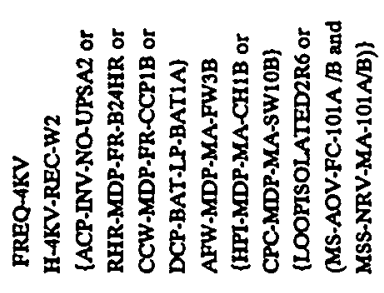 \\
\hline$\frac{8}{3}$ & 旁 & 害 & 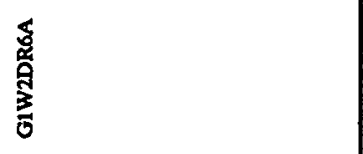 & 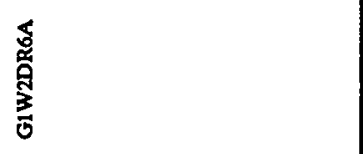 & 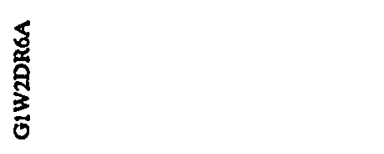 \\
\hline 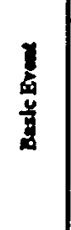 & 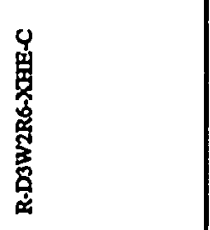 & 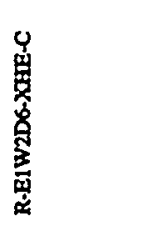 & 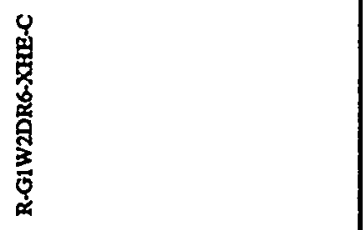 & 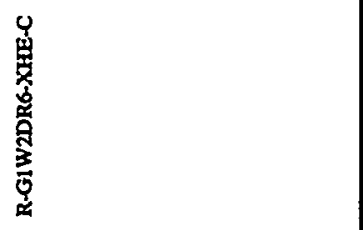 & 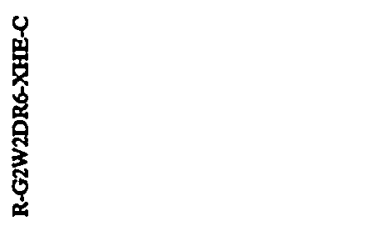 \\
\hline
\end{tabular}




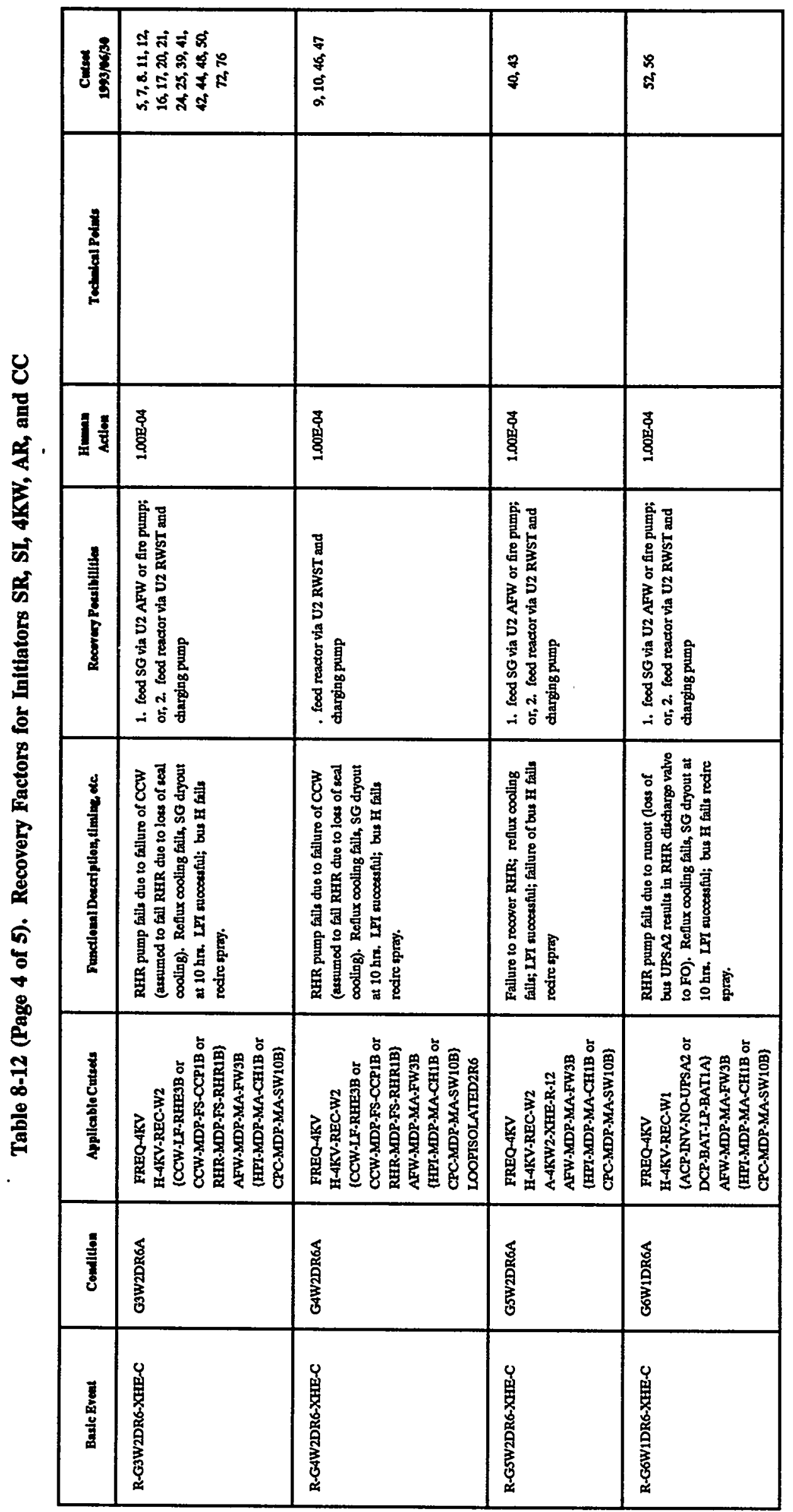


Table 8-13 (Page 1 of 84). Quantitative Results of BNL/Surry Human Action Evaluations

\begin{tabular}{|c|c|c|c|c|c|}
\hline \multirow{2}{*}{ Human Action } & \multirow{2}{*}{ Basis } & \multicolumn{3}{|c|}{ Mean Fallure Lkellhood } & \multirow{2}{*}{ Description } \\
\hline & & RB & D8 & R10 & \\
\hline D-RAW1-XHE & Calculated & 1.50E-05 & Same as R6 & N/A & Failure to Diagnose Overdraining \\
\hline D-RAW2-XHE & Calculated & $5.10 E-06$ & Same as R6 & N/A & \\
\hline D-RAW3-XHE & D-RAW2-XHE & $5.10 E-06$ & Same as $R 6$ & Same as $\mathrm{R} 6$ & \\
\hline D-RAW4-XHE & Calculated & $1.10 E-06$ & Same as R6 & Same as R6 & \\
\hline A-RAW1-XHE-M-12 & Calculated & $1.10 E-04$ & Same as R6 & N/A & Fail To Makeup Given Inventory Loss \\
\hline A-RAW2-XHE-M-12 & Calculated & $2.00 E-05$ & Same as R6 & N/A & \\
\hline A-RAW3-XHE-M-12 & A-RAW2-XHE-M-12 & $2.00 \mathrm{E}-05$ & Same as R6 & Same as $\mathrm{R6}$ & \\
\hline A-RAW4-XHE-M-12 & Calculated & $6.70 E-06$ & Same as R6 & Same as R6 & \\
\hline A-RAW1-XHE-R-4 & Calculated & $1.20 E-03$ & Same as R6 & N/A & Failure To Restore RHR Given Successtul \\
\hline A-RAW2-XHE-R-4 & Calculated & $5.20 E-04$ & Same as $\mathrm{R} 6$ & N/A & Makeup \\
\hline A-RAWB-XHE-PR-4 & A-RAW2-XHE-R-4 & $5.20 E-04$ & Same as $\mathrm{R} 6$ & Same as R6 & \\
\hline A-RAW4-XHE-R-4 & Calculated & $1.20 \mathrm{E}-04$ & Same as $\mathrm{R} 6$ & Same as R6 & \\
\hline A-RAW1-XHE-SF-9 & Calculated & $1.00 E-03$ & N/A & N/A & REFLUX: Fail To Feed SGs Given Fail To Restore \\
\hline A-RAW2-XHE-SF-9 & Calculated & $1.00 E-03$ & Same as R6 & N/A & RHR but Successtul Level Control \\
\hline A-RAWB-XHE-SF-9 & A-RAW2-XHE-SF-9 & $1.00 \mathrm{E}-03$ & Same as R6 & Same as R6 & \\
\hline A-RAW4-XHE-SF-9 & Calculated & $1.00 \mathrm{E}-03$ & Same as R6 & Same as R6 & \\
\hline
\end{tabular}




\begin{tabular}{|c|c|c|c|c|c|}
\hline 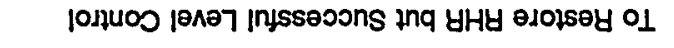 & $\forall / N$ & 94 SB owes & S0- $\exists 00^{\circ} Z$ & pojejno|вo & 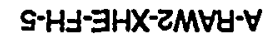 \\
\hline 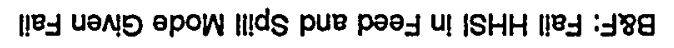 & $\forall / N$ & 9y se ours & s0- $\exists 00$ 's & pajв|пово & 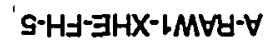 \\
\hline & 94 SB EWES & $9 y$ se ours & $80-\exists 0 Z^{\prime} \vdash$ & 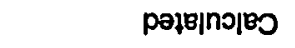 & 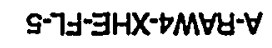 \\
\hline jodjuos $1 \theta \wedge \theta 7$ Injsseoons & 94 SB aures & $9 y$ se eures & $\varepsilon 0-\exists 0 Z ' \vdash$ & S-7 $7 y-\exists H X-Z M \forall \forall-\forall$ & $s-7 \pm-\exists H X-\varepsilon M \forall \forall-\forall$ \\
\hline 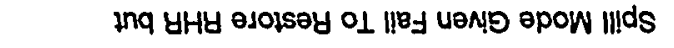 & $\forall / N$ & 9y sB owes & $80-\exists 0 z^{\prime} !$ & pojвinolвo & 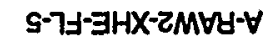 \\
\hline 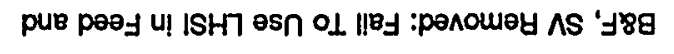 & $\forall / N$ & 9y se ewes & $80-\exists 00 \cdot 9$ & 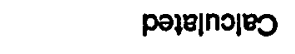 & S- $7 J-\exists H X-1 M \forall Z-\forall$ \\
\hline & 9H SB EWES & 9y se əurs & $\downarrow$ & uol!dunss $\forall$ NesuoO & $8-2 S-\exists H X-\square M V Z-\forall$ \\
\hline 1017400 $10 \wedge \theta 7$ & 94 se oures & 9y se omes & $\downarrow$ & uolydunss niesuos & $8-Z S-\exists H X-\varepsilon M \forall \forall-\forall$ \\
\hline 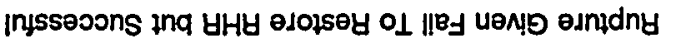 & $\forall / N$ & $9 y$ se əures & $\downarrow$ & uọldunss\} NosuoO & $8-Z S-\exists H X-Z M \forall Y-\forall$ \\
\hline & 9H SB owres & 9y SB aurs & $80-\exists 00^{\circ} \mathrm{l}$ & 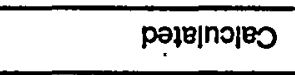 & $6-1 S-\exists H X-b M \forall Y-\forall$ \\
\hline & 94 se owes & $9 y$ SB oures & $\varepsilon 0-\exists 0^{\circ} Z$ & $6-1 S-\exists H X-Z M \forall Z-\forall$ & $6-1 S-\exists H X-8 M V Z-\forall$ \\
\hline 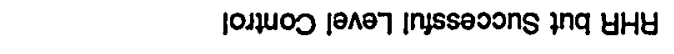 & $\forall / N$ & 9H se owes & $80-\exists 09^{\circ} Z$ & рә|в|пэвว & $6-1 S-\exists H X-Z M \forall \forall-\forall$ \\
\hline 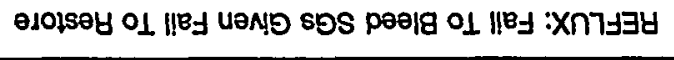 & $\forall / N$ & $\forall / N$ & $20-300^{\circ} \downarrow$ & 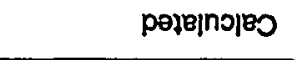 & $6-1 S-\exists H X-1 M \forall \forall-\forall$ \\
\hline & & & & & $!$ \\
\hline uonduseen & OLY & sd & 94 & \multirow{2}{*}{$8 j 889$} & \multirow{2}{*}{ uonov uвunH } \\
\hline & \multicolumn{3}{|c|}{ poou\|lesn osn } & & \\
\hline
\end{tabular}


Table 8-13 (Page 3 of 84). Quantitative Results of BNL/Surry Human Action Evaluations

\begin{tabular}{|c|c|c|c|c|c|}
\hline \multirow{2}{*}{ Human Action } & \multirow{2}{*}{ Basls } & \multicolumn{3}{|c|}{ Mean Failure Likellhood } & \multirow{2}{*}{ Description } \\
\hline & & R6 & D6 & R10 & \\
\hline A-RAW3-XHE-FH-5 & A-RAW2-XHE-FH-5 & $2.00 E-05$ & Same as $\mathrm{R} 6$ & Same as R6 & \\
\hline A-RAW4-XHE-FH-5 & Calculated & 2.00E-05 & Same as R6 & Same as R6 & \\
\hline A-RAW1-XHE-FH-10 & Calculated & $5.00 E-05$ & Same as R6 & N/A & B\&F SV Not Removed: Fail HHSI in Foed and \\
\hline A-RAW2-XHE-FH-10 & Calculated & $2.00 E-05$ & Same as R6 & N/A & Spill Given Fail To Restore RHR but Successful \\
\hline A-RAW3-XHE-FH-10 & A-RAW2-XHE-FH-10 & $2.00 E-05$ & Same as R6 & Same as R6 & Level Control; Failure of Reflux Cooling \\
\hline A-RAW4-XHE-FH-10 & A-RAW2-XHE-FH-10 & $2.00 E-05$ & Same as $\mathrm{R} 6$ & Same as R6 & \\
\hline A-RAW1-XHE-FL-10 & Calculated & $1.00 E-02$ & Same as R6 & N/A & B\&F: Fail LHSI in Feed and Spill Given Fail To \\
\hline A-RAW2-XHE-FL-10 & Calculated & $1.20 \mathrm{E}-03$ & Same as R6 & N/A & Restore RHR but Successtul Level Control; \\
\hline A-RAW3-XHE-FL-10 & A-RAW2-XHE-FL-10 & $1.20 E-03$ & Same as R6 & Same as R6 & Failure of Reflux Cooling \\
\hline A-RAW4-XHE-FL-10 & A-RAW2-XHE-FL-10 & $1.20 E-03$ & Same as R6 & Same as R6 & \\
\hline A-RAW 1-XHE-C-9 & Calculated & $1.00 E-03$ & Same as R6 & N/A & RECIRC: Fail HP Recirc with SV Not Removed \\
\hline A-RAW2-XHE-C-9 & Calculated & $1.20 \mathrm{E}-03$ & Same as R6 & N/A & Given Fail To Restore RHR \\
\hline A-RAW3-XHE-C-9 & A-RAW2-XHE-C-9 & $1.20 \mathrm{E}-03$ & N/A & Same as R6 & \\
\hline A-RAW4-XHE-C-9 & A-RAW2-XHE-C-9 & $1.20 \mathrm{E}-03$ & N/A & Same as R6 & \\
\hline
\end{tabular}


Table 8-13 (Page 4 of 84). Quantitative Results of BNL/Surry Human Action Evaluations

\begin{tabular}{|c|c|c|c|c|c|}
\hline \multirow{2}{*}{ Human Action } & \multirow{2}{*}{ Baols } & \multicolumn{3}{|c|}{ Mean Fallure Likellhood } & \multirow{2}{*}{ Doscription } \\
\hline & & R6 & D6 & R10 & \\
\hline A-RAW1-XHE-C-4 & Calculated & $1.00 E-03$ & Same as $\mathrm{R} 6$ & N/A & RECIRC: Fail HP Recire with SV Removed Given \\
\hline A-RAW2-XHE-C-4 & A-RAW1-XHE-C-4 & $1.00 E-03$ & Same as $\mathrm{R6}$ & N/A & Fail To Restore RHR \\
\hline A-RAWB-XHE-C-4 & A-RAW1-XHE-C-4 & $1.00 E-03$ & N/A & Șame as R6 & \\
\hline A-RAW4-XHE-C-4 & A-RAW1-XHE-C-4 & $1.00 E-03$ & N/A & Same as R6 & \\
\hline & . & & & & \\
\hline A-RAWZ-XHE-X & Calculated & $1.00 E-03$ & Same as R6 & N/A & Fail To Cross Connect RWST \\
\hline A-RAWB-XHE-X & A-RAW2-XHE-X & $1.00 E-03$ & Same as $\mathrm{R} 6$ & N/A & \\
\hline \\
\hline A-RAW1-XHE-P-4 & Calculated & $1.00 E-03$ & Same as R6 & N/A & RECIRC: Fall To Establish Recirc Spray \\
\hline A-RAW2-XHE-P-4 & A-RAW1-XHE-P-4 & $1.00 E-03$ & Same as R6 & N/A & \\
\hline A-RAW1-XHE-G-6 & Consen Assumption & 1 & N/A & Same as R6 & GRAVITY: Fail To Establish Gravity Feed Given \\
\hline A-RAW2-XHE-G-6 & Conserv Assumption & 1 & N/A & Same as R6 & Successtul Level Control but Fail To Restore RHR \\
\hline A-RAW3-XHE-G-6 & Conserv Assumption & 1 & N/A & Same as R6 & \\
\hline A-RAW4-XHE-G-6 & Conserv Assumption & 1 & N/A & Same as $R 6$ & \\
\hline D-RBW1-XHE & Calculated & $1.50 E-05$ & Same as R6 & N/A & Failure To Diagnose Failure To Maintain Level \\
\hline D-RBW2-XHE & Calculated & $5.10 E-06$ & Same as $\mathrm{R} 6$ & N/A & \\
\hline
\end{tabular}


Table 8-13 (Page 5 of 84). Quantitative Results of BNL/Surry Human Action Evaluations

\begin{tabular}{|c|c|c|c|c|c|}
\hline \multirow{2}{*}{ Human Action } & \multirow{2}{*}{ Baslo } & \multicolumn{3}{|c|}{ Mean Fallure Lkellhood } & \multirow{2}{*}{ Description } \\
\hline & & R8 & DB & R10 & \\
\hline D-RBW3-XHE & D-RBW2-XHE & $5.10 E-06$ & Same as $\mathrm{R} 6$ & Same as $\mathrm{R} 6$ & \\
\hline D-RBW4-XHE & Calculated & $1.10 E-06$ & Same as $\mathrm{R} 6$ & Same as $\mathrm{R} 6$ & \\
\hline A-RBW1-XHË-M-12 & A-RAW1-XHE-M-12 & $1.10 E-04$ & Same as R6 & N/A & Fail To Makeup Given Inventory Loss \\
\hline A-RBW2-XHE-M-12 & A-RAW2-XHE-M-12 & 2.00E-05 & Same as $\mathrm{R} 6$ & N/A & \\
\hline A-RBW3-XHE-M-12 & A-RAW3-XHE-M-12 & $2.00 E-05$ & Same as R6 & Same as $\mathrm{R} 6$ & \\
\hline A-RBW4-XHE-M-12 & A-RAW4-XHE-M-12 & $6.70 E-06$ & Same as R6 & Same as $\mathrm{R} 6$ & \\
\hline \\
\hline A-RBW1-XHE-R-4 & A-RAW1-XHE-R-4 & $1.20 \mathrm{E}-03$ & Same as $\mathrm{R} 6$ & N/A & Failure To Restore RHR Given Successful \\
\hline A-RBW2-XHE-R-4 & A-RAW2-XHE-R-4 & $5.20 E-04$ & Same as $\mathrm{R} 6$ & N/A & Makoup \\
\hline A-RBWB-XHE-R-4 & A-RAW3-XHE-R-4 & $5.20 E-04$ & Same as R6 & Same as $\mathrm{R} 6$ & \\
\hline A-ABW4-XHE-R-4 & A-RAW4-XHE-R-4 & $1.20 \mathrm{E}-04$ & Same as R6 & Same as $\mathrm{R} 6$ & \\
\hline A-ABW1-XHE-SF-9 & A-RAW1-XHE-SF-9 & $1.00 E-03$ & N/A & N/A & REFLUX: Fail To Feed SGs Given Fail To Restore \\
\hline A-RBW2-XHE-SF-9 & A-RAW2-XHE-SF-9 & $1.00 E-03$ & N/A & N/A & RHR but Successful Level Control \\
\hline A-RBWB-XHE-SF-9 & A-RAW3-XHE-SF-9 & $1.00 E-03$ & N/A & Same as $\mathrm{R} 6$ & \\
\hline A-RBW4-XHE-SF-9 & A-RAW4-XHE-SF-9 & $1.00 E-03$ & N/A & Same as $\mathrm{R} 6$ & \\
\hline
\end{tabular}


Table 8-13 (Page 6 of 84). Quantitative Results of BNL/Surry Human Action Evaluations

\begin{tabular}{|c|c|c|c|c|c|}
\hline \multirow{2}{*}{ Human Action } & \multirow{2}{*}{ Basls } & \multicolumn{3}{|c|}{ Mean Fallure Lkelihood } & \multirow{2}{*}{ Description } \\
\hline & & R6 & D6 & R10 & \\
\hline A-RBW1-XHE-S1-9 & A-RAW1-XHE-S1-9 & $4.00 E-02$ & N/A & N/A & REFLUX: Fail To Bleed SGs Given Fail To Restore \\
\hline A-RBW2-XHE-S1-9 & A-RAW2-XHE-S1-9 & $2.60 E-03$ & N/A & N/A & RHR but Successtul Level Control \\
\hline A-RBW3-XHE-S1-9 & A-RAW3-XHE-S1-9 & 2.60E-03 & N/A & Same as R6 & \\
\hline A-RBW4-XHE-S1-9 & A-RAW4-XHE-S1-9 & $1.00 E-03$ & N/A & Same as R6 & \\
\hline A-RBW1-XHE-S2-8 & Conserv Assumption & 1 & Same as R6 & N/A & REFLUX: Fail To Establish Reflux after PRT \\
\hline A-RBW2-XHE-S2-8 & Conserv Assumption & 1 & Same as R6 & N/A & Rupture Given Fail To Restore RHR but Successtul \\
\hline A-RBW3-XHE-S2-8 & Conserv Assumption & 1 & Same as R6 & Same as R6 & Level Control \\
\hline A-RBW4-XHE-S2-8 & Conserv Assumption & 1 & Same as $\mathrm{R} 6$ & Same as $\mathrm{R} 6$ & \\
\hline A-RBW1-XHE-FL-5 & A-RAW1-XHE-FL-5 & $5.00 E-03$ & Same as R6 & N/A & B\&F, SV Removed: Fail To Use LHSI in Feed and \\
\hline A-RBW2-XHE-FL-5 & A-RAW2-XHE-FL-5 & $1.20 E-03$ & Same as R6 & N/A & Spill Mode Given Fail To Restore RHR but \\
\hline A-RBW3-XHE-FL-5 & A-RAW3-XHE-FL-5 & $1.20 E-03$ & Same as R6 & Same as R6 & Successful Level Control \\
\hline A-RBW4-XHE-FL-5 & A-RAW4-XHE-FL-5 & $1.20 E-03$ & Same as R6 & Same as R6 & \\
\hline A-RBW1-XHE-FH-5 & A-RAW1-XHE-FH-5 & $5.00 E-05$ & Same as R6 & N/A & B\&F: Fail HHSI in Feed and Spill Mode Given Fail \\
\hline A-RBW2-XHE-FH-5 & A-RAW2-XHE-FH-5 & 2.00E-05 & Same as $\mathrm{R} 6$ & N/A & To Restore RHR but Successful Level Control \\
\hline A-RBW3-XHE-FH-5 & A-RAW3-XHE-FH-5 & 2.00E-05 & Same as $\mathrm{R} 6$ & Same as R6 & \\
\hline
\end{tabular}


Table 8-13 (Page 7 of 84). Quantitative Results of BNL/Surry Human Action Evaluations

\begin{tabular}{|c|c|c|c|c|c|}
\hline \multirow{2}{*}{ Human Action } & \multirow{2}{*}{ Basis } & \multicolumn{3}{|c|}{ Mean Failure Lkellhood } & \multirow{2}{*}{ Doscription } \\
\hline & & R6 & D6 & R10 & \\
\hline A-RBW4-XHE-FH-5 & A-RAW4-XHE-FH-5 & 2.00E-05 & Same as R6 & Same as $\mathrm{A6}$ & \\
\hline A-RBW1-XHE-FH-10 & A-RAW1-XHE-FH-10 & 5.00E-05 & Same as R6 & N/A & B\&F SV Not Removed: Fail HHSI in Feed and \\
\hline A-RBW2-XHE-FH-10 & A-RAW2-XHE-FH-10 & 2.00E-05 & Same as R6 & N/A & Spill Given Fail To Restore RHR But Successtul \\
\hline A-RBW3-XHE-FH-10 & A-RAW3-XHE-FH-10 & 2.00E-05 & Same as R6 & Same as $\mathrm{R} 6$ & Level Control; Failure of Reflux Cooling \\
\hline A-RBW4-XHE-FH-10 & A-RAW4-XHE-FH-10 & 2.00E-05 & Same as R6 & Same as $\mathrm{R} 6$ & \\
\hline A-RBW1-XHE-FL-10 & A-RAW1-XHE-FL-10 & 1.00E-02 & Same as R6 & N/A & B\&F: Fail LHSI in Feed and Spill Given Fail To \\
\hline A-RBW2-XHE-FL-10 & A-RAW2-XHE-FL-10 & $1.20 \mathrm{E}-03$ & Same as R6 & N/A & Restore RHR But Successful Level Control; \\
\hline A-RBW3-XHE-FL-10 & A-RAW3-XHE-FL-10 & $1.20 E-03$ & Same as $\mathrm{R} 6$ & Same as $\mathrm{R} 6$ & Failure of Reflux Cooling \\
\hline A-RBW4-XHE-FL-10 & A-RAW4-XHE-FL-10 & $1.20 \mathrm{E}-03$ & Same as $\mathrm{R} 6$ & Same as $\mathrm{R} 6$ & \\
\hline A-RBW 1-XHE-C-9 & A-RAW1-XHE-C-9 & $1.00 \mathrm{E}-03$ & Same as R6 & N/A & RECIRC: Fail HP Recirc with SV Not Removed \\
\hline A-RBW2-XHE-C-9 & A-RAW2-XHE-C-4 & $1.00 E-03$ & Same as R6 & N/A & Given Fail To Restore RHR \\
\hline A-RBW1-XHE-C-4 & A-RAW1-XHE-C-4 & $1.00 E-03$ & Same as R6 & N/A & RECIRC: Fall HP Recirc with SV Removed Given \\
\hline A-RBW2-XHE-C-4 & A-RAW2-XHE-C-4 & $1.00 \mathrm{E}-03$ & Same as R6 & N/A & Fail To Restore RHR \\
\hline
\end{tabular}




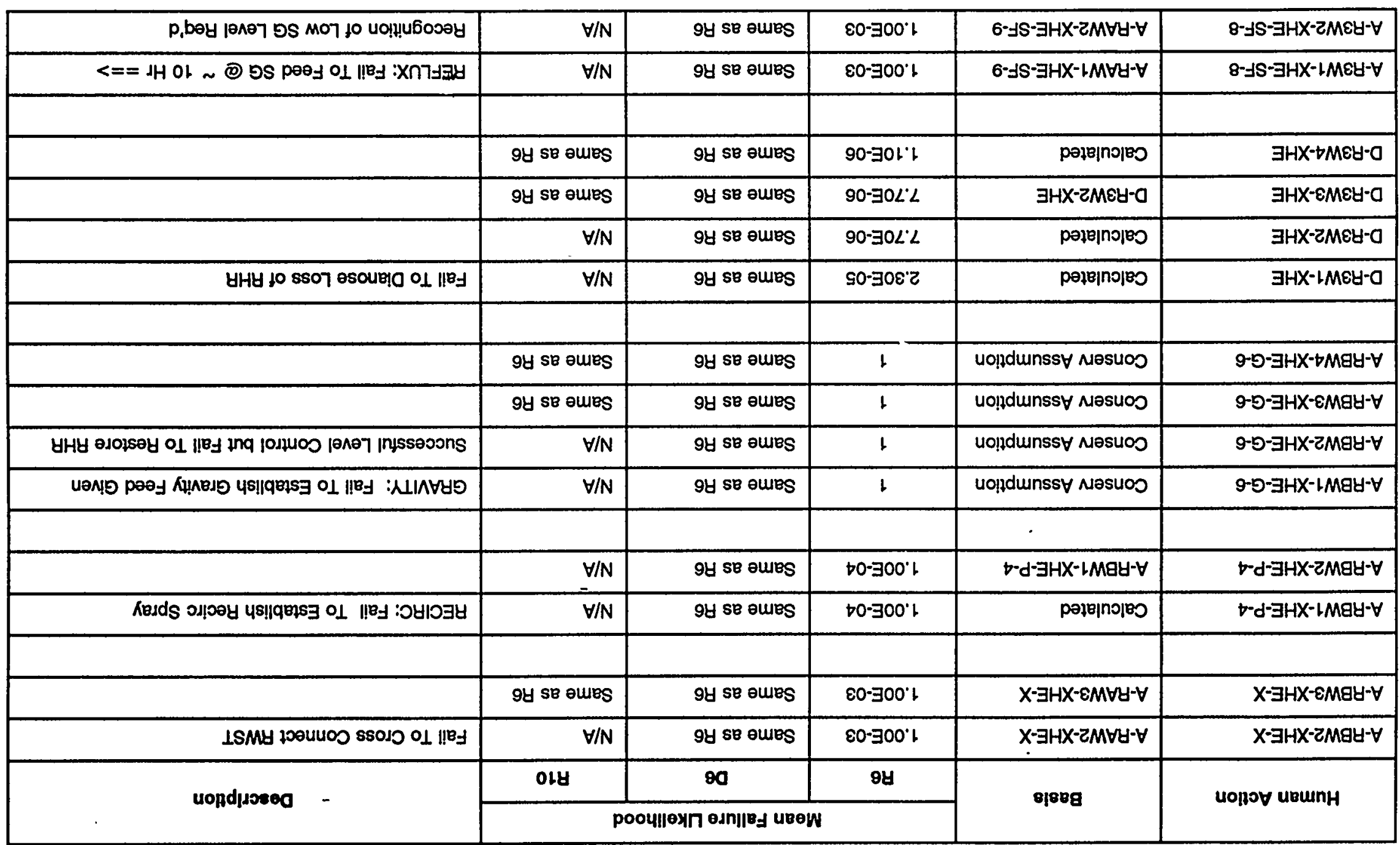


Table 8-13 (Page 9 of 84). Quantitative Results of BNL/Surry Human Action Evaluations

\begin{tabular}{|c|c|c|c|c|c|}
\hline \multirow{2}{*}{ Human Action } & \multirow{2}{*}{ Baslo } & \multicolumn{3}{|c|}{ Moan Falluro Lkellhood } & \multirow{2}{*}{ Doscription } \\
\hline & & RE & D6 & R10 & \\
\hline A-R3W3-XHE-SF-7 & A-RAWB-XHE-SF-9 & $1.00 E-03$ & Same as R6 & Same as R6 & \\
\hline A-R3W4-XHE-SF-7 & A-RAW4-XHE-SF-9 & $1.00 E-03$ & Same as R6 & Same as $\mathrm{R} 6$ & \\
\hline & & & & & 1 \\
\hline A-R3W1-XHE-S1-8 & Calculated & 4.10E-02 & N/A & N/A & REFLUX: Fail To Bleed SG via ADV -Operator \\
\hline A-R3W2-XHE-S1-8 & Calculated & 4.20E-02 & Same as R6 & N/A & will Attempt (Successful Diagnosis) \\
\hline A-R3W3-XHE-S1-7 & A-R3W2-XHE-S1-8 & 4.20E-02 & Same as R6 & N/A & \\
\hline A-R3W4-XHE-S1-7 & A-R3W2-XHE-S1-8 & 4.20E-02 & Same as R6 & Same as $\mathrm{A6}$ & \\
\hline \multicolumn{6}{|c|}{$\infty$} \\
\hline A-R3W1-XHE-S2-8 & Conserv Assumption & 1 & N/A & N/A & REFLUX: After PAT O/P, FTC PORVs \& Fail To \\
\hline A-R3W2-XHE-S2-8 & Conserv Assumption & 1 & Same as R6 & N/A & Bleed SG via ADV; Late Action in Response to \\
\hline A-R3W3-XHE-S2-7 & Conserv Assumption & 1 & Same as R6 & Same as $\mathrm{R} 6$ & PRT Rupture-Only Reasonable Scenario is that \\
\hline \multirow[t]{3}{*}{ A-R3W4-XHE-S2-7 } & Conserv Assumption & 1 & Same as R6 & Same as R6 & Operator is Distracted by HW or Other Failures. \\
\hline & & & & & PRT Rupture is Strong Cue To Move Ahead in \\
\hline & & & & & AP-27 \\
\hline \multirow[t]{3}{*}{ SSHR-AOV-XHE-105 } & Calculated & $1.30 \mathrm{E}-02$ & Same as R6 & Same as R6 & REFLUX: Fail To Est. B/P Path to cond- \\
\hline & & & & & - Operator will Attempt (Successful Diagnosis \& \\
\hline & & & & & PORV FTC) \\
\hline
\end{tabular}


Table 8-13 (Page 10 of 84). Quantitative Results of BNL/Surry Human Action Evaluations

\begin{tabular}{|c|c|c|c|c|c|}
\hline \multirow{2}{*}{ Human Actlon } & \multirow{2}{*}{ Basls } & \multicolumn{3}{|c|}{ Mean Fallure Lkellhood } & \multirow{2}{*}{ Descriptlon } \\
\hline & & R6 & D6 & R10 & \\
\hline A-R3W1-XHE-FL-4 & A-RAW1-XHE-FL-5 & $5.00 E-03$ & Same as R6 & N/A & B\&F, SV Removed $==>$ First Action. \\
\hline A-R3W2-XHE-FL-4 & A-RAW2-XHE-FL-5 & $1.20 \mathrm{E}-03$ & Same as R6 & N/A & Fail To Use LHSI F\&S - -Operator will Attempt \\
\hline A-R3W3-XHE-FL-3 & A-RAW3-XHE-FL-5 & $1.20 E-03$ & Same as R6 & Same as $\mathrm{R} 6$ & (Successful Diagnosis) \\
\hline A-R3W4-XHE-FL-3 & A-RAW4-XHE-FL-5 & $1.20 E-03$ & Same as R6 & Same as R6 & $\cdot$ \\
\hline A-R3W1-XHE-FH-4 & A-RAW 1-XHE-FH-5 & $5.00 E-05$ & Same as R6 & N/A & B\&F: Fail To Use HHSI | LHSI Failed - --Operator \\
\hline A-R3W2-XHE-FH-4 & A-RAW2-XHE-FH-5 & $2.00 E-05$ & Same as R6 & N/A & will Attempt (Successful Diagnosis \& LHSI \\
\hline A-R3W3-XHE-FH-4 & A-RAW3-XHE-FH-5 & $2.00 E-05$ & Same as R6 & Same as $\mathrm{R} 6$ & Attempted and Failed) \\
\hline A-R3W4-XHE-FH-4 & A-RAW4-XHE-FH-5 & 2.00E-05 & Same as R6 & Same as $\mathrm{R} 6$ & \\
\hline A-R3W1-XHE-FL-9 & A-RAW1-XHE-FL-10 & 1.00E-02 & Same as R6 & N/A & B\&F, SV Not Removed $==>$ Reflux Failed. \\
\hline A-R3W2-XHE-FL-9 & A-RAW2-XHE-FL-10 & $1.20 \mathrm{E}-03$ & Same as R6 & N/A & Fail To Use LHSI F\&S - --Operator will Attempt \\
\hline A-R3W3-XHE-FL-7 & A-RAW3-XHE-FL-10 & $1.20 \mathrm{E}-03$ & Same as R6 & Same as R6 & when Reflux Fails To Provide Cooling (Successful \\
\hline A-R3W4-XHE-FL-7 & A-RAW4-XHE-FL-10 & $1.20 \mathrm{E}-03$ & Same as R6 & Same as R6 & Diagnosis). Timing and Cues Worse than FL-4 \\
\hline A-R3W1-XHE-FH-9 & A-RAW1-XHE-FH-10 & $5.00 \mathrm{E}-05$ & Same as R6 & N/A & B\&Ffifail To Use HHSI | LHSI Failed - --Operator \\
\hline A-R3W2-XHE-FH-9 & A-RAW2-XHE-FH-10 & 2.00E-05 & Same as $R 6$ & N/A & will Attempt (Successful Diagnosis \& LHSI Failed) \\
\hline
\end{tabular}




\begin{tabular}{|c|c|c|c|c|c|}
\hline & $\forall / N$ & $\forall / N$ & $\forall / N$ & $\forall / N$ & $8-\supset-\exists H X-\downarrow M E \forall-\forall$ \\
\hline 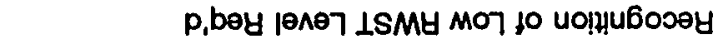 & $\forall / N$ & $\forall / N$ & $\forall / N$ & $\forall / N$ & $8-\supset-\exists H X-\varepsilon M \varepsilon \forall-\forall$ \\
\hline 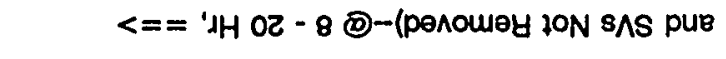 & $\forall / N$ & 9t se oures & $\varepsilon 0-\exists 00 \%$ & $D-0-\exists H X-2 M \theta \forall-\forall$ & $8-5-\exists H X-Z M E \forall-\forall$ \\
\hline \multirow[t]{2}{*}{ 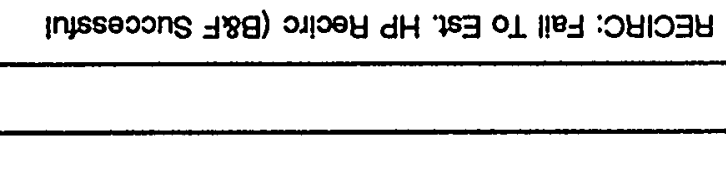 } & $\forall / N$ & 94 se oures & $80-300$ ' & $B-O-\exists H X-1 M B Z-\forall$ & $8-0-\exists H X-1 M E \theta-\forall$ \\
\hline & $\forall / N$ & $\forall / N$ & $\forall / N$ & $\forall / N$ & $\varepsilon-0-\exists H X-\triangleright M \varepsilon \forall-\forall$ \\
\hline P. bey & $\forall / N$ & $\forall / N$ & $\forall / N$ & $\forall / \mathbb{N}$ & $\varepsilon-0-\exists H X-\varepsilon M \varepsilon \forall-\forall$ \\
\hline UO!!น & $\forall / N$ & 9y se oures & $80-\exists 00^{\circ} \mathrm{L}$ & $H-O-\exists H X-Z M A Y-\forall$ & $\varepsilon-0-\exists H X-Z M \varepsilon \forall-\forall$ \\
\hline 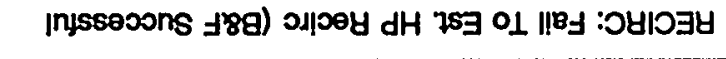 & $\forall / N$ & 9H se oures & $80-300 \%$ & $\forall-D-\exists H X-L M \forall Z-\forall$ & $\varepsilon-0-\exists H X-1 M \varepsilon \forall-\forall$ \\
\hline \multicolumn{6}{|l|}{ 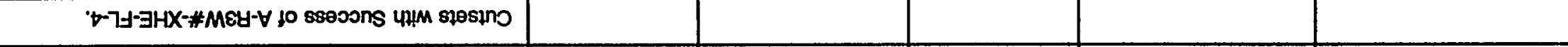 } \\
\hline 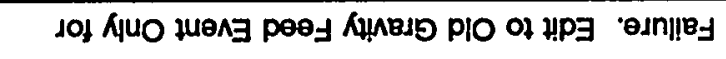 & $\forall / N$ & $\forall / N$ & 1 & uol!dunss $\forall$ Nesuos & $\nabla-\vartheta-\exists H X-t M \varepsilon \forall-\forall$ \\
\hline poofuejeng esก 'MH Ol onp po|lig IMEY & $\forall / N$ & $\forall / N$ & 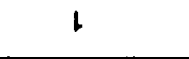 & uolgdunss $\forall$ Nesuos & $\forall-Ð-\exists H X-\varepsilon M \varepsilon \forall-\forall$ \\
\hline 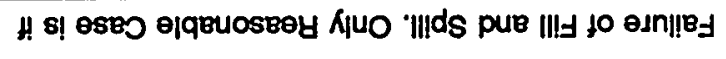 & $\forall / N$ & $\forall / N$ & 1 & uondunss $\forall$ nosuos & $S-5-\exists H X-Z M \varepsilon Y-\forall$ \\
\hline 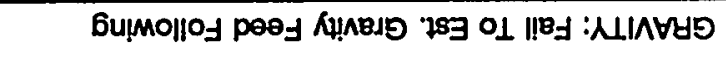 & $\forall / N$ & $\forall / N$ & 1 & uol!dunss $\forall$ Nesuos & $\varsigma-Ð-\exists H X-\vdash M \varepsilon \forall-\forall$ \\
\hline & 9y se oures & 9H SB oures & $\$ 0-\exists 000^{\circ} Z$ & $01 \cdot H \exists-\exists H X-\triangleright M \forall Z-\forall$ & $L-H y-\exists H X-\nabla M \varepsilon \forall-\forall$ \\
\hline & gy se oures & gy sB awes & $90-\exists 00^{\circ} Z$ & $01-H \exists-\exists H X-\varepsilon M \forall Z-\forall$ & $L \cdot H \exists-\exists H X-\varepsilon M E Y-\forall$ \\
\hline \multirow{2}{*}{ uopd|1,0eed } & OLty & 90 & 9y & \multirow{2}{*}{ 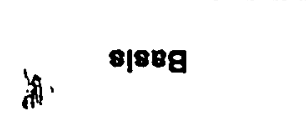 } & \multirow{2}{*}{ uopov uвwnH } \\
\hline & & nedn|fBg uBe & & & \\
\hline
\end{tabular}


Table 8-13 (Page 12 of 84). Quantitative Results of BNL/Surry Human Action Evaluations

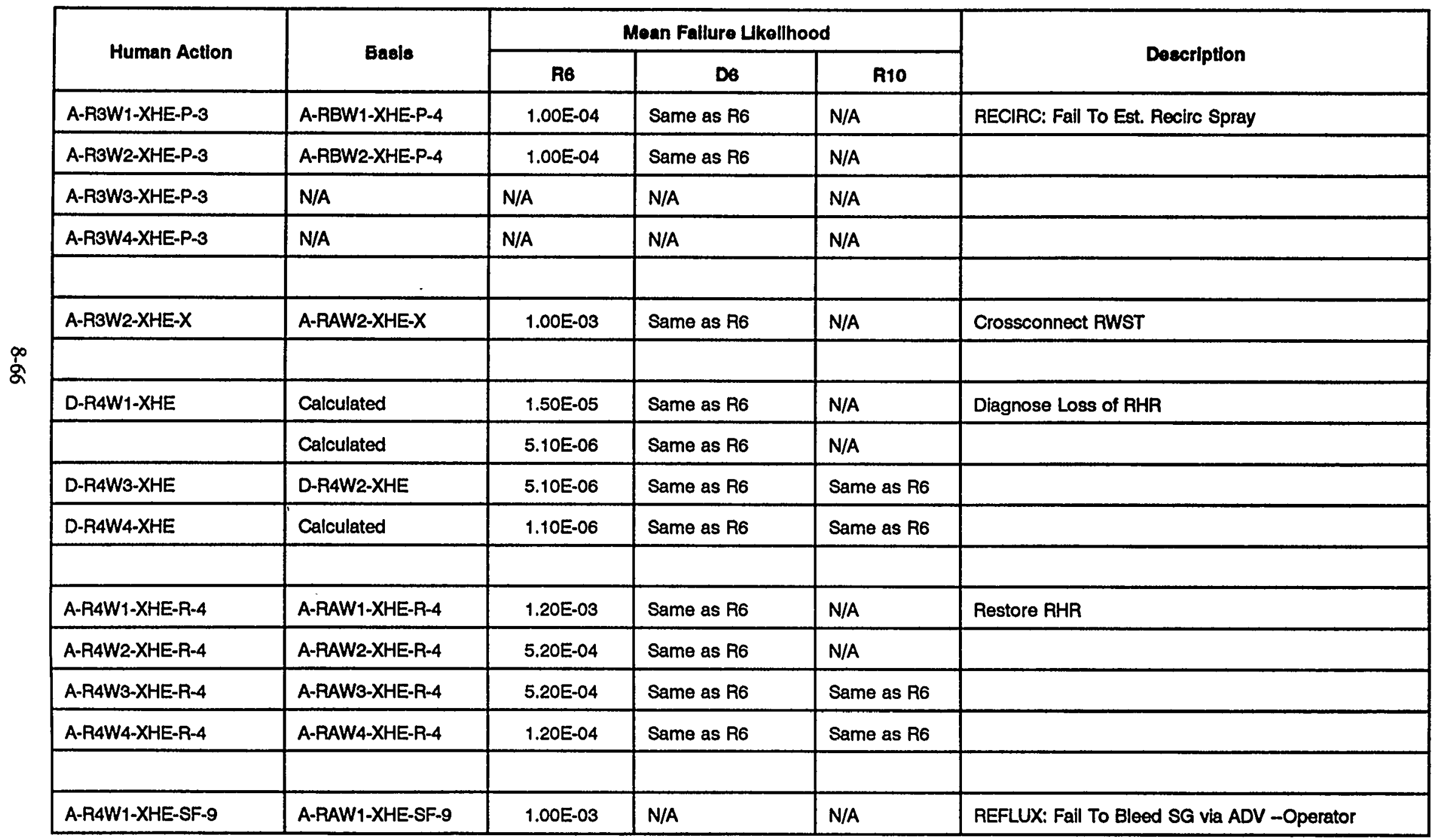


Table 8-13 (Page 13 of 84). Quantitative Results of BNL/Surry Human Action Evaluations

\begin{tabular}{|c|c|c|c|c|c|}
\hline \multirow{2}{*}{ Human Action } & \multirow{2}{*}{ Basls } & \multicolumn{3}{|c|}{ Mean Failure Likelthood } & \multirow{2}{*}{ Description } \\
\hline & & R6 & D6 & R10 & \\
\hline A-R4W2-XHE-SF-9 & A-RAW2-XHE-SF-9 & $1.00 \mathrm{E}-03$ & Same as R6 & N/A & will Attempt (Successtul Diagnosis) \\
\hline A-R4W3-XHE-SF-4 & A-RAW3-XHE-SF-9 & 1.00E-03 & Same as R6 & Same as R6 & \\
\hline A-R4W4-XHE-SF-4 & A-RAW4-XHE-SF-9 & $1.00 \mathrm{E}-03$ & Same as $\mathrm{R} 6$ & Same as $R 6$ & \\
\hline A-R4W1-XHE-S1-9 & A-RAW1-XHE-S1-9 & 4.00E-02 & N/A & N/A & REFLUX: Fail To Bleed SG via ADV --Operator \\
\hline A-R4W2-XHE-S1-9 & A-RAW2-XHE-S1-9 & $2.60 \mathrm{E}-03$ & Same as R6 & N/A & will Attempt (Successtul Diagnosis) \\
\hline A-R4W3-XHE-S1-4 & A-RAW3-XHE-S1-9 & $2.60 E-03$ & Same as R6 & Same as $\mathrm{R} 6$ & \\
\hline A-R4W4-XHE-S1-4 & A-RAW4-XHE-S1-9 & $1.00 E-03$ & Same as $\mathrm{R} 6$ & Same as $R 6$ & \\
\hline A-R4W2-XHE-S2-9 & Conserv Assumption & 1 & Same as R6 & N/A & Bleed SG via ADV; Late Action in Response to \\
\hline A-R4W3-XHE-S2-4 & Conserv Assumption & 1 & Same as $\mathrm{R} 6$ & Same as $\mathrm{R} 6$ & PRT Rupture-Only Reasonable Scenario is that \\
\hline A-R4W4-XHE-S2-4 & Conserv Assumption & 1 & Same as $\mathrm{R} 6$ & Same as R6 & Operator is Distracted by HW or Other Failures. \\
\hline & & & & & PRT Rupture is Strong Cue To Move Ahead in \\
\hline & & & & & AP-27 \\
\hline A-R4W1-XHE-FL-5 & A-RAW1-XHE-FL-5 & $5.00 E-03$ & Same as $\mathrm{R} 6$ & N/A & $\begin{array}{l}\text { Fail LHSI in Feed and Spill Mode Given Fail To } \\
\text { Restore RHR but Successful Level Control }\end{array}$ \\
\hline A-R4W2-XHE-FL-5 & A-RAW2-XHE-FL-5 & $1.20 E-03$ & Same as $\mathrm{R} 6$ & N/A & \\
\hline
\end{tabular}


Table 8-13 (Page 14 of 84). Quantitative Results of BNL/Surry Human Action Evaluations

\begin{tabular}{|c|c|c|c|c|c|}
\hline Human Actlon & Basla & \multicolumn{3}{|c|}{ Mean Fallure Likellhood } & Desteription \\
\hline A-R4W3-XHE-FL-5 & A-RAW3-XHE-FL-5 & $1.20 \mathrm{E}-03$ & Same as $R 6$ & Same as R6 & \\
\hline A-R4W4-XHE-FL-5 & A-RAW4-XHE-FL-5 & $1.20 E-03$ & Same as R6 & Same as R6 & \\
\hline $\begin{array}{c}A-R 4 W 1-X H E-F H-5 \\
-\end{array}$ & A-RAW1-XHE-FH-5 & 5.00E-05 & Same as R6 & N/A & $\begin{array}{l}\text { Fail HHSI in Feed and Spill Mode Given Fail To } \\
\text { Restore RHR but Successtul Level Control }\end{array}$ \\
\hline A-R4W2-XHE-FH-5 & A-RAW2-XHE-FH-5 & 2.00E-05 & Same as $\mathrm{R} 6$ & N/A & \\
\hline A-R4W3-XHE-FH-5 & A-RAW3-XHE-FH-5 & $2.00 E-05$ & Same as R6 & Same as R6 & \\
\hline A-R4W4-XHE-FH-5 & A-RAW4-XHE-FH-5 & $2.00 E-05$ & Same as R6 & Same as R6 & \\
\hline A-R4W2-XHE-FL-10 & A-RAW2-XHE-FL-10 & $2.00 E-05$ & Same as $\mathrm{R} 6$ & $N / A$ & \\
\hline A-R4WB-XHE-FL-7 & A-RAW3-XHE-FL-10 & 2.00E-05 & Same as R6 & Same as $R 6$ & \\
\hline A-R4W4-XHE-FL-7 & A-RAW4-XHE-FL-10 & 2.00E-05 & Same as R6 & Same as R6 & \\
\hline A-R4W1-XHE-FH-10 & Calculated & $1.00 E-02$ & Same as $R 6$ & N/A & $\begin{array}{l}\text { Fail HHSI in Feed and Spill Given Fail To Restore } \\
\text { RHR but Successful Level Control; Failure of Reflux } \\
\text { Cooling }\end{array}$ \\
\hline A-R4W2-XHE-FH-10 & Calculated & $1.20 E-03$ & Same as $R 6$ & N/A & \\
\hline
\end{tabular}


Table 8-13 (Page 15 of 84). Quantitative Results of BNL/Surry Human Action Evaluations

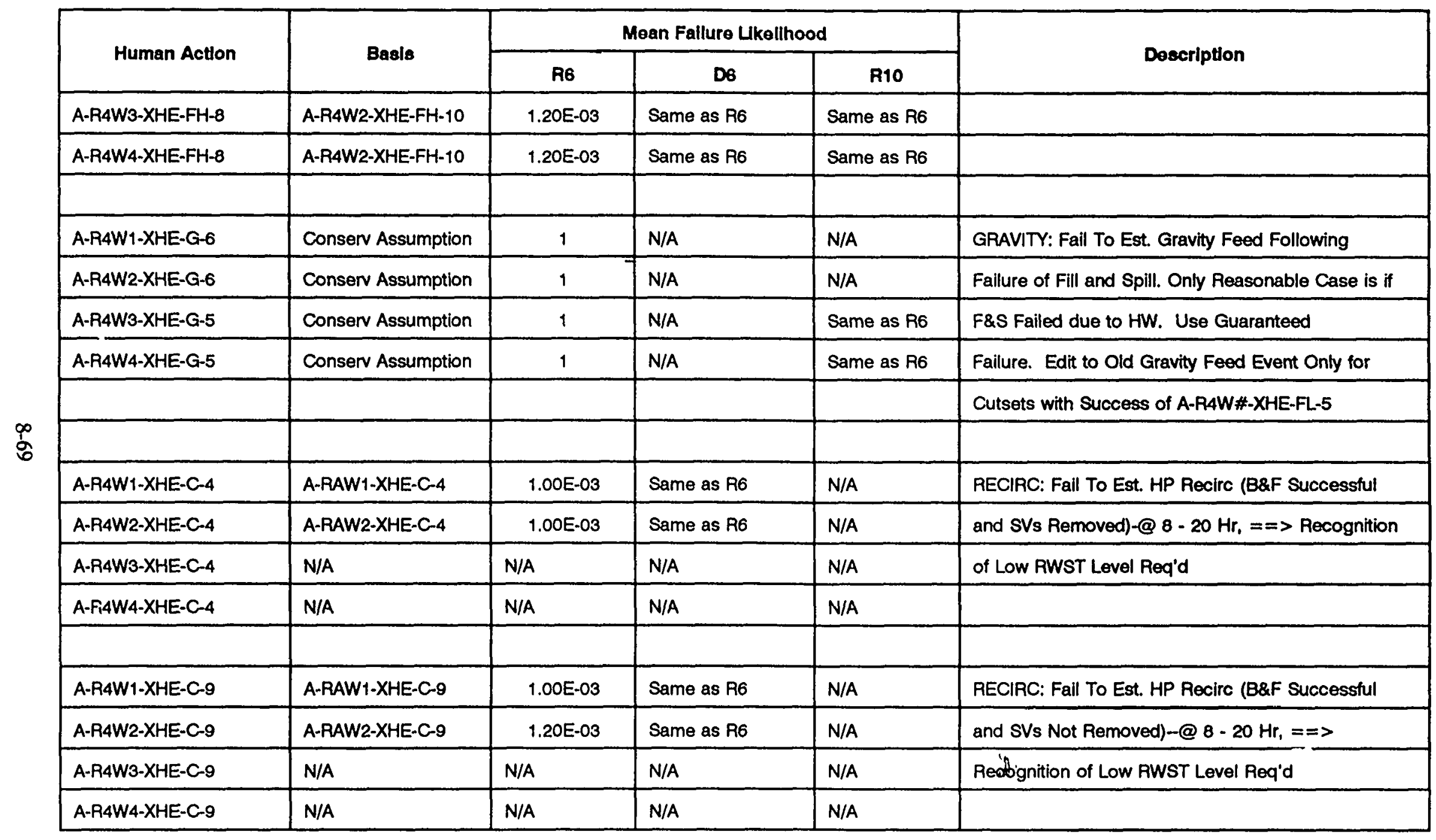


Table 8-13 (Page 16 of 84). Quantitative Results of BNL/Surry Human Action Evaluations

\begin{tabular}{|c|c|c|c|c|c|}
\hline Human Action & Basle & \multicolumn{3}{|c|}{ Mean Fallure Likellhood } & Description \\
\hline A-R4W2-XHE-P-4 & A-RBW2-XHE-P-4 & 1.00E-04 & Same as $\mathrm{R} 6$ & N/A & \\
\hline A-R4W3-XHE-P-4 & N/A & N/A & N/A & N/A & \\
\hline A-R4W1-XHE-P-9 & A-RBW1-XHE-P-4 & $1.00 E-04$ & Same as $\mathrm{R} 6$ & N/A & RECIRC: Fail To Est. Recirc Spray \\
\hline A-R4W2-XHE-P-9 & A-RBW2-XHE-P-4 & $1.00 E-04$ & Same as $\mathrm{R} 6$ & N/A & \\
\hline A-R4W3-XHE-P-9 & N/A & N/A & N/A & N/A & \\
\hline A-R4W2-XHE-X & A-RAW2-XHE-X & $1.00 \mathrm{E}-03$ & & N/A & Fail To Cross Connect RWST \\
\hline D.R5W1-XHE & Calculated & $2.30 E-05$ & Same as R6 & N/A & Diagnose Loss of RHR \\
\hline D-R5W2-XHE & Calculated & $1.20 \mathrm{E}-05$ & Same as R6 & N/A & \\
\hline D-R5W3-XHE & D-R5W2-XHE & $1.20 E-05$ & Same as $\mathrm{R} 6$ & Same as R6 & \\
\hline D-R5W4-XHE & Calculated & $1.10 E-06$ & Same as R6 & Same as $\mathrm{R} 6$ & \\
\hline
\end{tabular}


Table 8-13 (Page 17 of 84). Quantitative Results of BNL/Surry Human Action Evaluations

\begin{tabular}{|c|c|c|c|c|c|}
\hline \multirow{2}{*}{ Human Action } & \multirow{2}{*}{ Basis } & \multicolumn{3}{|c|}{ Mean Fallure Lkelihood } & \multirow{2}{*}{ Description } \\
\hline & & R6 & D6 & R10 & \\
\hline A-R5W1-XHE-R-4 & A-RAW 1-XHE-R-4 & $1.20 \mathrm{E}-03$ & Same as R6 & N/A & Fail To Restore RHR \\
\hline A-R5W2-XHE-R-4 & A-RAW2-XHE-R-4 & $5.20 \mathrm{E}-04$ & Same as R6 & N/A & \\
\hline A-R5W3-XHE-R-4 & A-RAW3-XHE-R-4 & $5.20 \mathrm{E}-04$ & Same as $R 6$ & Same as R6 & \\
\hline A-R5W4-XHE-R-5 & A-RAW4-XHE-R-4 & $1.20 \mathrm{E}-04$ & Same as R6 & Same as R6 & \\
\hline A-R5W1-XHE-SF-9 & A-RAW 1-XHE-SF-9 & $1.00 \mathrm{E}-03$ & N/A & N/A & $\begin{array}{l}\text { REFLUX: Fail To Feed SGs Given Fail To Restore } \\
\text { RHR but Successtul Level Control }\end{array}$ \\
\hline A-R5W2-XHE-SF-9 & A-RAW2-XHE-SF-9 & $1.00 \mathrm{E}-03$ & Same as R6 & N/A & \\
\hline A-R5W3-XHE-SF-6 & N/A & N/A & $\mathrm{N} / \mathrm{A}$ & N/A & \\
\hline A-R5W4-XHE-SF-6 & N/A & N/A & N/A & N/A & \\
\hline A-R5W1-XHE-S1-9 & A-RAW1-XHE-S1-9 & $4.00 E-02$ & N/A & N/A & REFLUX: Fail To Bleed SG via ADV -Operator \\
\hline A-R5W2-XHE-S1-9 & A-RAW2-XHE-S1-9 & $2.60 \mathrm{E}-03$ & Same as R6 & N/A & will Attempt (Successful Diagnosis) \\
\hline A-R5W3-XHE-S1-6 & N/A & N/A & N/A & N/A & \\
\hline A-R5W4-XHE-S1-6 & N/A & N/A & N/A & N/A & \\
\hline A-R5W1-XHE-S2-9 & Conserv Assumption & 1 & N/A & N/A & $\begin{array}{l}\text { Fair To Establish Reflux after PRT Rupture Given Fail } \\
\text { To Hestore RHR but Successful Level Control }\end{array}$ \\
\hline A-R5W2-XHE-S2-9 & Conserv Assumption & 1 & Same as $R 6$ & N/A & \\
\hline
\end{tabular}


Table 8-13 (Page 18 of 84). Quantitative Results of BNL/Surry Human Action Evaluations

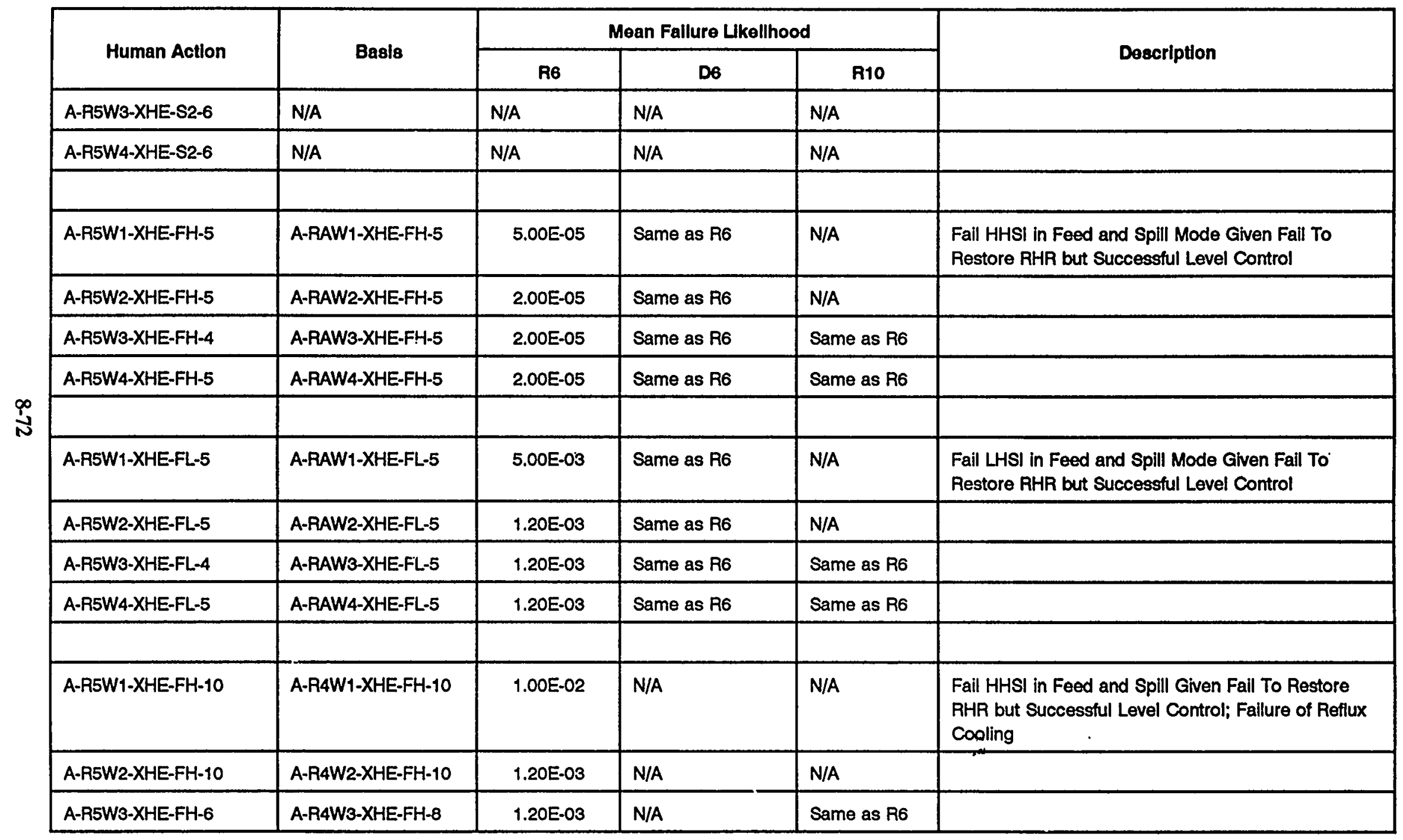


Table 8-13 (Page 19 of 84). Quantitative Results of BNU/Surry Human Action Evaluations

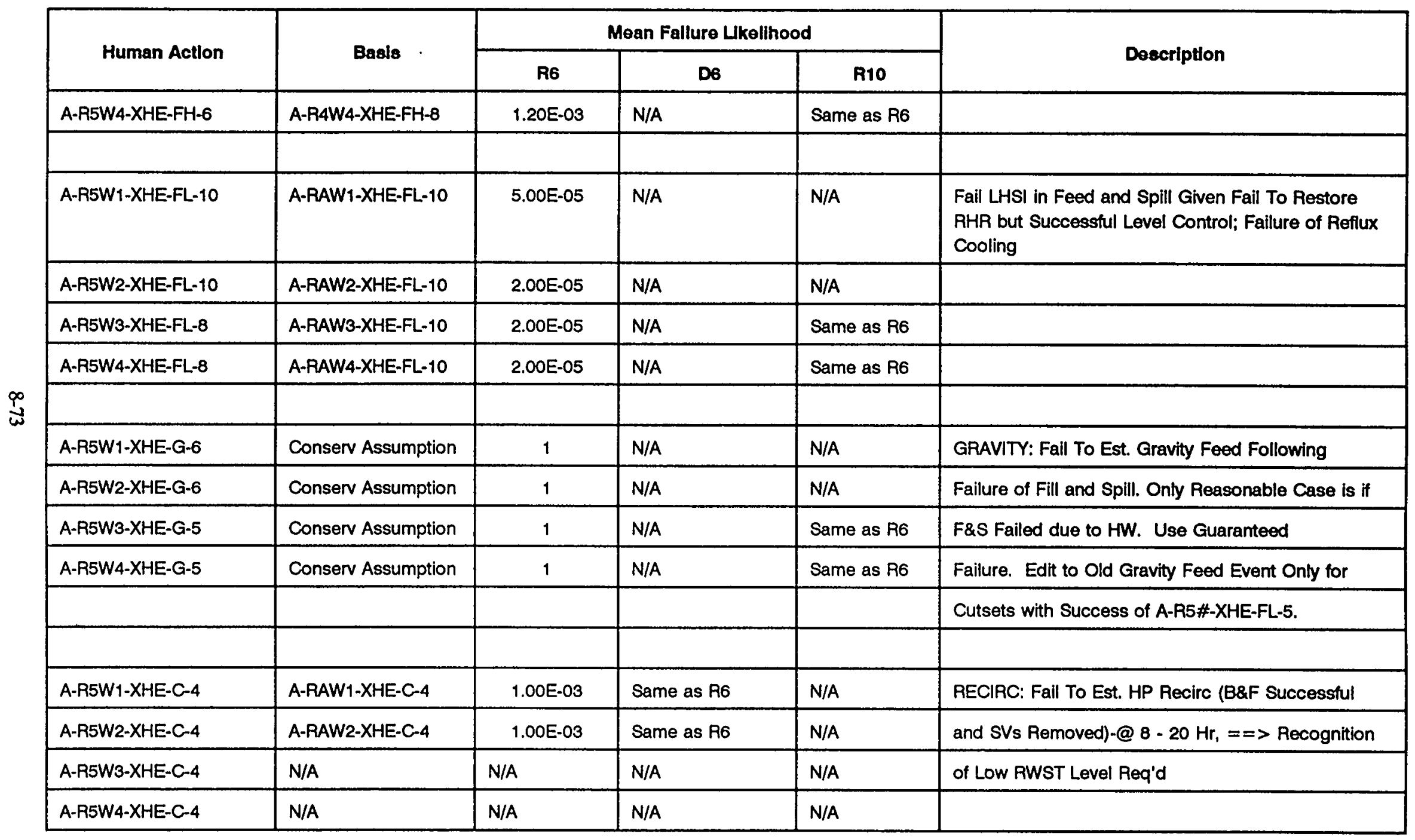


Table 8-13 (Page 20 of 84). Quantitative Results of BNL/Surry Human Action Evaluations

\begin{tabular}{|c|c|c|c|c|c|}
\hline Human Action & Basis & \multicolumn{3}{|c|}{ Mean Fallure Lkellhood } & Description \\
\hline A-R5W2-XHE-C-9 & A-RAW2-XHE-C-9 & $1.20 \mathrm{E}-03$ & Same as R6 & N/A & and SVs Not Removed)--@8-20 Hr, ==> \\
\hline A-R5W3-XHE-C-9 & N/A & N/A & N/A & N/A & Recognition of Low RWST Level Req'd \\
\hline \multirow[t]{2}{*}{ A-R5W4-XHE-C-9 } & N/A & N/A & N/A & N/A & \\
\hline & & & 1 & 1 & \\
\hline A-R5W1-XHE-P-4 & A-RBW1-XHE-P-4 & $1.00 E-04$ & Same as R6 & N/A & RECIRC: Fail To Est. Recirc Spray \\
\hline A-R5W2-XHE-P-4 & A-RBW2-XHE-P-4 & $1.00 \mathrm{E}-04$ & Same as R6 & N/A & \\
\hline A-R5W3-XHE-P-4 & N/A & N/A & N/A & N/A & \\
\hline \multirow[t]{2}{*}{ A-R5W4-XHE-P-4 } & N/A & N/A & N/A & N/A & \\
\hline & & 1 & & . & \\
\hline A-R5W1-XHE-P-9 & A-RBW1-XHE-P-4 & $1.00 \mathrm{E}-04$ & Same as $R 6$ & N/A & $\begin{array}{l}\text { REFLUX: Fail To Feed SGs Given Fail To Restore } \\
\text { RHR but Successful Level Control }\end{array}$ \\
\hline A-R5W2-XHE-P-9 & A-RBW2-XHE-P-4 & $1.00 E-04$ & Same as $\mathrm{R} 6$ & $N / A$ & \\
\hline A-R5W3-XHE-P-9 & N/A & N/A & $N / A$ & N/A & \\
\hline A-R5W4-XHE-P.9 & N/A & N/A & $N / A$ & N/A & \\
\hline & & 1 & & $\vdots$ & \\
\hline D-SIW1-XHE & Calculated & 0.00002 & Same as R6 & N/A & $\begin{array}{l}\text { Failure To Diagnose Inadvertent Safety Injection in } \\
\text { POS } 6\end{array}$ \\
\hline
\end{tabular}




\begin{tabular}{|c|c|c|c|c|c|}
\hline & $\forall / N$ & $100 \%$ & $\forall / N$ & $6-I S-3 H X-2 M S G-\forall$ & $\nabla-I S-\exists H X-t M I S-\forall$ \\
\hline & $\forall / N$ & $100 \%$ & $\forall / N$ & $6-\exists S-3 H X-2 M S Y-\forall$ & $\nabla-L S-\exists H X-\varepsilon M I S-\forall$ \\
\hline 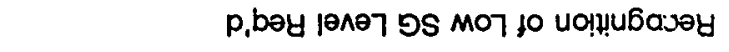 & $\forall / N$ & 94 se aures & $100^{\circ} 0$ & $6-1 S-\exists H X-2 M S 4-\forall$ & $6-1 S-\exists H X-2 M I S-\forall$ \\
\hline 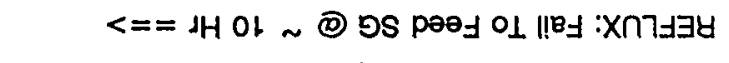 & $\forall / N$ & $\forall / N$ & $100 \cdot 0$ & $6-1 S-\exists H X-1 M S G-\forall$ & $6-1 S-\exists H X-1 M I S-\forall$ \\
\hline & 90 se ames & 90 se әures & $96000^{\prime} 0$ & peje|nગeว & $6-y-\exists r X-t M \mid S-\forall$ \\
\hline & 90 se ames & 90 se aures & $800^{\circ} 0$ & $\varepsilon l-\forall-\exists H X-Z M I S-\forall$ & $6-y-\exists H X-\varepsilon M I S-\forall$ \\
\hline & $\forall / N$ & 90 se ames & $800 \%$ & pełe!no|eว & $\varepsilon \downarrow-\psi-\exists H X-Z M I S-\forall$ \\
\hline 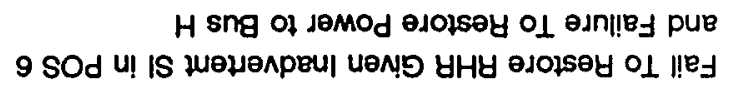 & $\forall / N$ & 90 se oures & $\$ 800^{\circ} 0$ & 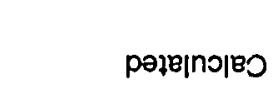 & $\varepsilon L-\forall-\exists H X-L M I S-\forall$ \\
\hline & 9d se ames & 90 se aures & $21000^{\prime} 0$ & $s-y-M H X-\triangleright M S G-\forall$ & $b-y-\exists H X-t M I S-\forall$ \\
\hline & 90 se ames & 90 sB өues & $2 s 0000^{\prime} 0$ & $D-\forall-M H X-\varepsilon M S \forall-\forall$ & $b-y-\exists H X-\varepsilon M I S-\forall$ \\
\hline & $\forall / N$ & 90 se oures & $2 \$ 000^{\circ} 0$ & $\theta-\forall-M H X-Z M S G-\forall$ & $\forall-\forall-\exists H X-Z M I S-\forall$ \\
\hline 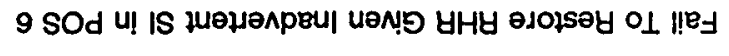 & $\forall / N$ & 90 se awes & 21000 & $\nabla-\forall-M H X-1 M S Y-\forall$ & $\nabla-\forall-\exists H X-1 M I S-\forall$ \\
\hline & $\forall / N$ & 94 SE aUres & $90-\partial+\cdot /$ & 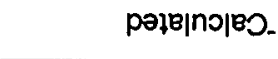 & $\exists H X-\triangleright M I S-a$ \\
\hline & $\forall / N$ & $9 y$ se awes & $10000^{\circ} 0$ & $\exists H X-Z M I S-O$ & $\exists H X-\varepsilon M I S-\sigma$ \\
\hline & $\forall / N$ & 94 se awrs & $10000^{\prime} 0$ & 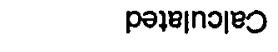 & $\exists H X-2 M I S-O$ \\
\hline undugen & ory & 90 & 98 & \multirow{2}{*}{89889} & \multirow{2}{*}{ uollo urunH } \\
\hline & \multicolumn{3}{|c|}{ 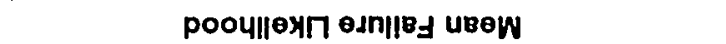 } & & \\
\hline
\end{tabular}

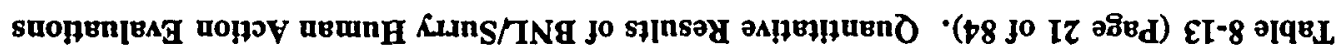




\begin{tabular}{|c|c|c|c|c|c|}
\hline & $\forall / N$ & $100 \%$ & $\forall / N$ & $6-\exists S-\exists H X-Z M S H-\forall$ & $8 L-1 S-\exists H X-t M I S-\forall$ \\
\hline & $\forall / N$ & $100 \%$ & $\forall / N$ & $6-J S-\exists H X-Z M S G-\forall$ & $8 L-L S-\exists H X-8 M I S-\forall$ \\
\hline 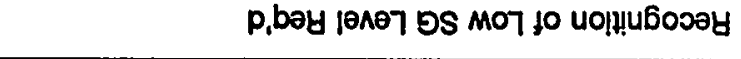 & $\forall / N$ & 9y se oures & $100^{\circ} 0$ & $6-J S-\exists H X-Z M S Y-\forall$ & $81-I S-\exists H X-Z M I S-\forall$ \\
\hline 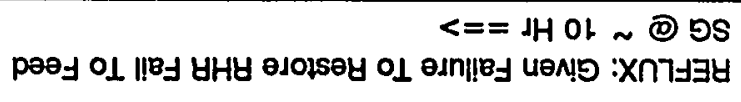 & $\forall / N$ & $\forall / N$ & $100^{\circ} 0$ & $6-J S-\exists H X-1 M S G-V$ & $8 L-L S-\exists H X-L M I S-\forall$ \\
\hline \multicolumn{6}{|l|}{$L Z \cdot d \forall$} \\
\hline \multicolumn{6}{|l|}{ 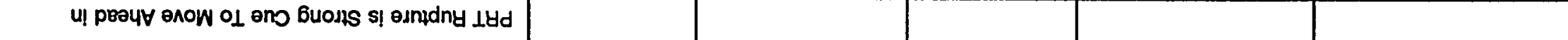 } \\
\hline 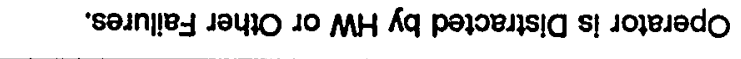 & $\forall / N$ & 1 & $\forall / N$ & uo!̣dunss $\forall$ NasuoO & $\downarrow-\varepsilon S-\exists H X-\downarrow M I S-\forall$ \\
\hline 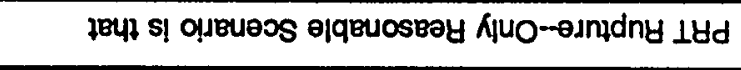 & $\forall / N$ & $\vdash$ & $\forall / N$ & uo!?dunss $\forall$ Nesuoo & $\forall-\varepsilon S-\exists H X-\varepsilon M I S-\forall$ \\
\hline 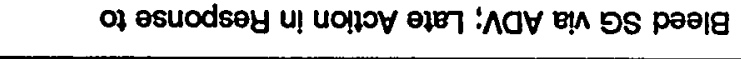 & $\forall / N$ & gy se aures & 1 & Uo!̣dunss $\forall$ NasuoO & $6-\varepsilon S-\exists H X-Z M I S-\forall$ \\
\hline 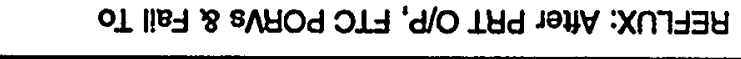 & $\forall / N$ & $\forall / N$ & 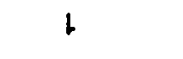 & uo!̣dunss $\forall$ NesuoO & $6-8 S-\exists H X-L M I S-\forall$ \\
\hline & $\forall / N$ & $100^{\circ} 0$ & $\forall / N$ & $6-I S-\exists H X-\downarrow M \forall \forall-\forall$ & $b-2 S-\exists H X-b M I S-\forall$ \\
\hline & $\forall / N$ & $9200^{\circ} 0$ & $\forall / N$ & $6-Z S-\exists H X-Z M I S-\forall$ & $\forall-Z S-\exists H X-E M I S-\forall$ \\
\hline 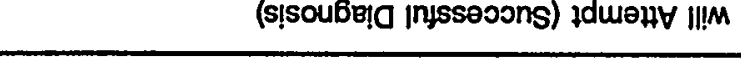 & $\forall / N$ & $9 y$ SE awrs & $9200^{\circ} 0$ & -6-เS-تHX-ZMSY- $\forall$ & $6-Z S-\exists H X-Z M I S-\forall$ \\
\hline дов. & $\forall / N$ & $\forall / N$ & $\$ 0^{\prime} 0$ & $6-1 S-\exists H X-1 M S U-\forall$ & $6-Z S-\exists H X-1 M I S-\forall$ \\
\hline \multirow{2}{*}{ uopd_10sea } & oly & 80 & 98 & \multirow{2}{*}{81889} & \multirow{2}{*}{ uopov uBunH } \\
\hline & \multicolumn{3}{|c|}{ 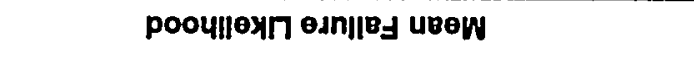 } & & \\
\hline
\end{tabular}


Table 8-13 (Page 23 of 84). Quantitative Results of BNL/Surry Human Action Evaluations

\begin{tabular}{|c|c|c|c|c|c|}
\hline \multirow{2}{*}{ Human Action } & \multirow{2}{*}{ Basls } & \multicolumn{3}{|c|}{ Mean Fallure Lkellhood } & \multirow{2}{*}{ Description } \\
\hline & & R6 & DB & R10 & \\
\hline A-SIW1-XHE-S2-18 & Calculated & 0.08 & N/A & N/A & $\begin{array}{l}\text { REFLUX: Given Failure To Restore RHR, Fail To Bleed } \\
\text { SG via ADV -Operator }\end{array}$ \\
\hline A-SIW2-XHE-S2-18 & Calculated & 0.0053 & Same as R6 & N/A & will Attempt (Successful Diagnosis) \\
\hline A-SIW3-XHE-S2-18 & A-SIW2-XHE-S2-18 & N/A & 0.0053 & N/A & \\
\hline A-SIW4-XHE-S2-18 & Calculated & N/A & 0.002 & N/A & \\
\hline A-SIW1-XHE-S3-18 & Conserv Assumption & 1 & N/A & N/A & $\begin{array}{l}\text { REFLUX: After PRT O/P Given Failure To Restore } \\
\text { RHR, FTC PORVs \& Fail To }\end{array}$ \\
\hline A-SIW2-XHE-S3-18 & Conserv Assumption & 1 & Same as R6 & N/A & Bleed SG via ADV; Late Action in Response to \\
\hline A-SIW3-XHE-S3-18 & Conserv Assumption & N/A & 1 & N/A & PRT Rupture--Only Reasonable Scenario is that \\
\hline \multirow[t]{3}{*}{ A-SIW4-XHE-S3-18 } & Conserv Assumption & N/A & 1 & N/A & Operator is Distracted by HW or Other Failures. \\
\hline & & & & & PRT Rupture is Strong Cue To Move Ahead in \\
\hline & & & & & AP-27 \\
\hline A-SIW1-XHE-FL-5 & Calculated & 0.01 & Same as R6 & $N / A$ & $\begin{array}{l}\text { Fail F\&B: SI System Recovered (Secured); RHR Not } \\
\text { Restored; SVs Removed }\end{array}$ \\
\hline A-SIW2-XHE-FL-5 & Calcuiated & 0.00076 & Same as R6 & $N / A$ & \\
\hline A-SIW3-XHE-FL-4 & A-SIW2-XHE-FL-5 & 0.00076 & Same as R6 & Same as R6 & \\
\hline A-SIW4-XHE-FL-4 & Calculated & 0.00007 & Same as R6 & Same as R6 & \\
\hline
\end{tabular}


Table 8-13 (Page 24 of 84). Quantitative Results of BNL/Surry Human Action Evaluations

\begin{tabular}{|c|c|c|c|c|c|}
\hline \multirow{2}{*}{ Human Action } & \multirow{2}{*}{ Basis } & \multicolumn{3}{|c|}{ Mean Fallure Lkelihood } & \multirow{2}{*}{ Doscription } \\
\hline & & R6 & D8 & R10 & \\
\hline A-SIW2-XHE-FL-10 & Calculated & 0.002 & Same as R6 & N/A & \\
\hline A-SIW4-XHE-FL-13 & Calculated & 0.00007 & Same as R6 & Same as $\mathrm{R6}$ & \\
\hline A-SIW1-XHE-FL-14 & Calculated & 0.061 & Same as R6 & N/A & $\begin{array}{l}\text { Fail F\&B: SI Sécured; FHR Not Restored; SVs } \\
\text { Removed }\end{array}$ \\
\hline A-SIW2-XHE-FL-14 & Calculated & 0.008 & Same as R6 & N/A & \\
\hline A-SIW1-XHE-FL-19 & A-SIW1-XHE-FL-14 & 0.061 & Same as R6 & N/A & $\begin{array}{l}\text { Fail F\&B: SI Secured; RHR Not Restored; SVs Not } \\
\text { Removed }\end{array}$ \\
\hline A-SIW2-XHE-FL-19 & A-SIW2-XHE-FL-14 & 0.013 & Same as R6 & N/A & \\
\hline A-SIW3-XHE-FL-7 & A-SIW3-XHE-FL-10 & 0.013 & Same as R6 & Same as R6 & \\
\hline A-SIW4-XHE-FL-7 & A-SIW4-XHE-FL-10 & 0.0011 & Same as $\mathrm{R} 6$ & Same as R6 & \\
\hline
\end{tabular}


Table 8-13 (Page 25 of 84). Quantitative Results of BNL/Surry Human Action Evaluations

\begin{tabular}{|c|c|c|c|c|c|}
\hline \multirow{2}{*}{ Human Action } & \multirow{2}{*}{ Basis } & \multicolumn{3}{|c|}{ Mean Fallure Likelihood } & \multirow{2}{*}{ Description } \\
\hline & & R6 & D6 & R10 & \\
\hline A-SIW1-XHE-FH-5 & A-R5W1-XHE-FH-5 & 0.00005 & Same as R6 & N/A & $\begin{array}{l}\text { Fail F\&B: SI Secured; RHR Not Restored; SVs } \\
\text { Removed }\end{array}$ \\
\hline A-SIW2-XHE-FH-5 & A-R5W2-XHE-FH-5 & 0.00002 & Same as R6 & N/A & \\
\hline A-SIW3-XHE-FH-4 & A-R5W3-XHE-FH-5 & 0.00002 & Same as R6 & Same as $\mathrm{R} 6$ & \\
\hline A-SIW4-XHE-FH-4 & A-R5W4-XHE-FH-5 & 0.00002 & Same as R6 & Same as R6 & \\
\hline A-SIW1-XHE-FH-10 & A-R5W1-XHE-FH-5 & 0.00005 & Same as $\mathrm{R} 6$ & N/A & $\begin{array}{l}\text { Fail F\&B: SI Secured; AHR Not Restored; SVs Not } \\
\text { Removed }\end{array}$ \\
\hline A-SIW2-XHE-FH-10 & A-R5W2-XHE-FH-5 & 0.00002 & Same as R6 & N/A & \\
\hline A-SIW3-XHE-FH-13 & A-R5W3-XHE-FH-5 & 0.00002 & Same as R6 & Same as R6 & \\
\hline A-SIW4-XHE-FH-13 & A-R5W4-XHE-FH-5 & 0.00002 & Same as R6 & Same as $\mathrm{R} 6$ & \\
\hline A-SIW1-XHE-FH-14 & A-R5W1-XHE-FH-5 & 0.00005 & Same as R6 & N/A & $\begin{array}{l}\text { Fail F\&B: SI Secured; RHR Not Restored; SVs } \\
\text { Removed }\end{array}$ \\
\hline A-SIW2-XHE-FH-14 & A-R5W2-XHE-FH-5 & 0.00002 & Same as $\mathrm{R} 6$ & N/A & \\
\hline A-SIW3-XHE-FH-10 & A-R5W3-XHE-FH-5 & 0.00002 & Same as R6 & Same as R6 & \\
\hline A-SIW4-XHE-FH-10 & A-R5W4-XHE-FH-5 & 0.00002 & Same as $\mathrm{R} 6$ & Same as R6 & \\
\hline A-SIW1-XHE-FH-19 & A-R5W 1-XHE-FH-5 & 0.00005 & Same as $\mathrm{R} 6$ & N/A & $\begin{array}{l}\text { Fail F\&B: SI Secured; RHR Not Restored; SVs Not } \\
\text { Removed }\end{array}$ \\
\hline
\end{tabular}


Table 8-13 (Page 26 of 84). Quantitative Results of BNL/Surry Human Action Evaluations

\begin{tabular}{|c|c|c|c|c|c|}
\hline \multirow{2}{*}{ Human Actlon } & \multirow{2}{*}{ Basls } & \multicolumn{3}{|c|}{ Mean Fallure Lkellhood } & \multirow{2}{*}{ Description } \\
\hline & & $\mathbf{R 6}$ & D6 & R10 & \\
\hline A-SIW2-XHE-FH-19 & A-R5W2-XHE-FH-5 & 0.00002 & Same as R6 & N/A & \\
\hline A-SIW3-XHE-FH-7 & A-R5WB-XHE-FH-5 & 0.00002 & Same as $\mathrm{R} 6$ & Same as $\mathrm{R} 6$ & \\
\hline A-SIW4-XHE-FH-7 & A-R5W4-XHE-FH-5 & 0.00002 & Same as R6 & Same as R6 & \\
\hline & & & & & . \\
\hline A-SIW1-XHE-G6 & Conserv Assumption & 1 & N/A & N/A & GRAVITY: Fail To Est. Gravity Feed Following \\
\hline A-SIW2-XHE-G6 & Conserv Assumption & 1 & N/A & N/A & Failure of Fill and Spill. SI Secured \\
\hline A-SIW3-XHE-G5 & Conserv Assumption & 1 & N/A & Same as R6 & \\
\hline A-SIW4-XHE-G5 & Conserv Assumption & 1 & N/A & Same as R6 & \\
\hline A-SIW2-XHE-G15 & Conserv Assumption & 1 & N/A & N/A & Failure of Fill and Spill. Si Continues \\
\hline A-SIW3-XHE-G11 & Conserv Assumption & 1 & N/A & Same as $\mathrm{R} 6$ & \\
\hline A-SIW4-XHE-G11 & Conserv Assumption & 1 & N/A & Same as R6 & \\
\hline A-SIW1-XHE-C-4 & A-R5W1-XHE-C-4 & 0.001 & Same as R6 & N/A & $\begin{array}{l}\text { RECIRC: Fail To Est. HP Recirc (SI Secured, B\&F } \\
\text { Successful) }\end{array}$ \\
\hline A-SIW2-XHE-C-4 & A-R5W2-XHE-C-4 & 0.001 & Same as R6 & N/A & and (j) Removed)-@ $8-20 \mathrm{Hr}_{1}==>$ Recognition \\
\hline A-SIW3-XHE-C-4 & N/A & N/A & N/A & N/A & of Low RWST Level Req'd \\
\hline A-SIW4-XHE-C-4 & N/A & N/A & N/A & N/A & \\
\hline
\end{tabular}


Table 8-13 (Page 27 of 84). Quantitative Results of BNL/Surry Human Action Evaluations

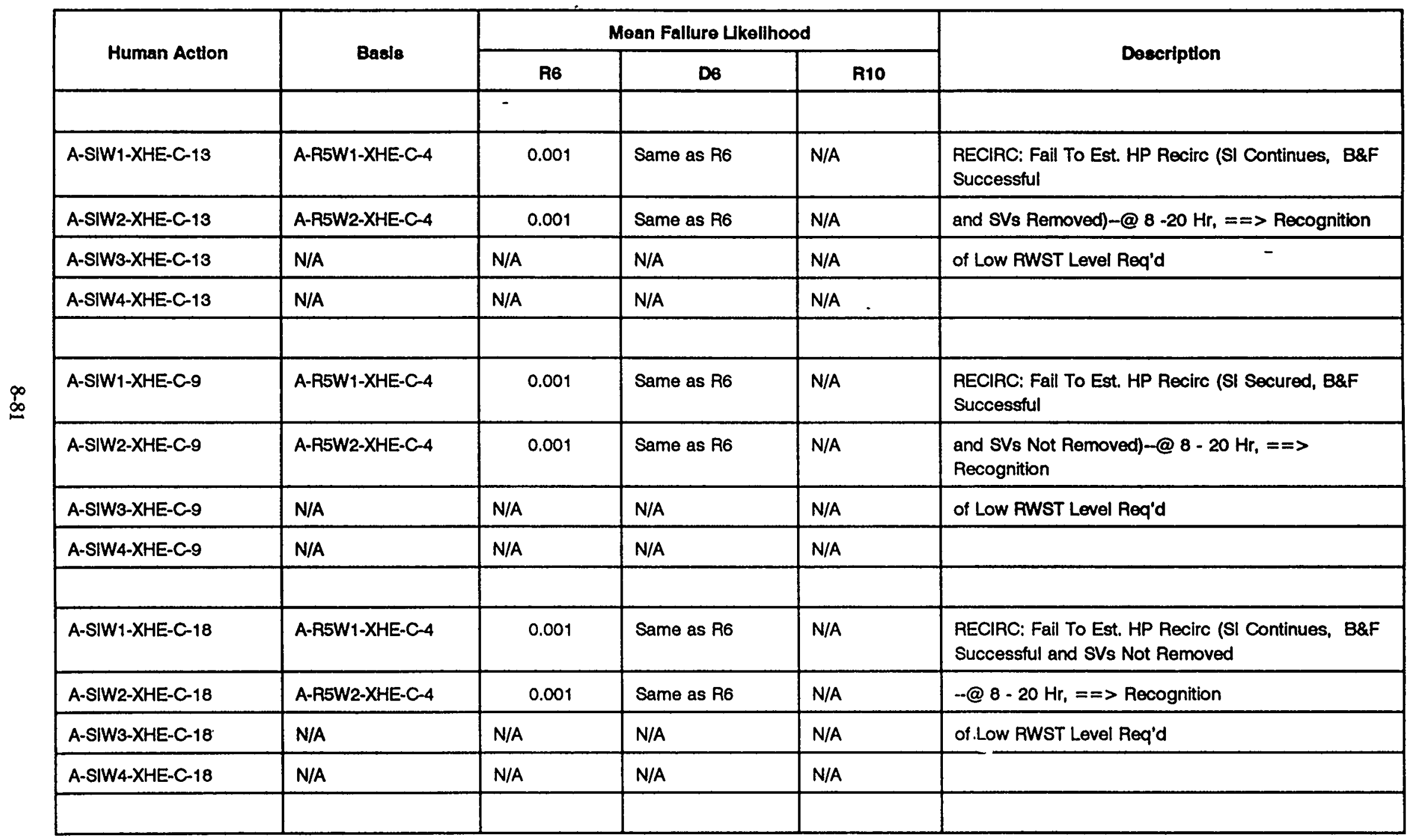


Table 8-13 (Page 28 of 84). Quantitative Results of BNL/Surry Human Action Evaluations

\begin{tabular}{|c|c|c|c|c|c|}
\hline \multirow{2}{*}{ Human Action } & \multirow{2}{*}{ Bagis } & \multicolumn{3}{|c|}{ Moan Fallure Lkkelihood } & \multirow{2}{*}{ Description } \\
\hline & & R6 & $-\quad D 6$ & R10 & \\
\hline A-SIW2-XHE-X & A-RAW2-XHE-X & 0.001 & Same as R6 & N/A & \\
\hline A-SIW1-XHE-P-4 & A-R5W1-XHE-P-4 & 0.0001 & Same as R6 & N/A & $\begin{array}{l}\text { RECIRC: Fail To Est. Recirc Spray (SI Secured, B\&F } \\
\text { Successful and SVs Not Removed) }\end{array}$ \\
\hline A-SIW2-XHE-P-4 & A-R5W2-XHE-P-4 & 0.0001 & Same as R6 & N/A & \\
\hline A-SIW3-XHE-P-4 & N/A & N/A & N/A & N/A & \\
\hline A-SIW4-XHE-P-4 & N/A & N/A & N/A & N/A & \\
\hline A-SIW1-XHE-P-13 & A-R5W1-XHE-P-4 & 0.0001 & Same as R6 & N/A & $\begin{array}{l}\text { RECIRC: Fail To Est. Recirc Spray (SI Continues, } \\
\text { B\&F Successful and SVs Not Removed) }\end{array}$ \\
\hline A-SIW2-XHE-P-13 & A-R5W2-XHE-P-4 & 0.0001 & Same as R6 & N/A & \\
\hline A-SIW3-XHE-P-13 & N/A & N/A & N/A & N/A & \\
\hline A-SIW4-XHE-P-13 & N/A & N/A & N/A & N/A & \\
\hline A-SIW1-XHE-P-9 & A-R5W 1-XHE-P-4 & 0.0001 & Same as R6 & N/A & $\begin{array}{l}\text { RECIRC: Fail To Est. Recirc Spray (SI Secured, B\&F } \\
\text { Successful and SVs Not Removed) }\end{array}$ \\
\hline A-SIW2-XHE-P-9 & A-R5W2-XHE-P-4 & 0.0001 & Same as R6 & N/A & \\
\hline A-SIW3-XHE-P-9 & N/A & N/A & N/A & N/A & \\
\hline A-SIW4-XHE-P-9 & N/A & N/A & N/A & N/A & \\
\hline
\end{tabular}


Table 8-13 (Page 29 of 84). Quantitative Results of BNL/Surry Human Action Evaluations

\begin{tabular}{|c|c|c|c|c|c|}
\hline \multirow{2}{*}{ Human Action } & \multirow{2}{*}{ Basis } & \multicolumn{3}{|c|}{ Mean Fallure Likellhood } & \multirow{2}{*}{ Description } \\
\hline & & R6 & D6 & R10 & \\
\hline A-SIW1-XHE-P-18 & A-RSW1-XHE-P-4 & 0.0001 & Same as $\mathrm{R} 6$ & N/A & $\begin{array}{l}\text { RECIRC: Fail To Est. Recirc Spray (SI Continues, } \\
\text { B\&F Successful and SVs Not Removedo }\end{array}$ \\
\hline A-SIW2-XHE-P-18 & A-R5W2-XHE-P-4 & 0.0001 & Same as R6 & N/A & \\
\hline A-SIW3-XHE-P-18 & N/A & N/A & N/A & N/A & \\
\hline A-SIW4-XHE-P-18 & N/A & N/A & N/A & N/A & \\
\hline D-CCW1-XHE & Calculated & $2.30 \mathrm{E}-05$ & Same as R6 & N/A & Fail To Diagnose Loss of Component Cooling Water \\
\hline D-CCW2-XHE & Calculated & 7.70E-06 & Same as R6 & N/A & \\
\hline D-CCW3-XHE & D.CCW2-XHE & 7.70E-06 & Same as $\mathrm{R} 6$ & Same as $\mathrm{A6}$ & \\
\hline D-CCW4-XHE & Calculated & 1.10E-06 & Same as $\mathrm{R6}$ & Same as R6 & \\
\hline A-CCW1-XHE-HCC & Not HRA based & & & N/A & Fail To locally Recover Air to HX Valves \\
\hline A-CCW2-XHE-HCC & Not HRA based & & & N/A & $\begin{array}{l}\text { NOTE: Based on Review of Data Presented } \\
\text { Elsewhere in this Report }\end{array}$ \\
\hline A-CCW3-XHE-HCC & Not HRA based & & & & \\
\hline A-CCW4-XHE-HCC & Not HRA based & & & & \\
\hline A-CCW1-XHE-SF-8 & A-R5W 1-XHE-SF-9 & $1.00 E-03$ & N/A & N/A & REFLUX: Fail To Foed SG @ $10 \mathrm{Hr}=x>$ \\
\hline
\end{tabular}


Table 8-13 (Page 30 of 84). Quantitative Results of BNL/Surry Human Action Evaluations

\begin{tabular}{|c|c|c|c|c|c|}
\hline \multirow{2}{*}{ Human Action } & \multirow{2}{*}{ Basis } & \multicolumn{3}{|c|}{ Mean Fallure Ukelihood } & \multirow{2}{*}{ Doscription } \\
\hline & & R6 & DB & R10 & \\
\hline A-CCW2-XHE-SF-8 & A-R5W2-XHE-SF-9 & $1.00 \mathrm{E}-03$ & $1.00 \mathrm{E}-03$ & N/A & Recognition of Low SG Level Req'd \\
\hline A-CCWB-XHE-SF-7 & A-R5W2-XHE-SF-9 & N/A & $1.00 \mathrm{E}-03$ & N/A & \\
\hline A-CCW4-XHE-SF-7 & A-R5W2-XHE-SF-9 & N/A & $1.00 E-03$ & N/A & \\
\hline A-CCW1-XHE-S1-8 & Calculated & 4.10E-02 & N/A & N/A & REFLUX: Fail To Bleed SG via ADV -Operator \\
\hline A-CCW2-XHE-S1-8 & A-CCW1-XHE-S1-8 & 4.20E-02 & 4.20E-02 & N/A & will Attempt (Successful Diagnosis) \\
\hline A-CCWB-XHE-S1-7 & A-CCW1-XHE-S1-8 & N/A & 4.20E-02 & N/A & \\
\hline A-CCW4-XHE-S1-7 & A-CCW1-XHE-S1-8 & N/A & 4.20E-02 & N/A & \\
\hline A-CCW1-XHE-S2-8 & Conserv Assumption & 1 & N/A & N/A & REFLUX: Atter PRT O/P, FTC PORVs \& Fail To \\
\hline A-CCW2-XHE-S2-8 & Conserv Assumption & 1 & 1 & N/A & Bleed SG via ADV; Late Action in Response to \\
\hline A-CCW3-XHE-S2-7 & Conserv Assumption & N/A & 1 & N/A & PRT Rupture-Only Reasonable Scenario is that \\
\hline A-CCW4-XHE-S2-7 & Conserv Assumption & N/A & 1 & N/A & Operator is Distracted by HW or Other Failures. \\
\hline & & & & & PRT Rupture is Strong Cue To Move Ahead in \\
\hline & & & & & AP-27 \\
\hline A-CCW1-XHE-FL-7 & A-R5W1-XHE-FL-5 & $5.00 E-03$ & Same as R6 & N/A & B\&F Fail To Use LHSI \\
\hline A-CCW2-XHE-FL-7 & A-R5W2-XHE-FL-5 & $1.20 E-03$ & Same as $\mathrm{R} 6$ & N/A & \\
\hline
\end{tabular}


Table 8-13 (Page 31 of 84). Quantitative Results of BNL/Surry Human Action Evaluations

\begin{tabular}{|c|c|c|c|c|c|}
\hline \multirow{2}{*}{ Human Action } & \multirow{2}{*}{ Basls } & \multicolumn{3}{|c|}{ Mean Fallure Ukellhood } & \multirow{2}{*}{ Description } \\
\hline & & R6 & D8 & $\mathbf{R 1 0}$ & \\
\hline A-CCW3-XHE-FL-7 & A-R5W3-XHE-FL-4 & $1.20 \mathrm{E}-03$ & Same as R6 & Same as R6 & \\
\hline A-CCW4-XHE-FL-7 & A-R5W4-XHE-FL-5 & $1.20 E-03$ & Same as R6 & Same as R6 & \\
\hline A-CCW1-XHE-FH-5 & A-R5W1-XHE-FH-5 & $5.00 E-05$ & Same as R6 & N/A & B\&F: Fail To Use HHSI \\
\hline A-CCW2-XHE-FH-5 & A-R5W2-XHE-FH-5 & 2.00E-05 & Same as R6 & N/A & \\
\hline A-CCW3-XHE-FH-5 & A-R5W3-XHE-FH-4 & 2.00E-05 & Same as R6 & Same as R6 & \\
\hline A-CCW4-XHE-FH-5 & A-R5W4-XHE-FH-5 & 2.00E-05 & Same as $\mathrm{R} 6$ & Same as R6 & \\
\hline \\
\hline A-CCW1-XHE-FL-10 & A-R5W1-XHE-FL-10 & $1.00 E-02$ & Same as $\mathrm{R} 6$ & N/A & Fail Low Pressure F\&B Given SVs in Place \\
\hline A-CCW2-XHE-FL-10 & A-R5W2-XHE-FL-10 & $1.20 E-03$ & Same as R6 & N/A & \\
\hline A-CCW3-XHE-FL-10 & A-R5W3-XHE-FL-8 & $1.20 E-03$ & Same as R6 & Same as R6 & \\
\hline A-CCW4-XHE-FL-10 & A-R5W4-XHE-FL-8 & $1.20 \mathrm{E}-03$ & Same as R6 & Same as R6 & \\
\hline A-CCW1-XHE-FH-10 & A-R5W1-XHE-FH-5 & 5.00E-05 & Same as R6 & N/A & Fail High Pressure F\&B Given SVs in Place \\
\hline A-CCW2-XHE-FH-10 & A-R5W2-XHE-FH-5 & $2.00 E-05$ & Same as R6 & N/A & \\
\hline A-CCW3-XHE-FH-10 & A-R5W3-XHE-FH-5 & 2.00E-05 & Same as R6 & Same as R6 & \\
\hline A-CCW4-XHE-FH-10 & A-R5W4-XHE-FH-5 & $2.00 E-05$ & Same as R6 & Same as R6 & \\
\hline
\end{tabular}


Table 8-13 (Page 32 of 84). Quantitative Results of BNL/Surry Human Action Evaluations

\begin{tabular}{|c|c|c|c|c|c|}
\hline Human Action & Basls & \multicolumn{3}{|c|}{ Mean Failure Lkelihood } & Descriptlon \\
\hline A-CCW1-XHE-G-6 & Conserv Assumption & 1 & N/A & N/A & GRAVITY: Fail To Est. Gravity Feed Following \\
\hline A-CCWB-XHE-G-6 & Conserv Assumption & 1 & N/A & Same as $\mathrm{R} 6$ & \\
\hline A-CCW4-XHE-G-6 & Conserv Assumption & 1 & N/A & Same as R6 & \\
\hline A-COW1-XHE-C-4 & A-R5W1-XHE-C-4 & 1.00E-03 & Same as R6 & N/A & RECIRC: Fail To Est. HP Recirc \\
\hline A-CCW2-XHE-C-4 & A-R5W2-XHE-C-4 & 1.00E-03 & Same as R6 & N/A & \\
\hline A-CCW3-XHE-C-4 & N/A & N/A & N/A & N/A & \\
\hline A-CCW4-XHE-C-4 & N/A & N/A & N/A & N/A & \\
\hline A-CCW3-XHE-C-9 & N/A & N/A & N/A & N/A & Recognition of Low RWST Level Req'd \\
\hline A-CCW4-XHE-C-9 & N/A & N/A & N/A & N/A & \\
\hline A-CCW2-XHE-X & A-RAW2-XHE-X & $1.00 E-03$ & Same as R6 & N/A & Fail To Cross Tie RWST \\
\hline A-CCW1-XHE-P-4 & A-R5W1-XHE-P-4 & $1.00 E-04$ & Same as R6 & N/A & RECIRC: Fail To Est. Recirc Spray \\
\hline
\end{tabular}


Table 8-13 (Page 33 of 84). Quantitative Results of BNL/Surry Buman Action Evaluations

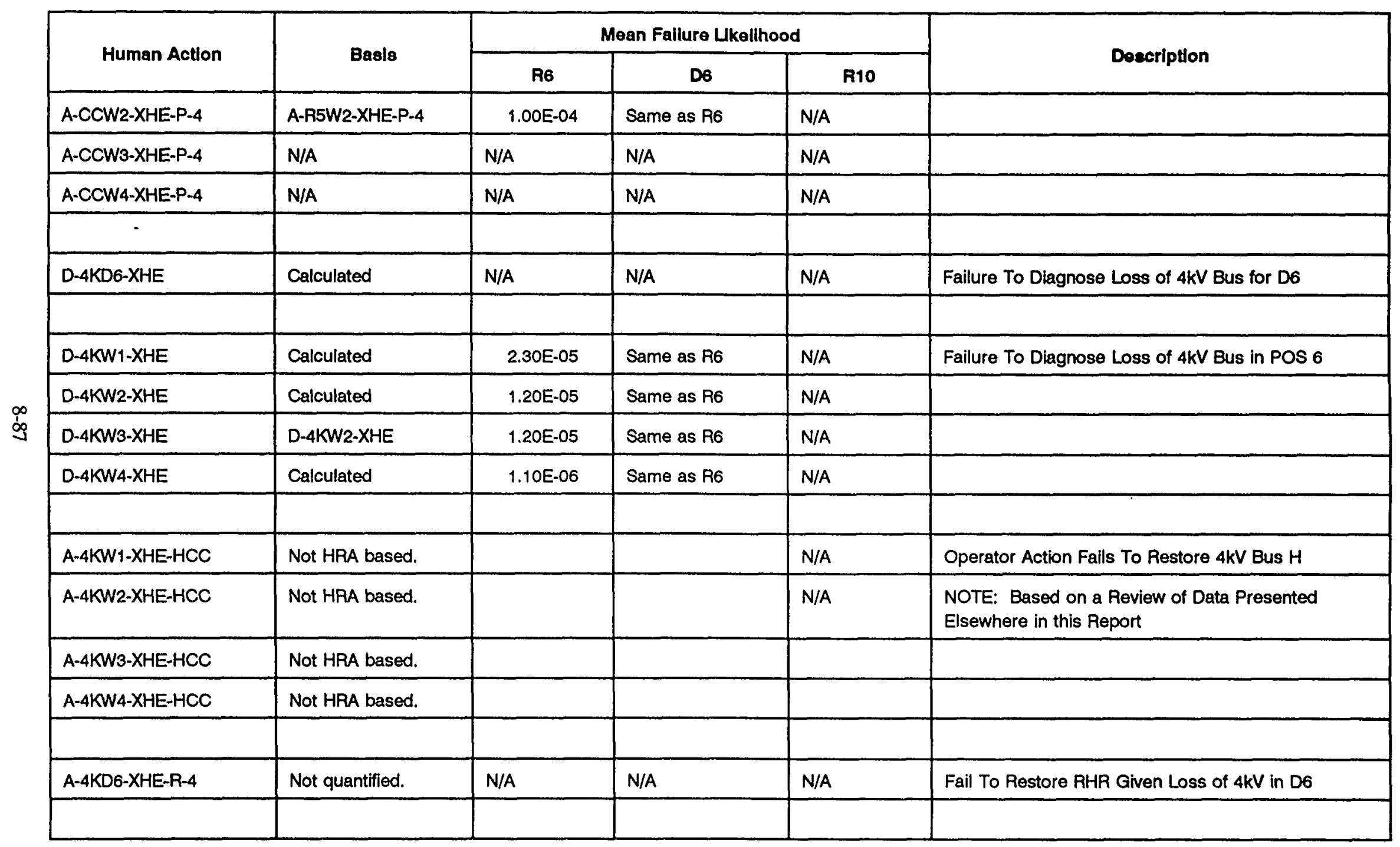


Table 8-13 (Page 34 of 84). Quantitative Results of BNL/Surry Human Action Evaluations

\begin{tabular}{|c|c|c|c|c|c|}
\hline \multirow{2}{*}{ Human Action } & \multirow{2}{*}{ Basle } & \multicolumn{3}{|c|}{ Mean Fallure Lkellhood } & \multirow{2}{*}{ Description } \\
\hline & & R6 & D6 & R10 & \\
\hline$A-4 K W 1-X H E-R-3$ & A-R5W1-XHE-R-4 & $1.20 E-03$ & Same as D6 & N/A & Fail To Restore RHR Given Loss of $4 \mathrm{kV}$ in POS 6 \\
\hline A-4KW2-XHE-R-3 & A-R5W2-XHE-R-4 & $5.20 E-04$ & Same as D6 & N/A & \\
\hline A-4KWB-XHE-R-3 & A-R5W3-XHE-R-4 & $5.20 \mathrm{E}-04$ & Same as D6 & Same as D6 & \\
\hline A-4KW4-XHE-R-3 & A-R5W4-XHE-R-5 & $1.20 E-04$ & Same as D6 & Same as D6 & \\
\hline$A-4 K W 1-X H E-R-12$ & Calculated & 8.50E-03 & Same as D6 & N/A & $\begin{array}{l}\text { Fail To Restore RHR Given Loss of } 4 \mathrm{kV} \text { in POS } 6 \text { and } \\
\text { Failure To Restore Power to Bus H }\end{array}$ \\
\hline A-4KW2-XHE-R-12 & Calculated & 3.00E-03 & Same as D6 & N/A & \\
\hline A-4KW3-XHE-R-9 & $A-4 K W 2-X H E-R-12$ & 3.00E-03 & Same as D6 & Same as D6 & \\
\hline A-4KW4-XHE-R-9 & Calculated & 9.60E-04 & Same as D6 & Same as D6 & \\
\hline$A-4 K W 1-X H E-S 1-8$ & A-R5W1-XHE-SF-9 & $1.00 E-03$ & N/A & N/A & REFLUX: Fall To Feed SG @ $10 \mathrm{Hr}==>$ \\
\hline A-4KW2-XHE-S1-8 & A-R5W2-XHE-SF-9 & $1.00 E-03$ & Same as $\mathrm{R} 6$ & N/A & Recognition of Low SG Level Reg'd \\
\hline A-4KWB-XHE-S1-8 & A-R5W2-XHE-SF-9 & N/A & $1.00 \mathrm{E}-03$ & N/A & \\
\hline A-4KW4-XHE-S1-8 & A-R5W2-XHE-SF-9 & N/A & $1.00 \mathrm{E}-03$ & N/A & \\
\hline$A-4 K W 1-X H E-S 2-8$ & A-RAW1-XHE-S1-9 & 4.00E-02 & N/A & N/A & REFLUX: Fall To Bleed SG via ADV -Operator \\
\hline A-4KW2-XHE-S2-8 & A-RAW2-XHE-S1-9 & 2.60E-03 & Same as R6 & N/A & will Attempt (Successful Dlagnosis) \\
\hline A-4KWB-XHE-S2-8 & A-RAW3-XHE-S1-9 & N/A & $2.60 \mathrm{E}-03$ & N/A & \\
\hline
\end{tabular}


Table 8-13 (Page 35 of 84). Quantitative Results of BNL/Surry Human Action Evaluations

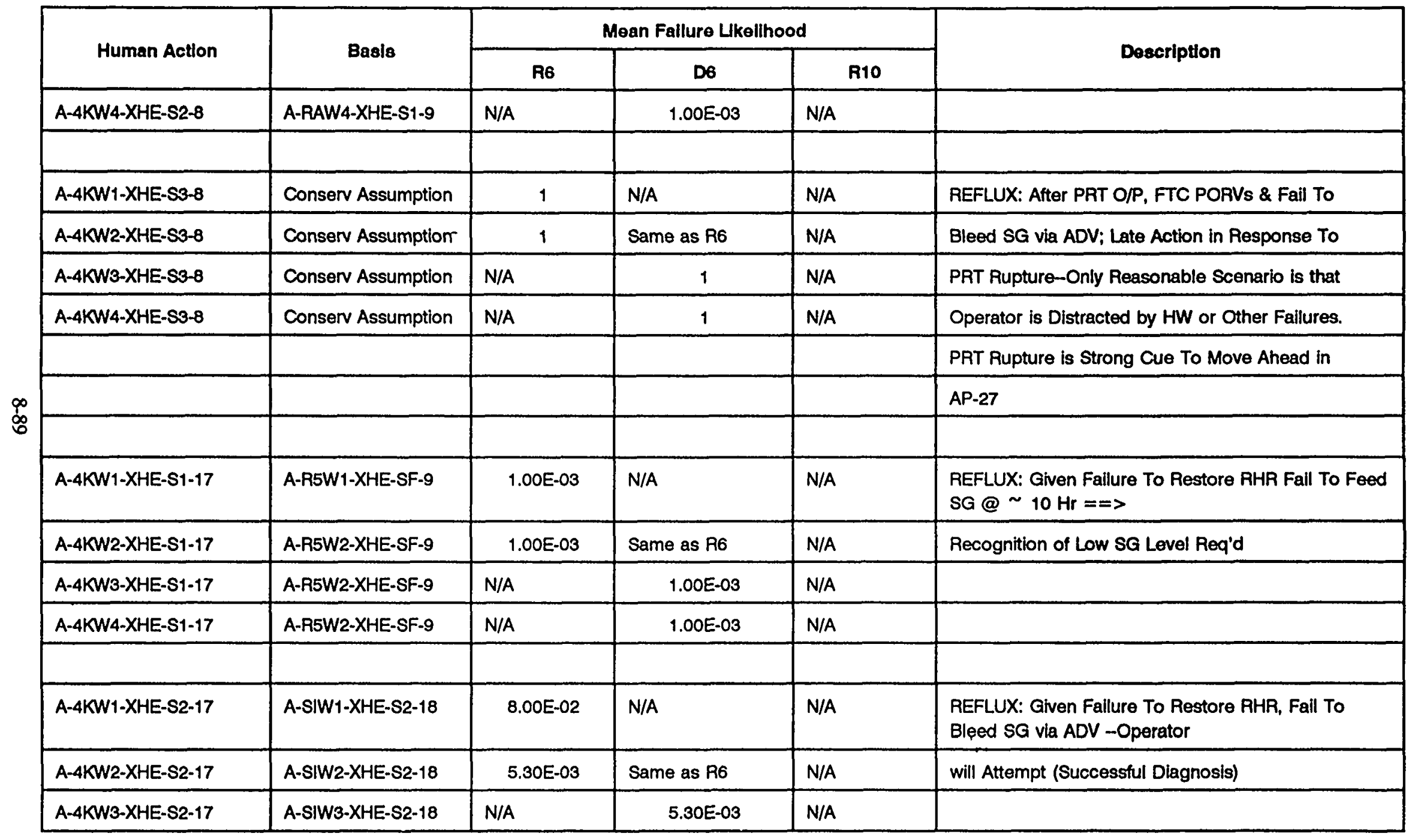


Table 8-13 (Page 36 of 84). Quantitative Results of BNL/Surry Human Action Evaluations

\begin{tabular}{|c|c|c|c|c|c|}
\hline \multirow{2}{*}{ Human Action } & \multirow{2}{*}{ Baslo } & \multicolumn{3}{|c|}{ Mean Fallure Llkellhood } & \multirow{2}{*}{ Description } \\
\hline & & R6 & D6 & R10 & \\
\hline A-4KW4-XHE-S2-17 & A-SIW4-XHE-S2-18 & N/A & $2.00 \mathrm{E}-03$ & N/A & \\
\hline A-4KW1-XHE-S3-17 & Conserv Assumption & 1 & N/A & N/A & $\begin{array}{l}\text { REFLUX: After PRT O/P Given Failure To Restore } \\
\text { RHR, FTC PORVs \& Fail To }\end{array}$ \\
\hline$-A-4 K W 2-X H E-S 3-17$ & Conserv Assumption & 1 & Same as R6 & N/A & Bleed SG via ADV; Late Action in Response to \\
\hline A-4KW3-XHE-S3-17 & Conserv Assumption & N/A & 1 & N/A & PRT Rupture-Only Reasonable Scenario is that \\
\hline \multirow[t]{3}{*}{ A-4KW4-XHE-S3-17 } & Conserv Assumption & N/A & 1 & N/A & Operator is —Distracted by HW or Other Failures. \\
\hline & & & & & PRTRupture is Strong Cue To Move Ahead in \\
\hline & & & & & AP-27 \\
\hline A-4KW1-XHE-FL-5 & A-SIW1-XHE-FL-5 & $1.00 E-02$ & Same as $\mathrm{R} 6$ & N/A & $\begin{array}{l}\text { Fail F\&B: Power Recovered at } 4 \mathrm{kV} \text { Bus H; RHA Not } \\
\text { Restored; SVs Removed }\end{array}$ \\
\hline A-4KW2-XHE-FL-5 & A-SIW2-XHE-FL-5 & $7.60 E-04$ & Same as R6 & N/A & \\
\hline$A-4 K W 3-X H E-F L-4$ & A-SIWB-XHE-FL-4 & $7.60 E-04$ & Same as $\mathrm{R} 6$ & Same as $\mathrm{R} 6$ & \\
\hline A-4KW4-XHE-FL-4 & A-SIW4-XHE-FL-4 & 6.90E-05 & Same as R6 & Same as R6 & \\
\hline A-4KW1-XHE-FL-10 & A-SIW1-XHE-FL-10 & $6.60 \mathrm{E}-02$ & Same as R6 & N/A & $\begin{array}{l}\text { Fail F\&B: Power Recovered at } 4 \mathrm{kV} \text { BBs H; RHR Not } \\
\text { Restored; SVs Not Removed }\end{array}$ \\
\hline A-4KW2-XHE-FL-10 & A-SIW2-XHE-FL-10 & $2.00 \mathrm{E}-03$ & Same as $\mathrm{R} 6$ & N/A & \\
\hline
\end{tabular}


Table 8-13 (Page 37 of 84). Quantitative Results of FiNL/Surry Human Action Evaluations

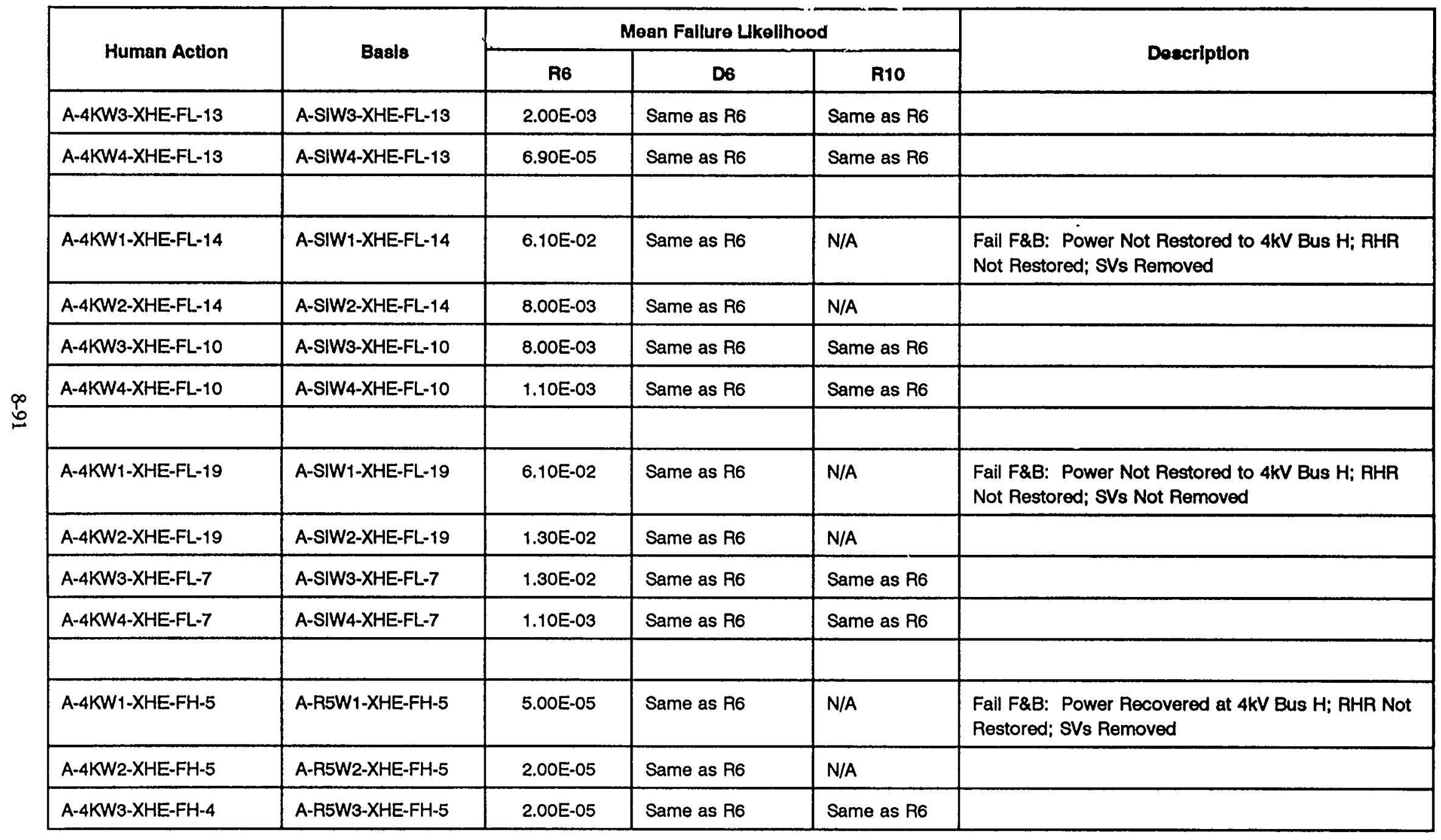


Table 8-13 (Page 38 of 84). Quantitative Results of BNL/Surry Human Action Evaluations

\begin{tabular}{|c|c|c|c|c|c|}
\hline \multirow{2}{*}{ Human Actlon } & \multirow{2}{*}{ Basls } & \multicolumn{3}{|c|}{ Mean Fallure Lkellhood } & \multirow{2}{*}{ Description } \\
\hline & & A6 & DB & R10 & \\
\hline A-4KW4-XHE-FH-4 & A-R5W4-XHE-FH-5 & $2.00 \mathrm{E}-05$ & Same as R6 & Same as R6 & \\
\hline A-4KW1-XHE-FH-10 & A-R5W1-XHE-FH-5 & $5.00 \mathrm{E}-05$ & Same as R6 & N/A & $\begin{array}{l}\text { Fail F\&B: Power Recovered at } 4 \mathrm{kV} \text { Bus H; RHR Not } \\
\text { Restored; SVs Not Removed }\end{array}$ \\
\hline A-4KW2-XHE-FH-10 & A-R5W2-XHE-FH-5 & $2.00 E-05$ & Same as R6 & N/A & \\
\hline A-4KW3-XHE-FH-13 & A-R5W3-XHE-FH-5 & 2.00E-05 & Same as R6 & Same as $\mathrm{R} 6$ & \\
\hline A-4KW4-XHE-FH-13 & A-R5W4-XHE-FH-5 & $2.00 E-05$ & Same as R6 & Same as R6 & \\
\hline A-4KW1-XHE-FH-14 & A-R5W1-XHE-FH.5 & 5.00E-05 & Same as R6 & N/A & $\begin{array}{l}\text { Fail F\&B: Power Not Restored to 4kV Bus H; AHR } \\
\text { Not Restored; SVs Removed }\end{array}$ \\
\hline A-4KW1-XHE-FH-19 & A-R5W1-XHE-FH-5 & 5.00E-05 & Same as R6 & N/A & $\begin{array}{l}\text { Fail F\&B: Power Not Restored to } 4 k V \text { Bus H; RHR } \\
\text { Not Restored; SVs Not Removed }\end{array}$ \\
\hline A-4KW2-XHE-FH-19 & A-R5W2-XHE-FH-5 & $2.00 E-05$ & Same as R6 & N/A & \\
\hline A-4KWB-XHE-FH-7 & A-R5W3-XHE-FH-5 & $2.00 \mathrm{E}-05$ & Same as $R 6$ & Same as R6 & \\
\hline A-4KW4-XHE-FH-7 & A-R5W4-XHE-FH-5 & $2.00 E-05$ & Same as R6 & Same as R6 & \\
\hline
\end{tabular}


Table 8-13 (Page 39 of 84). Quantitative Results of BNL/Surry Human Action Evaluations

\begin{tabular}{|c|c|c|c|c|c|}
\hline \multirow{2}{*}{ Human Action . } & \multirow{2}{*}{ Basis } & \multicolumn{3}{|c|}{ Mean Fallure Lkellhood } & \multirow{2}{*}{ Description } \\
\hline & & R6 & D8 & R10 & \\
\hline A-4KW1-XHE-G6 & Conserv Assumption & 1 & N/A & N/A & GRAVITY: Fail To Est. Gravity Feed Following \\
\hline A-4KW2-XHE-G6 & Conserv Assumption & 1 & N/A & N/A & $\begin{array}{l}\text { Failure of Fill and Spill. Power Restored to } 4 \mathrm{kV} \\
\text { Bus H }\end{array}$ \\
\hline A-4KW3-XHE-G5 & Conserv Assumption & 1 & N/A & Same as R6 & \\
\hline A-4KW4-XHE-G5 & Conserv Assumption & 1 & N/A & Same as $\mathrm{R} 6$ & \\
\hline A-4KW1-XHE-G15 & Conserv Assumption & 1 & N/A & N/A & GRAVITY: Fail To Est. Gravity Foed Following \\
\hline A-4KW2-XHE-G15 & Conserv Assumption & 1 & N/A & N/A & $\begin{array}{l}\text { Failure of Fill and Spill. Power Not Restored to } 4 \mathrm{kV} \\
\text { Bus } \mathrm{H}\end{array}$ \\
\hline A-4KW3-XHE-G11 & Conserv Assumption & 1 & N/A & Same as $\mathrm{R} 6$ & \\
\hline A-4KW4-XHE-G11 & Conserv Assumption & 1 & N/A & Same as $\mathrm{R} 6$ & \\
\hline A-4KW1-XHE-C-4 & A-RSW1-XHE-C-4 & $1.00 \mathrm{E}-03$ & Same as R6 & N/A & $\begin{array}{l}\text { RECIRC: Fail To Est. HP Recirc (Power Restored to } \\
\text { 4kV Bus, B\&F Successful }\end{array}$ \\
\hline A-4KW2-XHE-C-4 & A-R5W2-XHE-C-4 & $1.00 \mathrm{E}-03$ & Same as R6 & N/A & and SVs Removed) $-\ldots 8-20 \mathrm{Hr},==>$ \\
\hline A-4KW3-XHE-C-4 & N/A & N/A & N/A & N/A & Recognition of Low RWST Level Req'd \\
\hline A-4KW4-XHE-C-4 & N/A & N/A & N/A & N/A & \\
\hline
\end{tabular}


Table 8-13 (Page 40 of 84). Quantitative Results of BNL/Surry Human Action Evaluations

\begin{tabular}{|c|c|c|c|c|c|}
\hline Human Action & Basis & \multicolumn{3}{|c|}{ Mean Fallure Likellhood } & Description \\
\hline A-4KW1-XHE-C-13 & A-R5W1-XHE-C-9 & $1.00 E-03$ & Same as R6 & N/A & $\begin{array}{l}\text { RECIRC: Fall To Est. HP Recirc (Power Not Restored } \\
\text { to } 4 \mathrm{kV} \text { Bus, B\&F Successful }\end{array}$ \\
\hline A-4KW2-XHE-C-13 & A-R5W2-XHE-C-9 & $1.00 E-03$ & Same as $\mathrm{R} 6$ & N/A & and SVs Removed)--@ 8 - $20 \mathrm{Hr},==>$ \\
\hline A-4KW3-XHE-C-13 & N/A & N/A & N/A & N/A & Recognition of Low RWST Level Req'd. \\
\hline A-4KW1-XHE-C-9 & A-R5W1-XHE-C-4 & $1.00 E-03$ & Same as R6 & N/A & $\begin{array}{l}\text { RECIRC: Fail To Est. HP Recirc (Power Restored to } \\
\text { 4kV Bus, B\&F Successful }\end{array}$ \\
\hline A-4KW2-XHE-C-9 & A-R5W2-XHE-C-4 & $1.00 \mathrm{E}-03$ & Same as $\mathrm{R} 6$ & N/A & $\begin{array}{l}\text { and SVs Not Removed)--@ } 8-20 \mathrm{Hr},==> \\
\text { Recognition }\end{array}$ \\
\hline A-4KW3-XHE-C-9 & N/A & N/A & N/A & N/A & of Low RWST Level Req'd \\
\hline A-4KW4-XHE-C-9 & N/A & N/A & N/A & N/A & \\
\hline$A-4 K W 1-X H E-C-18$ & A-R5W1-XHE-C-9 & $1.00 E-03$ & Same as $\mathrm{R} 6$ & N/A & $\begin{array}{l}\text { RECIRC: Fail To Est. HP Recirc (Power Not Restored } \\
\text { to } 4 \mathrm{kV} \text { Bus, B\&F Successtul }\end{array}$ \\
\hline A-4KW2-XHE-C-18 & A-R5W2-XHE-C-9 & $1.00 \mathrm{E}-03$ & Same as R6 & N/A & $\begin{array}{l}\text { and SVs Not Removed)--@8 - } 20 \mathrm{Hr},==> \\
\text { Recognition }\end{array}$ \\
\hline A-4KW3-XHE-C-18 & N/A & N/A & N/A & N/A & of Low RWST Level Req'd \\
\hline A-4KW4-XHE-C-18 & N/A & N/A & N/A & N/A & \\
\hline
\end{tabular}


Table 8-13 (Page 41 of 84). Quantitative Results of BNL/Surry Human Action Evaluations

\begin{tabular}{|c|c|c|c|c|c|}
\hline Human Action & Basis & \multicolumn{3}{|c|}{ Mean Fallure Lkellhood } & Description \\
\hline$A-4 K W 2-X H E-X$ & A-R5W2-XHE-X & $1.00 \mathrm{E}-03$ & Same as R6 & N/A & Fail To Cross Tie RWST \\
\hline$A-4 K W 1-X H E-P-4$ & A-R5W1-XHE-P-4 & $1.00 \mathrm{E}-04$ & Same as R6 & N/A & $\begin{array}{l}\text { RECIRC: Fail To Est. Recirc Spray (Power Restored } \\
\text { to } 4 \mathrm{kV} \text { Bus, B\&F Successful }\end{array}$ \\
\hline A-4KW3-XHE-P-4 & N/A & N/A & N/A & N/A & \\
\hline A-4KW4-XHE-P-4 & N/A & N/A & N/A & N/A & \\
\hline$A-4 K W 1-X H E-P-13$ & A-R5W1-XHE-P-4 & $1.00 \mathrm{E}-04$ & Same as $\mathrm{R} 6$ & $N / A$ & $\begin{array}{l}\text { RECIRC: Fail To Est. Recirc Spray (Power Not } \\
\text { Restored to } 4 \mathrm{kV} \text { Bus B\&F Successful }\end{array}$ \\
\hline A-4KW1-XHE-P-9 & $A-R 5 W_{1}-X H E-P-4$ & $1.00 E-04$ & Same as $\mathrm{R} 6$ & N/A & $\begin{array}{l}\text { RECIRC: Fail To Est Recirc Spray (Power Restored to } \\
4 \mathrm{kV} \text { Bus, B\&F Successful }\end{array}$ \\
\hline A-4KW2-XHE-P-9 & A-R5W2-XHE-P-4 & $1.00 E-04$ & Same as R6 & N/A & and SVs Not Removed)- \\
\hline A-4KWW-XHE-P-9 & N/A & $N / A$ & N/A & N/A & \\
\hline A-4KW4-XHE-P-9 & N/A & N/A & $N / A$ & N/A & \\
\hline
\end{tabular}


Table 8-13 (Page 42 of 84). Quantitative Results of BNL/Surry Buman Action Evaluations

\begin{tabular}{|c|c|c|c|c|c|}
\hline \multirow{2}{*}{ Human Action } & \multirow{2}{*}{ Basls } & \multicolumn{3}{|c|}{ Mean Fallure Lkellhood } & \multirow{2}{*}{ Description } \\
\hline & & R6 & D6 & R10 & \\
\hline A-4KW1-XHE-P-18 & A-R5W1-XHE-P-4 & $1.00 \mathrm{E}-04$ & Same as R6 & N/A & $\begin{array}{l}\text { RECIRC: Fail To Est. Recirc Spray (Power Not } \\
\text { Restored to 4kV Bus B\&F Successful }\end{array}$ \\
\hline A-4KW2-XHE-P-18 & A-R5W2-XHE-P-4 & $1.00 E-04$ & Same as R6 & N/A & and SVs Not Removed) \\
\hline A-4KWB-XHE-P-18 & N/A & N/A & N/A & NTA & \\
\hline A-4KW4-XHE-P-18 & N/A & N/A & N/A & N/A & \\
\hline D-LIW1-XHE & Calculated & $8.20 E-04$ & Same as R6 & N/A & Diagnose Loss of Offsite Power \\
\hline D-LIW2-XHE & Calculated & $3.60 E-04$ & Same as R6 & N/A & \\
\hline D-LIW3-XHE & D-L1W2-XHE & $3.60 E-04$ & Same as R6 & Same as R6 & \\
\hline D-LIW4-XHE & Calculated & 8.00E-05 & Same as R6 & Same as R6 & \\
\hline A-L1W1-XHE-R-4 & Calculated & $1.60 \mathrm{E}-02$ & Same as R6 & N/A & Fail To Restore RHR \\
\hline A-LIW2-XHE-R-4 & Calculated & 5.90E-03 & Same as R6 & N/A & \\
\hline A-LIWO-XHE-R-4 & A-L1W2-XHE-R-4 & 5.90E-03 & Same as R6 & Same as $\mathrm{R} 6$ & \\
\hline A-L1W4-XHE-R-4 & Calculated & 1.60E-03 & Same as R6 & Same as R6 & \\
\hline A-LIW1-XHE-SF-13 & A-R5W1-XHE-SF-9 & $1.00 E-03$ & N/A & N/A & $\begin{array}{l}\text { Fail To Feed SGs Given Fail To Restore RHR but } \\
\text { Successful Level Control }\end{array}$ \\
\hline
\end{tabular}


Table 8-13 (Page 43 of 84). Quantitative Results of BNL/Surry Human Action Evaluations

\begin{tabular}{|c|c|c|c|c|c|}
\hline \multirow{2}{*}{ Human Action } & \multirow{2}{*}{ Basle } & \multicolumn{3}{|c|}{ Mean Fallure Lkellihood } & \multirow{2}{*}{ Description } \\
\hline & & R6 & D6 & R10 & \\
\hline A-L1W2-XHE-SF-13 & A-R5W2-XHE-SF-9 & 1.00E-03 & $1.00 \mathrm{E}-03$ & N/A & \\
\hline A-L1W3-XHE-SF-13 & A-RAW3-XHE-SF-9 & N/A & $1.00 \mathrm{E}-03$ & N/A & \\
\hline A-L1W4-XHE-SF-13 & A-RAW4-XHE-SF-9 & N/A & $1.00 E-03$ & N/A & \\
\hline A-L1W1-XHE-S1-13 & A-R5W1-XHE-S1-9 & 4.00E-02 & N/A & N/A & REFFLUX: Fail To Bleed SG via ADV -Operator \\
\hline A-L1W2-XHE-S1-13 & A-R5W2-XHE-S1-9 & 2.60E-03 & 2.60E-03 & N/A & will Attempt (Successful Diagnosis) \\
\hline A-L1W3-XHE-S1-13 & A-RAWB-XHE-S1-9 & N/A & $2.60 \mathrm{E}-03$ & N/A & \\
\hline A-L1W4-XHE-S1-13 & A-RAW4-XHE-S1-9 & N/A & $1.00 \mathrm{E}-03$ & N/A & \\
\hline A-LIW1-XHE-S2-13 & Conserv Assumption & 1 & N/A & N/A & $\begin{array}{l}\text { Fail To Establish Reflux after PRT Rupture Given Feil } \\
\text { To Restore RHR but Successful Level Control }\end{array}$ \\
\hline A-L1W2-XHE-S2-13 & Conserv Assumption & 1 & 1 & N/A & \\
\hline A-L1W3-XHE-S2-13 & Conserv Assumption & N/A & 1 & $N / A$ & \\
\hline A-L1W4-XHE-S2-13 & Conserv Assumption & N/A & 1 & $N / A$ & \\
\hline A-L1W1-XHE-SF-17 & A-R5W1-XHE-SF-9 & $1.00 E-03$ & N/A & $N / A$ & $\begin{array}{l}\text { Fail To Feed SGs Given Fail To Restore RHR but } \\
\text { Successful Level Control;SVs Not Removed }\end{array}$ \\
\hline A-L1W2-XHE-SF-17 & A-R5W2-XHE-SF-9 & $1.00 \mathrm{E}-03$ & $1.00 E-03$ & N/A & \\
\hline A-L1W3-XHE-SF-17 & A-RAW3-XHE-SF-9 & N/A & $1.00 \mathrm{E}-03$ & N/A & \\
\hline
\end{tabular}


Table 8-13 (Page 44 of 84). Quantitative Results of BNL/Surry Human Action Evaluations

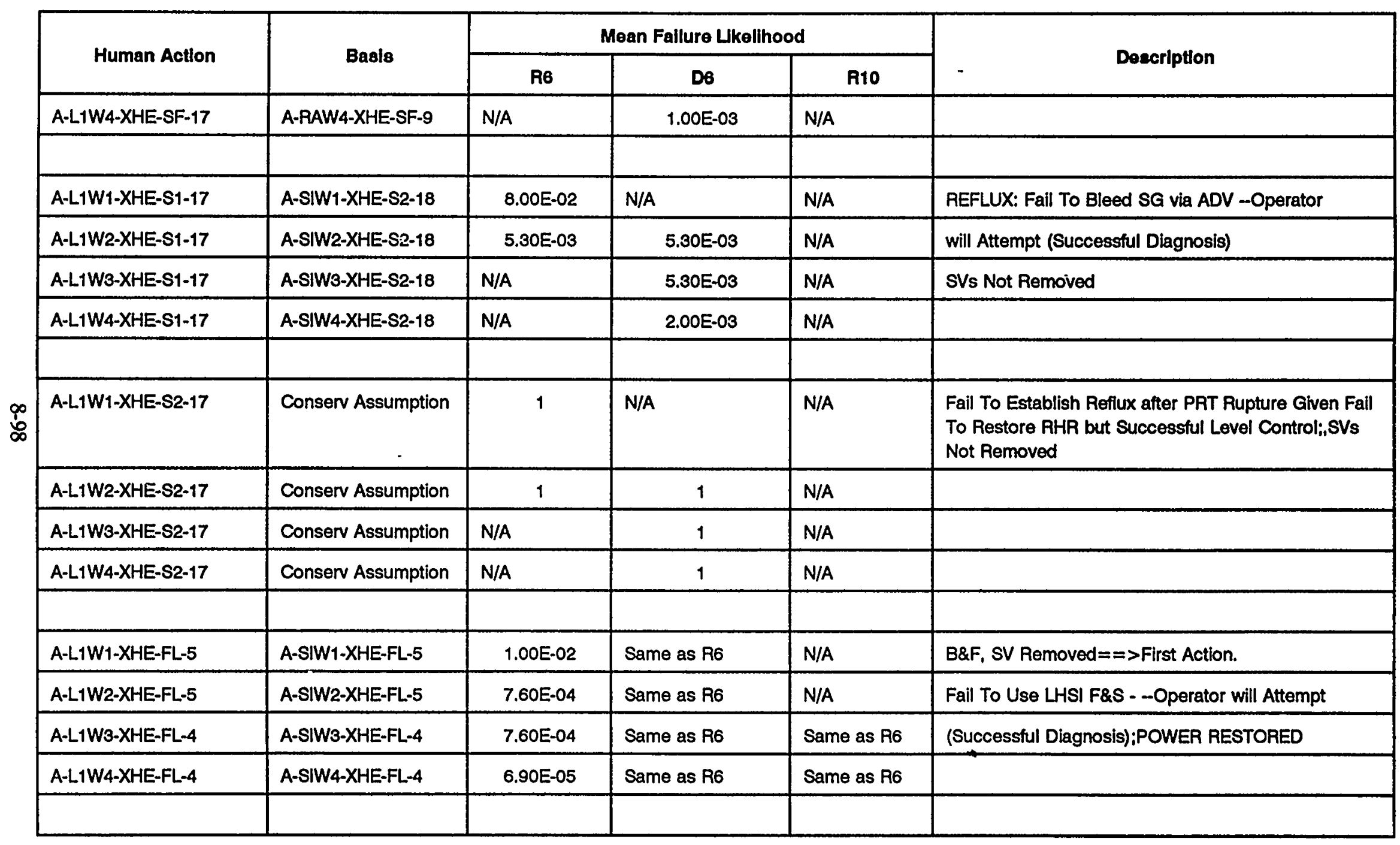


Table 8-13 (Page 45 of 84). Quantitative Results of BNL/Surry Human Action Evaluations

\begin{tabular}{|c|c|c|c|c|c|}
\hline \multirow{2}{*}{ Human Action } & \multirow{2}{*}{ Basls } & \multicolumn{3}{|c|}{ Mean Failure Lkellhood } & \multirow{2}{*}{ Description } \\
\hline & & R6 & Ds & Rio & \\
\hline A-LIW1-XHE-FH-5 & A-R5W1-XHE-FH-5 & 5.00E-05 & Same as R6 & N/A & B\&F: Fail To Use HHSI | LHSI Failed - -Operator \\
\hline A-LIW2-XHE-FH-5 & A-R5W2-XHE-FH-5 & 2.00E-05 & Same as $\mathrm{R} 6$ & N/A & will Attempt (Successful Diagnosis \& LHSI \\
\hline A-LIWB-XHE-FH-4 & A-R5W3-XHE-FH-4 & 2.00E-05 & Same as R6 & Same as R6 & Attempted and Failed) POWER RESTORED \\
\hline A-LIW4-XHE-FH-4 & A-R5W4-XHE-FH-5 & 2.00E-05 & Same as $\mathrm{R6}$ & Same as R6 & \\
\hline A-L1W1-XHE-FL-9 & A-SIWI-XHE-FL-10 & 6.60E-02 & Same as $R 6$ & N/A & B\&F, SV Removed $==>$ First Action. \\
\hline A-L1W2-XHE-FL-9 & A-SIW2-XHE-FL-10 & $2.00 E-03$ & Same as $\mathrm{R} 6$ & N/A & Fail To Use LHSI F\&S - -Operator will Attempt \\
\hline A-LIW3-XHE-FL-7 & A-SIWB-XHE-FL-13 & 2.00E-03 & Same as R6 & Same as R6 & (Successful Diagnosis);POWER NOT RESTORED \\
\hline A-L1W4-XHE-FL-7 & A-SIW4-XHE-FL-13 & $6.90 \mathrm{E}-05$ & Same as R6 & Same as R6 & \\
\hline A-LIW1-XHE-FH-9 & A-R5W1-XHE-FH-10 & 5.00E-05 & Same as $\mathrm{R} 6$ & N/A & B\&F: Fail To Use HHSI | LHSI Failed - -Operator \\
\hline A-L1W2-XHE-FH-9 & A-R5W2-XHE-FH-10 & 2.00E-05 & Same as R6 & N/A & will Attempt (Successful Diagnosis \& LHSI \\
\hline A-L1W3-XHE-FH-7 & A-R5W3-XHE-FH-13 & $2.00 E-05$ & Same as $\mathrm{R} 6$ & Same as R6 & Attempted and Failed) POWER NOT RESTORED \\
\hline A-L1W4-XHE-FH-7 & A-R5W4-XHE-FH-13 & $2.00 E-05$ & Same as $\mathrm{R} 6$ & Same as $\mathrm{R} 6$ & \\
\hline A-L1W1-XHE-FL-14 & A-SIW1-XHE-FL-14 & $6.10 \mathrm{E}-02$ & Same as $\mathrm{R} 6$ & $N / A$ & B\&F, SV Not Removed==>Reflux Failed. \\
\hline A-L1W2-XHE-FL-14 & A-SIW2-XHE-FL-14 & $8.00 E-03$ & Same as R6 & $N / A$ & Faikhto Use LHSI F\&S - --Operator will Attempt \\
\hline A-L1W3-XHE-FL-14 & A-SIW3-XHE-FL-10 & 8.00E-03 & Same as R6 & Same as $R 6$ & when Reflux Fails To Provide Cooling (Successtul \\
\hline
\end{tabular}


Table 8-13 (Page 46 of 84). Quantitative Results of BNL/Surry Human Action Evaluations

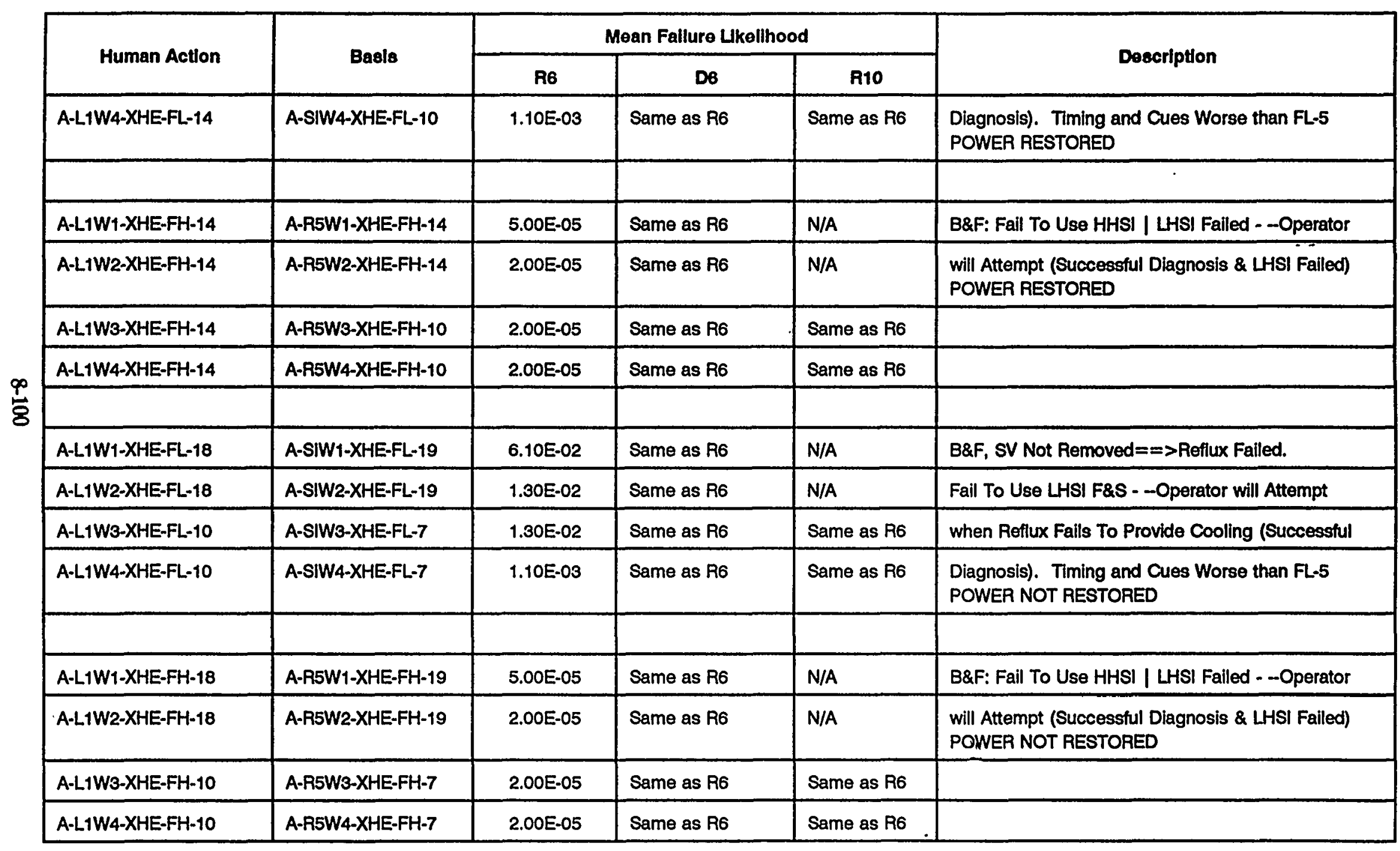


Table 8-13 (Page 47 of 84). Quantitative Results of BNL/Surry Human Action Evaluations

\begin{tabular}{|c|c|c|c|c|c|}
\hline Human Action & Basls & \multicolumn{3}{|c|}{ Mean Fallure Likelthood } & Description \\
\hline A-LIW2-XHE-G-6 - & Conserv Assumption & 1 & N/A & N/A & Failure of Fill and Spill. Only Reasonable Case is if \\
\hline A-L1W3-XHE-G-5 & Conserv Assumption & 1 & N/A & Same as R6 & FR3W1 Failed due to HW. Use Guaranteed \\
\hline A-LIW4-XHE-G-5 & & & & & $\begin{array}{l}\text { Cutsets with Success of A-R3W\#-XHE-FL-5 POWER } \\
\text { RESTORED }\end{array}$ \\
\hline & & & & & \\
\hline A-L1W1-XHE-G-10 & Conserv Assumption & 1 & N/A & N/A & GRAVITY: Fail To Est. Gravity Feed Following \\
\hline A-L1W4-XHE-G-7 & & & & & $\begin{array}{l}\text { Cutsets with Success of A-R3W\#-XHE-FL-5. POWER } \\
\text { NOT RESTORED }\end{array}$ \\
\hline A-L1W1-XHE-C-4 & A-R5W $1-X H E-C-4$ & $1.00 E-03$ & Same as $\mathrm{R} 6$ & N/A & $\begin{array}{l}\text { Fail HP Recirc with SV Removed Given Fail To } \\
\text { Restore RHR POWER RESTORED }\end{array}$ \\
\hline A-L1W2-XHE-C-4 & A-R5W2-XHE-C-4 & $1.00 E-03$ & Same as R6 & N/A & \\
\hline A-LIW3-XHE-C-4 & N/A & N/A & N/A & N/A & \\
\hline
\end{tabular}




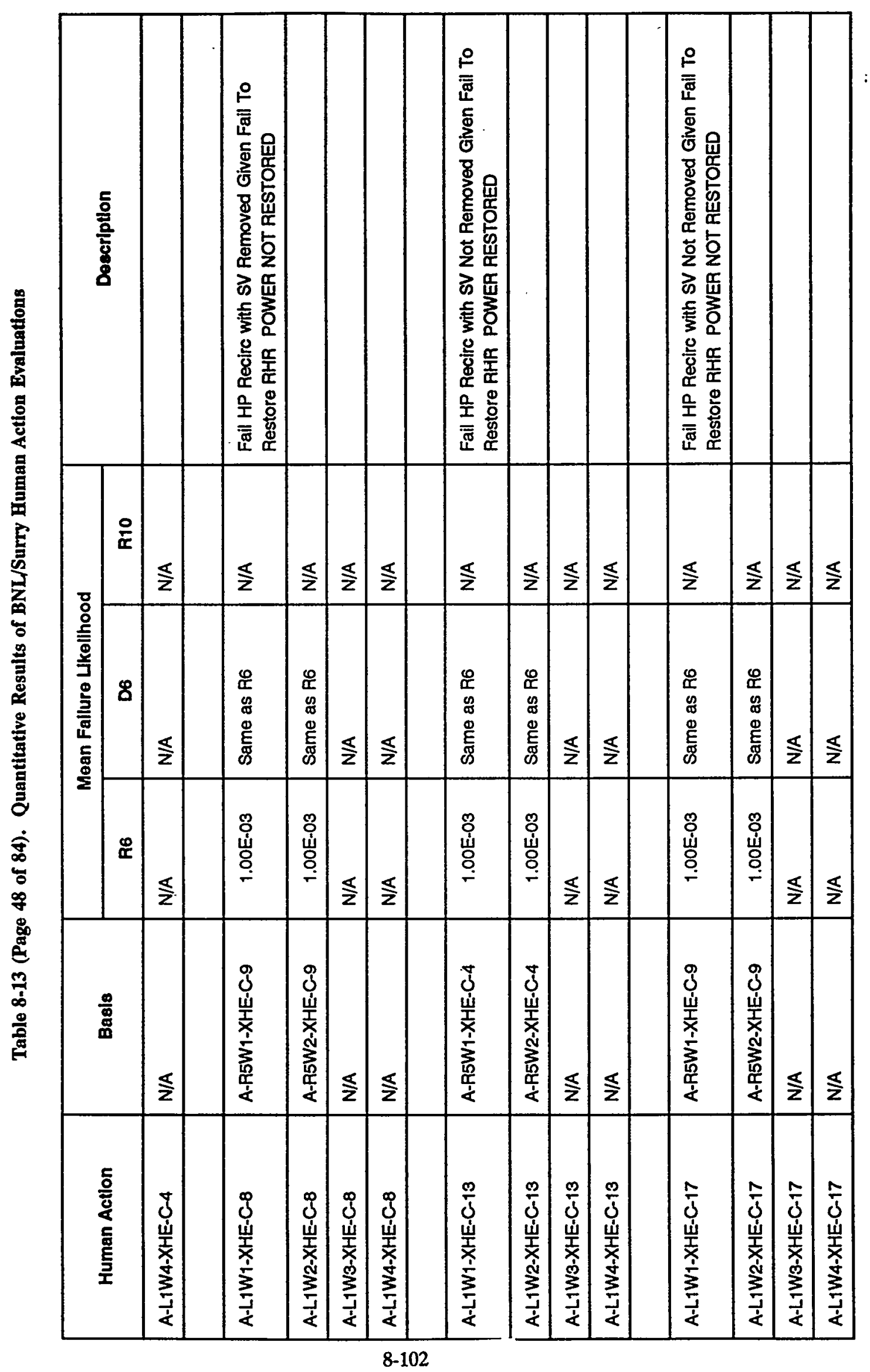


Table 8-13 (Page 49 of 84). Quantitative Results of BNL/Surry Human Action Evaluations

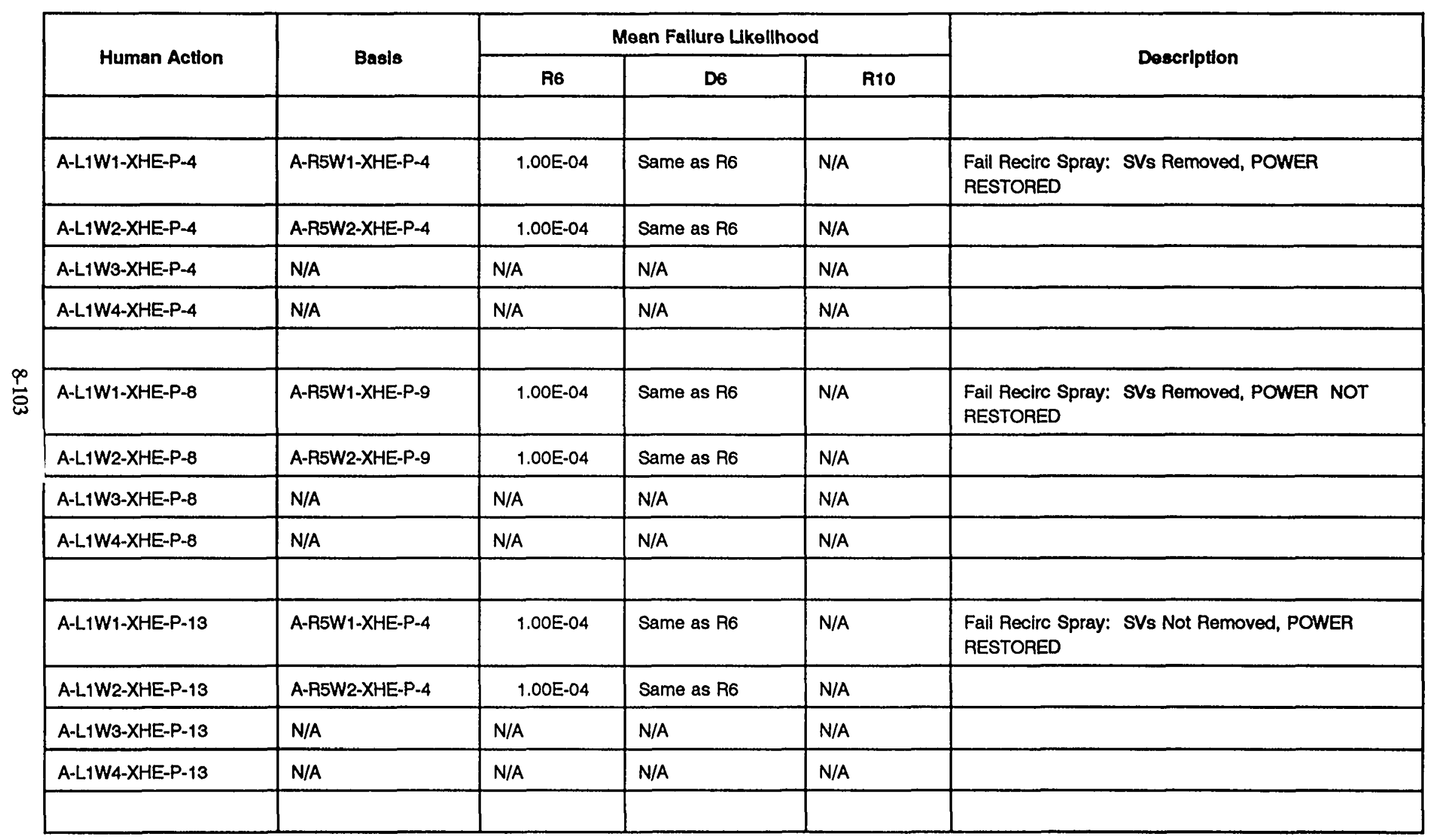


Table 8-13 (Page 50 of 84). Quantitative Results of BNL/Surry Human Action Evaluations

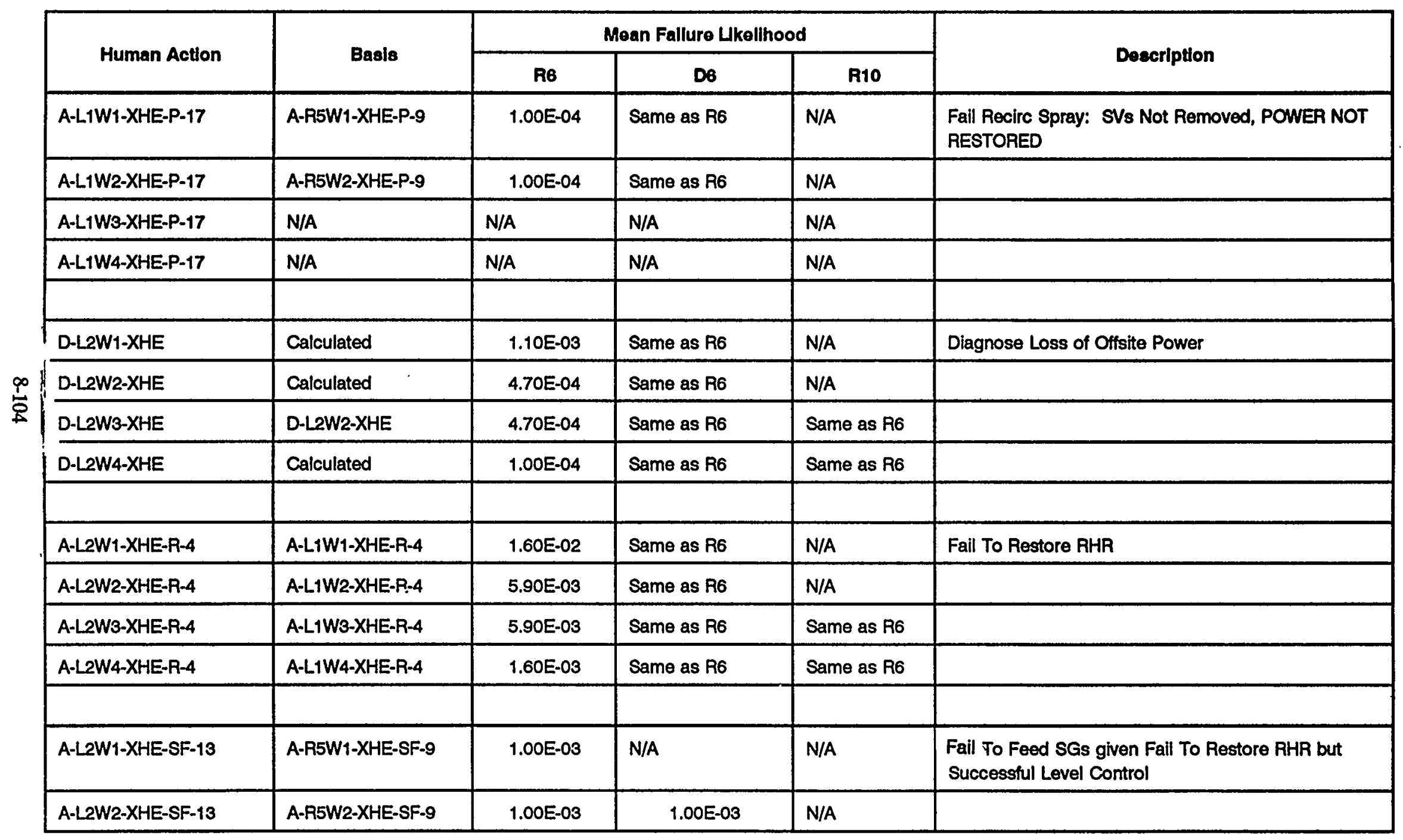


Table 8-13 (Page 51 of 84). Quantitative Results of BNL/Surry Human Action Evaluations

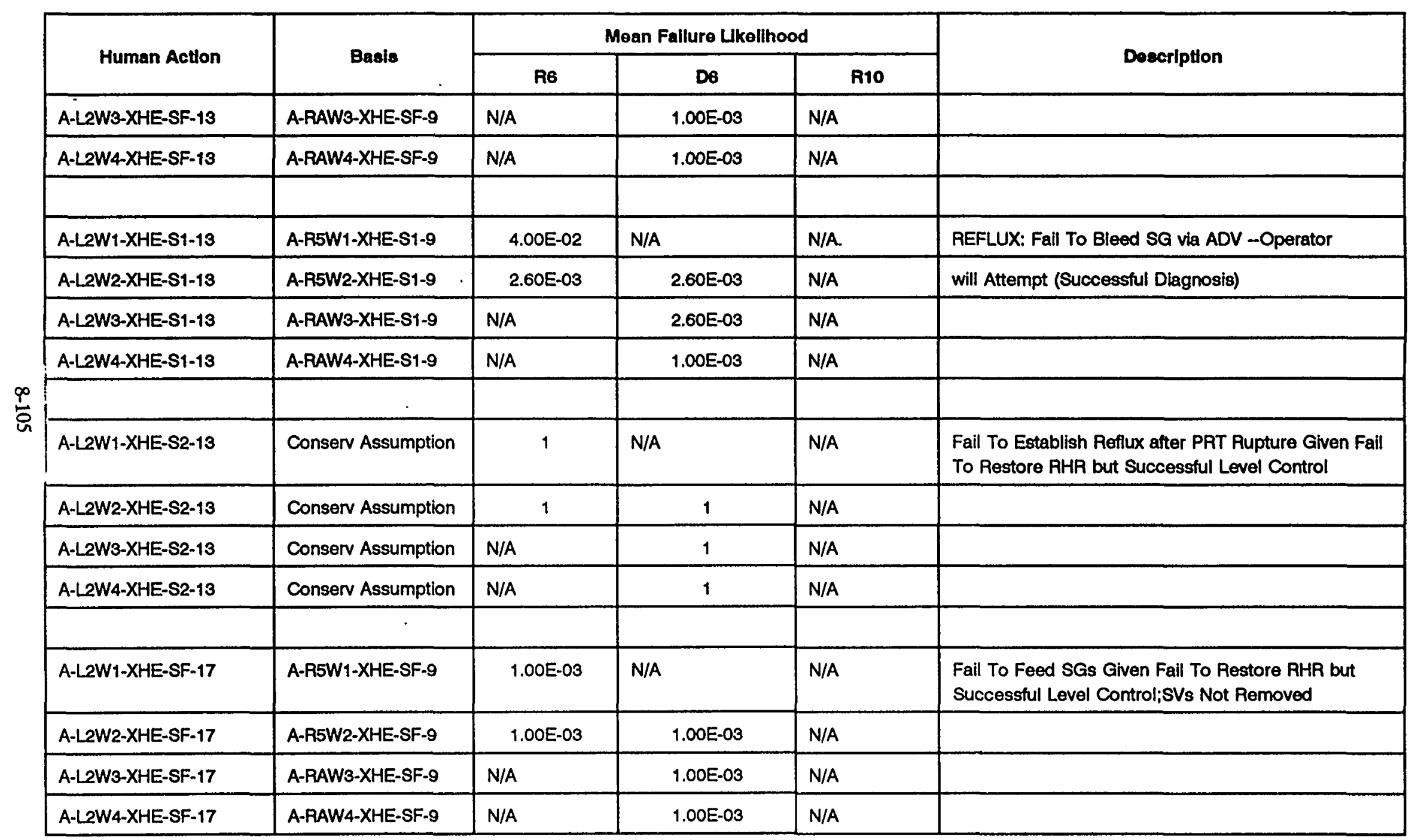


Table 8-13 (Page 52 of 84). Quantitative Results of BNL/Surry Human Action Evaluations

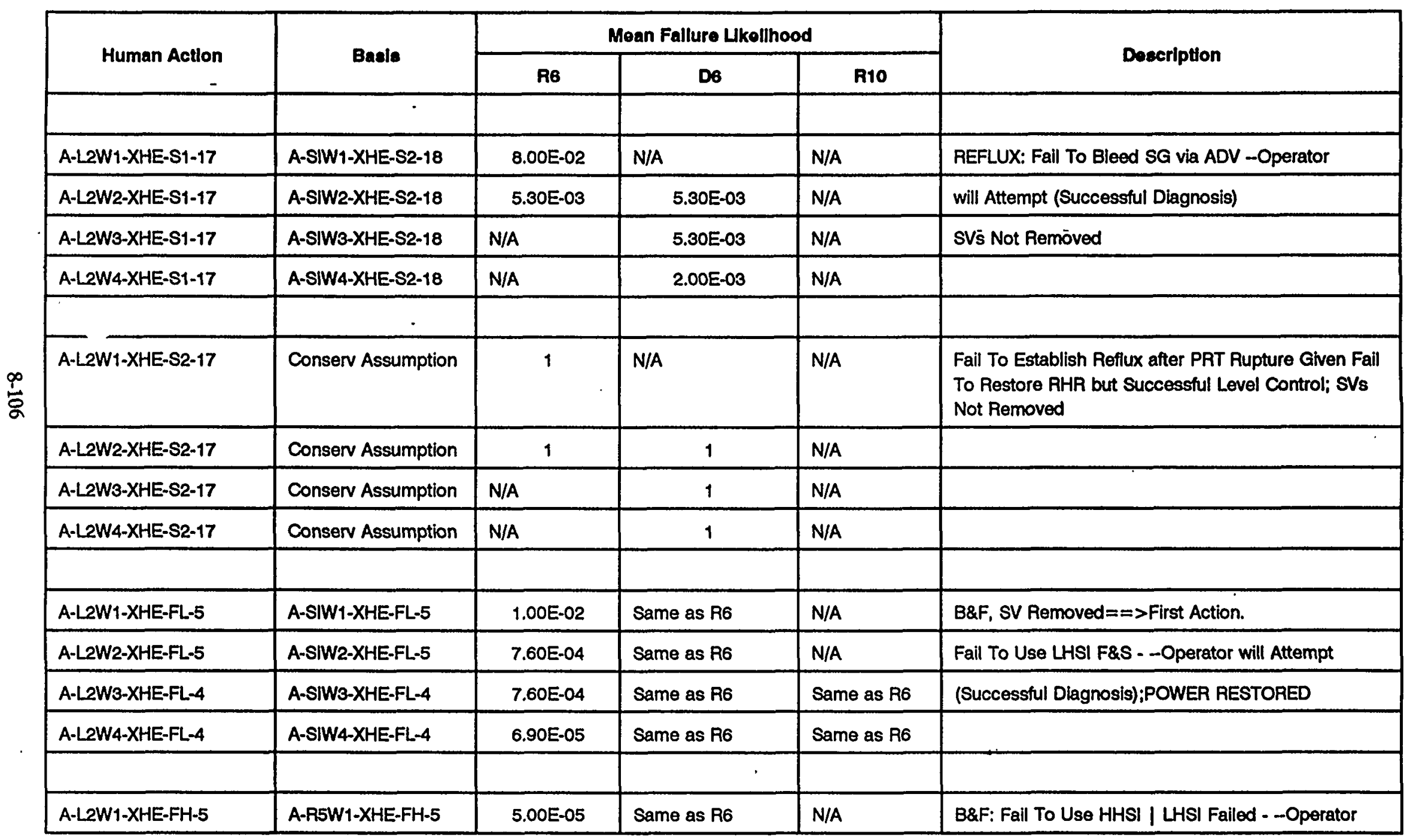


Table 8-13 (Page 53 of 84). Quantitative Results of BNL/Surry Human Action Evaluations

\begin{tabular}{|c|c|c|c|c|c|}
\hline \multirow{2}{*}{ Human Action } & \multirow{2}{*}{ Basis } & \multicolumn{3}{|c|}{ Mean Fallure Lkelihood } & \multirow{2}{*}{ Doscription } \\
\hline & & $\mathbf{R 6}$ & D8 & R10 & \\
\hline A-L2W2-XHE-FH-5 & A-R5W2-XHE-FH-5 & $2.00 E-05$ & Same as R6 & N/A & will Attempt (Successful Diagnosis \& LHSI \\
\hline \multirow[t]{2}{*}{ A-L2W4-XHE-FH-4 } & A-R5W4-XHE-FH-5 & $2.00 E-05$ & Same as R6 & Same as R6 & \\
\hline & & & & & - \\
\hline A-L2W2-XHE-FL-9 & A-SIW2-XHE-FL-10 & 2.00E-03 & Same as R6 & N/A & Fail To Use LHSI F\&S - -Operator will Attempt \\
\hline A-L2W3-XHE-FL-7 & A-SIW3-XHE-FL-13 & $2.00 E-03$ & Same as R6 & Same as $\mathrm{R} 6$ & (Successful Diagnosis);POWER NOT RESTORED \\
\hline A-L2W4-XHE-FL-7 & A-SIW4-XHE-FL-13 & $6.90 E-05$ & Same as R6 & Same as $\mathrm{R} 6$ & \\
\hline A-L2W2-XHE-FH-9 & A-R5W2-XHE-FH-10 & $2.00 E-05$ & Same as R6 & N/A & will Attempt (Successtul Diagnosis \& LHSI \\
\hline A-L2W3-XHE-FH-7 & A-R5W3-XHE-FH-13 & 2.00E-05 & Same as R6 & Same as R6 & Attempted and Failed) POWER NOT RESTORED \\
\hline A-L2W4-XHE-FH-7 & A-R5W4-XHE-FH-13 & $2.00 \mathrm{E}-05$ & Same as R6 & Same as R6 & \\
\hline A-L2W1-XHE-FL-14 & A-SIW1-XHE-FL-14 & $6.10 E-02$ & Same as $\mathrm{R} 6$ & N/A & B\&F, SV Not Removed==>Reflux Failed. \\
\hline A-L2W2-XHE-FL-14 & A-SIW2-XHE-FL-14 & 8.00E-03 & Same as R6 & N/A & Fail To Use LHSI F\&S - -Operator will Attempt \\
\hline A-L2W3-XHE-FL-14 & A-SIW3-XHE-FL-10 & 8.00E-03 & Same as R6 & Same as R6 & whet Reflux Fails To Provide Cooling (Successful \\
\hline A-L2W4-XHE-FL-14 & A-SIW4-XHE-FL-10 & 1.10E-03 & Same as $\mathrm{R} 6$ & Same as R6 & $\begin{array}{l}\text { diagnosis). Timing and Cues Worse than FL-5 } \\
\text { POWER RESTORED }\end{array}$ \\
\hline
\end{tabular}


Table 8-13 (Page 54 of 84). Quantitative Results of BNL/Surry Human Action Evaluntions

\begin{tabular}{|c|c|c|c|c|c|}
\hline Human Action & Baslo & \multicolumn{3}{|c|}{ Mean Fallure Lkellhood } & Description \\
\hline A-L2W1-XHE-FH-14 & A-R5W1-XHE-FH-14 & 5.00E-05 & Same as R6 & N/A & B\&F: Fall To Use HHSI | LHSI Failed - . Operator \\
\hline A-L.2W2-XHE-FH-14 & A-R5W2-XHE-FH-14 & 2.00E-05 & Same as R6 & N/A & $\begin{array}{l}\text { will Attempt (Successtul Diagnosis \& LHSI Failed) } \\
\text { POWER RESTORED }\end{array}$ \\
\hline A-L2W3-XHE-FH-14 & A-R5WB-XHE-FH-10 & $2.00 E-05$ & Same as R6 & Same as $R 6$ & \\
\hline A-L2W4-XHE-FH-14 & A-R5W4-XHE-FH-10 & 2.00E-05 & Same as R6 & Same as R6 & \\
\hline A-L2W1-XHE-FL-18 & A-SIW1-XHE-FL-19 & $6.10 \mathrm{E}-02$ & Same as R6 & N/A & B\&F, SV Not Removed $==>$ Reflux Failed. \\
\hline A-L2W2-XHE-FL-18 & A-SIW2-XHE-FL-19 & $1.30 \mathrm{E}-02$ & Same as R6 & N/A & Fail To Use LHSI F\&S - -Operator will Attempt \\
\hline A-L2W3-XHE-FL-10 & A-SIW3-XHE-FL-7 & $1.30 \mathrm{E}-02$ & Same as R6 & Same as R6 & when Reflux Fails To Provide Cooling (Successful \\
\hline A-L2W4-XHE-FL-10 & A-SIW4-XHE-FL-7 & $1.10 \mathrm{E}-03$ & Same as R6 & Same as R6 & $\begin{array}{l}\text { Diagnosis). Timing and Cues Worse than FL-5 } \\
\text { POWER NOT RESTORED }\end{array}$ \\
\hline A-L2W1-XHE-FH-18 & A-R5W1-XHE-FH-19 & $5.00 E-05$ & Same as R6 & N/A & B\&F: Fail To Use HHSI | LHSI Failed - -.Operator \\
\hline A-L2W2-XHE-FH-18 & A-R5W2-XHE-FH-19 & $2.00 \mathrm{E}-05$ & Same as R6 & N/A & $\begin{array}{l}\text { will Attempt (Successful Diagnosis \& LHSI Failed) } \\
\text { POWER NOT RESTORED }\end{array}$ \\
\hline A-L2W3-XHE-FH-10 & A-A5W3-XHE-FH-7 & $2.00 E-05$ & Same as $\mathrm{R} 6$ & Same as $\mathrm{R} 6$ & \\
\hline A-L2W4-XHE-FH-10 & A-R5W4-XHE-FH-7 & $2.00 \mathrm{E}-05$ & Same as R6 & Same as R6 & \\
\hline
\end{tabular}


Table 8-13 (Page 55 of 84). Quantitative Results of BNL/Surry Human Action Evaluations

\begin{tabular}{|c|c|c|c|c|c|}
\hline \multirow{2}{*}{ Human Action } & \multirow{2}{*}{ Basie } & \multicolumn{3}{|c|}{ Mean Fallure Lukollhood } & \multirow{2}{*}{ Doscription } \\
\hline & & R6 & Do & $\mathbf{R 1 0}$ & \\
\hline A-L2W1-XHE-G-6 & Conserv Assumption & 1 & N/A & N/A & GRAVITY: Fall To Est. Gravity Feed Following \\
\hline A-L2W2-XHE-G-6 & Conserv Assumption & 1 & N/A & N/A & Failure of Fill and Spill. Only Reasonable Case is if \\
\hline A-L2W3-XHE-G-5 & Consen Assumption & 1 & N/A & Same as R6 & FR3W1 Failed due to HW. Use Guaranteed \\
\hline \multirow[t]{2}{*}{ A-L2W4-XHE-G-5 } & Conserv Assumption & 1 & N/A & Same as R6 & Failure. Edit to Old Gravity Feed Event Only for \\
\hline & $\cdots$ & & & & $\begin{array}{l}\text { Cutsets with Success of A-R3W\#-XHE-FL-5 POWER } \\
\text { RESTORED }\end{array}$ \\
\hline A-L2W1-XHE-G-10 & Conserv Assumption & 1 & N/A & N/A & GRAVITY: Fall To Est. Gravity Feed Following \\
\hline A-L2W2-XHE-G-10 & Conserv Assumption & 1 & N/A & N/A & Failure of Fill and Spill. Only Reasonable Case is if \\
\hline A-L2W3-XHE-G-7 & Conserv Assumption & 1 & N/A & Same as $\mathrm{R} 6$ & FR3W1 Failed due to HW. Use Guaranteed \\
\hline \multirow[t]{2}{*}{ A-L2W4-XHE-G-7 } & Conserv Assumption & 1 & N/A & Same as $\mathrm{R} 6$ & Failure. Edit to Old Gravity Feed Event Only for \\
\hline & & & & & $\begin{array}{l}\text { Cutsets with Success of A-R3W\#-XHE-FL-5. POWER } \\
\text { NOT RESTORED }\end{array}$ \\
\hline A-L2W1-XHE-C-4 & A-R5W1-XHE-C-4 & $1.00 E-03$ & Same as R6 & N/A & $\begin{array}{l}\text { Fail HP Recirc with SV Removed Given Fail To } \\
\text { Restore RHR POWER RESTORED }\end{array}$ \\
\hline A-L2W2-XHE-C-4 & A-R5W2-XHE-C-4 & $1.00 \mathrm{E}-03$ & Same as R6 & N/A & \\
\hline A-L2W3-XHE-C-4 & N/A & N/A & N/A & N/A & \\
\hline A-L2W4-XHE-C-4 & N/A & N/A & N/A & N/A & \\
\hline
\end{tabular}


Table 8-13 (Page 56 of 84). Quantitative Results of BNL/Surry Human Action Evaluations

\begin{tabular}{|c|c|c|c|c|c|}
\hline Human Action & Basis & \multicolumn{3}{|c|}{ Mean Fallure Lkelihood } & Description \\
\hline \multicolumn{6}{|l|}{ A-L2W1-XHE-C-8 } \\
\hline & A-R5W1-XHE-C-9 & $1.00 E-03$ & Same as R6 & N/A & $\begin{array}{l}\text { Fail HP Recirc with SV Removed Given Fail To } \\
\text { Restore RHR POWER NOT RESTORED }\end{array}$ \\
\hline A-L2W2-XHE-C-8 & A-R5W2-XHE-C-9 & $1.00 E-03$ & Same as R6 & N/A & \\
\hline A-L2W4-XHE-C-8 & N/A & N/A & N/A & N/A & \\
\hline A-L2W1-XHE-C-13 & A-R5W1-XHE-C-4 & $1.00 E-03$ & Same as R6 & N/A & $\begin{array}{l}\text { Fail HP Recirc with SV Not Removed Given Fail To } \\
\text { Restore RHR POWER RESTORED }\end{array}$ \\
\hline A-L2W2-XHE-C-13 & A-R5W2-XHE-C-4 & $1.00 E-03$ & Same as R6 & N/A & \\
\hline A-L2W1-XHE-G-17 & A-R5W1-XHE-C-9 & $1.00 \mathrm{E}-03$ & Same as R6 & N/A & $\begin{array}{l}\text { Fail HP Recirc with SV Not Removed Given Fail To } \\
\text { Restore RHR POWER NOT RESTORED }\end{array}$ \\
\hline A-L2W2-XHE-C-17 & A-R5W2-XHE-C-9 & $1.00 E-03$ & Same as $\mathrm{R} 6$ & N/A & \\
\hline A-L2W3-XHE-C-17 & N/A & N/A & N/A & N/A & \\
\hline A-L2W4-XHE-C-17 & N/A & N/A & N/A & N/A & \\
\hline
\end{tabular}


Table 8-13 (Page 57 of 84). Quantitative Results of BNL/Surry Human Action Evaluations

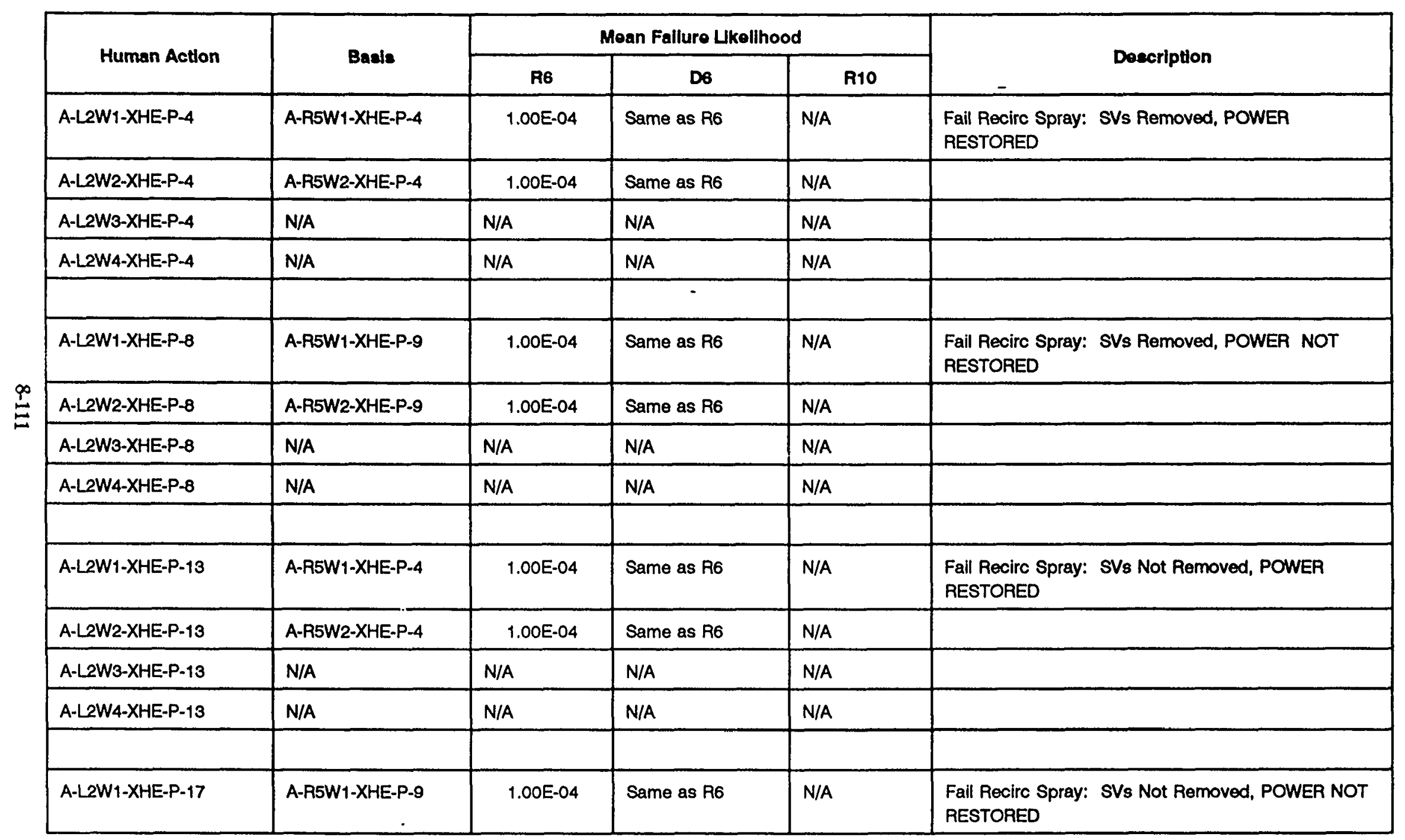


Table 8-13 (Page 58 of 84). Quantitative Results of BNL/Surry Human Action Evaluations

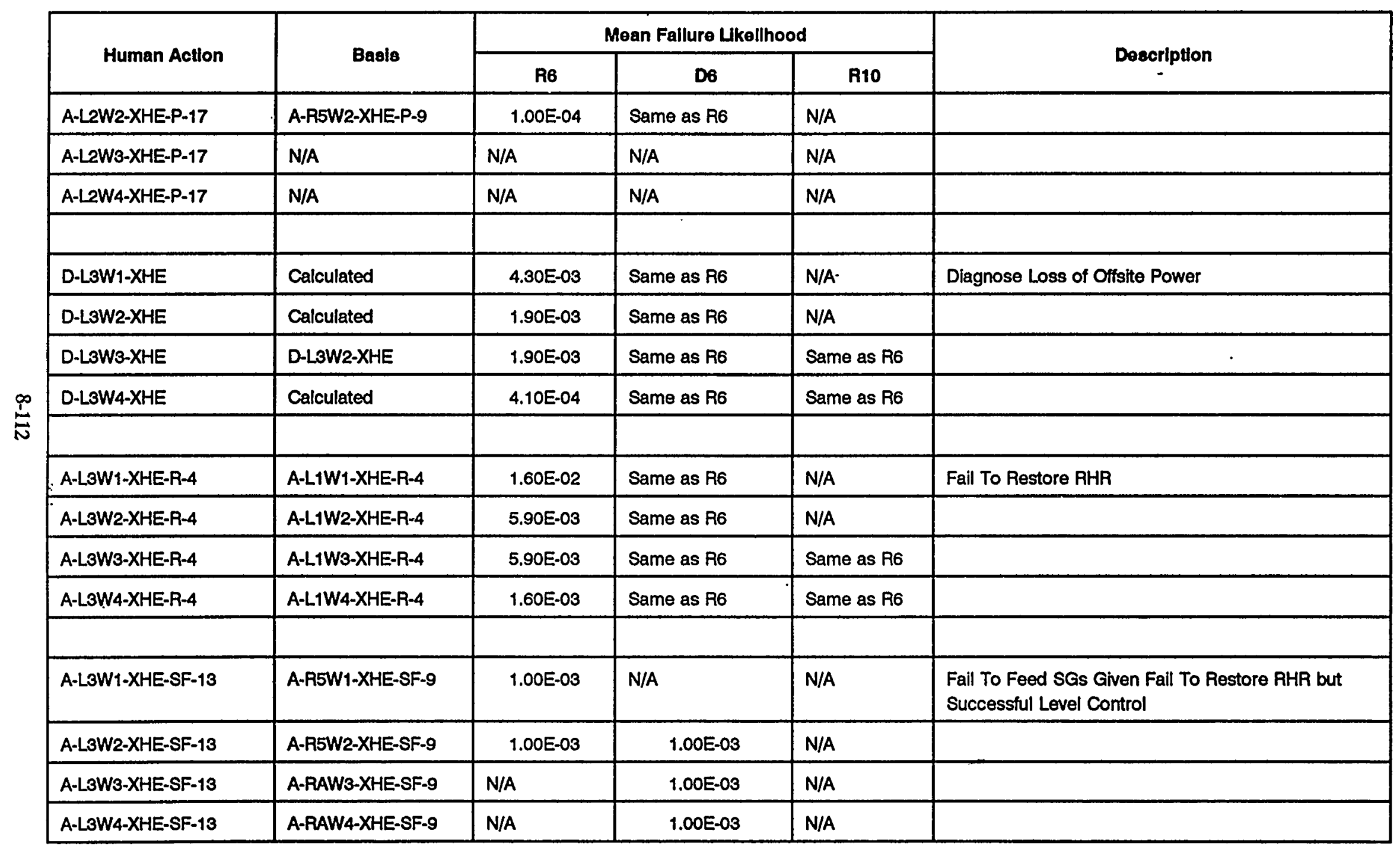


Table 8-13 (Page 59 of 84). Quantitative Results of BNL/Surry Human Action Evaluations

\begin{tabular}{|c|c|c|c|c|c|}
\hline \multirow{2}{*}{ Human Action } & \multirow{2}{*}{ Basis } & \multicolumn{3}{|c|}{ Mean Failure LJkellhood } & \multirow{2}{*}{ Description } \\
\hline & & R6 & D6 & R10 & \\
\hline A-L3W2-XHE-S1-13 & A-R5W2-XHE-S1-9 & $2.60 \mathrm{E}-03$ & 2.60E-03 & N/A & will Attempt (Successful Diagnosis) \\
\hline A-L3WB-XHE-S1-13 & A-RAW3-XHE-S1-9 & N/A & 2.60E-03 & N/A & \\
\hline A-L3W1-XHE-S2-13 & Conserv Assumption & 1 & N/A & N/A & $\begin{array}{l}\text { Fail To Establish Reflux after PRT Rupture given Fail } \\
\text { To Restore RHR but Successful Level Control }\end{array}$ \\
\hline A-L3W2-XHE-S2-13 & Conserv Assumption & 1 & 1 & N/A & \\
\hline A-L3W3-XHE-S2-13 & Conserv Assumption & N/A & 1 & N/A & \\
\hline A-L3W4-XHE-S2-13 & Conserv Assumption & N/A & 1 & N/A & \\
\hline A-L3W1-XHE-SF-17 & A-R5W1-XHE-SF-9 & $1.00 \mathrm{E}-03$ & N/A & N/A & $\begin{array}{l}\text { Fail To Feed SGs Given fail To Restore RHR but } \\
\text { Successful Level Control;SVs Not Removed }\end{array}$ \\
\hline A-L3W2-XHE-SF-17 & A-R5W2-XHE-SF-9 & $1.00 \mathrm{E}-03$ & $1.00 \mathrm{E}-03$ & N/A & \\
\hline A-L3W3-XHE-SF-17 & A-RAW3-XHE-SF-9 & N/A & $1.00 E-03$ & N/A & \\
\hline A-L3W4-XHE-SF-17 & A-RAW4-XHE-SF-9 & N/A & $1.00 \mathrm{E}-03$ & N/A & \\
\hline A-L3W1-XHE-S1-17 & A-SIW1-XHE-S2-18 & 8.00E-02 & N/A & N/A & REFLUX: Fail To Bleed SG via ADV -Operator \\
\hline
\end{tabular}


Table 8-13 (Page 60 of 84). Quantitative Results of BNL/Surry Human Action Evaluations

\begin{tabular}{|c|c|c|c|c|c|}
\hline \multirow{2}{*}{ Human Action } & \multirow{2}{*}{ Baslo } & \multicolumn{3}{|c|}{ Mean Fallure Likellhood } & \multirow{2}{*}{ Description } \\
\hline & & RB & D6 & R10 & \\
\hline A-L3W2-XHE-S1-17 & A-SIW2-XHE-S2-18 & $5.30 E-03$ & $5.30 E-03$ & N/A & will Attempt (Successful Diagnosis) \\
\hline A-L3W4-XHE-S1-17 & A-SIW4-XHE-S2-18 & N/A & $2.00 \mathrm{E}-03$ & N/A & \\
\hline \multicolumn{6}{|l|}{-} \\
\hline A-L3W2-XHE-S2-17 & Conserv Assumption & 1 & 1 & N/A & \\
\hline A-L3W3-XHE-S2-17 & Conserv Assumption & N/A & 1 & N/A & \\
\hline A-L3W4-XHE-S2-17 & Conserv Assumption & N/A & 1 & N/A & . \\
\hline A-L3W2-XHE-FL-5 & A-SIW2-XHE-FL-5 & $7.60 E-04$ & Same as $\mathrm{R} 6$ & N/A & Fail To Use LHSI F\&S - -Operator will Attempt \\
\hline A-L3W3-XHE-FL-4 & A-SIW3-XHE-FL-4 & 7.60E-04 & Same as $\mathrm{R} 6$ & Same as R6 & (Successful Diagnosis);POWER RESTORED \\
\hline A-L3W4-XHE-FL-4 & A-SIW4-XHE-FL-4 & $6.90 \mathrm{E}-05$ & Same as $\mathrm{R} 6$ & Same as R6 & \\
\hline A-L3W1-XHE-FH-5 & A-A5W1-XHE-FH-5 & $5.00 E-05$ & Same as $\mathrm{R} 6$ & N/A & B\&F: Fail To Use HHSI | LHSI Failed - -Operator \\
\hline A-L3W2-XHE-FH-5 & A-R5W2-XHE-FH-5 & $2.00 E-05$ & Same as $\mathrm{R} 6$ & N/A & will Attempt (Successful Diagnosis \& LHSI \\
\hline A-L3W3-XHE-FH-4 & A-R5W3-XHE-FH-4 & $2.00 \mathrm{E}-05$ & Same as $R 6$ & Same as $R 6$ & Attempted and Failed) POWER RESTORED \\
\hline
\end{tabular}


Table 8-13 (Page 61 of 84). Quantitative Results of BNL/Surry Human Action Evaluations

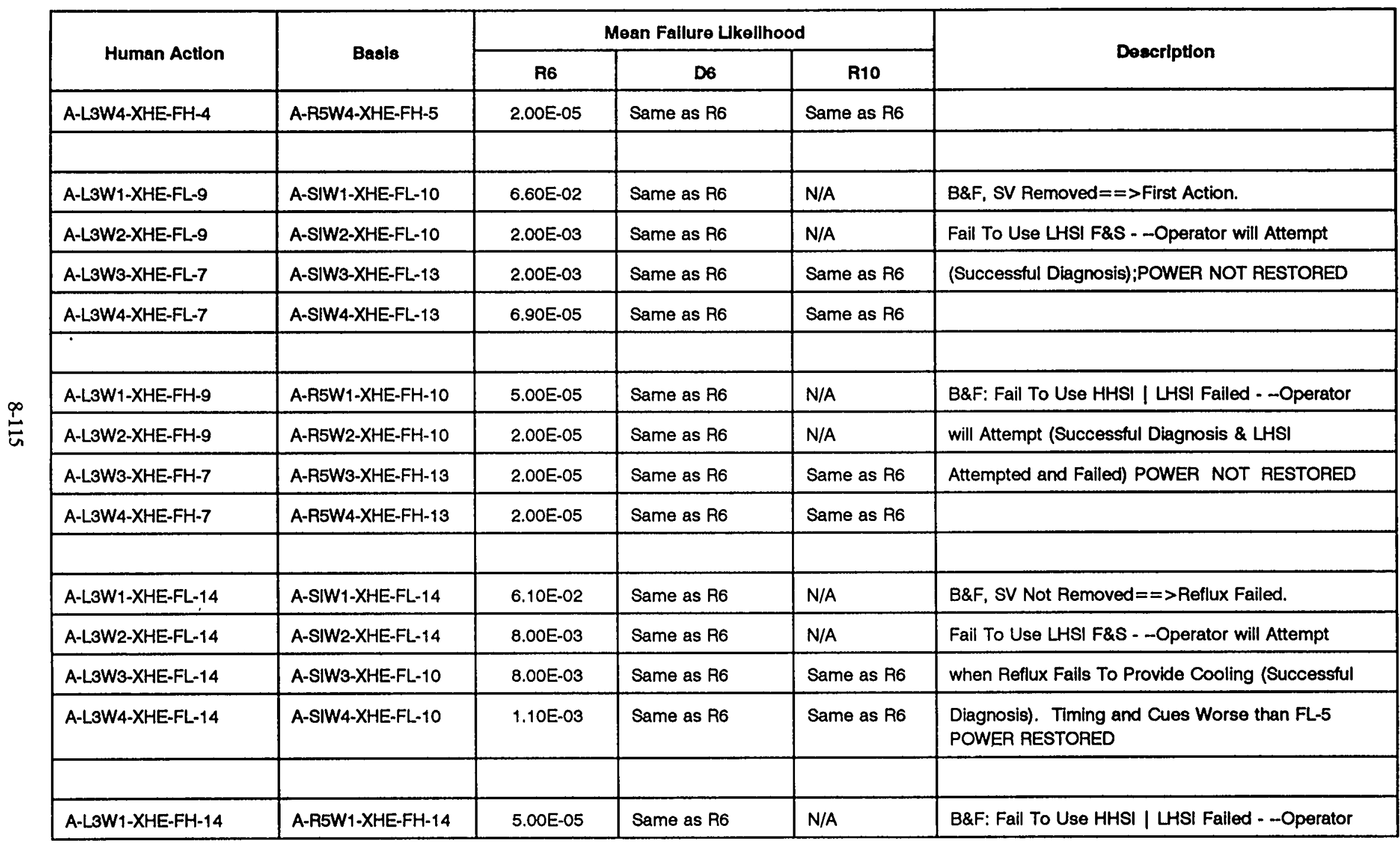


Table 8-13 (Page 62 of 84). Quantitative Results of BNL/Surry Human Action Evaluations

\begin{tabular}{|c|c|c|c|c|c|}
\hline Human Action & Basls . & \multicolumn{3}{|c|}{ Moan Fallure Llkollhood } & Doscription \\
\hline A-L3W2-XHE-FH-14 & A-R5W2-XHE-FH-14 & 2.00E-05 & Same as R6 & N/A & $\begin{array}{l}\text { will Attempt (Successful Dlagnosis \& LHSI failed) } \\
\text { POWER RESTORED }\end{array}$ \\
\hline A-L3W3-XHE-FH-14 & A-R5WB-XHE-FH-10 & 2.00E-05 & Same as $\mathrm{R} 6$ & Same as R6 & \\
\hline A-L3W4-XHE-FH-14 & A-R5W4-XHE-FH-10 & 2.00E-05 & Same as R6 & Same as R6 & \\
\hline A-L3W2-XHE-FL-18 & A-SIW2-XHE-FL-19 & 1.30E-02 & Same as R6 & N/A & Fail To Use LHSI F\&S - -Operator will Attempt \\
\hline A-L3W3-XHE-FL-10 & A-SIW3-XHE-FL-7 & 1.30E-02 & Same as R6 & Same as R6 & when Reflux Fails To Provide Cooling (Successful \\
\hline A-L3W4-XHE-FL-10 & A-SIW4-XHE-FL-7 & $1.10 \mathrm{E}-03$ & Same as R6 & Same as R6 & $\begin{array}{l}\text { diagnosis). Timing and Cues Worse than FL-5 } \\
\text { POWER NOT RESTORED }\end{array}$ \\
\hline A-L3W1-XHE-FH-18 & A-R5W1-XHE-FH-19 & $5.00 E-05$ & Same as R6 & N/A & B\&F: Fail To Use HHSI | LHSI Failed - -Operator \\
\hline A-L3W2-XHE-FH-18 & A-R5W2-XHE-FH-19 & $2.00 E-05$ & Same as R6 & N/A & $\begin{array}{l}\text { will Attempt (Successful Diagnosis \& LHSI Failed) } \\
\text { POWER NOT RESTORED }\end{array}$ \\
\hline A.L3W3-XHE-FH-10 & A-R5W3-XHE-FH-7 & $2.00 E-05$ & Same as R6 & Same as R6 & \\
\hline A-L3W4-XHE-FH-10 & A-R5W4-XHE-FH-7 & $2.00 E-05$ & Same as $\mathrm{R6}$ & Same as R6 & \\
\hline A-L3W1-XHE-G-6 & Conserv Assumption & 1 & N/A & N/A & GRAVITY: Fail To Est. Gravity Feed Following \\
\hline A-L3W2-XHE-G-6 & Conserv Assumption & 1 & N/A & N/A & Failure of Fill and Spill. Only Reasonable Case is if \\
\hline
\end{tabular}


Table 8-13 (Page 63 of 84). Quantitative Results of BNL/Surry Human Action Evaluations

\begin{tabular}{|c|c|c|c|c|c|}
\hline Human Action & Basis & \multicolumn{3}{|c|}{ Mean Fallure Lkellhood } & Description \\
\hline A-L3W3-XHE-G-5 & Conserv Assumption & 1 & N/A & Same as R6 & FR3W1 Falled Due to HW. Use Guaranteed \\
\hline A-L3W4-XHE-G-5 & & & & & $\begin{array}{l}\text { Cutsets with Success of A-R3W\#-XHE-FL-5 POWER } \\
\text { RESTORED }\end{array}$ \\
\hline A-L3W2-XHE-G-10 & Conserv Assumption & 1 & N/A & N/A & Failure of Fill and Spill. Only Reasonable Case is if \\
\hline A-L3W3-XHE-G-7 & Conserv Assumption & 1 & N/A & Same as R6 & FR3W1 Failed due to HW. Use Guaranteed \\
\hline A-L3W4-XHE-G-7 & Conserv Assumption & 1 & N/A & Same as $\mathrm{R} 6$ & Failure. Edit to Old Gravity Feed Event Only for \\
\hline A-L3W1-XHE-C-4 & A-R5W1-XHE-C-4 & $1.00 \mathrm{E}-03$ & Same as R6 & N/A & $\begin{array}{l}\text { Fail HP Recire with SV Removed Given Fail To } \\
\text { Restore RHR POWER RESTORED }\end{array}$ \\
\hline A-L3W2-XHE-C-4 & A-R5W2-XHE-C-4 & $1.00 E-03$ & Same as $R 6$ & N/A & \\
\hline A-L3W3-XHE-C-4 & N/A & N/A & N/A & N/A & \\
\hline A-L3W4-XHE-C-4 & N/A & N/A & N/A & N/A & \\
\hline A-L3W1-XHE-C-8 & A-R5W1-XHE-C-9 & $1.00 E-03$ & Same as R6 & N/A & $\begin{array}{l}\text { Fail HP Recire with SV Removed Given Fail To } \\
\text { Restore RHR. POWER NOT RESTORED }\end{array}$ \\
\hline
\end{tabular}




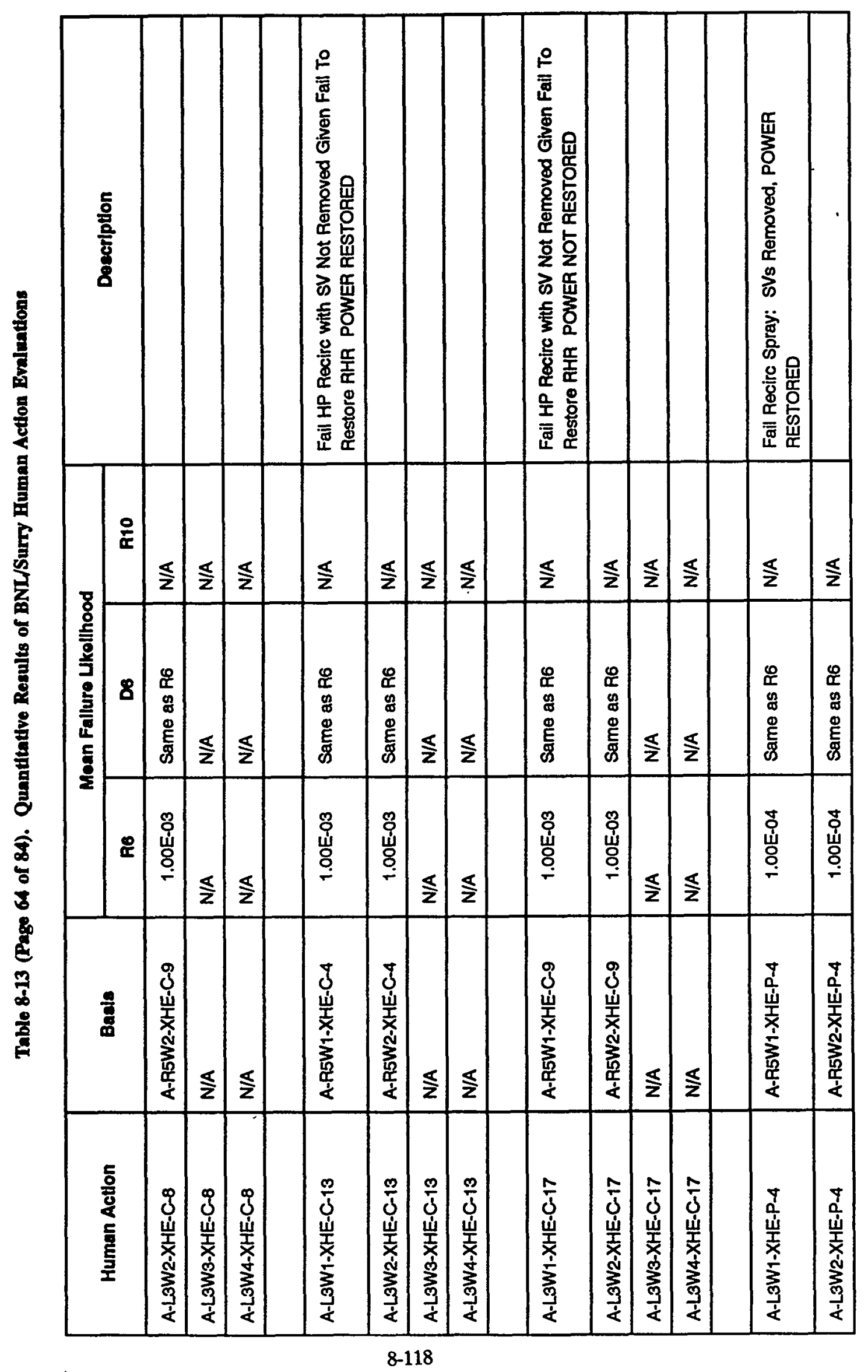




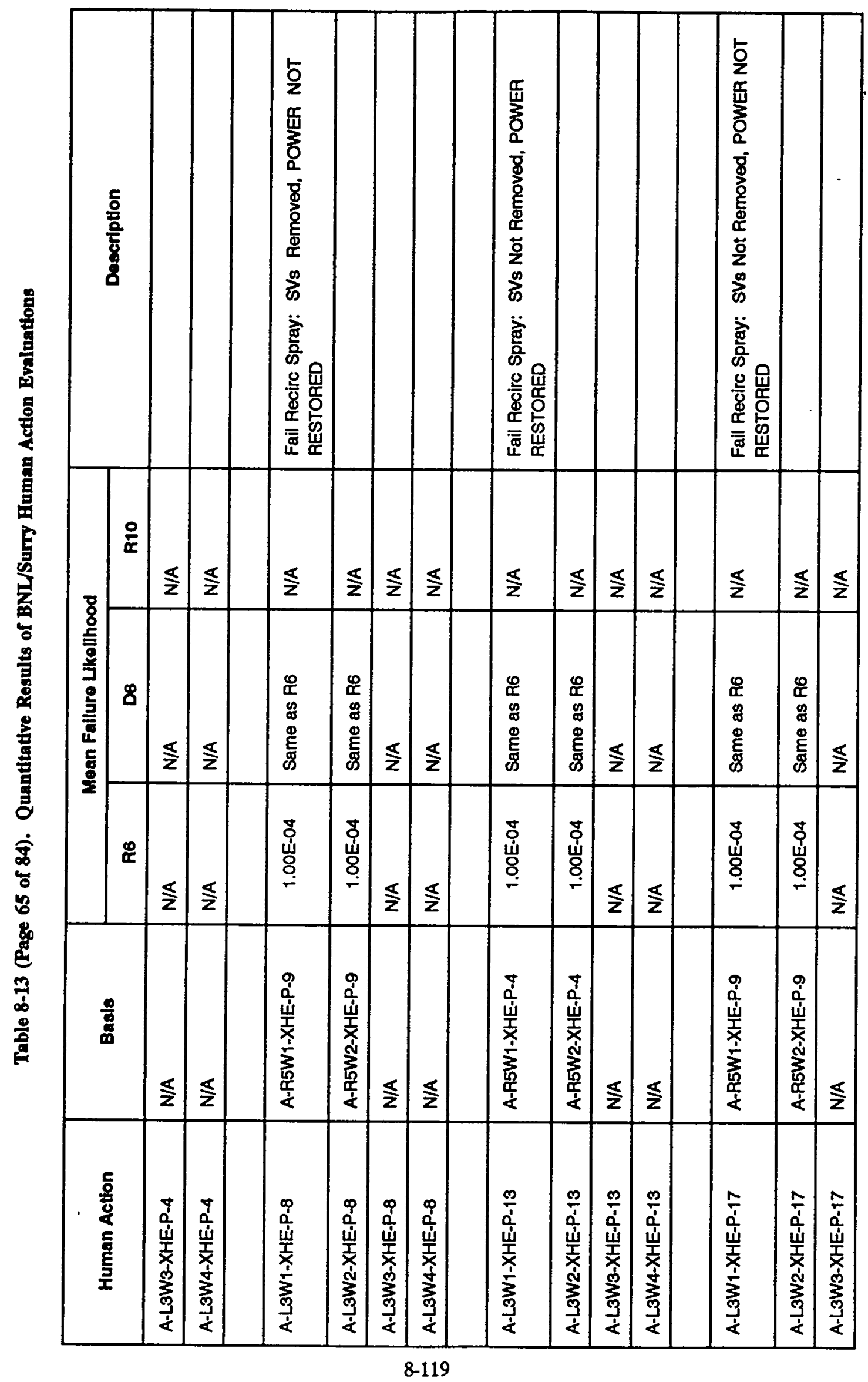




\begin{tabular}{|c|c|c|c|c|c|}
\hline 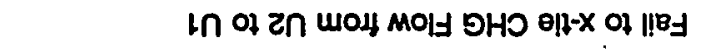 & $\forall / N$ & 9y sB owes & เ०-ヨ08' $\varepsilon$ & pojejnojes & $\checkmark-H O Z-\exists H X-\llcorner M เ g-\forall$ \\
\hline \multirow[t]{3}{*}{. } & 9y se aures & 94 se oures & 20-ヨ0S' & $\forall-M O-\exists H X-b M L \theta-\forall$ & $L-M O-\exists H X-\triangleright M L G-\forall$ \\
\hline & gy se oures & 9H SB oures & 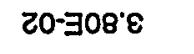 & $\forall-M D-\exists H X-\varepsilon M L Q-\forall$ & $L-M O-\exists H X-\varepsilon M L \theta-\forall$ \\
\hline & $\forall / N$ & 9y s8 oures & 20-ヨ08' $\varepsilon$ & $\nabla-M D-\exists H X-Z M L 8-\forall$ & $L-M O-\exists H X-Z M L \theta-\forall$ \\
\hline \multirow[t]{4}{*}{ 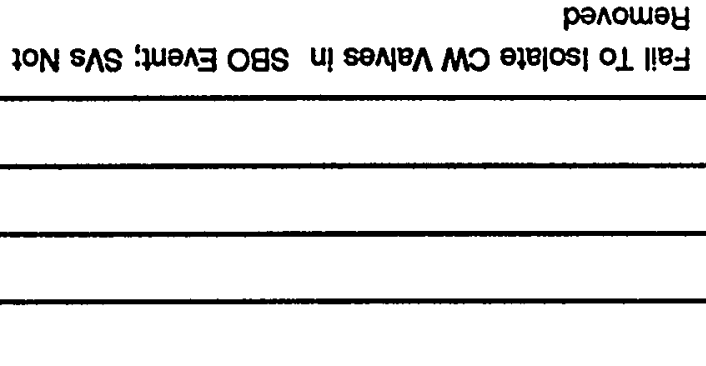 } & $\forall / N$ & 9y se oures & $\left\llcorner 0-\exists 0 S^{\prime}\llcorner\right.$ & $\nabla-M O-\exists H X-L M L \theta-\forall$ & $L-M O-\exists H X-L M L \theta-\forall$ \\
\hline & 94 sB oures & 9y se oures & $20-\exists 0 S^{\prime}$ & peje|nO|в0 & $\checkmark-M O-\exists H X-\nabla M L g-\forall$ \\
\hline & 94 se oures & $9 y$ se əues & $20-\exists 08^{\circ} \varepsilon$ & $\checkmark-M O-\exists H X-Z M L 8-\forall$ & $\checkmark-M D-\exists H X-\varepsilon M L \theta-\forall$ \\
\hline & $\forall / N$ & 9y se әures & $20-\exists 08^{\prime} \varepsilon$ & 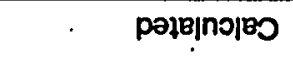 & $\checkmark-M O-\exists H X-Z M L Q-\forall$ \\
\hline \multirow[t]{4}{*}{ 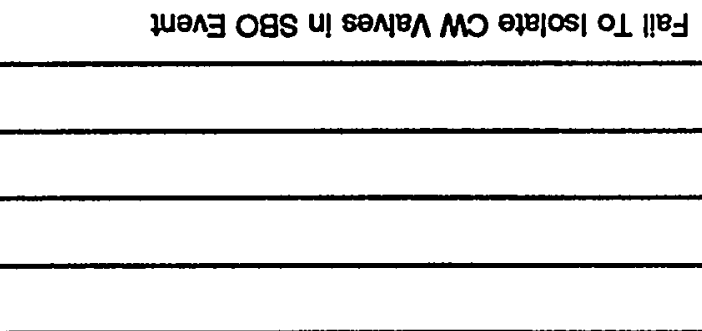 } & $\forall / N$ & 94 SB oures & เO- $\exists 0 S^{\circ}\llcorner$ & poie|nO|вO & $\checkmark-M O-\exists H X-1 M L 8-\forall$ \\
\hline & $9 y \mathrm{sB}$ olues & $9 y$ SB әWBS & $80-\exists 0 Z \vdash$ & pəjв|nD|в0 & $\exists H X-b M+8-0$ \\
\hline & 9y se oules & $9 y$ se owrs & $20-\exists 08 \%$ & $\exists H X-Z M เ \theta-0$ & $\exists H X-8 M L B-O$ \\
\hline & $\forall / N$ & $9 y$ se owes & $20-\exists 0 \varepsilon^{\prime}$ & рә|в|п৩|в0 & $\exists H X-Z M L g-O$ \\
\hline \multirow[t]{4}{*}{ Inoxpघ!g esoube! } & $\forall / N$ & 9y se oures & $20-\exists 0 z \cdot 2$ & pejeinojes & $\exists H X-1 M L 8-O$ \\
\hline & $\forall / N$ & $\forall / N$ & $\forall / N$ & $\forall / N$ & $\angle L-d-\exists H X-b M E T-\forall$ \\
\hline & 나 & 80 & $9 \mathbf{y}$ & \multirow{2}{*}{$\$ 1008$} & \multirow{2}{*}{ uopov uswnH } \\
\hline & \multicolumn{3}{|c|}{ 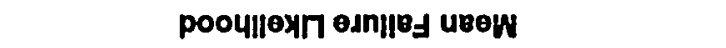 } & & \\
\hline
\end{tabular}


Table 8-13 (Page 67 of 84). Quantitative Results of BNL/Surry Human Action Evaluations

\begin{tabular}{|c|c|c|c|c|c|}
\hline \multirow{2}{*}{ Human Action } & \multirow{2}{*}{ Basls } & \multicolumn{3}{|c|}{ Mean Fallure Lkellhood } & \multirow{2}{*}{ Description } \\
\hline & & $\mathbf{R 6}$ & D6 & R10 & \\
\hline $\mathrm{A}-\mathrm{B} 1 \mathrm{~W} 2-\mathrm{XHE}-2 \mathrm{CH}-4$ & Calculated & $3.70 \mathrm{E}-02$ & Same as $\mathrm{R} 6$ & N/A & \\
\hline $\mathrm{A}-\mathrm{B} 1 \mathrm{~W} 3-\mathrm{XHE}-2 \mathrm{CH}-4$ & A-B1W2-XHE-2CH-4 & 3.70E-02 & Same as R6 & Same as R6 & \\
\hline$A-B 1 W 4-X H E-2 C H-4$ & Calculated & $1.40 \mathrm{E}-03$ & Same as $\mathrm{R} 6$ & Same as R6 & \\
\hline $\mathrm{A}-\mathrm{B} 1 \mathrm{~W}_{1}-\mathrm{XHE}-2 \mathrm{CH}-7$ & Calculated & $3.30 E-01$ & Same as $\mathrm{R} 6$ & N/A & $\begin{array}{l}\text { Fail to } x \text {-tie CHG Flow from U2 to U1; SVs Not } \\
\text { Removed }\end{array}$ \\
\hline $\mathrm{A}-\mathrm{B}+\mathrm{W} 2-\mathrm{XHE}-2 \mathrm{CH}-7$ & Calculated & $3.70 \mathrm{E}-02$ & Same as R6 & N/A & \\
\hline A-B1W3-XHE-2CH-7 & $\mathrm{A}-\mathrm{B} 1 \mathrm{~W} 2-\mathrm{XHE}-2 \mathrm{CH}-4$ & $3.70 E-02$ & Same as $\mathrm{R} 6$ & Same as R6 & \\
\hline A-B1W4-XHE-2CH-7 & Calculated & $1.40 \mathrm{E}-03$ & Same as R6 & Same as R6 & \\
\hline A-B1W1-XHE-S1 & Calculated & 0.55 & Same as R6 & N/A & \\
\hline A-B1W2-XHE-S1 & Calculated & 0.36 & Same as R6 & N/A & \\
\hline A-B1W3-XHE-S1 & Calculated & 0.11 & Same as R6 & Same as R6 & - \\
\hline A-B1W4-XHE-S1 & A-B1W3-XHE-S1 & 0.11 & Same as R6 & Same as R6 & \\
\hline A-B1W1-XHE-G-6 & Conserv Assumption & 1 & N/A & N/A & GRAVITY: Fail To Est. Gravity Foed Following \\
\hline A-BiW2-XHE-G-6 & Conserv Assumption & 1 & N/A & N/A & Failure of Fill and Spill. Only Reasonable Case is if \\
\hline A-B1W3-XHE-G-6 & Conserv Assumption & 1 & N/A & & FR3W1 Failed Due to HW. Use Guaranteed \\
\hline A-B1W4-XHE-G-6 & Conserv Assumption & 1 & N/A & & Failure. Edit to Old Gravity Feed Event only for \\
\hline
\end{tabular}


Table 8-13 (Page 68 of 84). Quantitative Results of BNL/Surry Human Action Evaluations

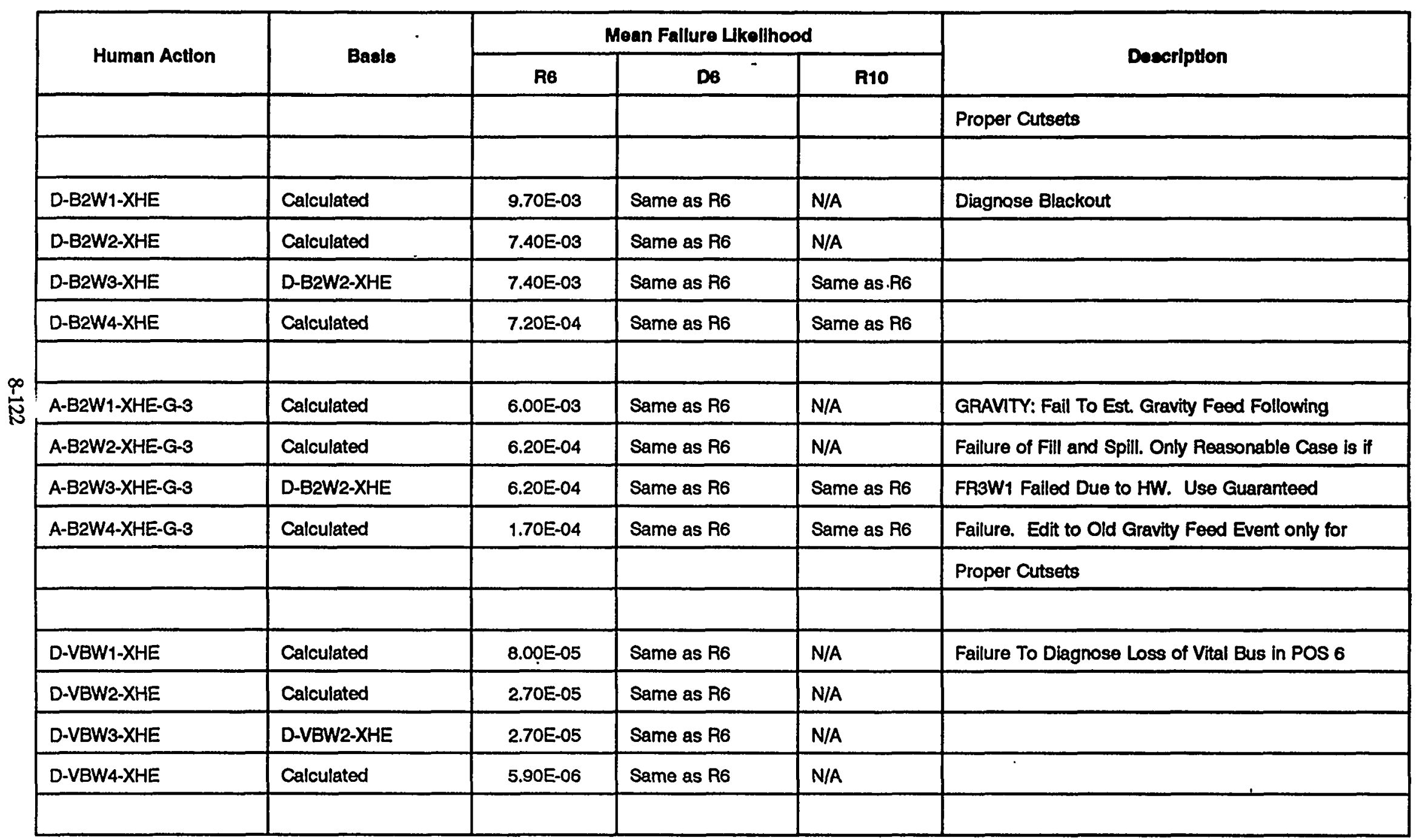


Table 8-13 (Page 69 of 84). Quantitative Results of BNL/Surry Human Action Evaluations

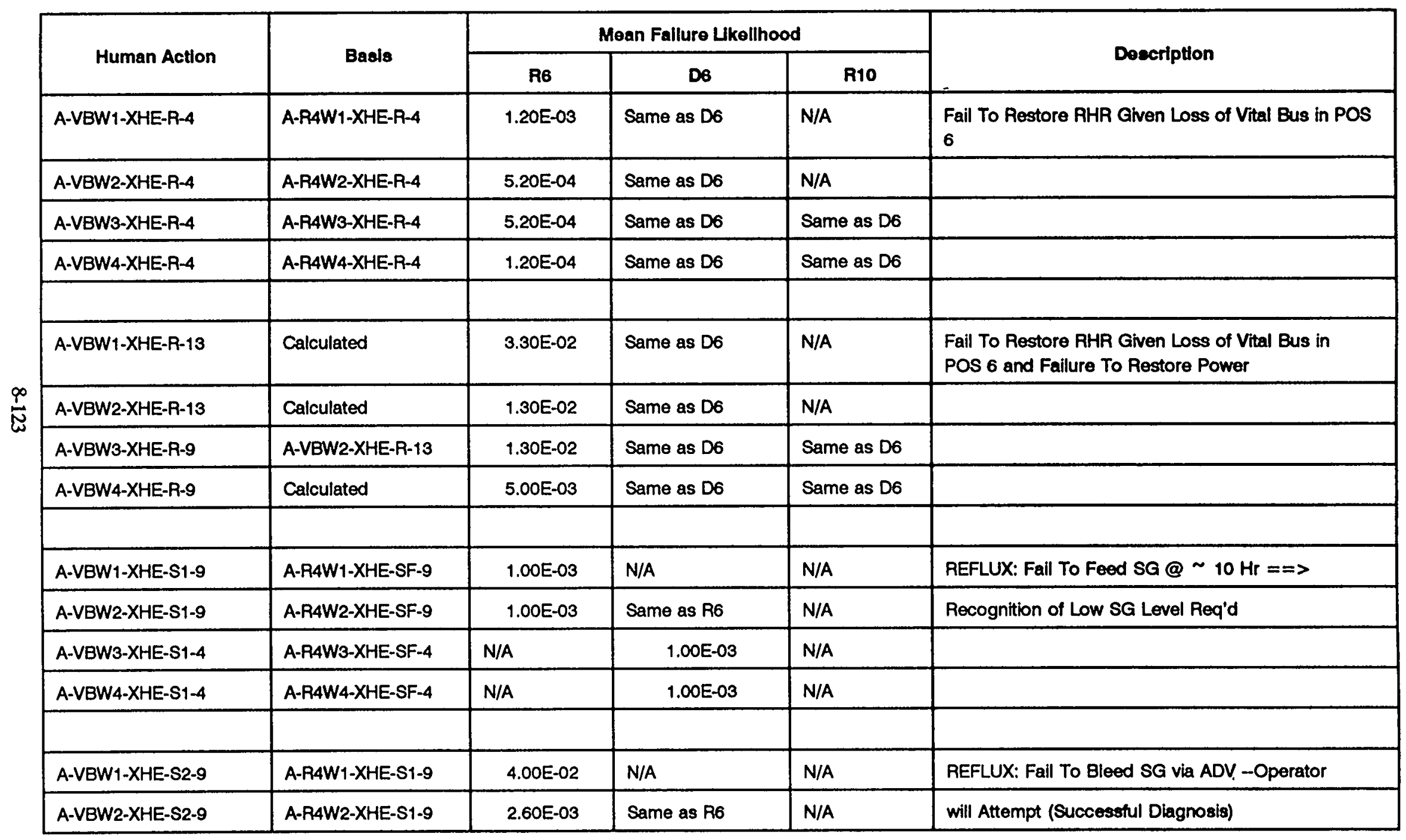


Table 8-13 (Page 70 of 84). Quantitative Results of BNL/Surry Human Action Evaluations

\begin{tabular}{|c|c|c|c|c|c|}
\hline Human Action & Basls & \multicolumn{3}{|c|}{ Mean Fallure Likelihood } & Doscription \\
\hline A-VBW3-XHE-S2-4 & A-R4W3-XHE-S1-4 & N/A & 2.60E-03 & N/A & \\
\hline A-VBW1-XHE-S3-9 & Conserv Assumption & 1 & N/A & N/A & REFLUX: After PAT O/P, FTC PORVs \& Fail To \\
\hline A-VBW2-XHE-S3-9 & Conserv Assumption & 1 & Same as $\mathrm{R} 6$ & N/A & Bleed SG via ADV; Late Action in Response to \\
\hline A-VBW3-XHE-S3-4 & Conserv Assumption & N/A & 1 & N/A & PRT Rupture--Only Reasonable Scenario is that \\
\hline \multirow[t]{3}{*}{ A-VBW4-XHE-S3-4 } & Conserv Assumption & N/A & 1 & N/A & Operator is Distracted by HW or Other Failures. \\
\hline & & & & & PRT Rupture is Strong Cue To Move Ahead in \\
\hline & & & & & AP-27 \\
\hline A-VBW1-XHE-S1-18 & A-SIW1-XHE-S1-9 & $1.00 E-03$ & N/A & N/A & $\begin{array}{l}\text { REFLUX: Given Failure To Restore RHR Fail To Feed } \\
\text { SG @ } \sim 10 \mathrm{Hr}==>\end{array}$ \\
\hline A-VBW2-XHE-S1-18 & A-SIW2-XHE-S1-9 & $1.00 E-03$ & Same as R6 & N/A & Recognition of Low SG Level Req'd \\
\hline A-VBW3-XHE-S1-18 & A-SIW3-XHE-S1-4 & N/A & $1.00 E-03$ & N/A & \\
\hline A-VBW4-XHE-S1-18 & A-SIW4-XHE-S1-4 & N/A & $1.00 \mathrm{E}-03$ & N/A & \\
\hline A-VBW1-XHE-S2-18 & Calculated & 4.00E-01 & N/A & N/A & $\begin{array}{l}\text { REFLUX: Given failure to restore RHA, Fail to bleed } \\
\text { SG via ADV - Operator }\end{array}$ \\
\hline A-VBW2-XHE-S2-18 & Calculated & 2.60E-02 & Same as $\mathrm{R} 6$ & N/A & will Attempt (Successful Diagnosis) \\
\hline
\end{tabular}


Table 8-13 (Page 71 of 84). Quantitative Results of BNL/Surry Human Action Evaluations

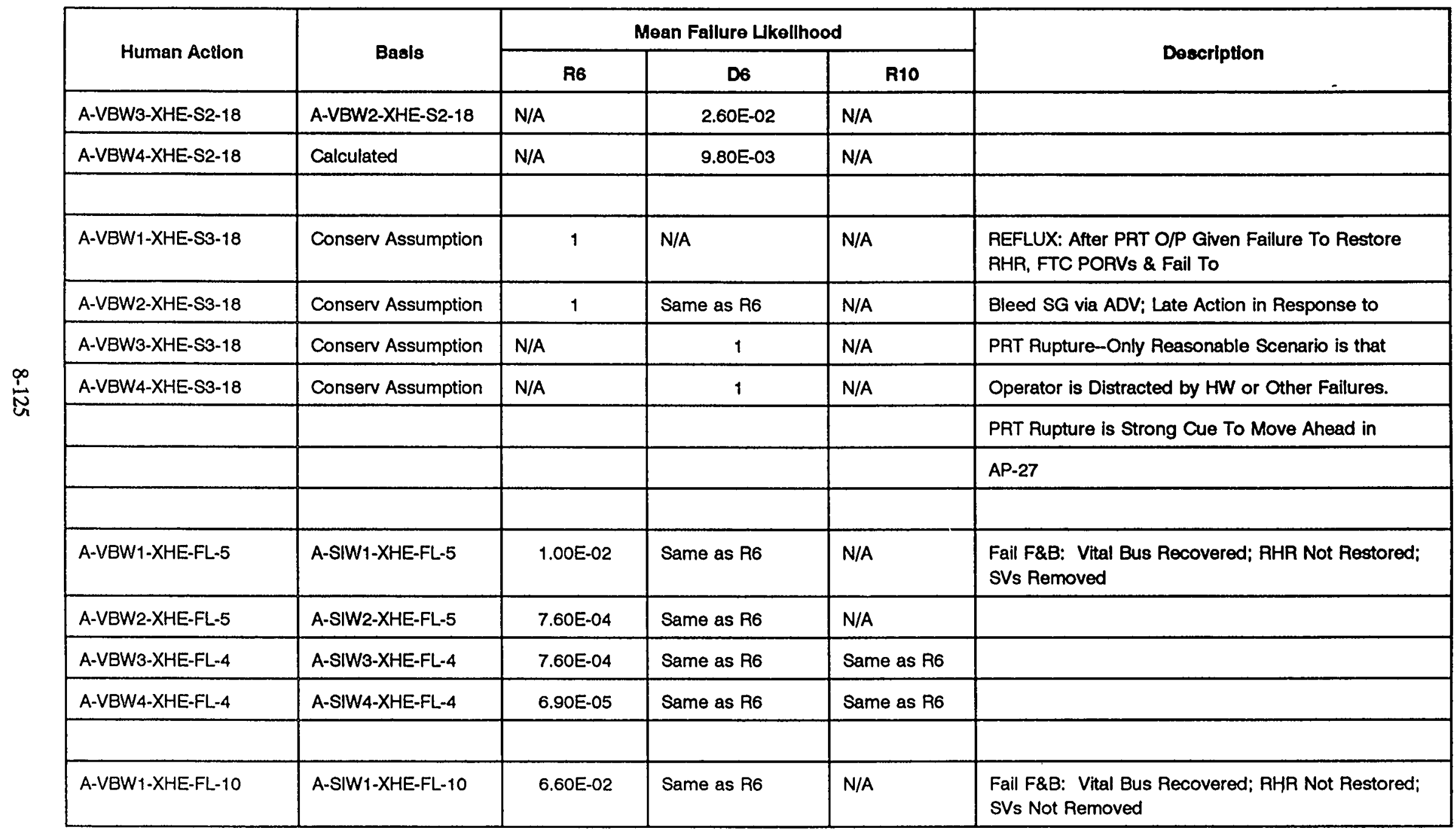


Table 8-13 (Page 72 of 84). Quantitative Results of BNL/Surry Human Action Evaluations

\begin{tabular}{|c|c|c|c|c|c|}
\hline Human Action & Basls & \multicolumn{3}{|c|}{ Moan Fallure Likellhood } & Description \\
\hline A-VBW2-XHE-FL-10 & A-SIW2-XHE-FL-10 & $2.00 \mathrm{E}-03$ & Same as R6 & N/A & \\
\hline A-VBW4-XHE-FL-13 & A-SIW4-XHE-FL-13 & $6.90 \mathrm{E}-05$ & Same as $\mathrm{R} 6$ & Same as R6 & \\
\hline \multirow[t]{3}{*}{ A-VBW2-XHE-FL-14 } & Calculated & $3.50 \mathrm{E}-02$ & Same as R6 & N/A & \\
\hline & A-VBW2-XHE-FL-14 & $3.50 \mathrm{E}-02$ & Same as R6 & Same as R6 & \\
\hline & Calculated & $5.00 E-03$ & Same as R6 & Same as R6 & \\
\hline A-VBW3-XHE-FL-7 & A-VBW3-XHE-FL-10 & $5.40 E-02$ & Same as R6 & Same as R6 & \\
\hline A-VBW4-XHE-FL-7 & A-VBW4-XHE-FL-10 & 5.00 E-03 & Same as R6 & Same as R6 & \\
\hline A-VBW1-XHE-FH-5 & A-RAW1-XHE-FH-5 & $5.00 E-05$ & Same as R6 & N/A & $\begin{array}{l}\text { Fail F\&B: Vital Bus Recovered; RHA Not Restored; } \\
\text { SVs Removed }\end{array}$ \\
\hline A-VBW2-XHE-FH-5 & A-RAW2-XHE-FH-5 & $2.00 E-05$ & Same as R6 & N/A & \\
\hline
\end{tabular}


Table 8-13 (Page 73 of 84). Quantitative Results of BNL/Surry Human Action Eraluations

\begin{tabular}{|c|c|c|c|c|c|}
\hline \multirow{2}{*}{ Human Action } & \multirow{2}{*}{ Baels } & \multicolumn{3}{|c|}{ Mean Fallure Ukellhood } & \multirow{2}{*}{ Description } \\
\hline & & R8 & D6 & $\mathbf{R} 10$ & \\
\hline A-VBW3-XHE-FH-4 & A-RAWB-XHE-FH-5 & $2.00 E-05$ & Same as R6 & Same as R6 & \\
\hline A-VBW4-XHE-FH-4 & A-RAW4-XHE-FH-5 & $2.00 E-05$ & Same as R6 & Same as R6 & \\
\hline A-VBW1-XHE-FH-10 & A-RAW1-XHE-FH-5 & $5.00 E-05$ & Same as R6 & N/A & $\begin{array}{l}\text { Fail F\&B: Vital Bus Recovered; RHR Not Restored; } \\
\text { SVs Not Removed }\end{array}$ \\
\hline A-VBW2-XHE-FH-10 & A-RAW2-XHE-FH-5 & $2.00 E-05$ & Same as R6 & N/A & \\
\hline A-VBW3-XHE-FH-13 & A-RAW3-XHE-FH-5 & $2.00 E-05$ & Same as R6 & Same as $\mathrm{R} 6$ & \\
\hline A-VBW4-XHE-FH-13 & A-RAW4-XHE-FH-5 & $2.00 E-05$ & Same as R6 & Same as R6 & \\
\hline A-VBW1-XHE-FH-14 & A-RAW1-XHE-FH-5 & $5.00 E-05$ & Same as R6 & N/A & $\begin{array}{l}\text { Fail F\&B: Vital Bus Recovered; RHA Not Restored; } \\
\text { SVs Removed }\end{array}$ \\
\hline A-VBW2-XHE-FH-14 & A-RAW2-XHE-FH-5 & $2.00 E-05$ & Same as R6 & N/A & \\
\hline A-VBW3-XHE-FH-10 & A-RAW3-XHE-FH-5 & $2.00 E-05$ & Same as $\mathrm{R} 6$ & Same as R6 & \\
\hline A-VBW4-XHE-FH-10 & A-RAW4-XHE-FH-5 & $2.00 E-05$ & Same as R6 & Same as R6 & \\
\hline A-VBW1-XHE-FH-19 & A-RAW1-XHE-FH-5 & 5.00E-05 & Same as R6 & N/A & $\begin{array}{l}\text { Fail F\&B: Vital Bus Recovered; RHR Not Restored; } \\
\text { SVs Not Removed }\end{array}$ \\
\hline A-VBW2-XHE-FH-19 & A-PAW2-XHE-FH-5 & $2.00 E-05$ & Same as $\mathrm{R} 6$ & N/A & \\
\hline A-VBW3-XHE-FH-7 & A-RAW3-XHE-FH-5 & $2.00 \mathrm{E}-05$ & Same as R6 & Same as R6 & \\
\hline
\end{tabular}


Table 8-13 (Page 74 of 84). Quantitative Results of BNL/Surry Human Action Evaluations

\begin{tabular}{|c|c|c|c|c|c|}
\hline \multirow{2}{*}{ Human Action } & \multirow{2}{*}{ Basis } & \multicolumn{3}{|c|}{ Mean Fallure Llkellhood } & \multirow{2}{*}{ Doscription } \\
\hline & & $\mathbf{A B}$ & D6 & R10 & \\
\hline Aं-VBW4-XHE-FH-7 & A-RAW'-XHE-FH-5 & $2.00 E-05$ & Same as R6 & Same as R6 & \\
\hline A-VBW1-XHE-G6 & Conserv Assumption & 1 & N/A & N/A & GRAVITY: Fail To Est. Gravity Feed Following \\
\hline A-VBW2-XHE-G6 & Consẹrv Assumption & 1 & N/A & N/A & Failure of Fill and Spill. Vital Bus Recovered. \\
\hline A-VBW3-XHE-G5 & Consérv Assumption & 1 & N/A & Same as R6 & \\
\hline A-VBW4-XHE-G5 & Conserv Assumption & 1 & N/A & Same as R6 & \\
\hline \\
\hline A-VBW1-XHE-G15 & Conserv Assumption & 1 & N/A & N/A & GRAVITY: Fail To Est. Gravity Feed Following \\
\hline A-VBW2-XHE-G15 & Conserv Assumption & 1 & N/A & N/A & Failure of Fill and Spill. Vital Bus Not Recovered \\
\hline$A^{\prime}-V B W 3-X H E-G 11$ & Conserv Assumption & 1 & N/A & Same as R6 & \\
\hline A-VBW4-XHE-G11 & Conserv Assumption & 1 & N/A & Same as R6 & \\
\hline A-VBW1-XHE-C-4 & A-RAW $1-X H E-C-4$ & $1.00 E-03$ & Same as R6 & N/A & $\begin{array}{l}\text { RECIRC: Fail To Est. HP Recirc Nital Bus Recovered, } \\
\text { B\&F Successful) }\end{array}$ \\
\hline A-VBW2-XHE-C-4 & A-R4W2-XHE-C-4 & $1.00 \mathrm{E}-03$ & Same as R6 & N/A & and SVs Removed)-@ 8 - $20 \mathrm{Hr},==>$ Recognition \\
\hline A-VBW3-XHE-C-4 & N/A & N/A & N/A & N/A & of Low RWST Level Req'd. \\
\hline A-VBW4-XHE-C-4 & N/A & N/A & N/A & N/A & . \\
\hline
\end{tabular}


Table 8-13 (Page 75 of 84). Quantitative Results of BNL/Surry Human Action Evaluations

\begin{tabular}{|c|c|c|c|c|c|}
\hline \multirow{2}{*}{ Human Action } & \multirow{2}{*}{ Basis } & \multicolumn{3}{|c|}{ Moan Fallure Ukelihood } & \multirow{2}{*}{ Description } \\
\hline & & R6 & DE & R10 & \\
\hline A-VBW1-XHE-C-13 & A-R5W1-XHE-C-9 & $1.00 E-03$ & Same as $\mathrm{R} 6$ & N/A & $\begin{array}{l}\text { RECIRC: Fail To Est. HP Recirc Nital Bus Not } \\
\text { Recovered, B\&F Successful }\end{array}$ \\
\hline A-VBW2-XHE-C-13 & A-R5W2-XHE-C-9 & $1.00 E-03$ & Same as $\mathrm{R} 6$ & N/A & and SVs Removed)-@8 - 20 Hr, ==> Recognition \\
\hline A-VBW3-XHE-C-13 & N/A & N/A & N/A & N/A & of Low RWST Level Req'd \\
\hline A-VBW4-XHE-C-13 & N/A & N/A & N/A & N/A & \\
\hline A-VBW1-XHE-C-9 & A-RAW1-XHE-C-4 & $1.00 \mathrm{E}-03$ & Same as R6 & N/A & $\begin{array}{l}\text { RECIRC: Fail To Est. HP Recirc Nital Bus Recovered } \\
\text { B\&F Successful }\end{array}$ \\
\hline A-VBW2-XHE-C-9 & A-PAW2-XHE-C-4 & $1.00 \mathrm{E}-03$ & Same as R6 & N/A & $\begin{array}{l}\text { and SVs Not Removed)-@ } 8-20 \mathrm{Hr},==> \\
\text { Recognition }\end{array}$ \\
\hline A-VBW1-XHE-C-18 & A-RSW1-XHE-C-9 & $1.00 E-03$ & Same as R6 & N/A & $\begin{array}{l}\text { RECIRC: Fail To Est. HP Recirc Nital Bus Not } \\
\text { Recovered, B\&F Successful }\end{array}$ \\
\hline A-VBW2-XHE-C-18 & A-R5W2-XHE-C-9 & $1.00 E-03$ & Same as $\mathrm{R} 6$ & N/A & $\begin{array}{l}\text { and SVs Not Removed)-@ } 8-20 \mathrm{Hr},==> \\
\text { Recognition }\end{array}$ \\
\hline A-VBW3-XHE-C-18 & N/A & N/A & N/A & N/A & of Low RWST Level Req'd \\
\hline A-VBW4-XHE-C-18 & N/A & N/A & N/A & N/A & \\
\hline
\end{tabular}


Table 8-13 (Page 76 of 84). Quantitative Results of BNL/Surry Human Action Evaluations

\begin{tabular}{|c|c|c|c|c|c|}
\hline Human Action & Basls & \multicolumn{3}{|c|}{ Moan Fallure Lkollhood } & Description \\
\hline A-VBW2-XHE-X & A-RAW2-XHE-X & $1.00 \mathrm{E}-03$ & Same as $\mathrm{R} 6$ & N/A & Fall To Cross Tie RWST \\
\hline A-VBW1-XHE-P-4 & A-RAW1-XHE-P-4 & $1.00 E-04$ & Same as R6 & N/A & $\begin{array}{l}\text { RECIRC: Fail To Est. Recirc Spray Nital Bus } \\
\text { Recovered, B\&F Successful }\end{array}$ \\
\hline A-VBW3-XHE-P-4 & N/A & N/A & N/A & N/A & \\
\hline A-VBW4-XHE-P-4 & N/A & N/A & N/A & N/A & \\
\hline A-VBW1-XHE-P-13 & A-R5W1-XHE-P-9 & $1.00 E-04$ & Same as R6 & N/A & $\begin{array}{l}\text { RECIRC: Fail To Est. Recirc Spray Nital Bus Not } \\
\text { Recovered, B\&F Successful }\end{array}$ \\
\hline A-VBW1-XHE-P-9 & A-RAW1-XHE-P-4 & $1.00 E-04$ & Same as $\mathrm{R} 6$ & N/A & $\begin{array}{l}\text { RECIRC: Fail To Est. Recirc Spray Nital Bus } \\
\text { Recovered, B\&F Successful }\end{array}$ \\
\hline A-VBWZ-XHE-P-9 & A-RAW2-XHE-P-4 & $1.00 \mathrm{E}-04$ & Same as $\mathrm{R} 6$ & N/A & and SVs Not Removed) \\
\hline A-VBW3-XHE-P-9 & N/A & N/A & N/A & N/A & \\
\hline A-VBW4-XHE-P-9 & N/A & N/A & N/A & N/A & \\
\hline
\end{tabular}


Table 8-13 (Page 77 of 84). Quantitative Results of BNU/Surry Human Action Evaluations

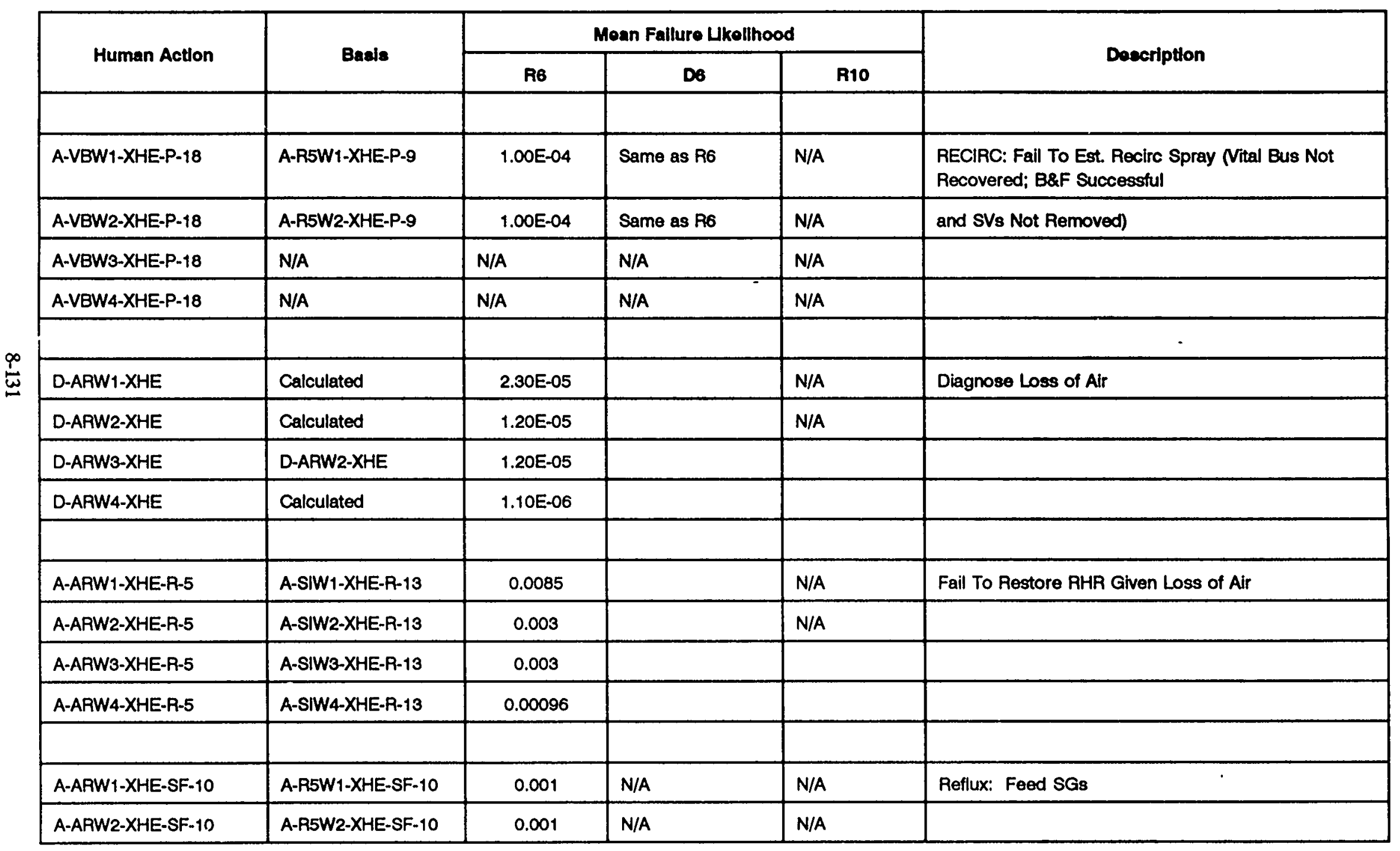


Table 8-13 (Page 78 of 84). Quantitative Results of BNL/Surry Human Action Evaluations

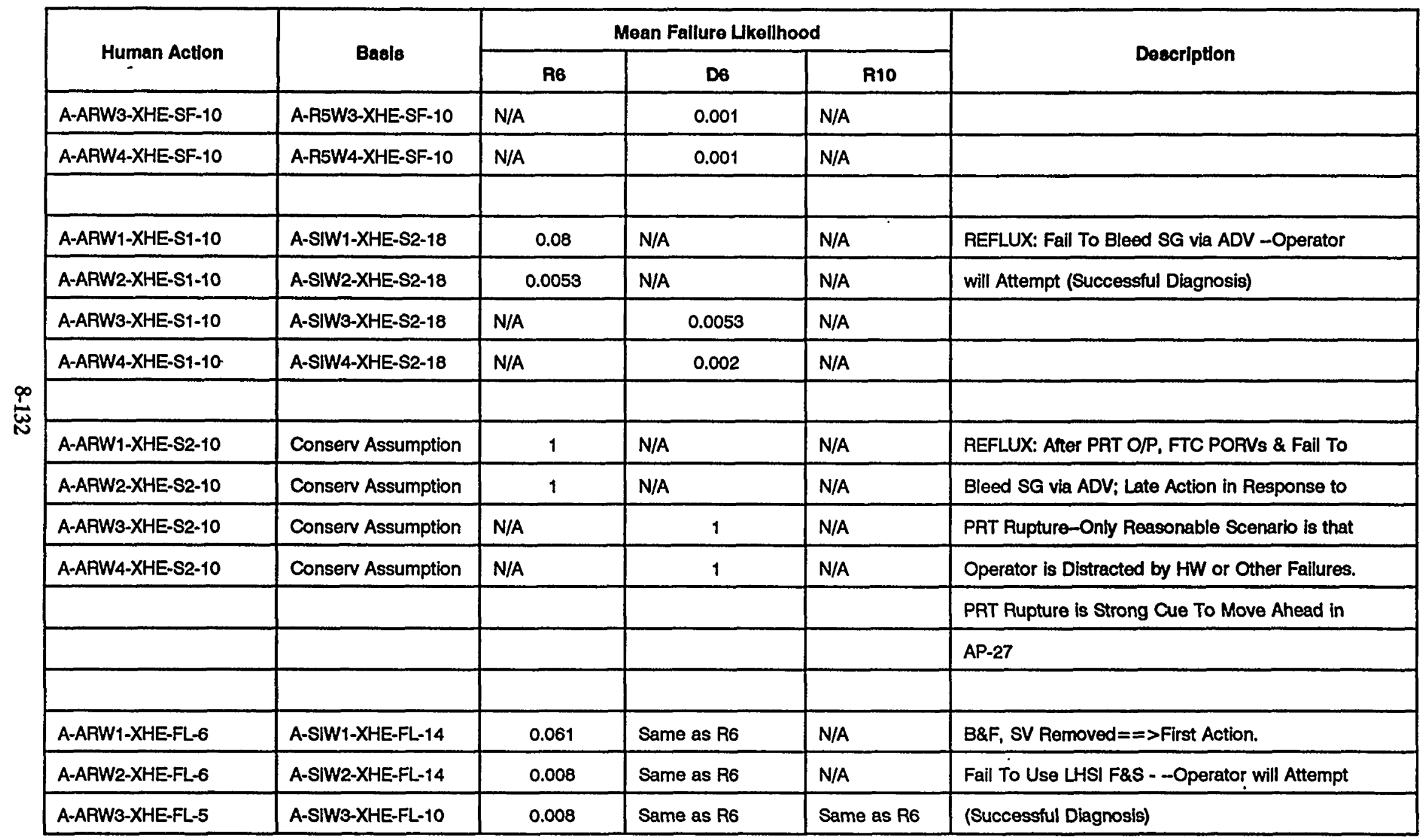


Table 8-13 (Page 79 of 84). Quantitative Results of BNL/Surry Human Action Evaluations

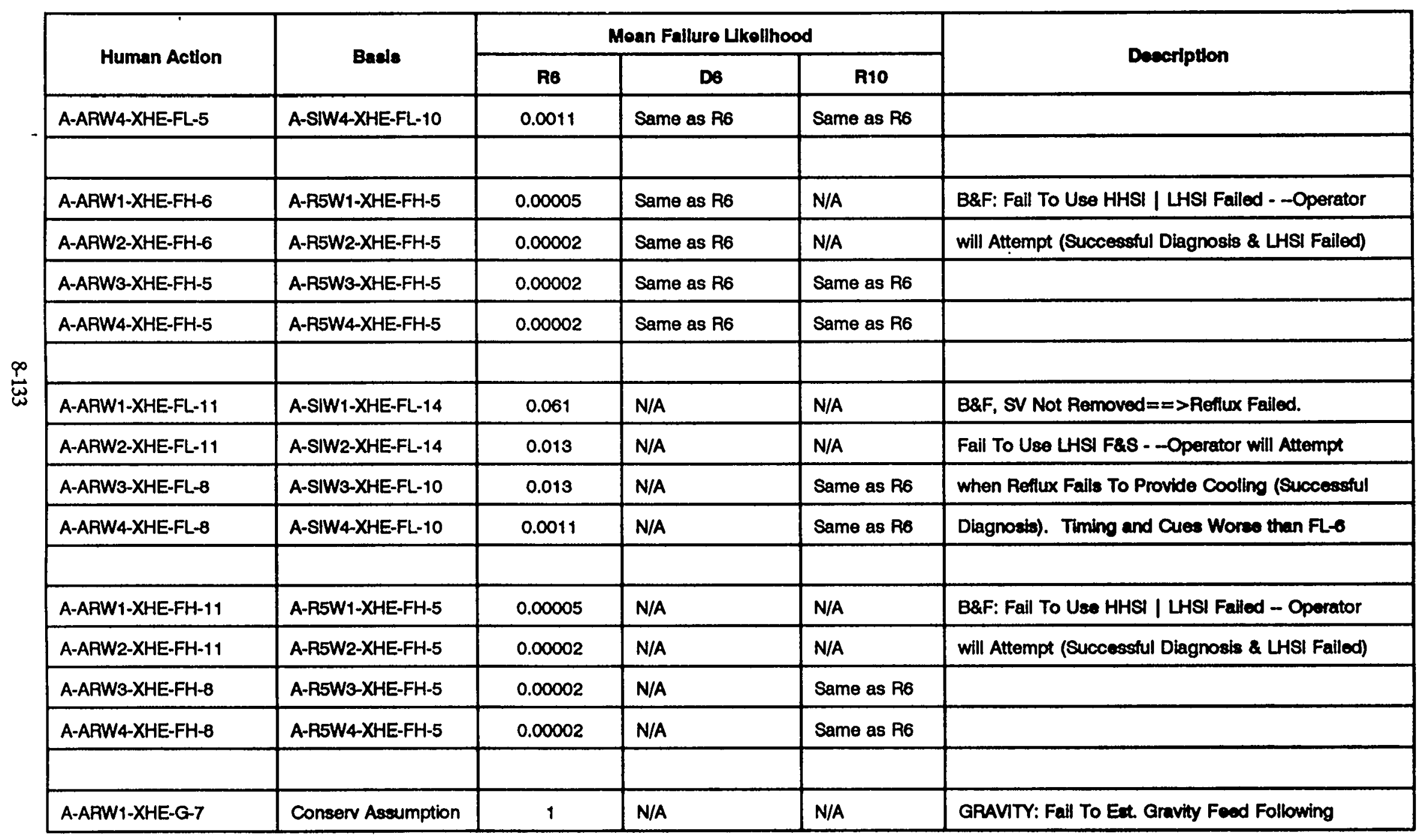


Table 8-13 (Page 80 of 84). Quantitative Results of BNL/Surry Human Action Evaluations

\begin{tabular}{|c|c|c|c|c|c|}
\hline \multirow{2}{*}{ Human Action } & \multirow{2}{*}{ Basis } & \multicolumn{3}{|c|}{ Mean Fallure Lkellhood } & \multirow{2}{*}{ Description } \\
\hline & & $\mathbf{R 6}$ & D6 & $\mathbf{R 1 0}$ & \\
\hline A-ARW2-XHE-G-7 & Conserv Assumption & 1 & N/A & N/A & Failure of Fill and Spill. Only Reasonable Case is if \\
\hline A-ARW3-XHE-G-6 & Conserv Assumption & 1 & N/A & Same as R6 & F\&S Failed Due to HW. Use Guaranteed \\
\hline \multirow[t]{2}{*}{ A-ARW4-XHE-G-6 } & Conserv Assumption & 1 & N/A & Same as R6 & Failure. Edit to Old Gravity Feed Event Only for \\
\hline & & & & & Cutsets with Success of A-AFW\#-XHE-FL-6. \\
\hline A-ARW1-XHE-C-5 & A-R5W1-XHE-C-4 & 0.001 & Same as R6 & N/A & RECIRC: Fail T Est. HP Rcirc (B\&F Successful \\
\hline A-ARW2-XHE-C-5 & A-R5W2-XHE-C-4 & 0.001 & Same as R6 & N/A & and SVs Removed)-@ 8 - $20 \mathrm{Hr},==>$ Recognition \\
\hline A-ARW3-XHE-C-5 & A-R5WB-XHE-C-4 & N/A & N/A & N/A & of Low RWST Level Req'd. \\
\hline A-ARW4-XHE-C-5 & A-R5W4-XHE-C-4 & N/A & N/A & N/A & \\
\hline A-ARW3-XHE-C-10 & A-R5W3-XHE-C-9 & N/A & N/A & N/A & Recognition of Low RWST Level Req'd \\
\hline A-ARW4-XHE-C-10 & A-R5W4-XHE-C-9 & N/A & N/A & N/A & \\
\hline A-ARW1-XHE-P-5 & A-R4W1-XHE-P-4 & 0.0001 & Same as R6 & N/A & RECIRC: Fail To Est. Recirc Spray \\
\hline A-ARW2-XHE-P-5 & A-R4W2-XHE-P-4 & 0.0001 & Same as $\mathrm{R} 6$ & N/A & \\
\hline A-ARW3-XHE-P-5 & N/A & N/A & N/A & N/A & \\
\hline
\end{tabular}




\begin{tabular}{|c|c|c|c|c|c|}
\hline & 9y SB aUtes & 9H SB OUIES & SO- $\exists 0 L^{\prime} 9$ & 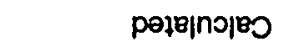 & $\varepsilon-\supset H-\exists H X-\sqcup M U S-H$ \\
\hline . & 9y se әures & $9 y$ se ames & †O-ヨ0Z' & $\varepsilon-\supset H-3 H X-Z M Y S-\forall$ & $\varepsilon-\partial y-\exists H X-\varepsilon M H S-y$ \\
\hline & $\forall / N$ & 9y se oures & DO- $\exists 0 Z^{\prime} \downarrow$ & рә|в|пગ|в૦ & $\varepsilon-\supset H-\exists H X-2 M U S-H$ \\
\hline \multirow[t]{4}{*}{ 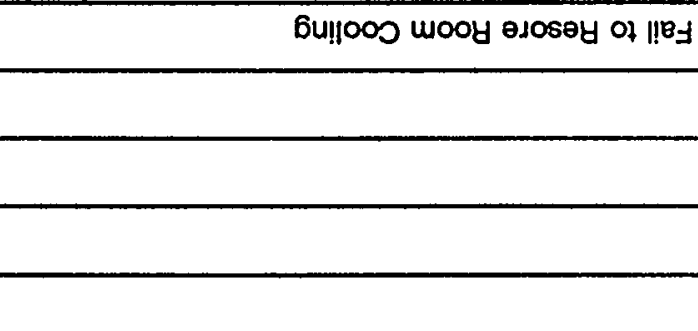 } & $\forall / N$ & 94 se oures & $\square 0-\exists 06^{\prime} 2$ & 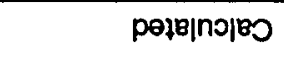 & $\varepsilon-\partial y-\exists H X-L M Y S-H$ \\
\hline & 94 SB awres & 94 se oures & $80-\exists 08^{\circ}$ & 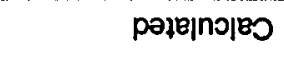 & $\exists H X-b M U S-O$ \\
\hline & 9t se oures & 9y se oures & $20-\exists 0 \nabla^{\circ} \mathrm{L}$ & $\exists H X-Z M B S-O$ & $\exists H X-\varepsilon M G S-\square$ \\
\hline & $\forall / N$ & 9y se omes & $20-\exists 00 \cdot 1$ & рәје|пэво & $\exists H X-Z M U S-O$ \\
\hline Bu!!1000 woot jo sso7 esoube!̣ & $\forall / N$ & 94 se oures & $20-300 \div$ & рө|в|пગво & $\exists H X-1 M G S-O$ \\
\hline \multirow[t]{4}{*}{ LSMH LOULUOS SSOJO OL } & $\forall / N$ & $9 y$ se ames & 1000 & $X-\exists H X-Z M \forall \forall-\forall$ & $X-\exists H X-Z M \forall \forall \forall-\forall$ \\
\hline & $\forall / N$ & $\forall / N$ & $\forall / N$ & $\forall / N$ & 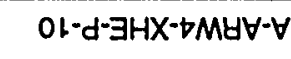 \\
\hline & $\forall / N$ & $\forall / N$ & $\forall / N$ & $\forall / N$ & OL-d-ヨHX-EMU $\forall-\forall$ \\
\hline & $\forall / N$ & 9y se ames & $1000^{\circ} 0$ & $6-d-\exists H X-Z M S Y-\forall$ & $O L-d-\exists H X-Z M \forall \forall-\forall$ \\
\hline \multirow[t]{3}{*}{ 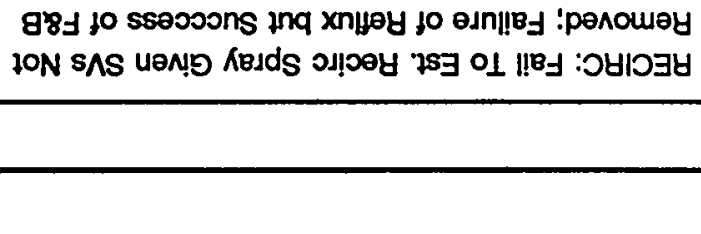 } & $\forall / N$ & 9y se aures & $1000^{\circ} 0$ & $6-d-\exists H X-1 M S G-\forall$ & OL-d-ヨHX-1MUV- $\forall$ \\
\hline & & & & . & \\
\hline & $\forall / N$ & $\forall / N$ & $\forall / N$ & $\forall / N$ & $s-d-\exists H X-\nabla M U \forall-\forall$ \\
\hline \multirow{2}{*}{ uopdpsoeed } & Oty & 80 & $9 \mathbf{y}$ & \multirow{2}{*}{$8 / 888$} & \multirow{2}{*}{ บo|po UвunH } \\
\hline & \multicolumn{3}{|c|}{ 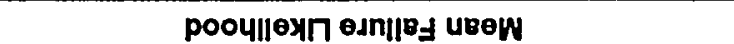 } & & \\
\hline
\end{tabular}




\begin{tabular}{|c|c|c|c|c|c|}
\hline :Renosey & & & SLE00.0 & pejeinojes & $0-\exists H X-9 y Z M \varepsilon O-H$ \\
\hline :Renosery & & sle00'0 & StE00'0 & 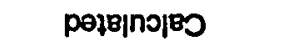 & 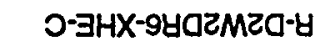 \\
\hline :Nienosey & & & SiE00.0 & peje|nO|вO & $10-0-\exists H X-9 \forall Z M L O-H$ \\
\hline 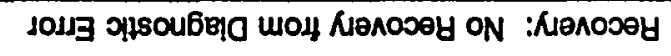 & & $\vdash$ & 1 & pounssy & $0-3 H X-940$ L \\
\hline 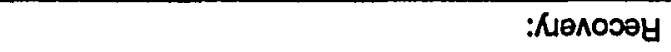 & & & $1 \varepsilon t 00^{\circ} 0$ & pejejnojes & $0-\exists H X-9 \forall L M Z L \forall-Y$ \\
\hline :RIOnOSOY & & & $18600^{\circ} 0$ & 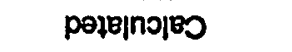 & $0-3 H X-9 \forall$ LMLLV-Y \\
\hline :Renosey & & & $\varepsilon t b 00^{\circ} 0$ & peje|ñ|в & $8 \forall-0-\exists H X-9 \forall+M 8 \forall-Y$ \\
\hline :R⿴囗лоӭH & & & SLEOO'O & pə|в|nэ|в & $\angle \forall-0-\exists H X-9 \forall Z M \angle \forall-\forall$ \\
\hline :RenOsøy & & Letoo'o & & poje|nojes & $2 \forall-0-\exists H X-90+M Z \forall-\forall$ \\
\hline :Renosey & & $18 t 00^{\circ} 0$ & & 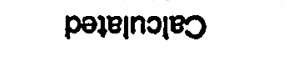 & $0-\exists H X-90$ IMZV- \\
\hline :Rønosy & & LEt00.0 & & 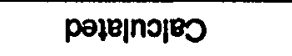 & LV-D-JHX-9OLMLV-Y \\
\hline :NenOxOy & & $18+\infty 0^{\circ} 0$ & & poleinoleo & $0-\exists H X-9 O L M L \forall-Y$ \\
\hline & 9y sB owrs & 9Y SB OUIES & $20-\exists 0 S^{\prime} b$ & $\forall-M O-\exists H X+\neg M L 8-\forall$ & $E-M D-\exists H X+M H S-\forall$ \\
\hline & gy se owes & 9488 owes & $20-\exists 08^{\prime} \varepsilon$ & $\forall-M D-\exists H X-\varepsilon M L \theta-\forall$ & $\varepsilon-M D-\exists H X-\varepsilon M U S-\forall$ \\
\hline & $\forall / N$ & 94 se ours & $20-308^{\prime} \varepsilon$ & $\checkmark-M O-\exists H X-Z M L \theta \forall$ & $\varepsilon-M D-\exists H X-2 M H S-\forall$ \\
\hline 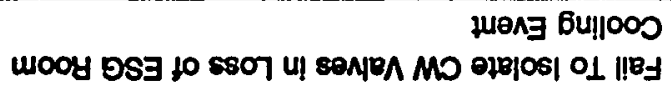 & $\forall / N$ & OH 88 owres & $10-\exists 0 s^{\circ} \downarrow$ & $D-M O-\exists H X-L M L \theta-\forall$ & $E-M O-\exists H X-L M Y S-\forall$ \\
\hline \multirow{2}{*}{ uopdposed } & OLty & $\infty$ & oy & \multirow{2}{*}{ operg } & \multirow{2}{*}{ uopov usunH } \\
\hline & \multicolumn{3}{|c|}{ 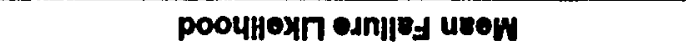 } & & \\
\hline
\end{tabular}

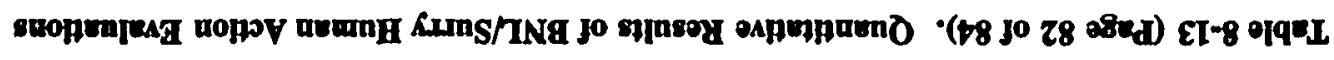




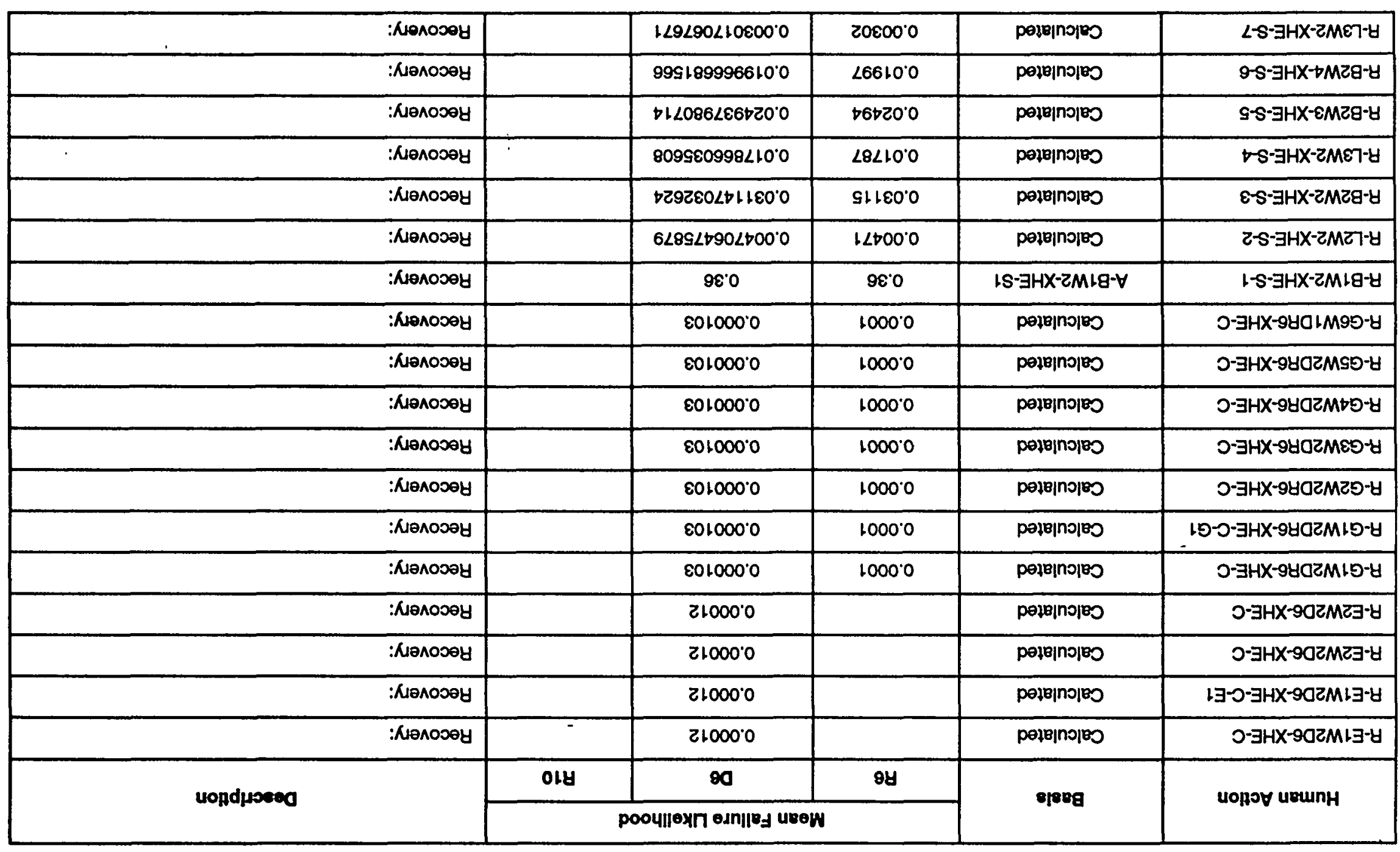


Table 8-13 (Page 84 of 84). Quantitative Results of BNL/Surry Human Action Evaluations

\begin{tabular}{|l|c|c|c|c|l|}
\hline \multirow{2}{*}{ Human Action } & \multirow{2}{*}{ Basls } & \multicolumn{3}{|c|}{ Mean Fallure Lkellhood } & \multicolumn{2}{c}{ Doscription } \\
\cline { 3 - 6 } & & R6 & D6 & R10 & \\
\hline R-L3W2-XHE-C-8 & Calculated & 0.01568 & 0.015680300366 & & Recovery: \\
\hline R-B1W3-XHE-S-9 & Calculated & 0.32942 & 0.329415064253 & & Recovery: \\
\hline
\end{tabular}




\section{DATA BASE DEVELOPMENT}

\subsection{Maintenance Unavailability}

Maintenance unavailability of components was estimated for each plant operational state (POS) using data extracted from the shift supervisor's log books and the minimum equipment lists. Ten years of $\log$ books, five years for each unit (from 1985 to 1989), plus the 1990 refueling outage of unit 1, were obtained from Virginia Power. Deciphering the information in the hand written log books was a very time-consuming task; therefore, we selected to review the log books for only three of these refueling outages. The outages selected were 1986 refueling outages of unit 1 and unit 2, respectively, and 1990 refueling outage of unit 1.

The following four types of information were of particular interest:

(a) Maintenance/repairon safety and support systems

(b) Important events associated with important systems or components.

(c) Potential fire, and flood-related events.

(d) Periodic tests.

The information collected was entered into DBASE databases.

Minimum equipment lists for these three refueling outages also were obtained from Virginia Power. During an outage, these lists are filled out once every shift for components that are subject to requirements as stipulated in plant technical specifications for a given operational mode. Surry Station uses two types of minimum equipment lists: one for cold shutdown conditions, and the other for non-cold shutdown conditions. In this study, these minimum equipment lists were used to supplement information obtained from the $\log$ books. Figure 9.1-1 is an example of the information collected from the log books and minimum equipment lists.

In collecting maintenance data, the times at which a component was taken out of service (OOS) and later returned to service (RTS) were identified. However, some data in the log books or the minimum equipment lists were ambiguous. Sometimes an entry in the log book indicated that a particular component was tagged out, but the record of the tag-in of the same component could not be found. In contrast, a component might be mentioned several times as being taken out of service but without any entry in-between about its return-toservice. In these situations, the relevant OOS and RTS times were estimated based on judgment, and these times then were used to derive the duration that the specific component was available in each POS. The maintenance unavailabilities were estimated by taking the average over all three refueling outages. For example, the maintenance unavailability of a particular component during POS-6 is the sum of its downtime during POS- 6 of each outage divided by the total duration of POS-6 for all three outages. Table 9.1-1 lists the estimated maintenance unavailabilities for each POS.

Since POS-6 and POS-10 were of most interest, Figures 9.1-2 to 9.1-4 illustrate the time lines for components whose downtimes covered the midloop operations. These time lines are based on data collected specifically at BNL for quantitatively assessing the risks associated with mid-loop operations. The same sets of data are listed in Tables 9.1-2 to 9.1-4.

To supplement the maintenance unavailabilities listed in Table 9.1-1, the NUREG/CR-4550, Vol. 3 estimates for full-power operations are used in accordance with the following rules: 
(a) If no shutdown data is available for a maintenance event modeled in NUREG/CR-4550, the full power data is used.

(b) If shutdown data is available for a maintenance event modeled in NUREG/CR-4550, the shutdown data is used.

(c) If shutdown data is collected for a maintenance event that was not modeled in NUREG/CR-4550, it is added by modifying the NUREG/CR-4550 fault trees.

We further assumed that the maintenance unavailabilities estimated using refueling outage data are applicable to "like" POSs of other types of outage.

Recently, the Surry Station implemented a change to the operating procedures that involve reduced (reactor vessel) inventory conditions during an outage. Before entering a reduced inventory condition, such as midloop, a check list must be completed for certain pieces of equipment that are not allowed for maintenance. Therefore, the maintenance unavailabilities in Table 9.1-1 were modified by eliminating from the database the maintenance and/or periodic test activities that are not allowed for in the check list. The results are given in Table 9.1-5, which is used as the basis for the quantifying of risk in this study. 


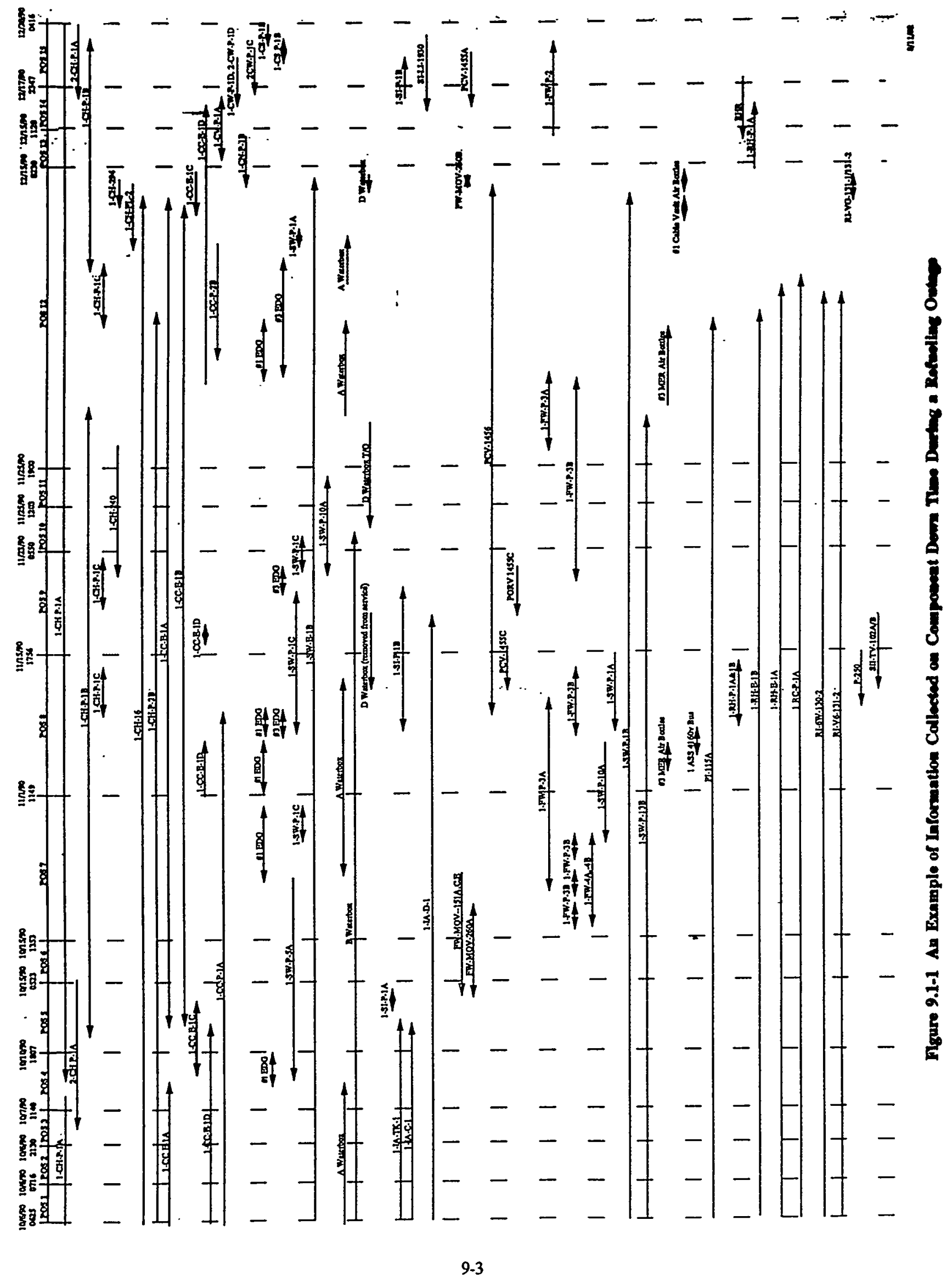




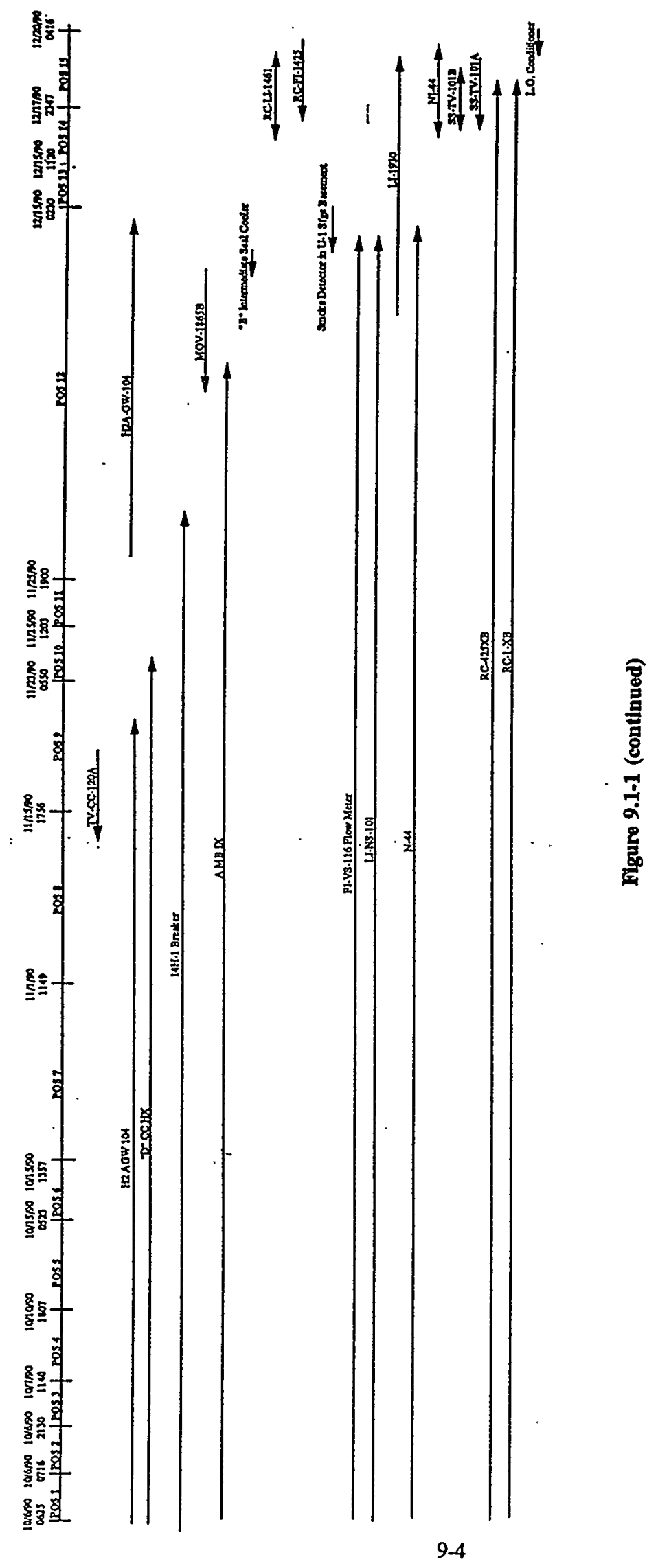




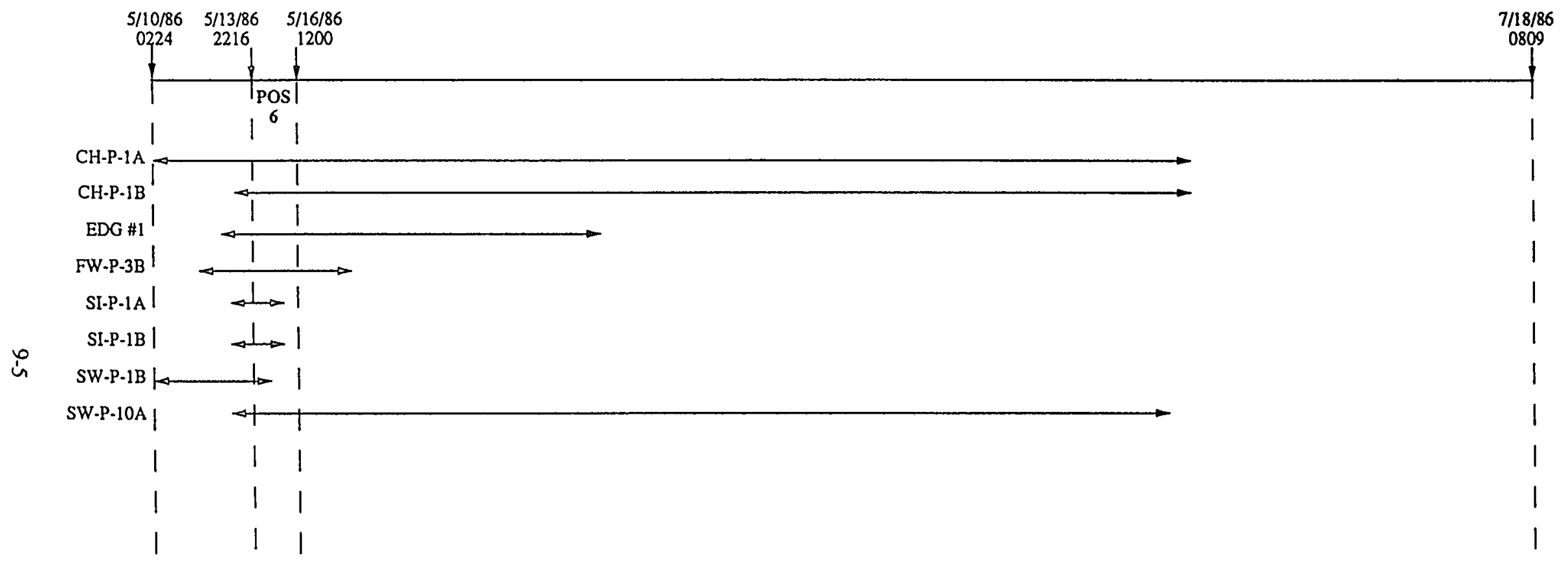

Figure 9.1-2 Time-Line Diagram for Safety-Related Component Down Time that Covered Mid-loop Operations (POS 6) during Surry 1, 1986 Refueling OutageFig. 


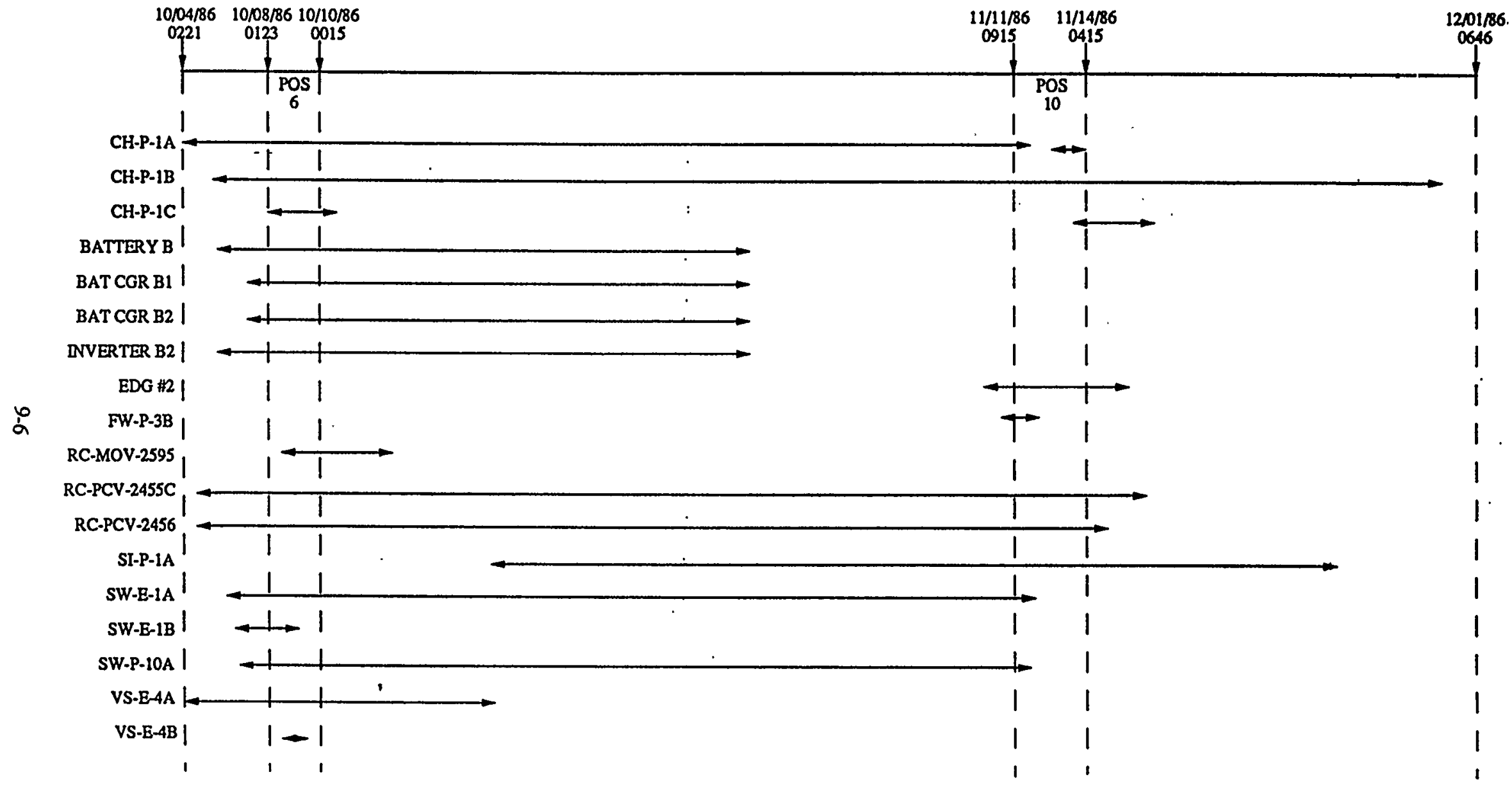

Figure 9.1-3 Time-Line Dlagram for Safety-Related Component Downtime that Covered Midloop Operations (POS6/POS 10) during Surry 2, 1986 Refueling Outage 


$$
\mathbb{t}
$$


Table 9.1-1

Maintenance Unavailability Estimates Based on Data Collected from Log Books

and Minimum Equipment Lists

State 1 state 2 state 3 state 4 state 5 state 6 state 7 state 8 state 9 state 10 state 11 state 12 state 13 state 14 state 15

$A C P-B A C-M A-1 A+$

$A C P-B A C-M A-1 B+$

$A C P-B A C-M A-1 C+$

$A C P-B A C-M A-1 G+$

$A C P-B A C-M A-1 H+$

$A C P-B A C-M A-1 J+$

$A C P-B A C-M A-V B 111$

$\dot{\infty}$

ACP-BCH-MA-UPSB1*

ACP-BCH-MA-UPSB2*

$A F H-M O P$ - HA - FH3A

AFH-MDP-MA-FH3B

AFK-MOV-MA-15q*A/C/E

AFH-MOV-MA-260A+

AFH-TDP-MA-FH2+

$C C H \cdot H T X \cdot M A-E 1 B$

CCH-HTX-MA-U2EIA'

$C P C \cdot M D P-M A-C C 2 B$
0.0124

$0.0222 \quad 0.0891$

0.0316

$0.0533 \quad 0.0752$

0.0193

0.0158

0.2412

0.4003

0.4003

$\begin{array}{lll}0.1097 & 0.2784 & 0.0869\end{array}$

0.5272

0.3863

0.2089

0.2515

0.4304

0.1297

0.2564

0.5190

0.0154

0.2694

0.0726

0.2118

0.0726

0.5460

0.2491

0.6002

0.5993

0.0154

0.4602

$\begin{array}{llll}0.3154 & 0.3185 & 0.3998 & 0.4907\end{array}$

0.1094

0.4584

$0.7414 \cdot 0.5404 \quad 0.41 .28$

$0.0614 \quad 0.8152$

0.1452

1.0000

0.5947

0.8946

0.8946

0.0308

0.6533

$\begin{array}{llll}0.0050 & 0.0162 & 0.0425 & 0.0528\end{array}$

0.0049
$0.2375 \quad 0.6317$

0.3128

0.1355 


\section{Table 9.1-1 (continued)}

State 1 state 2 state 3 state 4 state 5 state 6 state 7 state 8 state 9 state 10 state 11 state 12 state 13 state 14 state 15

\begin{tabular}{|c|c|c|c|c|c|c|c|c|c|c|c|c|c|c|}
\hline$C P C-M D P-M A-S H 1 O B$ & 0.3816 & 0.2175 & 0.2695 & 0.1381 & 0.9274 & 0.5013 & 0.4540 & 0.7384 & 0.4473 & 0.1094 & 0.1832 & & & \\
\hline CSS-MDP-MA-CS1B & & & & & & & & & & & & & & 0.0198 \\
\hline$D C P-B D C \cdot M A-B A T I B$ & & & & & 0.4003 & & 0.0875 & & & & & & & \\
\hline$D C P=C G R-H A-1 A 1+$ & & & & & & 0.0018 & & & & & & & & \\
\hline$H P 1-M D P-M A-C H 1 A^{*}$ & & & & & 0.3864 & & & & & & & & & \\
\hline HPI-MDP-MA-CHIB & 0.2470 & 0.2175 & 0.2695 & 1.0000 & 1.0000 & 1.0000 & 1.0000 & 1.0000 & 1.0000 & & 0.1445 & 0.3184 & 0.3776 & 0.3096 \\
\hline$M P I-M D P-M A-C H 1 C$ & & & 0.0319 & 1.0000 & 1.0000 & 1.0000 & 1.0000 & 1.0000 & 1.0000 & 0.1094 & 0.1964 & & & \\
\hline$L P I-M D P-M A-S I 1 A$ & & & & 0.3422 & 0.9127 & 0.5468 & 0.5480 & 0.5527 & 0.5527 & 0.1248 & 0.7348 & & & \\
\hline$L P I-M D P-M A-S 118$ & & & & & 0.4339 & & 0.2591 & 0.6002 & 0.5093 & 0.8904 & 0.6158 & 0.3184 & 0.2887 & 0.1989 \\
\hline$L P I-M O V \cdot M A-1862 A$ & & & & & & & & & & & & 0.1965 & 0.0363 & \\
\hline$O E P-D G H-M A-D G O 1$ & & & 0.1627 & 0.0869 & 0.5272 & 0.1359 & 0.2990 & 0.1289 & 0.5527 & 0.0650 & 0.2531 & & & \\
\hline$O E P-D G N \cdot M A-D G 03$ & & & & & & & 0.2919 & 0.2422 & & & & & & \\
\hline PPS-PCV-MA-145SC & 0.0024 & 0.3294 & 0.2425 & & & 0.4293 & 0.7509 & 0.3998 & & 0.8125 & & & & \\
\hline PPS-PCV-MA- 1456 & 0.0024 & 0.3294 & 0.2425 & & & 0.1859 & 0.7509 & 0.3998 & 0.0441 & 0.7110 & & & & \\
\hline$R C S-M D P-M A-R C P 1 B+$ & & & & & & & & & & & 0.0706 & & & \\
\hline$R C S \cdot M D P-M A-R C P I C$ & & & & & & & & & & & 0.0951 & & & \\
\hline
\end{tabular}




\section{Table 9.1-1 (continued)}

State 1 state 2 stote 3 stote 4 State 5 state 6 state 7 state 8 state 9 state 10 state 11 State 12 state 13 state 14 state 15

\begin{tabular}{|c|c|c|c|c|c|c|c|c|c|c|}
\hline RHR-MDP-MA-RHR1B & & & & 0.5760 & 0.6002 & 0.5093 & 0.0154 & 0.4760 & 0.3184 & 0.2228 \\
\hline RHR-MOV-MA-1720A & & & & 0.1887 & & & & & & \\
\hline SWS-HTX-MA-E $1 B+$ & & & 0.4781 & & & 0.2935 & & 0.2004 & & \\
\hline SHS-MOV-HA- $103 \mathrm{~A}$ & 0.2527 & 0.1062 & & & & & & & & \\
\hline SHS-MOV-MA- $104 D$ & & & & & & & & & & 0.0255 \\
\hline VS-CHL-MA-VSE4B & & & 0.4163 & & & & & & & \\
\hline
\end{tabular}

+ These basic events are not modelled for state 6 and state 10.

* These events were added July 1992.

table919. Hq1 


\begin{tabular}{|c|c|c|c|c|c|c|c|c|c|}
\hline \multirow{3}{*}{ 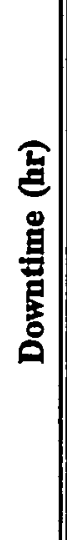 } & 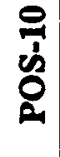 & $\mathbb{Z}^{\prime}$ & $\S$ & $\mathbb{z}$ & $\mathbb{z}$ & $\mathbb{z}$ & $\overleftarrow{z}$ & $\mathbb{Z}$ & $\mathbb{z}$ \\
\hline & $\begin{array}{l}\text { : } \\
\text { ஜ் } \\
\text { L }\end{array}$ & 웡 & 웡 & ㄷㅇㅇ & 동 & 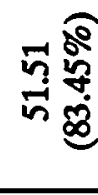 & 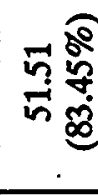 & ๙ & 웡ㅇㅇㅇ \\
\hline & $\stackrel{\bar{\Phi}}{\overline{0}}$ & \begin{tabular}{l}
\multirow{f}{*}{} \\
$\stackrel{0}{ٍ}$
\end{tabular} & $\begin{array}{l}\text { જ̆ } \\
\text { Sু }\end{array}$ & 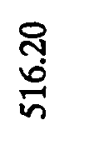 & 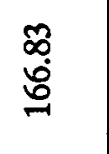 & 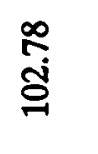 & $\stackrel{\infty}{\stackrel{\infty}{\sigma}}$ & $\stackrel{8}{\stackrel{8}{9}}$ & 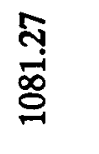 \\
\hline \multirow{2}{*}{ 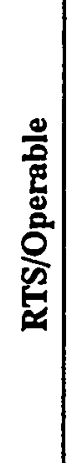 } & $\stackrel{2}{0}$ & $\Rightarrow$ & $\Rightarrow$ & $\infty$ & $N$ & 0 & 0 & 0 & $\exists$ \\
\hline & 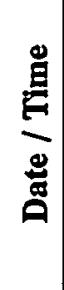 & 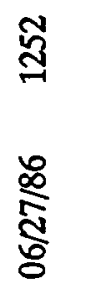 & 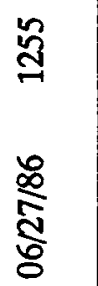 & 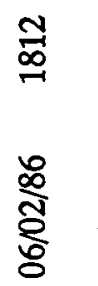 & 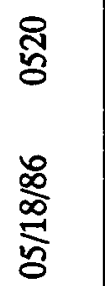 & $\begin{array}{l}\text { 于 } \\
\text { 于 } \\
\frac{8}{0} \\
\frac{8}{8}\end{array}$ & $\begin{array}{l}\underset{8}{8} \\
\frac{8}{0} \\
\frac{8}{8}\end{array}$ & $\begin{array}{l}\text { 융 } \\
\frac{8}{2} \\
\stackrel{8}{8}\end{array}$ & 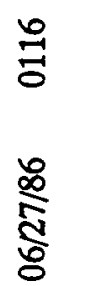 \\
\hline \multirow[b]{2}{*}{ 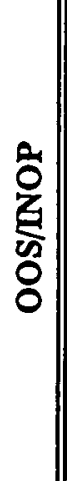 } & \& & $-r$ & nn & $\nabla$ & in & $\forall$ & $\nabla$ & - & $n$ \\
\hline & 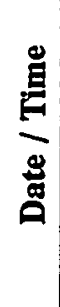 & 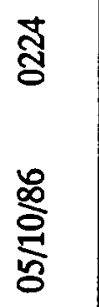 & 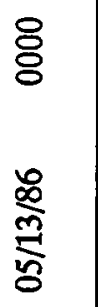 & $\frac{\infty}{\stackrel{8}{8}}$ & $\underset{8}{\stackrel{\infty}{8}}$ & 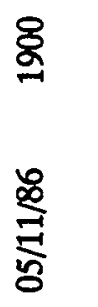 & 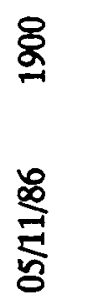 & $\underset{8}{\stackrel{8}{8}}$ & $\begin{array}{l}8 \\
8 \\
8 \\
\frac{8}{2} \\
\frac{2}{8}\end{array}$ \\
\hline & 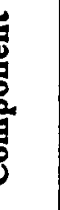 & 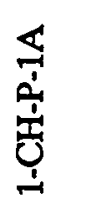 & 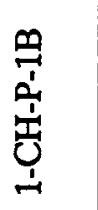 & $\begin{array}{l}-1 \\
0 \\
0 \\
01\end{array}$ & 竞 & $\begin{array}{l}\frac{5}{1} \\
\frac{1}{1} \\
\frac{5}{2}\end{array}$ & $\begin{array}{l}\frac{9}{1} \\
\frac{1}{1} \\
\frac{1}{3}\end{array}$ & 量 & 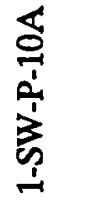 \\
\hline
\end{tabular}


Table 9.1-3 Component Downtime (that covered POS-6/POS-10) for Surry 2, October 1986

\begin{tabular}{|c|c|c|c|c|c|c|c|c|c|}
\hline \multirow{4}{*}{$\begin{array}{l}\text { Component } \\
2-\mathrm{CH}-\mathrm{P}-1 \mathrm{~A}\end{array}$} & \multicolumn{3}{|c|}{ OOS/INOP } & \multicolumn{3}{|c|}{ RTS/Operable } & \multicolumn{3}{|c|}{ Downtime (hr) } \\
\hline & \multicolumn{2}{|c|}{ Date/Time } & \multirow{2}{*}{$\frac{\text { POS }}{2}$} & \multicolumn{2}{|c|}{ Date/Time } & \multirow{2}{*}{$\frac{\text { POS }}{10}$} & \multirow{2}{*}{$\frac{\text { Total }}{958.42}$} & \multirow{2}{*}{$\begin{array}{c}\text { POS-6 } \\
46.87 \\
(100 \%)\end{array}$} & \multirow{2}{*}{$\begin{array}{c}\text { POS-10 } \\
\begin{array}{c}51.83 \\
(77.36 \%)\end{array}\end{array}$} \\
\hline & $10 / 04 / 86$ & 1440 & & $11 / 13 / 86$ & 1305 & & & & \\
\hline & $11 / 13 / 86$ & 2115 & 10 & $11 / 14 / 86$ & 0413 & 10 & 6.97 & - & $\begin{array}{c}6.97 \\
(10.40 \%)\end{array}$ \\
\hline 2-CH-P-1B & $10 / 05 / 86$ & 2112 & 4 & $11 / 29 / 86$ & 1838 & 14 & 1317.43 & $\begin{array}{c}46.87 \\
(100 \%)\end{array}$ & $\begin{array}{c}67.00 \\
(100 \%)\end{array}$ \\
\hline \multirow[t]{2}{*}{ 2-CH-P-1C } & $10 / 08 / 86$ & 0300 & 6 & $10 / 11 / 86$ & 1200 & 7 & 81.00 & $\begin{array}{c}45.25 \\
(96.54 \%)\end{array}$ & - \\
\hline & $11 / 13 / 86$ & 1500 & 10 & $11 / 20 / 86$ & 0626 & 12 & 159.43 & - & $\begin{array}{c}13.25 \\
(19.78 \%)\end{array}$ \\
\hline 2B-Battery & $10 / 05 / 86$ & 1325 & 4 & $10 / 29 / 86$ & 1500 & 8 & 577.58 & $\begin{array}{c}46.87 \\
(100 \%)\end{array}$ & - \\
\hline $\begin{array}{l}\text { 2B1 } \\
\text { Battery } \\
\text { Charger }\end{array}$ & $10 / 06 / 86$ & 0912 & 4 & $10 / 29 / 86$ & 1500 & 8 & 557.80 . & $\begin{array}{c}46.87 \\
(100 \%)\end{array}$ & - \\
\hline $\begin{array}{l}2 \mathrm{~B} 2 \\
\text { Battery } \\
\text { Charger }\end{array}$ & $10 / 06 / 86$ & 0912 & 4 & $10 / 29 / 86$ & 1500 & 8 & 557.80 & $\begin{array}{c}46.87 \\
(100 \%)\end{array}$ & - \\
\hline $\begin{array}{l}\text { 2B3 } \\
\text { Inverter }\end{array}$ & $10 / 05 / 86$ & 1325 & 4 & $10 / 29 / 86$ & 1500 & 8 & 577.58 & $\begin{array}{c}46.87 \\
(100 \%)\end{array}$ & - \\
\hline EDG \#2 & $11 / 10 / 86$ & 0922 & 9 & $11 / 15 / 86$ & 1936 & 11 & 130.23 & - & $\begin{array}{c}67.00 \\
(100 \%)\end{array}$ \\
\hline
\end{tabular}


Table 9.1-3 (continued)

\begin{tabular}{|c|c|c|c|c|c|c|c|c|c|}
\hline \multirow{3}{*}{$\begin{array}{l}\text { Component } \\
\text { 2-SI-P-1A }\end{array}$} & \multicolumn{3}{|c|}{ OOS/INOP } & \multicolumn{3}{|c|}{ RTS/Operable } & \multicolumn{3}{|c|}{ Downtime (hr) } \\
\hline & \multicolumn{2}{|c|}{ Date/Time } & \multirow{2}{*}{$\frac{\text { POS }}{8}$} & \multicolumn{2}{|c|}{ Date/Time } & \multirow{2}{*}{$\frac{\text { POS }}{12}$} & \multirow{2}{*}{$\frac{\text { Total }}{901.92}$} & \multirow{2}{*}{$\frac{\text { POS-6 }}{-}$} & \multirow{2}{*}{$\begin{array}{c}\text { POS-10 } \\
67.00 \\
(100 \%)\end{array}$} \\
\hline & $10 / 20 / 86$ & 2136 & & $11 / 27 / 86$ & 1131 & & & & \\
\hline 2-FW-P-1A & $10 / 07 / 86$ & 1100 & 5 & $11 / 19 / 86$ & 1440 & 12 & 1035.67 & $\begin{array}{c}46.87 \\
(100 \%)\end{array}$ & $\begin{array}{l}67.00 \\
(100 \%)\end{array}$ \\
\hline 2-FW-P-3B & $11 / 11 / 86$ & 0706 & 10 & $11 / 11 / 86$ & 1658 & 10 & 9.87 & - & $\begin{array}{c}7.72 \\
(11.52 \%)\end{array}$ \\
\hline $\begin{array}{l}\text { 2-RC- } \\
\text { MOV-2595 }\end{array}$ & $10 / 08 / 86$ & 1749 & 6 & $10 / 13 / 86$ & 2357 & 7 & $\begin{array}{r}126.13 \\
-\quad\end{array}$ & $\begin{array}{c}42.07 \\
(89.75 \%)\end{array}$ & - \\
\hline $\begin{array}{l}2-R C- \\
\text { PCV- } \\
2455 C\end{array}$ & $10 / 04 / 86$ & 1730 & 1 & $11 / 15 / 86$ & 0210 & 11 & 992.67 & $(*)$ & $(*)$ \\
\hline $\begin{array}{l}2-\mathrm{RC}- \\
\text { PCV- } \\
2456\end{array}$ & $10 / 04 / 86$ & 1730 & 1 & $11 / 14 / 86$ & 1504 & 11 & 981.57 & (*) & $\begin{array}{c}5.35 \\
(7.99 \%)\end{array}$ \\
\hline 2-SW-E-1A & $10 / 06 / 86$ & 2215 & 4 & $11 / 12 / 86$ & 2050 & 10 & 886.58 & $\begin{array}{c}46.87 \\
(100 \%)\end{array}$ & $\begin{array}{c}35.58 \\
(53.11 \%)\end{array}$ \\
\hline 2-SW-E-1B & $10 / 06 / 86$ & 2332 & 4 & $10 / 08 / 86$ & 1030 & 6 & 34.97 & $\begin{array}{c}9.12 \\
(19.46 \%)\end{array}$ & - \\
\hline $\begin{array}{l}2-S W-P-10= \\
\mathrm{A}\end{array}$ & $10 / 06 / 86$ & 2215 & 4 & $11 / 12 / 86$ & 2050 & 10 & 886.58 & $\begin{array}{c}46.87 \\
(100 \%)\end{array}$ & $\begin{array}{c}35.58 \\
(53.11 \%)\end{array}$ \\
\hline 1-VS-E-4A & $10 / 04 / 86$ & 0221 & 1 & $10 / 18 / 86$ & 2400 & 7 & 333.65 & $\begin{array}{c}46.87 \\
(100 \%)\end{array}$ & - \\
\hline
\end{tabular}


Table 9.1-3 (continued)

\begin{tabular}{||c|c|c|c|c|c|c|c|c|c||}
\hline \multirow{2}{*}{ Component } & \multicolumn{3}{|c|}{ OOS/INOP } & \multicolumn{3}{c|}{ RTS/Operable } & \multicolumn{3}{c|}{ Downtime (hr) } \\
\cline { 2 - 10 } & \multicolumn{2}{|c|}{ Date/Time } & POS & \multicolumn{2}{c|}{ Date/Time } & POS & Total & POS-6 & POS-10 \\
\hline 1-VS-E-4B & $10 / 09 / 86$ & 0137 & 6 & $10 / 09 / 86$ & 0330 & 6 & 1.88 & $\begin{array}{c}1.99 \\
(4.02 \%)\end{array}$ \\
\hline
\end{tabular}

["]: Valve blocked open, thus deemed available, during marked state.

$\stackrel{゚}{\stackrel{1}{+}}$ 
Table 9.1-4 Component Downtime (that covered POS-6/POS-10) for Surry 1, October 1990

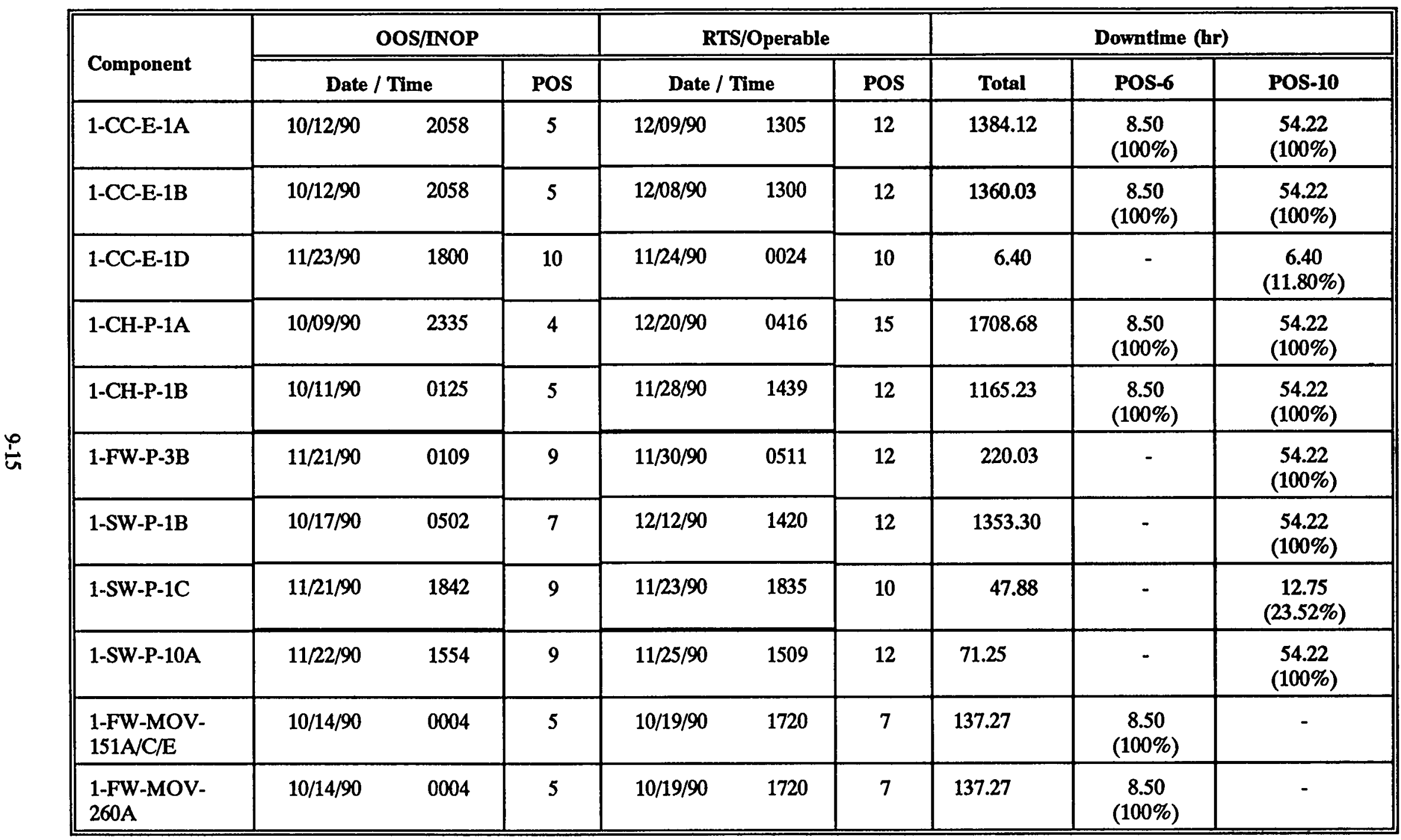


9 Database Development

Table 9.1-5 Modified Maintenance Unavallability for POS 6 and POS 10

\begin{tabular}{|c|c|c|c|}
\hline COMPONENT & POS 6 & $\operatorname{POS} 10$ & SOURCE \\
\hline ACP-BAC-MA-VB1II & 0.0 & 0.0 & Log Book \\
\hline ACP-BCH-MA-UPSB1 & 0.4 & 0.0 & Log Book \\
\hline ACP-BCH-MA-UPSB2 & 0.4 & 0.0 & Log Book \\
\hline AFW-MDP-MA-FW3A & $2.00 \mathrm{E}-03$ & $2.00 \mathrm{E}-03$ & NUREG-1150 \\
\hline AFW-MDP-MA-FW3B & 0.5272 & 0.5110 & Log Book \\
\hline AFW-MOV-MA-151A/C/E & 0.0726 & 0.0 & Log Book \\
\hline . CCW-HTX-MA-E1B & 0.1452 & 0.8946 & Log Book \\
\hline CCW-HTX-MA-U2E-1A & 0.0 & 0.0528 & Log Book \\
\hline CCW-MDP-MA-CCP1B & $2.0 \mathrm{E}-03$ & $2.0 \mathrm{E}-03$ & NUREG-1150 \\
\hline CPC-MDP-MA-CC2B & $2.0 \mathrm{E}-03$ & $2.0 \mathrm{E}-03$ & NUREG-1150 \\
\hline CPC-MDP-MA-SW10A & 0.0 & 0.0 & Log Book \\
\hline CPC-MDP-MA-SW10B & 0.9274 & 0.4473 & Log Book \\
\hline CSS-MDP-MA-CS1B & $2.0 \mathrm{E}-03$ & $2.0 \mathrm{E}-03$ & NUREG-1150 \\
\hline DCP-BDC-MA-BAT1B & 0. & 0.0 & Log Book \& Checklist \\
\hline HPI-MDP-MA-CHIA & 0. & 0. & \\
\hline HPI-MDP-MA-CH1B & 1.0 & 1.0 & Log Book \& Checklist \\
\hline HPI-MDP-MA-CH1C & 1.0 & 1.0 & Log Book \& Checklist \\
\hline LPI-MDP-MA-SI1A & 1.0 & 1.0 & Log Book \& Checklist \\
\hline LPI-MDP-MA-SI1B & 0.0 & 0.0 & Log Book \& Checklist \\
\hline LPI-MOV-MA-1862A & 0.0 & 0.0 & Log Book \\
\hline OEP-DGN-MA-DG01 & 0.0 & 0.0 & Log Book \& Checklist \\
\hline OEP-DGN-MA-DG03 & 0.0 & 0.0 & Log Book \\
\hline PPS-PCV-MA-1455C & 0.0 & 0.0 & Log Book \\
\hline PPS-PCV-MA-1456 & 0.0 & 0.0441 & Log Book \\
\hline RCS-MDP-MA-RCP1C & 0.0 & 0.0 & Log Book \\
\hline RHR-MDP-MA-RHR1B & 0.0 & 0.0 & Log Book \& Checklist \\
\hline RHR-MOV-MA-1720A & 0.0 & 0.0 & Log Book \& Checklist \\
\hline SWS-HTX-MA-E1B & 0.4781 (not modeled) & 0.2935 (not modeled) & Log Book \\
\hline SWS-MOV-MA-103A i & $2.0 \mathrm{E}-04$ & $2.0 \mathrm{E}-04$ & NUREG-1150 \\
\hline SWS-MOV-MA-104D & 0.0 & 0.0 & Log Book \\
\hline VS-AHU-MA-VSAC6 & 0.0 & 0.0 & IPE \& Checklist \\
\hline VS-CHL-MA-VSEAB & 0.0 & 0.0 & Log Book \& Checklist \\
\hline
\end{tabular}




\subsection{Duration and Frequency of Plant Operational States}

The duration of each plant operational state is used to determine some important parameters related to the time after shutdown, e.g., decay heat level and the frequency that an initiating events occurs in a POS. The durations were estimated from the monthly operating reports that Virginia Power submitted to NRC, and the shift supervisor's log books. Monthly operating reports (or, so called "gray books") from the Surry Station for about ten years were obtained from the NRC public document room, which explicitly tabulate the instants and durations when the plant condition changes. The gray books, along with the log books, allowed us to construct Tables 9.2-1 to 9.2-4 for every outage between 1985 and 1989. Some judgment was exercised in estimating these durations because the plant may not always follow the evolution depicted in the definitions of each POS for this study. For example, the plant may reach the mid-loop condition at an early stage of the outage, and then keep varying the RCS levels, as needed, between mid-loop and the vessel flange for quite some time, before conducting refueling. Thus, in an actual plant outage, the line to be drawn between POS 6 and POS 7 might be ambiguous and to distinguish between theses two states needs some judgment by the analyst.

In the phase 1 study, the mean durations of the POSs, (Tables 9.2-1 to 9.2-4), were used to calculate the frequency of initiating events. For the thermal hydraulic calculations, a more conservative approach was used. In reviewing the data in Tables 9.2-1 to 9.2-4, as well as the operating procedures for cooling down and draining to mid-loop, the earliest time at which a POS can be reached was estimated. These times are listed in Table 9.2-5 and were used to determine the representative decay heat for each of the POSs due to their conservative nature, these times were not used in the PRA for mid-loop operation. In the time window approach, the time when the accident occurs is modeled by a probability distribution which is estimated in Section 9.3. Table 9.2-6 lists the elapsed periods, determined from the log books and the gray books; the shortest elapsed time to mid-loop was approximately 1 day after reactor shutdown. The times to mid-loop of Table 9.2-6 were used in the statistical analysis.

In searching for data on the duration of each outage and of each POS, the NRC graybook data-base, in the form of a magnetic tape, was used. The tape was converted into a DBASE file at BNL. The graybook database compiles records of every nuclear power plant shutdown in the United States. It can be used to estimate the frequency and duration of different types of outages. Unfortunately, the information in the graybook was not sufficient for estimating the duration of each POS. Table 9.2-7 lists a summary of some statistics that were obtained from the graybook data base. In Chapter 4, the graybook data base was used to estimate the number of hours that a plant was on RHR during 1979 to 1989 . Such information is important for estimating the frequency of loss of RHR. 
Table 9.2-1 Duration of Plant Operational States - Non-Drained Maintenance w.RHR(N1)

\begin{tabular}{|c|c|c|c|c|c|c|c|c|c|c|c|c|c|c|c|c|c|c|c|c|c|c|c|c|c|c|c|c|c|c|c|}
\hline \multirow[b]{2}{*}{ Date } & \multirow[b]{2}{*}{ Unit } & \multicolumn{2}{|c|}{ POS 1} & \multicolumn{2}{|c|}{ POS 2} & \multicolumn{2}{|c|}{ POS 3} & \multicolumn{2}{|c|}{ POS 4} & \multicolumn{2}{|c|}{ POS 5} & \multicolumn{2}{|c|}{ POS 6} & \multicolumn{2}{|c|}{ POS 7} & \multicolumn{2}{|c|}{ POS 8} & \multicolumn{2}{|c|}{ POS 9} & \multicolumn{2}{|c|}{ POS 10} & \multicolumn{2}{|c|}{ POS 11} & \multicolumn{2}{|c|}{ POS 12} & \multicolumn{2}{|c|}{ POS 13} & \multicolumn{2}{|c|}{ pos 14} & \multicolumn{2}{|c|}{ POS 15} \\
\hline & & hr & $\min$ & hr & $\min$ & hr & $\min$ & hr & min & hr & $\min$ & $\mathbf{h r}$ & min & $\mathbf{h r}$ & $\min$ & $\mathbf{h r}$ & $\min$ & $\mathbf{h r}$ & $\min$ & $\mathbf{h r}$ & $\min$ & hr & $\min$ & $\mathbf{h r}$ & min & hr & ain & $\mathrm{hr}$ & min & $\mathrm{hr}$ & nin \\
\hline $02 / 16 / 86$ & Surry 2 & 0 & 2 & 13 & 41 & 14 & 3 & 143 & 82 & 0 & 0 & 0 & 0 & 0 & 0 & 0 & 0 & 0 & 0 & 0 & 0 & 0 & 0 & 0 & 0 & 0 & 0 & 18 & 1 & 15 & 54 \\
\hline $07 / 23 / 86$ & Surry 2 & 0 & 17 & 6 & 28 & 7 & 49 & 44 & 100 & 0 & 0 & 0 & 0 & 0 & 0 & 0 & 0 & 0 & 0 & 0 & 0 & 0 & 0 & 01 & 0 & 0 & 0 & 20 & 7 & 2 & 46 \\
\hline $09 / 19 / 86$ & Surry 1 & 0 & 0 & 12 & 5 & 9 & 19 & 66 & 63 & 0 & 0 & 0 & 0 & 0 & 0 & 0 & 0 & 0 & 0 & 0 & 0 & 0 & 0 & 0 & 0 & 0 & 0 & 17 & 33 & 170 & 9 \\
\hline $06 / 08 / 87$ & surry 1 & 0 & 11 & 13 & 3 & 55 & 7 & 253 & 70 & 0 & 0 & 0 & 0 & 0 & 0 & 0 & 0 & 0 & 0 & 0 & 0 & 0 & 0 & 01 & 0 & 0 & 0 & 16 & 2 & 4 & 55 \\
\hline $09 / 20 / 87$ & Surry 1 & 0 & 0 & 16 & 47 & 13 & 43 & 166 & 42 & 0 & 0 & 0 & 0 & 0 & 0 & 0 & 0 & 0 & 0 & 0 & 0 & 0 & 0 & 0 & 0 & 0 & 0 & 36 & 18 & 6 & 17 \\
\hline $10 / 03 / 87$ & Surry 1 & 0 & 5 & 11 & 28 & 4 & 32 & 73 & 56 & 0 & 0 & 0 & 0 & 0 & 0 & 0 & 0 & 0 & 0 & 0 & 0 & 0 & 0 & 0 & 0 & 0 & 0 & 16 & 4 & 5 & 14 \\
\hline $11 / 26 / 87$ & Surry 1 & 0 & 6 & 8 & 25 & 12 & 34 & 111 & 79 & 0 & 0 & 0 & 0 & 0 & 0 & 0 & 0 & 0 & 0 & 0 & 0 & 0 & 0 & 0 & 0 & 0 & 0 & 19 & 15. & 16 & 16 \\
\hline $03 / 27 / 88$ & Surry 2 & 0 & 0 & 16 & 57 & 17 & 40 & 158 & 95 & 0 & 0 & 0 & 0 & 0 & 0 & 0 & 0 & 0 & 0 & 0 & 0 & 0 & 0 & $0 ;$ & 0 & 0 & 0 & 24 & 57 & 27 & 57 \\
\hline Total & & 0 & 41 & 95 & 234 & 131 & 227 & 1014 & 587 & & & & & & & & & & & & & & & & & & & 166 & 137 & 145 & 268 \\
\hline $\begin{array}{l}\text { Mean dura } \\
\text { POS }\end{array}$ & tion of & 0.08 & & 12.3 & & 16.8 & & 127.9 & & & & & & & & & & & & & & & & & & & & 21.0 & & 18. & \\
\hline
\end{tabular}

$\stackrel{\infty}{\infty}$ 


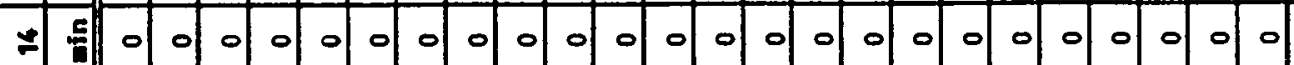

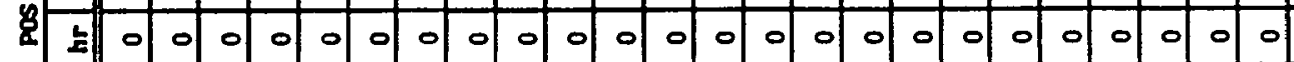

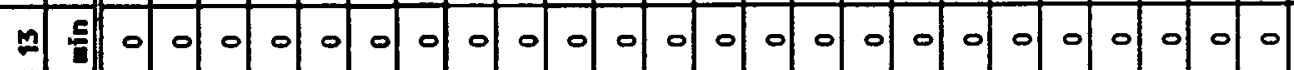

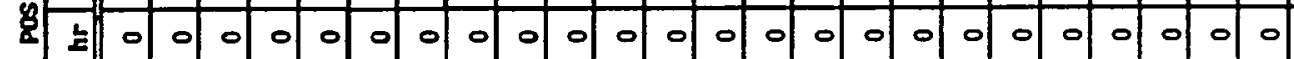

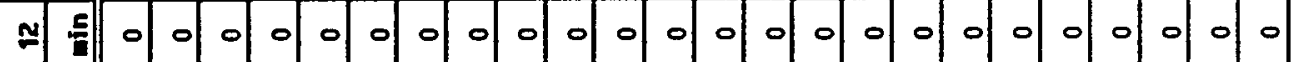

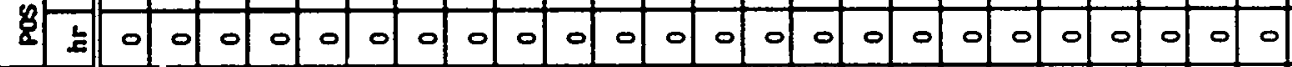

$=\begin{array}{lllllllllllllllllllllllll}5 & 0 & 0 & 0 & 0 & 0 & 0 & 0 & 0 & 0 & 0 & 0 & 0 & 0 & 0 & 0 & 0 & 0 & 0 & 0 & 0 & 0 & 0 & 0 & 0\end{array}$

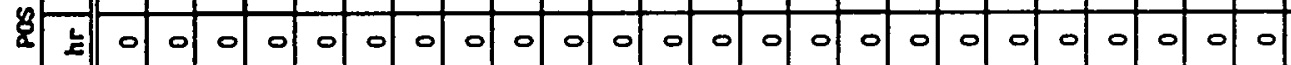

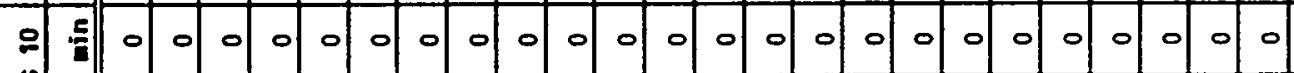

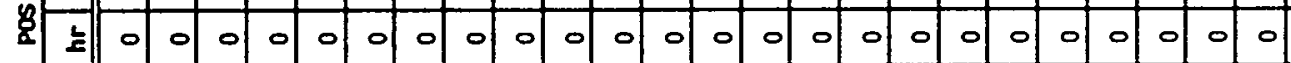

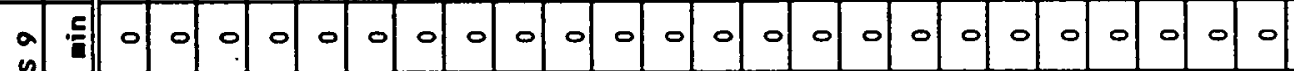

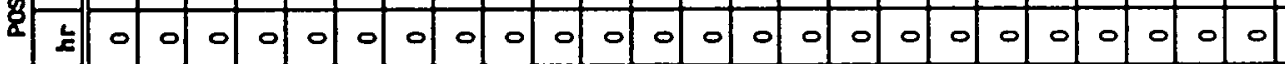

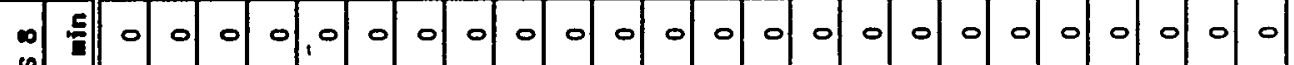

\& 50 \begin{tabular}{llllllllllllllllllllllll}
\hline & 0 & 0 & 0 & 0 & 0 & 0 & 0 & 0 & 0 & 0 & 0 & 0 & 0 & 0 & 0 & 0 & 0 & 0 & 0 & 0 & 0 & 0 & 0
\end{tabular}

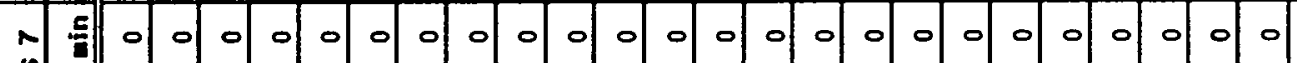

\&

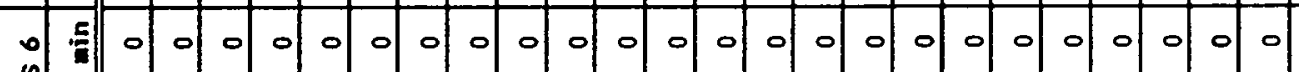

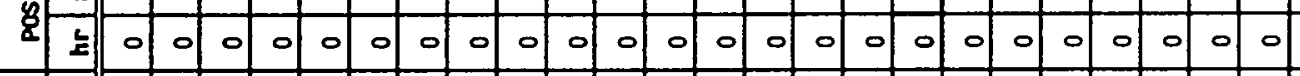

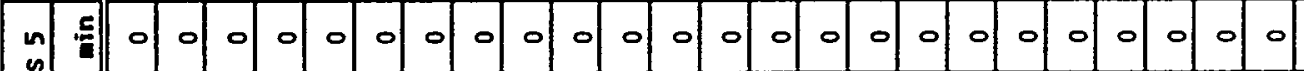

\begin{tabular}{llllllllllllllllllllllllll}
\hline & 0 & 0 & 0 & 0 & 0 & 0 & 0 & 0 & 0 & 0 & 0 & 0 & 0 & 0 & 0 & 0 & 0 & 0 & 0 & 0 & 0 & 0 & 0 & 0
\end{tabular}

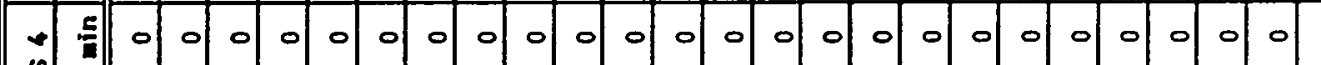

8 (

$m$ m

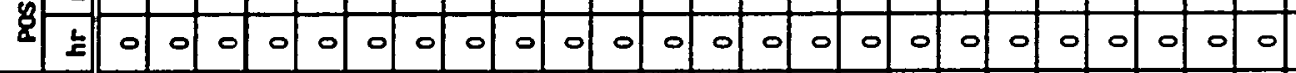

N

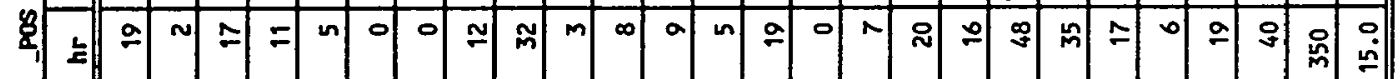

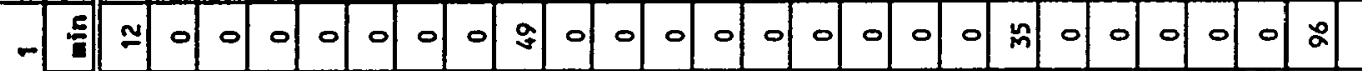

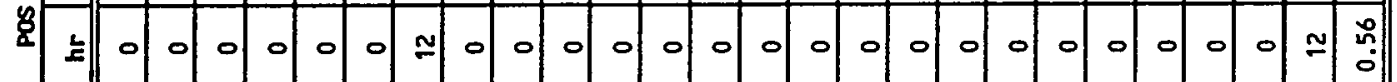

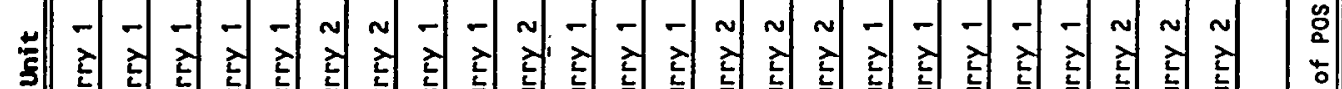

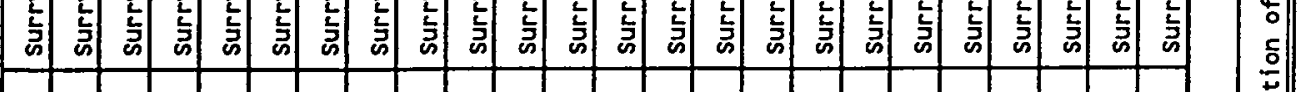

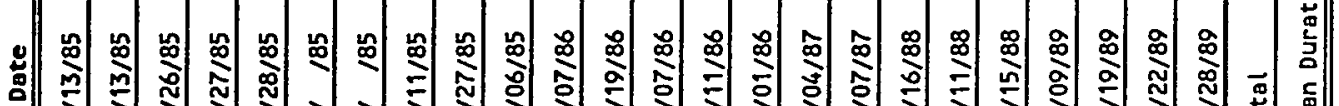
前 


\begin{tabular}{|c|c|c|c|c|c|c|c|c|c|c|c|c|c|c|c|}
\hline 年 & 5 & ที & $\approx$ & 涪 & $\bar{m}$ & -1 & $\stackrel{\infty}{\sim}$ & $\checkmark$ & 思 & 요 & m & 이 & in & \multirow{2}{*}{\multicolumn{2}{|c|}{ نُ }} \\
\hline & 노 & 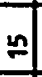 & mิ & $m$ & in & in & in & N| & 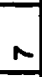 & 0 & 위 & in & & & \\
\hline$\approx$ & 드 & $m$ & a. & 욤 & ษ & in & $\hat{m}$ & $\bar{m}$ & $N$ & 욤 & in & 9 & $R$ & \multirow{2}{*}{\multicolumn{2}{|c|}{ : }} \\
\hline 8 & $\underline{\underline{s}}$ & N| & N & $\mathbf{N}$ & జ & $\dot{m}$ & in & 吸 & $\approx$ & N & ลి & $\boldsymbol{N}$ & \& & & \\
\hline$m$ & 들 & 이 & $\cong$ & $\approx$ & 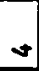 & $\bar{m}$ & in & $\div$ & ฉ & m & Nㅐ & $\cong$ & 요 & $\frac{0}{m}$ & \multirow{2}{*}{$\stackrel{m}{\circ}$} \\
\hline \& & $\underline{\xi}$ & 우 & $=$ & $N$ & 0 & $\approx$ & $=$ & 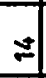 & 吩 & $\checkmark$ & 0 & & & $\stackrel{2}{\underline{2}}$ & \\
\hline $\boldsymbol{N}$ & 히 & $=1$ & 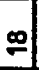 & 미 & m & a & \& & $\approx$ & ָ̄ & $\stackrel{\infty}{i}$ & $\begin{array}{l}\vdots \\
\vdots \\
\vdots\end{array}$ & 令 & 7 & & \\
\hline 悹 & 노 & $\approx$ & 이 & 능 & N & mे & 㤐 & 岕 & 이 & $\approx$ & $\star$ & 壳 & $\stackrel{\infty}{\leftarrow}$ & N & \\
\hline$=$ & 드 & in & ஸ) & 이 & N & 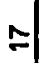 & - & 와 & 0 & $\hat{N}$ & $m^{*}$ & m & $\mathscr{q}$ & & \multirow{2}{*}{$\bar{v}$} \\
\hline & $\underline{\mathbf{s}}$ & f & 2. & 히 & ని & $\vec{m}$ & 7 & $\bar{N}$ & $\stackrel{m}{m}$ & 우 & $\mathbf{N}$ & 의 & $\bar{m}$ & $\mathbb{N}$ & \\
\hline 인) & 듬 & 이 & 이 & 0 & 0 & 우 & 이 & 의 & 이 & 0 & 인 & 이 & 으 & 0 & \\
\hline 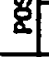 & $\underline{E}$ & 이 & 이 & 0 & 0 & 0 & ol & 이 & 0 & 0 & 0 & 0 & 0 & 0 & \\
\hline & 도 & 이 & 이 & 의 & 이 & 이 & 이 & 이 & 이 & 이 & 으 & 0 & 오 & 응 & \\
\hline & 호 & 이 & 이 & 0 & 0 & 0 & 0 & 이 & 0 & 0 & 0 & 0 & 0 & 0 & \\
\hline & 氞 & 이 & 이 & 이 & 으 & 의 & o & 이 & 이 & 이 & 요 & 0 & 0 & 이 & \multirow[t]{2}{*}{0} \\
\hline & 노 & 이 & 이 & 0 & 0 & 0 & 이 & 이 & 이 & 0 & 이 & 0 & 0 & 0 & \\
\hline & 들 & 아 & 이 & 0 & 우 & 요 & 이 & 의 & 이 & 으 & 인 & 인 & 으 & $c$ & \\
\hline & 노 & 이 & 이 & 0 & 0 & 0 & 0 & 0 & 이 & 0 & 의 & 0 & 0 & 0 & \\
\hline - & 들 & ஸิ & mి & ( ) & - & 怘 & 이 & แn & $\mathbf{m}$ & นำ & 의 & $\stackrel{\sim}{\sim}$ & 寸 & in & \multirow{2}{*}{ ญิ่ } \\
\hline 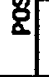 & $\underline{E}$ & 官 & 기 & 이 & Ф) & ㅇ & 힝 & in & $\underset{J}{*}$ & 아 & $\stackrel{20}{\sim} \mid$ & & 恣 & $\mathfrak{y}$ & \\
\hline in & 들 & 의 & 识 & mे & 이 & m & ถి & 이 & ma & $\tilde{n}$ & in & $\Xi$ & ‥ & $\begin{array}{l}\text { 吕 } \\
\text { | }\end{array}$ & \multirow{2}{*}{ 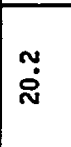 } \\
\hline 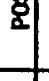 & દ & in & 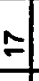 & m) & $\simeq$ & 의 & \pm & 의 & $\bar{N}$ & 의 & m & & 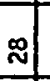 & 命 & \\
\hline & 5 & of & $\forall$ & (7) & 이 & of & $\approx$ & ก & 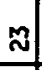 & $\sim$ & m & น & $m$ & 男 & \multirow{2}{*}{$\stackrel{m}{\circ}$} \\
\hline 多 & 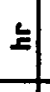 & 이 & 이 & $m$ & m & $\div$ & $\mathbf{N}$ & ㄴ. & $\neq$ & N & 기 & & స్లి & & \\
\hline in & 들 & ₹) & 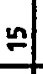 & $\bar{m}$ & 임 & 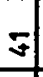 & 间 & 요 & $=$ & ஸ) & m & 이 & q. & 量 & \multirow{2}{*}{ mò } \\
\hline & $\underline{\$}$ & $\approx 1$ & 의 & $\approx$ & $\simeq$ & $\div$ & $=$ & 0 & \pm & $M$ & 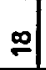 & & & $\stackrel{2}{\circ}$ & \\
\hline N & 들 & 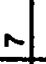 & sิ & $\therefore$ & 의 & $\approx$ & 0 & M & m̊l & $N$ & कि & $\bar{m}$ & $\mathrm{R}$ & $\frac{4}{m}$ & \multirow{2}{*}{$\dot{\bar{g}}$} \\
\hline 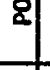 & 企 & $\infty_{1}$ & $\therefore$ & $\simeq$ & $=$ & $u$ & 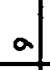 & a & సI & $m$ & $\infty$ & & & 픈 & \\
\hline & 드 & & 이 & ๓ & 이 & 이 & 이 & 이 & 이 & $\cong$ & 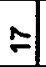 & 이 & $\stackrel{m}{-1}$ & & \multirow{2}{*}{ R } \\
\hline & 多 & & 이 & 의 & 이 & 이 & $\pi$ & 의 & 의 & 0 & 이 & & 이 & $\lambda$ & \\
\hline st & & & 占 & 占 & $\infty$ & 눈 & ș & 놓 & 产 & & 占 & 出 & 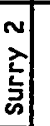 & \multirow{2}{*}{\multicolumn{2}{|c|}{ 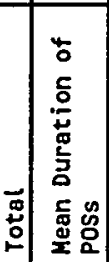 }} \\
\hline 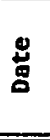 & & & | & 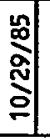 & & 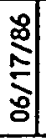 & 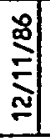 & 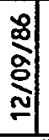 & 商 & & $\begin{array}{l}0 \\
0 \\
0 \\
\vdots\end{array}$ & 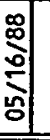 & 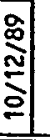 & & \\
\hline
\end{tabular}




\begin{tabular}{|c|c|c|c|c|c|c|c|c|c|c|}
\hline \multirow{2}{*}{8} & $E \leq$ & Nof & $n+$ & $\infty-$ & +0 & $-\infty$ & $\infty 0$ & \multirow{2}{*}{ ชิ } & $\alpha-\infty$ & 0 \\
\hline & $\Sigma 0$ & 8 & $R$ & ม & $\Phi$ & 9 & 7 & & 80 & 8 \\
\hline \multirow{2}{*}{$\begin{array}{l}\stackrel{8}{0} \\
8 \\
8\end{array}$} & $\bar{E}=$ & 5 & $P$ & 7 & 8 & $\hat{\mathbf{N}}$ & $\mathscr{y}$ & & No $^{\circ}$ & 0 \\
\hline & \pm 0 & N & 8 & 8 & 8 & 8 & $\pi$ & 84 & $=0^{\circ}$ & 80 \\
\hline \multirow{2}{*}{$\begin{array}{l}\frac{2}{8} \\
8 \\
8\end{array}$} & $\vec{E}=$ & $n$ & 8 & 7 & $\approx$ & 8 & $\infty$ & & \pm 0 & 0 \\
\hline & $z$ & I & 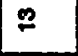 & $=$ & 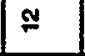 & $\Phi$ & 8 & \begin{tabular}{|c|}
$\infty_{0}^{\circ}$ \\
$\infty$
\end{tabular} & $8^{\circ}$ & $\dot{\delta}^{\top}$ \\
\hline \multirow{2}{*}{ 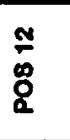 } & 'E = & $\stackrel{\mathscr{0}}{ }$ & 8 & $\div$ & $\overline{5}$ & 8 & $\stackrel{2}{2}$ & & ఏ్ & 0 \\
\hline & ż & 9 & 8 & ลู & 8 & "ृ० $^{\circ}$ & $8^{\circ}$ & $\ddot{8}$ & $\stackrel{0}{2} 8$ & $\Phi^{\circ}$ \\
\hline \multirow{2}{*}{$\begin{array}{l}= \\
8 \\
8\end{array}$} & E & $\Phi$ & 6 & $\mathscr{B}$ & 0 & 0 & 5 & & $\bar{\Xi}$ & 0 \\
\hline & $\underline{E}$ & $\stackrel{\circ}{*}$ & \% & 9 & $\hat{n}$ & 0 & $\Phi$ & \begin{tabular}{|l|l|} 
\\
\end{tabular} & 8 & $\stackrel{\oplus}{=}$ \\
\hline \multirow{2}{*}{$\begin{array}{l}\stackrel{0}{\circ} \\
8 \\
8\end{array}$} & $\frac{\bar{c}}{E}$ & $\infty$ & 0 & D & 0 & 0 & 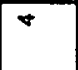 & & $\widehat{s}$ & 0 \\
\hline & $E$ & $\mp$ & 0 & $\bar{n}$ & 0 & 0 & y̆ & พั & $\frac{1}{8}$ & $\stackrel{\dot{\Phi}}{\circ}$ \\
\hline \multirow{2}{*}{$\begin{array}{l}\infty \\
\text { o } \\
8 \\
\&\end{array}$} & $\overline{\frac{5}{E}}$ & 8 & 0 & 8 & 8 & 0 & $\tilde{g}$ & & ูั & 0 \\
\hline & 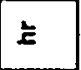 & $\overline{8}$ & 0 & $\stackrel{\Phi}{=}$ & q & 0 & $\infty$ & 8 & $\stackrel{\mathscr{N}}{N}$ & \&్ల \\
\hline \multirow{2}{*}{$\begin{array}{l}\infty \\
\stackrel{0}{0} \\
\stackrel{8}{\alpha}\end{array}$} & $\frac{\tau}{\varepsilon}$ & 7 & 5 & ฐึ & 8 & $K$ & 8 & & $\mathscr{్}$ & 0 \\
\hline & $\Sigma$ & R̊ & 哭 & $\hat{7}$ & 5 & $\stackrel{\bar{\alpha}}{\underline{\mathbf{\alpha}}}$ & $g$ & $\overline{\mathrm{J}}$ & 8 & 象 \\
\hline \multirow{2}{*}{$\begin{array}{l}\hat{o} \\
\stackrel{\circ}{a}\end{array}$} & 듵 & 8 & 0 & $\widehat{\mathbf{v}}$ & $=$ & $N$ & $\bar{n}$ & & $\Phi$ & 0 \\
\hline & 上 & 8 & 8 & 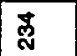 & f & 9 & $\stackrel{20}{\infty}$ & "ूं & $\overline{\mathbb{N}^{N}}$ & 宫 \\
\hline \multirow{2}{*}{$\begin{array}{l}\stackrel{0}{0} \\
\stackrel{0}{0}\end{array}$} & 듵 & $=$ & 7 & 8 & $\overline{\bar{N}}$ & 0 & 9 & & $\Phi$ & 0 \\
\hline & $\underline{\Sigma}$ & 步 & 5 & $\overline{7}$ & 9 & 8 & \& & $\infty$ & $8^{\prime \prime}$ & $\stackrel{8}{10}$ \\
\hline \multirow{2}{*}{$\begin{array}{l}0 \\
\text { : } \\
0 \\
0\end{array}$} & $\frac{\underline{E}}{E}$ & 8 & $N$ & $r$ & 9 & 8 & $\infty$ & & $\stackrel{\mathscr{I}}{\underline{I}}$ & 0 \\
\hline & $\frac{E}{r}$ & $\stackrel{8}{E}$ & $\cong$ & $\stackrel{\Phi}{9}$ & 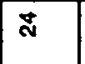 & $\overline{\mathbf{N}}$ & 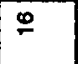 & $\hat{o}$ & $\overline{\mathrm{A}}$ & $8^{\infty}$ \\
\hline \multirow{2}{*}{$\begin{array}{l}+ \\
8 \\
8\end{array}$} & $\frac{c}{E}$ & + & $\underline{\Phi}$ & $y$ & 8 & $\Phi$ & $\stackrel{\mathbb{N}}{ }$ & & $\stackrel{9}{\stackrel{9}{2}}$ & 0 \\
\hline & $\frac{E}{E}$ & 8 & 9 & $q$ & 总 & s & $\underline{\underline{p}}$ & م: $^{\circ}$ & ฐ & $\underline{\mathrm{g}}^{\circ}$ \\
\hline \multirow{2}{*}{$\begin{array}{l}0 \\
0 \\
8 \\
8\end{array}$} & $\frac{\bar{C}}{E}$ & 웅 & $\mathscr{\mathscr { \omega }}$ & 9 & 8 & $\infty$ & $\bar{d}$ & & ఫ్ & 0 \\
\hline & $E$ & 2 & 은 & 0 & \pm & $\circ$ & 웅 & $\overline{\dot{I}}$ & $\bar{\Phi}$ & 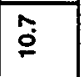 \\
\hline \multirow{2}{*}{$\begin{array}{l}\text { r } \\
\text { ö } \\
\text { o }\end{array}$} & $\frac{\bar{c}}{E}$ & $F$ & 9 & $\stackrel{\infty}{\underline{D}}$ & $E$ & $\$$ & $\bar{N}$ & & $\mathbb{్}$ & 0 \\
\hline & $\frac{2}{5}$ & 9 & 8 & $\hat{N}$ & 8 & 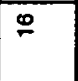 & $\overline{\bar{N}}$ & 葆 & ळి & ֶี \\
\hline \multirow{2}{*}{ ס্் } & $\frac{E}{E}$ & F & 8 & $\stackrel{\infty}{\sim}$ & 8 & मे & $\sigma$ & & : & 0 \\
\hline & $\frac{2}{2}$ & 0 & 0 & 0 & 0 & 0 & 0 & $\stackrel{8}{\mathbb{8}}$ & 0 & $\stackrel{8}{8}$ \\
\hline \multicolumn{2}{|l|}{$\overline{\overline{5}}$} & 蒿 & 竞 & $\stackrel{N}{\mathbb{S}}$ & 紊 & 文 & 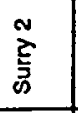 & 㐓 & & $\begin{array}{l}\bar{\delta} \\
\bar{c}\end{array}$ \\
\hline \multicolumn{2}{|l|}{$\frac{\omega}{\Delta}$} & 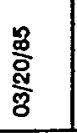 & $\frac{\$ 2}{\frac{8}{8}}$ & 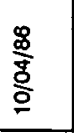 & $\begin{array}{l}\frac{8}{8} \\
\frac{8}{8} \\
\end{array}$ & $\frac{8}{8}$ & $\frac{\frac{9}{8}}{\frac{8}{8}}$ & $\begin{array}{l}8 \\
\text { g }\end{array}$ & $\begin{array}{l}\overrightarrow{1} \\
\text { : }\end{array}$ & 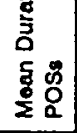 \\
\hline
\end{tabular}


9 Database Developement

Table 9.2-5 Conservative Estimates of the Earliest Time (after shutdown) That a POS Can Be Reached

\begin{tabular}{|c|c|c|c|c|}
\hline & Refueling & $\begin{array}{c}\text { Drained } \\
\text { Maintenance }\end{array}$ & $\begin{array}{c}\text { Non-Drained (w. } \\
\text { RHR) }\end{array}$ & $\begin{array}{c}\text { Non-Drained } \\
\text { (w/o RHR) }\end{array}$ \\
\hline POS 1 & N.A. & N.A. & N.A. & N.A. \\
\hline POS 2 & 0. & 0. & 0. & 0. \\
\hline POS 3 & $6 \mathrm{hr}$ & $6 \mathrm{hr}$ & $6 \mathrm{hr}$ & \\
\hline POS 4 & $6 \mathrm{hrs}$ & $6 \mathrm{hrs}$ & $6 \mathrm{hrs}$ & \\
\hline POS 5 & $6 \mathrm{hrs}$ & $6 \mathrm{hrs}$ & & \\
\hline POS 6 & 4 days & & 1 day & \\
\hline POS 7 & 4 days & & & \\
\hline POS 8 & 6 days & & & \\
\hline POS 9 & 27 days & & & \\
\hline POS 10 & 29 days & & & \\
\hline POS 11 & 34 days & & $34 \mathrm{hrs}$ & \\
\hline POS 12 & 39 days & & $54 \mathrm{hrs}$ & \\
\hline POS 13 & 49 days & & $78 \mathrm{hrs}$ & \\
\hline POS 14 & 50 days & & $84 \mathrm{hrs}$ & $24 \mathrm{hrs}$ \\
\hline POS 15 & 50 days & & $108 \mathrm{hrs}$ & $48 \mathrm{hrs}$ \\
\hline
\end{tabular}


Table 9.2-6 Operational Experience Data of Elapsed Time to Mid-loop at Surry

\begin{tabular}{|c|c|c|}
\hline Date of Outage & Time to Mid-Loop & Cause of Shutdown \\
\hline $\begin{array}{l}\text { May } 1988 \\
\text { Drained Maintenance }\end{array}$ & 444 Hours 56 minutes & "An RCP failure \\
\hline $\begin{array}{l}\text { April } 1988 \\
\text { Refuel }\end{array}$ & 173 hours 44 minutes & Refueling \\
\hline $\begin{array}{l}\text { December } 1987 \\
\text { Drained Maintenance }\end{array}$ & 180 hours 54 minutes & Scheduled Maintenance \\
\hline $\begin{array}{l}\text { June } 1987 \\
\text { Drained Maintenance }\end{array}$ & 54 hours 14 minutes & $\begin{array}{l}\text { Excessive RCS leakage } \\
\text { MOV-RC-1593 and } \\
\text { MOV-RC-1591 were repacked. }\end{array}$ \\
\hline $\begin{array}{l}\text { May } 1987 \\
\text { Drained Maintenance }\end{array}$ & 74 hours 53 minutes & $\begin{array}{l}\text { Low flow in "A" } \mathrm{RC} \text { loop. } \\
\text { MOV-1591 valve shaft cracked. }\end{array}$ \\
\hline $\begin{array}{l}\text { December } 1986 \\
\text { Drained Maintenance }\end{array}$ & 82 hours 24 minutes & $\begin{array}{l}\text { Secondary Piping } \\
\text { Inspection, Snubber Outage }\end{array}$ \\
\hline $\begin{array}{l}\text { October } 1986 \\
\text { Refueling }\end{array}$ & 100 hours 16 minutes & Refueling \\
\hline $\begin{array}{l}\text { June } 1986 \\
\text { Drained Maintenance }\end{array}$ & 53 hours 20 minutes & $\begin{array}{l}\text { Increasing level in "A" steam } \\
\text { generator. Indication of a SG tube leak. } \\
\text { Feed regulating valve inspected and } \\
\text { repaired. }\end{array}$ \\
\hline $\begin{array}{l}\text { May } 1986 \\
\text { Refuel } \\
\end{array}$ & 91 hours 52 minutes & Refuel \\
\hline $\begin{array}{l}\text { January } 1986 \\
\text { Drained Maintenance }\end{array}$ & 74 hours 50 minutes & Snubber outage \\
\hline $\begin{array}{l}\text { October } 1985 \\
\text { Drained Maintenance }\end{array}$ & 61 hours 30 minutes & Scheduled snubber outage. \\
\hline $\begin{array}{l}\text { August } 1985 \\
\text { Drained Maintenance }\end{array}$ & 105 hours 24 minutes & Repair of 1-SI-243. \\
\hline $\begin{array}{l}\text { March } 1985 \\
\text { Refueling }\end{array}$ & 238 hours 28 minutes & $\begin{array}{l}\text { 1. Refueling } \\
\text { 2. MOV-RH-2700 packing gland } \\
\text { leakage. }\end{array}$ \\
\hline $\begin{array}{l}\text { October } 1984 \\
\text { Drained Maintenance }\end{array}$ & 82 hours 32 minutes & Repair of "An RCP. \\
\hline $\begin{array}{l}\text { September } 1984 \\
\text { Refueling } \\
\end{array}$ & 161 hours 1 minute & Loss of "C" RCP. \\
\hline $\begin{array}{l}\text { March } 1984 \\
\text { Drained Maintenance }\end{array}$ & 37 hours 37 minutes & $\begin{array}{l}\text { "B" RCP tripping. Scheduled } \\
\text { snubber outage. }\end{array}$ \\
\hline
\end{tabular}


Table 9.2-6 (Continued)

\begin{tabular}{|c|c|c|}
\hline Date of Outage & Time to Mid-Loop & Cause of Shutdown \\
\hline $\begin{array}{l}\text { February } 1984 \\
\text { Refuel } \\
\end{array}$ & 88 Hours 4 minutes & Snubber outage with head evacuation. \\
\hline $\begin{array}{l}\text { December } 1983 \text { Drained } \\
\text { Maintenance }\end{array}$ & 27 hours 53 minutes & Repair "C" RCP \#1 seal. \\
\hline $\begin{array}{l}\text { December } 1983 \\
\text { Drained Maintenance }\end{array}$ & 42 hours 5 minutes & Repair 2-SI-88,238 \\
\hline $\begin{array}{l}\text { September } 1983 \\
\text { Drained Maintenance }\end{array}$ & 105 hours 50 minutes & Snubber Outage \\
\hline $\begin{array}{l}\text { June } 1983 \\
\text { Refueling }\end{array}$ & 292 hours 5 minutes & Scheduled refueling outage. \\
\hline $\begin{array}{l}\text { June } 1983 \\
\text { Drained Maintenance }\end{array}$ & 23 hours 58 minutes & $\begin{array}{l}\text { Repair 1-SI-82 bonnet leak. Shutdown } \\
\text { to balance turbine Unit was delayed in } \\
\text { Startup to repack MOV-1587. }\end{array}$ \\
\hline $\begin{array}{l}\text { Does not begin with } \\
\text { reactor shutdown. }\end{array}$ & 11 hours 47 minutes & Repair 1-RCP-1B seals. \\
\hline $\begin{array}{l}\text { February } 1983 \\
\text { Refueling }\end{array}$ & 183 hours 30 minutes & $\begin{array}{l}\text { "C" S/G low level with a steam/feed flow } \\
\text { mismatch. } \\
\text { Scheduled refueling outage. }\end{array}$ \\
\hline $\begin{array}{l}\text { December } 1982 \\
\text { Drained Maintenance } \\
\end{array}$ & 44 hours 3 minutes & $\begin{array}{l}\text { Scheduled maintenance outage. } \\
\text { Repair "C' RCP flange leak. }\end{array}$ \\
\hline $\begin{array}{l}\text { October } 1982 \\
\text { Drained Maintenance }\end{array}$ & 120 hours 40 minutes & $\ldots+\ldots$ \\
\hline
\end{tabular}




\section{Table 9.2-7 Gray Book Data Base}

1. Covers 1979-1989

2. Data on Frequency and Duration of Outages

3. 15587 Outages

\section{WCEB\&WSurry GE}

Refueling $\quad 247 \quad 71 \quad 47 \quad 9185$

Total $\quad 6541128716893275694$

4. Duration of Refueling Outages

WestinghouseSurry

Mean 22902860

Std. $\quad 12901910$ 


\section{Database Developement}

\subsection{Time to Mid-loop and Duration of Mid-loop Operations}

The time after shutdown when the assumed accident initiator occurs is an important parameter in this study because it determines the level of decay heat in the reactor core. The decay heat, in turn, determines the timing of the accident scenarios and time available for operator actions. A statistical analysis of the time to mid-loop and the duration of mid-loop was made; it is documented in Appendix D. In the analysis, a twostage Bayesian analysis was done for the time to POS 6. The PWR plants' responses to generic letter 87-12 were used as the prior information, and Surry specific data was used in the second stage. For the time to POS 10, and the duration of the POSs, a single-stage Bayesian analysis was done, using Surry-specific data. In Appendix D, a statistical analysis also is given of the duration of mid-loop operation for the 3 POSs. Table 9.3-1 lists the key characteristics of the time to mid-loop, and duration of mid-loop. Table 9.3-2 lists the characteristicparameters for the time when the accident initiating event is assumed to occur for the three midloop POSs. It was calculated as the time to mid-loop plus the duration of mid-loop multiplied by an uniform distribution between 0 and 1 . For the over-draining initiating event, RHR2A, the time when the initiating event occurs is assumed to be the same as the time to mid-loop.

The mean values of the durations of the POSs were used to calculate the frequency of initiating events and the point-estimate quantification of the core-damage cutsets. The distribution for the time after shutdown when an initiating event is assumed to occur, is used to determine the conditional probability that the initiating event occurs in each of the time windows. Table 9.3-3 lists the probability as a function of the time windows and POSs. The values in parenthesis are the probabilities for the over-draining event. 
9 Database Development

Table 9.3-1 Characteristics of Time to Midloop and Characteristic Duration of Mid-loop

\begin{tabular}{||l|c|c|c|c|c||}
\hline \multicolumn{1}{|c|}{ Time to Mid-loop } & Mean (hrs.) & $5 \%$ & $50 \%$ & $95 \%$ & EF \\
\hline POS 6 Refuel & 191 & 72.2 & 167.6 & 388.8 & 2.32 \\
\hline POS 10 Refuel & 2619 & 833 & 968 & 4828 & 2.41 \\
\hline POS 6 Drained & 190 & 27.0 & 105 & 618 & 4.78 \\
\hline & & & & & \\
\hline Duration of Mid-loop & Mean (hrs.) & $5 \%$ & $50 \%$ & $95 \%$ & EF \\
\hline POS 6 Refuel & 238 & 14.2 & 112 & 876 & 7.85 \\
\hline POS 10 Refuel & 444 & 6.3 & 151 & 2586 & 20.3 \\
\hline POS 6 & 255 & 11.9 & 109 & 958 & 8.97 \\
\hline
\end{tabular}


9. Database Developement

Table 9.3-2

Distribution of the Time When the Accident Initiating Event Occurs

\begin{tabular}{||l|c|c|c|c|c||}
\hline \multicolumn{1}{|c|}{ Time of IE } & Mean (hrs.) & $5 \%$ & $50 \%$ & $95 \%$ & EF \\
\hline (all IE except RHR2A) & & & & & \\
\hline POS 6 Refuel & 310 & 98.7 & 260.5 & 687.6 & 2.64 \\
\hline POS 10 Refuel & 2819 & 1009 & 2440 & 5903 & 2.42 \\
\hline POS 6 Drained & 313.1 & 50.4 & 213.2 & 901.8 & 4.23 \\
\hline \multicolumn{1}{|c|}{ Time of IE } & & & & & \\
\hline (RHR2A only) & Mean (hrs.) & $5 \%$ & $50 \%$ & $95 \%$ & EF \\
\hline POS 6 Refuel & & & & & \\
\hline POS 10 Refuel & 191 & 72.2 & 167.6 & 388.8 & 2.32 \\
\hline POS 6 Drained & 2619 & 833.3 & 968 & 4828 & 2.41 \\
\hline
\end{tabular}


Table 9.3-3

Probability that IE Occurs in the Window

\begin{tabular}{||l|l|l|l|l||}
\hline & \multicolumn{1}{|c|}{ WINDOW 1 } & \multicolumn{1}{|c|}{ WINDOW 2 } & \multicolumn{1}{c||}{ WINDOW 3 } & \multicolumn{1}{|c||}{ WINDOW 4 } \\
\hline Definition & $<=75$ hours & $\begin{array}{l}>75 \text { hours and } \\
<=240 \text { hours }\end{array}$ & $\begin{array}{l}>240 \text { hours and } \\
<=32 \text { days }\end{array}$ & $>32$ days \\
\hline $\begin{array}{l}\text { Representative } \\
\text { Decay Heat }\end{array}$ & $13.23 \mathrm{MW}(2$ days $)$ & $10 \mathrm{MW}(5$ days $)$ & $7 \mathrm{MW}(12$ days $)$ & $5 \mathrm{MW}(32$ days $)$ \\
\hline D6 & $\begin{array}{l}0.117 \\
(0.31)^{\circ}\end{array}$ & $\begin{array}{l}0.436 \\
(0.454)\end{array}$ & $\begin{array}{l}0.375 \\
(0.21)\end{array}$ & $\begin{array}{l}7.20 \mathrm{E}-02 \\
(2.6 \mathrm{E}-02)\end{array}$ \\
\hline R6 & $\begin{array}{l}1.7 \mathrm{E}-02 \\
(5.82 \mathrm{E}-02)\end{array}$ & $\begin{array}{l}0.543 \\
(0.7)\end{array}$ & $\begin{array}{l}0.41 \\
(0.24)\end{array}$ & $\begin{array}{l}3.4 \mathrm{E}-02 \\
(1.48 \mathrm{E}-03)\end{array}$ \\
\hline R10 & 0.0 & 0.0 & $\begin{array}{l}0.016 \\
(2.2 \mathrm{E}-02)\end{array}$ & $\begin{array}{l}9.84 \mathrm{E}-01 \\
(0.98)\end{array}$ \\
\hline
\end{tabular}

* Applicable to RHR2A, over-draining event, only. 
9 Database Developement

\subsection{Use of Log Book Data}

The shift supervisor's log books were reviewed to identify the fraction of the duration that the plant might be placed in some specific configurations that are of particular concern in terms of risk. These configurations may occur in some of the POSs, and can affect plant response to the initiating events. In addition, discussions with Virginia Power staff and Westinghouse staff also provided some information needed for making relevant estimates.

\subsubsection{Isolation of RCS LOOPs}

At Surry, the RCS loops are routinely isolated for an extended period during a refueling outage. This is necessary for the tests and maintenance that are performed on components in the RCS loops, e.g., the steamgenerator eddy current test. To ensure that primary coolant in the steam generator tubes is drained, the RCS loops will not be isolated until the reactor vessel level is low enough (close to mid-loop). The individual RCS loops, IAW OP 5.12, are drained after they are isolated.

When refueling operations are completed IAW OP 4.1, preparation is made for startup from ambient to 1950F IAW OP 1.1, where OP 5.1.1, (filling the RCS), is referenced. In OP 5.1.1, the loop stop valves are to be verified open. However, the loops remain isolated until a level in the pressurizer is established.

It is recognized that a temporary operating procedure (TOP 3061) allows un-isolation of one loop when the RCS level is above 18 feet; this was implemented during the 1990 outage of Unit 1, after refueling operations were completed and the vessel head was tensioned.

The impact of isolated RCS loops on shutdown safety lies in loss of secondary heat-removal capability when it could be needed. This is included in the fault tree for the function of secondary heat removal.

The fraction of time that the RCS loops were isolated is estimated for both refueling outages and drained maintenance outages and as discussed in the following sections:

Refueling

At the beginning of mid-loop operation, the RCS loops may remain un-isolated as was the case in the Unit 2 outage during October 1986, and the Unit 1 outage during October 1990. In the Unit one refueling outage in October 1986, the loops were isolated just before the level reached mid-loop. Past plant experience shows that the 3 loops are isolated and un-isolated at about the same time. Hence, the probability that the loops are isolated could be estimated for each of the time windows of a refueling outage. Table 9.4-1 lists the resulting probabilities.

\section{Drained Maintenance}

In a drained maintenance, only one loop would be possibly isolated. In this study, we assumed that only one loop is isolated during D6. In window 1, this means that the success criteria for reflux cooling can not be met, but in other time windows, reflux cooling is possible.

\subsubsection{Steam Generator in Wet Layup vs Drained}

If an outage is scheduled for longer than 5 days, the steam generators are placed in wet layup (IAW GOP 2.6) Judging from the mean duration of the outage types, it is assumed that in all cold shutdown outages, the steam generators are placed in wet layup in POS 3. In wet layup, the steam generator recirculation and transfer system is placed in service to ensure homogeneity of the SG water chemistry. 
Based on discussion with Virginia Power staff, we ascertained that the secondary side of the steam generators is almost always filled with a large quantity of water. There are two commonly known situations that require draining of the secondary side of the steam generators, i.e., before placing the SGs in wet layup, and during sludge-lancing of the steam generators. From a review of the log books, we judged that before placing the SGs in wet layup, they stay in a drained condition only for a short period. Furthermore, the SGs are drained one at a time. Therefore, the unavailability of the SGs before wet layup is small. For each steam generator, a probability of $2.3 \mathrm{E}-02$ is used to model the individual draining.

\section{Refueling}

Through discussions with on-site Westinghouse personnel familiar with sludge lancing, it was estimated that three steam generators may be in a drained condition for 5-days during a refueling outage. Among other things, sludge-lancing is done on a SG when the plant is in cold shutdown condition with the SG drained. No other constraint is imposed on planning sludge-lancing operations, except that operation of the reactor's coolant pump requires the secondary side to be filled. Therefore, we assumed that sludge lancing is equally likely to take place any time when the plant is in cold shutdown with no RCP running, i.e., in POSs 5 to 11 . Using the $\log$ book data on the time the plant is in such a condition during a refueling, an unavailability of 8.3E-03(SGS-DRAINED-R) was estimated for the SGs to be drained in these POSs.

\section{Others.}

In the March 27, 1988 Unit 1 outage, all three steam generators were drained for less than one day, with the plant in cold shutdown. Therefore, an unavailability of 1.0E-03(SGS-DRAINED-CSD) is used for all CSD POSs of outages other than refueling.

Due to insufficient information on the time, when the activities requiring draining the SGs take place, these probabilities are assumed to be the same for all time windows.

\subsubsection{RCS Vented with Pressurizer Safety Valves Removed}

In reviewing the log books, we recognized that in past refueling outages, the safety valves on the pressurizer were removed for an extended period. They were removed while the RCS was in mid-loop, and re-installed after refueling was completed and the vessel head set. This removal of the safety valves provided a large vent of the RCS and would help relieve the system pressure if needed. It makes gravity feed from RWST possible. On the other hand, with such a large opening, reflux cooling becomes impossible, due to loss of inventory through the opening. The effects of safety valve removal are modeled in the fault trees and event trees.

Based on the log books of the 3 refueling outages, and the outage plan of the 1992 Unit 1 refueling outage, the safety valves are removed approximately 2 weeks into the refueling outage, and re-installed after refueling is completed. Table 9.4-2 lists the estimated probability that the safety valves are removed in each of the time windows. We assumed that the pressurized safety valves are not removed during drained maintenance.

\subsubsection{Time Period in Which the RCS Is Closed and The Temporary Seals at the Seal Table Were Installed}

At step 5.8 of OP 4.1, refueling operations, the flux mapping detectors and thimbles are verified retracted. Therefore, the high pressure seals at the seal table are removed. At step 5.9, the vessel level is raised to 20 feet to check the temporary seals for leakage. At step 5.26, the vessel head is lifted. Between step 5.8 and step 5.26, the RCS should be closed. The vessel head vent hose is removed at step 5.24 and the head vent valve 1-RC-36 is left open. The head vent is a $3 / 4$ inch line. 


\section{Database Developement}

These activities occur in POS 7. The RCS is vented through the open PORVs and pressurizer relief tank to the process vent. The vessel level is changed by adjusting the charging and letdown flow rates. A similar configuration may exist in POS 9, after refueling is completed, and the vessel head is set. The concern is that a pressurization of the RCS may open the temporary seals, and further pressurization may expel coolant through the opening. Pressurization could result from RCS heatup and boiling caused by, e.g., a loss of RHR. In POS 7 of a refueling outage, the RCS loops are isolated and secondary heat removal is not available. The head vent, if opened, or the PORVs should be capable of relieving nitrogen during heatup. POS 7 can be reached as early as 4 days into a shutdown, and the level of decay heat could be as high as $8.7 \mathrm{MW}$. When boiling occurs in the vessel, the relief paths cannot keep the RCS pressure below 40 psia, that the temporary seals can withstand. Then the core is expected to uncover relatively rapidly.

From the log books, and through discussions with on-site Westinghouse personnel who are familiar with the use of the seals, we concluded that the plant may be in a closed condition with the temporary seal in place for 5 to 7 days during a refueling outage. There is little information about the time span that the RCS would possibly be in such a configuration when the vessel head is set after the refueling is done. Based on the Unit 1 refueling outage plan, there are approximately 3 days between the time the vessel is set and the high pressure seals are installed. We estimated that, for approximately 10 days per refueling, the RCS is in such a configuration. 
Table 9.4-1

Probability that the RCS Loops Are Isolated

Such that Reflux Cooling Is Unavailable or Ineffective

\begin{tabular}{|c|c|c|c||}
\hline & R6 & R10 & D6 \\
\hline W1 & 0.3 & - & True \\
\hline W2 & 0.7 & - & False \\
\hline W3 & True $^{\prime}$ & True & False \\
\hline W4 & True & True & False \\
\hline
\end{tabular}


9 Database Developement

Table 9.4-2

Probability that the Safety Valves on the Pressurizer Are Removed

\begin{tabular}{|c|c|c|c|}
\hline & R6 & R10 & D6 \\
\hline W1 & 0.01 & - & False \\
\hline W2 & 0.05 & - & False \\
\hline W3 & 0.9 & 0.9 & False \\
\hline W4 & 0.3 & 0.3 & False \\
\hline
\end{tabular}




\section{ACCIDENT SEQUENCE QUANTIFICATION}

The core-damage sequences were quantified using the IRRAS code. A truncation limit of $1.00 \mathrm{E}-10$ per year was used to generate the system cutsets and sequence cutsets. Tables 10-1 to 10-48 list the results of the event tree quantifications, which show the frequency of each core-damage sequence before and after recovery actions are modeled. Recovery actions are operator actions that are not included in the fault-tree model and are added to the applicable cutsets after they are generated. A hyphen in the table indicates that there is no cutset above the truncation limit. Table 10-49 lists the dominant core-damage cutsets before core uncovery. Table 10-50 lists the dominant cutsets after the recovery actions are applied. Appendix F lists the complete sets of core damage cutsets before and after recovery actions are applied. The important measures of the basic events are also listed.

\subsection{Descriptions of Recovery Actions}

Recovery factors were applied to individual cutsets using the IRRAS code by specifying the rules that define their applicability. Tables 10-51 to $10-58$ list the recovery actions, their failure probabilities, applicable sequences, and applicability rules. The basic events used to model recovery actions usually have two contributors, human-error probability and hardware failure probability. The following types of recovery actions were modeled; they were quantified on the different boundary conditions in different sequence cutsets. Chapter 8 gives details of the operator actions and their quantification. Tables 10-51 to 10-58 summarize the calculation of the basic event probabilities.

Uncertainty in the Success Criteria of Reflux Cooling in window 1 of Drained Maintenance- In the window 1 event trees for POS 6 of drained maintenance (D6), no credit was taken for reflux cooling because we assumed only 2 steam generators are available, while 3 are needed for reflux cooling. It was assumed that one reactor coolant loop is isolated due to maintenance in POS 6 of a drained maintenance outage. The decay heat of this time window corresponds to that of 2 days after shutdown. The conservative thermal hydraulic considerations of Virginia Power technical report $865^{[1]}$, rev. 1, led to the requirement of 3 steam generators during the first 75 hours after shutdown, which is specifically written into the procedure for loss of RHR, AP $27.00^{(2)}$, rev. 4.

INEL $^{[3-5]}$ and Westinghouse ${ }^{[6]}$ performed more realistic thermal hydraulic analyses of reflux cooling. Their studies show that reflux cooling with only one steam generator is sufficient to remove decay heat as early as one day after shutdown. To eliminate the conservatism in the loss of RHR procedure, it was decided that when everything else failed, the operators will use the 2 steam generators to establish reflux cooling. A failure probability of 0.1 was used.

Local Manual Operation of MOVs- In some cutsets, recirculation failure occurs when the MOVs in the low head injection/recirculation suction fail. Based on the data on MOV failure, ${ }^{\left[{ }^{[}\right]}$we estimated that only $10 \%$ of the MOV failures cannot be manually corrected locally. This is used as a recovery factor for those cutsets that involve failure of the low pressure injection/recirculation suction valves. Figure 10-1 is a simple event tree that is used to calculate the non-recovery probability for a cutset that contains such failure and is in time window 1 of a drained maintenance outage; this example involves the above 2 recovery actions.

Use of Unit 2 Charging Pump in Time Window 2- In time window 2, recirculation from the containment sump is needed in a feed-and-spilloperation. Use of the unit 2 RWST by cross-connection of the 2 RWSTs is modeled in the fault trees for recirculation, by using the unit 1-charging pump taking suction from the unit 2 RWST. In some core damage cutsets, no unit 1 charging pump is available so causing this method of 


\section{Accident Sequence Quantification}

operation to fail. For these cutsets, the recovery action would be use of the unit 2 charging pump as well as the unit 2 RWST to support the feed and spill operation. A simplified fault tree model for the unit 2 charging pump was used to quantify the hardware contribution, $1.91 \mathrm{E}-02$, to the failure of this recovery action.

Use of Unit 2 AFW to Support Reflux Cooling- In some cutsets, reflux cooling is failed due to failure of the auxiliary feedwater system. The use of unit 2 auxiliary feedwater pump to support reflux cooling is treated as a recovery action. Typically, this action is not needed until after 10 hours of successful reflux cooling. The hardware failure contribution of 7.33E-03 is calculated using the fault tree for the unit 1 auxiliary feedwater system.

Use of RWST to Provide Initial Makeup to Restore RHR- In the fault tree analysis, a basic event RWTTNK-LF-RWST representing insufficient inventory in the RWST would cause failures of RCS makeup, and feed-and-spill operation. Failure of RCS makeup in an over-draining or loss of inventory event would cause failure to restore RHR. In reality, for either event, only a small amount of makeup is needed, and a low RWST inventory should not be a cause of failure. Therefore, in those cutsets containing this event, a recovery was used to model recovery of RHR.

\section{Recovery Actions for Loss of Offsite Power Sequences}

Recovery actions in loss of offsite power sequences have several possibilities: cross-connect from Unit 2 (charging, AFW or RWST), gravity feed, reflux cooling (bleed path) recovery actions and cross-tying of emergency electrical buses, either within the Unit or between the Units. These are arranged in three steps for every cutset, but some steps may not apply to certain cutsets.

The first step that might be tried by the operators is a simple action such as cross-connecting the Unit 2 charging, or the gravity feed. These actions were not credited in quantifying most unrecovered sequences, as it was a screening evaluation (charging cross-connect was only credited in B1 sequences, and gravity feed was only credited in B2 sequences). These actions will extend the time available for recovery of offsite power (or, depending on the window, will lead to success in the $24 \mathrm{hr}$ mission time).

The second step is more complicated, such as establishing the bleed path for reflux cooling. When a LOSP event occurs, instrument air will be lost due to failure of bearing cooling water system, which depends on normal power. This, in turn, will lead to a loss of steam generator PORVs, i.e. the normal bleed path in reflux cooling. The model gives credit to the operators for a quick recovery of compressed air (by connecting the standby diesel compressor, or using fire-water for cooling of instrument compressor bearings, both proceduralized actions). Then, the operators may need to switch the semi-vital bus (controlling the PORVs) to a live source of power, depending on which emergency bus is up. Therefore, in L1, L2 and L3, the reflux cooling bleed path will be established (except for operator failure to follow procedure, or hardware failures), and Step 2 will be automatically accomplished, i.e. no recovery action is needed.

In B1 and B2, no power will be available to the semi-vital bus, and the PORV bleed path will fail. Another option then would be for the operators to open the steam dump path to the condensers (into the turbine building), which will involve manually opening the main steam non-return valve. This action is not simple and may take a lot of time, so the HEPs, given this recovery action in B1 and B2, are relatively high. Fig. 10-2 $2^{[8]}$ shows the construction of this valve. The valve disc is supported by steam pressure drop against gravity when the valve is open and the shaft is unscrewed. To open the valve, steam pressure is needed on the "in" side and the shaft has to be unscrewed (normally done with electric power). The shaft screw has a very low pitch 
(as it is a big valve) and it would take a couple of operators 15-20 minutes to open it (per discussion with the plant). The valve needs to be only partially open to relieve steam pressure. Once open, the steam pressure may burst the condenser rupture discs (depending on conditions), thus relieving the steam inside the turbine building.

The second step will further extend the time available for recovery of offsite power. Depending on the window, the combination of the first two steps could extend the allowable time past the 24 hour success criterion.

As discussed in Section 7.4, recovery of offsite power will open up many possibilities for recovery, so the residual core-damage frequency will be small compared to the situation where offsite power is not recovered.

The third step would involve cross-tying the emergency buses. There are hardware provisions for this (see Fig. $10-3)^{[9]}$, and it is assumed to successfully conclude the sequence.

The LOSP recovery action will be calculated using the following equation:

$$
\begin{gathered}
\mathrm{R}_{\mathrm{LOSP}}=\eta_{1}{ }^{*}\left[\rho_{2}+\left(1-\rho_{2}\right)^{*} \eta_{2}{ }^{*} \rho_{3}\right] \\
=\eta_{1}{ }^{*} \rho_{2}+\left(1-\rho_{2}\right)^{*} \eta_{1}{ }^{*} \eta_{2}{ }^{*} \rho_{3}
\end{gathered}
$$

where $\eta \mathrm{s}$ refer to adjustments in probability of non-recovery of offsite power due to extension of time to core uncovery as a result of recovery actions (simple recovery actions in Step 1, or more complex actions in Step 2); $\rho$ s refer to human error probabilities assigned to recovery actions in Steps 2 and 3. Furthermore,

$$
\begin{aligned}
& \eta_{1}=\operatorname{NRAC}\left(\mathrm{t}_{1}\right) * \operatorname{DG}\left(\mathrm{t}_{1}\right) / \operatorname{NRAC}\left(\mathrm{t}_{0}\right) \ldots \ldots \\
& \eta_{1}{ }^{*} \eta_{2}=\operatorname{NRAC}\left(\mathrm{t}_{2}\right) * \operatorname{DG}\left(\mathrm{t}_{2}\right) / \operatorname{NRAC}\left(\mathrm{t}_{0}\right)
\end{aligned}
$$

where NRAC $(t)$ is the probability of non-recovery of a.c. power at time $t$ (taken from Table 4.3-5); $D G(t)$ is the probability of non-recovery of the diesel generator at time $t$ (see Table $10-53$ ); ${ }^{[10]} t_{0}$ is the original time given for recovery of offsite power (i.e. time to core uncovery, see Section 7.4); $t_{1}$ is the new (i.e. extended) time given for recovery of offsite power or the diesel generator, due to simple recovery actions taken in Step 1 (Unit 2 charging cross-connect, gravity feed); $t_{2}$ is the new (i.e. extended) time given for recovery from combination of Steps 1 and 2. Step 2 is recovery by reflux cooling bleed path, and further extends the time available for recovery of offsite power or the diesel generator.

Hardware failures are not included in equation 10.1, because they are included in the rules for recovery action; otherwise they are small compared to the NRACs and $\rho$ s.

If step 1 does not apply to a cutset (e.g. Unit 2 is having a blackout, and gravity feed does not work in drained maintenance) then $\eta_{1}=1$; if step 2 does not apply (e.g. steam generator PORVs fail to open), then $\eta_{2}=1$ and $\rho_{2}=0$; if step 3 does not apply (e.g. in a two Unit blackout), then $\rho_{3}=1$.

The names of the recovery action basic event have the following form:

R-IEWK-LMN-S1-S3-F

where IE refers to the LOSP initiating event category (e.g. IE $=\mathrm{L} 1$ or $\mathrm{IE}=\mathrm{B} 2$ ); WK refers to the window (e.g. W2 would be window 2); $\mathrm{LMN}$ is a string of 1-3 digits, depending on which steps in the recovery action, discussed above, are applicable (e.g. 123 means all three steps are applicable, 13 means steps 1 and 3 are 
applicable, and 2 means only step 2 is applicable); $S 1$ refers to the type of system used in step 1 (C stands for charging from Unit 2, G stands for gravity feed); S3 refers to the systems that will be enabled by step 3 in recovery (A refers to AFW, C refers to forced circulation and recirculation); the last character in the string, $\mathrm{F}$, appears only in recovery actions that apply to sequences where forced feed and bleed has failed (however, the recovery action was quantified the same as for other sequences, if everything else was the same).

Tables 10-54 and 10-57 show different steps in the quantification of LOSP recovery actions.

Table 10-54 shows calculation of the $\eta$ parameters in the 4 windows, including the time available for recovery of offsite power or diesel generators, if various combinations of steps 1 and 2 are successful. The offsite power non-recovery probability is shown, as well as the diesel generator non-recovery probabilities; these are combined to show the $\eta$ values as per equations 10.2 and 10.3. If steps 1 and/or 2 do not apply in a certain situation, the corresponding $\eta$ will be calculated using the procedure above for non-applicability of that step (i.e. that procedure has precedence over Table 10-54)

Table 10-55 shows the HEP parameter $\rho_{2}$ for recovery action in step 2, for the five LOSP categories, and the 4 windows. This action (reflux bleed path) is included in the model for L1, L2 and L3, so $\rho_{2}=0$ for these categories. If step 2 does not apply for a certain recovery, the non-applicability procedure above has priority.

Table 10-56 shows the HEP parameter $\rho_{3}$. The same caveat as above applies if step 3 does not apply.

Table 10-57 shows the summary of calculation for each recovery action that is used in the LOSP analysis.

The rules for applying recovery actions are shown in Table 10-58.

\subsection{Results}

Table 10-59 summarizes the results of the event tree quantification, showing the core damage frequency as a function of the initiating events and POSs taken from Tables 10-1 to 10-48. The frequencies in this table include the fraction of a year that the plant is in each of the POS. This makes the frequencies additive, i.e., the sum of a row or a column is meaningful. POS 6 of a drained maintenance outage (D6) and POS 6 of a refueling outage are the most dominant POSs. The characteristics of these POSs are high level of decay heat and a relatively short time available for operator action. In contrast, POS 10 of a refueling outage has a very low decay heat, and its core-damage frequency is approximately 1 order of magnitude lower.

Table 10-60 shows the core damage frequency as a function of the time windows and POSs. The frequencies were estimated using the basic event importance measures with respect to the total core damage frequency. Note that the totals for POSs R10 and D6 differ from those of Table 10-59. This is due to the different methods used in estimating them. The frequencies in parenthesis are the contribution of over-draining events whose occurrence is modeled by a demand failure probability, while other initiating events are modeled by failure rates. Table 10-61 lists the estimated fraction of a year that the plant is in each of the time windows and POSs. It is obtained by multiplying the fraction of a year that the plant is in a POS by the conditional probability (Table 9.3-3) that the initiating event occurs in the time window given it occurred in the POS. The fraction of a year that the plant spent in a given POS is the frequency of the POS times its mean duration. Table 10-62 lists the conditional core damage frequency as a function of the time windows and POSs. 
Conditional core damage frequency is the rate at which core damage occurs given that the plant is in the time window of the POS. It is obtained by dividing the core damage frequency (minus the contribution of overdraining events) of Table 10-60 by the fraction of Table 10-61. The numbers in parenthesis are the conditional probability of core damage due to over-draining, given that the plant reaches mid-loop in the time window of the given POS. This probability is the ratio of the frequency of core damage due to over draining listed in Table 10-60 and the frequency that the plant reaches mid-loop in the time window of the given POS. The latter is the frequency of the POS times the conditional probability of the time window for the given POS.

The conditional core damage frequency/probability is a measure that can be used to compare the vulnerability of the time windows and POSs with respect to core damage. It can be seen, from Table 10-62, that for each POS the conditional core damage frequency decreases with time window. This is due to the relaxed success criteria and more time available for operator actions. The same is true with the conditional probability of core damage due to over-draining(with the exception for R10 discussed in the next paragraph). The conditional core damage frequency/probability for R6 or R10 is higher than that of D6 mainly due to that the RCS loops have a high probability of being isolated in a refueling outage; that makes reflux cooling impossible. For example, in window 1 , the probability that the loops are isolated in a refueling outage is 0.3 , and the probability that reflux cooling fails in a drained maintenance outage is 0.1 (modeled as a recovery action). The difference between R6 and R10 in windows 3 and 4 is due to the difference in maintenance unavailabilities.

Two reversals of the expected trend occur in Table 10-62. First, the conditional core damage probability for window 4 of R6 is zero, while that for D6 is not. It is zero because the core damage frequency due to overdraining, listed in Table 10-60, is zero. The core damage frequency due to over-draining is zero because no cutsets survived truncation(at 1.00E-10 per year). If a lower truncation limit is used, then the core damage frequency due to over draining would not be zero. As a result, the conditional probability of core damage would be non-zero and is expected to be higher than that of D6. The second reversal is in the conditional probability of core damage for windows 3 and 4 of R10. This is also caused by the error introduced by the truncation limit used. A lower truncation limit shows that the conditional probability of core damage for window 3 is, as expected, higher than that for window 4.

The total and sub-totals in Table 10-62 represent the averaged conditional core damage frequency/probability. For example, the averaged conditional core damage frequency for R6 is $8.09 \mathrm{E}-05$ per year, while that for D6 is $8.55 \mathrm{E}-05$ per year. This means that the plant is better off if in R6, given it is at mid-loop. This does not contradict the comparison made earlier for a given time window of the POSs, because given that plant is in D6 the plant is more likely to be in the earlier time windows that have higher conditional core damage frequency. The averaged conditional core damage frequency over the POSs, shown in the right most column of Table 10-62, does show the trend of decreasing with decay heat. The reversed trend for the averaged conditional core damage probability for windows 3 and 4 is caused by the same error introduced by truncation that made the trend reversed for the conditional core damage probability of R10 in windows 3 and 4 .

Below we discuss some of the results:

Human Errors-We found that operator failure is the dominant cause of core damage. In particular, failure to diagnose, such that the correct actions are not taken to prevent core damage, is the most important operator error. It occurs in many different initiating events, time windows, and POSs, and contributes to approximately $56 \%$ the total core-damage frequency. Failure to diagnose is assumed to lead directly to core damage. It represents the inability of the operator to use the information available and determine the proper 


\section{Accident Sequence Quantification}

corrective actions. It is recognized that the quantification of such human errors has a very large uncertainty; an error factor of 20 was used in the uncertainty analysis.

Isolation of Reactor Coolant Loops- Review of the plant shutdown experience indicated that the reactor coolant loops are isolated for an extended period in a refueling outage. This practice makes the steam generators unavailable for removing decay heat upon loss of RHR. In a cold shutdown condition, the steam generators are usually maintained in the wet lay-up condition with the secondary side filled with water. During mid-loop operation, the availability of the SGs makes reflux cooling a possible way to mitigate a loss of RHR; it might be the only mitigation function available in a station blackout. In this study, we found that isolation of the RCS loops is an important contributor to core damage frequency, being responsible for approximately $22 \%$ of the total core-damage frequency.

Plugging the Containment Sump When Recirculation Is Needed- Due to the activitiesinside the containment, transient material and equipment are brought in. For example, large plastic Herculite sheets are often used to separate work areas from the rest of the containment. When an accident requiring recirculation from the containment sump occurs, as is the case in time windows 1 and 2, this material would increase the chance that the containment sump would be blocked. In this study, the probability of the sump plugging was assumed to be 0.01 and 0.1 for time windows 1 and 2 , respectively. It contributed to approximately $11 \%$ of the total coredamage frequency.

\subsection{Descriptions of Dominant Core Damage Cutsets}

The following are the descriptions of those cutsets whose frequency is above $1.0 \mathrm{E}-07$ per year:

\section{2.203E-007 PROB-W2D6, FREQ-L1, DR-MT, DURATION-D6, D-L1W2-XHE,/NRAC262}

In this cutset, a loss of offsite power event(FREQ-L1) occurs in time window 2(PROB-W2D6) of a drained maintenance outage(DR-MT) and diesel generators 1 and 3 start and feed the two unit 1 emergency buses $1 \mathrm{H}$ and $1 \mathrm{~J}$ (FREQ-L1). Because offsite power is lost, the stub bus that supplies power to the normally running RHR pump is shed and will not be automatically connected to the emergency bus. The component cooling water system would stop functioning for the same reason. Loss of offsite power also causes loss of motive power of the normally running service-air compressor. The instrument air compressor also will lose its cooling due to loss of power to the bearing cooling water system. Loss of instrument air causes the RHR flow control valve to open fully, and the CCW 109A and B valves in the CCW flow paths to the RHR pumps and RHR heat exchangers to close.

In this cutset, the operators fail to diagnose(D-L1W2-XHE) the accident scenario correctly, and fail to decide on the proper corrective actions to mitigate the accident. As a result, core damage occurs even if the offsite power is recovered(/NRAC262).

\section{2.074E-007 PROB-W3D6, FREQ-L1, DR-MT, DURATION-D6, D-L1W3-XHE, /NRAC346}

This cutset is the same as cutset number 1, except that it occurs in time window 3(PROB-W3D6) instead of 2.

\section{1.697E-007 PROB-W2D6, DR-MT, DURATION-D6, D-SIW2-XHE, FREQ-SI}


In this cutset, a spurious safety-injection signal(FREQ-SI) occurs in time window 2(PROB-W2D6) of a drained maintenance outage(DR-MT). As a result, the CCW 109A and B valves close automatically and shut off the CCW flow to the RHR heat exchangers and RHR pumps. The operators fail to diagnose(D-SIW2-XHE) the scenario correctly, and fail to decide on the proper corrective actions. As a result, the core is damaged.

\section{1.464E-007 FREQ-RHR3, PROB-W1D6, DR-MT, DURATION-D6, LPR-CCF-PG-SUMP1, R-A3W1D6-XHE-C}

In this cutset, a loss of RHR event(FREQ-RHR3) occurs in time window 1(PROB-W1D6) of a drained maintenance outage(DR-MT) and is not recoverable within the time available. Insufficient steam generators are available for reflux cooling in time window 1 of a drained maintenance outage because 1 steam generator is assumed to be unavailable due to maintenance and 3 are needed. Because studies have shown that 1 steam generator is enough for all decay-heat levels, a recovery action(R-A3W1D6-XHE-C) with failure probability of 0.1 is used to take some credit for reflux cooling. With reflux cooling failed, the operators use feed-andspill to remove decay heat. This mode of cooling lasts approximately 10 hours until the RWST inventory becomes low. Then, the operators switch to recirculation from the containment sump. Recirculation fails because the containment sump is plugged (LPR-CCF-PG-SUMP1) by transient material inside the containment. As a result, core damage occurs.

5. 1.460E-007 PROB-W3D6, DR-MT, DURATION-D6, D-SIW3-XHE, FREQ-SI

This cutset is the same as cutset 3, except that it occurs in time window 3(PROB-W3D6) instead of 2.

6. 1.237E-007 PROB-W1D6, FREQ-L1, D-L1W1-XHE, DR-MT, DURATION-D6, /NRAC200

This cutset is the same as cutset 1, except that it occurs in time window 1(PROB-W1D6) instead of 2.

7. 1.216E-007 REFUEL, DURATION-R6, /PZR-SV-REMOVEDW2,PROB-W2R6, FREQ-L1, D-L1W2-XHE, /NRAC262

This cutset is the same as cutset 1 , except that it occurs in a refueling outage(REFUEL) instead of a drained maintenance outage.

8. 1.077E-007 FREQ-CCW, H-CCW-REC-W1, PROB-W1D6, LPR-CCF-PG-SUMP1, DR-MT, DURATION-D6,R-W1D6-XHE-C-A3

This cutset is the same as cutset 4, except that the initiating event is a loss of CCW(FREQ-CCW) that is not recovered(FREQ-CCW) instead of loss of RHR. 
10 Accident Sequence Quantification

\subsection{References:}

1. "Background and Guidance For Ensuring Adequate Decay Heat Removal when RCS Loop stop valves are closed, Surry and North Anna Power Stations, "NE technical Report No. 865, Rev. 1, Virginia Power, June 1992.

2. "Loss of Decay Heat Removal Capability,"Virginia Power Surry Power Station, Abnormal Procedure 1-AP27.00, Revision 4, February 15, 1993.

3. Naff, S.A., et. al., "Thermal Hydraulic Processes During Reduced inventory Operation with Loss of Residual Heat Removal," Idaho National. Engineering Laboratory, NUREG/CR-5855, April 1992.

4. Fletcher, C.D., et. al., "Thermal-Hydraulic Processes Involved in Loss of Residual Heat Removal During Mid-Loop Operation, EGG-East-9337, Idaho National Engineering Laboratory, October 1990.

5. Wald, L.W., et. al., "Consequence of the Loss of Residual Heat Removal Systems in Pressurized Water Reactors," Idaho National Engineering Laboratory, NUREG/CR-5820, May 1992.

6. T.S. Audreycheck, et. al., "Loss of RHRs Cooling while the RCS is partially filled," WCAP - 11916, Westinghouse Electric Corporation, July 1988.

7. "FERMI 2 - Level 1 Probabilistic Risk Assessment," Pickard, Lowe, and Garrick, Inc., PLG-0676, January 1989.

8. Virginia Power Company, "Main Steam Supply System", Nuclear Control Room Operator Development Program, Surry Power Station, module NCRODP-23.

9. Virginia Power Company, "Vital and Emergency Electrical Distribution System", Nuclear Control Room Operator Development Program, Surry Power Station, module NCRODP-35, May 1990.

10. Consolidated Edison Company of New York, Inc. \& Power Authority of the State of New York, "Indian Point Probabilistic Safety Study", Volume 1, Section 1.3, 1982. 


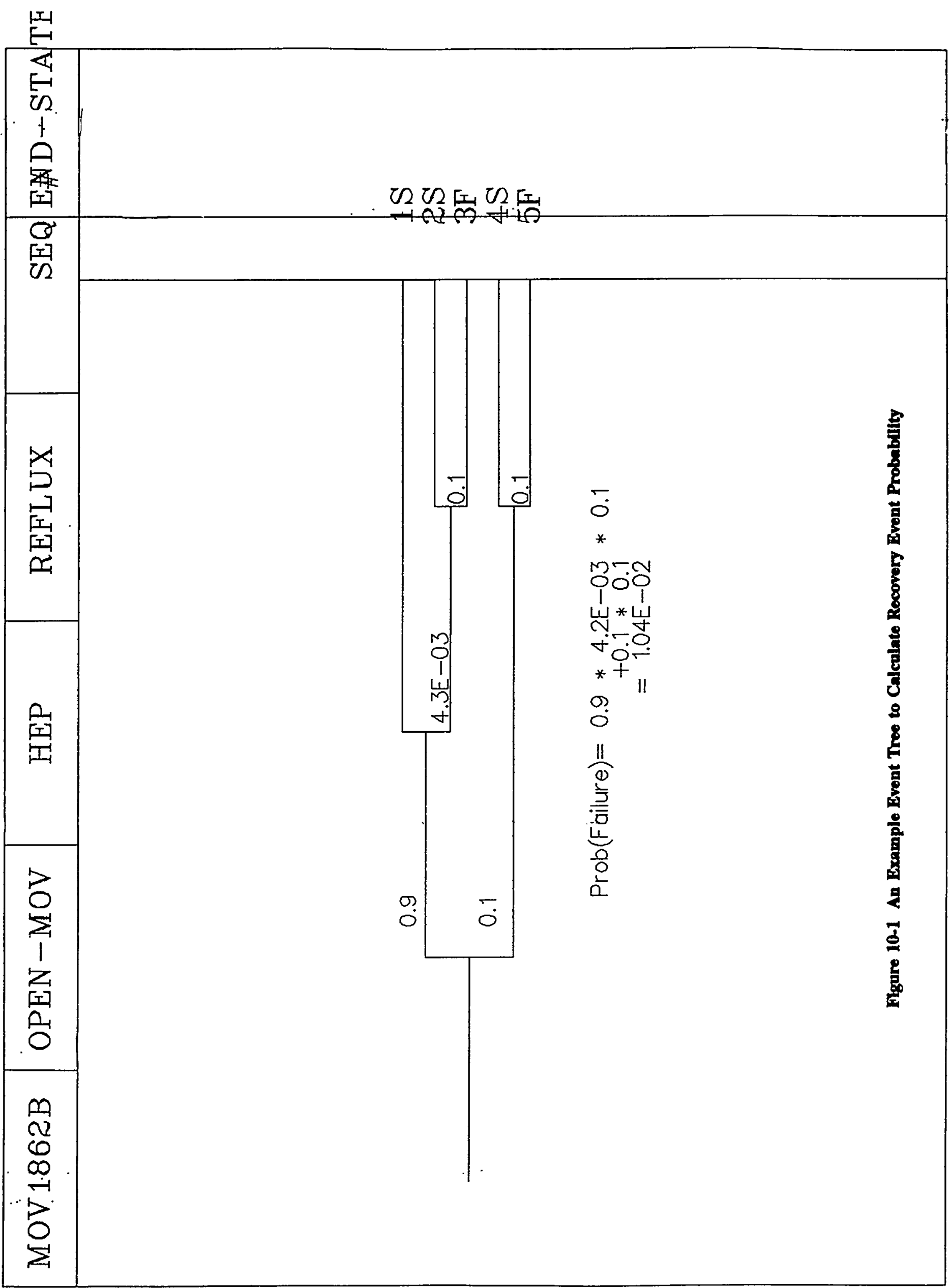




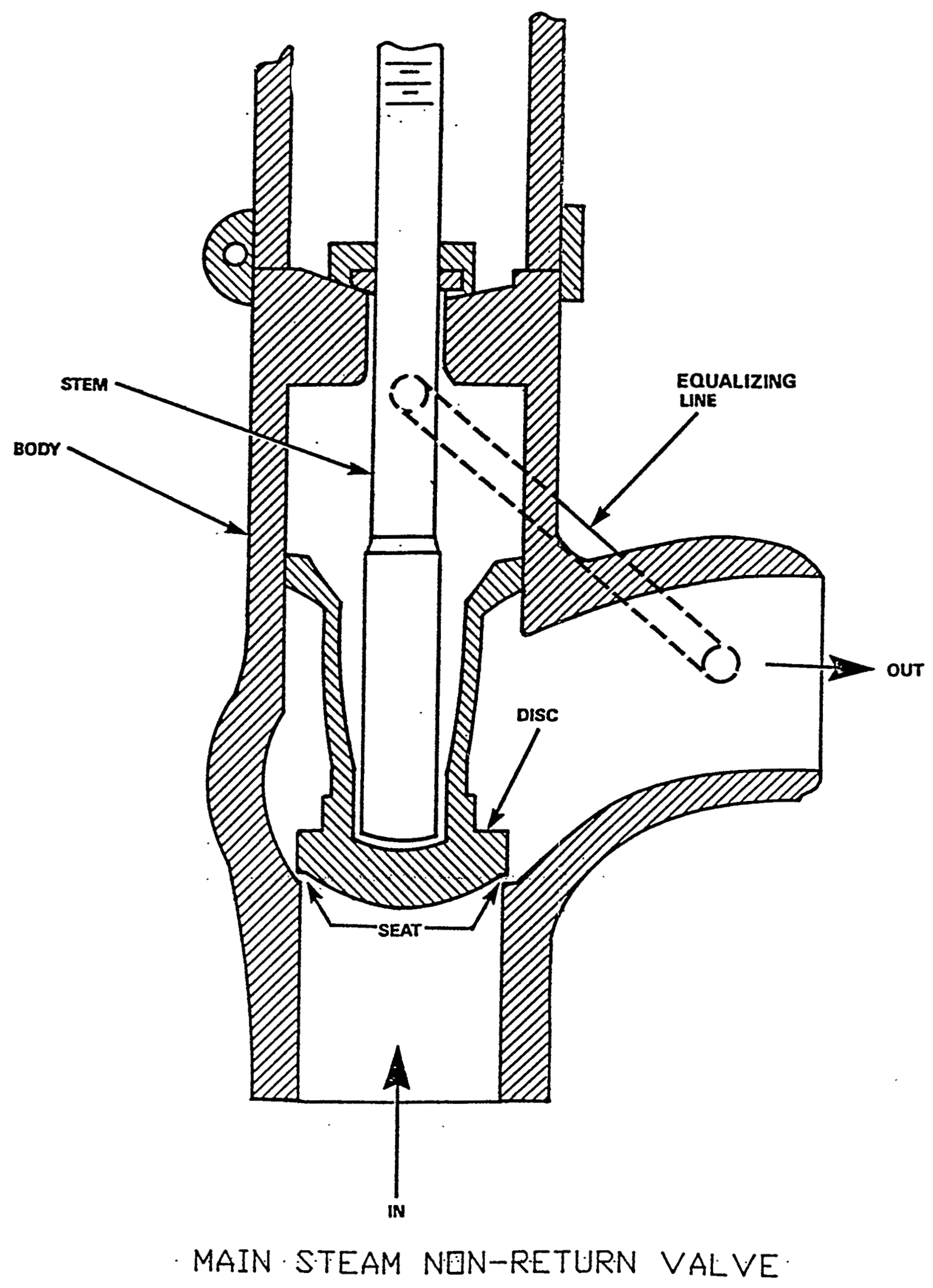

Figure 10-2 Main Steam Non-Return Valve 


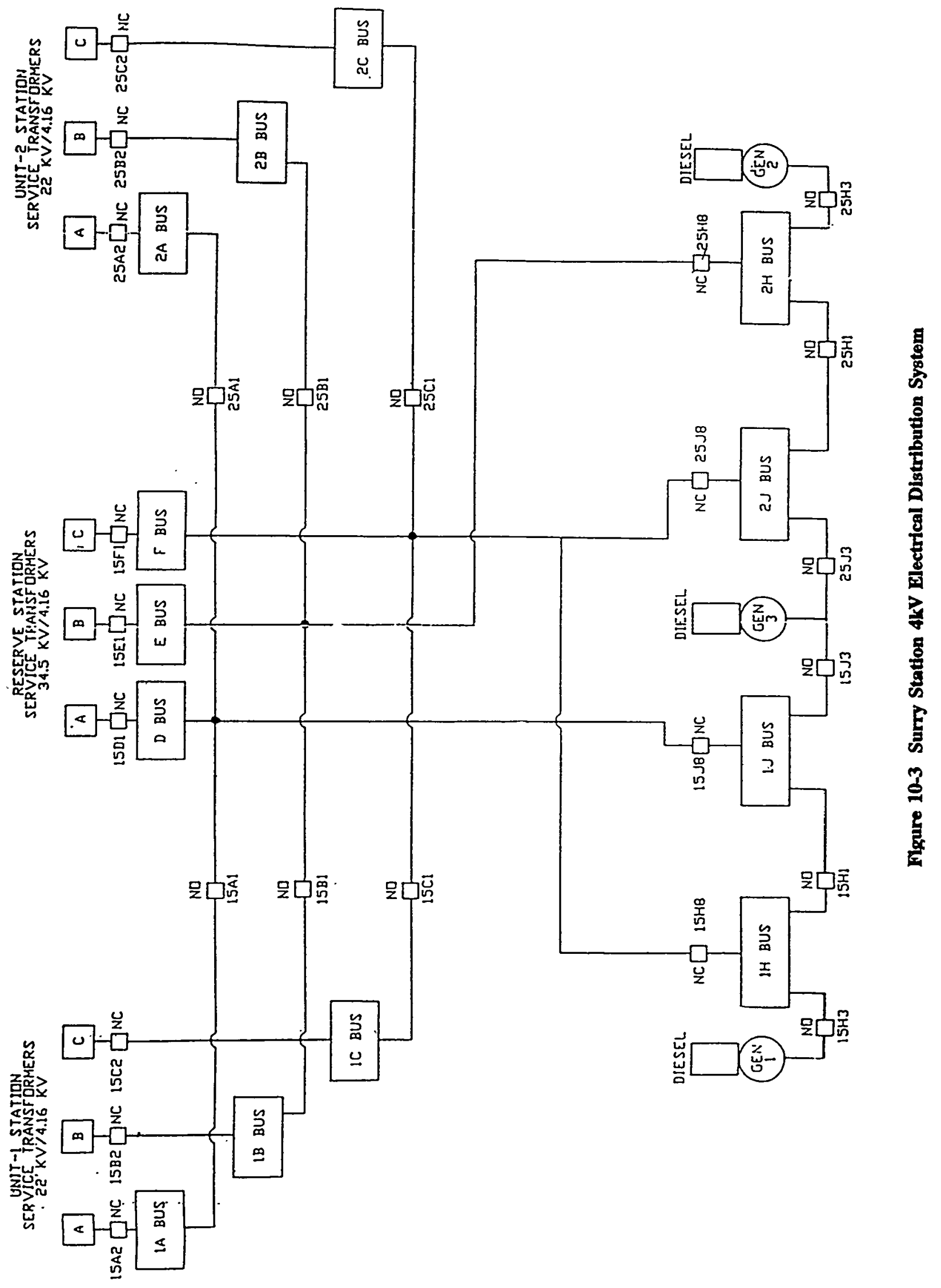


10 Accident Sequence Quantification

Table 10-1

Core Damage Frequencies of Loss RHR Event Trees RAW\#R6 Over-Draining in POS 6 of Refueling

\begin{tabular}{|c|c|c|c|}
\hline Event Tree & Sequence & $\begin{array}{c}\text { Core Damage } \\
\text { Frequency-No } \\
\text { Recovery } \\
\text { (Per Year) }\end{array}$ & $\begin{array}{c}\text { Core Damage } \\
\text { Frequency with } \\
\text { Recovery (Per } \\
\text { Year) }\end{array}$ \\
\hline \multirow[t]{10}{*}{ RAW1R6 } & 4 & - & - \\
\hline & 5 & - & - \\
\hline & 6 & - & - \\
\hline & 9 & $4.070 \mathrm{E}-08$ & $2.998 \mathrm{E}-08$ \\
\hline & 10 & - & - \\
\hline & 12 & - & - \\
\hline & 13 & - & - \\
\hline & 14 & - & - \\
\hline & 17 & $1.848 \mathrm{E}-10$ & $1.848 \mathrm{E}-10$ \\
\hline & 18 & 1.189E-08 & 8.722E-09 \\
\hline \multirow[t]{2}{*}{ RAW2R6 } & 4 & $4.746 \mathrm{E}-10$ & - \\
\hline & 5 & - & - \\
\hline \multirow[t]{8}{*}{1} & 6 & - & - \\
\hline & 9 & 1.307E-07 & $1.270 \mathrm{E}-08$ \\
\hline & 10 & - & - \\
\hline & 12 & - & - \\
\hline & 13 & - & - \\
\hline & 14 & 8.576E-09 & $3.629 \mathrm{E}-09$ \\
\hline & 17 & - & - \\
\hline & 18 & $1.537 \mathrm{E}-07$ & 8.591E-08 \\
\hline \multirow[t]{5}{*}{ RAW3R6 } & 4 & - & - \\
\hline & 5 & - & - \\
\hline & 7 & - & - \\
\hline & 9 & - & - \\
\hline & 10 & $6.305 \mathrm{E}-08$ & $3.223 \mathrm{E}-08$ \\
\hline
\end{tabular}


Table 10-1 (continued)

\begin{tabular}{||c|c|c|c||}
\hline Event Tree & Sequence & $\begin{array}{c}\text { Core Damage } \\
\text { Frequency-No } \\
\text { Recovery } \\
\text { (Per Year) }\end{array}$ & $\begin{array}{c}\text { Core Damage } \\
\text { Frequency with } \\
\text { Recovery (Per } \\
\text { Year) }\end{array}$ \\
\hline RAW4R6 & 12 & $5.249 \mathrm{E}-09$ & $1.857 \mathrm{E}-09$ \\
\hline & 5 & - & - \\
\hline & 8 & - & - \\
\hline & 11 & - & - \\
\hline TOTAL & 14 & $1.075 \mathrm{E}-10$ & $1.752 \mathrm{E}-07$ \\
\hline
\end{tabular}


10 Accident Sequence Quantification

Table 10-2

Core Damage Frequencies of Loss RHR Event Tree RBW\#R6 Inventory Problem in POS 6 of Refueling

\begin{tabular}{|c|c|c|c|}
\hline Event Tree & Sequence & $\begin{array}{c}\text { Core Damage } \\
\text { Frequency-No } \\
\text { Recovery } \\
\text { (Per Year) } \\
\end{array}$ & $\begin{array}{c}\text { Core Damage } \\
\text { Frequency with } \\
\text { Recovery (Per } \\
\text { Year) } \\
\end{array}$ \\
\hline \multirow[t]{10}{*}{ RBW1R6 } & 4 & - & - \\
\hline & 5 & - & - \\
\hline & 6 & - & - \\
\hline & 9 & $7.127 \mathrm{E}-10$ & $6.050 \mathrm{E}-10$ \\
\hline & 10 & - & - \\
\hline & 12 & - & - \\
\hline & 13 & - & - \\
\hline & 14 & - & - \\
\hline & 17 & - & - \\
\hline & 18 & 4.398E-10 & $4.398 \mathrm{E}-10$ \\
\hline \multirow[t]{10}{*}{ RBW2R6 } & 4 & - & - \\
\hline & 5 & - & - \\
\hline & 6 & - & - \\
\hline & 9 & $1.608 \mathrm{E}-08$ & $1.289 \mathrm{E}-09$ \\
\hline & 10 & - & - \\
\hline & 12 & - & - \\
\hline & 13 & & - \\
\hline & 14 & 8.742E-10 & 2.412E-10 \\
\hline & 17 & - & - \\
\hline & 18 & $1.898 \mathrm{E}-08$ & $9.728 \mathrm{E}-09$ \\
\hline \multirow[t]{4}{*}{ RBW3R6 } & 4 & - & - \\
\hline & 5 & - & - \\
\hline & 7 & - & - \\
\hline & 9 & - & - \\
\hline
\end{tabular}


Table 10-2 (continued)

\begin{tabular}{|c|c|c|c||}
\hline Event Tree & Sequence & $\begin{array}{c}\text { Core Damage } \\
\text { Frequency-No } \\
\text { Recovery } \\
\text { (Per Year) }\end{array}$ & $\begin{array}{c}\text { Core Damage } \\
\text { Frequency with } \\
\text { Recovery (Per } \\
\text { Year) }\end{array}$ \\
\hline & 10 & $1.749 \mathrm{E}-08$ & $8.145 \mathrm{E}-09$ \\
\hline RBW4R6 & 12 & $1.434 \mathrm{E}-09$ & $3.642 \mathrm{E}-10$ \\
\hline & 5 & - & - \\
\hline & 7 & - & - \\
\hline TOTAL & 10 & $1.898 \mathrm{E}-10$ & - \\
\hline & 12 & $5.549 \mathrm{E}-10$ & - \\
\hline
\end{tabular}


10 Accident Sequence Quantification

Table 10-3

Core Damage Frequencies of Loss RHR Event Tree R3W\#R6

Non-Recoverable Loss of RHR in POS 6 of Refueling

\begin{tabular}{|c|c|c|c|}
\hline Event Tree & Sequence & $\begin{array}{c}\text { Core Damage } \\
\text { Frequency-No } \\
\text { Recovery } \\
\text { (Per Year) }\end{array}$ & $\begin{array}{c}\text { Core Damage } \\
\text { Frequency with } \\
\text { Recovery } \\
\text { (Per Year) }\end{array}$ \\
\hline \multirow[t]{5}{*}{ R3W1R6 } & 3 & 2.229E-09 & $1.414 \mathrm{E}-09$ \\
\hline & 4 & - & - \\
\hline & 5 & - & - \\
\hline & 8 & $1.125 \mathrm{E}-07$ & $7.709 \mathrm{E}-08$ \\
\hline & 9 & 3.311E-10 & 3.311E-10 \\
\hline \multirow[t]{5}{*}{ R3W2R6 } & 3 & $9.696 \mathrm{E}-09$ & 3.305E-09 \\
\hline & 4 & - & - \\
\hline & 5 & $2.915 \mathrm{E}-10$ & $2.915 \mathrm{E}-10$ \\
\hline & 8 & $2.980 \mathrm{E}-07$ & $5.575 \mathrm{E}-08$ \\
\hline & 9 & 8.797E-09 & 8.797E-09 \\
\hline \multirow[t]{3}{*}{ R3W3R6 } & 3 & - & - \\
\hline & 4 & $6.330 \mathrm{E}-09$ & $6.330 \mathrm{E}-09$ \\
\hline & 6 & $5.425 \mathrm{E}-10$ & $5.425 \mathrm{E}-10$ \\
\hline \multirow[t]{2}{*}{ R3W4R6 } & 4 & - & - \\
\hline & 6 & $1.485 \mathrm{E}-10$ & $1.485 \mathrm{E}-10$ \\
\hline TOTAL & & 4.388E-07 & $1.540 \mathrm{E}-07$ \\
\hline
\end{tabular}


Table 10-4

Core Damage Frequencies of Loss RHR Event Tree R4W\#R6 Non-Recoverable Loss of Operating Train of RHR in POS 6 of Refueling

\begin{tabular}{|c|c|c|c|}
\hline Event Tree & Sequence & $\begin{array}{c}\text { Core Damage Frequency- } \\
\text { No Recovery } \\
\text { (Per Year) }\end{array}$ & $\begin{array}{c}\text { Core Damage } \\
\text { Frequency with Recovery } \\
\text { (Per Year) }\end{array}$ \\
\hline \multirow[t]{5}{*}{ R4W1R6 } & 4 & - & - \\
\hline & 5 & - & - \\
\hline & 6 & - & - \\
\hline & 9 & $2.739 \mathrm{E}-09$ & 2.159E-09 \\
\hline & 10 & $1.903 \mathrm{E}-10$ & $1.903 \mathrm{E}-10$ \\
\hline \multirow[t]{5}{*}{ R4W2R6 } & 4 & $1.355 \mathrm{E}-10$ & - \\
\hline & 5 & - & - \\
\hline & 6 & $1.044 \mathrm{E}-10$ & $1.044 \mathrm{E}-10$ \\
\hline & 9 & $1.158 \mathrm{E}-08$ & $1.333 \mathrm{E}-09$ \\
\hline & 10 & $2.095 \mathrm{E}-09$ & $2.095 \mathrm{E}-09$ \\
\hline \multirow[t]{3}{*}{ R4W3R6 } & 4 & - & - \\
\hline & 5 & $1.533 \mathrm{E}-09$ & $1.533 \mathrm{E}-09$ \\
\hline & 7 & $1.576 \mathrm{E}-10$ & $1.576 \mathrm{E}-10$ \\
\hline \multirow[t]{2}{*}{ R4W4R6 } & 5 & - & - \\
\hline & 7 & - & - \\
\hline TOTAL & & $1.853 \mathrm{E}-08$ & $7.572 \mathrm{E}-09$ \\
\hline
\end{tabular}


Table 10-5

Core Damage Frequencies of Loss RHR Event Tree RSW\#R6 Recoverable Loss of RHR in POS 6 of Refueling

\begin{tabular}{|c|c|c|c|}
\hline Event Tree & Sequence & $\begin{array}{c}\text { Core Damage } \\
\text { Frequency-No } \\
\text { Recovery } \\
\text { (Per Year) } \\
\end{array}$ & $\begin{array}{c}\text { Core Damage } \\
\text { Frequency with } \\
\text { Recovery (Per Year) }\end{array}$ \\
\hline \multirow[t]{5}{*}{ R5W1R6 } & 4 & - & - \\
\hline & 5 & - & - \\
\hline & 6 & - & - \\
\hline & 9 & $1.442 \mathrm{E}-09$ & $1.051 \mathrm{E}-09$ \\
\hline & 10 & $1.171 \mathrm{E}-09$ & $1.171 \mathrm{E}-09$ \\
\hline \multirow[t]{5}{*}{ R5W2R6 } & 4 & - & - \\
\hline & 5 & - & - \\
\hline & 6 & $9.863 \mathrm{E}-10$ & $9.863 \mathrm{E}-10$ \\
\hline & 9 & $2.897 \mathrm{E}-08$ & $2.240 \mathrm{E}-09$ \\
\hline & 10 & $1.938 \mathrm{E}-08$ & $1.906 \mathrm{E}-08$ \\
\hline \multirow[t]{3}{*}{ R5W3R6 } & 4 & - & - \\
\hline & 5 & $1.370 \mathrm{E}-08$ & $1.356 \mathrm{E}-08$ \\
\hline & 7 & $1.489 \mathrm{E}-09$ & $1.489 \mathrm{E}-09$ \\
\hline \multirow[t]{2}{*}{ R5W4R6 } & 5 & - & - \\
\hline & 7 & - & - \\
\hline TOTAL & & 6.713E-08 & $3.955 \mathrm{E}-08$ \\
\hline
\end{tabular}


Table 10-6

Core Damage Frequencies of Loss RHR Event Tree RAW\#D6 Over-Draining in POS 6 of Drained Maintenance

\begin{tabular}{|c|c|c|c|}
\hline Event Tree & Sequence & $\begin{array}{c}\text { Core Damage } \\
\text { Frequency-No } \\
\text { Recovery } \\
\text { (Per Year) }\end{array}$ & $\begin{array}{c}\text { Core Damage } \\
\text { Frequency with } \\
\text { Recovery (Per Year) }\end{array}$ \\
\hline RAW1D6 & 4 & $1.001 \mathrm{E}-06$ & $7.082 \mathrm{E}-08$ \\
\hline & 5 & $1.199 \mathrm{E}-09$ & - \\
\hline & 7 & $1.646 \mathrm{E}-08$ & $8.617 \mathrm{E}-10$ \\
\hline RAW2D6 & 8 & $2.472 \mathrm{E}-07$ & $9.536 \mathrm{E}-08$ \\
\hline & 5 & $8.806 \mathrm{E}-08$ & $1.522 \mathrm{E}-08$ \\
\hline & 6 & - & - \\
\hline RAW3D6 & 8 & - & $5.103 \mathrm{E}-08$ \\
\hline & 10 & $6.149 \mathrm{E}-08$ & - \\
\hline RAW4D6 & 5 & - & $2.316 \mathrm{E}-08$ \\
\hline & 8 & $2.744 \mathrm{E}-08$ & - \\
\hline TOTAL & 5 & - & $5.559 \mathrm{E}-10$ \\
\hline & & $1.443 \mathrm{E}-06$ & $2.570 \mathrm{E}-07$ \\
\hline
\end{tabular}


10 Accident Sequence Quantification

Table 10-7

Core Damage Frequencies of Loss RHR Event Tree RBW\#D6

Inventory Problem in POS 6 of Drained Maintenance

\begin{tabular}{|c|c|c|c||}
\hline Event Tree & Sequence & $\begin{array}{c}\text { Core Damage Frequency- } \\
\text { No Recovery } \\
\text { (Per Year) }\end{array}$ & $\begin{array}{c}\text { Core Damage } \\
\text { Frequency with } \\
\text { Recovery (Per Year) }\end{array}$ \\
\hline RBW1D6 & 4 & $6.308 \mathrm{E}-08$ & $2.839 \mathrm{E}-09$ \\
\hline & 5 & - & - \\
\hline & 7 & $1.018 \mathrm{E}-09$ & - \\
\hline & 8 & $1.613 \mathrm{E}-08$ & $6.746 \mathrm{E}-09$ \\
\hline RBW2D6 & 5 & $1.395 \mathrm{E}-08$ & $2.335 \mathrm{E}-09$ \\
\hline & 6 & - & - \\
\hline & 9 & - & - \\
\hline & 10 & $1.070 \mathrm{E}-08$ & $9.101 \mathrm{E}-09$ \\
\hline RBW3D6 & 5 & - & - \\
\hline & 8 & $8.935 \mathrm{E}-09$ & $7.734 \mathrm{E}-09$ \\
\hline RBW4D6 & 5 & - & - \\
\hline & 8 & $2.956 \mathrm{E}-10$ & $2.956 \mathrm{E}-10$ \\
\hline TOTAL & & $1.141 \mathrm{E}-07$ & $2.905 \mathrm{E}-08$ \\
\hline
\end{tabular}


10 Accident Sequence Quantification

Table 10-8

Core Damage Frequencies of Loss RHR Event Tree R3W\#D6

Non-Recoverable Loss of RHR in POS 6 of Drained Maintenance

\begin{tabular}{|c|c|c|c||}
\hline Event Tree & Sequence & $\begin{array}{c}\text { Core Damage } \\
\text { Frequency-No } \\
\text { Recovery } \\
\text { (Per Year) }\end{array}$ & $\begin{array}{c}\text { Core Damage } \\
\text { Frequency with } \\
\text { Recovery (Per } \\
\text { Year) }\end{array}$ \\
\hline R3W1D6 & 3 & $3.888 \mathrm{E}-06$ & $2.731 \mathrm{E}-07$ \\
\hline & 4 & $1.405 \mathrm{E}-08$ & $4.150 \mathrm{E}-09$ \\
\hline R3W2D6 & 4 & $1.020 \mathrm{E}-07$ & $1.295 \mathrm{E}-08$ \\
\hline & 5 & $4.877 \mathrm{E}-09$ & $4.877 \mathrm{E}-09$ \\
\hline R3W3D6 & 4 & $4.055 \mathrm{E}-09$ & $4.055 \mathrm{E}-09$ \\
\hline R3W4D6 & 4 & - & - \\
\hline TOTAL & & $4.013 \mathrm{E}-06$ & $2.991 \mathrm{E}-07$ \\
\hline
\end{tabular}


10 Accident Sequence Quantification

Table 10-9

Core Damage Frequencies of Loss RHR Event Tree R4W\#D6

Non-Recoverable Loss of Operating Train of RHR in POS 6 of Drained Maintenance

\begin{tabular}{|c|c|c|c|}
\hline Event Tree & Sequence & $\begin{array}{c}\text { Core Damage } \\
\text { Frequency-No } \\
\text { Recovery } \\
\text { (Per Year) }\end{array}$ & $\begin{array}{c}\text { Core Damage } \\
\text { Frequency with } \\
\text { Recovery (Per } \\
\text { Year) }\end{array}$ \\
\hline R4W1D6 & 4 & $1.943 \mathrm{E}-07$ & $1.262 \mathrm{E}-08$ \\
\hline & 5 & $3.499 \mathrm{E}-09$ & $2.835 \mathrm{E}-09$ \\
\hline R4W2D6 & 5 & $5.550 \mathrm{E}-09$ & $9.119 \mathrm{E}-10$ \\
\hline R4W3D6 & 6 & $3.592 \mathrm{E}-09$ & $3.592 \mathrm{E}-09$ \\
\hline R4W4D6 & 5 & $3.090 \mathrm{E}-09$ & $3.090 \mathrm{E}-09$ \\
\hline TOTAL & 5 & $1.279 \mathrm{E}-10$ & $1.279 \mathrm{E}-10$ \\
\hline
\end{tabular}


10 Accident Sequence Quantification

Table 10-10

Core Damage Frequencies of Loss RHR Event Tree R5W\#D6

Recoverable Loss of RHR in POS 6 of Drained Maintenance

\begin{tabular}{||c|c|c|c||}
\hline Event Tree & Sequence & $\begin{array}{c}\text { Core Damage Frequency- } \\
\text { No Recovery } \\
\text { (Per Year) }\end{array}$ & $\begin{array}{c}\text { Core Damage Frequency } \\
\text { with Recovery (Per Year) }\end{array}$ \\
\hline R5W1D6 & 4 & $1.140 \mathrm{E}-07$ & $6.060 \mathrm{E}-09$ \\
\hline & 5 & $1.756 \mathrm{E}-08$ & $1.745 \mathrm{E}-08$ \\
\hline R5W2D6 & 5 & $2.507 \mathrm{E}-08$ & $4.275 \mathrm{E}-09$ \\
\hline & 6 & $3.510 \mathrm{E}-08$ & $3.452 \mathrm{E}-08$ \\
\hline R5W3D6 & 5 & $3.019 \mathrm{E}-08$ & $2.969 \mathrm{E}-08$ \\
\hline R5W4D6 & 5 & $5.137 \mathrm{E}-10$ & $5.137 \mathrm{E}-10$ \\
\hline TOTAL & & $2.224 \mathrm{E}-07$ & $9.250 \mathrm{E}-08$ \\
\hline
\end{tabular}


10 Accident Sequence Quantification

Table 10-11

Core Damage Frequencies of Loss RHR Event Tree- RAW\#R10 Over-Draining in POS 10 of Refueling

\begin{tabular}{|c|c|c|c|}
\hline Event Tree & Sequence & $\begin{array}{c}\text { Core Damage } \\
\text { Frequency-No } \\
\text { Recovery } \\
\text { (Per Year) }\end{array}$ & $\begin{array}{c}\text { Core Damage } \\
\text { Frequency with } \\
\text { Recovery (Per } \\
\text { Year) }\end{array}$ \\
\hline RAW3R10 & 4 & - & - \\
\hline & 5 & - & - \\
\hline & 7 & - & - \\
\hline & 9 & - & - \\
\hline & 10 & $1.355 \mathrm{E}-09$ & $1.095 \mathrm{E}-09$ \\
\hline RAW4R10 & 12 & - & - \\
\hline & 5 & - & - \\
\hline & 8 & - & $1.928 \mathrm{E}-08$ \\
\hline & 11 & $2.344 \mathrm{E}-08$ & $3.226 \mathrm{E}-08$ \\
\hline & 14 & $5.841 \mathrm{E}-08$ & $5.263 \mathrm{E}-08$ \\
\hline
\end{tabular}


10 Accident Sequence Quantification

Table 10-12

Core Damage Frequencies of Loss RHR Event Tree RBW\#R10 Inventory Problem in POS 10 of Refueling

\begin{tabular}{|c|c|c|c|}
\hline Event Tree & Sequence & $\begin{array}{c}\text { Core Damage } \\
\text { Frequency-No } \\
\text { Recovery } \\
\text { (Per Year) }\end{array}$ & $\begin{array}{c}\text { Core Damage } \\
\text { Frequency with } \\
\text { Recovery (Per Year) }\end{array}$ \\
\hline RBW3R10 & 4 & - & - \\
\hline & 5 & - & - \\
\hline & 7 & - & - \\
\hline & 9 & - & $2.399 \mathrm{E}-10$ \\
\hline & 10 & $2.399 \mathrm{E}-10$ & - \\
\hline RBW4R10 & 12 & - & - \\
\hline & 5 & - & - \\
\hline & 7 & - & $5.376 \mathrm{E}-09$ \\
\hline & 10 & $6.671 \mathrm{E}-09$ & $1.483 \mathrm{E}-08$ \\
\hline & 12 & $1.799 \mathrm{E}-08$ & $2.044 \mathrm{E}-08$ \\
\hline
\end{tabular}


10 Accident Sequence Quantification

Table 10-13

Core Damage Frequencies of Loss RHR Event Tree R3W\#R10

Non-Recoverable Loss of RHR in POS 10 of Refueling

\begin{tabular}{|c|c|c|c||}
\hline Event Tree & Sequence & $\begin{array}{c}\text { Core Damage } \\
\text { Frequency-No } \\
\text { Recovery } \\
\text { (Per Year) }\end{array}$ & $\begin{array}{c}\text { Core Damage } \\
\text { Frequency with } \\
\text { Recovery (Per } \\
\text { Year) }\end{array}$ \\
\hline R3W3R10 & 3 & - & - \\
\hline & 4 & - & - \\
\hline R3W4R10 & 6 & - & - \\
\hline & 4 & $2.203 \mathrm{E}-09$ & $2.203 \mathrm{E}-09$ \\
\hline TOTAL & 6 & $6.188 \mathrm{E}-09$ & $6.188 \mathrm{E}-09$ \\
\hline
\end{tabular}


10 Accident Sequence Quantification

Table 10-14

Core Damage Frequencies of Loss RHR Event Tree R4W\#R10

Non-Recoverable Loss of Operating Train of RHR in POS 10 of Refueling

\begin{tabular}{|c|c|c|c|}
\hline Event Tree & Sequence & $\begin{array}{c}\text { Core Damage } \\
\text { Frequency-No } \\
\text { Recovery } \\
\text { (Per Year) }\end{array}$ & $\begin{array}{c}\text { Core Damage } \\
\text { Frequency with } \\
\text { Recovery (Per Year) }\end{array}$ \\
\hline R4W3R10 & 4 & - & - \\
\hline & 5 & - & - \\
\hline R4W4R10 & 7 & - & - \\
\hline & 5 & $2.283 \mathrm{E}-10$ & $2.283 \mathrm{E}-10$ \\
\hline TOTAL & 7 & $9.618 \mathrm{E}-10$ & $9.618 \mathrm{E}-10$ \\
\hline
\end{tabular}


10 Accident Sequence Quantification

Table 10-15

Core Damage Frequencies of Loss RHR Event Tree R5W\#R10

\begin{tabular}{|c|c|c|c|}
\hline Event Tree & Sequence & $\begin{array}{c}\text { Core Damage } \\
\text { Frequency-No } \\
\text { Recovery } \\
\text { (Per Year) }\end{array}$ & $\begin{array}{c}\text { Core Damage } \\
\text { Frequency with } \\
\text { Recovery (Per Year) }\end{array}$ \\
\hline R5W3R10 & 4 & - & - \\
\hline & 5 & $4.879 \mathrm{E}-10$ & $4.879 \mathrm{E}-10$ \\
\hline & 7 & - & - \\
\hline R5W4R10 & 5 & $1.138 \mathrm{E}-09$ & $1.033 \mathrm{E}-09$ \\
\hline & 7 & $2.942 \mathrm{E}-09$ & $2.542 \mathrm{E}-09$ \\
\hline TOTAL & & $4.567 \mathrm{E}-09$ & $4.062 \mathrm{E}-09$ \\
\hline
\end{tabular}


Table 10-16

Core Damage Frequencies of Loss of Ofisite Power for Event Tree L1W\#D6

\begin{tabular}{|c|c|c|c|}
\hline Event Tree & Sequence & $\begin{array}{c}\text { Core Damage } \\
\text { Frequency-No } \\
\text { Recovery } \\
\text { (Per Year) }\end{array}$ & $\begin{array}{c}\text { Core Damage } \\
\text { Frequency with } \\
\text { Recovery } \\
\text { (Per Year) }\end{array}$ \\
\hline L1W1D6 & 4 & $1.163 \mathrm{E}-07$ & $3.925 \mathrm{E}-09$ \\
\hline & 5 & $1.827 \mathrm{E}-07$ & $1.242 \mathrm{E}-07$ \\
\hline L1W2D6 & 7 & $3.471 \mathrm{E}-08$ & $1.596 \mathrm{E}-09$ \\
\hline & 8 & $5.846 \mathrm{E}-08$ & $5.846 \mathrm{E}-08$ \\
\hline & 5 & $6.836 \mathrm{E}-09$ & $2.664 \mathrm{E}-09$ \\
\hline & 6 & $2.977 \mathrm{E}-07$ & $2.202 \mathrm{E}-07$ \\
\hline & 9 & $2.153 \mathrm{E}-10$ & $2.153 \mathrm{E}-10$ \\
\hline & 10 & $7.738 \mathrm{E}-08$ & $7.738 \mathrm{E}-08$ \\
\hline L1W3D6 & 5 & $2.560 \mathrm{E}-07$ & $2.073 \mathrm{E}-07$ \\
\hline & 8 & $4.864 \mathrm{E}-08$ & $4.864 \mathrm{E}-08$ \\
\hline & 5 & $1.092 \mathrm{E}-08$ & $9.393 \mathrm{E}-09$ \\
\hline & 8 & $1.529 \mathrm{E}-09$ & $1.529 \mathrm{E}-09$ \\
\hline & & $1.091 \mathrm{E}-06$ & $7.555 \mathrm{E}-07$ \\
\hline
\end{tabular}


10 Accident Sequence Quantification

Table 10-17

Core Damage Frequencies of Loss of Offsite Power for Event Tree L1W\#R6

\begin{tabular}{|c|c|c|c|}
\hline Event Tree & Sequence & $\begin{array}{c}\text { Core Damage } \\
\text { Frequency-No } \\
\text { Recovery } \\
\text { (Per Year) }\end{array}$ & $\begin{array}{l}\text { Core Damage } \\
\text { Frequency with } \\
\text { Recovery } \\
\text { (Per Year) }\end{array}$ \\
\hline \multirow[t]{10}{*}{ L1W1R6 } & 4 & - & - \\
\hline & 5 & - & - \\
\hline & 6 & $1.233 \mathrm{E}-10$ & - \\
\hline & 8 & - & - \\
\hline & 9 & - & - \\
\hline & 10 & - & - \\
\hline & 13 & $1.515 \mathrm{E}-09$ & $1.030 \mathrm{E}-09$ \\
\hline & 14 & $1.221 \mathrm{E}-08$ & 8.304E-09 \\
\hline & 17 & $6.908 \mathrm{E}-10$ & $6.908 \mathrm{E}-10$ \\
\hline & 18 & $3.908 \mathrm{E}-09$ & $3.908 \mathrm{E}-09$ \\
\hline \multirow[t]{10}{*}{ L1W2R6 } & 4 & - & - \\
\hline & 5 & - & - \\
\hline & 6 & 8.649E-09 & $6.400 \mathrm{E}-09$ \\
\hline & 8 & - & - \\
\hline & 9 & - & - \\
\hline & 10 & $2.248 \mathrm{E}-09$ & $2.248 \mathrm{E}-09$ \\
\hline & 13 & $9.092 \mathrm{E}-09$ & $5.468 \mathrm{E}-09$ \\
\hline & 14 & $1.643 \mathrm{E}-07$ & $1.216 \mathrm{E}-07$ \\
\hline & 17 & $6.867 \mathrm{E}-10$ & $6.867 \mathrm{E}-10$ \\
\hline & 18 & 4.272E-08 & 4.272E-08 \\
\hline \multirow[t]{4}{*}{ L1W3R6 } & 4 & - & - \\
\hline & 5 & $1.175 \mathrm{E}-07$ & $9.521 \mathrm{E}-08$ \\
\hline & 7 & - & - \\
\hline & 8 & $2.233 \mathrm{E}-08$ & 2.233E-08 \\
\hline
\end{tabular}


10 Accident Sequence Quantification

Table 10-17 (continued)

\begin{tabular}{|c|c|c|c||}
\hline Event Tree & Sequence & $\begin{array}{c}\text { Core Damage } \\
\text { Frequency-No } \\
\text { Recovery } \\
\text { (Per Year) }\end{array}$ & $\begin{array}{c}\text { Core Damage } \\
\text { Frequency with } \\
\text { Recovery } \\
\text { (Per Year) }\end{array}$ \\
\hline & 10 & $1.306 \mathrm{E}-08$ & $1.058 \mathrm{E}-08$ \\
\hline L1W4R6 & 12 & $2.481 \mathrm{E}-09$ & $2.481 \mathrm{E}-09$ \\
\hline & 5 & $7.221 \mathrm{E}-10$ & $6.210 \mathrm{E}-10$ \\
\hline & 8 & $1.010 \mathrm{E}-10$ & $1.010 \mathrm{E}-10$ \\
\hline & 10 & $1.684 \mathrm{E}-09$ & $1.449 \mathrm{E}-09$ \\
\hline TOTAL & 12 & $2.358 \mathrm{E}-10$ & $2.358 \mathrm{E}-10$ \\
\hline
\end{tabular}


10 Accident Sequence Quantification

Table 10-18

Core Damage Frequencies of Loss of Offsite Power for Event Tree L1W\#R10

\begin{tabular}{|c|c|c|c||}
\hline Event Tree & Sequence & $\begin{array}{c}\text { Core Damage } \\
\text { Frequency-No } \\
\text { Recovery } \\
\text { Per Year) }\end{array}$ & $\begin{array}{c}\text { Core Damage } \\
\text { Frequency with } \\
\text { Recovery } \\
\text { (Per Year) }\end{array}$ \\
\hline L1W3R10 & 4 & - & - \\
\hline & 5 & $4.279 \mathrm{E}-09$ & $3.466 \mathrm{E}-09$ \\
\hline & 7 & - & - \\
\hline & 8 & $8.130 \mathrm{E}-10$ & $8.130 \mathrm{E}-10$ \\
\hline L1W4R10 & 10 & $4.754 \mathrm{E}-10$ & $3.851 \mathrm{E}-10$ \\
\hline & 12 & - & - \\
\hline & 5 & $1.949 \mathrm{E}-08$ & $1.676 \mathrm{E}-08$ \\
\hline & 10 & $2.729 \mathrm{E}-09$ & $2.729 \mathrm{E}-09$ \\
\hline & 12 & $4.548 \mathrm{E}-08$ & $3.911 \mathrm{E}-08$ \\
\hline & & $6.367 \mathrm{E}-09$ & $6.367 \mathrm{E}-09$ \\
\hline
\end{tabular}


10 Accident Sequence Quantification

Table 10-19

Core Damage Frequencies of Loss of Offsite Power for Event Tree L2W\#D6

\begin{tabular}{|c|c|c|c|}
\hline Event Tree & Sequence & $\begin{array}{c}\text { Core Damage } \\
\text { Frequency-No } \\
\text { Recovery } \\
\text { (Per Year) }\end{array}$ & $\begin{array}{c}\text { Core Damage } \\
\text { Frequency with } \\
\text { Recovery } \\
\text { (Per Year) }\end{array}$ \\
\hline L2W1D6 & 4 & $1.074 \mathrm{E}-08$ & $2.870 \mathrm{E}-10$ \\
\hline & 5 & $2.637 \mathrm{E}-08$ & $1.793 \mathrm{E}-08$ \\
\hline L2W2D6 & 7 & $7.541 \mathrm{E}-07$ & $1.153 \mathrm{E}-09$ \\
\hline & 8 & $1.203 \mathrm{E}-07$ & $8.766 \mathrm{E}-09$ \\
\hline & 5 & $5.478 \mathrm{E}-10$ & $5.478 \mathrm{E}-10$ \\
\hline & 6 & $7.274 \mathrm{E}-08$ & $5.383 \mathrm{E}-08$ \\
\hline L2W3D6 & 9 & $6.870 \mathrm{E}-07$ & $1.839 \mathrm{E}-09$ \\
\hline & 10 & $1.507 \mathrm{E}-07$ & $1.911 \mathrm{E}-08$ \\
\hline L2W4D6 & 5 & $6.256 \mathrm{E}-08$ & $5.067 \mathrm{E}-08$ \\
\hline & 8 & $9.101 \mathrm{E}-08$ & $1.188 \mathrm{E}-08$ \\
\hline TOTAL & 5 & $1.623 \mathrm{E}-09$ & $1.396 \mathrm{E}-09$ \\
\hline & 8 & $1.022 \mathrm{E}-09$ & $1.022 \mathrm{E}-09$ \\
\hline & & $1.978 \mathrm{E}-06$ & $1.684 \mathrm{E}-07$ \\
\hline
\end{tabular}


10 Accident Sequence Quantification

Table 10-20

Core Damage Frequencies of Loss of Offsite Power for Event Tree L2W\#R6

\begin{tabular}{|c|c|c|c|}
\hline Event Tree & Sequence & $\begin{array}{c}\text { Core Damage } \\
\text { Frequency-No } \\
\text { Recovery } \\
\text { (Per Year) }\end{array}$ & $\begin{array}{l}\text { Core Damage } \\
\text { Frequency with } \\
\text { Recovery } \\
\text { (Per Year) }\end{array}$ \\
\hline \multirow[t]{8}{*}{ L2W1R6 } & 4 & - & - \\
\hline & 5 & - & - \\
\hline & 6 & - & - \\
\hline & 8 & $1.536 \mathrm{E}-10$ & $1.536 \mathrm{E}-10$ \\
\hline & 9 & - & - \\
\hline & 10 & - & - \\
\hline & $13 \mid$ & - & - \\
\hline & 14 & $1.770 \mathrm{E}-09$ & $1.204 \mathrm{E}-09$ \\
\hline \multirow[t]{2}{*}{ ' } & 17 & $5.767 \mathrm{E}-08$ & - \\
\hline & 18 & $5.840 \mathrm{E}-09$ & $5.840 \mathrm{E}-09$ \\
\hline \multirow[t]{10}{*}{ L2W2R6 } & 4 & - & - \\
\hline & 5 & - & - \\
\hline & 6 & 2.113E-09 & $1.564 \mathrm{E}-09$ \\
\hline & 8 & 1.771E-09 & $1.771 \mathrm{E}-09$ \\
\hline & 9 & - & - \\
\hline & 10 & 7.062E-09 & 7.062E-09 \\
\hline & 13 & $5.660 \mathrm{E}-10$ & $1.012 \mathrm{E}-10$ \\
\hline & 14 & $4.016 \mathrm{E}-08$ & 2.972E-08 \\
\hline & 17 & 5.213E-07 & $2.469 \mathrm{E}-09$ \\
\hline & 18 & 1.379E-07 & $1.094 \mathrm{E}-08$ \\
\hline \multirow[t]{4}{*}{ L2W3R6 } & 4 & - & - \\
\hline & 5 & 2.873E-08 & $2.327 \mathrm{E}-08$ \\
\hline & 7 & - & - \\
\hline & 8 & $7.877 \mathrm{E}-08$ & $5.458 \mathrm{E}-09$ \\
\hline
\end{tabular}


10 Accident Sequence Quantification

Table $\mathbf{1 0 - 2 0}$ (continued)

\begin{tabular}{|c|c|c|c|}
\hline Event Tree & Sequence & $\begin{array}{c}\text { Core Damage } \\
\text { Frequency-No } \\
\text { Recovery } \\
\text { (Per Year) }\end{array}$ & $\begin{array}{l}\text { Core Damage } \\
\text { Frequency with } \\
\text { Recovery } \\
\text { (Per Year) }\end{array}$ \\
\hline & 10 & 3.192E-09 & 2.585E-09 \\
\hline & 12 & 7.933E-09 & 7.933E-09 \\
\hline \multirow[t]{3}{*}{ L2W4R6 } & 5 & $1.073 \mathrm{E}-10$ & - \\
\hline & 81 & $1.069 \mathrm{E}-09$ & $1.069 \mathrm{E}-09$ \\
\hline & 10 & $2.504 \mathrm{E}-10$ & 2.153E-10 \\
\hline & 12 & $2.750 \mathrm{E}-09$ & $2.750 \mathrm{E}-09$ \\
\hline TOTAL & & 8.991E-07 & $1.041 \mathrm{E}-07$ \\
\hline
\end{tabular}


10 Accident Sequence Quantification

Table 10-21

Core Damage Frequencies of Loss of Offsite Power for Event Tree L2W\#R10

\begin{tabular}{|c|c|c|c|}
\hline Event Tree & Sequence & $\begin{array}{c}\text { Core Damage } \\
\text { Frequency-No } \\
\text { Recovery } \\
\text { (Per Year) }\end{array}$ & $\begin{array}{c}\text { Core Damage } \\
\text { Frequency with } \\
\text { Recovery } \\
\text { (Per Year) }\end{array}$ \\
\hline L2W3R10 & 4 & - & - \\
\hline & 5 & $1.045 \mathrm{E}-09$ & $8.471 \mathrm{E}-10$ \\
\hline & 7 & - & - \\
\hline & 8 & $2.302 \mathrm{E}-09$ & $2.302 \mathrm{E}-09$ \\
\hline L2W4R10 & 10 & $1.162 \mathrm{E}-10$ & - \\
\hline & 12 & $1.449 \mathrm{E}-10$ & $1.449 \mathrm{E}-10$ \\
\hline & 5 & $2.897 \mathrm{E}-09$ & $2.491 \mathrm{E}-09$ \\
\hline & 8 & $3.795 \mathrm{E}-08$ & $4.056 \mathrm{E}-10$ \\
\hline & 10 & $6.760 \mathrm{E}-09$ & $5.813 \mathrm{E}-09$ \\
\hline & 12 & $9.066 \mathrm{E}-08$ & $9.464 \mathrm{E}-10$ \\
\hline & & $1.418 \mathrm{E}-07$ & $1.295 \mathrm{E}-08$ \\
\hline
\end{tabular}


10 Accident Sequence Quantification

Table 10-22

Core Damage Frequencies of Loss of Offsite Power for Event Tree L3W\#D6

\begin{tabular}{|c|c|c|c||}
\hline Event Tree & Sequence & $\begin{array}{c}\text { Core Damage } \\
\text { Frequency-No } \\
\text { Recovery } \\
\text { (Per Year) }\end{array}$ & $\begin{array}{c}\text { Core Damage } \\
\text { Frequency with } \\
\text { Recovery } \\
\text { (Per Year) }\end{array}$ \\
\hline L3W1D6 & 4 & $3.317 \mathrm{E}-10$ & $1.484 \mathrm{E}-10$ \\
\hline & 5 & $5.865 \mathrm{E}-09$ & $3.988 \mathrm{E}-09$ \\
\hline & 7 & $5.162 \mathrm{E}-08$ & $3.273 \mathrm{E}-08$ \\
\hline L3W2D6 & 8 & $4.083 \mathrm{E}-08$ & $2.060 \mathrm{E}-08$ \\
\hline & 5 & - & - \\
\hline & 6 & $9.658 \mathrm{E}-09$ & $7.146 \mathrm{E}-09$ \\
\hline & 9 & $6.827 \mathrm{E}-08$ & $1.268 \mathrm{E}-08$ \\
\hline L3W3D6 & 10 & $3.237 \mathrm{E}-08$ & $8.806 \mathrm{E}-09$ \\
\hline & 5 & $8.306 \mathrm{E}-09$ & $6.728 \mathrm{E}-09$ \\
\hline L3W4D6 & 8 & $1.994 \mathrm{E}-08$ & $5.535 \mathrm{E}-09$ \\
\hline & 5 & $3.441 \mathrm{E}-10$ & $2.959 \mathrm{E}-10$ \\
\hline TOTAL & 8 & - & - \\
\hline
\end{tabular}


10 Accident Sequence Quantification

Table 10-23

Core Damage Frequencies of Loss of Offsite Power for Event Tree L3W\#R6

\begin{tabular}{|c|c|c|c|}
\hline Event Tree & Sequence & $\begin{array}{c}\text { Core Damage } \\
\text { Frequency-No } \\
\text { Recovery } \\
\text { (Per Year) }\end{array}$ & $\begin{array}{l}\text { Core Damage } \\
\text { Frequency with } \\
\text { Recovery } \\
\text { (Per Year) } \\
\end{array}$ \\
\hline \multirow[t]{10}{*}{ L3W1R6 } & 4 & - & - \\
\hline & 5 & - & - \\
\hline & 6 & - & - \\
\hline & 8 & - & - \\
\hline & 9 & - & - \\
\hline & 10 & - & - \\
\hline & 13 & - & - \\
\hline & 14 & $2.677 \mathrm{E}-10$ & $2.677 \mathrm{E}-10$ \\
\hline & 17 & $3.455 \mathrm{E}-09$ & $3.455 \mathrm{E}-09$ \\
\hline & 18 & $1.147 \mathrm{E}-09$ & $1.147 \mathrm{E}-09$ \\
\hline \multirow[t]{10}{*}{ L3W2R6 } & 4 & - & - \\
\hline & 5 & - & - \\
\hline & 6 & $2.806 \mathrm{E}-10$ & $2.806 \mathrm{E}-10$ \\
\hline & 8 & - & - \\
\hline & 9 & - & - \\
\hline & 10 & $1.638 \mathrm{E}-09$ & $1.638 \mathrm{E}-09$ \\
\hline & 13 & - & - \\
\hline & 14 & 5.332E-09 & $5.332 \mathrm{E}-09$ \\
\hline & 17 & $5.305 \mathrm{E}-08$ & $1.248 \mathrm{E}-08$ \\
\hline & 18 & $3.051 \mathrm{E}-08$ & 7.396E-09 \\
\hline \multirow[t]{4}{*}{ L3W3R6 } & 4 & - & - \\
\hline & 5 & 3.814E-09 & $3.089 \mathrm{E}-09$ \\
\hline & 7 & - & - \\
\hline & 8 & $1.892 \mathrm{E}-08$ & $4.428 \mathrm{E}-09$ \\
\hline
\end{tabular}


10 Accident Sequence Quantification

Table 10-23 (continued)

\begin{tabular}{||c|c|c|c|}
\hline Event Tree & Sequence & $\begin{array}{c}\text { Core Damage } \\
\text { Frequency-No } \\
\text { Recovery } \\
\text { (Per Year) }\end{array}$ & $\begin{array}{c}\text { Core Damage } \\
\text { Frequency with } \\
\text { Recovery } \\
\text { (Per Year) }\end{array}$ \\
\hline & 10 & $4.238 \mathrm{E}-10$ & $3.433 \mathrm{E}-10$ \\
\hline L3W4R6 & 12 & $1.808 \mathrm{E}-09$ & $1.808 \mathrm{E}-09$ \\
\hline & 5 & - & - \\
\hline & 8 & $1.588 \mathrm{E}-10$ & $1.588 \mathrm{E}-10$ \\
\hline & 10 & - & - \\
\hline TOTAL & 12 & $5.428 \mathrm{E}-10$ & $5.428 \mathrm{E}-10$ \\
\hline
\end{tabular}


10 Accident Sequence Quantification

Table 10-24

Core Damage Frequencles of Loss of Ofisite Power for Event Tree L3W\#R10

\begin{tabular}{|c|c|c|c||}
\hline Event Tree & Sequence & $\begin{array}{c}\text { Core Damage } \\
\text { Frequency-No Recovery } \\
\text { (Per Year) }\end{array}$ & $\begin{array}{c}\text { Core Damage } \\
\text { Frequency with Recovery } \\
\text { (Per Year) }\end{array}$ \\
\hline I3W3R10 & 4 & - & - \\
\hline & 5 & $1.388 \mathrm{E}-10$ & $1.124 \mathrm{E}-10$ \\
\hline & 7 & - & - \\
\hline & 8 & $5.505 \mathrm{E}-10$ & $5.505 \mathrm{E}-10$ \\
\hline L3W4R10 & 10 & - & - \\
\hline & 12 & - & - \\
\hline & 5 & $6.142 \mathrm{E}-10$ & $8.282 \mathrm{E}-10$ \\
\hline & 8 & $8.081 \mathrm{E}-09$ & $1.081 \mathrm{E}-09$ \\
\hline & 10 & $1.433 \mathrm{E}-09$ & $2.076 \mathrm{E}-09$ \\
\hline & 12 & $2.004 \mathrm{E}-08$ & $1.258 \mathrm{E}-08$ \\
\hline
\end{tabular}




\section{Accident Sequence Quantification}

Table 10-25

Core Damage Frequencies of Unit-1 Blackout for Event Tree B1W\#D6

\begin{tabular}{|c|c|c|c|}
\hline Event Tree & Sequence & $\begin{array}{c}\text { Core Damage } \\
\text { Frequency-No } \\
\text { Recovery } \\
\text { (Per Year) }\end{array}$ & $\begin{array}{c}\text { Core Damage } \\
\text { Frequency with } \\
\text { Recovery } \\
\text { (Per Year) }\end{array}$ \\
\hline B1W1D6 & $2-3$ & $1.735 \mathrm{E}-08$ & $6.177 \mathrm{E}-10$ \\
\hline & $2-4$ & - & - \\
\hline B1W2D6 & 3 & $2.236 \mathrm{E}-07$ & $4.405 \mathrm{E}-10$ \\
\hline & 4 & $9.950 \mathrm{E}-08$ & $9.611 \mathrm{E}-08$ \\
\hline & $2-4$ & $1.235 \mathrm{E}-10$ & - \\
\hline & $2-5$ & - & - \\
\hline B1W3D6 & 4 & $6.771 \mathrm{E}-07$ & $2.906 \mathrm{E}-09$ \\
\hline & 5 & $7.981 \mathrm{E}-08$ & $4.719 \mathrm{E}-08$ \\
\hline B1W4D6 & $2-4$ & - & - \\
\hline & 5 & $4.993 \mathrm{E}-08$ & $2.168 \mathrm{E}-08$ \\
\hline & $2-4$ & - & - \\
\hline
\end{tabular}


Table 10-26

Core Damage Frequencies of Unit-1 Blackout for Event Tree B1W\#R6

\begin{tabular}{|c|c|c|c|}
\hline Event Tree & Sequence & $\begin{array}{c}\text { Core Damage } \\
\text { Frequency-No } \\
\text { Recovery } \\
\text { (Per Year) } \\
\end{array}$ & $\begin{array}{l}\text { Core Damage } \\
\text { Frequency with } \\
\text { Recovery } \\
\text { (Per Year) } \\
\end{array}$ \\
\hline \multirow[t]{10}{*}{ B1W1R6 } & $2-3$ & - & - \\
\hline & $2-4$ & - & - \\
\hline & $2-5$ & - & - \\
\hline & 3 & $1.516 \mathrm{E}-10$ & $1.516 \mathrm{E}-10$ \\
\hline & 4 & - & - \\
\hline & 5 & - & - \\
\hline & $6-8$ & - & - \\
\hline & $6-9$ & - & - \\
\hline & 8 & $1.501 \mathrm{E}-08$ & $1.621 \mathrm{E}-10$ \\
\hline & 9 & $6.530 \mathrm{E}-09$ & $6.530 \mathrm{E}-09$ \\
\hline \multirow[t]{10}{*}{ B1W2R6 } & $2-3$ & - & - \\
\hline & $2-4$ & - & - \\
\hline & $2-5$ & - & - \\
\hline & 3 & $1.967 \mathrm{E}-08$ & - \\
\hline & 4 & - & - \\
\hline & 5 & $2.105 \mathrm{E}-09$ & $2.105 \mathrm{E}-09$ \\
\hline & $6-8$ & - & - \\
\hline & $6-9$ & - & - \\
\hline & 8 & 3.738E-07 & $1.604 \mathrm{E}-09$ \\
\hline & 9 & $4.386 \mathrm{E}-08$ & $2.605 \mathrm{E}-08$ \\
\hline \multirow[t]{4}{*}{ B1W3R6 } & $2-3$ & - & - \\
\hline & $2-4$ & - & - \\
\hline & 4 & - & - \\
\hline & 5 & $2.285 \mathrm{E}-08$ & $8.530 \mathrm{E}-09$ \\
\hline
\end{tabular}


10 Accident Sequence Quantification

Table 10-26 (continued)

\begin{tabular}{|c|c|c|c|}
\hline Event Tree & Sequence & $\begin{array}{c}\text { Core Damage } \\
\text { Frequency-No } \\
\text { Recovery } \\
\text { (Per Year) }\end{array}$ & $\begin{array}{c}\text { Core Damage } \\
\text { Frequency with } \\
\text { Recovery } \\
\text { (Per Year) }\end{array}$ \\
\hline & $6-6$ & - & - \\
\hline B1W4R6 & 8 & $2.323 \mathrm{E}-09$ & $2.323 \mathrm{E}-09$ \\
\hline & $2-4$ & - & - \\
\hline & 5 & - & - \\
\hline & $6-6$ & - & - \\
\hline TOTAL & 8 & - & $4.745 \mathrm{E}-08$ \\
\hline
\end{tabular}


10 Accident Sequence Quantification

Table 10-27

Core Damage Frequencies of Unit-1 Blackout for

Event Tree B1W\#R10

\begin{tabular}{|c|c|c|c|}
\hline Event Tree & Sequence & $\begin{array}{c}\text { Core Damage } \\
\text { Frequency-No } \\
\text { Recovery } \\
\text { (Per Year) }\end{array}$ & $\begin{array}{c}\text { Core Damage } \\
\text { Frequency with } \\
\text { Recovery } \\
\text { (Per Year) }\end{array}$ \\
\hline B1W3R10 & $2-3$ & - & - \\
\hline & $2-4$ & - & - \\
\hline & 4 & - & - \\
\hline & 5 & $7.042 \mathrm{E}-10$ & $7.042 \mathrm{E}-10$ \\
\hline & $6-6$ & - & - \\
\hline & 8 & - & - \\
\hline B1W4R10 & $2-4$ & - & - \\
\hline & 5 & $3.015 \mathrm{E}-09$ & $3.015 \mathrm{E}-09$ \\
\hline & $6-6$ & - & - \\
\hline & 8 & $7.035 \mathrm{E}-09$ & $7.035 \mathrm{E}-09$ \\
\hline & & $1.075 \mathrm{E}-08$ & $1.075 \mathrm{E}-08$ \\
\hline
\end{tabular}


10 Accident Sequence Quantification

Table 10-28

Core Damage Frequencies of 2-Units Blackout for Event Tree B2W\#D6

\begin{tabular}{|c|c|c|c||}
\hline Event Tree & Sequence & $\begin{array}{c}\text { Core Damage } \\
\text { Frequency-No } \\
\text { Recovery } \\
\text { (Per Year) }\end{array}$ & $\begin{array}{c}\text { Core Damage } \\
\text { Frequency with } \\
\text { Recovery } \\
\text { (Per Year) }\end{array}$ \\
\hline B2W1D6 & $2-3$ & $2.658 \mathrm{E}-09$ & $1.634 \mathrm{E}-09$ \\
\hline & $2-4$ & - & - \\
\hline B2W2D6 & 3 & $3.628 \mathrm{E}-08$ & $3.628 \mathrm{E}-08$ \\
\hline & $2-4$ & - & - \\
\hline & $2-5$ & - & $4.745 \mathrm{E}-08$ \\
\hline B2W3D6 & 3 & $1.098 \mathrm{E}-07$ & - \\
\hline & $2-4$ & - & $2.126 \mathrm{E}-08$ \\
\hline B2W4D6 & 3 & $6.904 \mathrm{E}-08$ & - \\
\hline & $2-4$ & - & $2.041 \mathrm{E}-09$ \\
\hline TOTAL & 3 & $9.768 \mathrm{E}-09$ & $1.086 \mathrm{E}-07$ \\
\hline
\end{tabular}


10 Accident Sequence Quantification

Table 10-29

Core Damage Frequencies of 2-Units Blackout for Event Tree B2W\#R6

\begin{tabular}{|c|c|c|c|}
\hline Event Tree & Sequence & $\begin{array}{c}\text { Core Damage } \\
\text { Frequency-No } \\
\text { Recovery (Per Year) }\end{array}$ & $\begin{array}{c}\text { Core Damage } \\
\text { Frequency with } \\
\text { Recovery (Per Year) }\end{array}$ \\
\hline \multirow[t]{8}{*}{ B2W1R6 } & $2-3$ & - & - \\
\hline & $2-4$ & . & - \\
\hline & $2-5$ & - & - \\
\hline & 3 & - & - \\
\hline & 4 & - & - \\
\hline & $5-8$ & - & - \\
\hline & $5-9$ & - & - \\
\hline & 6 & $2.435 \mathrm{E}-09$ & $2.435 \mathrm{E}-09$ \\
\hline \multirow[t]{8}{*}{ B2W2R6 } & $2-3$ & - & - \\
\hline & $2-4$ & - & - \\
\hline & $2-5$ & - & - \\
\hline & 3 & 3.192E-09 & 3.192E-09 \\
\hline & 4 & - & - \\
\hline & $5-8$ & - & - \\
\hline & $5-9$ & - & - \\
\hline & 6 & $6.065 \mathrm{E}-08$ & $2.620 \mathrm{E}-08$ \\
\hline \multirow[t]{6}{*}{ B2W3R6 } & $2-3$ & - & - \\
\hline & $2-4$ & - & - \\
\hline & 3 & $5.548 \mathrm{E}-08$ & $5.548 \mathrm{E}-10$ \\
\hline & 4 & $2.346 \mathrm{E}-10$ & $2.346 \mathrm{E}-10$ \\
\hline & $5-6$ & - & - \\
\hline & 6 & $3.523 \mathrm{E}-09$ & 3.523E-09 \\
\hline \multirow[t]{3}{*}{ B2W4R6 } & $2-4$ & - & - \\
\hline & 4 & - & - \\
\hline & $5-6$ & - & - \\
\hline
\end{tabular}


Table 10-29 (continued)

10 Accident Sequence Quantification

\begin{tabular}{|c|c|c|c|}
\hline Event Tree & Sequence & $\begin{array}{c}\text { Core Damage } \\
\text { Frequency-No } \\
\text { Recovery (Per Year) }\end{array}$ & $\begin{array}{c}\text { Core Damage } \\
\text { Frequency with } \\
\text { Recovery (Per Year) }\end{array}$ \\
\hline & 6 & $1.506 \mathrm{E}-09$ & $1.506 \mathrm{E}-09$ \\
\hline TOTAL & & $7.209 \mathrm{E}-08$ & $3.764 \mathrm{E}-08$ \\
\hline
\end{tabular}


10 Accident Sequence Quantification

Table 10-30

Core Damage Frequencies of 2-Units Blackout for Event Tree B2W\#R10

\begin{tabular}{|c|c|c|c|}
\hline Event Tree & Sequence & $\begin{array}{c}\text { Core Damage } \\
\text { Frequency-No } \\
\text { Recovery (Per Year) }\end{array}$ & $\begin{array}{c}\text { Core Damage } \\
\text { Frequency with } \\
\text { Recovery (Per Year) }\end{array}$ \\
\hline B2W3R10 & $2-3$ & - & - \\
\hline & $2-4$ & - & - \\
\hline & 3 & $1.154 \mathrm{E}-09$ & $1.154 \mathrm{E}-09$ \\
\hline & 4 & - & - \\
\hline B2W4R10 & $5-6$ & - & - \\
\hline & 6 & $1.282 \mathrm{E}-10$ & $1.282 \mathrm{E}-10$ \\
\hline & $2-4$ & - & - \\
\hline & 4 & - & - \\
\hline & $5-6$ & - & $4.067 \mathrm{E}-08$ \\
\hline & 6 & $4.067 \mathrm{E}-08$ & $4.195 \mathrm{E}-08$ \\
\hline
\end{tabular}


10 Accident Sequence Quantification

Table 10-31

Core Damage Frequencies of Loss of 4KV Event Tree 4KW\#D6

\begin{tabular}{|c|c|c|c||}
\hline Event Tree & Sequence & $\begin{array}{c}\text { Core Damage } \\
\text { Frequency - No } \\
\text { Recovery (Per Year) }\end{array}$ & $\begin{array}{c}\text { Core Damage } \\
\text { Frequency with } \\
\text { Recovery (Per Year) }\end{array}$ \\
\hline 4KW1D6 & 4 & $1.130 \mathrm{E}-07$ & $6.002 \mathrm{E}-09$ \\
\hline & 5 & $1.830 \mathrm{E}-08$ & $1.729 \mathrm{E}-08$ \\
\hline & 8 & $1.103 \mathrm{E}-06$ & $1.095 \mathrm{E}-07$ \\
\hline 4KW2D6 & 9 & $7.963 \mathrm{E}-08$ & $7.343 \mathrm{E}-09$ \\
\hline & 5 & $2.484 \mathrm{E}-08$ & - \\
\hline & 6 & $3.477 \mathrm{E}-08$ & $3.420 \mathrm{E}-08$ \\
\hline 4KW3D6 & 10 & $1.740 \mathrm{E}-06$ & $1.453 \mathrm{E}-08$ \\
\hline & 11 & $4.571 \mathrm{E}-08$ & $1.303 \mathrm{E}-08$ \\
\hline 4KW4D6 & 5 & $3.002 \mathrm{E}-08$ & $2.941 \mathrm{E}-08$ \\
\hline & 9 & $1.887 \mathrm{E}-08$ & $7.108 \mathrm{E}-09$ \\
\hline TOTAL & 5 & $5.089 \mathrm{E}-10$ & $5.089 \mathrm{E}-10$ \\
\hline
\end{tabular}


10 Accident Sequence Quantification

Table 10-32

Core Damage Frequencies of Loss of 4KV Event Tree 4KW\#R6

\begin{tabular}{|c|c|c|c|}
\hline Event Tree & Sequence & $\begin{array}{c}\text { Core Damage } \\
\text { Frequency - No } \\
\text { Recovery (Per Year) }\end{array}$ & $\begin{array}{c}\text { Core Damage } \\
\text { Frequency With } \\
\text { Recovery (Per Year) }\end{array}$ \\
\hline \multirow[t]{10}{*}{ 4KW1R6 } & 4 & - & - \\
\hline & 5 & - & - \\
\hline & 6 & - & - \\
\hline & 9 & $1.428 \mathrm{E}-09$ & $1.041 \mathrm{E}-09$ \\
\hline & 10 & $1.160 \mathrm{E}-09$ & $1.160 \mathrm{E}-09$ \\
\hline & 13 & - & - \\
\hline & 14 & - & - \\
\hline & 15 & - & - \\
\hline & 18 & $7.201 \mathrm{E}-08$ & $3.438 \mathrm{E}-08$ \\
\hline & 19 & $3.358 \mathrm{E}-09$ & $1.397 \mathrm{E}-09$ \\
\hline \multirow[t]{10}{*}{ 4KW2R6 } & 4 & - & - \\
\hline & 5 & - & - \\
\hline & 6 & $9.770 \mathrm{E}-10$ & $9.770 \mathrm{E}-10$ \\
\hline & 9 & $2.869 \mathrm{E}-08$ & - \\
\hline & 10 & $1.920 \mathrm{E}-08$ & $1.888 \mathrm{E}-08$ \\
\hline & 13 & $9.056 \mathrm{E}-09$ & - \\
\hline & 14 & - & - \\
\hline & 15 & 8.723E-10 & $8.723 \mathrm{E}-10$ \\
\hline & 18 & $1.907 \mathrm{E}-06$ & $2.926 \mathrm{E}-08$ \\
\hline & 19 & $4.421 \mathrm{E}-08$ & $2.855 \mathrm{E}-08$ \\
\hline \multirow[t]{5}{*}{ 4KW3R6 } & 4 & - & - \\
\hline & 5 & $1.357 \mathrm{E}-08$ & $1.343 \mathrm{E}-08$ \\
\hline & 7 & $1.475 \mathrm{E}-09$ & $1.475 \mathrm{E}-09$ \\
\hline & 10 & - & - \\
\hline & 11 & 8.397E-09 & 8.397E-09 \\
\hline
\end{tabular}


Table 10-32 (continued)

10 Accident Sequence Quantification

\begin{tabular}{|c|c|c|c|}
\hline Event Tree & Sequence & $\begin{array}{c}\text { Core Damage } \\
\text { Frequency - No } \\
\text { Recovery (Per Year) }\end{array}$ & $\begin{array}{c}\text { Core Damage } \\
\text { Frequency With } \\
\text { Recovery (Per Year) }\end{array}$ \\
\hline & 13 & $9.119 \mathrm{E}-10$ & $9.119 \mathrm{E}-10$ \\
\hline 4KW4R6 & 5 & - & - \\
\hline & 7 & - & - \\
\hline & 11 & - & - \\
\hline TOTAL & 13 & - & $1.407 \mathrm{E}-07$ \\
\hline
\end{tabular}


10 Accident Sequence Quantification

Table 10-33

Core Damage Frequencies of Loss of 4KV Event Tree 4KW\#R10

\begin{tabular}{||c|c|c|c|}
\hline Event Tree & Sequence & $\begin{array}{c}\text { Core Damage } \\
\text { Frequency - No } \\
\text { Recovery (Per Year) }\end{array}$ & $\begin{array}{c}\text { Core Damage } \\
\text { Frequency with } \\
\text { Recovery (Per Year) }\end{array}$ \\
\hline 4KW3R10 & 4 & - & - \\
\hline & 5 & $4.833 \mathrm{E}-10$ & $4.833 \mathrm{E}-10$ \\
\hline & 7 & - & - \\
\hline & 10 & - & - \\
\hline 4KW4R10 & 11 & - & - \\
\hline & 13 & - & $1.024 \mathrm{E}-09$ \\
\hline & 5 & $1.127 \mathrm{E}-09$ & $2.518 \mathrm{E}-09$ \\
\hline & 7 & $2.915 \mathrm{E}-09$ & $3.805 \mathrm{E}-09$ \\
\hline & 11 & $3.805 \mathrm{E}-09$ & $1.090 \mathrm{E}-08$ \\
\hline & 13 & $1.090 \mathrm{E}-08$ & $1.873 \mathrm{E}-08$ \\
\hline
\end{tabular}


Table 10-34

Core Damage Frequencies of Inadvertent SI Signal - SIW\#D6

\begin{tabular}{||c|c|c|c|}
\hline Event Tree & Sequence & $\begin{array}{c}\text { Core Damage } \\
\text { Frequency - No } \\
\text { Recovery (Per Year) }\end{array}$ & $\begin{array}{c}\text { Core Damage } \\
\text { Frequency with } \\
\text { Recovery (Per Year) }\end{array}$ \\
\hline SIW1D6 & 4 & $6.234 \mathrm{E}-07$ & $4.309 \mathrm{E}-08$ \\
\hline & 5 & $9.707 \mathrm{E}-08$ & $8.739 \mathrm{E}-08$ \\
\hline & 9 & $1.644 \mathrm{E}-06$ & $1.220 \mathrm{E}-07$ \\
\hline SIW2D6 & 5 & $4.692 \mathrm{E}-08$ & $3.133 \mathrm{E}-08$ \\
\hline & 6 & $1.434 \mathrm{E}-07$ & $6.140 \mathrm{E}-10$ \\
\hline & 10 & $1.786 \mathrm{E}-07$ & $1.753 \mathrm{E}-07$ \\
\hline & 11 & $3.122 \mathrm{E}-08$ & - \\
\hline SIW3D6 & 5 & $3.876 \mathrm{E}-08$ & $3.798 \mathrm{E}-08$ \\
\hline & 9 & $1.545 \mathrm{E}-07$ & $1.509 \mathrm{E}-07$ \\
\hline SIW4D6 & 5 & $2.415 \mathrm{E}-08$ & $2.375 \mathrm{E}-08$ \\
\hline & 9 & $3.533 \mathrm{E}-09$ & $3.052 \mathrm{E}-09$ \\
\hline TOTAL & & $3.339 \mathrm{E}-10$ & $3.339 \mathrm{E}-10$ \\
\hline
\end{tabular}


10 Accident Sequence Quantification

Table 10-35

Core Damage Frequencies of Inadvertent SI Signal - SIW\#R6

\begin{tabular}{|c|c|c|c|}
\hline Event Tree & Sequence & $\begin{array}{c}\text { Core Damage } \\
\text { Frequency - No } \\
\text { Recovery (Per Year) }\end{array}$ & $\begin{array}{c}\text { Core Damage } \\
\text { Frequency with } \\
\text { Recovery (Per Year) }\end{array}$ \\
\hline \multirow[t]{10}{*}{ SIW1R6 } & 4 & - & - \\
\hline & 5 & - & - \\
\hline & 6 & - & - \\
\hline & 9 & $1.604 \mathrm{E}-08$ & $1.127 \mathrm{E}-08$ \\
\hline & 10 & $5.859 \mathrm{E}-09$ & $5.859 \mathrm{E}-09$ \\
\hline & 13 & 2.714E-10 & $2.714 \mathrm{E}-10$ \\
\hline & 14 & - & - \\
\hline & 15 & - & - \\
\hline & 18 & 4.366E-08 & $3.355 \mathrm{E}-08$ \\
\hline & 19 & $2.158 \mathrm{E}-09$ & 2.158E-09 \\
\hline \multirow[t]{10}{*}{ SIW2R6 } & 4 & $1.553 \mathrm{E}-09$ & - \\
\hline & 5 & - & - \\
\hline & 6 & 4.931E-09 & 4.931E-09 \\
\hline & 9 & $1.606 \mathrm{E}-07$ & $1.615 \mathrm{E}-09$ \\
\hline & 10 & $9.760 \mathrm{E}-08$ & 9.611E-08 \\
\hline & 13 & $2.823 \mathrm{E}-09$ & - \\
\hline & 14 & - & - \\
\hline & 15 & $1.084 \mathrm{E}-09$ & $1.084 \mathrm{E}-09$ \\
\hline & 18 & $6.419 \mathrm{E}-08$ & $2.899 \mathrm{E}-10$ \\
\hline & 19 & $2.514 \mathrm{E}-08$ & $2.479 \mathrm{E}-08$ \\
\hline \multirow[t]{5}{*}{ SIW3R6 } & 4 & - & - \\
\hline & 5 & $6.945 \mathrm{E}-08$ & $6.830 \mathrm{E}-08$ \\
\hline & 7 & 7.447E-09 & 7.447E-09 \\
\hline & 10 & - & - \\
\hline & 11 & $1.305 \mathrm{E}-08$ & $1.294 \mathrm{E}-08$ \\
\hline
\end{tabular}


Table 10-35 (continued)

10 Accident Sequence Quantification

\begin{tabular}{|c|c|c|c||}
\hline Event Tree & Sequence & $\begin{array}{c}\text { Core Damage } \\
\text { Frequency - No } \\
\text { Recovery (Per Year) }\end{array}$ & $\begin{array}{c}\text { Core Damage } \\
\text { Frequency with } \\
\text { Recovery (Per Year) }\end{array}$ \\
\hline SIW4R6 & 13 & $1.191 \mathrm{E}-09$ & $1.191 \mathrm{E}-09$ \\
\hline & 5 & $1.698 \mathrm{E}-10$ & $1.698 \mathrm{E}-10$ \\
\hline & 7 & $3.962 \mathrm{E}-10$ & $3.962 \mathrm{E}-10$ \\
\hline & 11 & - & - \\
\hline TOTAL & 13 & - & - \\
\hline
\end{tabular}


10 Accident Sequence Quantification

Table 10-36

Core Damage Frequencies of Inadvertent SI Signal - SIW\#R10

\begin{tabular}{|c|c|c|c|}
\hline Event Tree & Sequence & $\begin{array}{c}\text { Core Damage } \\
\text { Frequency - No } \\
\text { Recovery (Per Year) }\end{array}$ & $\begin{array}{c}\text { Core Damage } \\
\text { Frequency with } \\
\text { Recovery (Per Year) }\end{array}$ \\
\hline SIW3R10 & 4 & - & - \\
\hline & 5 & $2.439 \mathrm{E}-09$ & $2.439 \mathrm{E}-09$ \\
\hline & 7 & $2.710 \mathrm{E}-10$ & $2.710 \mathrm{E}-10$ \\
\hline & 10 & - & - \\
\hline & 11 & $3.903 \mathrm{E}-10$ & $3.903 \mathrm{E}-10$ \\
\hline SIW4R10 & 13 & - & - \\
\hline & 5 & $6.305 \mathrm{E}-09$ & $5.448 \mathrm{E}-09$ \\
\hline & 7 & $1.686 \mathrm{E}-08$ & $1.469 \mathrm{E}-08$ \\
\hline & 11 & $1.075 \mathrm{E}-09$ & $1.075 \mathrm{E}-09$ \\
\hline & 13 & $3.264 \mathrm{E}-09$ & $3.004 \mathrm{E}-09$ \\
\hline & & $3.060 \mathrm{E}-08$ & $2.731 \mathrm{E}-08$ \\
\hline
\end{tabular}


Table 10-37

Core Damage Frequencies of Loss of Vital Bus - VBW\#D6

\begin{tabular}{||c|c|c|c||}
\hline Event Tree & Sequence & $\begin{array}{c}\text { Core Damage } \\
\text { Frequency - No } \\
\text { Recovery (Per Year) }\end{array}$ & $\begin{array}{c}\text { Core Damage } \\
\text { Frequency with } \\
\text { Recovery (Per Year) }\end{array}$ \\
\hline VBW1D6 & 4 & $2.511 \mathrm{E}-08$ & $3.531 \mathrm{E}-10$ \\
\hline & 5 & $1.598 \mathrm{E}-08$ & $1.598 \mathrm{E}-08$ \\
\hline & 8 & $1.058 \mathrm{E}-07$ & $6.777 \mathrm{E}-09$ \\
\hline VBW2D6 & 9 & $8.128 \mathrm{E}-09$ & $4.970 \mathrm{E}-09$ \\
\hline & 5 & $5.947 \mathrm{E}-09$ & - \\
\hline & 6 & $2.020 \mathrm{E}-08$ & $2.020 \mathrm{E}-08$ \\
\hline & 10 & $9.611 \mathrm{E}-10$ & - \\
\hline VBW3D6 & 11 & $4.020 \mathrm{E}-09$ & $4.020 \mathrm{E}-09$ \\
\hline & 5 & $1.741 \mathrm{E}-08$ & $1.728 \mathrm{E}-08$ \\
\hline VBW4D6 & 9 & $2.593 \mathrm{E}-09$ & $2.593 \mathrm{E}-09$ \\
\hline & 5 & $7.253 \mathrm{E}-10$ & $7.253 \mathrm{E}-10$ \\
\hline TOTAL & 9 & - & - \\
\hline
\end{tabular}


10 Accident Sequence Quantification

Table 10-38

Core Damage Frequencies of

Loss of Vital Bus - VBW\#R6

\begin{tabular}{|c|c|c|c|}
\hline Event Tree & Sequence & $\begin{array}{c}\text { Core Damage } \\
\text { Frequency - No } \\
\text { Recovery (Per Year) }\end{array}$ & $\begin{array}{c}\text { Core Damage } \\
\text { Frequency with } \\
\text { Recovery (Per Year) }\end{array}$ \\
\hline \multirow[t]{10}{*}{ VBW1R6 } & 4 & - & - \\
\hline & $5^{1}$ & - & - \\
\hline & 6 & - & - \\
\hline & 9 & - & - \\
\hline & 10 & $1.072 \mathrm{E}-09$ & $1.072 \mathrm{E}-09$ \\
\hline & 13 & - & - \\
\hline & 14 & - & - \\
\hline & 15 & - & - \\
\hline & 18 & $3.598 \mathrm{E}-09$ & $2.563 \mathrm{E}-09$ \\
\hline & 19 & $3.218 \mathrm{E}-10$ & $3.218 \mathrm{E}-10$ \\
\hline \multirow[t]{10}{*}{ VBW2R6 } & 4 & - & - \\
\hline & 5 & - & - \\
\hline & 6 & $5.841 \mathrm{E}-10$ & $5.841 \mathrm{E}-10$ \\
\hline & 9 & $6.529 \mathrm{E}-09$ & - \\
\hline & 10 & $1.109 \mathrm{E}-08$ & $1.109 \mathrm{E}-08$ \\
\hline & 13 & - & - \\
\hline & 14 & - & - \\
\hline & 15 & $1.168 \mathrm{E}-10$ & $1.168 \mathrm{E}-10$ \\
\hline & 18 & $2.016 \mathrm{E}-09$ & - \\
\hline & 19 & $2.569 \mathrm{E}-09$ & $2.569 \mathrm{E}-09$ \\
\hline \multirow[t]{4}{*}{ VBW3R6 } & 4 & - & - \\
\hline & 5 & $7.938 \mathrm{E}-09$ & $7.938 \mathrm{E}-09$ \\
\hline & 7 & $8.820 \mathrm{E}-10$ & $8.820 \mathrm{E}-10$ \\
\hline & 10 & - & - \\
\hline
\end{tabular}


Table 10-38 (continued)

10 Accident Sequence Quantification

\begin{tabular}{|c|c|c|c|}
\hline Event Tree & Sequence & $\begin{array}{c}\text { Core Damage } \\
\text { Frequency - No } \\
\text { Recovery (Per Year) }\end{array}$ & $\begin{array}{c}\text { Core Damage } \\
\text { Frequency with } \\
\text { Recovery (Per Year) }\end{array}$ \\
\hline & 11 & $1.022 \mathrm{E}-10$ & $1.022 \mathrm{E}-10$ \\
\hline VBW3R6 & 13 & $1.323 \mathrm{E}-10$ & $1.323 \mathrm{E}-10$ \\
\hline VBW4R6 & 5 & - & - \\
\hline & 7 & $1.118 \mathrm{E}-10$ & $1.118 \mathrm{E}-10$ \\
\hline & 11 & - & - \\
\hline & 13 & - & - \\
\hline TOTAL & & $3.706 \mathrm{E}-08$ & $2.748 \mathrm{E}-08$ \\
\hline
\end{tabular}


10 Accident Sequence Quantification

Table 10.39

Core Damage Frequencies of

Loss of Vital Bus - VBW\#R10

\begin{tabular}{|c|c|c|c|}
\hline Event Tree & Sequence & $\begin{array}{c}\text { Core Damage } \\
\text { Frequency - No } \\
\text { Recovery (Per Year) }\end{array}$ & $\begin{array}{c}\text { Core Damage } \\
\text { Frequency with } \\
\text { Recovery (Per Year) }\end{array}$ \\
\hline VBW3R10 & 4 & - & - \\
\hline & 5 & $2.889 \mathrm{E}-10$ & $2.889 \mathrm{E}-10$ \\
\hline & 7 & - & - \\
\hline & 10 & - & - \\
\hline & 11 & - & - \\
\hline VBW4R10 & 13 & - & $1.294 \mathrm{E}-09$ \\
\hline & 5 & $1.294 \mathrm{E}-09$ & $3.020 \mathrm{E}-09$ \\
\hline & 7 & $3.020 \mathrm{E}-09$ & $1.553 \mathrm{E}-10$ \\
\hline & 11 & $1.553 \mathrm{E}-10$ & $3.624 \mathrm{E}-10$ \\
\hline & 13 & $3.624 \mathrm{E}-10$ & $5.120 \mathrm{E}-09$ \\
\hline
\end{tabular}




\section{Accident Sequence Quantification}

\section{Table 10-40}

Core Damage Frequencies of Loss RHR Event Tree ARW\#R6 Loss of Instrument Air in POS 6 of Refueling

\begin{tabular}{|c|c|c|c|}
\hline Event Tree & Sequence & $\begin{array}{c}\text { Core Damage } \\
\text { Frequency-No } \\
\text { Recovery (Per Year) }\end{array}$ & $\begin{array}{c}\text { Core Damage } \\
\text { Frequency with } \\
\text { Recovery (Per Year) }\end{array}$ \\
\hline \multirow[t]{5}{*}{ ARW1R6 } & 5 & - & - \\
\hline & 6 & - & - \\
\hline & 7 & - & - \\
\hline & 10 & - & - \\
\hline & 11 & - & - \\
\hline \multirow[t]{5}{*}{ ARW2R6 } & 5 & - & - \\
\hline & 6 & - & - \\
\hline & 7 & - & - \\
\hline & 10 & $3.692 \mathrm{E}-10$ & - \\
\hline & 11 & $6.559 \mathrm{E}-10$ & $6.559 \mathrm{E}-10$ \\
\hline \multirow[t]{3}{*}{ ARW3R6 } & 5 & - & - \\
\hline & 6 & $1.340 \mathrm{E}-10$ & $1.340 \mathrm{E}-10$ \\
\hline & 8 & - & - \\
\hline \multirow[t]{2}{*}{ ARW4R6 } & 6 & - & - \\
\hline & 8 & - & - \\
\hline TOTAL & & $1.159 \mathrm{E}-09$ & $7.899 \mathrm{E}-10$ \\
\hline
\end{tabular}


10 Accident Sequence Quantification

Table 10-41

Core Damage Frequencies of Loss RHR Event Tree ARW\#D6

Loss of Instrument Air in POS 6 of Refueling

\begin{tabular}{||c|c|c|c||}
\hline Event Tree & Sequence & $\begin{array}{c}\text { Core Damage } \\
\text { Frequency-No } \\
\text { Recovery (Per Year) }\end{array}$ & $\begin{array}{c}\text { Core Damage } \\
\text { Frequency with } \\
\text { Recovery (Per Year) }\end{array}$ \\
\hline ARW1D6 & 5 & $1.376 \mathrm{E}-08$ & $5.451 \mathrm{E}-10$ \\
\hline & 6 & $1.134 \mathrm{E}-09$ & $1.134 \mathrm{E}-09$ \\
\hline ARW2D6 & 6 & $1.878 \mathrm{E}-09$ & - \\
\hline & 7 & $1.187 \mathrm{E}-09$ & $1.187 \mathrm{E}-09$ \\
\hline ARW3D6 & 6 & $2.919 \mathrm{E}-10$ & $2.919 \mathrm{E}-10$ \\
\hline ARW4D6 & 6 & - & - \\
\hline TOTAL & & $1.656 \mathrm{E}-08$ & $3.158 \mathrm{E}-09$ \\
\hline
\end{tabular}


10 Accident Sequence Quantification

Table 10-42

Core Damage Frequencies of Loss RHR Event Tree ARW\#R10 Loss of Instrument Air in POS 6 of Refueling

\begin{tabular}{|c|c|c|c|}
\hline Event Tree & Sequence & $\begin{array}{c}\text { Core Damage } \\
\text { Frequency-No } \\
\text { Recovery (Per Year) }\end{array}$ & $\begin{array}{c}\text { Core Damage } \\
\text { Frequency with } \\
\text { Recovery (Per Year) }\end{array}$ \\
\hline ARW3R10 & 5 & - & - \\
\hline & 6 & - & - \\
\hline ARW4R10 & 8 & - & - \\
\hline & 8 & - & - \\
\hline TOTAL & & - & - \\
\hline
\end{tabular}


10 Accident Sequence Quantification

Table 10-43

Core Damage Frequencies of

Loss of CCW - CCW\#D6

\begin{tabular}{|c|c|c|c|}
\hline \hline Event Tree & Sequence & $\begin{array}{c}\text { Core Damage } \\
\text { Frequency - No } \\
\text { Recovery (Per Year) }\end{array}$ & $\begin{array}{c}\text { Core Damage } \\
\text { Frequency with } \\
\text { Recovery (Per Year) }\end{array}$ \\
\hline CCW1D6 & 4 & $2.859 \mathrm{E}-06$ & $2.005 \mathrm{E}-07$ \\
\hline & 5 & $9.897 \mathrm{E}-09$ & $2.975 \mathrm{E}-09$ \\
\hline CCW2D6 & 5 & $3.813 \mathrm{E}-08$ & - \\
\hline & 6 & $1.839 \mathrm{E}-09$ & $1.839 \mathrm{E}-09$ \\
\hline CCW3D6 & 5 & $8.305 \mathrm{E}-10$ & $8.305 \mathrm{E}-10$ \\
\hline CCW4D6 & 5 & - & - \\
\hline TOTAL & & $2.909 \mathrm{E}-06$ & $2.061 \mathrm{E}-07$ \\
\hline
\end{tabular}


Table 10-44

Core Damage Frequencies of

Loss of CCW - CCW\#R6

\begin{tabular}{|c|c|c|c|}
\hline Event Tree & Sequence & $\begin{array}{c}\text { Core Damage } \\
\text { Frequency - No } \\
\text { Recovery (Per Year) }\end{array}$ & $\begin{array}{c}\text { Core Damage } \\
\text { Frequency with } \\
\text { Recovery (Per Year) }\end{array}$ \\
\hline \multirow[t]{5}{*}{ CCW1R6 } & 4 & $1.548 \mathrm{E}-09$ & $9.492 \mathrm{E}-10$ \\
\hline & 5 & - & - \\
\hline & 6 & - & - \\
\hline & 9 & $8.155 \mathrm{E}-08$ & $5.560 \mathrm{E}-08$ \\
\hline & 10 & $1.662 \mathrm{E}-10$ & $1.662 \mathrm{E}-10$ \\
\hline \multirow[t]{5}{*}{ CCW2R6 } & 4 & $3.641 \mathrm{E}-09$ & - \\
\hline & 5 & - & - \\
\hline & 6 & - & - \\
\hline & 9 : & $1.205 \mathrm{E}-07$ & $1.665 \mathrm{E}-09$ \\
\hline & 10 & $3.261 \mathrm{E}-09$ & $3.261 \mathrm{E}-09$ \\
\hline \multirow[t]{3}{*}{ CCW3R6 } & 4 & - & - \\
\hline & 5 & $1.256 \mathrm{E}-09$ & $1.256 \mathrm{E}-09$ \\
\hline & 7 & - & - \\
\hline \multirow[t]{2}{*}{ CCW4R6 } & 5 & - & - \\
\hline & 7 & - & - \\
\hline TOTAL & & $2.119 \mathrm{E}-07$ & $6.289 \mathrm{E}-08$ \\
\hline
\end{tabular}


10 Accident Sequence Quantification

Table 10-45

Core Damage Frequencies of Loss of CCW - CCW \#R10

\begin{tabular}{|c|c|c|c|}
\hline Event Tree & Sequence & $\begin{array}{c}\text { Core Damage } \\
\text { Frequency - No } \\
\text { Recovery (Per Year) }\end{array}$ & $\begin{array}{c}\text { Core Damage } \\
\text { Frequency with } \\
\text { Recovery (Per Year) }\end{array}$ \\
\hline CCW3R10 & 4 & - & - \\
\hline & 5 & - & - \\
\hline CCW4R10 & 7 & - & - \\
\hline & 5 & $1.142 \mathrm{E}-10$ & $1.142 \mathrm{E}-10$ \\
\hline TOTAL & 7 & - & - \\
\hline
\end{tabular}


Table 10-46

Core Damage Frequencies for SR Loss of Emergency Switchgear Room Cooling for Event Tree SRW\#D6

\begin{tabular}{|c|c|c|c|}
\hline Event Tree & Sequence & $\begin{array}{c}\text { Core Damage } \\
\text { Frequency-No } \\
\text { Recovery (Per Year) }\end{array}$ & $\begin{array}{c}\text { Core Damage } \\
\text { Frequency with } \\
\text { Recovery (Per Year) }\end{array}$ \\
\hline SRW1D6 & 3 & $1.879 \mathrm{E}-10$ & $1.879 \mathrm{E}-10$ \\
\hline SRW2D6 & 4 & $9.072 \mathrm{E}-09$ & $9.072 \mathrm{E}-09$ \\
\hline & 4 & - & - \\
\hline SRW3D6 & 5 & $3.380 \mathrm{E}-08$ & $3.380 \mathrm{E}-08$ \\
\hline SRW4D6 & 5 & $2.907 \mathrm{E}-08$ & $2.907 \mathrm{E}-08$ \\
\hline TOTAL & 5 & $1.914 \mathrm{E}-09$ & $1.914 \mathrm{E}-09$ \\
\hline
\end{tabular}


10 Accident Sequence Quantification

Table 10-47

Core Damage Frequencies for SR Loss of Emergency Switchgear Room Cooling for Event Tree SRW\#R6

\begin{tabular}{|c|c|c|c|}
\hline Event Tree & Sequence & $\begin{array}{c}\text { Core Damage } \\
\text { Frequency-No } \\
\text { Recovery (Per Year) }\end{array}$ & $\begin{array}{c}\text { Core Damage } \\
\text { Frequency with } \\
\text { Recovery (Per Year) }\end{array}$ \\
\hline SRW1R6 & 3 & $6.151 \mathrm{E}-10$ & - \\
\hline & 4 & - & - \\
\hline & 5 & - & - \\
\hline SRW2R6 & 7 & - & $6.090 \mathrm{E}-10$ \\
\hline & 8 & $6.090 \mathrm{E}-10$ & $1.684 \mathrm{E}-10$ \\
\hline & 3 & $1.981 \mathrm{E}-08$ & - \\
\hline & 4 & - & $9.824 \mathrm{E}-10$ \\
\hline & 5 & $9.824 \mathrm{E}-10$ & $1.120 \mathrm{E}-10$ \\
\hline & 7 & $1.120 \mathrm{E}-10$ & $1.866 \mathrm{E}-08$ \\
\hline & 8 & $1.866 \mathrm{E}-08$ & - \\
\hline SRW3R6 & 4 & - & $1.335 \mathrm{E}-08$ \\
\hline & 5 & $1.335 \mathrm{E}-08$ & $1.483 \mathrm{E}-09$ \\
\hline & 7 & $1.483 \mathrm{E}-09$ & $1.265 \mathrm{E}-10$ \\
\hline & 5 & $1.265 \mathrm{E}-10$ & $2.952 \mathrm{E}-10$ \\
\hline & & $2.952 \mathrm{E}-10$ & $3.578 \mathrm{E}-08$ \\
\hline
\end{tabular}


10 Accident Sequence Quantification

Table 10-48

Core Damage Frequencies for SR Loss of Emergency Switchgear Room Cooling for Event Tree SRW\#\#10

\begin{tabular}{|c|c|c|c|}
\hline Event Tree & Sequence & $\begin{array}{c}\text { Core Damage } \\
\text { Frequency-No } \\
\text { Recovery (Per Year) }\end{array}$ & $\begin{array}{c}\text { Core Damage } \\
\text { Frequency with } \\
\text { Recovery (Per Year) }\end{array}$ \\
\hline SRW3R10 & 4 & - & - \\
\hline & 5 & $4.860 \mathrm{E}-10$ & $4.860 \mathrm{E}-10$ \\
\hline SRW4R10 & 7 & - & - \\
\hline & 5 & $3.416 \mathrm{E}-09$ & $3.416 \mathrm{E}-09$ \\
\hline TOTAL & 7 & $7.971 \mathrm{E}-09$ & $7.971 \mathrm{E}-09$ \\
\hline
\end{tabular}


10 Accident Sequence Quantification

\author{
Table 10-49 \\ Dominant Core Damage Cutsets \\ Before Recovery Actions
}

Family->RHRMODEL

Mincut Upper Bound $\rightarrow$ 2.011E-005
End State $->\mathrm{CD}$

This Partition $\rightarrow$ 2.011E-005

Cut \% \% Cut

No. Total Set Frequency

Cut Sets

17.27 .2 1.464E-006 UNITY, FREQ-RHR3, PROB-W1D6, DR-MT, DURATION-D6, LPR-CCF-PG-SUMP1

$212.65 .3 \quad$ 1.077E-006 UNITY, FREQ-CCW, H-CCW-REC-W1, PROB-W1D6, LPR-CCF-PG-SUMP1, DR-MT, DURATION-D6

$3 \quad 16.43 .8 \quad 7.681 E-007$ UNITY, ACP-INV-NO-UPSA2, AFW-MDP-MA-FW3B, PROB-W2D6, DR-MT, DURATION-D6, H-4KV-REC-W2, FREQ-4KV

420.23 .7 7.614E-007 UNITY, LPR-MOV-FT-1862B, FREQ-RHR3, PROB-W1D6, DR-MT, DURATION-D6

$5 \quad 23.6 \quad 3.3 \quad$ 6.771E-007 UNITY, PROB-W2D6, DR-MT, DURATION-D6, FREQ-B1, NRAC262

626.42 .8 5.631E-007 UNITY, ACP-INV-NO-UPSA2, LOOPISOLATED2R6, REFUEL, DURATION-R6, /PZR-SV-REMOVEDW2, PROB-W2R6, H-4KV-REC-W2, FREQ-4KV

729.12 .7 5.600E-007 UNITY, FREQ-CCW, LPR-MOV-FT-1862B, H-CCW-REC-W1, PROB-W1D6, DR-MT, DURATION-D6

$831.8 \quad 2.6 \quad 5.413 E-007$ UNITY, ACP-INV-NO-UPSA2, PROB-W1D6, DR-MT, DURATION-D6, H-4KV-REC-W1, FREQ-4KV

934.02 .1 4.393E-007 UNITY, LPI-MDP-FS-SI1B, FREQ-RHR3, PROB-W1D6, DR-MT, DURATION-D6

$1036.2 \quad 2.1$ 4.393E-007 UNITY, LPR-MOV-FT-1860B, FREQ-RHR3, PROB-W1D6, DR-MT, DURATION-D6

$1138.32 .1 \quad 4.241 E-007$ UNITY, ACP-INV-NO-UPSA2, AFW-MDP-MA-FW3B, REFUEL, DURATION-R6, /PZR-SV-REMOVEDW2, PROB-W2R6, H-4KV-REC-W2, FREQ-4KV

$12 \quad 40.2 \quad 1.8 \quad 3.739 E-007$ UNITY, REFUEL, DURATION-R6, /PZR-SV-REMOVEDW2, PROB-W2R6, FREQ-B1, NRAC262

$13 \quad 42.0 \quad 1.7$ 3.572E-007 UNITY, AFW-MDP-MA-FW3B, CCW-LF-RHE2B, PROB-W2D6, DR-MT, DURATION-D6, H-4KV-REC-W2, FREQ-4KV

$14 \quad 43.6 \quad 1.6 \quad 3.231 E-007$ UNITY, FREQ-CCW, LPI-MDP-FS-SI1B, H-CCW-REC-W1, PROB-W1D6, DR-MT, DURATION-D6

$1545.2 \quad 1.6 \quad 3.231 E-007$ UNITY, FREQ-CCW, LPR-MOV-FT-1860B, H-CCW-REC-W1, PROB-W1D6, DR-MT, DURATION-D6

$1646.61 .42 .976 \mathrm{E}-007$ UNITY, PROB-W2D6, DR-MT, DURATION-D6, FREQ-L1, D-L1W2-XHE

$1747.9 \quad 1.3 \quad 2.618 E-007$ UNITY, LOOPISOLATED2R6, REFUEL, DURATION-R6, CCW-LF-RHE2B, /PZR-SV-REMOVEDW2, PROB-W2R6, H-4KV-REC-W2, FREQ-4KV

$1849.2 \quad 1.2$ 2.560E-007 UNITY, PROB-W3D6, DR-MT, DURATION-D6, FREQ-L1, 
Table 10-49 (continued)

Family->RHRMODEL

Mincut Upper Bound -> 2.011E-005
End State $\rightarrow C D$

This Partition $->$ 2.011E-005

Cut \% \% Cut

No. Total Set Frequency Cut Sets

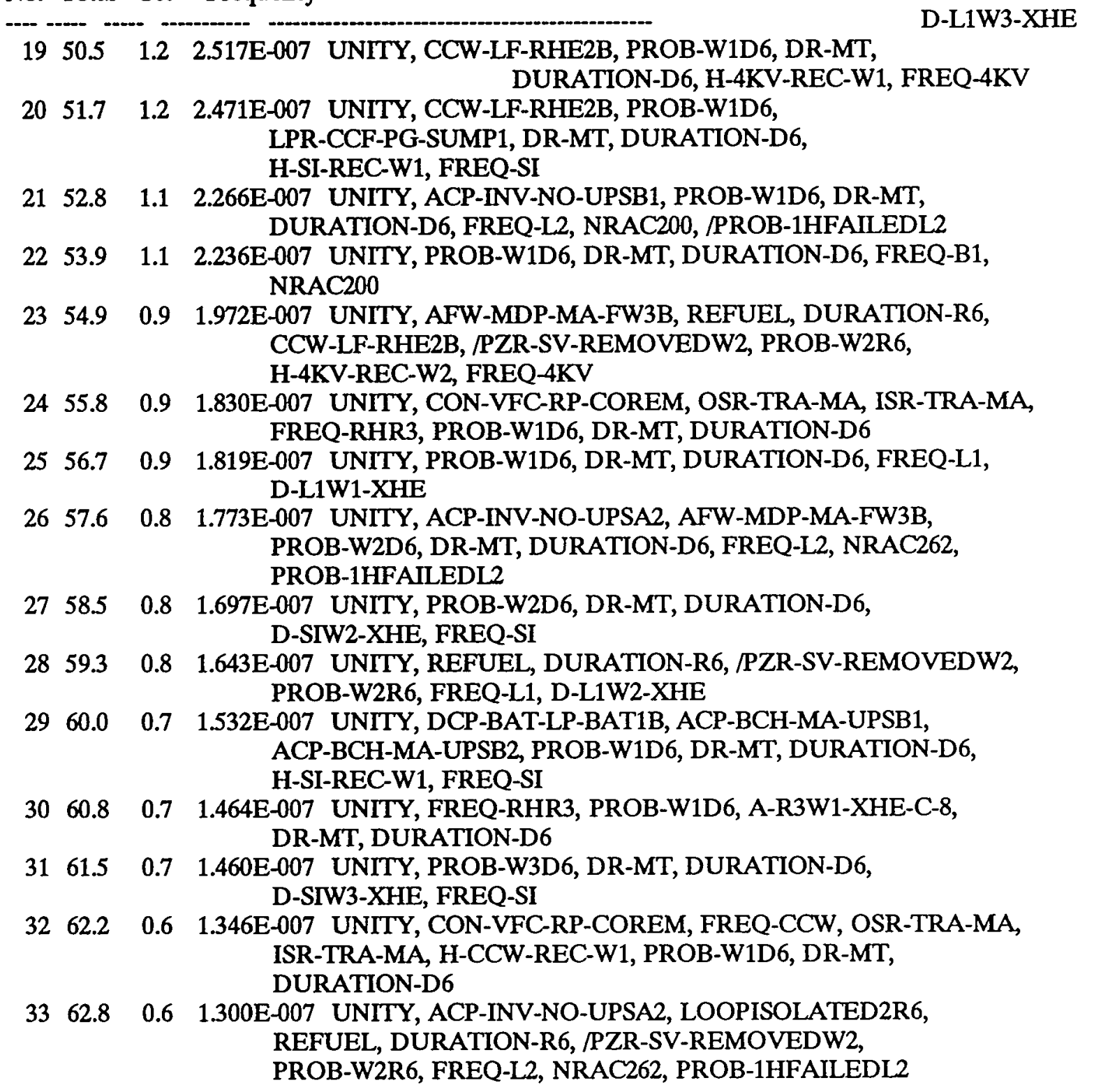


10 Accident Sequence Quantification

Table 10-49 (continued)

Family->RHRMODEL

Mincut Upper Bound -> 2.011E-005

End State $\rightarrow C D$

This Partition $\rightarrow$ 2.011E-005

Cut \% \% Cut

No. Total Set Frequency Cut Sets

\begin{tabular}{|c|c|c|c|}
\hline & & & \\
\hline 34 & 63.4 & 0.6 & $\begin{array}{l}\text { 1.285E-007 UNITY, LPR-MOV-FT-1862B, CCW-LF-RHE2B, } \\
\text { PROB-W1D6, DR-MT, DURATION-D6, H-SI-REC-W1, } \\
\text { FREQ-SI }\end{array}$ \\
\hline 35 & 64.0 & 0.5 & $\begin{array}{l}\text { 1.195E-007 UNITY, DCP-BDC-ST-BUS1B, PROB-W1D6, DR-MT, } \\
\text { DURATION-D6, H-SI-REC-W1, FREQ-SI }\end{array}$ \\
\hline 36 & 64.6 & 0.5 & $\begin{array}{l}\text { 1.195E-007 UNITY, ACP-BAC-ST-4KV1J, PROB-W1D6, DR-MT, } \\
\text { DURATION-D6, H-SI-REC-W1, FREQ-SI }\end{array}$ \\
\hline 37 & 65.2 & 0.5 & $\begin{array}{l}\text { 1.176E-007 UNITY, REFUEL, DURATION-R6, PZR-SV-REMOVEDW3, } \\
\text { PROB-W3R6, FREQ-L1, D-L1W3-XHE }\end{array}$ \\
\hline 38 & 65.8 & 0.5 & $\begin{array}{l}\text { 1.150E-007 UNITY, PROB-W1D6, DR-MT, DURATION-D6, } \\
\text { H-4KV-REC-W1, FREQ-4KV, A-4KW1-XHE-R-12 } \\
\text { Partition Cut Set Report }\end{array}$ \\
\hline 39 & 66.4 & 0.5 & $\begin{array}{l}\text { 1.129E-007 UNITY, PROB-W1D6, LPR-CCF-PG-SUMP1, DR-MT, } \\
\text { DURATION-D6, H-SI-REC-W1, FREQ-SI, } \\
\text { A-SIW1-XHE-R-12 }\end{array}$ \\
\hline 40 & 66.9 & 0.5 & $\begin{array}{l}\text { 1.111E-007 UNITY, ACP-INV-NO-UPSA2, PROB-W1D6, DR-MT, } \\
\text { DURATION-D6, FREQ-L2, NRAC200, PROB-1HFAILEDL2 }\end{array}$ \\
\hline 41 & 67.5 & 0.5 & $\begin{array}{l}\text { 1.099E-007 UNITY, PROB-W2D6, DR-MT, DURATION-D6, FREQ-B2, } \\
\text { NRAC262 }\end{array}$ \\
\hline 42 & 68.0 & 0.5 & $\begin{array}{l}\text { 1.077E-007 UNITY, FREQ-CCW, H-CCW-REC-W1, PROB-W1D6, } \\
\text { A-CCW1-XHE-C-9, DR-MT, DURATION-D6 }\end{array}$ \\
\hline 43 & 68.5 & 0.5 & $\begin{array}{l}\text { 1.054E-007 UNITY, CCW-LF-RHE2A, PROB-W1D6, DR-MT, } \\
\text { DURATION-D6, FREQ-L2, NRAC200, /PROB-1HFAIIEDL2 }\end{array}$ \\
\hline 44 & 69.0 & 0.4 & $\begin{array}{l}\text { 9.791E-008 UNITY, ACP-INV-NO-UPSA2, AFW-MDP-MA-FW3B, } \\
\text { REFUEL, DURATION-R6, /PZR-SV-REMOVEDW2, } \\
\text { PROB-W2R6, FREQ-L2, NRAC262, PROB-1HFAIIEDL2 }\end{array}$ \\
\hline 45 & 69.5 & 0.4 & $\begin{array}{l}\text { 9.370E-008 UNITY, REFUEL, DURATION-R6, /PZR-SV-REMOVEDW2, } \\
\text { PROB-W2R6, D-SIW2-XHE, FREQ-SI }\end{array}$ \\
\hline 46 & 69.9 & 0.4 & $\begin{array}{l}\text { 9.063E-008 UNITY, PROB-W1D6, DR-MT, DURATION-D6, FREQ-L2, } \\
\text { NRAC200, /PROB-1HFAILEDL2, A-L2W1-XHE-R-4 }\end{array}$ \\
\hline 47 & 70.4 & 0.4 & $\begin{array}{l}\text { 9.040E-008 UNITY, PROB-RHR2A, DR-MT, D-RAW1-XHE, } \\
\text { PROB-W1D6A }\end{array}$ \\
\hline 48 & 70.8 & 0.4 & $\begin{array}{l}\text { 8.729E-008 UNITY, PROB-W1D6, DR-MT, DURATION-D6, } \\
\text { D-SIW1-XHE, FREQ-SI }\end{array}$ \\
\hline 49 & 71.2 & 0.4 & $\begin{array}{l}\text { 8.245E-008 UNITY, AFW-MDP-MA-FW3B, CCW-LF-RHE2B, PROB-W2D6, } \\
\text { DR-MT, DURATION-D6, FREQ-L2, NRAC262, } \\
\text { PROB-1HFAILEDL2 }\end{array}$ \\
\hline 50 & 71.6 & 0.3 & $\begin{array}{l}\text { 7.511E-008 UNITY, LOOPISOLATED2R6, CPC-MDP-FR-SW10A, } \\
\text { CPC-MDP-MA-SW10B, REFUEL, DURATION-R6, } \\
\text { FREQ-RHR3, /PZR-SV-REMOVEDW2, PROB-W2R6, } \\
\text { LPR-CCF-PG-SUMP2 }\end{array}$ \\
\hline
\end{tabular}

NUREG/CR-6144

$10-72$ 
Table 10-49 (continued)

Family->RHRMODEL

Mincut Upper Bound -> 2.011E-005
End State $->C D$

This Partition -> 2.011E-005

Cut \% \% Cut

No. Total Set Frequency

Cut Sets

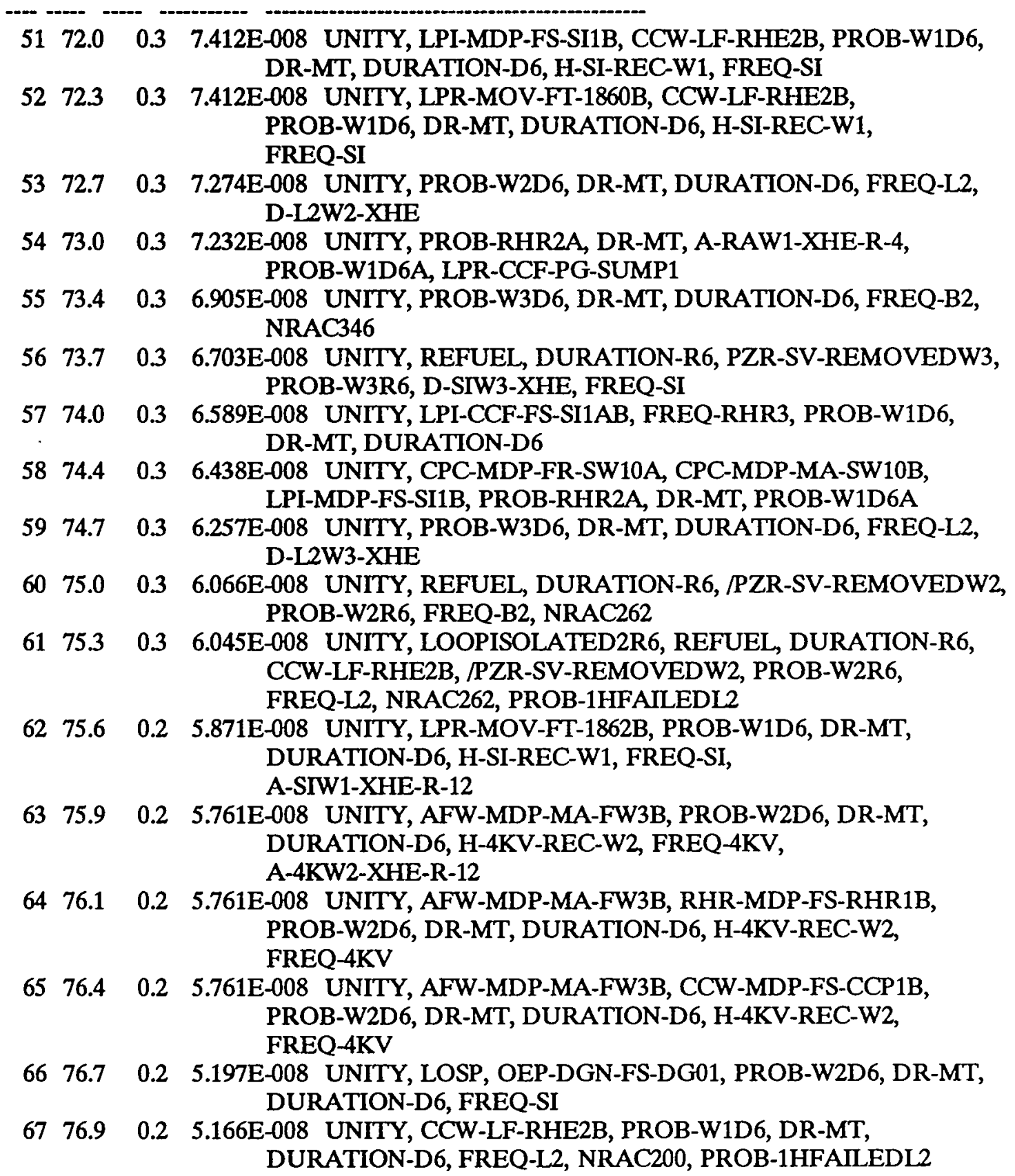


10 Accident Sequence Quantification

Table 10-49 (continued)

Family->RHRMODEL

Mincut Upper Bound -> 2.011E-005

End State $->C D$

This Partition -> 2.011E-005

Cut \% \% Cut

No. Total Set Frequency Cut Sets

$68 \quad 77.2 \quad 0.2 \quad 5.045 E-008$ UNITY, ACP-INV-NO-UPSA2, MSS-AOV-FC-101B, PROB-W2D6, DR-MT, DURATION-D6, FREQ-L2, NRAC262, PROB-1HFAILEDL2

$6977.4 \quad 0.2 \quad 5.045 E-008$ UNITY, ACP-INV-NO-UPSA2, MSS-AOV-FC-101A, PROB-W2D6, DR-MT, DURATION-D6, FREQ-L2, NRAC262, PROB-1HFAILEDL2

$7077.7 \quad 0.2 \quad 4.846 E-008$ UNITY, LPI-CCF-FS-SI1AB, FREQ-CCW, H-CCW-REC-W1, PROB-W1D6, DR-MT, DURATION-D6

$71 \quad 77.9 \quad 0.2 \quad 4.834 E-008$ UNITY, LOOPISOLATED2R6, CPC-MDP-FR-SW10A, CPC-MDP-MA-SW10B, REFUEL, LPI-MDP-FS-SI1B, PROB-RHR2A, /PZR-SV-REMOVEDW2, PROB-W2R6A

$7278.2 \quad 0.2 \quad 4.799 E-008$ UNITY, ACP-INV-NO-UPSB1, LOOPISOLATED2R6, REFUEL, DURATION-R6, /PZR-SV-REMOVEDW2, PROB-W2R6, FREQ-L2, NRAC262, /PROB-1HFAILEDL2, 2EH1L2

$7378.4 \quad 0.2$ 4.694E-008 UNITY, LOOPISOLATED2R6, CPC-MDP-FR-SW10A, CPC-MDP-MA-SW10B, REFUEL, DURATION-R6, OSR-TRA-MA, ISR-TRA-MA, FREQ-RHR3, /PZR-SV-REMOVEDW2, PROB-W2R6

$74 \quad 78.6 \quad 0.2 \quad 4.598 E-008$ UNITY, ACP-INV-NO-UPSB1, REFUEL, /PZR-SV-REMOVEDW4, PROB-W4R10, FRAC-POS10, DURATION-R10, FREQ-L2, NRAC455, /PROB-1HFAILEDL2, 2EH1L2

$7578.9 \quad 0.2 \quad 4.554 E-008$ UNITY, PROB-W1D6, LPR-CCF-PG-SUMP1, DR-MT, DURATION-D6, FREQ-SI, A-SIW1-XHE-R-3

$7679.1 \quad 0.2$ 4.553E-008 UNITY, AFW-MDP-MA-FW3B, REFUEL, DURATION-R6, CCW-LF-RHE2B, /PZR-SV-REMOVEDW2, PROB-W2R6, FREQ-L2, NRAC262, PROB-1HFAILEDL2

$7779.3 \quad 0.2$ 4.549E-008 UNITY, REFUEL, /PZR-SV-REMOVEDW4, PROB-W4R10, FRAC-POS10, DURATION-R10, FREQ-L1, D-L1W4-XHE

$7879.5 \quad 0.2 \quad 4.501 E-008$ UNITY, PROB-RHR2A, DR-MT, D-RAW2-XHE, PROB-W2D6A

$7979.8 \quad 0.2 \quad 4.443 E-008$ UNITY, PROB-W1D6, DR-MT, DURATION-D6, FREQ-L2, NRAC200, PROB-1HFAILEDL2, A-L2W1-XHE-R-4

$8080.0 \quad 0.2$ 4.223E-008 UNITY, LOOPISOLATED2R6, REFUEL, DURATION-R6, /PZR-SV-REMOVEDW2, PROB-W2R6, H-4KV-REC-W2, FREQ-4KV, A-4KW2-XHE-R-12

$81 \quad 80.2 \quad 0.2 \quad 4.223 E-008$ UNITY, LOOPISOLATED2R6, REFUEL, RHR-MDP-FS-RHR1B, DURATION-R6, , /PZR-SV-REMOVEDW2, PROB-W2R6, H-4KV-REC-W2, FREQ-4KV 
Table 10-49 (continued)

Family->RHRMODEL

Mincut Upper Bound -> 2.011E-005
End State $->C D$

This Partition $->$ 2.011E-005

Cut \% \% Cut

No. Total Set Frequency Cut Sets

\begin{tabular}{|c|c|c|c|}
\hline 82 & 80.4 & 0.2 & $\begin{array}{l}\text { 4.223E-008 UNITY, CCW-MDP-FS-CCP1B, LOOPISOLATED2R6, } \\
\text { REFUEL, DURATION-R6, /PZR-SV-REMOVEDW2, } \\
\text { PROB-W2R6, H-4KV-REC-W2, FREQ-4KV }\end{array}$ \\
\hline 83 & 80.6 & 0.2 & $\begin{array}{l}\text { 4.068E-008 UNITY, REFUEL, /PZR-SV-REMOVEDW4, PROB-W4R10, } \\
\text { FRAC-POS10, DURATION-R10, FREQ-B2, NRAC455 }\end{array}$ \\
\hline 84 & 80.8 & 0.2 & $\begin{array}{l}\text { 4.060E-008 UNITY, RHR-MDP-FS-RHR1B, PROB-W1D6, DR-MT, } \\
\text { DURATION-D6, H-4KV-REC-W1, FREQ-4KV }\end{array}$ \\
\hline 85 & 81.0 & 0.2 & $\begin{array}{l}\text { 4.060E-008 UNITY, CCW-MDP-FS-CCP1B, PROB-W1D6, DR-MT, } \\
\text { DURATION-D6, H-4KV-REC-W1, FREQ-4KV }\end{array}$ \\
\hline 86 & 81.2 & 0.2 & $\begin{array}{l}\text { 4.016E-008 UNITY, REFUEL, DURATION-R6, /PZR-SV-REMOVEDW2, } \\
\text { PROB-W2R6, FREQ-L2, D-L2W2-XHE }\end{array}$ \\
\hline 87 & 81.4 & 0.2 & $\begin{array}{l}\text { 3.985E-008 UNITY, RHR-MDP-FS-RHR1B, PROB-W1D6, } \\
\text { LPR-CCF-PG-SUMP1, DR-MT, DURATION-D6, } \\
\text { H-SI-REC-W1, FREQ-SI }\end{array}$ \\
\hline 88 & 81.6 & 0.1 & $\begin{array}{l}\text { 3.840E-008 UNITY, AFW-MDP-MA-FW3B, CCW-MDP-MA-CCP1B, } \\
\text { PROB-W2D6, DR-MT, DURATION-D6, H-4KV-REC-W2, } \\
\text { FREQ-4KV }\end{array}$ \\
\hline 89 & 81.8 & 0.1 & $\begin{array}{l}\text { 3.807E-008 UNITY, LPR-CCF-FT-862AB, FREQ-RHR3, PROB-W1D6, } \\
\text { DR-MT, DURATION-D6 }\end{array}$ \\
\hline 90 & 82.0 & 0.1 & $\begin{array}{l}\text { 3.807E-008 UNITY, LPR-CCF-FT-860AB, FREQ-RHR3, PROB-W1D6, } \\
\text { DR-MT, DURATION-D6 }\end{array}$ \\
\hline 91 & 82.1 & 0.1 & $\begin{array}{l}\text { 3.760E-008 UNITY, LPR-MOV-FT-1862B, PROB-RHR2A, DR-MT, } \\
\text { A-RAW1-XHE-R-4, PROB-W1D6A }\end{array}$ \\
\hline 92 & 82.3 & 0.1 & $\begin{array}{l}\text { 3.628E-008 UNITY, PROB-W1D6, DR-MT, DURATION-D6, FREQ-B2, } \\
\text { NRAC200 }\end{array}$ \\
\hline 93 & 82.5 & 0.1 & $\begin{array}{l}\text { 3.584E-008 UNITY, ACP-INV-NO-UPSB1, REFUEL, DURATION-R6, } \\
\text { PZR-SV-REMOVEDW3, PROB-W3R6, FREQ-L2, NRAC346, } \\
\text { /PROB-1HFAILEDL2, 2EH1L2 }\end{array}$ \\
\hline 94 & 82.7 & 0.1 & $\begin{array}{l}\text { 3.550E-008 UNITY, PROB-W1D6, DR-MT, DURATION-D6, } \\
\text { LPR-CCF-PG-SUMP1, FREQ-L1, A-L1W1-XHE-R-4 }\end{array}$ \\
\hline 95 & 82.9 & 0.1 & $\begin{array}{l}\text { 3.516E-008 UNITY, CCW-LF-RHE2B, PROB-W1D6, FREQ-RHR4, } \\
\text { ' DR-MT, DURATION-D6, LPR-CCF-PG-SUMP1 }\end{array}$ \\
\hline 96 & 83.0 & 0.1 & $\begin{array}{l}\text { 3.423E-008 UNITY, LOSP, OEP-DGN-FC-DG3U2, PROB-RHR2A, } \\
\text { DR-MT, PROB-W1D6A }\end{array}$ \\
\hline 97 & 83.2 & 0.1 & $\begin{array}{l}\text { 3.394E-008 UNITY, PROB-W2D6, FREQ-RHR5, DR-MT, DURATION-D6, } \\
\text { D-R5W2-XHE }\end{array}$ \\
\hline 98 & 83.4 & 0.1 & $\begin{array}{l}\text { 3.387E-008 UNITY, LPI-MDP-FS-SI1B, PROB-W1D6, DR-MT, } \\
\text { DURATION-D6, H-SI-REC-W1, FREQ-SI, } \\
\text { A-SIW1-XHE-R-12 }\end{array}$ \\
\hline
\end{tabular}


10 Accident Sequence Quantification

Table 10-49 (continued)

Family->RHRMODEL

Mincut Upper Bound -> 2.011E-005

End State $->C D$

This Partition $\rightarrow$ 2.011E-005

Cut \% \% Cut

No. Total Set Frequency Cut Sets

\begin{tabular}{|c|c|c|c|}
\hline 99 & 83.5 & 0.1 & $\begin{array}{l}\text { 3.387E-008 UNITY, LPR-MOV-FT-1860B, PROB-W1D6, DR-MT, } \\
\text { DURATION-D6, H-SI-REC-W1, FREQ-SI, } \\
\text { A-SIW1-XHE-R-12 }\end{array}$ \\
\hline 100 & 83.7 & 0.1 & $\begin{array}{l}\text { 3.381E-008 UNITY, PROB-W2D6, DR-MT, DURATION-D6, FREQ-SR, } \\
\text { D-SRW2-XHE }\end{array}$ \\
\hline 101 & 83.9 & 0.1 & $\begin{array}{l}\text { 3.362E-008 UNITY, PROB-W2D6, DR-MT, DURATION-D6, FREQ-4KV, } \\
\text { D-4KW2-XHE }\end{array}$ \\
\hline 102 & 84.0 & 0.1 & $\begin{array}{l}\text { 3.351E-008 UNITY, ACP-INV-NO-UPSA2, SGB-DRAINED-R, } \\
\text { PROB-W2D6, DR-MT, DURATION-D6, H-4KV-REC-W2, } \\
\text { FREQ-4KV }\end{array}$ \\
\hline 103 & 84.2 & 0.1 & $\begin{array}{l}\text { 3.351E-008 UNITY, ACP-INV-NO-UPSA2, SGA-DRAINED-R, } \\
\text { PROB-W2D6, DR-MT, DURATION-D6, H-4KV-REC-W2, } \\
\text { FREQ-4KV }\end{array}$ \\
\hline 104 & 84.4 & 0.1 & $\begin{array}{l}\text { 3.297E-008 UNITY, REFUEL, PROB-RHR2A, /PZR-SV-REMOVEDW2, } \\
\text { D-RAW2-XHE, PROB-W2R6A }\end{array}$ \\
\hline 105 & 84.5 & 0.1 & $\begin{array}{l}\text { 3.274E-008 UNITY, PROB-W1D6, DR-MT, DURATION-D6, FREQ-L3, } \\
\text { NRAC200, A-L3W1-XHE-CW-4 }\end{array}$ \\
\hline 106 & 84.7 & 0.1 & $\begin{array}{l}\text { 3.259E-008 UNITY, CPC-MDP-FR-SW10A, CPC-MDP-MA-SW10B, } \\
\text { OSR-TRA-MA, ISR-TRA-MA, FREQ-RHR3, PROB-W1D6, } \\
\text { DR-MT, DURATION-D6 }\end{array}$ \\
\hline 107 & 84.9 & 0.1 & $\begin{array}{l}\text { 3.243E-008 UNITY, LOSP, OEP-DGN-FS-DG01, PROB-RHR2A, DR-MT, } \\
\text {, PROB-W2D6A }\end{array}$ \\
\hline 108 & 85.0 & 0.1 & $\begin{array}{l}\text { 3.181E-008 UNITY, AFW-MDP-MA-FW3B, REFUEL, } \\
\text { RHR-MDP-FS-RHR1B, DURATION-R6, } \\
\text { /PZR-SV-REMOVEDW2, PROB-W2R6, H-4KV-REC-W2, } \\
\text { FREQ-4KV }\end{array}$ \\
\hline 109 & 85.2 & 0.1 & $\begin{array}{l}\text { 3.181E-008 UNITY, AFW-MDP-MA-FW3B, REFUEL, DURATION-R6, } \\
\text { /PZR-SV-REMOVEDW2, PROB-W2R6, H-4KV-REC-W2, } \\
\text { FREQ-4KV, A-4KW2-XHE-R-12 }\end{array}$ \\
\hline 110 & 85.3 & 0.1 & $\begin{array}{l}\text { 3.181E-008 UNITY, AFW-MDP-MA-FW3B, CCW-MDP-FS-CCP1B, } \\
\text { REFUEL, DURATION-R6, /PZR-SV-REMOVEDW2, } \\
\text { PROB-W2R6, H-4KV-REC-W2, FREQ-4KV }\end{array}$ \\
\hline 111 & 85.5 & 0.1 & $\begin{array}{l}\text { 3.107E-008 UNITY, LOOPISOLATED2R6, CPC-MDP-FR-SW10A, } \\
\text { CPC-MDP-MA-SW10B, REFUEL, FREQ-CCW, DURATION-R6, } \\
\text { H-CCW-REC-W2, /PZR-SV-REMOVEDW2, PROB-W2R6, } \\
\text { LPR-CCF-PG-SUMP2 }\end{array}$ \\
\hline 112 & 85.6 & 0.1 & $\begin{array}{l}\text { 3.088E-008 UNITY, CON-VFC-RP-COREM, OSR-TRA-MA, ISR-TRA-MA, } \\
\text { CCW-LF-RHE2B, PROB-W1D6, DR-MT, DURATION-D6, } \\
\text { H-SI-REC-W1, FREQ-SI }\end{array}$ \\
\hline
\end{tabular}

H-SI-REC-W1, FREQ-SI 
Table 10-49 (continued)

Family->RHRMODEL

Mincut Upper Bound $->$ 2.011E-005

Cut \% \% Cut

No. Total Set Frequency
End State $->C D$

This Partition $\rightarrow$ 2.011E-005

$113 \quad 85.8 \quad 0.1 \quad$ 2.949E-008 UNITY, REFUEL, DURATION-R6, FREQ-RHR3, PROB-W1R6, LOOPISOLATED1R6, /PZR-SV-REMOVEDW1, LPR-CCF-PG-SUMP1

$11485.9 \quad 0.1 \quad 2.919 E-008$ UNITY, PROB-W3D6, FREQ-RHR5, DR-MT, DURATION-D6, D-R5W3-XHE

11586.10 .1 2.908E-008 UNITY, PROB-W3D6, DR-MT, DURATION-D6, FREQ-SR, D-SRW3-XHE

11686.20 .1 2.892E-008 UNITY, PROB-W3D6, DR-MT, DURATION-D6, FREQ-4KV,

$11786.4 \quad 0.1 \quad$ D-4KW3E-008 UNITY, REFUEL, DURATION-R6, PZR-SV-REMOVEDW3,

PROB-W3R6, FREQ-L2, D-L2W3-XHE

$118 \quad 86.5 \quad 0.1 \quad 2.869 E-008$ UNITY, REFUEL, LOSP, OEP-DGN-FS-DG01, 'DURATION-R6, /PZR-SV-REMOVEDW2, PROB-W2R6, FREQ-SI

11986.60 .1 2.815E-008 UNITY, CCW-MDP-MA-CCP1B, LOOPISOLATED2R6, REFUEL, DURATION-R6, /PZR-SV-REMOVEDW2, PROB-W2R6, H-4KV-REC-W2, FREQ-4KV

$12086.8 \quad 0.1 \quad 2.800$ E-008 UNITY, FREQ-CCW, LPR-CCF-FT-862AB, H-CCW-REC-W1, PROB-W1D6, DR-MT, DURATION-D6

$12186.90 .1 \quad 2.800$ E-008 UNITY, FREQ-CCW, LPR-CCF-FT-860AB, H-CCW-REC-W1, PROB-W1D6, DR-MT, DURATION-D6

$12287.1 \quad 0.1 \quad 2.782 E-008$ UNITY, CON-VFC-RP-COREM, ISR-MDP-FS-RS1A, OSR-TRA-MA, FREQ-RHR3, PROB-W1D6, DR-MT, DURATION-D6

$123 \quad 87.20 .12 .712 E-008$ UNITY, PROB-RHR2A, RHR-CCF-FS-MDPAB, DR-MT, PROB-W1D6A, LPR-CCF-PG-SUMP1

$124 \quad 87.3 \quad 0.1 \quad 2.707 E-008$ UNITY, CCW-MDP-MA-CCP1B, PROB-W1D6, DR-MT, DURATION-D6, H-4KV-REC-W1, FREQ-4KV

$12587.5 \quad 0.1 \quad 2.684 \mathrm{E}-008$ UNITY, ACP-BAC-ST-4KV1H, ACP-INV-NO-UPSA2, AFW-MDP-MA-FW3B, PROB-W2D6, DR-MT, DURATION-D6, FREQ-SI

$12687.60 .1 \quad 2.638 E-008$ UNITY, PROB-W1D6, DR-MT, DURATION-D6, FREQ-L2, D-L2W1-XHE

$12787.7 \quad 0.1 \quad 2.615 E-008$ UNITY, AFW-MDP-MA-FW3B, PROB-W2D6, DR-MT, DURATION-D6, FREQ-L2, NRAC262, PROB-1HFAILEDL2, A-L2W2-XHE-R-4

$128 \quad 87.8 \quad 0.1 \quad 2.589 \mathrm{E}-008$ UNITY, ACP-BAC-ST-4KV1H, AFW-MDP-MA-FW3B, FREQ-RHR3, PROB-W2D6, DR-MT, DURATION-D6 
10 Accident Sequence Quantification

Table 10-49 (continued)

Family->RHRMODEL

Mincut Upper Bound -> 2.011E-005

End State $\rightarrow C D$

This Partition $\rightarrow>$ 2.011E-005

Cut \% \% Cut

No. Total Set Frequency

Cut Sets

$12988.0 \quad 0.1 \quad 2.471 E-008$ UNITY, CCW-LF-RHE2B, PROB-W1D6, DR-MT, DURATION-D6, A-SIW1-XHE-C-18, H-SI-REC-W1, FREQ-SI

$13088.1 \quad 0.1 \quad$ 2.397E-008 UNITY, CPC-MDP-FR-SW10A, CPC-MDP-MA-SW10B, , FREQ-CCW, OSR-TRA-MA, ISR-TRA-MA, H-CCW-REC-W1, PROB-W1D6, DR-MT, DURATION-D6

$13188.2 \quad 0.1 \quad 2.375 E-008$ UNITY, REFUEL, LOSP, OEP-DGN-FS-DG01, PROB-RHR2A, /PZR-SV-REMOVEDW2, PROB-W2R6A

$13288.3 \quad 0.1 \quad 2.368 E-008$ UNITY, LPR-MOV-FT-1862B, PROB-W1D6, DR-MT, DURATION-D6, FREQ-SI, A-SIW1-XHE-R-3

13388.40 .1 2.346E-008 UNITY, MSS-AOV-FC-101B, CCW-LF-RHE2B, PROB-W2D6, DR-MT, DURATION-D6, FREQ-L2, NRAC262, PROB-1HFAILEDL2

13488.60 .1 2.346E-008 UNITY, MSS-AOV-FC-101A, CCW-LF-RHE2B, PROB-W2D6, DR-MT, DURATION-D6, FREQ-L2, NRAC262, PROB-1HFAILEDL2

$13588.7 \quad 0.1 \quad 2.314 E-008$ UNITY, PROB-RHR2A, SAS-CPS-FR-1SAC1, IAS-CPS-FS-IAC-1, DR-MT, PROB-W1D6A, LPR-CCF-PG-SUMP1

$13688.8 \quad 0.1 \quad 2.314 E-008$ UNITY, PROB-RHR2A, SAS-CPS-FR-2SAC1, IAS-CPS-FS-IAC-1, DR-MT, PROB-W1D6A, LPR-CCF-PG-SUMP1

$13788.90 .1 \quad 2.243 E-008$ UNITY, CPC-MDP-FR-SW10A, CPC-MDP-MA-SW10B, REFUEL, LPI-MDP-FS-SI1B, PROB-RHR2A, PZR-SV-REMOVEDW3, PROB-W3R6A

$138 \quad 89.0 \quad 0.1 \quad 2.231 E-008$ UNITY, LOOPISOLATED2R6, REFUEL, DURATION-R6, CCW-LF-RHE2A, /PZR-SV-REMOVEDW2, PROB-W2R6, FREQ-L2, NRAC262, /PROB-1HFAILEDL2, 2EH1L2

$13989.1 \quad 0.1 \quad 2.215 E-008$ UNITY, LOSP, OEP-DGN-FS-DG01, PROB-RHR2A, DR-MT, PROB-W1D6A

$140 \quad 89.2 \quad 0.1 \quad 2.215 E-008$ UNITY, LOSP, OEP-DGN-FS-DG03, PROB-RHR2A, DR-MT, PROB-W1D6A

$14189.3 \quad 0.1 \quad 2.181 E-008$ UNITY, DCP-BAT-LP-BAT1B, ACP-BCH-MA-UPSB1, ACP-BCH-MA-UPSB2, PROB-W1D6, FREQ-RHR4, DR-MT, DURATION-D6

$14289.4 \quad 0.12 .170 \mathrm{E}-008$ UNITY, ACP-BAC-ST-4KV1H, ACP-INV-NO-UPSA2, PROB-RHR2A, DR-MT, PROB-W1D6A

$14389.60 .1 \quad 2.170$ E-008 UNITY, ACP-BAC-ST-4KV1J, ACP-INV-NO-UPSB1, PROB-RHR2A, DR-MT, PROB-W1D6A

$14489.70 .1 \quad 2.170 \mathrm{E}-008$ UNITY, ACP-BAC-ST-1J1, ACP-INV-NO-UPSB1, PROB-RHR2A, DR-MT, PROB-W1D6A 
10 Accident Sequence Quantification

Table 10-49 (continued)

Family->RHRMODEL

Mincut Upper Bound -> 2.011E-005
End State $->\mathrm{CD}$

This Partition $\rightarrow$ 2.011E-005

Cut $\% \quad \%$ Cut

No. Total Set Frequency

Cut Sets

$14589.8 \quad 0.1 \quad 2.170 E-008$ UNITY, ACP-BAC-ST-1J1-2, ACP-INV-NO-UPSB1, PROB-RHR2A, DR-MT, PROB-W1D6A

14689.90 .12 .170 E-008 UNITY, LPI-MDP-FS-SI1B, PROB-RHR2A, DR-MT, A-RAW1-XHE-R-4, PROB-W1D6A

$14790.0 \quad 0.1 \quad 2.170 E-008$ UNITY, LPR-MOV-FT-1860B, PROB-RHR2A, DR-MT, A-RAW1-XHE-R-4, PROB-W1D6A

$14890.1 \quad 0.1 \quad 2.169 E-008$ UNITY, REFUEL, FREQ-CCW, DURATION-R6, H-CCW-REC-W1, PROB-W1R6, LOOPISOLATED1R6, /PZR-SV-REMOVEDW1, LPR-CCF-PG-SUMP1

$14990.2 \quad 0.1$ 2.155E-008 UNITY, LOSP, OEP-DGN-FC-DG3U2, PROB-W1D6, DR-MT, DURATION-D6, FREQ-SI

15090.30 .1 2.138E-008 UNITY, REFUEL, CCW-LF-RHE2A, /PZR-SV-REMOVEDW4, PROB-W4R10, FRAC-POS10, DURATION-R10, FREQ-L2, NRAC455, /PROB-1HFAILEDL2, 2EH1L2

$15190.4 \quad 0.1 \quad 2.120 \mathrm{E}-008$ UNITY, AFW-MDP-MA-FW3B, CCW-MDP-MA-CCP1B, REFUEL, DURATION-R6, /PZR-SV-REMOVEDW2, PROB-W2R6, H-4KV-REC-W2, FREQ-4KV

15290.50 .1 2.109E-008 UNITY, LOOPISOLATED2R6, REFUEL, DURATION-R6, FREQ-RHR3, /PZR-SV-REMOVEDW2, PROB-W2R6, A-R3W2-XHE-X, LPR-CCF-PG-SUMP2

15390.60 .1 2.085E-008 UNITY, PROB-RHR2A, CCW-LF-RHE2A, CCW-LF-RHE2B, DR-MT, PROB-W1D6A, LPR-CCF-PG-SUMP1

$15490.7 \quad 0.1 \quad$ 2.082E-008 UNITY, PROB-RHR2A, DR-MT, D-RAW3-XHE, PROB-W3D6A

$15590.8 \quad 0.1 \quad 2.072 E-008$ UNITY, LPR-MOV-FT-1862B, RHR-MDP-FS-RHR1B, PROB-W1D6, DR-MT, DURATION-D6, H-SI-REC-W1, FREQ-SI

$15690.9 \quad 0.1 \quad 2.046 E-008$ UNITY, CON-VFC-RP-COREM, ISR-MDP-FS-RS1A, FREQ-CCW, OSR-TRA-MA, H-CCW-REC-W1, PROB-W1D6, DR-MT, DURATION-D6

$15791.0 \quad 0.1 \quad 2.012 E-008$ UNITY, ACP-BAC-ST-1H1, ACP-INV-NO-UPSA2, CPC-MDP-MA-SW10B, PROB-RHR2A, DR-MT, PROB-W1D6A

$15891.1 \quad 0.1 \quad 2.010 \mathrm{E}-008$ UNITY, PROB-W2D6, DR-MT, DURATION-D6, D-VBW2-XHE, FREQ-VB

$15991.20 .1 \quad$ 1.978E-008 UNITY, PROB-W1D6, LPR-CCF-PG-SUMP1, DR-MT, DURATION-D6, H-VB-REC-W1, FREQ-VB, A-VBW1-XHE-R-12

$16091.3 \quad 0.1 \quad 1.970 E-008$ UNITY, ACP-INV-NO-UPSB1, REFUEL, PZR-SV-REMOVEDW4, PROB-W4R10, FRAC-POS10, DURATION-R10, FREQ-L2, NRAC455, /PROB-1HFAILEDL2, 2EH1L2 
10 Accident Sequence Quantification

Table 10-49 (continued)

Family->RHRMODEL

Mincut Upper Bound -> 2.011E-005
End State $\rightarrow C D$

This Partition $\rightarrow$ 2.011E-005

Cut \% \% Cut

No. Total Set Frequency Cut Sets

$16191.4 \quad 0.1 \quad 1.968 E-008$ UNITY, ACP-BAC-ST-4KV1H, ACP-INV-NO-UPSA2, LOOPISOLATED2R6, REFUEL, DURATION-R6, /PZR-SV-REMOVEDW2, PROB-W2R6, FREQ-SI

16291.50 .1 1.968E-008 UNITY, REFUEL, DURATION-R6, PZR-SV-REMOVEDW2, PROB-W2R6, FREQ-B1, NRAC262

16391.60 .1 1.965E-008 UNITY, REFUEL, DURATION-R6, PROB-W2R6, FREQ-SR, D-SRW2-XHE

16491.70 .1 1.949E-008 UNITY, REFUEL, PZR-SV-REMOVEDW4, PROB-W4R10,

FRAC-POS10, DURATION-R10, FREQ-L1, D-L1W4-XHE

$16591.8 \quad 0.1 \quad$ 1.942E-008 UNITY, LOOPISOLATED2R6, CPC-MDP-FR-SW10A, CPC-MDP-MA-SW10B, REFUEL, FREQ-CCW, DURATION-R6, OSR-TRA-MA, ISR-TRA-MA, H-CCW-REC-W2, /PZR-SV-REMOVEDW2, PROB-W2R6

16691.90 .1 1.917E-008 UNITY, LOOPISOLATED2R6, REFUEL, DURATION-R6, /PZR-SV-REMOVEDW2, PROB-W2R6, FREQ-L2, NRAC262, PROB-1HFAILEDL2, A-L2W2-XHE-R-4

$16792.0 \quad 0.1 \quad 1.916 \mathrm{E}-008$ UNITY, ACP-INV-NO-UPSA2, AFW-MDP-MA-FW3B, REFUEL, DURATION-R6, PROB-W1R6, /PZR-SV-REMOVEDW1, H-4KV-REC-W1, FREQ-4KV

$16892.10 .0 \quad 1.898 \mathrm{E}-008$ UNITY, ACP-BAC-ST-4KV1H, LOOPISOLATED2R6, REFUEL, DURATION-R6, FREQ-RHR3, /PZR-SV-REMOVEDW2, PROB-W2R6

$16992.20 .0 \quad 1.874 E-008$ UNITY, REFUEL, DURATION-R6, /PZR-SV-REMOVEDW2, PROB-W2R6, FREQ-RHR5, D-R5W2-XHE

$170 \quad 92.3 \quad 0.0 \quad 1.862 E-008$ UNITY, ACP-INV-NO-UPSB1, MSS-AOV-FC-101B, PROB-W2D6, DR-MT, DURATION-D6, FREQ-L2, NRAC262, /PROB-1HFAILEDL2, 2EH1L2

$17192.4 \quad 0.0 \quad 1.862 E-008$ UNITY, ACP-INV-NO-UPSB1, MSS-AOV-FC-101A, PROB-W2D6, DR-MT, DURATION-D6, FREQ-L2, NRAC262, /PROB-1HFAILEDL2, 2EH1L2

$17292.50 .0 \quad 1.856 \mathrm{E}-008$ UNITY, REFUEL, DURATION-R6, /PZR-SV-REMOVEDW2, PROB-W2R6, FREQ-4KV, D-4KW2-XHE

$17392.6 \quad 0.0 \quad 1.846 \mathrm{E}-008$ UNITY, LPR-MOV-FT-1862B, PROB-W1D6, DR-MT, DURATION-D6, FREQ-L1, A-L1W1-XHE-R-4

$17492.7 \quad 0.0 \quad 1.830$ E-008 UNITY, PROB-W3D6, DR-MT, DURATION-D6, FREQ-B1, NRAC346, D-B1W3-XHE

$17592.7 \quad 0.0 \quad 1.828 E-008$ UNITY, LPR-MOV-FT-1862B, CCW-LF-RHE2B, PROB-W1D6, FREQ-RHR4, DR-MT, DURATION-D6 
10 Accident Sequence Quantification

Table 10-49 (continued)

Family->RHRMODEL

Mincut Upper Bound -> 2.011E-005
End State $->C D$

This Partition $->$ 2.011E-005

Cut \% \% Cut

No. Total Set Frequency

Cut Sets

$17692.8 \quad 0.0 \quad 1.825 \mathrm{E}-008$ UNITY, ACP-BAC-ST-1H1, ACP-INV-NO-UPSA2, LOOPISOLATED2R6, CPC-MDP-MA-SW10B, REFUEL, DURATION-R6, /PZR-SV-REMOVEDW2, PROB-W2R6, FREQ-SI

$17792.9 \quad 0.0 \quad 1.808 E-008$ UNITY, PROB-RHR2A, RHR-ASF-PG-1605, DR-MT, PROB-W1D6A, LPR-CCF-PG-SUMP1

$17893.0 \quad 0.0 \quad 1.760 \mathrm{E}-008$ UNITY, ACP-BAC-ST-1H1, LOOPISOLATED2R6, CPC-MDP-MA-SW10B, REFUEL, DURATION-R6, FREQ-RHR3, /PZR-SV-REMOVEDW2, PROB-W2R6

$17993.1 \quad 0.0 \quad 1.746 \mathrm{E}-008$ UNITY, PROB-W1D6, FREQ-RHR5, DR-MT, DURATION-D6, D-R5W1-XHE

$18093.2 \quad 0.0 \quad$ 1.729E-008 UNITY, PROB-W1D6, DR-MT, DURATION-D6, FREQ-4KV, D-4KW1-XHE

$18193.3 \quad 0.0 \quad 1.729 E-008$ UNITY, PROB-W3D6, DR-MT, DURATION-D6, D-VBW3-XHE, FREQ-VB

$18293.4 \quad 0.0 \quad 1.718 \mathrm{E}-008$ UNITY, CPC-MDP-FR-SW10A, REFUEL, LPI-MDP-FS-SI1B, PROB-RHR2A, /PZR-SV-REMOVEDW4, FRAC-POS10, PROB-W4R10A, CPC-MDP-MA0SW10B

$18393.4 \quad 0.0 \quad 1.708 E-008$ UNITY, RHR-CCF-FS-MDPAB, PROB-W1D6, LPR-CCF-PG-SUMP1, DR-MT, DURATION-D6, FREQ-SI

$18493.5 \quad 0.0 \quad 1.701 E-008$ UNITY, DCP-BDC-ST-BUS1B, PROB-W1D6, FREQ-RHR4, DR-MT, DURATION-D6

$18593.6 \quad 0.0 \quad 1.701 E-008$ UNITY, ACP-BAC-ST-4KV1J, PROB-W1D6, FREQ-RHR4, DR-MT, DURATION-D6

$18693.7 \quad 0.0 \quad 1.699 \mathrm{E}-008$ UNITY, RHR-MDP-FS-RHR1A, PROB-W1D6, DR-MT, DURATION-D6, FREQ-L2, NRAC200, /PROB-1HFAILEDL2

$18793.8 \quad 0.0 \quad 1.699 \mathrm{E}-008$ UNITY, PROB-W1D6, DR-MT, DURATION-D6, FREQ-L2, NRAC200, /PROB-1HFAILEDL2, CCW-MDP-FS-CCP1A

$18893.9 \quad 0.0 \quad 1.689 E-008$ UNITY, DCP-BAT-LP-BAT1B, FREQ-RHR3, ACP-BCH-MA-UPSB1, ACP-BCH-MA-UPSB2, PROB-W1D6, DR-MT, DURATION-D6

$18993.9 \quad 0.0 \quad 1.682 E-008$ UNITY, ACP-INV-NO-UPSA2, MSS-AOV-MA-101B, PROB-W2D6, DR-MT, DURATION-D6, FREQ-L2, NRAC262, PROB-1HFAILEDL2

$19094.0 \quad 0.0 \quad 1.682 E-008$ UNITY, ACP-INV-NO-UPSA2, MSS-AOV-MA-101A, PROB-W2D6, DR-MT, DURATION-D6, FREQ-L2, NRAC262, PROB-1HFAILEDL2

$19194.1 \quad 0.0 \quad$ 1.675E-008 UNITY, ACP-BAC-ST-4KV1H, ACP-INV-NO-UPSA2, AFW-MDP-MA-FW3B, PROB-RHR2A, DR-MT, PROB-W2D6A 
10 Accident Sequence Quantification

Table 10-49 (continued)

Family->RHRMODEL

Mincut Upper Bound -> 2.011E-005

End State $->C D$

This Partition $->$ 2.011E-005

Cut \% \% Cut

No. Total Set Frequency

Cut Sets

$19294.20 .0 \quad 1.666 \mathrm{E}-008$ UNITY, REFUEL, DURATION-R6, CCW-LF-RHE2A, PZR-SV-REMOVEDW3, PROB-W3R6, FREQ-L2, NRAC346, /PROB-1HFAILEDL2, 2EH1L2

$19394.3 \quad 0.0 \quad 1.629 \mathrm{E}-008$ UNITY, ACP-BAC-ST-4KV1H, ACP-INV-NO-UPSA2, LOOPISOLATED2R6, REFUEL, PROB-RHR2A, /PZR-SV-REMOVEDW2, PROB-W2R6A

$19494.4 \quad 0.0 \quad 1.627 E-008$ UNITY, PROB-RHR2A, RWT-TNK-LF-RWST, DR-MT, PROB-W1D6A

$19594.4 \quad 0.0$ 1.598E-008 UNITY, PROB-W1D6, DR-MT, DURATION-D6, D-VBW1-XHE, FREQ-VB

19694.50 .0 1.575E-008 UNITY, PROB-W3D6, DR-MT, DURATION-D6, FREQ-B1, NRAC346, A-B1W3-XHE-2CH-8

$19794.6 \quad 0.0$ 1.558E-008 UNITY, SGB-DRAINED-R, CCW-LF-RHE2B, PROB-W2D6, DR-MT, DURATION-D6, H-4KV-REC-W2, FREQ-4KV

19894.70 .0 1.558E-008 UNITY, SGA-DRAINED-R, CCW-LF-RHE2B, PROB-W2D6, DR-MT, DURATION-D6, H-4KV-REC-W2, FREQ-4KV

$19994.7 \quad 0.0 \quad 1.533 E-008$ UNITY, REFUEL, LPR-MOV-FT-1862B, DURATION-R6, FREQ-RHR3, PROB-W1R6, LOOPISOLATED1R6, /PZR-SV-REMOVEDW1

$20094.8 \quad 0.0 \quad 1.511 E-008$ UNITY, ACP-BAC-ST-1H1, ACP-INV-NO-UPSA2, LOOPISOLATED2R6, CPC-MDP-MA-SW10B, REFUEL, PROB-RHR2A, /PZR-SV-REMOVEDW2, PROB-W2R6A

$20194.90 .0 \quad 1.501 E-008$ UNITY, REFUEL, DURATION-R6, PROB-W1R6, /PZR-SV-REMOVEDW1, FREQ-B1, NRAC200

$20295.0 \quad 0.0 \quad$ 1.482E-008 UNITY, ACP-BAC-ST-4KV1H, ACP-INV-NO-UPSA2, AFW-MDP-MA-FW3B, REFUEL, DURATION-R6, /PZR-SV-REMOVEDW2, PROB-W2R6, FREQ-SI

$20395.0 \quad 0.0 \quad 1.464 E-008$ UNITY, LPI-CKV-FT-CV50, FREQ-RHR3, PROB-W1D6, DR-MT, DURATION-D6

$20495.1 \quad 0.0 \quad$ 1.464E-008 UNITY, LPR-CKV-FT-CV47, FREQ-RHR3, PROB-W1D6, DR-MT, DURATION-D6

$20595.2 \quad 0.0 \quad$ 1.457E-008 UNITY, SAS-CPS-FR-1SAC1, IAS-CPS-FS-IAC-1, PROB-W1D6, LPR-CCF-PG-SUMP1, DR-MT, DURATION-D6, FREQ-SI

$20695.3 \quad 0.0 \quad$ 1.457E-008 UNITY, SAS-CPS-FR-2SAC1, IAS-CPS-FS-IAC-1, PROB-W1D6, LPR-CCF-PG-SUMP1, DR-MT, DURATION-D6, FREQ-SI

$20795.3 \quad 0.0$ 1.444E-008 UNITY, AFW-MDP-MA-FW3B, REFUEL, DURATION-R6, /PZR-SV-REMOVEDW2, PROB-W2R6, FREQ-L2, NRAC262, PROB-1HFAILEDL2, A-L2W2-XHE-R-4 
Table 10-49 (continued)

Family->RHRMODEL

Mincut Upper Bound -> 2.011E-005

Cut \% \% Cut

No. Total Set Frequency
End State $->C D$

This Partition $->$ 2.011E-005

$20895.4 \quad 0.0 \quad 1.430$ E-008 UNITY, ACP-BAC-ST-4KV1H, AFW-MDP-MA-FW3B, REFUEL, DURATION-R6, FREQ-RHR3, /PZR-SV-REMOVEDW2, PROB-W2R6

$20995.5 \quad 0.0 \quad$ 1.411E-008 UNITY, CON-VFC-RP-COREM, OSR-TRA-MA, ISR-TRA-MA, PROB-W1D6, DR-MT, DURATION-D6, H-SI-REC-W1, FREQ-SI, A-SIW1-XHE-R-12

$21095.5 \quad 0.0 \quad 1.410 \mathrm{E}-008$ UNITY, LPR-MOV-FT-1862B, PROB-RHR2A, RHR-CCF-FS-MDPAB, DR-MT, PROB-W1D6A

$21195.6 \quad 0.0 \quad 1.399 E-008$ UNITY, SAS-CPS-FR-1SAC1, IAS-CPS-FS-IAC-1, PROB-W2D6, DR-MT, DURATION-D6, H-4KV-REC-W2, FREQ-4KV

$21295.7 \quad 0.0 \quad 1.399 E-008$ UNITY, SAS-CPS-FR-2SAC1, IAS-CPS-FS-IAC-1, PROB-W2D6, DR-MT, DURATION-D6, H-4KV-REC-W2, FREQ-4KV

$21395.8 \quad 0.0 \quad$ 1.395E-008 UNITY, LOSP, OEP-DGN-FS-DG01, PROB-W1D6, DR-MT, DURATION-D6, FREQ-SI

$21495.8 \quad 0.0 \quad 1.395 E-008$ UNITY, LOSP, OEP-DGN-FS-DG03, PROB-W1D6, DR-MT, DURATION-D6, FREQ-SI

$21595.9 \quad 0.0 \quad$ 1.383E-008 UNITY, AFW-MDP-MA-FW3B, DCP-BAT-LP-BAT1A, PROB-W2D6, DR-MT, DURATION-D6, H-4KV-REC-W2, FREQ-4KV

$21696.0 \quad 0.0 \quad 1.383 E-008$ UNITY, AFW-MDP-MA-FW3B, RHR-MDP-FR-B24HR, PROB-W2D6, DR-MT, DURATION-D6, H-4KV-REC-W2, FREQ-4KV

$21796.0 \quad 0.0 \quad 1.383 E-008$ UNITY, AFW-MDP-MA-FW3B, CCW-MDP-FR-CCP1B, PROB-W2D6, DR-MT, DURATION-D6, H-4KV-REC-W2, FREQ-4KV

$21896.1 \quad 0.0 \quad 1.366 \mathrm{E}-008$ UNITY, LPI-MDP-FS-SI1B, PROB-W1D6, DR-MT, DURATION-D6, FREQ-SI, A-SIW1-XHE-R-3

$21996.20 .0 \quad$ 1.366E-008 UNITY, LPR-MOV-FT-1860B, PROB-W1D6, DR-MT, DURATION-D6, FREQ-SI, A-SIW1-XHE-R-3

$22096.2 \quad 0.0 \quad 1.366 \mathrm{E}-008$ UNITY, ACP-BAC-ST-4KV1H, ACP-INV-NO-UPSA2, PROB-W1D6, DR-MT, DURATION-D6, FREQ-SI

$22196.3 \quad 0.0 \quad 1.366$ E-008 UNITY, ACP-BAC-ST-1J1-2, ACP-INV-NO-UPSB1, PROB-W1D6, DR-MT, DURATION-D6, FREQ-SI

$22296.4 \quad 0.0 \quad 1.366 \mathrm{E}-0.08$ UNITY, ACP-BAC-ST-4KV1J, ACP-INV-NO-UPSB1, PROB-W1D6, DR-MT, DURATION-D6, FREQ-SI

$22396.4 \quad 0.0 \quad 1.366 \mathrm{E}-008$ UNITY, ACP-BAC-ST-1J1, ACP-INV-NO-UPSB1, PROB-W1D6, DR-MT, DURATION-D6, FREQ-SI 
10 Accident Sequence Quantification

Table 10-49 (continued)

Family->RHRMODEL

Mincut Upper Bound -> 2.011E-005

End State $->C D$

This Partition $\rightarrow>$ 2.011E-005

Cut \% \% Cut

No. Total Set Frequency Cut Sets

\begin{tabular}{|c|c|c|c|}
\hline & 96.5 & 0.0 & $\begin{array}{l}\text { 1.363E-008 UNITY, ACP-INV-NO-UPSA2, AFW-MDP-MA-FW3B, } \\
\text { PROB-W2D6, DR-MT, DURATION-D6, FREQ-L3, NRAC262, } \\
\text { PROB-1HFAILEDL3 }\end{array}$ \\
\hline 225 & 96.6 & 0.0 & $\begin{array}{l}\text { 1.341E-008 UNITY, REFUEL, DURATION-R6, PZR-SV-REMOVEDW3, } \\
\text { PROB-W3R6, FREQ-RHR5, D-R5W3-XHE }\end{array}$ \\
\hline 226 & 96.6 & 0.0 & $\begin{array}{l}\text { 1.335E-008 UNITY, REFUEL, DURATION-R6, PZR-SV-REMOVEDW3, } \\
\text { PROB-W3R6, FREQ-SR, D-SRW3-XHE }\end{array}$ \\
\hline 227 & 96.7 & 0.0 & $\begin{array}{l}\text { 1.330E-008 UNITY, AFW-MDP-MA-FW3B, RHR-MDP-FS-RHR1B, } \\
\text { PROB-W2D6, DR-MT, DURATION-D6, FREQ-L2, NRAC262, } \\
\text { PROB-1HFAILEDL2 }\end{array}$ \\
\hline 228 & 96.8 & 0.0 & $\begin{array}{l}\text { 1.330E-008 UNITY, AFW-MDP-MA-FW3B, CCW-MDP-FS-CCP1B, } \\
\text { PROB-W2D6, DR-MT, DURATION-D6, FREQ-L2, NRAC262, } \\
\text { PROB-1HFAILEDL2 }\end{array}$ \\
\hline 229 & 96.8 & 0.0 & $\begin{array}{l}\text { 1.328E-008 UNITY, REFUEL, DURATION-R6, PZR-SV-REMOVEDW3, } \\
\text { PROB-W3R6, FREQ-4KV, D-4KW3-XHE }\end{array}$ \\
\hline 230 & 96.9 & 0.0 & $\begin{array}{l}\text { 1.318E-008 UNITY, DCP-BDC-ST-BUS1B, FREQ-RHR3, PROB-W1D6, } \\
\text { DR-MT, DURATION-D6 }\end{array}$ \\
\hline 231 & 97.0 & 0.0 & $\begin{array}{l}\text { 1.318E-008 UNITY, ACP-BAC-ST-1J1, FREQ-RHR3, PROB-W1D6, } \\
\text { DR-MT, DURATION-D6 }\end{array}$ \\
\hline 232 & 97.0 & 0.0 & $\begin{array}{l}\text { 1.318E-008 UNITY, ACP-BAC-ST-4KV1J, FREQ-RHR3, PROB-W1D6, } \\
\text { DR-MT, DURATION-D6 }\end{array}$ \\
\hline 233 & 97.1 & 0.0 & $\begin{array}{l}\text { 1.318E-008 UNITY, ACP-BAC-ST-1J1-2, FREQ-RHR3, PROB-W1D6, } \\
\text { DR-MT, DURATION-D6 }\end{array}$ \\
\hline 234 & 97.2 & 0.0 & $\begin{array}{l}\text { 1.318E-008 UNITY, ACP-BAC-ST-4KV1H, FREQ-RHR3, PROB-W1D6, } \\
\text { DR-MT, DURATION-D6 }\end{array}$ \\
\hline 235 & 97.2 & 0.0 & $\begin{array}{l}\text { 1.318E-008 UNITY, ACP-BAC-ST-4801J, FREQ-RHR3, PROB-W1D6, } \\
\text { DR-MT, DURATION-D6 }\end{array}$ \\
\hline 236 & 97.3 & 0.0 & $\begin{array}{l}\text { 1.313E-008 UNITY, CCW-LF-RHE2A, CCW-LF-RHE2B, PROB-W1D6, } \\
\text { LPR-CCF-PG-SUMP1, DR-MT, DURATION-D6, FREQ-SI }\end{array}$ \\
\hline 237 & 97.4 & 0.0 & $\begin{array}{l}\text { 1.306E-008 UNITY, REFUEL, DURATION-R6, /PZR-SV-REMOVEDW3, } \\
\text { PROB-W3R6, FREQ-L1, D-L1W3-XHE }\end{array}$ \\
\hline 238 & 97.4 & 0.0 & $\begin{array}{l}\text { 1.293E-008 UNITY, DCP-BAT-LP-BAT1B, PROB-RHR2A, } \\
\text { CCW-LF-RHE2A, ACP-BCH-MA-UPSB1, } \\
\text { ACP-BCH-MA-UPSB2, DR-MT, PROB-W1D6A }\end{array}$ \\
\hline 239 & 97.5 & 0.0 & $\begin{array}{l}\text { 1.267E-008 UNITY, ACP-BAC-ST-1H1, ACP-INV-NO-UPSA2, } \\
\text { CPC-MDP-MA-SW10B, PROB-W1D6, DR-MT, DURATION-D6, } \\
\text { FREQ-SI }\end{array}$ \\
\hline 240 & 97.5 & 0.0 & $\begin{array}{l}\text { 1.248E-008 UNITY, ACP-BAC-ST-4KV1H, AFW-MDP-MA-FW3B, } \\
\text { CCW-LF-RHE2B, PROB-W2D6, DR-MT, DURATION-D6, } \\
\text { FREQ-SI }\end{array}$ \\
\hline
\end{tabular}


Table 10-49 (continued)

Family-> RHRMODEL

Mincut Upper Bound -> 2.011E-005
End State - $>$ CD

This Partition -> 2.011E-005

Cut \% \% Cut

No. Total Set Frequency Cut Sets

$24197.6 \quad 0.0 \quad 1.242 E-008$ UNITY, DCP-BAT-LP-BAT1B, FREQ-CCW, ACP-BCH-MA-UPSB1, ACP-BCH-MA-UPSB2, H-CCW-REC-W1, PROB-W1D6, DR-MT, DURATION-D6

$24297.7 \quad 0.0 \quad 1.227 \mathrm{E}-008$ UNITY, ACP-BAC-ST-4KV1H, ACP-INV-NO-UPSA2, AFW-MDP-MA-FW3B, REFUEL, PROB-RHR2A, /PZR-SV-REMOVEDW2, PROB-W2R6A

$24397.7 \quad 0.0 \quad 1.222 E-008$ UNITY, ACP-BAC-ST-1H1, CPC-MDP-MA-SW10B, FREQ-RHR3, PROB-W1D6, DR-MT, DURATION-D6

$24497.8 \quad 0.0 \quad 1.222 E-008$ UNITY, LOOPISOLATED2R6, REFUEL, PROB-RHR2A, RWT-TNK-LF-RWST, /PZR-SV-REMOVEDW2, PROB-W2R6A

$24597.9 \quad 0.0 \quad 1.221 E-008$ UNITY, REFUEL, DURATION-R6, PROB-W1R6, /PZR-SV-REMOVEDW1, FREQ-L1, D-L1W1-XHE

$24697.9 \quad 0.0 \quad 1.203 E-008$ UNITY, LPR-MOV-FT-1862B, PROB-RHR2A, SAS-CPS-FR-1SAC1, IAS-CPS-FS-IAC-1, DR-MT, PROB-W1D6A

$24798.0 \quad 0.0 \quad 1.203 E-008$ UNITY, LPR-MOV-FT-1862B, PROB-RHR2A, SAS-CPS-FR-2SAC1, IAS-CPS-FS-IAC-1, DR-MT, PROB-W1D6A

$248 \quad 98.0 \quad 0.0 \quad 1.195 E-008$ UNITY, LPI-MDP-FS-SI1B, RHR-MDP-FS-RHR1B, PROB-W1D6, DR-MT, DURATION-D6, H-SI-REC-W1, FREQ-SI

$24998.1 \quad 0.0$ 1.195E-008 UNITY, LPR-MOV-FT-1860B, RHR-MDP-FS-RHR1B, PROB-W1D6, DR-MT, DURATION-D6, H-SI-REC-W1, FREQ-SI

$25098.2 \quad 0.0 \quad$ 1.171E-008 UNITY, ACP-INV-NO-UPSB1, MSS-AOV-FC-101B, PROB-W3D6, DR-MT, DURATION-D6, FREQ-L2, NRAC346, /PROB-1HFAILEDL2, 2EH1L2

$25198.2 \quad 0.0 \quad 1.171 \mathrm{E}-008$ UNITY, ACP-INV-NO-UPSB1, MSS-AOV-FC-101A, PROB-W3D6, DR-MT, DURATION-D6, FREQ-L2, NRAC346, /PROB-1HFAILEDL2, 2EH1L2

$25298.3 \quad 0.0 \quad 1.139 E-008$ UNITY, RHR-ASF-PG-1605, PROB-W1D6, LPR-CCF-PG-SUMP1, DR-MT, DURATION-D6, FREQ-SI

$25398.3 \quad 0.0 \quad 1.129 E-008$ UNITY, PROB-W1D6, DR-MT, DURATION-D6, A-SIW1-XHE-C-18, H-SI-REC-W1, FREQ-SI, A-SIW1-XHE-R-12

$25498.4 \quad 0.0 \quad$ 1.128E-008 UNITY, REFUEL, FREQ-CCW, LPR-MOV-FT-1862B, DURATION-R6, H-CCW-REC-W1, PROB-W1R6, LOOPISOLATED1R6, /PZR-SV-REMOVEDW1

$25598.4 \quad 0.0 \quad 1.120$ E-008 UNITY, HPR-MDP-FR-A18HR, OSR-TRA-MA, ISR-TRA-MA, FREQ-RHR3, PROB-W1D6, DR-MT, DURATION-D6 
10 Accident Sequence Quantification

Table 10-49 (continued)

Family->RHRMODEL

Mincut Upper Bound -> 2.011E-005

Cut \% \% Cut

No. Total Set Frequency Cut Sets

$25698.50 .0 \quad 1.115 E-008$ UNITY, CCW-LF-RHE2B, PROB-W1D6, LPR-CCF-PG-SUMP1, DR-MT, DURATION-D6, H-VB-REC-W1, FREQ-VB

$25798.5 \quad 0.0 \quad 1.112 E-008$ UNITY, LPI-CCF-FS-SI1AB, CCW-LF-RHE2B, PROB-W1D6, DR-MT, DURATION-D6, H-SI-REC-W1, FREQ-SI

$25898.6 \quad 0.0 \quad$ 1.110E-008 UNITY, REFUEL, DURATION-R6, /PZR-SV-REMOVEDW2, PROB-W2R6, D-VBW2-XHE, FREQ-VB

$25998.7 \quad 0.0 \quad 1.093 E-008$ UNITY, ACP-INV-NO-UPSA2, MSS-AOV-FC-101A, MSS-NRV-MA-101A, PROB-W2D6, DR-MT, DURATION-D6, H-4KV-REC-W2, FREQ-4KV

$26098.7 \quad 0.0 \quad 1.093 E-008$ UNITY, ACP-INV-NO-UPSA2, MSS-AOV-FC-101B, MSS-NRV-MA-101B, PROB-W2D6, DR-MT, DURATION-D6, H-4KV-REC-W2, FREQ-4KV

26198.80 .0 1.092E-008 UNITY, PROB-W4D6, DR-MT, DURATION-D6, FREQ-L1, D-L1W4-XHE

$26298.8 \quad 0.0 \quad 1.090 \mathrm{E}-008$ UNITY, ACP-INV-NO-UPSA2, REFUEL, DURATION-R6, PROB-W1R6, LOOPISOLATED1R6, /PZR-SV-REMOVEDW1, H-4KV-REC-W1, FREQ-4KV

26398.90 .0 1.084E-008 UNITY, LPR-MOV-FT-1862B, PROB-RHR2A, CCW-LF-RHE2A, CCW-LF-RHE2B, DR-MT, PROB-W1D6A

26498.90 .0 1.077E-008 UNITY, FREQ-CCW, LPR-CKV-FT-CV47, H-CCW-REC-W1, PROB-W1D6, DR-MT, DURATION-D6

$26599.0 \quad 0.0 \quad 1.077 E-008$ UNITY, LPI-CKV-FT-CV50, FREQ-CCW, H-CCW-REC-W1, PROB-W1D6, DR-MT, DURATION-D6

$26699.0 \quad 0.0 \quad 1.071 E-008$ UNITY, ACP-BAC-ST-4KV1H, AFW-MDP-MA-FW3B, FREQ-CCW, H-CCW-REC-W2, PROB-W2D6, DR-MT, DURATION-D6

$26799.10 .0 \quad$ 1.071E-008 UNITY, REFUEL, PROB-RHR2A, PZR-SV-REMOVEDW3, D-RAW3-XHE, PROB-W3R6A

$26899.1 \quad 0.0 \quad$ 1.070E-008 UNITY, REFUEL, /PZR-SV-REMOVEDW4, PROB-W4R10, FRAC-POS10, DURATION-R10, D-SIW4-XHE, FREQ-SI

$26999.20 .0 \quad 1.065 E-008$ UNITY, LPI-MDP-FS-SI1B, PROB-W1D6, DR-MT, DURATION-D6, FREQ-L1, A-L1W1-XHE-R-4

$27099.20 .0 \quad$ 1.065E-008 UNITY, LPR-MOV-FT-1860B, PROB-W1D6, DR-MT,

DURATION-D6, FREQ-L1, A-L1W1-XHE-R-4

$27199.3 \quad 0.0 \quad 1.055 E-008$ UNITY, LPI-MDP-FS-SI1B, CCW-LF-RHE2B, PROB-W1D6, FREQ-RHR4, DR-MT, DURATION-D6

$27299.3 \quad 0.0 \quad 1.055 E-008$ UNITY, LPR-MOV-FT-1860B, CCW-LF-RHE2B, PROB-W1D6, FREQ-RHR4, DR-MT, DURATION-D6 
Table 10-49 (continued)

Family-> RHRMODEL

Mincut Upper Bound -> 2.011E-005
End State $->C D$

This Partition $->$ 2.011E-005

Cut \% \% Cut

No. Total Set Frequency

Cut Sets

$27399.4 \quad 0.0 \quad 1.044 E-008$ UNITY, ACP-INV-NO-UPSB1, LOOPISOLATED2R6, REFUEL, DURATION-R6, /PZR-SV-REMOVEDW2, PROB-W2R6, FREQ-L3, NRAC262, /PROB-1HFAILEDL3

$27499.5 \quad 0.0 \quad 1.039 \mathrm{E}-008$ UNITY, LOSP, OEP-DGN-FS-DG01, PROB-W2D6, FREQ-RHR5, DR-MT, DURATION-D6

$27599.50 .0 \quad 1.030 E-008$ UNITY, LOSP, OEP-DGN-FS-DG01, PROB-W2D6, DR-MT, DURATION-D6, FREQ-4KV

$27699.60 .0 \quad$ 1.028E-008 UNITY, LPR-MOV-FT-1862B, PROB-W1D6, DR-MT, DURATION-D6, H-VB-REC-W1, FREQ-VB, A-VBW1-XHE-R-12

$27799.6 \quad 0.0 \quad 1.014 E-008$ UNITY, CCW-MDP-FR-CCP1B, LOOPISOLATED2R6, REFUEL, DURATION-R6, /PZR-SV-REMOVEDW2, PROB-W2R6, H-4KV-REC-W2, FREQ-4KV

$27899.7 \quad 0.0 \quad 1.014 E-008$ UNITY, LOOPISOLATED2R6, REFUEL, RHR-MDP-FR-B24HR, DURATION-R6, /PZR-SV-REMOVEDW2, PROB-W2R6, H-4KV-REC-W2, FREQ-4KV

$27999.7 \quad 0.0 \quad 1.014 E-008$ UNITY, LOOPISOLATED2R6, DCP-BAT-LP-BAT1A, REFUEL, DURATION-R6, /PZR-SV-REMOVEDW2, PROB-W2R6, H-4KV-REC-W2, FREQ-4KV

$28099.8 \quad 0.0 \quad 1.009 E-008$ UNITY, DCP-BDC-ST-BUS1B, PROB-RHR2A, CCW-LF-RHE2A, DR-MT, PROB-W1D6A

$28199.8 \quad 0.0 \quad 1.009 E-008$ UNITY, ACP-BAC-ST-4KV1H, PROB-RHR2A, CCW-LF-RHE2B, DR-MT, PROB-W1D6A

$28299.90 .0 \quad 1.009 \mathrm{E}-008$ UNITY, ACP-BAC-ST-4KV1J, PROB-RHR2A, CCW-LF-RHE2A, DR-MT, PROB-W1D6A

$28399.90 .0 \quad 1.007 E-008$ UNITY, LOSP, PROB-RHR2A, DR-MT, PROB-W1D6A, LPR-CCF-PG-SUMP1

$284100.0 \quad 0.0 \quad 1.000 \mathrm{E}-008 \quad$ UNITY, ACP-INV-NO-UPSB1, REFUEL, /PZR-SV-REMOVEDW4, PROB-W4R10, FRAC-POS10, DURATION-R10, FREQ-L3, NRAC455, /PROB-1HFAILEDL3 
Table 10-50

Dominant Core Damage Cutsets After Recovery Actions

Family $>$ RHRMODEL

Mincut Upper Bound -> 3.466E-006
End State $->C D$

This Partition $\rightarrow$ 3.466E-006

Cut \% \% Cut

No. Total Set Frequency

Cut Sets

16.36 .3 2.203E-007 UNITY, PROB-W2D6, DR-MT, DURATION-D6, FREQ-L1, D-L1W2-XHE, INAC262

212.35 .9 2.074E-007 UNITY, PROB-W3D6, DR-MT, DURATION-D6, FREQ-L1, D-L1W3-XHE, /NRAC346

317.24 .9 1.697E-007 UNITY, PROB-W2D6, DR-MT, DURATION-D6, D-SIW2-XHE, FREQ-SI

$421.4 \quad 4.2$ 1.464E-007 UNITY, FREQ-RHR3, PROB-W1D6, DR-MT, DURATION-D6 LPR-CCF-PG-SUMP1, R-A3W1D6-XHE-C

$525.6 \quad 4.2$ 1.460E-007 UNITY, PROB-W3D6, DR-MT, DURATION-D6, D-SIW3-XHE, FREQ-SI

629.23 .5 1.237E-007 UNITY, PROB-W1D6, DR-MT, DURATION-D6, FREQ-L1, D-L1W1-XHE, /NRAC200

732.73 .5 1.216E-007 UNITY, REFUEL, DURATION-R6, /PZR-SV-REMOVEDW2, PROB-W2R6, FREQ-L1, D-L1W2-XHE, NRAC262

$835.8 \quad 3.1 \quad$ 1.077E-007 UNITY, FREQ-CCW, H-CCW-REC-W1, PROB-W1D6, LPR-CCF-PG-SUMP1, DR-MT, DURATION-D6, R-W1D6-XHE-C-A3

$938.5 \quad 2.7$ 9.522E-008 UNITY, REFUEL, DURATION-R6, PZR-SV-REMOVEDW3, PROB-W3R6, FREQ-L1, D-L1W3-XHE, /NRAC346

$10 \quad 41.3 \quad 2.7$ 9.370E-008 UNITY, REFUEL, DURATION-R6, /PZR-SV-REMOVEDW2, i PROB-W2R6, D-SIW2-XHE, FREQ-SI

1143.92 .6 9.040E-008 UNITY, PROB-RHR2A, DR-MT, D-RAW1-XHE, PROB-W1D6A

$1246.42 .5 \quad$ 8.729E-008 UNITY, PROB-W1D6, DR-MT, DURATION-D6, D-SIW1-XHE, FREQ-SI

$1348.62 .27 .739 \mathrm{E}-008$ UNITY, PROB-W2D6, DR-MT, DURATION-D6, FREQ-L1, NRAC262, D-L1W2-XHE

$1450.72 .1 \quad 7.380 E-008$ UNITY, PROB-W1D6, DR-MT, DURATION-D6, FREQ-B1, NRAC200, A-B1W1-XHE-2CH-8

1552.71 .9 6.703E-008 UNITY, REFUEL, DURATION-R6, PZR-SV-REMOVEDW3, PROB-W3R6, D-SIW3-XHE, FREQ-SI

1654.41 .6 5.822E-008 UNITY, PROB-W1D6, DR-MT, DURATION-D6, FREQ-L1, NRAC200, D-L1W1-XHE

$1755.9 \quad 1.5 \quad 5.413 E-008$ UNITY, ACP-INV-NO-UPSA2, PROB-W1D6, DR-MT, DURATION-D6, H-4KV-REC-W1, FREQ-4KV, R-W1D6-XHE-C-A3

$1857.5 \quad 1.5 \quad 5.383 E-008$ UNITY, PROB-W2D6, DR-MT, DURATION-D6, FREQ-L2, D-L2W2-XHE, /NRAC262

$1958.91 .4 \quad 5.068 \mathrm{E}-008$ UNITY, PRÖB-W3D6, DR-MT, DURATION-D6, FREQ-L2, D-L2W3-XHE, /NRAC346

2060.31 .4 4.864E-008 UNITY, PROB-W3D6, DR-MT, DURATION-D6, FREQ-L1, NRAC346, D-L1W3-XHE 
Table 10-50 (continued)

10 Accident Sequence Quantification

$2161.7 \quad 1.3$ 4.746E-008 UNITY, PROB-W2D6, DR-MT, DURATION-D6, FREQ-B2, NRAC262, R-B2W2-2

$2263.0 \quad 1.3 \quad$ 4.501E-008 UNITY, PROB-RHR2A, DR-MT, D-RAW2-XHE, PROB-W2D6A

$2364.3 \quad 1.2$ 4.393E-008 UNITY, LPI-MDP-FS-SI1B, FREQ-RHR3, PROB-W1D6, DR-MT, DURATION-D6, R-A3W1D6-XHE-C

$2465.5 \quad 1.2 \quad$ 4.273E-008 UNITY, REFUEL, DURATION-R6, /PZR-SV-REMOVEDW2, PROB-W2R6, FREQ-L1, NRAC262, D-L1W2-XHE

$2566.7 \quad 1.1 \quad$ 4.068E-008 UNITY, REFUEL, /PZR-SV-REMOVEDW4, PROB-W4R10, FRAC-POS10, DURATION-R10, FREQ-B2, NRAC455

$2667.8 \quad 1.1 \quad 3.912 E-008$ UNITY, REFUEL, /PZR-SV-REMOVEDW4, PROB-W4R10, FRAC-POS10, DURATION-R10, FREQ-L1, D-L1W4-XHE, NRAC455

$2768.8 \quad 1.0 \quad$ 3.628E-008 UNITY, PROB-W1D6, DR-MT, DURATION-D6, FREQ-B2, NRAC200

2869.80 .9 3.394E-008 UNITY, PROB-W2D6, FREQ-RHR5, DR-MT, DURATION-D6 D-R5W2-XHE

$2970.8 \quad 0.9 \quad 3.381 E-008$ UNITY, PROB-W2D6, DR-MT, DURATION-D6, FREQ-SR, D-SRW2-XHE

$3071.8 \quad 0.9 \quad 3.362 E-008$ UNITY, PROB-W2D6, DR-MT, DURATION-D6, FREQ-4KV, D-4KW2-XHE

$3172.7 \quad 0.9$ 3.297E-008 UNITY, REFUEL, PROB-RHR2A, /PZR-SV-REMOVEDW2, D-RAW2-XHE, PROB-W2R6A

$3273.7 \quad 0.9$ 3.274E-008 UNITY, PROB-W1D6, DR-MT, DURATION-D6, FREQ-L3, NRAC200, A-L3W1-XHE-CW-4

$33 \quad 74.6 \quad 0.9 \quad 3.231 E-008$ UNITY, FREQ-CCW, LPI-MDP-FS-SI1B, H-CCW-REC-W1, PROB-W1D6, DR-MT, DURATION-D6, R-W1D6-XHE-C-A3

$3475.5 \quad 0.8$ 2.972E-008 UNITY, REFUEL, DURATION-R6, /PZR-SV-REMOVEDW2, PROB-W2R6, FREQ-L2, D-L2W2-XHE, NRAC262

3576.30 .8 2.949E-008 UNITY, REFUEL, DURATION-R6, FREQ-RHR3, PROB-W1R6, LOOPISOLATED1R6, /PZR-SV-REMOVEDW1, LPR-CCF-PG-SUMP1

$3677.1 \quad 0.8 \quad 2.919 E-008$ UNITY, PROB-W3D6, FREQ-RHR5, DR-MT, DURATION-D6 D-R5W3-XHE

$37 \quad 78.0 \quad 0.8$ 2.912E-008 UNITY, PROB-W2D6, DR-MT, DURATION-D6, FREQ-B1, NRAC262, D-B1W2-XHE

$3878.8 \quad 0.8 \quad 2.908 E-008$ UNITY, PROB-W3D6, DR-MT, DURATION-D6, FREQ-SR, D-SRW3-XHE

3979.70 .8 2.892E-008 UNITY, PROB-W3D6, DR-MT, DURATION-D6, FREQ-4KV, D-4KW3-XHE

$40 \quad 80.4 \quad 0.7$ 2.620E-008 UNITY, REFUEL, DURATION-R6, /PZR-SV-REMOVEDW2, PROB-W2R6, FREQ-B2, NRAC262, R-B2W2-2

$4181.1 \quad 0.7 \quad 2.517 E-008$ UNITY, CCW-LF-RHE2B, PROB-W1D6, DR-MT, DURATION-D6, H-4KV-REC-W1, FREQ-4KV, R-W1D6-XHE-C-A3

$4281.9 \quad 0.7 \quad 2.471 E-008$ UNITY, CCW-LF-RHE2B, PROB-W1D6, LPR-CCF-PG-SUMP1, DR-MT, DURATION-D6, H-SI-REC-W1, FREQ-SI, R-W1D6-XHE-C-A3 
10 Accident Sequence Quantification

Table 10-50 (continued)

4382.50 .6 2.327E-008 UNITY, REFUEL, DURATION-R6, PZR-SV-REMOVEDW3, PROB-W3R6, FREQ-L2, D-L2W3-XHE, INRAC346

44 \$3.2 0.6 2.234E-008 UNITY, REFUEL, DURATION-R6, PZR-SV-REMOVEDW3, PROB-W3R6, FREQ-L1, NRAC346, D-L1W3-XHE

$45 \quad 83.8 \quad 0.6 \quad 2.169 E-008$ UNITY, REFUEL, FREQ-CCW, DURATION-R6, H-CCW-REC-W1, PROB-W1R6, LOOPISOLATED1R6, /PZR-SV-REMOVEDW1, LPR-CCF-PG-SUMP1

4684.40 .6 2.127E-008 UNITY, PROB-W3D6, DR-MT, DURATION-D6, FREQ-B2, NRAC346, R-B2W3-2

$4785.0 \quad 0.6$ 2.109E-008 UNITY, LOOPISOLATED2R6, REFUEL, DURATION-R6, FREQ-RHR3, /PZR-SV-REMOVEDW2, PROB-W2R6, A-R3W2-XHE-X, LPR-CCF-PG-SUMP2

$48 \quad 85.60 .6 \quad 2.082 E-008$ UNITY, PROB-RHR2A, DR-MT, D-RAW3-XHE, PROB-W3D6A

$4986.20 .5 \quad 2.010 E-008$ UNITY, PROB-W2D6, DR-MT, DURATION-D6, D-VBW2-XHE, FREQ-VB

$5086.7 \quad 0.5 \quad 1.891 E-008$ UNITY, PROB-W2D6, DR-MT, DURATION-D6, FREQ-L2, NRAC262, D-L2W2-XHE

$51 \quad 87.3 \quad 0.5 \quad 1.874 E-008$ UNITY, REFUEL, DURATION-R6, /PZR-SV-REMOVEDW2, PROB-W2R6, FREQ-RHR5, D-R5W2-XHE

$52 \quad 87.8 \quad 0.5$ 1.867E-008 UNITY, REFUEL, DURATION-R6, /PZR-SV-REMOVEDW2, PROB-W2R6, FREQ-SR, D-SRW2-XHE

$53 \quad 88.40 .5 \quad 1.856 E-008$ UNITY, REFUEL, DURATION-R6, /PZR-SV-REMOVEDW2, PROB-W2R6, FREQ-4KV, D-4KW2-XHE

$5488.9 \quad 0.5 \quad 1.830 \mathrm{E}-008$ UNITY, CON-VFC-RP-COREM, OSR-TRA-MA, ISR-TRA-MA, FREQ-RHR3, PROB-W1D6, DR-MT, DURATION-D6, R-A3W1D6-XHE-C

$5589.4 \quad 0.5 \quad 1.830$ E-008 UNITY, PROB-W3D6, DR-MT, DURATION-D6, FREQ-B1, NRAC346, D-B1W3-XHE

$5689.9 \quad 0.5 \quad 1.794 E-008$ UNITY, PROB-W1D6, DR-MT, DURATION-D6, FREQ-L2, D-L2W1-XHE, /NRAC200

$5790.4 \quad 0.5$ 1.746E-008 UNITY, PROB-W1D6, FREQ-RHR5, DR-MT, DURATION-D6, D-R5W1-XHE

$5890.9 \quad 0.5 \quad$ 1.729E-008 UNITY, PROB-W1D6, DR-MT, DURATION-D6, FREQ-4KV, D-4KW1-XHE

$5991.4 \quad 0.5 \quad$ 1.729E-008 UNITY, PROB-W3D6, DR-MT, DURATION-D6, D-VBW3-XHE, FREQ-VB

6091.90 .4 1.677E-008 UNITY, PROB-W1D6, DR-MT, DURATION-D6, FREQ-B1, NRAC200, A-B1W1-XHE-CW-8

$6192.40 .4 \quad 1.676 E-008$ UNITY, REFUEL, PZR-SV-REMOVEDW4, PROB-W4R10, FRAC-POS10, DURATION-R10, FREQ-L1, D-L1W4-XHE, INRAC455

6292.90 .4 1.608E-008 UNITY, REFUEL, DURATION-R6, /PZR-SV-REMOVEDW2, PROB-W2R6, FREQ-B1, NRAC262, D-B1W2-XHE

$63 \quad 93.3 \quad 0.4 \quad 1.598 E-008$ UNITY, PROB-W1D6, DR-MT, DURATION-D6, D-VBW1-XHE, FREQ-VB

$6493.8 \quad 0.4$ 1.532E-008 UNITY, DCP-BAT-LP-BAT1B, ACP-BCH-MA-UPSB1, ACP-BCH-MA-UPSB2, PROB-W1D6, DR-MT, DURATION-D6, 
Table 10-50 (continued)

10 Accident Sequence Quantification

H-SI-REC-W1, FREQ-SI, R-W1D6-XHE-C-A3

6594.20 .4 1.464E-008 UNITY, FREQ-RHR3, PROB-W1D6, A-R3W1-XHE-C-8, DR-MT, DURATION-D6, R-A3W1D6-XHE-C

$6694.60 .3 \quad 1.346 \mathrm{E}-008$ UNITY, CON-VFC-RP-COREM, FREQ-CCW, OSR-TRA-MA, ISR-TRA-MA, H-CCW-REC-W1, PROB-W1D6, DR-MT, DURATION-D6, R-W1D6-XHE-C-A3

$6795.0 \quad 0.3 \quad$ 1.341E-008 UNITY, REFUEL, DURATION-R6, PZR-SV-REMOVEDW3, PROB-W3R6, FREQ-RHR5, D-R5W3-XHE

$6895.3 \quad 0.3 \quad 1.335 E-008$ UNITY, REFUEL, DURATION-R6, PZR-SV-REMOVEDW3, PROB-W3R6, FREQ-SR, D-SRW3-XHE

$6995.7 \quad 0.3 \quad 1.328 E-008$ UNITY, REFUEL, DURATION-R6, PZR-SV-REMOVEDW3, PROB-W3R6, FREQ-4KV, D-4KW3-XHE

$7096.1 \quad 0.3 \quad$ 1.261E-008 UNITY, ACP-INV-NO-UPSA2, LOOPISOLATED2R6, REFUEL, DURATION-R6, /PZR-SV-REMOVEDW2, PROB-W2R6, H-4KV-REC-W2, FREQ-4KV, R-W2D6-XHE-C-A9

$7196.4 \quad 0.3 \quad 1.195 E-008$ UNITY, ACP-BAC-ST-4KV1J, PROB-W1D6, DR-MT, DURATION-D6, H-SI-REC-W1, FREQ-SI, R-W1D6-XHE-C-A3

$7296.8 \quad 0.3$ 1.195E-008 UNITY, DCP-BDC-ST-BUS1B, PROB-W1D6, DR-MT, DURATION-D6, H-SI-REC-W1, FREQ-SI, R-W1D6-XHE-C-A3

$7397.10 .3 \quad$ 1.189E-008 UNITY, PROB-W3D6, DR-MT, DURATION-D6, FREQ-L2, NRAC346, D-L2W3-XHE

$7497.5 \quad 0.3 \quad 1.150 E-008$ UNITY, PROB-W1D6, DR-MT, DURATION-D6, H-4KV-REC-W1, FREQ-4KV, A-4KW1-XHE-R-12, R-W1D6-XHE-C-A3

$7597.8 \quad 0.3 \quad$ 1.129E-008 UNITY, PROB-W1D6, LPR-CCF-PG-SUMP1, DR-MT, DURATION-D6, H-SI-REC-W1, FREQ-SI, A-SIW1-XHE-R-12, R-W1D6-XHE-C-A3

$7698.1 \quad 0.3 \quad$ 1.110E-008 UNITY, REFUEL, DURATION-R6, /PZR-SV-REMOVEDW2, PROB-W2R6, D-VBW2-XHE, FREQ-VB

$7798.4 \quad 0.3 \quad 1.090$ E-008 UNITY, ACP-INV-NO-UPSA2, REFUEL, DURATION-R6, PROB-W1R6, LOOPISOLATED1R6, /PZR-SV-REMOVEDW1, H-4KV-REC-W1, FREQ-4KV

$7898.7 \quad 0.3 \quad 1.077 E-008$ UNITY, FREQ-CCW, H-CCW-REC-W1, PROB-W1D6, A-CCW1-XHE-C-9, DR-MT, DURATION-D6, R-W1D6-XHE-C-A3

$7999.0 \quad 0.3 \quad$ 1.071E-008 UNITY, REFUEL, PROB-RHR2A, PZR-SV-REMOVEDW3, D-RAW3-XHE, PROB-W3R6A

$8099.3 \quad 0.3 \quad$ 1.070E-008 UNITY, REFUEL, /PZR-SV-REMOVEDW4, PROB-W4R10, FRAC-POS10, DURATION-R10, FREQ-SI, D-SIW4-XHE

8199.70 .3 1.058E-008 UNITY, REFUEL, DURATION-R6, /PZR-SV-REMOVEDW3, PROB-W3R6, FREQ-L1, D-L1W3-XHE, /NRAC346

$82100.0 \quad 0.3 \quad 1.044 E-008$ UNITY, REFUEL, DURATION-R6, /PZR-SV-REMOVEDW2, PROB-W2R6, FREQ-L2, NRAC262, D-L2W2-XHE 
Table 10-51

\begin{tabular}{|c|c|c|c|c|}
\hline \multicolumn{5}{|c|}{ Recovery Actions and Their Applicability to the Event Tree Sequences(Loss of RHR and Loss of Instrument Air) } \\
\hline Basic Event Name & Recovery Rules & $\begin{array}{l}\text { Calculation of Basic } \\
\text { Event Probability }\end{array}$ & Applicable Sequences & Notes \\
\hline R-A1W1D6-XHE-C & LPR-MOV-FT-1862B + LPR-CCF-FT-862AB & $\begin{array}{l}0.9 * 4.3 \mathrm{E}-03 * 0.1 \\
+0.1 * 0.1 \\
=1.04 \mathrm{E}-02\end{array}$ & $\begin{array}{l}\text { RAW1D6 \#4,\#7 } \\
\text { RBW1D6 \#4 \#7 } \\
\text { R3W1D6 \#3 } \\
\text { R4W1D6 \#4 } \\
\text { R5W1D6 \#4 } \\
\text { ARW1D6 \#5 }\end{array}$ & $\begin{array}{l}\text { Mnnuully close the MOV or wes } \\
\text { reflux cooling with } 2 \text { SGs } \\
\text { 1.All W1D6 sequences with failure } \\
\text { of recirculation(Those sequences } \\
\text { without failure of recirc will not } \\
\text { meet the rule) }\end{array}$ \\
\hline R-A2W1D6-XHE-C & LPR-MOV-FT-1860B + LPR-CCF-FT-860AB & SAME & $\begin{array}{l}\text { RAW1D6 \#4,\#7 } \\
\text { RBW1D6 \#4 \#7 } \\
\text { R3W1D6 \#3 } \\
\text { R4W1D6 \#4 } \\
\text { R5W1D6 \#4 } \\
\text { ARW1D6 \#5 }\end{array}$ & $\begin{array}{l}\text { Mnnually Open the MOV or use } \\
\text { reflux cooling with } 2 \text { SGs } \\
\text { 1.All W1D6 sequences with failure } \\
\text { of recirculation(Those sequences } \\
\text { without failure of recirc will not } \\
\text { meet the rule) }\end{array}$ \\
\hline R-A3W1D6-XHE-C & $\begin{array}{l}\text { All W1D6 cutsets except those meeting A1 or } \\
\text { A2. }\end{array}$ & 0.1 & $\begin{array}{l}\text { RAW1D6 *4, \#7 } \\
\text { RBW1D6 \#4 \#7 } \\
\text { R3W1D6 *3 } \\
\text { R4W1D6 \#4 } \\
\text { R5W1D6 \#4 } \\
\text { ARW1D6 \#5 }\end{array}$ & $\begin{array}{l}\text { Use roflux cooling with } 2 \text { SGs } \\
\text { 1.All W1D6 cutsets that do not meet } \\
\text { A1 or A2. }\end{array}$ \\
\hline R-A4W1D6-XHE-C & Covered by A3 & 0.1 & $\begin{array}{l}\text { RAW1D6 \#4,\#7 } \\
\text { RBW1D6 \#4 \#7 } \\
\text { R3W1D6 \#3 } \\
\text { R4W1D6 \#4 } \\
\text { R5W1D6 \#4 } \\
\text { ARW1D6 \#5 }\end{array}$ & $\begin{array}{l}\text { Use reftux cooling with } 2 \text { SGs } \\
\text { 1.All W1D6 sequences with failure } \\
\text { of recirculation. } \\
\text { 2. Covered by A3. }\end{array}$ \\
\hline R-A5W1D6-XHE-C & Covered by $\mathrm{A} 3$ & 0.1 & $\begin{array}{l}\text { RAW1D6 \#4,\#7 } \\
\text { RBW1D6 \#4 \#7 } \\
\text { R3W1D6 \#3 } \\
\text { R4W1D6 \#4 } \\
\text { R5W1D6 \#4 } \\
\text { ARW1D6 \#5 } \\
\end{array}$ & $\begin{array}{l}\text { Use rellux cooling with } 2 \text { SGs } \\
\text { 1.All W1D6 sequences with failure } \\
\text { of recirculation. } \\
\text { 2. Covered by A3. }\end{array}$ \\
\hline $\begin{array}{l}\text { R-A6W1D6-XHE- } \\
\text { C }\end{array}$ & Covered by $\mathbf{A} 3$ & 0.1 & $\begin{array}{l}\text { RAW1D6 \#4,\#7 } \\
\text { RBW1D6 \#4 \#7 } \\
\text { R3W1D6 \#3 } \\
\text { R4W1D6 \#4 } \\
\text { R5W1D6 \#4 } \\
\text { ARW1D6 \#5 }\end{array}$ & $\begin{array}{l}\text { Use reflux cooling with } 2 \text { SGs } \\
\text { 1.All W1D6 sequences with } \\
\text { failure of recirculation. } \\
\text { 2. Covered by A3. }\end{array}$ \\
\hline
\end{tabular}


Table 10-51 (continued)

\begin{tabular}{|c|c|c|c|c|}
\hline Basic Event Name & Recovery Rules & $\begin{array}{l}\text { Calculation of Basic } \\
\text { Event Probability }\end{array}$ & Applicable Sequences & Notes \\
\hline R-ATW2R6-XHE-C & 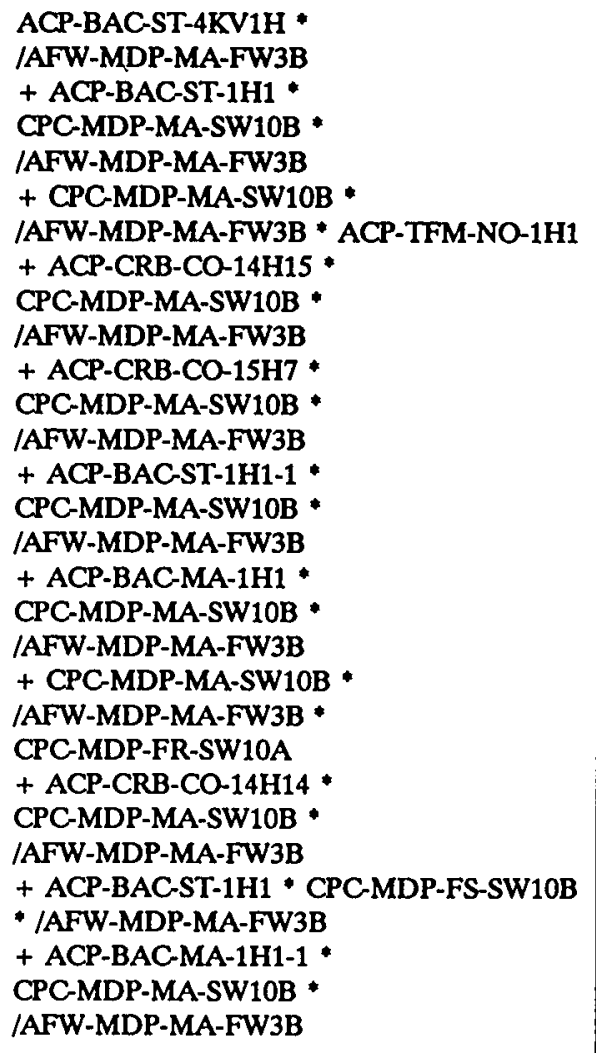 & $\begin{array}{l}3.2 \mathrm{E}-03+1.91 \mathrm{E}-02 \text { (U2 } \\
\text { charging) } \\
=2.23 \mathrm{E}-02\end{array}$ & $\begin{array}{l}\text { RAW2R6 \#4 \#9 } \\
\# 12 \# 17 \\
\text { RAW2D6 \#5 \#9 } \\
\text { RBW2R6 *4 \#9 \#12 } \\
\# 17 \\
\text { RBW2D6 \#5 \#9 } \\
\text { R3W2R6 \#3 \#8 } \\
\text { R3W2D6 \#4 } \\
\text { R4W2R6 \#4 \#9 } \\
\text { R4W2DD \#5 } \\
\text { R5W2R6 \#4 \#9 } \\
\text { R5W2D6 \#5 } \\
\text { ARW2R6 \#5 \#10 } \\
\text { ARW2D6 \#6 }\end{array}$ & $\begin{array}{l}\text { Use of U2 charging pamp and } \\
\text { RWST } \\
\text { 1.All W2 sequences with failure of } \\
\text { recirculation EXCEPT those covered } \\
\text { by E1 (AFW-MDP-MA-3B). } \\
\text { 2. The recovery action is possible } \\
\text { when unit } 1 \text { charging pumps or their } \\
\text { support system are not available. } \\
\text { 3. Use of unit } 2 \text { charging pump was } \\
\text { not taken credit in the logic model. }\end{array}$ \\
\hline
\end{tabular}

$z$
0
0
0
0
0
0
0
$\vdots$ 
Table 10-51 (continued)

\begin{tabular}{|c|c|c|c|c|}
\hline Basic Event Name & Recovery Rules & $\begin{array}{l}\text { Calculation of Basic } \\
\text { Event Probability }\end{array}$ & Applicable Sequences & Notes \\
\hline R-A8W1R6-XHE-C & $\begin{array}{l}\text { LPR-MOV-FT-1862B + LPR-MOV-FT-1850B } \\
\text { + LPR-MOV-CCF-862AB + LPR-CCF-FT- } \\
\text { 860AB }\end{array}$ & $\begin{array}{l}4.4 \mathrm{E}-03+0.1 \\
=1.00 \mathrm{E}-01\end{array}$ & $\begin{array}{l}\text { RAW1R6 \#4 \#9 } \\
\text { \#12 \#17 } \\
\text { RBW1R6 \#4 \#9 \#12 } \\
\text { \#17 } \\
\text { R3W1R6 \#3 \#8 } \\
\text { R4W1R6 \#4 \#9 } \\
\text { R5W1R6 \#4 \#9 } \\
\text { ARW1R6 \#5 } \\
\text { \#10RAW2R6 \#4 \#9 } \\
\text { \#12 \#17 } \\
\text { RAW2D6 \#5 \#9 } \\
\text { RBW2R6 \#4 \#9 \#12 } \\
\text { \#17 } \\
\text { RBW2D6 \#5 \#9 } \\
\text { R3W2R6 \#3 \#8 } \\
\text { R3W2D6 \#4 } \\
\text { R4W2R6 \#4 \#9 } \\
\text { R4W2D6 \#5 } \\
\text { R5W2R6 \#4 \#9 } \\
\text { R5W2D6 \#5 } \\
\text { ARW2R6 \#5 \#10 } \\
\text { ARW2D6 \#6 }\end{array}$ & $\begin{array}{l}\text { Manually open or close MOV. } \\
\text { 1.All W1R6,W2R6, W2D6 sequences } \\
\text { with failure of recirculation. }\end{array}$ \\
\hline $\begin{array}{l}\text { R-C1W1D6A-XHE- } \\
\text { R }\end{array}$ & $\begin{array}{l}\text { CPC-MDP-FR-SW10A * } \\
\text { CPC-MDP-MA-SW10B * LPI-MDP-FS-SI1B }\end{array}$ & $1 / 24=4.17 \mathrm{E}-2$ & $\begin{array}{l}\text { RAW1R6 \#14 \#18 } \\
\text { RAW1D6 \#8 } \\
\text { RAW2R6 \#14 \#18 } \\
\text { RAW2D6 \#10 } \\
\text { RAW3R6 \#10 \#12 } \\
\text { RAW3D6 \#8 } \\
\text { RAW3R10 \#10 \#12 } \\
\text { RAW4R6 \#11 \#14 } \\
\text { RAW4D6 \#8 } \\
\text { RAW4R10 \#11 \#14 } \\
\text { RBW1R6 \#14 \#18 } \\
\text { RBW1D6 \#8 } \\
\text { RBW2R6 \#14 \#18 } \\
\text { RBW2D6 \#10 } \\
\text { RBW3R6 \#10 \#12 } \\
\text { RBW3D6 \#8 } \\
\text { RBW3R10 \#10 \#12 } \\
\text { RBW4R6 \#10 \#12 } \\
\text { RBW4D6 \#8 } \\
\text { RBW4R10 \#10 \#12 }\end{array}$ & $\begin{array}{l}\text { Use more realistic mission time for } \\
\text { SW10A in providing makeup } \\
\text { 1.All RHR2A and RHR 2B } \\
\text { sequences with failure to makeup } \\
\text { and failure to feed and spill. }\end{array}$ \\
\hline
\end{tabular}


Table 10-51 (continued)

\begin{tabular}{|c|c|c|c|c|}
\hline Basic Event Name & $\begin{array}{c}\text { Recovery Rules } \\
\text {. }\end{array}$ & $\begin{array}{l}\text { Calculation of Basic } \\
\text { Event Probability }\end{array}$ & Applicable Sequences & Notes \\
\hline $\begin{array}{l}\text { R-C2W2D6A-XHE- } \\
\text { R }\end{array}$ & $\begin{array}{l}\text { CPC-MDP-FR-SW10A } \\
\text { CPC-MDP-MA-SW10B * LPI-CCF-FS-SI1AB }\end{array}$ & $1 / 24=4.17 \mathrm{E}-2$ & SAME & SAME \\
\hline $\begin{array}{l}\text { R-C2W3D6A-XHE- } \\
\text { R }\end{array}$ & covered by $\mathrm{Cl}$ or $\mathrm{C} 2$ & $1 / 24=4.17 \mathrm{E}-2$ & SAME & SAME \\
\hline $\begin{array}{l}\mathrm{R}-\mathrm{C} \text { W4D6A-XHE- } \\
\mathrm{R}\end{array}$ & covered by $\mathrm{Cl}$ or $\mathrm{C} 2$ & $1 / 24=4.17 \mathrm{E}-2$ & SAME & SAME \\
\hline R-D1W2R6-XHE-C & ISR-TRA-MA * OSR-TRA-MA & 3.2E-03 & $\begin{array}{l}\text { RAW2R6 \#4 \#9 } \\
\# 12 \text { \#17 } \\
\text { RAW2D6 \#5 \#9 } \\
\text { RBW2R6 \#4 \#9 \#12 } \\
\# 17 \\
\text { RBW2D6 \#5 \#9 } \\
\text { R3W2R6 \#3 \#8 } \\
\text { R3W2D6 \#4 } \\
\text { R4W2R6 \#4 \#9 } \\
\text { R4W2D6 \#5 } \\
\text { R5W2R6 \#4 \#9 } \\
\text { R5W2D6 \#5 } \\
\text { ARW2R6 \#5 \#10 } \\
\text { ARW2D6 \#6 }\end{array}$ & $\begin{array}{l}\text { Use of U2 charging pump and } \\
\text { RWST } \\
\text { 1. All W2 sequences with failure of } \\
\text { recirculation. } \\
\text { 2. This recovery action is covered by } \\
\text { A7 event, except the cutsets } \\
\text { involving maintenance of } \\
\text { recirculation spray trains. } \\
\text { 3.The only recovery rule entered } \\
\text { involves maintenance of recirculation } \\
\text { spray trains. }\end{array}$ \\
\hline
\end{tabular}


Table 10-51 (continued)

\begin{tabular}{|c|c|c|c|c|}
\hline Basic Event Name & Recovery Rules & $\begin{array}{l}\text { Calculation of Basic } \\
\text { Event Probability }\end{array}$ & Applicable Sequences & Notes \\
\hline R-E1W2D6-XHE-C & AFW-MDP-MA-FW3B & $\begin{array}{l}1 \mathrm{E}-04+7.33 \mathrm{E}-03(\mathrm{LSW} 1) \\
=7.43 \mathrm{E}-03\end{array}$ & $\begin{array}{l}\text { RAW1R6 \#4 \#9 } \\
\text { \#12 \#17 } \\
\text { RBW1R6 \#4 \#9 \#12 } \\
\text { \#17 } \\
\text { R3W1R6 \#3 \#8 } \\
\text { R4W1R6 \#4 \#9 } \\
\text { R5W1R6 \#4 \#9 } \\
\text { ARW1R6 \#5 } \\
\text { \#10RAW2R6 \#4 \#9 } \\
\text { \#12 \#17 } \\
\text { RAW2D6 \#5 \#9 } \\
\text { RBW2R6 \#4 \#9 \#12 } \\
\text { \#17 } \\
\text { RBW2D6 \#5 \#9 } \\
\text { R3W2R6 \#3 \#8 } \\
\text { R3W2D6 \#4 } \\
\text { R4W2R6 \#4 \#9 } \\
\text { R4W2D6 \#5 } \\
\text { R5W2R6 \#4 \#9 } \\
\text { R5W2D6 \#5 } \\
\text { ARW2R6 \#5 \#10 } \\
\text { ARW2D6 \#6 }\end{array}$ & $\begin{array}{l}\text { Use of U2 AFW to support miflux } \\
\text { cooling (use of U2 charging and } \\
\text { RWST also possible) } \\
\text { 1.All W1R6, W2R6 and W2D6 } \\
\text { sequences with recir failed and MA- } \\
\text { FW3B. }\end{array}$ \\
\hline R-F1W1D6-XHE-C & cover by $\mathbf{A} 3$ & 0.1 & $\begin{array}{l}\text { RAW1D6 \#4, \#7 } \\
\text { RBW1D6 \#4 \#7 } \\
\text { R3W1D6 \#3 } \\
\text { R4W1D6 \#4 \#9 } \\
\text { RSW1D6 \#4 } \\
\text { RBW1D6 \#4 \#7 } \\
\text { ARW1D6 \#5 }\end{array}$ & $\begin{array}{l}\text { Use reflux cooling with } 2 \text { SGs } \\
\text { 1. All W1D6 sequences with failure } \\
\text { to recirc. } \\
\text { 2. This is covered by A3. }\end{array}$ \\
\hline $\begin{array}{l}\text { R-G1W2DR6-XHE- } \\
\text { C }\end{array}$ & covered by E1 & $\begin{array}{l}\text { 1E-04 + 7.33E-03(LSW1) } \\
=7.43 \mathrm{E}-03\end{array}$ & $\begin{array}{l}\text { Practically the same } \\
\text { as E1. }\end{array}$ & $\begin{array}{l}\text { Use of U2 AFW to support reflux } \\
\text { cooling (use of U2 charging and } \\
\text { RWST also possible) } \\
\text { 1. This is the same as E1. The } \\
\text { operator can use Unit } 2 \text { AFW or } \\
\text { charging. AFW is modeled. }\end{array}$ \\
\hline
\end{tabular}


Table 10-51 (continued)

\begin{tabular}{|c|c|c|c|c|}
\hline Basic Event Name & Recovery Rules & $\begin{array}{l}\text { Calculation of Basic } \\
\text { Event Probability }\end{array}$ & Applicable Sequences & Notes \\
\hline $\begin{array}{l}\text { R-H1W1DR6-XHE- } \\
\mathbf{R}\end{array}$ & RWT-TNK-LF-RWST & $\begin{array}{l}\text { 1.2E-03(HEP for A- } \\
\text { RAW1-Xhe-R) }\end{array}$ & $\begin{array}{l}\text { RAW1R6 \#14 \#18 } \\
\text { RAW1D6 *8 } \\
\text { RAW2R6 \#14 \#18 } \\
\text { RAW2D6 *10 } \\
\text { RAW3R6 \#10 \#12 } \\
\text { RAW3D6 *8 } \\
\text { RAW3R10 \#10 \#12 } \\
\text { RAW4R6 \#11 \#14 } \\
\text { RAW4D6 \#8 } \\
\text { RAW4R10 \#11 \#14 } \\
\text { RBW1R6 *14 \#18 } \\
\text { RBW1D6 \#8 } \\
\text { RBW2R6 \#14 \#18 } \\
\text { RBW2D6 \#10 } \\
\text { RBW3R6 \#10 \#12 } \\
\text { RBW3D6 \#8 } \\
\text { RBW3R10 \#10 \#12 } \\
\text { RBW4R6 *10 \#12 } \\
\text { RBW4D6 \#8 } \\
\text { RBW4R10 \#10 \#12 }\end{array}$ & $\begin{array}{l}\text { Une of RWST to provide alort torm } \\
\text { makoup in onder to rectore RHR } \\
\text { 1.All RHR2A and RHR2B } \\
\text { sequences. } \\
\text { 2. The HEP is based on restoring } \\
\text { RHR.(A-RAW1D6-XHE-R) }\end{array}$ \\
\hline
\end{tabular}


Table 10-52

Recovery Actions and Their Applicability to the Loss of Support System Event Trees

\begin{tabular}{|c|c|c|c|c|}
\hline Basic Event Name & Recovery Rules & $\begin{array}{c}\text { Calculation of Basic Event } \\
\text { Probability }\end{array}$ & Applicable Sequences & Notes \\
\hline R-W1D6-XHE-C-A1 & $\begin{array}{l}\text { LPR-MOV-FT-1862B + LPR- } \\
\text { CCF-FT-862AB }\end{array}$ & $\begin{array}{l}0.9 * 4.3 \mathrm{E}-03 * 0.1 \\
+0.1 * 0.1 \\
=1.04 \mathrm{E}-02\end{array}$ & $\begin{array}{l}\text { 4KW1D6-\#4,\#8 } \\
\text { VBW1D6-\#4,\#8 } \\
\text { SIW1D6-\#4,\#8 } \\
\text { CCW1D6-\#4 } \\
\end{array}$ & $\begin{array}{l}\text { Manually close the MOV or use reflux } \\
\text { cooling with } 2 \text { SGs } \\
\text { 1. All W1D6 sequences with failure of } \\
\text { recirculation. }\end{array}$ \\
\hline R-W1D6-XHE-C-A2 & $\begin{array}{l}\text { LPR-MOV-FT-1860B + } \\
\text { LPR-CCF-FT-860AB }\end{array}$ & same & $\begin{array}{l}\text { 4KW1D6-\#4,\#8 } \\
\text { VBW1D6-\#4,\#8 } \\
\text { SIW1D6-\#4,\#8- } \\
\text { CCW1D6-\#4 }\end{array}$ & $\begin{array}{l}\text { Manually open the MOV or use reflux } \\
\text { cooling with } 2 \text { SGs } \\
\text { 1. All W1D6 sequences with failure of } \\
\text { recirculation. }\end{array}$ \\
\hline R-W1D6-XHE-C-A3 & $\begin{array}{l}\text { 1. All W1D6 cutsets that do not } \\
\text { meet A1, A2 and A10 and not } \\
\text { due to failure to diagnose. } \\
\text { 2. SGA-DRAINED-R + } \\
\text { SGB-DRAINED-R + } \\
\text { SGC-DRAINED-R }\end{array}$ & .1 & $\begin{array}{l}\text { 4KW1D6-\#4,\#5,\#8,\#9 } \\
\text { VBW1D6-\#4,\#5,\#8,\#9 } \\
\text { SIW1D6-\#4,\#5,\#8,\#9 } \\
\text { CCW1D6-\#4,\#5 } \\
\text { 4KW1R6-\#10,\#19 } \\
\text { VBW1R5-\#10,\#19 } \\
\text { SIW1R6-\#10,\#19 } \\
\text { CCW1R6-\#10 } \\
\text { 4KW2D6-\#6,\#11 } \\
\text { VBW2D6-\#6,\#11 } \\
\text { SIW2D6-\#6,\#11 } \\
\text { CCW2D6-\#6 } \\
\text { 4KW2R6-\#10,\#19 } \\
\text { VBW2R6-\#10,\#19 } \\
\text { SIW2R6-\#10,\#19 } \\
\text { CCW2R6-\#10 }\end{array}$ & $\begin{array}{l}\text { Use reflux cooling with } 2 \text { SGs } \\
\text { 1. All W1D6 cutsets that do not meet A1 } \\
\text { or A2 and not due to failure to diagnose. } \\
\text { 2. All W1R6, W2D6, and W2R6 } \\
\text { sequences with "S" top event Failed and } \\
\text { "SG"-DRAINED-R" that are not } \\
\text { otherwise recoverable. }\end{array}$ \\
\hline R-W1D6-XHE-C-A4 & Covered by $\mathbf{A} 3$ & .1 & Covered by $\mathrm{A} 3$ & $\begin{array}{l}\text { Use reflux cooling with } 2 \text { SGs } \\
\text { 1. Covered by } \mathrm{A} 3\end{array}$ \\
\hline R-W1D6-XHE-C-A5 & Covered by A3 & .1 & Covered by $\mathrm{A} 3$ & $\begin{array}{l}\text { Use reflux cooling with } 2 \text { SGs } \\
\text { 1. Covered by } A 3\end{array}$ \\
\hline
\end{tabular}


Table 10-52 (continued)

\begin{tabular}{|c|c|c|c|c|}
\hline Basic Event Name & Recovery Rules & $\begin{array}{c}\text { Calculation of Basic Event } \\
\text { Probability }\end{array}$ & Applicable Sequences & Notes \\
\hline R-W2D6-XHE-C-A9 & $\begin{array}{l}\text { All except those meeting } \\
\text { E1(AFW-MDP-MA-FW3B) }\end{array}$ & $\begin{array}{l}3.2 \mathrm{E}-03+1.91 \mathrm{E}-02 \\
=2.23 \mathrm{E}-02\end{array}$ & $\begin{array}{l}\text { 4KW2D6-\#05,\#10,\#11? } \\
\text { VBW2D6-\#05,\#10 } \\
\text { SIW2D6-\#05,\#10 } \\
\text { CCW2D6-\#5 } \\
\text { 4KW2R6-\#04,\#09,\#13,\#18 } \\
\text { VBW2R6-\#04,\#09,\#13,\#18 } \\
\text { SIW2R6-\#04,\#08,\#13,\#18 } \\
\text { CCW2R6-\#4,\#9 }\end{array}$ & $\begin{array}{l}\text { Use of Unit } 2 \text { charging pump and RWST } \\
\text { 1. All W2D6 and W2R6 sequences with } \\
\text { failure to recirculate except those } \\
\text { covered by E1 (AFW-MDP-MA-3B) }\end{array}$ \\
\hline R-W1D6-XHE-C-A10 & A-CCW1-XHE-C-9 & 1. & CCW1D6 - 4 & Not recoverable \\
\hline R-W1R6-XHE-C-A11 & $\begin{array}{l}\text { (LPR-MOV-FT-1862B + LPR- } \\
\text { CCF-FT-862AB + } \\
\text { LPR-MOV-FT-1860B + } \\
\text { LPR-CCF-FT-860AB) * /AFW- } \\
\text { MDP-MA-FW3B }\end{array}$ & $\begin{array}{l}4.31 \mathrm{E}-03+0.1 \\
=1.04 \mathrm{E}-01\end{array}$ & $\begin{array}{l}\text { 4KW1R6-\#04,\#09,\#13,\#18 } \\
\text { VBW1R6-\#04,\#09,\#13,\#18 } \\
\text { SIW1R6-\#04,\#09,\#13,\#18 } \\
\text { CCW1R6-\#04,\#09 }\end{array}$ & $\begin{array}{l}\text { Manually open or close the MOV } \\
\text { 1. All W1R6 sequences with failure to } \\
\text { recirculate and not covered by E1. }\end{array}$ \\
\hline R-W1R6-XHE-C-A12 & $\begin{array}{l}\text { ACP-INV-NO-UPSA2 * } \\
\text { LOOPISOLATED1R6 }\end{array}$ & 1.0 & $4 \mathrm{KW} 1 \mathrm{R} 6-18,19$ & Not recoverable(in my judgment) \\
\hline $\begin{array}{l}\text { R-B1W2/W3/D6/R6- } \\
\text { XHE-D }\end{array}$ & $\begin{array}{l}\text { D-4KW2-XHE } \\
\text { D-4KW3-XHE }\end{array}$ & 1.0 & $\begin{array}{l}\text { 4KW2D6/R6 } \\
\text { 4KW3D6/R6 }\end{array}$ & Not recoverable \\
\hline R-W2D6-XHE-C-D2 & Covered by $\mathrm{A} 9$. & $\begin{array}{l}3.2 \mathrm{E}-03+1.91 \mathrm{E}-02 \\
=2.23 \mathrm{E}-02\end{array}$ & Covered by $\mathrm{A} 9$. & $\begin{array}{l}\text { Use of Unit } 2 \text { charging pump and } \\
\text { RWST(same as A9) } \\
\text { 1. All W2D6 and W2R6 sequences with } \\
\text { failure to recirculate except those } \\
\text { covered by E1 (AFW-MDP-MA-3B) }\end{array}$ \\
\hline R-D3W2R6-XHE-C & Covered by $\mathrm{A} 9$. & $\begin{array}{l}3.2 \mathrm{E}-03+1.91 \mathrm{E}-02 \\
=2.23 \mathrm{E}-02\end{array}$ & Covered by A9. & $\begin{array}{l}\text { Use of Unit } 2 \text { charging pump and } \\
\text { RWST(same as A9) } \\
\text { 1. All W2D6 and W2R6 sequences with } \\
\text { failure to recirculate except those } \\
\text { covered by E1 (AFW-MDP-MA-3B) }\end{array}$ \\
\hline
\end{tabular}


Table 10-52 (continued)

\begin{tabular}{|c|c|c|c|c|}
\hline \\
\hline Basic Event Name & Recovery Rules & $\begin{array}{c}\text { Calculation of Basic Event } \\
\text { Probability }\end{array}$ & Applicable Sequences & Notes \\
\hline R-W2D6-XHE-C-E1 & AFW-MDP-MA-FW3B & $\begin{array}{l}1.20 \mathrm{E}-04+7.33 \mathrm{E}-03 \\
=7.45 \mathrm{E}-03\end{array}$ & $\begin{array}{l}\text { 4KW1R6-\#04,\#09,\#13,\#18 } \\
\text { VBW1R6-\#04,\#09,\#13,\#18 } \\
\text { SIW1R6-\#04,\#09,\#13,\#18 } \\
\text { CCW1R6-\#04,\#09 } \\
\text { 4KW2D6-\#05,\#10 } \\
\text { VBW2D6-\#05,\#10 } \\
\text { SIW2D6-\#05,\#10 } \\
\text { CCW2D6-\#5 } \\
\text { 4KW2R6-\#04,\#09,\#13,\#18 } \\
\text { VBW2R6-\#04,\#09,\#13,\#18 } \\
\text { SIW2R6-\#04,\#08,\#13,\#18 } \\
\text { CCW2R6-\#4,\#9 } \\
\text { 4KW3D6-\#5 } \\
\text { 4KW4D6-\#9 } \\
\text { SIW3D6-\#5 } \\
\text { 4KW1R6-\#10,\#19 } \\
\text { VBW1R6-\#10,\#19 } \\
\text { SIW1R6-\#10,\#19 } \\
\text { CCW1R6-\#10 } \\
\text { 4KW2D6-\#6,\#11 } \\
\text { VBW2D6-\#6,\#11 } \\
\text { SIW2D6-\#6,\#11 } \\
\text { CCW2D6-\#6 } \\
\text { 4KW2R6-\#10,\#19 } \\
\text { VBW2R6-\#10,\#19 } \\
\text { SIW2R6-\#10,\#19 } \\
\text { CCW2R6-\#10 }\end{array}$ & $\begin{array}{l}\text { Use of U2 AFW to support reflux } \\
\text { cooling(use of U2 changing and RWST } \\
\text { also posslble) } \\
\text { 1. All W1R6(charging not sufficient), } \\
\text { W2R6 and W2D6 sequences with } \\
\text { recirculation failed. } \\
\text { 2. All sequences not otherwise } \\
\text { recoverable. }\end{array}$ \\
\hline R-W2D6-XHE-C-E2 & Covered by E1. & $\begin{array}{l}1.20 \mathrm{E}-04+7.33 \mathrm{E}-03 \\
=7.45 \mathrm{E}-03\end{array}$ & Covered by E1. & $\begin{array}{l}\text { Use of U2 AFW to support reflux } \\
\text { cooling(use of U2 charging and RWST } \\
\text { also possible) } \\
\text { 1. Covered by E1. }\end{array}$ \\
\hline 2R-W2D6-XHE-C-G1 & Covered by E1. & $\begin{array}{l}1.20 \mathrm{E}-04+7.33 \mathrm{E}-03 \\
=7.45 \mathrm{E}-03\end{array}$ & Covered by E1. & $\begin{array}{l}\text { Use of U2 AFW to support reflux } \\
\text { cooling(use of } \mathrm{U} 2 \text { charging and RWST } \\
\text { also possible) } \\
\text { 1. Covered by E1. }\end{array}$ \\
\hline
\end{tabular}


Table 10-52 (continued)

\begin{tabular}{|c|c|c|c|c|}
\hline Basic Event Name & Recovery Rules & $\begin{array}{c}\text { Calculation of Basic Event } \\
\text { Probability }\end{array}$ & Applicable Sequences & Notes \\
\hline R-W2R6-XHE-C-G2 & Covered by E1. & $\begin{array}{l}1.20 \mathrm{E}-04+7.33 \mathrm{E}-03 \\
=7.45 \mathrm{E}-03\end{array}$ & Covered by E1. & $\begin{array}{l}\text { Use of U2 AFW to support reflux } \\
\text { cooling(use of U2 charging and RWST } \\
\text { also possible) } \\
\text { 1. Covered by E1. }\end{array}$ \\
\hline R-W2D6-XHE-C-G3 & Covered by E1. & $\begin{array}{l}1.20 \mathrm{E}-04+7.33 \mathrm{E}-03 \\
=7.45 \mathrm{E}-03\end{array}$ & Covered by E1. & $\begin{array}{l}\text { Use of U2 AFW to support reflux } \\
\text { cooling(use of U2 charging and RWST } \\
\text { also possible) } \\
\text { 1. Covered by E1. }\end{array}$ \\
\hline R-W2R6-XHE-C-G4 & Covered by A9. & $\begin{array}{l}3.2 \mathrm{E}-03+1.91 \mathrm{E}-02 \\
=2.23 \mathrm{E}-02\end{array}$ & Covered by $A 9$. & $\begin{array}{l}\text { Use of Unit } 2 \text { charging pump and } \\
\text { RWST(same as A9) } \\
\text { 1. All W2D6 and W2R6 sequences with } \\
\text { failure to recirculate except those } \\
\text { covered by E1 (AFW-MDP-MA-3B) }\end{array}$ \\
\hline $\begin{array}{l}\text { R-W2D6/R6-XHE-C- } \\
\text { G5 }\end{array}$ & Covered by E1. & $\begin{array}{l}1.20 \mathrm{E}-04+7.33 \mathrm{E}-03 \\
=7.45 \mathrm{E}-03\end{array}$ & Covered by E1. & $\begin{array}{l}\text { Use of U2 AFW to support reflux } \\
\text { cooling(use of U2 charging and RWST } \\
\text { also possible) } \\
\text { 1. Covered by E1. }\end{array}$ \\
\hline $\begin{array}{l}\text { R-W1D6/R6-XHE-C- } \\
\text { G6 }\end{array}$ & Covered by E1. & $\begin{array}{l}1.20 \mathrm{E}-04+7.33 \mathrm{E}-03 \\
=7.45 \mathrm{E}-03\end{array}$ & Covered by E1. & $\begin{array}{l}\text { Use of U2 AFW to support reflux } \\
\text { cooling(use of U2 charging and RWST } \\
\text { also possible) } \\
\text { 1. Covered by E1. }\end{array}$ \\
\hline
\end{tabular}


Table 10-53

Time To Recovery of Failed Diesel Generator

\begin{tabular}{|c|c|}
\hline Time Following Operator Response & Probability Density \\
\hline $0-5$ minutes & .05 \\
\hline $5-15$ minutes & .10 \\
\hline $15-30$ minutes & .10 \\
\hline $30-60$ minutes & .05 \\
\hline $1-2$ hours & .13 \\
\hline $2-4$ hours & .12 \\
\hline $4-8$ hours & .25 \\
\hline $8-24$ hours & .10 \\
\hline $24-72$ hours & .07 \\
\hline $3-7$ days & .025 \\
\hline$>7$ days & .005 \\
\hline
\end{tabular}


Table 10-54

Calculation of $\eta$ Parameters in Windows 1-4

\begin{tabular}{|c|c|c|c|c|c|c|c|c|}
\hline \multicolumn{5}{|c|}{ W1 } & \multicolumn{4}{|c|}{ w2 } \\
\hline & Time(hr) & NRAC ${ }^{1}$ & $\mathrm{DG}^{2}$ & $\eta^{3}$ & Time(hr) & NRAC & DG & $\eta$ \\
\hline $\begin{array}{c}\text { Original } \\
\text { Evaluation }\end{array}$ & 2.0 & 0.32 & N/A & N/A & 2.62 & 0.26 & $\mathbf{N} / \mathbf{A}$ & N/A \\
\hline $\begin{array}{l}\text { Action } 1 \\
\text { only, } \eta\end{array}$ & 12 & 0.034 & 0.175 & 0.0186 & 16.1 & 0.02 & 0.15 & 0.0115 \\
\hline $\begin{array}{c}\text { Action } 1 \& 2, \\
\eta_{1} \eta_{2} \\
\end{array}$ & 22 & 0.012 & 0.113 & 0.0042 & 26.1 & N/A & N/A & N/A \\
\hline $\begin{array}{c}\text { Action } 2 \text { only, } \\
\eta_{1} \eta_{2}\end{array}$ & 12 & 0.034 & 0.175 & 0.0186 & 12.6 & 0.03 & 0.175 & 0.0202 \\
\hline $\begin{array}{l}\text { Action } 1 \text { only, } \\
\text { but with gravity } \\
\text { feed, } \eta_{1}\end{array}$ & 6.3 & 0.09 & 0.325 & 0.91 & 9.1 & 0.05 & 0.194 & 0.0373 \\
\hline
\end{tabular}

${ }^{1} \mathrm{NRAC}=$ Probability of non-recovery of offsite power in designed time

${ }^{2} \mathrm{DG}=$ Probability of non-recovery of emergency diesel generator in designated time

${ }^{3} \eta=\eta_{2}$ or $\eta_{1} \eta_{2}$ for the designated combination of recovery actions 
Table 10-54 (continued)

Calculation of $\boldsymbol{\eta}$ Parameters in Windows 1-4

\begin{tabular}{|c|c|c|c|c|c|c|c|c|}
\hline \multicolumn{5}{|c|}{ W3 } & \multicolumn{4}{|c|}{ W4 } \\
\hline & Time(hr) & NRAC $^{4}$ & $\mathrm{DG}^{5}$ & $\eta^{6}$ & Time(hr) & NRAC & DG & $\eta$ \\
\hline $\begin{array}{c}\text { Original } \\
\text { Evaluation }\end{array}$ & 3.46 & 0.19 & N/A & N/A & 4.55 & 0.14 & N/A & $\mathbf{N} / \mathbf{A}$ \\
\hline $\begin{array}{c}\text { Action } 1 \\
\text { only, } \eta \\
\end{array}$ & 22.5 & 0.011 & 0.1125 & 0.0065 & 43 & N/A & N/A & N/A \\
\hline $\begin{array}{c}\text { Action 1\&2, } \\
\eta_{1} \eta_{2}\end{array}$ & 32.5 & N/A & N/A & N/A & 53 & N/A & N/A & $\mathbf{N} / \mathbf{A}$ \\
\hline $\begin{array}{c}\text { Action } 2 \text { only, } \\
\eta_{1} \eta_{2}\end{array}$ & 13.5 & 0.03 & 0.1625 & 0.0257 & 14.6 & 0.02 & 0.16 & 0.0229 \\
\hline $\begin{array}{l}\text { Action } 1 \text { only, } \\
\text { but with gravity } \\
\text { feed, } \eta_{1}\end{array}$ & 15.5 & 0.02 & 0.15 & 0.0158 & N/A & N/A & N/A & $\mathbf{N} / \mathbf{A}$ \\
\hline
\end{tabular}

${ }^{4}$ NRAC $=$ Probability of non-recovery of offsite power in designated time

${ }^{5} \mathrm{DG}=$ Probability of non-recovery of emergency diesel generator in designated time

${ }^{6} \eta=\eta_{1}$ or $\eta_{1} \eta_{2}$ for the designated combination of recovery actions 
Table 10-55

$\rho_{2}$ for LOSP Categories and Windows 1-4

\begin{tabular}{|c|c|c|c|c|}
\hline & W1 & W2 & W3 & W4 \\
\hline L1 & 0 & 0 & 0 & 0 \\
\hline L2 & 0 & 0 & 0 & 0 \\
\hline L3 & 0 & 0 & 0 & 0 \\
\hline B1 & .55 & .36 & .11 & .11 \\
\hline B2 & N/A & .42 & .29 & .19 \\
\hline
\end{tabular}




\section{Accident Sequence Quantification}

Table 10.56

$\rho_{3}$ for LOSP Categories

\begin{tabular}{||l|l|}
\hline & $\mathrm{P}_{3}$ \\
\hline $\mathrm{L} 1$ & 1.0 \\
\hline $\mathrm{L} 2$ & 0.1 \\
\hline $\mathrm{L} 3$ & 0.1 \\
\hline $\mathrm{B} 1$ & 0.1 \\
\hline $\mathrm{B} 2$ & 1.0 \\
\hline
\end{tabular}




\begin{tabular}{|c|c|c|c|c|c|}
\hline$\varepsilon-98 \mathfrak{I}$ & I0 & 0 & $9810^{\circ} 0$ & $9810^{\circ} 0$ & כ-כ-દI-IMZT-४ \\
\hline$t-2 z t$ & I0 & 0 & $\varepsilon-2 \tau{ }^{\circ} \phi$ & $9810^{\circ} 0$ & 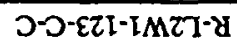 \\
\hline$t-z z^{\circ}$ & I0 & 0 & $\varepsilon-\tau \tau " \emptyset$ & $9810^{\circ} 0$ & $\forall-\supset-\varepsilon Z I-I M Z T-ষ$ \\
\hline$z-98 \cdot I$ & $0^{\circ} \mathrm{I}$ & 0 & $9810^{\circ} 0$ & $9810^{\circ} 0$ & $d-J-I-I M Z T-\mathcal{d}$ \\
\hline$\tau-98+\mathrm{I}$ & $0^{\circ} \mathrm{I}$ & 0 & $9810^{\circ} 0$ & $9810^{\circ} 0$ & J-I-IMZT- \\
\hline $2-98 \cdot I$ & $0^{\circ} I$ & 0 & $9810^{\circ} 0$ & $9810^{\circ} 0$ & כ-I-IMIT-8 \\
\hline 6020 & 0.1 & $6 l^{\circ} 0$ & $6220^{\circ} 0$ & $\mathbf{I}$ & $z-t M Z g-\dot{d}$ \\
\hline $80 E 0$ & $0 . I$ & 620 & $\angle S 20^{\circ} O$ & I & $Z-\varepsilon M Z g-\gamma$ \\
\hline$\tau-851$ & $0^{\circ} I$ & 0 & $85100^{\circ}$ & 85100 & $D-I-\varepsilon M Z \mathbf{D}-\mathbf{d}$ \\
\hline ZE†'O & $0^{\circ} \mathrm{I}$ & $2 \nabla^{\circ} 0$ & $2020^{\circ} 0$ & I & $z-Z M Z \mathbf{z}-\mathrm{d}$ \\
\hline zrI:0 & I0 & IIO & $\angle S Z O^{\circ} 0$ & $I$ & 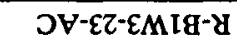 \\
\hline ZIIOO & I0 & II00 & $\angle S Z O^{\circ} 0$ & I & $\forall-\varepsilon Z-\varepsilon M I \theta-\not$ \\
\hline $\mathcal{E}-85 \mathfrak{I}$ & I0 & 0 & $8 S 100^{\circ}$ & 8SI0०0 & 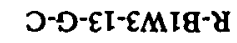 \\
\hline$z-85 I$ & $0^{\circ} \mathrm{I}$ & 0 & $85100^{\circ}$ & $8 S I 00^{\circ}$ & D-I-EM IG-乙 \\
\hline IOEO & l'o & $9 \varepsilon^{\circ} 0$ & $2020^{\circ} 0$ & I & OV-£Z-ZMIQ- \\
\hline IOEO & I’0 & $9 E^{\circ} 0$ & $2020^{\circ} 0$ & I & $\forall-\varepsilon Z-Z M I g-\mathcal{d}$ \\
\hline E-SII & I00 & 0 & SIIOOO & SII0'0 & 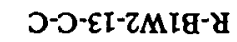 \\
\hline$\varepsilon \rightarrow I^{*} \boldsymbol{b}$ & I’0 & $9 E^{\circ} 0$ & $\mathbf{0}$ & SII0*0 & $\forall-\supset-\varepsilon Z I-\tau M I Q-\forall$ \\
\hline I:0 & I'0 & 0 & I & I & J- $\varepsilon-$ IM L\&-\& \\
\hline $\mathcal{E}-98^{\circ} I$ & I'0 & 0 & $9810^{\circ} 0$ & $98 \mathrm{LO} 0$ & つ-つ-દI-IM L\&-४ \\
\hline $2+0.1$ & I0 & SSO & $\varepsilon-z z z^{\circ}$ & $98 \mathrm{~L} 0^{\circ} 0$ & つ-つ-EZI-IML\&-\& \\
\hline TVIOI & $\varepsilon d$ & $z_{d}$ & 2416 & Th & \\
\hline
\end{tabular}

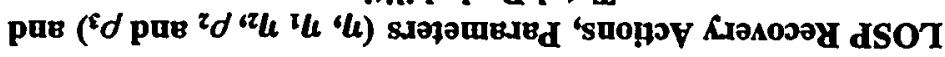

LS-0I әIQBL 


\begin{tabular}{|c|c|c|c|c|c|}
\hline 0 & ro & 0 & 0 & $5110^{\circ} 0$ & $\Xi-\supset-J-\varepsilon Z I-Z M E T-\searrow$ \\
\hline 0 & $I^{\circ} 0$ & 0 & 0 & silo 0 & כ-כ-EZI-ZMET-ע \\
\hline 0 & I'0 & 0 & 0 & $\sin 0^{\circ} 0$ & $\Xi-\forall-J-\varepsilon Z I-Z \Lambda \Lambda E T-\varangle$ \\
\hline 0 & ro & 0 & 0 & siro.0 & $\forall-J-\varepsilon Z I-\tau M E T-\searrow$ \\
\hline $\mathcal{E}^{-98^{\prime} \mathfrak{I}}$ & $1 \cdot 0$ & 0 & $9810^{\circ} 0$ & $9810^{\circ} 0$ & 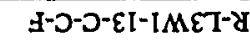 \\
\hline$\varepsilon^{-9} 98^{\prime} I$ & $I^{\circ} 0$ & 0 & $9810^{\circ} 0$ & $9810^{\circ} 0$ & כ-כ-EI-IMET-ষ \\
\hline$\tau-98^{\circ} \mathrm{I}$ & 0.1 & 0 & $9810^{\circ} 0$ & $9810^{\circ} 0$ & $A-J-I-I M E I-Y$ \\
\hline$\tau-98^{\imath} \mathrm{I}$ & 0.1 & 0 & $9810^{\circ} 0$ & $9810^{\circ} 0$ & כ-I-IMET-Y \\
\hline 0 & I.0 & 0 & 0 & 0 & $I-J-\supset-\varepsilon I-\downarrow M Z T-\not$ \\
\hline$t I S \cdot 9$ & ro & 0 & $\varepsilon-I \zeta^{*} 9$ & $\varepsilon-I \zeta^{*} 9$ & $\beth-\supset-\supset-\varepsilon[-\varepsilon M Z T-\not$ \\
\hline 0 & $I^{\circ} 0$ & 0 & 0 & $\mathcal{E}-I S^{\prime} 9$ & $\exists-J-J-\varepsilon Z I-\varepsilon M Z T-\not d$ \\
\hline 0 & $I^{\circ} 0$ & 0 & 0 & $\varepsilon-1 \varsigma^{*} 9$ & $d-\forall-0-\varepsilon Z[-\varepsilon M Z]-\not$ \\
\hline ro 0 & $I^{\circ} 0$ & 0 & I & 1 & D-E-ZMZT-ষ \\
\hline $\mathcal{E}-\varepsilon L^{\prime} \cdot \mathcal{\varepsilon}$ & $1 \cdot 0$ & 0 & $\mathcal{E} \angle E 0^{\circ} 0$ & $\varepsilon \angle \varepsilon 0^{\circ} 0$ & $d-\supset-D-\varepsilon[-\tau M Z T-\chi$ \\
\hline $\mathcal{E}-\mathcal{E} L^{\prime} \mathcal{E}$ & $r^{\prime} 0$ & 0 & $\varepsilon \angle E 0^{\circ} 0$ & $\varepsilon \angle E 0^{\circ} 0$ & כ-כ-EI-ZMZT-ð] \\
\hline$\varepsilon-\mathcal{S} I^{\top} I$ & I'0 & 0 & sito.0 & SII0 0 & $d-כ-כ-\varepsilon[-Z M Z T-\not$ \\
\hline $\mathcal{E}$-SI'I & $I^{\circ} 0$ & 0 & sito. & sito 0 & 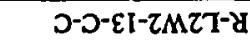 \\
\hline 0 & ro 0 & 0 & 0 & SII0.0 & $A-\supset-\supset-\varepsilon Z I-Z M Z T-\downarrow$ \\
\hline 0 & $I^{\circ} 0$ & 0 & 0 & SII0.0 & 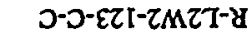 \\
\hline 0 & I'0 & 0 & 0 & SItóo & $d-\forall-D-\varepsilon Z I-Z M Z T-d$ \\
\hline 0 & $1 \% 0$ & 0 & 0 & sitoo & $\forall-0-\varepsilon Z[-Z M Z T-\varangle$ \\
\hline $\mathcal{E}^{-98^{\prime} \mathrm{I}}$ & I0 & 0 & $9810^{\circ} 0$ & $9810^{\circ} 0$ & $\exists=0-\supset-\varepsilon \mid-I M Z 7-\bar{d}$ \\
\hline TVIOI & $\varepsilon_{d}$ & $\overline{z_{d}}$ & $\overline{z_{l^{1}} u^{\prime}}$ & $T^{T} /$ & \\
\hline
\end{tabular}


Table 10-57 (continued)

\begin{tabular}{|c|c|c|c|c|c|}
\hline & $\eta_{1}$ & $\eta_{1} \eta_{2}$ & $\mathrm{P}_{2}$ & $\mathbf{P}_{3}$ & TOTAL \\
\hline R-L3W2-13-C-C & 0.0115 & 0.0115 & 0 & 0.1 & $1.15-3$ \\
\hline R-L3W2-13-C-C-F & 0.0115 & 0.0115 & 0 & 0.1 & $1.15-3$ \\
\hline$R-L 3 W 2-13-G-C$ & 0.0373 & 0.0373 & 0 & 0.1 & 3.73-3 \\
\hline R-L3W2-23-A & 1 & 0.0202 & 0 & 0.1 & $2.02-3$ \\
\hline R-L3W2-23-A-F & 1 & 0.0202 & 0 & 0.1 & $2.02-3$ \\
\hline R-L3W3-123-C-A-F & $6.51-3$ & 0 & 0 & 0.1 & 0 \\
\hline R-L3W3-123-C-C-F & $6.51-3$ & 0 & 0 & 0.1 & 0 \\
\hline$R-L 3 W 3-13-C-C-F$ & $6.51-3$ & $6.51-3$ & 0 & 0.1 & $6.51-4$ \\
\hline R-L3W3-23-A-F & 1 & 0.0257 & 0 & 0.1 & $2.57-3$ \\
\hline R-L3W4-13-C-C-F & 0 & 0 & 0 & 0.1 & 0 \\
\hline
\end{tabular}


10 Accident Sequence Quantification

Table 10-58

Recovery Actions Sequence Rules for LOSP Sequences

RHRMODEL, B1W1D6, 2-3=

DES A1 LPR-MOV-FT-1862B

IF LPR-MOV-FT-1862B

THEN R-A1W1D6-XHE-C.

DES A2 LPR-MOV-FT-1860B

IF LPR-MOV-FT-1860B

THEN R-A2W1D6-XHE-C.

DES A1 LPR-CCF-FT-862AB

IF LPR-CCF-FT-862AB

THEN R-A1W1D6-XHE-C.

DES A2 LPR-CCF-FT-860AB

IF LPR-CCF-FT-860AB

THEN R-A2W1D6-XHE-C.

DES A3 CREDIT REFLUX IN W1D6 (INCLUDE A4-A6)

IF NOT LPR-MOV-FT-1862B * NOT LPR-MOV-FT-1860B * NOT LPR-CCF-FT-862AB * NOT LPR-CCF-FT-860AB * NOT D-R3W1-XHE

THEN R-A3W1D6-XHE-C.

DES /NRAC200

IF DURATION-D6

THEN A-CCW3-XHE-S1-7.

AEOS

RHRMODEL, B1W1D6, $3=$

DES / XXX

IF NOT XXX

THEN R-B1W1-13-C-C.

^EOS

RHRMODEL, B1W1D6, 4=

DES /D-B1W1-XHENOT A-B1W1-XHE-2CH-8NOT A-B1W1-XHE-CW-8 *

IF NOT D-B1W1-XHE * NOT A-B1W1-XHE-2CH-8 * NOT A-B1W1-XHE-CW-8 *

NOT HPI-CKV-OO-267U2 * NOT HPI-CKV-OO-276U2

THEN R-B1W1-3-C.

AEOS

RHRMODEL, B1W1R6, 8=

DES /XXX

IF NOT XXX

THEN R-B1W1-123-C-C.

^EOS

RHRMODEL, B1W2D6, 2-4=

DES Use U2 AFW to Support Reflux Cooling

IF ACP-BAC-ST-4KV1H = AFW-MDP-MA-FW3B $=$ PROB-W2D6 $=$ DR-MT $=$ DURATION-D6 $=$ FREQ-B1

THEN R-E1W2D6-XHE-C.

DES /NRAC262

IF DURATION-D6

THEN A-CCW3-XHE-S1-7.

^EOS

RHRMODEL, B1W2D6, 4=

NUREG/CR-6144

$10-110$ 
DES /XXX

IF NOT XXX

THEN R-B1W2-123-C-A.

A EOS

RHRMODEL, B1W2D6, $5=$

DES /D-B1W2-XHENOT A-B1W2-XHE-2CH-8NOT A-B1W2-XHE-CW-8 *

IF NOT D-B1W2-XHE * NOT A-B1W2-XHE-2CH-8 * NOT A-B1W2-XHE-CW-8 * NOT HPI-CKV-OO-267U2 * NOT HPI-CKV-OO-276U2

THEN R-B1W2-23-AC.

DES /D-B1W2-XHE * NOT R-B1W2-23-AC

IF NOT D-B1W2-XHE * NOT R-B1W2-23-AC

THEN R-B1W2-23-A.

^EOS

RHRMODEL, B1W2R6, 3=

DES /XXX

IF NOT XXX

THEN R-B1W2-13-C-C.

^EOS

RHRMODEL, B1W2R6, 8=

DES / XXX

IF NOT XXX

THEN R-B1W2-123-C-A.

^ EOS

RHRMODEL, B1W2R6, 9=

DES /D-B1W2-XHENOT A-B1W2-XHE-2CH-8NOT A-B1W2-XHE-CW-8 *

IF NOT D-B1W2-XHE * NOT A-B1W2-XHE-2CH-8 * NOT A-B1W2-XHE-CW-8 * ' NOT HPI-CKV-OO-267U2 * NOT HPI-CKV-OO-276U2

THEN R-B1W2-23-AC.

DES /D-B1W2-XHE * NOT R-B1W2-23-AC

IF NOT D-B1W2-XHE * NOT R-B1W2-23-AC

THEN R-B1W2-23-A.

^EOS

RHRMODEL, B1W3D6, $5=$

DES /D-B1W3-XHENOT A-B1W3-XHE-CW-8NOT A-B1W3-XHE-2CH-8 *

IF NOT D-B1W3-XHE * NOT A-B1W3-XHE-CW-8 * NOT A-B1W3-XHE-2CH-8 * NOT HPI-CKV-OO-267U2 * NOT HPI-CKV-OO-276U2

THEN R-B1W3-23-AC.

DES /D-B1W3-XHE * NOT R-B1W3-23-AC

IF NOT D-B1W3-XHE * NOT R-B1W3-23-AC

THEN R-B1W3-23-A.

^ EOS

RHRMODEL, B1W3R6, 5=

DES /D-B1W3-XHENOT A-B1W3-XHE-2CH-4NOT A-B1W3-XHE-CW-4 *

IF NOT D-B1W3-XHE * NOT A-B1W3-XHE-2CH-4 * NOT A-B1W3-XHE-CW-4 * NOT HPI-CKV-OO-267U2 * NOT HPI-CKV-OO-276U2

THEN R-B1W3-13-G-C.

DES /D-B1W3-XHE * NOT R-B1W3-13-G-C

IF NOT D-B1W3-XHE * NOT R-B1W3-13-G-C

THEN R-B1W3-1-G.

^EOS

RHRMODEL, B2W1D6, 2-3=

DES /nrac200 
10 Accident Sequence Quantification

Table 10-58 (continued)

IF FREQ-B2

THEN A-CCW3-XHE-S1-7.

$\wedge$ EOS

RHRMODEL, B2W2D6, 3=

DES /XXX

IF NOT XXX

THEN R-B2W2-2.

^EOS

RHRMODEL, B2W2R6, 6=

DES IXXX

IF NOT XXX

THEN R-B2W2-2.

$\wedge$ EOS

RHRMODEL, B2W3D6, $3=$

DES /XXX

IF NOT XXX

THEN R-B2W3-2.

^EOS

RHRMODEL, B2W3R6, 3=

DES / XXX

IF NOT XXX

THEN R-B2W3-1-G.

^EOS

RHRMODEL, B2W4D6, 3= DES /XXX

IF NOT XXX

THEN R-B2W4-2.

^EOS

RHRMODEL, L1W1D6, 4= DES A1 LPR-MOV-FT-1862B

IF LPR-MOV-FT-1862B

THEN R-A1W1D6-XHE-C.

DES A2 LPR-MOV-FT-1860B

IF LPR-MOV-FT-1860B

THEN R-A2W1D6-XHE-C.

DES A1 LPR-CCF-FT-862AB

IF LPR-CCF-FT-862AB

THEN R-A1W1D6-XHE-C.

DES A2 LPR-CCF-FT-860AB

IF LPR-CCF-FT-860AB

THEN R-A2W1D6-XHE-C.

DES A3 CREDIT REFLUX IN W1D6 (INCLUDE A4-A6)

IF NOT LPR-MOV-FT-1862B * NOT LPR-MOV-FT-1860B * NOT LPR-CCF-FT-862AB * NOT LPR-CCF-FT-860AB * NOT D-R3W1-XHE

THEN R-A3W1D6-XHE-C.

DES /NRAC200 L1W1D6

IF FREQ-L1

THEN A-CCW3-XHE-S1-7.

NUREG/CR-6144

$10-112$ 
Table 10-58 (continued)

^EOS

RHRMODEL, L1W1D6, 5=

DES /NRAC200 L1W1D6

IF FREQ-L1

THEN A-CCW3-XHE-S1-7.

^EOS

RHRMODEL, L1W1D6, 7=

DES /A-L1W1-XHE-C-17 * NOT D-L1W1-XHE

IF NOT A-L1W1-XHE-C-17 * NOT D-L1W1-XHE

THEN R-L1W1-1-C.

^EOS

RHRMODEL, L1W1R6, 06=

DES /NRAC200 L1W1R6

IF FREQ-L1

THEN A-CCW3-XHE-S1-7.

^ EOS

RHRMODEL, L1W1R6, 13=

DES /NRAC200 L1W1R6

IF FREQ-L1

THEN A-CCW3-XHE-S1-7.

$\wedge$ EOS

RHRMODEL, L1W1R6, 14= DES /NRAC200 L1W1R6

IF FREQ-L1

THEN A-CCW3-XHE-S1-7.

^EOS

RHRMODEL, L1W2D6, 05= DES /NRAC262 L1W2D6

IF FREQ-L1

THEN A-CCW3-XHE-S1-7.

$\wedge$ EOS

RHRMODEL, L1W2D6, 06= DES /NRAC262 L1W2D6

IF FREQ-L1

THEN A-CCW3-XHE-S1-7.

^EOS

RHRMODEL, L1W2R6, 06= DES /nrac262

IF FREQ-L1

THEN A-CCW3-XHE-S1-7.

^EOS

RHRMODEL, L1W2R6, 13= DES NRAC262 L1W2R6

IF FREQ-L1

THEN A-CCW3-XHE-S1-7.

$\wedge$ EOS

RHRMODEL, L1W2R6, 14= DES /NRAC262 
10 Accident Sequence Quantification

Table 10-58 (continued)

IF FREQ-L1

THEN A-CCW3-XHE-S1-7.

^EOS

RHRMODEL, L1W3D6, 5=

DES /NRAC346 L1W3D6

IF FREQ-L1

THEN A-CCW3-XHE-S2-7.

^EOS

RHRMODEL, L1W3R10, 05=

DES INRAC346 L1W3R10

IF FREQ-L1

THEN A-CCW3-XHE-S2-7.

^EOS

RHRMODEL, L1W3R10, 10=

DES /NRAC346 L1W3R10

IF FREQ-L1

THEN A-CCW3-XHE-S2-7.

$\wedge$ EOS

RHRMODEL, L1W3R6, 05= DES IRAC346 L1W3R6

IF FREQ-L1

THEN A-CCW3-XHE-S2-7.

$\wedge$ EOS

RHRMODEL, L1W3R6, 10= DES /NRAC346 L1W3R6

IF FREQ-L1

THEN A-CCW3-XHE-S2-7.

$\wedge$ EOS

RHRMODEL, L1W4D6, 5=

DES NRAC455 L1W4D6

IF FREQ-L1

THEN A-CCW3-XHE-S2-7.

^EOS

RHRMODEL, L1W4R10, 05= DES /NRAC455 L1W4R10

IF FREQ-L1

THEN A-CCW3-XHE-S2-7.

^EOS

RHRMODEL, L1W4R10, 10=

DES /NRAC455 L1W4R10

IF FREQ-L1

THEN A-CCW3-XHE-S2-7.

^EOS

RHRMODEL, L1W4R6, 05= DES /NRAC455 L1W4R6

IF FREQ-L1

THEN A-CCW3-XHE-S2-7.

^EOS

NUREG/CR-6144

10-114 
Table 10-58 (continued)

RHRMODEL, L1W4R6, 10= DES NRAC455 L1W4R6

IF FREQ-L1

THEN A-CCW3-XHE-S2-7.

$\wedge$ EOS

RHRMODEL, L2W1D6, 4=

DES A1 LPR-MOV-FT-1862B

IF LPR-MOV-FT-1862B

THEN R-A1W1D6-XHE-C.

DES A2 LPR-MOV-FT-1860B

IF LPR-MOV-FT-1860B

THEN R-A2W1D6-XHE-C.

DES A1 LPR-CCF-FT-862AB

IF LPR-CCF-FT-862AB

THEN R-A1W1D6-XHE-C.

DES A2 LPR-CCF-FT-860AB

IF LPR-CCF-FT-860AB

THEN R-A2W1D6-XHE-C.

DES A3 CREDIT REFLUX IN W1D6 (INCLUDE A4-A6)

IF NOT LPR-MOV-FT-1862B * NOT LPR-MOV-FT-1860B * NOT LPR-CCF-FT-862AB *

NOT LPR-CCF-FT-860AB * NOT D-R3W1-XHE

THEN R-A3W1D6-XHE-C.

DES NRAC200 L2W1D6

IF FREQ-L2

THEN A-CCW3-XHE-S1-7.

^EOS

RHRMODEL, L2W1D6, 5=

DES /NRAC200 L2W1D6

IF FREQ-L2

THEN A-CCW3-XHE-S1-7.

^EOS

RHRMODEL, L2W1D6, 7=

DES /LPR-CCF-PG-SÚMP1NOT LPI-MDP-FS-SI1BNOT A-L2W1-XHE-C-17 *

IF NOT LPR-CCF-PG-SUMP1 * NOT LPI-MDP-FS-SI1B * NOT A-L2W1-XHE-C-17 *

NOT CON-VFC-RP-COREM * NOT 2EH1L2 * NOT SWS-XHE-AP12 *

NOT A-L2W1-XHE-FH-18 * NOT A-L2W1-XHE-FL-18 * NOT D-L2W1-XHE

THEN R-L2W1-13-C-C.

DES /D-L2W1-XHE * NOT R-L2W1-13-C-C

IF NOT D-L2W1-XHE * NOT R-L2W1-13-C-C

THEN R-L2W1-1-C.

^EOS

RHRMODEL, L2W1D6, 8=

DES /D-L2W1-XHE * NOT PORV-PATH-CLSD *

IF NOT D-L2W1-XHE * NOT PORV-PATH-CLSD * A-L2W1-XHE-FL-18

THEN R-L2W1-1-C-F.

DES /D-L2W1-XHE * NOT PORV-PATH-CLSD *

IF NOT D-L2W1-XHE * NOT PORV-PATH-CLSD * LPI-MDP-FS-SI1B

THEN R-L2W1-1-C-F. 
10 Accident Sequence Quantification

Table 10-58 (continued)

DES /D-L2W1-XHE * NOT PORV-PATH-CLSD *

IF NOT D-L2W1-XHE * NOT PORV-PATH-CLSD * DCP-BDC-ST-BUS1B

THEN R-L2W1-1-C-F.

DES /D-L2W1-XHE * NOT PORV-PATH-CLSD * NOT R-L2W1-1-C

IF NOT D-L2W1-XHE * NOT PORV-PATH-CLSD * NOT R-L2W1-1-C

THEN R-L2W1-13-C-C-F.

^EOS

RHRMODEL, L2W1R6, 14=

DES NRAC200 L2W1R6

IF FREQ-L2

THEN A-CCW3-XHE-S1-7.

^EOS

RHRMODEL, L2W1R6, $17=$

DES AFW-MDP-MA-FW3B * PROB-1HFAILEDL2 * NOT D-L2W1-XHE

IF AFW-MDP-MA-FW3B * PROB-1HFAILEDL2 * NOT D-L2W1-XHE

THEN R-L2W1-123-C-A.

DES AFW-MDP-MA-FW3A * /PROB-1HFAILEDL2 * NOT D-L2W1-XHE

IF AFW-MDP-MA-FW3A * PROB-1HFAILEDL2 * NOT D-L2W1-XHE

THEN R-L2W1-123-C-A.

DES /R-L2W1-123-C-A * NOT D-L2W1-XHENOT MSS-AOV-FC-101A *

IF NOT R-L2W1-123-C-A * NOT D-L2W1-XHE * NOT MSS-AOV-FC-101A *

NOT MSS-AOV-FC-101B * NOT MSS-AOV-FC-101C * NOT MSS-AOV-MA-101A *

NOT MSS-AOV-MA-101B * NOT MSS-AOV-MA-101C * NOT LOOPISOLATED1R6 *

NOT SGA-DRAINED-R * NOT SGB-DRAINED-R * NOT SGC-DRAINED-R *

NOT A-L2W1-XHE-S1-17 * NOT SOLAIR-COMP * NOT FIRE-PUMP *

NOT SAS-CPS-FR-1SAC1 * NOT SAS-CPS-FR-2SAC1 * NOT IAS-CPS-FS-IAC-1 *

NOT IAS-CPS-FR-IAC-1

THEN R-L2W1-123-C-C.

DES /R-L2W1-123-C-A * NOT D-L2W1-XHE * NOT R-L2W1-123-C-C

IF NOT R-L2W1-123-C-A * NOT D-L2W1-XHE * NOT R-L2W1-123-C-C

THEN R-L2W1-13-C-C.

$\wedge$ EOS

RHRMODEL, L2W2D6, 05=

DES /NRAC262 L2W2D6

IF FREQ-L2

THEN A-CCW3-XHE-S1-7.

$\wedge$ EOS

RHRMODEL, L2W2D6, 06=

DES /NRAC262 L2W2D6

IF FREQ-L2

THEN A-CCW3-XHE-S1-7.

$\wedge$ EOS

RHRMODEL, L2W2D6, 09=

DES AFW-MDP-MA-FW3B + AFW-MDP-MA-FW3A + AFW-MDP-FS-FW3A +

IF AFW-MDP-MA-FW3B + AFW-MDP-MA-FW3A + AFW-MDP-FS-FW3A + AFW-MDP-FS-FW3B + AFW-MOV-MA-151A + AFW-MOV-MA-151B + AFW-MOV-MA-151C + AFW-MOV-MA-151D + AFW-MOV-MA-151E + AFW-MOV-MA-151F + AFW-MOV-FT-151A + AFW-MOV-FT-151B + AFW-MOV-FT-151C + AFW-MOV-FT-151D + AFW-MOV-FT-151E + AFW-MOV-FT-151F 
10 Accident Sequence Quantification

Table 10-58 (continued)

THEN R-L2W2-123-C-A.

DES /R-L2W2-123-C-A * NOT D-L2W2-XHENOT MSS-AOV-FC-101A *

IF NOT R-L2W2-123-C-A * NOT D-L2W2-XHE * NOT MSS-AOV-FC-101A *

NOT MSS-AOV-FC-101B * NOT MSS-AOV-FC-101C * NOT MSS-AOV-MA-101A *

NOT MSS-AOV-MA-101B * NOT MSS-AOV-MA-101C * NOT LOOPISOLATED2D6 *

NOT SGA-DRAINED-R * NOT SGB-DRAINED-R * NOT SGC-DRAINED-R *

NOT A-L2W2-XHE-S1-17 * NOT SOLAIR-COMP * NOT FIRE-PUMP *

NOT SAS-CPS-FR-1SAC1 * NOT SAS-CPS-FR-2SAC1 * NOT IAS-CPS-FS-IAC-1 *

NOT IAS-CPS-FR-IAC-1 * NOT SGS-DRAINED-CSD * NOT A-L2-XHE-S *

NOT MSS-AOV-FT-101A * NOT MSS-AOV-FT-101B * NOT MSS-AOV-FT-101C *

NOT ISR-TRA-MA * NOT OSR-TRA-MA * NOT LPR-CCF-PG-SUMP2 *

NOT IAS-CCF-LF-INAIR

THEN R-L2W2-123-C-C.

DES AFW-CCF-FS-FW3AB + AFW-CKV-OO-CV142 + A-L2W2-XHE-SF-17

IF AFW-CCF-FS-FW3AB + AFW-CKV-OO-CV142 + A-L2W2-XHE-SF-17

THEN R-L2W2-123-C-C.

DES A-L2W2-XHE-X

IF A-L2W2-XHE-X

THEN R-L2W2-3-C.

DES /R-L2W2-123-C-A * NOT D-L2W2-XHE * NOT R-L2W2-123-C-C *

IF NOT R-L2W2-123-C-A * NOT D-L2W2-XHE * NOT R-L2W2-123-C-C *

NOT ISR-TRA-MA * NOT OSR-TRA-MA * NOT LPR-CCF-PG-SUMP2 * NOT R-L2W2-3-C

THEN R-L2W2-13-C-C.

^EOS

RHRMODEL, L2W2D6, $10=$

DES AFW-MDP-MA-FW3B + AFW-MDP-MA-FW3A + AFW-MDP-FS-FW3A +

IF AFW-MDP-MA-FW3B + AFW-MDP-MA-FW3A + AFW-MDP-FS-FW3A + AFW-MDP-FS-FW3B + AFW-MOV-MA-151A + AFW-MOV-MA-151B + AFW-MOV-MA-151C + AFW-MOV-MA-151D + AFW-MOV-MA-151E + AFW-MOV-MA-151F + AFW-MOV-FT-151A + AFW-MOV-FT-151B + AFW-MOV-FT-151C + AFW-MOV-FT-151D + AFW-MOV-FT-151E + AFW-MOV-FT-151F

THEN R-L2W2-123-C-A-F.

DES DCP-BDC-ST-BUS1B

IF DCP-BDC-ST-BUS1B

THEN R-L2W2-123-C-A-F.

DES LPI-MDP-FS-SI1B * AFW-MDP-MA-FW3B

IF LPI-MDP-FS-SI1B * AFW-MDP-MA-FW3B

THEN R-L2W2-123-C-A-F.

DES A-L2W2-XHE-FL-18 * AFW-MDP-MA-FW3B

IF A-L2W2-XHE-FL-18 * AFW-MDP-MA-FW3B

THEN R-L2W2-123-C-A-F.

DES LPI-MDP-FS-SI1B * AFW-MDP-FS-FW3B

IF LPI-MDP-FS-SI1B * AFW-MDP-FS-FW3B

THEN R-L2W2-123-C-A-F.

DES A-L2W2-XHE-FL-18 * AFW-MDP-FS-FW3B

IF A-L2W2-XHE-FL-18 * AFW-MDP-FS-FW3B

THEN R-L2W2-123-C-A-F.

DES /R-L2W2-123-C-A-F * NOT D-L2W2-XHENOT MSS-AOV-FC-101A *

IF NOT R-L2W2-123-C-A-F * NOT D-L2W2-XHE * NOT MSS-AOV-FC-101A * 
10 Accident Sequence Quantification

Table 10-58 (continued)

NOT MSS-AOV-FC-101B * NOT MSS-AOV-FC-101C * NOT MSS-AOV-MA-101A *

NOT MSS-AOV-MA-101B * NOT MSS-AOV-MA-101C * NOT LOOPISOLATED2D6 *

NOT SGA-DRAINED-R * NOT SGB-DRAINED-R * NOT SGC-DRAINED-R *

NOT A-L2W2-XHE-S1-17 * NOT SOLAIR-COMP * NOT FIRE-PUMP *

NOT SAS-CPS-FR-1SAC1 * NOT SAS-CPS-FR-2SAC1 * NOT IAS-CPS-FS-IAC-1 *

NOT IAS-CPS-FR-IAC-1 * NOT SGS-DRAINED-CSD * NOT A-L2-XHE-S *

NOT MSS-AOV-FT-101A * NOT MSS-AOV-FT-101B * NOT MSS-AOV-FT-101C *

NOT IAS-CCF-LF-INAIR * NOT PORV-PATH-CLSD * NOT DCP-BDC-ST-BUS1B *

NOT LPI-MDP-FS-SI1B * NOT A-L2W2-XHE-FL-18

THEN R-L2W2-123-C-C-F.

DES AFW-CCF-FS-FW3AB + AFW-CKV-OO-CV142 + A-L2W2-XHE-SF-17

IF AFW-CCF-FS-FW3AB + AFW-CKV-OO-CV142 + A-L2W2-XHE-SF-17

THEN R-L2W2-123-C-C-F.

DES /R-L2W2-123-C-A-F * NOT D-L2W2-XHE * NOT R-L2W2-123-C-C-F *

IF NOT R-L2W2-123-C-A-F * NOT D-L2W2-XHE * NOT R-L2W2-123-C-C-F *

NOT PORV-PATH-CLSD * NOT DCP-BDC-ST-BUS1B * NOT LPI-MDP-FS-SI1B *

NOT A-L2W2-XHE-FL-18

THEN R-L2W2-13-C-C-F.

DES LPI-MDP-FS-SI1BNOT R-L2W2-123-C-A-F

IF LPI-MDP-FS-SI1B * NOT R-L2W2-123-C-A-F

THEN R-L2W2-13-C-C-F.

DES A-L2W2-XHE-FL-18NOT R-L2W2-123-C-A-F

IF A-L2W2-XHE-FL-18 * NOT R-L2W2-123-C-A-F

THEN R-L2W2-13-C-C-F.

^EOS

RHRMODEL, L2W2R6, 06=

DES /NRAC262 L2W2R6

IF FREQ-L2

THEN A-CCW3-XHE-S1-7.

^EOS

RHRMODEL, L2W2R6, $13=$

DES /NRAC262 L2W2R6

IF FREQ-L2

THEN A-CCW3-XHE-S1-7.

^EOS

RHRMODEL, L2W2R6, 14=

DES INRAC262 L2W2R6

IF FREQ-L2

THEN A-CCW3-XHE-S1-7.

^EOS

RHRMODEL, L2W2R6, 17=

DES AFW-MDP-MA-FW3B + AFW-MDP-MA-FW3A + AFW-MDP-FS-FW3A +

IF AFW-MDP-MA-FW3B + AFW-MDP-MA-FW3A + AFW-MDP-FS-FW3A + AFW-MDP-FS-FW3B + AFW-MOV-MA-151A + AFW-MOV-MA-151B + AFW-MOV-MA-151C + AFW-MOV-MA-151D + AFW-MOV-MA-151E + AFW-MOV-MA-151F + AFW-MOV-FT-151A + AFW-MOV-FT-151B + AFW-MOV-FT-151C + AFW-MOV-FT-151D + AFW-MOV-FT-151E + AFW-MOV-FT-151F

THEN R-L2W2-123-C-A.

DES /R-L2W2-123-C-A * NOT D-L2W2-XHENOT MSS-AOV-FC-101A *

NUREG/CR-6144

$10-118$ 
10 Accident Sequence Quantification

Table 10-58 (continued)

IF NOT R-L2W2-123-C-A * NOT D-L2W2-XHE * NOT MSS-AOV-FC-101A *

NOT MSS-AOV-FC-101B * NOT MSS-AOV-FC-101C * NOT MSS-AOV-MA-101A *

NOT MSS-AOV-MA-101B * NOT MSS-AOV-MA-101C * NOT LOOPISOLATED2R6 *

NOT SGA-DRAINED-R * NOT SGB-DRAINED-R * NOT SGC-DRAINED-R *

NOT A-L2W2-XHE-S1-17 * NOT SOLAIR-COMP * NOT FIRE-PUMP *

NOT SAS-CPS-FR-1SAC1 * NOT SAS-CPS-FR-2SAC1 * NOT IAS-CPS-FS-IAC-1 *

NOT IAS-CPS-FR-IAC-1 * NOT SGS-DRAINED-CSD * NOT A-L2-XHE-S *

NOT MSS-AOV-FT-101A * NOT MSS-AOV-FT-101B * NOT MSS-AOV-FT-101C *

NOT ISR-TRA-MA * NOT OSR-TRA-MA * NOT LPR-CCF-PG-SUMP2 *

NOT IAS-CCF-LF-INAIR

THEN R-L2W2-123-C-C.

DES AFW-CCF-FS-FW3AB + AFW-CKV-OO-CV142 + A-L2W2-XHE-SF-17

IF AFW-CCF-FS-FW3AB + AFW-CKV-OO-CV142 + A-L2W2-XHE-SF-17

THEN R-L2W2-123-C-C.

DES A-L2W2-XHE-X

IF A-L2W2-XHE-X

THEN R-L2W2-13-G-C.

DES /R-L2W2-123-C-A * NOT D-L2W2-XHE * NOT R-L2W2-123-C-C *

IF NOT R-L2W2-123-C-A * NOT D-L2W2-XHE * NOT R-L2W2-123-C-C *

NOT ISR-TRA-MA * NOT OSR-TRA-MA * NOT LPR-CCF-PG-SUMP2 * NOT R-L2W2-13-G-C

THEN R-L2W2-13-C-C.

^EOS

RHRMODEL, L2W2R6, 18=

DES AFW-MDP-MA-FW3B + AFW-MDP-MA-FW3A + AFW-MDP-FS-FW3A +

IF AFW-MDP-MA-FW3B + AFW-MDP-MA-FW3A + AFW-MDP-FS-FW3A + AFW-MDP-FS-FW3B + AFW-MOV-MA-151A + AFW-MOV-MA-151B + AFW-MOV-MA-151C + AFW-MOV-MA-151D + AFW-MOV-MA-151E + AFW-MOV-MA-151F + AFW-MOV-FT-151A + AFW-MOV-FT-151B + AFW-MOV-FT-151C + AFW-MOV-FT-151D + AFW-MOV-FT-151E + AFW-MOV-FT-151F

THEN R-L2W2-123-C-A-F.

DES DCP-BDC-ST-BUS1B

IF DCP-BDC-ST-BUS1B

THEN R-L2W2-123-C-A-F.

DES LPI-MDP-FS-SI1B * AFW-MDP-MA-FW3B

IF LPI-MDP-FS-SI1B * AFW-MDP-MA-FW3B

THEN R-L2W2-123-C-A-F.

DES A-L2W2-XHE-FL-18 * AFW-MDP-MA-FW3B

IF A-L2W2-XHE-FL-18 * AFW-MDP-MA-FW3B

THEN R-L2W2-123-C-A-F.

DES LPI-MDP-FS-SI1B * AFW-MDP-FS-FW3B

IF LPI-MDP-FS-SI1B * AFW-MDP-FS-FW3B

THEN R-L2W2-123-C-A-F.

DES A-L2W2-XHE-FL-18 * AFW-MDP-FS-FW3B

IF A-L2W2-XHE-FL-18 * AFW-MDP-FS-FW3B

THEN R-L2W2-123-C-A-F.

DES /R-L2W2-123-C-A-F * NOT D-L2W2-XHENOT MSS-AOV-FC-101A *

IF NOT R-L2W2-123-C-A-F * NOT D-L2W2-XHE * NOT MSS-AOV-FC-101A *

NOT MSS-AOV-FC-101B * NOT MSS-AOV-FC-101C * NOT MSS-AOV-MA-101A *

NOT MSS-AOV-MA-101B * NOT MSS-AOV-MA-101C * NOT LOOPISOLATED2R6 * 
10 Accident Sequence Quantification

Table 10-58 (continued)

NOT SGA-DRAINED-R * NOT SGB-DRAINED-R * NOT SGC-DRAINED-R * NOT A-L2W2-XHE-S1-17 * NOT SOLAIR-COMP * NOT FIRE-PUMP * NOT SAS-CPS-FR-1SAC1 * NOT SAS-CPS-FR-2SAC1 * NOT IAS-CPS-FS-IAC-1 * NOT IAS-CPS-FR-IAC-1 * NOT SGS-DRAINED-CSD * NOT A-L2-XHE-S * NOT MSS-AOV-FT-101A * NOT MSS-AOV-FT-101B * NOT MSS-AOV-FT-101C * NOT IAS-CCF-LF-INAIR * NOT PORV-PATH-CLSD * NOT DCP-BDC-ST-BUS1B * NOT LPI-MDP-FS-SI1B * NOT A-L2W2-XHE-FL-18

THEN R-L2W2-123-C-C-F.

DES AFW-CCF-FS-FW3AB + AFW-CKV-OO-CV142 + A-L2W2-XHE-SF-17

IF AFW-CCF-FS-FW3AB + AFW-CKV-OO-CV142 + A-L2W2-XHE-SF-17

THEN R-L2W2-123-C-C-F.

DES A-L2W2-XHE-X

IF A-L2W2-XHE-X

THEN R-L2W2-13-G-C-F.

DES /R-L2W2-123-C-A-F * NOT D-L2W2-XHE * NOT R-L2W2-123-C-C-F *

IF NOT R-L2W2-123-C-A-F * NOT D-L2W2-XHE * NOT R-L2W2-123-C-C-F * NOT PORV-PATH-CLSD * NOT DCP-BDC-ST-BUS1B * NOT LPI-MDP-FS-SI1B * NOT A-L2W2-XHE-FL-18 * NOT R-L2W2-13-G-C-F

THEN R-L2W2-13-C-C-F.

DES LPI-MDP-FS-SI1BNOT R-L2W2-123-C-A-F

IF LPI-MDP-FS-SI1B * NOT R-L2W2-123-C-A-F

THEN R-L2W2-13-C-C-F.

DES A-L2W2-XHE-FL-18NOT R-L2W2-123-C-A-F

IF A-L2W2-XHE-FL-18 * NOT R-L2W2-123-C-A-F

THEN R-L2W2-13-C-C-F.

^EOS

RHRMODEL, L2W3D6, $5=$

DES NRAC346 L2W3D6

IF FREQ-L2

THEN A-CCW3-XHE-S2-7.

^EOS

RHRMODEL, L2W3D6, $8=$

DES AFW-MDP-MA-FW3B + AFW-MDP-MA-FW3A + AFW-MDP-FS-FW3A +

IF AFW-MDP-MA-FW3B + AFW-MDP-MA-FW3A + AFW-MDP-FS-FW3A + AFW-MDP-FS-FW3B + AFW-MOV-MA-151A + AFW-MOV-MA-151B + AFW-MOV-MA-151C + AFW-MOV-MA-151D + AFW-MOV-MA-151E + AFW-MOV-MA-151F + AFW-MOV-FT-151A + AFW-MOV-FT-151B + AFW-MOV-FT-151C + AFW-MOV-FT-151D + AFW-MOV-FT-151E + AFW-MOV-FT-151F

THEN R-L2W3-123-C-A-F.

DES DCP-BDC-ST-BUS1B

IF DCP-BDC-ST-BUS1B

THEN R-L2W3-123-C-A-F. DES LPI-MDP-FS-SI1B * AFW-MDP-MA-FW3B

IF LPI-MDP-FS-SI1B * AFW-MDP-MA-FW3B

THEN R-L2W3-123-C-A-F.

DES A-L2W3-XHE-FL-12 * AFW-MDP-MA-FW3B

IF A-L2W3-XHE-FL-12 * AFW-MDP-MA-FW3B

THEN R-L2W3-123-C-A-F.

DES LPI-MDP-FS-SI1B * AFW-MDP-FS-FW3B

NUREG/CR-6144

$10-120$ 
Table 10-58 (continued)

IF LPI-MDP-FS-SI1B * AFW-MDP-FS-FW3B

THEN R-L2W3-123-C-A-F.

DES A-L2W3-XHE-FL-12 * AFW-MDP-FS-FW3B

IF A-L2W3-XHE-FL-12 * AFW-MDP-FS-FW3B

THEN R-L2W3-123-C-A-F.

DES /R-L2W3-123-C-A-F * NOT D-L2W3-XHENOT MSS-AOV-FC-101A *

IF NOT R-L2W3-123-C-A-F * NOT D-L2W3-XHE * NOT MSS-AOV-FC-101A *

NOT MSS-AOV-FC-101B * NOT MSS-AOV-FC-101C * NOT MSS-AOV-MA-101A *

NOT MSS-AOV-MA-101B * NOT MSS-AOV-MA-101C * NOT LOOPISOLATED3D6 *

NOT SGA-DRAINED-R * NOT SGB-DRAINED-R * NOT SGC-DRAINED-R *

NOT A-L2W3-XHE-S1-8 * NOT SOLAIR-COMP * NOT FIRE-PUMP *

NOT SAS-CPS-FR-1SAC1 * NOT SAS-CPS-FR-2SAC1 * NOT IAS-CPS-FS-IAC-1 *

NOT IAS-CPS-FR-IAC-1 * NOT SGS-DRAINED-CSD * NOT A-L2-XHE-S *

NOT MSS-AOV-FT-101A * NOT MSS-AOV-FT-101B * NOT MSS-AOV-FT-101C *

NOT IAS-CCF-LF-INAIR * NOT PORV-PATH-CLSD * NOT DCP-BDC-ST-BUS1B *

NOT LPI-MDP-FS-SI1B * NOT A-L2W3-XHE-FL-12

THEN R-L2W3-123-C-C-F.

DES AFW-CCF-FS-FW3AB + AFW-CKV-OO-CV142 + A-L2W3-XHE-SF-8

IF AFW-CCF-FS-FW3AB + AFW-CKV-OO-CV142 + A-L2W3-XHE-SF-8

THEN R-L2W3-123-C-C-F.

DES /R-L2W3-123-C-A-F * NOT D-L2W3-XHE * NOT R-L2W3-123-C-C-F *

IF NOT R-L2W3-123-C-A-F * NOT D-L2W3-XHE * NOT R-L2W3-123-C-C-F *

NOT PORV-PATH-CLSD * NOT DCP-BDC-ST-BUS1B * NOT LPI-MDP-FS-SI1B *

NOT A-L2W3-XHE-FL-12

THEN R-L2W3-13-C-C-F.

DES LPI-MDP-FS-SI1BNOT R-L2W3-123-C-A-F

IF LPI-MDP-FS-SI1B * NOT R-L2W3-123-C-A-F

THEN R-L2W3-13-C-C-F.

DES A-L2W3-XHE-FL-12NOT R-L2W3-123-C-A-F

IF A-L2W3-XHE-FL-12 * NOT R-L2W3-123-C-A-F

THEN R-L2W3-13-C-C-F.

^ EOS

RHRMODEL, L2W3R10, 05=

DES /NRAC346 L2W3R10

IF FREQ-L2

THEN A-CCW3-XHE-S2-7.

$\wedge$ EOS

RHRMODEL, L2W3R10, 10=

DES /NRAC346 L2W3R10

IF FREQ-L2

THEN A-CCW3-XHE-S2-7.

^EOS

RHRMODEL, L2W3R6, 05=

DES NRAC346 L2W3R6

IF FREQ-L2

THEN A-CCW3-XHE-S2-7.

^EOS

RHRMODEL, L2W3R6, 08= 
10 Accident Sequence Quantification

Table 10-58 (continued)

DES /D-L2W3-XHE

IF NOT D-L2W3-XHE

THEN R-L2W3-13-C-C-F.

^EOS

RHRMODEL, L2W3R6, 10=

DES NRAC346 L2W3R6

IF FREQ-L2

THEN A-CCW3-XHE-S2-7.

^EOS

RHRMODEL, L2W4D6, 5=

DES /NRAC455 L2W4D6

IF FREQ-L2

THEN A-CCW3-XHE-S2-7.

^EOS

RHRMODEL, L2W4R10, 05=

DES /NRAC455 L2W4R10

IF FREQ-L2

THEN A-CCW3-XHE-S2-7.

^EOS

RHRMODEL, L2W4R10, 08= DES /D-L2W4-XHE

IF NOT D-L2W4-XHE

THEN R-L2W4-13-C-C-F.

^ EOS

RHRMODEL, L2W4R10, 10=

DES /NRAC455 L2W4R10

IF FREQ-L2

THEN A-CCW3-XHE-S2-7.

$\wedge$ EOS

RHRMODEL, L2W4R10, $12=$ DES /D-L2W4-XHE

IF NOT D-L2W4-XHE

THEN R-L2W4-13-C-C-F.

^EOS

RHRMODEL, L2W4R6, 05=

DES /NRAC455 L2W4R6

IF FREQ-L2

THEN A-CCW3-XHE-S2-7.

^EOS

RHRMODEL, L2W4R6, 10=

DES NRAC455 L2W4R6

IF FREQ-L2

THEN A-CCW3-XHE-S2-7.

^EOS

RHRMODEL, L3W1D6, 4=

DES /NRAC200 L3W1D6

IF FREQ-L3

THEN A-CCW3-XHE-S1-7.

NUREG/CR-6144 
Table 10-58 (continued)

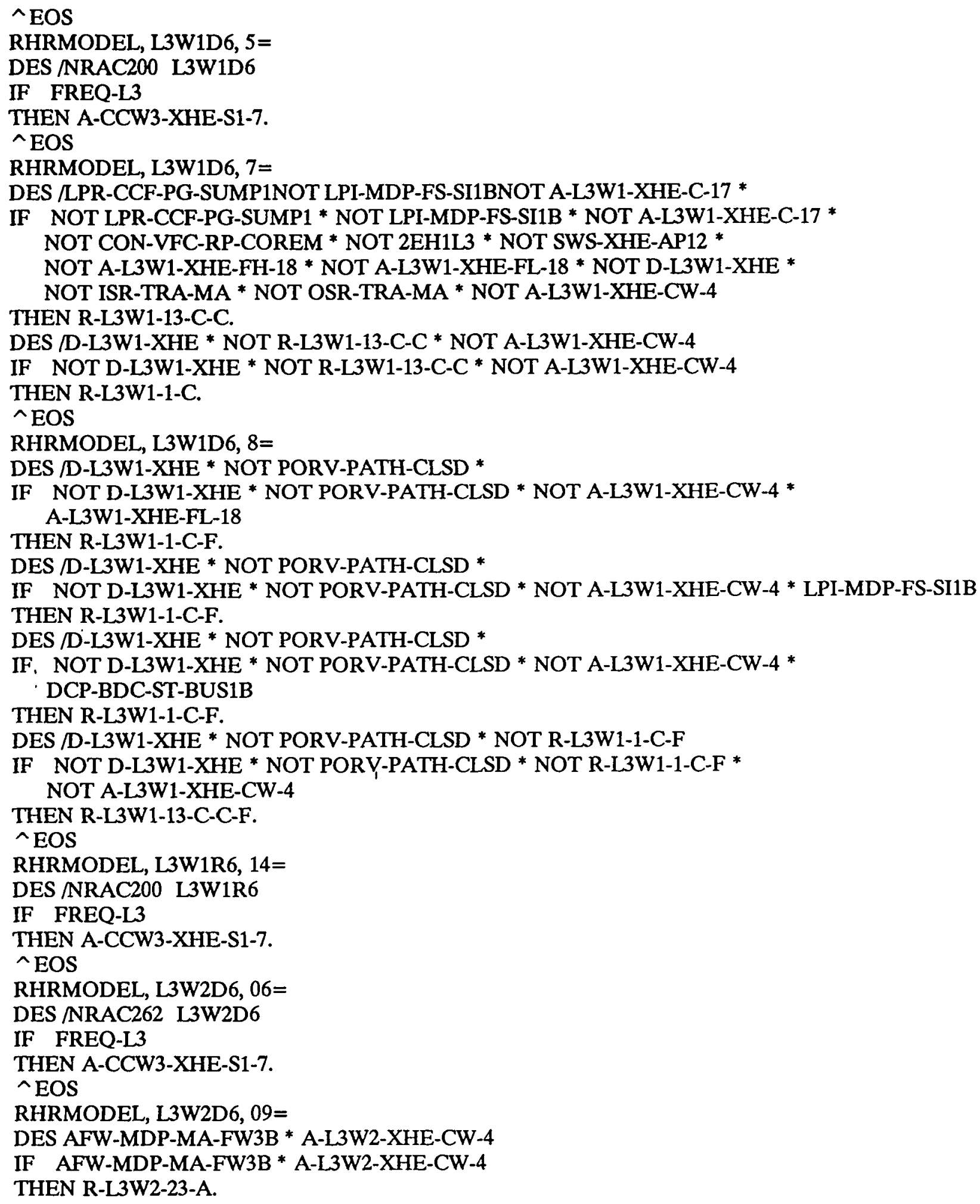


10 Accident Sequence Quantification

Table 10-58 (continued)

DES AFW-MDP-FS-FW3B * A-L3W2-XHE-CW-4

IF AFW-MDP-FS-FW3B * A-L3W2-XHE-CW-4

THEN R-L3W2-23-A.

DES AFW-MDP-MA-FW3B * NOT A-L3W2-XHE-CW-4

IF AFW-MDP-MA-FW3B * NOT A-L3W2-XHE-CW-4

THEN R-L3W2-123-C-A.

DES AFW-MDP-FS-FW3B * NOT A-L3W2-XHE-CW-4

IF AFW-MDP-FS-FW3B * NOT A-L3W2-XHE-CW-4

THEN R-L3W2-123-C-A.

DES /R-L3W2-123-C-A * NOT D-L3W2-XHENOT MSS-AOV-FC-101A *

IF NOT R-L3W2-123-C-A * NOT D-L3W2-XHE * NOT MSS-AOV-FC-101A *

NOT MSS-AOV-FC-101B * NOT MSS-AOV-FC-101C * NOT MSS-AOV-MA-101A *

NOT MSS-AOV-MA-101B * NOT MSS-AOV-MA-101C * NOT LOOPISOLATED2R6 *

NOT SGA-DRAINED-R * NOT SGB-DRAINED-R * NOT SGC-DRAINED-R *

NOT A-L3W2-XHE-S1-17 * NOT SOLAIR-COMP * NOT FIRE-PUMP *

NOT SAS-CPS-FR-1SAC1 * NOT SAS-CPS-FR-2SAC1 * NOT IAS-CPS-FS-IAC-1 *

NOT IAS-CPS-FR-IAC-1 * NOT SGS-DRAINED-CSD * NOT A-L3-XHE-S *

NOT MSS-AOV-FT-101A * NOT MSS-AOV-FT-101B * NOT MSS-AOV-FT-101C *

NOT ISR-TRA-MA * NOT OSR-TRA-MA * NOT LPR-CCF-PG-SUMP2 *

NOT IAS-CCF-LF-INAIR * NOT A-L3W2-XHE-CW-4

THEN R-L3W2-123-C-C.

DES AFW-CCF-FS-FW3AB + AFW-CKV-OO-CV142 + A-L3W2-XHE-SF-17

IF AFW-CCF-FS-FW3AB + AFW-CKV-OO-CV142 + A-L3W2-XHE-SF-17

THEN R-L3W2-123-C-C.

DES A-L3W2-XHE-X

IF A-L3W2-XHE-X * NOT A-L3W2-XHE-CW-4

THEN R-L3W2-13-C-C.

DES /R-L3W2-123-C-A * NOT D-L3W2-XHE * NOT R-L3W2-123-C-C *

IF NOT R-L3W2-123-C-A * NOT D-L3W2-XHE * NOT R-L3W2-123-C-C * NOT ISR-TRA-MA * NOT OSR-TRA-MA * NOT LPR-CCF-PG-SUMP2 * NOT R-L3W2-13-C-C * NOT A-L3W2-XHE-CW-4

THEN R-L3W2-13-C-C.

$\wedge$ EOS

RHRMODEL, L3W2D6, 10=

DES AFW-MDP-MA-FW3B * A-L3W2-XHE-CW-4

IF AFW-MDP-MA-FW3B * A-L3W2-XHE-CW-4

THEN R-L3W2-23-A-F.

DES AFW-MDP-FS-FW3B * A-L3W2-XHE-CW-4

IF AFW-MDP-FS-FW3B * A-L3W2-XHE-CW-4

THEN R-L3W2-23-A-F.

DES AFW-MDP-MA-FW3B * NOT A-L3W2-XHE-CW-4

IF AFW-MDP-MA-FW3B * NOT A-L3W2-XHE-CW-4

THEN R-L3W2-123-C-A-F.

DES AFW-MDP-FS-FW3B * NOT A-L3W2-XHE-CW-4

IF AFW-MDP-FS-FW3B * NOT A-L3W2-XHE-CW-4

THEN R-L3W2-123-C-A-F.

DES A-L3W2-XHE-FL-18 * AFW-MDP-MA-FW3B

IF A-L3W2-XHE-FL-18 * AFW-MDP-MA-FW3B

NUREG/CR-6144

$10-124$ 
Table 10-58 (continued)

THEN R-L3W2-123-C-A-F.

DES /R-L3W2-123-C-A-F * NOT D-L3W2-XHENOT MSS-AOV-FC-101A *

IF NOT R-L3W2-123-C-A-F * NOT D-L3W2-XHE * NOT MSS-AOV-FC-101A *

NOT MSS-AOV-FC-101B * NOT MSS-AOV-FC-101C * NOT MSS-AOV-MA-101A *

NOT MSS-AOV-MA-101B * NOT MSS-AOV-MA-101C * NOT LOOPISOLATED2D6 *

NOT SGA-DRAINED-R * NOT SGB-DRAINED-R * NOT SGC-DRAINED-R *

NOT A-L3W2-XHE-S1-17 * NOT SOLAIR-COMP * NOT FIRE-PUMP *

NOT SAS-CPS-FR-1SAC1 * NOT SAS-CPS-FR-2SAC1 * NOT IAS-CPS-FS-IAC-1 *

NOT IAS-CPS-FR-IAC-1 * NOT SGS-DRAINED-CSD * NOT A-L3-XHE-S *

NOT MSS-AOV-FT-101A * NOT MSS-AOV-FT-101B * NOT MSS-AOV-FT-101C *

NOT IAS-CCF-LF-INAIR * NOT PORV-PATH-CLSD * NOT DCP-BDC-ST-BUS1B *

NOT LPI-MDP-FS-SI1B * NOT A-L3W2-XHE-FL-18 * NOT A-L3W2-XHE-CW-4

THEN R-L3W2-123-C-C-F.

DES /R-L3W2-123-C-A-F * NOT D-L3W2-XHE * NOT R-L3W2-123-C-C-F *

IF, NOT R-L3W2-123-C-A-F * NOT D-L3W2-XHE * NOT R-L3W2-123-C-C-F *

NOT PORV-PATH-CLSD * NOT DCP-BDC-ST-BUS1B * NOT LPI-MDP-FS-SI1B *

NOT A-L3W2-XHE-FL-18 * NOT A-L3W2-XHE-CW-4

THEN R-L3W2-13-C-C-F.

$\wedge$ EOS

RHRMODEL, L3W2R6, 06=

DES /NRAC262 L3W2R6

IF FREQ-L3

THEN A-CCW3-XHE-S1-7.

^EOS

RHRMODEL, L3W2R6, 14=

DES /NRAC262 L3W2R6

IF FREQ-L3

THEN A-CCW3-XHE-S1-7.

$\wedge$ EOS

RHRMODEL, L3W2R6, 17=

DES AFW-MDP-MA-FW3B * A-L3W2-XHE-CW-4

IF AFW-MDP-MA-FW3B * A-L3W2-XHE-CW-4

THEN R-L3W2-23-A.

DES AFW-MDP-FS-FW3B * A-L3W2-XHE-CW-4

IF AFW-MDP-FS-FW3B * A-L3W2-XHE-CW-4

THEN R-L3W2-23-A.

DES AFW-MDP-MA-FW3B * NOT A-L3W2-XHE-CW-4

IF AFW-MDP-MA-FW3B * NOT A-L3W2-XHE-CW-4

THEN R-L3W2-123-C-A.

DES AFW-MDP-FS-FW3B * NOT A-L3W2-XHE-CW-4

IF AFW-MDP-FS-FW3B * NOT A-L3W2-XHE-CW-4

THEN R-L3W2-123-C-A.

DES /R-L3W2-123-C-A * NOT D-L3W2-XHENOT MSS-AOV-FC-101A *

IF NOT R-L3W2-123-C-A * NOT D-L3W2-XHE * NOT MSS-AOV-FC-101A *

NOT MSS-AOV-FC-101B * NOT MSS-AOV-FC-101C * NOT MSS-AOV-MA-101A *

NOT MSS-AOV-MA-101B * NOT MSS-AOV-MA-101C * NOT LOOPISOLATED2R6 *

NOT SGA-DRAINED-R * NOT SGB-DRAINED-R * NOT SGC-DRAINED-R *

NOT A-L3W2-XHE-S1-17 * NOT SOLAIR-COMP * NOT FIRE-PUMP * 
Table 10-58 (continued)

NOT SAS-CPS-FR-1SAC1 * NOT SAS-CPS-FR-2SAC1 * NOT IAS-CPS-FS-IAC-1 * NOT IAS-CPS-FR-IAC-1 * NOT SGS-DRAINED-CSD * NOT A-L3-XHE-S * NOT MSS-AOV-FT-101A * NOT MSS-AOV-FT-101B * NOT MSS-AOV-FT-101C * NOT ISR-TRA-MA * NOT OSR-TRA-MA * NOT LPR-CCF-PG-SUMP2 *

NOT IAS-CCF-LF-INAIR * NOT A-L3W2-XHE-CW-4 * NOT A-L3W2-XHE-FL-18 THEN R-L3W2-123-C-C. DES /R-L3W2-123-C-A * NOT D-L3W2-XHE * NOT R-L3W2-123-C-C *

IF NOT R-L3W2-123-C-A * NOT D-L3W2-XHE * NOT R-L3W2-123-C-C * NOT ISR-TRA-MA * NOT OSR-TRA-MA * NOT LPR-CCF-PG-SUMP2 * ! NOT A-L3W2-XHE-CW-4 * NOT A-L3W2-XHE-FL-18 THEN R-L3W2-13-C-C.

^EOS

RHRMODEL, L3W2R6, 18=

DES AFW-MDP-MA-FW3B * A-L3W2LXHE-CW-4

IF AFW-MDP-MA-FW3B * A-L3W2-XHE-CW-4

THEN R-L3W2-23-A-F.

DES AFW-MDP-FS-FW3B * A-L3W2-XHE-CW-4

IF AFW-MDP-FS-FW3B * A-L3W2-XHE-CW-4

THEN R-L3W2-23-A-F.

DES AFW-MDP-MA-FW3B * NOT A-L3W2-XHE-CW-4

IF AFW-MDP-MA-FW3B * NOT A-L3W2-XHE-CW-4

THEN R-L3W2-123-C-A-F.

DES AFW-MDP-FS-FW3B * NOT A-L3W2-XHE-CW-4

IF AFW-MDP-FS-FW3B * NOT A-L3W2-XHE-CW-4

THEN R-L3W2-123-C-A-F.

DES A-L3W2-XHE-FL-18 * AFW-MDP-MA-FW3B

IF A-L3W2-XHE-FL-18 * AFW-MDP-MA-FW3B

THEN R-L3W2-123-C-A-F.

DES /R-L3W2-123-C-A-F * NOT D-L3W2-XHENOT MSS-AOV-FC-101A *

IF NOT R-L3W2-123-C-A-F * NOT D-L3W2-XHE * NOT MSS-AOV-FC-101A * NOT MSS-AOV-FC-101B * NOT MSS-AOV-FC-101C * NOT MSS-AOV-MA-101A * NOT MSS-AOV-MA-101B * NOT MSS-AOV-MA-101C * NOT LOOPISOLATED2R6 * NOT SGA-DRAINED-R * NOT SGB-DRAINED-R * NOT SGC-DRAINED-R * NOT A-L3W2-XHE-S1-17 * NOT SOLAIR-COMP * NOT FIRE-PUMP * NOT SAS-CPS-FR-1SAC1 * NOT SAS-CPS-FR-2SAC1 * NOT IAS-CPS-FS-IAC-1 * NOT IAS-CPS-FR-IAC-1 * NOT SGS-DRAINED-CSD * NOT A-L3-XHE-S * NOT MSS-AOV-FT-101A * NOT MSS-AOV-FT-101B * NOT MSS-AOV-FT-101C * NOT IAS-CCF-LF-INAIR * NOT PORV-PATH-CLSD * NOT DCP-BDC-ST-BUS1B * NOT LPI-MDP-FS-SI1B * NOT A-L3W2-XHE-FL-18 * NOT A-L3W2-XHE-CW-4 THEN R-L3W2-123-C-C-F.

DES /R-L3W2-123-C-A-F * NOT D-L3W2-XHE * NOT R-L3W2-123-C-C-F *

IF NOT R-L3W2-123-C-A-F * NOT D-L3W2-XHE * NOT R-L3W2-123-C-C-F * NOT PORV-PATH-CLSD * NOT DCP-BDC-ST-BUS1B * NOT LPI-MDP-FS-SI1B * NOT A-L3W2-XHE-FL-18 * NOT A-L3W2-XHE-CW-4

THEN R-L3W2-13-C-G-F.

^EOS

RHRMODEL, L3W3D6, $5=$

DES /NRAC346 L3W3D6 
10 Accident Sequence Quantification

Table 10-58 (continued)

IF FREQ-L3

THEN A-CCW3-XHE-S2-7.

^EOS

RHRMODEL, L3W3D6, 8=

DES AFW-MDP-MA-FW3B * A-L3W3-XHE-CW-4

IF AFW-MDP-MA-FW3B * A-L3W3-XHE-CW-4

THEN R-L3W3-23-A-F.

DES AFW-MDP-FS-FW3B * A-L3W3-XHE-CW-4

IF AFW-MDP-FS-FW3B * A-L 3W3-XHE-CW-4

THEN R-L3W3-23-A-F.

DES AFW-MDP-MA-FW3B * NOT A-L3W3-XHE-CW-4

IF AFW-MDP-MA-FW3B * NOT A-L3W3-XHE-CW-4

THEN R-L3W3-123-C-A-F.

DES AFW-MDP-FS-FW3B * NOT A-L3W3-XHE-CW-4

IF AFW-MDP-FS-FW3B * NOT A-L3W3-XHE-CW-4

THEN R-L3W3-123-C-A-F.

DES A-L3W3-XHE-FL-12 * AFW-MDP-MA-FW3B

IF A-L3W3-XHE-FL-12 * AFW-MDP-MA-FW3B

THEN R-L3W3-123-C-A-F.

DES /R-L3W3-123-C-A-F * NOT D-L3W3-XHENOT MSS-AOV-FC-101A *

IF NOT R-L3W3-123-C-A-F * NOT D-L3W3-XHE * NOT MSS-AOV-FC-101A *

NOT MSS-AOV-FC-101B * NOT MSS-AOV-FC-101C * NOT MSS-AOV-MA-101A *

NOT MSS-AOV-MA-101B * NOT MSS-AOV-MA-101C * NOT LOOPISOLATED3D6 *

NOT SGA-DRAINED-R * NOT SGB-DRAINED-R * NOT SGC-DRAINED-R *

NOT A-L3W3-XHE-S1-12 * NOT SOLAIR-COMP * NOT FIRE-PUMP *

NOT SAS-CPS-FR-1SAC1 * NOT SAS-CPS-FR-2SAC1 * NOT IAS-CPS-FS-IAC-1 *

NOT IAS-CPS-FR-IAC- 1 * NOT SGS-DRAINED-CSD * NOT A-L3-XHE-S *

NOT MSS-AOV-FT-101A * NOT MSS-AOV-FT-101B * NOT MSS-AOV-FT-101C *

NOT IAS-CCF-LF-INAIR * NOT PORV-PATH-CLSD * NOT DCP-BDC-ST-BUS1B *

NOT LPI-MDP-FS-SI1B * NOT A-L3W3-XHE-FL-12 * NOT A-L3W3-XHE-CW-4

THEN R-L3W3-123-C-C-F.

DES /R-L3W3-123-C-A-F * NOT D-L3W3-XHE * NOT R-L3W3-123-C-C-F *

IF NOT R-L3W3-123-C-A-F * NOT D-L3W3-XHE * NOT R-L3W3-123-C-C-F *

NOT PORV-PATH-CLSD * NOT DCP-BDC-ST-BUS1B * NOT LPI-MDP-FS-SI1B *

NOT A-L3W3-XHE-FL-12 * NOT A-L3W3-XHE-CW-4

THEN R-L3W3-13-C-C-F.

^EOS

RHRMODEL, L3W3R10, 05=

DES NRAC346 L3W3R10

IF FREQ-L3

THEN A-CCW3-XHE-S2-7.

$\wedge$ EOS

RHRMODEL, L3W3R6, 05=

DES /NRAC346 L3W3R6

IF FREQ-L3

THEN A-CCW3-XHE-S2-7.

$\wedge$ EOS

RHRMODEL, L3W3R6, 08= 
10 Accident Sequence Quantification

Table 10-58 (continued)

DES /D-L3W3-XHENOT A-L3W3-XHE-CW-4

IF NOT D-L3W3-XHE * NOT A-L3W3-XHE-CW-4

THEN R-L3W3-13-C-C-F.

^EOS

RHRMODEL, L3W3R6, 10=

DES /NRAC346 L3W3R6

IF FREQ-L3

THEN A-CCW3-XHE-S2-7.

^EOS

RHRMODEL, L3W4D6, 5=

DES /nrac455

IF DURATION-D6

THEN A-CCW3-XHE-S2-7.

^EOS

RHRMODEL, L3W4R10, 05=

DES /NRAC455 L3W4R10

IF FREQ-L3

THEN A-CCW3-XHE-S2-7.

AEOS

RHRMODEL, L3W4R10, 10=

DES /NRAC455 L3W4R10

IF FREQ-L3

THEN A-CCW3-XHE-S2-7.

^EOS

RHRMODEL, L3W4R10, 12=

DES /D-L3W4-XHENOT A-L3W4-XHE-CW-5

IF NOT D-L3W4-XHE * NOT A-L3W4-XHE-CW-5

THEN R-L3W4-13-C-C-F. 
uọ!n!̣ uosoq 8u!pnpu! 10N

\begin{tabular}{|c|c|c|c|c|c|c|}
\hline $.9-890 \%$ & 9-BLZ'E & $L-386 Z^{2} Z$ & $9-966^{\circ} \mathrm{I}$ & & & TVIOI \\
\hline $80-88^{\circ} 9$ & & & & $s 4 / L 0-3002 z$ & 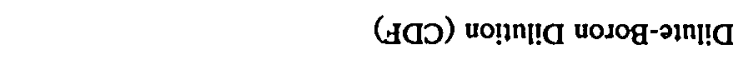 & 6 \\
\hline L-GSL'6 & L-BQL'9 & $8-3 \varepsilon\left\llcorner L^{\prime} Z\right.$ & $L-\mathrm{H} Z L Z Z$ & $\mathrm{AH} / \mathrm{t0}-\mathrm{B} 9 \mathrm{O}^{\circ} \mathrm{I}$ & 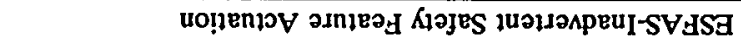 & 8 \\
\hline L-azz'I & 8-G0tiL & $8-96 I^{*} \mathrm{I}$ & 8-a85 $\varepsilon$ & 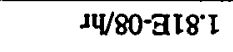 & 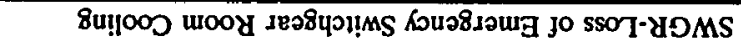 & ¿ \\
\hline$L-369^{\circ} Z$ & $L-390^{\circ} Z$ & $0 I-a b I^{\circ} I$ & 8-762.9 & $s 4 / 90-89 L^{*} \varepsilon$ & MOJ Jo SSOT-MDO & 9 \\
\hline $6-a s 6^{\circ} \varepsilon$ & $6-9 I^{\prime} \varepsilon$ & - & $0 \mathrm{I}-\mathrm{B} 06^{\circ} \mathrm{L}$ & $\mathrm{st} / \mathrm{g}-\mathrm{azI} Z \mathrm{Z}$ & 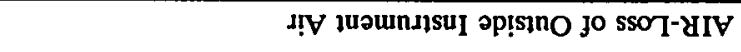 & 's \\
\hline$L \cdot 3900^{\prime} I$ & $8-36 Z^{2} L$ & 6-azI's & $8-\operatorname{BSL} \mathcal{L}$ & $\mathrm{s} 4 / 90-\mathrm{B} 8 \mathrm{~S} \mathrm{~S}$ & 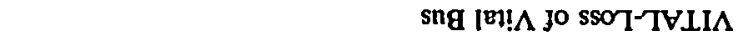 & it \\
\hline$\left\llcorner-\mathbf{a} 66^{\circ} \varepsilon\right.$ & $L-\mathbf{a} 0 \boldsymbol{t}^{\prime} \tau$ & $8-3<8^{\prime} \mathrm{I}$ & $L-\mathbf{A}$ It $\cdot I$ & $\mathrm{dy} / \mathrm{SO} 0-\mathrm{30I} 2$ & sng AYt jo ssoT- $\Lambda$ Xtp & $\mathfrak{\varepsilon}$ \\
\hline L-G88'I & $L-\mathbf{B} 60^{\circ} \mathbf{I}$ & $8-a 0 z$ & $8-\mathbf{Z} 9 L^{\circ} \mathcal{E}$ & $\triangle 4 / 60-\exists \angle[\cdot \mathcal{E}$ & 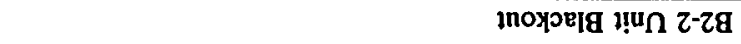 & \\
\hline$L-\mathbf{a} 62 \tau$ & $L-\mathbf{G} 0 L^{\prime} \mathbf{I}$ & $8-980^{\circ} \mathrm{I}$ & 8-asL't & $\mathrm{AL} / 80-\mathrm{GS} 6^{\circ} \mathrm{I}$ & 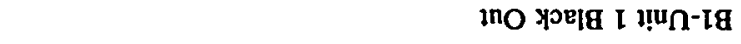 & \\
\hline$L-\mathbf{B} b S \mathbf{L}$ & $8-3<8^{\prime} 6$ & 8-a92 I & $8-a+z \boldsymbol{t}$ & sน/80-aโ8'E & 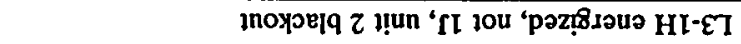 & \\
\hline L-assz & $L-\mathbf{B 8 9} \mathrm{I}$ & 8-ä0EI & $L-\mathrm{A}+0^{\circ} \mathrm{I}$ & $J \Psi / \angle 0-3 L E L$ & 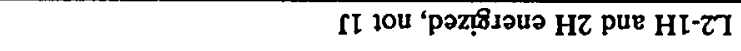 & \\
\hline \multirow[t]{2}{*}{$9-\mathrm{BSI} \cdot \mathrm{I}$} & $L-39 S L$ & 8-a969 & L- $\mathbf{G 9 \tau \varepsilon}$ & IU/90-30Z9 9 & paz!osoug fI pue HI ч108-IT & \\
\hline & & & & s4/90-396.9 & 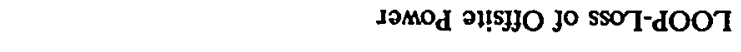 & $\tau$ \\
\hline L-G9EI & $8-75266$ & $60-390^{\circ} \mathrm{t}$ & $8-996{ }^{\circ} \varepsilon$ & $s 4 / 50-3 z I \cdot Z$ & 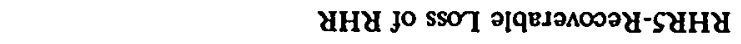 & \\
\hline $8-\mathbf{a} 6 \mathrm{I}^{\circ} \mathrm{E}$ & 8- $-\exists Z E Z$ & $6-36 I^{2} I$ & $6-3<S L$ & $34 / 90-360^{\circ} t$ & 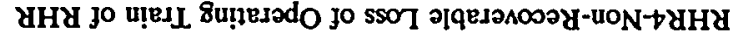 & \\
\hline$\angle-\mathbf{A z 9} \mathbf{b}^{\circ}$ & $L-9662$ & 6-76E8 & $L-a \uplus S \mathfrak{I}$ & $\mathrm{s} 4 / 90-962 \mathrm{~L}$ & 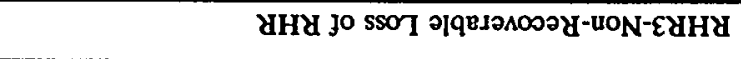 & \\
\hline $8-\mathrm{aE0} 0^{\circ} \mathrm{L}$ & $8-9162$ & $8-8+0 z$ & $80-880 \mathrm{z}$ & JW/SO-BZZ'I & 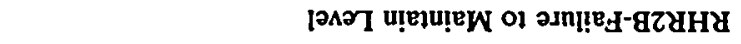 & \\
\hline$\angle-\mathbf{A} 58^{\circ} \mathrm{b}$ & $L$-aLSZ & 8-a92s & $L-\bar{B} S L^{\prime} \cdot \mathbf{I}$ & $\begin{array}{l}\text { pueurad/ } \\
\text { zo-azg't }\end{array}$ & 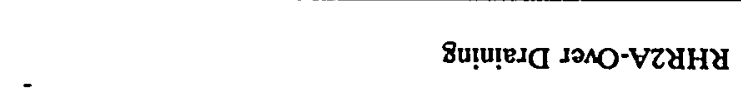 & \\
\hline [E1OL & 90 & oId & 98 & & XHষ JO SSOT & ' $\mathbf{I}$ \\
\hline \multicolumn{4}{|c|}{ 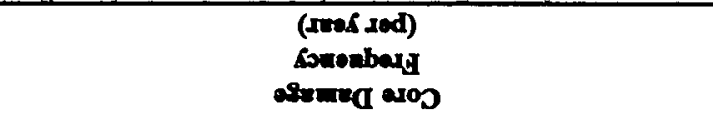 } & 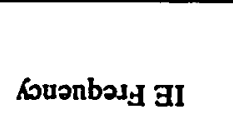 & JUอง 8น!̣ห!̣!̣I & \\
\hline
\end{tabular}

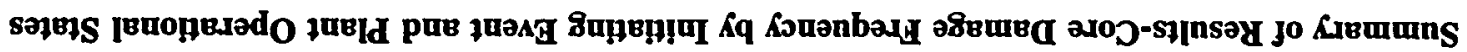

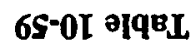


Table 10-60

Core Damage Frequency As a Function of the Time Windows and POSs (per year)

\begin{tabular}{||l|c|c|c|c||}
\hline & R6 & R10 & D6 & Total \\
\hline Window 1 (13hr-75hr) & $3.16 \mathrm{E}-07(4.04 \mathrm{E}-08)^{*}$ & - & $1.56 \mathrm{E}-06(1.74 \mathrm{E}-07)^{*}$ & $1.88 \mathrm{E}-06(2.14 \mathrm{E}-07)^{*}$ \\
\hline Window 2 (75hr-240hr) & $7.71 \mathrm{E}-07(1.06 \mathrm{E}-07)^{*}$ & - & $9.65 \mathrm{E}-07(6.88 \mathrm{E}-08)^{*}$ & $1.74 \mathrm{E}-06(1.75 \mathrm{E}-07)^{*}$ \\
\hline Window 3 (240-768hr) & $4.03 \mathrm{E}-07(3.54 \mathrm{E}-08)^{*}$ & $1.70 \mathrm{E}-08(1.14 \mathrm{E}-09)^{*}$ & $7.02 \mathrm{E}-07(2.41 \mathrm{E}-08)^{*}$ & $1.12 \mathrm{E}-06(6.06 \mathrm{E}-08)^{*}$ \\
\hline Window 4 (> 768 hr) & $1.03 \mathrm{E}-08(<1.0 \mathrm{E}-10)^{*}$ & $2.89 \mathrm{E}-07(5.36 \mathrm{E}-08)^{*}$ & $2.68 \mathrm{E}-08(5.78 \mathrm{E}-10)^{*}$ & $3.26 \mathrm{E}-07(5.41 \mathrm{E}-08)^{*}$ \\
\hline \hline TOTAL & $1.49 \mathrm{E}-06(1.82 \mathrm{E}-07)^{*}$ & $3.06 \mathrm{E}-07(5.47 \mathrm{E}-08)^{*}$ & $3.25 \mathrm{E}-06(2.67 \mathrm{E}-07)^{*}$ & $5.06 \mathrm{E}-06(5.04 \mathrm{E}-07)^{*}$ \\
\hline
\end{tabular}

- The numbers in parenthesis are the contributions of over-draining events. 
Table 10-61

Fraction of a Year That the Plant is in a Time Window of a POS

\begin{tabular}{||l|c|c|c|c|}
\hline & R6 & R10 & D6 & Total \\
\hline Window 1 (13hr-75hr) & $2.77 \mathrm{E}-02 \%$ & - & $0.41 \%$ & $0.44 \%$ \\
\hline Window 2 (75hr-240hr) & $0.88 \%$ & - & $1.52 \%$ & $2.4 \%$ \\
\hline Window 3 $(240-768 \mathrm{hr})$ & $0.67 \%$ & $2.43 \mathrm{E}-02 \%$ & $1.31 \%$ & $2.00 \%$ \\
\hline Window 4 (>768hr) & $5.50 \mathrm{E}-02 \%$ & $1.50 \%$ & $0.25 \%$ & $1.81 \%$ \\
\hline \hline TOTAL & $1.63 \%$ & $1.52 \%$ & $3.49 \%$ & $6.64 \%$ \\
\hline
\end{tabular}


Table 10-62

Conditional Core Damage Frequency As a Function of the Time Windows and POSs (per year)

\begin{tabular}{|l|c|c|c|l||}
\hline & \multicolumn{1}{|c|}{ R6 } & \multicolumn{1}{c|}{ R10 } & \multicolumn{1}{c|}{ D6 } & \multicolumn{1}{c|}{ Total } \\
\hline $\begin{array}{l}\text { Window 1 } \\
(13 \mathrm{hr}-75 \mathrm{hr})\end{array}$ & $9.96 \mathrm{E}-04(1.16 \mathrm{E}-06)^{*}$ & - & $3.37 \mathrm{E}-04(4.68 \mathrm{E}-07)^{*}$ & $\begin{array}{l}3.77 \mathrm{E}- \\
04(5.27 \mathrm{E}-07)^{*}\end{array}$ \\
\hline $\begin{array}{l}\text { Window 2 } \\
(75 \mathrm{hr}- \\
240 \mathrm{hr})\end{array}$ & $7.55 \mathrm{E}-05(2.52 \mathrm{E}-07)^{*}$ & - & $5.90 \mathrm{E}-05(1.26 \mathrm{E}-07)^{*}$ & $\begin{array}{l}7.25 \mathrm{E}- \\
05(1.81 \mathrm{E}-07)^{*}\end{array}$ \\
\hline $\begin{array}{l}\text { Window 3 } \\
(240-768 \mathrm{hr})\end{array}$ & $5.49 \mathrm{E}-05(2.46 \mathrm{E}-07)^{*}$ & $6.54 \mathrm{E}-05(1.73 \mathrm{E}-7)^{*}$ & $5.18 \mathrm{E}-05(9.56 \mathrm{E}-08)^{*}$ & $\begin{array}{l}5.60 \mathrm{E}- \\
05(1.51 \mathrm{E}-07)^{*}\end{array}$ \\
\hline $\begin{array}{l}\text { Window 4 } \\
(>768 \mathrm{hr})\end{array}$ & $1.87 \mathrm{E}-05(-)^{*}$ & $1.57 \mathrm{E}-05(1.82 \mathrm{E}-7)^{*}$ & $1.05 \mathrm{E}-05(1.85 \mathrm{E}-08)^{*}$ & $\begin{array}{l}1.80 \mathrm{E}- \\
05(1.66 \mathrm{E}-07)^{*}\end{array}$ \\
\hline TOTAL & $8.09 \mathrm{E}-05(3.03 \mathrm{E}-07)^{*}$ & $1.65 \mathrm{E}-05(1.82 \mathrm{E}-07)^{*}$ & $8.55 \mathrm{E}-05(2.23 \mathrm{E}-07)^{*}$ & $\begin{array}{l}7.62 \mathrm{E}- \\
05(2.40 \mathrm{E}-07)^{*}\end{array}$ \\
\hline
\end{tabular}

* Conditional core damage probability due to an over-draining event, given that mid-loop is reached in the time window. 


\section{PLANT DAMAge STATE ANALYSIS}

Plant damage state analysis was performed using the following approach:

Discussion with level-2/3 staffAfter a total of 2186 core damage cutsets above the $1.00 \mathrm{E}-10$ per truncation limit were generated, the scenarios depicted by the dominant cutsets were discussed with level- $2 / 3$ staff. This allows a common understanding of the level- 1 scenarios and permit the level-2 3 effort to proceed accordingly. It was found that 82 cutsets above the frequency of $1.00 \mathrm{E}-08$ per year, listed in Tables $10-50$, constitutes only $71 \%$ of the total core damage frequency and 409 cutsets above $1.00 \mathrm{E}-09$ per year constitutes $89 \%$ of the total. It was decided to include all cutsets above $1.00 \mathrm{E}-10$ per year in the plant damage state analysis.

Development of 7 letter designator for plant damage statesBy a joined effort of the level 1,2, and 3 staff, a list of 7 questions were developed. Those 82 cutsets above $1.00 \mathrm{E}-08$ per year were evaluated based on the questions. Depending on the answer to each of the questions, a letter is assigned to the cutset. Table 11-1 lists the questions and the associated letters. An important consideration of the level-2 analysis is the possibility of preventing vessel breach given that core damage had occurred. This corresponds to what happened at Three Mile island accident in which the release to the environment is very limited. Table 11-2 shows the assignment of the plant damage states to the first 82 cutsets.

The following discusses the assignment of answers to the questions listed in Table 11-1.

1. Time Window-The time window in which the accident represented by the core damage cutset occurs can be easily determined by the basic event names used.

2. AC Power- This question determines whether or not recovery of offsite power after core damage can prevent further degradation of the condition. If core damage is caused by loss of offsite power, then it may be possible to re-establish injection after offsite power is recovered.

Y: If $\mathrm{AC}$ power is available in the cutset, then recovery of offsite power would not be beneficial.

U: This answer is used when the initiating event is a loss of emergency switchgear room cooling and cooling is not recovered. For such cutsets, the loss of power is not recoverable and vessel breach is unavoidable.

B: If the cutset represents a station blackout, then recovery of offsite power should restore power to the equipment that can be used to prevent vessel breach. Recovery of offsite power is characterized by the recovery curve given in chapter 4.

F: If the cutset involves a loss of the $4 \mathrm{KV}$ Bus, then restoring power to the bus should restore power to the equipment needed to prevent vessel breach. The recovery of $4 \mathrm{KV}$ bus is characterized by a different recovery curve than that of offsite power.

3. Human Error-If the core damage is the result of human error, then with more time available after core damage and additional alarms as a result of core damage, it is possible that the operators could recover from the error and initiate safety injection to prevent vessel breach. The type of human errors can be easily identified by the names of the human error events used.

4. RCS Status at onset of Core Damage-Based on the thermal hydraulic analysis of chapter 5, the RCS pressure could reach 600 psi if core damage occurs in time window 1 with only 1 PORV open to relieve system pressure. This is a condition for potential direct containment heating(DCH) to take place. Therefore, for those window 1 cutsets in which the pressurizer safety valves are not removed, a letter " $G$ " is assigned. For these cutsets, only 2 PORVs are potentially available to relieve the pressure. By, judgment, we estimated that 
during mid-loop operation there is a probability of 0.05 that one of the PORVs is closed. This is the probability that the condition for DCH exists for the cutsets.

5. ECCS Status-This question determines the cause of failure of the ECCS, which in turn determines the possibility to restore safety injection to prevent vessel breach.

U: This represents that hardware failure is the reason that ECCS is not available. Therefore, it is impossible to establish safety injection.

R: It the cause is due to either human error, loss of offsite power, or loss of $4 \mathrm{KV}$ bus, the recovery from these would permit safety injection to prevent vessel breach.

C: This letter is never used.

6. Recirculation Spray Status-The operation of recirculation spray systems can reduce the release inside the containment. Therefore, its operability is questioned. Unavailability of recirculation spray is determined by a set of basic events that were identified by reviewing the cutsets involving loss of recirculation spray. The set is used in the rules to assign the " $U$ " letter to this question.

7. RWST Status-The availability of RWST inventory determines the possibility of safety injection to prevent vessel breach. The RWST is injected in those event tree sequences in which failure occurs in the recirculation phase, gravity feed is successful, or use of unit 2 charging pump is successful. Otherwise, RWST inventory is available.

Development of Rules of PDS AssigmmentIn manually assigning PDS to the first 82 cutsets, the patterns or rules for the assignment were identified. The rules were implemented using a database software, REFLEX, to automatically assign the PDSs to all the cutsets. An ASCII file containing all the core damage cutsets was created using the IRRAS code and imported into the REFLEX database. The results of the assignment were verified to ensure that the assignments for the first 82 cutsets agree with the results of manual assignment. A total of 48 different PDS were obtained. The are listed in Table 11-3.

Performance of uncertainty analysis of the PDSsUncertainty analyses of the PDSs were performed in two ways. First, uncertainty analysis of each PDS was performed using the IRRAS code with 10,000 Latin Hyper-cube Sampling (LHS) samples. The results of the analysis are shown in Table 11-3. Then, a "group" analyses of all 48 PDSs was performed using 1,000 LHS samples. In the "group" analysis, the same samples for a basic event that appears in many PDSs were used in those PDSs. This allows the uncertainty analysis to account for the fact that the PDSs share many basic events. An ASCII file containing the values of the samples of the basic events and the calculated values of the PDSs using these basic event values was created. This file is used in the uncertainty analysis of the overall risks. 
11 Plant Damage State Analysis

1. Time of Accident Initiation

\section{Table 11-1PDS Definition}

1: Window 1

2: Window 2

3: Window 3

4: Window 4

2. AC Power

Y: Available

U: Non-recoverable blackout(FREQ-SR)

B: Blackout(recoverable by recovery of offsite power)

F: Loss of 4KV Bus(its own recovery curve)

3. Human Error

N: No human error or non-recoverable human error

D: Diagnosis error

A: Action error

4. RCS Status at Onset of Core Damage

L: Low pressure

G: $5 \%$ probability that pressure is high

5. ECCS Status

U: Hardware failure

R: Recoverable if human error, LOSP, or $4 \mathrm{KV}$ is recovered

C: Failure of recirculation

6. Recirculation Spray Status

R: recoverable

$\mathrm{U}$ : not recoverable

7. RWST Status

Y: Injected

R: Not injected but recoverable

$\mathrm{N}$ : Not injected and not recoverable 
11 Plant Damage State Analysis

Table 11-2

Plant Damage State Assignment of the Dominant Cutsets

\begin{tabular}{|c|c|c|}
\hline 1 & 2YDLRRR & $2.20 \mathrm{E}-07$ \\
\hline 2 & 3YDLRRR & 2.07E-07 \\
\hline 3 & 2YDLRRR & $1.70 \mathrm{E}-07$ \\
\hline 4 & 1YNGCUY & $1.46 \mathrm{E}-07$ \\
\hline 5 & 3YDLRRR & $1.46 \mathrm{E}-07$ \\
\hline 6 & 1YDGRRR & $1.24 \mathrm{E}-07$ \\
\hline 7 & 2YDLRRR & $1.22 \mathrm{E}-07$ \\
\hline 8 & 1YNGCUY & $1.08 \mathrm{E}-07$ \\
\hline 9 & 3YDLRRR & 9.52E-08 \\
\hline 10 & 2YDLRRR & 9.37E-08 \\
\hline 11 & 1YDGRRR & $9.04 \mathrm{E}-08$ \\
\hline 12 & 1YDGRRR & 8.73E-08 \\
\hline 13 & 2YDLRRR & 7.74E-08 \\
\hline 14 & 1BNGRRR & 7.38E-08 \\
\hline 15 & 3YDLRRR & $6.70 \mathrm{E}-08$ \\
\hline 16 & 1YDGRRR & $5.82 \mathrm{E}-08$ \\
\hline 17 & 1FNGRRY & $5.41 \mathrm{E}-08$ \\
\hline 18 & 2YDLRRR & 5.38E-08 \\
\hline 19 & 3YDLRRR & $5.29 \mathrm{E}-08$ \\
\hline 20 & 3YDLRRR & 5.07E-08 \\
\hline 21 & 3YDLRRR & $4.86 \mathrm{E}-08$ \\
\hline 22 & 2BNLRRR & $4.75 \mathrm{E}-08$ \\
\hline 23 & 1YNGCYY & $4.39 \mathrm{E}-08$ \\
\hline 24 & 2YDLRRR & 4.27E-08 \\
\hline 25 & 4BNLRRR & 4.07E-08 \\
\hline 26 & 4YDLRRR & $3.91 \mathrm{E}-08$ \\
\hline 27 & 1BNGRRR & 3.63E-08 \\
\hline 28 & 2YDLRRR & 3.39E-08 \\
\hline
\end{tabular}


Table 11-2 (continued)

11 Plant Damage State Analysis

\begin{tabular}{|c|c|c|}
\hline 29 & 2UDLRUR & 3.38E-08 \\
\hline 30 & 2YDLRRR & $3.36 \mathrm{E}-08$ \\
\hline 31 & 2YDLRRR & 3.30E-08 \\
\hline 32 & 1BNGRRR & $3.27 \mathrm{E}-08$ \\
\hline 33 & 1YNGCYY & $3.23 \mathrm{E}-08$ \\
\hline 34 & 2YDLRRR & $2.97 \mathrm{E}-08$ \\
\hline 35 & 1YNGCUY & $2.95 \mathrm{E}-08$ \\
\hline 36 & 3YDLRRR & $2.92 \mathrm{E}-08$ \\
\hline 37 & 2YDLRRR & $2.91 \mathrm{E}-08$ \\
\hline 38 & 3UDLRUR & $2.91 \mathrm{E}-08$ \\
\hline 39 & 3YDLRRR & $2.89 \mathrm{E}-08$ \\
\hline 40 & 2BNLRRR & 2.62E-08 \\
\hline 41 & 1FNGRRY & $2.52 \mathrm{E}-08$ \\
\hline 42 & 1YNGCUY & $2.47 \mathrm{E}-08$ \\
\hline 43 & 3YDLRRR & 2.33E- 08 \\
\hline 44 & 3YDLRRR & $2.23 E-08$ \\
\hline 45 & 1YNGCUY & 2.17E-08 \\
\hline 46 & 3BNLRRR & $2.13 \mathrm{E}-08$ \\
\hline 47 & 2YALRUY & $2.11 \mathrm{E}-08$ \\
\hline 48 & 2YDLRRR & $2.01 \mathrm{E}-08$ \\
\hline 49 & 2YDLRRR & $1.89 \mathrm{E}-08$ \\
\hline 50 & 2YDLRRR & $1.87 \mathrm{E}-08$ \\
\hline 51 & 2UDLRUR & $1.87 \mathrm{E}-08$ \\
\hline 52 & 2YDLRRR & $1.86 \mathrm{E}-08$ \\
\hline 53 & 1YNGCUY & $1.83 \mathrm{E}-08$ \\
\hline 54 & 3YDLRRR & $1.83 \mathrm{E}-08$ \\
\hline 55 & 1YDGRRR & $1.79 \mathrm{E}-08$ \\
\hline 56 & 1YDGRRR & $1.75 \mathrm{E}-08$ \\
\hline
\end{tabular}


Table 11-2 (continued)

\begin{tabular}{|c|c|c|}
\hline 57 & 1YDGRRR & $1.73 E-08$ \\
\hline 58 & 3YDLRRR & $1.73 \mathrm{E}-08$ \\
\hline 59 & 1BNGRRR & $1.68 \mathrm{E}-08$ \\
\hline 60 & 4YDLRRR & $1.68 \mathrm{E}-08$ \\
\hline 61 & 2YDLRRR & $1.61 \mathrm{E}-08$ \\
\hline 62 & 1YDGRRR & $1.60 \mathrm{E}-08$ \\
\hline 63 & 1YNGCYY & $1.53 \mathrm{E}-08$ \\
\hline 64 & 1YAGCRY & $1.46 \mathrm{E}-08$ \\
\hline 65 & 1YNGCUY & $1.35 \mathrm{E}-08$ \\
\hline 66 & 3YDLRRR & $1.34 \mathrm{E}-08$ \\
\hline 67 & 3UDLRUR & $1.34 \mathrm{E}-08$ \\
\hline 68 & 3YDLRRR & $1.33 \mathrm{E}-08$ \\
\hline 69 & 2YDLRRR & $1.29 \mathrm{E}-08$ \\
\hline 70 & 2FALRRY & $1.26 \mathrm{E}-08$ \\
\hline 71 & 1YNGCYY & $1.19 \mathrm{E}-08$ \\
\hline 72 & 1YNGCYY & $1.19 \mathrm{E}-08$ \\
\hline 73 & 3YDLRRR & $1.19 \mathrm{E}-08$ \\
\hline 74 & 1FNGRRY & $1.15 \mathrm{E}-08$ \\
\hline 75 & 1YNGCUY & $1.13 \mathrm{E}-08$ \\
\hline 76 & 2YDLRRR & $1.11 \mathrm{E}-08$ \\
\hline 77 & 1FNGRRY & $1.09 \mathrm{E}-08$ \\
\hline 78 & 1YAGCRY & $1.08 \mathrm{E}-08$ \\
\hline 79 & 3YDLRRR & $1.07 \mathrm{E}-08$ \\
\hline 80 & 4YDLRRR & $1.07 \mathrm{E}-08$ \\
\hline 81 & 3YDLRRR & $1.06 \mathrm{E}-08$ \\
\hline 82 & 2YDLRRR & $1.04 \mathrm{E}-08$ \\
\hline
\end{tabular}


Table 11-3

11 Plant Damage State Analysis

Results of Uncertainty Analysis of Plant Damage States

\begin{tabular}{|c|c|c|c|c|c|}
\hline & PDS & MEAN & $5 \%$ & MEDIAN & $95 \%$ \\
\hline 1 & 1BNGCRY & 2.95E-09 & $5.90 \mathrm{E}-11$ & $7.48 \mathrm{E}-10$ & 1.11E-08 \\
\hline 2 & 1BNGRRR & $1.71 \mathrm{E}-07$ & 4.07E-09 & 4.40E-08 & $6.35 \mathrm{E}-07$ \\
\hline 3 & 1BNLCRY & $1.43 \mathrm{E}-10$ & $3.93 \mathrm{E}-13$ & $1.40 \mathrm{E}-11$ & $4.70 \mathrm{E}-10$ \\
\hline 4 & 1FAGRRY & 9.07E-09 & $1.39 \mathrm{E}-10$ & 2.12E-09 & $3.31 \mathrm{E}-08$ \\
\hline 5 & 1FNGRRR & $4.78 \mathrm{E}-10$ & $6.02 \mathrm{E}-12$ & 9.57E-11 & 1.73E-09 \\
\hline 6 & 1FNGRRY & $1.25 \mathrm{E}-07$ & 2.69E-09 & $3.43 \mathrm{E}-08$ & 4.62E-07 \\
\hline 7 & 1UAGCUY & $1.89 \mathrm{E}-10$ & $1.27 \mathrm{E}-12$ & $2.92 \mathrm{E}-11$ & 7.31E-10 \\
\hline 8 & 1UDGUUR & 8.29E-09 & 7.73E-12 & $4.40 \mathrm{E}-10$ & $2.51 \mathrm{E}-08$ \\
\hline 9 & 1UDLCUY & $6.08 \mathrm{E}-10$ & 8.79E-13 & $4.23 \mathrm{E}-11$ & $1.86 \mathrm{E}-09$ \\
\hline 10 & 1YAGCRY & 8.11E-08 & 4.12E-09 & $2.84 \mathrm{E}-08$ & $2.76 \mathrm{E}-07$ \\
\hline 11 & 1YAGCUY & $2.12 \mathrm{E}-08$ & $5.18 \mathrm{E}-10$ & 5.48E-09 & 7.93E-08 \\
\hline 12 & 1YAGRRR & 2.75E-09 & $1.46 \mathrm{E}-10$ & $1.04 \mathrm{E}-09$ & 9.32E-09 \\
\hline 13 & 1YDGRRR & $4.64 \mathrm{E}-07$ & $1.22 \mathrm{E}-08$ & $1.19 \mathrm{E}-07$ & $1.68 \mathrm{E}-06$ \\
\hline 14 & 1YNGCUY & 5.41E-07 & $1.29 \mathrm{E}-08$ & $1.28 \mathrm{E}-07$ & $1.96 \mathrm{E}-06$ \\
\hline 15 & $1 Y N G C Y Y$ & 3.15E-07 & $1.90 \mathrm{E}-08$ & $1.08 \mathrm{E}-07$ & $1.01 E-06$ \\
\hline 16 & 1YNGUUR & $1.49 \mathrm{E}-09$ & $2.67 \mathrm{E}-11$ & $3.54 \mathrm{E}-10$ & 5.50E-09 \\
\hline 17 & 1YNGUYR & 8.84E-09 & 6.17E-10 & 3.93E-09 & $3.03 \mathrm{E}-08$ \\
\hline 18 & 1YNLCUY & 2.22E-09 & $2.91 \mathrm{E}-12$ & $1.30 \mathrm{E}-10$ & $6.00 \mathrm{E}-09$ \\
\hline 19 & 1YNLCYY & $7.02 \mathrm{E}-10$ & $2.15 \mathrm{E}-12$ & $7.03 E-11$ & $2.45 \mathrm{E}-09$ \\
\hline 20 & 2BNLCRY & 3.34E-08 & $9.03 E-10$ & $9.76 \mathrm{E}-09$ & $1.18 \mathrm{E}-07$ \\
\hline 21 & 2BNLCUY & 2.99E-09 & $1.12 \mathrm{E}-11$ & $4.46 \mathrm{E}-10$ & $1.09 \mathrm{E}-08$ \\
\hline 22 & 2BNLRR & $1.05 \mathrm{E}-07$ & 4.01E-09 & 3.57E-08 & 3.75E-07 \\
\hline 23 & 2FALRRR & $1.46 \mathrm{E}^{\prime}-08$ & $2.44 \mathrm{E}-10$ & 3.57E-09 & $5.48 \mathrm{E}-08$ \\
\hline 24 & 2FALRRY & $4.31 \mathrm{E}-08$ & 1.17E-09 & $1.41 \mathrm{E}-08$ & $1.62 \mathrm{E}-07$ \\
\hline
\end{tabular}


11 Plant Damage State Analysis

Table 11-3 (continued)

\begin{tabular}{|c|c|c|c|c|c|}
\hline & PDS & MEAN & $5 \%$ & MEDIAN & $95 \%$ \\
\hline 25 & 2FNLRRR & 2.75E-08 & 7.12E-10 & 8.11E-09 & 9.97E-08 \\
\hline 26 & 2UALRUY & $1.17 \mathrm{E}-10$ & $1.26 \mathrm{E}-12$ & $2.40 \mathrm{E}-11$ & 4.19E-10 \\
\hline 27 & 2UDLRUR & 5.12E-08 & $1.08 \mathrm{E}-10$ & 4.21E-09 & $1.68 \mathrm{E}-07$ \\
\hline 28 & 2YALRRR & 7.30E-09 & 4.48E-10 & $3.08 \mathrm{E}-09$ & $2.58 \mathrm{E}-08$ \\
\hline 29 & 2YALRRY & 8.72E-09 & $5.40 \mathrm{E}-10$ & $3.78 \mathrm{E}-09$ & $3.02 \mathrm{E}-08$ \\
\hline 30 & 2YALRUR & $1.50 \mathrm{E}-08$ & 8.43E-10 & 5.81E-09 & $5.20 \mathrm{E}-08$ \\
\hline 31 & 2YALRUY & 4.93E-08 & 2.05E-09 & $1.61 \mathrm{E}-08$ & $1.85 \mathrm{E}-07$ \\
\hline 32 & 2YALRYR & $7.06 \mathrm{E}-08$ & $1.14 \mathrm{E}-08$ & 4.11E-08 & 2.06E-07 \\
\hline 33 & 2YDLRRR & $1.08 \mathrm{E}-06$ & $3.10 \mathrm{E}-08$ & $2.80 \mathrm{E}-07$ & 3.62E-06 \\
\hline 34 & 2YNLCUY & 4.84E-08 & 1.12E-09 & $1.28 \mathrm{E}-08$ & $1.59 \mathrm{E}-07$ \\
\hline 35 & 2YNLCYY & $1.94 \mathrm{E}-08$ & $1.39 \mathrm{E}-09$ & 8.11E-09 & $6.61 \mathrm{E}-08$ \\
\hline 36 & 3BDLRRR & $2.39 \mathrm{E}-10$ & 2.31E-13 & $1.30 \mathrm{E}-11$ & $6.68 \mathrm{E}-10$ \\
\hline 37 & 3BNLRRR & 4.18E-08 & $1.65 \mathrm{E}-09$ & $1.38 \mathrm{E}-08$ & $1.40 \mathrm{E}-07$ \\
\hline 38 & 3UDLRUR & $4.24 \mathrm{E}-08$ & $9.48 \mathrm{E}-11$ & $3.49 \mathrm{E}-09$ & $1.34 \mathrm{E}-07$ \\
\hline 39 & 3YALRRR & 5.31E-09 & $4.18 \mathrm{E}-10$ & 2.41E-09 & $1.80 \mathrm{E}-08$ \\
\hline 40 & 3YALRUR & 2.55E-08 & $1.53 \mathrm{E}-09$ & $1.05 \mathrm{E}-08$ & $8.64 \mathrm{E}-08$ \\
\hline 41 & 3YALRYR & $4.38 \mathrm{E}-08$ & $6.96 \mathrm{E}-09$ & 2.57E-08 & $1.30 \mathrm{E}-07$ \\
\hline 42 & 3YDLRRR & $9.15 \mathrm{E}-07$ & $2.51 E-08$ & 2.42E-07 & 3.19E-06 \\
\hline 43 & 4BNLRRR & 5.81E-08 & $7.00 \mathrm{E}-10$ & $8.98 \mathrm{E}-09$ & $1.96 \mathrm{E}-07$ \\
\hline 44 & 4UDLRUR & $1.16 \mathrm{E}-08$ & $1.47 \mathrm{E}-11$ & $6.35 \mathrm{E}-10$ & 3.37E-08 \\
\hline 45 & 4YALRRR & 2.75E:09 & $1.37 \mathrm{E}-11$ & $3.86 \mathrm{E}-10$ & 9.32E-09 \\
\hline 46 & 4YALRUR & 2.28E-08 & $3.76 \mathrm{E}-10$ & 4.85E-09 & 7.55E-08 \\
\hline 47 & 4YALRYR & 8.06E-08 & 3.34E-09 & $2.95 \mathrm{E}-08$ & $2.54 \mathrm{E}-07$ \\
\hline 48 & 4YDLRRR & $1.28 \mathrm{E}-07$ & 1.42E-09 & 1.81E-08 & $3.85 \mathrm{E}-07$ \\
\hline
\end{tabular}




\section{UNCERTAINTY AND SENSITIVITY ANALYSIS}

This chapter discusses the sources of uncertainty in this study and briefly summarizes how they are treated (Table 12-1). The discussions address the uncertainty analysis of mid-loop operation only. Chapters 4 and 6 contain analyses of initiating events and fault trees that cover the 15 POSs defined for low power and shutdown conditions. Section 12.1 discusses the sources of uncertainty, in particular, the modeling uncertainty, i.e., due to the assumptions made in the model. Section 12.2 discusses the uncertainty in the parameters used in the analysis. Section 12.3 discusses the propagation of uncertainty. The results of the uncertainty analysis are described in Section 12.4 .

\subsection{Sources and Treatment of Uncertainty}

Two types of uncertainty were addressed in this study, parameter uncertainty and modeling uncertainty. The parameters used in the model, e.g., frequency of outage types, frequency of initiating events, duration of POSs, hardware failure rates, and human error probabilities are represented by various probabilistic distributions. Section 12.2 discusses the assessment of parameter uncertainty in more detail. Modeling uncertainty addresses the uncertainty in the assumptions used in the model. Different assumptions can lead to different logic models. The following is a discussion of the various modeling issues and how they were treated in this study.

Success Criteria - Success criteria were determined by reviewing various existing studies, ${ }^{[1-7]}$ and making a supporting thermal hydraulic analysis based on the Surry-specific design. Chapter 5 gives details of this effort.

The determination of success criteria for shutdown conditions is complicated by the changing levels of decay heat. This was accounted for by defining 4 time windows after shutdown, each with its own set of success criteria. In general, whenever the success criteria for one system or mitigating function changes, a new time window must be defined and significantly more than 4 time windows are needed. The use of 4 time windows is a trade off between the accuracy of the model and the level of effort involed. We believe that 4 time windows adequately represent a much larger set of time windows.

In developing the time window approach, we recognized that the procedure for loss of RHR, AP-27.00, ${ }^{[8]}$ is conservative in the success criteria for reflux cooling and feed-and-spill, and does not include all possible methods of establishing recirculation; these are the areas in which the model of this study deviated from the abnormal procedure. The following describes how these issues were treated.

Reflux cooling - In AP 27.00, the number of steam generators needed for reflux cooling is given as a function of the decay heat, e.g, 3 SGs are needed for the first 75 hours after shutdown. The number is based on the thermal hydraulic considerations of Virginia Power NE technical report $865 .{ }^{[7]}$ From our review of studies ${ }^{[1-4]}$ on reflux cooling, and unpublished BNL calculations, one steam generator should be sufficient although the abnormal procedure states 3 would be needed. The issue is how much credit should be given to reflux cooling when insufficient SGs are available, based on the procedure. In this study, the conservative success criteria of the procedure is used in the logic model, and whenever reflux cooling is failed due to insufficient SGs, a recovery action is entered with a failure probability of 0.1 .

Feed-and-spill - In AP27.00 ${ }^{[8]}$ and its supporting study, ${ }^{[7]}$ the number of pumps and PORVs needed for this operation was determined from the flow from RWST needed to maintain the sub-cooling capacity and shut-off head of the pumps, and the relieving capability of the PORVs. For example, during the first 129 hours after shutdown, 2 charging pumps and 2 PORVs would be needed. Such success criteria were derived from the requirement of maintaining sub-cooling. This requirement is more stringent than what is needed for feed-and- 


\section{Uncertainty and Sensitivity Analysis}

shutdown, 2 charging pumps and 2 PORVs would be needed. Such success criteria were derived from the requirement of maintainingsub-cooling. This requirement is more stringent than what is needed for feed-andbleed in an accident that occurs during full power operations. An alternative to feed-and-spill, namely feedand-steam, (discussed in reference [7]), is much less demanding in terms of the needed flow. However, it is not the recommended method because of the difficulty in maintaining level, and potential for overpressurization. In this study, a success criterion of 1 charging pump and 1 PORV is used, based on the understanding that this is sufficient to prevent core damage.

Recirculation - AP $27.00^{[8]}$ instructs the operators to establish high-pressure recirculation by using the low pressure injection pump to take suction from the containment sump, and discharge to the suction of high pressure injection system. This requires a low head injection pump and a charging pump be available. In the fault-tree model for recirculation, two alternative methods are also modeled; the low-pressure feed-and-steam by taking suction from the containment sump, and low-pressure feed-and-spill by taking suction from the sump and using spray recirculation. For both, only low head injection is needed. The feed-and-steammode requires that the safety valves are removed to give an adequate vent path, and does not require cooling of the sump water. The feed-and-spill operation requires operation of the spray recirculation systems to cool the water in the sump, so establishing sub-cooling in the reactor vessel.

Changing Plant Configuration - Due to the activities taking place during shutdown, the plant's configuration changes in time, which, in turn, affects the likelihood of accident initiating events and the plant's ability to mitigate the accidents. In general, at any time, the plant could be in a different configuration. In this study, the constantly changing plant configuration is approximated by a few discrete configurations, by introducing different outage types, POSs, and time windows. Chapter 3 discusses the differences among the outage types, POSs and time windows that are reflected in the different basic events and different event trees. Chapter 9 discusses the estimation of some of the basic event probabilities that vary with outage types, POSs, and time windows. The following is a description of the basic events and how they are varied.

1. Initiating event frequency - The initiating events are assumed to occur with constant rates independent of the outage type or POS. The conditional probability that an IE occurs in a POS is the product of the rate and the duration of the POS. The initiating event frequency is the frequency of the POS times this conditional probability. The frequency that it occurs in a given time window of a given POS of a given outage type is the frequency that the initiating event occurs in the POS times the conditional probability of the time window of the given POS.

2. Loop isolation probability - Isolation of the loops makes it impossible to establish reflux cooling. Its probability was estimated by judgment, using information gathered by reviewing the log books for outages, and an outage plan for a refueling outage. It was estimated as a function of the outage types, and time windows.

3. Removal of pressurizer safety valves - The fraction of time that the safety valves are removed in a given time window of a given POS in a given outage type was estimated by judgment using information gathered by reviewing log books for outages, and an outage plan for a refueling outage. With the safety valves removed, it is possible to use gravity feed from the RWST, and impossible to use reflux cooling due to loss: through the opening.

4. Maintenance unavailabilities - Maintenance unavailability was estimated as a function of the POSs of a refueling outage by reviewing the log books for 3 refueling outages. The data was collected for the time period when the plant was at mid-loop. Due to insufficient information, maintenance unavailability is assumed 
to be independent of the time windows. It also is assumed that the data collected for a refueling outage is applicable to a drained maintenance outage.

Changing plant practices and information - It has been BNL's observation that the plant is aware of the potential safety concerns of reduced inventory operations and is constantly improving its practice regarding such operations. This concern is reflected in the improvement in the operating procedures and abnormal procedures used during shutdown as well as changes in plant practice. The most significant practice started in the refueling outage of unit one in 1992, during which mid-loop operation was totally avoided; this appears to be the new plant policy. Another way of reducing the risk due to reduced inventory operation is to perform it while the fuel in the core is removed refueling.

To limit the changes in the model developed in this study to account for the changes in plant practice and information, it was decided that the study would use the procedures and other plant information available as of April 30, 1993. Regarding the plant's policy of avoiding mid-loop operation, it was decided that this study would use the data collected from past outages prior to the unit 1 refueling outage of 1992 when mid-loop operation was avoided. As a result, the estimated core-damage frequency of this study is expected to be an over estimation of that of the current plant.

Operator Response - The operator's actions modeled in this study were identified while developing the event trees that involved reviewing the relevant abnormal and emergency procedures, talking through the accident scenarios, and discussing them with plant personnel. Chapter 7 gives details of the scenario development. The operator's response to various accidents are in most cases, identified in the applicable procedures. For example, abnormal procedures for loss of RHR, ${ }^{[8]}$ loss of instrument air ${ }^{[9]}$, and loss of offsite power ${ }^{[10]}$ provide guidance on what to do in case of these losses during shutdown. The latter two procedures are not written specifically for shutdown conditions. In case of a station blackout, the procedure, $1-E C A-0.0,{ }^{[11]}$ written with power operation in mind, does not address shutdown conditions. Therefore, only the relevant steps in the procedure are applicable. Similarly, for other initiating events, such as loss of component cooling, spurious safety injection, and loss of a vital bus, there is no specific procedure for shutdown, and the knowledge of the operators about the relevant steps of the procedures for power operations becomes very important. As discussed under success criteria, some of the operator's action modeled in this study are not explicitiy spelled out in the existing plant procedures, and some recovery actions modeled are extension of the existings procedures.

The operator actions needed to mitigate an accident are included in the high-level fault trees that model different methods of mitigating the accident, e.g., feed-and-spill operation. The model typically contains two human error events and one transfer to the fault tree for hardware failures. One human error event represents failure of the operator to diagnose, so that the correct actions can not be decided upon; the other represents failure to carry out the action after successful diagnosis. Human error probabilities were quantified using the failure likelihood index method that involves assessing weights and scores on various performanceshaping factors, and calibration using the HEPs from existing studies.

\subsection{Parameter Uncertainty}

The following is a discussion of the assessment of the uncertainty associated with the parameters used in this study. 


\section{Uncertainty and Sensitivity Analysis}

Initiating Event Frequency- The initiating event frequency was estimated by using the two-stage Bayesian analysis. In the first stage, data from the population of reactors was collected and used to derive a population variability curve. This curve, then was used as the prior distribution of the second stage in which the Surryspecific data was used as the evidence. The only exception is the initiating event of loss of emergency switch-gear room cooling, for which a fault tree was used to derive a point estimate of the initiating event frequency, and an error factor of 4 was estimated by propagating the uncertainty of parameters used in the fault tree.

Hardware Failure Data - The hardware failure data was taken from the NUREG-1150 study for Surry. In some cases, new failure events were added to the system models using information and data from the IPE of Surry. To account for the state of knowledge uncertainty, similar events were assigned the same "correlation class" as defined in the IRRAS computer code. ${ }^{[12]}$ In propagating uncertainty, a single sample is taken from one correlation class and used for all events in the same class. Table 12-2 lists the failure data associated with each correlation class.

MaintenanceUnavailability- The assessment of maintenance unavailabilityis documented in chapter 9 in more detail; basically, it was accomplished by reviewing the outage log books for 3 refueling outages. The fraction of time that equipment is out of service in a given POS is used as maintenance unavailability. Just like other parameters discussed under changing plant practice, such use of an averaged parameter represents an approximation of the real-time dependent behavior of the plant. The accuracy of the approximation has to be assessed by performing sensitivity calculations.

The uncertainty of the maintenance unavailabilities was derived by judgement using the following rules:

1. If the mean is small, a lognormal distribution with some EF is assumed.

2. If the mean is close to 1 , a uniform distribution is assumed. If the mean is larger than 0.5 , the upper bound is set to 1 . If the mean is lower than 0.5 , the upper bound is set to twice the mean.

Human Error Probability - The quantification of HEPs is documented in chapter 8. Chapter 10 documents the quantification of the recovery actions that consist of hardware failures and human errors. Similar to the failure events for hardware failures, the human error events, that represent similar operator actions and were estimated to have the same HEPs, were assigned the same correlation class. The following guidelines were used in assigning the error factors for the HEPs:

1) Action(A) and Recovery(R) events:

Mean of DistributionError Factor

mean $<=1 \mathrm{E}-035$

$1 \mathrm{E}-03<$ mean $<=0.13$

$0.1<$ mean2

2) Diagnosis(D) events:

Error factor $=20$.

Recovery from Initiating Events - All the experienced loss of RHR events throughout the population terminated successfully before core damage occurs. To account for this fact, in some of the event trees, a top event is used representing recovery from the initiating event. The probability that the initiating event is 
recovered before bulk boiling takes place in the RCS is estimated from the respective "recovery curves", derived by using the experienced recovery times in a Bayesian analysis. Appendix D provides more detail of the recovery curves. The error factor of the non-recovery probability was assumed to be 3 .

\subsection{Uncertainty Analysis Results}

The uncertainty of total core damage frequency was assessed using the IRRAS computer code ${ }^{[12]}$ using 10,000 LHS samples. The basic event uncertainty data is given in appendix G. Table 12-3 lists the results of the uncertainty analysis. 
12 Uncertainty and Sensitivity Analysis

\subsection{References:}

1. Naff, S.A., et. al., "Thermal Hydraulic Processes During Reduced inventory Operation with Loss of Residual Heat Removal," Idaho National Engineering Laboratory, NUREG/CR-5855, April 1992.

2. Fletcher, C.D., et. al., "Thermal-HydraulicProcesses Involved in Loss of Residual Heat Removal During Mid-Loop Operation, EGG-East-9337, Idaho National Engineering Laboratory, October 1990.

3. Wald, L.W. and W.C. Arcieri, "Evaluation of the Loss of Residual Heat Removal Systems in pressurized water Reactors," Idaho National Engineering Laboratory, NUREG/CR-5820, May 1992.

4. Audreycheck, T.S., et. al., "Loss of RHRs Cooling while the RCS is partially filled," WCAP - 11916, Westinghouse Electric Corporation, July 1988.

5. "Loss of Residual Heat Removal System," NUREG-1269, U.S. Nuclear Regulatory Commission, June 1987.

6. Loss of Vital AC Power and the Residual Heat Removal System During Mid-Loop Operations at Vogtle Unit 1 on March 20, 1990," NUREG-1410, U. S. Nuclear Regulatory Commission, June, 1990.

7. "Background and Guidance for Ensuring Adequate Backup Decay Heat Removal Following Loss of RHR Surry and North Anna Power Stations,", Nuclear Analysis and Fuel Nuclear Engineering Services, Virginia Power, NE Technical Report No. 865, Revision 1, June 1992.

8. "Loss of Decay Heat Removal Capability," Virginia Power Surry Power Station, Abnormal Procedure 1-AP-27.00, Revision 4, February 15, 1993.

9. "Non-Recoverable Loss of Instrument Air," Virginia Power Surry Power Station, Abnormal Procedure AP 1-40.00, Revision 3, December 19, 1991.

10. "Station Blackout," Virginia Power Surry Power Station, Abnormal Procedure 1-AP 10.00, Revision 7, July 2, 1992.

11. "Loss of All AC Power," Virginia Power Surry Power Station, Emergency Contingency Action, Rev. 6, April 27, 1992.

12. Russell, K., et. al., "Integrated Reliability and Risk Analysis System," Version NEW5, (a test version)Developed by Idaho National Engineering Laboratory. 
Table 12-1

Sources and Treatment of Uncertainty

\begin{tabular}{|c|c|c|}
\hline Sources of Uncertainty & Description & Treatment \\
\hline Success Criteria & $\begin{array}{l}\text { a. Insufficient } \\
\text { understanding of thermal } \\
\text { hydraulic behavior } \\
\text { b. Conservatism in Virginia } \\
\text { Power Procedure } \\
\text { c. Changing success } \\
\text { criteria with decay heat }\end{array}$ & $\begin{array}{l}\text { a. Performance of } \\
\text { supporting analysis, } \\
\text { review of existing } \\
\text { studies } \\
\text { b. relaxed success criteria in } \\
\text { some cases } \\
\text { c. time window approach } \\
\text { allows window dependent } \\
\text { success criteria }\end{array}$ \\
\hline Changing Plant Configuration & $\begin{array}{l}\text { Ability to mitigate an } \\
\text { accident depends on the } \\
\text { plant configuration. For } \\
\text { example: } \\
\text { 1. SGs in wet lay-up } \\
\text { ensures that SG } \\
\text { inventory is initially } \\
\text { sufficient for reflux } \\
\text { cooling, } \\
\text { 2. RCS loops isolation or } \\
\text { PZR SVs removal } \\
\text { makes reflux cooling } \\
\text { impossible, and } \\
\text { 3. PZR SVs removal } \\
\text { makes gravity feed from } \\
\text { RWST possible. }\end{array}$ & $\begin{array}{l}\text { Used basic events whose } \\
\text { probabilities vary with } \\
\text { outage types, POSs, and time } \\
\text { windows. The probabilities } \\
\text { were estimated by reviewing } \\
\text { past plant outage experience, } \\
\text { outage plans, and operating } \\
\text { procedures. }\end{array}$ \\
\hline Changing Plant Practice & $\begin{array}{l}\text { a. Procedures and other } \\
\text { plant information } \\
\text { b. Virginia Power avoided } \\
\text { going to mid-loop in the } \\
\text { most recent refueling } \\
\text { outages }\end{array}$ & $\begin{array}{l}\text { a. Used what is available to } \\
\text { BNL as of April } 30,1993 \text {. } \\
\text { b. Used past plant } \\
\text { experience prior to this } \\
\text { change. }\end{array}$ \\
\hline Operator Response & $\begin{array}{l}\text { a. Lack of abnormal or } \\
\text { emergency procedure } \\
\text { for the specific scenarios } \\
\text { b. Extension of the existing } \\
\text { procedures }\end{array}$ & $\begin{array}{l}\text { Used procedures that } \\
\text { contain relevant instructions } \\
\text { to the operators. } \\
\text { Discussions with plant } \\
\text { personnel. }\end{array}$ \\
\hline
\end{tabular}


12 Uncertainty and Sensitivity Analysis

Table 12-1 (continued)

\begin{tabular}{||l|l|l||}
\hline \multicolumn{1}{|c|}{ Sources of Uncertainty } & \multicolumn{1}{|c|}{ Description } & \multicolumn{1}{c|}{ Treatment } \\
\hline Parameter Uncertainty: & & Two-stage Bayesian Analysis \\
\hline 1. Initiating Event Frequency & & $\begin{array}{l}\text { Used data from NUREG- } \\
1150 \text { and IPE }\end{array}$ \\
\hline 2. Hardware Failure Data & $\begin{array}{l}\text { a. Mean values were } \\
\text { estimated using plant data. } \\
\text { Uncertainty parameters } \\
\text { were assigned by } \\
\text { judgment. }\end{array}$ \\
\hline 3. Maintenance Unavailability & $\begin{array}{l}\text { a. High maintenance } \\
\text { component }\end{array}$ & $\begin{array}{l}\text { b. Use of average } \\
\text { unavailability instead of } \\
\text { time dependent } \\
\text { unavailability }\end{array}$ \\
\hline 4. Recovery of Initiating Event & $\begin{array}{l}\text { Actual incidents during } \\
\text { status with time } \\
\text { before core damage occurs. }\end{array}$ & $\begin{array}{l}\text { Use of recovery curves } \\
\text { derived from Bayesian } \\
\text { analysis for loss of offsite } \\
\text { power, and loss of support } \\
\text { systems }\end{array}$ \\
\hline
\end{tabular}


Table 12-2

12 Uncertainty and Sensitivity Analysis

Failure Data Associated with the Correlation Classes

\begin{tabular}{|c|c|c|c|}
\hline $\mathrm{CC}^{*}$ & Description & Mean & $\begin{array}{l}\text { Error } \\
\text { Factor }\end{array}$ \\
\hline 1 & No signal from CLCS train & $1.6 \mathrm{E}-03$ & 5 \\
\hline 2 & No actuation signal for AFW & $6.0 \mathrm{E}-04$ & 5 \\
\hline 3 & No actuation Signal to CPC Pump & 3.2E-04 & 5 \\
\hline 4 & SG PORV Bolcked & $1.5 \mathrm{E}-01$ & 3 \\
\hline 5 & AOV Fails to Open & $1.0 \mathrm{E}-03$ & 3 \\
\hline 6 & AOV Leaks & $2.4 \mathrm{E}-05$ & 3 \\
\hline 7 & AOV transfers closed & 7.5E-07 & 3 \\
\hline 8 & AOV Spuriously Opens & $2.4 \mathrm{E}-06$ & 10 \\
\hline 9 & AOV plugged & $4.0 \mathrm{E}-05$ & 3 \\
\hline 10 & Flow Orifice Plugged & $3.0 \mathrm{E}-04$ & 3 \\
\hline 11 & Bus Failure & $9.0 \mathrm{E}-05$ & 5 \\
\hline 12 & Battery Failure & 7.2E-04 & 3 \\
\hline 13 & Beta Factor for AFW MDPs & $5.6 \mathrm{E}-02$ & 3 \\
\hline 14 & HPI MDP CCF & $8.4 \mathrm{E}-04$ & 5 \\
\hline 15 & MOV CCF & $2.6 \mathrm{E}-04$ & 13 \\
\hline 16 & CPC TCV CCF & $1.0 \mathrm{E}-04$ & 5 \\
\hline 17 & Beta Factor for DGs & $3.8 \mathrm{E}-02$ & 3 \\
\hline 18 & Beta Factor for 3 DGs & $1.8 \mathrm{E}-02$ & 3 \\
\hline 20 & Beta Factor for LPI Pumps & $1.5 \mathrm{E}-01$ & 3 \\
\hline 21 & Beta Factor for SRV & 7.0E-02 & 3 \\
\hline 24 & Beta Factor for MOV & $8.8 \mathrm{E}-02$ & 3 \\
\hline 25 & $\mathrm{AFW} C \mathrm{CCF}$ & $1.0 \mathrm{E}-5$ & 30 \\
\hline 26 & Compressor CCF & $2.7 \mathrm{E}-05$ & 10 \\
\hline 27 & Containment Sump Plugged & $5.0 \mathrm{E}-05$ & 100 \\
\hline 30 & Mis-calibration of Signals & 3.0E-04 & 10 \\
\hline 31 & Check Valve Fails on Demand & 1.0E-04 & 3 \\
\hline 32 & Back Flow through Check Valve & $2.0 \mathrm{E}-03$ & 3 \\
\hline
\end{tabular}


12 Uncertainty and Sensitivity Analysis

Table 12-2 (continued)

\begin{tabular}{|c|c|c|c|}
\hline $\mathrm{CC}^{*}$ & Description & Mean & $\begin{array}{l}\text { Error } \\
\text { Factor }\end{array}$ \\
\hline 33 & Back Flow through CHK VLV & $1.0 \mathrm{E}-03$ & 3 \\
\hline 34 & Breaker Spurious Opens & 2.9E-05 & 3 \\
\hline 35 & DG Breaker Fails to Close & $3.0 \mathrm{E}-03$ & 10 \\
\hline 37 & DG Fails to Run ( $1 \mathrm{hr})$ & $2.0 \mathrm{E}-03$ & 10 \\
\hline 38 & DG Fails to Run (6 hrs) & $1.2 \mathrm{E}-02$ & 10 \\
\hline 39 & DG Fails to Start & 2.2E-02 & 3 \\
\hline 41 & CCW HTX Leaks & 7.2E-05 & 10 \\
\hline 43 & CCW HTX Plugged & $1.4 \mathrm{E}-04$ & 10 \\
\hline 44 & Inverter Failure & 4.0E-02 & 3 \\
\hline 45 & CPC MDP Fail to Run (24 hrs) & 3.8E-03 & 3 \\
\hline 47 & CPC MDP Fails to Run (6 hrs) & 9.6E-04 & 3 \\
\hline $47 \mathrm{~A}$ & CPC MDP Fails to Run (24 hrs) & $3.84 \mathrm{E}-03$ & 3 \\
\hline 49 & PHI MDP Fails to Run (24 hrs) & $1.6 \mathrm{E}-03$ & 2.9 \\
\hline 50 & MPD Fails to Run (18 hrs) & $1.2 \mathrm{E}-03$ & 2.9 \\
\hline 51 & HPI MDP Fails to Run (12 hrs) & 8.0E-04 & 2.9 \\
\hline 52 & HPI MDP Fails to Run & 4.0E-04 & 2.9 \\
\hline 55 & MDP Fails to Run (1 hr) & $3.0 \mathrm{E}-05$ & 10 \\
\hline 57 & MDP Fails to Run & 7.2E-04 & 10 \\
\hline 58 & LPI MDP Fails to Run (18 hrs) & 5.4E-04 & 3 \\
\hline 59 & LPI MDP Fails to Run ( $21 \mathrm{hrs}$ ) & $6.3 \mathrm{E}-04$ & 3 \\
\hline 60 & MDP Fails to Run (6 hrs) & $1.8 \mathrm{E}-04$ & 10 \\
\hline 61 & MDP Fails to Start & $6.3 \mathrm{E}-03$ & 3 \\
\hline 62 & CPC MDP Fails to Start & 8.0E-03 & 3.5 \\
\hline 63 & HPI MDP Fails to Start & $4.0 \mathrm{E}-03$ & 3.5 \\
\hline 64 & ISR MDP Fails to Start & 3.3E-02 & 3.8 \\
\hline 65 & MDP Fails to Start & $3.0 \mathrm{E}-03$ & 10 \\
\hline 66 & AFW Pump Maintenance & $2.0 \mathrm{E}-3$ & 10 \\
\hline 68 & MOV Fails to Close & $5.2 \mathrm{E}-03$ & 10 \\
\hline
\end{tabular}


Table 12-2 (continued)

\begin{tabular}{|c|c|c|c|}
\hline $\mathrm{CC}^{*}$ & Description & Mean & $\begin{array}{l}\text { Error } \\
\text { Factor }\end{array}$ \\
\hline 69 & MOV Fails on Demand & $3.0 \mathrm{E}-03$ & 10 \\
\hline 70 & SWS MOV Maintenance & $2.0 \mathrm{E}-04$ & 10 \\
\hline 71 & MOV Plugged & $6.6 \mathrm{E}-04$ & 3 \\
\hline 72 & MOV Plugged & $6.5 \mathrm{E}-04$ & 3 \\
\hline 73 & MOV Plugged & 4.4E-04 & 3 \\
\hline 74 & MOV Plugged & 4.0E-5 & 3 \\
\hline 75 & Flow Diversion to Unit 2 & $1.5 \mathrm{E}-04$ & 3 \\
\hline 77 & Rectifier Failure & 4.0E-4 & 3 \\
\hline 78 & PORV Fails to Open & $1.0 \mathrm{E}-03$ & 3 \\
\hline 79 & PORV Fails to Re-close & $3.0 \mathrm{E}-02$ & 10 \\
\hline 80 & RV Spuriously Opens & $9.36 \mathrm{E}-05$ & 10 \\
\hline 81 & Strainer Plugged $(1 \mathrm{hr})$ & 3.0E-05 & 10 \\
\hline 82 & Strainer Plugged ( $3 \mathrm{hrs}$ ) & $9.0 \mathrm{E}-05$ & 10 \\
\hline 83 & Strainer Plugged (6 hrs) & $1.8 \mathrm{E}-04$ & 10 \\
\hline 85 & Strainer Plugged $924 \mathrm{hrs}$ ) & 7.2E-04 & 10 \\
\hline 86 & TDP Fails to Run & $5.0 \mathrm{E}-03$ & 10 \\
\hline 87 & TDP Fails to Run & 3.0E-02 & 10 \\
\hline 89 & TDP Fails to Start & $1.1 \mathrm{E}-02$ & 10 \\
\hline 91 & Transformer Failure & 4.0E-05 & 3 \\
\hline 93 & Tank Insufficient Inventory & $1.0 \mathrm{E}-06$ & 3 \\
\hline 94 & Containment Failure Induced LPI Failure & $2.0 \mathrm{E}-02$ & 3 \\
\hline 133 & Manual Valve Plugged (standby) & 4.4E-04 & 3 \\
\hline 134 & Manual Valve Plugged (during operation) & $4.0 \mathrm{E}-5$ & 10 \\
\hline 135 & Manual Valve Plugged & 8.4E-06 & 3 \\
\hline 136 & Manual Valve Left Open & $3.0 \mathrm{E}-03$ & 10 \\
\hline 193 & SRV Fails to Open & $1.0 \mathrm{E}-03$ & 3 \\
\hline 196 & MOV Plugged & $1.095 \mathrm{E}-04$ & 3 \\
\hline 198 & Manual Valve Plugged & 3.65E-05 & 3 \\
\hline
\end{tabular}


12 Uncertainty and Sensitivity Analysis

Table 12-2 (continued)

\begin{tabular}{|c|c|c|c|}
\hline $\mathrm{CC}^{*}$ & Description & Mean & $\begin{array}{l}\text { Error } \\
\text { Factor }\end{array}$ \\
\hline 201 & Manual Valve Fails to Open & $1.0 \mathrm{E}-04$ & 3 \\
\hline 202 & Compressor Fails to Run & 4.8E-3 & 10 \\
\hline 203 & Compressor Fails to Start & $8.0 \mathrm{E}-02$ & 3 \\
\hline 301 & AOV CCF & $1.0 \mathrm{E}-04$ & 3 \\
\hline 302 & CHK CCF & $1.0 \mathrm{E}-05$ & 10 \\
\hline 304 & NRV Plugged & $6.0 \mathrm{E}-04$ & 3 \\
\hline 303 & Battery CCF & $5.8 \mathrm{E}-06$ & 3 \\
\hline 305 & MOV CCF & $2.6 \mathrm{E}-04$ & 3 \\
\hline 306 & LPI MDP CCF to Start & 4.5E-04 & 3 \\
\hline 307 & SG Drained & 2.3E-02 & 5 \\
\hline 801 & Inverter Maintenance & $2.0 \mathrm{E}-4$ & 3 \\
\hline 802 & SG PORV Maintenance & $5.0 \mathrm{E}-02$ & 5 \\
\hline 804 & Recirculation Spray Maintenance & $\mathbf{U}(0,0.5)$ & \\
\hline 903 & AFW MOV Maintenance & $1.0 \mathrm{E}-03$ & 10 \\
\hline IPE0 & Fan Motor Fails to Start & $3.9 \mathrm{E}-03$ & 3 \\
\hline IPE & Air Handling Unit Maintenance & $3.75 \mathrm{E}-03$ & 3 \\
\hline IPE1 & Bus Maintenance & 7.27E-06 & 3 \\
\hline IPE2 & MDP Fails to Run & $1.08 \mathrm{E}-02$ & 3 \\
\hline IPE3 & RHR Pump Seal Cooler Failure & $1.86 \mathrm{E}-02$ & 3 \\
\hline IPE4 & RV Spuriour Opens & 9.33E-05 & 3 \\
\hline IPE5 & Motor Operated Damper Fails to Operate & $1.09 \mathrm{E}-02$ & 3 \\
\hline IPE6 & AOV Opens Spuriously & $1.2 \mathrm{E}-05$ & 3 \\
\hline IPE7 & Air Handling Unit Failure & 3.4E-05 & 10 \\
\hline IPE8 & Chiller Fails to Run & $3.6 \mathrm{E}-03$ & 10 \\
\hline IPE9 & Evaporative Condenser Fails to Run & 3.6E-03 & 10 \\
\hline
\end{tabular}

* CC: Correlation Class 
Table 12-3

Result of the Uncertainty Analysis for Total Core Damage Frequency (per year)

\begin{tabular}{|c|c|}
\hline Point Estimate & $4.88 \mathrm{E}-06$ \\
\hline Mean & $4.86 \mathrm{E}-06$ \\
\hline 5th Percentile & $4.76 \mathrm{E}-07$ \\
\hline 50th Percentile & $2.14 \mathrm{E}-06$ \\
\hline 95th Percentile & $1.54 \mathrm{E}-05$ \\
\hline Error Factor & 5.69 \\
\hline
\end{tabular}


Kiyoharu Abe

Dept. of Reactor Safety Research Nuclear Safety Research Center Tokai Research Establishment JAERI

Tokai-mura, Naga-gun

Ibaraki-ken, JAPAN

Sarbes Acharya

Department of Energy

NS - 1 /FORS

Washington, DC 20585

Dr. Ulvi Adalioglu

Cekmece Nukleer Arastraima ve Egitim Merekezi

P.K. 1

Havaalani/ISTANBUL TURKEY

Dr. Eng. Kiyoto Aizawa

Senior Engineer

Reactor Eng. Dev. Department PNC

9-13, Chome, Akasaka

Minato-K, Tokyo

JAPAN

Harry Alter

Manager Applied Tech

Nuclear Systems Tech

$\mathrm{NE}-46$

US DOE

Washington, DC 20585

R.M. Andrews

Nuclear Installations Insp.

st. Peters House

Balliol Raod, Bootle

Merseyside L20 312

UNITED KINGDOM

George Apostolakis

UCLA

Boelter Hall, Room 5532

LOs Angeles, CA 90024-1597

Director of Reactor Engineering Argonne National Laboratory

9700 S Cass Ave

Bldg 208

Argonne, IL 60439
Ephraim Asculai

Division of Nuclear Safety

Wagramestrasse, 5

P.O. Box 100

A-1400 Wien

AUSTRIA

Vladimar Asmolov

Head, Nuclear Safety Department

I. V. Kurchatov Institute of Atomic Enegry

Moscow, 123181

RUSSIA

$\mathrm{J}$. de Assuncao

Cabinete de Proteccao è

Seguranca Nuclear

Ministerio da Indusstria

Ave. de Republica 45-6

1000 Lisbon

PORTUGAL

H.P. Balfanz, Head

Institute of Probabilistic Safety Analysis

TUV Nord

Grosse Bahnstrasse 31

D-22525 Hamburg 54

GERMANY

Pat Baranowsky

USNRC - AEOD/TPAB

MS : $T-4 A 9$

Robert A. Bari, Deputy Chairman Dept of Nuclear Energy

Bldg $197 \mathrm{C}$

Brookhaven National Iaboratory

Upton, NY 11973

Librarian

Technical Information Section

Battelle Pacific Northwest Lab

P. O. Box 999

Richland, WA 99352

Dr. John Baum

Dept of Nuclear Energy

Radiological Sciences Div

Bldg $703 \mathrm{M}$

Brookhaven National Laboratory

Upton, NY 11973 
Eric Beckjord

USNRC-RES/DO

MS : T-10F12

Robert Bernero

USNRC-NMSS/DO

MS : $T-8$ A23

Andrea Besi

Institute for Systems Engineering and Informatics

CEC Joint Research Centre

CP $N 1$

1-21020 Ispra (Varese)

ITALY

John Bickel

Idaho National Engineering Lab.

EG\&G MS: 3850

B.O. Box 1625

Idaho Falls, ID 83415

Vicki Bier

Dept. of Industrial Engineering University of Wisconsin-Madison 1513 University Avenue, Room 389 Wisconsin, WI 53706

Scott Bigelow

$S$-CUBED

2501 Yale SE, Suite 300

Albuquerque, NM 87106

Prof. Dr. Dr.-Ing. E. H. Adolf Birkhofer

Gesellschaft füx Anlagen und

Reaktorsicherheit (GRS) $\mathrm{mbH}$ Forschungsgelănde

D-8046 Garching

Federal Republic of Germany

David Black

American Electric Power

1 Riverside Plaza

Columbus, $\mathrm{OH} 43215$

Harold Blackman

Idaho National Engineering Lab.

EG\&G MS : 3850

P.O. Box 1625

Idaho Falls, ID 83415-3850

\author{
Dennis Bley \\ Buttonwood Consulting \\ 17291 Buttonwood St. \\ Fountain Valley, CA 92708 \\ Roger Blond \\ Booz-Allen \& Hamilton \\ 4330 East West Highway \\ Bethesda, MD 20814 \\ M. P. Bohn \\ Division 6449 \\ Sandia National Laboratories \\ Albuquerque, NM 87185
}

\author{
Dr. Mario Bonaca \\ Manager, Reactor Engineering \\ Northeast Utilities \\ P.O. Box 270 \\ Hartford, Conn. 06141
}

Robert B. Borsum

Nuclear Power Division

$B$ \& $W$ Nuclear Tech

1700 Rockville Pike

Suite 525

Rockville, MD 20852

Stephen Boult

Blectrowatt Engineering Services

(UK) Itd.

Grandford House

16 Carfax, Horsham

West. Sussex RH12 IUP

ENGLAND

Gary Boyd

Safety \& Reliability Optimization Services

9724 Kingston Pike, Suite 102

Knoxville, TN $\mathbf{3 7 9 2 2}$

Brookhaven National Laboratory (2)

Attn: Lev Neymotin

Building 130 Arthur Tingle

Upton, NY 11973

David M. Brown

Paul C. Rizzo Associates, Inc.

300 Oxford Drive

Monroeville, PA 15146-2347 
Tom D. Brown

Sandia National Laboratories

Dept. 6413

P.O. BOX 5800

Albuquerque, NM 87185

Robert J. Budnitz

Future Resources Associates, Inc. 2039 Shattuck Avenue, Suite 402

Berkeley, CA 94704

Gary Burdick

USNRC-RES/SAIB

MS : T-10F13

Arthur Buslik

USNRC-RES / PRAB

MS : T-9F31

Edward Butcher

USNRC-NRR/SPSB

MS : O-10E4

Technical Library

B\&W Nuclear Service Co

P. O. BOX 10935

Lynchburg, VA 24506

Stefaan Caeymaex

Safety \& Systems section

Nuclear Generation Dept.

TRACTEBEL

Avenue Ariane 7

B-1200 Bruxelles

BELGIUM

Leonard Callan, Administrator

U.S. Nuclear Regulatory Commission

Harris Tower and Pavilion

611 Ryan Plaza Drive, Suite 400

Arlington, TX 76011-8064

J. Calvo

Division of PSA \& Human Factors

Consejo de Seguridad Nuclear

Calle Justo Dorado, 11

28040 Madrid

SPAIN

\author{
A. I. Camp \\ Division 6412 \\ MS : 0748 \\ Sandia National Laboratories \\ Albuquerque, NM 87185-0748 \\ John Forbes Campbel \\ HM Superintending Inspector \\ Health \& Safety Executive \\ St. Peter's House \\ Balliol Road \\ Bootle L20 $31 \mathrm{z}$ \\ UNITED KINGDOM \\ Leonel Canelas \\ New University of Lisbon \\ Quinta de Torre \\ 2825 Monte de Caparica \\ PORTUGAI \\ Harold Careway \\ General Electric Co., M/C 754 \\ 175 Curtner Ave. \\ San Jose, CA 95129 \\ D. D. Carison \\ Division 6411 \\ Sandia National Laboratories \\ Albuquerque, NM 87185 \\ Jose E. De Carlos \\ CSN International Coordinator \\ Consejo de Seguridad Nuclear \\ Calle Justo Dorado 11 \\ 28040 Madrid \\ SPAIN
}

Annick Carnino

International Atomic Energy Agency

Wagramerstrasse 5, P.0. Box 100

A-1400 Vienna

AUSTRIA

S. Chakraborty

Swiss Federal Nuclear Safety Inspectorate

Hauptabteilung für die Sicherheit der Kernanlagen

$\mathrm{CH}-5232$ Villigen-HSK

SWITZERIAND

Erulappa Chelliah

USNRC - RES/PRAB

MS : $T-9 F 31$

Dist-3 
Mike Cheok

NOS

910 Clopper Road

Gaithersburg, MD 20878

Nilesh Chokshi

USNRC - RES/SSEB

MS : T-1OLI

T. I. Chu

Brookhaven National Laboratory

Department of Nuclear Energy

Bldg. 130

Upton, NY 11973

Peter Cooper

SRD/AEA Technology

Wigshaw Lane

Culcheth

Cheshire WA3 4NE

England

Susan E. Cooper

Science Applications Int'1. Corp.

11251 Roger Bacon Drive

Reston, VA 22090

Michael Corradini

University of Wisconsin

1500 Johnson Drive

Madison, WI 53706

E.R. Corran

ANSTO Reasearch Establishment

Lucas Heights Reserch Labs.

Private Mail Bag 1

Manai, NSW 2234

AUSTRALIA

Massimo Cozzone

A.N.P.A.

Via V. Brancati, 48

I-00144 Rome

ITALY

George Crane

$1570 \mathrm{E}$. Hobble Creek Dr.

Springville, Utah 84663

Mark Cunningham

USNRC-RES/PRAB

MS : T-9F31
S. Daggupaty

Environment Canada

4905 Dufferin Street

Downsview

Ontario, M3H ST4

CANADA

Louise Dahlerup

Inspectorate of Nuclear Inst.

Danish Civil Defense \&

Emergency Planning Agency

16, Datavej

DK-3460 Birkerod

DENMARK

John Darby

SEA, Ine.

6100 Uptown Blvd. NE

Albuquerque, NM 87110

Gerald Davidson

Fauske and Associates, Inc.

16 W 070 Fest 83rd Street

Burr Ridge, IL 60521

Peter Davis

PRD Consulting

P.O. Box 2046

Sheridan, WY 82801

P. De Gelder

Secretary, BELGIAN NUCLEAR SOCIETY (BNS)

A V Nuclear

Avenue du Roi 157

B-1060 Brussels

BELGIUM

Lennart Devell

Studsvik Nuclear

Studsvik Energiteknik AB

S-611 82 Nykoping

SWEDEN

J. Devooght

Service de la Metrologie Nucl

University Libre de Bruxelles

Faculte des Sciees Appliqu.

50 Avenue F-D Roosevelt

Bruxelles 5

BELGIUM 
G. Diederick

Commonwealth Bdison Co. Lasalle County station

RRI, BOX 220

2601 North 21 st Rd.

Marsielles, II 61341

Chuck Dobbe

Idaho National Engineering Lab. EGEG MS : 3840

P.O. Box 1625

Idaho Palls, ID 83415

Mary Drouin

USNRC-RBS \SAIB

MS : T-10F13

Duke Power Co. (2)

Attn: Duncan Brewer Steve Deskevich

422 South Church Street

Charlotte, NC 28242

Bill Bakin

Northeast Utilities

Box 270

Hartford, CT 06141

Stewart D. Bbneter

OSNRC

101 Marietta St. Suite 2900

Atlanta, GA 30323-0199

Adel A. El-Bassioni

OSNRC - NRR/PRAB

MS : 0-1084

BNEA/DISP (2)

Attn: Alvaro Valeri Alfredo Bottino

Via Vitaliano Brancati, 48

00144 Roma BUR

ITALY

Walter P. Bngel

PRAG MGR Analybis \& Reg Matter NB -60

CRYCITY

US DOB

Hashington, DC 20585
John Flack

USNRC-RBS/SAIB

MS : T-10F13

Karl Fleming

Pickard, Lowe \& Garrick

2260 University Drive

Newport Beach, CA 92660

Terry Foppe

Safety Analysis Bngineering

Rocky Plats Plant

Energy Systems Group

Rockwell International Corp

P.O. Box 464

Golden, CO 80401

R H. Gauger

Manager-Reliability Bngr

A/B Div

Holmes \& Narver Inc.

$R$ Roanne Circle

Irvine, CA 92714

Robert Gobel

Clark University

Center for Technology, Environment and Development

950 Main St.

Worcester, MA 01610-1477

Paul Govaerts

Studiecentrum voor Kernenergie

(SCK/CBN)

Boeretang, 200

B-2400 Mol

BELGIUM

Mr. Gubler

International Atomic Bnergy Agency NENS/SAD BO842

Wagramerstrasse 5, P.O. Box 100

A-1140 Vienna

AUSTRIA

Paul M. Haas, President Concord Associates, Inc. 725 Pellissippi Parkway

Suite 101, Box 6

Knoxville, TN 37933 


\author{
F. T. Harper \\ Division 6413 \\ MS : 0748 \\ Sandia National Laboratories \\ Albuquerque, NM 87185-0748
}

Dr. O. Hauptmanns

Gesellschaft Für Anlagen und Reaktorsicherheit (GRS) $\mathrm{mgH}$ Schwertnergasse 1

D-5000 KöIn 1

GERMANY

Sharif Heger

UNM Chemical and Nuclear Engineering Department

Farris Engineering, Room 209

Albuquerque, NM 87131

Jon C. Helton

Dept. uf Mathematics

Arizona state University

Tempa, AZ 85287

Dr. p. M. Herttrich

Gesellschaft für Anlagen und Reaktorsicherheit (GRS) mbH

Schwertnergasse 1

$5000 \mathrm{kJln} 1$

GBRMANY

Dr. D.J. Higson

Radiological Safety Bureau

Australian Nuclear Science \& Technology Organisation

P.O. BOX 153

Roseberry, NSW 2018

AUSTRALIA

Dr. Mitsumasa Hirano

Deputy General Manager

Institute of Nuclear Safety NUPBC

3-6-2, Toranomon, Minato-ku

Tokyo 108

JAPAN

Dr. S. Hirschberg

Paul Scherrer Institute

Vurenlingen and Villigen

CH-5232 Villigen PSI

SWITZERIAND
Steven Hodge

Oak Ridge National Laboratories

P. O. Box $Y$

Oak Ridge, TN 37831

Gary Holahan

USNRC-AEOD/OSP

MS : $T-4 A 9$

N.J. Holloway

A72. 1

Atomic Feapons Establishment

Ademaston

Reading RG7 4PR

UNITBD KINGDOM

Griff Holmes

Westinghouse Blectric Co.

Energy Center Bast

Bldg. 371

P.O. Box 355

Pittgburgh, PA 15230

William Hopkins

Bechtel Power Corporation

15740 Shady Grove Road

Gaithersburg, MD 20877

Dean Houston

USNRC-ACRS

MS : $\mathrm{P}-315$

Der-Yu Hsia

Institute of Nuclear Bnergy Research Iung-Tan 325

TAIWAN

Alejandro Huerta-Bahena National Commission on Nuclear

Safety and Safeguards (CNSNS)

Insurgentes Sur N. 1776

C. P. 04230 Mexico, D. F. MEXICO

Peter Humphreys

OS Atcmic Energy Authority

Wigshaw Iane, Culcheth

Warrington, Cheshire

UNITED KINGDOM, WA3 $4 \mathrm{NB}$ 
พ. Huntington

Commonwealth Edison Co. Lasalle County Station

RR1, BOX 220

2601 North 21st Rd.

Marsielles, IL 61341

\section{J.S. Hyslop}

USNRC-RES/PRAB

MS : T-9F3I

Idaho National Engineering Lab. (2)

Attn: Doug Brownson Darrel Knudson

EG\&G MS : $\quad 3840$

P.O. Box 1625

Idaho Falls, ID 83415

Idaho National Engineering Lab. (2)

Attn: Art Rood Mike Abbott

EG\&G MS : 2110

P.O. Box 1625

Idaho Falls, ID 83415

Hanspeter Isaak

Abteilung Strahlenschutz

Hauptabteilung für die Sicherheit der Kernanlagen (HSK)

$\mathrm{CH}-5303$ wurenlingen

SWITZERLAND

Brian Ives

UNC Nuclear Industries

P. O. Box 490

Richland, WA 99352

Kamiar Jamili

DP - 62/FTN

Department of Energy

Washington, D.C. 20585

Robert .Jones

USNRC - NRR/DSSA

MS : $0-8 E 1$

Edward Jordan

USNRC-AEOD/DO

MS : T-4D18
Dr. H. Kalfsbeek

DG/XII/D/1

Commission of the European

Commurities

Rue de la Loi, 200

B-1049 Brussels

BELGIUM

Yoshio Kano

General Mngr. \& Sr. Engineer

Systems Analysis Section

O-arai Engineer. Centr, PNC

Higashi-Ibaraki-gun

Ibaraki-Ken, 133-13

JAPAN

William Kastenberg

UCLA

Boelter Hall, Room 5532

Los Angeles, CA 90024

Barry Kaufer

OECD/NEA

"Le Seine st. Germain" 12

Boulevard des Iles

92130 Issy-les-Moulineaux

FRANCE

Paul Kayser

Division de la Radioprotection

Avenue des Archiducs, 1

I-1135 Luxembourg-Belair

IUXXEMBOURG

Ken Keith

TVA

W 20 D 201

400 West Surmnit $\mathrm{Hill}$

Knoxville, TN 37092

G. Neale Kelly

Commission of the European Communities

Joint Research Centre

Rue de la Loi 200

B-1049 Brussels

BELGIUM

John Kelly

Sandia National Laboratories

P. O. Box 5800

MS 0742

Albuquerque, NM 87185

Dist -7 
Knolls Atomic Power Laboratory (2)

Attn: Ken McDonough Dominic Sciaudone

Box 1072

Schenectady, NY 12301

Dr. K. Koberlein

Gesellschaft für

Reaktorsicherheit mbH

Forschungsgelānde

D-8046 Garching

GERMANY

Alan Kolaczkowski

Science Applications International Corporation

2109 Air Park Rd. S. E.

Albuquerque, NM 871.06

Jim Kolanowski

Commonwealth Edison Co.

35 1st National West

Chicago, IL 60690

John G. Kollas

Institute of Nuclear Technology and

Radiation Protection

N.R.C.P.S. "Demokritos"

P.O. Box 60228

GR-153 10 Aghia Paraskevi

Attiki

GREECE

S. Kondo

Department of Nuclear Engineering

Facility of Engineering

University of Tokyo

3-1, Hongo 7, Bunkyo-ku

Tokyo '

JAPAN

D. Lamy

CEN/SCK

Dept. Scientific Irradiation

Experiment \& Study BR2

Boeretang, 200

B-2400 Mol

BEIGIUM
Dr. J.M. Lanore

CEA/IPSN/DAS

Centre d'Etudes Nucléaires de Fontenay-aux-Roses

B.P. $n^{\circ} 6$

92265 Fontenay-aux-Roses CEDEX

FRANCE

Jose A. Iantaron

Consejo de Seguridad Nuclear

Sub. Analisis y Evaluaciones

Calle Justo Dorado, 11

28040 Madrid

SPAIN

Josette Larchier-Boulanger

Electricte de France

Direction des Etudes Et Recherches

30, Rue de Conde

75006 Paris

FRANCE

H. Larsen

Head of Department

Riso National Laboratory

P.O. Box 49

DK-4000 Roskilde

DENMARK

Lawrence Livermore Nat' I Lab.

(4)

Attn: George Greenly

Marvin Dickerson

Rolf Lange

Sandra Brereton

Livermore, CA 94550

Shengdar Lee

Yankee Atomic Electric Company

580 Main St.

Boston, MA 17407

B.T.F. Iiwaang

Dept. of Plant Safety Assessment

Swedish Nuclear Power Inspec.

P.O. Box 27106

S-10252 Stockholm

SWEDEN

Peter Lohnberg

Expresswork International, Inc.

1740 Technology Drive

San Jose, CA 95110 
Steven $M$. Iong

USNRC - NRR/SPSB

MS : O-10E4

D. Eugenio Gil Lopez

Consejo de Seguridad Nuclear

Calle Justo Dorado, 11

28040 Madrid

SPAIN

Los Alamos National Laboratory

(2)

Attn: Kent Sasser

$\mathrm{N}-6, \mathrm{~K}-557$

Los Alamos, NM 87545

Christiana H. Lui

USNRC-RES / PRAB

MS : $T-9 F 31$

John Luke

Florida Power \& Light

P.O. Box 14000

Juno Beach, FI 33408

Daniel Manesse

ISPN

Boite Postale $n^{\circ} 6$

92265 Fontenay-aux-Roses CEDEX

FRANCE

Fred Mann

Westinghouse Hanford Co.

WIA -53

P.O. Box 1970

Richland, WA 99352

Nadia Soido Falcao Martins

Comissao Nacional de Energia Nuclear

$R$ General Severianao 90 S/408-1

Rio de Janeiro

BRAZIL

Harry F. Martz

Analysis and Assessment Division

Los Alamos National Laboratory

Los Alamos, NM 87545

Herbert Massin

Commonwealth Edison $\mathrm{Co}$.

35 1st National West

Chicago, IL 60690
Hideo Matsuzuru

Tokai Research Establishment

Tokai-mur

Maka-gun

Ibaraki-ken, 319-11

JAPAN

Jim Mayberry

Ebasco Services

60 Chubb Ave.

Lyndhurst, NJ 07071

Andrew S. McClymont

IT-Delian Corporation

1340 Saratoga-Sunnyvale Rd.

Suite 206

San Jose, CA 95129

Michael McKay

Los Alamos National Laboratory

A-1, MS F600 Services

P.O. Box 1663

Los Alamos, NM87545

Zen Mendoza

SAIC

5150 El Camino Real

Suite C3 1

Los Altos, CA 94022

Dr. J. Mertens

Division of Risk Analysis \& Reactor Technology

Institute of Safety Research

Research Centre Julich (KFA)

D-52425 Julich

GERMANY

Jim Meyer

Scientech .

11821 Parklawn Dr.

Suite 100

Rockvilie, MD 20852

Joe Minarick

Science Applications Int'l Corp.

301 Laboratory Road

P.O. Box 2501

Oak Ridge, TN 37830

Dist-9 
Jose I. Calvo Molins, Head

Division of P.S.A. and Human Factors Consejo de Seguridad Nuclear

Calle Justo Dorado, 11

28040 Madrid

SPAIN

Ken Muramatsu

Risk Analysis Laboratory

Japan Atomic Energy Research

Institute

Tokai-mura, Naka-gun

Ibaraki-ken, 319-11, Tokyo

JAPAN

Joseph A. Murphy

Division of Safety Issue Resolution

D.S. Nuclear Regulatory Commission

MS : T-10E50

Washington, DC 20555

Kenneth G. Murphy, Jr.

US Department of Energy

19901 Germantown Rd.

Germantown, MD 20545

Shankaran Nair

Central Electricity

Generating Board

Berkeley Nuclear Laboratories

Berkeley

Gloucestrshire CL13 9PB

UNITED KINGDOM

Ray Ng

NEI

1776 Eye St. $N$

Suite 300

Washington, DC 20006-2496

G. Niederauer

Los Alamos National Laboratory

P. O. Box 1663

MSK 575

LOs Alamos, NM 87545

Oak Ridge National Laboratory

MS - 8057

Sherrel Greene

P.O. Box 2009

Oak Ridge, TN 37831
Ken O'Brien

University of Wisconsin

Nuclear Engineering Dept.

153 Engineering Research Blvd.

Madison, WI 53706

Theresa Oh

INEI Tech Library

EG\&G MS : 2300

P. O. Box 1625

Idaho Falls, ID 83415-2300

N. R. Ortiz, Director

Nuclear Energy Technology

Division 6400

Sandia National Laboratories

Albuquerque, NM 87185

Robert Ostmeyer

U.S. Department of Energy

Rocky Flats Area Office

P. O. Box 928

Golden, CO 80402

Robert Palla

USNRC-NRR/SPSB

MS : 0-10E4

Gareth Parry

NUS Corporation

910 Clopper Rd.

Gaithersburg, MD 20878

Vern Peterson

Building T886B

EG\&G Rocky Flats

P.O. Box 464

Golden, CO 80402

G. Petrangeli

ENEA Nuclear Energy ALT Disp

Via V. Brancati, 48

00144 Rome

ITALY

Ing. Jose Antonio Becerra Perez Comision Nacional De Seguridad Nuclear $Y$ Salvaguardias

Insurgentes Sur 1806

01030 Mexico, D. F.

MEXICO 
William T. Pratt

Brookhaven National Laboratory

Building 130

Upton, NY 11973

Urho Pulkkinen

Technical Research Centre of Finland

Laboratory of Electrical \&

Automation Engineeering

Otakaari 7B, 02150 Espoo 15

FINLAND

Blake Putney

Science Applications

International Corporation

5150 El Camino Real, Suite C31

Los Altos, Ca 94022

Dr. V. M. Raina

Project Manager-Risk Assessment Ontario Hydro H11 G1

700 University Ave.

Toronto, Ontario M5G $1 \times 6$

CANADA

William Raisin

NEI

1726 M. St. NW

Suite 904

Washington, DC 20036

Ann Ramey-Smith

USNRC-RES/PRAB

MS : T-9F31

Dale Rasmuson

USNRC - AEOD/TPAB

MS : T-4AS

John Ridgely

USNRC - RES / SAIB

MS : T-10F13

Richard Robinson (2)

USNRC - RES / PRAB

MS : T-9F31
M. Roch

Manager of Design, Nuclear

Department

TRACTEBEL

Avenue Ariane 7

B-1200 Bruxelles

BEIGIUM

A.E. Rogers

General Electric Co

175 Curtner Ave

MC -489

San Jose, CA 95125

Judy Rollstin

GRAM Inc

8500 Menual Blvd. NE

Albuquerque, NM 87112

Marc Rothschild

Halliburton NUS

1303 S. Central Ave.

Suite 202

Kent, WA 98032

Christopher Ryder

USNRC-RES / PRAB

MS : $T-9 F 31$

Takashi Sato, Deputy Manager

Nuclear Safety Engineering Section

Reactor Design Engineering Dept.

Nuclear Energy Group, Toshiba Corp. Isogo Engineering Center

8, Shinsugita-cho, Isogo-ku,

Yokohama 235, JAPAN

Martin Sattison

Idaho National Engineering Lab.

P. O. Box 1625

Idaho Falls, ID 83415

Dr. U. Schmocker

Hauptabteilung für die

Sicherheit der Kernanlagen

$\mathrm{CH}-5232$ Villigen HSK

SWITZERLAND

A.J. Seebregts

ECN Nuclear Energy

Westerduinweg, 3

Postbus 1

NL-1755 Petten ZG

THE NETHERIANDS 
Dr. S. Serra

Ente Naxionale per I'Energia

Electtrica (ENEL)

via G.B. Martini 3

I-00198 Rome

ITALY

H. Shapiro

Licensing \& Risk Branch

Atomic Energy of Canada Ltd.

Sheridan Park Research Comm.

Mississauga, Ontario I5K 1B2

CANADA

Nathan 0. Siu

Center for Reliability and Risk

Assessment

Idaho National Engineering Lab.

EG\&G MS : 3850

P.O. Box 1625

Idaho Falls, ID 83415-3855

E. Soederman

ES-Konsult $A B$

Energy and Safety

P.O. Box 3096

S-16103 Bromma

SWEDEN

Desmond Stack

Los Alamos National Iaboratory

Group Q-6, Mail Stop K556

Los Alamos, NM 87545

Jao Van de Steen

KEMA Laboratories

Utrechtseweg, 310

Postbus 9035

NL 800 ET Arnhem

THE NETHERIANDS

Eli Stern

Israel ABC Iicensing Div.

P.O. Box 7061

Tel-Aviv 61070

ISRAEI

Dr. Egil stokke

Advisory Group

OECD Halden Reactor Project

P.O. Box 173

N-1751 Halden

NORWAY
Stone \& Webster Engineering Corp

Technical Information Center

A. Hosford

245 Summer street

245/01

Boston, MA 02210

Dennis Strenge

Pacific Northwest Laboratory

RTO/ 125

P.O. Box 999

Richland, WA 99352

Technadyne Engineer. Consultants (3)

Attn: David Chanin Jeffery Foster Walt Murfin

Suite A225

8500 Menual Blva. N

Albuquerque, NM 87112

Ashok Thadani

USNRC-NRR/ADT

MS : $0-12 \mathrm{G} 18$

T. G. Theofanous

University of California, S. B.

Department of Chemical and Nuclear Engineering

Santa Barbara, CA 93106

Catherine Thompson

USNRC-RES/SAIB

MS : $T-10 F 13$

Soren Thykier-Nielsen

Riso National Laboratory

Postbox 49

DK4000 Roskile

DENMARK

R. Toossi

Physical Research, Inc. 25500 Hawthorn Blvd.

Torrance, CA 90505

Ennio Traine

ENEL

Via Vialiano, 48

00144 Rome

ITALY 
Ulf Tveten

Environmental Physics section Institutt for Energiteknikk

Postboks 40

N-2007 Kjellex

NORWAY

US Department of Energy

Energy Library

Room G 034/GTN

$A D-622.1$

Washington, DC 20585

US Department of Energy

NS - 50 (GTN)

NS -10.1

S-161

Washington, DC 20585

U.S. Environmental Protection Agency (2)

Attn: Allen Richardson Joe Logsdon

Office of Radiation Programs Environmental Analysis Division Washington, DC 20460

Harold VanderMolen

USNRC - RES / PRAB

MS : $T-9 F 31$

Dr. A. Valeri

A.N.P.A.

Via Vitaliano Brancati, 48

I-00144 Rome

ITALY

Magiel F. Versteeg

Ministry of Social Affairs and Employment

P.O. BOX 90804

2509 LV Den Haag

THE NETHERLANDS

Martin Virgilio

USNRC - NRR/DSSA

MS : $0-8 E 2$

R. Virolainen, (Chairman PWG5)

Systems Integ. Off. (STUK)

P.O. Box 268

Kumpulanite 7

SF-60101 Helsinki

FINI.AND
Seppo Vuori

Technical Research Centre of Finland Nuclear Engineering Laboratory

Lonnrotinkatu 37

Q.O. Box 169

Sf-00181 Helsinki 18

EINLAND

Dr. Ian B. Wall

81 Irving Avenue

Atherton, CA 94027

Edward Warman

Stone \& Webster Engineering Corp. P.O. Box 2325

Boston, MA 02107

\section{J.E. Werner}

Reactor Research \& Techn Division US DOE Idaho Operations

MS : $\quad 1219$

850 Energy Drive

Idaho Falls, ID 83401-1563

Dr. Wolfgang Werner

Safety Assessment Consulting $\mathrm{GmbH}$ Veilchenweg 8

D 83254 Breitbrunn

GERMANY

Westinghouse Electric Corp

Technical Iibrary

P. O. Box 355

East 209

Pittsburgh, PA 15230

Westinghouse Electric Corp

NTD

Central File Nuclear Safety

P. O. Box 355

$4081-A$

Pittsburgh, PA 15230

Westinghouse Electric Company (3)

Attn: John Lacovin

Burt Morris

Griff Holmes

Energy Center East, Bldg. 371

p.O. Box 355

Pittsburgh, PA 15230

Dist -13 
Westinghouse Savannah River Co. (2)

Attn: Kevin O'Kula

Jackie East

Safety Technology Section

1991 S. Centennial Ave., Bldg. 1

Aiken, SC 29803

Donnie Whitehead

Department 6412, MS: 0747

Sandia National Laboratories

P.O. Box 5800

Albuquerque, NM 87185-0747

Keith Woodard

PLG, Ine.

7315 Wisconsin Ave.

Suite 620 East

Bethesda, MD 20814-3209

John Wreathall

John Wreathall \& Co.

4157 MacDuff Way

Dubin, OH 43017

M. K. Yeung

University of Hong Kong

Mechanical Engineering Dept.

Polfulam

HONG KONG

Bob Youngblood

Brookhaven National Laboratory

Department of Nuclear Energy

Blag. 130

Upton, NY 11973

Carlo Zaffiro

A.N.P.A.

Directorate for Nuclear

Via Vitaliano Brancate, 48

I-00144 Rome

ITALY

Dr. X. Zikidis

Greek Atomic Energy Comm.

N.R.C.P.S. "Demokritos"

GR-153 10 Agia Paraskevi

Attiki

GREECE 
(See instructions on the reverse)

2. TITLE AND SUBTITLE

Evaluation of Potential Severe Accidents During Low

Power and Shutdown Operations at Surry, Unit 1:

Analysis of Core Damage Frequency from Internal

Events During Mid-loop Operations-Main Report

(Chapters 7-12)

5. AUTHOR(S)

T.L. Chu, Z. Musicki, P. Kohut, D. Bley ${ }^{1}$, J.Yang,

B. Holmes , G. Bozoki, C.J, Hsu, D.J. Piamond, D. Johnson ${ }^{\prime}$,

J. Lin , R.F. Su ${ }^{3}$ V. Dang, D. Ilberg', S.M. Wong, N. Siu

1. REPORT NUMBER

IAsslgnod by NRC. Add Vol., Supp., Rov., and Addondum Numbers, if any.

NUREG/CR-6144

BNL-NUREG-52399

Vol.2, Part 1B

3. DATE REPORT PUBLISHED

\begin{tabular}{l|r} 
MONTH & YEAR \\
\hline
\end{tabular}

June 1994

4. FIN OR GRANT NUMBER L 1922

6. TYPE OF REPORT

7. PERIOD COVERED (Inc/usive Dates)

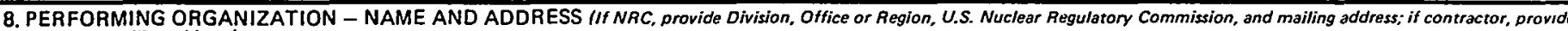
name and malling address)

Brookhaven National Laboratory

${ }^{1}$ PLG Inc., 4590 McArthur Blvd. Newport Bch. CA 92660-2027

Upton, NY 11973

2 AEA Technology, Winfrith, Dorchester, Dorset, England, DT2 8DH

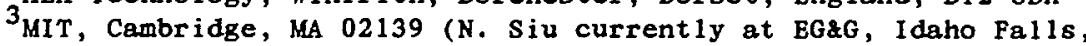

ID 84315)

4 Soreq Nuclear Research Center, Yavne 70600, Israel

SPONSORING ORGANIZATION - NAME AND ADDRESS (If NRC, type "Same as above"; if contractor, provide NRC Division, Office or Region, U.S. Nuclear Regulatory Commission, and malling address.)

Division of Safety Issue Resolution

Office of Nuclear Regulatory Research

U.S. Nuclear Regulatory Commission

Washington, DC 20555-0001

10. SUPPLEMENTARY NOTES

11. ABSTRACT 1200 words or less)

During 1989, the Nuclear Regulatory Commission (NRC) initiated an extensive program to carefully examine the potential risks during low power and shutdown operations. The program includes two parallel projects being performed by Brookhaven National

Laboratory (BNL) and Sandia National Laboratories (SNL). Two plants, Surry

(pressurized water reactor) and Grand Gulf (boiling water reactor), were selected as the plants to be studied. The objectives of the program are to assess the risks of severe accidents initiated during plant operational states other than full power operation and to compare the estimated core damage frequencies, important accident sequences and other qualitative and quantitative results with those accidents initiated during full power operation as assessed in NUREG-1150. The objective of this report is to document the approach utilized in the Surry plant and discuss the results obtained. A parallel report for the Grand Gulf plant is prepared by SNL. This study shows that the core-damage frequency during mid-loop operation at the Surry plant is comparable to that of power operation. We recognize that there is very large uncertainty in the human error probabilities in this study. This study identified that only a few procedures are available for mitigating accidents that may occur during shutdown. Procedures written specifically for shutdown accidents would be useful. 12. KEY WORDS/DESCR!PTORS (List words or phrases that will assist researchers in locating the report.)

Surry-1 Reactor-Reactor Shutdown; Surry-1 Reactor-Risk Assessment; Surry-2 Reactor-Reactor Shutdown; Surry-2 Reactor-Risk Assessment; Failure Mode Analysis, Reactor Accidents, Reactor Core Disruption, Reactor Start-up, RHR Systems, Systems Analysis, Thermodynamics, Sandia National Laboratories

\begin{tabular}{|c|}
\hline \multirow[t]{2}{*}{$\begin{array}{l}\text { 13. AVAILABILITY STATEMENT } \\
\text { Unlimited } \\
\text { 19. SECURITY CLASSIFICATION }\end{array}$} \\
\hline \\
\hline $\begin{array}{l}\text { This Pagel } \\
\text { Unclassified }\end{array}$ \\
\hline $\begin{array}{l}\text { (This Report) } \\
\text { Unclassified }\end{array}$ \\
\hline 15. NUMBER OF PAGES \\
\hline 16. PRICE \\
\hline
\end{tabular}

